\title{
Quality of
}

\section{Surface Waters of the}

\section{United States,}

\section{8}

\section{Part 3. Ohio River Basin}

Prepared in cooperation with the States of Alabama, Illinois, Indiana, Kentucky, Maryland, New York, North Carolina, Ohio, Pennsylvania, Tennessee, Virginia, West Virginia, and

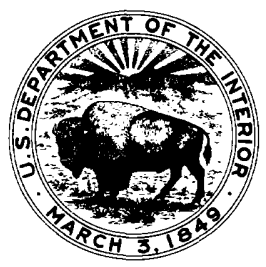
with other agencies 


\title{
UNITED STATES DEPARTMENT OF THE INTERIOR
}

ROGERS C. B. MORTON, Secretary

\section{GEOLOGICAL SURVEY}

V. E. McKelvey, Director

\author{
Library of Congress catalog-card No. GS 43-68
}

For sale by the Superintendent of Documents, U.S. Government Printing Office Washington, D.C. 20402 - Price $\$ 2.10$ domestic postpaid or $\$ 1.75$ GPO Bookstore Stock Number 2401-02384 


\section{PREFACE}

This report was prepared by the U.S. Geological Survey in cooperation with the States of Alabama, Illinois, Indiana, Kentucky, Maryland, New York, North Carolina, Ohio, Pennsylvania, Tennessee, Virginia, West Virginia, and with other agencies, by personnel of the Water Resources Division, E. L. Hendricks, chief hydrologist, G. W. Whetstone, assistant chief hydrologist for Scientific Publications and Data Management, under the general direction of G. A. Billingsley, chief, Reports Section, and B. A. Anderson, chief, Data Reports Unit.

The data were collected under the supervision of district chiefs of the Water Resources Division, as follows:
N. H. Beamer
Harrisburg, $\mathrm{Pa}$
W. L. Broadhurst
Tuscaloosa, Ala.
R. J. Dingman. Albany, N.Y.
J. W. Gambrell Richmond, Va.
W. C. Griffin. Charleston, W. Va.
M. D. Hale... Indianapolis, Ind.
R. C. Heath Raleigh, N.C.
E. J. Kennedy. Nashville, Tenn.
W. D. Mitchell Champaign, IIl.
J. J. Molloy. Columbus, Ohio
F. F. Schrader Louisville, $\mathrm{Ky}$.
W. F. White Parkville, Md. 


\section{CONTENTS}

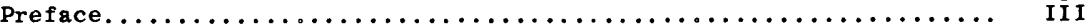

List of water-quality stations, in downstream order, for which

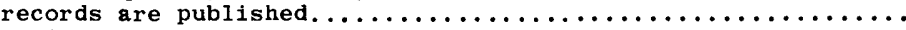

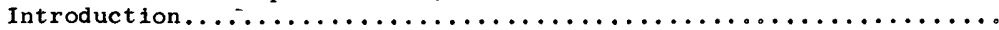

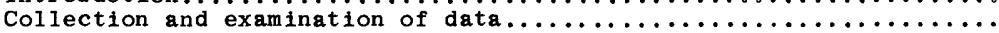

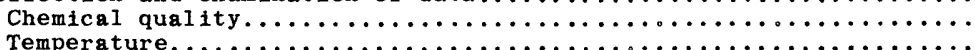

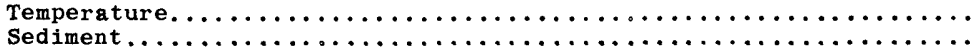

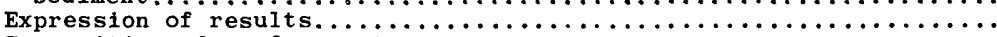

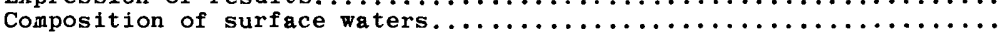

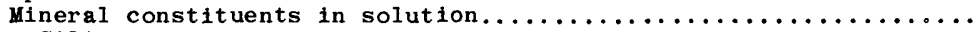

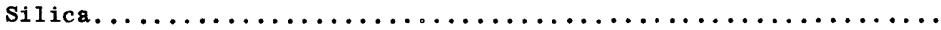

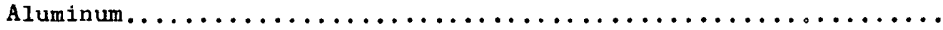

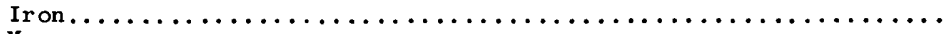

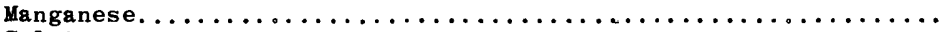

Calcium. . . . . . . . . . . . . . . . . . . . . . . . . .

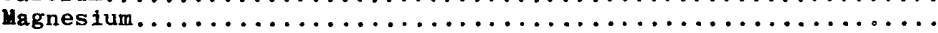

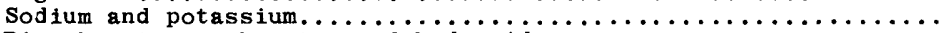

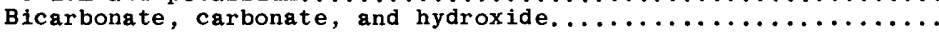

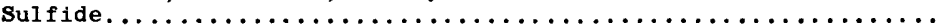

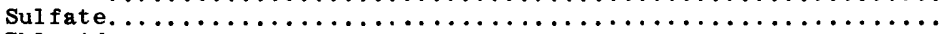

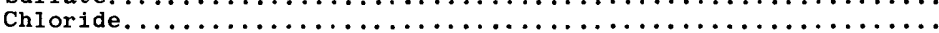

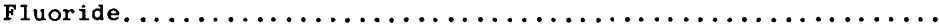

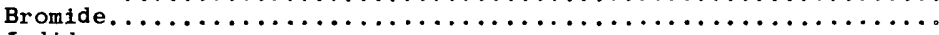

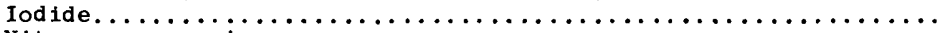

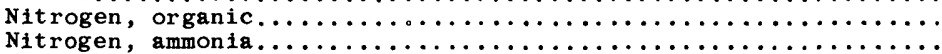

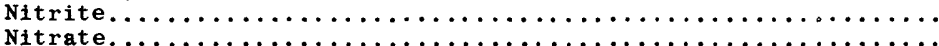

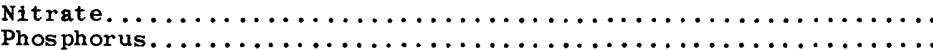

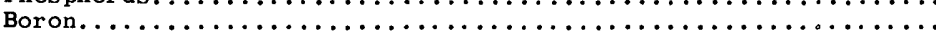

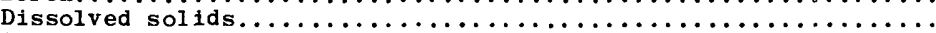

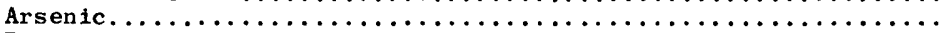

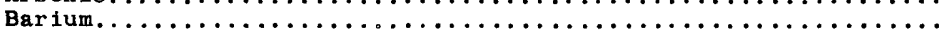

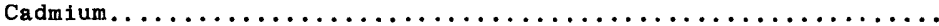

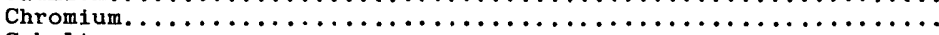

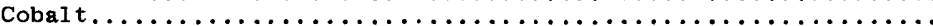

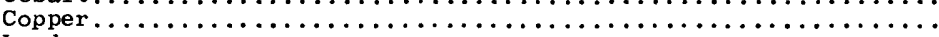

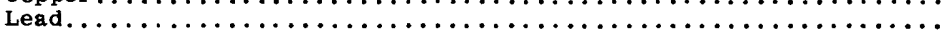

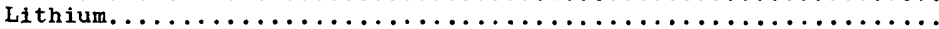

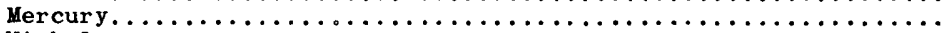

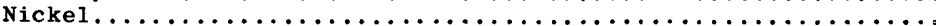

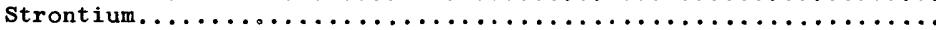

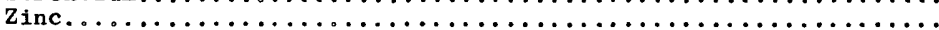

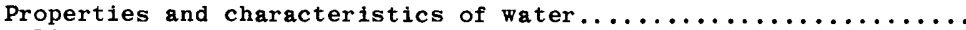

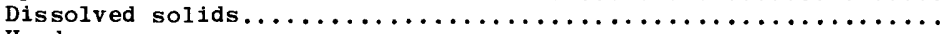

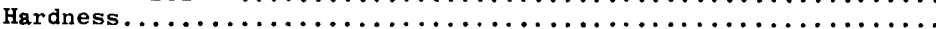

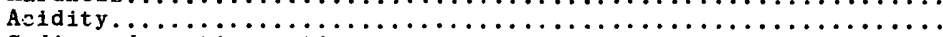

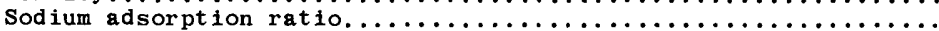

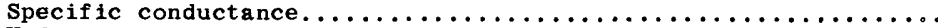

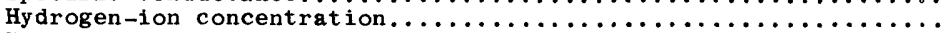

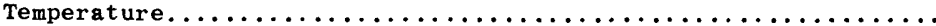

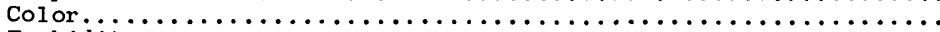

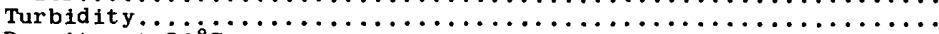

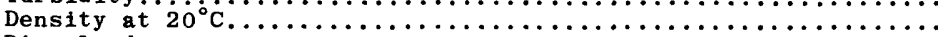

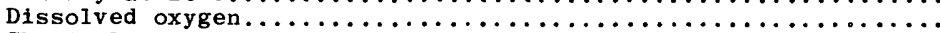

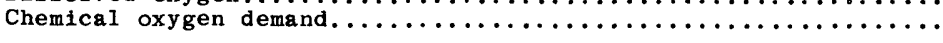


Composition of surface waters--Continued

properties and characteristics of water--continued

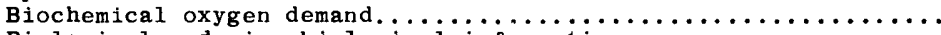

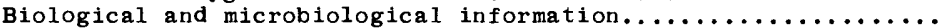

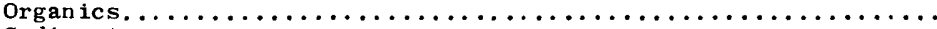

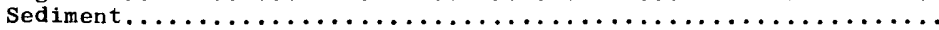

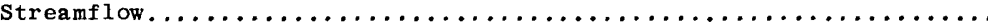

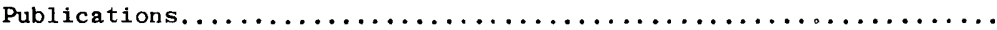

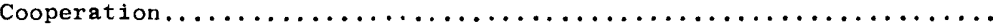

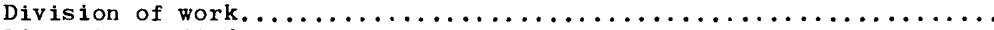

Literature cited.

Index.

\section{ILLUSTRATION}

Figure 1. Map of the United States showing basins covered by the ten water-supply papers of quality of surface waters in 1968. 


\title{
WATER-QUALITY STATIONS, IN DOWNSTREAM ORDER, FOR WHICH RECORDS ARE PUBLISHED
}

\author{
[Letters after station name designate type of data: (c) chemical,
}

(t) water temperature, (s) sediment]

\section{OHIO RIVER BASIN}

Allegheny River (head of Ohio River) near Kinzua, Pa. (ct)........ CONEWANGO CREEK BASIN

Con ewango Creek at Waterboro, N.Y. (c) $\ldots \ldots \ldots \ldots \ldots \ldots \ldots \ldots \ldots$

CLAR ION RIVER BASIN

Clarion River:

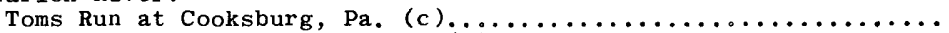

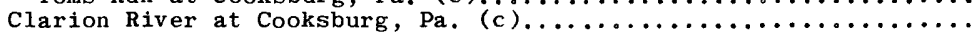

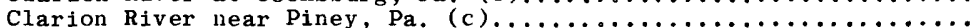

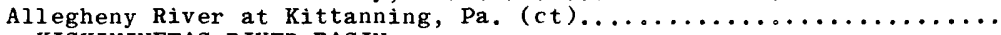
KISKIMINETAS RIVER BASIN

Stony Creek (head of Kiskiminetas River):

Conemaugh River (continuation of Stony Creek) at Seward, $\mathrm{Pa} .(\mathrm{t})$..

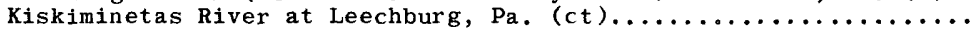

MONONGAHELA RIVER BASIN

Tygart Valley River (head of Monongahela River) at Elkins,

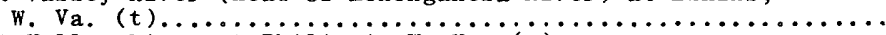

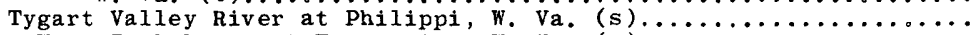

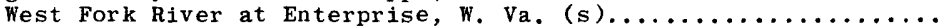

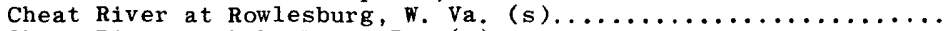

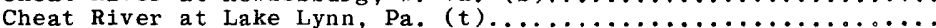

Youghiogheny River at Friendsville, Md. $(t) \ldots \ldots \ldots \ldots \ldots \ldots \ldots$

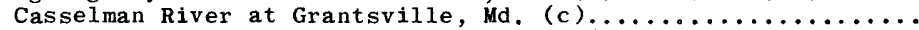

Youghiogheny River at Connellsvilie, Pa. $(\mathrm{c}) \ldots \ldots \ldots \ldots \ldots \ldots \ldots \ldots$

Ohio River at South Heights, $\mathrm{Pa} .(\mathrm{ct}) \ldots \ldots \ldots \ldots \ldots \ldots \ldots \ldots \ldots \ldots$ BEAVER RIVER BASIN

Mahoning River (head of Beaver River):

West Branch Mahoning River near Ravenna, Ohio $(t) \ldots \ldots \ldots \ldots \ldots . . \ldots 40$

Mahoning River at Leavittsburg, Ohio $(c t) \ldots \ldots \ldots \ldots \ldots \ldots \ldots \ldots \ldots . \ldots \ldots$

Mahoning River at Ohio-Pennsylvania State line, below

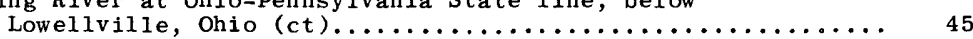

Ohio River at Stratton, Ohio (ct) $\ldots \ldots \ldots \ldots \ldots \ldots \ldots \ldots \ldots \ldots \ldots \ldots \ldots .49$

MIDDLE ISLAND CREEK BASIN

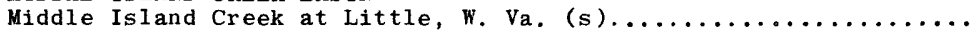
MUSKINGUM RIVER BASIN

Tuscarawas River (head of Muskingum River) at Navarre, Ohio (ct).

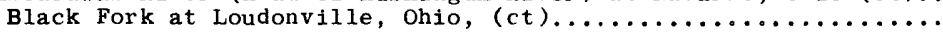
Walhonding River:

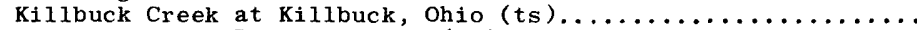

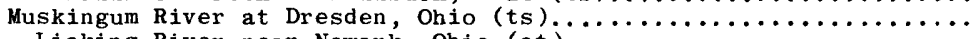

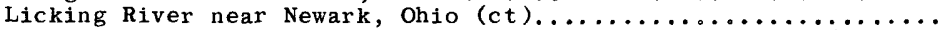

Licking River below Dillon Dam, near Dilion Falis, Ohio $(t) \ldots .$.

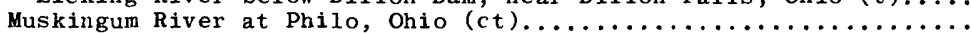

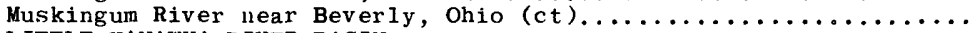

LITTLE KANAWHA RIVER BASIN

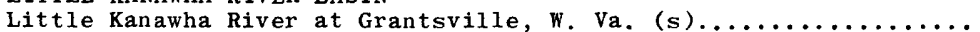

HOCKING RIVER BASIN

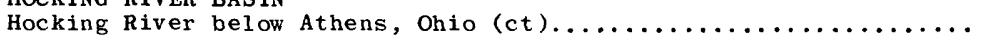

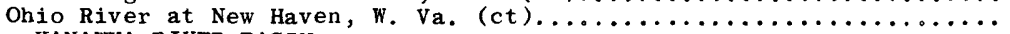
KANAWHA RIVER BASIN

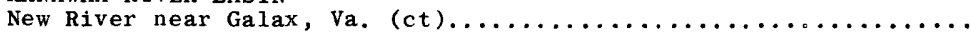

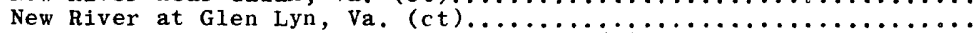

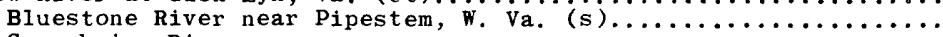
Greenbrier River:

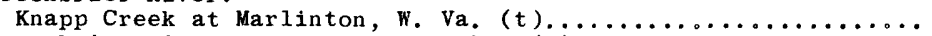

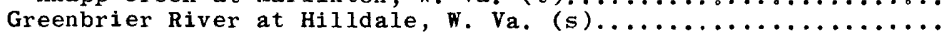


OHIO RIVER BASIN--Cont inued

KANAWHA RIVER BASIN--Continued

New River--Continued

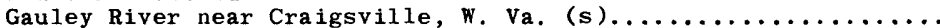

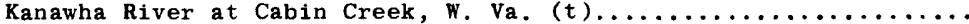

Elk River below Webster Springs, w. Va. (s) $\ldots \ldots \ldots \ldots \ldots \ldots \ldots$

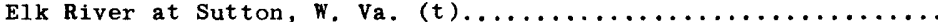

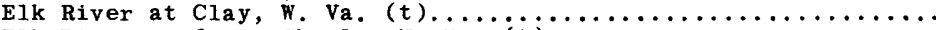

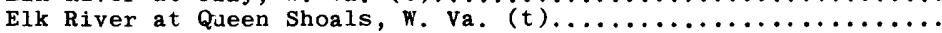

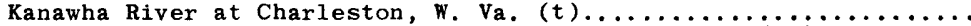

Kanawha River at Winfield Dam, at Winfield, w. va. (ct).........

RACCOON CREEK BASIN

Raccoon Creek at Adamsville, Ohio (ct) $\ldots \ldots \ldots \ldots \ldots \ldots \ldots \ldots \ldots$

BIG SANDY RIVER BASIN

Levisa Fork (head of Big Sandy River):

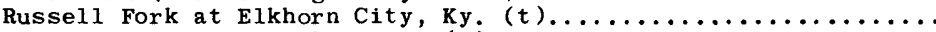

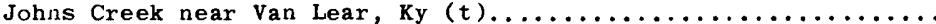

Levisa Fork at Paintsville, Ky. (ts) $\ldots \ldots \ldots \ldots \ldots \ldots \ldots \ldots \ldots$

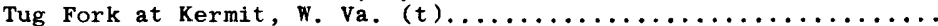
LITTLE SANDY RIVER BASIN

Little Sandy River below Grayson Dam, near Leon, Ky. ( $t$ )....... TYGARTS CREEK BASIN

Tygarts Creek near Greenup, Ky. (ts $\ldots \ldots \ldots \ldots \ldots \ldots \ldots \ldots \ldots$ SCIOTO RIVER BASIN

Scioto River:

Olentangy River:

Whetstone Creek near Ashley, Ohio (c)..................

olentangy River near Worthington, Ohio $(t) \ldots \ldots \ldots \ldots \ldots \ldots \ldots \ldots \ldots$ Big Walnut Creek:

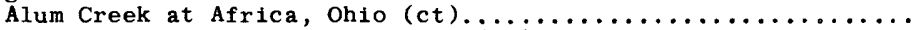

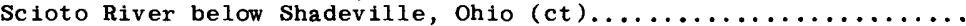

Deer Creek at Williamsport, Ohio (ct) $\ldots \ldots \ldots \ldots \ldots \ldots \ldots \ldots \ldots$

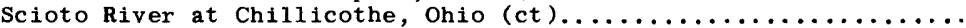

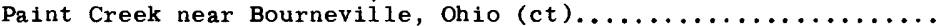

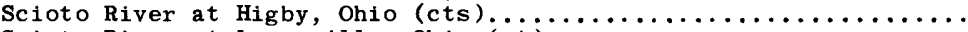

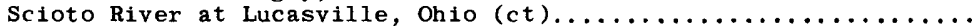
UPPER TWIN CREEK BASIN

Upper Twin Creek at McGaw, Ohio (cts) $\ldots \ldots \ldots \ldots \ldots \ldots \ldots \ldots \ldots$ LITTLE MIAMI RIVER BASIN

Little Miami River:

East Fork Little Miami River at Perintown, Ohio (ct).........

LICKING RIVER BASIN

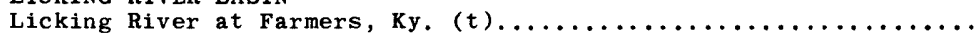

Licking River at McKinneysburg, Ky. (cts)............... South Fork Licking River at Cynthiana, Ky. $(t) \ldots \ldots \ldots \ldots \ldots \ldots \ldots$ GREAT MIAMI RIVER BASIN

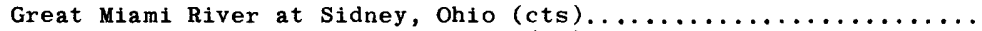

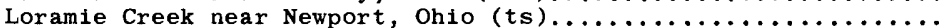

Great Miami River near Taylorsville Dam, at Taylorsville, Ohio (c)

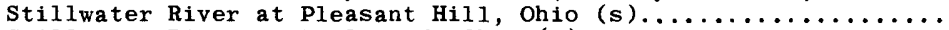

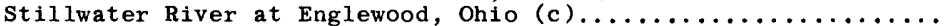

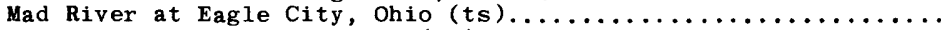

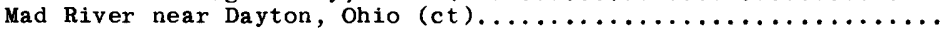

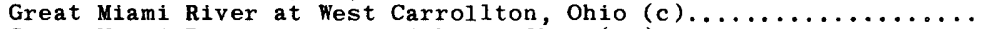

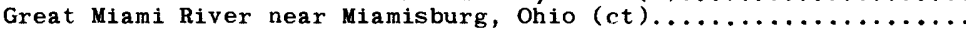

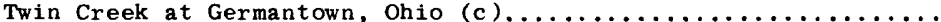

Great Miami River at Middletown, Ohio $(c) \ldots \ldots \ldots \ldots \ldots \ldots \ldots \ldots$

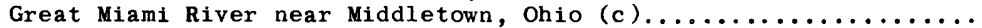

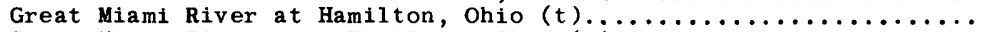

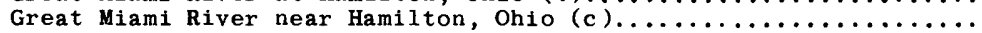

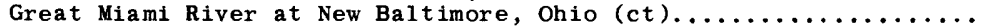
Great Miami River at Elizabethtown, Ohio (ct) $\ldots \ldots \ldots \ldots \ldots \ldots \ldots \ldots$

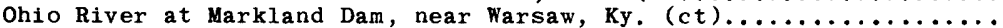
KENTUCKY RIVER BASIN

North Fork Kentucky River:

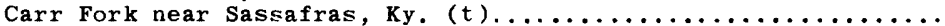

North Fork Kentucky River at Hazard, $\mathrm{ky} .(\mathrm{ct}) \ldots \ldots \ldots \ldots \ldots \ldots \ldots \ldots \ldots$

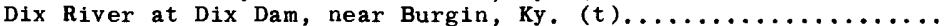

Kentucky River at lock 4 , at Frankfort, Ky, (cts).............

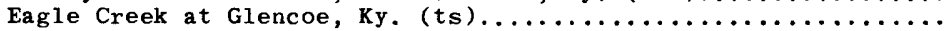

Page

80

81

81

82

83

84

85

86

88

93

94

95

98

98

99

102

103

103

106

108

111

114

117

123

125

127

129

130

134

135

139

142

144

146

147

150

153

155

159

161

163

165

165

167

170

173 
OHIO RIVER BASIN--Continued

Ohio River--Continued

SALT RIVER BASIN

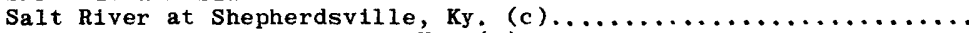

Rolling Fork near Boston, $\mathrm{Ky} .(\mathrm{t}) \ldots \ldots \ldots \ldots \ldots \ldots \ldots \ldots \ldots \ldots$ GREEN RIVER BASIN

Green River near Campbellsville, Ky. (t) $\ldots \ldots \ldots \ldots \ldots \ldots \ldots \ldots$

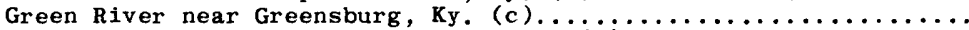

Little Barren River near Monroe, $\mathrm{Ky},(\mathrm{c}) \ldots \ldots \ldots \ldots \ldots \ldots \ldots \ldots \ldots$

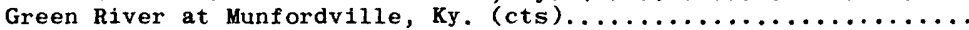

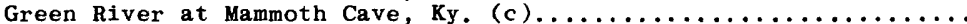

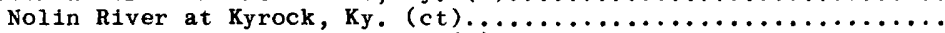

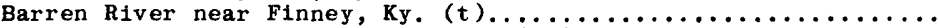

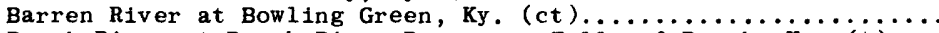

Rough River at Rough River Dam, near Falis of Rough, Ky. (t)...

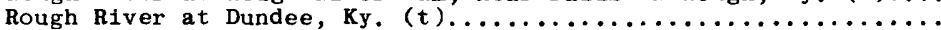

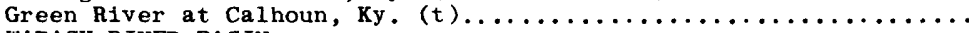

WABASH RIVER BASIN

Wabash River at Huntington, Ind. (t) $\ldots \ldots \ldots \ldots \ldots \ldots \ldots \ldots \ldots$

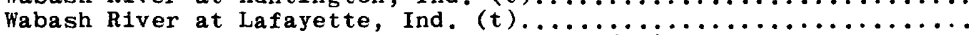

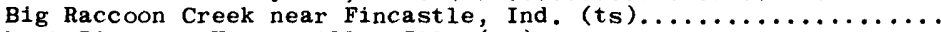

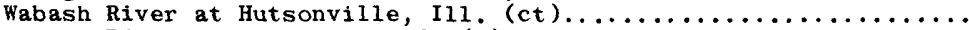

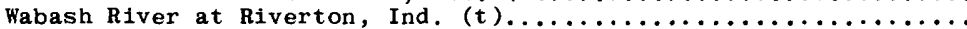

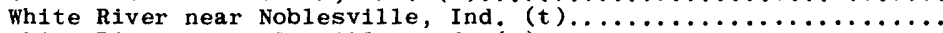

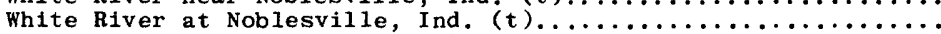

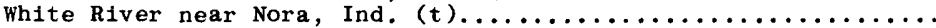

East Fork White River at Seymour, Ind (ts) $\ldots \ldots \ldots \ldots \ldots \ldots$

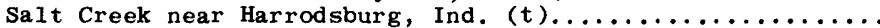

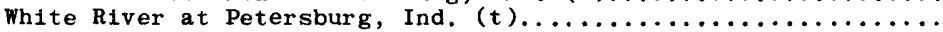
TRADEWATER RIVER BASIN

Tradewater River:

Buffalo Creek at State Highway 1338, near Dawson Springs,

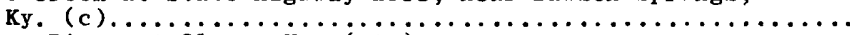

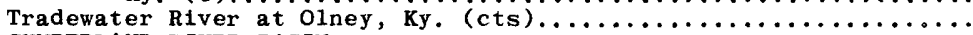

CUMBERLAND RIVER BASIN

Cumberland River:

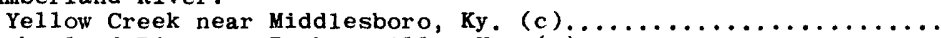

Cumberland River at Barbourville, Ky. (t) . . . . . . . . . . . . . .

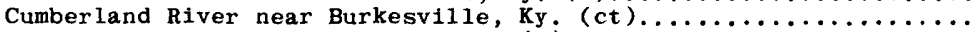

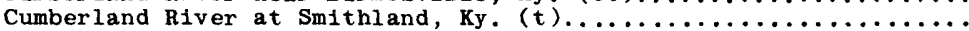

TENNESSEE RIVER BASIN

French Broad River (head of Tennessee River):

Pigeon River:

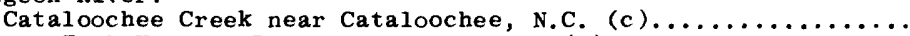

South Fork Holston River at Vestal, Va. $(t) \ldots \ldots \ldots \ldots \ldots \ldots \ldots \ldots$

North Fork Holston River near Gate City, Va. $(\mathrm{t}) \ldots \ldots \ldots \ldots \ldots$.

Holston River:

Beech Creek at Kepler, Tenn. (t)..................

Holston River near Rogersvilie, Tenn. $(t) \ldots \ldots \ldots \ldots \ldots \ldots \ldots \ldots \ldots$

Tennessee River:

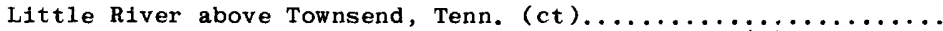

Little Tennessee River below Chilhowe Dam, Tenn. $(t) \ldots \ldots \ldots \ldots$ Tellico River at Tellico Plains, Tenn. $(t) \ldots \ldots \ldots \ldots \ldots \ldots$

Clinch River:

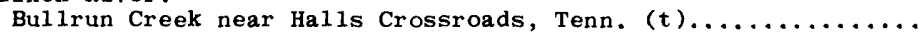

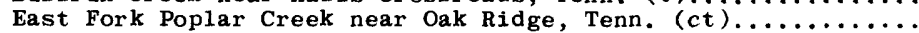
Emory River:

Crab Orchard Creek near Deermont, Tenn. (ct) .............

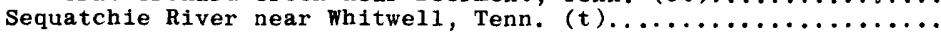

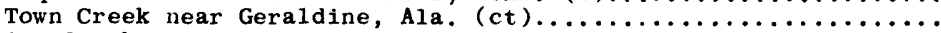

Flint Creek:

E1k River:

Richland Creek near Pulaski, Tenn. (t) $\ldots \ldots \ldots \ldots \ldots \ldots \ldots \ldots$

Tennessee River:

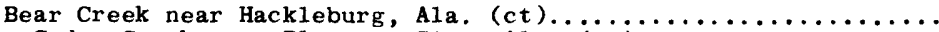

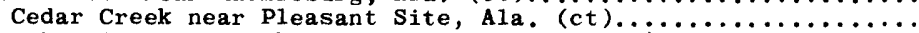

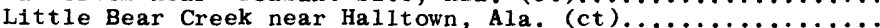

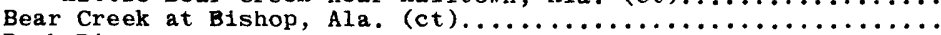
Duck River:

Buffalo River near Flat woods, Tenn. (ct)..............

Page

186

187

188

189

189

190

194

194

195

196

197

199

200

201

202

203

206

208

209

209

210

211

214

215 
OHIO RIVER BASIN--Continued

TENNESSEE RIVER BASIN--Continued $\quad$ Page

Tennessee River at Kentucky Dam, near Paducah, Ky. (c)......... 244

Ohio River at Metropolis, Ill. ( $t) \ldots \ldots \ldots \ldots \ldots \ldots \ldots \ldots \ldots \ldots \ldots \ldots \ldots .245$

Ohio River at lock and dam 53, near Grand Chain, Ill. (ct)....... 246

Analyses of samples collected at partial-record stations........... 249

Analyses of samples collected at low-flow on streams in the

Ohio River basin in Ohio...................... 264

Pesticide analyses of streams in the ohio River basin in ohio...... 268

Miscellaneous analyses of streams in the Ohio River basin in:

New York.

268

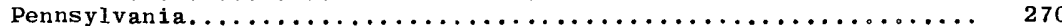

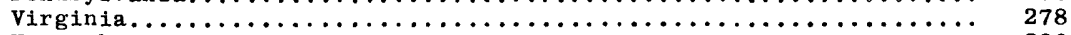

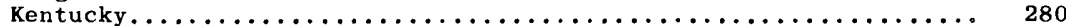

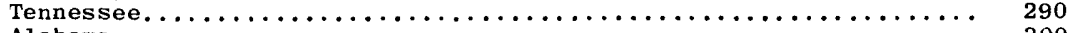

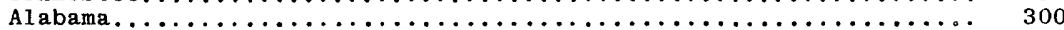

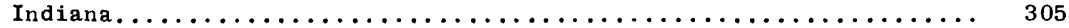

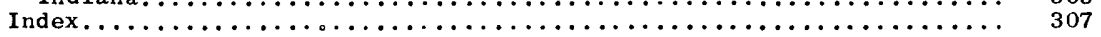




\title{
QUALITY OF SURFACE WATERS OF THE UNITED STATES, 1968
}

\author{
PART 3
}

\section{INTRODUCTION}

The water-quality investigations of the United States Geological Survey are concerned with chemical and physical characteristics of surface- and ground-water supplies of the Nation. The data herein deal with the amounts of matter in solution and in suspension in streams, and represent that portion of the National Water Data System collected by the U.S. Geological Survey in cooperation with State, municipal, and other Federal agencies.

The records of chemical analysis, water temperature, and suspended sediment of surface waters given in this volume serve as a basis for determining the suitability of waters for various uses. The flow and water quality of a stream are related to variations in rainfall and other forms of precipitation. In general, lower concentrations of dissolved solids may be expected during periods of high flow than during periods of low flow. Conversely, the suspended solids in some streams may change materially with relatively small variations in flow, whereas for other streams the quality of the water may remain relatively uniform throughout large ranges in discharge.

The Geological Survey has published annual records of chemical quality, water temperature, and suspended sediment since 1941. The records prior to 1948 were published each year in a single volume for the entire country, and in two volumes in 1948 and in 1949. From 1950 to 1958 , the records were published in 4 volumes; from 1959 to 1963 in 5 volumes; from 1964 to 1967 in 6 volumes; and since 1968 in 10 volumes. The drainage basins covered by the 10 volumes are shown in Figure 1 . The shaded area in Figure 1 represents the section of the country covered in this volume for the water year 1968 (October 1, 1967 to September 30, 1968).

To meet interim requirements, water-quality records have been released by the Geological Survey in annual reports, beginning with the 1964 water year, by State. These reports are entitled, "Water Resources Data for (State), Part 2. Water Quality Records." Distribution of these reports is limited and primarily for local needs. Any revisions or corrections found necessary to the records published in these annual State reports have been made and published in this volume without reference.

The records herein are listed by drainage basins in a downstream direction along the main stream. All stations on a tributary entering above a mainstream station are listed before that station. A station on a tributary that enters between two mainstream stations is listed between them. A similar order is followed in listing stations on first rank, second rank, and other ranks of tributaries. In the list of water-quality stations in the front of this volume, the rank of the tributaries is indicated by an indention. Each indention represents one rank.

As an added means of identification, a station number has been assigned for each stream location where regular measurements of water quantity or quality have been made. The numbers have been assigned to conform with the standard downstream order of listing gaging stations. The numbering system consists of an 8-digit number, such as 03144500. The first 2 digits, "03" identifies the Part or hydrologic region used by the Geological Survey for reporting hydrologic data. The next 6 digits is the 
station number which represents the location of the station in the standard downstream order within each of the 16 parts (Fig. 1). The complete number (03144500) appears just to the left of the station name. The assigned numbers are in numerical order but are not consecutive. Gaps are left in the numbers to allow for new stations that may be established.

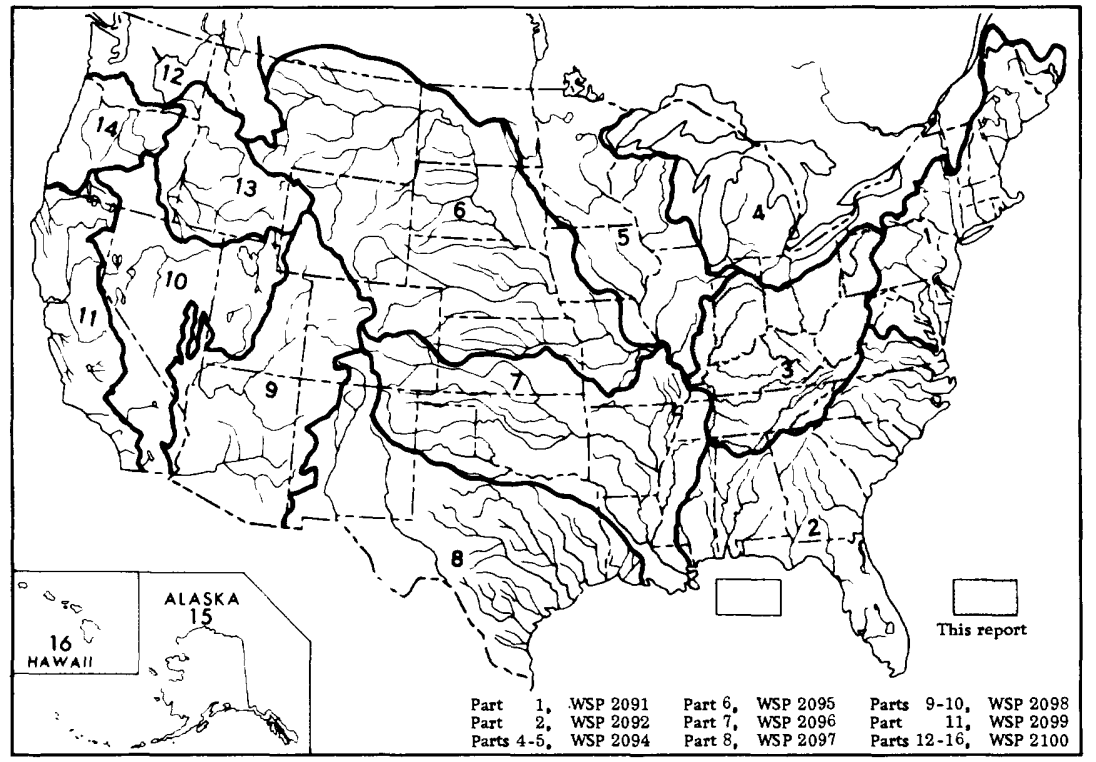

Figure 1.--Map of the United States showing basins covered by the 10 water-supply papers on quality of surface waters in 1968 . The shaded part represents the section of the country covered by this volume; the unshaded part represents the section of the country covered by other water-supply papers.

Descriptive statements are given for each sampling station where chemical analyses, temperature measurements, or sediment determinations have been made. These statements include location of the station, drainage area, periods of records available, extremes of dissolved solids, hardness, specific conductance, temperature, sediment loads, and other pertinent data. Records of discharge of the streams at or near the sampling station are included in most tables of analyses.

During the water year ending September 30, 1968, the Geological Survey maintained 141 stations on 92 streams for the study of chemical and physical characteristics of surface water. Samples were collected daily and monthly at 75 of these locations for chemical-quality studies. Samples also were collected less frequently at many other points. Water temperatures were measured continuously at 67 and daily at 42 stations. All surface water samples collected and analyzed during the year have not been included. Single analyses made of daily samples before compositing have not been reported. Specific conductance is determined and reported for almost all daily samples.

At chemical-quality stations where data are continuously recorded at the stream site (monitors), the records consist of daily maximum, minimum, and mean values for each constituent measured. More detailed records (hourly values) may be obtained by writing the district office listed under Division of Work on page 21 . 
Quantities of suspended sediment are reported for 21 stations during the year ending September 30, 1968. Sediment samples were collected one or more times daily at most stations, depending on the rate of flow and changes in stage of the stream. Particle-size distributions of sediments were not determined.

Some of the stations for which data are published in this volume are included in special networks and programs. These stations are identified by their title, set in parentheses, under the station name.

Hydrologic bench-mark station is one that provides hydrologic data for a basin in which the hydrologic regimen will likely be governed solely by natural conditions. Data collected at a bench-mark station may be used to separate effects of natural from manmade changes in other basins which have been developed and in which the physiography, climate, and geology are similar to those in the undeveloped bench-mark basin.

International Hydrological Decade (IHD) River Stations provide a general index of runoff and materials in the water balance (discharge of water, and dissolved and transported solids) of the world. In the United States, IHD Stations provide indices of runoff and the general distribution of water in the principal river basins of the conterminous United States and Alaska.

Irrigation network stations are water-quality stations located at or near certain streamflow gaging stations west of the main stem of the Mississippi River. Data collected at these stations are used to evaluate the chemical quality of surface waters used for irrigation and the changes resulting from the drainage of irrigated lands. Prior to water year 1966, these data were published in the annual water-supply paper series, "Quality of Surface Water for Irrigation, Western States."

Pesticide program is a network of regularly sampled water-quality stations where additional monthly samples are collected to determine the concentration and distribution of pesticides in streams whose waters are used for irrigation or in streams in areas where potential contamination could result from the application of the commonly used insecticides and herbicides.

Radiochemical program is a network of regularly sampled water-quality stations where additional samples are collected twice a year (at high and low flow) to be analyzed for radioisotopes. The streams that are sampled represent major drainage basins in the conterminous United States.

\section{COLLECTION AND EXAMINATION OF DATA}

Quality of water stations usually are located at or near points on streams where streamflow is measured by the U.S. Geological Survey. The concentration of solutes and sediments at different locations in the stream-cross section may vary widely with different rates of water discharge depending on the source of the material and the turbulence and mixing of the stream. In general, the distribution of sediment in a stream section is much more variable than the distribution of solutes. It is necessary to sample some streams at several verticals across the channel and especially for sediment, to uniformly traverse the depth of flow. These measurements require special sampling equipment to adequately integrate the vertical and lateral variability of the concentration in the section. These procedures yield a velocity-weighted mean concentration for the section.

The near uniformly dispersed ions of the solute load move with the velocity of the transporting water. Accordingly, the mean section concentration of solutes determined from samples is a precise measure of the total solute load. The mean section concentration obtained from suspended sediment samples is a less precise measure of the total sediment load, because the sediment samplers do not traverse the bottom 0.3 foot of the sampling vertical where the concentration of suspended sediment is greatest and because a significant part of the coarser particles in many streams move in essentially continuous contact with the bed and are not represented in the suspended sediment sample. Hence, the computed sediment loads presented 
in this report are usually less than the total sediment loads. For most streams the difference between the computed and total sediment loads will be small, in the order of a few percent.

\section{CHEMICAL QUALITY}

The methods of collecting and compositing water samples for chemical analysis are described by Rainwater and Thatcher (1960) and by Brown, Skougstad, and Fishman (1970). No single method of compositing samples is applicable to all problems related to the study of water quality. Composites are made on the basis of dissolved-solids content as indicated by measurements of conductivity of daily samples, supplemented by other information such as chloride content, river stage, weather conditions and other background information of the stream.

\section{TEMPERATURE}

Daily water temperatures were measured at most of the stations at the time samples were collected for chemical quality or sediment content. So far as practicable, the water temperatures were taken at about the same time each day. Large streams have a small diurnal temperature change while small, shallow streams may have a daily range of several degrees and may follow closely the changes in air temperature. Some streams may be affected by waste-heat discharges.

At stations where continuously recording thermographs are present, the records consist of maximum and minimum temperatures for each day, and the monthly averages.

\section{SEDIMENT}

In general, suspended-sediment samples were collected daily with depth-integrating samplers (U.S. Inter-Agency, 1963). At some stations, samples were collected at a fixed sampling point at one vertical in the cross section. Depth-integrated samples were collected periodically at three or more verticals in the cross section to determine the cross-sectional distribution of the concentration of suspended sediment with respect to that at the daily sampling vertical. In streams where transverse distribution of sediment concentration ranged widely, samples were taken at two or more verticals to define more accurately the average concentration of the cross section. During periods of high or rapidly changing flow, samples generally were taken several times a day and, in some instances, hourly.

Sediment concentrations were determined by filtration-evaporation method. At many stations the daily mean concentration for some days was obtained by plotting the velocity-weighted instantaneous concentrations on the gage-height chart. The plotted concentrations, adjusted if necessary, for cross-sectional distribution were connected or averaged by continuous curves to obtain a concentration graph. This graph represented the estimated velocity-weighted concentration at any time, and for most periods daily mean concentrations were determined from the graph. The days were divided into shorter intervals when the concentration or water discharge were changing rapidly. During some periods of minor variation in concentration, the average concentration of the samples was used as the daily mean concentration. During extended periods of relatively uniform concentration and flow, samples for a number of days were composited to obtain average concentrations and average daily loads for each period. (See Expression of Results, p. 5.)

For periods when no samples were collected, daily loads of suspended sediment were estimated on the basis of water discharge, sediment concentrations observed immediately before and after the periods, and suspended-sediment loads for other periods of similar discharge. The estimates were further guided by precipitation records and sediment discharge at other stations in the same or adjacent basins. 
In many instances where there were no observations for several days, the suspendedsediment loads for individual days were not estimated, because numerous factors influencing the quantities of transported sediment made it very difficult to make accurate estimates for individual days. However, estimated loads of suspended sediment for missing days in an otherwise continuous period of sampling have been included in monthly and annual totals in order to provide a complete record. For some streams, samples were collected weekly, monthly, or less frequently, and only rates of sediment discharge at the time of sampling are shown.

In addition to the records of quantities of suspended sediment transported, records of particle sizes of sediment are included. The particle sizes of suspended sediment for many of the stations, and the particle sizes of the bed material for some of the stations were determined intermittently.

The size of particles carried in suspension by streams commonly ranges from colloids (finer than about 0.24 microns) to coarse sand $(2.0 \mathrm{~mm}$ ). The common methods of particle-size analysis cannot accommodate such a wide range. Hence, it was necessary to separate most samples into two parts, that part coarser than $0.062 \mathrm{~mm}$ and that part finer than $0.062 \mathrm{~mm}$. The separations were made by sieve or by fall velocity technique. The coarse fractions were classified by sieve separation or by visual-accumulation tube (U.S. Inter-Agency, 1957). The fine fractions were classified by the pipet method (Kilmer and Alexander, 1949) or the bottom withdrawal tube method (U.S. Inter-Agency, 1943).

\section{EXPRESSION OF RESULTS}

The quantities of solute concentrations analyzed in the laboratory are measured in milligrams per liter. Milligrams per liter $(\mathrm{mg} / \mathrm{l}, \mathrm{MG} / \mathrm{L})$ is a unit which represents the weight of solute per unit volume of water.

Milliequivalents per liter are not reported but they can be converted easily from milligrams per liter data. A milliequivalent per liter $(\mathrm{me} / \mathrm{l})$ is one thousandth of a gram equivalent weight of a constituent. Chemical equivalence in milliequivalents per liter can be obtained by (a) dividing the concentration in milligrams per liter by the combining weight of that ion, or (b) by multiplying the concentration (in $\mathrm{mg} / \mathrm{l}$ ) by the reciprocals of the combining weights. Table 1 below, lists the reciprocals of the combining atomic weights based on carbon-12 (International Union of Pure and Applied Chemistry, 1961).

Table 1.--Factors for conversion of chemical constituents in milligrams per liter to milliequivalents per liter

Multi-

Ion ply by

Aluminum $\left(\mathrm{Al}^{+3}\right) \ldots \ldots . . .0 .11119$

Ammonia as $\mathrm{NH}^{+1} \ldots \ldots . . . .05544$

Arsenic $\left(\mathrm{As}^{+3}\right) \ldots \ldots . . . . .04004$

Barium $\left(\mathrm{Ba}^{+2}\right) \ldots \ldots . . . . .01456$

Bicarbonate $\left(\mathrm{HCO}_{3}^{-1}\right) \ldots \ldots . .01639$

Bromide $\left(\mathrm{Br}^{-1}\right) \ldots \ldots \ldots . . . .01251$

Cadmium $\left(\mathrm{Cd}^{+2}\right) \ldots \ldots \ldots . \quad .01779$

Calcium $\left(\mathrm{Ca}^{+2}\right) \ldots \ldots \ldots . . . .04990$

Carbonate $\left(\mathrm{CO}_{3}{ }^{-2}\right) \ldots \ldots \ldots . .03333$

Chloride $\left(\mathrm{Cl}^{-1}\right) \ldots \ldots \ldots \ldots . . .02821$

Chromium $(\mathrm{Cr}+6) \ldots \ldots \ldots . .11539$

Cobalt $\left(\mathrm{Co}^{+2}\right) \ldots \ldots \ldots . . . .03394$

Copper $\left(\mathrm{Cu}^{+2}\right) \ldots \ldots \ldots \ldots . . .03148$

Cyanide $\left(\mathrm{CN}^{-1}\right) \ldots \ldots \ldots \ldots . .03844$

Fluoride $\left(\mathrm{F}^{-1}\right) \ldots \ldots \ldots . . .0 .05264$

Hydrogen $\left(\mathrm{H}^{+1}\right) \ldots \ldots \ldots \ldots . .96209$

Hydroxide $\left(\mathrm{OH}^{-1}\right) \ldots \ldots \ldots . \quad .05880$
Multi-

ply by

Iodide $(\mathrm{I}-1) \ldots \ldots \ldots . \ldots 00788$

Iron $\left(\mathrm{Fe}^{+3}\right) \ldots \ldots \ldots . . . . .05372$

Lead $(\mathrm{Pb}+2) \ldots \ldots \ldots . . . . .00965$

Lithium $\left(\mathrm{L}_{\mathrm{i}+1}\right) \ldots \ldots \ldots \ldots . . .14411$

Magnesium $(\mathrm{Mg}+2) \ldots \ldots . . .08226$

Manganese $(\mathrm{Mn}+2) \ldots \ldots . . .03640$

Mercury $\left(\mathrm{Hg}_{+2}\right) \ldots \ldots \ldots \ldots . . .00997$

Nickel $\left(\mathrm{Ni}^{+2}\right) \ldots \ldots . . . . .0 . .03406$

Nitrate $\left(\mathrm{NO}_{3}{ }^{-1}\right) \ldots \ldots \ldots \ldots . . .01613$

Nitrite $\left(\mathrm{NO}_{2}{ }^{-1}\right) \ldots \ldots \ldots \ldots . .02174$

Plosphate $\left(\mathrm{PO}_{4}^{-3}\right) \ldots \ldots . .03159$

Potassium $(K+1) \ldots \ldots . . . .02557$

Sodium $(\mathrm{Na}+1) \ldots \ldots \ldots . . . .04350$

Strontium $\left(\mathrm{Sr}^{+2}\right) \ldots \ldots \ldots \ldots \ldots . .02283$

Sulfate $\left(\mathrm{SO}_{4}^{-2}\right) \ldots \ldots \ldots \ldots . .02082$

Sulfide $(\mathrm{S}-2) \ldots \ldots \ldots \ldots \ldots . \ldots . .006238$

Zinc $(Z n+2) \ldots \ldots \ldots \ldots . . . . . .03060$ 
The hardness of water is conventionally expressed in all water analyses in terms of an equivalent quantity of calcium carbonate. Such a procedure is required because hardness is caused by several different cations, present in variable proportions. It should be remembered that hardness is an expression in conventional terms of a property of water. The actual presence of calcium carbonate in the concentration given is not to be assumed. The hardness caused by calcium and magnesium (and other cations if significant) equivalent to the carbonate and bicarbonate is called carbonate hardness; the hardness in excess of this quantity is called noncarbonate hardness. Hardness or alkalinity values expressed in milligrams per liter as calcium carbonate may be converted to milliequivalents per liter by dividing by 50 .

The value usually reported as dissolved solids is the residue on evaporation after drying at $180^{\circ} \mathrm{C}$ for 1 hour. For some waters, particularly those containing moderately large quantities of soluble salts, the value reported is calculated from the quantities of the various determined constituents using the carbonate equivalent of the reported bicarbonate. The calculated sum of the constituents may be given instead of or in addition to the residue. In the analyses of most waters used for irrigation, the quantity of dissolved solids is given in tons per acre-foot as well as in milligrams per liter.

Specific conductance is given for most analyses and was determined by means of a conductance bridge and using a standard potassium chloride solution as reference. Specific conductance values are expressed in micromhos per centimeter at $25^{\circ} \mathrm{C}$. Specific conductance in micromhos is 1 million times the reciprocal of specific resistance at $25^{\circ} \mathrm{C}$. Specific resistance is the resistance in ohms of a column of water 1 centimeter long and 1 square centimeter in cross section.

The discharge of the streams is reported in cubic feet per second (see Streamflow, p. 19) and the temperature in degrees Celsius ( C). Color is expressed in units of the platinum-cobalt scale proposed by Hazen (1892). A unit of color is produced by one milligram per liter of platinum in the form of the chloroplatinate ion. Hydrogenion concentration is expressed in terms of $\mathrm{pH}$ units. By definition the $\mathrm{pH}$ value of a solution is the negative logarithm of the concentration of gram ions of hydrogen.

An average of analyses for the water year is given for most daily sampling stations. Most of these averages are arithmetical, time-weighted, or discharge-weighted; when analyses during a year are all on 10-day composites of daily samples with no missing days, the arithmetical and time-weighted averages are equivalent. A time-weighted average represents the composition of water that would be contained in a vessel or reservoir that had received equal quantities of water from the river each day for the water year. A discharge-weighted average approximates the composition of water that would be found in a reservoir containing all of the water passing a given station during the year. A discharge-weighted average is computed by multiplying the discharge for the sampling period by the concentrations of individual constituents for the corresponding period and dividing the sum of the products by the sum of the discharges. For most streams, discharge-weighted averages are lower than arithmetical averages because at times of high discharge the rivers generally have low concentrations of dissolved solids.

A program for computing these averages by digital computer was instituted in the 1962 water year. This program extended computations to include averages for $\mathrm{pH}$ values expressed in terms of hydrogen ion and averages for the concentration of individual constituents expressed in tons per day. Concentrations in tons per day are computed the same as daily sediment loads.

The concentration of sediment in milligrams per liter is computed as $1,000,000$ times the ratio of the weight of sediment to the weight of water-sediment mixture. Daily sediment loads are expressed in tons per day and except for subdivided days, are usually obtained by multiplying daily mean sediment concentrations in $\mathrm{mg} / \mathrm{l}$ by the daily mean discharge in cubic feet per second, and the conversion factor, normally 0.0027.

For those days when the published sediment discharge value differs from the value computed, the reader can assume that the sediment discharge for that day was computed by the subdivided-day method. 
Particle-size analyses are expressed in percentages of material finer than classified sizes (in millimeters). The size classification used in this report agrees with recommendations made by the American Geophysical Union Subcommittee on Sediment Terminology. The classification is as follows:

$\begin{array}{ll}\text { Clay: } & \text { Smaller than } 0.004 \mathrm{~mm} \\ \text { Silt: } & \text { Between } 0.004 \text { and } 0.062 \mathrm{~mm} \\ \text { Sand: } & \text { Between } 0.062 \text { and } 2.0 \mathrm{~mm} \\ \text { Gravel: } & \text { Between } 2.0 \text { and } 64.0 \mathrm{~mm}\end{array}$

The particle-size distributicns given in this report are not necessarily representative of the particle sizes of sediment in transport in the natural stream. Most of the organic matter is removed and the sample is subjected to mechanical and chemical dispersion before analysis of the silt and clay.

Prior to the 1968 water year, data for chemical constituents and concentrations of suspended sediment were reported in parts per million (ppm) and water temperatures were reported in degrees Fahrenheit $(F)$. In October 1967, the U.S. Geological Survey began to use the metric system; data for chemical constituents and concentrations of suspended sediment are now reported in milligrams per liter $(\mathrm{mg} / \mathrm{l})$ and water temperatures are given in degrees Celsius (centigrade, ${ }^{\circ} \mathrm{C}$ ). In waters with a density of $1.000 \mathrm{~g} / \mathrm{ml}$ (grams per milliliter), parts per million and milligrams per liter can be considered equal. In waters with a density greater than $1.000 \mathrm{~g} / \mathrm{ml}$, values in parts per million should be multiplied by the density to convert to milligrams per liter. (See table 2 on page 8.) To convert temperature in degrees Celsius to degrees Fahrenheit see table 3 on page 8.

\section{COMPOSITION OF SURFACE WATERS}

All natural waters contain dissolved mineral matter. The quantity of dissolved mineral matter in a natural water depends primarily on the type of rocks or soils with which the water has been in contact and the length of time of contact. Ground water is generally more highly mineralized than surface runoff because it remains in contact with the rocks and soils for much longer periods. Some streams are fed by both surface runoff and ground water from springs or seeps. Such streams reflect the chemical character of their concentrated underground sources during dry periods and are more dilute during periods of heavy rainfall. The dissolved-solids content in a river is frequently increased by drainage from mines or oil fields, by the addition of industrial or municipal wastes, or--in irrigated regions--by drainage from irrigated lands.

The mineral constituents and physical properties of natural waters reported in the tables of analyses include those that have a practical bearing on water use. The results of analyses generally include silica, iron, calcium, magnesium, sodium, potassium (or sodium and potassium together calculated as sodium), carbonate, bicarbonate, sulfate, chloride, fluoride, nitrate, boron, $\mathrm{pH}$, dissolved solids, and specific conductance. Aluminum, manganese, color, acidity, dissolved oxygen, and other dissolved constituents and physical properties are reported for certain streams. Microbiologic (coliforms) and organic components (pesticides, total organic carbon) and minor elements (arsenic, cobalt, cadmium, copper, lead, mercury, nickel, strontium, zinc, etc.) are determined occasionally for some streams in connection with specific problems and the results are reported. The source and significance of the different constituents and properties of natural waters are discussed in the following paragraphs. The constituents are arranged in the order that they appear in the tables.

\section{MINERAL CONSTITUENTS IN SOLUTION}

\section{Silica $\left(\mathrm{SiO}_{2}\right)$}

Silica is dissolved from practically all rocks. Some natural surface waters contain less than 5 milligrams per liter of silica and few contain more than $50 \mathrm{mg} / \mathrm{l}$, but the more common range is from 10 to $30 \mathrm{mg} / \mathrm{l}$. Silica affects the usefulness of a water because it contributes to the formation of boiler scale; it usually is removed from 
Talie 2.--Factors for conversion of sediment concentration in parts per million to milligrams per liter *

[All values calculated to three significant figures]

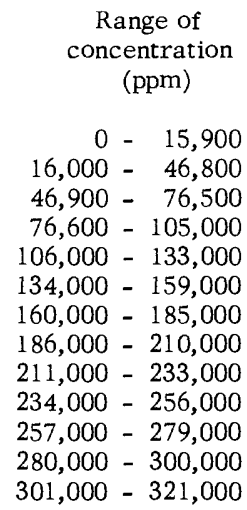

$\begin{aligned} & \text { Multi- } \\ & \text { ply by }\end{aligned}$
1.00
1.02
1.04
1.06
1.08
1.10
1.12
1.14
1.16
1.18
1.20
1.22
1.24
Range of concentration (ppm)

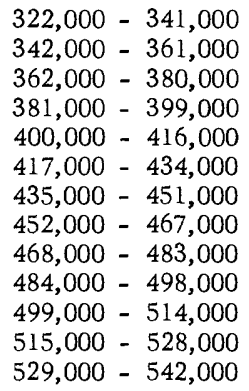

Multiply by

1.32

1.34

1.36

1.38

1.40

1.42

1.44

1.46

1.48

1.50

* Based on water density of $1.000 \mathrm{~g} / \mathrm{ml}$ and sediment density of $2.65 \mathrm{~g} / \mathrm{cc}$.

Table 3.--Degrees Celsius ( $\mathrm{C}$ ) to degrees Fahrenheit $\left({ }^{\circ} \mathrm{F}\right)^{*}$ (Temperature reported to nearest $0.5^{\circ} \mathrm{C}$ )

$\begin{array}{rrrrrrrrrr}{ }^{\circ} \mathrm{C} & { }^{\circ} \mathrm{F} & { }^{\circ} \mathrm{C} & { }^{\circ} \mathrm{F} & { }^{\circ} \mathrm{C} & { }^{\circ} \mathrm{F} & { }^{\circ} \mathrm{C} & { }^{\circ} \mathrm{F} & { }^{\circ} \mathrm{C} & { }^{\circ} \mathrm{F} \\ 0.0 & 32 & 10.0 & 50 & 20.0 & 68 & 30.0 & 86 & 40.0 & 104 \\ .5 & 33 & 10.5 & 51 & 20.5 & 69 & 30.5 & 87 & 40.5 & 105 \\ 1.0 & 34 & 11.0 & 52 & 21.0 & 70 & 31.0 & 88 & 41.0 & 106 \\ 1.5 & 35 & 11.5 & 53 & 21.5 & 71 & 31.5 & 89 & 41.5 & 107 \\ 2.0 & 36 & 12.0 & 54 & 22.0 & 72 & 32.0 & 90 & 42.0 & 108 \\ 2.5 & 36 & 12.5 & 54 & 22.5 & 72 & 32.5 & 90 & 42.5 & 108 \\ 3.0 & 37 & 13.0 & 55 & 23.0 & 73 & 33.0 & 91 & 43.0 & 109 \\ 3.5 & 38 & 13.5 & 56 & 23.5 & 74 & 33.5 & 92 & 43.5 & 110 \\ 4.0 & 39 & 14.0 & 57 & 24.0 & 75 & 34.0 & 93 & 44.0 & 111 \\ 4.5 & 40 & 14.5 & 58 & 24.5 & 76 & 34.5 & 94 & 44.5 & 112 \\ 5.0 & 41 & 15.0 & 59 & 25.0 & 77 & 35.0 & 95 & 45.0 & 113 \\ 5.5 & 42 & 15.5 & 60 & 25.5 & 78 & 35.5 & 96 & 45.5 & 114 \\ 6.0 & 43 & 16.0 & 61 & 26.0 & 79 & 36.0 & 97 & 46.0 & 115 \\ 6.5 & 44 & 16.5 & 62 & 26.5 & 80 & 36.5 & 98 & 46.5 & 116 \\ 7.0 & 45 & 17.0 & 63 & 27.0 & 81 & 37.0 & 99 & 47.0 & 117 \\ 7.5 & 45 & 17.5 & 63 & 27.5 & 81 & 37.5 & 99 & 47.5 & 117 \\ 8.0 & 46 & 18.0 & 64 & 28.0 & 82 & 38.0 & 100 & 48.0 & 118 \\ 8.5 & 47 & 18.5 & 65 & 28.5 & 83 & 38.5 & 101 & 48.5 & 119 \\ 9.0 & 48 & 19.0 & 66 & 29.0 & 84 & 39.0 & 102 & 49.0 & 120 \\ 9.5 & 49 & 19.5 & 67 & 29.5 & 85 & 39.5 & 103 & 49.5 & 121\end{array}$

\footnotetext{
${ }^{*} \mathrm{C}=5 / 9(\mathrm{~F}-32)$ or ${ }^{\circ} \mathrm{F}=9 / 5(\mathrm{C})+32$.
} 
feed water for high-pressure boilers. Silica also forms troublesome deposits on the blades of steam turbines. However, it is not physiologically significant to humans, livestock, or fish, nor is it of importance in irrigation water.

Aluminum (Al)

Aluminum is usually present only in negligible quantities in natural waters except in areas where the waters have been in contact with the more soluble rocks of high aluminum content such as bauxite and certain shales. Acid waters often contain large amounts of aluminum. It may be troublesome in feed waters where it tends to be deposited as a scale on boiler tubes.

Iron $(\mathrm{Fe})$

Iron is dissolved from many rocks and soils. On exposure to air, normal basic waters that contain more than $1 \mathrm{mg} / 1$ of iron soon become turbid with the insoluble reddish ferric compounds produced by oxidation. Surface waters, therefore, seldom contain as much as $1 \mathrm{mg} / 1$ of dissolved iron, although some acid waters carry large quantities of iron in solution. Iron causes reddish-brown stains on porcelain or enameled ware and fixtures and on fabrics washed in the water. Concentrations of more than $0.3 \mathrm{mg} / 1$ are not acceptable for drinking and culinary use. (U.S. Public Health Service, 1962).

Manganese (Mn)

Manganese is dissolved in appreciable quantities from rocks in some sections of the country. It resembles iron in its chemical behavior and in its occurrence in natural waters. However, manganese in rocks is less abundant than iron. As a result the concentration of manganese is much less than that of iron and is not regularly determined in many areas. It is especially objectionable in water used in laundry work and in textile processing. Concentrations as low as $0.2 \mathrm{mg} / 1$ may cause a dark-brown or black stain on fabrics and porcelain fixtures. Appreciable quantities of manganese are often found in waters containing objectionable quantities of iron.

\section{Calćium (Ca)}

Calcium is dissolved from almost all rocks and soils, but the highest concentrations are usually found in waters that have been in contact with limestone, dolomite, and gypsum. Calcium and magnesium make water hard and are largely responsible for the formation of boiler scale. Most waters associated with granite or silicious sands contain less than $10 \mathrm{mg} / 1$ of calcium; waters in areas where rocks are composed of dolomite and limestone contain from 30 to $100 \mathrm{mg} / \mathrm{l}$; and waters that have come in contact with deposits of gypsum may contain several hundred $\mathrm{mg} / \mathrm{l}$.

\section{Magnesium (Mg)}

Magnesium is dissolved from many rocks, particularly from dolomitic rocks. Its effect in water is similar to that of calcium. The magnesium in soft waters may amount to only 1 or $2 \mathrm{mg} / \mathrm{l}$, but water in areas that contain large quantities of dolomite or other magnesium-bearing rocks may contain from 20 to $100 \mathrm{mg} / 1$ or more of magnesium.

Sodium and potassium ( $\mathrm{Na}$ and $\mathrm{K}$ )

Sodium and potassium are dissolved from practically all rocks. Sodium is the predominant cation in some of the more highly mineralized waters found in the western United States. Natural waters that contain only 3 or $4 \mathrm{mg} / \mathrm{l}$ of the two together are likely to carry almost as much potassium as sodium. As the total quantity of these constituents increases, the proportion of sodium becomes much greater. Moderate quantities of sodium and potassium have little effect on the usefulness of the water for most purposes, but waters that carry more than 50 to $100 \mathrm{mg} / 1$ of the two may require careful operation of steam boilers to prevent foaming. More highly mineralized waters that contain a large proportion of sodium salts may be unsatisfactory for irrigation.

Bicarbonate, carbonate and hydroxide $\left(\mathrm{HCO}_{3}, \mathrm{CO}_{3}, \mathrm{OH}\right)$

Bicarbonate, carbonate, or hydroxide is sometimes reported as alkalinity. The alkalinity of a water is produced by anions or molecular species of weak acids which 
are not fully dissociated above a $\mathrm{pH}$ of 4.5 . Since the major causes of alkalinity in most natural waters are carbonate and bicarbonate ions dissolved from carbonate rocks, the results are usually reported in terms of these constituents. Although alkalinity may suggest the presence of definite amounts of carbonate, bicarbonate or hydroxide, there are other ions that contribute to alkalinity such as silicates, phosphates, borates, possibly fluoride, and certain organic anions which may occur in colored waters. The significance of alkalinity to the domestic, agricultural, and industrial user is usually dependent upon the nature of the cations $(\mathrm{Ca}, \mathrm{Mg}, \mathrm{Na}, \mathrm{K}$ ) associated with it. Alkalinity in moderate amounts does not adversely affect most users.

Hydroxide may occur in water that has been softened by the lime process. lts presence in streams usually can be taken as an indication of contamination and does not represent the natural chemical character of the water.

Sulfide (S)

Sulfide occurs in water as a result of bacterial and chemical processes. It usually is present as hydrogen sulfide. Variable amounts may be found in waters receiving sewage and (or) industrial wastes, such as from tanneries, papermills, chemical plants, and gas manufacturing work (California State Water Quality Control Board, 1963).

Waters containing sulfides, especially hydrogen sulfide, may be considered undesirable because of their odor. The U.S. Public Health Service (1962) states that water on carriers subject to Federal quarantine regulations shall have no objectionable taste or odor. The toxicity to aquatic organisms differs significantly with the species and the nature of associated ions.

Sulfate $\left(\mathrm{SO}_{4}\right)$

Sulfate is dissolved from most sedimentary rocks. Large quantities may be derived from beds of gypsum, sodium sulfate deposits, and some types of shale. Organic material containing sulfur adds sulfate to the water as a phase of the sulfur cycle. In natural waters, concentrations range from a few $\mathrm{mg} / \mathrm{l}$ to several thousand $\mathrm{mg} / \mathrm{l}$.

The U.S. Public Health Service (1962) recommends that the sulfate concentration not exceed $250 \mathrm{mg} / 1$ in drinking and culinary water on carriers subject to Federal quarantine regulations.

Sulfates are less toxic to crops than chlorides.

Chloride (Cl)

Chloride is dissolved from rock materials in all parts of the country. Surface waters in the humid regions are usually low in chloride, whereas streams in arid or semiarid regions may contain several hundred $\mathrm{mg} / \mathrm{l}$ of chloride leached from soils and rocks, especially where the streams receive return drainage from irrigated lands or are affected by ground-water-inflow carrying appreciable quantities of chloride. Large quantities of chloride in water that contains a high content of calcium and magnesium increases the water's corrosiveness. The presence of abnormal concentrations of chloride and nitrogenous material together in water supplies indicates possible pollution by human or animal wastes.

Fluoride (F)

Fluoride has been reported as being present in some rocks to about the same extent as chloride. However, the quantity of fluoride in natural surface waters is ordinarily very small compared to that of chloride. Investigations have proved that fluoride concentrations of about 0.6 to $1.7 \mathrm{mg} / \mathrm{l}$ reduced the incidence of dental caries and that concentrations greater than $1.7 \mathrm{mg} / \mathrm{l}$ also protect the teeth from cavities but cause an undesirable black stain (Durfor and Becker, 1964, p. 20). Public Health Service, 1962, states, "When fluoride is naturally present in drinking water, the concentration should not average more than the appropriate upper control limit $(0.6$ to $1.7 \mathrm{mg} / \mathrm{l})$. Presence of fluoride in average concentration greater than two times the optimum values shall constitute grounds for rejection of the supply." Concentration higher than the stated limits may cause mottled enamel in teeth, endemic cumulative fluorosis, and skeletal effects. 


\section{Bromide (Br)}

Bromine is a very minor element in the earth's crust and is normally present in surface waters in only minute quantities. Measurable amounts may be found in some streams that receive industrial wastes, and some natural brines may contain rather high concentrations. It resembles chloride in that it tends to be concentrated in sea water.

Iodide (I)

Iodide is considerably less abundant both in rocks and water than bromine. Measurable amounts may be found in some streams that receive industrial wastes, and some natural brines may contain rather high concentrations. It occurs in sea water to the extent of less than $\mathrm{l} \mathrm{mg} / \mathrm{l}$. Rankama and Sahama (1950) report iodide present in rainwater to the extent of 0.001 to $0.003 \mathrm{mg} / \mathrm{l}$ and in river water in about the same amount. Few waters will contain over $2.0 \mathrm{mg} / \mathrm{l}$.

Nitrogen, organic $(\mathrm{N})$

Organic nitrogen includes all nitrogenous organic compounds, such as amino acid, polypeptides, and proteins. It is present naturally in all surface waters as the result of inflow of nitrogenous products from the watershed and the normal biological life of the stream.

Organic nitrogen is not pathologically significant but is sometimes an indication of pollution.

Nitrogen, ammonia $\left(\mathrm{NH}_{4}\right.$, as $\left.\mathrm{N}\right)$

Ammonia nitrogen includes nitrogen in the forms of $\mathrm{NH}_{3}$ and $\mathrm{NH}_{4}^{+1}$. As a component of the nitrogen cycle, it is often present in water, but usually in only small amounts. More than $0.1 \mathrm{mg} / \mathrm{l}$ usually indicates organic pollution (Rudolph, 1931).

There is no evidence that ammonia nitrogen in water is physiologically significant to man or livestock. Fish, however, cannot tolerate large quantities.

Nitrite $\left(\mathrm{NO}_{2}\right)$

Nitrite is unstable in the presence of oxygen and is, therefore, absent or present in only minute quantities in most natural waters under aerobic condition. The presence of nitrite in water is sometimes an indication of organic pollution.

Recommended tolerances of nitrite in domestic water supplies differ widely. A generally accepted limit is $2 \mathrm{mg} / \mathrm{l}$, but as little as $0.1 \mathrm{mg} / \mathrm{l}$ has been proposed (California State Water Quality Control Board, 1963).

\section{Nitrate $\left(\mathrm{NO}_{3}\right)$}

Nitrate in water is considered a final oxidation product of nitrogenous material and may indicate contamination by sewage or other organic matter, such as agricultural runoff, or industrial waste. The quantities of nitrate present in surface waters are generally less than $5 \mathrm{mg} / \mathrm{l}\left(\right.$ as $\left.\mathrm{NO}_{3}\right)$ and have no effect on the value of the water for ordinary uses.

It has been reported that as much as $2 \mathrm{mg} / \mathrm{l}$ of nitrate in boiler water tends to decrease intercrystalline cracking of boiler steel. Studies made by Faucett and Miller (1946), Waring (1949) and by the National Research Council (Maxcy, 1950) concluded that drinking water containing nitrates in excess of $44 \mathrm{mg} / \mathrm{l}\left(\right.$ as $\mathrm{NO}_{3}$ ) should be regarded as unsafe for infant feeding. U.S. Public Health Service (1962) sets $45 \mathrm{mg} / \mathrm{l}$ as the upper limit.

\section{Phosphorus (P)}

Phosphorus is an essential element in the growth of plants and animals. It occurs in water as organically bound phosphorus or as phosphate $\left(\mathrm{PO}_{4}\right)$. Some sources that contribute nitrate, such as organic wastes are also important sources of phosphorus. The addition of phosphates in water treatment constitutes a possible source although the dosage is usually small. In some areas phosphate fertilizers may yield some phosphorus to water. Another important source is the use of phosphates in detergents. 
Domestic and industrial sewage effluents often contain considerable amounts of phosphorus. Concentrations of phosphorus found in water are not reported to be toxic to man, animal, or fish. However, the element can stimulate the growth of algae, which may cause taste and odor problems in public water treatment and esthetic problems in recreation areas.

Boron (B)

Boron in small quantities has been found essential for plant growth, but irrigation water containing more than $1 \mathrm{mg} / \mathrm{l}$ boron is detrimental to citrus and other boronsensitive crops. Boron is reported in Survey analyses of surface waters in arid and semiarid regions of the Southwest and West where irrigation is practiced or contemplated, but few of the surface waters analyzed have harmful concentrations of boron.

\section{Dissolved solids}

The reported quantity of dissolved solids--the residue on evaporation--consists mainly of the dissolved mineral constituents in the water. It may also contain some organic matter and water of crystallization. Waters with less than $500 \mathrm{mg} / 1$ of dissolved solids are usually satisfactory for domestic and some industrial uses. Water containing several thousand $\mathrm{mg} / \mathrm{l}$ of dissolved solids are sometimes successfully used for irrigation where practices permit the removal of soluble salts through the application of large volumes of water on well-drained lands, but generally water containing more than about $2,000 \mathrm{mg} / 1$ is considered to be unsuitable for long-term irrigation under average conditions.

Arsenic (As)

Arsenic compounds are present naturally in some waters, but the occurrence of quantities detrimental to health is rare. Weed killers, insecticides and many industrial effluents contain arsenic and are potential sources of water pollution. The U.S. Public Health Service (1962) states that the concentration of arsenic in drinking water on carriers subject to Federal quarantine regulations should not exceed $0.01 \mathrm{mg} / 1$ and concentrations in excess of $0.05 \mathrm{mg} / \mathrm{I}$ are grounds for rejection of the supply. Concentrations of 2-4 mg of arsenic per liter are reported not to interfere with the selfpurification of streams (Rudolfs and others, 1944) but concentrations in excess of $15 \mathrm{mg} / 1$ may be harmful to some fish.

\section{Barium (Ba)}

Barium may replace potassium in some of the igneous rock minerals, especially feldspar, and barium sulfate (barite) is a common barium mineral of secondary origin. Only traces of barium are present in surface water and sea water. Because natural water contains sulfate, barium will dissolve only in trace amounts. Barium sometimes occurs in brines from oil-well wastes.

The U.S. Public Health Service (1962) states that water containing concentrations of barium in excess of $1.0 \mathrm{mg} / 1$ is not suitable for drinking and culinary use because of the serious toxic effects of barium on heart, blood vessels, and nerves.

Cadmium (Cd)

This element is found in nature largely in the form of the sulfide, and as an impurity in zinc-lead ores. The carbonate and hydroxide are not very soluble in water and will precipitate at high $\mathrm{pH}$ values; the chloride, nitrate, and sulfate are soluble and remain in solution under most $\mathrm{pH}$ conditions.

The extensive use of the element and its salts in metallurgy, electroplating, ceramics, and photography make it a frequent component of industrial wastes.

The U.S. Public Health Service (1962) established as grounds for rejection any water containing more than $0.01 \mathrm{mg} / 1$ of cadmium.

Chromium (Cr)

Few if any waters contain chromium from natural sources. Natural waters can probably contain only traces of chromium as a cation unless the $\mathrm{pH}$ is very low. When 
chromium is present in water, it is usually the result of pollution by industrial wastes. Concentrations of more than $0.05 \mathrm{mg} / 1$ of chromium in the hexavalent form constitute grounds for rejection of a water for domestic use on the basis of the standards of the U.S. Public Health Service (1962).

Cobalt (Co)

Cobalt occurs in nature in the minerals smaltite, (Co,Ni)As, and cobaltite, CoAsS. Alluvial deposits and soils derived from shales often contain cobalt in the form of phosphate or sulfate, but other soil types may be markedly deficient in cobalt in any form (Bear, 1955). Ruminant animals may be adversely affected by grazing on land deficient in cobalt.

For domestic water supplies, no maximum safe concentration has been established.

Copper (Cu)

Copper is a fairly common trace constituent of natural water. Small amounts may be introduced into water by solution of copper and brass water pipes and other copperbearing equipment in contact with the water, or from copper salts added to control algae in open reservoirs. Copper salts such as the sulfate and chloride are highly soluble in waters with a low $\mathrm{pH}$ but in water of normal alkalinity the salts hydrolyze and the copper may be precipitated. In the normal pH range of natural water containing carbon dioxide, the copper might be precipitated as carbonate. The oxidized portions of sulfide-copper ore bodies contain other copper compounds. The presence of copper in mine water is common.

Copper imparts a disagreeable metallic taste to water. As little as $1.5 \mathrm{mg} / 1 \mathrm{can}$ usually be detected, and $5 \mathrm{mg} / \mathrm{lcan}$ render the water unpalatable. Copper is not considered to be a cumulative systemic poison like lead and mercury; most copper ingested is excreted by the body and very little is retained. The pathological effects of copper are controversial, but it is generally believed very unlikely that humans could unknowingly ingest toxic quantities from palatable drinking water. The U.S. Public Health Service (1962) recommends that copper should not exceed $1.0 \mathrm{mg} / 1$ in drinking and culinary water.

Lead $(\mathrm{Pb})$

Lead seldom occurs in most natural waters, but industrial mine and smelter effluents may contain relatively large amounts of lead which contaminates the streams. Also, atmospheric contamination which is produced from several types of engine exhausts has considerably increased the availability of this element for solution in rainfall, resulting in contamination of lead in streams (Hem, 1970).

Lead in the form of sulfate is reported to be soluble in water to the extent of $31 \mathrm{mg} / 1$ (Seidell, 1940) at $25^{\circ} \mathrm{C}$. In natural water this concentration would not be approached, however, since a $\mathrm{pH}$ of less than 4.5 would probably be required to prevent formation of lead hydroxide and carbonate. It is reported (Pleissner, 1907) that at $18^{\circ} \mathrm{C}$ water free of carbon dioxide will dissolve the equivalent of $1.4 \mathrm{mg} / 1$ of lead and the solubility is increased nearly four fold by the presence of $2.8 \mathrm{mg} / \mathrm{l}$ of carbon dioxide in the solution. Presence of other ions may increase the solubility of lead. Reports on human tolerance of lead vary widely, but the U.S. Public Health Service (1962) states that lead shall not exceed $0.05 \mathrm{mg} / 1$ in drinking and culinary water on carriers subject to Federal quarantine regulations.

Lithium ( $\mathrm{Li}$ )

Lithium is present in some minerals but is not abundant in nature. From available information, most fresh waters rarely contain lithium of concentrations exceeding $10 \mathrm{mg} / \mathrm{l}$, but larger quantities may be present in brines and thermal waters. Lithium is used in metallurgy, medicinal water, and some types of glass and storage batteries. Waste from such industries may contain lithium.

\section{Mercury (Hg)}

Mercury is the only common metal which is liquid at ordinary temperatures. It occurs free in nature but its chief source is cinnabar (HgS). Mercury compounds are virulent culminative poisons which are readily absorbed through the respiratory and gastrointestinal tracts or through unbroken skin (Weast and Selby, 1967). 
The main source of high concentrations of dissolved mercury in water, in the form of highly toxic methyl mercury, $\mathrm{Hg}\left(\mathrm{CH}_{3}\right)_{2}$, comes from waste discharges from industrial users of mercury and from mercurial pesticides.

Fish from streams and lakes subject to mercury contamination have been found to contain amounts of mercury above the safe limits for food consumption. The U.S. Public Health Service has proposed that the upper limits of dissolved mercury in water for domestic use should not exceed 5 micrograms per liter $(0.005 \mathrm{mg} / 1)$. Nickel (Ni)

Elemental nickel seldom occurs in nature, but its compounds are found in many ores and minerals. Many nickel salts are quite soluble and may contribute to water pollution, especially when discharged from metal-plating industries.

The U.S. Public Health Service (1962) has not placed a limit on nickel concentration in public water supplies.

Strontium (Sr)

Strontium is a typical alkaline-earth element and is similar chemically to calcium. Strontium may be present in natural water in amounts up to a few $\mathrm{mg} / \mathrm{l}$ much more frequently than the available data indicate. In most surface water the amount of strontium is small in proportion to calcium. However, in sea water the ratio of strontium to calcium is $1: 30$.

Zinc $(\mathrm{Zn})$

Zinc is abundant in rocks and ores but is only a minor constituent in natural water because the free metal and its oxides are only sparingly soluble. In most alkaline surface waters it is present only in trace quantities, but more may be present in acid water. Chlorides and sulfates of zinc are highly soluble. Zinc is used in many commercial products, and industrial wastes may contain large amounts.

Zinc in water does not cause serious effects on health, but produces undesirable esthetic effects. The U.S. Public Health Service (1962, p. 55) recommends that the zinc content not exceed $5 \mathrm{mg} / 1$ in drinking and culinary water.

\section{PROPERTIES AND CHARACTERISTICS OF WATER}

\section{Dissolved solids}

Theoretically, dissolved solids are anhydrous residues of the dissolved substances in water.

All solutes affect the chemical and physical properties of the water and result in an osmotic pressure. Water with several thousand $\mathrm{mg} / \mathrm{l}$ of dissolved solids is generally not palatable, although those accustomed to highly mineralized water may complain that less concentrated water tastes flat. The U.S. Public Health Service (1962) recommends that the maximum concentration of dissolved solids not exceed $500 \mathrm{mg} / \mathrm{l}$ in drinking and culinary water on carriers subject to Federal quarantine regulations, but permits 1,000 $\mathrm{mg} / 1$ if no better water is available. Reported livestock tolerances range from $3,000 \mathrm{mg} / 1$ (Colorado Agricultural Experiment Station, 1943) to 15,000 $\mathrm{mg} / \mathrm{l}$ (Heller, 1933).

lndustrial tolerances for dissolved solids differ widely, but few industrial processes will permit more than $1,000 \mathrm{mg} / \mathrm{l}$. The Geological Survey classifies the degree of sal inity of these more mineralized bodies of water as follows (Swenson and Baldwin, 1965):

$$
\begin{aligned}
& \text { Dissolved solids }(\mathrm{mg} / \mathrm{l}) \quad \text { Degree of salinity } \\
& \text { Less than 1,000 . . . . . Nonsaline. } \\
& 1,000 \text { to } 3,000 \ldots \text {. . . . Slightly saline. } \\
& 3,000 \text { to } 10,000 \text {. . . . . . . Moderately saline. } \\
& 10,000 \text { to } 35,000 \ldots \text {. . . . Very saline. }
\end{aligned}
$$




\section{Hardness}

Hardness is the characteristic of water that receives the most attention in industrial and domestic use. It is commonly recognized by the increased quantity of soap required to produce lather. The use of hard water is also objectionable because it contributes to the formation of scale in boilers, water heaters, radiators, and pipes, with the resultant decrease in rate of heat transfer, possibility of boiler failure, and loss of flow.

Hardness is caused almost entirely by compounds of calcium and magnesium. Other constituents--such as iron, manganese, aluminum, barium, strontium, and free acid--also cause hardness, although they usually are not present in quantities large enough to have any appreciable effect.

Generally, bicarbonate and carbonate determine the proportions of "carbonate" hardness of water. Carbonate hardness is the amount of hardness chemically equivalent to the amount of bicarbonate and carbonate in solution. Carbonate hardness is approximately equal to the amount of hardness that is removed from water by boiling.

Noncarbonate hardness is the difference between the hardness calculated from the total amount of calcium and magnesium in solution and the carbonate hardness. The scale formed at high temperatures by the evaporation of water containing noncarbonate hardness commonly is tough, heat resistant, and difficult to remove.

Although many people talk about soft water and hard water, there has been no firm line of demarcation. Water that seems hard to an easterner may seem soft to a westerner. In this report hardness of water is classified as follows:

\begin{tabular}{|c|c|}
\hline $\begin{array}{l}\text { Hardness range } \\
\text { (calcium carbonate in } \mathrm{mg} / \mathrm{l} \text { ) }\end{array}$ & Hardness description \\
\hline $\begin{array}{l}0-60 \\
61-120 . \\
121-180 \\
\text { More than } 180 .\end{array}$ & $\begin{array}{l}\text { Soft } \\
\text { Moderately hard } \\
\text { Hard } \\
\text { Very hard }\end{array}$ \\
\hline
\end{tabular}

Durfor and Becker, 1964, p. 23-27.

Acidity $\left(\mathrm{H}^{+1}\right)$

The use of the terms acidity and alkalinity is widespread in the literature of water analysis and is a cause of confusion to those who are more accustomed to seeing a $\mathrm{pH}$ of 7.0 used as a neutral point. Acidity of a natural water represents the content of free carbon dioxide and other uncombined gases, organic acids and salts of strong acids and weak bases that hydrolyze to give hydrogen ions. Sulfates of iron and aluminum in mine and industrial wastes are common sources of acidity.

Sodium adsorption ratio (SAR)

The term "sodium adsorption ratio (SAR)" was introduced by the U.S. Salinity Laboratory Staff (1954). It is a ratio expressing the relative activity of sodium ions in exchange reaction with soil and is an index of the sodium or alkali hazard to the soil. Sodium adsorption ratio is expressed by the equation:

$$
\mathrm{SAR}=\frac{\mathrm{Na}^{+}}{\sqrt{\frac{\mathrm{Ca}^{++}+\mathrm{Nig}^{++}}{2}}}
$$

where the concentrations of the ions are expressed in milliequivalents per liter.

Waters are divided into four classes with respect to sodium or alkali hazard: low, medium, high, and very high, depending upon the SAR and the specific conductance. At a conductance of 100 micromhos per centimeter the dividing points are at SAR values of 10,18 , and 26 , but at 5,000 micromhos the corresponding dividing points are SAR values of approximately $2.5,6.5$, and 11 . Waters range in respect to sodium hazard from those which can be used for irrigation on almost all soils to those which are generally unsatisfactory for irrigation. 
Specific conductance (micromhos per centimeter at $25^{\circ} \mathrm{C}$ )

Specific conductance is a convenient, rapid determination used to estimate the amount of dissolved solids in water. It is a measure of the ability of water to transmit a small electrical current (see p. 6). The more dissolved solids in water that can transmit electricity the greater the specific conductance of the water. Commonly, the amount of dissolved solids (in $\mathrm{mg} / \mathrm{l}$ ) is about 65 percent of the specific conductance (in micromhos). This relation is not constant from stream to stream or from well to well and it may even vary in the same source with changes in the composition of the water (Durfor and Becker, 1964 p. 27-29).

Specific conductance of most waters in the eastern United States is less than 1,000 micromhos, but in the arid western parts of the country, a specific conductance of more than 1,000 micromhos is common.

Hydrogen-ion concentration $(\mathrm{pH})$

Hydrogen-ion concentration is expressed in terms of $\mathrm{pH}$ units (see p. 6). The values of $\mathrm{pH}$ often are used as a measure of the solvent power of water or as an indicator of the chemical behavior certain solutions may have toward rock minerals.

The degree of acidity or alkalinity of water, as indicated by the hydrogen-ion concentration, expressed as $\mathrm{pH}$, is related to the corrosive properties of water and is useful in determining the proper treatment for coagulation that may be necessary at water-treatment plants. $\mathrm{A} \mathrm{pH}$ of 7.0 indicates that the water is neither acid nor alkaline. $\mathrm{pH}$ readings progressively lower than 7.0 denote increasing acidity and those progressively higher than 7.0 denote increasing alkalinity. The $\mathrm{pH}$ of most natural surface waters ranges between 6 and 8 . Some alkaline surface waters have pH values greater than 8.0 and waters containing free mineral acid or organic matter usually have pH values less than 4.5 .

The investigator who utilizes $\mathrm{pH}$ data in his interpretations of water analyses should be careful to place $\mathrm{pH}$ values in their proper perspective.

\section{Temperature}

Temperature is an important factor in properly determining the quality of water. This is very evident for such a direct use as an industrial coolant. Temperature is also important, but perhaps not so evident, for its indirect influence upon aquatic biota, concentrations of dissolved gases, and distribution of chemical solutes in lakes and reservoirs as a consequence of thermal stratification and variation.

Surface water temperaturestend to change seasonally and daily with air temperatures, except for the outflow of large springs. Superimposed upon the annual temperature cycle is a daily fluctuation of temperature which is greater in warm seasons than in cold and greater in sunny periods than with a cloud cover. Natural warming is due mainly to absorption of a solar radiation by the water and secondarily to transfer of heat from the air. Condensation of water vapor at the water surface is reported to furnish measurable quantities of heat. Heat loss takes place largely through radiation, with further losses through evaporation and conduction to the air and to the streambed. Thus the temperature of a small stream generally reaches a maximum in mid- to late afternoon due to solar heating and reaches a minimum from early to mid-morning after nocturnal radiation.

Color

In water analysis the term "color" refers to the appearance of water that is free from suspended solids. Many turbid waters that appear yellow, red, or brown when viewed in the stream show very little color after the suspended matter has been removed. The yellow-to-brown color of some waters is usually caused by organic matter extracted from leaves, roots, and other organic substances in the ground. In some areas objectionable color in water results from industrial wastes and sewage. Clear deep water may appear blue as the result of a scattering of sunlight by the water molecules. Water for domestic use and some industrial uses should be free from any perceptible color. A color less than 15 units generally passes unnoticed (U.S. Public Health Service, 1962). Some swamp waters have natural color in excess of 300 units. 
The extent to which a water is colored by material in solution is commonly reported as a part of a water analysis because a significant color in water may indicate the presence of organic material that may have some bearing on the dissolved solids content. Color in water is expressed in terms of units between 0 and 500 or more based on the above standard (see p. 6).

Turbidity

Turbidity is the optical property of a suspension with reference to the extent to which the penetration of light is inhibited by the presence of insoluble material. Turbidity is a function of both the concentration and particle size of the suspended material. It is reported in terms of $\mathrm{mg} / 1$ of silica or Jackson turbidity units (JTU).

Turbid water is abrasive in pipes, pumps, and turbine blades. Although turbidity does not directly measure the safety of drinking water, it is related to the consumer's acceptance of the water. A level of $5 \mathrm{JTU}$ of turbidity becomes objectionable to a considerable number of people (U.S. Public Health, 1962).

Density at $20^{\circ} \mathrm{C}$

Density is the mass of any substance per unit volume at a designated standard temperature. Density should not be confused with specific gravity, which is a massto-mass relation.

The density value has some use in industries that utilize brines and whose basic unit of concentration of dissolved material is density. Density is used primarily by the chemist in the computation of milligrams per liter for highly mineralized waters.

Dissolved oxygen (DO)

Oxygen dissolved in water is derived from the air and from the oxygen given off in the process of photosynthesis by aquatic plants.

Dissolved oxygen in water has no adverse physiological effect and actually increases the palatability of the water. No minimum concentration of dissolved oxygen required to support fish life has been listed because the oxygen requirements of fish vary with the species and age, with temperature, and with concentration of other substances in the water.

Dissolved oxygen is responsible for many of the corrosion problems in industry. Chemical Oxygen demand (COD)

Chemical oxygen demand is a measure of the chemically oxidizable material in the water, and furnishes an approximation of the amount of organic and reducing material present. The determined value may correlate with natural-water color or with carbonaceous organic pollution from sewage or industrial wastes.

Biochemical oxygen demand (BOD)

Biochemical oxygen demand is a measure of the oxygen required to oxidize the organic material usable as a source of food by aerobic organisms.

Biological and microbiological information

Biological and microbiological information is an important aspect in the evaluation of water quality. The kinds and amount of aquatic biota in a stream or lake can be useful "indicators" of environmental conditions and particularly of the degree of pollution of water with organic wastes (Doudoroff and Warren, 1957). Biological information includes qualitative and quantitative analyses of plankton, bottom organisms, and particulate inorganic and amorphous matter present. Microbiological information includes quantitative identification of certain bacteriological indicator organisms.

Chlorophyll (plant pigment).--The concentrations of photosynthetic pigments in natural waters vary with time and changing aquatic conditions. Concentrations of chlorophyll $\mathrm{a}, \underline{b}$, and $\underline{c}$ (spectrophotometric determination) are used to estimate the biomass and photosynthetic capacity of phytoplankton (blue-green algae). Ratios between the different forms of chlorophyll are thought to indicate the taxonomic composition or the physiological state of the algae community (Slack, 1970). 
Plankton.--Plankton is the floating (or weakly swimming) animal or plant life in a body of water consisting, chiefly of minute plants (as diatomes and blue-green algae) and of minute animals (as protozoan, entomostracans and various larvae). Algae are known to cause tastes and odor in water supply.

Plankton population in water is obtained by count level (the number of organisms per milliliter).

Coliform bacteria.--Coliform organisms have long been used as indicators of sewage pollution, although the group includes bacteria from diverse natural sources and habitats. For example, members of the coliform group are indigenous to soil and vegetation as well as feces. Standards for drinking-water quality provide definite minimums as to number of samples examined and the maximum number of coliform organisms allowable per 100 milliliters ( $\mathrm{ml}$ ) of finished water (Slack, 1970). The coliform population of water is determined either by the most probable number (MPN), or by the incubation membrane filter method, a direct count of coliform colonies per plate.

Fecal coliform bacteria.--Fecal coliform is that portion of the coliform group that is present in the intestinal tract of warm-blooded animals and is capable of producing gas from lactos in suitable culture medium at $44.5^{\circ} \mathrm{C}$. Organisms from other sources generally cannot produce gas in this manner. (American Public Health Assoc. and others, 1965). Thus, in general, the presence of fecal coliform organisms indicates recent pollution (Slack, 1970).

\section{Organics}

Phenols.-- Phenolic material in water resources is invariably the result of pollution. Phenols are widely used as disinfectants and in the synthesis of many organic compounds. Waste products from oil refineries, coke areas, and chemical plants may contain high concentrations. Fortunately, phenols decompose in the presence of oxygen and microorganisms, and their persistence downstream from point of entry is relatively short lived. The rate of decomposition is dependent on the environment.

Very low concentrations impart such a disagreeable taste to water that it is highly improbable that harmful amounts could be consumed unknowingly. Reported thresholds of detection of taste and odor range from 0.001 to $0.01 \mathrm{mg} / 1$.

Cyanide $(\mathrm{CN})$.-- Cyanides are not found free in nature, but may become contaminants of water supplies by means of effluents from gasworks, coke ovens, steel mills, electroplating processes, and chemical industries. In natural streams and organic soils, simple cyanides are decomposed by bacterial action, whereas the metal-cyanide complexes are often quite stable and more resistant to degradation. The U.S. Public Health Service (1962) set a recommended limit of $0.01 \mathrm{mg}$ cyanide per liter and a mandatory limit of $0.2 \mathrm{mg} / 1$ for waters subject to interstate regulations.

Detergents (methylene blue active substance, MBAS).--Anionic surfactants in detergents resist chemical oxidation and biological breakdown. Soap is an example of this class and the synthetic members are sodium salts of organic sulfonates or sulfates (Rose, 1966). Their persistence in water over long periods of time contributes to pollution of both ground water and surface water. Some of the effects produced from detergent pollution are unpleasant taste, odor, and foaming (Wayman, and others, 1962). Although the physiological implications of MBAS to human beings is unknown, prolonged ingestion of this material by rats is believed to be nontoxic (Paynter, 1960). The U.S. Public Health Service (1962) recommends that MBAS should not exceed $0.5 \mathrm{mg} / \mathrm{l}$ in drinking and culinary waters.

Total Organic Carbon (TOC).--Total organic carbon is a measure of the organically related carbonaceous content of water. It includes all natural and manmade organic compounds which are combustable at a temperature of $950^{\circ} \mathrm{C}$.

\section{Sediment}

Fluvial sediment generally is regarded as that material which is transported by, suspended in, or deposited by water. Suspended sediment is that part which remains in suspension in water owing to the upward components of turbulent currents or by 
colloidal suspension. Much fluvial sediment results from the natural process of erosion, which in turn is part of the geologic cycle of rock transformation. This natural process may be accelerated by agricultural practices. Sediment also is contributed by a number of industrial and construction activities. In certain sections, waste materials from mining, logging, oil-field, and other industrial operations introduce large quantities of suspended material.

The quantity of sediment, transported or available for transportation, is affected by climatic conditions, form or nature of precipitation, character of the solid mantle, plant cover, topography, and land use. The mode and rate of sediment erosion, transport, and deposition is determined largely by the size distribution of the particles or more precisely by the fall velocities of the particles in water. Sediment particles in the sand size range (larger than $0.062 \mathrm{~mm}$ ) do not appear to be affected by flocculation or dispersion resulting from the mineral constituents in solution. In contrast, the sedimentation diameter of clay and silt particles in suspension may vary considerably from point to point in a stream or reservoir, depending on the mineral matter in solution and in suspension and the degree of turbulence present. The size of sediment particles in transport at any point depends on the type of erodible and soluble material in the drainage area, the degree of flocculation present, time in transport, and characteristics of the transporting flow. The flow characteristics include velocity of water, turbulence, and the depth, width, and roughness of the channel. As a result of these variable characteristics, the size of particles transported, as well as the total sediment load, is in constant adjustment with the characteristics and physical features of the stream and drainage area.

\section{STREAMFLOW}

Most of the records of stream discharge, used in conjunction with the chemical analyses and in the computation of sediment loads in this volume, are published in the Geological Survey water-supply paper series, "Surface Water Supply of the United States, 1966-70." The discharge reported for a composite sample is usually the average of daily mean discharges for the composite period. The discharges reported in the tables of single analyses are either daily meandischarges or discharges obtained the time samples were collected and computed from a stage-discharge relation or from a discharge measurement.

\section{PUBLICATIONS}

Reports giving records of chemical quality and temperatures of surface waters and suspended-sediment loads of streams in the area covered by this volume for the water years 1941-68, are listed below:

Numbers of water-supply papers containing records for Part 3, 1941-68

$\begin{array}{lrllllll}\text { Year } & \text { WSP } & \text { Year } & \text { WSP } & \text { Year } & \text { WSP } & \text { Year } & \text { WSP } \\ 1941 & 942 & 1948 & 1132 & 1955 & 1400 & 1962 & 1942 \\ 1942 & 950 & 1949 & 1162 & 1956 & 1450 & 1963 & 1948 \\ 1943 & 970 & 1950 & 1186 & 1957 & 1520 & 1964 & 1955 \\ 1944 & 1022 & 1951 & 1197 & 1958 & 1571 & 1965 & 1962 \\ 1945 & 1030 & 1952 & 1250 & 1959 & 1642 & 1966 & 1992 \\ 1946 & 1050 & 1953 & 1290 & 1960 & 1742 & 1967 & 2012 \\ 1947 & 1102 & 1954 & 1350 & 1961 & 1882 & 1968 & 2093\end{array}$

Geological Survey reports containing chemical quality, temperature, and sediment data obtained before 1941 are listed on next page. Publications dealing largely with the quality of ground-water supplies and only incidentally covering the chemical composition of surface waters are not included. Publications that are out of print are preceded by an asterisk. 
PROFESSIONAL PAPER

*135. Composition of river and lake waters of the United States, 1924.

BULLETINS

*479. The geochemical interpretation of water analyses, 1911.

770. The data of geochemistry, 1924.

WATER-SUPPLY PAPERS

*108. Quality of water in the Susquehanna River drainage basin, with an introductory chapter on physiographic features, 1904.

*161. Quality of water in the upper Ohio River basin and at Erie, Pa., 1906.

*193. The quality of surface waters in Minnesota, 1907.

*236. The quality of surface waters in the United States, Part 1, Analyses of waters east of the one hundredth meridian, 1909.

*237. The quality of the surface waters of California, 1910.

*239. The quality of surface waters of lllinois, 1910.

*273. Quality of the water supplies of Kansas, with a preliminary report on stream pollution by mine waters in southeastern Kansas, 1911.

*274. Some stream waters of the western United States, with chapters on sediment carried by the Rio Grande and the industrial application of water analyses, 1911.

*339. Quality of the surface waters of Washington, 1914.

*363. Quality of the surface waters of Oregon, 1914.

*418. Mineral springs of Alaska, with a chapter on the chemical character of some surface waters of Alaska, 1917.

*596-B. Quality of water of Colorado River in 1925-26, 1928.

*596-D. Quality of water of Pecos River in Texas, 1928.

*596-E. Quality of the surface waters of New Jersey, 1928.

*636-A. Quality of water of the Colorado River in 1926-28, 1930 .

*636-B. Suspended matter in the Colorado River in 1925-28, 1930.

*638-D. Quality of water of the Colorado River in 1928-30, 1932.

*839. Quality of water of the Rio Grande basin above Fort Quitman, Tex., 1938.

*889-E. Chemical character of surface water of Georgia, 1944.

*998. Suspended sediment in the Colorado River, 1925-41, 1947.

1048. Discharge and sediment loads in the Boise River drainage basin, Idaho, 1939-40, 1948.

1110-C. Quality of water of Conchas Reservoir, New Mexico, 1939-49, 1952.

Many of the reports listed are available for consultation in the larger public and institutional libraries. Copies of Geological Survey publications still in print may be purchased at a nominal cost from the Superintendent of Documents, Government Printing Office, Washington, D.C. 20402, who will, upon request, furnish lists giving prices.

\section{COOPERATION}

Many Municipal, State and Federal agencies assisted in collecting records for these quality-of-water investigations. Many of the investigations were supported by funds appropriated directly to the U.S. Geological Survey. The State, local, and Federal agencies that cooperated in these quality-of-water investigations are listed below:

Alabama--Geological Survey of Alabama, P. E. LaMoreaux, State geologist; Tennessee Valley Authority.

Illinois--Illinois State Department of Public Works and Buildings, F. S. Lorenz, succeeded by Norbert Johnson, director, through Division of Waterways, J. C. Guillou, 
chief waterway engineer; Ohio River Valley Water Sanitation Commission (including the States of Indiana, Kentucky, Ohio, and West Virginia), R. K. Horton, executive director and chief engineer.

Indiana--Indiana Department of Natural Resources, F. P. Provost, director, through Bureau of Water and Mineral Resources, W. J. Andrews, deputy director; Indiana Board of Health, A. C. Offuct, commissioner, and B. A. Poole, director, Bureau of Environmental Sanitation; Indiana State Highway Commission, R. W. Steele, chairman, R. H. Harrell, executive director, and F. L. Ashbaucher, chief engineer.

Kentucky--University of Kentucky, J. W. Oswald, president, succeeded by A. D. Kirwan, through State Geological Survey, W. W. Hagan, director and State geologist; Lexington and Fayette County Planning Commission, W. H. Qualls, executive director; Tennessee Valley Authority; National Park Service, U.S. Department of the Interior; Corps of Engineers, U.S. Army.

Maryland--Maryland Geological Survey, K. N. Weaver, director; Maryland National Park and Planning Commission, J. S. Hewins, director.

New York--New York State Department of Health, Environmental Health Service, D. F. Metzler, deputy commissioner; New York State Department of Conservation, Division of Water Resources, F. W. Montanari, assistant commissioner; Atomic Energy Commission.

North Carolina--North Carolina Department of Water Resources, G. E. Pickett, director; Soil Conservation Service, U.S. Department of Agriculture.

Ohio--Ohio Department of Natural Resources, F. E. Morr, director, and C. V. Youngquist, chief, Division of Water; Ohio Department of Health, Dr. E. W. Arnold, director, and G. H. Eagle, chief engineer; Miami Conservancy District, M. L. Mitchell, chief engineer.

Pennsylvania-- Pennsylvania Department of Forests and Waters, M. K. Goddard, secretary, through Water and Power Resources Board, C. H. McConnell, chief engineer; Pennsylvania Department of Agriculture, L. H. Bull, secretary, through Soil and Water Conservation Commission, C. F. Hess, director.

Tennessee--Tennessee Department of Conservation, E. B. Garrett, commissioner, through Division of Water Resources, R. W. Robinson, director; Tennessee Valley Authority.

Virginia--Virginia Department of Conservation and Economic Development, M. M. Sutherland, director; Corps of Engineers, U.S. Army.

West Virginia--West Virginia Department of Natural Resources, T. R. Samsell, director, through Division of Water Resources, E. N. Henry, chief; Corps of Engineers, U.S. Army.

\section{DIVISION OF WORK}

The quality-of-water work was performed by the Water Resources Division of the Geological Survey, E. L. Hendricks, chief hydrologist, and under the direction of the district chiefs listed in the preface.

Correspondence regarding the records in this report or any additional information should be directed to the district chief of the appropriate Geological Survey-Water Resources Division district office as indicated in the following table.

State

Alabama

Illinois

Indiana
District Office

Tuscaloosa 35486

Champaign 61820

Indianapolis 46202
Address

P. O. Box V

University, Ala.

P. O. Box 1026

605 N. Neil Street

1819 N. Meridian St. 
State

Kentucky

Maryland

New York

North Carolina

Ohio

Pennsylvania

Tennessee

Virginia

West Virginia
District Office

Louisville 40202

Parkville 21234

Albany 12201

Raleigh 27602

Columbus 43212

Harrisburg 17108

Nashville 37203

Richmond 23220

Charleston 25301
Address

Room 572,

Federal Bldg.

600 Federal Place

8809 Satyr Hill Road

P. O. Box 948

Room 343, U.S. Post

Office and Court House

P. O. Box 2857

Room 440, Century Sta.

P. O. Bldg.

975 West Third Avenue

P. O. Box 1107 4th Floor, Federal Bldg. 228 Walnut Street

144 Federal Office Bldg.

Room 304

200 West Grace St.

Room 3303

Federal Bldg. and

U.S. Court House

500 Quarrier St., East

\section{LITERATURE CITED}

Bartsch, A. F., 1948, Biological aspects of stream pollution: Sewage Works Jour., vol. 20 , p. $292-302$.

Bear, F. E., 1955, Chemistry of the soil: New York, Reinhold Co., 373 p.

Brown, Eugene, Skougstad, M. W., and Fishman, M. J., 1970, Methods for collection and analysis of water samples for dissolved minerals and gases: U.S. Geol. Survey Techniques of Water-Resources lnv., book 5, chap. A1, 160 p.

California State Water Quality Control Board, 1963, Water quality criteria: Pub. 3-A, p. 226.

Colorado Agriculture Experiment Station, 1943, Mineral tolerances in livestock drinking water: 56 th Ann. Rept.

Doudoroff, Peter and Warren, C. E., 1957, Biological indices of water pollution with special reference to fish populations; Biological problems in water pollution: Cincinnati, U.S. Pub. Health Service, Robert A. Taft Sanitary Eng. Cent., p. 144-163.

Durfor, C. N. and Becker, E., 1964, Public water supplies of the 100 largest cities in the United States; 1962: U.S. Geol. Survey Water-Supply Paper 1812, p. 20.

Faucett, R. L, and Miller, H. C., 1946, Methemoglobinemia occuring in infants fed milk diluted with well waters of high nitrate content: Jour. Pediatrics, v. 29, p. 593.

Hazen, Allen, 1892, A new color standard for natural waters: Am. Chem. Jour. v. 12, p. 427-428.

Heller, V. G., 1933, The effect of saline and alkaline waters on domestic animals: Oklahoma Agr. Mech. Coll. Expt. Sta. Bull. 217.

Hem, J. D., 1970, Study and interpretation of chemical characteristics of natural water, revised edition: U.S. Geol. Survey Water-Supply Paper 1473, 363 p.

International Union of Pure and Applied Chemistry, 1961, Table of Atomic weights based on carbon-12: Chem. and Eng. News, v. 39, no. 42, Nov. 20, 1961, p. 43.

Kilmer, V. J. and Alexander, L. T., 1949, Methods of making mechanical analyses of soils: Soil Sci., v. 68, p. $15-24$.

Lane, E. W., and others, 1947, Report of the Subcommittee on sediment terminology: Am. Geophys. Union Trans., v. 28, no. 6, p. 936-938.

Magistad, O. C., and Christiansen, J. E., 1944, Saline Soils, their nature and management: U.S. Dept., Agriculture Circ. 707, p. 8-9. 
Maxcy, K. F., 1950, Report on the relation of nitrate concentrations in well waters to the occurrence of methemoglobinemia: Natl. Research Council, Bull. Sanitary Eng. and Environment, App. D., p. 271.

Paynter, O. E., 1960, The chronic toxicity of dodecylbenzene sodium sulfonate: U.S. Public Health Conference on Physiological Aspects of Water Quality Proc., Washington, D.C., Sept. 8-9, 1960, p. 175-179.

Pleissner, M., 1907, Uber die Löslichkeit eimiger Bleiverbindungen in wasser: Arb. Kais. Gesundeitsamt. v. 26, p. 384-443.

Rainwater, F. H., and Thatcher, L. L., 1960, Methods for collection and analysis of water samples: U.S. Geol. Survey Water-Supply Paper 1454, 301 p.

Rankama, K., and Sahama, T. G., 1950, Geochemistry: Chicago Univ. Press, Chicago, Ill., p. 767.

Riffenburg, H. B., 1925, Chemical character of ground waters of the northern Great Plains: U.S. Geol. Survey Water-Supply Paper 560-B, p. 31-52.

Rose, Arthur and Elizabeth, 1966, The condensed chemical dictionary: Reinhold Pub. Corp., New York, 7th ed., p. 285.

Rudolfs, Willem, and others, 1944, Critical review of the literature of 1943: Sewage Works Jour., v. 16, p. 222.

Rudolph, Z, 1931, Principles of the determination of the physical and chemical standards of water for drinking, industrial, and domestic purposes: Water Pollution Abs. 4 (March).

Seidell, Atherton, 1940, Solubilities of inorganic and metal organic compounds, 3d ed., v. 1, D. van Nostrand, New York. p. 1409.

Slack, K. V., 1970, Selected interim procedures for biological and microbiological investigations: U.S. Geol. Survey, Water Resources Division, preliminary rept. by WRD Committee on Biology and Microbiology, 80 p. (open file).

Swenson, H. A. and Baldwin, H. L., 1965, A Primer on water quality: Washington, U.S. Govt. Printing Office, 27 p.

U.S. Inter-Agency Committee on Water Resources, Subcommittee on Sedimentation, A study of methods used in measurement and analysis of sediment loads in streams. Published by the St. Anthony Falls Hydraulic Laboratory, Minneapolis, Minn. 1943, A study of new methods of size analysis of suspended-sediment samplers, Rept. 7.

1957. The development and calibration of visual-accumulation tube: Rept 11 . 1957, Some fundamentals of particle-size analysis: Rept. 12.

1959, Federal Inter-agency sedimentation instruments and reports: Rept. AA. 1963, Determinations of fluvial sediment discharge: Rept. 14.

U.S. Public Health Service, 1962, Drinking water standards: U.S. Dept. Health, Education, and Welfare, Public Health Service: Pub. no. 956.

U.S. Salinity Laboratory Staff, 1954, Diagnosis and improvement of saline and alkali soils: U.S. Dept. Agriculture, Agriculture Handb. 60, p. 1-160.

Waring, F. H., 1949, Significance of nitrates in water supplies: Am. Water Works Assoc. Jour., v. 41 , no. 2 ., p. 147-150.

Wayman, C. H., 1962, Limitations of the methylene blue method for ABS determinations: U.S. Geol. Survey, Prof. Paper 450-B, art. 49, p. B117-B120.

Wayman, C. H., Robertson, J. B., and Page, H. G., 1962, Foaming characteristics of synthetic-detergent solutions: U.S. Geol. Survey, Prof. Paper 450D, art. 178, p. D198.

Weast, R. C. and Selby, S. M., 1967, Handbook of chemistry and physics: Cleveland, The Chem. Rubber Co., 48th ed., p. B-120-121. 
PART 3, OHIO RIVER BASIN

OHIO RIVER MAIN STEM

03012500 ALLEGHENY RIVER NEAR KINZUA, PA.

LOCATION. --Lat $41^{\circ} 49^{\prime} 25^{\prime \prime}$, long $79^{\circ} 07^{\prime} 10^{\prime \prime}$, Warren County, at bridge on U.S. Highway $6,6.9 \mathrm{miles}$ downstream from Kinzua Dam, and at mile 191.2 .

DRAINAGE AREA. $--2,223 \mathrm{sq} \mathrm{m} 1$.

PERIOD OF RECORD.--Chemical analyses: October 1948 to September 1951, October 1961 to September 1968.

Water temperatures: October 1948 to September 1951, October 1961 to September 1968.

EXTREMES. - -1967-68:

Specific conductance: Maximum daily, 302 micromhos Mar. 18; minimum da1ly, 46 micromhos Mar. 23.

water temperatures: Maximum, $22.0^{\circ} \mathrm{C}$ Aug. 23-25; minimum, $1.0^{\circ} \mathrm{C}$ on several days during January to March.

Period of record:

Dissolved sol ids (1948-49): Maximum, $573 \mathrm{mg} / 1$ Sept. 11-20, 1949; minimum, $100 \mathrm{mg} / 1$ Apr. $11-20,1949$.

Spectffc conductance: Maximum dal1y, 1,110 micromhos oct. 13, 1948; minimum daily, 43 micromhos Jan. 22,1962

water temperatures: Maximum, $29.0^{\circ} \mathrm{C}$ Juiy 13,14,1949; minimum, freezing point on many days during inter periods.

REMARKS.--Samples collected on Oct. 25, Dec. 8, Jan. 5, Feb. 2, Apr. 18, June 6, 13, July 2, 23, and Sept. 5 are 3 point cross sections composited.

CHEMICAL ANALYSES IN MILLIGRAMS PER LITER, WATER YEAR OCTOBER 1967 TO SEPTEMBER 1968

\begin{tabular}{|c|c|c|c|c|c|c|c|c|c|c|c|}
\hline DATE & $\begin{array}{l}\text { MEAN } \\
\text { DIS- } \\
\text { CHARGE } \\
\text { (CFS) }\end{array}$ & $\begin{array}{l}\text { SILICA } \\
\text { (SIO2) }\end{array}$ & $\begin{array}{l}\text { DIS- } \\
\text { SOLVED } \\
\text { IRON } \\
\text { (FE) }\end{array}$ & $\begin{array}{l}\text { DIS- } \\
\text { SOLVED } \\
\text { MAN- } \\
\text { GANESE } \\
\text { (MN) }\end{array}$ & $\begin{array}{l}\text { CAL- } \\
\text { CIUM } \\
\text { (CA) }\end{array}$ & $\begin{array}{l}\text { MAG- } \\
\text { NE- } \\
\text { SIUM } \\
\text { (MG) }\end{array}$ & $\begin{array}{l}\text { SODIUM } \\
\text { (NA) }\end{array}$ & $\begin{array}{l}\text { PO- } \\
\text { TAS- } \\
\text { SIUM } \\
\text { (K) }\end{array}$ & $\begin{array}{l}\text { SODIUM } \\
\text { PLUS } \\
\text { POTAS- } \\
\text { SIUH } \\
\text { (NA+K) }\end{array}$ & $\begin{array}{l}\text { BICAR- } \\
\text { BONATE } \\
\text { (HCO3) }\end{array}$ & $\begin{array}{l}\text { CAR- } \\
\text { BONATE } \\
\text { (CO3) }\end{array}$ \\
\hline $\begin{array}{l}\text { OCT. } \\
\text { O1-10 }\end{array}$ & 18610 & -- & -- & -- & -- & -- & -- & -- & 15 & 32 & 0 \\
\hline $25 \ldots$ & 7390 & 3.4 & 0.02 & 0.00 & 14 & 2.8 & 12 & 1.7 & -- & 36 & 0 \\
\hline $\begin{array}{l}\text { NOV. } \\
\text { O1-10 } \\
\text { DEC. }\end{array}$ & 7830 & -. & -- & -- & 11 & 3.1 & -- & -- & 13 & 31 & 0 \\
\hline $\begin{array}{l}01-10 \\
08 . . .\end{array}$ & $\begin{array}{l}7190 \\
8530\end{array}$ & $=-$ & -- & $\overline{-}$ & $\begin{array}{l}12 \\
13\end{array}$ & $\begin{array}{l}2.8 \\
2.8\end{array}$ & - & $=$ & $\frac{12}{11}$ & $\begin{array}{l}31 \\
32\end{array}$ & $\begin{array}{l}0 \\
0\end{array}$ \\
\hline JAN. & & & & & & & & & & & \\
\hline $\begin{array}{l}01-10 \\
05 . .\end{array}$ & $\begin{array}{r}9630 \\
10900\end{array}$ & 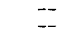 & $=$ & -- & $\begin{array}{l}11 \\
12\end{array}$ & $\begin{array}{l}2.5 \\
2.6\end{array}$ & $=$ & $=$ & $\frac{11}{8.5}$ & $\begin{array}{l}28 \\
27\end{array}$ & $\begin{array}{l}0 \\
0\end{array}$ \\
\hline $\begin{array}{l}\text { FEB. } \\
\text { O2... } \\
\text { MAR. }\end{array}$ & 2000 & -- & - & -- & 16 & 3.8 & -- & -- & 17 & 40 & 0 \\
\hline $\begin{array}{l}01-10 \\
\text { APR. }\end{array}$ & 673 & -- & -- & -- & 15 & 3.5 & -- & - & 21 & 46 & 0 \\
\hline $\begin{array}{l}01-03, \\
05-10 \\
18 \ldots\end{array}$ & $\begin{array}{r}3880 \\
662\end{array}$ & $\begin{array}{l}4.5 \\
7.2\end{array}$ & $\begin{array}{l}.00 \\
.03\end{array}$ & $\begin{array}{l}.00 \\
.00\end{array}$ & $\begin{array}{l}12 \\
11\end{array}$ & $\begin{array}{l}2.4 \\
2.5\end{array}$ & $\begin{array}{l}9.2 \\
8.2\end{array}$ & $\begin{array}{l}1.1 \\
1.1\end{array}$ & -- & $\begin{array}{l}26 \\
30\end{array}$ & $\begin{array}{l}0 \\
0\end{array}$ \\
\hline $\begin{array}{l}\text { MAY } \\
\text { O1-09 } \\
\text { JUNE }\end{array}$ & 664 & -- & - & - & 10 & 2.4 & -- & - & 17 & 40 & 0 \\
\hline $\begin{array}{l}01-10 \\
06 \ldots \\
13 \ldots\end{array}$ & $\begin{array}{l}3470 \\
3520 \\
2360\end{array}$ & $\begin{array}{l}-. \overline{5} \\
5.2\end{array}$ & $\begin{array}{l}. \overline{-} \\
.00 \\
.02\end{array}$ & $\begin{array}{l}-\overline{-} \\
.00 \\
.00\end{array}$ & $\begin{array}{l}11 \\
12 \\
12\end{array}$ & $\begin{array}{l}2.6 \\
2.8 \\
2.6\end{array}$ & $\begin{array}{l}10^{--} \\
10^{--}\end{array}$ & $\begin{array}{l}-- \\
1.0 \\
1.0\end{array}$ & ${ }^{13}=$ & $\begin{array}{l}30 \\
30 \\
29\end{array}$ & $\begin{array}{l}0 \\
0 \\
0\end{array}$ \\
\hline JULY & & & & & & & & & & & \\
\hline $02 \ldots$ & $\begin{array}{l}4320 \\
4250\end{array}$ & $\begin{array}{l}3.8 \\
5.8\end{array}$ & .02 & .00 & $\begin{array}{l}13 \\
10\end{array}$ & $\begin{array}{l}2.9 \\
1.9\end{array}$ & $\begin{array}{l}10 \\
16\end{array}$ & $\begin{array}{l}1.0 \\
2.2\end{array}$ & -- & $\begin{array}{l}32 \\
32\end{array}$ & $\begin{array}{l}0 \\
0\end{array}$ \\
\hline $\begin{array}{l}23 . . . \\
\text { AUG. }\end{array}$ & 1610 & 4.3 & .00 & .00 & 16 & 2.6 & 13 & 1.3 & -- & 38 & 0 \\
\hline $\begin{array}{l}01-10 \\
\text { SEPT. }\end{array}$ & 1620 & -- & -- & -- & 14 & 3.0 & -- & -- & 14 & 36 & 0 \\
\hline $\begin{array}{l}01-10 \\
05 . . .\end{array}$ & $\begin{array}{l}2030 \\
2390\end{array}$ & -- & -- & $=$ & $\begin{array}{l}17 \\
14\end{array}$ & $\begin{array}{l}3.0 \\
3.0\end{array}$ & -- & -- & $\begin{array}{l}15 \\
16\end{array}$ & $\begin{array}{l}41 \\
40\end{array}$ & $\begin{array}{l}0 \\
0\end{array}$ \\
\hline DATE & $\begin{array}{l}\text { SULFATE } \\
(\mathrm{SO} 4)\end{array}$ & $\begin{array}{l}\text { CHLO- } \\
\text { RIDE } \\
(\mathrm{CL})\end{array}$ & $\begin{array}{l}\text { FLUD- } \\
\text { RIDE } \\
(F)\end{array}$ & $\begin{array}{l}\text { NI TRATE } \\
\text { (NO3) }\end{array}$ & $\begin{array}{l}\text { DIS- } \\
\text { SOLVED } \\
\text { SOLIDS } \\
\text { (RESI- } \\
\text { DUE AT } \\
180^{\circ} \mathrm{C} \text { ) }\end{array}$ & $\begin{array}{l}\text { HARD- } \\
\text { NESS } \\
(C A, M G)\end{array}$ & $\begin{array}{c}\text { NON- } \\
\text { CAR- } \\
\text { BONATE } \\
\text { HARD- } \\
\text { NESS }\end{array}$ & $\begin{array}{l}\text { SPE- } \\
\text { CIFIC } \\
\text { CONDUCT- } \\
\text { ANCE } \\
\text { (MICRO- } \\
\text { MHOS) }\end{array}$ & $\mathrm{PH}$ & COLOR & $\begin{array}{c}\text { TEM- } \\
\text { PERA- } \\
\text { TURE } \\
\text { (DEG C) }\end{array}$ \\
\hline${ }_{01-10}^{O C T .}$ & 18 & 19 & -- & 1.5 & -- & & & & & & \\
\hline $\begin{array}{l}25 . \cdots \\
\text { NDV. }\end{array}$ & 16 & 22 & 0.2 & .2 & 101 & 47 & $\begin{array}{l}13 \\
17\end{array}$ & $\begin{array}{l}149 \\
162\end{array}$ & $\begin{array}{l}6.8 \\
6.9\end{array}$ & $\begin{array}{l}8 \\
8\end{array}$ & $\begin{array}{l}13 \\
12\end{array}$ \\
\hline $\begin{array}{l}\text { NOV. } \\
\text { O1-10 } \\
\text { DEC. }\end{array}$ & 16 & 19 & -- & .6 & -- & 41 & 15 & 136 & 7.4 & 5 & -- \\
\hline $\begin{array}{l}01-10 \\
08 . .\end{array}$ & $\begin{array}{l}14 \\
15\end{array}$ & $\begin{array}{l}18 \\
18\end{array}$ & - & $\begin{array}{r}1.4 \\
.7\end{array}$ & $=$ & $\begin{array}{l}42 \\
44\end{array}$ & $\begin{array}{l}16 \\
18\end{array}$ & $\begin{array}{l}147 \\
146\end{array}$ & $\begin{array}{l}6.9 \\
7.3\end{array}$ & $\begin{array}{l}1 \\
4\end{array}$ & $-\overline{2}$ \\
\hline $\begin{array}{l}\text { JAN. } \\
01-10\end{array}$ & 14 & 16 & -- & 1.4 & - & 38 & 15 & 136 & 6.9 & 5 & -- \\
\hline $\begin{array}{l}05 . . \\
\text { FEB. }\end{array}$ & 13 & 16 & -- & 1.3 & -- & 41 & 19 & 134 & 7.0 & 3 & 3 \\
\hline $\begin{array}{l}02 \ldots \\
\text { MAR... }\end{array}$ & 15 & 29 & -- & 2.8 & -- & 56 & 23 & 201 & 7.4 & 3 & 2 \\
\hline $\begin{array}{l}\text { OI-10 } \\
\text { APR. } \\
\text { OI-03, }\end{array}$ & 15 & 30 & -- & 2.3 & -- & 52 & 15 & 211 & 7.3 & 1 & -- \\
\hline $\begin{array}{l}05-10 \\
18 . . \\
\text { MAY }\end{array}$ & $\begin{array}{l}14 \\
14\end{array}$ & $\begin{array}{l}18 \\
14\end{array}$ & $\begin{array}{l}.0 \\
.0\end{array}$ & $\begin{array}{r}2.0 \\
.8\end{array}$ & $\begin{array}{l}82 \\
74\end{array}$ & $\begin{array}{l}40 \\
38\end{array}$ & $\begin{array}{l}19 \\
14\end{array}$ & $\begin{array}{l}137 \\
127\end{array}$ & $\begin{array}{l}7.4 \\
7.5\end{array}$ & $\begin{array}{l}1 \\
1\end{array}$ & $\overline{11}$ \\
\hline $\begin{array}{l}\text { 01-09 } \\
\text { JUNE }\end{array}$ & 15 & 15 & -- & 2.3 & -- & 35 & 2 & 129 & 6.9 & 7 & -- \\
\hline $\begin{array}{c}01-10 \\
06 . . \\
13 \ldots \\
\text { JULY }\end{array}$ & $\begin{array}{l}15 \\
16 \\
15\end{array}$ & $\begin{array}{l}18 \\
18 \\
18\end{array}$ & $\begin{array}{l}-\overline{1} \\
.1\end{array}$ & $\begin{array}{r}1.4 \\
.8 \\
.8\end{array}$ & $\begin{array}{l}-- \\
96 \\
87\end{array}$ & $\begin{array}{l}38 \\
42 \\
41\end{array}$ & $\begin{array}{l}14 \\
17 \\
17\end{array}$ & $\begin{array}{l}145 \\
149 \\
140\end{array}$ & $\begin{array}{l}7.0 \\
7.1 \\
6.8\end{array}$ & $\begin{array}{l}3 \\
2 \\
2\end{array}$ & $\begin{array}{l}77 \\
17\end{array}$ \\
\hline $\begin{array}{l}02 \ldots \\
02-10 \\
23 \ldots\end{array}$ & $\begin{array}{l}15 \\
14 \\
14\end{array}$ & $\begin{array}{l}18 \\
18 \\
22\end{array}$ & $\begin{array}{l}.1 \\
.1 \\
.2\end{array}$ & $\begin{array}{l}1.3 \\
1.4 \\
1.2\end{array}$ & $\begin{array}{l}95 \\
91 \\
98\end{array}$ & $\begin{array}{l}45 \\
33 \\
51\end{array}$ & $\begin{array}{r}19 \\
7 \\
20\end{array}$ & $\begin{array}{l}145 \\
152 \\
160\end{array}$ & $\begin{array}{l}7.2 \\
7.1 \\
7.5\end{array}$ & $\begin{array}{l}2 \\
5 \\
5\end{array}$ & $\frac{21}{25}$ \\
\hline $\begin{array}{l}\text { AUG. } \\
\text { O1-10 } \\
\text { SEPT. }\end{array}$ & 15 & 22 & -- & 1.4 & -- & 48 & 18 & 164 & 7.6 & 3 & -- \\
\hline $\begin{array}{l}01-10 \\
05 . .\end{array}$ & $\begin{array}{l}13 \\
12\end{array}$ & $\begin{array}{r}28 \\
26\end{array}$ & 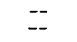 & $\begin{array}{r}1.6 \\
.9\end{array}$ & -- & $\begin{array}{l}55 \\
48\end{array}$ & $\begin{array}{l}22 \\
15\end{array}$ & $\begin{array}{l}193 \\
186\end{array}$ & $\begin{array}{l}7.7 \\
7.8\end{array}$ & $\begin{array}{l}1 \\
5\end{array}$ & $\overline{21}$ \\
\hline
\end{tabular}


03012500 ALLEGHENY RIVER NEAR KINZUA, PA.--Continued

SPECIFIC CONDUCTANCE (MICROMHOS AT $25^{\circ} \mathrm{C}$ ), WATER YEAR OCTOBER 1967 TO SEPTEMBER 1968

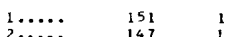

$2 \ldots \ldots \quad 147$

$4 \cdots \cdots \cdot 129$

134

$7 \ldots . .154$

$9 \ldots \ldots \quad 146$

$10 . . .1 \quad 150 \quad 147$

$11 \ldots \ldots . \quad 136$

$13 \ldots \ldots . \quad 125$

$14 \ldots \cdots \cdot \quad 125$

$16 \ldots . . \quad 148$

$17 \ldots \ldots . \quad 140$

$\begin{array}{ll}13 \ldots \ldots & 139 \\ 19 . \ldots . & 136\end{array}$

141

$21 \ldots \ldots .158$

$22 \ldots \ldots . \quad 159$

$24 \ldots \ldots .161$

$25 . \ldots .165$

$26 \ldots \ldots . \quad 154$

$29 . \ldots .1149$

$29 . . .10 \quad 150$

$30 \ldots \ldots \quad 159$

AVERAGE 146

\begin{tabular}{|c|c|c|c|c|}
\hline 158 & 152 & 137 & 229 & 173 \\
\hline 150 & 148 & 138 & 227 & 178 \\
\hline 149 & 149 & 135 & - & 153 \\
\hline 143 & 149 & 136 & $4 B$ & 208 \\
\hline 109 & 154 & 136 & 179 & 222 \\
\hline 140 & 147 & 136 & 178 & 230 \\
\hline 142 & 141 & 135 & 177 & 240 \\
\hline 144 & 143 & 136 & 157 & 250 \\
\hline 147 & 123 & 134 & 149 & 254 \\
\hline 147 & 145 & 132 & 145 & 263 \\
\hline 148 & 145 & 131 & 151 & 268 \\
\hline 157 & 147 & 131 & 147 & 234 \\
\hline 156 & 146 & 134 & 144 & 279 \\
\hline 159 & 146 & 139 & 152 & 275 \\
\hline 157 & 147 & 136 & 147 & 284 \\
\hline 153 & 147 & 138 & -. & 301 \\
\hline 156 & $15 \mathrm{~L}$ & 138 & 171 & 298 \\
\hline 150 & 152 & - & 170 & 302 \\
\hline 156 & 147 & 141 & 166 & 289 \\
\hline 158 & 146 & 151 & 131 & 281 \\
\hline 157 & 146 & 150 & 159 & 288 \\
\hline 159 & $\begin{array}{l}146 \\
\end{array}$ & 142 & 131 & 292 \\
\hline 158 & - & 205 & 131 & 46 \\
\hline 161 & 145 & 193 & 132 & 227 \\
\hline 160 & 149 & 198 & 132 & 192 \\
\hline 152 & 163 & 227 & 161 & 162 \\
\hline 155 & 143 & 231 & 156 & 153 \\
\hline 154 & 144 & 206 & 162 & 148 \\
\hline 153 & 141 & 239 & 165 & 140 \\
\hline 161 & 140 & 275 & -- & 153 \\
\hline . & 135 & - & -- & 144 \\
\hline 151 & 145 & 158 & 155 & 225 \\
\hline
\end{tabular}

APRIL MAY

$\begin{array}{rr}162 & 128 \\ 166 & 125 \\ 98 & 131 \\ -5 & 129 \\ 146 & 128 \\ 124 & 128 \\ 115 & 130 \\ 115 & 129 \\ 120 & 130 \\ 124 & 72 \\ 125 & 129\end{array}$

$\begin{array}{lll}125 & 129 & 139 \\ 114 & 132 & 140 \\ 120 & 125 & 13 \\ 119 & 125 & 14\end{array}$

$119 \quad 12$

$\begin{array}{lll}-- & 122 & 142 \\ -- & 125 & 139\end{array}$

$\begin{array}{ll}-- & 125 \\ -- & 127 \\ -- & 128\end{array}$

$\begin{array}{ll}131 & 127 \\ 122 & 129 \\ 121 & 131 \\ 126 & 130\end{array}$

$125 \quad 147$

122
122

$\begin{array}{lll}122 & 144 & 143 \\ 22 & 146 & 144\end{array}$

$\begin{array}{ll}123 & 148 \\ 124 & 142\end{array}$

$\begin{array}{rr}124 & 142 \\ --\quad 139\end{array}$
JUNE JULY AUguSt SEPTEMBER

$\begin{array}{llll}139 & 17 & 156 & 195 \\ 150 & 172 & 163 & 183 \\ 137 & 147 & 162 & 191 \\ 136 & 146 & 161 & 191 \\ 138 & 146 & 161 & 190 \\ 138 & 145 & 161 & 178 \\ 137 & 144 & 162 & 188 \\ 145 & 143 & 167 & 187 \\ 152 & 151 & 166 & 185 \\ 139 & 143 & 169 & 188 \\ 139 & 150 & 176 & 193 \\ 140 & 152 & 170 & 196 \\ 139 & 156 & 169 & 196 \\ 142 & 151 & 176 & 192 \\ 142 & 159 & 171 & 196 \\ 142 & 151 & 180 & 201 \\ 139 & 155 & 167 & 198 \\ 141 & 152 & 169 & 192 \\ 142 & 155 & 139 & 195 \\ 143 & 160 & 167 & 188 \\ 143 & 158 & 178 & 182 \\ 146 & 154 & 179 & 185 \\ 145 & 160 & 178 & 193 \\ 143 & 158 & 178 & 178 \\ 141 & 157 & 172 & 177 \\ 143 & 158 & 180 & 178 \\ 146 & 156 & 190 & 178 \\ 144 & 156 & 185 & 172 \\ 141 & 154 & 184 & 172 \\ 141 & 159 & 183 & 169 \\ -- & 156 & 183 & -- \\ 141 & 153 & 171 & 186 \\ 141 & 153 & & \\ 149 & & & \end{array}$

TEMPERATURE $\left({ }^{\circ} \mathrm{C}\right\}$ OF WATER, WATER YEAR OCTOBER 1967 TO SEPTEMBER 1968

\begin{tabular}{|c|c|c|c|c|c|c|c|c|c|c|c|c|}
\hline DAY & DC T & NUV & UEL & JAN & FEB $B$ & MAR & $A P R$ & YAY & JUN & JUL & AUG & SEP \\
\hline $\begin{array}{l}1 \\
2 \\
3 \\
4 \\
5\end{array}$ & $\begin{array}{l}13.0 \\
13.0 \\
13.0 \\
13.0 \\
13.0\end{array}$ & $\begin{array}{l}11.0 \\
11.0 \\
11.0 \\
11.0 \\
11.0\end{array}$ & $\begin{array}{l}6.0 \\
0.0 \\
4.0 \\
4.0 \\
4.0\end{array}$ & $\begin{array}{l}3.0 \\
3.0 \\
3.0 \\
3.0 \\
3.0\end{array}$ & $\begin{array}{l}3.0 \\
4.0 \\
-0.0 \\
3.0 \\
---\end{array}$ & $\begin{array}{l}2.0 \\
2.0 \\
2.0 \\
2.0 \\
2.0\end{array}$ & $\begin{array}{l}-- \\
\overline{--} \\
\overline{-0} \\
2.0\end{array}$ & $\begin{array}{l}11.0 \\
11.0 \\
11.0 \\
11.0 \\
10.0\end{array}$ & $\begin{array}{l}13.0 \\
14.0 \\
14.0 \\
14.0 \\
15.0\end{array}$ & $\begin{array}{l}--- \\
16.0 \\
16.0 \\
16.0 \\
16.0\end{array}$ & $\begin{array}{l}21.0 \\
20.0 \\
20.0 \\
20.0 \\
20.0\end{array}$ & $\begin{array}{l}20.0 \\
20.0 \\
20.0 \\
20.0 \\
22.0\end{array}$ \\
\hline $\begin{array}{r}6 \\
7 \\
8 \\
7 \\
10\end{array}$ & $\begin{array}{l}13.0 \\
13.0 \\
13.0 \\
13.0 \\
13.0\end{array}$ & $\begin{array}{r}10.0 \\
9.0 \\
9.0 \\
9.0 \\
9.0\end{array}$ & $\begin{array}{l}4.0 \\
4.0 \\
4.0 \\
4.0 \\
4.0\end{array}$ & $\begin{array}{l}3.0 \\
3.0 \\
3.0 \\
3.0 \\
3.0\end{array}$ & $\begin{array}{l}3.0 \\
1.0 \\
2.0 \\
3.0 \\
2.0\end{array}$ & $\begin{array}{l}2.0 \\
2.0 \\
2.0 \\
1.0 \\
3.0\end{array}$ & $\begin{array}{l}2.0 \\
3.0 \\
3.0 \\
3.0 \\
.0 .\end{array}$ & $\begin{array}{l}10.0 \\
10.0 \\
11.0 \\
12.0 \\
12.0\end{array}$ & $\begin{array}{l}-1.0 \\
14.0 \\
14.0 \\
14.0 \\
14.0\end{array}$ & $\begin{array}{l}16.0 \\
16.0 \\
16.0 \\
18.0 \\
16.0\end{array}$ & $\begin{array}{l}20.0 \\
20.0 \\
21.0 \\
21.0 \\
21.0\end{array}$ & $\begin{array}{l}22.0 \\
21.0 \\
21.0 \\
20.0 \\
20.0\end{array}$ \\
\hline $\begin{array}{l}11 \\
12 \\
13 \\
14 \\
15\end{array}$ & $\begin{array}{l}13.0 \\
13.0 \\
13.0 \\
12.0 \\
12.0\end{array}$ & $\begin{array}{r}9.0 \\
10.0 \\
10.0 \\
9.0 \\
8.0\end{array}$ & $\begin{array}{l}4.0 \\
4.0 \\
4.0 \\
4.0 \\
+.0\end{array}$ & $\begin{array}{l}3.0 \\
2.0 \\
2.0 \\
2.0 \\
3.0\end{array}$ & \begin{tabular}{l}
2.0 \\
2.0 \\
\hdashline-0
\end{tabular} & $\begin{array}{l}1.0 \\
1.0 \\
1.0 \\
1.0 \\
1.0\end{array}$ & $\begin{array}{l}\cdots \\
\cdots \\
\cdots \\
\cdots\end{array}$ & $\begin{array}{l}11.0 \\
11.0 \\
11.0 \\
12.0 \\
11.0\end{array}$ & $\begin{array}{l}15.0 \\
15.0 \\
15.0 \\
15.0 \\
15.0\end{array}$ & $\begin{array}{l}17.0 \\
20.0 \\
20.0 \\
20.0 \\
20.0\end{array}$ & $\begin{array}{l}21.0 \\
21.0 \\
21.0 \\
21.0 \\
21.0\end{array}$ & $\begin{array}{l}20.0 \\
19.0 \\
19.0 \\
19.0 \\
19.0\end{array}$ \\
\hline $\begin{array}{l}16 \\
17 \\
18 \\
19 \\
20\end{array}$ & $\begin{array}{l}13.0 \\
13.0 \\
13.0 \\
13.0\end{array}$ & $\begin{array}{l}6.0 \\
7.0 \\
9.0 \\
8.0\end{array}$ & $\begin{array}{l}3.0 \\
3.0 \\
3.0 \\
3.0 \\
3.0\end{array}$ & $\begin{array}{l}2.0 \\
2.0 \\
2.0 \\
2.0 \\
-\end{array}$ & $\begin{array}{l}-1.0 \\
2.0 \\
1.0 \\
2.0\end{array}$ & $\begin{array}{l}2.0 \\
2.0 \\
2.0 \\
3.0 \\
3.0\end{array}$ & $\begin{array}{l}-\cdots \\
\cdots- \\
\cdots- \\
-\cdots\end{array}$ & $\begin{array}{l}11.0 \\
11.0 \\
11.0 \\
10.0 \\
13.0\end{array}$ & $\begin{array}{l}14.0 \\
16.0 \\
16.0 \\
16.0 \\
13.0\end{array}$ & $\begin{array}{l}20.0 \\
20.0 \\
20.0 \\
20.0 \\
20.0\end{array}$ & $\begin{array}{l}21.0 \\
21.0 \\
21.0 \\
21.0 \\
20.0\end{array}$ & $\begin{array}{l}19.0 \\
19.0 \\
19.0 \\
18.0 \\
18.0\end{array}$ \\
\hline $\begin{array}{l}21 \\
22 \\
21 \\
24 \\
25\end{array}$ & $\begin{array}{l}13.0 \\
13.0 \\
13.0 \\
13.0 \\
13.0\end{array}$ & $\begin{array}{l}6.0 \\
8.0 \\
8.0 \\
7.0 \\
7.0\end{array}$ & $\begin{array}{l}3.0 \\
3.0 \\
3.0 \\
3.0 \\
-.-\end{array}$ & $\begin{array}{l}2.0 \\
2.0 \\
2.0 \\
2.0 \\
2.0\end{array}$ & $\begin{array}{l}-1 . \\
2.0 \\
2.0 \\
2.0 \\
2.0\end{array}$ & $\begin{array}{l}4.0 \\
4.0 \\
4.0 \\
2.0 \\
2.0\end{array}$ & $\begin{array}{l}12.0 \\
12.0 \\
12.0 \\
12.0 \\
12.0\end{array}$ & $\begin{array}{l}10.0 \\
11.0 \\
10.0 \\
10.0 \\
12.0\end{array}$ & $\begin{array}{l}16.0 \\
16.0 \\
16.0 \\
17.0 \\
17.0\end{array}$ & $\begin{array}{l}20.0 \\
20.0 \\
20.0 \\
21.0 \\
20.0\end{array}$ & $\begin{array}{l}21.0 \\
21.0 \\
22.0 \\
22.0 \\
22.0\end{array}$ & $\begin{array}{l}17.0 \\
20.0 \\
18.0 \\
16.0 \\
16.0\end{array}$ \\
\hline $\begin{array}{l}26 \\
27 \\
28 \\
29 \\
30 \\
31\end{array}$ & 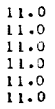 & $\begin{array}{l}7.0 \\
7.0 \\
7.0 \\
0.0 \\
6.0 \\
-.-0\end{array}$ & $\begin{array}{l}3.0 \\
2.0 \\
3.0 \\
3.0 \\
3.0 \\
3.0\end{array}$ & $\begin{array}{l}1.0 \\
2.0 \\
2.0 \\
3.0 \\
3.0 \\
-.-\end{array}$ & $\begin{array}{l}1.0 \\
1.0 \\
3.0 \\
2.0 \\
-\cdots\end{array}$ & $\begin{array}{l}2.0 \\
2.0 \\
2.0 \\
--- \\
--\end{array}$ & $\begin{array}{l}11.0 \\
12.0 \\
12.0 \\
11.0 \\
11.0 \\
-\end{array}$ & $\begin{array}{l}12.0 \\
13.0 \\
13.0 \\
13.0 \\
13.0 \\
13.0\end{array}$ & $\begin{array}{c}18.0 \\
17.0 \\
17.0 \\
15.0 \\
16.0 \\
-.0\end{array}$ & $\begin{array}{l}21.0 \\
21.0 \\
21.0 \\
21.0 \\
21.0 \\
21.0\end{array}$ & $\begin{array}{l}21.0 \\
20.0 \\
20.0 \\
20.0 \\
20.0 \\
20.0\end{array}$ & $\begin{array}{c}15.0 \\
15.0 \\
15.0 \\
15.0 \\
15.0 \\
-0-\end{array}$ \\
\hline ERAGE & 12.5 & 8.5 & 3.5 & 2.5 & -- & 2.0 & -- & 11.0 & 15.0 & 19.0 & 20.5 & 18.5 \\
\hline
\end{tabular}


03013000 CONEWANGO CREEK AT WATERBORO, N. $\mathbf{Y}$.

LOCATION (revised).--Lat $42^{\circ} 10^{\prime} 15^{\prime \prime}$, long $79^{\circ} 04^{\prime} 10^{\prime \prime}$, Chautauqua County, at gaging station $300 \mathrm{ft}$ downstream $\mathrm{from}$ bridge on State Highway 17 at Waterboro, 0.2 mile downstream from Davis Brook, and 1.9 miles northeast of Kennedy.

DRAINAGE AREA. --290 sq mi.

PERIOD OF RECORD.--Chemical analyses: August 1965 to September 1968.

CHEMIrAL ANAIYSES IN MILLIGRAMS PER LIIER, WATER YEAR OCTOBER 1967 TO SEPTEMBER 1968

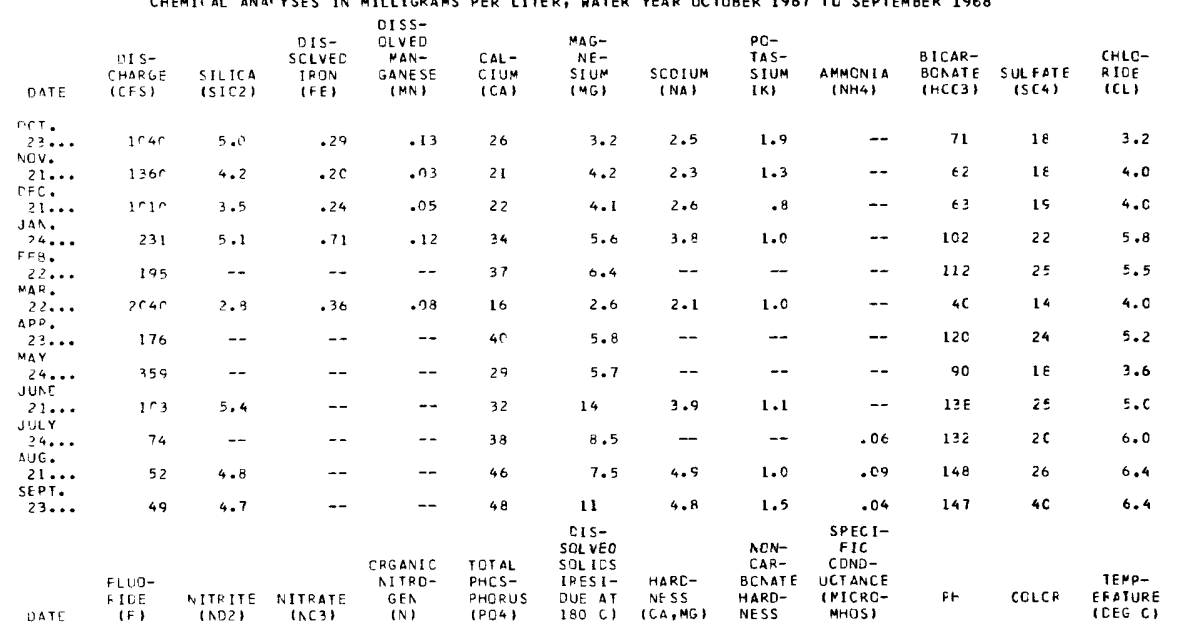

\begin{tabular}{|c|c|c|c|c|c|c|c|c|c|c|c|}
\hline $\begin{array}{l}{ }^{1 C T} \cdot \\
2^{3} . \ldots\end{array}$ & .2 & -- & .6 & $\cdots$ & -- & 97 & 78 & $2 \mathrm{C}$ & 169 & 7.1 & -- \\
\hline 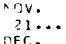 & $\cdot{ }^{n}$ & -- & 1.2 & -- & $\cdots$ & 95 & $7 C$ & 19 & 152 & 7.3 & 14 \\
\hline,$\ldots$ & .1 & - & 1.2 & - & - & gC & 72 & 20 & 156 & 7.4 & -. \\
\hline $\begin{array}{l}\mathrm{JAA} . \\
>4\end{array}$ & .2 & -- & 2.5 & -- & -- & 132 & $1 C 8$ & 24 & 228 & 7.4 & 7 \\
\hline $\begin{array}{r}F F E . \\
2 ? \\
N \triangle E\end{array}$ & -- & -- & -- & -- & -- & -- & 119 & 27 & 254 & 7.3 & - \\
\hline $\begin{array}{l}22 \ldots \\
\triangle D F\end{array}$ & $\cdot 1$ & -- & 1.4 & - & -- & 72 & 50 & 17 & 110 & 6.5 & 25 \\
\hline $23 \ldots$ & - & -- & - & -- & -- & -- & 124 & 26 & 258 & 7.6 & -- \\
\hline $74 \ldots$ & -- & - & -- & - & -- & -- & 96 & 22 & 191 & 7.5 & - \\
\hline$\rightarrow \ldots$ & $\therefore$ & -- & I. I & $\cdots$ & - & 162 & 136 & 23 & 294 & 7.7 & 5 \\
\hline $\begin{array}{l}\text { JIJLY } \\
24 \ldots\end{array}$ & -- & in & 1.2 & .03 & . ns & -- & 130 & 22 & 275 & 7.5 & - \\
\hline $\begin{array}{l}\text { AUG. } \\
21 \ldots \\
\text { SEDT. }\end{array}$ & .1 & .12 & .8 & .21 & $.1 \mathrm{C}$ & 177 & 146 & 25 & 302 & 7.4 & s \\
\hline $3 \ldots$ & .1 & .22 & .7 & .03 & .13 & 186 & 164 & 44 & 310 & 7.8 & $t$ \\
\hline
\end{tabular}

CLARION RIVER BASIN

03029400 TOWS RUN AT COOKSBURG, PA.

LOCATION.--Lat $41^{\circ} 20^{\prime} 15^{\prime \prime}$, long $79^{\circ} 12^{\prime} 50^{\prime \prime}$, Forest County, at gaging station on right bank about 100 ft downstream

from footbridge on Longfellow Trail, 0.6 mile upstream from mouth, and 0.5 mile northwest of cooksburg.

DRAINAGE AREA,--12.6 sq mi.

PERIOD OF RECORD.--Chemical analyses: October 1964 to September 1968.

CHEMICAL ANALYSES IN MILLIGRAMS PER LITER, WATER YEAR OCTOBER 1967 TO SEPTEMBER 2968

\begin{tabular}{|c|c|c|c|c|c|c|c|c|c|c|c|}
\hline DATE & $\begin{array}{l}\text { MEAN } \\
\text { DIS- } \\
\text { CHARGE } \\
\text { (CFS | }\end{array}$ & $\begin{array}{l}\text { SILICA } \\
\text { (SIOZ2) }\end{array}$ & $\begin{array}{l}\text { DIS- } \\
\text { SOLVED } \\
\text { IRON } \\
\text { (FE) }\end{array}$ & $\begin{array}{l}\text { DIS- } \\
\text { SOLVED } \\
\text { MAN- } \\
\text { GANESE } \\
\text { (MN) }\end{array}$ & $\begin{array}{l}\text { CAL- } \\
\text { CIUM } \\
\text { (CA) }\end{array}$ & $\begin{array}{l}\text { MAG- } \\
\text { NE- } \\
\text { SIUM } \\
\text { (MG) }\end{array}$ & $\begin{array}{l}\text { SODIUM } \\
\text { (NA) }\end{array}$ & $\begin{array}{l}\text { PQ- } \\
\text { TAS- } \\
\text { SIUM } \\
(\mathrm{K})\end{array}$ & $\begin{array}{l}\text { SODIUM } \\
\text { PLUS } \\
\text { POTAS- } \\
\text { SIUM } \\
\text { (NA+K) }\end{array}$ & $\begin{array}{l}\text { BICAR- } \\
\text { BONATE } \\
\text { (HCO3) }\end{array}$ & $\begin{array}{l}\text { CAR- } \\
\text { BONATE } \\
\text { (CO } 3)\end{array}$ \\
\hline $\begin{array}{l}\text { OCT. } \\
23 . . . \\
\text { JAN. }\end{array}$ & 24 & 6.0 & 0.00 & 0.01 & 4.8 & 2.3 & 2.5 & 1.2 & -- & 2 & 0 \\
\hline $\begin{array}{l}02 \ldots \\
29 \ldots\end{array}$ & $\begin{array}{l}12 \\
26\end{array}$ & $=-$ & $=-$ & $=-$ & $\begin{array}{l}6.0 \\
8.7\end{array}$ & $\begin{array}{l}1.7 \\
5.5\end{array}$ & -- & -- & $\begin{array}{l}9.7 \\
9.7\end{array}$ & $\begin{array}{l}8 \\
3\end{array}$ & $\begin{array}{l}0 \\
0\end{array}$ \\
\hline $\begin{array}{l}\text { FEB. } \\
27 . . . \\
\text { MAR. }\end{array}$ & 5.0 & -- & -- & -- & 6.5 & 5.0 & -- & -- & 11 & 8 & 0 \\
\hline $\begin{array}{l}20 . . \\
\text { APR. }\end{array}$ & 37 & -- & -- & -- & 5.0 & 3.0 & -- & -- & 5.8 & 4 & 0 \\
\hline MAY 15 & 12 & 5.3 & .00 & .38 & 6.9 & 3.3 & 4.8 & 1.1 & -- & 7 & 0 \\
\hline JUNE & 57 & -- & -- & -- & 5.0 & 2.1 & -- & -- & 3.4 & 3 & 0 \\
\hline $\begin{array}{l}04 \ldots \\
\text { JULYY }\end{array}$ & 21 & 5.8 & .00 & .30 & 5.0 & 3. 8 & 3.0 & .9 & -- & 4 & 0 \\
\hline $\begin{array}{l}01 \\
29 . . \\
\text { SEPT. }\end{array}$ & $\begin{array}{l}7.9 \\
1.8\end{array}$ & $\begin{array}{l}5.8 \\
6.2\end{array}$ & .02 & $\begin{array}{l}.16 \\
.00\end{array}$ & $12^{7.5}$ & $\begin{array}{l}4.1 \\
6.1\end{array}$ & $1_{14}^{5.5}$ & $\begin{array}{l}1.1 \\
2.1\end{array}$ & -- & $\begin{array}{r}6 \\
16\end{array}$ & $\begin{array}{l}0 \\
0\end{array}$ \\
\hline $05 \ldots$ & 2.7 & -- & -- & -- & 11 & 6.0 & -- & - & 19 & 21 & 0 \\
\hline
\end{tabular}


LOCATION, --Lat $41^{\circ} 11^{\prime} 33^{\prime \prime}$, long $79^{\circ} 26^{\prime} 25^{\prime \prime}$, Clarion County, 0.2 mile downstream from hydroelectric plant of Pennsy 1 vania Electric Co., 2.2 miles northeast of Piney, 2.4 miles upstream from Piney Creek, and 3 miles southwest of Clarion.

DRAINAGE AREA, --951 sq mi.

PERIOD OF RECORD.--Chemical analyses: October 1964 to September 1968.

REMARKS. --Samples collected by Pennsylvania Electric Co. Records of specific conductance of daily samples available in district office at Harrisburg, $\mathrm{Pa}$. CHEMICAL ANALYSES IN MILLIGRAMS PER LITER, WATER YEAR OCTOBER 1967 TO SEPTEMBER 1968

\begin{tabular}{|c|c|c|c|c|c|c|c|c|c|c|c|c|}
\hline DATE & $\begin{array}{l}\text { MEAN } \\
\text { DIS- } \\
\text { CHARGE } \\
\text { (CFS) }\end{array}$ & $\begin{array}{l}\text { SILICA } \\
\text { (SIO2) }\end{array}$ & $\begin{array}{l}\text { DIS- } \\
\text { SOLVED } \\
\text { I RON } \\
\text { (FE) }\end{array}$ & $\begin{array}{l}\text { DIS- } \\
\text { SOLVED } \\
\text { MAN- } \\
\text { GANESE } \\
\text { (MN) }\end{array}$ & $\begin{array}{l}\text { CAL- } \\
\text { CIUM } \\
\text { (CA) }\end{array}$ & $\begin{array}{l}\text { MAG- } \\
\text { NE- } \\
\text { SIUM } \\
\text { (MG) }\end{array}$ & $\begin{array}{l}\text { SOD IUM } \\
\text { (NA) }\end{array}$ & $\begin{array}{l}\text { PO- } \\
\text { TAS- } \\
\text { SIUM } \\
\text { (K) }\end{array}$ & $\begin{array}{l}\text { SODIUM } \\
\text { PLUS } \\
\text { POTAS- } \\
\text { SIUM } \\
\text { (NA+K) }\end{array}$ & $\begin{array}{l}\text { BICAR- } \\
\text { BONATE } \\
\text { (HCO3) }\end{array}$ & $\begin{array}{l}\text { CAR- } \\
\text { BONATE } \\
(C O 3)\end{array}$ & $\begin{array}{l}\text { SULFATE } \\
\text { (SO4) }\end{array}$ \\
\hline $\begin{array}{l}\text { OCT. } \\
\text { O3.... } \\
\text { JAN. }\end{array}$ & 1800 & 6.4 & 0.02 & 0.00 & 11 & 3.1 & 4.3 & 1.8 & -- & 6 & 0 & 40 \\
\hline O9... & 730 & $-\infty$ & -- & -- & 16 & 6.5 & -- & -- & 11 & 3 & 0 & 63 \\
\hline $\begin{array}{l}01 \ldots \\
\text { MAR. }\end{array}$ & 7220 & -- & -- & -- & 10 & 5.0 & -- & -- & 12 & 2 & 0 & 49 \\
\hline $\begin{array}{l}05 \ldots \\
19 . . \\
\text { APR. }\end{array}$ & $\begin{array}{r}630 \\
3410\end{array}$ & -- & $\overline{--}$ & $\overline{--}$ & $\begin{array}{l}14 \\
18\end{array}$ & $\frac{11}{7.8}$ & $=-$ & $=$ & $\begin{array}{l}28 \\
18\end{array}$ & $\begin{array}{l}4 \\
6\end{array}$ & $\begin{array}{l}0 \\
0\end{array}$ & $\begin{array}{r}110 \\
77\end{array}$ \\
\hline JUNE & 882 & 5.2 & .06 & .00 & 14 & 4.8 & 6.0 & 1.2 & -- & 5 & 0 & 48 \\
\hline $\begin{array}{l}04 \ldots . \\
04 \ldots \\
\text { JULY }\end{array}$ & $\begin{array}{r}432 \\
B 4200\end{array}$ & $\begin{array}{l}4.8 \\
4.8\end{array}$ & $\begin{array}{l}.00 \\
.00\end{array}$ & $\begin{array}{r}.88 \\
.90\end{array}$ & $\begin{array}{l}13 \\
13\end{array}$ & $\begin{array}{l}5.1 \\
5.0\end{array}$ & $\begin{array}{l}5.2 \\
4.8\end{array}$ & $\begin{array}{r}1.0 \\
.9\end{array}$ & $=-$ & $\begin{array}{l}3 \\
6\end{array}$ & $\begin{array}{l}0 \\
0\end{array}$ & $\begin{array}{l}48 \\
48\end{array}$ \\
\hline $\begin{array}{l}02 \ldots \\
30 \ldots \\
\text { SEPT. }\end{array}$ & $\begin{array}{r}1420 \\
423\end{array}$ & $\overline{4.6}$ & .02 & $2.4^{--}$ & $\begin{array}{l}16 \\
25\end{array}$ & $\begin{array}{l}8.0 \\
9.7\end{array}$ & $10^{--}$ & $\overline{1 .-8}$ & 14 & $\begin{array}{l}2 \\
0\end{array}$ & $\begin{array}{l}0 \\
0\end{array}$ & $\begin{array}{r}84 \\
108\end{array}$ \\
\hline $06 \ldots$ & 630 & -- & -- & -- & 29 & 11 & -- & - & 20 & 2 & 0 & 121 \\
\hline
\end{tabular}

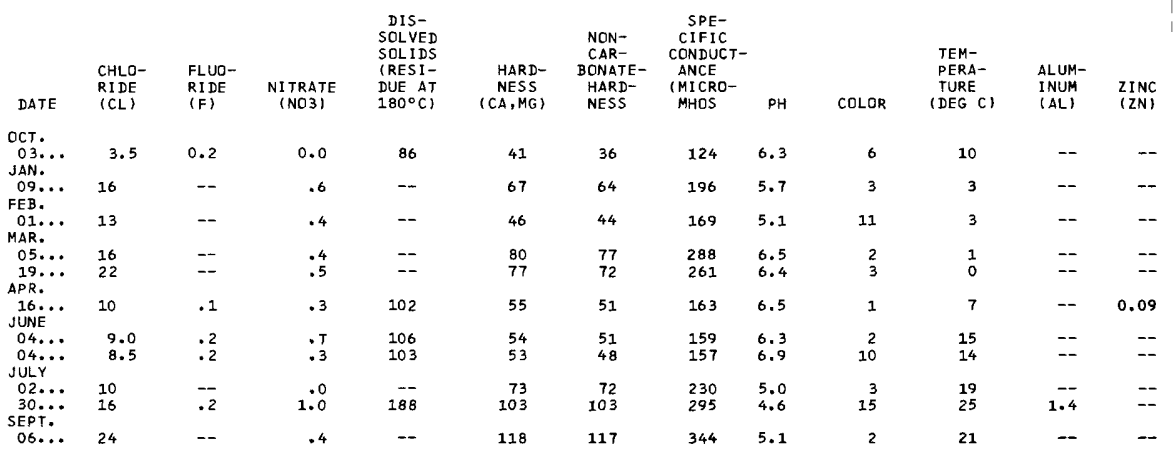

A SAMPLE COLlected at 0800 (INSTANTANEOUS DISCHARge MEasurement).

B SAMPLE COLLECTED AT 1100 (INSTANTANEOUS DISCHARGE MEASUREMENT): 
03036500 ALLEGHENY RIVER AT KITTANNING, PA.

LOCATION.--Lat $40^{\circ} 49^{\prime} 15^{\prime \prime}$, long $79^{\circ} 31^{\prime} 55^{\prime \prime}$, Armstrong County, at center of bridge on U.S, Highway 422 at Kittanning, $2,500 \mathrm{ft}$ downstream from gaging station.

DRA INAGE AREA. --8,973 sq $\mathrm{mi}$.

PERIOD OF RECORD.--Chemical analyses: October 1944 to June 1953, October 1956 to September 1968.

EXTREMES, - -1967-68:

Specific conductance: Maximum daily, 303 micromhos Aug. $25 ;$ minimum daily, 127 micrombos Oct. 2.
Water temperatures: Maximum, $27.0^{\circ} \mathrm{C}$ Aug, 21, 22, 25-27; minimus, $1.0^{\circ} \mathrm{C}$ on several days during January and February.

Pertod of record:

Dissolved solids (1944-47, 1958-59): Maximum, $304 \mathrm{mg} / 1$ Oct. 11-20, 1946 ; minimum, $63 \mathrm{mg} / 1 \mathrm{Mar} .1-10,1945$. Hardness (1944-47,1949-53, 1956-59): Maximum, $148 \mathrm{mg} / 1$ Sept. 11-20, 1952; minimum, $34 \mathrm{mg} / 1 \mathrm{Feb}$. 21-28 and Mar, 1-10, 1951 .

Specific conductance: Maximum daily, 580 micrombos Oct. 18, 1946; minimum daily, 76 micrombos Apr. 8, 9, 1947 . Water temperatures: Maximum, $30.0^{\circ} \mathrm{C}$ July 31 and Aug. 4, 1957; minimum, freezing point on many days during $\rightarrow$ inter periods.

CHEMICAL ANALYSES IN MILLIGRAMS PER LITER, WATER YEAR OCTOBER 1967 TO SEPTEMBER 1968

\begin{tabular}{|c|c|c|c|c|c|c|c|c|c|c|c|}
\hline DATE & $\begin{array}{l}\text { MEAN } \\
\text { DIS- } \\
\text { CHARGE } \\
\text { (CFS) }\end{array}$ & $\begin{array}{l}\text { SILICA } \\
\text { (SIO2) }\end{array}$ & $\begin{array}{l}\text { DIS- } \\
\text { SOLVED } \\
\text { IRON } \\
\text { (FE) }\end{array}$ & $\begin{array}{l}\text { DIS- } \\
\text { SOLVED } \\
\text { MAN- } \\
\text { GANESE } \\
\text { (MN) }\end{array}$ & $\begin{array}{l}\text { CAL- } \\
\text { CIUM } \\
\text { (CA) }\end{array}$ & $\begin{array}{l}\text { MAG- } \\
\text { NE- } \\
\text { SIUM } \\
\text { (MG) }\end{array}$ & $\begin{array}{l}\text { SODIUM } \\
\text { (NA) }\end{array}$ & $\begin{array}{l}\text { PO- } \\
\text { TAS- } \\
\text { SIUM } \\
\text { (K) }\end{array}$ & $\begin{array}{l}\text { SODIUM } \\
\text { PLUS } \\
\text { POTAS- } \\
\text { SIUM } \\
\text { (NA+K) }\end{array}$ & $\begin{array}{l}\text { BICAR- } \\
\text { BONATE } \\
\text { (HCO3) }\end{array}$ & $\begin{array}{r}\text { CAR- } \\
\text { BONAT } \\
\text { (CO3) }\end{array}$ \\
\hline $\begin{array}{l}\text { OCT. } \\
01-10 \\
\text { NOV. }\end{array}$ & 31020 & -- & - & $\rightarrow$ & 16 & 2.8 & -- & -- & 13 & 36 & 0 \\
\hline $\begin{array}{l}\text { O1-10 } \\
\text { DEC. }\end{array}$ & 17940 & -- & -- & -- & 17 & 4.8 & -- & -- & 9.4 & 34 & 0 \\
\hline $\begin{array}{l}01-10 \\
\text { JAN. } \\
02-03 \text {, } \\
05-08,\end{array}$ & 26420 & -- & -- & -- & 17 & 5.4 & -- & -- & 8.0 & 25 & 0 \\
\hline FEB. & 14740 & -- & -- & -- & 17 & 4.6 & -- & - & 10 & 31 & 0 \\
\hline $\begin{array}{l}\text { 01-09 } \\
\text { MAR. }\end{array}$ & 49830 & -- & -- & -- & 13 & 4.3 & -- & -- & 6.9 & 16 & 0 \\
\hline $\begin{array}{l}01-10 \\
\text { APR. }\end{array}$ & 4930 & -- & -- & -- & 21 & 7.2 & -- & - & 14 & 32 & 0 \\
\hline $\begin{array}{l}\text { 01-10 } \\
\text { MAY }\end{array}$ & 25600 & 4.1 & 0.00 & 0.00 & 15 & 4.4 & 5.9 & 1.3 & -- & 20 & 0 \\
\hline $\begin{array}{l}\text { 01-10 } \\
\text { JUNE }\end{array}$ & 5690 & -- & -- & -- & 22 & 7.0 & -- & -- & 9.4 & 26 & 0 \\
\hline $\begin{array}{l}01-10 \\
\text { JULY }\end{array}$ & 10600 & -- & -- & -- & 17 & 5.8 & -- & -- & 12 & 28 & 0 \\
\hline $\begin{array}{l}\text { 01-10 } \\
\text { AUG. }\end{array}$ & 7560 & -- & -- & -- & 20 & 5.3 & -- & - & 11 & 40 & 0 \\
\hline $\begin{array}{l}\text { 01-10 } \\
\text { SEPT. }\end{array}$ & 3320 & -- & -- & -- & 25 & 6.9 & -- & -- & 14 & 44 & 0 \\
\hline $02-10$ & 3840 & -- & -- & -- & 31 & 6.6 & + & -- & 7.4 & 50 & 0 \\
\hline DATE & $\begin{array}{c}\text { SULFATE } \\
(504)\end{array}$ & $\begin{array}{l}\text { CHLO- } \\
\text { RIDE } \\
\text { (CL) }\end{array}$ & $\begin{array}{l}\text { FLUD- } \\
\text { RIDE } \\
\text { IFI }\end{array}$ & $\begin{array}{l}\text { NI TRATE } \\
\text { (NO3) }\end{array}$ & $\begin{array}{l}\text { DIS- } \\
\text { SOLVED } \\
\text { SOLIDS } \\
\text { (RESI- } \\
\text { DUE AT } \\
180^{\circ} \mathrm{C} \text { ) }\end{array}$ & $\begin{array}{l}\text { HARD- } \\
\text { NESS } \\
(C A, M G)\end{array}$ & $\begin{array}{l}\text { NON- } \\
\text { CAR- } \\
\text { BONATE } \\
\text { HARD- } \\
\text { NESS }\end{array}$ & $\begin{array}{l}\text { SPE- } \\
\text { CIFIC } \\
\text { CONDUCT- } \\
\text { ANCE } \\
\text { (MICRO- } \\
\text { MHOS) }\end{array}$ & $\mathrm{PH}$ & COLOR & $\begin{array}{l}\text { TEM- } \\
\text { PERA- } \\
\text { TURE } \\
\text { IDEG C }\end{array}$ \\
\hline OCT. & 30 & 14 & -- & 0.3 & -- & 52 & 22 & 155 & 7.1 & 5 & 14 \\
\hline $\begin{array}{l}\text { NOV. } \\
\text { O1-10 } \\
\text { DEC. }\end{array}$ & 32 & 15 & -- & .2 & -- & 62 & 34 & 178 & 6.6 & 5 & -- \\
\hline $\begin{array}{l}01-10 \\
\text { JAN. } \\
02-03, \\
05-08\end{array}$ & 41 & 13 & -- & .9 & -- & 65 & 44 & 181 & 7.1 & 2 & -- \\
\hline FEB. & 36 & 14 & -- & 1.4 & -- & 62 & 36 & 180 & 7.2 & 3 & -- \\
\hline $\begin{array}{l}\text { 01-09 } \\
\text { MAR. }\end{array}$ & 35 & 10 & -- & 1.6 & -- & 50 & 37 & 147 & 6.0 & 4 & -- \\
\hline $\begin{array}{l}\text { 01-10 } \\
\text { APR. }\end{array}$ & 61 & 16 & -- & 1.7 & -- & 82 & 56 & 252 & 6.9 & 3 & - \\
\hline $\begin{array}{l}01-10 \\
\text { MAY }\end{array}$ & 39 & 10 & 0.1 & 1.0 & 97 & 56 & 39 & 163 & 7.1 & 2 & -- \\
\hline $\begin{array}{l}\text { O1-10 } \\
\text { JUNE }\end{array}$ & 61 & 14 & -- & .0 & -- & 84 & 63 & 244 & 7.2 & 3 & - \\
\hline $\begin{array}{l}\text { O1-10 } \\
\text { JULY }\end{array}$ & 50 & 12 & -- & .4 & -- & 67 & 44 & 203 & 6.7 & 2 & - \\
\hline $\begin{array}{l}\text { O1-10 } \\
\text { AUG. }\end{array}$ & 39 & 15 & -- & 1.2 & - & 72 & 39 & 204 & 7.4 & 9 & -- \\
\hline $\begin{array}{l}\text { 01-10 } \\
\text { SEPT. }\end{array}$ & 57 & 18 & -- & .9 & -- & 91 & 55 & 254 & 7.7 & 6 & -- \\
\hline $02-10$ & 43 & 24 & -- & .4 & -- & 105 & 64 & 272 & 7.9 & 1 & -- \\
\hline
\end{tabular}


03036500 ALLEGHENY RIVER AT KITTANNING, PA.--Cont1nued

TEMPERATURE $\left({ }^{\circ} \mathrm{C}\right)$ OF WATER, WATER YEAR OCTOBER 1967 TO SEPTEMBER 1968

\begin{tabular}{|c|c|c|c|c|c|c|c|c|c|c|c|c|}
\hline DAY & OLT & Nav & DEC & JAN & FEB & MAR & $A P R$ & MAY & JUN & JUL & AUG & SEP \\
\hline $\begin{array}{l}1 \\
2 \\
3 \\
4 \\
5\end{array}$ & $\begin{array}{l}17.0 \\
17.0 \\
12.0 \\
13.0 \\
13.0\end{array}$ & $\begin{array}{l}10.0 \\
10.0 \\
10.0 \\
10.0 \\
10.0\end{array}$ & $\begin{array}{l}4.0 \\
4.0 \\
4.0 \\
4.0 \\
4.0\end{array}$ & $\begin{array}{l}-1.0 \\
2.0 \\
2.0 \\
1.0\end{array}$ & $\begin{array}{l}3.0 \\
3.0 \\
2.0 \\
2.0 \\
1.0\end{array}$ & $\begin{array}{l}2.0 \\
2.0 \\
2.0 \\
2.0 \\
2.0\end{array}$ & $\begin{array}{l}7.0 \\
8.0 \\
2.0 \\
8.0 \\
8.0\end{array}$ & $\begin{array}{l}14.0 \\
13.0 \\
13.0 \\
14.0 \\
15.0\end{array}$ & $\begin{array}{l}14.0 \\
14.0 \\
13.0 \\
14.0 \\
14.0\end{array}$ & $\begin{array}{l}21.0 \\
23.0 \\
23.0 \\
23.0 \\
23.0\end{array}$ & $\begin{array}{l}25.0 \\
24.0 \\
24.0 \\
25.0 \\
26.0\end{array}$ & $\begin{array}{l}25.0 \\
24.0 \\
24.0 \\
25.0\end{array}$ \\
\hline $\begin{array}{r}6 \\
7 \\
8 \\
9 \\
10\end{array}$ & $\begin{array}{l}13.0 \\
14.0 \\
13.0 \\
13.0 \\
14.0\end{array}$ & $\begin{array}{l}9.0 \\
9.0 \\
7.0 \\
7.0 \\
7.0\end{array}$ & $\begin{array}{l}3.0 \\
4.0 \\
4.0 \\
3.0 \\
---\end{array}$ & $\begin{array}{l}2.0 \\
2.0 \\
2.0 \\
2.0\end{array}$ & $\begin{array}{l}2.0 \\
2.0 \\
2.0 \\
2.0 \\
-2\end{array}$ & $\begin{array}{l}2.0 \\
2.0 \\
2.0 \\
2.0 \\
2.0\end{array}$ & $\begin{array}{r}6.0 \\
7.0 \\
12.0 \\
11.0 \\
11.0\end{array}$ & $\begin{array}{l}14.0 \\
14.0 \\
14.0 \\
14.0 \\
14.0\end{array}$ & $\begin{array}{l}14.0 \\
18.0 \\
18.0 \\
20.0 \\
16.0\end{array}$ & $\begin{array}{l}23.0 \\
23.0 \\
23.0 \\
23.0 \\
24.0\end{array}$ & $\begin{array}{l}25.0 \\
26.0 \\
26.0 \\
26.0 \\
25.0\end{array}$ & $\begin{array}{l}24.0 \\
25.0 \\
23.0 \\
24.0 \\
23.0\end{array}$ \\
\hline $\begin{array}{l}11 \\
12 \\
13 \\
14 \\
15\end{array}$ & $\begin{array}{l}14.0 \\
14.0 \\
14.0 \\
13.0 \\
13.0\end{array}$ & $\begin{array}{l}9.0 \\
7.0 \\
7.0 \\
7.0 \\
7.0\end{array}$ & $\begin{array}{l}4.0 \\
4.0 \\
6.0 \\
4.0\end{array}$ & $\begin{array}{l}2.0 \\
2.0 \\
2.0 \\
1.0 \\
2.0\end{array}$ & $\begin{array}{l}2.0 \\
2.0 \\
2.0 \\
2.0 \\
2.0\end{array}$ & $\begin{array}{l}-- \\
2.0 \\
2.0 \\
2.0 \\
2.0\end{array}$ & $\begin{array}{l}--- \\
11.0 \\
11.0 \\
11.0 \\
11.0\end{array}$ & $\begin{array}{l}14.0 \\
14.0 \\
14.0 \\
14.0 \\
14.0\end{array}$ & $\begin{array}{l}17.0 \\
20.0 \\
23.0 \\
23.0 \\
24.0\end{array}$ & $\begin{array}{l}24.0 \\
24.0 \\
24.0 \\
24.0 \\
24.0\end{array}$ & $\begin{array}{l}25.0 \\
25.0 \\
25.0 \\
25.0 \\
25.0\end{array}$ & $\begin{array}{l}23.0 \\
22.0 \\
22.0 \\
22.0 \\
22.0\end{array}$ \\
\hline $\begin{array}{l}16 \\
17 \\
18 \\
19 \\
20\end{array}$ & $\begin{array}{r}13.0 \\
14.0 \\
13.0 \\
14.0 \\
\end{array}$ & $\begin{array}{l}7.0 \\
6.0 \\
6.0 \\
6.0 \\
6.0\end{array}$ & $\begin{array}{l}4.0 \\
4.0 \\
4.0 \\
4.0 \\
-.-\end{array}$ & $\begin{array}{l}1.0 \\
2.0 \\
2.0 \\
2.0 \\
2.0\end{array}$ & $\begin{array}{l}2.0 \\
2.0 \\
2.0 \\
2.0 \\
2.0\end{array}$ & $\begin{array}{l}2.0 \\
2.0 \\
2.0 \\
2.0 \\
3.0\end{array}$ & $\begin{array}{l}11.0 \\
11.0 \\
11.0 \\
12.0 \\
12.0\end{array}$ & $\begin{array}{r}14.0 \\
14.0 \\
14.0 \\
13.0\end{array}$ & $\begin{array}{l}24.0 \\
24.0 \\
24.0 \\
24.0 \\
22.0\end{array}$ & $\begin{array}{l}24.0 \\
26.0 \\
26.0 \\
26.0 \\
24.0\end{array}$ & $\begin{array}{l}25.0 \\
25.0 \\
25.0 \\
25.0 \\
25.0\end{array}$ & $\begin{array}{l}22.0 \\
22.0 \\
22.0 \\
22.0 \\
22.0\end{array}$ \\
\hline $\begin{array}{l}21 \\
22 \\
23 \\
24 \\
25\end{array}$ & $\begin{array}{l}14.0 \\
13.0 \\
13.0 \\
12.0 \\
13.0\end{array}$ & $\begin{array}{l}6.0 \\
5.0 \\
5.0 \\
5.0 \\
5.0\end{array}$ & \begin{tabular}{l}
4.0 \\
6.0 \\
\hdashline-- \\
---
\end{tabular} & $\begin{array}{l}2.0 \\
2.0 \\
2.0 \\
2.0 \\
2.0\end{array}$ & $\begin{array}{l}1.0 \\
1.0 \\
1.0 \\
1.0 \\
1.0\end{array}$ & $\begin{array}{l}3.0 \\
3.0 \\
4.0 \\
5.0 \\
8.0\end{array}$ & $\begin{array}{l}13.0 \\
13.0 \\
23.0 \\
13.0 \\
14.0\end{array}$ & $\begin{array}{l}14.0 \\
13.0 \\
13.0 \\
16.0 \\
13.0\end{array}$ & $\begin{array}{l}22.0 \\
23.0 \\
21.0 \\
22.0 \\
22.0\end{array}$ & $\begin{array}{l}25.0 \\
26.0 \\
26.0 \\
26.0 \\
26.0\end{array}$ & $\begin{array}{l}27.0 \\
27.0 \\
26.0 \\
26.0 \\
27.0\end{array}$ & $\begin{array}{l}22.0 \\
22.0 \\
21.0 \\
21.0 \\
21.0\end{array}$ \\
\hline $\begin{array}{l}26 \\
27 \\
28 \\
29 \\
30 \\
31\end{array}$ & $\begin{array}{l}12.0 \\
12.0 \\
12.0 \\
122.0 \\
12.0 \\
111.0\end{array}$ & $\begin{array}{l}5.0 \\
5.0 \\
5.0 \\
5.0 \\
3.0 \\
-. .\end{array}$ & $\begin{array}{l}4.0 \\
3.0 \\
3.0 \\
-0\end{array}$ & $\begin{array}{l}2.0 \\
2.0 \\
2.0 \\
2.0 \\
2.0 \\
3.0\end{array}$ & $\begin{array}{l}1.0 \\
2.0 \\
2.0 \\
2.0 \\
-\cdots \\
---\end{array}$ & $\begin{array}{l}7.0 \\
4.0 \\
5.0 \\
6.0 \\
6.0 \\
6.0\end{array}$ & $\begin{array}{l}14.0 \\
13.0 \\
14.0 \\
14.0 \\
14.0 \\
-\end{array}$ & $\begin{array}{l}23.0 \\
13.0 \\
13.0 \\
23.0 \\
23.0 \\
13.0\end{array}$ & $\begin{array}{l}21.0 \\
23.0 \\
22.0 \\
22.0 \\
21.0 \\
-\end{array}$ & $\begin{array}{l}26.0 \\
26.0 \\
26.0 \\
25.0 \\
26.0 \\
26.0\end{array}$ & $\begin{array}{l}27.0 \\
27.0 \\
25.0 \\
25.0 \\
25.0 \\
24.0\end{array}$ & $\begin{array}{r}21.0 \\
21.0 \\
21.0 \\
22.0 \\
---\end{array}$ \\
\hline AVERAGE & 13.0 & 7.0 & $\cdots$ & 2.0 & 2.0 & 3.0 & 11.0 & 13.5 & 20.0 & 24.5 & 25.5 & 22.5 \\
\hline
\end{tabular}

SPECIFIC CONDUCTANCE (MICTOMHOS AT $25^{\circ} \mathrm{C}$ ), WATER YEAR OCTNBER 1967 TO SEPTEMBER 1968

DAY OCTOBER NOVEABER DECEMBER JANUARY FEBRUARY MARCH APRIL MAY JUNE JULY AUGUST SEPTEMBER

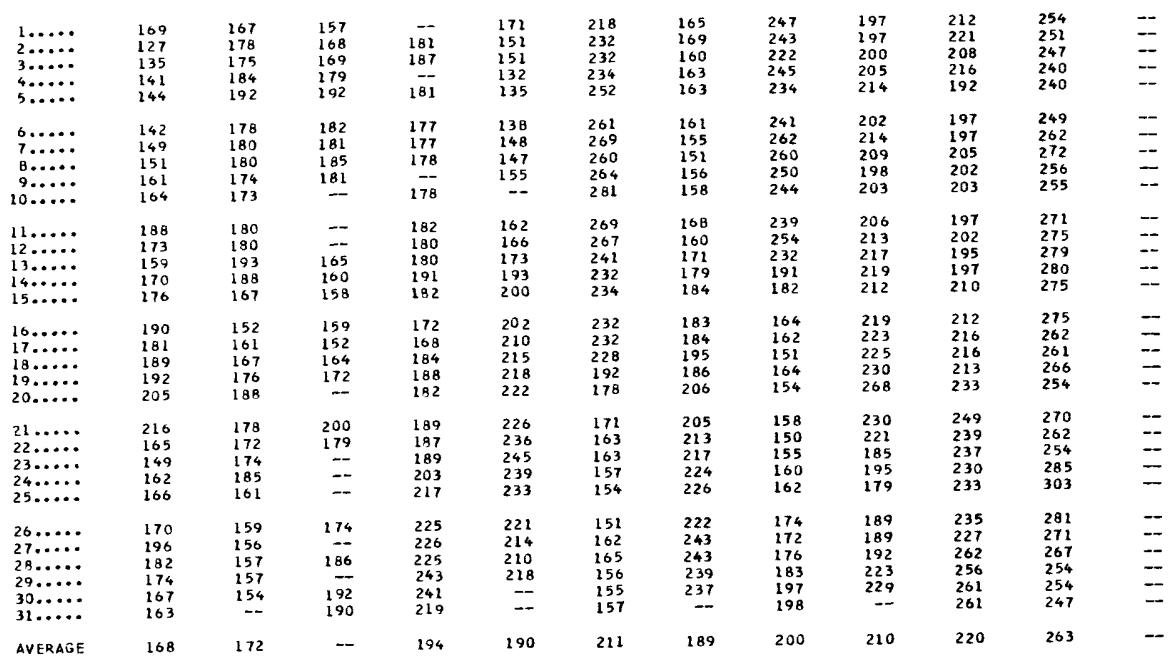


03041500 CONEMAUGH RIVER AT SEWARD, PA.

LOCATION. --Lat $40^{\circ} 25^{\prime} 10^{\prime \prime}$, long $79^{\circ} 01^{\prime} 40^{\prime \prime}$, Nestmoreland County, temperature recorder at gaging station on left bank at highway bridge on' State Highway 56 at Seward, 2,0 miles downstream from Findley Run and 9 miles northwest of
Johnstown.

DRA INAGE AREA, $--715 \mathrm{sq} \mathrm{mi}$.

PERIOD OF RECORD. -- Water temperatures: October 1962 to September 1968.

EXTREMES. --1967-68:

Water temperatures: Maximum, 29.0 $0^{\circ} \mathrm{July} 1,16$ and Aug. 23-25; minimum, freezing point Feb. 12-14, 17, Period of record:

Water temperatures: Maximum, $31.0^{\circ} \mathrm{C}$ Aug. 16, 1965; minimum, freezing point on many days during $1962-68$ REMARS. - Records furnished by the Pennsylvania Electric co.

CHEMICAL ANALYSES IN MILLIGRAMS PER LITER, hATER YEAR OCTOBER 1967 TO SEPTEMBER 1968

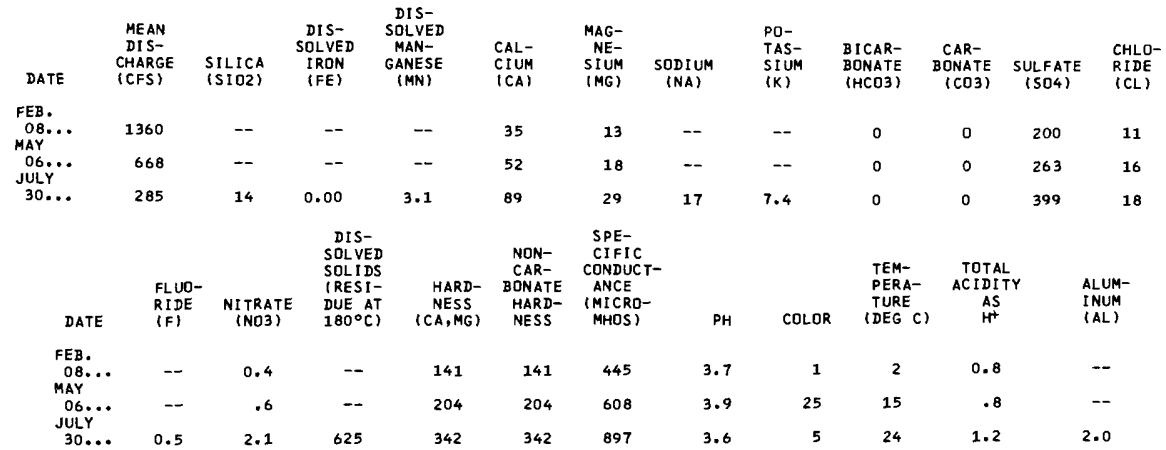

TEMPERATURE $\left({ }^{\circ} \mathrm{C}\right)$ OF WATER, WATER YEAR OCTOBER 1967 TO SEPTEMBER 1968

DAY

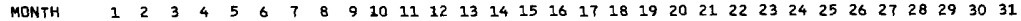

DCTOBER

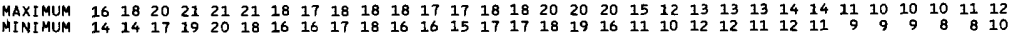
NOVEMBER

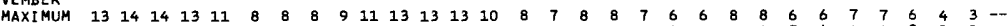

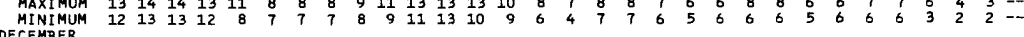
DECEMBER

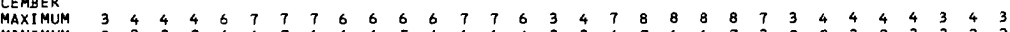
$\begin{array}{lllllllllllllllllllllllllllllllll}\text { MINIMUM } & 2 & 2 & 3 & 3 & 4 & 6 & 7 & 6 & 6 & 6 & 5 & 6 & 6 & 6 & 4 & 3 & 3 & 4 & 7 & 6 & 6 & 7 & 3 & 2 & 2 & 3 & 2 & 3 & 3 & 2 & 2\end{array}$

MAXIMUM -- - - - - - - - - - - - - - - - - - - - MINIMUM --

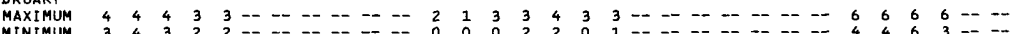
MINIMUM

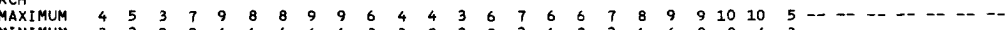
APRIL

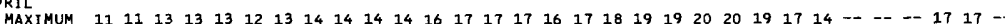

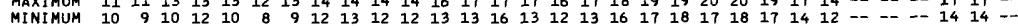
MAXIMUM $17 \begin{array}{llllllllllllllllllllllllllllllll}18 & 19 & 19 & 17 & 16 & 18 & 19 & 18 & 19 & 19 & 17 & 18 & 18 & 18 & 18 & 18 & -- & - & 12 & 13 & 14 & 14 & 13 & 16 & 16 & 16 & 12 & 14 & 14 & 13\end{array}$ MINIMUM $14 \begin{array}{llllllllllllllllllllllllllllll}14 & 17 & 17 & 14 & 13 & 14 & 16 & 18 & 18 & 17 & 16 & 16 & 16 & 16 & 17 & 16 & -2 & -0 & 12 & 12 & 12 & 13 & 12 & 12 & 13 & 11 & 11 & 11 & 13 & 12\end{array}$ JUNE

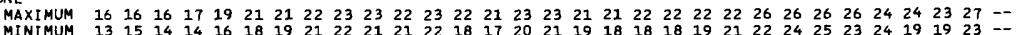
JULY

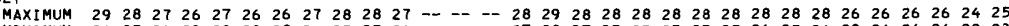

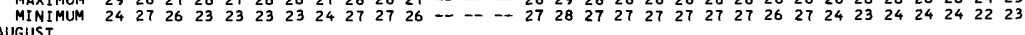
AUGUST

$\begin{array}{llllllllllllllllllllllllllllllll}\text { MAXIMUM } & 25 & 24 & 26 & 26 & 27 & 28 & 28 & 27 & 27 & 28 & 28 & 24 & 24 & 26 & 28 & 27 & 28 & 28 & 28 & 27 & 27 & 28 & 29 & 29 & 29 & 21 & 22 & 22 & 22 & 22 & 22 \\ \text { MINIMUM } & 22 & 22 & 23 & 26 & 25 & 27 & 27 & 27 & 27 & 27 & 26 & 22 & 22 & 24 & 25 & 26 & 26 & 27 & 27 & 26 & 27 & 27 & 29 & 29 & 29 & 20 & 21 & 21 & 20 & 20 & 20\end{array}$ SEPTEMBER

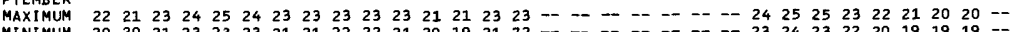

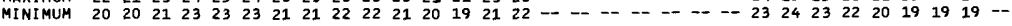


LOCATION, -lat $40^{\circ} 36^{\prime} 20^{\prime \prime}$, long $79^{\circ} 33^{\prime} 15^{\prime \prime}$, Armstrong County, at raw-water intake of West Leechburg plant of Allegheny-Ludium Steel Corp., 0.2 mile downstream from Brady Run and 6.7 mlles downstream from gaging station at Vandergrift.

DRAINAGE AREA. $--1,860 \mathrm{sq} \mathrm{mi}$.

PERION OF RECORD. - Chemical analyses: October 1946 to September 1951, October 1958 to July 1959, October 1959 to Sep tember 1968 .

water temperatures: October 1946 to September 1951, October 1958 to July 1959, October 1959 to September 1968.

EXTREMES $-1967-68$ :

Specific conductance: Haximum daily, 1,730 micromhos Sept. 7; minimum daily, 286 micromhos May 27.

Water temperatures: Maximum, $31.0^{\circ} \mathrm{C}$ Aug. $23,25,26$; minimum, freezing point Jan. 8.

Period of record:

Dissolved solids (1946-47, 1959-62): Maximum, $945 \mathrm{mg} / 1$ Aug. 27 to Sept. 12, 1960; minimum, $141 \mathrm{mg} / 1 \mathrm{mar} .30$

to Apr. 8, 1960. 1959-62): Maximum, $514 \mathrm{mg} / 1$ Oct. 1-10, 1946 ; minimum, $74 \mathrm{mg} / 1 \mathrm{Mar}$. 30 to Apr. $8,1960$.

Specific conductance: Maximum daily, 5,420 micromhos Aug. 12, 1951; minimum daily, 175 micromhos July 22 , 1950

Ver temperatures: Maximum, $320^{\circ} \mathrm{C}$ Juiy 25, 1950; minimum, freezing point on many days during vinter periods,

REMARKS. - Records of discharge are based on records for Kiskiminetas River at Vandergrift. CHEMICAL ANALYSES IN MILLIGRAMS PER LITER, WATER YEAR OCTOBER 1967 TO SEPTEMBER 1968

\begin{tabular}{|c|c|c|c|c|c|c|c|c|c|c|c|}
\hline DATE & $\begin{array}{l}\text { MEAN } \\
\text { DIS- } \\
\text { CHARGE } \\
\text { (CFS) }\end{array}$ & $\begin{array}{l}\text { SILICA } \\
\text { (S102) }\end{array}$ & $\begin{array}{l}\text { DIS- } \\
\text { SOLVED } \\
\text { IRON } \\
\text { (FE) }\end{array}$ & $\begin{array}{l}\text { DIS- } \\
\text { SOLVED } \\
\text { MAN- } \\
\text { GANESE } \\
\text { (MN) }\end{array}$ & $\begin{array}{l}\text { CAL- } \\
\text { CIUM } \\
\text { (CA) }\end{array}$ & $\begin{array}{l}\text { MAG- } \\
\text { NE- } \\
\text { SIUM } \\
(M G)\end{array}$ & $\begin{array}{l}\text { SODIUM } \\
\text { (NA) }\end{array}$ & $\begin{array}{l}\text { PO- } \\
\text { TAS- } \\
\text { SIUM } \\
\text { (K) }\end{array}$ & $\begin{array}{l}\text { BICAR- } \\
\text { BONATE } \\
\text { (HCO3) }\end{array}$ & $\begin{array}{r}\text { CAR- } \\
\text { BONATE } \\
\text { (CO3) }\end{array}$ & $\begin{array}{l}\text { SULFATE } \\
\left.(\mathrm{SO})^{2}\right)\end{array}$ \\
\hline $\begin{array}{l}\text { OCT. } \\
\text { O1-10 } \\
\text { NOV. }\end{array}$ & 1530 & -- & -- & -- & -- & -- & -- & -- & 0 & 0 & 267 \\
\hline $\begin{array}{l}01-10 \\
\text { DEC. }\end{array}$ & 1610 & -- & -- & -- & 48 & 16 & -- & - & 0 & 0 & 256 \\
\hline $\begin{array}{l}01-10 \\
\text { JAN. } \\
01-08 \text {, }\end{array}$ & 3510 & -- & -- & -- & 31 & 12 & -- & -- & 0 & 0 & 159 \\
\hline $\begin{array}{l}10 . . \\
\text { FEB. } \\
01, \\
03,\end{array}$ & 2470 & -- & -- & - & 48 & 17 & -- & $=$ & 0 & 0 & 278 \\
\hline $\begin{array}{l}08-10 \\
\text { MAR. }\end{array}$ & 8970 & -- & + & -- & 27 & 11 & -- & - & 0 & 0 & 134 \\
\hline $\begin{array}{l}\text { O1-10 } \\
\text { APR. }\end{array}$ & 970 & -- & - & -- & 60 & 24 & -- & -- & 0 & 0 & 416 \\
\hline $\begin{array}{l}\text { O1-10 } \\
\text { MAY } \\
01-06,\end{array}$ & 5560 & 9.5 & 0.04 & 0.78 & 33 & 11 & 12 & 2.2 & 0 & 0 & 160 \\
\hline $\begin{array}{l}\text { O8-10 } \\
\text { JUNE }\end{array}$ & 1330 & -- & -- & -- & 54 & 18 & -- & -- & 0 & 0 & 316 \\
\hline $\begin{array}{l}\text { 01-10 } \\
\text { JULY }\end{array}$ & 7100 & -- & -- & -- & 28 & 9.5 & - & -- & 0 & 0 & 140 \\
\hline $\begin{array}{l}\text { O1-10 } \\
\text { AUG. }\end{array}$ & 745 & -- & - & -- & 78 & 28 & -- & -- & 0 & 0 & 443 \\
\hline $\begin{array}{l}01-10 \\
\text { SEPT. } \\
01-02 \text {, } \\
06-10\end{array}$ & 735 & -- & -- & -- & 79 & 26 & -- & -- & 0 & 0 & $\begin{array}{l}451 \\
538\end{array}$ \\
\hline DATE & $\begin{array}{l}\text { CHLO- } \\
\text { RIDE } \\
\text { (CL) }\end{array}$ & $\begin{array}{l}\text { FLUO- } \\
\text { RIDE } \\
\text { (F) }\end{array}$ & $\begin{array}{l}\text { NITRATE } \\
\text { (NO3) }\end{array}$ & $\begin{array}{l}\text { DIS- } \\
\text { SOLVED } \\
\text { SOLIDS } \\
\text { (RESI- } \\
\text { DUE AT } \\
180^{\circ} \mathrm{C} \text { ) }\end{array}$ & $\begin{array}{c}\text { HARD- } \\
\text { NESS } \\
(C A, M G)\end{array}$ & $\begin{array}{l}\text { NON- } \\
\text { CAR- } \\
\text { BONATE } \\
\text { HARD- } \\
\text { NESS }\end{array}$ & $\begin{array}{l}\text { SPE- } \\
\text { CIFIC } \\
\text { CONDUCT- } \\
\text { ANCE } \\
\text { (MICRO- } \\
\text { MHOS) }\end{array}$ & PH & COLOR & $\begin{array}{c}\text { TEM- } \\
\text { PERA- } \\
\text { TURE } \\
\text { (DEG C) }\end{array}$ & $\begin{array}{c}\text { TOTAL } \\
\text { ACIDITY } \\
\text { AS } \\
\mathrm{H}^{+}\end{array}$ \\
\hline OCT. & 11 & -- & 2,5 & -- & 196 & 196 & 712 & 3.4 & 2 & 17 & 1.2 \\
\hline $\begin{array}{l}\text { NOV. } \\
\text { O1-10 } \\
\text { DEC. }\end{array}$ & 14 & - & 1.9 & -- & 186 & 186 & 614 & 3.7 & 2 & -- & .9 \\
\hline $\begin{array}{l}01-10 \\
\text { JAN. } \\
01-08\end{array}$ & 14 & - & 1.4 & -- & 127 & 127 & 461 & 3.8 & 2 & -- & .7 \\
\hline $\begin{array}{l}10 . . \\
\text { FEB. } \\
01, \\
03, \\
08-10\end{array}$ & 16 & -- & .7 & -- & 190 & 190 & 715 & 3,4 & 2 & -- & 1.4 \\
\hline $\begin{array}{l}\text { MAR. } \\
01-10\end{array}$ & & & & & & & & & & & \\
\hline $\begin{array}{l}\text { 01-10 } \\
\text { APR. }\end{array}$ & 24 & - & 2.7 & -- & 248 & 248 & 1050 & 3.3 & 2 & -- & 2.1 \\
\hline $\begin{array}{l}01-10 \\
\text { MAY }\end{array}$ & 12 & 0.1 & .9 & 254 & 128 & 128 & 462 & 3.7 & 1 & -- & .7 \\
\hline $\begin{array}{l}\text { O1-06, } \\
\text { O8-10 } \\
\text { JUNE }\end{array}$ & 16 & - & 7.5 & -- & 209 & 209 & 735 & 3.5 & 5 & -- & 1.4 \\
\hline $\begin{array}{l}01-10 \\
\text { JULY }\end{array}$ & 9.0 & -- & .8 & - & 109 & 109 & 409 & 3.7 & 1 & -- & .9 \\
\hline $\begin{array}{l}\text { O1-10 } \\
\text { AUG. }\end{array}$ & 28 & -- & 1.3 & -- & 310 & 310 & 1090 & 3.1 & 1 & -- & 2.2 \\
\hline $\begin{array}{l}\text { O1-10 } \\
\text { SEPT. } \\
\text { O1-02, } \\
08-10\end{array}$ & 20 & $\sim$ & 1.0 & -- & 304 & 304 & 1080 & 3.3 & 3 & -- & 2.0 \\
\hline
\end{tabular}


KISKIMI NETAS RIVER BASIN

03048500 KISKIMINETAS RIVER AT LEESBURG (YANDERGRIFT), PA,--Continued

SPECIFIC CONDUCTANCE (MICROMHOS AT $25^{\circ} \mathrm{C}$ ), WATER YEAR OCTOBER 1967 TO SEPTEMBER 1968

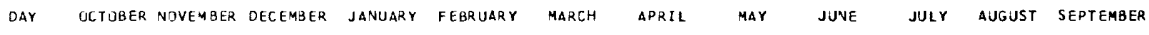

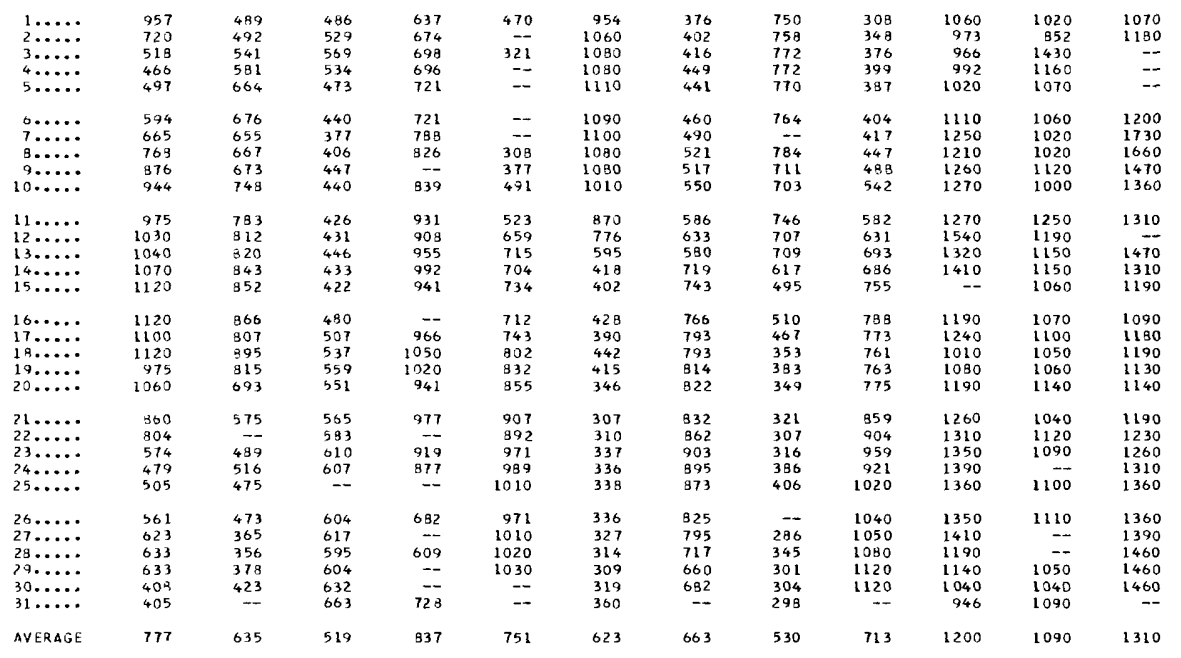

TEMPERATURE (OC) OF WATER, WATER YEAR OCTOBER 1967 TO SEPTEMBER 1968

\begin{tabular}{|c|c|c|c|c|c|c|c|c|c|c|c|c|}
\hline DAY & OCT & NOV & DEC & JAN & $F E B$ & MAK & $A P R$ & yar & JUN & JUL & AUG & SEP \\
\hline $\begin{array}{l}1 \\
2 \\
3 \\
4 \\
5\end{array}$ & $\begin{array}{l}17.0 \\
16.0 \\
18.0 \\
10.0 \\
19.0\end{array}$ & $\begin{array}{l}12.0 \\
13.0 \\
11.0 \\
12.0 \\
12.0\end{array}$ & $\begin{array}{l}3.0 \\
4.0 \\
6.0 \\
5.0 \\
5.0\end{array}$ & $\begin{array}{l}2.0 \\
1.0 \\
3.0 \\
3.0 \\
3.0\end{array}$ & $\begin{array}{l}7.0 \\
4.0 \\
--.\end{array}$ & $\begin{array}{l}1.0 \\
2.0 \\
2.0 \\
2.0 \\
3.0\end{array}$ & $\begin{array}{l}10.0 \\
11.0 \\
12.0 \\
14.0 \\
14.0\end{array}$ & $\begin{array}{l}16.0 \\
17.0 \\
18.0 \\
18.0 \\
17.0\end{array}$ & $\begin{array}{l}17.0 \\
17.0 \\
18.0 \\
18.0 \\
19.0\end{array}$ & $\begin{array}{l}27.0 \\
27.0 \\
28.0 \\
20.0 \\
25.0\end{array}$ & $\begin{array}{l}27.0 \\
26.0 \\
27.0 \\
27.0 \\
28.0\end{array}$ & \begin{tabular}{r}
23.0 \\
22.0 \\
\hdashline- \\
--
\end{tabular} \\
\hline $\begin{array}{r}6 \\
7 \\
8 \\
9 \\
10\end{array}$ & $\begin{array}{l}17.0 \\
19.0 \\
17.0 \\
18.0 \\
17.0\end{array}$ & $\begin{array}{l}9.0 \\
8.0 \\
6.0 \\
8.0 \\
6.0\end{array}$ & $\begin{array}{l}7.0 \\
7.0 \\
6.0 \\
7.0 \\
4.0\end{array}$ & $\begin{array}{l}2.0 \\
3.0 \\
0 \\
-1.0\end{array}$ & $\begin{array}{l}--. \\
-0.0 \\
5.0 \\
6.0\end{array}$ & $\begin{array}{l}3.0 \\
3.0 \\
4.0 \\
0.0 \\
7.0\end{array}$ & $\begin{array}{l}13.0 \\
13.0 \\
14.0 \\
15.0 \\
14.0\end{array}$ & $\begin{array}{l}17.0 \\
17.0 \\
17.0 \\
17.0\end{array}$ & $\begin{array}{l}20.0 \\
18.0 \\
19.0 \\
23.0 \\
24.0\end{array}$ & $\begin{array}{l}26.0 \\
26.0 \\
27.0 \\
27.0 \\
27.0\end{array}$ & $\begin{array}{r}29.0 \\
29.0 \\
29.0 \\
29.0 \\
-.-\end{array}$ & $\begin{array}{l}24.0 \\
26.0 \\
24.0 \\
23.0 \\
24.0\end{array}$ \\
\hline $\begin{array}{l}11 \\
12 \\
13 \\
14 \\
15\end{array}$ & $\begin{array}{l}19.0 \\
14.0 \\
13.0 \\
14.0 \\
14.0\end{array}$ & $\begin{array}{l}9.0 \\
9.0 \\
9.0 \\
9.0 \\
0.0\end{array}$ & $\begin{array}{l}7.0 \\
8.0 \\
7.0 \\
8.0 \\
7.0\end{array}$ & $\begin{array}{l}2.0 \\
1.0 \\
2.0 \\
2.0 \\
2.0\end{array}$ & $\begin{array}{l}2.0 \\
2.0 \\
3.0 \\
2.0 \\
3.0\end{array}$ & $\begin{array}{l}7.0 \\
0.0 \\
4.0 \\
4.0 \\
6.0\end{array}$ & $\begin{array}{l}14.0 \\
14.0 \\
16.0 \\
17.0 \\
16.0\end{array}$ & $\begin{array}{l}19.0 \\
20.0 \\
18.0 \\
18.0 \\
19.0\end{array}$ & $\begin{array}{l}27.0 \\
24.0 \\
24.0 \\
26.0 \\
26.0\end{array}$ & $\begin{array}{r}27.0 \\
27.0 \\
28.0 \\
29.0 \\
-.-\end{array}$ & $\begin{array}{l}30.0 \\
24.0 \\
26.0 \\
26.0 \\
27.0\end{array}$ & $\begin{array}{r}22.0 \\
22.0 \\
20.0 \\
22.0\end{array}$ \\
\hline $\begin{array}{l}16 \\
17 \\
18 \\
19 \\
20\end{array}$ & $\begin{array}{l}16.0 \\
17.0 \\
17.0 \\
16.0 \\
11.0\end{array}$ & $\begin{array}{l}6.0 \\
7.0 \\
7.0 \\
7.0 \\
7.0\end{array}$ & $\begin{array}{l}7.0 \\
7.0 \\
8.0 \\
9.0 \\
0.0\end{array}$ & $\begin{array}{l}--.0 \\
2.0 \\
2.0 \\
3.0 \\
2.0\end{array}$ & $\begin{array}{l}3.0 \\
3.0 \\
3.0 \\
3.0 \\
3.0\end{array}$ & $\begin{array}{l}0.0 \\
7.0 \\
7.0 \\
6.0 \\
8.0\end{array}$ & $\begin{array}{l}14.0 \\
16.0 \\
16.0 \\
17.0 \\
17.0\end{array}$ & $\begin{array}{l}17.0 \\
20.0 \\
21.0 \\
19.0 \\
20.0\end{array}$ & $\begin{array}{l}26.0 \\
22.0 \\
21.0 \\
23.0 \\
22.0\end{array}$ & $\begin{array}{l}30.0 \\
29.0 \\
30.0 \\
30.0 \\
29.0\end{array}$ & $\begin{array}{l}28.0 \\
28.0 \\
28.0 \\
28.0 \\
28.0\end{array}$ & $\begin{array}{l}23.3 \\
23.0 \\
23.0 \\
23.0 \\
21.0\end{array}$ \\
\hline $\begin{array}{l}21 \\
22 \\
23 \\
24 \\
25\end{array}$ & $\begin{array}{l}15.0 \\
14.0 \\
12.0 \\
12.0 \\
13.0\end{array}$ & $\begin{array}{l}6.0 \\
7.0 \\
0.0 \\
7.0 \\
7.0\end{array}$ & $\begin{array}{l}6.0 \\
6.0 \\
4.0 \\
4.0 \\
--.0\end{array}$ & $\begin{array}{l}3.0 \\
3.0 \\
2.0 \\
---0\end{array}$ & $\begin{array}{l}1.0 \\
3.0 \\
3.0 \\
3.0 \\
5.0\end{array}$ & $\begin{array}{r}9.0 \\
10.0 \\
9.0 \\
9.0 \\
9.0\end{array}$ & $\begin{array}{l}18.0 \\
18.0 \\
19.0 \\
18.0 \\
14.0\end{array}$ & $\begin{array}{l}16.0 \\
14.0 \\
14.0 \\
15.0 \\
14.0\end{array}$ & $\begin{array}{l}24.0 \\
23.0 \\
24.0 \\
24.0 \\
23.0\end{array}$ & $\begin{array}{l}28.0 \\
29.0 \\
29.0 \\
30.0 \\
20.0\end{array}$ & $\begin{array}{r}29.0 \\
29.0 \\
31.0 \\
31.0\end{array}$ & $\begin{array}{l}26.0 \\
26.0 \\
24.0 \\
26.0 \\
23.0\end{array}$ \\
\hline $\begin{array}{l}26 \\
27 \\
28 \\
29 \\
30 \\
31\end{array}$ & $\begin{array}{l}11.0 \\
10.0 \\
110.0 \\
10.0 \\
10.0 \\
10.0\end{array}$ & $\begin{array}{l}7.0 \\
3.0 \\
5.0 \\
0.0 \\
6.0 \\
-. .\end{array}$ & $\begin{array}{l}2.0 \\
2.0 \\
1.0 \\
3.0 \\
3.0 \\
3.0\end{array}$ & $\begin{array}{l}4.0 \\
-.0 \\
5.0 \\
2.0 \\
8.0\end{array}$ & $\begin{array}{l}3.0 \\
3.0 \\
3.0 \\
4.0 \\
-.- \\
-.-\end{array}$ & $\begin{array}{r}9.0 \\
10.0 \\
11.0 \\
11.0 \\
10.0 \\
11.0\end{array}$ & $\begin{array}{l}14.0 \\
16.0 \\
14.0 \\
16.0 \\
17.0 \\
\end{array}$ & $\begin{array}{l}17.0 \\
16.0 \\
16.0 \\
16.0 \\
15.0\end{array}$ & $\begin{array}{l}24.0 \\
26.0 \\
22.0 \\
24.0 \\
27.0 \\
-. .\end{array}$ & $\begin{array}{l}29.0 \\
29.0 \\
29.0 \\
27.0 \\
26.0 \\
26.0\end{array}$ & $\begin{array}{r}31.0 \\
\ldots-0 \\
30.0 \\
30.0 \\
30.0\end{array}$ & $\begin{array}{r}26.0 \\
23.0 \\
26.0 \\
26.0 \\
26.0 \\
\end{array}$ \\
\hline ERAGE & 14.5 & 8.0 & 5.5 & 2.5 & 3.5 & 6.5 & 15.0 & 17.4 & 22.5 & 27.5 & 28.5 & 23.5 \\
\hline
\end{tabular}


03048500 KISKIMINETAS RIVER AT LEESBURG (VANDERGRIFT), PA.--Continued

PH (UNITS), WATER YEAR OCTOBER 1967 TO SEPTEMBER 1968

DAY

\begin{tabular}{|c|c|c|}
\hline $\begin{array}{l}1 \ldots \ldots \\
2 \ldots \ldots \\
3 \ldots \ldots \\
4 \ldots \ldots\end{array}$ & $\begin{array}{l}3.4 \\
3.6 \\
3.7 \\
3.8 \\
3.7\end{array}$ & $\begin{array}{l}3.8 \\
4.0 \\
3.8 \\
3.8 \\
3.7\end{array}$ \\
\hline $\begin{array}{r}6 \ldots \ldots \\
7 \ldots \ldots \\
9 \ldots \ldots \\
10 \ldots \ldots\end{array}$ & $\begin{array}{l}3.6 \\
3.6 \\
3.5 \\
3.4 \\
3.4\end{array}$ & $\begin{array}{l}3.6 \\
3.7 \\
4.0 \\
3.9 \\
3.7\end{array}$ \\
\hline $\begin{array}{l}11 \ldots \ldots \\
12 \ldots \ldots \\
13 \ldots \ldots \\
14 \ldots \ldots \\
15 \ldots \ldots\end{array}$ & $\begin{array}{l}3.5 \\
3.4 \\
3.4 \\
3.5 \\
3.4\end{array}$ & $\begin{array}{l}3.7 \\
3.6 \\
3.6 \\
3.7 \\
3.6\end{array}$ \\
\hline $\begin{array}{l}16 \ldots \ldots \\
17 \ldots \ldots \\
18 \ldots \ldots \\
19 \ldots \ldots \\
20 \ldots \ldots\end{array}$ & $\begin{array}{l}3.5 \\
3.5 \\
3.5 \\
3.6 \\
3.4\end{array}$ & $\begin{array}{l}3.5 \\
3.8 \\
3.4 \\
3.5 \\
3.6\end{array}$ \\
\hline $\begin{array}{l}21 \ldots \ldots \\
22 \ldots \ldots \\
23 \ldots \ldots \\
24 \ldots \ldots \\
25 \ldots \ldots\end{array}$ & $\begin{array}{l}3.6 \\
3.6 \\
3.9 \\
4.0 \\
4.0\end{array}$ & $\begin{array}{l}4.0 \\
-.- \\
3.9 \\
3.8 \\
3.9\end{array}$ \\
\hline $\begin{array}{l}26 \ldots \ldots \\
27 \ldots \ldots \\
28 \ldots \ldots \\
29 \ldots \ldots \\
30 \ldots \ldots \\
31 \ldots \ldots\end{array}$ & $\begin{array}{l}3.8 \\
3.7 \\
3.8 \\
3.8 \\
4.2 \\
4.2\end{array}$ & $\begin{array}{l}3.9 \\
4.2 \\
4.2 \\
4.2 \\
4.0 \\
-7\end{array}$ \\
\hline
\end{tabular}

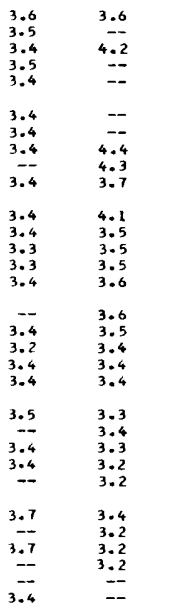

MONONGAHELA RIVER BASIV

$\begin{array}{ll}3.3 & 4.0 \\ 3.2 & 3.8 \\ 3.2 & 4.0 \\ 3.2 & 3.8 \\ 3.2 & 3.8 \\ 3.2 & 3.8 \\ 3.2 & 3.8 \\ 3.2 & 3.7 \\ 3.3 & 3.8 \\ 3.3 & 3.7 \\ 3.4 & 3.7 \\ 3.6 & 3.6 \\ 3.6 & 4.3 \\ 4.0 & 3.6 \\ 3.9 & 3.5 \\ 3.9 & 3.4 \\ 4.0 & 3.4 \\ 3.8 & 3.4 \\ 3.9 & 3.4 \\ 4.0 & 3.4 \\ 4.1 & 3.4 \\ 4.1 & 3.4 \\ 3.9 & 3.4 \\ 4.0 & 3.4 \\ 4.0 & 3.4 \\ 4.0 & 3.5 \\ 4.0 & 3.4 \\ 4.1 & 3.6 \\ 4.2 & 3.6 \\ 4.2 & 3.6 \\ 3.9 & -. \\ & \end{array}$

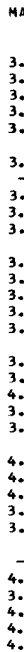

$\begin{array}{ll}3.4 & 4 . \\ 3.5 & 3.9 \\ 3.5 & 3.5 \\ 3.5 & 3.8 \\ 3.6 & 4.0 \\ 3.5 & 3 . \\ 3.5 & 3.8 \\ 3.4 & 3.5 \\ 3.5 & 3.7 \\ 3.4 & 3.6 \\ 3.4 & 3.8 \\ 3.5 & 3.6 \\ 3.5 & 3.4 \\ 3.5 & 3.4 \\ 3.6 & 3.5 \\ 3.7 & 3.4 \\ 4.0 & 3.5 \\ 3.6 & 3.6 \\ 3.8 & 3.4 \\ 4.0 & 3.4 \\ 4.2 & 3.3 \\ 4.2 & 3.3 \\ 3.8 & 3.3 \\ 3.8 & 3.3 \\ & \\ 4 .-3 & 3.2 \\ 3.9 & 3.3 \\ 4.0 & 3.2 \\ 4.0 & 3.3 \\ 4.1 & \\ & \end{array}$

JULY AUGUST SEPTEMBER

03050400 TYGART VALLEY RIVER AT ELKINS, W. VA.

LOCATION,--Lat $38^{\circ} 55^{\prime} 00^{\prime \prime}$, long $79^{\circ} 50^{\prime} 43^{\prime \prime}$, Randolph County, at city waterplant at Elkins, $2.5 \mathrm{miles}$ upstream from gaging station.

DRAINAGE AREA. --268 sq mi upstream from waterplant; 272 sq mi upstream from gaging station.

PERIOD OF RECORD. --Water temperatures: January 1947 to September 1968.

EXTREMES. --1967-68:

Water temperatures: $\operatorname{Maximum}, 27.0^{\circ} \mathrm{C}$ Aug. $8,20-25$; minimum, $1.0^{\circ} \mathrm{C}$ on many days during January to March,

Period of record:

Water temperatures: Maximum, $33.0^{\circ} \mathrm{C}$ July 22, 1952; minimum, freezing point on many days during winter period most years.

REMARKS, - No appreciable inflow between waterplant and gaging station except during periods of heavy local rains, During flood periods part of the flow is diverted around the waterplant in a flood by-pass channel.

TEMPERATURE ('O) OF WATER, WATER YEAR OCTOBER 1967 TO SEPTEMBER 1968 (ONCE-DAILY MEASUREMENTS)

DAY

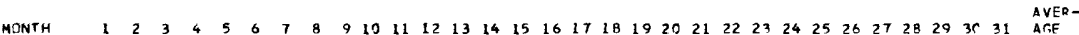
OCTOBER.. $14 \begin{array}{llllllllllllllllllllllllllllllll}14 & 16 & 17 & 17 & 16 & 16 & 17 & 15 & 14 & 13 & 13 & 13 & 12 & 13 & 15 & 16 & 14 & 11 & 10 & 11 & 11 & 11 & 12 & 11 & 11 & 10 & 9 & 9 & 9 & 10 & 12\end{array}$

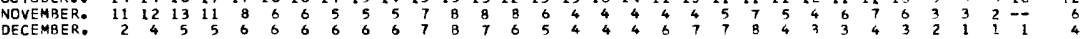
$\begin{array}{lllllllllllllllllllllllllllllllllllll}\text { JANUARY.: } & 1 & 1 & 2 & 1 & 1 & 1 & 1 & 1 & 2 & 2 & 1 & 1 & 1 & 1 & 1 & 1 & 1 & 1 & 1 & 2 & 2 & 2 & 2 & 1 & 1 & 1 & 1 & 2 & 2 & 3 & 4 & 1 \\ \text { FEBRUARY: } & 4 & 4 & 4 & 3 & 3 & 3 & 3 & 2 & 2 & 2 & 2 & 1 & 1 & 1 & 1 & 1 & 1 & 1 & 2 & 2 & 1 & 1 & 1 & 2 & 2 & 1 & 2 & 2 & 1 & -- & -- & 1\end{array}$ $\begin{array}{llllllllllllllllllllllllllllllllll}\text { FEBRUARY. } & 4 & 4 & 4 & 3 & 3 & 3 & 3 & 2 & 2 & 2 & 2 & 1 & 1 & 1 & 1 & 1 & 1 & 1 & 2 & 2 & 1 & 1 & 1 & 2 & 2 & 1 & 2 & 2 & 1 & -2 & -2 & 1 \\ \text { MARCH..... } & 1 & 1 & 1 & 2 & 2 & 2 & 1 & 1 & 2 & 2 & 3 & 6 & 4 & 3 & 4 & 6 & 7 & 7 & 7 & 9 & 9 & 11 & 7 & 5 & 7 & B & 19 & 9 & 11 & 13 & 14 & 5\end{array}$

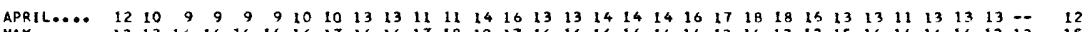

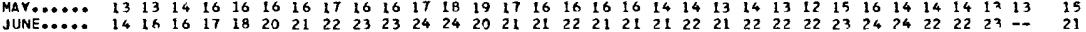

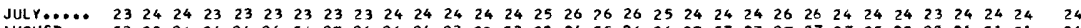

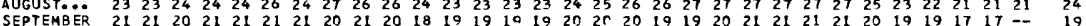
03054500 TYGART VALLEY RIVER AT PHILIPPI, $\boldsymbol{N}$. VA.

LOCATION,--Lat 39 $09^{\circ} 00^{\prime \prime}$, long $80^{\circ} 02^{\prime} 25^{\prime \prime}$, Barbour County, at Philippi, 0.2 mile downstream from Anglins Run and 5,0 miles downstream from Buckhannon' River.

DRA INAGE AREA, --916 sq $\mathrm{m} 1$.

PERIOD OF RECORD..--Sediment records: May to September 1968.

REMARKS.--Records of daily discharge for the water year 1968 are published in Part 1 of this report. PERIODIC DETERMINATIONS OF SUSPENDED-SEDIMENT DISCHARGE, MAY TO SEPTEMBER 1968

\begin{tabular}{|c|c|c|c|c|c|c|c|c|c|c|c|}
\hline & CAIE & TIME & $\begin{array}{l}\text { DISCHARGE } \\
\text { (CFS) }\end{array}$ & $\begin{array}{l}\text { CONCEN- } \\
\text { TRATION } \\
\text { (MGLL) }\end{array}$ & $\begin{array}{l}\text { SUSPENDEO } \\
\text { SEDIMENT } \\
\text { DISCHARGE } \\
\text { (IONS/OAY) }\end{array}$ & & DATE & TIME & $\begin{array}{l}\text { DISCHARGE } \\
\text { (CFS) }\end{array}$ & $\begin{array}{l}\text { CONCEN- } \\
\text { TRATION } \\
\text { (HGIL) }\end{array}$ & $\begin{array}{l}\text { SUSPENDED } \\
\text { SEOIMENT } \\
\text { DISCHARGE } \\
\text { (TONS/OAY) }\end{array}$ \\
\hline MAY & $\begin{array}{r}1.1968 \\
25 . \ldots\end{array}$ & $\begin{array}{l}1210 \\
1030\end{array}$ & $\begin{array}{r}410 \\
15100\end{array}$ & $\begin{array}{r}0 \\
B 9\end{array}$ & $\begin{array}{r}0 \\
3630^{\circ}\end{array}$ & $\begin{array}{l}\text { JUL } \\
\text { AUG }\end{array}$ & $\begin{array}{l}17 \ldots \ldots \\
20 \ldots \ldots\end{array}$ & $\begin{array}{l}1210 \\
1305\end{array}$ & $\begin{array}{r}76 \\
241\end{array}$ & 12 & 7.62 \\
\hline JUN & $10 \ldots \ldots$ & 1335 & 674 & 5 & 9.1 & & & & & & \\
\hline
\end{tabular}


03061000 WEST FORK RIVER AT ENTERPRISE, W. VA.

LOCATION.--Lat $39^{\circ} 25^{\prime} 20^{\prime \prime}$, long $80^{\circ} 16^{\prime} 40^{\prime \prime}$, Harrison County, $150 \mathrm{ft}$ downstream from h1ghway bridge at Enterprise and 0.75 mile upstream from Bingamon Creek.

DRA INAGE AREA. $--759 \mathrm{sq} \mathrm{mi}$.

PERIOD OF RECORD. --Sediment records: Hay to September 1968.

REMARKS.--Records of dally discharge for the water year 1968 are published in Part 1 of this report.

PERIODIC DETERMINATIONS OF SUSPENDED-SEDIMENT DISCHARGE, MAY TO SEPTEMBER 1968

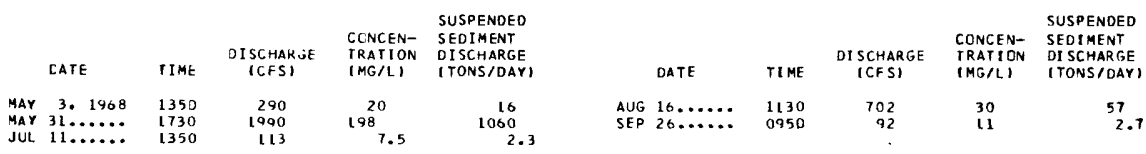

O3O70000 CHEAT RIVER AT ROTLESBURG, W. VA,

LOCATION. - Lat $39^{\circ} 20^{\prime} 50^{\prime \prime}$, long $79^{\circ} 40^{\prime} 00^{\prime \prime}$, Preston County, 50 ft downstream from Baltimore and Obio Ra1lroad bridge at Rowlesburg, and $300 \mathrm{ft}$ upstream from Saltilick Creek.

DRAINAGE AREA.--972 sq $\mathrm{mi}$.

PERIOD OF RECORD. - April to September 1968.

REMARKS, --Records of daily discharge for the water year 1968 are published in Part 1 of this report. PERIODIC DETERMINATIONS OF SUSPENDED-SEDIMENT DISCHARGE, APRIL TO SEPTEMBER 1968

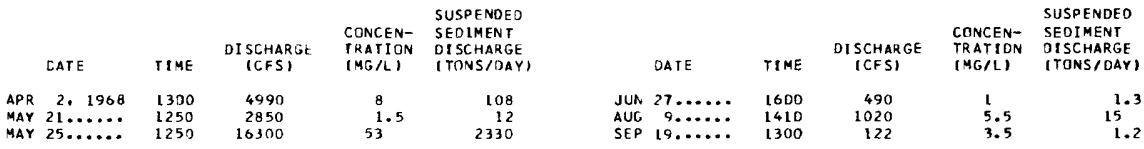

O3D71600 CHEAT RIVER AT LAKE LYNN, PA.

LOCATION,--Lat $39^{\circ} 43^{\prime} 15^{\prime \prime}$, long $79^{\circ} 51^{\prime} 20^{\prime \prime}$, Fayette County, at the Lake Lynn hydroelectric plant of the West penn Power Co., at Lake Lynn 3 miles upstream from mouth.

DRAINAGE AREA. $--1,411$ sq $\mathrm{m} 1$.

PERIOD OF RECORD, -- Water temperatures: October 1948 to September 1968.

EXTREMES. --1967-68:

Vater temperatures: Maximum, $28.0^{\circ} \mathrm{C}$ on several days in July and August; minimum, $1.0^{\circ} \mathrm{C}$ on several days in January.

Period of record:

Water temperatures: Maximum, $30.0^{\circ} \mathrm{C}$ July $28,29,1964 ;$ minimum, $1.0^{\circ} \mathrm{C}$ on several days during winter periods most years.

REMARKS. --Records furnished by the West penn power Co.

TEMPERATURE $\left({ }^{\circ} \mathrm{C}\right)$ DF WATER, WATER YEAR OCTOBER 1967 TO SEPTEMBER 1700 (DNCE-DAI LY MEASUREMENTS )

\begin{tabular}{|c|c|c|c|c|c|c|c|c|c|c|c|c|}
\hline DAY & UCT & Nuv & OEC & JAN & FEB & MAR & $A P R$ & MAV & JUN & JUL & AUG & SEP \\
\hline 1 & -- & 12.0 & 5.0 & -- & -- & 2.0 & 11.0 & 15.0 & -- & -- & 27.0 & $\rightarrow$ \\
\hline 2 & 20.0 & 12.0 & -- & 2.0 & 3.0 & -- & 12.0 & 10.0 & 16.0 & -- & 27.0 & - \\
\hline 3 & -- & 12.0 & 4.0 & 2.0 & -- & $\cdots$ & 13.0 & 17.0 & -- & 24.0 & - & 24.0 \\
\hline 4 & -- & -- & $\cdots$ & 2.0 & -- & 2.0 & 12.0 & 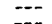 & 15.0 & $\overline{-1}$ & $\overline{-x}$ & 26.0 \\
\hline 5 & 21.0 & $\cdots$ & 3.0 & 2.0 & 4.0 & 3.0 & 11.0 & $\cdots$ & 18.0 & 26.0 & $2 A .0$ & 26.0 \\
\hline 6 & 17.0 & 10.0 & --- & --- & $\cdots$ & 2.0 & -- & 15.0 & 22.0 & --- & 28.0 & 25.0 \\
\hline 7 & -- & 9.0 & 4.0 & $\cdots$ & $=-$ & 2.0 & -- & 16.0 & 20.0 & $-\infty$ & 28.0 & - \\
\hline 8 & -- & 9.0 & 4.0 & 1.0 & 3.0 & 2.0 & 12.0 & 17.0 & -- & 26.0 & 28.0 & -- \\
\hline 9 & 17.0 & 9.0 & -- & 1.0 & 3.0 & -- & 12.0 & $\overrightarrow{7}$ & $\overline{-}$ & 26.0 & 28.0 & -- \\
\hline 10 & 19.0 & -- & --- & 1.0 & $\cdots$ & $\cdots$ & 12.0 & 17.0 & 24.0 & 27.0 & $\cdots$ & 24.0 \\
\hline 11 & 17.0 & --- & 5.0 & -- & -- & 3.0 & 11.0 & $\cdots$ & 26.0 & 26.0 & -- & 24.0 \\
\hline $1 c$ & 17.0 & -- & 5.0 & $\cdots$ & 2.0 & 3.0 & --- & --- & 26.0 & 26.0 & 26.0 & 24,0 \\
\hline 13 & 18.0 & 9.0 & 6.0 & -- & 2.0 & 3.0 & -- & 17.0 & 23.0 & $\cdots$ & 26.0 & 24.0 \\
\hline 14 & -- & 9.0 & 6.0 & -- & 2.0 & 3.0 & $\cdots$ & 17.0 & 23.0 & -- & 26.0 & -- \\
\hline 15 & -- & 9.0 & 6.0 & 1.0 & 2.0 & 3.0 & 13.0 & 17.0 & -- & 27.0 & 28.0 & -- \\
\hline 16 & 18.0 & -- & -- & -- & 2.0 & $\cdots$ & 13.0 & 13.0 & -- & 27.0 & 28.0 & 24.0 \\
\hline 17 & 18.0 & 8.0 & -- & 1.0 & $\cdots$ & $\cdots$ & $\cdots$ & 19.0 & 23.0 & 27.0 & --- & 25.0 \\
\hline 18 & 16.0 & -- & 7.0 & 1.0 & $\rightarrow$ & 4.0 & 13.0 & -- & 23.0 & 29.0 & $-\bar{x}$ & 25.0 \\
\hline 19 & 16.0 & $\cdots$ & $\cdots$ & 1.0 & 2.0 & $-\infty$ & 16.0 & -- & 23.0 & 27.0 & 27.0 & 25.0 \\
\hline 20 & 16.0 & 7.0 & -- & $\cdots$ & 2.0 & 7.0 & -- & 16.0 & 23.0 & --- & 28.0 & 25.0 \\
\hline 21 & $=-$ & 8.0 & -- & $=-$ & -- & -- & -- & 10.0 & 23.0 & --- & 28.0 & -- \\
\hline 22 & $\cdots$ & 8.0 & --- & 1.0 & $-\cdots$ & $\cdots$ & 17.0 & -- & --- & 27.0 & 28.0 & $\cdots$ \\
\hline 23 & -- & -- & -- & 1.0 & -- & -- & 16.0 & -- & -- & 27.0 & 28.0 & 26.0 \\
\hline 24 & 16.0 & 7.0 & $\cdots$ & --- & --- & -- & 16.0 & 14.0 & 24.0 & 28.0 & --- & 26.0 \\
\hline 25 & 14.0 & $\cdots$ & -- & 2.0 & $\cdots$ & 10.0 & 15.0 & --- & 24.0 & $27 . c$ & $\cdots$ & 24.0 \\
\hline 26 & 13.0 & --- & 4.0 & 1. $C$ & 2.0 & I C. 0 & 16.0 & $m$ & -- & 28.0 & 27.0 & 24.0 \\
\hline 27 & 13.0 & 6.0 & 4.0 & -- & 2.0 & 10.0 & -- & 13.0 & 24.0 & --- & 27.0 & 24.0 \\
\hline 28 & -- & 0.0 & $\cdots$ & $-\infty$ & 3.0 & 10.0 & $-\infty$ & 14.0 & 23.0 & --- & 26.0 & $\cdots$ \\
\hline 29 & -- & 0.0 & 4.0 & 1.0 & 2.0 & 10.0 & 15.0 & -- & -- & 27.0 & 26.0 & $--\overline{0}$ \\
\hline 30 & 12.0 & 6.0 & $\cdots$ & 1.0 & $\cdots$ & $\cdots$ & -- & $=$ & $\cdots$ & 27.0 & 26.0 & 22.0 \\
\hline 31 & 12.0 & $\cdots$ & --- & $\cdots$ & -- & $\cdots$ & --- & 15.0 & $\cdots$ & 27.0 & - & - \\
\hline VTH & -.. & --- & --- & -- & -.- & $\ldots$ & -- & $\ldots$ & $\ldots$ & --- & -- & -- \\
\hline
\end{tabular}


03076500 YOUGHIOGHENY RIVER AT FRIENDSVILLE, MD,

LOCATION. - Lat $39^{\circ} 39^{\prime} 13^{\prime \prime}$, long $79^{\circ} 24^{\prime} 31^{\prime \prime}$, Garrett County, temperature recorder at gaging stat1on on left bank $0.7 \mathrm{~m} 1 \mathrm{le}$ upstream from bridge on State Highway 42 at Friendsville, and 1.5 miles upstream from Bear Creek.

DRAI NAGE AREA. $--295 \mathrm{sq} \mathrm{m} 1$.

PERIOD OF RECORD, - Water temperatures: October 1962 to September 1968.

EXTREMES, - - 1967-68:

Water temperatures: Maximum recorded, $28.0^{\circ} \mathrm{C} \mathrm{July} \mathrm{15;} \mathrm{min1mum,} \mathrm{freezing} \mathrm{polnt} \mathrm{on} \mathrm{many} \mathrm{days} \mathrm{during} \mathrm{December} \mathrm{to}$ February.

period of record:

Fater temperatures: maximum recorded, $28.0^{\circ} \mathrm{C}$ July $22,27,28,1964$, July 4, 1966, July 15, 1968; m1n1mum, freezing point on many days during winter periods.

REMARKS.--Records falr, probably because of friction in recorder. No temperature record August 11-13, 21-30.

TEMPERATURE ('O) OF WATER, WATER YEAR OCTOBER 1967 TO SEPTEMBER 1968

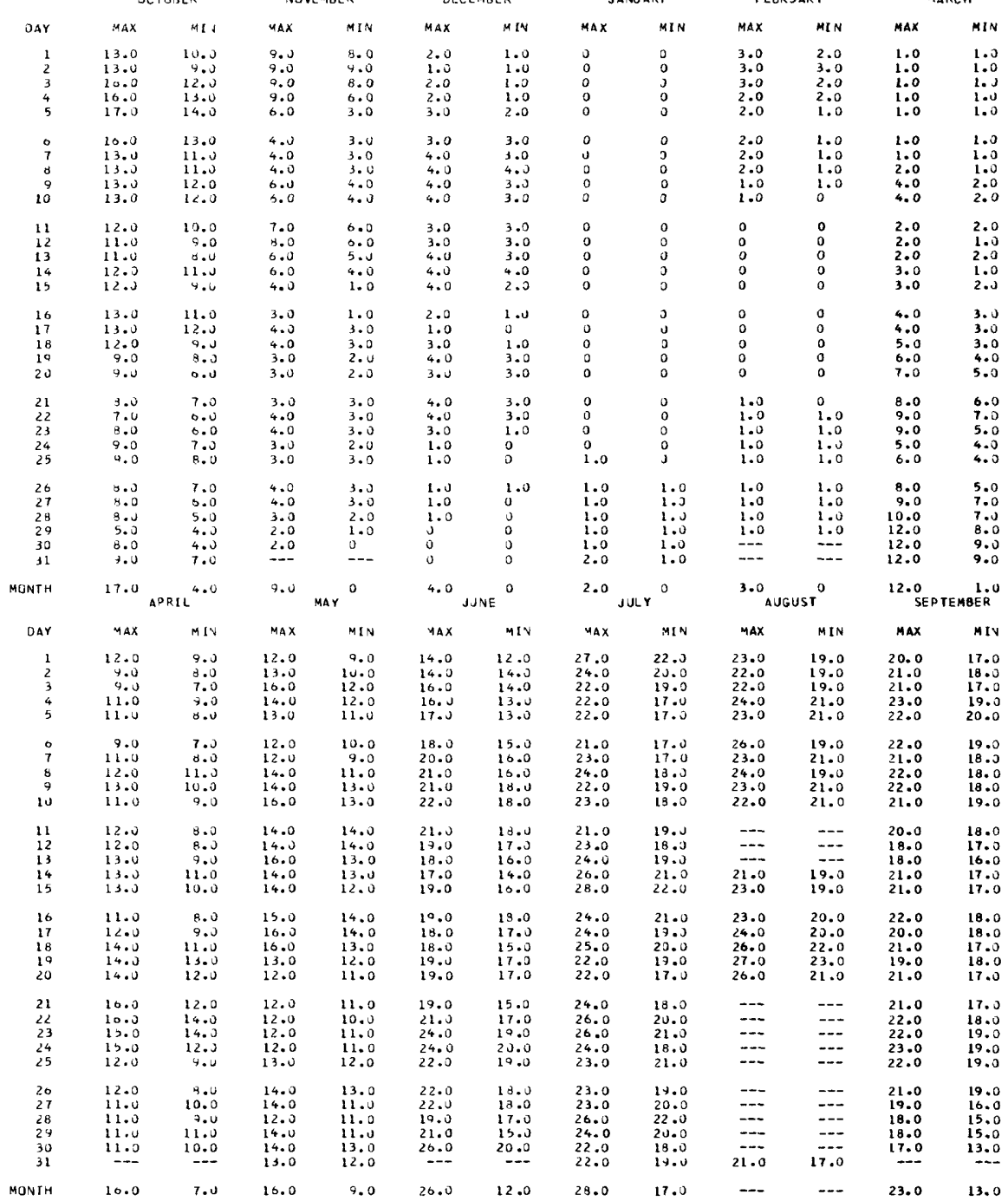


03078000 CASSELMAN RIVER AT GRANTSVILLE, MD.

LOCATION.--Lat $39^{\circ} 42^{\prime} 08^{\prime \prime}$, long $79^{\circ} 08^{\prime} 12^{\prime \prime}$, Garrett County, at gaging station on left bank at downstream side of highway bridge, 0.3 mile upstream from siaubough Run, 0.7 mile downstream from U.S. Highway 40 , and 1.0 mile northeast of Grantsville.

DRAINAGE AREA. --62.5 sq mi.

PERIOD OF RECORD.--Chemical analyses: August 1965 to September 1968. CHEMICAL ANALYSES IN MILLIGRAMS PER LITER, WATER YEAR OCTOBER 1967 TO SEPTEMBER 1968

\begin{tabular}{|c|c|c|c|c|c|c|c|c|c|c|}
\hline DATE & $\begin{array}{l}\text { OIS- } \\
\text { CHARGE } \\
\text { (CFS) }\end{array}$ & $\begin{array}{l}\text { SILICA } \\
\text { (SIOZ) }\end{array}$ & $\begin{array}{l}\text { TOTAL } \\
\text { IRON } \\
\text { (FE) }\end{array}$ & $\begin{array}{l}\text { MAN- } \\
\text { GANESE } \\
\text { [MN] }\end{array}$ & $\begin{array}{l}\text { CAL- } \\
\text { CIUM } \\
\text { (CAI }\end{array}$ & $\begin{array}{l}\text { MAG- } \\
\text { NE- } \\
\text { SIUM } \\
\text { (MG) }\end{array}$ & $\begin{array}{l}\text { SOOIUM } \\
\text { INAI }\end{array}$ & $\begin{array}{l}\text { PO- } \\
\text { IAS- } \\
\text { SIUM } \\
\text { (K) }\end{array}$ & $\begin{array}{l}\text { BICAR- } \\
\text { BUNATE } \\
\text { (HCO3) }\end{array}$ & $\begin{array}{l}\text { CAR- } \\
\text { BONATE } \\
\text { (CO3) }\end{array}$ \\
\hline $\begin{array}{l}\text { OCt. } \\
17 . . . \\
\text { JAN. }\end{array}$ & 6.6 & 3.5 & .27 & .20 & 28 & 7.7 & 12 & 2.4 & 36 & 0 \\
\hline $\begin{array}{l}10 \ldots \\
\text { FEB. }\end{array}$ & 63 & 4.6 & .11 & .23 & 10 & 3.4 & 4.0 & 1.1 & 9 & 0 \\
\hline OAR... & 103 & 4.4 & .17 & .14 & 8.4 & 2.5 & 3.4 & .8 & 6 & 0 \\
\hline${ }_{A P R}^{18}, \cdots$ & 420 & 3.8 & .27 & .20 & 6.7 & 1.9 & 3.3 & 1.0 & 5 & 0 \\
\hline MAY & 115 & 3.6 & .29 & .15 & 7.6 & 2.2 & 3.3 & .8 & $T$ & 0 \\
\hline $\begin{array}{l}06 \ldots \\
21\end{array}$ & $\begin{array}{l}101 \\
249\end{array}$ & $\begin{array}{l}2.1 \\
2.8\end{array}$ & $\begin{array}{l}.12 \\
.21\end{array}$ & $\begin{array}{r}.13 \\
.15\end{array}$ & $\begin{array}{l}8.7 \\
8.3\end{array}$ & $\begin{array}{l}2.4 \\
2.1\end{array}$ & $\begin{array}{l}3.8 \\
4.6\end{array}$ & $\begin{array}{r}1.9 \\
.8\end{array}$ & $\begin{array}{l}10 \\
10\end{array}$ & $\begin{array}{l}0 \\
0\end{array}$ \\
\hline $\begin{array}{l}\text { JUNE } \\
20 \ldots \ldots \\
\text { JULY }\end{array}$ & 54 & 3.9 & - & -- & 11 & 2.8 & 4.2 & 1.2 & 13 & 0 \\
\hline SEPT. & 7.6 & 2.9 & .71 & .49 & 20 & 5.0 & 4.9 & 2.9 & 33 & 0 \\
\hline $04 \ldots$ & 4.8 & 2.3 & FLUU- & -- & $\begin{array}{c}29 \\
\text { OIS- } \\
\text { SOLVED } \\
\text { SOLIOS } \\
\text { I SUM OF }\end{array}$ & HARD- & $\begin{array}{c}9.6 \\
\text { NON- } \\
\text { CAR- } \\
\text { BONATE }\end{array}$ & $\begin{array}{c}4.5 \\
\text { SPECI- } \\
\text { FIC } \\
\text { COND- } \\
\text { UCTANCE }\end{array}$ & 51 & 0 \\
\hline $\begin{array}{l}\text { DATE } \\
\text { OCT. }\end{array}$ & $\begin{array}{l}\text { SULFATE } \\
\text { (SO4) }\end{array}$ & $\begin{array}{l}\text { RIOE } \\
\text { (CL) }\end{array}$ & $\begin{array}{l}\text { RIOE } \\
\text { (F) }\end{array}$ & $\begin{array}{l}\text { NITRATE } \\
\text { (NO3) }\end{array}$ & $\begin{array}{l}\text { CONSTI- } \\
\text { TUENTSI }\end{array}$ & $\begin{array}{l}\text { NESS } \\
\text { (CA,MG) }\end{array}$ & $\begin{array}{l}\text { HARU- } \\
\text { NESS }\end{array}$ & $\begin{array}{l}\text { (MICRO- } \\
\text { MHOS) }\end{array}$ & PH & COLOR \\
\hline $\begin{array}{l}17 . . \\
\text { JAN." }\end{array}$ & 62 & 24 & .0 & 1.3 & 159 & 102 & 72 & 274 & 7.1 & 1 \\
\hline $\begin{array}{c}10 \ldots \\
\text { FEB. }\end{array}$ & 27 & 8.3 & .1 & 2.4 & 65 & 39 & 32 & 120 & 6.6 & 0 \\
\hline $\begin{array}{l}\text { DT... } \\
\text { MAR. }\end{array}$ & 21 & 6.7 & -1 & 2.3 & 53 & 32 & 27 & 92 & 6.5 & 3 \\
\hline $\begin{array}{l}18 . . \\
\text { APK. }\end{array}$ & 18 & 5.6 & .1 & 2.1 & 44 & 25 & 21 & 77 & 6.0 & 5 \\
\hline MAY & 19 & 0.2 & .1 & 1.3 & 47 & 28 & 22 & 85 & 7.1 & 2 \\
\hline $\begin{array}{l}06 \ldots \\
\text { JUNE }\end{array}$ & $\begin{array}{l}21 \\
19\end{array}$ & $\begin{array}{l}6.1 \\
8.0\end{array}$ & $\begin{array}{l}.1 \\
.1\end{array}$ & $\begin{array}{l}2.4 \\
1.7\end{array}$ & $\begin{array}{l}54 \\
52\end{array}$ & $\begin{array}{l}32 \\
28\end{array}$ & $\begin{array}{l}24 \\
21\end{array}$ & $\begin{array}{l}90 \\
90\end{array}$ & $\begin{array}{l}6.1 \\
6.8\end{array}$ & $\begin{array}{l}5 \\
3\end{array}$ \\
\hline $20 \ldots$ & 27 & 7.8 & .1 & 2.1 & 66 & 39 & 29 & 112 & 7.3 & 5 \\
\hline${ }_{\text {SEPI. }}^{24 .}$ & 41 & 9.0 & .2 & 2.5 & 105 & 71 & 44 & 183 & 7.8 & 5 \\
\hline $04 \ldots$ & 61 & 18 & .2 & 6.2 & 164 & 107 & 65 & 286 & 7.6 & 5 \\
\hline
\end{tabular}

03082500 YOUGHIOGHENY RIVER AT CONNELLSVILLE, PA.

LOCATION.--Lat $40^{\circ} 01^{\prime} 05^{\prime \prime}, 1$ long 79 $35^{\prime} 40^{\prime \prime}$, Fayette County, on left bank at downstream side of Crawford Avenue Bridge at Connellsville, 1.2 miles upstream from Mounts Creek and at mile 44.0 .

DRA INAGE AREA. $-1,326$ sq $\mathrm{mi}$.

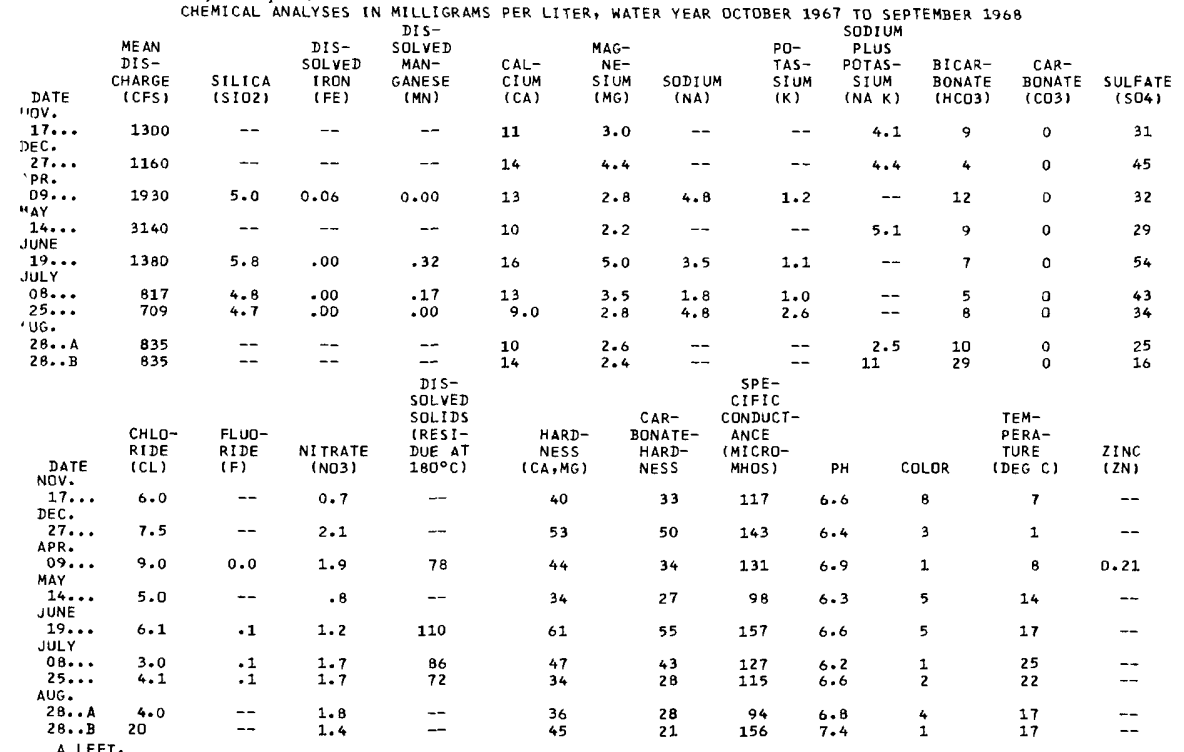

A LEFT. 
LOCATION,--Lat $40^{\circ} 34^{\prime} 12^{\prime \prime}$, long $80^{\circ} 13^{\prime} 47^{\prime \prime}$, Beaver County, on left bank at intake 11 ne to Ohio River Valley Water Sanitation Commission (ORSANCO) monitor station at Duquesne Powerplant at South Heights, 1.6 miles upstreatn from Ambridge-woodlawn Bridge, and at river mile 15.2 .

DRAINAGE AREA. - - $19,520 \mathrm{sq}$ mi (approximately).

PERIOD OF RECORD.--Chemical analyses: July 1963 to December 1965, October 1967 to September 1968.

Water temperatures: July 1963 to December 1965, October 1967 to September 1968.

EXTRENES. --1967-68:

Specific conductance: Maximum daily, 697 micromhos Aug, 15; minimum daily, 200 micromhos Dec. 17.

Water temperatures: Maximum, 29.0 $\mathrm{C}$ Aug. 9, 21-26; minimum, freezing point Jan. 2, 5-9, 11-15, 17.

Period of record:

Spectfic conductance: Naximum daily, 828 micromhos Oct. 12, 1963; mintmum daily, 142 micromhos Mar. 8,1964 Water temperatures: Maximum, $29.0^{\circ} \mathrm{C}$ July 25, 26, 1964, Aug. 9, 21-26, 1968; minimum, freezing point Jan. 31 to Feb. 2, Feb. 4, 1965, Jan. 2, 5-9, 11-15, 17, 1968.

REMARKS.-Daily samples were collected at this station and samples were selected for analysis on the following basis: (1) Maximum dally specific conductance for each month, (2) minimum dally specific conductance for each month, and (3) median dally specific conductance for each month, Samples for lron and manganese were 19,500 sq mi, approximately).

CHEMICAL ANALYSES IN MILLIGRAMS PER LITER, WATER YEAR OCTOBER 1967 TO SEPTEMBER 1968

\begin{tabular}{|c|c|c|c|c|c|c|c|c|}
\hline DATE & $\begin{array}{l}\text { DIS- } \\
\text { CHARGE } \\
\text { (CFS) }\end{array}$ & $\begin{array}{l}\text { IRON } \\
\text { (FE) }\end{array}$ & $\underset{\text { GANESE }}{\text { (MN) }}$ & $\begin{array}{l}\text { BICAR- } \\
\text { BONATE } \\
\left(\mathrm{HCO}_{3}\right)\end{array}$ & $\begin{array}{l}\text { CAR- } \\
\text { BONATE } \\
\left(\mathrm{CO}_{3}\right)\end{array}$ & $\begin{array}{c}\text { SULFATE } \\
\left(\mathrm{SO}_{4}\right)\end{array}$ & $\begin{array}{l}\text { CHLO- } \\
\text { RIDE } \\
\text { (CL) }\end{array}$ & $\begin{array}{c}\text { FLUO } \\
\text { RIDR } \\
\text { (F) }\end{array}$ \\
\hline \multicolumn{9}{|l|}{ OCT. } \\
\hline & 40300 & .69 & .33 & 25 & 0 & 58 & 11 & .4 \\
\hline $20 \ldots$ & 30300 & .44 & .62 & 6 & 0 & 136 & 18 & .3 \\
\hline $26 \ldots$ & 40900 & .67 & .42 & 18 & 0 & 88 & 14 & .2 \\
\hline \multicolumn{9}{|l|}{ Nov. } \\
\hline $02 \ldots$ & 28400 & 1.3 & .31 & 18 & 0 & 70 & 16 & .1 \\
\hline $21 \ldots$ & 38200 & 1.4 & .26 & 16 & 0 & 83 & 14 & 0 \\
\hline $26 \ldots$ & 62700 & - & - & 4 & 0 & 111 & 12 & .0 \\
\hline \multicolumn{9}{|l|}{ DEC. } \\
\hline $04 \ldots$ & 66800 & 3.3 & .34 & -- & -- & 102 & 14 & -- \\
\hline $07 .$. & 53100 & 1.4 & .20 & - & - & 77 & 9.0 & - \\
\hline $17, \ldots$ & 39800 & - & - & - & -- & 62 & 10 & - \\
\hline \multicolumn{8}{|l|}{ JAN." } & - \\
\hline $02, \ldots$ & $\begin{array}{l}25000 \\
22400\end{array}$ & 2.3 & $\begin{array}{r}.79 \\
.62\end{array}$ & $\overline{-}$ & $\overline{-}$ & $\begin{array}{r}81 \\
100\end{array}$ & $=$ & $=$ \\
\hline $29 .$. & 30900 & 1.2 & .63 & $=$ & $=$ & 128 & $=$ & $=$ \\
\hline \multicolumn{9}{|l|}{ FEB. } \\
\hline $05 \ldots$ & $\begin{array}{l}83900 \\
22100\end{array}$ & $\begin{array}{l}2.4 \\
1.2\end{array}$ & $\begin{array}{r}25 \\
28\end{array}$ & $=$ & $=$ & $\begin{array}{l}74 \\
80\end{array}$ & 10 & $=$ \\
\hline $29 .$. & 11000 & 1.9 & .53 & - & $-\infty$ & 122 & 19 & - \\
\hline \multicolumn{9}{|l|}{ MAR." } \\
\hline $10 \ldots$ & 23300 & -- & -- & - & -- & 174 & - & - \\
\hline $17 .$. & 67100 & $\rightarrow$ & $=$ & - & $\ldots$ & 85 & - & - \\
\hline \multirow{2}{*}{\multicolumn{9}{|c|}{ APR. }} \\
\hline & & & & & & & & \\
\hline $01 .$. & 48000 & .80 & .27 & - & -- & 74 & -- & - \\
\hline $17 \ldots$ & 18100 & .26 & .30 & - & - & 94 & -- & - \\
\hline $28, \ldots$ & 15200 & .40 & .30 & - & -- & 136 & $=$ & - \\
\hline \multicolumn{9}{|l|}{ MAY } \\
\hline $10 \ldots$ & 13800 & .29 & .25 & - & -- & 150 & - & - \\
\hline $19 .$. & 77700 & - & - & - & - & 117 & -- & - \\
\hline $26 \ldots$ & 109000 & -- & -- & -- & -- & 72 & - & - \\
\hline \multicolumn{9}{|l|}{ תUNE } \\
\hline $03 .$. & 71600 & 2.0 & .60 & - & - & 104 & - & - \\
\hline $16 .$. & 13900 & - & - & - & - & 136 & - & - \\
\hline \multirow{2}{*}{\multicolumn{9}{|c|}{ JULY }} \\
\hline & & & & & & & & \\
\hline $01 \ldots$ & 12700 & .31 & .89 & - & $=$ & 156 & $=$ & - \\
\hline $12 \ldots$ & 6100 & .36 & .06 & $=$ & $\overline{-}$ & 117 & $=$ & $\overline{-}$ \\
\hline \multicolumn{9}{|l|}{ AUG. } \\
\hline $01 .$. & 7670 & .30 & .12 & - & - & 167 & -- & - \\
\hline $15 \ldots$ & 9630 & .14 & 1.5 & - & - & 295 & - & - \\
\hline $23, \ldots$ & 7910 & - & - & - & - & 226 & - & - \\
\hline \multicolumn{9}{|l|}{ SEPT. } \\
\hline $10 \ldots$ & 9110 & .21 & .11 & - & - & 150 & - & - \\
\hline $20 .$. & $\begin{array}{l}\mathbf{5 8 8 0} \\
6650\end{array}$ & .26 & .17 & $\overline{-}$ & $=$ & 208 & $=$ & $=$ \\
\hline 20 & 6650 & .21 & .19 & -- & & 186 & & \\
\hline
\end{tabular}


OHIO RIVER MAIN STEM

03086060 OHIO RIVER AT SOUTH HEIGHTS, PA.--Continued

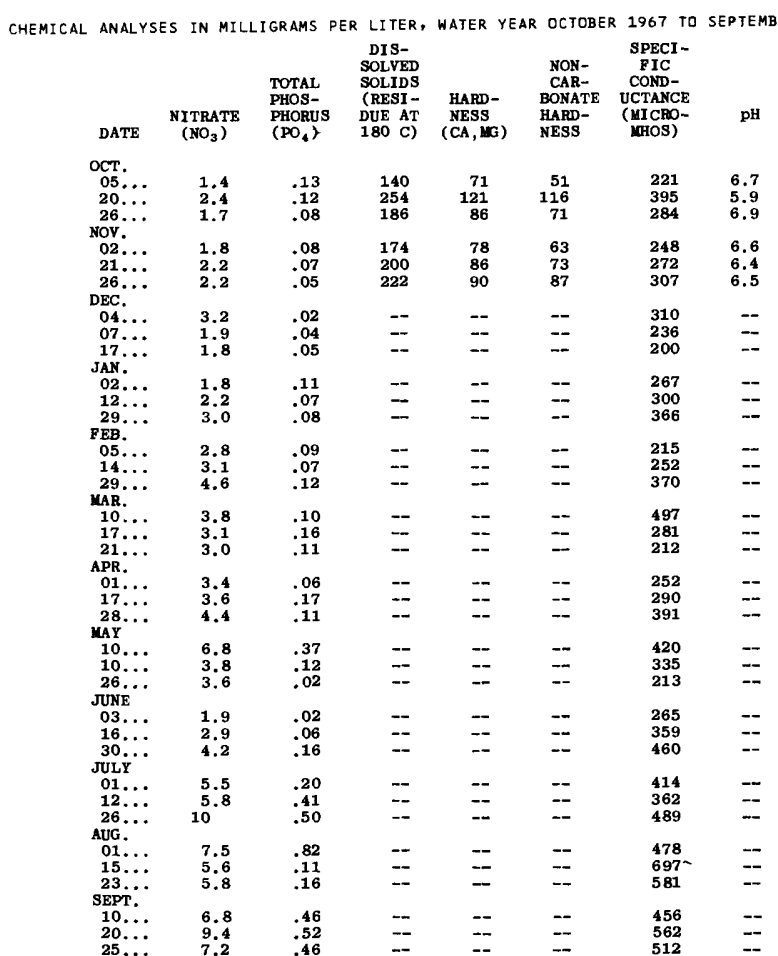

SPECIFIC CONDUCTANCE (MICROMHOS AT $25^{\circ} \mathrm{C}$ ), WATER YEAR OCTOBER 1967 TO SEPTEMBER 1968

DAY OCTOBER NOVEMBER DECEMBER JANUARY FEBRUARY MARCH APRIL MND OBOO) JUY JUNE JULY AUGUST SEPTEMBER

\begin{tabular}{|c|c|c|c|c|c|c|c|c|c|c|c|c|}
\hline $\begin{array}{l}1 \ldots \ldots \\
2 \ldots \ldots \\
3 \ldots \ldots \\
5 \ldots \ldots\end{array}$ & $\begin{array}{l}305 \\
333 \\
256 \\
231 \\
221\end{array}$ & $\begin{array}{l}255 \\
248 \\
258 \\
266 \\
266\end{array}$ & $\begin{array}{l}247 \\
257 \\
295 \\
310 \\
224\end{array}$ & $\begin{array}{l}281 \\
267 \\
271 \\
293 \\
310\end{array}$ & $\begin{array}{l}238 \\
245 \\
234 \\
230 \\
215\end{array}$ & $\begin{array}{l}391 \\
406 \\
406 \\
403 \\
405\end{array}$ & $\begin{array}{l}252 \\
281 \\
288 \\
279 \\
290\end{array}$ & $\begin{array}{l}388 \\
379 \\
374 \\
385 \\
395\end{array}$ & $\begin{array}{l}293 \\
273 \\
265 \\
277 \\
271\end{array}$ & $\begin{array}{l}414 \\
388 \\
380 \\
387 \\
392\end{array}$ & $\begin{array}{l}478 \\
524 \\
523 \\
560 \\
532\end{array}$ & $\begin{array}{l}493 \\
486 \\
486 \\
492 \\
504\end{array}$ \\
\hline $\begin{array}{c}6 \ldots \ldots \\
7 \ldots \ldots \\
8 \ldots \ldots \\
10 \ldots \ldots\end{array}$ & $\begin{array}{l}242 \\
236 \\
228 \\
231 \\
237\end{array}$ & $\begin{array}{l}274 \\
292 \\
290 \\
290 \\
276\end{array}$ & $\begin{array}{l}227 \\
236 \\
245 \\
236 \\
212\end{array}$ & $\begin{array}{l}316 \\
324 \\
324 \\
313 \\
290\end{array}$ & $\begin{array}{l}217 \\
224 \\
231 \\
243 \\
250\end{array}$ & $\begin{array}{l}397 \\
405 \\
449 \\
445 \\
497\end{array}$ & $\begin{array}{l}270 \\
265 \\
259 \\
265 \\
259\end{array}$ & $\begin{array}{l}409 \\
410 \\
418 \\
405 \\
420\end{array}$ & $\begin{array}{l}267 \\
279 \\
336 \\
298 \\
310\end{array}$ & $\begin{array}{l}411 \\
392 \\
369 \\
369 \\
376\end{array}$ & $\begin{array}{l}525 \\
554 \\
582 \\
589 \\
588\end{array}$ & $\begin{array}{l}531 \\
511 \\
482 \\
479 \\
456\end{array}$ \\
\hline $\begin{array}{l}11 \ldots \ldots \\
12 \ldots \ldots \\
13 \ldots \ldots \\
14 \ldots \ldots \\
15 \ldots \ldots\end{array}$ & $\begin{array}{l}242 \\
271 \\
302 \\
298 \\
318\end{array}$ & $\begin{array}{l}272 \\
274 \\
264 \\
266 \\
257\end{array}$ & $\begin{array}{l}214 \\
206 \\
204 \\
205 \\
216\end{array}$ & $\begin{array}{l}302 \\
300 \\
277 \\
273 \\
290\end{array}$ & $\begin{array}{l}245 \\
245 \\
248 \\
252 \\
248\end{array}$ & $\begin{array}{l}493 \\
436 \\
485 \\
458 \\
307\end{array}$ & $\begin{array}{l}261 \\
261 \\
275 \\
275 \\
282\end{array}$ & $\begin{array}{l}407 \\
376 \\
370 \\
335 \\
323\end{array}$ & $\begin{array}{l}316 \\
321 \\
336 \\
352 \\
373\end{array}$ & $\begin{array}{l}374 \\
362 \\
395 \\
387 \\
391\end{array}$ & $\begin{array}{l}620 \\
638 \\
648 \\
692 \\
697\end{array}$ & $\begin{array}{l}471 \\
476 \\
479 \\
486 \\
501\end{array}$ \\
\hline $\begin{array}{l}16 \ldots \ldots \\
17 \ldots \ldots \\
18 \ldots \ldots \\
19 \ldots \ldots \\
20 \ldots \ldots\end{array}$ & $\begin{array}{l}349 \\
352 \\
364 \\
392 \\
395\end{array}$ & $\begin{array}{l}255 \\
260 \\
266 \\
262 \\
260\end{array}$ & $\begin{array}{l}206 \\
200 \\
212 \\
215 \\
228\end{array}$ & $\begin{array}{l}-- \\
295 \\
277 \\
288 \\
293\end{array}$ & $\begin{array}{l}270 \\
279 \\
302 \\
304 \\
326\end{array}$ & $\begin{array}{l}248 \\
281 \\
233 \\
223 \\
214\end{array}$ & $\begin{array}{l}286 \\
290 \\
295 \\
292 \\
302\end{array}$ & $\begin{array}{l}380 \\
394 \\
285 \\
335 \\
266\end{array}$ & $\begin{array}{l}359 \\
363 \\
367 \\
368 \\
367\end{array}$ & $\begin{array}{l}394 \\
401 \\
423 \\
436 \\
440\end{array}$ & $\begin{array}{l}667 \\
637 \\
688 \\
681 \\
638\end{array}$ & $\begin{array}{l}521 \\
534 \\
551 \\
528 \\
562\end{array}$ \\
\hline $\begin{array}{l}21 \ldots \ldots \ldots \\
22 \ldots \ldots \ldots \\
23 \ldots \ldots \ldots \\
24 \ldots \ldots \\
25 \ldots \ldots\end{array}$ & $\begin{array}{l}324 \\
302 \\
293 \\
277 \\
259\end{array}$ & $\begin{array}{l}272 \\
270 \\
278 \\
297 \\
285\end{array}$ & $\begin{array}{l}237 \\
239 \\
257 \\
275 \\
298\end{array}$ & $\begin{array}{l}295 \\
298 \\
305 \\
340 \\
324\end{array}$ & $\begin{array}{l}332 \\
361 \\
354 \\
370 \\
361\end{array}$ & $\begin{array}{l}212 \\
233 \\
260 \\
251 \\
242\end{array}$ & $\begin{array}{l}307 \\
326 \\
338 \\
341 \\
364\end{array}$ & $\begin{array}{l}262 \\
257 \\
253 \\
294 \\
329\end{array}$ & $\begin{array}{l}370 \\
376 \\
373 \\
375 \\
396\end{array}$ & $\begin{array}{l}452 \\
475 \\
469 \\
480 \\
475\end{array}$ & $\begin{array}{l}658 \\
614 \\
581 \\
524 \\
519\end{array}$ & $\begin{array}{l}555 \\
548 \\
522 \\
512 \\
512\end{array}$ \\
\hline $\begin{array}{l}26 \ldots \ldots \\
27 \ldots \ldots \\
28 \ldots \ldots \\
29 \ldots \ldots \\
30 \ldots \ldots \\
31 \ldots \ldots \ldots\end{array}$ & $\begin{array}{l}284 \\
333 \\
330 \\
275 \\
275 \\
273\end{array}$ & $\begin{array}{l}307 \\
270 \\
248 \\
253 \\
258 \\
--\end{array}$ & $\begin{array}{l}293 \\
295 \\
298 \\
279 \\
275 \\
267\end{array}$ & $\begin{array}{l}346 \\
356 \\
343 \\
366 \\
364 \\
343\end{array}$ & $\begin{array}{c}351 \\
341 \\
358 \\
370 \\
-- \\
--\end{array}$ & $\begin{array}{l}226 \\
233 \\
228 \\
226 \\
238 \\
240\end{array}$ & $\begin{array}{r}369 \\
387 \\
391 \\
389 \\
372 \\
--\end{array}$ & $\begin{array}{l}213 \\
225 \\
268 \\
261 \\
261 \\
242\end{array}$ & $\begin{array}{l}426 \\
447 \\
445 \\
446 \\
460 \\
--\end{array}$ & $\begin{array}{l}489 \\
462 \\
483 \\
453 \\
459 \\
463\end{array}$ & $\begin{array}{l}526 \\
526 \\
493 \\
489 \\
487 \\
499\end{array}$ & $\begin{array}{l}546 \\
-- \\
546 \\
527 \\
535 \\
-\end{array}$ \\
\hline AVERAGE & 291 & 269 & 245 & 308 & 284 & 328 & 303 & 332 & 350 & 420 & 579 & 511 \\
\hline
\end{tabular}




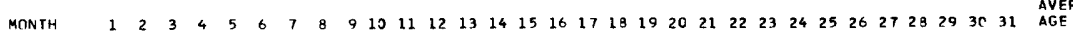
$\begin{array}{llllllllllllllllllllllllllllllllllllllll}\text { OCTOSER.. } & 16 & 17 & 16 & 16 & 17 & 16 & 15 & 15 & 17 & 16 & 16 & 16 & 16 & 16 & 16 & 17 & 16 & 17 & 16 & 16 & 15 & 14 & 14 & 13 & 12 & 11 & 11 & 12 & 12 & 12 & 11 & 14\end{array}$

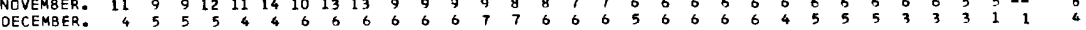
$\begin{array}{llllllllllllllllllllllllllllllllllllllll}\text { JANUARY.: } & 1 & 0 & 1 & 1 & 0 & 0 & 0 & 0 & 0 & 1 & 0 & 0 & 0 & 0 & 0 & - & 0 & 1 & 2 & 2 & 3 & 2 & 2 & 3 & 1 & 1 & 2 & 2 & 3 & 3 & 3 & 1 \\ \text { FEBRUARY. } & 1 & 2 & 4 & 3 & 3 & 3 & 3 & 3 & 4 & 3 & 2 & 1 & 1 & 1 & 1 & 1 & 2 & 1 & 1 & 2 & 1 & 1 & 1 & 2 & 2 & 1 & 2 & 3 & 2 & -- & -- & 1 & 1\end{array}$

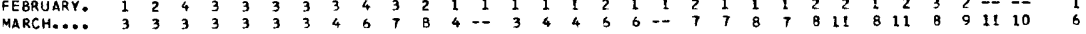

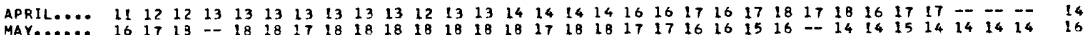

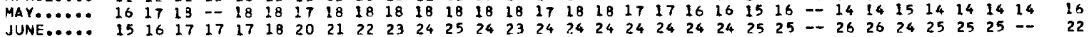

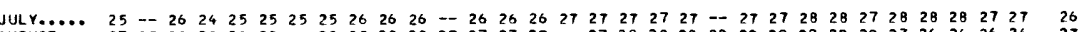
$\begin{array}{lllllllllllllllllllllllllllllllll}\text { AUGUST... } & 27 & 27 & 28 & 28 & 28 & 28 & - & 28 & 29 & 28 & 28 & 27 & 27 & 27 & 27 & - & 27 & 28 & 28 & 28 & 29 & 29 & 29 & 29 & 29 & 29 & 27 & 25 & 26 & 26 & 26 & 27 \\ \text { SEPTEMBER } & 25 & 25 & 25 & 25 & 26 & 25 & 25 & 24 & 25 & 24 & 24 & 24 & 23 & 23 & 23 & 23 & 23 & 23 & 23 & 23 & 23 & 24 & 24 & 24 & 24 & 24 & -- & 23 & 22 & 22 & -- & 23\end{array}$

\section{BEAYER RIVER BASIN}

03092090 WEST BRANCH MAHONING RIVER NEAR RAVENNA, OHIO

LOCATION.--Lat $41^{\circ} 09^{\prime} 40^{\prime \prime}$, long $81^{\circ} 11^{\prime} 50^{\prime \prime}$, in T.3 N, , R. 8 \%., Portage County, temperature recorder at gaging station on left bank at downstream side of bridge on County Highway 177, 2.5 miles east of Ravenna.

DRAINAGE AREA, --21.8 sq mi.

PERIOD OF RECORD, --Water temperatures: October 1965 to September 1968.

EXTREMES, - $-1967-68$ :

Water temperatures: Kaximum, $28.0^{\circ} \mathrm{C}$ Aug. 24 ; minimum, freezing point on several days during February and karch.

Period of record:

Water temperatures: Maximum, $28.0^{\circ} \mathrm{C}$ Aug. 24, 1968; minimum, freezing point on many days during winter periods. TEMPERATURE $\left({ }^{\circ} \mathrm{C}\right)$ OF WATER, WATER YEAR OCTOBER 1967 TO SEPTEMBER 1968 (CONTINUQUS ETHYL ALCOHOL-ACTUATED THERMOGRAPH)

\begin{tabular}{|c|c|c|c|c|c|c|c|c|c|c|c|c|}
\hline \multirow[b]{2}{*}{ OAY } & \multicolumn{2}{|c|}{ OL TUSE K } & \multicolumn{2}{|c|}{ NOVEMBER } & \multicolumn{2}{|c|}{ UECEMBER } & \multicolumn{2}{|c|}{ JANUARY } & \multicolumn{2}{|c|}{ FEBRUARY } & \multicolumn{2}{|c|}{ MARCH } \\
\hline & $14 x$ & YIV & $\operatorname{Max}$ & MIN & MAX & $M I^{N}$ & $\max$ & MIN & MAX & MIN & $\operatorname{MAX}$ & MIV \\
\hline $\begin{array}{l}1 \\
2 \\
3 \\
4 \\
5\end{array}$ & $\begin{array}{l}14.0 \\
15.0 \\
10.0 \\
17.0 \\
17.0\end{array}$ & $\begin{array}{l}11.0 \\
11.0 \\
13.0 \\
13.0 \\
15.0\end{array}$ & $\begin{array}{r}11.0 \\
11.0 \\
11.0 \\
11.0 \\
3.0\end{array}$ & $\begin{array}{r}7.0 \\
10.0 \\
9.0 \\
8.0 \\
6.0\end{array}$ & $\begin{array}{l}2.0 \\
1.0 \\
1.0 \\
2.0 \\
3.0\end{array}$ & $\begin{array}{l}1.0 \\
1.0 \\
1.0 \\
1.0 \\
2.0\end{array}$ & $\begin{array}{l}1.0 \\
1.0 \\
1.0 \\
1.0 \\
1.0\end{array}$ & $\begin{array}{l}1.0 \\
1.0 \\
1.0 \\
1.0 \\
1.0\end{array}$ & $\begin{array}{l}1.0 \\
3.0 \\
2.0 \\
1.0 \\
1.0\end{array}$ & $\begin{array}{l}1.0 \\
1.0 \\
1.0 \\
1.0 \\
1.0\end{array}$ & $\begin{array}{l}0.0 \\
0.0 \\
0.0 \\
0.0 \\
0.0\end{array}$ & $\begin{array}{l}0.0 \\
0.0 \\
0.0 \\
0.0 \\
0.0\end{array}$ \\
\hline $\begin{array}{r}0 \\
7 \\
9 \\
9 \\
10\end{array}$ & $\begin{array}{l}10.0 \\
14.0 \\
10.0 \\
13.0 \\
13.0\end{array}$ & $\begin{array}{l}12.0 \\
11.0 \\
13.0 \\
13.0 \\
12.0\end{array}$ & $\begin{array}{l}0.0 \\
4.0 \\
5.0 \\
6.0 \\
7.0\end{array}$ & $\begin{array}{l}4.0 \\
3.0 \\
1.0 \\
3.0 \\
4.0\end{array}$ & $\begin{array}{l}4.0 \\
0.0 \\
5.0 \\
5.0 \\
4.0\end{array}$ & $\begin{array}{l}3.0 \\
4.0 \\
5.0 \\
4.0 \\
4.0\end{array}$ & $\begin{array}{l}1.0 \\
1.0 \\
1.0 \\
1.0 \\
1.0\end{array}$ & $\begin{array}{l}1.0 \\
1.0 \\
1.0 \\
1.0 \\
1.0\end{array}$ & $\begin{array}{l}1.0 \\
1.0 \\
1.0 \\
1.0 \\
1.0\end{array}$ & $\begin{array}{l}1.0 \\
1.0 \\
1.0 \\
1.0 \\
1.0\end{array}$ & $\begin{array}{l}1.0 \\
1.0 \\
1.0 \\
1.0\end{array}$ & $\begin{array}{l}0.0 \\
0.0 \\
0.0 \\
0.0 \\
0.0\end{array}$ \\
\hline $\begin{array}{l}11 \\
12 \\
13 \\
14 \\
15\end{array}$ & $\begin{array}{l}12.0 \\
12.0 \\
11.0 \\
12.0 \\
13.0\end{array}$ & $\begin{array}{r}11.0 \\
10.0 \\
8.0 \\
11.0 \\
10.0\end{array}$ & $\begin{array}{l}3.0 \\
9.0 \\
9.0 \\
5.0 \\
4.0\end{array}$ & $\begin{array}{l}7.0 \\
9.0 \\
0.0 \\
4.0 \\
3.0\end{array}$ & $\begin{array}{l}5.0 \\
5.0 \\
6.0 \\
5.0 \\
4.0\end{array}$ & $\begin{array}{l}4.0 \\
5.0 \\
3.0 \\
4.0 \\
2.0\end{array}$ & $\begin{array}{l}1.0 \\
1.0 \\
1.0 \\
1.0 \\
1.0\end{array}$ & $\begin{array}{l}1.0 \\
1.3 \\
1.0 \\
1.0 \\
1.0\end{array}$ & $\begin{array}{l}1.0 \\
1.0 \\
1.0 \\
1.0 \\
1.0\end{array}$ & $\begin{array}{l}1.0 \\
1.0 \\
1.0 \\
1.0 \\
1.0\end{array}$ & $\begin{array}{l}3.0 \\
2.0 \\
0.0 \\
1.0 \\
1.0\end{array}$ & $\begin{array}{l}1.0 \\
0.0 \\
0.0 \\
0.0 \\
0.0\end{array}$ \\
\hline $\begin{array}{l}16 \\
17 \\
18 \\
19 \\
20\end{array}$ & $\begin{array}{l}13.0 \\
15.0 \\
14.0 \\
12.0 \\
10.0\end{array}$ & $\begin{array}{r}13.0 \\
14.0 \\
12.0 \\
9.0 \\
7.0\end{array}$ & $\begin{array}{l}3.0 \\
3.0 \\
4.0 \\
4.0 \\
4.0\end{array}$ & $\begin{array}{l}2.0 \\
3.0 \\
3.0 \\
4.0 \\
3.0\end{array}$ & $\begin{array}{l}2.0 \\
2.0 \\
4.0 \\
5.0 \\
4.0\end{array}$ & $\begin{array}{l}1.0 \\
1.0 \\
2.0 \\
4.0 \\
3.0\end{array}$ & $\begin{array}{l}1.0 \\
1.0 \\
1.0 \\
1.0 \\
1.0\end{array}$ & $\begin{array}{l}1.0 \\
1.0 \\
1.0 \\
1.0 \\
1.0\end{array}$ & $\begin{array}{l}1.0 \\
1.0 \\
1.0 \\
1.0 \\
1.0\end{array}$ & $\begin{array}{l}1.0 \\
1.0 \\
1.0 \\
1.0 \\
1.0\end{array}$ & $\begin{array}{l}1.0 \\
4.0 \\
6.0 \\
7.0 \\
7.0\end{array}$ & $\begin{array}{l}1.0 \\
1.0 \\
2.0 \\
3.0 \\
6.0\end{array}$ \\
\hline $\begin{array}{l}21 \\
22 \\
23 \\
24 \\
25\end{array}$ & $\begin{array}{l}11.0 \\
10.0 \\
10.0 \\
12.0 \\
11.0\end{array}$ & $\begin{array}{l}4.0 \\
7.0 \\
7.0 \\
8.0 \\
9.0\end{array}$ & $\begin{array}{l}4.0 \\
0.0 \\
5.0 \\
4.0 \\
5.0\end{array}$ & $\begin{array}{l}3.0 \\
4.0 \\
4.0 \\
3.0 \\
4.0\end{array}$ & $\begin{array}{l}8.0 \\
8.0 \\
4.0 \\
1.0 \\
2.0\end{array}$ & $\begin{array}{l}4.0 \\
4.0 \\
1.0 \\
1.0 \\
1.0\end{array}$ & $\begin{array}{l}1.0 \\
1.0 \\
1.0 \\
1.0 \\
1.0\end{array}$ & $\begin{array}{l}1.0 \\
1.0 \\
1.0 \\
1.0 \\
1.0\end{array}$ & $\begin{array}{l}1.0 \\
1.0 \\
1.0 \\
1.0 \\
1.0\end{array}$ & $\begin{array}{l}1.0 \\
1.0 \\
1.0 \\
1.0 \\
1.0\end{array}$ & $\begin{array}{l}7.0 \\
4.0 \\
2.0 \\
3.0 \\
5.0\end{array}$ & $\begin{array}{l}4.0 \\
2.0 \\
1.0 \\
0.0 \\
1.0\end{array}$ \\
\hline $\begin{array}{l}26 \\
27 \\
28 \\
27 \\
30 \\
31\end{array}$ & $\begin{array}{l}7.0 \\
8.0 \\
8.0 \\
8.0 \\
9.0 \\
9.0\end{array}$ & $\begin{array}{l}8.0 \\
1.0 \\
7.0 \\
3.0 \\
6.0 \\
3.0\end{array}$ & $\begin{array}{l}6.0 \\
4.0 \\
2.0 \\
2.0 \\
2.0 \\
-\end{array}$ & $\begin{array}{l}4.0 \\
2.0 \\
1.0 \\
1.0 \\
1.0 \\
-\cdots\end{array}$ & $\begin{array}{l}2.0 \\
1.0 \\
1.0 \\
1.0 \\
1.0 \\
1.0\end{array}$ & $\begin{array}{l}1.0 \\
1.0 \\
1.0 \\
1.0 \\
1.0 \\
1.0\end{array}$ & $\begin{array}{l}1.0 \\
1.0 \\
1.0 \\
1.0 \\
1.0 \\
1.0\end{array}$ & $\begin{array}{l}1.0 \\
1.0 \\
1.0 \\
1.0 \\
1.0 \\
1.0\end{array}$ & $\begin{array}{l}1.0 \\
1.0 \\
0.0 \\
0.0 \\
--- \\
---\end{array}$ & $\begin{array}{l}1.0 \\
0.0 \\
0.0 \\
0.0 \\
--0\end{array}$ & $\begin{array}{r}6.0 \\
9.0 \\
12.0 \\
14.0 \\
13.0 \\
13.0\end{array}$ & $\begin{array}{r}4.0 \\
4.0 \\
8.0 \\
10.0 \\
9.0 \\
9.0\end{array}$ \\
\hline ONTH & 17.0 & 5.0 & 11.0 & 1.0 & 9.0 & 1.0 & 1.0 & 1.0 & 3.0 & 1.0 & -- & $-\cdots$ \\
\hline
\end{tabular}


03092090 WEST BRANCH YAHONING RIVER NEAR RAVENA, OHIO --Cont inued TEMPERATURE $\left({ }^{\circ} \mathrm{C}\right)$ OF WATER, WATER YEAR OCTOBER 1967 TO SEPTEMBER 1968

\begin{tabular}{|c|c|c|c|c|c|c|c|c|c|c|c|c|}
\hline \multirow[b]{2}{*}{ OAY } & \multicolumn{2}{|c|}{ APQIt } & \multicolumn{2}{|c|}{ MAY } & \multicolumn{2}{|c|}{ JUVE } & \multicolumn{2}{|c|}{ JULY } & \multicolumn{2}{|c|}{ AUGUSI } & \multicolumn{2}{|c|}{ SEPIEMBER } \\
\hline & MAK & $M I N$ & $\operatorname{MAX}$ & MIN & $\operatorname{MAX}$ & MIN & $\max$ & MIN & $\max$ & MIN & $\max$ & MIV \\
\hline 1 & 12.0 & 9. 0 & 17.0 & $1 \mathrm{I} .0$ & 15.0 & 13.0 & 26.0 & 21.0 & 22.0 & 19.0 & 18.0 & 17.0 \\
\hline 2 & 11.0 & 0.0 & 17.0 & I U. U & 19.0 & 14.0 & 22.0 & 17.0 & 22.0 & 19.0 & 20.0 & 17.0 \\
\hline 3 & 12.0 & 0.0 & 16.0 & 13.0 & 20.0 & 16.0 & 20.0 & 19.0 & 22.0 & 10.3 & 19.0 & 16.0 \\
\hline 4 & $1+.0$ & 11.0 & 17.0 & 13.0 & 21.0 & 16.0 & 21.0 & 15.0 & 23.0 & 21.0 & 22.0 & 17.0 \\
\hline 5 & 12.0 & 7.0 & 14.0 & 12.0 & 22.0 & 16.0 & 21.0 & 16.0 & 23.0 & 21.0 & 21.0 & 19.0 \\
\hline 0 & 9.3 & 4.0 & 15.0 & 9.0 & 23.0 & 17.0 & 23.0 & 17.0 & 25.0 & 22.0 & 21.0 & 19.0 \\
\hline 7 & $12 . v$ & 6.0 & 16.0 & 9.0 & 24.0 & 19.0 & 22.0 & 17.0 & 24.0 & 22.0 & 20.0 & 10.0 \\
\hline B & 13.0 & 11.0 & 17.0 & 11.0 & 24.0 & 19.0 & 23.0 & 17.0 & 25.0 & 21.0 & 19.0 & 15.0 \\
\hline ; & 13.0 & 11.0 & 18.0 & 14.0 & 25.0 & 20.0 & 25.0 & 17.0 & 26.0 & 22.0 & 19.0 & 17.0 \\
\hline 10 & 12.0 & 9.0 & 18.0 & 14.0 & 24.0 & 20.0 & 23.0 & 21.0 & 24.0 & 20.0 & 19.0 & 17.0 \\
\hline 11 & 14.0 & 8.0 & 16.0 & 13.0 & 25.0 & 21.0 & 24.0 & 17.0 & 22.0 & 17.0 & 17.0 & 16.0 \\
\hline 12 & 15.0 & 9. 0 & 13.0 & 13.0 & 25.0 & 21.0 & 25.0 & 19.0 & 22.0 & 10.0 & 18.0 & 14.0 \\
\hline 13 & 15.0 & 11.0 & 17.0 & 13.0 & 22.0 & 17.0 & 25.0 & 20.0 & 21.0 & 17.0 & 19.0 & 14.5 \\
\hline 14 & 17.0 & 13.0 & 10,0 & 14.0 & 21.0 & 14.0 & 26.0 & 21.0 & 24.0 & 18.0 & 19.0 & 14.0 \\
\hline 15 & 14.0 & 11.0 & 15.0 & 14.0 & 23.0 & 18.0 & 27.0 & 22.0 & 24.0 & 19.0 & 20.0 & 16.0 \\
\hline 10 & 15.0 & y.u & 18.0 & 15.0 & 19.0 & 19.3 & 25.0 & 22.0 & 24.0 & 21.0 & 20.0 & 10.0 \\
\hline 17 & 13.0 & 10.0 & 18.0 & 15.0 & 17.0 & 17.0 & 23.0 & 21.0 & 24.0 & 21.0 & 20.0 & 17.0 \\
\hline 18 & 10.0 & 13.0 & 17.0 & 13.0 & 19.0 & 15.0 & 20.0 & 21.0 & 24.0 & 21.0 & 20.0 & 16.0 \\
\hline 19 & 18.0 & 13.0 & 14.0 & 12.0 & 22.0 & 17.0 & 25.0 & 22.0 & 25.0 & 21.3 & 18.0 & 17.3 \\
\hline 20 & 15.0 & 13.0 & 14,0 & 12.0 & 21.0 & 15.0 & 24.0 & 20.0 & 26.0 & 22.3 & 20.0 & 17.1 \\
\hline 21 & 10.0 & 12.3 & 16.0 & 13.0 & 19.0 & 14.0 & 24.0 & 18.0 & 27.0 & 22.0 & 20.0 & 17.0 \\
\hline & 18.3 & 12.0 & 16.0 & 12.0 & 22.0 & 17.0 & 23.0 & 20.0 & 27.0 & 23.0 & 21.0 & 17.0 \\
\hline 23 & 17.0 & 13.0 & 15.0 & 14.0 & 23.0 & 17.0 & 24.0 & 21.0 & 27.0 & 23.0 & 20.0 & 18.0 \\
\hline$<4$ & 15.0 & 11.0 & 14.0 & 13.0 & 22.0 & 19.0 & 23.0 & 22.0 & 28.0 & 23.0 & 21.0 & 18.0 \\
\hline 25 & 11.0 & 8.0 & 13.0 & 12.0 & 21.0 & 19.0 & 23.0 & 21.0 & 26.0 & 22.0 & 20.0 & 18.1 \\
\hline 20 & 13,0 & 0.0 & 16.0 & 14.0 & 20.0 & 19.0 & 24.0 & 19.0 & 22.0 & 19.0 & 18.0 & 14.0 \\
\hline 27 & 14.0 & 4.0 & 14.0 & 12.0 & 20.0 & 10.0 & 22.0 & 19.0 & 21.0 & 17.0 & 16.0 & 13.0 \\
\hline 28 & 10.0 & 9.0 & I 3.0 & 11.0 & 18.0 & 17.0 & 25.0 & 21.0 & 21.0 & 15.0 & 17.0 & 13.0 \\
\hline 29 & 17.0 & 11.0 & 14.0 & 13.0 & 21.0 & 16.0 & 23.0 & 18.0 & 20.0 & 14.0 & 15.0 & 12.0 \\
\hline 30 & 16.0 & 12.0 & 14.0 & 13.0 & 25.0 & 10.0 & 21.0 & 17.0 & 21.0 & 14.0 & 16.0 & 12.0 \\
\hline 31 & - & - & 16.0 & 13.0 & - & -- & 22.0 & 19.0 & 21.0 & 16.0 & -- & - \\
\hline $\mathrm{NIH}$ & 19.0 & 4.3 & 13.0 & 9.0 & 25.0 & 13.0 & 27.0 & 15.0 & 28.0 & 14.0 & 22.0 & 12.0 \\
\hline
\end{tabular}

03094000 MAHONING RIVER AT LEAVITTSBURG, OHIO

LOCATION. --Lat $41^{\circ} 14^{\prime} 20^{\prime \prime}$, long $80^{\circ} 52^{\prime} 50^{\prime \prime}$, In T.4 N., R.4 W., Trumbull County, at gaging station on right bank at upstream side of highwy bridge at Leavittsburg, $300 \mathrm{ft}$ downstream from Duck Creek, and 1.2 miles downstream from Eagle Creek.

DRA INAGE AREA. $--575 \mathrm{sq} \mathrm{m}$.

PER IOD OF RECORD. -..Chemical analyses: October 1951 to September 1953, July 1967 to September 1968.

Water temperatures: October 1948 to September 1968 .

EXTREMES. --Perlod of record:

Water temperatures: Haximum, $30.0^{\circ} \mathrm{C}$ July 2, 1949; minimum, freezing point on many days during winter periods.

REMarKs. - Continuous recorder located in an Armco shelter just above dam at substation, 350 ft upstream from gage. In addition to the continuous recorder, twice-weekly samples were collected by a local observer for the perlod
February to September. Partial analyses were made on the maximum specific conductance and the minimum specific conductance of the samples collected each month. Interruptions in the record were due to malfunctions of the instrument. Records for water temperatures are available in District office at Columbus.

CHEMICAL ANALYSES IN MILLIGRAMS PER LITER, FEBRUARY TO SEPTEMBER 1968

\begin{tabular}{|c|c|c|c|c|c|c|c|c|c|c|c|c|c|}
\hline DATE & TIME & $\begin{array}{l}\text { DIS- } \\
\text { CHARGE } \\
\text { (CFS) }\end{array}$ & $\begin{array}{l}\text { BICAR- } \\
\text { BONATE } \\
\text { (HCO3) }\end{array}$ & $\begin{array}{l}\text { CAR- } \\
\text { BONATE } \\
\text { (CO3) }\end{array}$ & $\begin{array}{l}\text { SULFATE } \\
\text { (SO4) }\end{array}$ & $\begin{array}{l}\text { CHLO- } \\
\text { RIDE } \\
\text { ( } C L)\end{array}$ & $\begin{array}{l}\text { FLUO- } \\
\text { RIDE } \\
\text { (F) }\end{array}$ & $\begin{array}{c}\text { NI TRATE } \\
\text { (NO3) }\end{array}$ & $\begin{array}{l}\text { DIS- } \\
\text { SOLVED } \\
\text { SOLIDS } \\
\text { (RESI- } \\
\text { DUE AT } \\
180^{\circ} \mathrm{C} \text { ) }\end{array}$ & $\begin{array}{l}\text { HARD- } \\
\text { NESS } \\
\text { (CA,MG) }\end{array}$ & $\begin{array}{l}\text { NON- } \\
\text { CAR- } \\
\text { BONATE } \\
\text { HARD- } \\
\text { NESS }\end{array}$ & $\begin{array}{l}\text { SPE- } \\
\text { CIFIC } \\
\text { CONDUCT- } \\
\text { ANCE } \\
\text { (MICRO- } \\
\text { MHOS) }\end{array}$ & PH \\
\hline $\begin{array}{l}\text { FEB. } \\
05 . .\end{array}$ & & & & & & & & & & & & & \\
\hline $\begin{array}{l}05 . . \\
26 . . \\
\text { MAR. }\end{array}$ & $\begin{array}{l}1200 \\
1600\end{array}$ & $\begin{array}{l}950 \\
136\end{array}$ & $\begin{array}{l}70 \\
72\end{array}$ & $\begin{array}{l}0 \\
0\end{array}$ & $\begin{array}{l}108 \\
148\end{array}$ & $\begin{array}{l}26 \\
33\end{array}$ & .4 & $\begin{array}{l}4.8 \\
4.4\end{array}$ & $\begin{array}{l}270 \\
384\end{array}$ & $\begin{array}{l}175 \\
254\end{array}$ & $\begin{array}{l}118 \\
195\end{array}$ & $\begin{array}{l}428 \\
581\end{array}$ & $\begin{array}{l}7.2 \\
7.2\end{array}$ \\
\hline $\begin{array}{l}04 \ldots \\
18 \ldots \\
\text { APR. }\end{array}$ & $\begin{array}{l}1600 \\
1700\end{array}$ & $\begin{array}{l}146 \\
756\end{array}$ & $\begin{array}{r}116 \\
40\end{array}$ & $\begin{array}{l}0 \\
0\end{array}$ & $\begin{array}{r}148 \\
57\end{array}$ & $\begin{array}{l}34 \\
27\end{array}$ & .2 & $\begin{array}{l}8.2 \\
5.6\end{array}$ & $\begin{array}{l}364 \\
170\end{array}$ & $\begin{array}{r}244 \\
98\end{array}$ & $\begin{array}{r}149 \\
65\end{array}$ & $\begin{array}{l}592 \\
282\end{array}$ & $\begin{array}{l}8.1 \\
7.4\end{array}$ \\
\hline MAY 25 & 1800 & 536 & 68 & 0 & 71 & 20 & .0 & 2.5 & 206 & 130 & 74 & 332 & -- \\
\hline $\begin{array}{l}02 \ldots \\
16 \ldots\end{array}$ & $\begin{array}{l}0900 \\
0800\end{array}$ & $\begin{array}{l}229 \\
850\end{array}$ & $\begin{array}{l}88 \\
50\end{array}$ & $\begin{array}{l}0 \\
0\end{array}$ & $\begin{array}{r}103 \\
53\end{array}$ & $\begin{array}{l}24 \\
14\end{array}$ & .2 & $\begin{array}{l}2.0 \\
4.2\end{array}$ & $\begin{array}{l}242 \\
136\end{array}$ & $\begin{array}{r}174 \\
93\end{array}$ & $\begin{array}{r}102 \\
52\end{array}$ & $\begin{array}{l}437 \\
252\end{array}$ & $\begin{array}{l}7.3 \\
6.4\end{array}$ \\
\hline $\begin{array}{l}\text { JUNE } \\
28 . .\end{array}$ & 1300 & 342 & 83 & 0 & 94 & 25 & .2 & 2.8 & 250 & 170 & 102 & 416 & 6.9 \\
\hline $\begin{array}{l}\text { JULY } \\
13 . . .\end{array}$ & 1600 & 308 & 86 & 0 & 87 & 24 & .1 & 3.8 & 254 & 164 & 94 & 390 & 7.1 \\
\hline $\begin{array}{l}29 . . \\
\text { AUG. }\end{array}$ & 1205 & 304 & 86 & 0 & 94 & 25 & $\ddot{-1}$ & 6.0 & 262 & $\begin{array}{l}104 \\
172\end{array}$ & $\begin{array}{r}94 \\
102\end{array}$ & 429 & $\begin{array}{l}1.1 \\
6.9\end{array}$ \\
\hline $\begin{array}{r}03 . \ldots \\
13 . \ldots \\
\text { SEPT. }\end{array}$ & $\begin{array}{l}1300 \\
1700\end{array}$ & $\begin{array}{l}325 \\
314\end{array}$ & $\begin{array}{l}96 \\
90\end{array}$ & $\begin{array}{l}0 \\
0\end{array}$ & $\begin{array}{l}89 \\
96\end{array}$ & $\begin{array}{l}24 \\
28\end{array}$ & $\begin{array}{l}.3 \\
.3\end{array}$ & $\begin{array}{l}4.4 \\
9.7\end{array}$ & $\begin{array}{l}280 \\
300\end{array}$ & $\begin{array}{l}170 \\
178\end{array}$ & $\begin{array}{r}92 \\
104\end{array}$ & $\begin{array}{l}418 \\
444\end{array}$ & 7.3 \\
\hline $\begin{array}{l}24 \ldots \\
27 \ldots\end{array}$ & $\begin{array}{l}1830 \\
0800\end{array}$ & $\begin{array}{l}388 \\
286\end{array}$ & $\begin{array}{l}112 \\
108\end{array}$ & $\begin{array}{l}0 \\
0\end{array}$ & $\begin{array}{l}71 \\
72\end{array}$ & $\begin{array}{l}28 \\
30\end{array}$ & $\begin{array}{l}.4 \\
.2\end{array}$ & $\begin{array}{l}5.3 \\
3.1\end{array}$ & $\begin{array}{l}282 \\
272\end{array}$ & $\begin{array}{l}164 \\
162\end{array}$ & $\begin{array}{l}72 \\
74\end{array}$ & $\begin{array}{l}420 \\
409\end{array}$ & $\begin{array}{l}8.0 \\
8.0\end{array}$ \\
\hline
\end{tabular}


03094000 WAHONING RIVER AT LEAVITTSBURG, OHIO--COntinued SPECIFIC CONDUCTANCE, pH, DISSOLVED OXYGEN, AND WATER TEMPERATURES, WATER YEAR OCTOBER 1967 TO SEPTEMBER 1968 OCTOBER

\begin{tabular}{|c|c|c|c|c|c|c|c|c|c|c|c|c|c|c|c|c|}
\hline \multirow[t]{2}{*}{ DAY } & \multicolumn{2}{|c|}{$\begin{array}{l}\text { SPECIFIC } \\
\text { CONDUCTANCE } \\
\text { (UICROMBOS } \\
\left.\text { AT 25 } 25^{\circ} \mathrm{C}\right)\end{array}$} & \multicolumn{2}{|c|}{$\mathrm{pH}$} & \multicolumn{2}{|c|}{$\begin{array}{l}\text { DISSOLYED } \\
\text { OXYGEN } \\
(\boldsymbol{M G} / \mathrm{L})\end{array}$} & \multicolumn{2}{|c|}{$\begin{array}{l}\text { TEMPER- } \\
\text { ATURE } \\
\left\langle{ }^{\circ} \mathrm{C}\right\rangle\end{array}$} & \multicolumn{2}{|c|}{$\begin{array}{l}\text { SPECIF IC } \\
\text { CONDUCTANCE } \\
\text { (XICROMBOS } \\
\text { AT 25. }\end{array}$} & \multicolumn{2}{|c|}{ pH } & \multicolumn{2}{|c|}{$\begin{array}{l}\text { DI SSOLVED } \\
\text { OXYGEN } \\
(\mathbf{K G} / L)\end{array}$} & \multicolumn{2}{|c|}{$\begin{array}{l}\text { TEMPER- } \\
\text { ATURE } \\
\left({ }^{\circ} \mathrm{C}\right)\end{array}$} \\
\hline & $\operatorname{MAX}$ & MI N & MAX & MIN & $\operatorname{MAX}$ & MIN & MAX & MIN & MAX & xIN & MAX & MIN & $\max$ & MIN & $\operatorname{MAX}$ & MIN \\
\hline $\begin{array}{l}1 \\
2 \\
3 \\
4 \\
5\end{array}$ & $\begin{array}{l}\mathbf{5 3 0} \\
\mathbf{5 0 0} \\
\mathbf{5 1 0} \\
\mathbf{4 8 0} \\
\mathbf{5 7 0}\end{array}$ & $\begin{array}{l}360 \\
450 \\
470 \\
460 \\
340\end{array}$ & & & $\begin{array}{l}9.2 \\
9.5 \\
8.4 \\
7.9 \\
8.7\end{array}$ & $\begin{array}{l}7.3 \\
7.5 \\
7.4 \\
7.4 \\
7.2\end{array}$ & $\begin{array}{l}15 \\
16 \\
16 \\
17 \\
18\end{array}$ & $\begin{array}{l}13 \\
14 \\
14 \\
15 \\
17\end{array}$ & $\begin{array}{l}\mathbf{6 4 0} \\
\mathbf{6 7 0} \\
670 \\
560 \\
\mathbf{5 7 0}\end{array}$ & $\begin{array}{l}380 \\
400 \\
400 \\
410 \\
520\end{array}$ & & & $\begin{array}{r}10.7 \\
10.5 \\
10.7 \\
8.6 \\
8.1\end{array}$ & $\begin{array}{l}8.4 \\
9.6 \\
8.2 \\
7.6 \\
7.6\end{array}$ & $\begin{array}{l}11 \\
12 \\
12 \\
12 \\
11\end{array}$ & $\begin{array}{r}8 \\
11 \\
11 \\
11 \\
10\end{array}$ \\
\hline $\begin{array}{r}6 \\
7 \\
8 \\
9 \\
10\end{array}$ & $\begin{array}{l}480 \\
480 \\
490 \\
490 \\
500\end{array}$ & $\begin{array}{l}470 \\
470 \\
460 \\
460 \\
450\end{array}$ & & & $\begin{array}{l}7.6 \\
7.3 \\
8.7 \\
7.7 \\
7.7\end{array}$ & $\begin{array}{l}7.0 \\
6.7 \\
6.7 \\
7.5 \\
7.0\end{array}$ & $\begin{array}{l}18 \\
17 \\
16 \\
16 \\
15\end{array}$ & $\begin{array}{l}17 \\
15 \\
15 \\
15 \\
14\end{array}$ & $\begin{array}{r}590 \\
610 \\
-2 \\
--\end{array}$ & $\begin{array}{r}530 \\
540 \\
- \\
--\end{array}$ & & & $\begin{array}{r}8.7 \\
9.2 \\
-- \\
-- \\
--\end{array}$ & $\begin{array}{r}8.1 \\
8.7 \\
-- \\
-- \\
--\end{array}$ & $\begin{array}{r}10 \\
9 \\
-- \\
--\end{array}$ & $\begin{array}{r}8 \\
7 \\
-- \\
-- \\
--\end{array}$ \\
\hline $\begin{array}{l}11 \\
12 \\
13 \\
14 \\
15\end{array}$ & $\begin{array}{l}500 \\
500 \\
490 \\
490 \\
510\end{array}$ & $\begin{array}{l}440 \\
450 \\
460 \\
440 \\
480\end{array}$ & & & $\begin{array}{r}7.1 \\
7.3 \\
7.6 \\
8.4 \\
13.8\end{array}$ & $\begin{array}{l}6.6 \\
6.6 \\
7.1 \\
7.6 \\
7.7\end{array}$ & $\begin{array}{l}14 \\
14 \\
14 \\
13 \\
13\end{array}$ & $\begin{array}{l}14 \\
13 \\
12 \\
13 \\
12\end{array}$ & $\begin{array}{l}-- \\
=- \\
=- \\
--\end{array}$ & $\begin{array}{l}=- \\
=- \\
=\end{array}$ & & & $\begin{array}{l}-- \\
\overline{--} \\
--\end{array}$ & $\begin{array}{l}= \\
=- \\
=-\end{array}$ & $\begin{array}{l}= \\
=- \\
=\end{array}$ & $\begin{array}{l}= \\
\bar{z} \\
\overline{-}\end{array}$ \\
\hline $\begin{array}{l}16 \\
17 \\
18 \\
19 \\
20\end{array}$ & $\begin{array}{l}\mathbf{6 0 0} \\
\mathbf{5 2 0} \\
\mathbf{4 9 0} \\
\mathbf{5 3 0} \\
\mathbf{5 3 0}\end{array}$ & $\begin{array}{l}\mathbf{3 6 0} \\
\mathbf{3 6 0} \\
370 \\
\mathbf{4 7 0} \\
\mathbf{4 7 0}\end{array}$ & & & $\begin{array}{l}8.5 \\
8.2 \\
9.6 \\
8.8 \\
9.9\end{array}$ & $\begin{array}{l}7.5 \\
7.3 \\
8.2 \\
7.4 \\
7.1\end{array}$ & $\begin{array}{l}14 \\
15 \\
15 \\
15 \\
14\end{array}$ & $\begin{array}{l}12 \\
13 \\
14 \\
14 \\
11\end{array}$ & $\begin{array}{l}-- \\
\ddot{--} \\
--\end{array}$ & $\begin{array}{l}=- \\
=- \\
= \\
--\end{array}$ & & & $\begin{array}{l}-- \\
-- \\
--\end{array}$ & $\begin{array}{l}-- \\
-- \\
-- \\
--\end{array}$ & $\begin{array}{l}= \\
\overline{-} \\
--\end{array}$ & - \\
\hline $\begin{array}{l}\mathbf{2 1} \\
22 \\
23 \\
24 \\
25\end{array}$ & $\begin{array}{l}\mathbf{5 0 0} \\
\mathbf{5 4 0} \\
\mathbf{5 9 0} \\
\mathbf{5 6 0} \\
\mathbf{5 5 0}\end{array}$ & $\begin{array}{l}\mathbf{4 7 0} \\
\mathbf{4 6 0} \\
470 \\
470 \\
\mathbf{4 8 0}\end{array}$ & & & $\begin{array}{l}7.6 \\
7.9 \\
8.2 \\
8.5 \\
8.3\end{array}$ & $\begin{array}{l}7.3 \\
7.5 \\
7.8 \\
7.7 \\
8.0\end{array}$ & $\begin{array}{l}13 \\
12 \\
12 \\
12 \\
12\end{array}$ & $\begin{array}{r}11 \\
10 \\
9 \\
10 \\
11\end{array}$ & $\begin{array}{l}= \\
=- \\
=-\end{array}$ & $\begin{array}{l}=- \\
\bar{z} \\
=\end{array}$ & & & $\begin{array}{l}=- \\
=- \\
=- \\
--\end{array}$ & $\begin{array}{l}=- \\
=- \\
=- \\
=-\end{array}$ & $\begin{array}{l}= \\
=- \\
--\end{array}$ & - \\
\hline $\begin{array}{l}26 \\
27 \\
28 \\
29 \\
30 \\
31\end{array}$ & $\begin{array}{l}\mathbf{5 5 0} \\
620 \\
\mathbf{5 6 0} \\
\mathbf{5 8 0} \\
\mathbf{6 6 0} \\
\mathbf{7 1 0}\end{array}$ & $\begin{array}{l}\mathbf{4 8 0} \\
500 \\
510 \\
500 \\
360 \\
\mathbf{4 6 0}\end{array}$ & & & $\begin{array}{l}8.0 \\
7.8 \\
7.8 \\
8.5 \\
8.3 \\
8.6\end{array}$ & $\begin{array}{l}7.7 \\
7.7 \\
7.7 \\
7.8 \\
8.0 \\
8.3\end{array}$ & $\begin{array}{l}12 \\
12 \\
11 \\
11 \\
10 \\
10\end{array}$ & $\begin{array}{r}12 \\
11 \\
11 \\
8 \\
8 \\
8\end{array}$ & $\begin{array}{l}\overline{-} \\
\overline{--} \\
\overline{--} \\
=-\end{array}$ & $\begin{array}{l}=- \\
=- \\
\bar{z} \\
=-\end{array}$ & & & $\begin{array}{l}- \\
=- \\
=- \\
--\end{array}$ & $\begin{array}{l}=- \\
=- \\
=- \\
=-\end{array}$ & $\begin{array}{l}\overline{-} \\
\overline{--} \\
=- \\
=\end{array}$ & -- \\
\hline
\end{tabular}

SPECIFIC CONDUCTANCE, PH, DISSOLVED OXYGEN, AND WATER TEMPERATURES, WATER YEAR OCTOBER 1967 TO SEPTEMBER 1968 DECEMRER JANUARY

\begin{tabular}{|c|c|c|c|c|c|c|c|c|}
\hline \multirow[t]{2}{*}{ DAY } & \multicolumn{2}{|c|}{$\begin{array}{l}\text { SPECIFIC } \\
\text { CONDUCTANCE } \\
\text { (HICROMBOS } \\
\text { AT } 25^{\circ} \mathrm{C} \text { ) }\end{array}$} & \multicolumn{2}{|c|}{ pH } & \multicolumn{2}{|c|}{$\begin{array}{l}\text { DISSOLVED } \\
\text { OXYGEN } \\
(\boldsymbol{M G} / \mathrm{L})\end{array}$} & \multicolumn{2}{|c|}{$\begin{array}{l}\text { TEMPER- } \\
\text { ATURE } \\
\left({ }^{\circ} \mathrm{C}\right)\end{array}$} \\
\hline & MAX & MIN & $\max$ & MIN & MAX & MIN & MAX & MIN \\
\hline 1 & -- & - & & & - & -- & -- & -- \\
\hline 2 & -- & -- & & & -- & -- & -- & -- \\
\hline 3 & -- & -- & & & -- & -- & -- & -- \\
\hline 4 & -- & -- & & & - & -- & -- & -- \\
\hline 5 & -- & -- & & & -- & - & -- & - \\
\hline 6 & -- & -- & & & -- & - & -- & -- \\
\hline 7 & -- & -- & & & -- & -- & -- & - \\
\hline 8 & -- & -- & & & -- & -- & -- & -- \\
\hline 9 & -- & -- & & & -- & $\cdots$ & -- & -- \\
\hline 10 & -- & -- & & & -- & -- & -- & - \\
\hline 11 & -- & -- & & & -- & -- & -- & -- \\
\hline 12 & -- & -- & & & -- & - & - & -- \\
\hline 13 & 450 & 440 & & & 12.8 & 10.6 & 6 & 5 \\
\hline 14 & 440 & 420 & & & 11.3 & 10.0 & 7 & 6 \\
\hline 15 & $\mathbf{4 4 0}$ & 420 & & & 11.3 & 11.2 & 6 & 4 \\
\hline 16 & $\mathbf{4 5 0}$ & 430 & & & 11.3 & 11.2 & 5 & 4 \\
\hline 17 & 470 & 450 & & & 11.4 & 11.2 & 6 & 4 \\
\hline 18 & 550 & 450 & & & 11.5 & 11.4 & 4 & 4 \\
\hline 19 & 450 & 420 & & & 11.4 & 11.2 & 6 & 4 \\
\hline 20 & 450 & 410 & & & 11.9 & 10.7 & 6 & 4 \\
\hline 21 & 480 & 420 & & & 13.1 & 10.8 & 6 & 4 \\
\hline 22 & $=$ & - & & & - & - & -- & - \\
\hline 23 & -- & -- & & & -- & -- & - & - \\
\hline 24 & -- & -- & & & -- & -- & -- & - \\
\hline 25 & -- & - & & & - & -- & -- & - \\
\hline 26 & - & -- & & & -- & -- & -- & -- \\
\hline 27 & - & -- & & & - & -- & 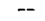 & -- \\
\hline 28 & -- & $=$ & & & -- & - & -- & -- \\
\hline 29 & -- & -- & & & -- & -- & -- & -- \\
\hline 30 & -- & -- & & & -- & -- & -- & - \\
\hline 31 & -- & -- & & & -- & -- & -- & -- \\
\hline
\end{tabular}


BEAVER RIVER BASIN

03094000 LABONING RIVER AT LEAVITTSBURG, OHIO--Cont1nued

SPECIFIC CONDUCTANCE, PH, DISSOLVED OXYGEN, AND WATER TEMPERATURES, NATER YEAR OCTOBER 1967 TO SEPTEMBER 1968

FEBRUARY

DAY

1
1
3
4
5
6
7
8
9
10
11
12
13
14
15
16
17
18
19
20
21
22
23
24
25
26
27
28
29
30
31

\begin{tabular}{|c|c|c|c|c|c|c|c|}
\hline \multicolumn{2}{|c|}{$\begin{array}{l}\text { SPECIFIC } \\
\text { CONDUCT } \\
\text { (MCROE } \\
\left.\text { AT } 25^{\circ} \mathrm{C}\right)\end{array}$} & \multicolumn{2}{|c|}{ pH } & \multicolumn{2}{|c|}{$\begin{array}{l}\text { DISSOLVED } \\
\text { OXYGEN } \\
(\mathbf{M G} / \mathrm{L})\end{array}$} & \multicolumn{2}{|c|}{$\begin{array}{c}\text { TEMPER- } \\
\text { ATURE } \\
\left({ }^{\circ} \mathrm{C}\right)\end{array}$} \\
\hline $\max$ & MIN & $\max$ & MIN & xaA & IIN & $\max$ & IIN \\
\hline & & -- & -- & -- & -- & -- & - \\
\hline & & 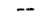 & - & -- & - & -- & - \\
\hline & & -- & $=$ & - & $=$ & - & -- \\
\hline & & $\overline{7.5}$ & $\overline{7.3}$ & $12 . \overline{6}$ & 12.4 & $\overline{2}$ & $\overline{0}$ \\
\hline & & $\begin{array}{l}7.6 \\
7.6 \\
7.6 \\
7.5 \\
7.5\end{array}$ & $\begin{array}{l}7.3 \\
7.4 \\
7.4 \\
7.4 \\
7.2\end{array}$ & $\begin{array}{l}12.8 \\
12.8 \\
12.8 \\
12.7 \\
12.4\end{array}$ & $\begin{array}{l}12.5 \\
12.4 \\
12.3 \\
12.4 \\
11.5\end{array}$ & $\begin{array}{l}1 \\
1 \\
1 \\
2 \\
2\end{array}$ & $\begin{array}{l}0 \\
0 \\
1 \\
1 \\
1\end{array}$ \\
\hline & & $\begin{array}{l}7.6 \\
7.6 \\
7.5 \\
7.5 \\
7.5\end{array}$ & $\begin{array}{l}7.4 \\
7.4 \\
7.4 \\
7.4 \\
7.4\end{array}$ & $\begin{array}{l}12.6 \\
12.6 \\
12.6 \\
12.5 \\
12.3\end{array}$ & $\begin{array}{l}11.8 \\
12.1 \\
11.6 \\
12.0 \\
11.9\end{array}$ & $\begin{array}{l}2 \\
2 \\
2 \\
1 \\
1\end{array}$ & $\begin{array}{l}1 \\
1 \\
1 \\
1 \\
1\end{array}$ \\
\hline & & 7.5 & 7.4 & 11.9 & 10.9 & 2 & 1 \\
\hline & & - & - & -- & - & -- & - \\
\hline & & -- & $\overrightarrow{-}$ & 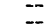 & $=$ & $\overline{z-}$ & $\bar{z}$ \\
\hline & & - & - & -- & - & -- & - \\
\hline & & -- & -- & -- & -- & - & -- \\
\hline & & -- & -- & - & -- & - & - \\
\hline & & $\sim$ & -- & -- & -- & -- & -- \\
\hline & & -- & -- & $\rightarrow$ & - & -- & -- \\
\hline & & -- & -- & -- & -- & -- & - \\
\hline & & -- & -- & -- & -- & -- & -- \\
\hline & & - & - & - & - & -- & -- \\
\hline & & - & $=$ & -- & - & -- & -- \\
\hline & & - & -- & $=$ & - & -- & - \\
\hline & & - & -- & -- & -- & -- & - \\
\hline & & -- & - & - & $m$ & - & - \\
\hline
\end{tabular}

MARCH

\begin{tabular}{|c|c|c|c|c|c|c|}
\hline $\begin{array}{l}\text { SPI } \\
\text { CONI } \\
(\mathbf{H I C} \\
\text { A? }\end{array}$ & $\begin{array}{l}\text { IC } \\
\text { INCE } \\
\text { IOS } \\
\left.{ }^{\circ} \mathrm{C}\right)\end{array}$ & & & $\begin{array}{l}\text { DIS } \\
\text { Ox } \\
(\mathrm{M}\end{array}$ & $\begin{array}{l}\text { VED } \\
\text { ON } \\
\text { L) }\end{array}$ & $\begin{array}{l}\text { TEMPER- } \\
\text { ATURE } \\
\left({ }^{\circ} \mathrm{C}\right)\end{array}$ \\
\hline MAX & MIN & xaX & MIN & $\max$ & MIN & MAX MIN \\
\hline
\end{tabular}

MAY

\begin{tabular}{|c|c|c|c|c|c|c|c|}
\hline \multicolumn{2}{|c|}{$\begin{array}{l}\text { SPECIFIC } \\
\text { CONDUCTANCE } \\
\text { (MICROMHOS } \\
\text { AT } 25^{\circ} \mathrm{C} \text { ) }\end{array}$} & \multicolumn{2}{|c|}{$\mathrm{pH}$} & \multicolumn{2}{|c|}{$\begin{array}{l}\text { DISSOLVED } \\
\text { OXYG EN } \\
(\mathbf{M G} / \mathrm{L})\end{array}$} & \multicolumn{2}{|c|}{$\begin{array}{c}\text { TEMPER- } \\
\text { ATURE } \\
\left({ }^{\circ} \mathbf{C}\right)\end{array}$} \\
\hline MAX & MIN & $\max$ & MIN & $\max$ & MIN & $\max$ & MIN \\
\hline $\begin{array}{l}430 \\
430 \\
430 \\
430 \\
420\end{array}$ & $\begin{array}{l}410 \\
420 \\
420 \\
410 \\
400\end{array}$ & $\begin{array}{l}7.5 \\
7.6 \\
7.5 \\
7.4 \\
7.4\end{array}$ & $\begin{array}{l}7.3 \\
7.3 \\
7.4 \\
7.3 \\
7.3\end{array}$ & $\begin{array}{l}=- \\
=- \\
=-\end{array}$ & $\begin{array}{l}=- \\
=- \\
=\end{array}$ & $\begin{array}{l}16 \\
16 \\
16 \\
17 \\
17\end{array}$ & $\begin{array}{l}14 \\
14 \\
15 \\
16 \\
16\end{array}$ \\
\hline $\begin{array}{l}410 \\
420 \\
460 \\
480 \\
470\end{array}$ & $\begin{array}{l}400 \\
400 \\
400 \\
410 \\
410\end{array}$ & $\begin{array}{l}7.5 \\
7.5 \\
7.6 \\
7.4 \\
7.3\end{array}$ & $\begin{array}{l}7.2 \\
7.2 \\
7.4 \\
7.3 \\
7.2\end{array}$ & $\begin{array}{r}-. \\
-\overline{-} \\
10.2 \\
9.6 \\
9.0\end{array}$ & $\begin{array}{l}-- \\
9.6 \\
9.0 \\
8.1\end{array}$ & $\begin{array}{l}16 \\
16 \\
17 \\
18 \\
18\end{array}$ & $\begin{array}{l}16 \\
14 \\
15 \\
17 \\
17\end{array}$ \\
\hline $\begin{array}{l}470 \\
420 \\
260 \\
270 \\
330\end{array}$ & $\begin{array}{l}410 \\
260 \\
200 \\
220 \\
270\end{array}$ & $\begin{array}{l}7.7 \\
8.0 \\
7.5 \\
7.1 \\
7.7\end{array}$ & $\begin{array}{l}6.9 \\
7.3 \\
6.3 \\
6.3 \\
7.0\end{array}$ & $\begin{array}{l}8.2 \\
7.3 \\
7.1 \\
6.9 \\
7.1\end{array}$ & $\begin{array}{l}7.3 \\
6.8 \\
6.9 \\
6.8 \\
6.7\end{array}$ & $\begin{array}{l}18 \\
17 \\
16 \\
17 \\
16\end{array}$ & $\begin{array}{l}17 \\
15 \\
14 \\
16 \\
15\end{array}$ \\
\hline $\begin{array}{l}320 \\
280 \\
310 \\
380 \\
380\end{array}$ & $\begin{array}{l}260 \\
250 \\
240 \\
310 \\
350\end{array}$ & $\begin{array}{l}7.8 \\
6.6 \\
7.0 \\
7.0 \\
7.3\end{array}$ & $\begin{array}{l}6.5 \\
6.5 \\
6.5 \\
6.8 \\
6.9\end{array}$ & $\begin{array}{l}6.8 \\
-7.2 \\
7.5 \\
7.9\end{array}$ & $\begin{array}{l}6.1 \\
6.0 \\
6.1 \\
7.5\end{array}$ & $\begin{array}{l}18 \\
18 \\
19 \\
18 \\
16\end{array}$ & $\begin{array}{l}16 \\
17 \\
17 \\
16 \\
14\end{array}$ \\
\hline $\begin{array}{l}380 \\
400 \\
410 \\
430 \\
420\end{array}$ & $\begin{array}{l}350 \\
370 \\
400 \\
400 \\
400\end{array}$ & $\begin{array}{l}7.5 \\
7.2 \\
7.1 \\
7.8 \\
7.8\end{array}$ & $\begin{array}{l}6.9 \\
6.8 \\
6.8 \\
7.0 \\
7.0\end{array}$ & $\begin{array}{l}8.0 \\
8.1 \\
8.0 \\
7.9 \\
8.1\end{array}$ & $\begin{array}{l}7.8 \\
7.8 \\
7.6 \\
7.7 \\
7.7\end{array}$ & $\begin{array}{l}16 \\
17 \\
17 \\
17 \\
17\end{array}$ & $\begin{array}{l}15 \\
16 \\
16 \\
16 \\
16\end{array}$ \\
\hline $\begin{array}{l}\mathbf{4 4 0} \\
420 \\
320 \\
280 \\
380 \\
390\end{array}$ & $\begin{array}{l}\mathbf{4 1 0} \\
320 \\
220 \\
220 \\
280 \\
370\end{array}$ & $\begin{array}{l}7.7 \\
7.7 \\
7.5 \\
7.8 \\
7.5 \\
7.5\end{array}$ & $\begin{array}{l}6.9 \\
7.1 \\
7.1 \\
6.9 \\
6.9 \\
7.0\end{array}$ & $\begin{array}{l}8.0 \\
7.8 \\
7.7 \\
7.8 \\
8.2 \\
8.2\end{array}$ & $\begin{array}{l}7.7 \\
7.4 \\
7.5 \\
7.6 \\
7.8 \\
8.1\end{array}$ & $\begin{array}{l}18 \\
17 \\
16 \\
15 \\
17 \\
17\end{array}$ & $\begin{array}{l}16 \\
16 \\
14 \\
14 \\
15 \\
16\end{array}$ \\
\hline
\end{tabular}


03094000 MAHONING RIVER AT LEAVITTSBURG, OHIO--COntInUed

SPECIFIC CONDUCTANCE, PH, DISSOLVED OXYGEN, AND WATER TEMPERATURES, WATER YEAR OCTOBER 1967 TO SEPTEMBER 1968 JUNE

JULY

\begin{tabular}{|c|c|c|c|c|c|c|c|c|}
\hline \multirow[t]{2}{*}{ DAY } & \multicolumn{2}{|c|}{$\begin{array}{l}\text { SPECIFIC } \\
\text { CONDUCTANCE } \\
\text { (MICROMHOS } \\
\left.\text { AT } 25^{\circ} \mathrm{C}\right)\end{array}$} & \multicolumn{2}{|c|}{$\mathrm{pH}$} & \multicolumn{2}{|c|}{$\begin{array}{l}\text { DI SSOLVED } \\
\text { OXYG EN } \\
(\mathbf{M G} / \mathbf{L})\end{array}$} & \multicolumn{2}{|c|}{$\begin{array}{l}\text { TEMPER- } \\
\text { ATURE } \\
\left({ }^{\circ} \mathrm{C}\right)\end{array}$} \\
\hline & $\operatorname{MAX}$ & MIN & $\operatorname{MAX}$ & MIN & $\operatorname{MAX}$ & MIN & MAX & MIN \\
\hline $\begin{array}{l}1 \\
2 \\
3 \\
4 \\
5\end{array}$ & $\begin{array}{l}390 \\
420 \\
410 \\
410 \\
420\end{array}$ & $\begin{array}{l}380 \\
390 \\
390 \\
400 \\
400\end{array}$ & $\begin{array}{l}7.8 \\
8.4 \\
8.2 \\
7.5 \\
7.3\end{array}$ & $\begin{array}{l}6.9 \\
7.1 \\
7.1 \\
7.1 \\
-.-\end{array}$ & $\begin{array}{l}8.1 \\
7.9 \\
6.7 \\
6.6 \\
6.5\end{array}$ & $\begin{array}{l}7.9 \\
6.5 \\
6.3 \\
6.1 \\
--\end{array}$ & $\begin{array}{l}17 \\
18 \\
19 \\
19 \\
19\end{array}$ & $\begin{array}{l}16 \\
16 \\
18 \\
18 \\
18\end{array}$ \\
\hline $\begin{array}{r}6 \\
7 \\
8 \\
9 \\
10\end{array}$ & $\begin{array}{l}=- \\
=- \\
=\end{array}$ & $\begin{array}{l}=- \\
\bar{z} \\
\overline{--}\end{array}$ & $\begin{array}{l}-- \\
-- \\
-- \\
--\end{array}$ & $\begin{array}{l}=- \\
=- \\
=-\end{array}$ & $\begin{array}{l}= \\
=- \\
= \\
-\end{array}$ & $\begin{array}{l}=- \\
=- \\
=-\end{array}$ & $\begin{array}{l}19 \\
18 \\
-- \\
--\end{array}$ & $\begin{array}{l}16 \\
14 \\
-- \\
--\end{array}$ \\
\hline $\begin{array}{l}11 \\
12 \\
13 \\
14 \\
15\end{array}$ & $\begin{array}{l}-- \\
-- \\
-- \\
--\end{array}$ & $\begin{array}{l}-- \\
\overline{--} \\
--\end{array}$ & $\begin{array}{l}= \\
= \\
=-\end{array}$ & $\begin{array}{l}=- \\
=- \\
=-\end{array}$ & $\begin{array}{l}=- \\
=- \\
=\end{array}$ & $\begin{array}{l}=- \\
=- \\
=- \\
--\end{array}$ & $\begin{array}{l}= \\
=- \\
=-\end{array}$ & $\begin{array}{l}= \\
\overline{-} \\
=\end{array}$ \\
\hline $\begin{array}{l}16 \\
17 \\
18 \\
19 \\
20\end{array}$ & $\begin{array}{l}-- \\
-- \\
-- \\
--\end{array}$ & $\begin{array}{l}=- \\
-- \\
--\end{array}$ & $\begin{array}{l}= \\
=- \\
=\end{array}$ & $\begin{array}{l}= \\
=- \\
=-\end{array}$ & $\begin{array}{l}=- \\
=- \\
= \\
=\end{array}$ & $\begin{array}{l}-- \\
=- \\
-- \\
--\end{array}$ & $\begin{array}{l}=- \\
=- \\
=-\end{array}$ & $\begin{array}{l}=- \\
=- \\
=\end{array}$ \\
\hline $\begin{array}{l}21 \\
22 \\
23 \\
24 \\
25\end{array}$ & $\begin{array}{l}-- \\
-- \\
-- \\
--\end{array}$ & $\begin{array}{l}= \\
=- \\
-- \\
--\end{array}$ & $\begin{array}{l}-- \\
-- \\
-- \\
--\end{array}$ & $\begin{array}{l}=- \\
=- \\
=-\end{array}$ & $\begin{array}{l}=- \\
=- \\
=- \\
--\end{array}$ & $\begin{array}{l}=- \\
=- \\
=- \\
=-\end{array}$ & $\begin{array}{l}-- \\
-- \\
=- \\
--\end{array}$ & $\begin{array}{l}=- \\
-- \\
--\end{array}$ \\
\hline $\begin{array}{l}26 \\
27 \\
28 \\
29 \\
30 \\
31\end{array}$ & $\begin{array}{l}=- \\
=- \\
=- \\
--\end{array}$ & $\begin{array}{l}=- \\
\overline{-} \\
\overline{-} \\
\overline{-}\end{array}$ & $\begin{array}{l}-- \\
-- \\
-- \\
-- \\
--\end{array}$ & $\begin{array}{l}= \\
= \\
= \\
=\end{array}$ & $\begin{array}{l}\overline{-} \\
\overline{-} \\
-- \\
--\end{array}$ & $\begin{array}{l}-- \\
-- \\
-- \\
-- \\
--\end{array}$ & $\begin{array}{l}\overline{-} \\
\overline{-} \\
\bar{z} \\
\overline{-}\end{array}$ & $\begin{array}{l}=- \\
=- \\
=- \\
=-\end{array}$ \\
\hline
\end{tabular}

AUGUST

\begin{tabular}{|c|c|c|c|c|c|c|c|c|}
\hline \multirow[t]{2}{*}{ DAY } & $\begin{array}{r}\text { SPE } \\
\text { COND } \\
\text { (HIC } \\
\text { AT }\end{array}$ & $\begin{array}{l}\text { IC } \\
\text { ANCE } \\
\text { HOS } \\
\left.{ }^{\circ} \mathrm{C}\right)\end{array}$ & p & & \multicolumn{2}{|c|}{$\begin{array}{l}\text { DISSOLVED } \\
\text { OXYGEN } \\
(\mathbf{H G} / \mathbf{L})\end{array}$} & \multicolumn{2}{|c|}{$\begin{array}{l}\text { TEMPER- } \\
\text { ATURE } \\
\left({ }^{\circ} \mathrm{C}\right)\end{array}$} \\
\hline & $\max$ & MIN & $\operatorname{Max}$ & MIN & MAX & MIN & $\operatorname{MAX}$ & MIN \\
\hline $\begin{array}{l}1 \\
2 \\
3 \\
4\end{array}$ & $\begin{array}{l}430 \\
420 \\
470 \\
470\end{array}$ & $\begin{array}{l}410 \\
390 \\
390 \\
440\end{array}$ & $\begin{array}{l}8.4 \\
8.4 \\
8.2 \\
8.0\end{array}$ & $\begin{array}{l}7.6 \\
7.4 \\
6.7 \\
7.3\end{array}$ & $\begin{array}{l}7.3 \\
6.6 \\
7.1 \\
7.1\end{array}$ & $\begin{array}{l}6.3 \\
6.0 \\
6.0 \\
5.8\end{array}$ & $\begin{array}{l}23 \\
22 \\
22 \\
23\end{array}$ & $\begin{array}{l}21 \\
21 \\
21 \\
22\end{array}$ \\
\hline 5 & 470 & 440 & 8.5 & 7.4 & 6.6 & 5.7 & 23 & 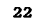 \\
\hline $\begin{array}{r}6 \\
7 \\
8 \\
9 \\
10\end{array}$ & $\begin{array}{l}470 \\
470 \\
470 \\
470 \\
480\end{array}$ & $\begin{array}{l}430 \\
420 \\
420 \\
430 \\
440\end{array}$ & $\begin{array}{l}8.4 \\
8.3 \\
8.2 \\
8.2 \\
8.2\end{array}$ & $\begin{array}{l}7.4 \\
7.0 \\
7.4 \\
7.4 \\
7.4\end{array}$ & $\begin{array}{l}7.0 \\
7.0 \\
6.4 \\
6.5 \\
6.6\end{array}$ & $\begin{array}{l}6.0 \\
6.1 \\
5.5 \\
5.8 \\
5.5\end{array}$ & $\begin{array}{l}24 \\
24 \\
24 \\
24 \\
25\end{array}$ & $\begin{array}{l}22 \\
22 \\
23 \\
22 \\
24\end{array}$ \\
\hline $\begin{array}{l}11 \\
12 \\
13 \\
14 \\
15\end{array}$ & $\begin{array}{l}480 \\
470 \\
480 \\
480 \\
470\end{array}$ & $\begin{array}{l}\mathbf{4 4 0} \\
\mathbf{4 4 0} \\
\mathbf{4 4 0} \\
\mathbf{4 4 0} \\
\mathbf{4 3 0}\end{array}$ & $\begin{array}{l}7.5 \\
7.6 \\
7.6 \\
7.8 \\
7.6\end{array}$ & $\begin{array}{l}7.4 \\
6.9 \\
7.5 \\
7.6 \\
7.5\end{array}$ & $\begin{array}{l}6.1 \\
6.7 \\
6.8 \\
6.5 \\
6.6\end{array}$ & $\begin{array}{l}5.2 \\
5.9 \\
6.2 \\
5.8 \\
5.8\end{array}$ & $\begin{array}{l}25 \\
24 \\
23 \\
24 \\
24\end{array}$ & $\begin{array}{l}22 \\
20 \\
20 \\
22 \\
22\end{array}$ \\
\hline $\begin{array}{l}16 \\
17 \\
18 \\
19 \\
20\end{array}$ & $\begin{array}{l}480 \\
490 \\
460 \\
460 \\
460\end{array}$ & $\begin{array}{l}440 \\
440 \\
440 \\
430 \\
430\end{array}$ & $\begin{array}{l}7.6 \\
8.0 \\
8.2 \\
8.2 \\
8.1\end{array}$ & $\begin{array}{l}7.5 \\
7.6 \\
7.6 \\
7.6 \\
7.6\end{array}$ & $\begin{array}{l}6.7 \\
6.5 \\
6.2 \\
6.2 \\
6.1\end{array}$ & $\begin{array}{l}5.8 \\
5.8 \\
5.8 \\
5.5 \\
5.5\end{array}$ & $\begin{array}{l}25 \\
25 \\
25 \\
25 \\
25\end{array}$ & $\begin{array}{l}23 \\
24 \\
24 \\
24\end{array}$ \\
\hline $\begin{array}{l}21 \\
22 \\
23 \\
24 \\
25\end{array}$ & $\begin{array}{l}480 \\
460 \\
450 \\
500 \\
440\end{array}$ & $\begin{array}{l}450 \\
440 \\
440 \\
440 \\
430\end{array}$ & $\begin{array}{l}8.0 \\
8.0 \\
8.0 \\
7.9 \\
8.0\end{array}$ & $\begin{array}{l}7.6 \\
7.4 \\
7.2 \\
7.5 \\
7.4\end{array}$ & $\begin{array}{l}6.0 \\
6.0 \\
6.1 \\
6.1 \\
5.9\end{array}$ & $\begin{array}{l}5.6 \\
5.0 \\
5.3 \\
5.3 \\
5.2\end{array}$ & $\begin{array}{l}26 \\
26 \\
26 \\
26 \\
27\end{array}$ & $\begin{array}{l}25 \\
25 \\
25 \\
25 \\
26\end{array}$ \\
\hline $\begin{array}{l}26 \\
27 \\
28 \\
29 \\
30 \\
31\end{array}$ & $\begin{array}{l}460 \\
450 \\
470 \\
480 \\
460 \\
440\end{array}$ & $\begin{array}{l}430 \\
420 \\
420 \\
420 \\
420 \\
420\end{array}$ & $\begin{array}{l}7.5 \\
7.5 \\
7.5 \\
7.5 \\
7.4 \\
7.4\end{array}$ & $\begin{array}{l}7.5 \\
6.8 \\
6.9 \\
7.1 \\
7.2 \\
7.3\end{array}$ & $\begin{array}{l}6.0 \\
6.2 \\
6.6 \\
6.9 \\
6.8 \\
6.7\end{array}$ & $\begin{array}{l}5.2 \\
5.3 \\
5.9 \\
6.1 \\
6.1 \\
6.1\end{array}$ & $\begin{array}{l}27 \\
25 \\
23 \\
22 \\
22 \\
22\end{array}$ & $\begin{array}{l}25 \\
23 \\
21 \\
21 \\
21 \\
21\end{array}$ \\
\hline
\end{tabular}

\begin{tabular}{|c|c|c|c|c|c|c|c|}
\hline \multicolumn{2}{|c|}{$\begin{array}{l}\text { SPECIFIC } \\
\text { CONDUCTANCE } \\
\text { (MICROMHOS } \\
\text { AT } 25^{\circ} \mathrm{C} \text { ) }\end{array}$} & \multicolumn{2}{|c|}{$\mathrm{pH}$} & \multicolumn{2}{|c|}{$\begin{array}{l}\text { DISSOLVED } \\
\text { OXYGEN } \\
(\mathbf{M G} / L)\end{array}$} & \multicolumn{2}{|c|}{$\begin{array}{l}\text { TEMPER- } \\
\text { ATURE } \\
\left({ }^{\circ} \mathrm{C}\right)\end{array}$} \\
\hline HAX & MIN & $\operatorname{MAX}$ & MIN & $\operatorname{MAX}$ & UIN & $\max$ & MIN \\
\hline-- & 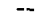 & -- & -- & -- & -- & - & -- \\
\hline-- & $-n$ & -- & -- & - & -- & $=$ & $=$ \\
\hline$=$ & $\because$ & $\overline{-}$ & $=$ & $=$ & $=$ & $=$ & $\overline{-}$ \\
\hline- & $\sim$ & -- & - & - & -- & -- & - \\
\hline -- & $-\infty$ & -- & -- & -- & -- & -- & -- \\
\hline-- & $\sim$ & -- & -- & -- & -- & -- & -- \\
\hline$=$ & $\approx$ & $=-$ & -- & $=$ & $\overline{-}$ & $\overline{-}$ & $=$ \\
\hline- & $\ldots$ & -- & -- & $=$ & -- & -- & - \\
\hline -- & - & -- & -- & - & -- & -- & - \\
\hline-- & - & - & -- & - & - & -- & - \\
\hline- & - & -- & -- & -- & - & - & - \\
\hline- & -- & -- & -- & - & -- & -- & - \\
\hline-- & $\cdots$ & - & -- & -- & -- & - & -- \\
\hline -- & - & -- & -- & -- & -- & -- & -- \\
\hline -- & -- & 7.2 & 6.8 & 6.3 & 5.2 & -- & -- \\
\hline-- & -- & 7.2 & 6.8 & 5.9 & 5.1 & -- & - \\
\hline-- & -- & 7.9 & 6.7 & 5.7 & 4.6 & -- & \\
\hline-- & -- & 6.8 & 6.6 & 5.5 & 4.4 & -- & - \\
\hline- & -- & - & - & - & - & -- & -- \\
\hline$\cdots$ & -- & - & - & - & -- & - & \\
\hline-- & -- & - & -- & -- & -- & -- & \\
\hline-- & -- & $-\infty$ & - & -- & 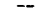 & -- & \\
\hline -- & -- & - & -- & - & -- & -- & -- \\
\hline -- & -- & -- & -- & - & - & -- & 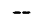 \\
\hline & 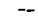 & 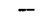 & & & & - & \\
\hline$\overline{0}$ & $=-$ & -- & -- & - & $\overline{0}$ & $\overline{24}$ & \\
\hline 430 & 420 & 7.6 & 6.9 & 7.0 & 6.0 & 24 & \\
\hline $\begin{array}{l}450 \\
450\end{array}$ & $\begin{array}{l}410 \\
410\end{array}$ & $\begin{array}{l}7.7 \\
7.8\end{array}$ & $\begin{array}{l}7.5 \\
7.6\end{array}$ & $\begin{array}{l}7.2 \\
7.3\end{array}$ & $\begin{array}{l}6.2 \\
6.3\end{array}$ & $\begin{array}{l}24 \\
23\end{array}$ & 22 \\
\hline
\end{tabular}

SEPTEMBER

\begin{tabular}{|c|c|c|c|c|c|c|c|}
\hline $\begin{array}{r}\text { SPE } \\
\text { COND } \\
\text { (MIC } \\
\text { AT }\end{array}$ & $\begin{array}{l}\text { C } \\
\text { NCE } \\
\text { OS } \\
\text { C) }\end{array}$ & & & $\begin{array}{c}\text { DIS } \\
\text { OX } \\
(\mathbf{K}\end{array}$ & $\begin{array}{l}\text { LVED } \\
\text { EN) }\end{array}$ & $\begin{array}{l}\text { TEMP } \\
{ }^{\circ} \mathrm{C}\end{array}$ & $\begin{array}{l}\text { PER- } \\
\text { JRE } \\
\text { C) }\end{array}$ \\
\hline $\max$ & MIN & $\operatorname{MAX}$ & UIN & $\max$ & MIN & $\max$ & MII \\
\hline $\begin{array}{l}430 \\
420 \\
420 \\
430 \\
430\end{array}$ & $\begin{array}{l}410 \\
410 \\
420 \\
420 \\
410\end{array}$ & $\begin{array}{l}7.4 \\
7.8 \\
7.9 \\
7.8 \\
7.7\end{array}$ & $\begin{array}{r}7.3 \\
7.3 \\
7.3 \\
7.2 \\
7.4\end{array}$ & $\begin{array}{l}6.6 \\
6.4 \\
6.5 \\
6.8 \\
6.4\end{array}$ & $\begin{array}{l}6.0 \\
6.0 \\
5.8 \\
6.0 \\
6.0\end{array}$ & $\begin{array}{l}22 \\
22 \\
22 \\
22 \\
23\end{array}$ & $\begin{array}{l}21 \\
21 \\
21 \\
21 \\
22\end{array}$ \\
\hline $\begin{array}{l}440 \\
430 \\
440 \\
440 \\
440\end{array}$ & $\begin{array}{l}420 \\
420 \\
420 \\
430 \\
430\end{array}$ & $\begin{array}{l}7.8 \\
7.7 \\
7.6 \\
7.2 \\
8.1\end{array}$ & $\begin{array}{l}7.2 \\
7.0 \\
7.0 \\
7.1 \\
7.2\end{array}$ & $\begin{array}{l}6.2 \\
6.0 \\
6.4 \\
6.4 \\
6.2\end{array}$ & $\begin{array}{l}5.7 \\
5.8 \\
5.9 \\
5.8 \\
5.9\end{array}$ & $\begin{array}{l}23 \\
23 \\
22 \\
22 \\
22\end{array}$ & $\begin{array}{l}22 \\
21 \\
21 \\
21 \\
21\end{array}$ \\
\hline $\begin{array}{l}440 \\
430 \\
430 \\
440 \\
440\end{array}$ & $\begin{array}{l}430 \\
420 \\
420 \\
430 \\
420\end{array}$ & $\begin{array}{l}-- \\
7.4 \\
7.2 \\
7.3 \\
7.4\end{array}$ & $\begin{array}{l}7 . \overline{1} \\
7.0 \\
6.9 \\
6.9\end{array}$ & $\begin{array}{l}6.3 \\
6.8 \\
6.4 \\
6.4 \\
6.5\end{array}$ & $\begin{array}{l}6.0 \\
6.1 \\
6.1 \\
6.2 \\
6.1\end{array}$ & $\begin{array}{l}22 \\
21 \\
21 \\
21 \\
22\end{array}$ & $\begin{array}{l}21 \\
20 \\
19 \\
19 \\
20\end{array}$ \\
\hline $\begin{array}{l}420 \\
420 \\
430 \\
440 \\
430\end{array}$ & $\begin{array}{l}410 \\
420 \\
420 \\
420 \\
420\end{array}$ & $\begin{array}{l}7.0 \\
7.1 \\
7.9 \\
8.2 \\
7.5\end{array}$ & $\begin{array}{l}6.8 \\
6.8 \\
6.8 \\
7.3 \\
6.8\end{array}$ & $\begin{array}{l}6.3 \\
6.3 \\
6.2 \\
6.2 \\
6.2\end{array}$ & $\begin{array}{l}6.0 \\
5.9 \\
5.9 \\
5.9 \\
5.9\end{array}$ & $\begin{array}{l}22 \\
22 \\
22 \\
22 \\
22\end{array}$ & $\begin{array}{l}20 \\
21 \\
21 \\
22 \\
21\end{array}$ \\
\hline $\begin{array}{l}430 \\
430 \\
430 \\
420 \\
430\end{array}$ & $\begin{array}{l}410 \\
420 \\
410 \\
410 \\
420\end{array}$ & $\begin{array}{r}7.7 \\
7.5 \\
=- \\
--\end{array}$ & $\begin{array}{r}6.8 \\
7.1 \\
-- \\
-- \\
--\end{array}$ & $\begin{array}{l}6.4 \\
6.2 \\
6.7 \\
6.4 \\
6.4\end{array}$ & $\begin{array}{l}5.9 \\
5.9 \\
5.8 \\
5.7 \\
6.0\end{array}$ & $\begin{array}{l}22 \\
23 \\
23 \\
23 \\
22\end{array}$ & $\begin{array}{l}21 \\
21 \\
22 \\
22 \\
21\end{array}$ \\
\hline $\begin{array}{l}\mathbf{4 2 0} \\
\mathbf{4 2 0} \\
\mathbf{4 2 0} \\
\mathbf{4 2 0} \\
\mathbf{4 2 0}\end{array}$ & $\begin{array}{l}410 \\
410 \\
410 \\
410 \\
410\end{array}$ & $\begin{array}{l}=- \\
=- \\
-- \\
--\end{array}$ & $\begin{array}{l}-- \\
=- \\
--\end{array}$ & $\begin{array}{l}6.2 \\
6.3 \\
6.4 \\
6.4 \\
6.6\end{array}$ & $\begin{array}{l}5.8 \\
6.0 \\
6.2 \\
6.3 \\
6.3\end{array}$ & $\begin{array}{l}22 \\
21 \\
20 \\
19 \\
19\end{array}$ & $\begin{array}{l}21 \\
19 \\
18 \\
18 \\
18\end{array}$ \\
\hline-- & & & & -- & -- & $\cdots$ & \\
\hline
\end{tabular}


03099510 MAHONING RIVER AT OHIO-PENNSYLVANIA STATE LINE, BELOW LOWELLVILLE, OHIO

LOCATION.--Lat $41^{\circ} 01^{\prime} 53^{\prime \prime}$, long $80^{\circ} 31^{\prime} 10^{\prime \prime}$, Mahoning County, on left bank 800 ft upstream from ohio-Pennsylvania State ine just below Loweilville, 0.9 mile downstream from gaging station at Lowellville and 4 miles downstream from Yellow Creek.

DRAINAGE AREA. $--1,075 \mathrm{sq} \mathrm{mi}$.

PERIOD OF RECORD.--Chemtcal analyses: January 1967 to September 1968.

Water temperatures: January 1967 to September 1968.

EXTREMES, --1967-68:

Water temperatures: Maximum, $36,0^{\circ} \mathrm{C}$ on several days during July and August; minimum, $6.0^{\circ} \mathrm{C} \mathrm{DeC} .27$.

period of record:

Water temperatures: Maximum, $36.0^{\circ} \mathrm{C}$ on several days during July and August $1968 ;$ minimum, 4. $0^{\circ} \mathrm{C}$ Feb. 3,4

REMARKS. - In addition to the recorder, samples were collected by a local observer on an approximate twice-weekly basis. Partial analyses were made on the maximum specific conductance and the minimum specific conductance of the samples collected each month. Interruptions in the record were due to malfunctions of
Records of discharge are given for Mahoning River at Lowellville (drainage area 1,073 sq mi).

CHEMICAL ANALYSES IN MILLIGRAMS PER LITER, WATER YEAR OCTOBER 1967 TO SEPTEMBER 1968

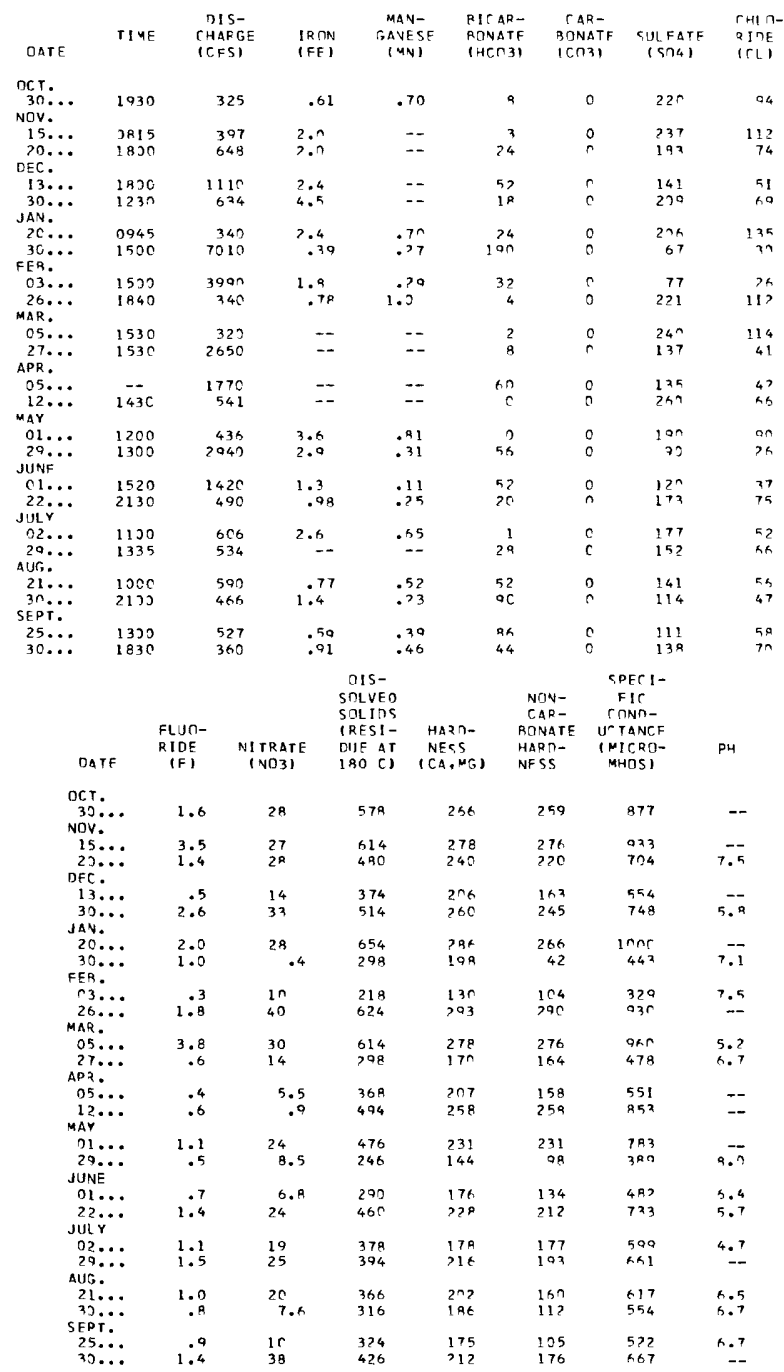


03099510 MAHONING RIVER AT OHIO-PENNSYLVANIA STATE LINE, BELOW LOWELLVILLE, OHIO--Continued SPECIFIC CONDUCTANCE, PH, DISSOLVED OXYGEN, AND WATER TEMPERATURES, WATER YEAR OCTOBER 1967 TO SEPTEMBER 1968 OCTOBER

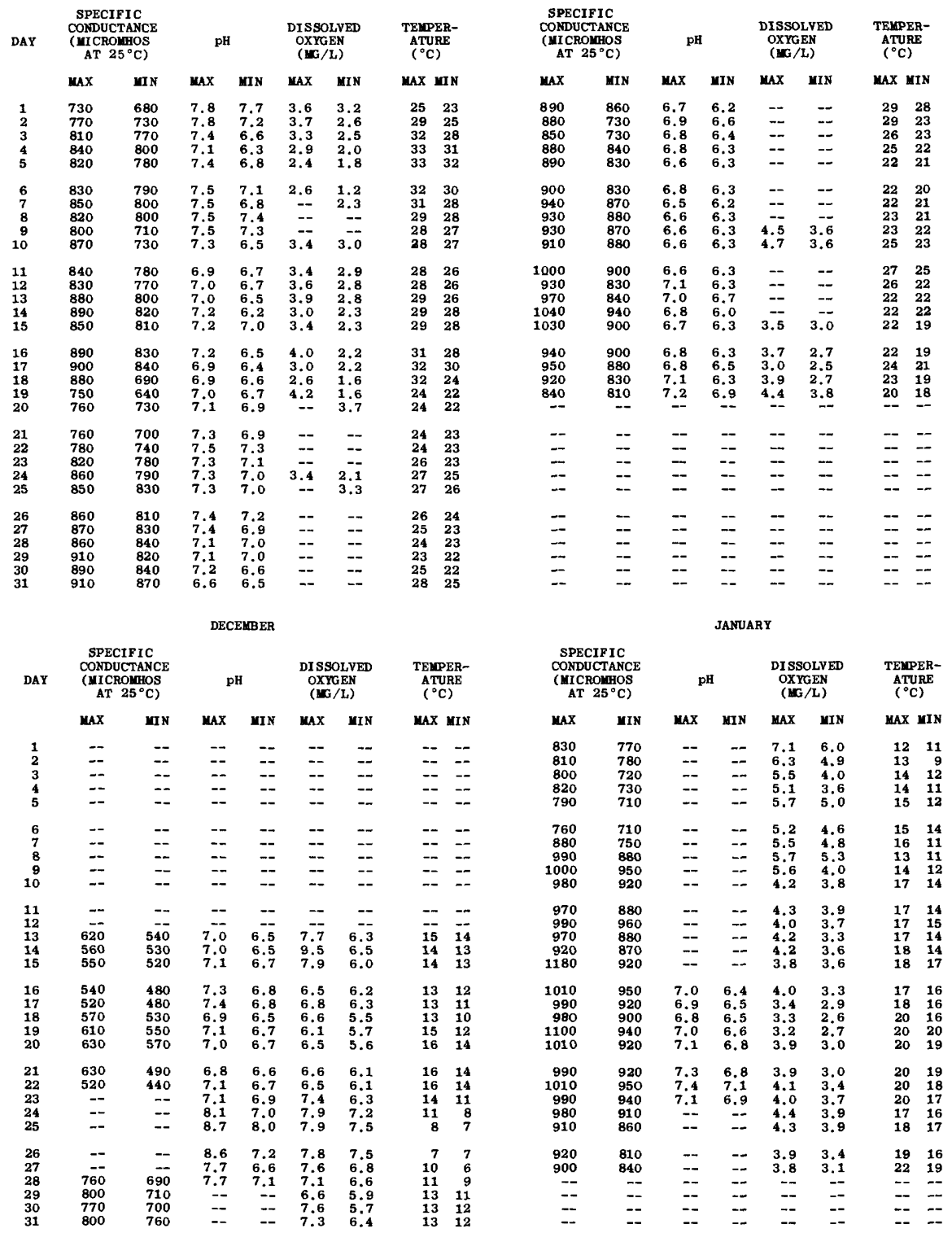


03099510 MAHONING RIVER AT OHIO-PENNSYLVANIA STATE LINE, BELOW LONELLVILLE, OHIO--Continued

SPECIFIC CONDUCTANCE, pH, DISSOLVED OXYGEN, AND WATER TEMPERATURES, WATER YEAR OCTOBER 1967 TO SEPTEMBER 1968 FEBRUARY

MARCH

\begin{tabular}{|c|c|c|c|c|c|c|c|c|}
\hline \multirow[t]{2}{*}{ DAY } & $\begin{array}{l}\text { sp } \\
\text { Comp } \\
\text { (MID } \\
\text { A? }\end{array}$ & $\begin{array}{l}\text { IC } \\
\text { aNCE } \\
\text { Bos } \\
{ }^{\circ} \text { C) }\end{array}$ & \multicolumn{2}{|c|}{ pH } & \multicolumn{2}{|c|}{$\begin{array}{l}\text { DISSOLVED } \\
\text { OXYGEN } \\
(\mathbf{M G} / \mathrm{L})\end{array}$} & \multicolumn{2}{|c|}{$\begin{array}{c}\text { TEMPER- } \\
\text { ATURE } \\
\left({ }^{\circ} \mathrm{C}\right)\end{array}$} \\
\hline & $\max$ & MIN & $\max$ & WIN & $\max$ & UIN & MaX & uin \\
\hline 1 & -- & - & - & -- & -- & -- & -- & -- \\
\hline 2 & -- & -- & - & -. & -- & $\cdots$ & $\cdots$ & - \\
\hline 3 & -- & -- & - & -- & -- & -- & - & - \\
\hline 4 & -- & -- & -- & -- & -- & - & -- & - \\
\hline 5 & -- & - & -- & -- & -- & - & - & -- \\
\hline 6 & -- & -- & -- & -- & -- & -. & - & - \\
\hline 7 & -- & -- & -- & -- & -- & - & -- & - \\
\hline 8 & -- & -- & $\cdots$ & -- & -- & -- & -- & -- \\
\hline 9 & -- & -- & -- & -- & -- & -- & -- & - \\
\hline 10 & -- & -- & - & -- & - & - & - & -- \\
\hline 11 & -- & - & - & - & -- & - & -- & -- \\
\hline 12 & - & - & -- & -- & -- & - & -- & -- \\
\hline 13 & $\cdots$ & $\cdots$ & -- & -- & -- & $\sim$ & -- & \\
\hline 14 & -- & -- & -- & -- & -- & - & -- & - \\
\hline 15 & $\cdots$ & -- & -- & -- & -- & -- & -- & \\
\hline 16 & -- & -- & -- & -- & -- & - & -- & - \\
\hline 17 & -- & $=-$ & -- & -- & -- & $=$ & $=$ & - \\
\hline 18 & - & -- & - & -- & -. & - & -- & -- \\
\hline 19 & 840 & 820 & 7.2 & 6.7 & 5.1 & 4.8 & 16 & 16 \\
\hline 20 & 850 & 790 & 7.0 & 6.6 & 5.5 & 4.8 & 17 & \\
\hline 21 & 970 & 840 & 7.0 & 6.5 & 5.6 & 5.0 & 16 & \\
\hline 22 & 880 & 830 & 7.2 & 6.7 & 5.5 & 4.7 & 16 & 14 \\
\hline 23 & 880 & 810 & 7.2 & 6.6 & 5.3 & 4.5 & 18 & 16 \\
\hline 24 & 990 & 820 & 7.0 & 6.4 & 5.1 & 4.6 & 19 & 18 \\
\hline 25 & 890 & 850 & 7.4 & 6.6 & 5.3 & 4.7 & 18 & 17 \\
\hline 26 & & 860 & 7.3 & 6.7 & 5.4 & 4.6 & 19 & 17 \\
\hline 27 & 990 & 880 & 6.9 & 6.2 & 4.8 & 4.3 & 20 & 18 \\
\hline 28 & 990 & 880 & 6.9 & 6.4 & 4.8 & 4.1 & 21 & 19 \\
\hline 29 & 1050 & 930 & 6.9 & 6.4 & 4.8 & 4.4 & 20 & 19 \\
\hline 30 & -- & -- & - & -- & -- & -- & -- & . \\
\hline 31 & -- & -- & -- & -- & - & -- & -- & - \\
\hline
\end{tabular}

APRIL

\begin{tabular}{|c|c|c|c|c|c|c|c|}
\hline \multicolumn{2}{|c|}{$\begin{array}{l}\text { CONDUCTASCE } \\
\text { (YICROMHOS } \\
\text { AT } 25^{\circ} \mathrm{C} \text { ) }\end{array}$} & \multicolumn{2}{|c|}{ pH } & \multicolumn{2}{|c|}{$\begin{array}{l}\text { DISSOLVED } \\
\text { OXYGEN } \\
(\operatorname{MG} / L)\end{array}$} & \multicolumn{2}{|c|}{$\begin{array}{l}\text { TEXPER- } \\
\text { ATURE } \\
\left({ }^{\circ} \mathrm{C}\right)\end{array}$} \\
\hline $\max$ & HIN & $\sin x$ & MIN & $\max$ & MIN & $\max$ & MIN \\
\hline $\begin{array}{r}1010 \\
950 \\
960 \\
970 \\
-\end{array}$ & $\begin{array}{r}930 \\
900 \\
810 \\
920 \\
--\end{array}$ & $\begin{array}{r}6.8 \\
7.4 \\
7.5 \\
7.6 \\
-.-\end{array}$ & $\begin{array}{r}6.5 \\
6.7 \\
7.1 \\
6.7 \\
-.-\end{array}$ & $\begin{array}{l}4.8 \\
4.6 \\
5.3 \\
5.0 \\
4.4\end{array}$ & $\begin{array}{l}4.5 \\
4.0 \\
4.3 \\
4.4 \\
3.7\end{array}$ & $\begin{array}{l}20 \\
19 \\
18 \\
17 \\
-.\end{array}$ & $\begin{array}{l}18 \\
18 \\
15 \\
15\end{array}$ \\
\hline -- & -- & -- & - & 4.3 & 3.6 & -- & $\ldots$ \\
\hline-- & $=$ & - & 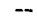 & 4.5 & 3.7 & - & - \\
\hline -- & -- & - & - & 3.9 & 3.1 & - & - \\
\hline- & - & -- & -- & 3.6 & 2.9 & -- & - \\
\hline-- & -- & -- & -- & 4.4 & 3.2 & - & - \\
\hline -- & -- & -- & - & 6.7 & 3.6 & -- & - \\
\hline-- & - & - & -- & 6.7 & 5.4 & -- & - \\
\hline-- & - & - & - & 7.0 & 5.4 & - & - \\
\hline- & - & -- & - & 7.1 & 6.7 & -- & - \\
\hline-- & - & - & $\cdots$ & 6.8 & 6.2 & -- & - \\
\hline-- & -- & - & -- & 7.7 & 5.9 & -- & -- \\
\hline$=$ & - & -- & -- & 7.7 & 2.9 & - & - \\
\hline- & - & - & - & 7.9 & 1.2 & -- & -- \\
\hline- & -- & -- & - & 7.9 & 7.3 & - & - \\
\hline-- & - & - & - & 7.4 & 7.0 & - & -- \\
\hline -- & -- & -- & -- & 7.1 & 6.8 & -- & - \\
\hline$=$ & - & - & & 7.4 & 4.6 & -- & - \\
\hline- & - & - & - & 8.1 & 7.2 & -- & - \\
\hline-- & - & - & - & 8.2 & 7.7 & -- & -- \\
\hline-- & - & -- & - & 8.5 & 7.4 & -- & - \\
\hline -- & - & -- & -- & 8.4 & 7.6 & -- & - \\
\hline 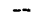 & -- & - & - & 8.0 & 7,4 & - & - \\
\hline-- & - & $=-$ & -- & 7.8 & 7.1 & - & - \\
\hline- & - & $=$ & - & - & $=$ & - & - \\
\hline-- & -- & - & - & - & -- & - & - \\
\hline- & -- & -- & -- & - & -- & -- & -- \\
\hline
\end{tabular}

D

1
1
1
1
1
1
1
1
1
1
2
2
2
2
2
2
2
2
2
2
3
3

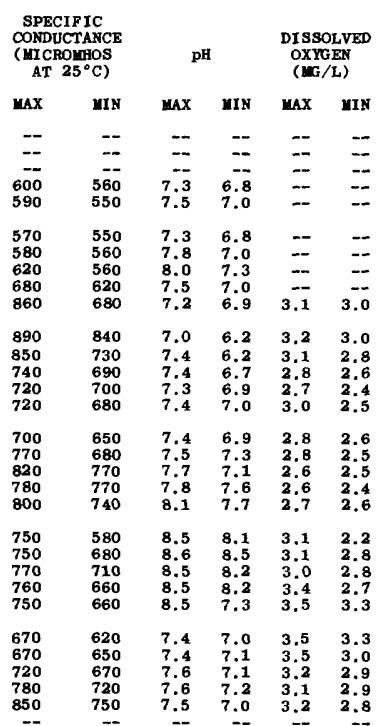

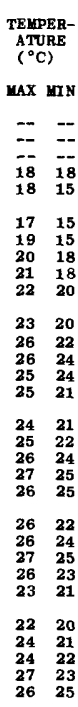

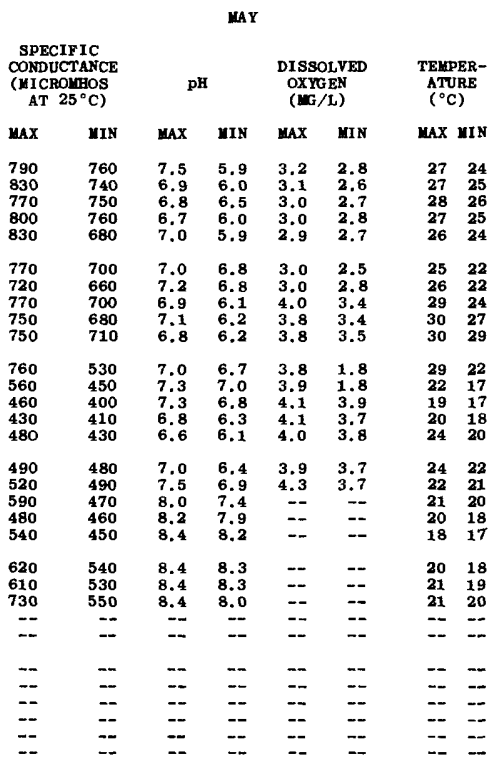


03099510 MAHONING RIVER AT OHIO-PENNSYLVANIA STATE LINE, BELOW LOWELLVILLE, OHIO --Continued SPECIFIC CONDUCTANCE, PH, DISSOLVED OXYGEN, AND WATER TEMPERATURES, WATER YEAR OCTOBER 1967 TO SEPTEMBER 1968

JUNE

\begin{tabular}{|c|c|c|c|c|}
\hline \multirow[t]{2}{*}{ DAY } & \multicolumn{2}{|c|}{$\begin{array}{l}\text { SPECIFIC } \\
\text { CONDUCTANCE } \\
\text { (MICROMHOS } \\
\text { AT } 25^{\circ} \mathrm{C} \text { ) }\end{array}$} & \multicolumn{2}{|c|}{ pH } \\
\hline & $\operatorname{MAX}$ & MIN & $\max$ & MIN \\
\hline 1 & -- & -- & -- & -- \\
\hline 2 & -- & -- & -- & -- \\
\hline 3 & -- & -- & -- & -- \\
\hline 4 & -- & -- & -- & - \\
\hline 5 & - & -- & -- & - \\
\hline 6 & 630 & 550 & 7.3 & 6.8 \\
\hline 7 & 600 & 560 & 7.0 & 6.5 \\
\hline 8 & 600 & 550 & 6.6 & 6.3 \\
\hline 9 & 600 & 540 & 7.0 & 6.1 \\
\hline 10 & 630 & 540 & 7.3 & 6.2 \\
\hline 11 & 590 & 570 & 7.1 & 6.3 \\
\hline 12 & 650 & 580 & 6.8 & 5.8 \\
\hline 13 & 700 & 650 & 7.0 & 6.3 \\
\hline 14 & 760 & 660 & -- & - \\
\hline 15 & 730 & 660 & -- & -- \\
\hline 16 & 720 & 640 & -- & -- \\
\hline 17 & 680 & 630 & -- & -- \\
\hline 18 & 640 & 600 & -- & - \\
\hline 19 & 690 & 620 & -- & -- \\
\hline 20 & 740 & 670 & -- & -- \\
\hline 21 & 750 & 700 & -- & -- \\
\hline 22 & 740 & 700 & -- & - \\
\hline 23 & 740 & 670 & - & -- \\
\hline 24 & 710 & 660 & -- & -- \\
\hline 25 & 710 & 650 & $-n$ & -- \\
\hline 26 & 670 & 600 & -- & -- \\
\hline 27 & 640 & 580 & - & -- \\
\hline 28 & 600 & 570 & -- & $\cdots$ \\
\hline 29 & 600 & 560 & -- & -- \\
\hline $\begin{array}{l}30 \\
31\end{array}$ & 600 & 590 & $\overline{-}$ & $=$ \\
\hline & & & - & \\
\hline
\end{tabular}

JLY

\begin{tabular}{|c|c|c|c|c|c|c|c|}
\hline \multicolumn{2}{|c|}{$\begin{array}{l}\text { CONDUCTANCE } \\
\text { (1MICROLHOS } \\
\text { AT } 25^{\circ} \mathrm{C} \text { ) }\end{array}$} & \multicolumn{2}{|c|}{$\mathrm{pH}$} & \multicolumn{2}{|c|}{$\begin{array}{l}\text { DISSOLVED } \\
\text { OXYGEN } \\
(\mathbf{M G} / \mathrm{L})\end{array}$} & \multicolumn{2}{|c|}{$\begin{array}{l}\text { TEMPER- } \\
\text { ATURE } \\
\left({ }^{\circ} \mathrm{C}\right)\end{array}$} \\
\hline MAX & MIN & $\max$ & MIN & MAX & MIN & MAX & MIN \\
\hline 630 & 600 & - & -- & - & -- & 35 & 32 \\
\hline 630 & 600 & -- & - & - & & 33 & 30 \\
\hline 650 & 610 & - & - & $=$ & -- & 33 & 32 \\
\hline 700 & 640 & -- & -- & -- & -- & 34 & 31 \\
\hline 720 & 640 & -- & - & -- & -- & 34 & 31 \\
\hline 670 & 630 & 7.2 & 6.5 & -- & -- & 33 & 28 \\
\hline 670 & 630 & 7.4 & 6.9 & -- & - & 32 & 29 \\
\hline 660 & 630 & 7.2 & 6.7 & - & -- & 34 & 30 \\
\hline 650 & 620 & 7.2 & 6.5 & -- & -- & 35 & 33 \\
\hline 690 & 630 & 7.0 & 6.4 & -- & -- & 36 & 34 \\
\hline 690 & 640 & 7.1 & 5.1 & -- & -- & 36 & 34 \\
\hline 680 & 640 & 6.9 & 6.1 & -- & -- & 36 & 35 \\
\hline 680 & 630 & 7.1 & 5.8 & -- & - & 36 & 34 \\
\hline 650 & 590 & 7.5 & 7.1 & -- & -- & 35 & 33 \\
\hline 630 & 610 & 7.4 & 7.1 & - & - & 35 & 33 \\
\hline 610 & 570 & 7.4 & 6.6 & -- & -- & 35 & 34 \\
\hline 650 & 590 & 7.3 & 5.9 & 2.3 & 2.0 & 36 & 33 \\
\hline 620 & 590 & 6.6 & 6.0 & 2.3 & 1.7 & 36 & 34 \\
\hline 650 & 590 & 6.6 & 5.9 & 2.2 & 1.6 & 35 & 33 \\
\hline 620 & 590 & 7.0 & 6.5 & 2.4 & 1.9 & 35 & 33 \\
\hline 640 & 580 & 7.3 & 6.8 & 2.5 & 1.6 & 34 & 32 \\
\hline 660 & 600 & 7.2 & 6.3 & 1.9 & 1.2 & 34 & 32 \\
\hline 650 & 600 & 6.8 & 6.3 & 1.4 & 1.1 & 36 & 33 \\
\hline 650 & 570 & 6.7 & 6.3 & 1.2 & .9 & 36 & 35 \\
\hline 700 & 570 & 6.9 & 6.4 & .9 & .6 & 35 & 34 \\
\hline 700 & 610 & 7.0 & 6.2 & 1.0 & 7 & 36 & 33 \\
\hline 680 & 610 & 6.9 & 6.4 & 1.9 & .8 & 36 & 34 \\
\hline $\begin{array}{l}690 \\
680\end{array}$ & 630 & 7.2 & 6. & 1.8 & 1. & 35 & 33 \\
\hline 680 & 640 & 7.5 & 6.6 & 1.8 & 1.4 & 33 & 31 \\
\hline 040 & 600 & 7.6 & 7.0 & 1.8 & .8 & 32 & 31 \\
\hline 650 & 600 & 7.3 & 6.7 & 1.8 & 1.2 & 33 & 32 \\
\hline
\end{tabular}

AugUST

\begin{tabular}{|c|c|c|c|c|c|c|c|c|}
\hline \multirow[t]{2}{*}{ DAY } & \multicolumn{2}{|c|}{$\begin{array}{l}\text { SPECIFIC } \\
\text { CONDUCTANCE } \\
\text { (MICROMHOS } \\
\text { AT } 25^{\circ} \mathrm{C} \text { ) }\end{array}$} & \multicolumn{2}{|c|}{ pH } & \multicolumn{2}{|c|}{$\begin{array}{l}\text { DI SSOLVED } \\
\text { OXYG EN } \\
(M G / L)\end{array}$} & \multicolumn{2}{|c|}{$\begin{array}{l}\text { TEMPER- } \\
\text { ATURE } \\
\left({ }^{\circ} \mathrm{C}\right)\end{array}$} \\
\hline & MAX & MIN & $\operatorname{Max}$ & MIN & MAX & MIN & MAX & MIN \\
\hline $\begin{array}{l}1 \\
2 \\
3 \\
4 \\
5\end{array}$ & $\begin{array}{l}620 \\
640 \\
620 \\
630 \\
660\end{array}$ & $\begin{array}{l}\mathbf{5 6 0} \\
\mathbf{5 7 0} \\
560 \\
\mathbf{5 9 0} \\
570\end{array}$ & $\begin{array}{l}=- \\
-- \\
=\end{array}$ & $\begin{array}{l}-- \\
-- \\
--\end{array}$ & $\begin{array}{l}2.0 \\
2.1 \\
1.6 \\
1.7 \\
1.6\end{array}$ & $\begin{array}{r}.8 \\
1.6 \\
1.1 \\
1.2 \\
1.1\end{array}$ & $\begin{array}{l}32 \\
32 \\
32 \\
33 \\
32\end{array}$ & $\begin{array}{l}30 \\
29 \\
31 \\
31 \\
31\end{array}$ \\
\hline $\begin{array}{r}6 \\
7 \\
8 \\
9 \\
10\end{array}$ & $\begin{array}{l}580 \\
580 \\
590 \\
570 \\
620\end{array}$ & $\begin{array}{l}550 \\
430 \\
540 \\
540 \\
570\end{array}$ & $\begin{array}{l}= \\
=- \\
=\end{array}$ & $\begin{array}{l}=- \\
=- \\
--\end{array}$ & $\begin{array}{l}1.1 \\
1.4 \\
1.7 \\
3.5 \\
3.4\end{array}$ & $\begin{array}{r}.7 \\
.5 \\
1.2 \\
1.2 \\
1.6\end{array}$ & $\begin{array}{l}33 \\
33 \\
33 \\
34 \\
34\end{array}$ & $\begin{array}{l}31 \\
29 \\
31 \\
32 \\
31\end{array}$ \\
\hline $\begin{array}{l}11 \\
12 \\
13 \\
14 \\
15\end{array}$ & $\begin{array}{l}650 \\
650 \\
620 \\
630 \\
650\end{array}$ & $\begin{array}{l}610 \\
600 \\
580 \\
590 \\
620\end{array}$ & $\begin{array}{l}=- \\
=- \\
=-\end{array}$ & $\begin{array}{l}-- \\
-- \\
--\end{array}$ & $\begin{array}{l}4.6 \\
5.1 \\
4.1 \\
4.0 \\
3.8\end{array}$ & $\begin{array}{l}3.1 \\
3.2 \\
2.4 \\
2.2 \\
1.8\end{array}$ & $\begin{array}{l}32 \\
32 \\
33 \\
34 \\
34\end{array}$ & $\begin{array}{l}31 \\
30 \\
30 \\
30 \\
32\end{array}$ \\
\hline $\begin{array}{l}16 \\
17 \\
18 \\
19 \\
20\end{array}$ & $\begin{array}{l}650 \\
600 \\
610 \\
610 \\
650\end{array}$ & $\begin{array}{l}570 \\
530 \\
570 \\
570 \\
560\end{array}$ & $\begin{array}{l}-- \\
-- \\
-- \\
--\end{array}$ & $\begin{array}{l}=- \\
=- \\
--\end{array}$ & $\begin{array}{l}3.0 \\
3.6 \\
4.1 \\
3.8 \\
3.7\end{array}$ & $\begin{array}{l}1.3 \\
1.4 \\
2.0 \\
2.2 \\
1.4\end{array}$ & $\begin{array}{l}34 \\
34 \\
33 \\
33 \\
34\end{array}$ & $\begin{array}{l}33 \\
32 \\
31 \\
31 \\
32\end{array}$ \\
\hline $\begin{array}{l}21 \\
22 \\
23 \\
24 \\
25\end{array}$ & $\begin{array}{l}620 \\
620 \\
640 \\
640 \\
610\end{array}$ & $\begin{array}{l}590 \\
580 \\
600 \\
590 \\
580\end{array}$ & $\begin{array}{r}-- \\
-- \\
7.1 \\
7.3\end{array}$ & $\begin{array}{r}-- \\
\overline{-} \\
6.9 \\
7.1\end{array}$ & $\begin{array}{l}3.0 \\
2.7 \\
2.5 \\
2.5 \\
3.0\end{array}$ & $\begin{array}{l}2.1 \\
1.7 \\
1.4 \\
1.0 \\
1.5\end{array}$ & $\begin{array}{l}36 \\
36 \\
36 \\
36 \\
35\end{array}$ & $\begin{array}{l}33 \\
\mathbf{3 4} \\
\mathbf{3 4} \\
\mathbf{3 5} \\
\mathbf{3 3}\end{array}$ \\
\hline $\begin{array}{l}26 \\
27 \\
28 \\
29 \\
30 \\
31\end{array}$ & $\begin{array}{l}640 \\
640 \\
640 \\
640 \\
610 \\
620\end{array}$ & $\begin{array}{l}600 \\
590 \\
580 \\
590 \\
560 \\
580\end{array}$ & $\begin{array}{r}7.2 \\
7.1 \\
7.1 \\
7.1 \\
7.1 \\
--\end{array}$ & $\begin{array}{r}7.0 \\
6.7 \\
6.6 \\
6.9 \\
6.0 \\
--\end{array}$ & $\begin{array}{l}3.6 \\
2.9 \\
2.9 \\
2.5 \\
2.3 \\
2.4\end{array}$ & $\begin{array}{l}2.1 \\
2.1 \\
1.8 \\
2.0 \\
1.3 \\
1.5\end{array}$ & $\begin{array}{l}33 \\
32 \\
32 \\
31 \\
32 \\
32\end{array}$ & $\begin{array}{l}31 \\
29 \\
29 \\
29 \\
29 \\
30\end{array}$ \\
\hline
\end{tabular}

SEPTEMBER

\begin{tabular}{|c|c|c|c|c|c|c|c|}
\hline \multicolumn{2}{|c|}{$\begin{array}{l}\text { SPECIFIC } \\
\text { CONDUCTANCE } \\
\text { (MI CROMHOS } \\
\text { AT } 25^{\circ} \mathrm{C} \text { ) }\end{array}$} & \multicolumn{2}{|c|}{ pH } & \multicolumn{2}{|c|}{$\begin{array}{l}\text { DISSOLVED } \\
\text { OXYGEN } \\
(\text { WG } / \mathrm{L})\end{array}$} & \multicolumn{2}{|c|}{$\begin{array}{l}\text { TEMPER- } \\
\text { ATURE } \\
\left({ }^{\circ} \mathrm{C}\right)\end{array}$} \\
\hline MAX & HIN & $\operatorname{MAX}$ & MIN & $\operatorname{MAX}$ & MIN & $\operatorname{MAX}$ & MIN \\
\hline 630 & 580 & -- & -- & - & $=$ & 31 & 29 \\
\hline 600 & 540 & -- & -- & -- & -- & 29 & 27 \\
\hline 570 & 540 & -- & -- & 1.9 & 1.0 & 29 & 27 \\
\hline 580 & 520 & -- & -- & -- & -- & 30 & 27 \\
\hline 600 & 470 & $=$ & -- & -- & - & 30 & 27 \\
\hline 550 & 480 & -- & -- & 2.5 & 1.6 & 29 & 27 \\
\hline 580 & 520 & 7.1 & 6.5 & 2.1 & 1.2 & 29 & 28 \\
\hline 580 & 540 & 7.4 & 7.1 & 1.7 & 1.0 & 29 & 27 \\
\hline 610 & 570 & 7.4 & 7.0 & - & -- & 30 & 28 \\
\hline 630 & 610 & 7.1 & 6.6 & - & - & 30 & 29 \\
\hline 710 & 600 & 7.4 & 6.8 & -- & -- & 30 & 29 \\
\hline 660 & 620 & 7.4 & 6.7 & -- & -- & 31 & 29 \\
\hline 680 & 630 & 7.4 & 7.0 & -- & - & 31 & 29 \\
\hline 660 & 620 & 7.5 & 7.1 & -- & -- & 31 & 29 \\
\hline 630 & 560 & 7.4 & 7.0 & -. & - & 32 & 29 \\
\hline 640 & 590 & 7.4 & 6.9 & -- & -- & 31 & 29 \\
\hline 650 & 630 & 7.3 & 6.8 & -- & -- & 31 & 29 \\
\hline 660 & 620 & 7.4 & 6.9 & - & -- & 31 & 28 \\
\hline 700 & 630 & 7.2 & 6.5 & - & - & 31 & 30 \\
\hline 680 & 650 & 7.2 & 6.6 & -- & 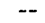 & 32 & 29 \\
\hline 680 & 640 & 7.2 & 6.7 & -- & -- & 33 & 30 \\
\hline 660 & 620 & 7.4 & 6.9 & -- & - & 32 & 30 \\
\hline 660 & 600 & 7.4 & 6.7 & -- & -- & 32 & 30 \\
\hline 610 & 570 & 7.1 & 6.2 & - & -- & 32 & 29 \\
\hline 620 & 530 & 7.1 & 6.1 & 4.3 & 2.2 & 31 & 29 \\
\hline 650 & 590 & 6.7 & 6.1 & 4.5 & 2.1 & 30 & 29 \\
\hline 670 & 600 & 6.8 & 6.5 & 4.1 & 2.8 & 30 & 28 \\
\hline 650 & 620 & 6.8 & 6.6 & 4.4 & 2.9 & 29 & 28 \\
\hline 660 & 620 & 7.0 & 6.8 & 4.4 & 3.0 & 28 & 27 \\
\hline 690 & 620 & 6.9 & 6.7 & 4.5 & 2.4 & 29 & 27 \\
\hline- & & - & . & - & - & $\sim$ & - \\
\hline
\end{tabular}


03110700 OHIO RIVER AT STRATTON, OHIO

LOCATION.--Lat $40^{\circ} 31^{\prime} 57^{\prime \prime}$, Iong $80^{\circ} 37^{\prime} 30^{\prime \prime}$, Jefferson County, at Ohio River Valley Fater Sanitation Commission (ORSANCO) monitor, at W. H. Sammis Piant of the Ohio Edison Co. at Stratton.

DRAINAGE AREA, $-23,500 \mathrm{sq} \mathrm{mi}$, approximately.

PERIOD OF RECORD. --Chemical analyses: January 1961 to June 1963 (at New Cumberland Dam), July 1963 to October 1964 (at East Liverpoo1). November 1964 to September 1968.

(at East Liverpool), November 1964 to September 1968.

Pertod of record:

Specific conductance (1961-67): Maximum daily, 844 micromhos Oct. 7, 1966; minimum daily, 150 micromhos

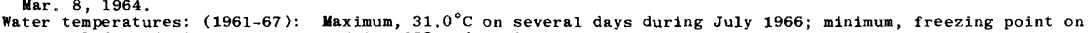
several days during winter period in 1962 and 1963 .

REMARKS. --Daily samples were collected at this station and samples were selected for analysis on the following basis: (1) Maximum daily specific conductance for each month, (2) minimum daily specific conductance for determine heavy metals. Samples for iron and manganese were fil tered clear when collected. No discharge records available.

CHEMICAL ANALYSES IN MILLIGRAMS PER LITER, WATER YEAR OCTOBER 1967 TO SEPTEMBER 1968

\begin{tabular}{|c|c|c|c|c|c|c|c|}
\hline DATE & $\begin{array}{l}\text { IRON } \\
\langle F E\rangle\end{array}$ & $\begin{array}{l}\text { MAN- } \\
\text { GANESE } \\
\text { (MN) }\end{array}$ & $\begin{array}{l}\text { BICAR- } \\
\text { BONATE } \\
\text { (HCO3) }\end{array}$ & $\begin{array}{l}\text { CAR- } \\
\text { BONATE } \\
\text { (CO3) }\end{array}$ & $\begin{array}{c}\text { SULFATE } \\
(\mathrm{SO4})\end{array}$ & $\begin{array}{l}\text { CHLO- } \\
\text { RIDE } \\
\text { (CL) }\end{array}$ & $\begin{array}{l}\text { FLUD- } \\
R I D E \\
(F)\end{array}$ \\
\hline \multicolumn{8}{|l|}{ OCT. } \\
\hline $\begin{array}{l}06 \ldots \\
17 \ldots\end{array}$ & $\begin{array}{r}.47 \\
.28\end{array}$ & $\begin{array}{r}.50 \\
.50\end{array}$ & $\begin{array}{l}22 \\
28\end{array}$ & $\begin{array}{l}0 \\
0\end{array}$ & 63 & 10 & .3 \\
\hline $\begin{array}{l}11 \ldots \\
21 \ldots\end{array}$ & .12 & $\begin{array}{l}.30 \\
.92\end{array}$ & $\begin{array}{l}20 \\
1.6\end{array}$ & $\begin{array}{l}0 \\
0\end{array}$ & $\begin{array}{r}76 \\
140\end{array}$ & $\begin{array}{l}20 \\
24\end{array}$ & .3 \\
\hline \multicolumn{8}{|l|}{ NOV. } \\
\hline $01 \ldots$ & .33 & .46 & 20 & 0 & 88 & 16 & 1 \\
\hline $10 \ldots$ & .29 & .30 & 26 & 0 & 92 & 19 & .1 \\
\hline $27 \ldots$ & 1.5 & .45 & 18 & 0 & 81 & 16 & .1 \\
\hline \multicolumn{8}{|l|}{ DEC. } \\
\hline $22 \ldots$ & .64 & .46 & 22 & 0 & $\begin{array}{l}61 \\
69\end{array}$ & 15 & .3 \\
\hline $27 \ldots$ & .52 & .23 & 20 & 0 & 86 & 14 & .3 \\
\hline \multicolumn{8}{|l|}{ J AN. } \\
\hline $02 \ldots$ & .41 & .55 & 20 & 0 & 84 & 18 & .4 \\
\hline $10 \ldots$ & 1.1 & .50 & 14 & 0 & 104 & 18 & .3 \\
\hline $29 \ldots$ & 1.4 & .68 & 1.6 & 0 & 122 & 22 & .4 \\
\hline \multicolumn{8}{|l|}{ FEB. } \\
\hline $06 \ldots$ & .56 & .14 & $\begin{array}{l}16 \\
20\end{array}$ & 0 & $\begin{array}{l}64 \\
82\end{array}$ & $\begin{array}{l}12 \\
17\end{array}$ & $\cdot 2$ \\
\hline $\begin{array}{l}14 \ldots \\
29 . \ldots\end{array}$ & $0_{1.71}$ & $\begin{array}{r}.09 \\
.88\end{array}$ & 8 & 0 & & 17 & .2 \\
\hline \multicolumn{8}{|l|}{ MAR. } \\
\hline $02 \ldots$ & 1.1 & .57 & 10 & 0 & 126 & 22 & .2 \\
\hline $11 \ldots$ & 1.9 & .89 & 4 & 0 & 160 & 26 & .2 \\
\hline $28 \ldots$ & -- & -- & 18 & 0 & 64 & 15 & .0 \\
\hline \multicolumn{8}{|l|}{ APR. } \\
\hline $01 \ldots$ & .39 & .22 & 20 & 0 & 71 & 14 & .2 \\
\hline $16 \ldots$ & .24 & .47 & 16 & 0 & 96 & 16 & .3 \\
\hline $30 \ldots$ & . 12 & .35 & 20 & 0 & 127 & 24 & .4 \\
\hline \multicolumn{8}{|l|}{ MAY } \\
\hline $10 \ldots$ & -- & -- & 20 & 0 & 146 & 21 & .3 \\
\hline $15 . \ldots$ & .13 & .38 & 24 & 0 & 106 & 18 & .2 \\
\hline $27 \ldots$ & .16 & .38 & 17 & 0 & 72 & 8.0 & .2 \\
\hline \multicolumn{8}{|l|}{ JUNE } \\
\hline $04 \ldots$ & .13 & .12 & 9 & 0 & 98 & 9.0 & .2 \\
\hline $30 \ldots$ & .18 & .86 & 18 & 0 & 158 & 26 & .5 \\
\hline \multicolumn{8}{|l|}{ JULY } \\
\hline $09 \ldots$ & .29 & .13 & 9 & 0 & 143 & 22 & .4 \\
\hline $31 \ldots$ & .16 & .17 & 14 & 0 & 173 & 22 & .6 \\
\hline \multicolumn{8}{|l|}{ AUG. } \\
\hline $07 \ldots$ & .08 & .34 & 20 & 0 & 159 & 28 & .7 \\
\hline $10 \ldots$ & .04 & .47 & 14 & 0 & 198 & 30 & .6 \\
\hline $\begin{array}{l}22 \ldots . . \\
\text { SEPT. }\end{array}$ & .12 & 1.8 & 6 & 0 & 274 & 26 & 5 \\
\hline $13 \ldots$ & .07 & .34 & 20 & 0 & 181 & 30 & .5 \\
\hline $18 \ldots$ & .08 & .22 & 30 & 0 & 154 & 29 & .5 \\
\hline $27 \ldots$ & .05 & .25 & 26 & 0 & 185 & 30 & .5 \\
\hline
\end{tabular}

SPECIFIC CONDUCTANCE (MICROMHOS AT $25^{\circ} \mathrm{C}$ ), WATER YEAR OCTOBER 1967 TO SEPTEMBER 1968

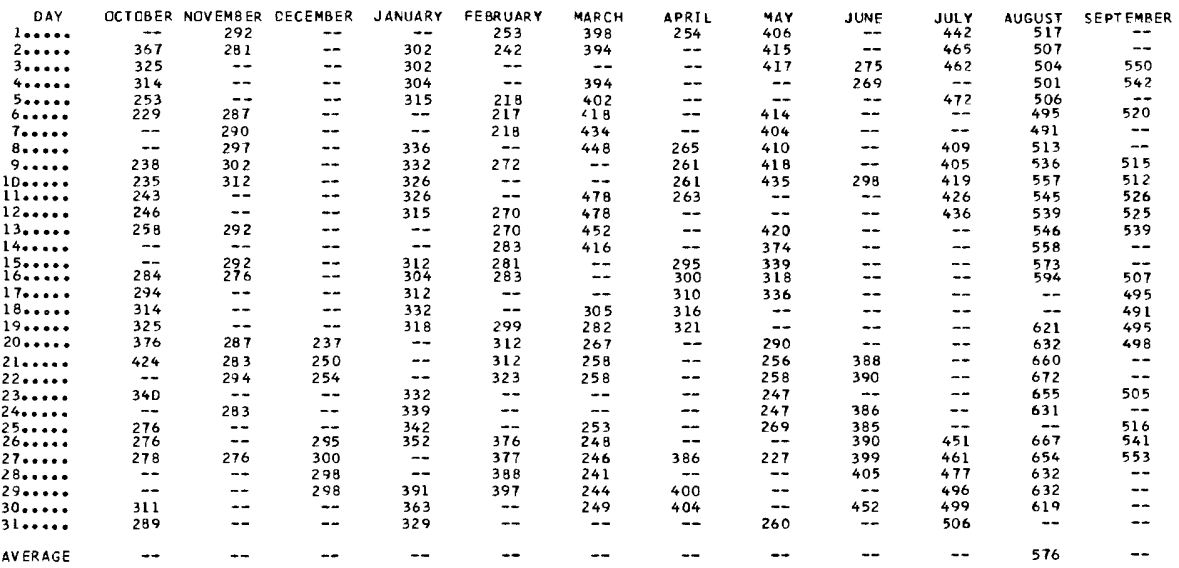


03110700 OHIO RIVER AT STRATTON, OHIO--Continued

CHEMICAL ANALYSES IN MILLIGRAMS PER LITER, WATER YEAR OCTOBER 1967 TO SEPTEMBER 1968

\begin{tabular}{|c|c|c|c|c|c|c|}
\hline DATE & $\begin{array}{c}\text { NITRATE } \\
\text { (NO3) }\end{array}$ & $\begin{array}{l}\text { TOTAL } \\
\text { PHOS- } \\
\text { PHORUS } \\
\text { (P04) }\end{array}$ & $\begin{array}{l}\text { DIS- } \\
\text { SDLVED } \\
\text { SOLIDS } \\
\text { (RESI- } \\
\text { DUE AT } \\
1 B 0^{\circ} \mathrm{C} \text { ) }\end{array}$ & $\begin{array}{l}\text { HARD- } \\
\text { NESS } \\
(C A, M G)\end{array}$ & $\begin{array}{l}\text { NON- } \\
\text { CAR- } \\
\text { BONATE } \\
\text { HARD- } \\
\text { NESS }\end{array}$ & $\begin{array}{l}\text { SPE- } \\
\text { CIFIC } \\
\text { CONDUCT- } \\
\text { ANCE } \\
\text { (MICRO- } \\
\text { MHOS) }\end{array}$ \\
\hline $\begin{array}{l}\text { OCT. } \\
06 \ldots \\
17 \ldots \\
21 \ldots\end{array}$ & $\begin{array}{l}2.0 \\
3.1 \\
3.6\end{array}$ & $\begin{array}{l}.14 \\
.11 \\
.10\end{array}$ & $\begin{array}{l}196 \\
228 \\
310\end{array}$ & $\begin{array}{r}77 \\
90 \\
134\end{array}$ & $\begin{array}{r}59 \\
67 \\
121\end{array}$ & $\begin{array}{l}229 \\
294 \\
424\end{array}$ \\
\hline $\begin{array}{l}\text { NOV. } \\
01 . . . \\
10 . . \\
27 . . \\
\text { DEC. }\end{array}$ & $\begin{array}{l}2.4 \\
1.0 \\
2.0\end{array}$ & $\begin{array}{l}.05 \\
.06 \\
.05\end{array}$ & $\begin{array}{l}186 \\
206 \\
180\end{array}$ & $\begin{array}{r}94 \\
102 \\
90\end{array}$ & $\begin{array}{l}78 \\
80 \\
75\end{array}$ & $\begin{array}{l}292 \\
312 \\
276\end{array}$ \\
\hline $\begin{array}{l}20 \ldots \\
22 \ldots \\
27 \ldots \\
\text { JAN. }\end{array}$ & $\begin{array}{l}2.5 \\
2.8 \\
3.2\end{array}$ & $\begin{array}{l}.05 \\
.10 \\
.05\end{array}$ & $\begin{array}{l}158 \\
176 \\
198\end{array}$ & $\begin{array}{r}83 \\
86 \\
102\end{array}$ & $\begin{array}{l}66 \\
68 \\
86\end{array}$ & $\begin{array}{l}237 \\
254 \\
300\end{array}$ \\
\hline $\begin{array}{l}02 \ldots \\
10 \ldots \\
29 \ldots \\
\text { FEB. }\end{array}$ & $\begin{array}{l}2.8 \\
3.0 \\
3.2\end{array}$ & $\begin{array}{l}.10 \\
.05 \\
.08\end{array}$ & $\begin{array}{l}176 \\
188 \\
220\end{array}$ & $\begin{array}{r}96 \\
106 \\
126\end{array}$ & $\begin{array}{r}80 \\
94 \\
113\end{array}$ & $\begin{array}{l}302 \\
326 \\
391\end{array}$ \\
\hline $\begin{array}{l}\text { O6... } \\
14 \ldots \\
29 \ldots \\
\text { MAR. }\end{array}$ & $\begin{array}{l}3.2 \\
2.0 \\
4.3\end{array}$ & $\begin{array}{l}.10 \\
.10 \\
.07\end{array}$ & $\begin{array}{l}136 \\
180 \\
242\end{array}$ & $\begin{array}{r}80 \\
100 \\
134\end{array}$ & $\begin{array}{r}67 \\
84 \\
128\end{array}$ & $\begin{array}{l}217 \\
283 \\
397\end{array}$ \\
\hline $\begin{array}{l}02 \ldots \\
11 \ldots \\
28 \ldots \\
\text { APR. }\end{array}$ & $\begin{array}{l}5.8 \\
6.6 \\
3.0\end{array}$ & $\begin{array}{l}.18 \\
.07 \\
.07\end{array}$ & $\begin{array}{l}264 \\
304 \\
146\end{array}$ & $\begin{array}{r}134 \\
158 \\
86\end{array}$ & $\begin{array}{r}126 \\
155 \\
71\end{array}$ & $\begin{array}{l}394 \\
478 \\
241\end{array}$ \\
\hline $\begin{array}{l}01 \ldots \\
16 \ldots \\
30 \ldots \\
\text { MAY }\end{array}$ & $\begin{array}{l}3.4 \\
4.0 \\
5.5\end{array}$ & $\begin{array}{l}.05 \\
.09 \\
.17\end{array}$ & $\begin{array}{l}172 \\
210 \\
264\end{array}$ & $\begin{array}{r}96 \\
108 \\
144\end{array}$ & $\begin{array}{r}80 \\
95 \\
128\end{array}$ & $\begin{array}{l}254 \\
300 \\
404\end{array}$ \\
\hline $\begin{array}{l}10 \ldots \\
15 \ldots \\
27 \ldots\end{array}$ & $\begin{array}{l}6.2 \\
2.8 \\
3.2\end{array}$ & $\begin{array}{l}.24 \\
.11 \\
.08\end{array}$ & $\begin{array}{l}282 \\
221 \\
146\end{array}$ & $\begin{array}{r}150 \\
121 \\
84\end{array}$ & $\begin{array}{r}134 \\
102 \\
70\end{array}$ & $\begin{array}{l}435 \\
339 \\
227\end{array}$ \\
\hline $\begin{array}{l}\text { JUNE } \\
04 \ldots\end{array}$ & 1.8 & .07 & 164 & 97 & 90 & 269 \\
\hline${ }_{\text {JULY }}^{30}$ & .8 & .08 & 272 & 170 & 155 & 452 \\
\hline $\begin{array}{l}09 \ldots \\
31 . . . \\
\text { AUG. }\end{array}$ & $\begin{array}{l}3.0 \\
7.2\end{array}$ & $\begin{array}{l}.24 \\
.19\end{array}$ & $\begin{array}{l}266 \\
346\end{array}$ & $\begin{array}{l}137 \\
167\end{array}$ & $\begin{array}{l}130 \\
156\end{array}$ & $\begin{array}{l}405 \\
506\end{array}$ \\
\hline $\begin{array}{l}07 \ldots \\
10 \ldots \\
22 \ldots \\
\text { SEPT. }\end{array}$ & $\begin{array}{l}9.0 \\
8.8 \\
6.5\end{array}$ & $\begin{array}{l}.15 \\
.15 \\
.11\end{array}$ & $\begin{array}{l}302 \\
354 \\
448\end{array}$ & $\begin{array}{l}164 \\
184 \\
221\end{array}$ & $\begin{array}{l}148 \\
173 \\
216\end{array}$ & $\begin{array}{l}491 \\
557 \\
672\end{array}$ \\
\hline $\begin{array}{l}13 \ldots \\
18 \ldots \\
27 \ldots\end{array}$ & $\begin{array}{r}10 \\
8.5 \\
8.8\end{array}$ & $\begin{array}{l}.13 \\
.19 \\
.19\end{array}$ & $\begin{array}{l}316 \\
284 \\
338\end{array}$ & $\begin{array}{l}176 \\
160 \\
160\end{array}$ & $\begin{array}{l}160 \\
136 \\
159\end{array}$ & $\begin{array}{l}539 \\
491 \\
553\end{array}$ \\
\hline
\end{tabular}

\begin{tabular}{|c|c|c|c|c|c|c|c|c|}
\hline DATE & $\begin{array}{l}\text { TOTAL } \\
\text { CHRO- } \\
\text { MIUM } \\
\text { (CR) }\end{array}$ & $\begin{array}{l}\text { NICKEL } \\
\text { (NI) }\end{array}$ & $\begin{array}{l}\text { COPPER } \\
\text { (CU) }\end{array}$ & $\begin{array}{l}\text { LEAD } \\
\text { (PB) }\end{array}$ & $\begin{array}{l}\text { ZINC } \\
\text { (ZN) }\end{array}$ & $\begin{array}{c}\text { COBALT } \\
(C O)\end{array}$ & $\begin{array}{c}\text { ARSENIC } \\
\text { (AS) }\end{array}$ & $\begin{array}{l}\text { CAD- } \\
\text { MIUM } \\
\text { (CD) }\end{array}$ \\
\hline $\begin{array}{l}\text { OCT. } \\
\text { O1-31 } \\
\text { NOV. }\end{array}$ & .00 & .00 & .01 & .00 & .05 & .00 & .00 & \\
\hline $\begin{array}{l}01-30 \\
\text { DEC. }\end{array}$ & .00 & .00 & .01 & .01 & .24 & .00 & .00 & \\
\hline $\begin{array}{l}20-29 \\
\text { JAN. }\end{array}$ & .00 & .00 & .01 & .01 & .05 & .00 & .00 & \\
\hline $\begin{array}{l}01-31 \\
F E B .\end{array}$ & .00 & .00 & .02 & .01 & .06 & .00 & .00 & \\
\hline $\begin{array}{l}01-29 \\
\text { MAR. }\end{array}$ & .00 & .01 & .02 & .01 & .06 & .00 & .00 & \\
\hline $\begin{array}{l}\text { O1-31 } \\
\text { APR. }\end{array}$ & .00 & .02 & .03 & .00 & .09 & .00 & .00 & \\
\hline MAY & .00 & .02 & .01 & .00 & .06 & .00 & .00 & \\
\hline $\begin{array}{l}\text { 01-31 } \\
\text { JUNE }\end{array}$ & .00 & .02 & .02 & .00 & .06 & .00 & .00 & \\
\hline $\begin{array}{l}01-30 \\
J U L Y\end{array}$ & .00 & .01 & .02 & .00 & .14 & .00 & .01 & 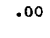 \\
\hline $\begin{array}{l}\text { 01-31 } \\
\text { AUG. }\end{array}$ & .00 & .01 & .01 & .00 & .03 & .00 & .00 & \\
\hline $\begin{array}{l}\text { OI-31 } \\
\text { SEPT. }\end{array}$ & .00 & .02 & .01 & .00 & .13 & .01 & .00 & \\
\hline $01-30$ & .00 & .01 & .01 & .01 & .05 & .00 & .01 & .0 \\
\hline
\end{tabular}


03110700 OHIO RIVER AT STRATTON, OHIO--Cont inued

TEMPERATURE $\left({ }^{\circ} \mathrm{C}\right)$ OF WATER, WATER YEAR OCTOBER 1967 TO SEPTEMBER 1968

\begin{tabular}{|c|c|c|c|c|c|c|c|c|c|c|c|c|}
\hline OAY & OCT & nOV & DEC & JAN & FEB & MAR & APR & MAY & JUN & JUL & AIJG & SEP \\
\hline $\begin{array}{l}1 \\
2 \\
3 \\
4 \\
5\end{array}$ & $\begin{array}{l}--.0 \\
18.0 \\
17.0 \\
17.0 \\
16.0\end{array}$ & $\begin{array}{r}12.0 \\
12.0 \\
-2 . \\
-\cdots \\
-\cdots\end{array}$ & 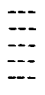 & $\begin{array}{l}--- \\
2.0 \\
2.0 \\
2.0 \\
1.0\end{array}$ & $\begin{array}{l}2.0 \\
3.0 \\
3.0\end{array}$ & $\begin{array}{l}2.0 \\
3.0 \\
-2.0 \\
3.0\end{array}$ & \begin{tabular}{r}
10.0 \\
--- \\
\hdashline- \\
$-\cdots$
\end{tabular} & $\begin{array}{r}17.0 \\
17.0 \\
18.0 \\
0-0\end{array}$ & $\begin{array}{r}17.0 \\
17.0 \\
\ldots-0\end{array}$ & $\begin{array}{c}25.0 \\
26.0 \\
26.0 \\
26.0 \\
26.0\end{array}$ & $\begin{array}{l}31.0 \\
29.0 \\
29.0 \\
29.0 \\
29.0\end{array}$ & $\begin{array}{r}-.- \\
27.0 \\
26.0 \\
-\ldots-\end{array}$ \\
\hline $\begin{array}{r}6 \\
7 \\
8 \\
9 \\
10\end{array}$ & $\begin{array}{r}14.0 \\
-2 . \\
15.0 \\
15.0\end{array}$ & \begin{tabular}{c}
11.0 \\
\hdashline-0 \\
$\cdots$ \\
$\cdots$
\end{tabular} & 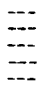 & \begin{tabular}{l}
--- \\
\hdashline 1.0 \\
1.0 \\
1.0
\end{tabular} & $\begin{array}{l}3.0 \\
3.0 \\
-3.0 \\
-0-\end{array}$ & $\begin{array}{l}4.0 \\
4.0 \\
5.0 \\
-.-0 \\
\ldots . .\end{array}$ & $\begin{array}{l}--- \\
12.0 \\
12.0 \\
12.0\end{array}$ & $\begin{array}{l}17.0 \\
18.0 \\
18.0 \\
18.0 \\
18.0\end{array}$ & \begin{tabular}{c}
-- \\
\hdashline-- \\
-0 \\
22.0
\end{tabular} & $\begin{array}{r}-.- \\
27.0 \\
27.0 \\
27.0\end{array}$ & $\begin{array}{l}29.0 \\
28.0 \\
28.0 \\
28.0 \\
28.0\end{array}$ & $\begin{array}{r}24.0 \\
-0 \\
25.0 \\
25.0\end{array}$ \\
\hline $\begin{array}{l}11 \\
12 \\
13 \\
14 \\
15\end{array}$ & $\begin{array}{r}15.0 \\
15.0 \\
14.0 \\
-\ldots\end{array}$ & $\begin{array}{l}\cdots \\
\cdots- \\
\cdots .0\end{array}$ & $\begin{array}{l}\cdots- \\
--- \\
-\cdots \\
---\end{array}$ & \begin{tabular}{l}
1.0 \\
0.0 \\
\hdashline. .0 \\
1.0
\end{tabular} & $\begin{array}{l}1.2 \\
1.0 \\
1.0 \\
1.0\end{array}$ & $\begin{array}{l}6.0 \\
7.0 \\
5.0 \\
5.0 \\
--.\end{array}$ & $\begin{array}{r}13.0 \\
0 \\
\hdashline 3.0\end{array}$ & $\begin{array}{l}12.0 \\
18.0 \\
18.0\end{array}$ & $\begin{array}{l}--- \\
-\cdots \\
--\end{array}$ & $\begin{array}{r}28.0 \\
28.0 \\
-0 \\
-\cdots\end{array}$ & $\begin{array}{l}28.0 \\
28.0 \\
28.0 \\
28.0 \\
28.0\end{array}$ & $\begin{array}{r}24.0 \\
24.0 \\
24.0 \\
-0 .\end{array}$ \\
\hline $\begin{array}{l}16 \\
17 \\
18 \\
19 \\
20\end{array}$ & $\begin{array}{l}16.0 \\
16.0 \\
15.0 \\
15.0 \\
16.0\end{array}$ & \begin{tabular}{l}
7.0 \\
\hdashline-1 \\
\hdashline 7.0
\end{tabular} & $\begin{array}{l}--- \\
--- \\
--- \\
--\end{array}$ & $\begin{array}{l}1.0 \\
2.0 \\
2.0 \\
2.0 \\
-.-\end{array}$ & \begin{tabular}{l}
1.0 \\
\hdashline-2 \\
1.0 \\
1.0
\end{tabular} & $\begin{array}{l}-.- \\
--. \\
7.0 \\
7.0 \\
7.0\end{array}$ & $\begin{array}{l}14.0 \\
14.0 \\
15.0 \\
16.0 \\
-\ldots .0\end{array}$ & $\begin{array}{r}17.0 \\
17.0 \\
16.0\end{array}$ & $\begin{array}{l}-\cdots \\
-\cdots \\
--- \\
--\end{array}$ & $\begin{array}{l}\cdots \\
\cdots- \\
\cdots \\
\cdots\end{array}$ & $\begin{array}{r}28.0 \\
=-0 \\
29.0 \\
20.0\end{array}$ & $\begin{array}{l}24.0 \\
24.0 \\
24.0 \\
24.0 \\
24.0\end{array}$ \\
\hline $\begin{array}{l}26 \\
27 \\
28 \\
29 \\
30 \\
31\end{array}$ & $\begin{array}{r}12.0 \\
12.0 \\
0.0 \\
13.0 \\
13.0\end{array}$ & $\begin{array}{l}0 .- \\
0.0 \\
--- \\
--- \\
---\end{array}$ & $\begin{array}{l}5.0 \\
5.0 \\
4.0 \\
3.0 \\
-.- \\
-.-\end{array}$ & \begin{tabular}{l}
2.0 \\
\hdashline. .0 \\
3.0 \\
3.0 \\
3.0
\end{tabular} & $\begin{array}{l}3.0 \\
3.0 \\
3.0 \\
2.0 \\
-.- \\
---\end{array}$ & $\begin{array}{r}7.0 \\
8.0 \\
8.0 \\
10.0 \\
11.0 \\
\end{array}$ & $\begin{array}{r}17.0 \\
19.0 \\
17.0 \\
-\end{array}$ & $\begin{array}{r}14.0 \\
-0 . \\
-0- \\
14.0\end{array}$ & $\begin{array}{r}24.0 \\
24.0 \\
24.0 \\
26.0 \\
-0.0\end{array}$ & $\begin{array}{l}30.0 \\
31.0 \\
29.0 \\
30.0 \\
29.0 \\
31.0\end{array}$ & $\begin{array}{l}28.0 \\
28.0 \\
28.0 \\
27.0 \\
27.0 \\
\ldots . .-\end{array}$ & $\begin{array}{r}25.0 \\
25.0 \\
\ldots- \\
\ldots \\
\ldots-\end{array}$ \\
\hline AVERAGE & -- & $\ldots$ & $\ldots$ & -- & $\ldots$ & $\begin{array}{l}\mathrm{ND} C \mathrm{C} \\
\mathrm{D} \mathrm{CRE}\end{array}$ & BASIN & --- & -- & $\ldots$ & 28.5 & -- \\
\hline
\end{tabular}

LOCATION. --Lat $39^{\circ} 28^{\circ} 30^{\prime \prime}$, long $80^{\circ} 59^{\circ} 50^{\prime \prime}$, Tyler County, at highway bridge at Little, 0.1 mile upstream from Stewarts Run, and 5.0 miles west of Hiddlebourne.

DRA INAGE AREA. --458 sq mi.

PERIOD OF RECORD.--Sediment records: April to September 1968.

PERIODIC DETERMINATIONS OF SUSPENDED-SEDIMENT DISCHARGE, APRIL TO SEPTEMBER 1968

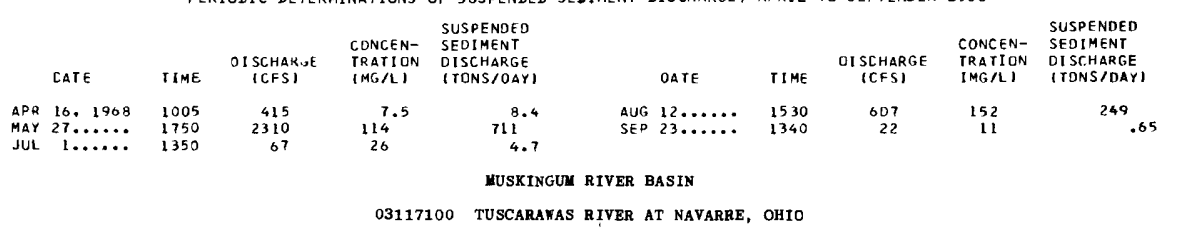

LOCATION,--Lat $40^{\circ} 43^{\prime} 36^{\prime \prime}$, long $81^{\circ} 31^{\prime} 47^{\prime \prime}$, Stark County, on left bank at Navarre water treatment plant, $800 \mathrm{ft}$ upstream from bridge on Elton Road at Navarre, 3.5 miles downstream from gaging station at Hassillon, 1.2 miles downstream from Pigeon Run, and just upstream from wolf Creek.

DRAINAGE AREA. - -534 sq mi.

PERTOD OF RECORD.--Chemical analyses: March to September 1968.

Water temperatures: March to September 1968.

REMARKS. - In addition to the continuous recorder, twice-weekly samples were collected by a local observer. Partial anaiyses were made on the maximum spectfic conductance and minimum specific conductance of samples coilected for period March to september. Interruptions in the record were due to malfunctions of the instrument. Records of discharge are given for Tuscarawas River at Hassillon (drainage area 518 sq mi).

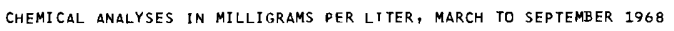

\begin{tabular}{|c|c|c|c|c|c|c|c|}
\hline & TIMF & $\begin{array}{l}\text { OIS- } \\
\text { CHAPGE }\end{array}$ & $\begin{array}{l}\text { BICAR- } \\
\text { BONATE }\end{array}$ & $\begin{array}{l}\text { CAR- } \\
\text { PONATF }\end{array}$ & SULFATE & $\begin{array}{l}\text { CHLn- } \\
\text { RIInF }\end{array}$ & 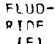 \\
\hline $\begin{array}{l}\text { DATE } \\
\text { MAR. }\end{array}$ & MAR. & & & & $1574 \mid$ & & \\
\hline $11 .$. & 1500 & $30 \mathrm{c}$ & $5 n$ & $n$ & 216 & $2>90$ & 1.3 \\
\hline $25 \ldots$ & - & $12 \mathrm{nn}$ & 148 & c & 95 & inn & .9 \\
\hline \multicolumn{8}{|l|}{ APR. } \\
\hline $20 \ldots$ & 1000 & $\begin{array}{l}430 \\
224\end{array}$ & 140 & 3 & $\begin{array}{r}54 \\
134\end{array}$ & 930 & 39 \\
\hline \multicolumn{8}{|l|}{ MAY } \\
\hline $08 \ldots$ & 1020 & $18 B$ & 119 & ? & 141 & 1400 & 3. ? \\
\hline $13 \ldots$ & $110 \mathrm{C}$ & 1236 & 165 & $r$ & 02 & $37 n$ & .5 \\
\hline \multicolumn{8}{|l|}{ JUNE } \\
\hline $18 \ldots$ & $\begin{array}{l}1000 \\
1400\end{array}$ & 1310 & $23 ?$ & $a^{\circ}-x-1$ & 55 & 105 & $\therefore 9$ \\
\hline \multicolumn{8}{|l|}{ JULY } \\
\hline $20 \ldots$ & $093 n$ & $128^{n}$ & 166 & $r$ & 72 & $54 n$ & .7 \\
\hline $24 \ldots$ & 1000 & 248 & $18 ?$ & $n$ & 132 & 1 anc & 2.4 \\
\hline \multicolumn{8}{|l|}{ AUG. } \\
\hline $14 \ldots$ & 1200 & 143 & 116 & 0 & $12 n$ & 2340 & 7.7 \\
\hline $\begin{array}{r}23 \ldots \\
\text { SEPT }\end{array}$ & 1500 & 154 & 134 & 0 & 160 & $172^{\circ}$ & .5 \\
\hline \multicolumn{8}{|l|}{ SEPT. } \\
\hline $\begin{array}{l}13 \ldots \\
25 \ldots\end{array}$ & $\begin{array}{l}1400 \\
1205\end{array}$ & $\begin{array}{l}138 \\
211\end{array}$ & $\begin{array}{l}156 \\
114\end{array}$ & $\hat{n}$ & $\begin{array}{l}15 ? \\
140\end{array}$ & $\begin{array}{l}21 \mathrm{nc} \\
134 \mathrm{C}\end{array}$ & $\begin{array}{l}1.3 \\
3.7\end{array}$ \\
\hline & & & 114 & & & & \\
\hline
\end{tabular}


03117100 TUSCARAFAS RIVER AT NAVARRE, OHIO--Cont Inued CHEMICAL ANALYSES IN MILLIGRAMS PER LITER, MARCH TO SEPTEMBER 1968

\begin{tabular}{|c|c|c|c|c|c|c|}
\hline & & $\begin{array}{l}\text { DIS- } \\
\text { SMLVFA } \\
\text { SOLIDS } \\
\text { TRESI- }\end{array}$ & HAP n- & $\begin{array}{l}\text { NON- } \\
\text { CAP- } \\
\text { RONATE }\end{array}$ & $\begin{array}{l}\text { SPECI - } \\
\text { FIC } \\
\text { COND- } \\
\text { UCT ANCE }\end{array}$ & \\
\hline & NITPATF & DUE AT & NFSS & HAPD- & (MICRN- & DH \\
\hline MAR. & & & & & & \\
\hline $11 \ldots$ & $\rightarrow$ & $4 a n c$ & $237 n$ & $19+0$ & $720 n$ & - \\
\hline $\begin{array}{l}25 \ldots \\
A P R\end{array}$ & 20 & $19 \geq 0$ & 719 & 596 & $256 \mathrm{C}$ & 7.4 \\
\hline $05 . .$. & 15 & 1998 & 672 & 554 & $3 n 5 n$ & 7.4 \\
\hline $20 \ldots$ & -- & 2740 & $141 C$ & 1270 & 5127 & 8. 2 \\
\hline Mar & & & & & & \\
\hline $\begin{array}{l}O R . . . \\
23 . . .\end{array}$ & 9.5 & $311 \%$ & 1178 & 1070 & $491 n$ & h. 5 \\
\hline JUVE & 7.3 & 1280 & & 315 & $16 \mathrm{~cm}$ & -- \\
\hline $03 .$. & 3.7 & תמד & 3.94 & 104 & $112 n$ & R.? \\
\hline $\operatorname{Jig}_{\mathbf{j}}^{19} \cdots$ & -- & 2910 & 11 an & $171 ?$ & $452^{\circ}$ & 5.9 \\
\hline $23 .$. & 5.1 & 1470 & 574 & $47 \mathrm{~A}$ & $203^{n}$ & 7,2 \\
\hline $24 \ldots$ & & $383 n$ & 1540 & $130 n$ & 5650 & 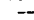 \\
\hline AlIS. & & & & & & \\
\hline $14 \ldots$ & -- & 4770 & lane & $17 n n$ & $717 n$ & 9.1 \\
\hline $23 \ldots$ & -- & 3600 & $142 \mathrm{C}$ & 1310 & $541 ?$ & 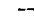 \\
\hline SFPT - & & & & & 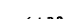 & \\
\hline $5 \ldots$ & -. & 3010 & $10 \% 0$ & $\begin{array}{l}143.17 \\
986\end{array}$ & $438 n$ & 7.7 \\
\hline
\end{tabular}

SPECIFIC CONDUCTANCE, PH, DISSOLVED OXYGEN, AND HATER TEMPERATURES, MARCH TO SEPTEUBER 1968

$$
\text { SPECIFIC }
$$

TELPER-

SPECIFIC

(MICROMAOS
AT $25^{\circ} \mathrm{C}$ )

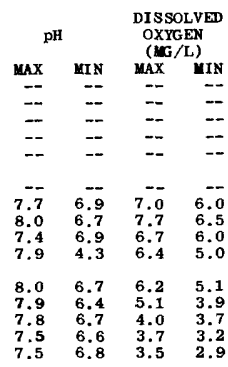

$\begin{array}{llll}8.0 & 7.3 & 3.0 & 2.6 \\ 8.0 & 7.3 & 3.0 & 2.6\end{array}$

$\begin{array}{llll}7.8 & 7.2 & 3.5 & 2.6 \\ 7.6 & 7.0 & 4.2 & 2.2\end{array}$

7

7.97 .5

$\begin{array}{llll}8.0 & 7.6 & 1.4 & 1.3 \\ 7.8 & 7.4 & 2.8 & 1.2\end{array}$

$\begin{array}{rrrr}7.8 & 7.4 & 1.2 & 1.0 \\ 7.8 & 5.6 & 6.1 & .9\end{array}$

$$
\begin{aligned}
& 1 \\
& 2 \\
& 3 \\
& 4 \\
& 5
\end{aligned}
$$

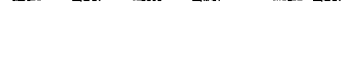

MAX MIN
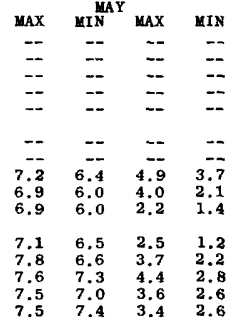

TEMPER-

ATURE $\left({ }^{\circ} \mathrm{C}\right)$

$--$

$\bar{z}=$

$\overline{---}$

$\overline{9} \overline{8}$ $10 \frac{9}{9}$ 
03117100 TUSCARAWAS RIVER AT NAYARRE, OHIO--ContInued

SPECIFIC CONDUCTANCE, PH, DISSOLVED OXYGEN, AND WATER TEMPERATURES, MARCH TO SEPTEMBER 1968

DAY



1
2
3
4
5
6
7
8
9
10
11
12
13
14
15
16
17
18
19
20
21
22
23
24
25

26
27
28
29
30
31

JUNE

JULY

SPECIFIC

\begin{tabular}{|c|c|c|c|}
\hline $\begin{array}{l}\text { CONDUCTANCE } \\
\text { (MICROMHOS } \\
\text { AT } 25^{\circ} \mathrm{C} \text { ) }\end{array}$ & PH & $\begin{array}{l}\text { DISSOLVED } \\
\text { OXYGEN } \\
(\mathbf{H G} / \mathrm{L})\end{array}$ & $\begin{array}{l}\text { TEMPER- } \\
\text { ATURE } \\
\left({ }^{\circ} \mathrm{C}\right)\end{array}$ \\
\hline
\end{tabular}

MAX MIN MAX MIN MAX MIN MAX MIN

\begin{tabular}{|c|c|c|c|c|c|c|c|}
\hline \multirow{2}{*}{\multicolumn{2}{|c|}{$\begin{array}{l}\text { SPECIFIC } \\
\text { CONDUCTANCE } \\
\text { (HICROMHOS } \\
\left.\text { AT } 25^{\circ} \mathrm{C}\right)\end{array}$}} & \multicolumn{4}{|c|}{ JULY } & & \\
\hline & & \multicolumn{2}{|c|}{$\mathrm{pH}$} & \multicolumn{2}{|c|}{$\begin{array}{l}\text { DISSOLVED } \\
\text { OXYGEN } \\
(\mathbf{M G} / L)\end{array}$} & \multicolumn{2}{|c|}{$\begin{array}{c}\text { TEMPER- } \\
\text { ATURE } \\
\left({ }^{\circ} \mathrm{C}\right)\end{array}$} \\
\hline MAX & MIN & $\operatorname{MAX}$ & MIN & KAX & MIN & $\max$ & MIN \\
\hline 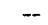 & -- & -- & -- & -- & -- & -- & \\
\hline- & -- & -- & -- & -- & -- & - & - \\
\hline$\cdots$ & -- & -- & -- & -- & -- & - & -- \\
\hline$\cdots$ & - & -- & -- & -- & -- & -- & -- \\
\hline- & -- & -- & -- & -- & -- & -- & - \\
\hline- & - & -- & -- & -- & -- & - & - \\
\hline-- & - & -- & -- & -- & -- & -- & - \\
\hline -- & -- & -- & -- & -- & -- & -- & - \\
\hline-- & -- & -- & -- & -- & -- & - & -- \\
\hline-- & - & - & -- & -- & -- & - & - \\
\hline 5200 & 5010 & 7.2 & 7.0 & 5.0 & 3.9 & 27 & 25 \\
\hline 5380 & 4400 & 7.1 & 6.1 & 3.9 & 2.1 & 27 & 22 \\
\hline 5740 & 4660 & 7.4 & 6.3 & 5,4 & 1.7 & 27 & 22 \\
\hline 6050 & 3800 & 7.4 & 5.4 & 4.6 & I. 2 & 26 & 23 \\
\hline 6180 & 4960 & 7.2 & 6.8 & 5.0 & $\mathbf{3 . 4}$ & 26 & 21 \\
\hline 6620 & 3110 & 7,0 & 6.4 & 3.8 & 1.0 & 25 & 23 \\
\hline 5400 & 1080 & 7.7 & 6. & 4.8 & .8 & 23 & 19 \\
\hline 3240 & 540 & 7.5 & 7. & 3.2 & 1.2 & 25 & 22 \\
\hline 3330 & 900 & 7.4 & 7.2 & 2.0 & 1. & 26 & 24 \\
\hline 2250 & 1980 & 7.4 & 7.1 & 1.8 & 1.0 & 25 & 23 \\
\hline 7650 & & & 6. & & & 26 & 23 \\
\hline 3010 & 1350 & 7.9 & 6.9 & 2.2 & .8 & 26 & 23 \\
\hline 4910 & 1080 & 7.8 & 7. & 1.5 & .8 & 26 & 22 \\
\hline 6300 & 2920 & 7.8 & 7. & 1.5 & .8 & 29 & 24 \\
\hline 5710 & 3060 & 7.8 & 6.7 & 2.1 & .8 & 27 & 24 \\
\hline 4810 & & & & .9 & & 30 & \\
\hline 6520 & 3780 & 7.5 & 6.5 & 1.4 & .7 & 27 & 23 \\
\hline 7060 & 5400 & 7.3 & 6.5 & 1.9 & .7 & 28 & 23 \\
\hline 7020 & 5400 & 7.4 & 6, & 2.6 & .7 & 24 & 19 \\
\hline & 6080 & & 6. & 4.1 & 1.6 & 24 & 19 \\
\hline 30 & 5440 & 7.1 & 6.8 & 3.4 & .8 & 24 & 21 \\
\hline
\end{tabular}

\begin{tabular}{|c|c|c|c|c|c|c|c|}
\hline & & & PTE & & & & \\
\hline $\begin{array}{r}\text { SPI } \\
\text { CONI } \\
\text { (MIC } \\
\text { A] }\end{array}$ & $\begin{array}{l}\text { FIC } \\
\text { TANCE } \\
\text { MHOS } \\
5^{\circ} \mathrm{C} \text { ) }\end{array}$ & P & & $\begin{array}{l}\text { DISS } \\
\text { (HO }\end{array}$ & $\begin{array}{l}\text { LVED } \\
\text { EN } \\
\text { L) }\end{array}$ & $\begin{array}{l}\text { TELP } \\
\text { ATU } \\
{ }^{\circ} \mathrm{C}\end{array}$ & $\begin{array}{l}\text { PER- } \\
\text { URE } \\
\text { c) }\end{array}$ \\
\hline $\operatorname{MAX}$ & MIN & $\mathbf{M A X}$ & MIN & $\operatorname{MAX}$ & WIN & $\max$ & MIN \\
\hline $\begin{array}{l}7580 \\
8960 \\
8780 \\
6760 \\
7600\end{array}$ & $\begin{array}{l}7040 \\
5140 \\
6520 \\
5170 \\
6120\end{array}$ & $\begin{array}{l}7.2 \\
7.2 \\
7.4 \\
7.3 \\
6.9\end{array}$ & $\begin{array}{l}6.9 \\
6.9 \\
6.4 \\
6.6 \\
6.4\end{array}$ & $\begin{array}{r}.0 \\
.4 \\
2.2 \\
2.0 \\
1.0\end{array}$ & $\begin{array}{l}.0 \\
.0 \\
.0 \\
.0 \\
.0\end{array}$ & $\begin{array}{l}21 \\
22 \\
22 \\
24 \\
22\end{array}$ & $\begin{array}{l}19 \\
18 \\
18 \\
19 \\
20\end{array}$ \\
\hline $\begin{array}{l}8540 \\
8260 \\
3800 \\
5090 \\
6520\end{array}$ & $\begin{array}{l}3100 \\
2450 \\
2630 \\
3600 \\
5080\end{array}$ & $\begin{array}{l}7.3 \\
7.5 \\
7.4 \\
7.4 \\
7.1\end{array}$ & $\begin{array}{l}6.6 \\
5.4 \\
7.2 \\
6.5 \\
6.6\end{array}$ & $\begin{array}{r}2.2 \\
1.0 \\
2.4 \\
2.0 \\
.6\end{array}$ & $\begin{array}{l}.0 \\
.0 \\
.0 \\
.0 \\
.0\end{array}$ & $\begin{array}{l}23 \\
23 \\
23 \\
22 \\
21\end{array}$ & $\begin{array}{l}19 \\
19 \\
18 \\
19 \\
20\end{array}$ \\
\hline $\begin{array}{l}6910 \\
6660 \\
6550 \\
7210 \\
7230\end{array}$ & $\begin{array}{l}4120 \\
5040 \\
5290 \\
5540 \\
6280\end{array}$ & $\begin{array}{l}7.0 \\
7.1 \\
7.1 \\
7.4 \\
7.4\end{array}$ & $\begin{array}{l}6.6 \\
6.8 \\
6.4 \\
5.4 \\
7.1\end{array}$ & $\begin{array}{r}.4 \\
1.0 \\
.5 \\
.2 \\
1.4\end{array}$ & $\begin{array}{l}.0 \\
.0 \\
.0 \\
.0 \\
.0\end{array}$ & $\begin{array}{l}20 \\
20 \\
21 \\
22 \\
23\end{array}$ & $\begin{array}{l}18 \\
16 \\
16 \\
17 \\
18\end{array}$ \\
\hline $\begin{array}{l}7410 \\
6680 \\
7260 \\
7380 \\
8750\end{array}$ & $\begin{array}{l}6430 \\
5020 \\
5950 \\
6120 \\
7060\end{array}$ & $\begin{array}{l}7.2 \\
7.0 \\
7.0 \\
7.0 \\
7.0\end{array}$ & $\begin{array}{l}6.2 \\
6.6 \\
6.6 \\
6.6 \\
6.4\end{array}$ & $\begin{array}{l}.8 \\
.5 \\
.2 \\
.3 \\
.5\end{array}$ & $\begin{array}{l}.0 \\
.0 \\
.1 \\
.2 \\
.3\end{array}$ & $\begin{array}{l}23 \\
21 \\
22 \\
20 \\
22\end{array}$ & $\begin{array}{l}19 \\
19 \\
19 \\
19 \\
18\end{array}$ \\
\hline $\begin{array}{l}7480 \\
8090 \\
7170 \\
9170 \\
4960\end{array}$ & $\begin{array}{l}5140 \\
6970 \\
4160 \\
4130 \\
3620\end{array}$ & $\begin{array}{l}7.0 \\
7.5 \\
7.3 \\
7.4 \\
7.1\end{array}$ & $\begin{array}{l}5.6 \\
7.0 \\
6.8 \\
7.1 \\
6.4\end{array}$ & $\begin{array}{r}.6 \\
.7 \\
.8 \\
.9 \\
2.2\end{array}$ & $\begin{array}{l}.5 \\
.6 \\
.7 \\
.8 \\
.8\end{array}$ & $\begin{array}{l}23 \\
24 \\
23 \\
25 \\
23\end{array}$ & $\begin{array}{l}19 \\
20 \\
21 \\
22 \\
21\end{array}$ \\
\hline $\begin{array}{l}6940 \\
7260 \\
6760 \\
7570 \\
7520\end{array}$ & $\begin{array}{l}4820 \\
5720 \\
5720 \\
5860 \\
6760\end{array}$ & $\begin{array}{l}7.0 \\
6.9 \\
7.0 \\
7.6 \\
7.6\end{array}$ & $\begin{array}{l}6.5 \\
6.7 \\
4.2 \\
7.0 \\
7.0\end{array}$ & $\begin{array}{l}1.4 \\
2.5 \\
1.0 \\
1.0 \\
1.0\end{array}$ & $\begin{array}{l}.8 \\
.8 \\
.2 \\
.9 \\
.9\end{array}$ & $\begin{array}{l}21 \\
20 \\
20 \\
20 \\
19\end{array}$ & $\begin{array}{l}18 \\
17 \\
15 \\
15 \\
15\end{array}$ \\
\hline & & & 0 & & -. & - & \\
\hline
\end{tabular}


03131500 BLACK FORK AT LOUDONVILLE, OHIO

LOCATION, --Lat $40^{\circ} 38^{\prime} 08^{\prime \prime}$, long $82^{\circ} 14^{\prime} 19^{\prime \prime}$, In NWł sec.1, T.19 N., R.16 w., Ashland County, on right bank at Loudonville water treatment plant, just downstream from gaging station and bridge on State Highway 3 at Loudonville,
1.5 miles downstreata from Big Run.

DRA INAGE AREA (revised).--349 sq mi.

PERIOD OF RECORD.--Chemical analyses: April to September 1968.

Water temperatures: April to September 1968.

REMARKS, -- In addition to the continuous recorder, twice-weekly samples were collected by a local observer. Partial analyses were made on the maximum specific conductance and minimum specific conductance of samples collected each month. Interruptions in the record were due to malfunctions of the instrument.

CHEMICAL ANALYSES IN MILLIGRAMS PER LITER, APRIL TO SEPTEMBER 1968

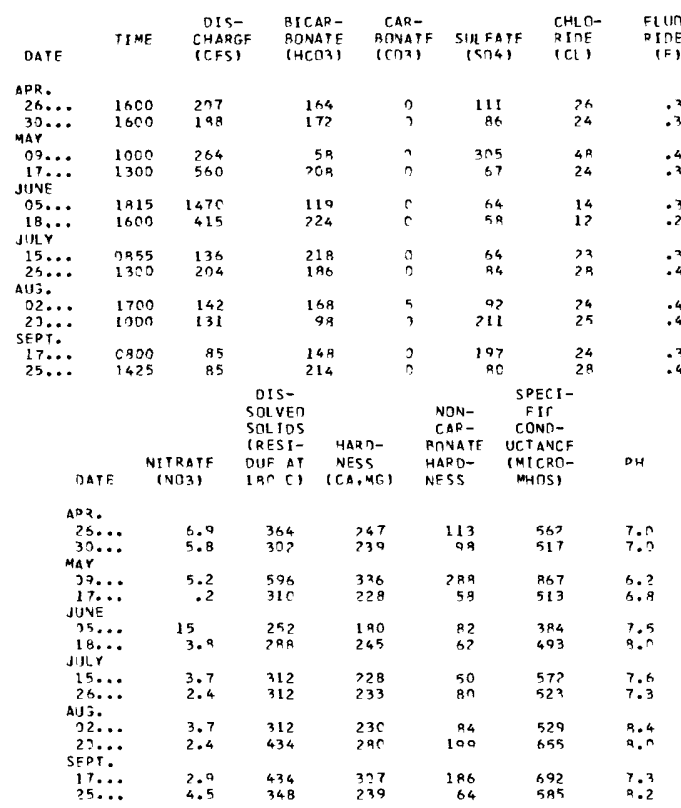

DISSOLVED OXYGEN, AND WATER TEMPERATURES, APRIL TO SEPTEMBER 1968

APRIL

MAY

JUNE

JULY

\begin{tabular}{|c|c|c|c|c|}
\hline \multirow[t]{2}{*}{ DAY } & \multicolumn{2}{|c|}{$\begin{array}{l}\text { DISSOLVED } \\
\text { OXYGEN } \\
(M G / L)\end{array}$} & \multicolumn{2}{|c|}{$\begin{array}{l}\text { TEMPER- } \\
\text { ATURE } \\
\left({ }^{\circ} \mathrm{C}\right)\end{array}$} \\
\hline & Max & MIN & $\max$ & MIN \\
\hline 1 & -- & - & -- & \\
\hline $\begin{array}{l}2 \\
3\end{array}$ & $=$ & $=$ & $\overline{--}$ & \\
\hline 4 & - & - & -- & \\
\hline 5 & -- & - & -- & \\
\hline 6 & -- & - & $-\infty$ & $\cdots$ \\
\hline $\begin{array}{l}7 \\
8\end{array}$ & $\overline{-}$ & $\overline{-}$ & $=$ & $=$ \\
\hline $\mathbf{g}$ & -- & - & -- & \\
\hline 10 & -- & -- & -- & - \\
\hline 11 & - & -- & -- & - \\
\hline 12 & -- & - & -- & \\
\hline 13 & -- & $\overline{-}$ & $\because$ & \\
\hline $\begin{array}{l}14 \\
15\end{array}$ & $=$ & $\overline{-}$ & $=$ & 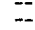 \\
\hline 16 & - & -- & -- & \\
\hline 17 & $\cdots$ & -- & $\because$ & \\
\hline 18 & $\because$ & -- & $=$ & \\
\hline $\begin{array}{l}19 \\
20\end{array}$ & - & - & - & \\
\hline 21 & -- & - & -- & \\
\hline 22 & $\overline{7}$ & $\overline{-5}$ & $\overline{\overline{7}}$ & \\
\hline $\begin{array}{l}23 \\
24\end{array}$ & $\begin{array}{l}8.7 \\
7.0\end{array}$ & $\begin{array}{l}6.2 \\
3.7\end{array}$ & $\begin{array}{l}17 \\
16\end{array}$ & \\
\hline 25 & - & - & 12 & \\
\hline 36 & -- & -- & 11 & \\
\hline 27 & -- & -- & 14 & \\
\hline 19 & $=-$ & -- & 15 & \\
\hline 29 & -- & -- & 16 & \\
\hline 30 & - & -- & 16 & \\
\hline 31 & - & $\cdots$ & - & \\
\hline
\end{tabular}

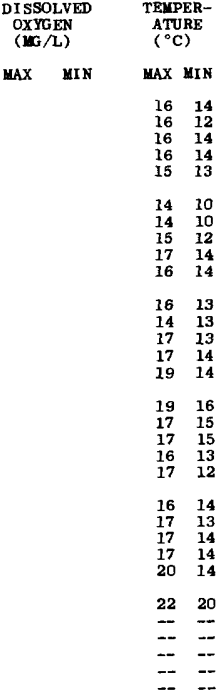

$\begin{array}{cc}\begin{array}{c}\text { DISSOLVED } \\ \text { OXXGEN } \\ (\text { MG } / L)\end{array} & \begin{array}{c}\text { TEMPER- } \\ \text { ATURE } \\ \left({ }^{\circ} \mathrm{C}\right)\end{array} \\ \text { MAX MIN } & \text { MAX MIN }\end{array}$

\begin{tabular}{|c|c|c|c|}
\hline \multicolumn{2}{|c|}{$\begin{array}{l}\text { DI SSOLVED } \\
\text { OXYGEN } \\
(\mathbf{M G} / \mathrm{L})\end{array}$} & \multicolumn{2}{|c|}{$\begin{array}{l}\text { TEMPER- } \\
\text { ATURE } \\
\left({ }^{\circ} \mathrm{C}\right)\end{array}$} \\
\hline $\max$ & MIN & $\max$ & MIN \\
\hline 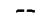 & -- & 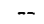 & 0 \\
\hline$-\sim$ & - & -- & - \\
\hline$=$ & - & $\because$ & - \\
\hline- & -- & - & - \\
\hline-- & -- & 24 & 22 \\
\hline-- & -- & 22 & 16 \\
\hline 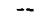 & - & 24 & 18 \\
\hline$\because$ & - & 22 & 19 \\
\hline 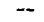 & -- & 22 & 20 \\
\hline- & -- & 22 & 19 \\
\hline-- & -- & 26 & 20 \\
\hline$\rightarrow$ & - & 25 & 22 \\
\hline & & 23 & 21 \\
\hline 6.5 & 2.7 & 22 & 20 \\
\hline 2.7 & 2.5 & 23 & 21 \\
\hline 2.5 & 2.0 & 25 & 21 \\
\hline .1 & $\begin{array}{l}2.1 \\
2.5\end{array}$ & 25 & $\begin{array}{l}22 \\
23\end{array}$ \\
\hline 3.6 & 2.4 & 23 & 21 \\
\hline 4.3 & 3.0 & 23 & \\
\hline 4.4 & 3.5 & 23 & 21 \\
\hline 4.1 & 3.0 & 24 & 21 \\
\hline 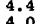 & 3.7 & 24 & 22 \\
\hline & & & 28 \\
\hline-- & -- & - & -- \\
\hline- & & - & - \\
\hline & & $=$ & - \\
\hline & & & \\
\hline & & $\cdots$ & 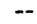 \\
\hline
\end{tabular}


03131500 BLACK FORK AT LOUDONVILLE, OHIO--Continued DISSOLVED OXYGEN, AND WATER TEMPERATURES, APRIL TO SEPTEMBER 1968

AUGUST

\begin{tabular}{rrrrr} 
DAY & \multicolumn{2}{c}{$\begin{array}{c}\text { DISSOLVED } \\
\text { OXYGEN } \\
(\text { MG } / \mathrm{L})\end{array}$} & $\begin{array}{c}\text { TEMPER } \\
\text { ATURE } \\
\left({ }^{\circ} \mathrm{C}\right)\end{array}$ \\
& MAX & MIN & \multicolumn{2}{c}{ MAX MI } \\
1 & -- & -- & -- & - \\
2 & -- & -- & -- & - \\
3 & -- & -- & -- & - \\
4 & -- & -- & -- & - \\
5 & -- & -- & -- & - \\
6 & -- & -- & -- & - \\
7 & 4.9 & 4.0 & 23 & 2 \\
8 & 5.9 & 3.3 & 24 & 21 \\
9 & 5.2 & 3.6 & 24 & 2 \\
10 & 5.1 & 2.6 & 23 & 2 \\
& & & & \\
11 & 6.3 & 3.9 & 20 & 18 \\
12 & 7.7 & 4.7 & 20 & 1 \\
13 & 8.4 & 5.0 & 20 & 1 \\
14 & 8.8 & 6.6 & 22 & 1 \\
15 & 11.9 & 5.6 & 22 & 2 \\
16 & 9.7 & 6.5 & 23 & 21
\end{tabular}

SEPTEMBER

\begin{tabular}{|c|c|c|c|}
\hline \multicolumn{2}{|c|}{$\begin{array}{l}\text { DI SSOLVED } \\
\text { OXYGEN } \\
(\text { MG } / L)\end{array}$} & \multicolumn{2}{|c|}{$\begin{array}{c}\text { T EMP ER- } \\
\text { AT URE } \\
\left({ }^{\circ} \mathrm{C}\right)\end{array}$} \\
\hline MAX & MIN & MAX & MIN \\
\hline $\begin{array}{r}12.8 \\
11.1 \\
7.4 \\
8.5 \\
7.5\end{array}$ & $\begin{array}{r}10.5 \\
3.6 \\
1.8 \\
4.0 \\
6.1\end{array}$ & $\begin{array}{l}18 \\
19 \\
20 \\
20 \\
19\end{array}$ & $\begin{array}{l}17 \\
17 \\
17 \\
18 \\
18\end{array}$ \\
\hline $\begin{array}{l}6.1 \\
7.9 \\
6.4 \\
6.9 \\
5.7\end{array}$ & $\begin{array}{l}3.2 \\
1.9 \\
4.0 \\
4.3 \\
4.7\end{array}$ & $\begin{array}{l}20 \\
20 \\
19 \\
19 \\
18\end{array}$ & $\begin{array}{l}19 \\
18 \\
17 \\
18 \\
18\end{array}$ \\
\hline $\begin{array}{l}4.8 \\
4.5 \\
5.6 \\
6.7 \\
7.0 \\
6.9\end{array}$ & $\begin{array}{l}2.9 \\
2.9 \\
3.8 \\
4.4 \\
5.2 \\
4.9\end{array}$ & $\begin{array}{l}18 \\
17 \\
18 \\
18 \\
19 \\
19\end{array}$ & $\begin{array}{l}17 \\
15 \\
15 \\
16 \\
16 \\
16\end{array}$ \\
\hline
\end{tabular}

AUGUST

SEPTEMBER

\begin{tabular}{|c|c|c|c|c|c|c|c|c|}
\hline \multirow[t]{2}{*}{ DAY } & \multicolumn{2}{|c|}{$\begin{array}{l}\text { DISSOLVED } \\
\text { OXYGEN } \\
(\text { MG } / L)\end{array}$} & \multicolumn{2}{|c|}{$\begin{array}{l}\text { TEMPER- } \\
\text { ATURE } \\
\left({ }^{\circ} \mathrm{C}\right)\end{array}$} & \multicolumn{2}{|c|}{$\begin{array}{l}\text { DI SSOLVED } \\
\text { OXYGEN } \\
(\mathbf{M G} / \mathrm{L})\end{array}$} & \multicolumn{2}{|c|}{$\begin{array}{l}\text { TEMPER- } \\
\text { AT URE } \\
\left({ }^{\circ} \mathrm{C}\right)\end{array}$} \\
\hline & MAX & MIN & MAX & MIN & MAX & MIN & MAX & MIN \\
\hline $\begin{array}{l}17 \\
18 \\
19 \\
20 \\
21\end{array}$ & $\begin{array}{r}10.0 \\
9.5 \\
9.2 \\
7.9 \\
9.1\end{array}$ & $\begin{array}{r}6.2 \\
.7 \\
5.0 \\
2.0 \\
3.4\end{array}$ & $\begin{array}{l}25 \\
24 \\
24 \\
25 \\
25\end{array}$ & $\begin{array}{l}22 \\
22 \\
21 \\
23 \\
23\end{array}$ & $\begin{array}{l}6.3 \\
5.3 \\
5.1 \\
5.7 \\
6.2\end{array}$ & $\begin{array}{l}4.9 \\
3.6 \\
3.7 \\
3.7 \\
4.5\end{array}$ & $\begin{array}{l}18 \\
18 \\
18 \\
19 \\
20\end{array}$ & $\begin{array}{l}17 \\
17 \\
17\end{array}$ \\
\hline $\begin{array}{l}22 \\
23 \\
24 \\
25 \\
26\end{array}$ & $\begin{array}{l}8.0 \\
7.9 \\
6.3 \\
5.5 \\
6.6\end{array}$ & $\begin{array}{l}4.6 \\
3.1 \\
3.8 \\
2.9 \\
1.8\end{array}$ & $\begin{array}{l}25 \\
25 \\
25 \\
24 \\
21\end{array}$ & $\begin{array}{l}22 \\
24 \\
24 \\
21 \\
18\end{array}$ & $\begin{array}{r}6.7 \\
6.9 \\
7.0 \\
5.9 \\
-\end{array}$ & $\begin{array}{r}4.7 \\
4.7 \\
4.9 \\
4.5 \\
--\end{array}$ & $\begin{array}{l}20 \\
20 \\
20 \\
20 \\
18\end{array}$ & 17 \\
\hline $\begin{array}{l}27 \\
28 \\
29 \\
30 \\
31\end{array}$ & $\begin{array}{r}7.3 \\
11.0 \\
11.9 \\
13.2 \\
13.0\end{array}$ & $\begin{array}{r}3.5 \\
6.8 \\
8.4 \\
10.4 \\
10.1\end{array}$ & $\begin{array}{l}19 \\
19 \\
19 \\
19 \\
19\end{array}$ & $\begin{array}{l}16 \\
16 \\
16 \\
16 \\
16\end{array}$ & $\begin{array}{l}-- \\
-- \\
--\end{array}$ & $\begin{array}{l}-- \\
-- \\
-- \\
-- \\
--\end{array}$ & $\begin{array}{l}17 \\
16 \\
15 \\
15 \\
-.\end{array}$ & 13 \\
\hline
\end{tabular}

03139000 KILLBUCK CREEK AT KILLBUCK, OHIO

LOCATION,--Lat $40^{\circ} 29^{\prime} 43^{\prime \prime}$, long $81^{\circ} 59^{\prime} 10^{\prime \prime}$, in $\mathrm{S} N \mathrm{sec}, 6, \mathrm{~T}, 8 \mathrm{~N}$, , R. 7 w., Holmes County, at gaging station at bridge on County Road 2B at Killbuck, 0.1 mile downstream from Biack Creek and 0.9 mile upstream from bridge on U.S. Highway 62 .

DRAINAGE AREA. $--462 \mathrm{sq} \mathrm{mi}$.

PERIOD OF RECORD,--Chemical anaiyses: October 1957 to September 1958.

Tater temperatures: October 1962 to September 1968.

Sediment records: October 1962 to September 1968 .

EXTREMES, - -1967-68:

Water temperatures: Maximum, $27.0^{\circ} \mathrm{C}$ Aug. $24 ;$ minimum, $1.0^{\circ} \mathrm{C}$ on many days during December, January, February,

Sediment concentrations: Maximum da1ly, $869 \mathrm{mg} / 1$ May $16 ; \mathrm{minimum}$ dally, $2 \mathrm{mg} / 1$ Nov, 30, Jan. 9, Feb. 24,

Mar. 3.
Sediment loads: Maximum daily, 3,700 tons Jan. 30; minimum da1ly, 0.52 ton Nov. 30.

Period of record:

Water temperatures: Maximum, $27.0^{\circ} \mathrm{C}$ July 27, 1964, Aug. 16, 1925, Aug. 24, 1968; minimum, freezing point on several days during December 1962 to March 1963, December 1963, and January 1964.

Sediment concentrations: Maximum daily, 2,170 mg/1 June 11, 1963; minimum daily, i mg/1 Dec. 14, 15, 17, 1962

Sediment loads: Kaximum daily, 7,790 tons Mar. 10, 1964; min1mum daily, 0,15 ton Jan. $15,1964$.

RBMARKS.--Daily sediment loads were computed by subdivision on Dec. 3, 22, Jan. 29, Mar. 16, Apr. 23, May 11, 16, 27, June 16, Flow affected by 1ce Jan. 1-19, 25-28, Feb. 11 to Mar. 2, i3. (ONCE-DAILY MEASUREMENT BETWEEN 1700 AND 1800)

\begin{tabular}{|c|c|c|c|c|c|c|c|c|c|c|c|c|}
\hline DAY & OCT & NOV & $D E C$ & $J A N$ & FEB & $M A R$ & $A P R$ & MAY & JUN & JUL & $A \cup G$ & SEP \\
\hline $\begin{array}{l}1 \\
2 \\
3 \\
4 \\
5\end{array}$ & $\begin{array}{l}14.0 \\
17.0 \\
17.0 \\
13.0 \\
17.0\end{array}$ & $\begin{array}{r}12.0 \\
13.0 \\
12.0 \\
11.0 \\
7.0\end{array}$ & $\begin{array}{l}2.0 \\
3.0 \\
3.0 \\
3.0 \\
3.0\end{array}$ & $\begin{array}{l}1.0 \\
1.0 \\
1.0 \\
1.0 \\
1.0\end{array}$ & $\begin{array}{l}--- \\
3.0 \\
2.0 \\
2.0 \\
3.0\end{array}$ & $\begin{array}{l}3.0 \\
3.0 \\
4.0 \\
4.0 \\
4.0\end{array}$ & $\begin{array}{l}11.0 \\
11.0 \\
12.0 \\
12.0 \\
11.0\end{array}$ & $\begin{array}{l}14.0 \\
16.0 \\
16.0 \\
16.0 \\
14.0\end{array}$ & $\begin{array}{l}16.0 \\
18.0 \\
19.0 \\
20.0 \\
21.0\end{array}$ & $\begin{array}{l}21.0 \\
22.0 \\
21.0 \\
19.0 \\
21.0\end{array}$ & $\begin{array}{l}21.0 \\
22.0 \\
22.0 \\
22.0 \\
22.0\end{array}$ & $\begin{array}{l}19.0 \\
19.0 \\
20.0 \\
20.0 \\
19.0\end{array}$ \\
\hline $\begin{array}{r}6 \\
7 \\
8 \\
9 \\
10\end{array}$ & $\begin{array}{l}15.0 \\
17.0 \\
14.0 \\
15.0 \\
13.0\end{array}$ & $\begin{array}{l}4.0 \\
3.0 \\
2.0 \\
7.0 \\
0.0\end{array}$ & $\begin{array}{l}4.0 \\
6.0 \\
7.0 \\
7.0 \\
7.0\end{array}$ & $\begin{array}{l}1.0 \\
1.0 \\
1.0 \\
1.0 \\
2.0\end{array}$ & $\begin{array}{l}2.0 \\
3.0 \\
3.0 \\
1.0 \\
-.-\end{array}$ & $\begin{array}{l}4.0 \\
0.0 \\
6.0 \\
9.0 \\
9.0\end{array}$ & $\begin{array}{l}11.0 \\
12.0 \\
13.0 \\
12.0 \\
13.0\end{array}$ & $\begin{array}{l}14.0 \\
15.0 \\
15.0 \\
15.0 \\
16.0\end{array}$ & $\begin{array}{l}21.0 \\
22.0 \\
22.0 \\
22.0 \\
22.0\end{array}$ & $\begin{array}{l}21.0 \\
22.0 \\
22.0 \\
22.0 \\
25.0\end{array}$ & $\begin{array}{l}25.0 \\
24.0 \\
25.0 \\
24.0 \\
24.0\end{array}$ & $\begin{array}{l}20.0 \\
18.0 \\
20.0 \\
19.0 \\
18.0\end{array}$ \\
\hline $\begin{array}{l}11 \\
12 \\
13 \\
14 \\
15\end{array}$ & $\begin{array}{r}13.0 \\
14.0 \\
15.0 \\
-0 .\end{array}$ & $\begin{array}{l}6.0 \\
7.0 \\
7.0 \\
0.0 \\
3.0\end{array}$ & $\begin{array}{l}7.0 \\
7.0 \\
6.0 \\
6.0 \\
6.0\end{array}$ & $\begin{array}{l}1.0 \\
1.0 \\
1.0 \\
1.0 \\
1.0\end{array}$ & $\begin{array}{l}1.0 \\
1.0 \\
1.0 \\
1.0 \\
1.0\end{array}$ & $\begin{array}{l}9.0 \\
4.0 \\
4.0 \\
3.0 \\
3.0\end{array}$ & $\begin{array}{l}13.0 \\
13.0 \\
16.0 \\
16.0 \\
13.0\end{array}$ & $\begin{array}{l}14.0 \\
13.0 \\
14.0 \\
14.0 \\
15.0\end{array}$ & $\begin{array}{l}23.0 \\
23.0 \\
19.0 \\
21.0 \\
21.0\end{array}$ & $\begin{array}{l}24.0 \\
24.0 \\
24.0 \\
24.0 \\
23.0\end{array}$ & $\begin{array}{l}22.0 \\
22.0 \\
21.0 \\
22.0 \\
22.0\end{array}$ & $\begin{array}{l}18.0 \\
18.0 \\
18.0 \\
19.0 \\
18.0\end{array}$ \\
\hline $\begin{array}{l}16 \\
17 \\
18 \\
19 \\
20\end{array}$ & $\begin{array}{l}16.0 \\
16.0 \\
13.0 \\
13.0 \\
11.0\end{array}$ & $\begin{array}{l}2.0 \\
4.0 \\
4.0 \\
4.0 \\
5.0\end{array}$ & $\begin{array}{l}5.0 \\
2.0 \\
3.0 \\
5.0 \\
6.0\end{array}$ & $\begin{array}{l}1.0 \\
1.0 \\
3.0 \\
3.0\end{array}$ & $\begin{array}{l}1.0 \\
1.0 \\
1.0 \\
1.0 \\
1.0\end{array}$ & $\begin{array}{l}4.0 \\
6.0 \\
9.0 \\
4.0 \\
9.0\end{array}$ & $\begin{array}{l}13.0 \\
13.0 \\
13.0 \\
14.0 \\
20.0\end{array}$ & $\begin{array}{l}14.0 \\
16.0 \\
16.0 \\
16.0 \\
14.0\end{array}$ & $\begin{array}{l}19.0 \\
18.0 \\
18.0 \\
19.0 \\
20.0\end{array}$ & $\begin{array}{l}23.0 \\
24.0 \\
24.0 \\
25.0 \\
24.0\end{array}$ & $\begin{array}{r}23.0 \\
24.0 \\
24.0 \\
25.0 \\
-.0\end{array}$ & $\begin{array}{l}19.0 \\
18.0 \\
17.0 \\
18.0 \\
19.0\end{array}$ \\
\hline $\begin{array}{l}21 \\
22 \\
23 \\
24 \\
25\end{array}$ & $\begin{array}{l}12.0 \\
12.0 \\
11 \\
12.0 \\
12.0\end{array}$ & $\begin{array}{l}5.0 \\
4.0 \\
5.0 \\
4.0 \\
4.0\end{array}$ & $\begin{array}{l}7.0 \\
5.0 \\
4.0 \\
4.0 \\
4.0\end{array}$ & $\begin{array}{l}4.0 \\
2.0 \\
2.0 \\
---\end{array}$ & $\begin{array}{l}1.0 \\
1.0 \\
1.0 \\
1.0 \\
1.0\end{array}$ & $\begin{array}{l}7.0 \\
4.0 \\
1.0 \\
3.0 \\
4.0\end{array}$ & $\begin{array}{l}16.0 \\
22.0 \\
17.0 \\
15.0 \\
14.0\end{array}$ & $\begin{array}{l}15.0 \\
15.0 \\
14.0 \\
13.0 \\
16.0\end{array}$ & $\begin{array}{r}19.0 \\
21.0 \\
22.0 \\
-22.0\end{array}$ & $\begin{array}{l}24.0 \\
23.0 \\
24.0 \\
24.0 \\
23.0\end{array}$ & $\begin{array}{l}26.0 \\
26.0 \\
26.0 \\
27.0 \\
25.0\end{array}$ & $\begin{array}{l}20.0 \\
21.0 \\
19.0 \\
20.0 \\
20.0\end{array}$ \\
\hline $\begin{array}{l}26 \\
27 \\
28 \\
29 \\
30 \\
31\end{array}$ & $\begin{array}{r}10.0 \\
14.0 \\
14.0 \\
14.0 \\
13.0\end{array}$ & $\begin{array}{l}4.0 \\
3.0 \\
3.0 \\
2.0 \\
2.0 \\
---\end{array}$ & $\begin{array}{l}3.0 \\
1.0 \\
1.0 \\
1.0 \\
1.0 \\
1.0\end{array}$ & $\begin{array}{l}3.0 \\
2.0 \\
2.0 \\
2.0 \\
3.0 \\
2.0\end{array}$ & $\begin{array}{l}2.0 \\
2.0 \\
3.0 \\
3.0 \\
--- \\
---\end{array}$ & $\begin{array}{r}8.0 \\
12.0 \\
13.0 \\
12.0 \\
13.0 \\
14.0\end{array}$ & $\begin{array}{r}12.0 \\
12.0 \\
13.0 \\
13.0 \\
14.0 \\
-\end{array}$ & $\begin{array}{l}16.0 \\
14.0 \\
15.0 \\
15.0 \\
16.0 \\
16.0\end{array}$ & $\begin{array}{l}21.0 \\
19.0 \\
21.0 \\
21.0 \\
21.0 \\
.0\end{array}$ & $\begin{array}{l}23.0 \\
23.0 \\
23.0 \\
22.0 \\
23.0 \\
21.0\end{array}$ & $\begin{array}{l}20.0 \\
20.0 \\
18.0 \\
19.0 \\
20.0 \\
20.0\end{array}$ & $\begin{array}{l}17.0 \\
18.0 \\
18.0 \\
16.0 \\
15.0 \\
-.-\end{array}$ \\
\hline ERAGE & 14.0 & 5.5 & 4.0 & 1.5 & 1.5 & 6.5 & 13.5 & 15.0 & 20.5 & 23.0 & 23.0 & 18.5 \\
\hline
\end{tabular}


03139000 KILLBUCK CREEK AT KILLBUCK, OHIO--CONTInued

SUSPENDED SEDIMENT, WATER YEAR OCTOBER 1967 TO SEPTEMBER 1968

\begin{tabular}{|c|c|c|c|c|c|c|c|c|c|}
\hline & & तCTCBE⿱ & & & ADVEMBFR & & & DECEMBER & \\
\hline JAY & $\begin{array}{l}\text { NEAV } \\
\text { OI SCHAKGE } \\
\text { (CFS) }\end{array}$ & $\begin{array}{l}\text { MFAN } \\
\text { CCNCEN- } \\
\text { TRATION } \\
\text { IMG/LI }\end{array}$ & $\begin{array}{l}\text { LOAD } \\
\text { ITONSI }\end{array}$ & $\begin{array}{l}\text { MEAN } \\
\text { OISCHAFGE } \\
\text { ICFSI }\end{array}$ & $\begin{array}{l}\text { MFAN } \\
\text { CONCEN- } \\
\text { TRATION } \\
\text { IMG } / L \text { I }\end{array}$ & $\begin{array}{l}\text { LIAO } \\
\text { ITONSI }\end{array}$ & $\begin{array}{l}\text { MEAN } \\
\text { DISCHARGE } \\
\text { (CFS) }\end{array}$ & $\begin{array}{l}\text { MFAN } \\
\text { CONCEN- } \\
\text { TRATI INN } \\
\text { (MGILI }\end{array}$ & $\begin{array}{l}\text { LnAD } \\
\text { ITONS }\end{array}$ \\
\hline 1 & 83 & 110 & 27 & 59 & 29 & 4.6 & 96 & 6 & 1.6 \\
\hline 2 & 65 & 93 & is & 114 & 45 & 14 & 94 & 9 & 2.3 \\
\hline 3 & 58 & 101 & 16 & 194 & 69 & 36 & 271 & 38 & 31 \\
\hline 4 & 52 & 99 & 14 & 159 & hi & 26 & 422 & 72 & 82 \\
\hline 5 & $4 B$ & 82 & 11 & 133 & 32 & 11 & 340 & 58 & 52 \\
\hline 6 & 54 & 73 & 11 & 197 & 13 & 3.8 & 316 & 32 & 27 \\
\hline 7 & 49 & 54 & 7.1 & 93 & 8 & 2.0 & $\begin{array}{l}359 \\
359\end{array}$ & 40 & 39 \\
\hline h & 54 & 57 & 8,3 & 83 & 7 & 1.6 & 349 & 39 & 37 \\
\hline 9 & 101 & $7 \%$ & 22 & 78 & 35 & 7.4 & 284 & 29 & 22 \\
\hline 12 & 96 & 70 & 18 & 74 & 29 & 5.8 & 238 & 30 & 24 \\
\hline 11 & 71 & TC & 13 & 75 & 27 & 5.5 & 291 & 43 & 34 \\
\hline 12 & 02 & 101 & 17 & 107 & 49 & 140 & 428 & 48 & 59 \\
\hline 13 & 59 & 77 & 12 & 113 & 63 & 19 & 421 & 50 & 57 \\
\hline 14 & 58 & 43 & 6.7 & $\ln 3$ & $4 n$ & 11 & 322 & 5? & 43 \\
\hline 15 & 57 & 47 & 7.2 & 98 & 11 & 2.0 & 271 & 44 & 32 \\
\hline 16 & 52 & 54 & 7.6 & 91 & 5 & 1.2 & 231 & 39 & 24 \\
\hline 17 & 52 & 55 & 7.7 & 106 & B & 2.3 & 201 & 23 & 11 \\
\hline is & 05 & 64 & 11 & 189 & 11 & 5.6 & 203 & B & 4.4 \\
\hline is & 93 & 52 & 12 & 184 & 15 & 7.5 & 243 & 26 & 16 \\
\hline 20 & 76 & 27 & 5.5 & 150 & 12 & 4.9 & 254 & 37 & 25 \\
\hline 21 & 71 & 46 & 8.8 & 125 & 8 & 2.7 & 254 & 53 & 36 \\
\hline 22 & 63 & 47 & 8.7 & 115 & 6 & 1.9 & 439 & 143 & 189 \\
\hline 23 & 59 & 37 & 5.8 & $13 n$ & 3 & 1.1 & 563 & 162 & 246 \\
\hline 24 & 56 & 37 & 5.6 & 129 & 4 & 1.4 & 440 & 90 & 107 \\
\hline 25 & 59 & 37 & 5.9 & 134 & 5 & 1.8 & 340 & 68 & 62 \\
\hline 26 & 59 & 32 & 5.1 & 130 & 5 & 1.8 & 347 & 45 & 42 \\
\hline 27 & 58 & $3 c$ & 4.7 & 117 & 4 & 1,3 & 273 & 13 & 9.6 \\
\hline 23 & 61 & 15 & 2.5 & 108 & 5 & 1.5 & 249 & 7 & 4.7 \\
\hline 27 & 59 & 14 & 2.2 & 94 & 3 & .76 & 218 & 16 & 0.4 \\
\hline 30 & 56 & 14 & 2.1 & 96 & 2 & .52 & 199 & 16 & P., \\
\hline 31 & 55 & 25 & $2 \cdot 2$ & -- & - & - & 176 & B & 3. $\mathrm{P}$ \\
\hline TCTAL & 1951 & -- & 303.9 & 3488 & - & 207.88 & 9132 & $=$ & 1338.4 \\
\hline & & JLNUARY & & & FEBRUARY & & & MARCH & \\
\hline & & MEAN & & & MEAN & & & MEAN & \\
\hline & ME $\triangle N$ & CCNCEN- & & MEAN & CNNCEN- & & MEAN & CONCEN- & \\
\hline & OI SCHAFGE & TRAT I ON & LOAD & DISCHARGE & TKATION & $\angle O A D$ & DISCHARGE & TRATINN & LOAC \\
\hline DAY & ICFSI & $\mid M G / L)$ & ITnNS) & ICFSI & IMG/L) & ITENSI & |CFS| & (MG/L) & ITONSI \\
\hline 1 & 160 & 18 & 7.8 & 2510 & 135 & 915 & 130 & 8 & 2.8 \\
\hline 2 & 150 & 11 & 4.5 & $293^{n}$ & 87 & $6 B 9$ & $13 n$ & $a$ & 2.1 \\
\hline 3 & $14 c$ & is & 5.7 & 3000 & 72 & 583 & 131 & 2 & .71 \\
\hline 4 & 130 & is & 3.5 & 2670 & 117 & 943 & 126 & 5 & 1.7 \\
\hline 5 & 120 & 15 & 4.9 & 2330 & 87 & 947 & 135 & 7 & $2 . t$ \\
\hline 0 & 112 & R & 2.4 & $192 n$ & 57 & 295 & 148 & 6 & 2.4 \\
\hline 7 & lic & 8 & 2.4 & 1480 & 65 & $26 n$ & 147 & 8 & 3.2 \\
\hline B & 160 & 5 & 1.4 & 1140 & 75 & 231 & 148 & 20 & 4.0 \\
\hline 9 & ice & 2 & .54 & 853 & 44 & 101 & 172 & 12 & 5.6 \\
\hline 10 & 102 & 16 & 4.3 & 594 & 56 & 90 & 217 & 8 & 4.7 \\
\hline 11 & 100 & 17 & 4.6 & 430 & 62 & 72 & 217 & in & 5.9 \\
\hline 12 & 100 & i1 & 3.0 & 350 & 15 & 14 & 196 & in & 5.3 \\
\hline 13 & 100 & 7 & 1.9 & $30 n$ & 3 & 2.4 & 200 & a & 2.7 \\
\hline 14 & 160 & 24 & 6.5 & 290 & 4 & $3, c$ & 201 & $c$ & 4.9 \\
\hline 15 & 110 & 19 & 5.5 & 260 & 7 & 4.9 & 219 & in & 5.9 \\
\hline 16 & 110 & 5 & 1.5 & 247 & 17 & 11 & 335 & $3 n$ & 29 \\
\hline 17 & 110 & 3 & .89 & 230 & 12 & 7.5 & 598 & 49 & 79 \\
\hline 18 & $12 \mathrm{c}$ & 6 & 1.9 & 210 & il & 6.2 & 592 & 79 & 126 \\
\hline 19 & 120 & 4 & 1.3 & 200 & ii & 5.9 & 545 & 75 & in \\
\hline 20 & 132 & 4 & 1.4 & $19 n$ & 5 & 2.6 & 500 & 68 & 92 \\
\hline 21 & 136 & 4 & 1.4 & 180 & 7 & 3.4 & 589 & 69 & 110 \\
\hline 22 & 138 & 6 & 2.2 & 170 & $a$ & 4.1 & 846 & 112 & 256 \\
\hline 23 & 139 & 5 & 1.9 & 270 & 5 & 2.3 & $124 n$ & 280 & 937 \\
\hline 24 & 126 & 7 & 2.4 & 160 & 2 & 86 & 1250 & 185 & 624 \\
\hline 25 & 110 & B & 2.4 & 150 & 5 & $2 . r$ & 1270 & 172 & 590 \\
\hline 26 & 110 & 11 & 3.3 & 149 & 7 & 2.6 & 1230 & 84 & 279 \\
\hline 27 & 110 & 9 & 2.7 & 140 & 8 & 3.0 & 1450 & 108 & 423 \\
\hline 28 & 130 & 7 & 2.5 & $140^{\circ}$ & \& & 3.5 & 1460 & or & 355 \\
\hline 29 & 816 & $45 \theta$ & $1360^{\circ}$ & 140 & p & 3.0 & $328 n$ & 118 & $4 \mathrm{C} 8$ \\
\hline 30 & 2130 & 644 & 3750 & -- & $\cdots$ & - & 1100 & 113 & 336 \\
\hline 31 & 2640 & 427 & $3 C 4 C$ & -- & $\cdots$ & -- & 900 & 45 & 109 \\
\hline TOT AL & 8905 & -- & 8184.83 & 23537 & -- & 4706.76 & 17702 & -- & 4917.51 \\
\hline
\end{tabular}


03139000 KILLBUCK CREEK AT KILLBUCK, OHIO--ContInued

SUSPENDED SEDIMENT, WATER YEAR OCTOBER 1967 TO SEPTEMBER 1968

\begin{tabular}{|c|c|c|c|c|c|c|c|c|c|}
\hline & & APRIL & & & MAY & & & JUNE & \\
\hline & & MEAN & & & MEAN & & & MEAN & \\
\hline & MEAN & CONCEN- & & MEAN & CONCEN- & & MEAN & CONCEN- & \\
\hline & DI SCHARGE & TF AT ION & LCAO & DISCHARGE & TPATION & LCAD & DI SCHARGE & TRATION & LoAr \\
\hline DAY & & $(M G / L)$ & \{TONS \} & & & (TOAS) & (CFS) & $(M G / L)$ & (TONS) \\
\hline 1 & 879 & 57 & 135 & 229 & 77 & 48 & $223 n$ & 112 & 674 \\
\hline 2 & 776 & 67 & 140 & 203 & 68 & 37 & 1950 & 102 & 577 \\
\hline 3 & 6ho & 57 & 102 & 191 & 64 & 33 & 1590 & 84 & 361 \\
\hline 4 & 628 & 60 & 102 & 195 & 59 & 31 & 1270 & K4 & 219 \\
\hline 5 & 663 & 64 & 115 & PRI & 51 & 25 & 974 & R5 & 224 \\
\hline 6 & 594 & 33 & 53 & 130 & 51 & 25 & 693 & 112 & 210 \\
\hline 7 & 517 & 22 & 31 & 173 & 63 & 29 & 531 & 127 & 175 \\
\hline 8 & 461 & 41 & 51 & 159 & 76 & 33 & $44 n$ & 117 & $130^{\circ}$ \\
\hline 9 & 409 & 64 & 71 & 225 & $\ln 5$ & 64 & 376 & $\ln 3$ & 105 \\
\hline 10 & 367 & 64 & 53 & 243 & 82 & 54 & 333 & 167 & $15 n$ \\
\hline 11 & 345 & 61 & 57 & 363 & 259 & 475 & 427 & 144 & $16 \mathrm{~A}$ \\
\hline 12 & 322 & 35 & 30 & 1210 & 318 & $104 \mathrm{C}$ & $6 \mathrm{C}_{3}$ & 110 & 194 \\
\hline 13 & 301 & 48 & 39 & 1110 & 114 & 342 & 504 & $15 \mathrm{e}$ & 215 \\
\hline 14 & 289 & 36 & 28 & 902 & 136 & 331 & 363 & 199 & 194 \\
\hline 15 & 447 & 57 & 69 & 720 & 132 & 257 & 301 & $1 ? 9$ & 104 \\
\hline 16 & 391 & 67 & 71 & 1127 & 859 & 2770 & 559 & 848 & $15 n c$ \\
\hline 17 & 335 & $10 n$ & 90 & 1340 & 422 & 1530 & 603 & $40 n$ & 651 \\
\hline 18 & 303 & 53 & 43 & 1350 & 282 & $103 n$ & 573 & 464 & $71^{\circ}$ \\
\hline 19 & 272 & 50 & 37 & 1420 & 171 & 656 & 493 & 372 & 495 \\
\hline 20 & 257 & 61 & 42 & 1310 & 146 & 516 & 369 & 20.2 & $2+1$ \\
\hline 21 & 244 & 38 & 25 & 1130 & 108 & 323 & 296 & $19 r$ & 144 \\
\hline 22 & 229 & 37 & 23 & 946 & 111 & $\geqslant 84$ & 257 & 127 & Ba \\
\hline 23 & 254 & 107 & 88 & 82 A & 112 & 250 & 230 & $\ln 5$ & 65 \\
\hline 24 & 513 & 206 & 298 & 1120 & 146 & 442 & 221 & 122 & 73 \\
\hline 25 & 439 & 118 & 140 & 1260 & 163 & 555 & 546 & 444 & 655 \\
\hline 26 & 350 & 82 & 79 & 118 n & $23 n$ & 733 & 598 & $35 ?$ & $56 \mathrm{~B}$ \\
\hline 27 & 331 & 51 & 45 & 1610 & 447 & $21 \Leftrightarrow C$ & 744 & 744 & 1495 \\
\hline 28 & 291 & 56 & 44 & 2920 & 367 & 2395 & 621 & 746 & $125 \hat{\circ}$ \\
\hline 27 & 202 & 50 & 35 & 2503 & 144 & $1 \cap 10$ & $49 n$ & 261 & 345 \\
\hline 30 & 248 & 72 & $4 B$ & 2460 & 135 & 897 & 363 & 146 & 143 \\
\hline 31 & - & - & $\because$ & 2428 & $18 \pi$ & 1180 & - & - & - \\
\hline TDTAL & 12388 & -- & 2185 & 31298 & -- & 20050 & 19547 & -- & 12053 \\
\hline & & JULY & & & AURUST & & & SFPTEMBER & \\
\hline & & MEAN & & & MFAN & & & MEAN & \\
\hline & MEAN & CONCEN- & & MEAN & CONCEN- & & $M E A N$ & CINCEN- & \\
\hline & DISCHAFGE & TRATION & LCAD & DISCHAF GE & TRATICN & LOAD & DISCHAPGE & TRATIAN & LOAD \\
\hline DAY & (CFS) & IMG/LI) & (TENS) & (CFS) & $(M G / L)$ & (TONS) & (CFS) & $(M C / L)$ & (TONS) \\
\hline
\end{tabular}

\begin{tabular}{|c|c|c|c|}
\hline 1 & 295 & 226 & 180 \\
\hline 2 & 310 & 281 & 235 \\
\hline 3 & 325 & 171 & 150 \\
\hline 4 & 257 & 128 & 89 \\
\hline 5 & 217 & 142 & 83 \\
\hline 5 & 222 & $12 \mathrm{C}$ & 85 \\
\hline 7 & 187 & 145 & 73 \\
\hline 8 & 168 & 127 & 58 \\
\hline 9 & 162 & 76 & 33 \\
\hline 10 & 161 & 95 & 41 \\
\hline 11 & 149 & 107 & 43 \\
\hline 12 & 130 & 85 & 31 \\
\hline 13 & 128 & 54 & 19 \\
\hline 14 & 120 & 40 & 13 \\
\hline 15 & 116 & 55 & 17 \\
\hline 16 & 115 & 68 & 21 \\
\hline 17 & 126 & 101 & 34 \\
\hline 18 & 122 & 97 & 32 \\
\hline 19 & 121 & 92 & 30 \\
\hline 20 & 107 & 67 & 19 \\
\hline 21 & 92 & 52 & 13 \\
\hline 22 & 87 & 56 & 13 \\
\hline 23 & 106 & 85 & 24 \\
\hline 24 & 98 & 115 & 30 \\
\hline 25 & 138 & 167 & 62 \\
\hline 26 & 156 & 153 & 64 \\
\hline 27 & 112 & 101 & 31 \\
\hline 28 & $\ln _{4}$ & 76 & 21 \\
\hline 29 & 98 & 76 & 18 \\
\hline 30 & 81 & $8 C$ & 17 \\
\hline 31 & 77 & 65 & 14 \\
\hline
\end{tabular}

71
109
171
87
91
88
81
139
179
97
84
75
69
65
64
64

25
31
24
18
18
19
18
47
47
31
22
16
15
14
7.8
7.3
13
16
12
12

$\begin{array}{rr}47 & 4 \\ 66 & 4 \\ 68 & 4 \\ 56 & 45 \\ 56 & 55 \\ 113 & 175 \\ 137 & 25 \\ 83 & 170 \\ 65 & 75 \\ 66 & 74\end{array}$

$\begin{array}{ll}41 & 5.2 \\ 40 & 7.1 \\ 41 & 7.5 \\ 45 & 4.8 \\ 55 & 9.3\end{array}$

TOTAL $4663 \quad--$

2335

INTAL DISCHARGE FDR YEAR ICFS-CAYS

- jtal lcad ficr yeaf (tuns)

$\begin{array}{ll}9.0 & \\ 7.9 & 56 \\ 8.6 & \\ 4.6 & \\ 7.6 & \\ & \\ 6.5 & \\ 5.4 & 55 \\ 3.8 & \\ 4.4 & 51 \\ 4.1 & 49 \\ 4.2 & \end{array}$

$\begin{array}{rrr}6 & 86 & 1 \\ 1 & 164 & 3 \\ 1 & 92 & 1 \\ 6 & 67 & 1\end{array}$

53
55
56
56

59

68
69

56
54
60
91

76

$5 n$
43
65
94

$\begin{array}{ll}7.6 \\ 5 & 11 \\ 4 & 23\end{array}$

$94 \quad 10$

49
30

33

482.6

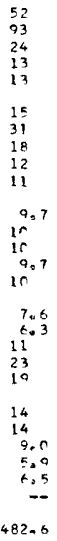

136896

56478.48 
03144500 MUSKINGUN RIVER AT DRESDEN, OHIO

LOCATION .--Lat $40^{\circ} 07^{\prime} 14^{\prime \prime}$, long $81^{\circ} 59^{\prime} 58^{\prime \prime}$, Muskingum County, at gaging station 70 ft downstream from bridge on State Highway $208,0.5$ milé east of Dresden and 0.5 mile downstream from Wakatomika Creek.

DRAINAGE AREA, $--5,993 \mathrm{sq} \mathrm{mi}$.

PERIOD OF RECORD.--Water temperatures: October 1952 to September 1961, October 1961 to September 1963, un-

published; October 1963 to September 1968.
Sediment records: October 1952 to September 1968.

EXTREMES, - -1967-68:

Water temperatures: Maximum, $30.0^{\circ} \mathrm{C}$ Aug. 24 ; minimum, freezing point on several days during December and January.

Sediment concentrations: Maximum daily, $350 \mathrm{mg} / 1 \mathrm{Jan} .31$; minimum dally, $6 \mathrm{mg} / 1 \mathrm{Jan} .18$.

Sediment loads: Maximum daily, 18,900 tons Jan. 31; m1nimum daily, 31 tons Sept. 15.

Period of record:

Water temperatures $(1952-60,1964-68)$ : Maximum, $31.0^{\circ} \mathrm{C}$ Aug. 4,1955 ; minimum, freezing point on many days

during $1952-59,1965-68$. Waximum daily, $1,600 \mathrm{mg} / 1 \mathrm{Jan} .22,1959 ; \mathrm{m} 1 \mathrm{nimum}$ daily, $1 \mathrm{mg} / 1$ on several days
sediment concentrations: Waxions

during 1952, 1954, 1956, and 1960,

REMARKS. - Flow is regulated by 14 flood-control reservoirs. Daily sediment loads were computed by subdivision on Dec. 21, Jan. 29,30 , May 12 .

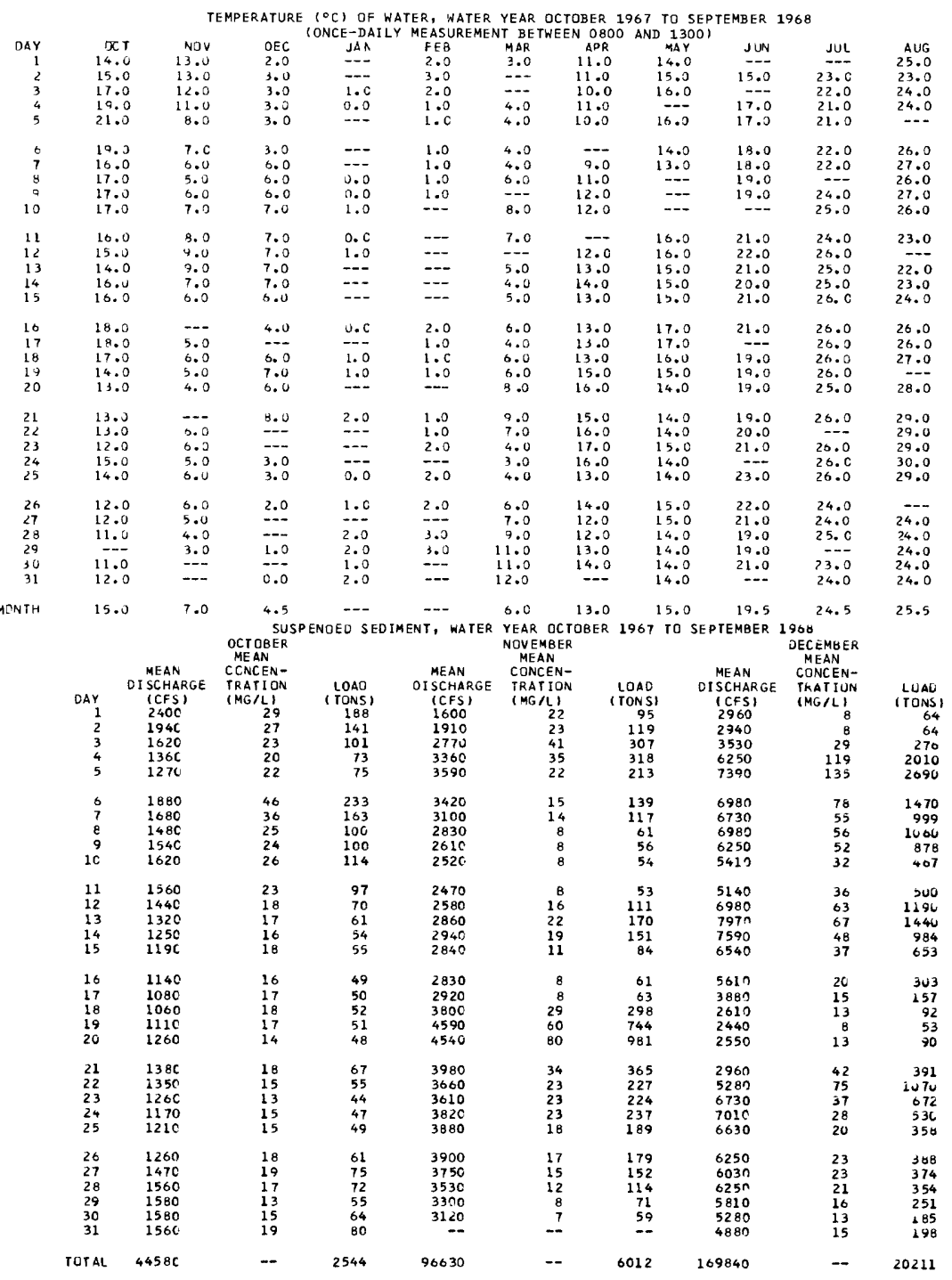


03144500 MUSKINGUM RIVER AT DRESDEN, OHIO--Continued

SUSPENDED SEOIMENT, WATER YEAR OCTOBER 1967 TO SEPTEMBER 1968

FEBRUARY

MARCH

OAY

MEAN MEAN

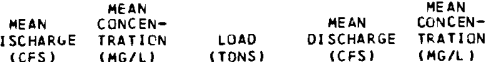
LOAD MEAN CONCEN$\begin{array}{ll}\text { DISCHARGE } & \text { TRATION LUAO } \\ \text { (CFS) } & \text { (MGIL) }\end{array}$

4320
$354 C$
2960
$318 C$

$\begin{array}{ll}15 & 175 \\ 15 & 143 \\ 13 & 104\end{array}$

20600

215

12000

2520

21800
22400

$\begin{array}{ll}146 & 22100 \\ 111 & 23800\end{array}$

215
152
116

12000
8950

$6920 \quad 2190$

$12 \quad 82$

$318 \mathrm{C}$
$274 \mathrm{C}$

2330
2450

2450
2080
2050

24300

24400

24200

$205 C$
$223 C$

$\begin{array}{rr}53 & 24400 \\ 45 & 24200 \\ 72 & 24000 \\ 102 & 21100\end{array}$

2296

2230
2240
2050

21100

$\begin{array}{llll}2050 & 13 & 72 & 13400 \\ 203 C & 10 & 55 & 12200\end{array}$

$\begin{array}{ll}74 & 17400 \\ 66 & 15600\end{array}$

$91 \quad 14700$

$203 \mathrm{C}$

2010

2170

$44 \quad 9570$

$\begin{array}{ll}38 & 5750 \\ 34 & 461 C \\ 41 & 3960\end{array}$

2300

$238 \mathrm{C}$

2550
$205 C$

2050
2880

$41 \quad 3850$

$\begin{array}{ll}56 & 3460 \\ 45 & 3070 \\ 55 & 3020\end{array}$

$\begin{array}{ll}45 & 3070 \\ 55 & 3020 \\ 50 & 3070\end{array}$

$298 \mathrm{C}$
$304 \mathrm{C}$

3040

$471 C$
14900

TOTAL $11060 \mathrm{C}$

$\begin{array}{rr}64 & 2680 \\ 115 & 2620 \\ 107 & 2580 \\ 703 & 2480 \\ 14900 & --\end{array}$

$\begin{array}{lll}68 & 4460 & 2200 \\ 62 & 4080 & 2260\end{array}$

2160

$\begin{array}{ll}10 & 61 \\ 12 & 62 \\ 11 & 71\end{array}$

$\begin{array}{ll}4080 & 2260 \\ 3720 & 2270\end{array}$

$3500 \quad 2400$

848

$10 \quad 61$

$2260 \quad 282 \mathrm{C}$

$1529 \quad 3010$

1360
11600

$\begin{array}{ll}15 & +14 \\ 17 & +18\end{array}$

$090 \quad 4640$
9020

$\begin{array}{ll}861 & 5020 \\ 916 & 6670 \\ 398 & 8850 \\ 171 & 941 n\end{array}$

$941 n$

8570

13400
18100

18100
19000

21500

22600
22900

22900
22900

22500

20400

287080

$\begin{array}{ll}24 & 241 \\ 35 & 490\end{array}$

$\begin{array}{rr}54 & 732 \\ 83 & 1490 \\ 109 & 2600 \\ 112 & 2850 \\ 88 & 1950\end{array}$

54
$290 \quad 10700$

$\begin{array}{rl}321 & 15706 \\ 173 & 6876\end{array}$

i28 7430

TOPR

ME AN MEAN CONCENDISCHAR

DA

$\begin{array}{rrr}1 & 15000 & 116 \\ 2 & 15900 & 133 \\ 3 & 15400 & 88 \\ 4 & 13900 & 67 \\ 5 & 12700 & 73\end{array}$

MEAN

MEAN
CONCEN-

CONCEN-
TRATION

$7 C 136$

$\begin{array}{ll}115 & 7020 \\ 112 & 6920\end{array}$

$84 \quad 6000$

78
67

-- 88608

JUNE

MEAN

MEAN CUNCEN-

OISCHARGE TRATIUN LUAD

LOAD CISCHAR

LOAD

TONSI

18700
19000

20000

$\begin{array}{ll}4700 & 4140 \\ 5710 & 3880\end{array}$

$\begin{array}{ll}3660 & 3660 \\ 2510 & 3620\end{array}$

$14 \quad 156$

$\begin{array}{ll}188 & 20000 \\ 195 & 21600\end{array}$

21200

20700

20200
19600

19000
18500

17600

16200

16300
13800

11800

11200

11300

11400
10700

10700

5860

5140

4540

4040

$\begin{array}{llll}4010 & 16 & 173 & 12200 \\ 4390 & 23 & 273 & 16290 \\ 5570 & 37 & 556 & 14700\end{array}$

5590
5140

5140
4850

$462 \mathrm{C}$

4400

28
19
19
18
14
-

42
264
24
22
16

16500

20300

20900

19600

17100
19000

TOTAL 224540

- $\quad 33547$

338010

$96 \quad 34.00$

$\begin{array}{ll}203 & 8880 \\ 176 & 6990\end{array}$

$\begin{array}{ll}112 & 4990 \\ 122 & 6690\end{array}$

$\begin{array}{rr}122 & 6690 \\ 168 & 9489 \\ 110 & 5820 \\ 83 & 3830 \\ 73 & 3740\end{array}$

5720
7290

7290
7790

7250
5840

83960

$\begin{array}{ll}65 & 3280 \\ 65 & 3330 \\ 66 & 3500 \\ 56 & 3270\end{array}$

$\begin{array}{ll}56 & 3270 \\ 45 & 2580\end{array}$

$\begin{array}{ll}42 & 2350 \\ 43 & 2250\end{array}$

$\begin{array}{ll}42 & 2220 \\ 35 & 1800\end{array}$

37
49

$43 \quad 1600$

$41 \quad 1324$

$39 \quad 1180$

42
53
46 1330

52

$39 \quad 541$

$\begin{array}{ll}35 & 429 \\ 28 & 307 \\ 32 & 349\end{array}$

-. 113982

84
176
143
105
68
-

1300
3460

3016

1070

35809 
03144500 MUSKINGUM RIVER AT DRESDEN, OHIO- Continued SUSPENDED SEDIMENT, WATER YEAR OCTOBER 1967 TO SEPTEMBER 1968 JULY AUGUST

SEPTEMBER

\begin{tabular}{|c|c|c|c|c|c|c|c|c|c|}
\hline DAY & $\begin{array}{l}\text { MEAN } \\
\text { DISCHARGE } \\
\text { ICFS I I }\end{array}$ & $\begin{array}{l}\text { MEAN } \\
\text { CONCEN- } \\
\text { TRATION } \\
\text { (MG/L) }\end{array}$ & $\begin{array}{l}\text { LOAD } \\
\text { (TONS) }\end{array}$ & $\begin{array}{l}\text { MEAN } \\
\text { DISCHARGE } \\
\text { ICFS I }\end{array}$ & $\begin{array}{l}\text { MEAN } \\
\text { CONCEN- } \\
\text { TRATION } \\
\text { IMG AII }\end{array}$ & $\begin{array}{l}\text { IOAD } \\
\text { ITONSI }\end{array}$ & $\begin{array}{l}\text { MEAN } \\
\text { D1SCHARGE } \\
\text { (CFS) }\end{array}$ & $\begin{array}{l}\text { MEAN } \\
\text { CUNCEN- } \\
\text { IRATION } \\
\text { (MG/L) }\end{array}$ & $\begin{array}{l}\text { LUAD } \\
\text { ITUNSI }\end{array}$ \\
\hline $\begin{array}{l}1 \\
2 \\
3 \\
4 \\
5\end{array}$ & $\begin{array}{l}4860 \\
5540 \\
4640 \\
4060 \\
3580\end{array}$ & $\begin{array}{r}53 \\
142 \\
92 \\
53 \\
42\end{array}$ & $\begin{array}{r}695 \\
2120 \\
1156 \\
581 \\
406\end{array}$ & $\begin{array}{l}2150 \\
2310 \\
2880 \\
3010 \\
2770\end{array}$ & $\begin{array}{l}40 \\
40 \\
52 \\
71 \\
53\end{array}$ & $\begin{array}{l}232 \\
249 \\
404 \\
577 \\
396\end{array}$ & $\begin{array}{r}971 \\
1030 \\
1200 \\
1270 \\
1170\end{array}$ & $\begin{array}{l}45 \\
37 \\
36 \\
42 \\
53\end{array}$ & $\begin{array}{l}118 \\
103 \\
117 \\
144 \\
107\end{array}$ \\
\hline $\begin{array}{r}6 \\
7 \\
8 \\
9 \\
10\end{array}$ & $\begin{array}{l}3200 \\
2960 \\
2820 \\
2710 \\
2640\end{array}$ & $\begin{array}{l}33 \\
32 \\
28 \\
37 \\
31\end{array}$ & $\begin{array}{l}285 \\
256 \\
213 \\
271 \\
221\end{array}$ & $\begin{array}{l}2640 \\
2620 \\
2820 \\
3020 \\
4060\end{array}$ & $\begin{array}{l}61 \\
63 \\
84 \\
66 \\
90\end{array}$ & $\begin{array}{l}435 \\
446 \\
640 \\
538 \\
987\end{array}$ & $\begin{array}{l}1230 \\
1473 \\
1870 \\
158 C \\
1320\end{array}$ & $\begin{array}{l}50 \\
56 \\
61 \\
36 \\
32\end{array}$ & $\begin{array}{l}166 \\
<22 \\
308 \\
154 \\
114\end{array}$ \\
\hline $\begin{array}{l}11 \\
12 \\
13 \\
14 \\
15\end{array}$ & $\begin{array}{l}2590 \\
2470 \\
2360 \\
2290 \\
2200\end{array}$ & $\begin{array}{l}30 \\
33 \\
22 \\
28 \\
32\end{array}$ & $\begin{array}{l}210 \\
22 C \\
14 C \\
173 \\
190\end{array}$ & $\begin{array}{l}3880 \\
3480 \\
3320 \\
2880 \\
2500\end{array}$ & $\begin{array}{l}83 \\
62 \\
58 \\
52 \\
47\end{array}$ & $\begin{array}{l}879 \\
583 \\
520 \\
404 \\
317\end{array}$ & $\begin{array}{l}1230 \\
1150 \\
1120 \\
1090 \\
1050\end{array}$ & $\begin{array}{l}31 \\
30 \\
28 \\
16 \\
11\end{array}$ & $\begin{array}{r}100 \\
93 \\
85 \\
47 \\
31\end{array}$ \\
\hline $\begin{array}{l}16 \\
17 \\
18 \\
19 \\
20\end{array}$ & $\begin{array}{l}2160 \\
2480 \\
3160 \\
4460 \\
4090\end{array}$ & $\begin{array}{r}36 \\
84 \\
83 \\
105 \\
125\end{array}$ & $\begin{array}{r}175 \\
562 \\
708 \\
1260 \\
1380\end{array}$ & $\begin{array}{l}2230 \\
2010 \\
1850 \\
1920 \\
1810\end{array}$ & $\begin{array}{l}38 \\
37 \\
43 \\
48 \\
53\end{array}$ & $\begin{array}{l}229 \\
201 \\
215 \\
249 \\
259\end{array}$ & $\begin{array}{r}1000 \\
949 \\
905 \\
905 \\
916\end{array}$ & $\begin{array}{l}13 \\
13 \\
16 \\
18 \\
19\end{array}$ & $\begin{array}{l}35 \\
33 \\
39 \\
44 \\
47\end{array}$ \\
\hline $\begin{array}{l}21 \\
22 \\
23 \\
24 \\
25\end{array}$ & $\begin{array}{l}3720 \\
3020 \\
2550 \\
2540 \\
3460\end{array}$ & $\begin{array}{r}97 \\
63 \\
51 \\
45 \\
276\end{array}$ & $\begin{array}{r}974 \\
514 \\
351 \\
309 \\
2580\end{array}$ & $\begin{array}{l}1680 \\
2560 \\
1500 \\
1420 \\
1310\end{array}$ & $\begin{array}{l}45 \\
34 \\
36 \\
27 \\
24\end{array}$ & $\begin{array}{r}204 \\
143 \\
146 \\
164 \\
85\end{array}$ & $\begin{array}{r}916 \\
916 \\
927 \\
960 \\
1080\end{array}$ & $\begin{array}{l}25 \\
18 \\
20 \\
18 \\
27\end{array}$ & $\begin{array}{l}62 \\
45 \\
56 \\
47 \\
79\end{array}$ \\
\hline $\begin{array}{l}26 \\
27 \\
28 \\
29 \\
36 \\
31\end{array}$ & $\begin{array}{l}4100 \\
3860 \\
3266 \\
2800 \\
2440 \\
2190\end{array}$ & $\begin{array}{r}134 \\
88 \\
57 \\
44 \\
34 \\
142\end{array}$ & $\begin{array}{r}1480 \\
917 \\
502 \\
333 \\
224 \\
840\end{array}$ & $\begin{array}{r}1200 \\
1140 \\
1080 \\
1060 \\
1020 \\
971\end{array}$ & $\begin{array}{l}34 \\
36 \\
45 \\
41 \\
44 \\
39\end{array}$ & $\begin{array}{l}110 \\
111 \\
131 \\
117 \\
121 \\
102\end{array}$ & $\begin{array}{r}1260 \\
1240 \\
1080 \\
971 \\
894 \\
--\end{array}$ & $\begin{array}{l}38 \\
31 \\
25 \\
26 \\
22 \\
--\end{array}$ & $\begin{array}{r}29 \\
104 \\
73 \\
68 \\
53 \\
-\end{array}$ \\
\hline TOTAL & 99210 & -. & 20240 & 68101 & -- & 10125 & 33652 & -- & 2077 \\
\hline
\end{tabular}

03146500 LICKING RIVER NEAR NEWARK, OHIO

LOCATION, --Lat $40^{\circ} 03^{\prime} 33^{\prime \prime}$, long $82^{\circ} 20^{\prime} 23^{\prime}$, in NE 1 SW 1 T.2 N., R.11 W., Licking County, at gaging station on right bank bank at downstream side of Stadden Bridge,

DRAINAGE AREA, $--537 \mathrm{sq} \mathrm{mi}$.

PERIOD OF RECORD. --Chemical analyses: July to September 1968.

Water temperatures: June 1962 to September 1968.

EXTREMES. - - 1967-68:

Water temperatures: Maximum, $26.0^{\circ} \mathrm{C}$ Aug. $20,21,23-25$; minimum, $1.0^{\circ} \mathrm{C}$ Mar. 23,24

Perlod of record:

Water temperatures: Maximum, $29.0^{\circ} \mathrm{C}$ Aug. 16, 17, $1965 ;$ m1n1mum, freezing point on many days during winter periods.

REHARKS. -- A continuous recorder was installed at this station on July 8, 1968 which records conductance, pH, dissolved oxygen, and temperature. Records of temperature for 1968 water year were taken from the thermograph. These data are shown in a separate temperature table. In addition to the continuous recorder, twice-weekly

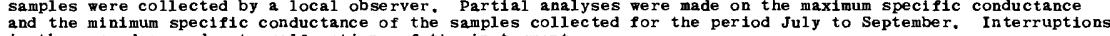
in the record were due to malfunctions of the instrument.

CHEMICAL ANALYSES IN MILLIGRAMS PER Liter, JULY TO SEPTEMBER 1968

\begin{tabular}{|c|c|c|c|c|c|c|c|}
\hline DATE & TIME & $\begin{array}{l}\text { DIS- } \\
\text { CHARGE } \\
\text { ICFSI }\end{array}$ & $\begin{array}{l}\text { RICAR- } \\
\text { RONATF } \\
\text { (MCOB) }\end{array}$ & $\begin{array}{l}\text { CAR- } \\
\text { BOVATE } \\
\text { (CD3) }\end{array}$ & $\begin{array}{l}\text { SILFATF } \\
\text { (504) }\end{array}$ & $\begin{array}{l}\text { CHLO- } \\
\text { RIDE } \\
\text { [CLI }\end{array}$ & $\begin{array}{l}\text { FLUO } \\
\text { RICF } \\
\text { (F) }\end{array}$ \\
\hline \multicolumn{8}{|l|}{ JULY } \\
\hline จด... & 1445 & 195 & 236 & 1) & $17 ?$ & $4 n$ & .4 \\
\hline $26 \ldots$ & 0945 & 630 & 234 & n & $7 R$ & 22 & . \\
\hline \multicolumn{7}{|l|}{ AUUG. } & . \\
\hline $\begin{array}{l}15 . . \\
\text { SFPT. }\end{array}$ & 1539 & 320 & 218 & R & 89 & 70 & \\
\hline $02 \ldots$ & $151 \mathrm{~A}$ & 109 & 316 & 8 & 124 & 41 & \\
\hline $12 \ldots$ & 0930 & 78 & 242 & R & 110 & 152 & \\
\hline
\end{tabular}

\begin{tabular}{|c|c|c|c|c|c|c|}
\hline TATE & $\begin{array}{l}\text { N1TRATF } \\
\text { INO3i) }\end{array}$ & $\begin{array}{l}\text { OIS- } \\
\text { SOLVEO } \\
\text { SOLIDS } \\
\text { IRESI- } \\
\text { DUE AT } \\
\text { IRC CI }\end{array}$ & $\begin{array}{l}\text { HARD- } \\
\text { NFSS } \\
\text { (CA, YG) }\end{array}$ & $\begin{array}{l}\text { NON- } \\
\text { CAR- } \\
\text { RTNATE } \\
\text { HARD- } \\
\text { NESS }\end{array}$ & $\begin{array}{l}\text { SPECI- } \\
\text { FIC } \\
\text { COND- } \\
\text { UCTANCE } \\
\text { IMICRO- } \\
\text { WHISI }\end{array}$ & $\mathrm{D}_{\mathrm{H}}$ \\
\hline $\begin{array}{l}\text { JULY } \\
\text { OR.. }\end{array}$ & 20 & & & & & \\
\hline $\begin{array}{r}25 . . \\
\text { Ailg. }\end{array}$ & 14 & 944 & 274 & A2 & $\begin{array}{l}715 \\
576\end{array}$ & 7.3 \\
\hline $\begin{array}{l}12 \ldots \\
15 \ldots \\
\text { SEOT. }\end{array}$ & $\begin{array}{l}14 \\
10\end{array}$ & $\begin{array}{l}344 \\
470\end{array}$ & $\begin{array}{l}230 \\
>04\end{array}$ & $\begin{array}{r}72 \\
172\end{array}$ & $\begin{array}{l}555 \\
805\end{array}$ & $9 . \overline{5}$ \\
\hline $\begin{array}{l}02 \ldots \\
12 \ldots\end{array}$ & $\begin{array}{l}26 \\
19\end{array}$ & $\begin{array}{l}440 \\
672\end{array}$ & $\begin{array}{l}314 \\
335\end{array}$ & $\begin{array}{l}123 \\
123\end{array}$ & $\begin{array}{r}715 \\
1130\end{array}$ & $\begin{array}{l}0.4 \\
3.4\end{array}$ \\
\hline
\end{tabular}


03146500 LICKING RIVER NEAR NEWARK, OHIO--ContInued JULY

SPECIFIC CONDUCTANCE, PH AND DISSOLVED OXYGEN, JULY TO SEPTEMBER 1968 AUGUST

SEPTEMBER

\begin{tabular}{|c|c|c|c|c|c|c|c|c|c|c|c|c|c|c|c|c|c|c|}
\hline \multirow[t]{2}{*}{ DAY } & \multicolumn{2}{|c|}{$\begin{array}{l}\text { SPECIFIC } \\
\text { CONDUCTANCE } \\
\text { (MICROMHOS } \\
\text { AT } 25^{\circ} \mathrm{C} \text { ) }\end{array}$} & \multicolumn{2}{|c|}{ pH } & \multicolumn{2}{|c|}{$\begin{array}{l}\text { DISSOLVED } \\
\text { OXYGEN } \\
(\mathbf{H G} / \mathbf{L})\end{array}$} & \multicolumn{2}{|c|}{$\begin{array}{l}\text { SPECIFIC } \\
\text { CONDUCTANCE } \\
\text { (MICROMHOS } \\
\left.\text { AT 25 } 25^{\circ} \mathrm{C}\right)\end{array}$} & \multicolumn{2}{|c|}{ pH } & \multicolumn{2}{|c|}{$\begin{array}{l}\text { DISSOLVED } \\
\text { OXYGEN } \\
(\mathbf{W G / L})\end{array}$} & \multicolumn{2}{|c|}{$\begin{array}{l}\text { SPECIFIC } \\
\text { CONDUCTANCE } \\
\text { (MICROMHOS } \\
\text { AT } 25^{\circ} \mathrm{C} \text { ) }\end{array}$} & \multicolumn{2}{|c|}{ pH } & \multicolumn{2}{|c|}{$\begin{array}{l}\text { DISSOLVED } \\
\text { OXYGEN } \\
(\mathbf{M G / L )}\end{array}$} \\
\hline & MAX & MIN & $\operatorname{MAX}$ & MIN & $\operatorname{MAX}$ & MIN & MAX & MIN & $\operatorname{Max}$ & MIN & MAX & MIN & $\operatorname{MAX}$ & MIN & MAX & MIN & MAX & MIN \\
\hline 1 & - & -- & -- & - & - & -- & - & -- & - & - & -- & - & - & -- & -- & - & -- & -- \\
\hline$\frac{2}{3}$ & $\overline{-}$ & $=$ & $=$ & $\overline{-}$ & $\overline{--}$ & $=$ & $\overline{--}$ & $\overline{--}$ & $=$ & $\overline{-}$ & $=$ & $=$ & $=$ & $=$ & $=$ & $=$ & $\overline{-}$ & - \\
\hline 4 & -- & -- & -- & -- & - & -- & -- & -- & $\because$ & -- & -- & - & -- & -- & -- & $\ldots$ & $=$ & 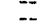 \\
\hline 5 & -- & -- & -- & -- & -- & -- & 730 & 580 & 7.8 & 7.1 & 6.6 & 4.3 & - & -- & -- & -- & -- & -- \\
\hline 6 & -- & -- & -- & -- & -- & -- & 730 & 600 & 7.2 & 6.9 & 5.1 & 3.9 & -- & -- & -- & 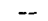 & -- & $\cdots$ \\
\hline 7 & $=$ & 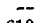 & - & 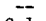 & - & $\cdots$ & 780 & 430 & 6.9 & 6.6 & 4.2 & 2.3 & - & -- & -- & - & -- & -- \\
\hline 8 & 710 & 610 & 8.3 & 8.1 & 7.6 & $\begin{array}{l}5.6 \\
4.9\end{array}$ & $\begin{array}{l}620 \\
580\end{array}$ & 440 & 6.8 & 6.7 & 4.6 & 3.3 & $\overline{-}$ & -- & -- & - & -- & -- \\
\hline $\begin{array}{r}9 \\
10\end{array}$ & $\begin{array}{l}700 \\
670\end{array}$ & $\begin{array}{l}670 \\
640\end{array}$ & $\begin{array}{l}8.2 \\
8.2\end{array}$ & 8.0 & $\begin{array}{l}6.1 \\
5.4\end{array}$ & & $\begin{array}{l}580 \\
580\end{array}$ & 540 & 6.7 & 6.5 & 4.0 & 2.5 & -- & $\cdots$ & -- & - & -- & -- \\
\hline & & & & & & & & 320 & 6.7 & 6.6 & 3.8 & 1.5 & -- & - & -- & - & - & -- \\
\hline 11 & $\begin{array}{l}700 \\
690\end{array}$ & 670 & 7.9 & 7.6 & 4.8 & 4.3 & 480 & 360 & 6.8 & 6.7 & 5.2 & 3.8 & $=-$ & - & -- & -- & -- & - \\
\hline $\begin{array}{l}12 \\
13\end{array}$ & $\begin{array}{r}690 \\
120\end{array}$ & 650 & 7.7 & 7.6 & $\begin{array}{r}6.0 \\
4.2\end{array}$ & $\begin{array}{l}4.2 \\
3.6\end{array}$ & $\begin{array}{l}620 \\
700\end{array}$ & $\begin{array}{l}480 \\
600\end{array}$ & $\begin{array}{l}6.9 \\
7.3\end{array}$ & 6.8 & 5.7 & 4.0 & 1170 & 850 & -- & -- & 3.3 & 1.8 \\
\hline 14 & $\begin{array}{l}1120 \\
1080\end{array}$ & $\begin{array}{l}670 \\
780\end{array}$ & 7.5 & $\begin{array}{l}7.5 \\
7.4\end{array}$ & $\begin{array}{l}4.2 \\
3.9\end{array}$ & 3. & 850 & 640 & -2 & $\begin{array}{r}6.9 \\
-2\end{array}$ & 5.3 & 2.0 & 1180 & 850 & $\overline{-}$ & $=$ & 2.9 & 1.7 \\
\hline 15 & 910 & 810 & 7.7 & 7.5 & 3.9 & 3.5 & 820 & 740 & -- & - & 8.7 & 5.4 & 1060 & 750 & 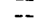 & - & $\begin{array}{l}2.0 \\
2.0\end{array}$ & $\begin{array}{l}1.8 \\
1.7\end{array}$ \\
\hline 16 & 810 & 690 & 7.6 & 7.5 & 5.0 & 3.4 & 790 & 690 & -- & - & 8.6 & 5.7 & 1000 & 750 & $\ldots$ & -- & 2.1 & 1.8 \\
\hline 17 & 930 & 770 & 7.5 & 7.4 & 4.1 & 3.4 & 870 & 740 & $=$ & - & 5.7 & 4.1 & 1100 & 950 & -- & - & 2.7 & 1.7 \\
\hline 18 & 830 & 620 & 7.6 & 7.3 & 4.0 & 3.2 & 750 & 670 & $=$ & $-\infty$ & 5. & 4.7 & 1140 & 970 & -- & -- & 2.4 & .6 \\
\hline $\begin{array}{l}19 \\
20\end{array}$ & $\begin{array}{r}640 \\
-\end{array}$ & 590 & 7.3 & 7.3 & $\begin{array}{r}3.7 \\
--\end{array}$ & 3.3 & $\begin{array}{l}720 \\
720\end{array}$ & $\begin{array}{l}670 \\
670\end{array}$ & $=$ & $=$ & $\begin{array}{l}5.5 \\
5.0\end{array}$ & 3.8 & 1060 & $\begin{array}{r}930 \\
1910\end{array}$ & $=$ & - & 1.2 & .5 \\
\hline & & & & & & & 830 & & & & & & & & & & & \\
\hline 21 & -- & $=$ & $=$ & $=$ & $=$ & - & 860 & 750 & -- & $=$ & 4.7 & $\begin{array}{l}4.1 \\
3.7\end{array}$ & $\begin{array}{l}1100 \\
1140\end{array}$ & 830 & $\overline{-}$ & $=$ & 1.6 & .9 \\
\hline 23 & -- & -- & -- & -- & -- & -- & 840 & 700 & -- & - & 5.2 & 4,1 & 1070 & 500 & - & $=$ & 1.9 & 1.1 \\
\hline 24 & -. & -- & -- & -- & -- & -- & 740 & 690 & - & - & 4.9 & 3.7 & 810 & 430 & - & - & 1.9 & 1.5 \\
\hline 25 & -- & -- & -- & -- & -- & -- & 730 & 670 & -- & $-\infty$ & 5.1 & 4.6 & 770 & 580 & -- & -- & 2.0 & 1.9 \\
\hline 26 & -- & -- & -- & -- & - & -- & 760 & 680 & -- & -- & 5.1 & 3.6 & 920 & 760 & 7.2 & 7.1 & 3.4 & 1.8 \\
\hline 27 & - & -- & $=$ & $=$ & $=$ & $\overline{--}$ & 780 & 630 & $=$ & $=$ & 3.7 & 2.5 & 1040 & 870 & 7.1 & 6.9 & 2.7 & 1.0 \\
\hline 28 & -- & -- & $\overline{-}$ & $=$ & $\overline{-}$ & $=$ & 740 & 480 & - & + & 3.2 & 1.9 & 1140 & 940 & 7.2 & 7.0 & 2.3 & .8 \\
\hline 29 & $=$ & $=$ & $\overline{-}$ & $\overline{-}$ & $\overline{-}$ & $=$ & $=$ & -- & - & - & - & -- & 1050 & 910 & 7.7 & 7.2 & 1.4 & .3 \\
\hline 30 & $=$ & - & $=$ & $\ldots$ & -- & $=$ & $=$ & $\overline{-}$ & $=$ & $=$ & -- & -- & 1040 & 790 & 7.9 & 7. & .8 & .3 \\
\hline 31 & - & & & & & & 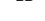 & 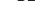 & 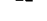 & - & - & -- & $\cdots$ & - & -- & - & - & -- \\
\hline
\end{tabular}

TEMPERATURE $\left({ }^{\circ} \mathrm{C}\right)$ OF WATER, WATER YEAR OCTOBER 1967 TO SEPTEMBER 1968 (CONTINUDUS ETHLY ALCOHOL-ACTUATED THERMOGRAPH)

DAY

MONTH $\quad 1 \quad 2 \quad 3 \quad 4 \quad 5 \quad 6 \quad 7 \quad 8 \quad 910111213141516171819202122 \quad 2324 \quad 25 \quad 26 \quad 27 \quad 282030 \quad 31$ AGER-

OCTORER

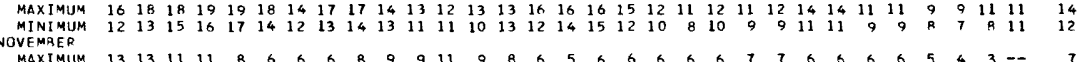
$\begin{array}{rrrrrrrrrrrrrrrrrrrrrrrrrrrrrrrrrrrrr}\text { MAXIMUM } & 13 & 13 & 11 & 11 & 8 & 6 & 6 & 6 & 8 & 9 & 9 & 11 & 9 & 8 & 6 & 5 & 6 & 6 & 6 & 6 & 6 & 7 & 7 & 6 & 6 & 6 & 6 & 5 & 4 & 3 & -- & 7 \\ \text { MINIMUM } & 11 & 11 & 11 & 8 & 6 & 5 & 5 & 4 & 4 & 6 & 9 & 9 & 8 & 6 & 4 & 3 & 5 & 5 & 5 & 4 & 4 & 6 & 6 & 4 & 5 & 6 & 5 & 3 & 2 & 3 & -- & 6\end{array}$ DECEMBER

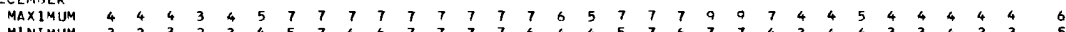
$\begin{array}{lllllllllllllllllllllllllllllllllll}\text { MINIMUM } & 3 & 3 & 3 & 2 & 3 & 4 & 5 & 7 & 6 & 6 & 7 & 7 & 7 & 7 & 6 & 4 & 4 & 5 & 7 & 6 & 7 & 7 & 4 & 3 & 4 & 4 & 3 & 3 & 4 & 3 & 3 & 5\end{array}$ $\begin{array}{lllllllllllllllllllllllllllllllllllllll}\text { MAXIMUM } & 3 & 3 & 4 & 4 & 3 & 3 & 3 & 3 & 4 & 4 & 4 & 4 & 4 & 4 & 4 & 4 & 5 & 6 & 7 & 7 & 7 & 7 & 7 & 5 & 4 & 4 & 7 & 7 & 4 & 3 & 4 & 5\end{array}$ $\begin{array}{rlllllllllllllllllllllllllllllllll}\text { MINIMUM } & 3 & 3 & 3 & 3 & 3 & 3 & 3 & 3 & 3 & 3 & 4 & 4 & 3 & 3 & 4 & 3 & 3 & 3 & 5 & 5 & 7 & 6 & 5 & 3 & 3 & 3 & 4 & 4 & 3 & 3 & 3 & 4\end{array}$ $\begin{array}{lllllllllllllllllllllllllllllllllllll}\text { MAXIMUM } & 6 & 7 & 7 & 6 & 7 & 7 & 7 & 7 & 7 & 6 & 4 & 4 & 5 & 6 & 6 & 7 & 6 & 6 & 7 & 6 & 6 & 6 & 7 & 7 & 6 & 7 & 7 & 7 & 6 & -- & -- & 6\end{array}$

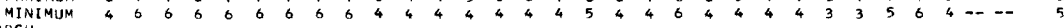

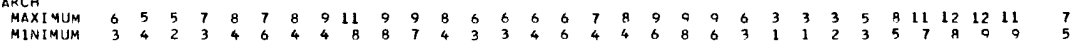

APRIL $\begin{array}{lrrrrrrrrrrrrrrrrrrrrrrrrrrrrrrrrr}\text { MAXIMUM } & 11 & 9 & 8 & 9 & 9 & 8 & 9 & 10 & 11 & 10 & 12 & 13 & 14 & 14 & 13 & 12 & 12 & 14 & 14 & 14 & 15 & 16 & 15 & 14 & 10 & 9 & 12 & 13 & 14 & 13 & -- & 12 \\ M I N I H U M & 8 & 6 & 7 & 8 & 7 & 5 & 6 & 9 & 8 & 8 & 8 & 8 & 9 & 11 & 10 & 8 & 9 & 10 & 11 & 12 & 11 & 12 & 12 & 10 & 8 & 7 & 8 & 9 & 10 & 12 & -- & 9 & 9\end{array}$

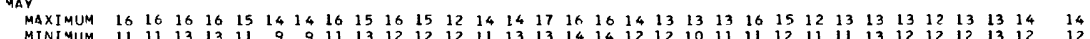

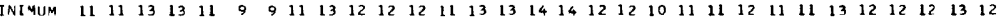
MAX[MUM $14 \begin{array}{lllllllllllllllllllllllllllllllll}15 & 17 & 17 & 18 & 19 & 19 & 21 & 22 & 21 & 22 & 21 & 19 & 18 & 19 & 18 & 17 & 18 & 18 & 19 & 19 & 18 & 19 & 21 & 21 & 19 & 18 & 16 & 21 & 23 & -- & 19\end{array}$ MINIMUM $13 \begin{array}{lllllllllllllllllllllllllllllllll}13 & 15 & 14 & 16 & 16 & 17 & 18 & 18 & 18 & 18 & 1 \mathrm{R} & 16 & 14 & 16 & 16 & 15 & 15 & 16 & 15 & 15 & 16 & 16 & 17 & 18 & 17 & 16 & 14 & 15 & 18 & -2 & 16\end{array}$ JULY

$\begin{array}{lllllllllllllllllllllllllllllllll}\text { MAXIMUM } & 23 & 23 & 19 & 20 & 21 & 22 & 22 & 22 & 23 & 23 & 23 & 22 & 23 & 22 & 22 & 22 & 24 & 25 & 25 & 24 & 24 & 24 & 24 & 24 & 22 & 23 & 22 & 22 & 22 & 21 & 21 & 23 \\ \text { MINIMUM } & 19 & 19 & 17 & 15 & 16 & 18 & 17 & 18 & 19 & 20 & 19 & 20 & 19 & 19 & 19 & 20 & 20 & 21 & 21 & 20 & 19 & 21 & 20 & 22 & 20 & 19 & 20 & 20 & 18 & 18 & 19 & 19\end{array}$ AUGUST

$\begin{array}{llllllllllllllllllllllllllllllllllll}\text { MAXIMUM } & 20 & 22 & 21 & 20 & 21 & 23 & 22 & 23 & 22 & 22 & 21 & 21 & 21 & 22 & 22 & 23 & 25 & 25 & 24 & 26 & 26 & 24 & 26 & 26 & 26 & 24 & 21 & 21 & 21 & 21 & 22 & 23 \\ \text { MINIMUM } & 19 & 18 & 19 & 19 & 18 & 20 & 21 & 19 & 20 & 20 & 19 & 17 & 18 & 18 & 19 & 20 & 22 & 22 & 21 & 22 & 23 & 23 & 24 & 24 & 23 & 20 & 18 & 18 & 18 & 18 & 10 & 20\end{array}$ SEPTEMBE

$\begin{array}{llllllllllllllllllllllllllllllllllll}\text { MAXIMUM } & 21 & 22 & 23 & 23 & 22 & 22 & 22 & 23 & 23 & 22 & 20 & 19 & 20 & 21 & 21 & 21 & 21 & 20 & 19 & 21 & 22 & 22 & 22 & 22 & 22 & 21 & 19 & 19 & 18 & 18 & -- & 21 \\ \text { MINIMUM } & 19 & 19 & 19 & 21 & 21 & 20 & 19 & 19 & 21 & 20 & 19 & 17 & 17 & 18 & 18 & 19 & 20 & 19 & 18 & 18 & 19 & 20 & 21 & 20 & 21 & 17 & 17 & 17 & 16 & 16 & -- & 19\end{array}$ 
03147500 LICKING RIVER BELOT DILLON DAX, NEAR DILLON FALLS, OHIO

LOCATION, --Lat $39^{\circ} 59^{\prime} 25^{\prime \prime}$, long $82^{\circ} 04^{\prime} 50^{\prime \prime}$, in T.1 N., R.8 w., Muskingum County, temperature recorder at gaging station on left bank, 500 $\mathrm{ft}$ downstream from Dilion Dam, 2 miles northwest of Dillon Falls and 5.8 miles upstream from mouth.

DRAINAGE AREA.--742 sq $\mathrm{si}$.

PERIOD OF RECORD, --Water temperatures: October 1961 to September 1968.

EXTREMES - $-1967-68$ :

Water temperatures: Maximum, $25.0^{\circ} \mathrm{C}$ Aug. 9-12; minimum, $3.0^{\circ} \mathrm{C}$ Feb. $1,3,5$, Mar. 13.

Period of record:

Water temperatures: Maximum, $27,0^{\circ} \mathrm{C}$ June 17-19, 1967; minimum, freezing point Feb. 7-12, 1967. TEMPERATURE ('0 $\mathrm{C}$ ) OF WATER, WATER YEAR OCTOBER 1967 TO SEPTEMBER 1968
(CONTINUOUS ETHYL ALCOHOL-ACTUATED THERMOGRAPH)

\begin{tabular}{|c|c|c|c|c|c|c|c|c|c|c|c|c|}
\hline \multirow[b]{2}{*}{ OAY } & \multicolumn{2}{|c|}{ JCTUBEK } & \multicolumn{2}{|c|}{ NVJVEMBER } & \multicolumn{2}{|c|}{ DËCEMAER } & \multicolumn{2}{|c|}{ JANUARY } & \multicolumn{2}{|c|}{ FEBRUARY } & \multicolumn{2}{|c|}{ MARCH } \\
\hline & $\operatorname{Max}$ & MIN & $\operatorname{MAX}$ & MIN & $\max$ & MIN & $\max$ & $M ! N$ & $\max$ & MIN & $\max$ & $\operatorname{MIN}$ \\
\hline $\begin{array}{l}1 \\
2 \\
3 \\
4 \\
5\end{array}$ & $\begin{array}{l}15.0 \\
14.0 \\
14.0 \\
15.0 \\
16.0\end{array}$ & $\begin{array}{l}14.0 \\
14.0 \\
14.0 \\
14.0 \\
15.0\end{array}$ & $\begin{array}{l}9.0 \\
9.0 \\
9.0 \\
9.0 \\
9.0\end{array}$ & $\begin{array}{l}9.0 \\
9.0 \\
9.0 \\
9.0 \\
8.0\end{array}$ & $\begin{array}{l}--- \\
-- \\
-\overline{5.0} \\
.0\end{array}$ & $\begin{array}{l}-- \\
-\overline{-} \\
-\overline{-} \\
5.0\end{array}$ & $\begin{array}{l}5.0 \\
5.0 \\
5.0 \\
5.0 \\
5.0\end{array}$ & $\begin{array}{l}5.0 \\
5.0 \\
5.0 \\
5.0 \\
5.0\end{array}$ & $\begin{array}{l}4.0 \\
4.0 \\
4.0 \\
4.0 \\
4.0\end{array}$ & $\begin{array}{l}3.0 \\
4.0 \\
3.0 \\
4.0 \\
3.0\end{array}$ & $\begin{array}{l}4.0 \\
4.0 \\
5.0 \\
5.0 \\
5.0\end{array}$ & $\begin{array}{l}4.0 \\
4.0 \\
4.0 \\
4.0 \\
4.0\end{array}$ \\
\hline $\begin{array}{r}0 \\
7 \\
y \\
9 \\
10\end{array}$ & $\begin{array}{l}16.0 \\
16.0 \\
16.0 \\
16.0 \\
16.0\end{array}$ & $\begin{array}{l}16.0 \\
16.0 \\
16.0 \\
16.0 \\
16.0\end{array}$ & $\begin{array}{l}8.0 \\
6.0 \\
7.0 \\
7.0 \\
7.0\end{array}$ & $\begin{array}{l}8.0 \\
7.0 \\
7.0 \\
0.0 \\
6.0\end{array}$ & $\begin{array}{l}5.0 \\
6.0 \\
7.0 \\
8.0 \\
8.0\end{array}$ & $\begin{array}{l}5.0 \\
5.0 \\
6.0 \\
7.0 \\
7.0\end{array}$ & $\begin{array}{l}5.0 \\
4.0 \\
4.0 \\
4.0 \\
5.0\end{array}$ & $\begin{array}{l}4.0 \\
4.0 \\
4.0 \\
4.0 \\
4.0\end{array}$ & $\begin{array}{l}4.0 \\
5.0 \\
5.0 \\
6.0 \\
6.0\end{array}$ & $\begin{array}{l}4.0 \\
4.0 \\
5.0 \\
5.0 \\
5.0\end{array}$ & $\begin{array}{l}5.0 \\
5.0 \\
5.0 \\
5.0 \\
5.0\end{array}$ & $\begin{array}{l}4.0 \\
4.0 \\
4.0 \\
4.0 \\
4.0\end{array}$ \\
\hline $\begin{array}{l}11 \\
12 \\
13 \\
14 \\
15\end{array}$ & $\begin{array}{l}16.0 \\
14.0 \\
14.0 \\
13.0 \\
13.0\end{array}$ & $\begin{array}{l}14.0 \\
14.0 \\
13.0 \\
13.0 \\
13.0\end{array}$ & $\begin{array}{l}6.0 \\
7.0 \\
7.0 \\
7.0 \\
6.0\end{array}$ & $\begin{array}{l}0.0 \\
6.0 \\
7.0 \\
0.0 \\
6.0\end{array}$ & $\begin{array}{l}8.0 \\
8.0 \\
8.0 \\
8.0 \\
8.0\end{array}$ & $\begin{array}{l}7.0 \\
8.0 \\
8.0 \\
8.0 \\
8.0\end{array}$ & $\begin{array}{l}5.0 \\
4.0 \\
4.0 \\
4.0 \\
4.0\end{array}$ & $\begin{array}{l}4.0 \\
4.0 \\
4.0 \\
4.0 \\
4.0\end{array}$ & $\begin{array}{l}6.0 \\
5.0 \\
4.0 \\
4.0 \\
4.0\end{array}$ & $\begin{array}{l}5.0 \\
4.0 \\
4.0 \\
4.0 \\
4.0\end{array}$ & $\begin{array}{l}5.0 \\
5.0 \\
5.0 \\
6.0 \\
6.0\end{array}$ & $\begin{array}{l}4.0 \\
4.0 \\
3.0 \\
5.0 \\
5.0\end{array}$ \\
\hline $\begin{array}{l}16 \\
17 \\
18 \\
19 \\
20\end{array}$ & $\begin{array}{l}13.0 \\
14.0 \\
14.0 \\
14.0 \\
13.0\end{array}$ & $\begin{array}{l}13.0 \\
13.0 \\
14.0 \\
13.0 \\
13.0\end{array}$ & $\begin{array}{l}6.0 \\
6.0 \\
6.0 \\
5.0 \\
5.0\end{array}$ & $\begin{array}{l}6.0 \\
5.0 \\
4.0 \\
4.0 \\
4.0\end{array}$ & $\begin{array}{l}8.0 \\
6.0 \\
6.0 \\
6.0 \\
6.0\end{array}$ & $\begin{array}{l}6.0 \\
6.0 \\
6.0 \\
6.0 \\
6.0\end{array}$ & $\begin{array}{l}4.0 \\
4.0 \\
4.0 \\
4.0 \\
4.0\end{array}$ & $\begin{array}{l}4.0 \\
4.0 \\
4.0 \\
4.0 \\
4.0\end{array}$ & $\begin{array}{l}4.0 \\
4.0 \\
4.0 \\
4.0 \\
4.0\end{array}$ & $\begin{array}{l}4.0 \\
4.0 \\
4.0 \\
4.0 \\
4.0\end{array}$ & $\begin{array}{l}6.0 \\
6.0 \\
6.0 \\
6.0 \\
8.0\end{array}$ & $\begin{array}{l}5.0 \\
6.0 \\
6.0 \\
6.0 \\
6.0\end{array}$ \\
\hline $\begin{array}{l}21 \\
22 \\
23 \\
24 \\
25\end{array}$ & $\begin{array}{l}13.0 \\
12.0 \\
12.0 \\
11.0 \\
12.0\end{array}$ & $\begin{array}{l}12.0 \\
12.0 \\
11.0 \\
11.0 \\
11.0\end{array}$ & $\begin{array}{l}5.0 \\
5.0 \\
5.0 \\
4.0 \\
---\end{array}$ & $\begin{array}{l}4.0 \\
4.0 \\
4.0 \\
4.0 \\
---.\end{array}$ & $\begin{array}{l}6.0 \\
6.0 \\
6.0 \\
6.0 \\
6.0\end{array}$ & $\begin{array}{l}6.0 \\
6.0 \\
6.0 \\
6.0 \\
6.0\end{array}$ & $\begin{array}{l}4.0 \\
4.0 \\
4.0 \\
4.0 \\
4.0\end{array}$ & $\begin{array}{l}4.0 \\
4.0 \\
4.0 \\
4.0 \\
4.0\end{array}$ & $\begin{array}{l}4.0 \\
4.0 \\
4.0 \\
4.0 \\
4.0\end{array}$ & $\begin{array}{l}4.0 \\
4.0 \\
4.0 \\
4.0 \\
4.0\end{array}$ & $\begin{array}{l}8.0 \\
8.0 \\
8.0 \\
8.0 \\
8.0\end{array}$ & $\begin{array}{l}8.0 \\
8.0 \\
8.0 \\
8.0 \\
7.0\end{array}$ \\
\hline $\begin{array}{l}26 \\
27 \\
28 \\
29 \\
30 \\
31\end{array}$ & $\begin{array}{r}12.0 \\
11.0 \\
11.0 \\
10.0 \\
9.0 \\
9.0\end{array}$ & $\begin{array}{r}11.0 \\
11.0 \\
10.0 \\
9.0 \\
4.0 \\
9.0\end{array}$ & $\begin{array}{l}--- \\
--- \\
--- \\
--- \\
--- \\
--\end{array}$ & $\begin{array}{l}-\infty \\
-- \\
-- \\
--\end{array}$ & $\begin{array}{l}0.0 \\
6.0 \\
6.0 \\
5.0 \\
5.0 \\
5.0\end{array}$ & $\begin{array}{l}6.0 \\
6.0 \\
5.0 \\
5.0 \\
5.0 \\
5.0\end{array}$ & $\begin{array}{l}4.0 \\
4.0 \\
4.0 \\
4.0 \\
4.0 \\
4.0\end{array}$ & $\begin{array}{l}4.0 \\
4.0 \\
4.0 \\
4.0 \\
4.0 \\
4.0\end{array}$ & $\begin{array}{l}4.0 \\
4.0 \\
4.0 \\
4.0 \\
-\ldots .0 \\
---\end{array}$ & $\begin{array}{l}4.0 \\
4.0 \\
4.0 \\
4.0 \\
--- \\
---\end{array}$ & $\begin{array}{r}7.0 \\
6.0 \\
6.0 \\
8.0 \\
10.0 \\
12.0\end{array}$ & $\begin{array}{r}6.0 \\
6.0 \\
5.0 \\
6.0 \\
8.0 \\
10.0\end{array}$ \\
\hline MONTH & \multicolumn{2}{|c|}{16.0 APRIL } & \multicolumn{2}{|c|}{ MAY ${ }^{4.0}$} & \multicolumn{2}{|c|}{ JUNE } & \multicolumn{2}{|c|}{ JULY } & \multicolumn{2}{|c|}{ AUGUST } & \multicolumn{2}{|c|}{ SEPT EMBER } \\
\hline DAY & $\max$ & $M[N$ & $\max$ & $M I N$ & $\operatorname{Max}$ & $\operatorname{MIN}$ & $\operatorname{MAX}$ & YIV & $\max$ & MIN & $\max$ & $\operatorname{MIN}$ \\
\hline $\begin{array}{l}1 \\
2 \\
3 \\
4 \\
5\end{array}$ & $\begin{array}{l}12.0 \\
12.0 \\
11.0 \\
11.0 \\
110.0\end{array}$ & $\begin{array}{r}12.0 \\
11.0 \\
11.0 \\
10.0 \\
9.0\end{array}$ & $\begin{array}{l}10.0 \\
10.0 \\
10.0 \\
10.0 \\
10.0\end{array}$ & $\begin{array}{l}9.0 \\
9.0 \\
9.0 \\
9.0 \\
9.0\end{array}$ & $\begin{array}{r}9.0 \\
9.0 \\
9.0 \\
9.0 \\
10.0\end{array}$ & $\begin{array}{l}8.0 \\
8.0 \\
8.0 \\
9.0 \\
9.0\end{array}$ & $\begin{array}{l}18.0 \\
18.0 \\
18.0 \\
18.0 \\
18.0\end{array}$ & $\begin{array}{l}17.0 \\
18.0 \\
18.0 \\
18.0 \\
17.0\end{array}$ & $\begin{array}{l}23.0 \\
23.0 \\
23.0 \\
23.0 \\
23.0\end{array}$ & $\begin{array}{l}22.0 \\
22.0 \\
22.0 \\
23.0 \\
22.0\end{array}$ & $\begin{array}{l}21.0 \\
21.0 \\
21.0 \\
21.0 \\
21.0\end{array}$ & $\begin{array}{l}21.0 \\
20.0 \\
21.0 \\
21.0 \\
20.0\end{array}$ \\
\hline $\begin{array}{r}6 \\
7 \\
8 \\
9 \\
10\end{array}$ & $\begin{array}{l}9.0 \\
9.0 \\
8.0 \\
8.0 \\
8.0\end{array}$ & $\begin{array}{l}8.0 \\
0.0 \\
0.0 \\
8.0 \\
8.0\end{array}$ & $\begin{array}{l}9.0 \\
9.0 \\
9.0 \\
9.0 \\
9.0\end{array}$ & $\begin{array}{l}9.0 \\
8.0 \\
8.0 \\
8.0 \\
8.0\end{array}$ & $\begin{array}{l}10.0 \\
11.0 \\
11.0 \\
11.0 \\
13.0\end{array}$ & $\begin{array}{l}10.0 \\
10.0 \\
11.0 \\
11.0 \\
11.0\end{array}$ & $\begin{array}{l}18.0 \\
18.0 \\
18.0 \\
18.0 \\
19.0\end{array}$ & $\begin{array}{l}18.0 \\
18.0 \\
18.0 \\
18.0 \\
18.0\end{array}$ & $\begin{array}{l}24.0 \\
24.0 \\
24.0 \\
25.0 \\
25.0\end{array}$ & $\begin{array}{l}22.0 \\
24.0 \\
24.0 \\
24.0 \\
24.0\end{array}$ & $\begin{array}{l}21.0 \\
21.0 \\
21.0 \\
21.0 \\
20.0\end{array}$ & $\begin{array}{l}20.0 \\
21.0 \\
21.0 \\
20.0 \\
20.0\end{array}$ \\
\hline $\begin{array}{l}11 \\
12 \\
13 \\
14 \\
15\end{array}$ & $\begin{array}{r}10.0 \\
9.0 \\
9.0 \\
9.0 \\
10.0\end{array}$ & $\begin{array}{l}9.0 \\
9.0 \\
8.0 \\
8.0 \\
9.0\end{array}$ & $\begin{array}{l}9.0 \\
9.0 \\
9.0 \\
9.0 \\
9.0\end{array}$ & $\begin{array}{l}9.0 \\
9.0 \\
9.0 \\
8.0 \\
0.0\end{array}$ & $\begin{array}{l}12.0 \\
14.0 \\
14.0 \\
13.0 \\
13.0\end{array}$ & $\begin{array}{l}11.0 \\
12.0 \\
13.0 \\
12.0 \\
12.0\end{array}$ & $\begin{array}{l}19.0 \\
19.0 \\
19.0 \\
19.0 \\
20.0\end{array}$ & $\begin{array}{l}19.0 \\
19.0 \\
19.0 \\
19.0 \\
19.0\end{array}$ & $\begin{array}{l}25.0 \\
25.0 \\
24.0 \\
23.0 \\
22.0\end{array}$ & $\begin{array}{l}25.0 \\
24.0 \\
23.0 \\
22.0 \\
22.0\end{array}$ & $\begin{array}{l}20.0 \\
21.0 \\
21.0 \\
21.0 \\
20.0\end{array}$ & $\begin{array}{l}20.0 \\
19.0 \\
21.0 \\
20.0 \\
20.0\end{array}$ \\
\hline $\begin{array}{l}16 \\
17 \\
18 \\
19 \\
20\end{array}$ & $\begin{array}{r}10.0 \\
9.0 \\
11.0 \\
11.0 \\
10.0\end{array}$ & $\begin{array}{l}9.0 \\
9.0 \\
9.0 \\
9.0 \\
9.0\end{array}$ & $\begin{array}{l}10.0 \\
11.0 \\
11.0 \\
11.0 \\
11.0\end{array}$ & $\begin{array}{r}8.0 \\
10.0 \\
11.0 \\
11.0 \\
11.0\end{array}$ & $\begin{array}{l}14.0 \\
14.0 \\
14.0 \\
14.0 \\
14.0\end{array}$ & $\begin{array}{l}13.0 \\
14.0 \\
13.0 \\
13.0 \\
14.0\end{array}$ & $\begin{array}{l}20.0 \\
20.0 \\
20.0 \\
21.0 \\
21.0\end{array}$ & $\begin{array}{l}20.0 \\
20.0 \\
19.0 \\
19.0 \\
21.0\end{array}$ & $\begin{array}{l}22.0 \\
23.0 \\
23.0 \\
22.0 \\
22.0\end{array}$ & $\begin{array}{l}22.0 \\
22.0 \\
22.0 \\
22.0 \\
22.0\end{array}$ & $\begin{array}{l}20.0 \\
19.0 \\
19.0 \\
19.0 \\
19.0\end{array}$ & $\begin{array}{l}19.0 \\
19.0 \\
19.0 \\
19.0 \\
19.0\end{array}$ \\
\hline $\begin{array}{l}21 \\
22 \\
23 \\
24 \\
25\end{array}$ & $\begin{array}{l}11.0 \\
11.0 \\
110.0 \\
10.0 \\
10.0\end{array}$ & $\begin{array}{r}9.0 \\
10.0 \\
4.0 \\
7.0 \\
9.0\end{array}$ & $\begin{array}{r}11.0 \\
11.0 \\
10.0 \\
9.0 \\
9.0\end{array}$ & $\begin{array}{r}10.0 \\
9.0 \\
9.0 \\
9.0 \\
8.0\end{array}$ & $\begin{array}{l}14.0 \\
14.0 \\
14.0 \\
16.0 \\
15.0\end{array}$ & $\begin{array}{l}14.0 \\
14.0 \\
14.0 \\
14.0 \\
14.0\end{array}$ & $\begin{array}{l}21.0 \\
22.0 \\
21.0 \\
22.0 \\
22.0\end{array}$ & $\begin{array}{l}20.0 \\
20.0 \\
21.0 \\
21.0 \\
22.0\end{array}$ & $\begin{array}{l}22.0 \\
22.0 \\
22.0 \\
22.0 \\
23.0\end{array}$ & $\begin{array}{l}22.0 \\
22.0 \\
22.0 \\
22.0 \\
22.0\end{array}$ & $\begin{array}{l}19.0 \\
19.0 \\
19.0 \\
20.0 \\
20.0\end{array}$ & $\begin{array}{l}19.0 \\
19.0 \\
19.0 \\
19.0 \\
20.0\end{array}$ \\
\hline $\begin{array}{l}26 \\
27 \\
28 \\
29 \\
30 \\
31\end{array}$ & $\begin{array}{r}10.0 \\
10.0 \\
9.0 \\
9.0 \\
11.0 \\
-\end{array}$ & $\begin{array}{l}9.0 \\
4.0 \\
9.0 \\
8.0 \\
9.0 \\
--.\end{array}$ & $\begin{array}{l}9.0 \\
9.0 \\
8.0 \\
8.0 \\
9.0 \\
9.0\end{array}$ & $\begin{array}{l}9.0 \\
8.0 \\
4.0 \\
8.0 \\
8.0 \\
9.0\end{array}$ & $\begin{array}{r}16.0 \\
17.0 \\
17.0 \\
17.0 \\
17.0 \\
-. .2\end{array}$ & $\begin{array}{r}15.0 \\
16.0 \\
17.0 \\
17.0 \\
17.0 \\
-\cdots\end{array}$ & $\begin{array}{l}22.0 \\
22.0 \\
23.0 \\
23.0 \\
23.0 \\
22.0\end{array}$ & $\begin{array}{l}22.0 \\
22.0 \\
22.0 \\
22.0 \\
22.0 \\
22.0\end{array}$ & $\begin{array}{l}23.0 \\
23.0 \\
22.0 \\
22.0 \\
22.0 \\
22.0\end{array}$ & $\begin{array}{l}23.0 \\
22.0 \\
22.0 \\
22.0 \\
21.0 \\
21.0\end{array}$ & $\begin{array}{c}20.0 \\
20.0 \\
20.0 \\
20.0 \\
20.0 \\
-\ldots\end{array}$ & $\begin{array}{l}20.0 \\
20.0 \\
20.0 \\
19.0 \\
19.0 \\
\end{array}$ \\
\hline MONTH & 12.0 & 8.0 & 11.0 & 8.0 & 17.0 & B. 0 & 23.0 & 17.0 & 25.0 & 21.0 & 21.0 & 19.0 \\
\hline
\end{tabular}


03149200 MUSKINGUM RIVER AT PHILO, OHIO

LOCATION, --Lat $39^{\circ} 41^{\prime} 51^{\prime \prime}$, long $81^{\circ} 54^{\prime 22 "}$, Muskingum County, along right bank of Muskingum River about 2,000 ft be low Phtlo Dam on canal which supplies river water from above the dam to Ohio Power Co,'s Philo Generating Diviston Pht10.

DRAINAGE AREA, $--7,196 \mathrm{sq} \mathrm{m} 1$.

PERIOD OF RBCORD.--Chemical analyses: April to September 1968.

Water temperatures: April 1965 to September 1968 .

EXTREIES. - -1967-68:

Speciftc conductance: Maxtmum dat1y, 1,890 micromhos July 23; mintmum datly, 340 micromhos May 24

pH: Maximum da1ly, 8,7 Mar. 2, Sept. 14; minimum da1ly, 4.9 Sept. 26.

ater temperatures: Maxtmum, 30.0 $\mathrm{C}$ Aug. 23,$24 ; \mathrm{m} 1 \mathrm{n}$ imum, freezing point on several days during January and February.

Period of record:

Specif ic conductance: Maximum da1ly, 1,950 micrombos Oct, 25, 1966; mintmum da1ly, 170 micromhos Apr. 28, 1965, pH: Maximum datly, 9.5 Jan. 12, 20, 1966; mintmum datly, 4.8 Mar. 16, 1966.

Dissolved oxygen (1965-67): Maximun da11y, 15.0 mg/1 or greater on many days during July, December 1966 , January, February and September $1967{ }_{i}$ mintmum daily, $2.0 \mathrm{mg} / 1$ June 15,1967

Water temperatures: Maximun, 31.0 $0^{6} \mathrm{C}$ July 3, 1966; mintmum, freezing point on many days in 1967 and 1968.

REMARKS. - The recorder is located in the basement of the generating plant. In addition to the monitor, datly samples were collected by a local observer. Partial analyses were made on the maximum and minimum datly specific conductance of samples collected each month. Dissolved oxygen concentrations listed as $15.0 \mathrm{mg} / 1$ represent concen-

functions of the instrument. No discharge records avallable. Ins. Interruptions in the record were due to mal

CHEMICAL ANALYSES IN MILLIGRAMS PER LITER, HATER YEAR OCTOBER 1967 TO SEPTEMBER 1968

\begin{tabular}{|c|c|c|c|c|c|c|c|c|c|c|c|c|}
\hline DATE & TIME & $\begin{array}{l}\text { BICAR- } \\
\text { ADNATE } \\
\text { (HCD3) }\end{array}$ & $\begin{array}{l}\text { CAR- } \\
\text { ADVATE } \\
\text { (CO3) }\end{array}$ & $\begin{array}{l}\text { SULFATE } \\
\text { (SO4) }\end{array}$ & $\begin{array}{l}\text { CHLn- } \\
\text { RIDE } \\
(\mathrm{CL})\end{array}$ & $\begin{array}{l}\text { FLUO- } \\
\text { RIDE } \\
\text { (F) }\end{array}$ & $\begin{array}{l}\text { NI PPATF } \\
\text { (Nก3) }\end{array}$ & $\begin{array}{l}\text { SOLICS } \\
\text { IRESI- } \\
\text { NUE AT } \\
\text { ISC II }\end{array}$ & $\begin{array}{l}\text { HAPD- } \\
\text { NESS } \\
\text { (CA.MG) }\end{array}$ & $\begin{array}{l}\text { PAR- } \\
\text { RNNATF } \\
\text { HARD- } \\
\text { NFSS }\end{array}$ & $\begin{array}{l}\text { COVN- } \\
\text { uTtavif } \\
\text { (mean- } \\
\text { mHOS) }\end{array}$ & $\mathrm{PH}$ \\
\hline \multicolumn{13}{|l|}{ רст. } \\
\hline $\begin{array}{l}25 \ldots . . \\
0\end{array}$ & 1515 & 136 & 0 & 207 & $4 n r$ & 1.0 & R.R & 1470 & 572 & $46 r$ & $125 \mathrm{C}$ & 2.2 \\
\hline \multicolumn{13}{|l|}{ N Jv. } \\
\hline DEC. & 0738 & 122 & 0 & 141 & 98 & .5 & 6.5 & 498 & 295 & 108 & 797 & - \\
\hline \multicolumn{13}{|l|}{ nEC. } \\
\hline $\begin{array}{l}04 \ldots \\
14 \ldots\end{array}$ & $\begin{array}{l}3725 \\
0735\end{array}$ & $\begin{array}{r}102 \\
96\end{array}$ & $\begin{array}{l}0 \\
0\end{array}$ & $\begin{array}{l}212 \\
109\end{array}$ & $\begin{array}{r}195 \\
55\end{array}$ & .4 & $\begin{array}{l}4.5 \\
6.8\end{array}$ & $\begin{array}{l}629 \\
334\end{array}$ & $\begin{array}{l}357 \\
235\end{array}$ & $\begin{array}{l}273 \\
156\end{array}$ & 564 & $=$ \\
\hline \multicolumn{13}{|l|}{ JAN. } \\
\hline $\begin{array}{l}20 \ldots \\
31 \ldots\end{array}$ & 0748 & 132 & 0 & 183 & 175 & .6 & 7.4 & 756 & 3AB & 278 & 1nan & 7.1 \\
\hline \multicolumn{2}{|l|}{ FEB. } & 34 & 0 & 125 & 40 & .2 & 4.5 & 324 & 172 & 144 & 450 & 9.9 \\
\hline $01 \ldots$ & 0728 & 36 & c & 107 & $5 \mathrm{c}$ & $\cdot 3$ & 7.8 & 282 & $17 n$ & 141 & 449 & -- \\
\hline $\begin{array}{l}\text { P7... } \\
\text { MAR: }\end{array}$ & 0722 & 134 & 0 & 177 & 136 & .5 & 0.1 & $63 \mathrm{C}$ & 354 & 244 & $1 n 9 n$ & -- \\
\hline \multicolumn{13}{|l|}{ MAR. } \\
\hline $\begin{array}{l}11 \ldots . \\
28, \ldots\end{array}$ & $\begin{array}{l}0730 \\
0735\end{array}$ & $\begin{array}{r}124 \\
62\end{array}$ & $\begin{array}{l}0 \\
0\end{array}$ & $\begin{array}{r}192 \\
B 9\end{array}$ & $\begin{array}{r}22 \mathrm{~A} \\
36\end{array}$ & .5 & $\begin{array}{l}6.7^{8} \\
4.4\end{array}$ & $\begin{array}{l}874 \\
276\end{array}$ & $\begin{array}{l}39 \mathrm{~A} \\
1 \mathrm{KG}\end{array}$ & $\begin{array}{l}306 \\
115\end{array}$ & $\begin{array}{l}13>4 \\
4>4\end{array}$ & $\begin{array}{l}7.2 \\
--\end{array}$ \\
\hline \multicolumn{13}{|l|}{$A D R$. } \\
\hline $\begin{array}{l}05 \ldots \\
74 \ldots\end{array}$ & 1615 & 80 & 0 & 123 & 42 & $\cdot 3$ & 3.0 & $35 \AA$ & 374 & 139 & 534 & 7.3 \\
\hline \multicolumn{2}{|l|}{ MAY } & 96 & 0 & 172 & 112 & .4 & 5.1 & 564 & & $23^{\circ}$ & 372 & 7.7 \\
\hline $11 \ldots$ & 0740 & 114 & 0 & 161 & 112 & .4 & 4.5 & 556 & $\Rightarrow I 1$ & 217 & Rर5 & -- \\
\hline JUNF & 9730 & 50 & 0 & 99 & 22 & $\cdot 2$ & 4.8 & 272 & $15 ?$ & 111 & 377 & -- \\
\hline $03 . .$. & \multicolumn{12}{|c|}{ JUNF } \\
\hline $29 \ldots$ & 0750 & 106 & 0 & 147 & 12? & .3 & 7.0 & $53 n$ & $2 n c$ & 213 & RQ? & - \\
\hline \multicolumn{13}{|l|}{ JuLY } \\
\hline $\begin{array}{l}04 \ldots \\
23 . \ldots\end{array}$ & $\begin{array}{l}1340 \\
2115\end{array}$ & $\begin{array}{l}116 \\
114\end{array}$ & $\begin{array}{l}0 \\
0\end{array}$ & $\begin{array}{l}141 \\
133\end{array}$ & $\begin{array}{r}79 \\
398\end{array}$ & .3 & $\begin{array}{l}6.2 \\
4.6\end{array}$ & $\begin{array}{l}44 ? \\
\operatorname{linn}\end{array}$ & $\begin{array}{l}281 \\
525\end{array}$ & $\begin{array}{l}18 h \\
431\end{array}$ & $\begin{array}{l}7>8 \\
177 n\end{array}$ & $\begin{array}{l}7.1 \\
7.1\end{array}$ \\
\hline \multicolumn{13}{|l|}{ AUG. } \\
\hline $\begin{array}{l}11 \ldots \ldots \\
24 \ldots\end{array}$ & 2230 & 128 & 0 & 120 & 96 & .2 & $4 . r$ & $43 ?$ & 275 & 170 & 745 & -- \\
\hline SFPT. & 2200 & 98 & 0 & 164 & 227 & .5 & 2.3 & 740 & 354 & 773 & $119 n$ & -- \\
\hline \multicolumn{12}{|l|}{ SFPT. } & 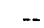 \\
\hline $30 \ldots$ & 1525 & II & 0 & 183 & $34 \mathrm{C}$ & .5 & 4.7 & $102 n$ & $4 A 0$ & 353 & $1+2 n$ & $7 . n$ \\
\hline
\end{tabular}


03149200 MUSKINGUAT RIVER AT PHILO, OHIO--Continued

SPECIFIC CONDUCTANCE, PH, DISSOLVED OXYGEN, AND PATER TEMPERATURES, WATER YEAR OCTOBER 1967 TO SEPTEMBER 1968 OCTOBER NOVEMBER

\begin{tabular}{|c|c|c|c|c|c|c|c|c|}
\hline \multirow[t]{2}{*}{ DAY } & \multicolumn{2}{|c|}{$\begin{array}{l}\text { SPECIFIC } \\
\text { CONDUCTANCE } \\
\text { (MICROMHOS } \\
\text { AT } 25^{\circ} \mathrm{C} \text { ) }\end{array}$} & \multicolumn{2}{|c|}{ pH } & \multicolumn{2}{|c|}{$\begin{array}{l}\text { DI SSOLVED } \\
\text { OXYGEN } \\
\text { (MG/L) }\end{array}$} & \multicolumn{2}{|c|}{$\begin{array}{l}\text { TELPER- } \\
\text { ATURE } \\
\left({ }^{\circ} \mathrm{C}\right)\end{array}$} \\
\hline & $\max$ & MIN & $\max$ & MIN & $\max$ & MIN & $\max$ & MIN \\
\hline $\begin{array}{l}1 \\
2 \\
3 \\
4 \\
5\end{array}$ & $\begin{array}{l}1410 \\
1780 \\
1650 \\
1450 \\
1340\end{array}$ & $\begin{array}{l}1120 \\
1410 \\
1450 \\
1330 \\
1230\end{array}$ & $\begin{array}{l}= \\
= \\
=\end{array}$ & $\begin{array}{l}=- \\
\bar{z}\end{array}$ & $\begin{array}{l}14.8 \\
15.0 \\
15.0 \\
15.0 \\
13.5\end{array}$ & $\begin{array}{r}9.9 \\
11.4 \\
10.4 \\
11.4 \\
10.6\end{array}$ & $\begin{array}{l}16 \\
16 \\
17 \\
18 \\
19\end{array}$ & $\begin{array}{l}15 \\
14 \\
16 \\
16 \\
18\end{array}$ \\
\hline $\begin{array}{r}6 \\
7 \\
8 \\
9 \\
10\end{array}$ & $\begin{array}{l}1290 \\
1360 \\
1280 \\
1040 \\
1020\end{array}$ & $\begin{array}{r}1230 \\
1280 \\
1030 \\
920 \\
940\end{array}$ & $\begin{array}{l}7.1 \\
7.3 \\
7.4 \\
7.3 \\
7.3\end{array}$ & $\begin{array}{l}6.8 \\
6.9 \\
7.1 \\
7.0 \\
7.1\end{array}$ & $\begin{array}{r}10.8 \\
8.9 \\
15.0 \\
13.7 \\
--\end{array}$ & $\begin{array}{l}7.9 \\
7.7 \\
8.0 \\
8.0 \\
-.\end{array}$ & $\begin{array}{l}18 \\
18 \\
18 \\
17 \\
17 \\
17\end{array}$ & $\begin{array}{l}18 \\
17 \\
17 \\
16 \\
16\end{array}$ \\
\hline $\begin{array}{l}11 \\
12 \\
13 \\
14 \\
15\end{array}$ & $\begin{array}{l}1150 \\
1180 \\
1180 \\
1190 \\
1310\end{array}$ & $\begin{array}{l}1020 \\
1150 \\
1130 \\
1140 \\
1150\end{array}$ & $\begin{array}{l}=- \\
=- \\
=-\end{array}$ & $\begin{array}{l}= \\
= \\
= \\
=\end{array}$ & $\begin{array}{l}=- \\
=- \\
=\end{array}$ & $\begin{array}{l}m \\
=- \\
=\end{array}$ & $\begin{array}{l}16 \\
16 \\
16 \\
16 \\
16\end{array}$ & $\begin{array}{l}15 \\
14 \\
14 \\
14 \\
14\end{array}$ \\
\hline $\begin{array}{l}16 \\
17 \\
18 \\
19 \\
20\end{array}$ & $\begin{array}{l}1360 \\
1380 \\
1440 \\
1530 \\
1650\end{array}$ & $\begin{array}{l}1300 \\
1350 \\
1370 \\
1440 \\
1530\end{array}$ & $\begin{array}{l}=- \\
=- \\
=-\end{array}$ & $\begin{array}{l}=- \\
z- \\
-- \\
--\end{array}$ & $\begin{array}{l}=- \\
\bar{z} \\
\bar{z}\end{array}$ & $\begin{array}{l}=- \\
=- \\
=-\end{array}$ & $\begin{array}{l}17 \\
17 \\
17 \\
16 \\
14\end{array}$ & $\begin{array}{l}15 \\
16 \\
16 \\
13 \\
13\end{array}$ \\
\hline $\begin{array}{l}21 \\
22 \\
23 \\
24 \\
25\end{array}$ & $\begin{array}{l}1690 \\
1520 \\
1500 \\
1750 \\
1850\end{array}$ & $\begin{array}{l}1510 \\
1320 \\
1330 \\
1500 \\
1750\end{array}$ & $\begin{array}{l}-- \\
=- \\
z-\end{array}$ & $\begin{array}{l}-- \\
-- \\
--\end{array}$ & $\begin{array}{l}-- \\
\overline{-} \\
\overline{--}\end{array}$ & $\begin{array}{l}-- \\
= \\
-- \\
-\end{array}$ & $\begin{array}{l}14 \\
14 \\
14 \\
14 \\
13\end{array}$ & $\begin{array}{l}13 \\
13 \\
12 \\
12 \\
13\end{array}$ \\
\hline $\begin{array}{l}26 \\
27 \\
28 \\
29 \\
30 \\
31\end{array}$ & $\begin{array}{l}1830 \\
1700 \\
1590 \\
1490 \\
1420 \\
1460\end{array}$ & $\begin{array}{l}1700 \\
1590 \\
1470 \\
1420 \\
1370 \\
1400\end{array}$ & $\begin{array}{l}=- \\
=- \\
=- \\
=-\end{array}$ & $\begin{array}{l}=- \\
=- \\
=- \\
--\end{array}$ & $\begin{array}{l}-- \\
-- \\
-- \\
--\end{array}$ & $\begin{array}{l}-- \\
=- \\
=- \\
--\end{array}$ & $\begin{array}{l}13 \\
12 \\
12 \\
11 \\
11 \\
12\end{array}$ & $\begin{array}{r}12 \\
11 \\
11 \\
10 \\
9 \\
10\end{array}$ \\
\hline
\end{tabular}

\begin{tabular}{|c|c|c|c|c|c|c|c|}
\hline $\begin{array}{r}\text { SPEC } \\
\text { COND } \\
\text { (UIC } \\
\text { AT }\end{array}$ & $\begin{array}{l}\text { IC } \\
\text { TANCE } \\
\text { UHOS } \\
\left.5^{\circ} \mathrm{C}\right)\end{array}$ & $\mathbf{P}$ & & $\begin{array}{l}\text { DISS } \\
\text { OXY } \\
\text { (MG }\end{array}$ & $\begin{array}{l}\text { LVED } \\
\text { EN } \\
\text { L) }\end{array}$ & $\begin{array}{l}\text { TEMP } \\
\text { ATU } \\
{ }^{\circ} \mathrm{C}\end{array}$ & $\begin{array}{l}\text { SER- } \\
\text { JRE } \\
\text { C) }\end{array}$ \\
\hline $\operatorname{MAX}$ & MIN & $\operatorname{Max}$ & MIN & $\max$ & IIN & $\max$ & MIN \\
\hline 1480 & 1420 & -- & -- & -- & -- & 12 & 11 \\
\hline 1440 & 1220 & - & - & - & - & 12 & 12 \\
\hline 1260 & 1220 & -- & - & -- & -- & 13 & 12 \\
\hline 1260 & 1110 & -- & - & -- & -- & 12 & 11 \\
\hline 1110 & 970 & - & -- & -- & -- & 11 & 9 \\
\hline 1050 & 1000 & -- & - & -. & -- & 9 & 8 \\
\hline 1080 & 1040 & -- & - & - & -- & 8 & 7 \\
\hline 1120 & 1060 & -- & - & -- & -- & 8 & 7 \\
\hline 1180 & 1050 & - & -- & -- & $m$ & 8 & 7 \\
\hline 1050 & 850 & - & $m$ & - & -- & 8 & 7 \\
\hline 900 & 840 & - & -- & - & -- & 9 & 8 \\
\hline 1010 & 900 & - & - & - & -- & 9 & 8 \\
\hline 1040 & 950 & -- & - & -- & - & 9 & 9 \\
\hline 950 & 920 & -- & - & - & - & 9 & 8 \\
\hline 950 & 920 & - & -- & - & -- & 8 & 7 \\
\hline 990 & 950 & - & - & - & - & 7 & 6 \\
\hline 1030 & 950 & - & - & - & - & 7 & 6 \\
\hline 1020 & 950 & - & - & -- & - & 7 & 6 \\
\hline 1010 & 810 & - & -- & - & -- & 7 & 6 \\
\hline 820 & 780 & - & -- & - & -- & 6 & 6 \\
\hline 880 & 820 & -- & -- & - & - & 6 & 6 \\
\hline 850 & 830 & 7.5 & 7.1 & 13,1 & 12.0 & 7 & 6 \\
\hline 910 & 850 & 7.2 & 6.9 & 14.6 & 12.5 & 7 & 7 \\
\hline 900 & 820 & 7.2 & 6.9 & - & -- & 7 & 6 \\
\hline 830 & 780 & 7.3 & 6.8 & - & -- & 7 & 7 \\
\hline 840 & 820 & 7.3 & 6.8 & -- & - & 7 & 6 \\
\hline 900 & 840 & 7.6 & 6.9 & - & - & 7 & 6 \\
\hline 890 & 820 & 7.8 & 7.4 & -- & - & 6 & 5 \\
\hline 840 & 820 & 7.8 & 7.4 & - & -- & 5 & 4 \\
\hline 830 & 810 & 8.0 & 7.7 & - & -- & 5 & 4 \\
\hline- & 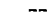 & 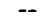 & & - & -- & -- & 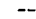 \\
\hline
\end{tabular}

DECEMBER

\begin{tabular}{|c|c|c|c|c|}
\hline \multirow[t]{2}{*}{ DAY } & \multicolumn{2}{|c|}{$\begin{array}{l}\text { SPECIFIC } \\
\text { CONDUCTANCE } \\
\text { (MICROMHOS } \\
\text { AT } 25^{\circ} \mathrm{C} \text { ) }\end{array}$} & \multicolumn{2}{|c|}{$\mathrm{pH}$} \\
\hline & MAX & MIN & MAX & MIN \\
\hline $\begin{array}{l}1 \\
2 \\
3 \\
4 \\
5\end{array}$ & $\begin{array}{l}840 \\
850 \\
870 \\
900 \\
760\end{array}$ & $\begin{array}{l}800 \\
830 \\
820 \\
760 \\
680\end{array}$ & $\begin{array}{l}8.0 \\
7.9 \\
7.8 \\
7.7 \\
7.7\end{array}$ & $\begin{array}{l}7.6 \\
7.6 \\
7.2 \\
7.0 \\
7.3\end{array}$ \\
\hline $\begin{array}{r}6 \\
7 \\
8 \\
9 \\
10\end{array}$ & $\begin{array}{l}850 \\
850 \\
640 \\
660 \\
690\end{array}$ & $\begin{array}{l}720 \\
640 \\
620 \\
620 \\
630\end{array}$ & $\begin{array}{l}7.5 \\
7.3 \\
7.5 \\
7.5 \\
7.5\end{array}$ & $\begin{array}{l}7.2 \\
7.0 \\
7.1 \\
7.3 \\
7.1\end{array}$ \\
\hline $\begin{array}{l}11 \\
12 \\
13 \\
14 \\
15\end{array}$ & $\begin{array}{l}720 \\
720 \\
620 \\
620 \\
660\end{array}$ & $\begin{array}{l}690 \\
620 \\
540 \\
540 \\
590\end{array}$ & $\begin{array}{l}7.2 \\
7.1 \\
7.1 \\
7.1 \\
7.6\end{array}$ & $\begin{array}{l}6.9 \\
6.7 \\
6.8 \\
6.9 \\
7.0\end{array}$ \\
\hline $\begin{array}{l}16 \\
17 \\
18 \\
19 \\
20\end{array}$ & $\begin{array}{l}640 \\
740 \\
780 \\
790 \\
790\end{array}$ & $\begin{array}{l}590 \\
580 \\
710 \\
720 \\
770\end{array}$ & $\begin{array}{r}7.5 \\
7.8 \\
7.5 \\
-- \\
--\end{array}$ & $\begin{array}{r}7.1 \\
7.0 \\
6.9 \\
-- \\
--\end{array}$ \\
\hline $\begin{array}{l}21 \\
22 \\
23 \\
24 \\
25\end{array}$ & $\begin{array}{l}780 \\
900 \\
880 \\
840 \\
770\end{array}$ & $\begin{array}{l}760 \\
760 \\
790 \\
670 \\
670\end{array}$ & $\begin{array}{l}\overline{-} \\
\overline{--} \\
--\end{array}$ & $\begin{array}{l}-- \\
-- \\
--\end{array}$ \\
\hline $\begin{array}{l}26 \\
27 \\
28\end{array}$ & $\begin{array}{l}800 \\
750 \\
610\end{array}$ & $\begin{array}{l}750 \\
590 \\
580\end{array}$ & $=$ & $=$ \\
\hline 29 & & & 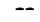 & \\
\hline $\begin{array}{l}30 \\
31\end{array}$ & -- & -- & $\overline{--}$ & $\begin{array}{l}-- \\
--\end{array}$ \\
\hline
\end{tabular}

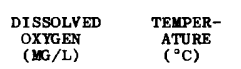

MAX MIN
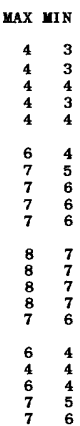

$\begin{array}{ll}8 & 7 \\ 8 & 7 \\ 7 & 5 \\ 5 & 4 \\ 4 & 4\end{array}$

$\begin{array}{ll}4 & 3 \\ 3 & 2 \\ 2 & 2\end{array}$

$--$
JANUARY

\begin{tabular}{|c|c|c|c|c|c|c|c|}
\hline \multicolumn{2}{|c|}{$\begin{array}{l}\text { SPECIFIC } \\
\text { CONDUCTANCE } \\
\text { (MICROMHOS } \\
\text { AT } 25^{\circ} \mathrm{C} \text { ) }\end{array}$} & \multicolumn{2}{|c|}{$\mathrm{pH}$} & \multicolumn{2}{|c|}{$\begin{array}{l}\text { DISSOLVED } \\
\text { OXYGEN } \\
(\text { MG } / L)\end{array}$} & \multicolumn{2}{|c|}{$\begin{array}{l}\text { TEMPER- } \\
\text { ATURE } \\
\left({ }^{\circ} \mathrm{C}\right)\end{array}$} \\
\hline MAX & IIN & MAX & UIN & $\operatorname{MAX}$ & MIN & yAX & XIN \\
\hline-- & -- & -- & -- & & & $-\infty$ & - \\
\hline-- & -- & - & - & & & 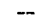 & -- \\
\hline- & -- & -- & -- & & & - & - \\
\hline $\begin{array}{l}690 \\
720\end{array}$ & 640 & -- & $=$ & & & 2 & 1 \\
\hline 800 & 720 & -- & - & & & 1 & 1 \\
\hline 850 & 800 & -- & -- & & & i & i \\
\hline 860 & 820 & - & - & & & 1 & 0 \\
\hline 840 & 790 & - & -- & & & 1 & 1 \\
\hline 860 & 830 & 7.7 & 7.0 & & & 1 & 1 \\
\hline 860 & 810 & 7.3 & 6.9 & & & 1 & 1 \\
\hline 910 & 840 & 7.2 & 6.7 & & & 1 & $\begin{array}{l}1 \\
0\end{array}$ \\
\hline 1020 & 910 & 7.2 & $\begin{array}{l}0.8 \\
6.8\end{array}$ & & & 1 & 1 \\
\hline 1060 & 1020 & 7.4 & 7.0 & & & 1 & 0 \\
\hline 1070 & 1030 & 7.8 & 7.2 & & & 1 & 0 \\
\hline 1050 & 1040 & 7.5 & 6.7 & & & 1 & 0 \\
\hline 1070 & 1050 & 7.2 & 6.8 & & & 1 & 0 \\
\hline 1060 & 1030 & 7.3 & 6.7 & & & 2 & 1 \\
\hline 1140 & 1060 & 7.0 & 6.5 & & & 3 & 2 \\
\hline 1140 & 1080 & 7.0 & 6.5 & & & 3 & 2 \\
\hline 1090 & 1030 & 6.9 & 6.5 & & & 3 & 2 \\
\hline 1060 & 1000 & 6.9 & 6.4 & & & 3 & 2 \\
\hline 1020 & 970 & 5.9 & 6.6 & & & 2 & 1 \\
\hline 980 & 950 & 7.0 & 6.6 & & & 2 & 1 \\
\hline 980 & 960 & 6.9 & 6.5 & & & 2 & 1 \\
\hline 980 & 930 & 6.8 & 6.5 & & & 3 & 1 \\
\hline 940 & 900 & 6.7 & 6.4 & & & 3 & 2 \\
\hline 900 & 590 & 6.7 & 6.3 & & & 4 & 2 \\
\hline 590 & 430 & 6.9 & 6.3 & & & 5 & 3 \\
\hline 470 & 440 & 6.8 & 6.2 & & & 3 & 3 \\
\hline
\end{tabular}


03149200 MUSKINGUM RIVER AT PHILO, OHI0--Continued

SPECIFIC CONDUCTANCE, $\mathrm{pH}$, DISSOLVED OXYGEN, AND NATER TEMPERATURES, WATER YEAR OCTOBER 1967 TO SEPTEMBER 1968 FEBRUARY

\begin{tabular}{|c|c|c|c|c|}
\hline \multirow[t]{2}{*}{ DAY } & \multicolumn{2}{|c|}{$\begin{array}{l}\text { SPECIFIC } \\
\text { CONDUCTANCE } \\
\text { (MICROMHOS } \\
\text { AT } 25^{\circ} \mathrm{C} \text { ) }\end{array}$} & \multicolumn{2}{|c|}{ pH } \\
\hline & MAX & MIN & vax & MIN \\
\hline $\begin{array}{l}1 \\
2 \\
3 \\
4 \\
5\end{array}$ & $\begin{array}{l}460 \\
620 \\
670 \\
710 \\
710\end{array}$ & $\begin{array}{l}390 \\
390 \\
620 \\
670 \\
680\end{array}$ & $\begin{array}{l}6.8 \\
6.9 \\
7.3 \\
7.4 \\
7.5\end{array}$ & $\begin{array}{l}6.6 \\
6.5 \\
6.8 \\
7.1 \\
7.2\end{array}$ \\
\hline $\begin{array}{r}6 \\
7 \\
8 \\
9 \\
10\end{array}$ & $\begin{array}{l}840 \\
850 \\
660 \\
580 \\
480\end{array}$ & $\begin{array}{l}680 \\
660 \\
580 \\
470 \\
450\end{array}$ & $\begin{array}{l}7.4 \\
7.6 \\
7.5 \\
7.3 \\
7.7\end{array}$ & $\begin{array}{l}7.0 \\
7.0 \\
6.8 \\
7.0 \\
7.2\end{array}$ \\
\hline $\begin{array}{l}11 \\
12 \\
13 \\
14 \\
15\end{array}$ & $\begin{array}{r}460 \\
-- \\
530 \\
570 \\
600\end{array}$ & $\begin{array}{l}430 \\
-- \\
480 \\
490 \\
480\end{array}$ & $\begin{array}{r}7.9 \\
-- \\
7.4 \\
7.5 \\
8.6\end{array}$ & $\begin{array}{l}7.5 \\
6.9 \\
6.9 \\
7.2\end{array}$ \\
\hline $\begin{array}{l}16 \\
17 \\
18 \\
19 \\
20\end{array}$ & $\begin{array}{l}610 \\
640 \\
750 \\
820 \\
870\end{array}$ & $\begin{array}{l}\mathbf{5 4 0} \\
\mathbf{5 7 0} \\
640 \\
720 \\
790\end{array}$ & $\begin{array}{l}8.5 \\
8.5 \\
8.4 \\
8.3 \\
8.3\end{array}$ & $\begin{array}{l}7.7 \\
8.1 \\
8.1 \\
7.4 \\
7.5\end{array}$ \\
\hline $\begin{array}{l}21 \\
22 \\
23 \\
24 \\
25\end{array}$ & $\begin{array}{r}900 \\
960 \\
960 \\
1000 \\
1010\end{array}$ & $\begin{array}{l}850 \\
850 \\
840 \\
960 \\
970\end{array}$ & $\begin{array}{l}8.3 \\
8.0 \\
7.9 \\
7.8 \\
8.0\end{array}$ & $\begin{array}{l}7.6 \\
7.4 \\
7.2 \\
7.2 \\
7.6\end{array}$ \\
\hline $\begin{array}{l}26 \\
27 \\
28 \\
29\end{array}$ & $\begin{array}{l}1040 \\
1070 \\
1010 \\
1010\end{array}$ & $\begin{array}{l}940 \\
960 \\
730 \\
740\end{array}$ & $\begin{array}{l}8.0 \\
7.8 \\
8.1 \\
8.1\end{array}$ & $\begin{array}{l}7.4 \\
7.2 \\
7.2 \\
7.4\end{array}$ \\
\hline 30 & $=$ & - & 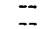 & $=$ \\
\hline
\end{tabular}

DISSOLVED
OXYGEN
$(\mathbf{H G} / \mathrm{L})$

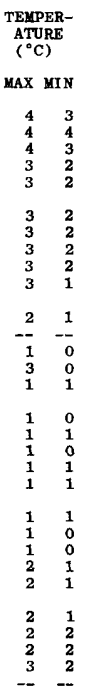

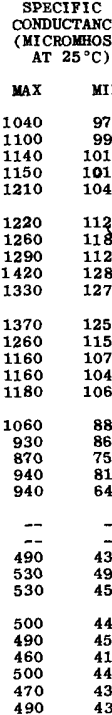

MARCH

APRIL

\begin{tabular}{|c|c|c|c|c|}
\hline \multirow[t]{2}{*}{ DAY } & \multicolumn{2}{|c|}{$\begin{array}{l}\text { SPECIFIC } \\
\text { CONDUCTANCE } \\
\text { (MICROMHOS } \\
\text { AT } 25^{\circ} \mathrm{C} \text { ) }\end{array}$} & \multicolumn{2}{|c|}{$\mathrm{pH}$} \\
\hline & $\max$ & MIN & $\operatorname{MAX}$ & MIN \\
\hline $\begin{array}{l}1 \\
2 \\
3 \\
4 \\
5\end{array}$ & $\begin{array}{l}\mathbf{5 6 0} \\
\mathbf{5 5 0} \\
\mathbf{5 7 0} \\
\mathbf{5 8 0} \\
\mathbf{5 3 0}\end{array}$ & $\begin{array}{l}\mathbf{4 4 0} \\
510 \\
\mathbf{5 3 0} \\
\mathbf{5 2 0} \\
\mathbf{5 2 0}\end{array}$ & $\begin{array}{l}7.6 \\
7.7 \\
7.9 \\
7.6 \\
7.7\end{array}$ & $\begin{array}{l}7.4 \\
7.4 \\
7.6 \\
7.4 \\
7.4\end{array}$ \\
\hline $\begin{array}{r}6 \\
7 \\
8 \\
9 \\
10\end{array}$ & $\begin{array}{l}600 \\
650 \\
630 \\
610 \\
640\end{array}$ & $\begin{array}{l}520 \\
550 \\
590 \\
590 \\
600\end{array}$ & $\begin{array}{l}7.9 \\
7.8 \\
7.6 \\
7.7 \\
7.8\end{array}$ & $\begin{array}{l}7.6 \\
7.6 \\
7.5 \\
7.5 \\
7.6\end{array}$ \\
\hline $\begin{array}{l}11 \\
12 \\
13 \\
14 \\
15\end{array}$ & $\begin{array}{l}640 \\
680 \\
710 \\
750 \\
780\end{array}$ & $\begin{array}{l}630 \\
640 \\
670 \\
710 \\
720\end{array}$ & $\begin{array}{l}7.7 \\
7.7 \\
7.6 \\
7.5 \\
7.4\end{array}$ & $\begin{array}{l}7.6 \\
7.6 \\
7.5 \\
7.4 \\
7.3\end{array}$ \\
\hline $\begin{array}{l}16 \\
17 \\
18 \\
19 \\
20\end{array}$ & $\begin{array}{l}740 \\
750 \\
800 \\
820 \\
840\end{array}$ & $\begin{array}{l}690 \\
700 \\
750 \\
760 \\
760\end{array}$ & $\begin{array}{l}7.6 \\
7.6 \\
7.5 \\
7.5 \\
7.4\end{array}$ & $\begin{array}{l}7.4 \\
7.4 \\
7.3 \\
7.2 \\
7.2\end{array}$ \\
\hline $\begin{array}{l}21 \\
22 \\
23 \\
24 \\
25\end{array}$ & $\begin{array}{l}850 \\
850 \\
850 \\
870 \\
870\end{array}$ & $\begin{array}{l}830 \\
810 \\
820 \\
850 \\
830\end{array}$ & $\begin{array}{l}7.3 \\
7.5 \\
7.6 \\
7.6 \\
7.7\end{array}$ & $\begin{array}{l}7.2 \\
7.3 \\
7.5 \\
7.3 \\
7.5\end{array}$ \\
\hline $\begin{array}{l}26 \\
27 \\
28 \\
29 \\
30\end{array}$ & $\begin{array}{l}830 \\
820 \\
860 \\
770 \\
790\end{array}$ & $\begin{array}{l}720 \\
740 \\
760 \\
720 \\
720\end{array}$ & $\begin{array}{l}7.7 \\
7.7 \\
7.6 \\
7.6 \\
7.6\end{array}$ & $\begin{array}{l}7.6 \\
7.4 \\
7.4 \\
7.5 \\
7.4\end{array}$ \\
\hline
\end{tabular}
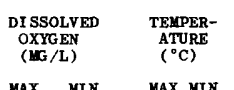

\begin{tabular}{|c|c|c|c|c|c|}
\hline \multirow{2}{*}{\multicolumn{2}{|c|}{$\begin{array}{l}\text { SPECIFIC } \\
\text { CONDUCTANCE } \\
\text { (MICROLHOS } \\
\text { AT } 25^{\circ} \mathrm{C} \text { ) }\end{array}$}} & \multicolumn{4}{|c|}{ MAY } \\
\hline & & & & $\begin{array}{l}\text { DISS } \\
\text { OXY } \\
\text { (HUG }\end{array}$ & $\begin{array}{l}\text { LVED } \\
\text { EN } \\
\text { L) }\end{array}$ \\
\hline MAX & MIN & MAX & MIN & $\operatorname{MAX}$ & MIN \\
\hline $\begin{array}{l}830 \\
790 \\
820 \\
780 \\
800\end{array}$ & $\begin{array}{l}750 \\
740 \\
760 \\
740 \\
760\end{array}$ & $\begin{array}{r}7.6 \\
7.6 \\
7.6 \\
7.5 \\
7.6\end{array}$ & $\begin{array}{r}7.4 \\
7.5 \\
7.4 \\
7.3 \\
7.4\end{array}$ & & \\
\hline $\begin{array}{l}840 \\
810 \\
820 \\
840 \\
840\end{array}$ & $\begin{array}{l}800 \\
790 \\
780 \\
800 \\
810\end{array}$ & $\begin{array}{l}7.7 \\
7.7 \\
7.8 \\
7.7 \\
7.5\end{array}$ & $\begin{array}{l}7.5 \\
7.6 \\
7.5 \\
7.5 \\
7.4\end{array}$ & & \\
\hline $\begin{array}{l}880 \\
880 \\
670 \\
560 \\
560\end{array}$ & $\begin{array}{l}840 \\
670 \\
520 \\
540 \\
480\end{array}$ & $\begin{array}{l}7.5 \\
7.3 \\
7.5 \\
7.5 \\
7.4\end{array}$ & $\begin{array}{r}7.3 \\
7.0 \\
7.0 \\
7.4 \\
7.3\end{array}$ & & \\
\hline $\begin{array}{l}560 \\
710 \\
700 \\
700 \\
620\end{array}$ & $\begin{array}{l}\mathbf{5 1 0} \\
\mathbf{5 6 0} \\
610 \\
600 \\
\mathbf{5 7 0}\end{array}$ & $\begin{array}{l}7.4 \\
7.3 \\
7.4 \\
7.4 \\
7.4\end{array}$ & $\begin{array}{l}7.1 \\
7.1 \\
7.1 \\
7.0 \\
7.3\end{array}$ & & \\
\hline $\begin{array}{l}570 \\
570 \\
600 \\
500 \\
500\end{array}$ & $\begin{array}{l}\mathbf{5 5 0} \\
\mathbf{5 5 0} \\
\mathbf{5 0 0} \\
\mathbf{3 4 0} \\
380\end{array}$ & $\begin{array}{l}7.5 \\
7.4 \\
7.4 \\
7.1 \\
7.0\end{array}$ & $\begin{array}{l}7.3 \\
7.3 \\
7.0 \\
6.9 \\
6.7\end{array}$ & & \\
\hline $\begin{array}{l}500 \\
420 \\
450 \\
500 \\
500 \\
460\end{array}$ & $\begin{array}{l}420 \\
370 \\
400 \\
420 \\
400 \\
420\end{array}$ & $\begin{array}{l}7.0 \\
7.1 \\
6.9 \\
6.9 \\
7.1 \\
7.1\end{array}$ & $\begin{array}{l}6.8 \\
6.8 \\
6.8 \\
6.8 \\
6.9 \\
7.0\end{array}$ & & \\
\hline
\end{tabular}

TEMPER$\left({ }^{\circ} \mathrm{C}\right)$

$\begin{array}{ll}14 & 13 \\ 14 & 12 \\ 12 & 11 \\ 13 & 12 \\ 12 & 11 \\ 12 & 11 \\ 12 & 10 \\ 12 & 11 \\ 13 & 12 \\ 13 & 12\end{array}$

$\begin{array}{ll}14 & 12 \\ 14 & 13\end{array}$

$\begin{array}{ll}14 & 13 \\ 15 & 14 \\ 16 & 15\end{array}$

$\begin{array}{ll}16 & 15 \\ 16 & 15\end{array}$

$16 \quad 15$

$\begin{array}{ll}15 & 14 \\ 18 & 15 \\ 19 & 17\end{array}$

$\begin{array}{ll}19 & 17 \\ 20 & 18\end{array}$

1815

2017

$\begin{array}{ll}19 & 17 \\ 17 & 15\end{array}$

$\begin{array}{ll}15 & 14 \\ 15 & 13 \\ 15 & 14 \\ 16 & 15 \\ 16 & 16 \\ -- & -\end{array}$

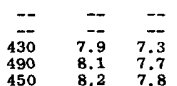

DISSOLVED

ATURE
$\left({ }^{\circ} \mathrm{C}\right)$

AX MIN

$\begin{array}{ll}8.0 & 7.6 \\ 8.7 & 7.1 \\ 8.0 & 7.5 \\ 8.1 & 7.5\end{array}$

\begin{tabular}{ll}
$\mathbf{2}$ & $\mathbf{2}$ \\
$\mathbf{3}$ & $\mathbf{2}$ \\
$\mathbf{3}$ & $\mathbf{2}$ \\
$\mathbf{3}$ & $\mathbf{2}$ \\
\hline & 2
\end{tabular}

7.96 .1

$\begin{array}{ll}5 & 4 \\ 5 & 4 \\ 6 & 5 \\ 7 & 6 \\ 8 & 7\end{array}$

$\begin{array}{ll}8.1 & 7.6 \\ 7.7 & 7.5\end{array}$

$7.9 \quad 7.3$

$\begin{array}{ll}7.7 & 7.0 \\ 7.6 & 7.2\end{array}$

$\begin{array}{ll}7.6 & 7.2 \\ 7.6 & 7.2\end{array}$

$\begin{array}{ll}7.6 & 7.4 \\ 7.6 & 7.2\end{array}$

$\begin{array}{ll}7.9 & 7.3 \\ 7.9 & 7.5\end{array}$

$\begin{array}{rr}-- & -- \\ .9 & 7.3 \\ .1 & 7.7 \\ .2 & 7.8\end{array}$

$\begin{array}{ll}8.2 & 7.8 \\ 8.0 & 7.5\end{array}$

$\begin{array}{ll}\mathbf{7 . 9} & \mathbf{7 . 5} \\ \mathbf{7 . 7} & \mathbf{7 . 5}\end{array}$

$\begin{array}{ll}7.6 & 7.4 \\ 7.7 & 7.4\end{array}$

$\begin{array}{ll}9 & 8 \\ 9 & 7 \\ 7 & 5 \\ 5 & 4 \\ 5 & 4 \\ & \\ 8 & 5 \\ 8 & 5 \\ 7 & 5 \\ 8 & 6 \\ 9 & 7\end{array}$

$\begin{array}{rr}-- & -- \\ -8 & 5 \\ 5 & 4 \\ 7 & 5\end{array}$

$\begin{array}{rr}7 & 6 \\ 8 & 7 \\ 10 & 8 \\ 11 & 9 \\ 13 & 11 \\ 14 & 12\end{array}$

MAX MIN

$\begin{array}{ll}17 & 16 \\ 18 & 16 \\ 19 & 17 \\ 20 & 18 \\ 20 & 17 \\ 17 & 15 \\ 18 & 14 \\ 19 & 16 \\ 18 & 17 \\ 19 & 18 \\ & \\ 23 & 18 \\ 23 & 22 \\ 22 & 16 \\ 18 & 17 \\ 19 & 16 \\ & \\ 21 & 17 \\ 18 & 17 \\ 18 & 17 \\ 17 & 16 \\ 16 & 15 \\ 16 & 15 \\ 16 & 15 \\ 16 & 15 \\ 15 & 14 \\ 15 & 14 \\ & \\ 16 & 15 \\ 16 & 15 \\ 15 & 14 \\ 15 & 14 \\ 15 & 15 \\ 16 & 15\end{array}$ 
03149200 MUSKINGUM RIVER AT PHILO, OHIO--Continued

SPECIFIC CONDUCTANCE, pH, DISSOLVED OXYGEN, AND WATER TEMPERATURES, WATER YEAR OCTOBER 1967 TO SEPTEMBER 1968 JUNE

JULY

\begin{tabular}{|c|c|c|c|c|c|c|c|c|c|c|c|c|c|c|c|c|}
\hline \multirow[t]{2}{*}{ DAY } & \multicolumn{2}{|c|}{$\begin{array}{l}\text { SPECIFIC } \\
\text { CONDUCTANCE } \\
\text { (MICROMHOS } \\
\text { AT } 25^{\circ} \mathrm{C} \text { ) }\end{array}$} & \multicolumn{2}{|c|}{$\mathrm{pH}$} & \multicolumn{2}{|c|}{$\begin{array}{l}\text { DISSOLVED } \\
\text { OXYGEN } \\
(\mathbf{U G} / \mathrm{L})\end{array}$} & \multicolumn{2}{|c|}{$\begin{array}{l}\text { TEMPER- } \\
\text { ATURE } \\
\left({ }^{\circ} \mathrm{C}\right)\end{array}$} & \multicolumn{2}{|c|}{$\begin{array}{l}\text { SPECIF IC } \\
\text { CONDUCTANCE } \\
\text { (MICROMHOS } \\
\text { AT } 25^{\circ} \mathrm{C} \text { ) }\end{array}$} & \multicolumn{2}{|c|}{$\mathrm{pH}$} & \multicolumn{2}{|c|}{$\begin{array}{l}\text { DI SSOLVED } \\
\text { OXYGEN } \\
(\mathbf{M G} / \mathrm{L})\end{array}$} & \multicolumn{2}{|c|}{$\begin{array}{l}\text { TEMPER- } \\
\text { ATURE } \\
\left({ }^{\circ} \mathrm{C}\right)\end{array}$} \\
\hline & $\max$ & MIN & IAX & $\operatorname{MIN}$ & MAX & MIN & $\max$ & MIN & MAX & MrN & MAX & MIN & $\operatorname{MAX}$ & MIN & MAXX & MIN \\
\hline $\begin{array}{l}1 \\
2 \\
3 \\
4 \\
5\end{array}$ & $\begin{array}{l}420 \\
440 \\
410 \\
420 \\
450\end{array}$ & $\begin{array}{l}410 \\
380 \\
390 \\
400 \\
420\end{array}$ & $\begin{array}{l}7.3 \\
7.2 \\
7.1 \\
7.2 \\
7.2\end{array}$ & $\begin{array}{l}7.1 \\
6.7 \\
6.8 \\
7.1 \\
7.0\end{array}$ & & & $\begin{array}{l}16 \\
17 \\
18 \\
18 \\
18\end{array}$ & $\begin{array}{l}15 \\
15 \\
17 \\
17 \\
17\end{array}$ & $\begin{array}{l}990 \\
910 \\
740 \\
790 \\
850\end{array}$ & $\begin{array}{l}870 \\
740 \\
700 \\
700 \\
790\end{array}$ & $\begin{array}{l}7.2 \\
7.5 \\
7.1 \\
7.6 \\
7.7\end{array}$ & $\begin{array}{l}7.1 \\
7.0 \\
6.9 \\
6.9 \\
7.2\end{array}$ & & & $\begin{array}{l}25 \\
25 \\
24 \\
23 \\
23\end{array}$ & $\begin{array}{l}23 \\
24 \\
23 \\
22 \\
22\end{array}$ \\
\hline $\begin{array}{r}6 \\
7 \\
8 \\
9 \\
10\end{array}$ & $\begin{array}{l}440 \\
420 \\
490 \\
460 \\
440\end{array}$ & $\begin{array}{l}420 \\
410 \\
420 \\
440 \\
430\end{array}$ & $\begin{array}{l}7.3 \\
7.3 \\
7.3 \\
7.3 \\
7.3\end{array}$ & $\begin{array}{l}7.1 \\
7.1 \\
7.1 \\
7.1 \\
7.0\end{array}$ & & & $\begin{array}{l}19 \\
19 \\
20 \\
20 \\
21\end{array}$ & $\begin{array}{l}18 \\
18 \\
19 \\
19 \\
20\end{array}$ & $\begin{array}{r}900 \\
940 \\
1010 \\
1050 \\
980\end{array}$ & $\begin{array}{l}850 \\
900 \\
940 \\
980 \\
900\end{array}$ & $\begin{array}{l}7.7 \\
7.8 \\
7.7 \\
8.1 \\
7.8\end{array}$ & $\begin{array}{l}7.3 \\
7.4 \\
7.5 \\
7.5 \\
7.5\end{array}$ & & & $\begin{array}{l}24 \\
24 \\
24 \\
26 \\
26\end{array}$ & $\begin{array}{l}22 \\
23 \\
23 \\
24 \\
25\end{array}$ \\
\hline $\begin{array}{l}11 \\
12 \\
13 \\
14 \\
15\end{array}$ & $\begin{array}{l}480 \\
510 \\
450 \\
480 \\
490\end{array}$ & $\begin{array}{l}410 \\
440 \\
430 \\
450 \\
460\end{array}$ & $\begin{array}{l}7.3 \\
7.3 \\
7.3 \\
7.4 \\
7.4\end{array}$ & $\begin{array}{l}6.9 \\
7.0 \\
7.2 \\
7.2 \\
7.3\end{array}$ & & & $\begin{array}{l}21 \\
22 \\
22 \\
20 \\
21\end{array}$ & $\begin{array}{l}21 \\
21 \\
20 \\
19 \\
20\end{array}$ & $\begin{array}{r}950 \\
950 \\
1040 \\
1060 \\
980\end{array}$ & $\begin{array}{l}920 \\
920 \\
940 \\
980 \\
950\end{array}$ & $\begin{array}{c}7.6 \\
-- \\
-- \\
--\end{array}$ & $\begin{array}{r}7.4 \\
-- \\
-- \\
--\end{array}$ & & & $\begin{array}{l}27 \\
27 \\
27 \\
27 \\
27\end{array}$ & $\begin{array}{l}26 \\
26 \\
26 \\
26 \\
26\end{array}$ \\
\hline $\begin{array}{l}16 \\
17 \\
18 \\
19 \\
20\end{array}$ & $\begin{array}{l}490 \\
500 \\
550 \\
660 \\
680\end{array}$ & $\begin{array}{l}460 \\
480 \\
460 \\
550 \\
620\end{array}$ & $\begin{array}{r}7.4 \\
7.4 \\
\overline{-} \\
7.2\end{array}$ & $\begin{array}{r}7.3 \\
7.3 \\
\overline{--} \\
7.1\end{array}$ & & & $\begin{array}{l}21 \\
21 \\
21 \\
21 \\
21\end{array}$ & $\begin{array}{l}20 \\
20 \\
20 \\
20 \\
20\end{array}$ & $\begin{array}{r}1010 \\
1020 \\
1050 \\
1160 \\
-\end{array}$ & $\begin{array}{r}920 \\
980 \\
1000 \\
940 \\
1160\end{array}$ & $\begin{array}{r}7 .- \\
6.9 \\
7.0 \\
7.1\end{array}$ & $\begin{array}{l}--\overline{8} \\
6.8 \\
6.7 \\
6.7\end{array}$ & & & $\begin{array}{l}27 \\
27 \\
28 \\
28 \\
27\end{array}$ & $\begin{array}{l}26 \\
26 \\
26 \\
26 \\
26\end{array}$ \\
\hline $\begin{array}{l}21 \\
22 \\
23 \\
24 \\
25\end{array}$ & $\begin{array}{l}730 \\
740 \\
760 \\
780 \\
870\end{array}$ & $\begin{array}{l}680 \\
710 \\
740 \\
750 \\
780\end{array}$ & $\begin{array}{l}7.2 \\
7.2 \\
7.3 \\
7.3 \\
7.2\end{array}$ & $\begin{array}{l}7.1 \\
7.1 \\
7.1 \\
7.1 \\
6.8\end{array}$ & & & $\begin{array}{l}21 \\
22 \\
22 \\
23 \\
23\end{array}$ & $\begin{array}{l}20 \\
21 \\
21 \\
22 \\
23\end{array}$ & $\begin{array}{l}1300 \\
1720 \\
1890 \\
1600 \\
1090\end{array}$ & $\begin{array}{r}1300 \\
1600 \\
1090 \\
1080\end{array}$ & $\begin{array}{l}6.9 \\
7.1 \\
7.2 \\
6.9 \\
6.8\end{array}$ & $\begin{array}{l}6.6 \\
6.7 \\
6.9 \\
6.7 \\
6.4\end{array}$ & & & $\begin{array}{l}27 \\
26 \\
27 \\
27 \\
27\end{array}$ & $\begin{array}{l}26 \\
25 \\
25 \\
26 \\
27\end{array}$ \\
\hline $\begin{array}{l}26 \\
27 \\
28 \\
29 \\
30 \\
31\end{array}$ & $\begin{array}{r}860 \\
880 \\
780 \\
890 \\
880 \\
--\end{array}$ & $\begin{array}{r}840 \\
740 \\
730 \\
700 \\
740 \\
--\end{array}$ & $\begin{array}{r}-. \\
7.1 \\
7.1 \\
7.5 \\
--\end{array}$ & $\begin{array}{r}-- \\
-- \\
7.0 \\
7.0 \\
7.1 \\
--\end{array}$ & & & $\begin{array}{l}23 \\
23 \\
22 \\
22 \\
23 \\
--\end{array}$ & $\begin{array}{l}23 \\
22 \\
21 \\
20 \\
21 \\
--\end{array}$ & $\begin{array}{r}1080 \\
980 \\
1230 \\
1420 \\
1040 \\
1060\end{array}$ & $\begin{array}{r}980 \\
920 \\
960 \\
1040 \\
900 \\
980\end{array}$ & $\begin{array}{l}6.5 \\
6.4 \\
6.7 \\
6.7 \\
6.9 \\
6.9\end{array}$ & $\begin{array}{l}6.3 \\
6.2 \\
6.4 \\
6.6 \\
6.7 \\
6.8\end{array}$ & & & $\begin{array}{l}27 \\
26 \\
26 \\
25 \\
25 \\
25\end{array}$ & $\begin{array}{l}26 \\
25 \\
25 \\
24 \\
24 \\
24\end{array}$ \\
\hline
\end{tabular}

AUGUST

\begin{tabular}{|c|c|c|c|c|}
\hline \multirow[t]{2}{*}{ DAY } & \multicolumn{2}{|c|}{$\begin{array}{l}\text { SPECIF IC } \\
\text { CONDUCTANCE } \\
\text { (MICROMHOS } \\
\text { AT } 25^{\circ} \mathrm{C} \text { ) }\end{array}$} & \multicolumn{2}{|c|}{ pH } \\
\hline & $\operatorname{MAX}$ & MIN & MAX & MIN \\
\hline $\begin{array}{l}1 \\
2 \\
3 \\
4 \\
5\end{array}$ & $\begin{array}{l}1020 \\
1020 \\
1100 \\
1100 \\
1100\end{array}$ & $\begin{array}{r}940 \\
940 \\
940 \\
1040 \\
1020\end{array}$ & $\begin{array}{l}7.0 \\
7.1 \\
7.0 \\
6.5 \\
7.2\end{array}$ & $\begin{array}{l}6.5 \\
6.1 \\
6.7 \\
6.7 \\
6.6\end{array}$ \\
\hline $\begin{array}{r}6 \\
7 \\
8 \\
9 \\
10\end{array}$ & $\begin{array}{r}1160 \\
1200 \\
1300 \\
1100 \\
890\end{array}$ & $\begin{array}{r}1100 \\
1140 \\
1100 \\
860 \\
810\end{array}$ & $\begin{array}{l}7.1 \\
6.9 \\
6.4 \\
6.4 \\
6.5\end{array}$ & $\begin{array}{l}6.6 \\
6.2 \\
5.7 \\
6.3 \\
5.9\end{array}$ \\
\hline $\begin{array}{l}11 \\
12 \\
13 \\
14 \\
15\end{array}$ & $\begin{array}{l}890 \\
800 \\
830 \\
920 \\
950\end{array}$ & $\begin{array}{l}750 \\
760 \\
790 \\
790 \\
920\end{array}$ & $\begin{array}{l}6.5 \\
6.8 \\
6.8 \\
6.9 \\
6.9\end{array}$ & $\begin{array}{l}6.0 \\
6.5 \\
6.6 \\
6.5 \\
6.6\end{array}$ \\
\hline $\begin{array}{l}16 \\
17 \\
18 \\
19 \\
20\end{array}$ & $\begin{array}{r}940 \\
940 \\
980 \\
1050 \\
1050\end{array}$ & $\begin{array}{r}830 \\
880 \\
940 \\
980 \\
1030\end{array}$ & $\begin{array}{l}6.9 \\
7.0 \\
6.8 \\
6.9 \\
6.7\end{array}$ & $\begin{array}{l}6.5 \\
6.5 \\
6.6 \\
6.5 \\
6.4\end{array}$ \\
\hline $\begin{array}{l}21 \\
22 \\
23 \\
24 \\
25\end{array}$ & $\begin{array}{l}1050 \\
1100 \\
1190 \\
1200 \\
1250\end{array}$ & $\begin{array}{l}1020 \\
1050 \\
1100 \\
1140 \\
1160\end{array}$ & $\begin{array}{l}6.5 \\
6.4 \\
6.3 \\
6.2 \\
6.2\end{array}$ & $\begin{array}{l}6.3 \\
6.1 \\
6.1 \\
6.0 \\
6.0\end{array}$ \\
\hline $\begin{array}{l}26 \\
27 \\
28 \\
29 \\
30 \\
31\end{array}$ & $\begin{array}{l}1330 \\
1460 \\
1500 \\
1480 \\
1350 \\
1440\end{array}$ & $\begin{array}{l}1200 \\
1300 \\
1460 \\
1320 \\
1300 \\
1350\end{array}$ & $\begin{array}{l}6.2 \\
5.9 \\
6.6 \\
8.0 \\
8.2 \\
7.9\end{array}$ & $\begin{array}{l}5.5 \\
5.3 \\
5.4 \\
6.6 \\
7.3 \\
7.5\end{array}$ \\
\hline
\end{tabular}

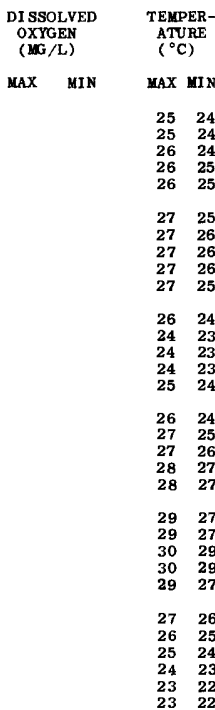

SEPTEMBER

\begin{tabular}{|c|c|c|c|c|c|c|c|}
\hline \multicolumn{2}{|c|}{$\begin{array}{l}\text { CONDUCTANCE } \\
\text { (MICROMHOS } \\
\text { AT } 25^{\circ} \mathrm{C} \text { ) }\end{array}$} & \multicolumn{2}{|c|}{$\mathrm{pH}$} & \multicolumn{2}{|c|}{$\begin{array}{l}\text { DISSOLVED } \\
\text { OXYGEN } \\
(\mathbf{M G} / \mathrm{L})\end{array}$} & \multicolumn{2}{|c|}{$\begin{array}{l}\text { TEMPER- } \\
\text { ATURE } \\
\left({ }^{\circ} \mathrm{C}\right)\end{array}$} \\
\hline MAX & MIN & $\operatorname{cax}$ & MIN & $\max$ & MIN & MAX & MIN $N$ \\
\hline $\begin{array}{l}1500 \\
1540 \\
1580 \\
1500 \\
1560\end{array}$ & $\begin{array}{l}1440 \\
1500 \\
1480 \\
1430 \\
1500\end{array}$ & $\begin{array}{l}7.8 \\
7.8 \\
7.6 \\
6.8 \\
6.6\end{array}$ & $\begin{array}{l}7.3 \\
7.2 \\
6.8 \\
6.1 \\
5.8\end{array}$ & & & $\begin{array}{l}23 \\
23 \\
24 \\
23 \\
23\end{array}$ & $\begin{array}{l}23 \\
23 \\
23 \\
23 \\
23\end{array}$ \\
\hline $\begin{array}{l}1560 \\
1560 \\
1610 \\
1610 \\
1520\end{array}$ & $\begin{array}{l}1290 \\
1290 \\
1560 \\
1500 \\
1320\end{array}$ & $\begin{array}{l}6.2 \\
6.7 \\
7.5 \\
7.2 \\
7.5\end{array}$ & $\begin{array}{l}5.8 \\
6.1 \\
6.1 \\
6.1 \\
6.0\end{array}$ & & & $\begin{array}{l}23 \\
23 \\
24 \\
24 \\
23\end{array}$ & $\begin{array}{l}23 \\
22 \\
22 \\
23 \\
22\end{array}$ \\
\hline $\begin{array}{l}1520 \\
1560 \\
1560 \\
1550 \\
1400\end{array}$ & $\begin{array}{l}1320 \\
1520 \\
1500 \\
1400 \\
1240\end{array}$ & $\begin{array}{l}7.4 \\
8.3 \\
8.6 \\
8.7 \\
8.0\end{array}$ & $\begin{array}{l}7.1 \\
7.1 \\
7.1 \\
7.7 \\
7.4\end{array}$ & & & $\begin{array}{l}22 \\
22 \\
22 \\
22 \\
22\end{array}$ & $\begin{array}{l}21 \\
21 \\
21 \\
21 \\
21\end{array}$ \\
\hline $\begin{array}{l}1570 \\
1660 \\
1560 \\
1240 \\
1320\end{array}$ & $\begin{array}{l}1290 \\
1560 \\
1230 \\
1180 \\
1180\end{array}$ & $\begin{array}{l}7.9 \\
7.4 \\
7.1 \\
6.7 \\
6.3\end{array}$ & $\begin{array}{l}7.1 \\
6.8 \\
6.6 \\
6.3 \\
5.7\end{array}$ & & & $\begin{array}{l}23 \\
23 \\
23 \\
22 \\
22\end{array}$ & $\begin{array}{l}22 \\
22 \\
22 \\
21 \\
21\end{array}$ \\
\hline $\begin{array}{l}1410 \\
1460 \\
1450 \\
1420 \\
1400\end{array}$ & $\begin{array}{r}1320 \\
1380 \\
1400 \\
1340\end{array}$ & $\begin{array}{l}6.6 \\
6.7 \\
6.5 \\
6.5 \\
6.0\end{array}$ & $\begin{array}{l}6.2 \\
6.2 \\
6.0 \\
5.6 \\
5.0\end{array}$ & & & $\begin{array}{l}22 \\
23 \\
23 \\
24 \\
24\end{array}$ & $\begin{array}{l}21 \\
22 \\
23 \\
23 \\
23\end{array}$ \\
\hline $\begin{array}{l}1360 \\
1360 \\
1440 \\
1480 \\
1660\end{array}$ & $\begin{array}{r}1300 \\
1240 \\
1360 \\
1310 \\
--\end{array}$ & $\begin{array}{r}6.3 \\
6.5 \\
6.5 \\
6.5 \\
-.-\end{array}$ & $\begin{array}{r}4.9 \\
6.3 \\
6.4 \\
-- \\
--\end{array}$ & & & $\begin{array}{l}23 \\
22 \\
22 \\
21 \\
21\end{array}$ & $\begin{array}{l}22 \\
21 \\
21 \\
21 \\
20\end{array}$ \\
\hline & $=$ & -- & -- & & & - & - \\
\hline
\end{tabular}


03150300 MUSKINGUM RIVER NEAR BEVEHLY, OHIO

LOCATION,--Lat $39^{\circ} 35^{\prime} 30^{\prime \prime}$, long $81^{\circ} 40^{\prime} 50^{\prime \prime}$, Washington County, at Ohio River Valley Water Sanitation Commission (ORSANCO) monitor station at Ohio Power Co. water intake near Beverly, 1 mile downstream from Meigs Creek, and 1.1 miles upstream from olive Green Creek.

DRAINAGE AREA. $--7,626 \mathrm{sq} \mathrm{m} 1$.

PERIOD OF RECORD. --Chemical analyses: July 1963 to September 1968.

Water temperatures: July 1963 to September 1968.

EXTREMES. $-1967-68$ :

Specific conductance: Maximum dat1y, 1,790 micromhos Nov, 1; minimum daily, 380 micromhos May $25,27$. Water temperatures: Maximum, $32.0^{\circ} \mathrm{C}$ Aug. 26 ; minimum, freezing point Jan. 2-5, 12.

Period of record:

Specific conductance: Maximum dally, 2,070 micromhos Oct. 12, 1963, Nov. 7, 1964; minimum daily

265 micromhos Mar. 12,1964

: Maximum, $36.0^{\circ} \mathrm{C}$ Sept. 1,1966 ; minimum, freezing point Jan. 2-5, 12, 1968

REMARKS.--Daily samples were collected at this station and samples were selected for analyses on the following basis: (1) Maximum daily specific conductance for each month, (2) minimum dally specific conductance for each month, and (3) median dally specific conductance for each month. Samples for iron and manganese were filtered clear when collected. Records of discharge are given for Muskingum River at McConnelsville (drainage area 7,422 sq $\mathrm{mi}$ ). Flow regulated by 15 flood-control reservotrs.

CHEMICAL ANALYSES IN MILLIGRAMS PER LITER, WATER YEAR OCTOBER 1967 TO SEPTEMBER 1968

\begin{tabular}{|c|c|c|c|c|c|c|c|c|}
\hline DATE & TIME & $\begin{array}{l}\text { DIS- } \\
\text { CHAGGE } \\
\text { (CFS) }\end{array}$ & $\begin{array}{l}\text { I RON } \\
\text { (FE) }\end{array}$ & $\begin{array}{l}\text { MAN - } \\
\text { GANESE } \\
\text { (MN) }\end{array}$ & $\begin{array}{l}\text { BICAR- } \\
\text { BDNATE } \\
\text { (HCO 3) }\end{array}$ & $\begin{array}{l}\text { CAR- } \\
\text { BONATF } \\
\text { (CD3) }\end{array}$ & $\begin{array}{l}\text { SULFATE } \\
\text { (ST4) }\end{array}$ & $\begin{array}{l}\text { CHLN } \\
\text { RIDE } \\
\text { ICLI }\end{array}$ \\
\hline \multicolumn{9}{|l|}{ OCT. } \\
\hline $\begin{array}{l}16 \ldots \\
25 . .\end{array}$ & $\begin{array}{l}1015 \\
0730\end{array}$ & $\begin{array}{l}1470 \\
1580\end{array}$ & $\begin{array}{l}.14 \\
.09\end{array}$ & $\begin{array}{r}.29 \\
.37\end{array}$ & $\begin{array}{l}116 \\
142\end{array}$ & $\begin{array}{l}0 \\
0\end{array}$ & $\begin{array}{l}169 \\
190\end{array}$ & $\begin{array}{l}150 \\
260\end{array}$ \\
\hline $2 B \ldots$ & 1030 & 1670 & .01 & 1.0 & 140 & 0 & 204 & 320 \\
\hline \multicolumn{9}{|l|}{ NOV. } \\
\hline $\begin{array}{l}01, \ldots \\
17, \ldots\end{array}$ & $\begin{array}{l}0,330 \\
0830\end{array}$ & $\begin{array}{l}2180 \\
3720\end{array}$ & $\begin{array}{l}.09 \\
.05\end{array}$ & .31 & $\begin{array}{l}143 \\
128\end{array}$ & $\begin{array}{l}0 \\
0\end{array}$ & $\begin{array}{l}203 \\
144\end{array}$ & $\begin{array}{l}400 \\
141\end{array}$ \\
\hline $28 \ldots$ & DR15 & 4190 & .21 & .37 & 116 & 0 & 151 & $1 O R$ \\
\hline \multicolumn{9}{|l|}{ OEC. } \\
\hline $01 \ldots$ & 0830 & 3650 & - & -- & -- & - & 153 & 120 \\
\hline $09 .$. & 2930 & BOBO & - & -- & -- & -- & 120 & 94 \\
\hline \multirow{2}{*}{\multicolumn{9}{|c|}{ JAN. }} \\
\hline & & & & & & & & \\
\hline $11 \ldots$ & 0845 & 3280 & -- & -- & -- & - & 174 & 119 \\
\hline $24 \ldots$ & 0900 & 3630 & -- & -- & -- & -- & 164 & 194 \\
\hline $31 \ldots$ & $O B 00$ & 26100 & -- & -- & -- & -- & 93 & 61 \\
\hline \multicolumn{9}{|l|}{ FEB. } \\
\hline $02 \ldots$ & C900 & 25000 & - & - & -- & $=$ & $B 2$ & 43 \\
\hline $21 \ldots$ & 1115 & 4570 & -- & -- & -- & -- & 108 & 90 \\
\hline MAR... & 1000 & 3120 & -- & -- & - & -- & 156 & 143 \\
\hline $01 \ldots$ & $-\overline{0}$ & 2980 & .55 & .30 & - & -- & 160 & 139 \\
\hline $12 \ldots$ & 0900 & 3400 & .76 & 1.3 & -- & -- & 168 & 210 \\
\hline $\begin{array}{l}\angle 8 \ldots \\
\text { APR. }\end{array}$ & 0830 & 27400 & . I8 & .30 & -2 & - & 86 & 46 \\
\hline $01 \ldots$ & 1100 & 17500 & $\cdots$ & -- & - & -- & 94 & 44 \\
\hline $13 \ldots$ & 0930 & 6680 & - & -- & -- & -- & 123 & 68 \\
\hline \multicolumn{9}{|l|}{ MAY } \\
\hline $09 .$. & 1000 & 3680 & -- & $\ldots$ & - & - & 139 & 106 \\
\hline $22 \ldots$ & 0900 & 15900 & -- & - & $\cdots$ & - & 97 & 61 \\
\hline \multirow{2}{*}{\multicolumn{9}{|c|}{ JUNE }} \\
\hline & & & & & & & & \\
\hline $03 \ldots$ & 0900 & 24900 & - & -- & $=$ & -- & 87 & 30 \\
\hline $13 \ldots$ & 1215 & 21500 & -- & -- & -- & -- & 91 & 32 \\
\hline $28 \ldots$ & - & 8610 & -- & -- & -- & -- & 145 & 106 \\
\hline \multicolumn{9}{|l|}{ JULY } \\
\hline $05 \ldots$ & $=$ & 4240 & -- & -- & -- & -- & 133 & 81 \\
\hline $16 \ldots$ & -- & 2620 & -- & - & -- & -- & 155 & 115 \\
\hline $23 \ldots$ & - & 3020 & - & -- & - & -- & 203 & 245 \\
\hline \multicolumn{9}{|l|}{ AUG. } \\
\hline $14 \ldots$ & 1300 & 3680 & -- & - & -- & -- & 131 & 98 \\
\hline $20 \ldots$ & 0900 & 2240 & -- & - & - & - & 151 & 140 \\
\hline $31 \ldots$ & 1330 & 1120 & -- & -- & -- & - & 170 & 205 \\
\hline \multicolumn{9}{|l|}{ SEPT. } \\
\hline $09 .$. & 1115 & 2040 & $=$ & -- & $=-$ & -- & 181 & 272 \\
\hline 16. & 1330 & 1200 & -- & -- & -- & -- & 189 & 315 \\
\hline $28 \ldots$ & 1100 & 1480 & $-\infty$ & -- & $m$ & -- & 202 & 200 \\
\hline
\end{tabular}


03150300 MUSKINGUY RIVER NEAR BEVERLY, OHIO--CODTInUEd

CHEMICAL ANALYSES IN MILLIGRAMS PER LITER, WATER YEAR OCTOBER 1967 TO SEPTEMBER 1968

\begin{tabular}{|c|c|c|c|c|c|c|c|c|}
\hline DATE & $\begin{array}{l}\text { FLUD- } \\
\text { RIOE } \\
\text { IF I }\end{array}$ & $\begin{array}{l}\text { NITRATE } \\
\text { (NO3) }\end{array}$ & $\begin{array}{l}\text { TOTAL } \\
\text { PHOS- } \\
\text { PHORUS } \\
\text { (PO4) }\end{array}$ & $\begin{array}{l}\text { DIS- } \\
\text { SOLVED } \\
\text { SOLIDS } \\
\text { IRESI- } \\
\text { DUE AT } \\
180 \text { CI }\end{array}$ & $\begin{array}{l}\text { HARO- } \\
\text { NESS } \\
\text { (CA.MG) }\end{array}$ & $\begin{array}{l}\text { NON- } \\
\text { CAR- } \\
\text { BONATE } \\
\text { HARD- } \\
\text { NAESS }\end{array}$ & $\begin{array}{l}\text { SPECI- } \\
\text { FIC } \\
\text { COND- } \\
\text { UCTANCE } \\
\text { IMICRO- } \\
\text { MHOSI }\end{array}$ & $\mathrm{PH}_{\mathrm{H}}$ \\
\hline \multicolumn{9}{|l|}{ OCT. } \\
\hline $16 \ldots$ & $\begin{array}{l}-5 \\
.8 \\
-7\end{array}$ & $\begin{array}{l}2.6 \\
3.6\end{array}$ & $\begin{array}{r}.22 \\
.18\end{array}$ & $\begin{array}{r}602 \\
962\end{array}$ & $\begin{array}{l}340 \\
449\end{array}$ & $\begin{array}{l}245 \\
332\end{array}$ & $\begin{array}{r}955 \\
1360\end{array}$ & $\begin{array}{l}7.9 \\
7.8\end{array}$ \\
\hline $\begin{array}{l}28 . . . \\
\text { NOV. }\end{array}$ & .7 & 2.1 & .04 & 1020 & 514 & 399 & 1590 & 7.9 \\
\hline $01 \ldots$. & $\begin{array}{r}1.0 \\
.4\end{array}$ & $\begin{array}{l}6.2 \\
3.4\end{array}$ & .09 & $\begin{array}{r}1190 \\
596\end{array}$ & $\begin{array}{l}555 \\
335\end{array}$ & $\begin{array}{l}438 \\
230\end{array}$ & $\begin{array}{r}1790 \\
958\end{array}$ & $\begin{array}{l}7.4 \\
7.6\end{array}$ \\
\hline DEC. & .4 & 3.9 & .08 & 490 & 304 & 209 & 321 & 7.7 \\
\hline $01 \ldots$ & -- & 4.8 & -- & -- & -- & -- & RR5 & -- \\
\hline $09 .$. & - & 6.8 & $\cdots$ & - & - & $\rightarrow$ & 717 & $\cdots$ \\
\hline $\begin{array}{l}15 \ldots \\
\text { JAN. }\end{array}$ & $\cdots$ & 8.0 & $\cdots$ & - & -- & $\cdots$ & $5 B 3$ & + \\
\hline $11 \ldots$ & -- & 2.6 & -- & -- & -- & -- & 896 & -- \\
\hline $24 \ldots$ & -- & 3.0 & -- & -- & -- & -- & 1160 & - \\
\hline $31 \ldots$ & -- & 3.8 & -- & -- & -- & - & 576 & -- \\
\hline \multicolumn{9}{|l|}{ FEB. } \\
\hline $02 \ldots$ & -- & 5.7 & -- & -- & - & -- & 420 & -- \\
\hline $21 \ldots$ & -- & 7.1 & 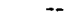 & -- & -- & $\cdots$ & 721 & -- \\
\hline MAR. & -- & 6.2 & -- & - & -- & -- & 982 & - \\
\hline $01 \ldots$ & - & 6.5 & - & -- & -- & -- & 979 & -- \\
\hline $12 \ldots$ & -- & 5.6 & - & -- & -- & -- & 1220 & - \\
\hline $\begin{array}{r}28 \\
\triangle P R .\end{array}$ & $\cdots$ & 5.0 & -- & $\cdots$ & $-\cdots$ & -- & 447 & -- \\
\hline $01 \ldots$ & -- & 4.8 & -- & -- & -- & -- & 489 & - \\
\hline $13 \ldots$ & -- & 3.1 & -- & -- & - & -- & 635 & -- \\
\hline $27 \ldots$ & -- & 2.6 & $\cdots$ & - & -- & - & 857 & - \\
\hline \multicolumn{9}{|l|}{ MAY } \\
\hline $09 .$. & - & 3.0 & -- & -- & -- & -- & 807 & -- \\
\hline $22 \ldots$ & $\cdots$ & 6.0 & $\rightarrow$ & - & -- & -- & 546 & - \\
\hline $27 \ldots$ & -- & 4.7 & -- & -- & -- & -- & 390 & -- \\
\hline \multicolumn{9}{|l|}{ JUNE } \\
\hline $03 \ldots$ & -- & 5.7 & -- & -- & -- & -- & 394 & -- \\
\hline $13 \ldots$ & -- & 0.0 & $\cdots$ & -- & -- & - & 458 & -- \\
\hline $\operatorname{suL}_{\gamma}^{28} \ldots$ & -- & 5.2 & -- & -- & -- & -- & 820 & $\cdots$ \\
\hline $05 \ldots$ & -- & 6.0 & - & $\ldots$ & -- & - & 715 & -- \\
\hline $16 . .$. & -- & 4.5 & -- & -- & -- & - & 927 & -- \\
\hline $23 \ldots$ & -- & 5.7 & -- & -- & -- & -- & 1370 & -- \\
\hline \multicolumn{9}{|l|}{ AUG. } \\
\hline $20 \ldots$ & -- & 2.4 & - & -- & -- & -- & 930 & -. \\
\hline $31 \ldots$ & -- & 3.3 & - & - & -- & -- & 1140 & $\cdots$ \\
\hline \multicolumn{9}{|l|}{ SEPT. } \\
\hline $\begin{array}{l}09 . . . \\
10 . . .\end{array}$ & -- & 3.8 & $\cdots$ & - & - & - & 1520 & $\ldots$ \\
\hline $28 \ldots$ & -- & 3.6 & - & -- & -- & $\cdots$ & 1250 & $=$ \\
\hline
\end{tabular}

(ONCE-DAILY MEASUREMENT USUALLY BETWEEN D800 AND 1200 )

MAY JUNE
JUL $Y$ UUGUST SEPTEMBER

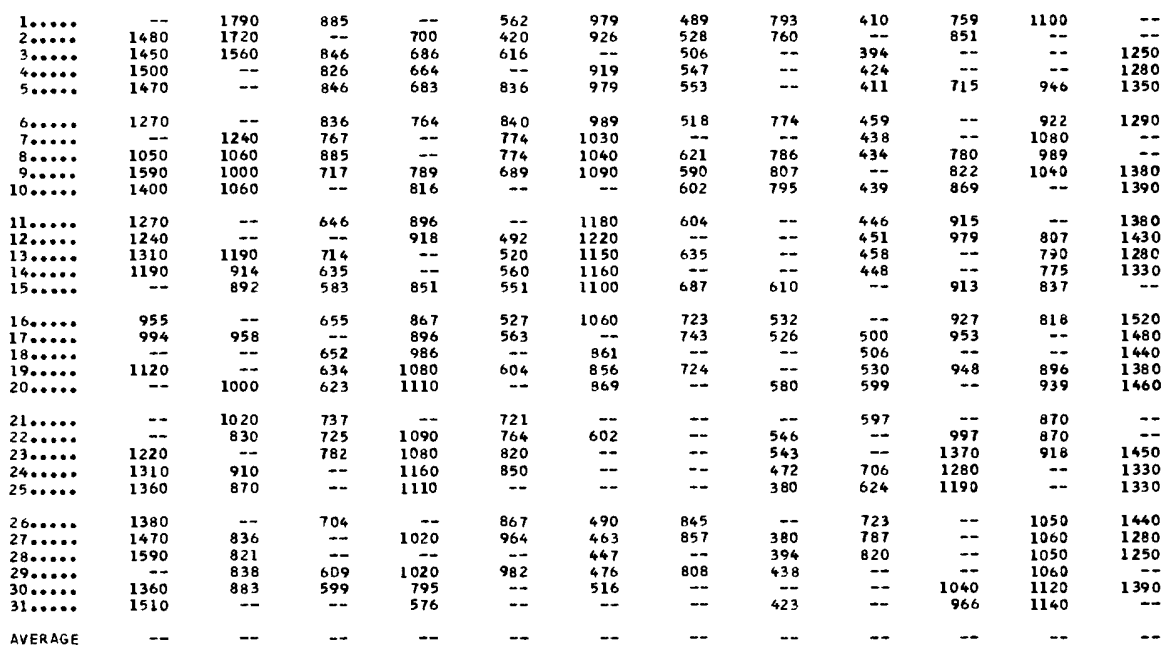


YUSKI NGUY RIVER BASIN

03150300 YUSKI NGUM RIVER NEAR BEVERLY, OHIO--CODTInUEd

TEMPERATURE $\left({ }^{\circ} \mathrm{C}\right)$ OF WATER, WATER YEAR OCTOBER 1967 TO SEPTEMBER 1968

(ONCE-DAILY MEASUREMENT USUALLY BETWEEN 0800 AND 1200)

\begin{tabular}{|c|c|c|c|c|c|c|c|c|c|c|c|c|}
\hline DAY & $O C t$ & NCV & OEC & JAA & FEB & MaR & $A P R$ & MAY & J UN & JUL & AUG & SE P \\
\hline 1 & -- & 14.0 & 4.0 & -- & 3.0 & --- & 19.0 &.- & 17.0 & 24.0 & 27.0 & -. \\
\hline 2 & 20.0 & 14.0 & $\cdots$ & 0.0 & 4.0 & 4.0 & 19.0 & -- & -- & 25.0 & $\cdots$ & $=-$ \\
\hline 3 & 20.0 & 14.0 & 3.0 & 0.0 & 6. C & $\cdots$ & 19.0 & -- & 17.0 & $\ldots$ & $\cdots$ & 28.0 \\
\hline 4 & 20.0 & - & 4.0 & 0.0 & $-\cdots$ & 5.0 & 19.0 & $\cdots$ & 18.0 & $\cdots$ & $\cdots$ & 27.0 \\
\hline 5 & 20.0 & -- & 3.0 & 0.0 & 3.0 & 4.0 & 19.0 & $\cdots$ & 18.0 & 24.0 & 27.0 & 27.0 \\
\hline 0 & 21.0 & -- & 3.0 & 1.0 & 2.0 & 6.0 & 18.0 & 10.0 & 19.0 & $\cdots$ & 27.0 & 28.0 \\
\hline 7 & - & 12.0 & 3.0 & $\ldots$ & 2.0 & 6.0 & -- & $=$ & 19.0 & $\cdots$ & - & $\ldots$ \\
\hline$B$ & 19.0 & 11.0 & 4.0 & -- & 3.0 & 6.0 & 19.0 & 24.0 & 21.0 & 26.0 & 27.0 & $\cdots$ \\
\hline 9 & 18.0 & 9.0 & 5.0 & 1.0 & 4.0 & 7.0 & 18.0 & 26.0 & $\cdots$ & 26.0 & - & 26.0 \\
\hline 10 & 18.0 & 9.0 & $\ldots$ & 1.0 & $\cdots$ & -- & 18.0 & 19.0 & 22.0 & 27.0 & $\cdots$ & 24.0 \\
\hline 11 & 19.0 & -- & 6.0 & 1.0 & $\ldots$ & 8.0 & 14.0 & $-\cdots$ & 22.0 & 27.0 & -- & 24.0 \\
\hline 12 & 19.0 & -- & $\ldots$ & 0.0 & 2.0 & 12.0 & - & -- & 22.0 & 27.0 & 26.0 & 23.0 \\
\hline 13 & 19.0 & 9.0 & 9.0 & $\cdots$ & 2.0 & 7.0 & 10.0 & $m$ & 22.0 & $\cdots$ & 25.0 & 23.0 \\
\hline 14 & 19.0 & 10.0 & 7.0 & -- & 2.0 & 7.0 & $\cdots$ & -- & 22.0 & $\cdots$ & 25.0 & 23.0 \\
\hline 15 & $\cdots$ & B. 0 & 7.0 & 1.0 & 2.0 & 9.0 & 16.0 & 17.0 & $\cdots$ & 29.0 & $\cdots$ & $\cdots$ \\
\hline 16 & 20.0 & $\ldots$ & 6.0 & 1.0 & 2.0 & 9.0 & 16.0 & 17.0 & -- & 29.0 & 27.0 & 27.0 \\
\hline 17 & 19.0 & 8.0 & - & 2.0 & 3.0 & $\cdots$ & 16.0 & 18.0 & 21.0 & 28.0 & $\cdots$ & $\begin{array}{l}27.0 \\
27.0\end{array}$ \\
\hline LB & -- & $\cdots$ & 6.0 & 1.0 & $\ldots$ & 7.0 & $-\cdot$ & -- & 21.0 & $-\cdot$ & $\cdots$ & 27.0 \\
\hline 19 & 19.0 & $\cdots$ & 6.0 & 2.0 & 2.0 & 7.0 & 16.0 & $\cdots$ & 21.0 & 29.0 & 27.0 & 26.0 \\
\hline 20 & $\ldots$ & 0.0 & 5.0 & 3.0 & -- & 9.0 & - & 17.0 & 21.0 & -- & 28.0 & 26.0 \\
\hline 21 &.- & 6.0 & 6.0 & $\ldots$ & 2.0 &.- & --- & --. & 21.0 & $\ldots$ & 28.0 & -.. \\
\hline 22 & -- & 0.0 & 6.0 & 0.0 & 3.0 & 11.0 & $\cdots$ & 16.0 & - & $2^{\circ} .0$ & 29.0 & $-\cdots$ \\
\hline 23 & 17.0 & $=-$ & 7.0 & 0.0 & 3. $\mathrm{C}$ & - & -- & 17.0 & $-\cdots$ & 29.0 & 31.0 & 20.0 \\
\hline 24 & 17.0 & 6.0 & $\cdots$ & 6.0 & 3.0 & $\cdots$ & - & 16.0 & 23.0 & 29.0 & $\cdots$ & 24.0 \\
\hline 25 & 17.0 & 8.0 & -- & 3.0 & $\cdots$ & --- & -- & 15.0 & 23.0 & 29.0 & $\cdots$ & $25 . \mathrm{C}$ \\
\hline 26 & 17.0 & -- & 3.0 & -- & 3.0 & 15.0 & --- & --- & 24.0 & -- & 32.0 & 27.0 \\
\hline 27 & 15.0 & 7.0 & -- & 3.0 & 4.0 & 16.0 & 16.0 & 17.0 & 24.0 & -- & 31.0 & 24.0 \\
\hline 28 & 14.0 & 0.0 & $\cdots$ & $\cdots$ & $\cdots$ & 19.0 & $\cdots$ & 16.0 & 23.0 & $=-$ & 29.0 & 24.0 \\
\hline 29 & $-\infty$ & 5.0 & 2.0 & 3.0 & 9.0 & 17.0 & $-\infty$ & 16.0 & -.. & -- & 29.0 & $\cdots$ \\
\hline 30 & 16.0 & 5.0 & 1.0 & 4.0 & $\cdots$ & 18.0 & -- & $\ldots$ & -- & -- & 28.0 & 27.0 \\
\hline $3 i$ & 16.0 & -- & $\cdots$ & 3.0 & $\cdots$ & ... & $\cdots$ & 17.0 & $\cdots$ & $\ldots$ & 29.0 & $\ldots$ \\
\hline ERAGE & --- & --- & -.- & $\cdots$ & -. & -- & $=-$ & -.- & - & $-\ldots$ & -.- & $\cdots$ \\
\hline
\end{tabular}

LITTLE KANAWHA RIVER BASIN

03153500 LITTLE KANAWHA RIVER AT GRANTSVILLE, W. VA.

LOCATION, - Lat $38^{\circ} 55^{\prime} 20^{\prime \prime}$, long $81^{\circ} 05^{\prime} 50^{\prime \prime}$, Calhoun County, 1,000 ft downstream from bridge on State Highway 16 at Grantsville, $1,200 \mathrm{f}$ ' downstream from Philip Run, and at mile 80.0 .

DRAINAGE ARER. $--913 \mathrm{sq} \mathrm{m} 1$.

PERIOD OF RECORD.---Sediment records: January to September 1968.

PERIODIC DETERMINATIONS OF SUSPENDED-SEDIMENT DISCHARGE, JANUARY IO SEPTEMBER 1968

CATE UISCHARGE TRAIION OISCHARGE

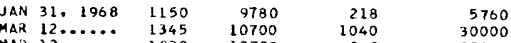

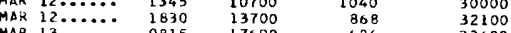

32100

\begin{tabular}{|c|c|c|c|c|c|}
\hline & DAIE & TIME & $\begin{array}{l}\text { DISCHARGE } \\
\text { (CFS) }\end{array}$ & $\begin{array}{l}\text { CONCEN- } \\
\text { TRATION } \\
\text { (MG/L) }\end{array}$ & $\begin{array}{l}\text { SUSPENOED } \\
\text { SEOIMENT } \\
\text { DISCHARGE } \\
\text { (TONS/OAY) }\end{array}$ \\
\hline$A R$ & $13 \ldots \ldots$ & 1230 & 16700 & 318 & 14300 \\
\hline$P R$ & $1 \ldots \ldots$ & 1230 & 3710 & 448 & 4490 \\
\hline & $26 \ldots \ldots$ & 1130 & 135 & 18 & 6. \\
\hline USG & $27 . \ldots \ldots$ & 1200 & 41 & 19 & 2 \\
\hline
\end{tabular}


03159510 HOCKING RIVER BELOW ATHENS, OHIO

LOCATION. --Lat $39^{\circ} 19^{\prime} 39^{\prime \prime}$, long $82^{\circ} 00^{\prime} 18^{\prime \prime}$, Athens County, at Harmony Lane Bridge, 5.5 miles downstream from gaging station at Athens.

DRAINAGE AREA. $--957 \mathrm{sq} \mathrm{mi}$

PERIOD OF RECORD,--Chemical analyses: May 1966 to September 1968.

Water temperatures: May 1966 to September 1968.

EXTREMES . $-1967-68$ :

Fater temperatures: Maximum, $31.0^{\circ} \mathrm{C} J u l y ~ 18 ;$ minimum, freezing point Jan. 29,30 .

Pertod of record:

Specific conductance (1966-67): Maximum daily, 1,500 micromhos July 12, 1966; minimum daily, 140 micromhos July 13, 1966, Mar. $5,1967$.

rater temperatures: Maximum, $30.0^{\circ} \mathrm{C}$ July 4, 1966, July 18, 1968: minimum, freezing point Feb, 25, 26, 1967, Jan. $29,30,1968$.

REMARKS.--In addition to the continuous recorder, twice-weekly samples were collected by a local observer.

Partial analyses were made on maximum specific conductance and minimum specific conductance of the samples collected each month. Specific conductance values listed as 1,500 micromhos represent values of $1,500 \mathrm{mi}-$ cromhos or greater, due to instrument limitations. Interruptions in the record were due to malfunctions of the instrument. Records of discharge are given for Hocking River at Athens (drainage area $943 \mathrm{sq} m i$ ).

CHEMiCAL ANALYSES IN MILLIGRAMS PER Liter, WATER YeAR DCTOBER 1967 TO SEPTEMBER 1968

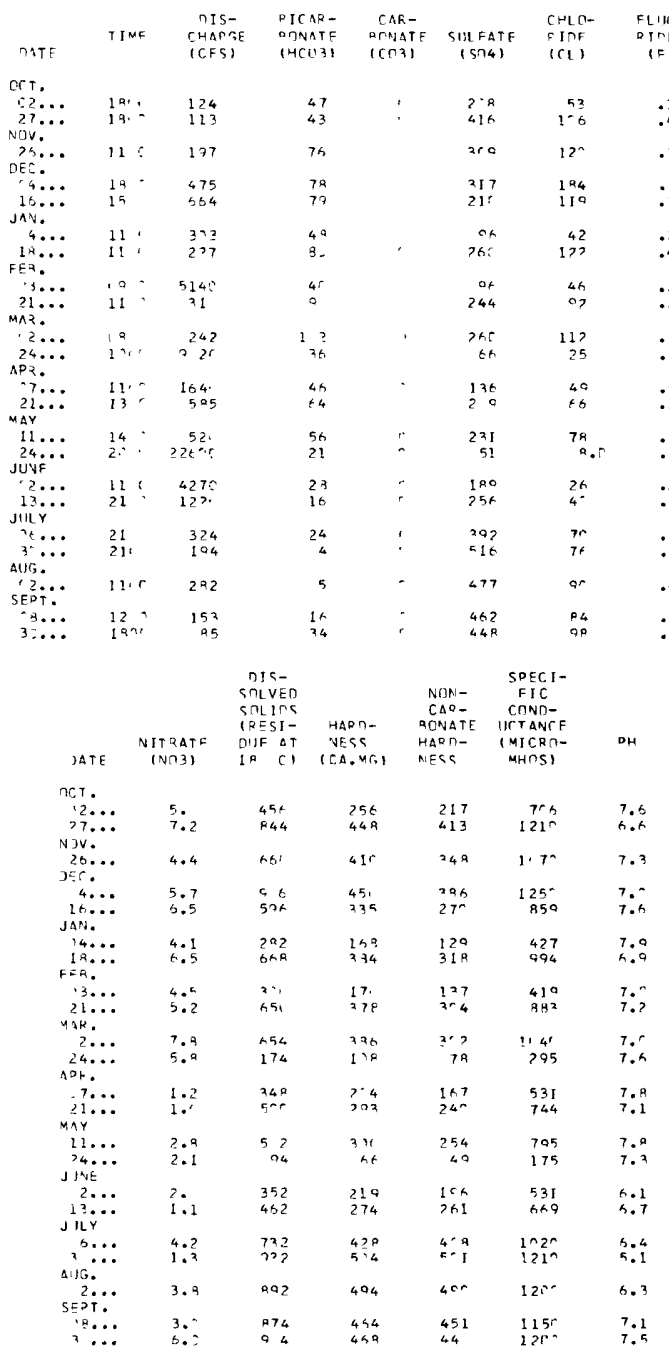


HOCXING RIVER BASIN

03159510 HOCKING RIVER BELON ATHENS, OHIO--Continued

SPECIFIC CONDUCTANCE, DISSOLVED OXYGEN, AND WATER TEMPERATURES, WATER YEAR OCTOBER 1967 TO SEPTEMBER 1968

$$
\text { OCTOBER }
$$

\begin{tabular}{|c|c|c|c|c|}
\hline \multirow[t]{2}{*}{$D A-$} & \multicolumn{2}{|c|}{$\begin{array}{l}\text { SPECIFIC } \\
\text { CONDUCTANCE } \\
\text { (HICROMOOS } \\
\left.\text { AT } 25^{\circ} \mathrm{C}\right)\end{array}$} & \multicolumn{2}{|c|}{$\begin{array}{l}\text { DI SSOLVED } \\
\text { OXYGEN } \\
(\mathbb{M G} / \mathrm{L})\end{array}$} \\
\hline & wax & MIN & $\max$ & IIN \\
\hline $\begin{array}{l}1 \\
2 \\
3 \\
4 \\
5\end{array}$ & $\begin{array}{r}1010 \\
860 \\
980 \\
1050 \\
1060\end{array}$ & $\begin{array}{l}860 \\
670 \\
840 \\
980 \\
990\end{array}$ & $\begin{array}{l}7.3 \\
7.1 \\
6.8 \\
6.7 \\
6.5\end{array}$ & $\begin{array}{l}6.9 \\
6.5 \\
6.3 \\
5.9 \\
5.8\end{array}$ \\
\hline $\begin{array}{r}6 \\
7 \\
8 \\
9 \\
10\end{array}$ & $\begin{array}{l}1000 \\
1030 \\
1080 \\
1050 \\
1100\end{array}$ & $\begin{array}{r}970 \\
950 \\
1020 \\
940 \\
1020\end{array}$ & $\begin{array}{l}6.0 \\
6.6 \\
6.9 \\
6.3 \\
6.8\end{array}$ & $\begin{array}{l}5.6 \\
5.9 \\
6.0 \\
5.8 \\
5.7\end{array}$ \\
\hline $\begin{array}{l}11 \\
12 \\
13 \\
14 \\
15\end{array}$ & $\begin{array}{l}1140 \\
1110 \\
1130 \\
1170 \\
1130\end{array}$ & $\begin{array}{l}1080 \\
1080 \\
1110 \\
1110 \\
1100\end{array}$ & $\begin{array}{l}6.9 \\
7.5 \\
7.1 \\
6.8 \\
6.8\end{array}$ & $\begin{array}{l}6.2 \\
6.6 \\
6.7 \\
6.4 \\
6.5\end{array}$ \\
\hline $\begin{array}{l}16 \\
17 \\
18 \\
19 \\
20\end{array}$ & $\begin{array}{l}1140 \\
1140 \\
1180 \\
1150 \\
1210\end{array}$ & $\begin{array}{l}1110 \\
1090 \\
1140 \\
1110 \\
1120\end{array}$ & $\begin{array}{l}6.9 \\
6.4 \\
6.4 \\
6.9 \\
7.0\end{array}$ & $\begin{array}{l}6.4 \\
6.1 \\
6.1 \\
5.7 \\
6.1\end{array}$ \\
\hline $\begin{array}{l}21 \\
22 \\
23 \\
24 \\
25\end{array}$ & $\begin{array}{l}1230 \\
1220 \\
1230 \\
1250 \\
1230\end{array}$ & $\begin{array}{l}1180 \\
1110 \\
1210 \\
1180 \\
1040\end{array}$ & $\begin{array}{l}7.2 \\
7.6 \\
8.0 \\
7.7 \\
7.3\end{array}$ & $\begin{array}{l}6.8 \\
7.2 \\
7.6 \\
6.4 \\
6.2\end{array}$ \\
\hline $\begin{array}{l}26 \\
27 \\
28 \\
29 \\
30 \\
31\end{array}$ & $\begin{array}{l}1220 \\
1230 \\
1250 \\
1240 \\
1270 \\
1260\end{array}$ & $\begin{array}{l}1170 \\
1190 \\
1200 \\
1210 \\
1230 \\
1220\end{array}$ & $\begin{array}{l}7.5 \\
7.6 \\
7.2 \\
7.3 \\
7.0 \\
6.6\end{array}$ & $\begin{array}{l}6.5 \\
7.1 \\
7.0 \\
6.8 \\
6.4 \\
5.8\end{array}$ \\
\hline
\end{tabular}

NOVEMBER

DECEMBER

\begin{tabular}{|c|c|c|c|c|}
\hline $\begin{array}{l}\text { TEMPER- } \\
\text { ATURE } \\
\left({ }^{\circ} \mathrm{C}\right)\end{array}$ & $\begin{array}{l}\text { SP } \\
\text { CONL } \\
\text { (MI } \\
\text { AT }\end{array}$ & $\begin{array}{l}\text { IC } \\
\text { CANCE } \\
\text { BOS } \\
\left.{ }^{\circ} \mathrm{C}\right)\end{array}$ & $\begin{array}{l}\text { DISS } \\
\text { OXY } \\
\text { (IMC }\end{array}$ & $\begin{array}{l}\text { LVED } \\
\text { EN } \\
\text { L) }\end{array}$ \\
\hline MAX MIN & MAX & IIN & $\max$ & MIN \\
\hline & 1260 & 1210 & -- & -- \\
\hline & 1220 & 1150 & -- & -- \\
\hline & 1200 & 1140 & -- & $=$ \\
\hline & 1160 & 1110 & -- & $=$ \\
\hline & 1170 & 1150 & & \\
\hline & -- & -- & -- & - \\
\hline & 1160 & 1130 & -- & -- \\
\hline & 1180 & 1120 & -- & -- \\
\hline & 1120 & 1080 & -- & -- \\
\hline & 1150 & 1070 & -- & - \\
\hline & 1120 & 1070 & -- & -- \\
\hline & 1120 & 1090 & -- & -- \\
\hline & 1140 & 1120 & -- & -- \\
\hline & 1140 & 1100 & -- & -- \\
\hline & -- & -- & -- & -- \\
\hline & -- & -- & -- & -- \\
\hline & 1030 & 990 & -- & -- \\
\hline & 1100 & 1030 & -- & $\cdots$ \\
\hline & - & - & -- & -- \\
\hline & $-\infty$ & & - & $=-$ \\
\hline & 1140 & 1090 & 10.8 & 10,3 \\
\hline & 1090 & 960 & 10.3 & 9.3 \\
\hline & 1080 & 1050 & 9.4 & 9.2 \\
\hline & -- & $\overline{-}$ & -- & - \\
\hline & & & & \\
\hline & 1090 & 1040 & 9.2 & 8.9 \\
\hline & 1080 & 1040 & 9.0 & 8.8 \\
\hline & -- & - & -- & -- \\
\hline & -- & & -- & - \\
\hline & -- & & - & -- \\
\hline & 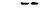 & & -- & \\
\hline
\end{tabular}

JANUARY

SPECIFIC

DISSOLVED TEPTE-

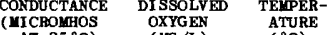

DAY

AT $25^{\circ} \mathrm{C}$

(MG/L)

MaX MIN MAX MIN MAX MIN

TELPER-

$\left({ }^{\circ} \mathrm{C}\right)$

SPECIFIC

(UICBOMHOS DISSOLVED TEMPER-

AT $\left.25^{\circ} \mathrm{C}\right) \quad$ OXYGEN $($ MTG $/ \mathrm{L}) \quad\left({ }^{\circ} \mathrm{C}\right)$

MAX MIN

MAX

MIN MAX MIN MAX MIN

$\begin{array}{llll}1220 & 980 & 12.4 & 10,4\end{array}$

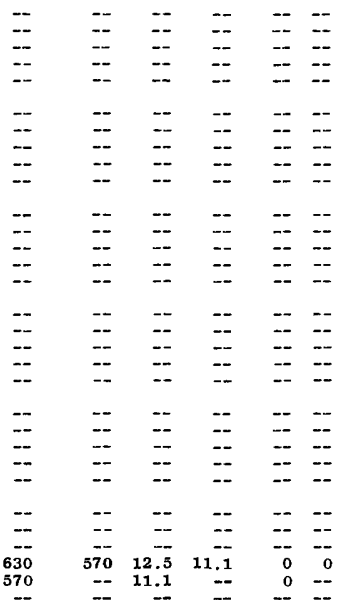

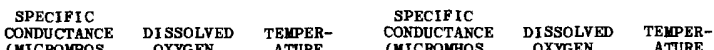

(MICHOMBOS OXYGEN ATURE (MICROMHOS OXYGEN ATUR

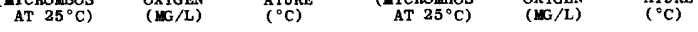

MAX MIN MAX MIN MAX MIN MAX MIN MAX MIN MAX MIN

$\begin{array}{llllllllllll}-- & -- & -- & -- & -- & -- & -- & -- & -z & -- & -- & - \\ -- & -- & -- & -- & -- & -- & -- & -- & -- & -- & -- & -\end{array}$

$\begin{array}{llllllllllll}-- & -- & -- & -- & -- & - & -- & -- & -- & -- & -- & - \\ -- & -- & -- & - & -- & -- & -- & -- & -- & -- & -- & -\end{array}$

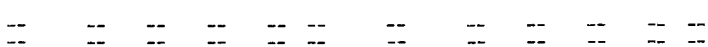

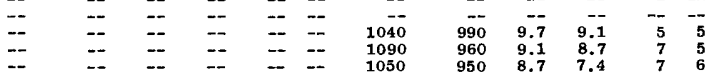

$\begin{array}{llllllllllll}-- & -- & -- & -- & -- & - & 1010 & 950 & 8.2 & 7.6 & 8 & 7\end{array}$

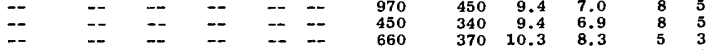

$\begin{array}{llllllllllll}-- & -- & -- & -- & - & - & 660 & 370 & 10.3 & 8.3 & 5 & 3 \\ -- & -- & -- & -- & -- & -- & 630 & 490 & 10.5 & 9.2 & 5 & 4\end{array}$

$\begin{array}{llllllllllll}850 & 810 & 11.3 & 10.4 & 1 & 1 & 680 & 600 & 10.6 & 7.8 & 6 & 5 \\ 870 & 830 & 10.5 & 10.2 & 2 & 1 & 640 & 540 & 10.5 & 8.5 & 7 & 6\end{array}$

$\begin{array}{rrrrrrrrrrrr}870 & 830 & 10.5 & 10.2 & 2 & 1 & 640 & 540 & 10.5 & 8.5 & 7 & 6\end{array}$

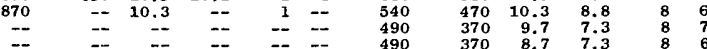

$\begin{array}{rrrrrrrrrrrr}-- & -- & -- & -- & -- & -- & 460 & 350 & \mathbf{7 . 9} & \mathbf{5 . 7} & \mathbf{7} & 5 \\ -- & -- & -- & -- & -- & -- & 390 & 230 & 8.3 & 6.9 & 7 & 4 \\ -- & -- & -- & -- & -- & -- & 350 & 220 & 9.0 & 6.8 & 6 & 4 \\ -- & -- & -- & -- & -- & 330 & 170 & 10.0 & 7.7 & 5 & 4\end{array}$

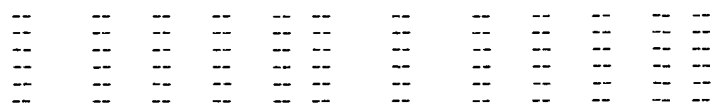


03159510 HOCKING RIVER BELOW ATHENS, OHIO_-_Continued

SPECIFIC CONDUCTANCE, DISSOLVED OXYGEN, AND WATER TEMPERATURES, WATER YEAR OCTOBER 1967 TO SEPTEMBER 1968

APRIL

$$
\begin{array}{r}
1 \\
2 \\
3 \\
4 \\
5 \\
6 \\
7 \\
8 \\
9 \\
10 \\
11 \\
12 \\
13 \\
14 \\
15 \\
6 \\
7 \\
3 \\
1 \\
20 \\
21 \\
22 \\
23 \\
24 \\
25 \\
26 \\
27 \\
28 \\
29 \\
30 \\
31
\end{array}
$$

JULY

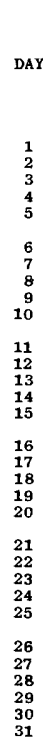

SPECIFIC CONDUCTANCE (MICROMHOS AT $25^{\circ} \mathrm{C}$ )

DISSOLVED
OXYGEN
$($ IG $/ L)$

TEMPER-
ATURE

\begin{tabular}{ccccc}
-- & -- & -- & -- \\
\hline-- & -- & -- & -- \\
-- & -- & -- & -- \\
-- & -- & -- & -- \\
-- & -- & -- & -- \\
-- & -- & -- & -- \\
-- & -- & -- & -- \\
-- & -- & -- & -- \\
7.8 & 6.2 & 25 & 25 \\
6.6 & 6.0 & 25 & 24 \\
7.1 & 5.6 & 25 & 25 \\
7.4 & 5.4 & 25 & 25 \\
7.0 & 5.2 & 25 & 25 \\
6.8 & 5.0 & 25 & 25 \\
7.2 & 5.4 & 30 & 25 \\
7.2 & 5.5 & 31 & 25 \\
6.2 & 5.1 & 26 & 25 \\
6.7 & 5.2 & 26 & 25 \\
7.3 & 5.4 & 26 & 25 \\
7.0 & 5.4 & 26 & 25 \\
6.6 & 4.4 & 26 & 25 \\
6.4 & 5.0 & 26 & 25 \\
6.4 & 5.2 & 26 & 25 \\
6.6 & 5.3 & 26 & 25 \\
6.4 & 5.1 & 25 & 25 \\
6.5 & 4.9 & 25 & 25 \\
-- & -- & -- & -- \\
-- & -- & -- & -- \\
-- & -- & -- & -
\end{tabular}

MAY

\begin{tabular}{|c|c|c|c|c|c|}
\hline \multicolumn{2}{|c|}{$\begin{array}{l}\text { SPECIFIC } \\
\text { CONDUCTANCE } \\
\text { (MICROMHOS } \\
\text { AT } 25^{\circ} \mathrm{C} \text { ) }\end{array}$} & \multicolumn{2}{|c|}{$\begin{array}{l}\text { DISSOLVED } \\
\text { OXYGEN } \\
(\text { MG/L) }\end{array}$} & \multicolumn{2}{|c|}{$\begin{array}{c}\text { TEMPER- } \\
\text { ATURE } \\
\left({ }^{\circ} \mathrm{C}\right)\end{array}$} \\
\hline MAX & MIN & MAX & MIN & $\max$ & MIN \\
\hline & & -- & -- & - & - \\
\hline 820 & 790 & $\begin{array}{l}8.0 \\
6.9 \\
7.0\end{array}$ & $\begin{array}{l}6.7 \\
6.6 \\
5.5\end{array}$ & $\begin{array}{l}17 \\
18 \\
18\end{array}$ & $\begin{array}{l}16 \\
17 \\
17\end{array}$ \\
\hline & & $\begin{array}{l}8.0 \\
8.9 \\
8.0 \\
6.5 \\
7.5\end{array}$ & $\begin{array}{l}5.6 \\
6.5 \\
5.9 \\
5.3 \\
5.6\end{array}$ & $\begin{array}{l}18 \\
20 \\
24 \\
22 \\
21\end{array}$ & $\begin{array}{l}16 \\
11 \\
15 \\
20 \\
16\end{array}$ \\
\hline & & $\begin{array}{l}7.0 \\
5.6 \\
3.7 \\
3.5 \\
4.9\end{array}$ & $\begin{array}{l}4.2 \\
3.2 \\
3.2 \\
2.9 \\
3.3\end{array}$ & $\begin{array}{l}17 \\
16 \\
15 \\
16 \\
16\end{array}$ & $\begin{array}{l}16 \\
15 \\
15 \\
15 \\
16\end{array}$ \\
\hline & & $\begin{array}{l}3.3 \\
3.3 \\
6.9 \\
7.6 \\
7.8\end{array}$ & $\begin{array}{l}2.2 \\
2.2 \\
2.7 \\
6.6 \\
7.5\end{array}$ & $\begin{array}{l}17 \\
18 \\
18 \\
15 \\
15\end{array}$ & $\begin{array}{l}16 \\
17 \\
15 \\
15 \\
14\end{array}$ \\
\hline & & $\begin{array}{l}7.7 \\
7.6 \\
7.5 \\
7.1 \\
8.0\end{array}$ & $\begin{array}{l}7.5 \\
7.3 \\
7.2 \\
6.2 \\
6.0\end{array}$ & $\begin{array}{l}15 \\
15 \\
15 \\
15 \\
16\end{array}$ & $\begin{array}{l}14 \\
15 \\
14 \\
14 \\
15\end{array}$ \\
\hline & & $\begin{array}{l}6.2 \\
6.3 \\
6.5 \\
6.2 \\
6.2 \\
6.3\end{array}$ & $\begin{array}{l}5.6 \\
5.2 \\
6.2 \\
6.0 \\
6.1 \\
6.1\end{array}$ & $\begin{array}{l}17 \\
17 \\
17 \\
16 \\
16 \\
16\end{array}$ & $\begin{array}{l}16 \\
17 \\
16 \\
16 \\
16 \\
16\end{array}$ \\
\hline
\end{tabular}

AUGUST

SPECIFIC

CONDUCTANCE
(MICROMHOS
AT $25^{\circ} \mathrm{C}$ )

DI SSOLVED OXYGEN

TEMPER-
ATURE
$\left({ }^{\circ} \mathrm{C}\right)$

SPECIFIC

DISSOLVED TEMPER-

$\begin{array}{lll}\left.\text { AT } 25^{\circ} \mathrm{C}\right) & \text { OXYGEN } & \text { ATURE } \\ \text { (MG } / \mathrm{L}) & \left({ }^{\circ} \mathrm{C}\right)\end{array}$

IAX

MIN

MAX MIN MAX MIN

$\begin{array}{llll}7.6 & 5.9 & 16 & 15 \\ 7.4 & 7.1 & 16 & 15\end{array}$

$\begin{array}{llll}7.4 & 7.1 & 16 & 15 \\ 7.2 & 6.8 & 18 & 16\end{array}$

$\begin{array}{llll}7.0 & 6.7 & 19 & 18 \\ 7.2 & 6.8 & 19 & 17\end{array}$

$\begin{array}{llll}7.2 & 6.9 & 19 & 18\end{array}$

$\begin{array}{llll}7.0 & 6.5 & 19 & 18\end{array}$

$\begin{array}{llll}7.1 & 6.8 & 19 & 18 \\ 7.0 & 6.7 & 20 & 19\end{array}$

$\begin{array}{llll}7.4 & 6.0 & 22 & 21 \\ 7.5 & 5.8 & 22 & 22\end{array}$

$\begin{array}{llll}7.5 & 5.8 & 22 & 22 \\ 8.7 & 7.2 & 22 & 20\end{array}$

$\begin{array}{llll}9.5 & 6.4 & 23 & 21 \\ 8.3 & 7.1 & 22 & 19\end{array}$

--

$\bar{z}=\bar{z} \quad \bar{z}=$

$=--\quad=-\overline{-}$

$\begin{array}{llll}-- & - & - & -\end{array}$

$\bar{z}=\bar{z} \quad \bar{z}$

-- $---\quad--$

$\bar{z}=\bar{z} \quad \bar{z}=$

$z \quad z \quad z=$

$\begin{array}{llllll}-- & -- & -- & -- & -- & -- \\ -- & -- & -- & -- & -- & --\end{array}$

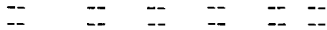

--

$\overline{--}$

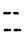

$\overline{--}--$

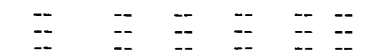

$\overline{--}$

$\overline{-z}$

$\overline{--}$

$\overline{z-}=$

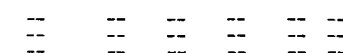

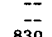

$\overline{7-\overline{0}}$

$\overline{-7} \quad \overline{-1}$

$\bar{z} \overline{24}$

$\begin{array}{lllll}850 & 700 & 6.0 & 5.6\end{array}$

$\begin{array}{llll}920 & 740 & 5.9 & 5.3\end{array}$

840

900

$\begin{array}{lll}740 & 5.9 & 5.3 \\ 790 & 5.8 & 5.2\end{array}$

$25 \quad 24$

\begin{tabular}{ll}
25 & 25 \\
27 & 25 \\
\hline &
\end{tabular}

$27 \quad 26$

910

940

89

$\begin{array}{lllll}890 & 5.6 & 5.2 & 28 & 26 \\ 910 & 8.1 & 5.1 & 29 & 27\end{array}$

$\begin{array}{lllll}910 & 8.1 & 5.1 & 29 & 27 \\ 830 & 7.3 & 5.1 & 29 & 28\end{array}$

$\begin{array}{lllll}960 & 8.0 & 5.1 & 30 & 28 \\ 990 & 7.3 & 5.1 & 29 & 27\end{array}$

\begin{tabular}{llllll}
1230 & 1160 & 8.4 & 6.8 & 23 & 22 \\
1230 & 1040 & 8.4 & 5.9 & 24 & 22 \\
\hline & - & 8.8 & 7.2 & 24 & 22
\end{tabular}

1030

$1010 \quad 7.3 \quad 6.0$

$\begin{array}{ll}28 & 26 \\ 26 & 25\end{array}$

$\begin{array}{llllll}1070 & 1030 & 7.3 & 6.0 & 28 & 26 \\ 1130 & 1050 & 8.6 & 6.2 & 26 & 25\end{array}$

$\begin{array}{llllll}1130 & 1050 & 8.0 & 6.6 & 25 & 24 \\ 1240 & 1070 & 8.4 & 6.7 & 24 & 23\end{array}$

$\begin{array}{llll}1140 & 1090 & 8.4 & 6.7 \\ 1130 & 1110 & 8.9 & 6.8 \\ & & & \end{array}$

$\begin{array}{ll}24 & 23 \\ 24 & 22\end{array}$

\begin{tabular}{|c|c|c|c|c|c|}
\hline \multicolumn{6}{|c|}{ SEPTEMBER } \\
\hline \multicolumn{2}{|c|}{$\begin{array}{l}\text { SPECIFIC } \\
\text { OONDUCTANCE } \\
\text { (HICROMHOS } \\
\text { AT } 25^{\circ} \mathrm{C} \text { ) }\end{array}$} & \multicolumn{2}{|c|}{$\begin{array}{l}\text { DI SSOLVED } \\
\text { OXYGEN } \\
(\mathbf{M G} / \mathrm{L})\end{array}$} & \multicolumn{2}{|c|}{$\begin{array}{l}\text { TEMPER- } \\
\text { ATURE } \\
\left({ }^{\circ} \mathrm{C}\right)\end{array}$} \\
\hline $\operatorname{MAX}$ & MIN & $\max$ & MIN & $\max$ & MIN \\
\hline $\begin{array}{l}1160 \\
1160 \\
1140 \\
1160 \\
1180\end{array}$ & $\begin{array}{l}1110 \\
1060 \\
1010 \\
1120 \\
1090\end{array}$ & $\begin{array}{l}8.6 \\
8.4 \\
8.4 \\
8.8 \\
7.3\end{array}$ & $\begin{array}{l}6.7 \\
6.6 \\
6.4 \\
6.1 \\
6.2\end{array}$ & $\begin{array}{l}23 \\
23 \\
23 \\
24 \\
23\end{array}$ & $\begin{array}{l}22 \\
22 \\
22 \\
23 \\
23\end{array}$ \\
\hline $\begin{array}{l}1160 \\
1160 \\
1180 \\
1220 \\
1170\end{array}$ & $\begin{array}{l}1090 \\
1120 \\
1130 \\
1170 \\
1150\end{array}$ & $\begin{array}{l}8.2 \\
8.7 \\
8.8 \\
7.4 \\
7.1\end{array}$ & $\begin{array}{l}6.0 \\
6.9 \\
6.8 \\
6.9 \\
6.5\end{array}$ & $\begin{array}{l}24 \\
23 \\
24 \\
23 \\
23\end{array}$ & $\begin{array}{l}23 \\
22 \\
22 \\
22 \\
22\end{array}$ \\
\hline $\begin{array}{l}1180 \\
1190 \\
1220 \\
1220 \\
1230\end{array}$ & $\begin{array}{l}1110 \\
1010 \\
1180 \\
1170 \\
1170\end{array}$ & $\begin{array}{l}6.8 \\
7.1 \\
7.4 \\
7.7 \\
7.6\end{array}$ & $\begin{array}{l}6.4 \\
6.5 \\
5.8 \\
6.6 \\
6.6\end{array}$ & $\begin{array}{l}22 \\
22 \\
22 \\
22 \\
22\end{array}$ & $\begin{array}{l}21 \\
20 \\
20 \\
21 \\
21\end{array}$ \\
\hline $\begin{array}{l}1180 \\
1210 \\
1220 \\
1180 \\
1190\end{array}$ & $\begin{array}{l}1170 \\
1170 \\
1180 \\
1140 \\
1130\end{array}$ & $\begin{array}{l}8.5 \\
8.8 \\
8.4 \\
7.6 \\
8.2\end{array}$ & $\begin{array}{l}7.1 \\
7.0 \\
7.0 \\
6.7 \\
6.8\end{array}$ & $\begin{array}{l}22 \\
22 \\
22 \\
21 \\
22\end{array}$ & $\begin{array}{l}21 \\
21 \\
21 \\
21 \\
20\end{array}$ \\
\hline $\begin{array}{r}1250 \\
1190 \\
1230 \\
1230 \\
-\end{array}$ & $\begin{array}{r}1160 \\
1160 \\
1040 \\
--\end{array}$ & $\begin{array}{l}8.4 \\
8.4 \\
8.4 \\
8.8 \\
8.4\end{array}$ & $\begin{array}{l}7.0 \\
6.8 \\
5.9 \\
7.2 \\
8.3\end{array}$ & $\begin{array}{l}23 \\
23 \\
24 \\
24 \\
24\end{array}$ & $\begin{array}{l}21 \\
22 \\
22 \\
22 \\
23\end{array}$ \\
\hline-- & -- & - & -- & -- & - \\
\hline- & & -1 & & - & - \\
\hline-- & & - & - & $\overline{-}$ & - \\
\hline 1200 & 1190 & 8.7 & 8.2 & 20 & 19 \\
\hline
\end{tabular}


03159900 OHIO RIVER AT NEF HAVEN, $\boldsymbol{W}$. VA.

LOCATION.--Lat $38^{\circ} 58^{\prime} 01^{\prime \prime}$, 10ng $81^{\circ} 55^{\prime} 18^{\prime \prime}$, Mason County, at raw water intake to Philip Sporn plant of American Electric Power Service Co. at New Haven, and at mile 241.6.

DRAINAGE AREA. $--40,200 \mathrm{sq} \mathrm{mi}$.

PERIOD OF RECORD.--Chemical analyses: October 1967 to September 1968.

Vater temperatures: October 1967 to September 1968.

EXTREMES. --1967-68:

Specific conductance: Maximum daily, 891 micromhos Sept. 17; minimum daily, 230 micromhos May 25.

Water temperatures: Maximum, 29.0 July 19,20,22, 24-26, Aug. 7, 23, 24, 26; minimum, 2.0 $0^{\circ} \mathrm{C}$ Jan. 10-13, $17-20,24,25$, Feb. 13-17, 19-22.

REMARKS. --Daily samples were collected at this station and samples were selected for analysis on the following basis: (1) Maximum daily specific conductance for each month, (2) minimum daily specific conductance for each month, (3) median daily specific conductance for each month, and (4) a composite analysis each month to determine heavy metals. Samples for iron and manganese were filtered clear when collected. Records of discharge are given for Ohio River at Pomeroy, Ohio (drainage area 40,500 sd mi approximately). CHEMICAL ANALYSES IN MILLIGRAMS PER LITER, WATER YEAR OCTOBER 1967 TO SEPTEMBER 1968

\begin{tabular}{|c|c|c|c|c|c|c|c|c|}
\hline DATE & $\begin{array}{l}\text { DIS- } \\
\text { CHARGE } \\
\text { (CFS) }\end{array}$ & $\begin{array}{l}\text { IRON } \\
\text { (FE) }\end{array}$ & $\begin{array}{l}\text { MAN- } \\
\text { GANESE } \\
\text { (MN) }\end{array}$ & $\begin{array}{l}\text { BICAR- } \\
\text { BONATE } \\
\text { (HCO3) }\end{array}$ & $\begin{array}{l}\text { CAR- } \\
\text { BONATE } \\
(C O 3)\end{array}$ & $\begin{array}{l}\text { SULFATE } \\
\left(\mathrm{SO}_{4}\right)\end{array}$ & $\begin{array}{l}\text { CHLO- } \\
\text { RIDE } \\
\text { (CL) }\end{array}$ & $\begin{array}{l}\text { FLUO- } \\
\text { RIDE } \\
\text { (F) }\end{array}$ \\
\hline \multicolumn{9}{|l|}{ ОСТ. } \\
\hline & -- & .14 & .54 & 25 & 0 & 152 & 48 & .6 \\
\hline $14 \ldots$ & -- & .31 & .50 & 32 & 0 & 82 & 33 & .3 \\
\hline $28 \ldots$ & 46200 & .17 & .69 & 22 & 0 & 123 & 29 & .4 \\
\hline \multicolumn{9}{|l|}{ NOV. } \\
\hline $07 .$. & -- & .26 & .46 & 32 & 0 & 102 & 60 & .2 \\
\hline $15 .$. & 37000 & .51 & .44 & 34 & 0 & 97 & 43 & .2 \\
\hline $30 .$. & 67600 & .56 & .42 & 24 & 0 & 86 & 23 & .1 \\
\hline \multicolumn{9}{|l|}{ DEC. } \\
\hline $14 \ldots$ & 86500 & .93 & .32 & 30 & 0 & 80 & 24 & .4 \\
\hline $23 . .$. & 58700 & .29 & .23 & 32 & 0 & 70 & 22 & .3 \\
\hline $23 \ldots$ & 50300 & .40 & .26 & 38 & 0 & 85 & 38 & .34 \\
\hline \multicolumn{9}{|l|}{ JAN. } \\
\hline $01 . .$. & 36900 & .29 & .62 & 36 & 0 & 87 & 34 & .3 \\
\hline $16 \ldots$ & 39300 & .29 & .68 & 32 & 0 & 107 & 34 & .6 \\
\hline $24 \ldots$ & 75700 & .93 & .63 & 34 & 0 & 74 & 29 & .3 \\
\hline FEB - & & & & & & & & \\
\hline $05 \ldots$ & 180000 & .08 & .39 & 30 & 0 & 80 & 21 & .3 \\
\hline $16 \ldots$ & 52200 & .12 & .42 & 44 & 0 & 89 & 33 & .3 \\
\hline $28 .$. & - & -- & .54 & 44 & 0 & 109 & 40 & .3 \\
\hline \multicolumn{9}{|l|}{ MAR. } \\
\hline $08 \ldots$ & -- & .55 & .83 & 46 & 0 & 124 & 54 & .2 \\
\hline $18 . .$. & 120000 & .34 & .89 & 21 & 0 & 127 & 32 & .1 \\
\hline \multirow{2}{*}{\multicolumn{9}{|c|}{ APR. }} \\
\hline & & & & & & & & \\
\hline $02 \ldots$ & 61300 & .20 & .24 & 36 & 0 & 68 & 22 & .2 \\
\hline $15 \ldots$ & - & .16 & .42 & 38 & 0 & 94 & 26 & .3 \\
\hline $30 \ldots$ & - & .20 & .34 & 54 & 0 & 108 & 42 & .3 \\
\hline \multicolumn{9}{|l|}{ MAY } \\
\hline $10 .$. & -- & .11 & .27 & 48 & 0 & 130 & 44 & .4 \\
\hline $16 \ldots$ & 97500 & .14 & .23 & 44 & 0 & 120 & 28 & .3 \\
\hline \multirow{2}{*}{\multicolumn{9}{|c|}{ JUNE }} \\
\hline & & & & & & & & \\
\hline $04 \ldots$ & 131000 & .32 & .14 & 36 & 0 & 78 & 14 & .2 \\
\hline $14 \ldots$ & 50000 & .74 & .16 & 58 & 0 & 111 & 26 & .4 \\
\hline $28 .$. & 3000 & .13 & .13 & 56 & 0 & 136 & 39 & .3 \\
\hline \multicolumn{9}{|l|}{ JULY } \\
\hline $0 I . .$. & -- & .10 & .08 & 64 & 0 & 143 & 40 & .4 \\
\hline $19 . .$. & -- & - & .12 & 80 & 0 & 137 & 50 & .5 \\
\hline $31 . .$. & - & .11 & .07 & 55 & 0 & 174 & 76 & .5 \\
\hline QUG. & & & & & & & & \\
\hline $05 \ldots$ & -- & .05 & .24 & 46 & 0 & 161 & 134 & .6 \\
\hline $12 \ldots$ & -- & .36 & .32 & 68 & 0 & 118 & 50 & .5 \\
\hline $29 \ldots$ & -- & .05 & .17 & 42 & 0 & 174 & 60 & .7 \\
\hline SEPT. & & & & & & & & \\
\hline $05 \ldots$ & - & .07 & .06 & 44 & 0 & 194 & 64 & .6 \\
\hline $17 \ldots$ & -- & .13 & .37 & 32 & 0 & 251 & 94 & .7 \\
\hline $27 \ldots$ & -- & .10 & .11 & 28 & 0 & 228 & 73 & .7 \\
\hline & TOTAL & & & & & & & \\
\hline & CHRO- & & & & & & & CAD- \\
\hline DATE & MIUM & NICKEL & COPPER & LEAD & ZINC & COBALT & ARSENIC & MIUM \\
\hline & & & & (PB) & $(Z N)$ & $(\mathrm{CO})$ & $(A S)$ & (CD) \\
\hline OCT. & & & & & & & & \\
\hline $\begin{array}{l}\text { 01-31 } \\
\text { NOV. }\end{array}$ & .00 & .00 & .00 & .00 & .04 & -- & -- & -- \\
\hline $\begin{array}{l}\text { NOV. } \\
\text { O1-30 }\end{array}$ & .00 & .00 & .01 & .01 & .23 & 00 & 00 & 00 \\
\hline DEC. & & & .01 & 01 & .22 & .00 & .00 & .00 \\
\hline $0 I-3 I$ & .00 & .00 & .01 & .01 & .08 & .00 & -- & .00 \\
\hline JAN. & & & & & & & & \\
\hline $\begin{array}{l}01-31 \\
\text { FEB. }\end{array}$ & .00 & .00 & .02 & .02 & .06 & .00 & - & .00 \\
\hline $\begin{array}{l}F E B . \\
O I-29\end{array}$ & .00 & .00 & .01 & .00 & .02 & .00 & -- & .00 \\
\hline MAR. & & & & & & & & \\
\hline $\begin{array}{l}\text { OI-3I } \\
\text { APR. }\end{array}$ & .00 & .01 & .01 & .00 & .02 & .00 & - & .00 \\
\hline $01-30$ & .00 & .01 & .01 & .00 & .01 & .00 & - & .00 \\
\hline MAY & & & & & & & & \\
\hline $01-31$ & .00 & .00 & .01 & .00 & .02 & .00 & - & .00 \\
\hline JUNE & & & & & & & & \\
\hline $01-30$ & .00 & .01 & .01 & .00 & .06 & .00 & -- & .00 \\
\hline JULY & .00 & .01 & 01 & 000 & & - & & \\
\hline $\begin{array}{l}\text { 01-31 } \\
\text { AUG. }\end{array}$ & .00 & .01 & .01 & .00 & .02 & .00 & -- & .00 \\
\hline $\begin{array}{l}01-31 \\
\text { SEPT. }\end{array}$ & .00 & .01 & .01 & .00 & .02 & .00 & - & .00 \\
\hline $01-30$ & .00 & .02 & .02 & .01 & .05 & .00 & -- & .00 \\
\hline
\end{tabular}


03159900 OHIO RIVER AT NEW HAVEN, W. VA.--Continued

CHEMICAL ANALYSES IN MILLIGRAMS PER LITER, WATER YEAR OCTOBER 1967 TO SEPTEMBER 1968

\begin{tabular}{|c|c|c|c|c|c|c|c|}
\hline DATE & $\begin{array}{l}\text { NI TRATE } \\
\text { (NO3) }\end{array}$ & $\begin{array}{l}\text { TOTAL } \\
\text { PHOS- } \\
\text { PHORUS } \\
\text { (P04) }\end{array}$ & $\begin{array}{l}\text { DIS- } \\
\text { SOLVED } \\
\text { SOLIDS } \\
\text { (RESI- } \\
\text { DUE AT } \\
180^{\circ} \mathrm{C} \text { ) }\end{array}$ & $\begin{array}{l}\text { HARD- } \\
\text { NESS } \\
(C A, M G)\end{array}$ & $\begin{array}{l}\text { NON- } \\
\text { CAR- } \\
\text { BONATE } \\
\text { HARD- } \\
\text { NESS }\end{array}$ & $\begin{array}{l}\text { SPE- } \\
\text { CIFIC } \\
\text { CONDUCT- } \\
\text { ANCE } \\
\text { (MICRO- } \\
\text { MHOS) }\end{array}$ & \\
\hline \multicolumn{8}{|l|}{ OCT. } \\
\hline $\begin{array}{l}02 \ldots \\
14 \ldots \\
28 \ldots\end{array}$ & $\begin{array}{l}3.4 \\
3.0 \\
2.9\end{array}$ & $\begin{array}{l}.12 \\
.11 \\
.08\end{array}$ & $\begin{array}{l}352 \\
206 \\
226\end{array}$ & $\begin{array}{l}166 \\
105 \\
130\end{array}$ & $\begin{array}{r}146 \\
79 \\
112\end{array}$ & $\begin{array}{l}550 \\
343 \\
411\end{array}$ & $\begin{array}{l}6 . \\
7 . \\
6 .\end{array}$ \\
\hline \multicolumn{8}{|l|}{ NOV." } \\
\hline $\begin{array}{l}07 \ldots \\
15 . .\end{array}$ & $\begin{array}{l}2.6 \\
2.6\end{array}$ & $\begin{array}{l}.08 \\
.09\end{array}$ & $\begin{array}{l}298 \\
228\end{array}$ & $\begin{array}{l}151 \\
126\end{array}$ & $\begin{array}{r}125 \\
98\end{array}$ & $\begin{array}{l}494 \\
412\end{array}$ & \\
\hline & 319 & \\
\hline $14 \ldots$ & 2.8 & .05 & 194 & 108 & 84 & 316 & \\
\hline $\begin{array}{l}23 \ldots \\
28 . .\end{array}$ & 2.7 & .07 & 188 & 94 & 68 & 286 & \\
\hline \multicolumn{8}{|l|}{ JAN. } \\
\hline $01 \ldots$ & 3.4 & .16 & 240 & 124 & 94 & 388 & \\
\hline $16 \ldots$ & 3.6 & .07 & 254 & 140 & 114 & 432 & \\
\hline FEB. & 2.5 & .18 & 192 & 104 & 76 & 343 & \\
\hline \multicolumn{8}{|l|}{ FEB. } \\
\hline $\begin{array}{l}05 \ldots \\
16 \ldots\end{array}$ & $\begin{array}{l}4.0 \\
4.3\end{array}$ & $\begin{array}{l}.07 \\
.27\end{array}$ & $\begin{array}{l}172 \\
244\end{array}$ & $\begin{array}{l}108 \\
138\end{array}$ & $\begin{array}{r}84 \\
102\end{array}$ & $\begin{array}{l}301 \\
381\end{array}$ & \\
\hline $28 .$. & 4.2 & .17 & 280 & 154 & 118 & 454 & \\
\hline \multicolumn{8}{|l|}{ MAR. } \\
\hline $\begin{array}{l}08 \ldots \\
18 . .\end{array}$ & $\begin{array}{l}5.9 \\
3.3\end{array}$ & $\begin{array}{l}.17 \\
.04\end{array}$ & $\begin{array}{l}354 \\
292\end{array}$ & $\begin{array}{l}184 \\
210\end{array}$ & $\begin{array}{l}147 \\
193\end{array}$ & $\begin{array}{l}535 \\
427\end{array}$ & \\
\hline $30 \ldots$ & 3.4 & .11 & 188 & 108 & 84 & 295 & \\
\hline \multicolumn{8}{|l|}{ APR. } \\
\hline $02 \ldots$ & 4.2 & .11 & 196 & 106 & 76 & 285 & \\
\hline $15 \ldots$ & 3.9 & .10 & 230 & 134 & 103 & 362 & \\
\hline $30 \ldots$ & 3.8 & .12 & 304 & 166 & 122 & 463 & \\
\hline \multicolumn{8}{|l|}{ MAY } \\
\hline $10 \ldots$ & 5.2 & .13 & 321 & 174 & 135 & 505 & \\
\hline $16 \ldots$ & 5.2 & .06 & 284 & 154 & 118 & 437 & \\
\hline $25 \ldots$ & 2.7 & .20 & 168 & 90 & 56 & 230 & \\
\hline \multicolumn{8}{|l|}{ JUNE } \\
\hline $04 \ldots$ & 2.0 & .12 & $\begin{array}{l}168 \\
256\end{array}$ & 111 & $\begin{array}{r}82 \\
\end{array}$ & 278 & \\
\hline $\begin{array}{l}14 \ldots \\
28 \ldots\end{array}$ & 3.2 & $\begin{array}{r}.08 \\
13\end{array}$ & 256 & 174 & 127 & 419 & \\
\hline $28 \ldots$ & 3.1 & .13 & 322 & 196 & 150 & 510 & \\
\hline \multicolumn{8}{|l|}{ JULY } \\
\hline $19 \ldots$ & 1.8 & .09 & 372 & 204 & 139 & 588 & \\
\hline $31 \ldots$ & 2.4 & .16 & 448 & 230 & 185 & 705 & \\
\hline \multicolumn{8}{|l|}{ AUG. } \\
\hline $05 \ldots$ & 5.5 & .08 & 516 & 262 & 224 & 861 & \\
\hline $12 \ldots$ & 1.0 & .08 & 318 & 176 & 121 & 530 & \\
\hline \multicolumn{3}{|l|}{ SEPT. } & 404 & 204 & 170 & 640 & \\
\hline $05 \ldots$ & 7.5 & .32 & 412 & 220 & 184 & 698 & \\
\hline $17 \ldots$ & 6.6 & .16 & 536 & 265 & 239 & 891 & \\
\hline & 7.6 & .13 & 446 & 238 & 215 & 764 & \\
\hline
\end{tabular}

SPECIFIC CONDUCTANCE (MICROMHOS AT $25^{\circ} \mathrm{C}$ ), WATER YEAR OCTOBER 1967 TO SEPTEMBER 1968

DAY OCTOBER NOVEMBER DECEMBER JANUARY FEgRUARY MARCH ADRIL MAY JUNE JULY AUGUST SEPTEMBER

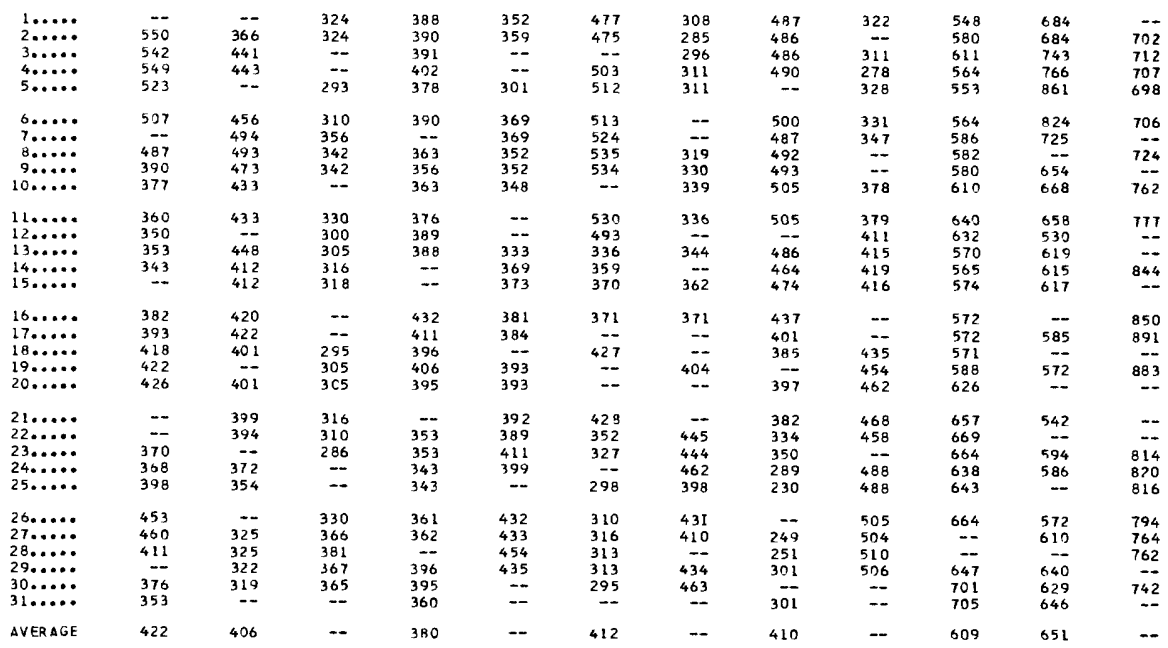


03159900 OHIO RIVER AT NEW HAVEN, W. YA.--Continued

\begin{tabular}{|c|c|c|c|c|c|c|c|c|c|c|c|c|}
\hline OAY & $O C T$ & Nov & $\begin{array}{c}\text { TEMPERATURE } \\
\text { DEC }\end{array}$ & $\begin{array}{l}\left({ }^{\circ} \mathrm{C}\right) \\
\text { JAN }\end{array}$ & $\begin{array}{c}\text { OF WATER, } \\
\text { FEB }\end{array}$ & $\begin{array}{c}\text { WATER YEAR } \\
\text { NAR }\end{array}$ & $\begin{array}{l}\text { OCTOBER } \\
A P R\end{array}$ & $\begin{array}{c}1967 \text { TO } \\
M \triangle Y\end{array}$ & $\begin{array}{c}\text { SEPTEMBER } \\
\text { JUN }\end{array}$ & $\begin{array}{l}1968 \\
\text { JUL }\end{array}$ & AUG & SEP \\
\hline 1 & -- & -- & -- & 4.0 & 4.0 & 3.0 & 12.0 & 17.0 & 15.0 & 25.0 & 28.0 & o \\
\hline 2 & 19.0 & 13.0 & 7.0 & 3.0 & 5.0 & 3.0 & 13.0 & 17.0 & -- & 26.0 & 28.0 & 27.0 \\
\hline 3 & 20.0 & 13.0 & --. & 3.0 & $\cdots$ & -- & 13.0 & 17.0 & 17.0 & 25.0 & 27.0 & 26.0 \\
\hline 4 & 21.0 & 14.0 & --- & 4.0 & + & 4.0 & 12.0 & 18.0 & 19.0 & 26.0 & 27.0 & 26.0 \\
\hline & 21.0 & --- & 7.0 & 3.0 & 4.0 & 4.0 & 12.0 & $-\cdots$ & 18.0 & 26.0 & 27.0 & 26.0 \\
\hline 6 & 23.0 & 12.0 & 7. 0 & 3.0 & 4.0 & 4.0 & $\cdots$ & 17.0 & 18.0 & 26.0 & 28.0 & 26.0 \\
\hline 7 & - & 11.0 & 7.0 & $\cdots$ & 4.0 & 5.0 & -- & 19.0 & 19.0 & 26.0 & 29.0 & $\cdots$ \\
\hline 8 & 21.0 & 11.0 & 6.0 & 3.0 & 4.0 & 5.0 & 13.0 & 19.0 & -- & 27.0 & $\cdots$ & 25.0 \\
\hline 9 & 19.0 & iu. 0 & 6.0 & 3.0 & 3.0 & 7.0 & 14.0 & 19.0 & -- & 27.0 & 28.0 & -- \\
\hline 10 & 18.0 & $\ldots$ & $\cdots$ & 2.0 & 3.0 & -- & 13.0 & 19.0 & 22.0 & 27.0 & 28.0 & 25.0 \\
\hline 11 & 18.0 & --- & 6.0 & 2.0 & --- & 7. $C$ & 13.0 & 19.0 & 22.0 & 27.0 & 27.0 & 25.0 \\
\hline 12 & 18.0 & -- & 7.0 & 2.0 & $-\cdots$ & 2.0 & -- & $\cdots$ & 23.0 & 27.0 & 27.0 &.- \\
\hline 13 & 18.0 & 11.0 & 8.0 & 2.0 & $2 . c$ & 8.0 & 14.0 & 19.0 & 23.0 & 27.0 & 27.0 & --- \\
\hline 14 & 18.0 & --- & 7.0 & $\cdots$ & 2.0 & 7.0 & $=-$ & 19.0 & 22.0 & 28.0 & 27.0 & 25.0 \\
\hline 15 & $\cdots$ & 10.0 & 7.0 & $=-$ & 2.0 & 8.0 & 15.0 & 19.0 & 22.0 & 28.0 & 27.0 & $\cdots$ \\
\hline 16 & 18.0 & 9.0 & - & 3.0 & 2.0 & 8.0 & 14.0 & 18.0 & $\cdots$ & 28.0 & -- & 25.0 \\
\hline 17 & 18.0 & 11.0 & $-\cdots$ & 2.0 & 2.0 & -- & -- & 18.0 & $\cdots$ & 28.0 & 27.0 & 25.0 \\
\hline 18 & 18.0 & 10.0 & 7.0 & 2.0 & $\cdots$ & 8.0 & -- & 20.0 & 23.0 & 27.0 & 27.0 & $\cdots$ \\
\hline 19 & 17.0 & -- & 7.0 & 2.0 & 2.0 & $\cdots$ & 16.0 & -- & 23.0 & 29.0 & 27.0 & 25.0 \\
\hline 20 & 17.0 & 9.0 & 7.0 & 2. C & 2.0 & --- & $\cdots$ & 17.0 & 23.0 & 29.0 & $\cdots$ & --- \\
\hline 21 & $\cdots$ & 9.0 & 7.0 & $\cdots$ & 2.0 & 8.0 & -- & 17.0 & 23.0 & 28.0 & 27.0 & --- \\
\hline 22 & -- & --- & 7.0 & 3.0 & 2.0 & 5. 0 & 17.0 & 16.0 & 23.0 & 29.0 & -- & -- \\
\hline 23 & 17.0 & -- & 7.0 & 4.0 & 3.0 & 9.0 & 18.0 & 16.0 & -- & 2 B. 0 & 20.0 & 24.0 \\
\hline 24 & 16.0 & 9.0 & --- & 2.0 & 3.0 & $\cdots$ & 18.0 & 16.0 & 24.0 & 29.0 & 29.0 & 24.0 \\
\hline 25 & 16.0 & 8.0 & -- & 2.0 & --- & 7.0 & 17.0 & 15.0 & 25.0 & 29.0 & $-\cdots$ & 24.0 \\
\hline 26 & 16.0 & $-\cdots$ & 7. 0 & 3.0 & 3.0 & 9.0 & 16.0 & -- & 25.0 & 29.0 & 29.0 & 25.0 \\
\hline 27 & 16.0 & 7.0 & 6.0 & 3.0 & 3.0 & 8.0 & 16.0 & 15.0 & 25.0 & -- & 28.0 & 24.0 \\
\hline 28 & 14.0 & 8.0 & 6.0 & -- & 4.0 & 9.0 & $\because-$ & 15.0 & 24.0 & -- & $m$ & 24.0 \\
\hline 29 & -- & 7.0 & 5.0 & 4.0 & 4.0 & 9.0 & 16.0 & 15.0 & 24.0 & 28.0 & 27.0 & -- \\
\hline 30 & 13.0 & $\cdots$ & 4.0 & 4.0 & -- & 11.0 & 17.0 & $\overline{-}$ & $\cdots$ & $29.0^{\circ}$ & 27.0 & 25.0 \\
\hline 31 & 13.0 & -- & --- & 4.0 & $\cdots$ & $\cdots$ & -- & 15.0 & -- & 29.0 & 27.0 & -.- \\
\hline RAGE & 17.5 & -- & -- & 3.0 & 3.0 & $\cdots$ & -- & 17.5 & $\cdots$ & 27.5 & 27.5 & -- \\
\hline
\end{tabular}

03164000 NEW RIVER NEAR GALAX, VA.

LOCATION, --Lat $36^{\circ} 38^{\prime} 50^{\prime \prime}$, long $80^{\circ} 58^{\prime} 45^{\prime \prime}$, Carroll County, on left bank at upstream side of bridge on U.S. Highway 58 , $500 \mathrm{ft}$ downstream from Meadow Creek, 1.2 miles southwest of old Town, 3.1 miles southwest of Galax and $3.6 \mathrm{miles}$
downstream from Elk Creek.

DRAINAGE AREA. - -1, $131 \mathrm{sq}$ mi.

PERIOD OF RECORD.--Chemical analyses: April 1930 to March 1931, October to December 1949, October 1951 to September 1952, October 1967 to February 1968 (monthly), Apri1 to September 1968 (daily).

Water temperatures: October to December 1949, Aprii to September 1968.

EXTREMES. --April to September 1968:

Dissolved solids: Maximum, $48 \mathrm{mg} / 1$ June 21-30, Aug. 21-31; minimum, $35 \mathrm{mg} / 1 \mathrm{Sept}$. 1-10.

Hardness: Maximum, $20 \mathrm{mg} / 1$ Aug. 11-20; minimum, $13 \mathrm{mg} / 1$ Apr. 11-20

Specific conductance: Maximum dally, 73 micromhos Aug. 8; mintmum da1ly, 39 micromhos May 8 .

Dissolved soltds: Maxtmum, $48 \mathrm{mg} / 1$ June 21-30, 1968; minimum, $27 \mathrm{mg} / 1 \mathrm{Apr}$. 1-10, 1930, Mar. 1-10, 1931.

Specific conductance (Aprt1 to September 1968): Maximum daily, 73 micromhos Aug. 8, 1968; mintmum daily,

39 micromhos May 8, 1968 .

ter temperatures (April to September 1968): Maximum, $30.0^{\circ} \mathrm{C}$ Aug. 23, 24, 1968.

\begin{tabular}{|c|c|c|c|c|c|c|c|c|c|c|}
\hline DATE & $\begin{array}{c}\text { EMICAL A } \\
\text { DIS- } \\
\text { CHAREE } \\
\text { ICFSI }\end{array}$ & $\begin{array}{l}\text { LYSES IN } \\
\text { SILICA } \\
\text { ISIO2I }\end{array}$ & $\begin{array}{l}\text { MILLIGRAMS } \\
\text { OII- } \\
\text { SOLVED } \\
\text { I IREN } \\
\text { IFEI }\end{array}$ & $\begin{array}{l}\text { PER } \\
\text { CAL- } \\
\text { CUUM } \\
\text { ICAI }\end{array}$ & $\begin{array}{l}\text { R, HATER } \\
\text { MAG- } \\
\text { NE- } \\
\text { SIUM } \\
\text { IMGI }\end{array}$ & $\begin{array}{l}\text { VEAF OC } \\
\text { SOD IUM } \\
\text { INAI }\end{array}$ & $\begin{array}{l}\text { BER } 19 \\
\text { POO- } \\
\text { TAS- } \\
\text { SIUM } \\
\text { IKI }\end{array}$ & $\begin{array}{l}\text { TO SEPT } \\
\text { BICAR- } \\
\text { BONATE } \\
\text { IHCO3) }\end{array}$ & $\begin{array}{l}\text { SULFATE } \\
\text { (SO4) }\end{array}$ & $\begin{array}{l}\text { CHLO- } \\
\text { RIOE } \\
\text { ICLI }\end{array}$ \\
\hline $\begin{array}{l}\text { uc T. } \\
06 . . .\end{array}$ & -- & 9.0 & .06 & 3.7 & 1.4 & 2.1 & 1.1 & 17 & $2 . B$ & 2.4 \\
\hline $\begin{array}{l}\text { NOV. } \\
15 . . . \\
D E C_{0}\end{array}$ & 1010 & 12 & .06 & 3.6 & 1.2 & 2.8 & 1.2 & 19 & 2.0 & 2.1 \\
\hline J $08 . .$. & $16 B C$ & 9.2 & .05 & 3.6 & 1.0 & 2.3 & 1.2 & 16 & 3.0 & 2.5 \\
\hline $\begin{array}{r}04 \ldots \\
30 . . .\end{array}$ & $\begin{array}{l}33 B 0 \\
2850\end{array}$ & $\begin{array}{l}11 \\
10\end{array}$ & .01 & $\begin{array}{l}4.3 \\
3.0\end{array}$ & $\begin{array}{l}2.0 \\
1.7\end{array}$ & $\begin{array}{l}2.3 \\
2.1\end{array}$ & $\begin{array}{l}1.0 \\
1.2\end{array}$ & $\begin{array}{l}17 \\
16\end{array}$ & $\begin{array}{l}3.4 \\
3.8\end{array}$ & 26.3 \\
\hline $\begin{array}{r}14 \ldots . \\
28, \ldots \\
\triangle P R_{0}\end{array}$ & $\begin{array}{l}7100 \\
2420\end{array}$ & $\begin{array}{l}10 \\
9.4\end{array}$ & $\begin{array}{l}.06 \\
.08\end{array}$ & $\begin{array}{l}4.6 \\
3.6\end{array}$ & $\begin{array}{r}1.0 \\
.5\end{array}$ & $\begin{array}{l}2.5 \\
2.5\end{array}$ & $\begin{array}{r}1.2 \\
.8\end{array}$ & $\begin{array}{l}16 \\
14\end{array}$ & $\begin{array}{l}3.6 \\
2.6\end{array}$ & $\begin{array}{l}3.2 \\
2.9\end{array}$ \\
\hline $\begin{array}{l}01-10 \\
11-20 \\
21-30 \\
\text { MAY }\end{array}$ & $\because=$ & $\begin{array}{l}9.4 \\
10^{10} \\
10\end{array}$ & $\begin{array}{l}.00 \\
: 09 \\
.06\end{array}$ & $\begin{array}{l}3.6 \\
3.2 \\
4.2\end{array}$ & $\begin{array}{l}1.2 \\
1.2 \\
1.3\end{array}$ & $\begin{array}{l}2.3 \\
4.8 \\
2.5\end{array}$ & $\begin{array}{r}1.2 \\
1.2 \\
.8\end{array}$ & $\begin{array}{l}16 \\
18 \\
18\end{array}$ & $\begin{array}{l}2.2 \\
3.0 \\
3.6\end{array}$ & $\begin{array}{l}3.1 \\
3.2 \\
3.5\end{array}$ \\
\hline $\begin{array}{l}01-10 \\
11-20 \\
2 l-31\end{array}$ & $\begin{array}{l}=- \\
=-\end{array}$ & $\begin{array}{l}11 \\
10 \\
9.8\end{array}$ & $\begin{array}{l}.00 \\
005 \\
.02\end{array}$ & $\begin{array}{l}4.2 \\
4.4 \\
4.0\end{array}$ & $\begin{array}{l}1.2 \\
1.2 \\
1.4\end{array}$ & $\begin{array}{l}3.7 \\
2.8 \\
3.2\end{array}$ & $\begin{array}{l}1.6 \\
1.2 \\
1.6\end{array}$ & $\begin{array}{l}19 \\
19 \\
18\end{array}$ & $\begin{array}{l}4.6 \\
2.6 \\
3.4\end{array}$ & $\begin{array}{l}4.0 \\
4.0 \\
2.4\end{array}$ \\
\hline $\begin{array}{l}\text { JUNE } \\
01-10\end{array}$ & -- & 9.9 & .05 & 3.8 & 1,4 & 3.2 & 1.6 & 17 & 67 & 2.4 \\
\hline $\begin{array}{l}11-20 \\
21-30\end{array}$ & -- & 11 & .02 & 3.8 & $\begin{array}{l}10.4 \\
1.8\end{array}$ & 3.4 & $\begin{array}{l}110 \\
1.6\end{array}$ & 20 & 3.4 & $\begin{array}{l}2.4 \\
3.6\end{array}$ \\
\hline $\mathrm{JUL}^{21-3]}$ & -- & 10 & .06 & 4.4 & 1.2 & 3.0 & 1.2 & 20 & 3.0 & 3.9 \\
\hline $\begin{array}{l}01-10 \\
11-20 \\
21-31\end{array}$ & $=$ & $\begin{array}{l}8.7 \\
9.1\end{array}$ & $\begin{array}{l}.03 \\
.06\end{array}$ & $\begin{array}{l}4.4 \\
4.4\end{array}$ & $\begin{array}{l}1.2 \\
1.4\end{array}$ & $\begin{array}{l}3.2 \\
3.4\end{array}$ & $\begin{array}{l}1.6 \\
1.6\end{array}$ & $\begin{array}{l}22 \\
22\end{array}$ & $\begin{array}{l}1.8 \\
2.4\end{array}$ & $\begin{array}{l}3.4 \\
3.5\end{array}$ \\
\hline $\begin{array}{l}21-31 \\
\text { AUG. }\end{array}$ & -- & 9.5 & .04 & 5.0 & 1.3 & & 1.6 & 22 & & \\
\hline $\begin{array}{l}01-10 \\
11-20 \\
21-31\end{array}$ & $=$ & $\begin{array}{l}9.9 \\
9.3 \\
7.6\end{array}$ & $\begin{array}{l}.07 \\
: 02 \\
.09\end{array}$ & $\begin{array}{l}4.8 \\
4.4 \\
4.0\end{array}$ & $\begin{array}{l}1.8 \\
2.1 \\
2.2\end{array}$ & $\begin{array}{l}3.4 \\
3.9 \\
3.7\end{array}$ & $\begin{array}{l}2.0 \\
2.0\end{array}$ & $\begin{array}{l}23 \\
23 \\
23\end{array}$ & $\begin{array}{l}4.4 \\
4.4\end{array}$ & $\begin{array}{l}3.7 \\
4.4\end{array}$ \\
\hline $\begin{array}{l}\text { SEPT. } \\
\text { OL-iO }\end{array}$ & $\ldots$ & & & & & & & & & \\
\hline $\begin{array}{r}01-10 \\
11-20 \\
21-30 \\
T 14 E-30\end{array}$ & $=$ & $\begin{array}{l}7.1 \\
9.7 \\
8.0\end{array}$ & $\begin{array}{l}.10 \\
.06 \\
.05\end{array}$ & $\begin{array}{l}4.0 \\
3.8 \\
4.8\end{array}$ & $\begin{array}{l}1.2 \\
1.1 \\
1.0\end{array}$ & $\begin{array}{l}3.2 \\
3.7 \\
3.0\end{array}$ & $\begin{array}{l}1.6 \\
2.3 \\
2.5\end{array}$ & $\begin{array}{l}22 \\
20 \\
22\end{array}$ & $\begin{array}{l}108 \\
2.0\end{array}$ & $\begin{array}{l}3.9 \\
4.2 \\
4.6\end{array}$ \\
\hline WTD. AYG. & - & 9.4 & $\begin{array}{l}.54 \\
\text { ANALYSTS }\end{array}$ & $\begin{array}{l}4.2 \\
S \quad 0 F\end{array}$ & $\begin{array}{l}1.4 \\
\text { IIONAL }\end{array}$ & $\begin{array}{c}3.3 \\
\text { SAMPLES }\end{array}$ & 1.5 & 20 & 3.1 & 3.8 \\
\hline & - & -- & .06 & 8.6 & 1.6 & 4.6 & 3.5 & 49 & 5.4 & 2.9 \\
\hline
\end{tabular}


03164000 NEW RIVER NEAR GALAX, YA,---Cont1nued

CHEMICAL ANALYSES IN MILLIGRAMS PER LITER, hater YEAR OCTCBER 1967 TO SEPTEMBER 1968

\begin{tabular}{|c|c|c|c|c|c|c|c|c|c|c|}
\hline DATE & $\begin{array}{l}\text { FLUO- } \\
\text { RIDE } \\
\text { IFI }\end{array}$ & $\begin{array}{l}\text { NITRATE } \\
\text { (ND3) }\end{array}$ & $\begin{array}{l}\text { PHOS- } \\
\text { PHATE } \\
\text { (PO4) }\end{array}$ & $\begin{array}{l}\text { DIS- } \\
\text { SOLVED } \\
\text { SOLIOS } \\
\text { IRESI- } \\
\text { CUEAT } \\
\text { IBC CI }\end{array}$ & $\begin{array}{l}\text { HARQ- } \\
\text { NESS } \\
\text { ICA,MGI }\end{array}$ & $\begin{array}{l}\text { NON- } \\
\text { CAR- } \\
\text { BONATE } \\
\text { HARO- } \\
\text { NESS }\end{array}$ & $\begin{array}{l}\text { SPECI - } \\
\text { FIC } \\
\text { COND- } \\
\text { UCTANCE } \\
\text { IMICRO- } \\
\text { MHOSI }\end{array}$ & PH & $\begin{array}{l}\text { TEMP- } \\
\text { EPATURE } \\
\text { IDEG CI }\end{array}$ & COLOR \\
\hline OCT. & .1 & .7 & .00 & 36 & 15 & 1 & 41 & 6.5 & 18 & 10 \\
\hline $\begin{array}{l}\text { NOY. } \\
15 . . . \\
\text { DEC. }\end{array}$ & .1 & 1.0 & - co & 35 & 14 & c & 44 & 6.9 & 6 & 8 \\
\hline J O8... & .1 & 1.8 & .15 & 31 & 13 & c & 37 & $7 \cdot c$ & 7 & $T$ \\
\hline $\begin{array}{l}04 \ldots \\
30 \ldots \\
F E B .\end{array}$ & .1 & $\begin{array}{l}1.1 \\
2.7\end{array}$ & $\begin{array}{l}.10 \\
.12\end{array}$ & $\begin{array}{l}32 \\
43\end{array}$ & $\begin{array}{l}19 \\
15\end{array}$ & $\begin{array}{l}5 \\
2\end{array}$ & $\begin{array}{l}47 \\
38\end{array}$ & $\begin{array}{l}6.9 \\
6.9\end{array}$ & $\begin{array}{l}4 \\
3\end{array}$ & $20^{5}$ \\
\hline $\begin{array}{l}14 \ldots \\
2 B \ldots \\
A P R .\end{array}$ & .1 & $\begin{array}{l}3.0 \\
2.6\end{array}$ & $\begin{array}{l}.00 \\
.04\end{array}$ & $\begin{array}{l}47 \\
40\end{array}$ & $\begin{array}{l}14 \\
11\end{array}$ & $\begin{array}{l}1 \\
0\end{array}$ & $\begin{array}{l}43 \\
37\end{array}$ & $\begin{array}{l}7.1 \\
6.8\end{array}$ & $\begin{array}{l}0 \\
1\end{array}$ & $\begin{array}{l}3 \\
6\end{array}$ \\
\hline $\begin{array}{l}01-10 \\
11-20 \\
21-30\end{array}$ & $\begin{array}{l}: 1 \\
: 0\end{array}$ & $\begin{array}{l}2.4 \\
2.1 \\
2.4\end{array}$ & $\begin{array}{l}.02 \\
.00 \\
.00\end{array}$ & $\begin{array}{l}40 \\
37 \\
40\end{array}$ & $\begin{array}{l}14 \\
13 \\
16\end{array}$ & 1 & $\begin{array}{l}44 \\
46\end{array}$ & $\begin{array}{l}7.0 \\
6.8\end{array}$ & $=$ & 10 \\
\hline MAY & & & & & 16 & 1 & 46 & 6.7 & & \\
\hline $\begin{array}{l}11-10 \\
11-20 \\
21-31\end{array}$ & $: 1$ & $\begin{array}{l}1.8 \\
2.7 \\
2.4\end{array}$ & $\begin{array}{l}.00 \\
.00 \\
.00\end{array}$ & $\begin{array}{l}38 \\
38 \\
42\end{array}$ & $\begin{array}{l}16 \\
16 \\
16\end{array}$ & c & $\begin{array}{l}49 \\
43 \\
45\end{array}$ & $\begin{array}{l}6.7 \\
7.1 \\
7.0\end{array}$ & $=$ & $\begin{array}{r}8 \\
7 \\
19\end{array}$ \\
\hline JUNE & & & & & & & & & & \\
\hline $\begin{array}{l}01-10 \\
11-20\end{array}$ & $\because 1$ & $\begin{array}{l}2.5 \\
3.4\end{array}$ & $\begin{array}{l}.01 \\
.01\end{array}$ & $\begin{array}{l}46 \\
46\end{array}$ & $\begin{array}{l}16 \\
17\end{array}$ & $\begin{array}{l}2 \\
1\end{array}$ & $\begin{array}{l}45 \\
53\end{array}$ & $\begin{array}{l}7.3 \\
7.0\end{array}$ & $=$ & $\begin{array}{r}12 \\
7\end{array}$ \\
\hline $21-30$ & .2 & 1.6 & .00 & 48 & 16 & c & 54 & 7.0 & -- & 15 \\
\hline $\begin{array}{l}01-10 \\
11-20 \\
21-31\end{array}$ & $\begin{array}{l}.0 \\
: 0 \\
.0\end{array}$ & $\begin{array}{r}.7 \\
1.5 \\
2.1\end{array}$ & $\begin{array}{l}.10 \\
.03 \\
.60\end{array}$ & $\begin{array}{l}41 \\
40 \\
38\end{array}$ & $\begin{array}{l}16 \\
17 \\
18\end{array}$ & $\begin{array}{l}0 \\
0 \\
c\end{array}$ & $\begin{array}{l}55 \\
55 \\
57\end{array}$ & $\begin{array}{l}7.0 \\
6.9 \\
7.0\end{array}$ & $=$ & $\begin{array}{r}8 \\
15 \\
10\end{array}$ \\
\hline AUG. & & & & & & & & & & \\
\hline $\begin{array}{l}01-10 \\
11-20\end{array}$ & $\because 1$ & $\begin{array}{l}2.0 \\
2.5\end{array}$ & $\begin{array}{l}.100 \\
.14\end{array}$ & $\begin{array}{l}44 \\
43\end{array}$ & $\begin{array}{l}20 \\
20\end{array}$ & $\begin{array}{l}0 \\
0\end{array}$ & $\begin{array}{l}58 \\
62\end{array}$ & $\begin{array}{l}6.8 \\
7.1\end{array}$ & $=$ & $\begin{array}{l}18 \\
15\end{array}$ \\
\hline $\begin{array}{l}21-31 \\
\text { SEPT. }\end{array}$ & .1 & .4 & .02 & 48 & 19 & 1 & 58 & 3.1 & -- & 18 \\
\hline $\begin{array}{l}01-10 \\
11-20 \\
21-30\end{array}$ & $\begin{array}{l}: 1 \\
: 1 \\
0\end{array}$ & $\begin{array}{l}.7 \\
.6 \\
.6\end{array}$ & $\begin{array}{l}.00 \\
.60 \\
.60\end{array}$ & $\begin{array}{l}35 \\
38 \\
39\end{array}$ & $\begin{array}{l}15 \\
14 \\
16\end{array}$ & $\begin{array}{l}0 \\
0 \\
0\end{array}$ & $\begin{array}{l}52 \\
52 \\
52\end{array}$ & $\begin{array}{l}7.1 \\
7.1 \\
7.1\end{array}$ & $=$ & $\begin{array}{r}8 \\
15 \\
10\end{array}$ \\
\hline ME & .1 & 1,8 & .50 & 41 & 16 & C & 1 & $c$ & -- & -- \\
\hline
\end{tabular}

ANALYSIS OF ADDITIONAL SAMPLES

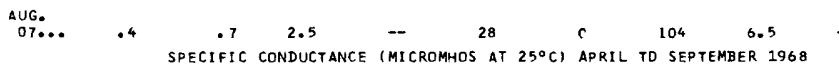

oAY OCTOBER NDVEMBER OECEMBER JANUARY FEBRUARY MARCH APRIL MAY JUNE JULY AUGUST SEPTEMBER

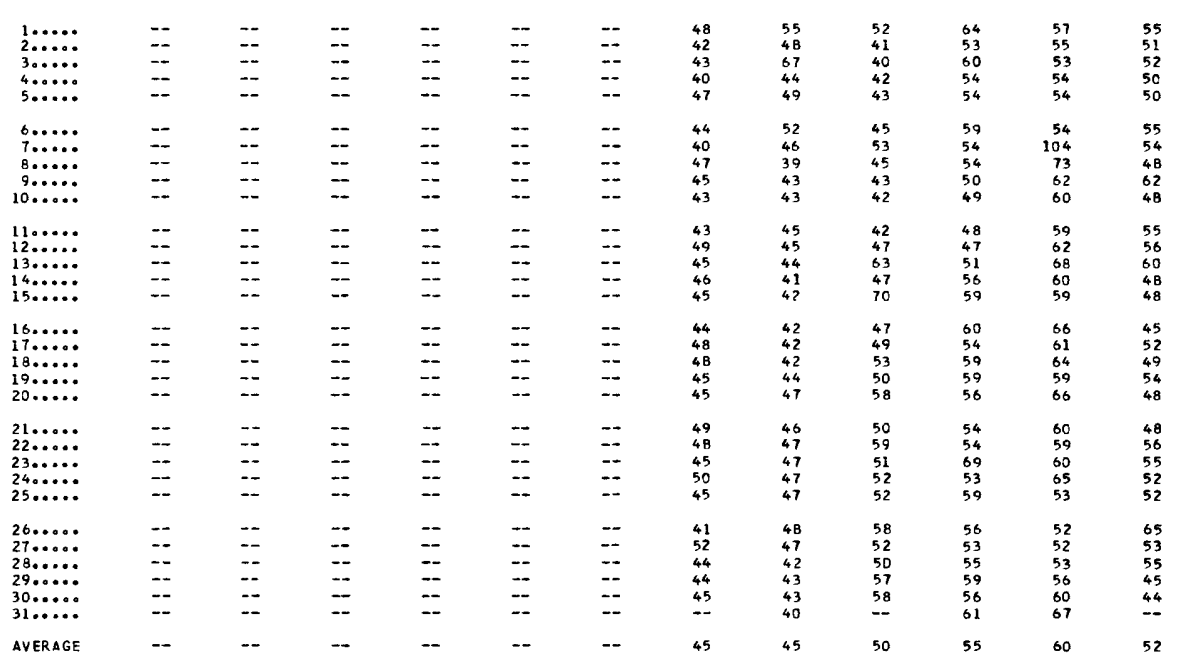


09164000 NEW RIVER NEAR GALAX, VA. --Continued

TEMPERATURE ( $\left.{ }^{\circ} \mathrm{C}\right)$ OF WATER, APRIL TO SEPTEMBER 1968

\begin{tabular}{|c|c|c|c|c|c|c|c|c|c|c|c|c|}
\hline DAY & CCI & NOV & OEC & JAN & FEB & MAR & APR & MAY & JUN & JUL & AU G & SEP \\
\hline i & $\cdots$ & $\cdots$ & --- & -- & -- & --- & 13.0 & 11.0 & 19.0 & 25.0 & 27.0 & 26.0 \\
\hline 2 & -- & -- & -- & -- & -- & -- & 9.0 & 12.0 & 18.0 & 27.0 & 25.0 & 26.0 \\
\hline 3 & $\cdots$ & --- & -- & -- & $\cdots$ & $=$ & 8.0 & 15.0 & 18.0 & 26.0 & 24.0 & 25.0 \\
\hline 4 & $\cdots$ & $\cdots$ & $\cdots$ & $\cdots$ & -- & --- & 11.0 & 15.0 & 19.0 & 27.0 & 22.0 & 21.0 \\
\hline 5 & -- & $\cdots$ & --- & $\cdots$ & -- & --- & 12.0 & 13.0 & 19.0 & 28.0 & 25.0 & 23.0 \\
\hline 6 & -- & --- & -- & --- & -- & $\cdots$ & 11.0 & 14.0 & 19.0 & 28.0 & 27.0 & 23.0 \\
\hline 7 & -- & $\cdots$ & -- & -- & -- & -.. & 12.0 & 14.0 & 20.0 & 27.0 & 29.0 & 23.0 \\
\hline 8 & -- & --- & -- & -- & --- & --- & 12.0 & 13.0 & -- & 28.0 & 29.0 & 23.0 \\
\hline 9 & $\cdots$ & -- & $\cdots$ & --- & -- & --- & 12.0 & 14.0 & 22.0 & 25.0 & 20.0 & 23.0 \\
\hline 10 & $\cdots$ & -- & ... & $\cdots$ & $-\infty$ & $\cdots$ & 11.0 & 14.0 & 20.0 & 25.0 & 26.0 & 21.0 \\
\hline 11 & -- & --- & --- & -- & -- & -- & 10.0 & 14.0 & 21.0 & 25.0 & 27.0 & 19.0 \\
\hline 12 & +- & $\cdots$ & $\cdots$ & $\cdots$ & $\cdots$ & -- & 12.0 & 16.0 & 22.0 & 21.0 & 26.0 & 20.0 \\
\hline 13 & $\cdots$ & -- & -- & $\cdots$ & -- & -- & 12.0 & 19.0 & 20.0 & 23.0 & 25.0 & 20.0 \\
\hline 14 & --- & $\ldots$ & -- & -- & -- & --- & 16.0 & 17.0 & 18.0 & 24.0 & 26.0 & 21.0 \\
\hline 15 & -- & -- & $=-$ & -- & $\cdots$ & -- & 14.0 & 14.0 & 22.0 & 24.0 & 27.0 & 21.0 \\
\hline 16 & -- & $-\cdots$ & --- & -- & --- & -- & 14.0 & 18.0 & 20.0 & 26.0 & 26.0 & 23.0 \\
\hline 17 & - & -- &.- & $\cdots$ & -- & $\cdots$ & 14.0 & 17.0 & 21.0 & 28.0 & 26.0 & 23.0 \\
\hline 18 & -- & -- & -- & -- & -- & -- & 16.0 & 17.0 & 20.0 & 27.0 & 26.0 & 21.0 \\
\hline 19 & -- & -- & --- & -- & -- & -.. & 14.0 & 15.0 & 23.0 & 26.0 & 28.0 & 22.0 \\
\hline 20 & $\cdots$ & -- & -- & $\cdots$ & -- & $\cdots$ & 15.0 & 17.0 & 23.0 & 27.0 & 28.0 & 23.0 \\
\hline 21 &.- & --- & -.- & -- & -- & -- & 14.0 & 15.0 & 21.0 & 27.0 & 29.0 & 22.0 \\
\hline 22 & $\cdots$ & --- & -- & -- & -- & --- & 15.0 & 15.0 & 23.0 & 21.0 & 20.0 & 21.0 \\
\hline 23 & $\cdots$ & $\cdots$ & $\cdots$ & -. & $\cdots$ & $\cdots$ & 15.0 & 17.0 & 21.0 & 27.0 & 30.0 & 24.0 \\
\hline 24 & $m-$ & -- & --- & -- & $\cdots$ & -- & 13. C & 18,0 & 21.0 & 28.0 & 30.0 & 24.0 \\
\hline 25 & -- & --- & --- & --- & -- & $-\cdots$ & 10.0 & 21.0 & 21.0 & $2 \pi .0$ & 25.0 & 24.0 \\
\hline 26 & $-\cdots$ & --- & -- & -- & -- & --- & 10.0 & 12.0 & 25.0 & 27.0 & 26.0 & 24.0 \\
\hline 27 & $-\cdots$ & $\cdots$ & -- & $\cdots$ & $\cdots$ & -- & 13.0 & 11.0 & 24.0 & 27.0 & 25.0 & 23.0 \\
\hline 28 & --- & -- & --- & -- & --- & --- & 11.0 & 13.0 & 19.0 & 21.0 & 25.0 & 20.0 \\
\hline 29 & $\cdots$ & -- & -- & -- & --- & -- & 11.0 & 15.0 & 21.0 & 23.0 & 24.0 & 21.0 \\
\hline 30 & -- & $\cdots$ & -- & -- & -- & $\cdots$ & 10.0 & 14.0 & 25.0 & 24.0 & 28.0 & 21.0 \\
\hline 31 & $m$ & -- & $\cdots$ & --- & $\cdots$ & --- & $\cdots$ & 14.0 & --- & 25.0 & 22.0 & \\
\hline AVERAGE & $-\cdots$ & -- & -- & --- & -- & $\cdots$ & 12.5 & 15.0 & 21.0 & 25.5 & 26.5 & 22.5 \\
\hline
\end{tabular}

LOCATION.--Lat $37^{\circ} 22^{\prime} 20^{\prime \prime}$, long $80^{\circ} 51^{\prime} 45^{\prime \prime}$, in Giles County, at the Glen Lyn stean electric plant of the Appalachian Electric Power Co. across the river from the gaging station, 0.3 mile upstream from East River, and 6.3 miles

DRAINAGE AREA. $--3,768 \mathrm{sq}$ mi.

PERIOD OF RECORD.--Chemical anal yses: April 1930 to Narch 1931, October 1949 to September 1950, October 1951 to September 1956 (monthly), April to September 1968 (da1ly).

Water temperatures: October 1950 to September 1968.

EXTREMES.--April to September 1968 :

Dissolved solids: Maximum, $177 \mathrm{mg} / 1$ Sept, $21-30$; minimum, $88 \mathrm{mg} / 1 \mathrm{Apr}, 1-10$

Hardness: Maximum, $132 \mathrm{mg} / 1 \mathrm{Sept}$. 21-30; minimum, $62 \mathrm{mg} / 1 \mathrm{Apr}$. $1-10$.

Specific conductance: Naximum daily, 340 micrombós Aug. 29 ; minimum daily, 105 micromhos Apr. 6.

water temperatures: Maximum, $28.0^{\circ} \mathrm{C}$ July 2 , Aug. $9,20,21,23$; minimum, freezing point Feb. $11-14$.

Period of record:

Water temperatures: Yaximum, $29.0^{\circ} \mathrm{C}$ June 28,1952 ; minimum, freezing point on many days during winter periods.

REMARKS.-- water temperatures for first six months of water year furnished by Appalachian power Co. CHEMICAL ANALYSES IN MILLIGRAMS PER L1TER, WATFR YEAR OCTOBER 1967 TO SEPTEMBER 1969

\begin{tabular}{|c|c|c|c|c|c|c|c|c|c|c|}
\hline DATE & $\begin{array}{l}\text { DIS- } \\
\text { CHARGE } \\
\text { (CFS) }\end{array}$ & $\begin{array}{l}\text { SILICA } \\
\text { (SIO2) }\end{array}$ & $\begin{array}{l}\text { DIS- } \\
\text { SOLVED } \\
\text { I RON } \\
\text { (FE) }\end{array}$ & $\begin{array}{l}\text { CAL- } \\
\text { CIUM } \\
\text { (CA) }\end{array}$ & $\begin{array}{l}\text { MAG- } \\
\text { NE- } \\
\text { SIUM } \\
\text { (MG) }\end{array}$ & $\begin{array}{l}\text { SOD IUM } \\
\text { (NA) }\end{array}$ & $\begin{array}{l}\text { PO- } \\
\text { TAS- } \\
\text { SIUM } \\
\text { (K) }\end{array}$ & $\begin{array}{l}\text { B ICAR- } \\
\text { BONATE } \\
\text { (HCO3) }\end{array}$ & $\begin{array}{l}\text { SULFATE } \\
\text { (SO4) }\end{array}$ & $\begin{array}{l}\text { CHLn= } \\
\text { RIOE } \\
\text { (CL) }\end{array}$ \\
\hline OCT. & & & & & & & & & & \\
\hline $\begin{array}{l}\text { O3... } \\
\text { Nov. }\end{array}$ & 2560 & 6.9 & .01 & 24 & 6.3 & 3.0 & 1.6 & 69 & 25 & 3.1 \\
\hline OEC... & 1250 & 6.4 & .00 & 23 & 7.2 & 3.6 & 1.4 & 74 & 23 & 2.9 \\
\hline $\begin{array}{l}07 \ldots . . \\
\text { JAN. }\end{array}$ & 7350 & 6.7 & .02 & 17 & 5.1 & 3.7 & 1.2 & 57 & 17 & 4.5 \\
\hline $\begin{array}{l}03 \ldots \\
31 \ldots \\
\text { FEB. }\end{array}$ & $\begin{array}{r}4980 \\
11370\end{array}$ & $\begin{array}{l}7.6 \\
6.7\end{array}$ & $\begin{array}{r}.02 \\
.09\end{array}$ & $\begin{array}{l}14 \\
18\end{array}$ & $\begin{array}{l}6.3 \\
4.7\end{array}$ & $\begin{array}{l}2.7 \\
2.3\end{array}$ & $\begin{array}{l}1.6 \\
1.2\end{array}$ & $\begin{array}{l}55 \\
60\end{array}$ & $\begin{array}{l}12 \\
13\end{array}$ & $\begin{array}{l}5.5 \\
3.1\end{array}$ \\
\hline $\begin{array}{l}12 \ldots \\
A P R_{0}\end{array}$ & 4580 & 6.3 & .06 & 22 & 5.6 & 2.5 & - 8 & 65 & 14 & 3.6 \\
\hline $\begin{array}{l}01-10 \\
11-20 \\
21-30\end{array}$ & $=$ & $\begin{array}{l}5.7 \\
5.3 \\
6.1\end{array}$ & $\begin{array}{l}.60 \\
.02 \\
.04\end{array}$ & $\begin{array}{l}17 \\
22 \\
20\end{array}$ & $\begin{array}{l}4.5 \\
6.0 \\
5.6\end{array}$ & $\begin{array}{l}1.8 \\
2.1 \\
2.3\end{array}$ & $\begin{array}{r}.8 \\
1.2\end{array}$ & $\begin{array}{l}56 \\
69 \\
65\end{array}$ & $\begin{array}{l}13 \\
18 \\
17\end{array}$ & $\begin{array}{l}2.9 \\
3.5 \\
3.9\end{array}$ \\
\hline MAY & & & & & & $2 \cdot 3$ & .8 & 65 & 17 & 3.2 \\
\hline $\begin{array}{l}01-10 \\
11-20 \\
21-31\end{array}$ & $=$ & $\begin{array}{l}6.0 \\
6.7 \\
5.4\end{array}$ & $\begin{array}{l}.00 \\
.00 \\
.01\end{array}$ & $\begin{array}{l}18 \\
21 \\
21\end{array}$ & $\begin{array}{l}4.9 \\
6.6 \\
5.7\end{array}$ & $\begin{array}{l}2.3 \\
2.8 \\
2.8\end{array}$ & $\begin{array}{l}.8 \\
1.2 \\
1.2\end{array}$ & $\begin{array}{l}60 \\
66 \\
66\end{array}$ & $\begin{array}{l}15 \\
18 \\
17\end{array}$ & $\begin{array}{l}3.7 \\
2.5 \\
2.9\end{array}$ \\
\hline JUNE & & & & & & & & & & \\
\hline $\begin{array}{l}01-10 \\
11-20 \\
21-30\end{array}$ & $=$ & $\begin{array}{l}5.3 \\
5.5 \\
4.9\end{array}$ & $\begin{array}{l}.01 \\
.02 \\
.00\end{array}$ & $\begin{array}{l}19 \\
19 \\
26\end{array}$ & $\begin{array}{l}5.7 \\
5.3 \\
7.0\end{array}$ & $\begin{array}{l}2.3 \\
2.3 \\
3.7\end{array}$ & $\begin{array}{l}1.2 \\
1.2 \\
1.2\end{array}$ & $\begin{array}{l}62 \\
64 \\
70\end{array}$ & $\begin{array}{l}15 \\
18 \\
26\end{array}$ & $\begin{array}{l}2.7 \\
2.9 \\
3.2\end{array}$ \\
\hline JULY & & & & & & & & & & \\
\hline $01-10$ & - & 5.0 & .09 & 29 & 7.0 & $3 . \mathrm{C}$ & 1.6 & 77 & 32 & 3.5 \\
\hline $11-16$ & $\cdots$ & 5.5 & .02 & 27 & 7.2 & 3.2 & 1.2 & 72 & 32 & 3.6 \\
\hline $17-19$ & -- & 5.9 & .01 & 20 & 6.1 & 2.8 & 1.6 & 66 & 19 & 3.5 \\
\hline $\begin{array}{l}20-31 \\
\text { AUG. }\end{array}$ & $=$ & 6.1 & .63 & 30 & 6.9 & 2.5 & 1.2 & SC & 34 & 2.8 \\
\hline $01-10$ & - & 5.8 & .04 & 26 & 6.6 & 2.8 & 1.6 & 78 & 27 & $4 . n$ \\
\hline $11-2 n$ & -- & 6.0 & .00 & 27 & 7.9 & 3.0 & 1.6 & 80 & 26 & 3.6 \\
\hline $21-31$ & -- & 6.2 & .01 & 31 & B. C & 4.6 & 1.2 & 90 & 39 & 3.8 \\
\hline SEPT. & & & & & & & & & & \\
\hline $01-10$ & - & 4.4 & .02 & 44 & 4.1 & 3.9 & 3.1 & B7 & 45 & 4.3 \\
\hline $11-20$ & -- & 6.0 & .01 & 40 & 7.4 & 4.4 & 2.0 & 85 & 52 & 3.2 \\
\hline $21-30$ & -- & 4.0 & .02 & 39 & 8.4 & 4.4 & 2.3 & 88 & 48 & 4.0 \\
\hline $\begin{array}{l}\text { IME } \\
\text { - AVG. }\end{array}$ & $-\infty$ & 5.6 & .51 & 26 & 6.4 & 3.0 & 1.4 & 72 & 27 & 3.3 \\
\hline
\end{tabular}


KANATHA RIVER BASIN

03176500 NEW RIVER AT GLEN LYN. W. VA,_-Cortinued

CHEMICAL ANALYSES IN MILLIGRAMS PER LITER, hater yeAR OCTOBER 1967 TO SEPTEMBEP $196 \mathrm{~A}$

\begin{tabular}{|c|c|c|c|c|c|c|c|c|c|c|}
\hline OATE & $\begin{array}{l}\text { FLUO- } \\
\text { RIOE } \\
\text { (F) }\end{array}$ & $\begin{array}{l}\text { NITRATE } \\
\text { (NO3) }\end{array}$ & $\begin{array}{l}\text { PHOS- } \\
\text { PHATE } \\
\text { (PO4) }\end{array}$ & $\begin{array}{l}\text { OIS- } \\
\text { SOLVED } \\
\text { SOLIOS } \\
\text { (RESI - } \\
\text { OUE AT } \\
\text { I CC CI }\end{array}$ & $\begin{array}{l}\text { HARD- } \\
\text { NESS } \\
(C A, 4 G)\end{array}$ & $\begin{array}{l}\text { NON- } \\
\text { CAP- } \\
\text { BONATE } \\
\text { HARQ- } \\
\text { NESS }\end{array}$ & $\begin{array}{l}\text { SPECI- } \\
\text { FIC } \\
\text { CONO- } \\
\text { UCTANCE } \\
\text { IMICRO- } \\
\text { MHOSI }\end{array}$ & $\mathrm{PH}$ & $\begin{array}{l}\text { TEMP- } \\
\text { ERATURE } \\
\text { IOEG CI }\end{array}$ & CCLOR \\
\hline $\begin{array}{l}\text { oc } r . \\
03 . . .\end{array}$ & .1 & 8.9 & .10 & 112 & 86 & 29 & 174 & 7.1 & 19 & 7 \\
\hline NOV. & & & & & & & & & & \\
\hline $\begin{array}{l}13 . . . \\
\text { OEC. }\end{array}$ & .1 & 6.5 & .00 & 115 & 88 & 16 & 177 & 6.9 & $\cdots$ & 7 \\
\hline $\begin{array}{l}\text { O7.... } \\
\text { JAN. }\end{array}$ & .0 & 4.3 & .12 & 89 & 63 & 17 & 142 & 7.4 & 6 & 5 \\
\hline $\begin{array}{l}03 \ldots \\
31 \ldots\end{array}$ & : 2 & $\begin{array}{l}1.4 \\
5.0\end{array}$ & $\begin{array}{l}.00 \\
.11\end{array}$ & $\begin{array}{l}72 \\
99\end{array}$ & $\begin{array}{l}61 \\
64\end{array}$ & $\begin{array}{l}16 \\
15\end{array}$ & $\begin{array}{l}121 \\
12 C\end{array}$ & $\begin{array}{l}6.9 \\
7.5\end{array}$ & $\begin{array}{l}4 \\
4\end{array}$ & $\begin{array}{r}5 \\
22\end{array}$ \\
\hline $\begin{array}{l}\text { FER. } \\
12 . . \\
\text { APR. }\end{array}$ & .2 & 6.1 & .09 & 88 & 70 & 16 & 142 & 7.6 & I & 2 \\
\hline $\begin{array}{l}41-10 \\
11-20 \\
21-30\end{array}$ & $\begin{array}{l}: 1 \\
: 3 \\
.3\end{array}$ & $\begin{array}{l}5.8 \\
7.5 \\
5.8\end{array}$ & $\begin{array}{l}.06 \\
.00 \\
.00\end{array}$ & $\begin{array}{l}98 \\
94 \\
96\end{array}$ & $\begin{array}{l}62 \\
78 \\
72\end{array}$ & $\begin{array}{l}16 \\
22 \\
16\end{array}$ & $\begin{array}{l}123 \\
164 \\
152\end{array}$ & $\begin{array}{l}6.8 \\
7.3 \\
7.2\end{array}$ & $=$ & $\begin{array}{l}5 \\
C \\
5\end{array}$ \\
\hline MAY & & & & & & & & & & \\
\hline $\begin{array}{l}01-10 \\
11-20 \\
21-31\end{array}$ & $\begin{array}{l}.0 \\
.0 \\
.1\end{array}$ & $\begin{array}{l}5.2 \\
7.6 \\
8.4\end{array}$ & $\begin{array}{l}.00 \\
.00 \\
.01\end{array}$ & $\begin{array}{r}97 \\
104 \\
109\end{array}$ & $\begin{array}{l}66 \\
86 \\
76\end{array}$ & $\begin{array}{l}16 \\
24 \\
22\end{array}$ & $\begin{array}{l}141 \\
159 \\
161\end{array}$ & $\begin{array}{l}7.6 \\
7.8 \\
7.8\end{array}$ & $=$ & $\begin{array}{l}5 \\
3 \\
5\end{array}$ \\
\hline JUNE & & & & & & & & & & \\
\hline $\begin{array}{l}01-10 \\
11-20\end{array}$ & $: 1$ & $\begin{array}{l}7.1 \\
5.3\end{array}$ & .00 & $\begin{array}{r}101 \\
89\end{array}$ & $\begin{array}{l}72 \\
70\end{array}$ & $\begin{array}{l}20 \\
1 \mathrm{~A}\end{array}$ & $\begin{array}{l}152 \\
153\end{array}$ & $\begin{array}{l}7.6 \\
7.4\end{array}$ & $=$ & $\begin{array}{l}3 \\
3\end{array}$ \\
\hline $21-30$ & .0 & 13 & $\cdot C 1$ & 128 & 94 & 36 & 215 & 7.6 & -- & 5 \\
\hline $01-10$ & .1 & 12 & .04 & 137 & 102 & 39 & 233 & 7.5 & -- & 5 \\
\hline $11-16$ & .0 & 15 & .03 & 129 & 97 & 38 & 214 & 8.1 & -- & 8 \\
\hline $17-19$ & .1 & 10 & .05 & 107 & 76 & 22 & 165 & 7.6 & - & 8 \\
\hline $20-31$ & .0 & 16 & .02 & 142 & 104 & 39 & 236 & 7.5 & -- & 8 \\
\hline AUG. & & & & & & & & & & \\
\hline $\begin{array}{l}01-10 \\
11-20\end{array}$ & $\because 0$ & $\begin{array}{l}13 \\
9.9\end{array}$ & $\begin{array}{l}.02 \\
.00\end{array}$ & $\begin{array}{l}127 \\
121\end{array}$ & $\begin{array}{l}93 \\
99\end{array}$ & $\begin{array}{l}29 \\
34\end{array}$ & $\begin{array}{l}214 \\
204\end{array}$ & $\begin{array}{l}7.4 \\
7.4\end{array}$ & $=$ & $\begin{array}{l}5 \\
7\end{array}$ \\
\hline $21-31$ & .1 & 13 & .03 & 150 & 110 & 45 & 245 & 7.7 & $\rightarrow$ & 15 \\
\hline $\begin{array}{l}\text { SEPT. } \\
\text { O1-io }\end{array}$ & $\cdot 1$ & 15 & .04 & 173 & 126 & 54 & 277 & 7.6 & -- & 3 \\
\hline $11-20$ & .1 & is & .02 & 172 & $13 \mathrm{C}$ & 60 & 282 & 7.8 & -- & 10 \\
\hline $21-30$ & .2 & 17 & .05 & 177 & 132 & 6C & 282 & 7.9 & - & 8 \\
\hline AVG. & .1 & 11 & .57 & 123 & 92 & 3) & 198 & 7.5 & -- & $=$ \\
\hline
\end{tabular}

SPECIFIC CONDUCTANCE (MICROMHOS AT $25^{\circ} \mathrm{C}$ ) APRIL TO SEPTEMBER 1968

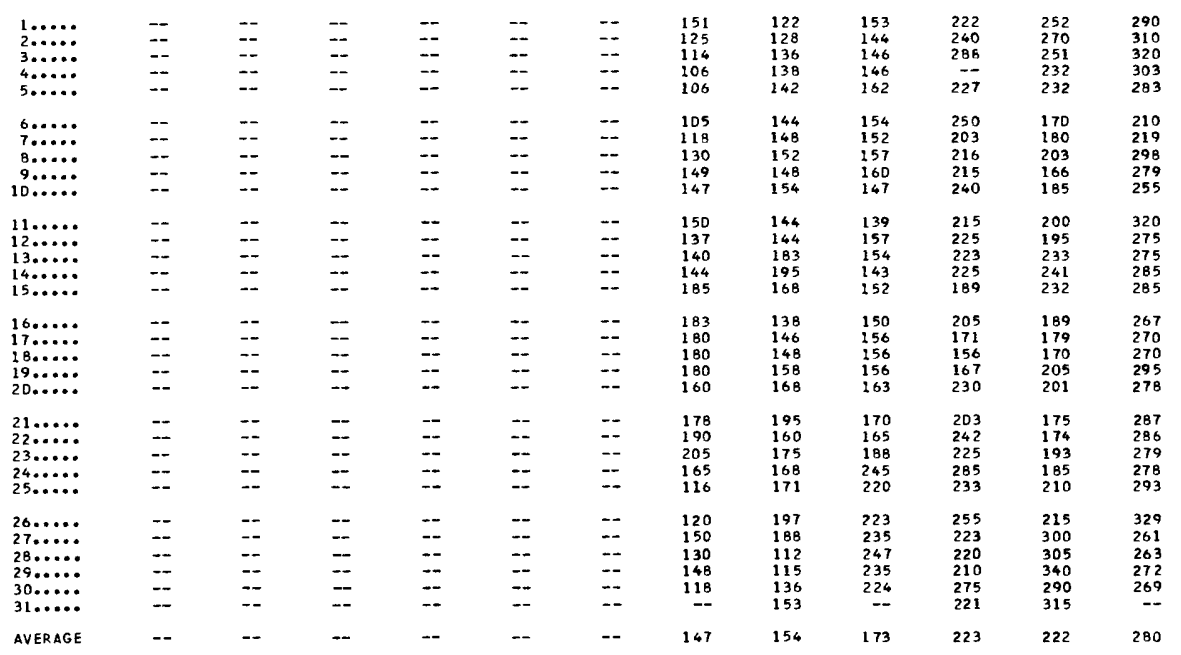


KANAWHA RIVER BASIN

03176500 NET RIVER AT GLEN LYN, $\%$. VA._-ContInued

TEMPERATURE $\left({ }^{\circ} \mathrm{C}\right)$ OF WATER, WATER YEAR OCTOBER 1967 TO SEPTEMBER 1968

\begin{tabular}{|c|c|c|c|c|c|c|c|c|c|c|c|c|}
\hline DAY & OCT & NOV & DEC & JAN & FEB & MAR & $A P R$ & MAY & JUN & JUL & AUG & SEP \\
\hline $\begin{array}{l}1 \\
2 \\
3 \\
4 \\
5\end{array}$ & $\begin{array}{l}17.0 \\
17.0 \\
19.0 \\
19.0 \\
19.0\end{array}$ & $\begin{array}{r}13.0 \\
13.0 \\
13.0 \\
12.0 \\
8.0\end{array}$ & $\begin{array}{l}7.0 \\
5.0 \\
4.0 \\
3.0 \\
7.0\end{array}$ & $\begin{array}{l}2.0 \\
2.0 \\
3.0 \\
4.0 \\
1.0\end{array}$ & $\begin{array}{l}3.0 \\
3.0 \\
2.0 \\
2.0 \\
3.0\end{array}$ & $\begin{array}{l}1.0 \\
3.0 \\
2.0 \\
3.0 \\
4.0\end{array}$ & $\begin{array}{l}14.0 \\
11.0 \\
10.0 \\
11.0 \\
12.0\end{array}$ & $\begin{array}{l}14.0 \\
14.0 \\
17.0 \\
17.0 \\
16.0\end{array}$ & $\begin{array}{l}16.0 \\
19.0 \\
19.0 \\
20.0 \\
21.0\end{array}$ & $\begin{array}{r}25.0 \\
28.0 \\
25.0 \\
24.0\end{array}$ & $\begin{array}{l}25.0 \\
26.0 \\
26.0 \\
26.0 \\
25.0\end{array}$ & $\begin{array}{l}22.0 \\
21.0 \\
22.0 \\
23.0 \\
23.0\end{array}$ \\
\hline $\begin{array}{r}5 \\
7 \\
8 \\
9 \\
10\end{array}$ & $\begin{array}{l}18.0 \\
17.0 \\
16.0 \\
16.0 \\
16.0\end{array}$ & $\begin{array}{l}7.0 \\
8.0 \\
7.0 \\
8.0 \\
9.0\end{array}$ & $\begin{array}{l}5.0 \\
8.0 \\
7.0 \\
6.0 \\
6.0\end{array}$ & $\begin{array}{l}1.0 \\
1.0 \\
1.0 \\
1.0 \\
2.0\end{array}$ & $\begin{array}{l}3.0 \\
3.0 \\
2.0 \\
2.0 \\
1.0\end{array}$ & $\begin{array}{l}4.0 \\
4.0 \\
7.0 \\
7.0 \\
5.0\end{array}$ & $\begin{array}{l}12.0 \\
14.0 \\
13.0 \\
13.0 \\
12.0\end{array}$ & $\begin{array}{l}15.0 \\
15.0 \\
16.0 \\
17.0 \\
18.0\end{array}$ & $\begin{array}{l}21.0 \\
20.0 \\
22.0 \\
21.0 \\
21.0\end{array}$ & $\begin{array}{l}25.0 \\
25.0 \\
25.0 \\
25.0 \\
26.0\end{array}$ & $\begin{array}{l}27.0 \\
27.0 \\
27.0 \\
28.0 \\
25.0\end{array}$ & $\begin{array}{l}23.0 \\
23.0 \\
23.0 \\
23.0 \\
23.0\end{array}$ \\
\hline $\begin{array}{l}11 \\
12 \\
13 \\
14 \\
15\end{array}$ & $\begin{array}{l}15.0 \\
15.0 \\
15.0 \\
16.0 \\
17.0\end{array}$ & $\begin{array}{r}11.0 \\
11.0 \\
10.0 \\
9.0 \\
7.0\end{array}$ & $\begin{array}{l}5.0 \\
5.0 \\
5.0 \\
6.0 \\
8.0\end{array}$ & $\begin{array}{l}1.0 \\
1.0 \\
1.0 \\
1.0 \\
1.0\end{array}$ & $\begin{array}{l}0.0 \\
0.0 \\
0.0 \\
0.0 \\
2.0\end{array}$ & $\begin{array}{l}8.0 \\
8.0 \\
3.0 \\
3.0 \\
4.0\end{array}$ & $\begin{array}{l}10.0 \\
12.0 \\
14.0 \\
14.0 \\
15.0\end{array}$ & $\begin{array}{l}13.0 \\
18.0 \\
20.0 \\
19.0 \\
18.0\end{array}$ & $\begin{array}{l}22.0 \\
21.0 \\
21.0 \\
21.0 \\
21.0\end{array}$ & $\begin{array}{l}26.0 \\
26.0 \\
25.0 \\
24.0 \\
27.0\end{array}$ & $\begin{array}{l}25.0 \\
24.0 \\
23.0 \\
24.0 \\
25.0\end{array}$ & $\begin{array}{l}22.0 \\
21.0 \\
20.0 \\
20.0 \\
21.0\end{array}$ \\
\hline $\begin{array}{l}16 \\
17 \\
18 \\
19 \\
20\end{array}$ & $\begin{array}{l}18.0 \\
17.0 \\
16.0 \\
13.0 \\
13.0\end{array}$ & $\begin{array}{l}6.0 \\
6.0 \\
6.0 \\
6.0 \\
6.0\end{array}$ & $\begin{array}{l}6.0 \\
3.0 \\
4.0 \\
7.0 \\
8.0\end{array}$ & $\begin{array}{l}1.0 \\
1.0 \\
1.0 \\
2.0 \\
3.0\end{array}$ & $\begin{array}{l}2.0 \\
2.0 \\
1.0 \\
1.0 \\
2.0\end{array}$ & $\begin{array}{l}4.0 \\
6.0 \\
7.0 \\
7.0 \\
9.0\end{array}$ & $\begin{array}{l}16.0 \\
17.0 \\
17.0 \\
17.0 \\
16.0\end{array}$ & $\begin{array}{l}19.0 \\
19.0 \\
18.0 \\
17.0 \\
16.0\end{array}$ & $\begin{array}{l}21.0 \\
22.0 \\
22.0 \\
22.0 \\
23.0\end{array}$ & $\begin{array}{l}27.0 \\
27.0 \\
27.0 \\
26.0 \\
26.0\end{array}$ & $\begin{array}{l}25.0 \\
26.0 \\
26.0 \\
27.0 \\
28.0\end{array}$ & $\begin{array}{l}22.0 \\
21.0 \\
21.0 \\
20.0 \\
21.0\end{array}$ \\
\hline $\begin{array}{l}21 \\
22 \\
23 \\
24 \\
25\end{array}$ & $\begin{array}{l}13.0 \\
13.0 \\
13.0 \\
14.0 \\
13.0\end{array}$ & $\begin{array}{l}7.0 \\
8.0 \\
7.0 \\
6.0 \\
6.0\end{array}$ & $\begin{array}{l}8.0 \\
7.0 \\
3.0 \\
2.0 \\
3.0\end{array}$ & $\begin{array}{l}4.0 \\
3.0 \\
3.0 \\
1.0 \\
1.0\end{array}$ & $\begin{array}{l}1.0 \\
1.0 \\
1.0 \\
2.0 \\
2.0\end{array}$ & $\begin{array}{r}10.0 \\
11.0 \\
8.0 \\
6.0 \\
7.0\end{array}$ & $\begin{array}{l}17.0 \\
18.0 \\
17.0 \\
16.0 \\
13.0\end{array}$ & $\begin{array}{l}16.0 \\
17.0 \\
18.0 \\
18.0 \\
19.0\end{array}$ & $\begin{array}{l}22.0 \\
23.0 \\
24.0 \\
25.0 \\
25.0\end{array}$ & $\begin{array}{l}26.0 \\
25.0 \\
27.0 \\
27.0 \\
27.0\end{array}$ & $\begin{array}{l}28.0 \\
27.0 \\
28.0 \\
27.0 \\
27.0\end{array}$ & $\begin{array}{l}21.0 \\
22.0 \\
23.0 \\
23.0 \\
24.0\end{array}$ \\
\hline $\begin{array}{l}26 \\
27 \\
28 \\
29 \\
30 \\
31\end{array}$ & $\begin{array}{l}13.0 \\
13.0 \\
12.0 \\
12.0 \\
12.0 \\
13.0\end{array}$ & $\begin{array}{l}7.0 \\
6.0 \\
3.0 \\
3.0 \\
4.0 \\
-. .\end{array}$ & $\begin{array}{l}3.0 \\
3.0 \\
2.0 \\
1.0 \\
2.0 \\
3.0\end{array}$ & $\begin{array}{l}1.0 \\
1.0 \\
3.0 \\
3.0 \\
3.0 \\
4.0\end{array}$ & $\begin{array}{l}2.0 \\
2.0 \\
4.0 \\
2.0 \\
--. \\
--\end{array}$ & $\begin{array}{r}8.0 \\
9.0 \\
10.0 \\
11.0 \\
12.0 \\
12.0\end{array}$ & $\begin{array}{l}14.0 \\
15.0 \\
14.0 \\
14.0 \\
13.0 \\
\end{array}$ & $\begin{array}{l}19.0 \\
19.0 \\
15.0 \\
16.0 \\
16.0 \\
16.0\end{array}$ & $\begin{array}{r}26.0 \\
25.0 \\
23.0 \\
22.0 \\
23.0 \\
\ldots\end{array}$ & $\begin{array}{l}27.0 \\
25.0 \\
25.0 \\
25.0 \\
25.0 \\
25.0\end{array}$ & $\begin{array}{l}27.0 \\
26.0 \\
23.0 \\
22.0 \\
22.0 \\
22.0\end{array}$ & $\begin{array}{r}24.0 \\
21.0 \\
21.0 \\
20.0 \\
21.0 \\
-\end{array}$ \\
\hline RAGE & 15.0 & 8.0 & 5.0 & 2.0 & 2.0 & t. 5 & 14.0 & 17.0 & 22.0 & 20.0 & 25.5 & 22.0 \\
\hline
\end{tabular}

03179000 BLUESTONE RIVER NEAR PIPESTEM, $\%$. VA.

LOCATION,--Lat $37^{\circ} 32^{\prime} 45^{\prime \prime}$, long $81^{\circ} 00^{\prime} 30^{\prime \prime}$, Summers County, 1.2 miles downstream from Mountain Creek, 2.5 miles west of Pipestem, and 8.0 miles upstream from mouth.

DRAINAGE AREA, - $-363 \mathrm{sq} \mathrm{ml}$.

PERIOD OF RECORD, --March to September 1968 ,

PERIODIC DETERMINATIONS OF SUSPENDED-SEDIMENT DISCHARGE, MARCH TO SEPTEMBER 1968

\begin{tabular}{|c|c|c|c|c|c|c|c|c|c|c|}
\hline DATE & TIME & $\begin{array}{l}\text { U1 SCHARGE } \\
\text { (CFS) }\end{array}$ & $\begin{array}{l}\text { CONCEN- } \\
\text { TRATION } \\
\text { IMG/LI }\end{array}$ & $\begin{array}{l}\text { SUSPENOED } \\
\text { SEDIMENT } \\
\text { DISCHARGE } \\
\text { (TONSIDAY) }\end{array}$ & & DATE & $T I M E$ & $\begin{array}{l}\text { DISCHARGE } \\
\text { (CFS) }\end{array}$ & $\begin{array}{l}\text { CONCEN- } \\
\text { TRATION } \\
\text { (MGILI }\end{array}$ & $\begin{array}{l}\text { SUSPENDEO } \\
\text { SFDIMENT } \\
\text { DISCHARGE } \\
\text { (TONS/DAY) }\end{array}$ \\
\hline $\begin{array}{l}\text { MAR } 21,1968 \\
\text { APR } 25 \ldots \ldots \cdots \\
\text { JUN } 12, \ldots \ldots\end{array}$ & $\begin{array}{l}1200 \\
1130 \\
1410\end{array}$ & $\begin{array}{l}668 \\
470 \\
644\end{array}$ & $\begin{array}{l}14 \\
17 \\
81\end{array}$ & $\begin{array}{r}25 \\
22 \\
141\end{array}$ & $\begin{array}{l}\text { JUL } \\
\text { SEP }\end{array}$ & $\begin{array}{r}24 \ldots \ldots \\
5 \ldots \ldots\end{array}$ & $\begin{array}{l}1220 \\
1230\end{array}$ & $\begin{array}{l}51 \\
36\end{array}$ & $\begin{array}{l}2.5 \\
4.5\end{array}$ & $\begin{array}{l}.34 \\
.44\end{array}$ \\
\hline
\end{tabular}


03182000 NNAPP CREEK AT MARLINTON, W. YA.

LOCATION,-Lat $38^{\circ} 12^{\prime} 40^{\prime \prime}$, long $80^{\circ} 04^{\prime} 30^{\prime \prime}$, POcahontas County, at city waterplant at Marlinton, 1 mile upstream from mouth and 2 miles downstream from discontinued gaging station.

DRAINAGE AREA. - - $108 \mathrm{sq}$ mi (at discontinued gaging station).

PERIOD OF RECORD.--Water temperatures: October 1946 to September 1968 .

EXTREYES, $--1967-68$ :

water temperatures: Maximum, $27.0^{\circ} \mathrm{C}$ July 17,18 ; minimum, freezing point on many days during November to March.

Pertod of record:

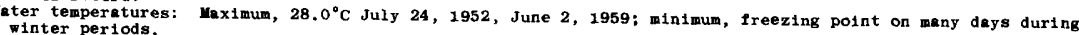

TEMPERATURE $\left({ }^{\circ} \mathrm{C}\right)$ OF WATER, HATER YEAR OCTOBER 1967 TO SEPTEMBER 1968

\begin{tabular}{|c|c|c|c|c|c|c|c|c|c|c|c|c|}
\hline WAY & $O C T$ & Nav & $D E C$ & JAN & $F E B$ & $M A R$ & $A P R$ & MaY & JUN & JUL & AUG & SEP \\
\hline $\begin{array}{l}1 \\
2 \\
3 \\
4 \\
5\end{array}$ & $\begin{array}{l}16.0 \\
16.0 \\
16.0 \\
16.0 \\
17.0\end{array}$ & $\begin{array}{l}8.0 \\
8.0 \\
8.0 \\
9.0 \\
7.0\end{array}$ & $\begin{array}{l}1.0 \\
1.0 \\
1.0 \\
1.0 \\
1.0\end{array}$ & $\begin{array}{l}0.0 \\
0.0 \\
0.0 \\
0.0 \\
0.0\end{array}$ & $\begin{array}{l}2.0 \\
2.0 \\
2.0 \\
1.0 \\
1.0\end{array}$ & $\begin{array}{l}0.0 \\
0.0 \\
0.0 \\
0.0 \\
1.0\end{array}$ & $\begin{array}{l}8.0 \\
2.0 \\
9.0 \\
7.0 \\
9.0\end{array}$ & $\begin{array}{l}13.0 \\
13.0 \\
13.0 \\
13.0 \\
11.0\end{array}$ & $\begin{array}{l}14.0 \\
15.0 \\
14.0 \\
14.0 \\
16.0\end{array}$ & $\begin{array}{l}21.0 \\
22.0 \\
24.0 \\
20.0 \\
20.0\end{array}$ & $\begin{array}{l}22.0 \\
23.0 \\
23.0 \\
23.0 \\
24.0\end{array}$ & $\begin{array}{l}18.0 \\
17.0 \\
18.0 \\
19.0 \\
18.0\end{array}$ \\
\hline $\begin{array}{r}6 \\
7 \\
8 \\
9 \\
10\end{array}$ & $\begin{array}{l}18.0 \\
17.0 \\
18.0 \\
17.0 \\
18.0\end{array}$ & $\begin{array}{l}6.0 \\
2.0 \\
2.0 \\
2.0 \\
3.0\end{array}$ & $\begin{array}{l}1.0 \\
1.0 \\
1.0 \\
1.0 \\
2.0\end{array}$ & $\begin{array}{l}0.0 \\
0.0 \\
0.0 \\
0.0 \\
0.0\end{array}$ & $\begin{array}{l}0.0 \\
0.0 \\
0.0 \\
1.0 \\
0.0\end{array}$ & $\begin{array}{l}1.0 \\
1.0 \\
1.0 \\
1.0 \\
4.0\end{array}$ & $\begin{array}{r}8.0 \\
8.0 \\
10.0 \\
9.0 \\
9.0\end{array}$ & $\begin{array}{l}11.0 \\
12.0 \\
12.0 \\
13.0 \\
14.0\end{array}$ & $\begin{array}{l}19.0 \\
19.0 \\
19.0 \\
18.0 \\
19.0\end{array}$ & $\begin{array}{l}21.0 \\
20.0 \\
20.0 \\
19.0 \\
21.0\end{array}$ & $\begin{array}{l}24.0 \\
25.0 \\
26.0 \\
24.0 \\
24.0\end{array}$ & $\begin{array}{l}19.0 \\
18.0 \\
18.0 \\
18.0 \\
18.0\end{array}$ \\
\hline $\begin{array}{l}11 \\
12 \\
13 \\
14 \\
15\end{array}$ & $\begin{array}{l}18.0 \\
17.0 \\
16.0 \\
16.0 \\
12.0\end{array}$ & $\begin{array}{l}3.0 \\
7.0 \\
7.0 \\
7.0 \\
4.0\end{array}$ & $\begin{array}{l}2.0 \\
2.0 \\
1.0 \\
2.0 \\
1.0\end{array}$ & $\begin{array}{l}0.0 \\
0.0 \\
0.0 \\
0.0 \\
0.0\end{array}$ & $\begin{array}{l}0.0 \\
0.0 \\
0.0 \\
0.0 \\
0.0\end{array}$ & $\begin{array}{l}6.0 \\
7.0 \\
4.0 \\
3.0 \\
2.0\end{array}$ & $\begin{array}{r}9.0 \\
8.0 \\
10.0 \\
10.0 \\
9.0\end{array}$ & $\begin{array}{l}14.0 \\
14.0 \\
16.0 \\
14.0 \\
14.0\end{array}$ & $\begin{array}{l}19.0 \\
18.0 \\
18.0 \\
17.0 \\
19.0\end{array}$ & $\begin{array}{l}21.0 \\
22.0 \\
23.0 \\
23.0 \\
24.0\end{array}$ & $\begin{array}{l}24.0 \\
22.0 \\
21.0 \\
22.0 \\
22.0\end{array}$ & $\begin{array}{l}18.0 \\
17.0 \\
16.0 \\
17.0 \\
16.0\end{array}$ \\
\hline $\begin{array}{l}16 \\
17 \\
18 \\
19 \\
20\end{array}$ & $\begin{array}{l}13.0 \\
13.0 \\
14.0 \\
13.0 \\
10.0\end{array}$ & $\begin{array}{l}1.0 \\
2.0 \\
2.0 \\
2.0 \\
2.0\end{array}$ & $\begin{array}{l}0.0 \\
0.0 \\
1.0 \\
2.0 \\
1.0\end{array}$ & $\begin{array}{l}0.0 \\
0.0 \\
0.0 \\
0.0 \\
0.0\end{array}$ & $\begin{array}{l}0.0 \\
0.0 \\
0.0 \\
0.0 \\
0.0\end{array}$ & $\begin{array}{l}2.0 \\
3.0 \\
3.0 \\
3.0 \\
3.0\end{array}$ & $\begin{array}{l}9.0 \\
9.0 \\
9.0 \\
9.0 \\
9.0\end{array}$ & $\begin{array}{l}16.0 \\
16.0 \\
16.0 \\
14.0 \\
14.0\end{array}$ & $\begin{array}{l}21.0 \\
20.0 \\
16.0 \\
18.0 \\
18.0\end{array}$ & $\begin{array}{l}24.0 \\
27.0 \\
27.0 \\
24.0 \\
24.0\end{array}$ & $\begin{array}{l}22.0 \\
24.0 \\
24.0 \\
24.0 \\
25.0\end{array}$ & $\begin{array}{l}17.0 \\
19.0 \\
18.0 \\
17.0 \\
17.0\end{array}$ \\
\hline $\begin{array}{l}21 \\
22 \\
23 \\
24 \\
23\end{array}$ & $\begin{array}{r}9.0 \\
8.0 \\
7.0 \\
8.0 \\
10.0\end{array}$ & $\begin{array}{l}3.0 \\
3.0 \\
2.0 \\
1.0 \\
1.0\end{array}$ & $\begin{array}{l}1.0 \\
1.0 \\
1.0 \\
0.0 \\
1.0\end{array}$ & $\begin{array}{l}1.0 \\
1.0 \\
1.0 \\
1.0 \\
1.0\end{array}$ & $\begin{array}{l}0.0 \\
0.0 \\
0.0 \\
0.0 \\
0.0\end{array}$ & $\begin{array}{l}4.0 \\
4.0 \\
6.0 \\
3.0 \\
3.0\end{array}$ & $\begin{array}{l}12.0 \\
13.0 \\
13.0 \\
14.0 \\
13.0\end{array}$ & $\begin{array}{l}14.0 \\
11.0 \\
12.0 \\
13.0 \\
14.0\end{array}$ & $\begin{array}{l}19.0 \\
19.0 \\
19.0 \\
19.0 \\
20.0\end{array}$ & $\begin{array}{l}22.0 \\
24.0 \\
24.0 \\
25.0 \\
26.0\end{array}$ & $\begin{array}{l}26.0 \\
25.0 \\
26.0 \\
25.0 \\
24.0\end{array}$ & $\begin{array}{l}18.0 \\
18.0 \\
18.0 \\
19.0 \\
19.0\end{array}$ \\
\hline $\begin{array}{l}26 \\
27 \\
28 \\
29 \\
30 \\
31\end{array}$ & $\begin{array}{l}9.0 \\
9.0 \\
9.0 \\
8.0 \\
6.0 \\
6.0\end{array}$ & $\begin{array}{l}3.0 \\
2.0 \\
1.0 \\
0.0 \\
1.0 \\
--.\end{array}$ & $\begin{array}{l}1.0 \\
0.0 \\
0.0 \\
1.0 \\
0.0 \\
0.0\end{array}$ & $\begin{array}{l}0.0 \\
0.0 \\
0.0 \\
0.0 \\
1.0 \\
1.0\end{array}$ & \begin{tabular}{l}
0.0 \\
0.0 \\
0.0 \\
0.0 \\
\hdashline-- \\
---
\end{tabular} & $\begin{array}{l}3.0 \\
4.0 \\
6.0 \\
7.0 \\
8.0 \\
8.0\end{array}$ & $\begin{array}{l}13.0 \\
13.0 \\
13.0 \\
12.0 \\
13.0 \\
-\ldots .\end{array}$ & $\begin{array}{l}14.0 \\
13.0 \\
13.0 \\
13.0 \\
13.0 \\
13.0\end{array}$ & $\begin{array}{l}20.0 \\
19.0 \\
19.0 \\
20.0 \\
21.0 \\
\ldots\end{array}$ & $\begin{array}{l}26.0 \\
24.0 \\
23.0 \\
23.0 \\
21.0 \\
21.0\end{array}$ & $\begin{array}{l}24.0 \\
23.0 \\
20.0 \\
19.0 \\
18.0 \\
19.0\end{array}$ & $\begin{array}{r}19.0 \\
18.0 \\
16.0 \\
14.0 \\
13.0 \\
\end{array}$ \\
\hline ERAGE & 13.0 & 3.5 & 1.0 & $0 . \mathrm{c}$ & 0.5 & 3.5 & 10.0 & 13.5 & 18.0 & 23.0 & 23.0 & 17.5 \\
\hline
\end{tabular}

03184000 GREENBRIER RIVER AT HILLDALE, w. YA.

LOCATION,--Lat $37^{\circ} 38^{\prime} 25^{\prime \prime}$, Iong $80^{\circ} 48^{\prime} 20^{\prime \prime}$, Summers County, $100 \mathrm{ft}$ downstream from highwey bridge on State Highway 3 at Hilidale, 0.1 mile upstream from Howard Creek, 0.9 mile upstream from Powley Creek, 5.0 miles southeast of Hinton, and $5.6 \mathrm{~m} \pm 1$ es ups tream from mouth.

DRAINAGE AREA, $-1,625 \mathrm{sq}$ m1.

PERIOD OF RECORD, -- Sediment records: March to September 1968.

PERIODIC DETERMINATIONS OF SUSPENDED-SEDIMENT DISCHARGE, MARCH TO SEPTEMBER 1968

\begin{tabular}{|c|c|c|c|c|c|c|c|c|c|c|c|}
\hline & DATE & TIME & $\begin{array}{l}\text { DISCHARGE } \\
\text { (CFS) }\end{array}$ & $\begin{array}{l}\text { CONCEN- } \\
\text { TRATION } \\
\text { (MGIL) }\end{array}$ & $\begin{array}{l}\text { SUSPENDEO } \\
\text { SEOI MENT } \\
\text { UISCHARGE } \\
\text { (TONS/DAY) }\end{array}$ & & DATE & I I ME & $\begin{array}{l}\text { DISCHARGE } \\
\text { (CFS) }\end{array}$ & $\begin{array}{l}\text { CONCEN- } \\
\text { TRATION } \\
\text { (MGILI) }\end{array}$ & $\begin{array}{l}\text { SUSPENDED } \\
\text { SEDIMENT } \\
\text { DISCHARGE } \\
\text { (TDNSIDAY) }\end{array}$ \\
\hline $\begin{array}{l}\text { MAR } \\
\triangle P P R\end{array}$ & $\begin{array}{l}26.1908 \\
23 . \ldots \ldots\end{array}$ & $\begin{array}{l}1520 \\
1505\end{array}$ & $\begin{array}{r}4460 \\
854\end{array}$ & $\begin{array}{l}8.3 \\
2.3\end{array}$ & 100 & $\begin{array}{l}\text { JUL } \\
\text { AUG }\end{array}$ & $23 \ldots \ldots$ & $\begin{array}{r}1530 \\
1400\end{array}$ & 827 & 38 & 85 \\
\hline MAY & $28 \ldots \ldots$ & 1430 & 11900 & 124 & 3980 & SEP & $24 \ldots \ldots$ & $\begin{array}{l}1400 \\
1540\end{array}$ & $\begin{array}{r}119 \\
84\end{array}$ & $\begin{array}{l}5.0 \\
7.3\end{array}$ & $\begin{array}{l}1.6 \\
1.7\end{array}$ \\
\hline UN & $27 \ldots \ldots$ & 1015 & 391 & 7.7 & B. 1 & & & & & & \\
\hline
\end{tabular}

03189100 GAULEY RIVER NEAR CRAIGSVILLE, W. YA,

LOCATION, --Lat $38^{\circ} 17^{\prime} 30^{\prime \prime}$, long $80^{\circ} 38^{\prime} 30^{\prime \prime}$, Nicholas County, àt highway bridge on w. VA. Route $20,200 \mathrm{ft}$ downtream

from Cherry River, 1,8 miles downtream from Cranberry River, and 2.7 miles south of Cratgsville,

DRAINAGE AREA, $--528 \mathrm{sq} \mathrm{mi}$.

PERIOD OF RECORD.--Sediment records: April to September 1968 .

PERIODIC DETERMINATIONS OF SUSPENDED-SEDIMENT DISCHARGE, APRIL TO SEPTEMBER 1968

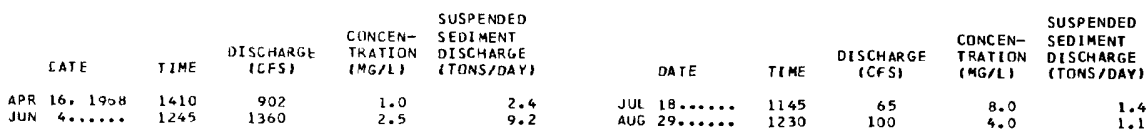


03193770 KANAwHA RIVER AT CABIN CREEK, W. VA.

LOCATION, -Lat $38^{\circ} 11^{\prime} 58^{\prime \prime}$, long $81^{\circ} 28^{\circ} 41^{\prime \prime}$, Kanawha County, at the Applachian Electric Power Co. Cabin Creek steam electric cooling water intakes at Cabin Creek.

DRAINAGE AREA. $--8,661 \mathrm{sq} \mathrm{m} 1$.

PERIOD OF RECORD. -- water temperatures: October 1950 to September 1968.

EXTREMES . --1967-68:

Water temperatures: Maximum, $32.0^{\circ} \mathrm{C} \mathrm{July} \mathrm{27;} \mathrm{minimum,} 1.0^{\circ} \mathrm{C}$ on several days during January and February.

Period of record:

Tater temperatures: Maximum, $33.0^{\circ} \mathrm{C}$ on several days in August 1955, 1959; minimum, freezing point Feb. 10, 1951, REMARKS.--Water temperature records furnished by the Applachian Electric power Co, TEMPERATURE $\left({ }^{\circ} \mathrm{C}\right)$ OF WATER, WATER YEAR OCTOBER 1967 TO SEPTEMBER 1968

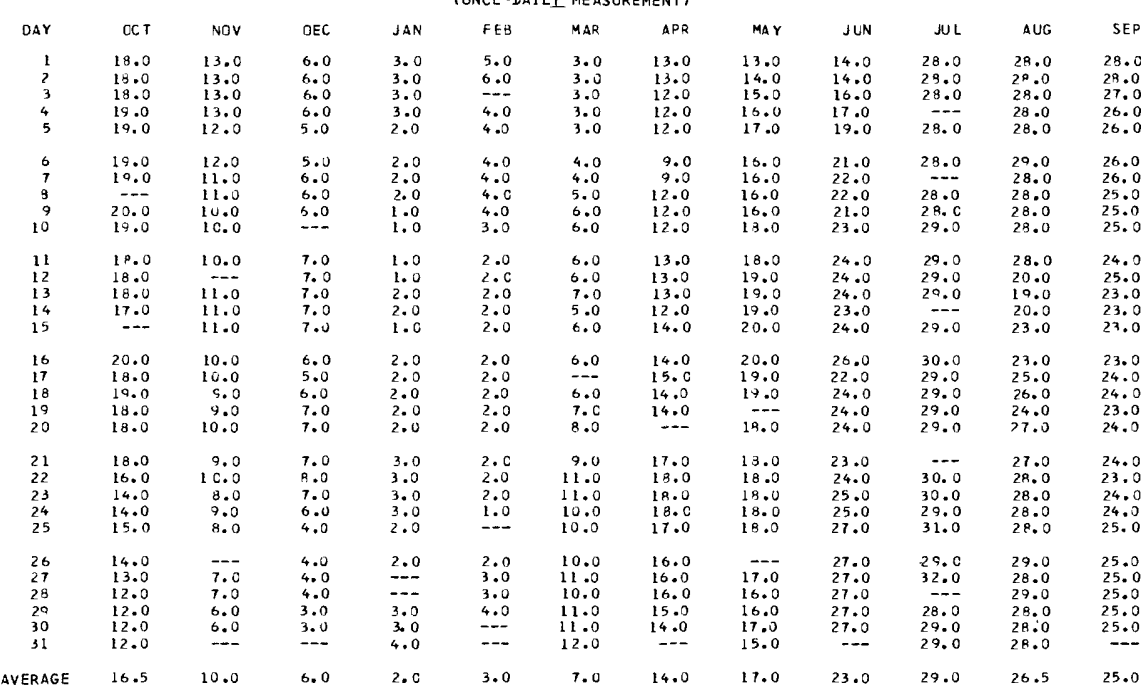

03194700 ELK RIVER BELOW WEBSTER SPRINGS,

LOCATION. --Lat $38^{\circ} 35^{\prime} 50^{\prime \prime}$, long $80^{\circ} 29^{\prime} 20^{\prime \prime}$, Nebster County, 6.5 miles upstream from town of Centralia, 8.9 miles southwest of Salisburg Station, 8.9 miles northwest of iebster Springs, and at mile 122.7.

DRAINAGE AREA, $--268 \mathrm{sq} \mathrm{ml}$.

PERIOD OF RECORD.--April to September 1968.

PERIODIC DETERMINATIUNS OF SUSPENDED-SEDIMENT DISCHARGE. APRIL TO SEPTEMBER 1968 INSTANTANEOUS SUSPENOEO SEOIMENT, WATER YEAR OCTOBER 1967 TO SEPTEMBER 1968 SUSPENDEO

$\begin{array}{lll} & \text { CONCEN- } & \text { SEOIMENT } \\ \text { DISCHARGE TRATION OISCHARGE }\end{array}$

$\begin{array}{lrrrrr}\text { APK } & 17.1968 & 1145 & 360 & 3.0 & 2.9 \\ \text { JUN } & 5.2 . & 1050 & 890 & 10^{\circ} & 24\end{array}$

31.... TIME

CONCEN- SUSPENDED

CONCEN- SEDIMENT (MGL) (TONSIOAY) 
LOCATION.--Lat $38^{\circ} 39^{\prime} 45^{\prime \prime}$, long $80^{\circ} 4 \varepsilon^{\prime} 35^{\prime \prime}$, Braxton County, temperature recorder at gaging station on left bank 150 ft upstream from highway bridge on Sutton, 0.5 mile upstream from Granny Creek, 0.9 mile downtream from Sutton Dam, DRAINAGE AREA. - 543 sq $\mathrm{m} 1$.

PERIOD OF RECORD. - Water temperatures: March 1960 to September 1968.

EXTREAES. - -1967-68:

Water temperatures: Maximum, $23.0^{\circ} \mathrm{C}$ Sept. 21.23 ; minimum, $1.0^{\circ} \mathrm{C}$ on several days during January to yarch.

pertod of record:

Water temperatures: Maximum, $29.0^{\circ} \mathrm{C}$ Aug. 30 and Sept. 1, 1960; mintmum, freezing point Feb. 25, $26,1963$. TEMPERATURE $\left.1{ }^{\circ} \mathrm{C}\right)$ OF WATER, WATER YEAR OCTOBER 1967 TO SEPTEMBER 1968

OCT JBER

MONTH

\begin{tabular}{|c|c|c|c|c|c|c|c|c|c|c|c|c|}
\hline \multirow[b]{2}{*}{ DAY } & \multicolumn{2}{|c|}{ OCT JBER } & \multicolumn{2}{|c|}{ NOVEMBER } & \multicolumn{2}{|c|}{ DECEMBER } & \multicolumn{2}{|c|}{ JANUARY } & \multicolumn{2}{|c|}{ FEBRUARY } & \multicolumn{2}{|c|}{ MARCH } \\
\hline & $\max$ & MIN & $\max$ & MIN & $\operatorname{m\Delta x}$ & MIN & $\operatorname{MAX}$ & MIN & MAX & MIN & $\max$ & MIN \\
\hline $\begin{array}{l}1 \\
2 \\
3 \\
4 \\
5\end{array}$ & $\begin{array}{l}18.0 \\
16.0 \\
15.0 \\
15.0 \\
16.0\end{array}$ & $\begin{array}{l}16.0 \\
14.0 \\
14.0 \\
14.0 \\
15.0\end{array}$ & $\begin{array}{l}9.0 \\
9.0 \\
9.0 \\
9.0 \\
9.0\end{array}$ & $\begin{array}{l}\text { S.c } \\
9.0 \\
9 . c \\
8 . c \\
B .0\end{array}$ & $\begin{array}{l}7.0 \\
7.0 \\
7.0 \\
6.0 \\
5.0\end{array}$ & $\begin{array}{l}7.6 \\
7.0 \\
6.0 \\
5.0 \\
4.0\end{array}$ & $\begin{array}{l}3.0 \\
3.0 \\
3.0 \\
2.0 \\
2.0\end{array}$ & $\begin{array}{l}2.0 \\
2.0 \\
2.0 \\
2.0 \\
2.0\end{array}$ & $\begin{array}{l}5.0 \\
6.0 \\
6.0 \\
5.0 \\
3.0\end{array}$ & $\begin{array}{l}4.0 \\
5.0 \\
5.0 \\
3.0 \\
3.0\end{array}$ & $\begin{array}{l}2.0 \\
2.0 \\
2.0 \\
3.0 \\
3.0\end{array}$ & $\begin{array}{l}1.0 \\
1.0 \\
1.0 \\
1.0 \\
1.0\end{array}$ \\
\hline $\begin{array}{r}6 \\
7 \\
8 \\
9 \\
10\end{array}$ & $\begin{array}{l}16.0 \\
17.0 \\
17.0 \\
17.0 \\
17.0\end{array}$ & $\begin{array}{l}16.0 \\
16.0 \\
17.0 \\
16.0 \\
16.0\end{array}$ & $\begin{array}{l}8.0 \\
9.0 \\
9.0 \\
9.0 \\
9.0\end{array}$ & $\begin{array}{l}8 . C \\
8.0 \\
9 . c \\
B .0 \\
8.0\end{array}$ & $\begin{array}{l}5.0 \\
5.0 \\
6.0 \\
0.0 \\
6.0\end{array}$ & $\begin{array}{l}5.0 \\
4.0 \\
5.0 \\
6.0 \\
5.0\end{array}$ & $\begin{array}{l}2.0 \\
1.0 \\
1.0 \\
1.0 \\
1.0\end{array}$ & $\begin{array}{l}1.0 \\
1.0 \\
1.0 \\
1.0 \\
1.0\end{array}$ & $\begin{array}{l}3.0 \\
3.0 \\
3.0 \\
3.0 \\
3.0\end{array}$ & $\begin{array}{l}3.0 \\
2.0 \\
2.0 \\
2.0 \\
2.0\end{array}$ & $\begin{array}{l}1.0 \\
2.0 \\
2.0 \\
2.0 \\
-. .\end{array}$ & $\begin{array}{l}1.0 \\
1.0 \\
1.0 \\
1.0 \\
-\cdots\end{array}$ \\
\hline $\begin{array}{l}11 \\
12 \\
13 \\
14 \\
15\end{array}$ & $\begin{array}{l}16.0 \\
17.0 \\
18.0 \\
18.0 \\
18.0\end{array}$ & $\begin{array}{l}16.0 \\
16.0 \\
16.0 \\
17.0 \\
17.0\end{array}$ & $\begin{array}{l}5.0 \\
9.0 \\
5.0 \\
8.0 \\
7.0\end{array}$ & $\begin{array}{l}8.0 \\
8.0 \\
8.0 \\
7.0 \\
7.0\end{array}$ & $\begin{array}{l}6.0 \\
7.0 \\
7.0 \\
7.0 \\
6.0\end{array}$ & $\begin{array}{l}5 . c \\
6 . c \\
7 . c \\
6 . c \\
6.0\end{array}$ & $\begin{array}{l}1.0 \\
1.0 \\
1.0 \\
1.0 \\
1.0\end{array}$ & $\begin{array}{l}1.0 \\
1.0 \\
1.0 \\
1.0 \\
1.0\end{array}$ & $\begin{array}{l}2.0 \\
3.0 \\
2.0 \\
3.0 \\
2.0\end{array}$ & $\begin{array}{l}2.0 \\
2.0 \\
2.0 \\
2.0 \\
2.0\end{array}$ & $\begin{array}{l}--- \\
--- \\
--- \\
---\end{array}$ & $\begin{array}{l}--- \\
--- \\
--- \\
--\end{array}$ \\
\hline $\begin{array}{l}16 \\
17 \\
18 \\
19 \\
20\end{array}$ & $\begin{array}{l}17.0 \\
17.0 \\
16.0 \\
16.0 \\
17.0\end{array}$ & $\begin{array}{l}16.0 \\
16.0 \\
16.0 \\
16.0 \\
16.0\end{array}$ & $\begin{array}{l}7.0 \\
8.0 \\
7.0 \\
8.0 \\
9.0\end{array}$ & $\begin{array}{l}0.0 \\
7.0 \\
7.0 \\
7.0 \\
7.0\end{array}$ & $\begin{array}{l}6.0 \\
6.0 \\
7.0 \\
6.0 \\
6.0\end{array}$ & $\begin{array}{l}5 . c \\
4.0 \\
5.0 \\
4.0 \\
4.0\end{array}$ & $\begin{array}{l}1.0 \\
1.0 \\
1.0 \\
1.0 \\
1.0\end{array}$ & $\begin{array}{l}1.0 \\
1.0 \\
1.0 \\
1.0 \\
1.0\end{array}$ & $\begin{array}{l}2.0 \\
2.0 \\
2.0 \\
3.0 \\
2.0\end{array}$ & $\begin{array}{l}1.0 \\
1.0 \\
1.0 \\
2.0 \\
2.0\end{array}$ & $\begin{array}{l}-\ldots \\
-\ldots \\
-- \\
--\end{array}$ & \begin{tabular}{l}
--- \\
\hdashline- \\
\hdashline- \\
$-\cdots$
\end{tabular} \\
\hline $\begin{array}{l}21 \\
22 \\
23 \\
24 \\
25\end{array}$ & $\begin{array}{l}17.0 \\
13.0 \\
12.0 \\
12.0 \\
12.0\end{array}$ & $\begin{array}{l}13.0 \\
11.0 \\
11.0 \\
11.0 \\
11.0\end{array}$ & $\begin{array}{l}8.0 \\
8.0 \\
8.0 \\
7.0 \\
7.0\end{array}$ & $\begin{array}{l}7 . c \\
8 . c \\
7.0 \\
7.0 \\
7.0\end{array}$ & $\begin{array}{l}5.0 \\
0.0 \\
6.0 \\
7.0 \\
6.0\end{array}$ & $\begin{array}{l}4.0 \\
4.0 \\
4.0 \\
6.0 \\
6.0\end{array}$ & $\begin{array}{l}1.0 \\
1.0 \\
3.0 \\
3.0 \\
3.0\end{array}$ & $\begin{array}{l}1.0 \\
1.0 \\
1.0 \\
3.0 \\
2.0\end{array}$ & $\begin{array}{l}3.0 \\
3.0 \\
3.0 \\
3.0 \\
2.0\end{array}$ & $\begin{array}{l}2.0 \\
2.0 \\
2.0 \\
2.0 \\
1.0\end{array}$ & 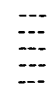 & $\begin{array}{l}--- \\
\cdots- \\
-- \\
--\end{array}$ \\
\hline $\begin{array}{l}26 \\
27 \\
28 \\
29 \\
30 \\
31\end{array}$ & $\begin{array}{l}12.0 \\
11.0 \\
11.0 \\
12.0 \\
12.0 \\
11.0\end{array}$ & $\begin{array}{l}9.0 \\
9.0 \\
9.0 \\
5.0 \\
5.0 \\
9.0\end{array}$ & $\begin{array}{l}7.0 \\
7.0 \\
7.0 \\
7.0 \\
7.0 \\
-\cdots\end{array}$ & $\begin{array}{l}7.0 \\
7.0 \\
6.0 \\
6.0 \\
7.0 \\
-.-\end{array}$ & $\begin{array}{l}6.0 \\
6.0 \\
6.0 \\
4.0 \\
3.0 \\
3.0\end{array}$ & $\begin{array}{l}6.0 \\
6.0 \\
4.0 \\
3.0 \\
3.0 \\
3.0\end{array}$ & $\begin{array}{l}2.0 \\
1.0 \\
1.0 \\
2.0 \\
4.0 \\
4.0\end{array}$ & $\begin{array}{l}1.0 \\
1.0 \\
1.0 \\
1.0 \\
2.0 \\
4.0\end{array}$ & \begin{tabular}{l}
3.0 \\
3.0 \\
2.0 \\
2.0 \\
\hdashline- \\
$-\cdots$
\end{tabular} & \begin{tabular}{l}
1.0 \\
1.0 \\
1.0 \\
1.0 \\
\hdashline-0
\end{tabular} & $\begin{array}{r}-0.0 \\
9.0 \\
9.0 \\
11.0 \\
12.0\end{array}$ & $\begin{array}{r}6.0 \\
8.0 \\
9.0 \\
5.0 \\
11.0\end{array}$ \\
\hline \multirow[t]{2}{*}{ MONTH } & 18.0 & s.o & 9.0 & $6 . c$ & 7.0 & 3.0 & 4.0 & 1.0 & 6.0 & 1.0 & -- & --- \\
\hline & \multicolumn{2}{|c|}{ APRIL } & \multicolumn{2}{|c|}{ MAY } & \multicolumn{2}{|c|}{ JUNE } & \multicolumn{2}{|c|}{ JUL $\gamma$} & \multicolumn{2}{|c|}{ AUGUST } & \multicolumn{2}{|c|}{ SEPTEMEEF } \\
\hline CAY & MAX & MIN & MAX & MIN & $\max$ & MIN & $\operatorname{MAX}$ & MIN & $\operatorname{MAX}$ & MIN & $\max$ & MIN \\
\hline $\begin{array}{l}1 \\
2 \\
3 \\
4 \\
5\end{array}$ & $\begin{array}{r}12.0 \\
12.0 \\
11.0 \\
9.0 \\
5.0\end{array}$ & $\begin{array}{r}11.0 \\
16.0 \\
5.0 \\
8.0 \\
7.0\end{array}$ & $\begin{array}{r}9.0 \\
9.0 \\
10.0 \\
9.0 \\
9.0\end{array}$ & $\begin{array}{l}8.0 \\
8.0 \\
8.0 \\
9.0 \\
8.0\end{array}$ & $\begin{array}{l}a- \\
=- \\
--- \\
---\end{array}$ & $\begin{array}{l}--- \\
-- \\
-- \\
--\end{array}$ & $\begin{array}{l}19.0 \\
18.0 \\
16.0 \\
17.0 \\
17.0\end{array}$ & $\begin{array}{l}14.0 \\
14.0 \\
14.0 \\
14.0 \\
13.0\end{array}$ & $\begin{array}{l}18.0 \\
19.0 \\
19.0 \\
17.0 \\
19.0\end{array}$ & $\begin{array}{l}14.0 \\
15.0 \\
15.0 \\
15.0 \\
15.0\end{array}$ & $\begin{array}{l}17.0 \\
18.0 \\
19.0 \\
19.0 \\
18.0\end{array}$ & $\begin{array}{l}17.0 \\
17.0 \\
17.0 \\
17.0 \\
17.0\end{array}$ \\
\hline $\begin{array}{r}6 \\
7 \\
8 \\
9 \\
10\end{array}$ & $\begin{array}{r}10.0 \\
11.0 \\
9.0 \\
11.0 \\
5.0\end{array}$ & $\begin{array}{l}8.0 \\
8.0 \\
8.0 \\
8.0 \\
8.0\end{array}$ & $\begin{array}{l}10.0 \\
10.0 \\
11.0 \\
10.0 \\
12.0\end{array}$ & $\begin{array}{l}8.0 \\
9.0 \\
9.0 \\
9.0 \\
9.0\end{array}$ & $\begin{array}{l}--- \\
--- \\
-\cdots \\
---\end{array}$ & $\begin{array}{l}\cdots \\
\cdots \\
\cdots- \\
\cdots-\end{array}$ & $\begin{array}{l}17.0 \\
17.0 \\
17.0 \\
17.0 \\
17.0\end{array}$ & $\begin{array}{l}13.0 \\
14.0 \\
14.0 \\
14.0 \\
14.0\end{array}$ & $\begin{array}{l}20.0 \\
19.0 \\
18.0 \\
17.0 \\
16.0\end{array}$ & $\begin{array}{l}15.0 \\
15.0 \\
14.0 \\
15.0 \\
14.0\end{array}$ & $\begin{array}{l}19.0 \\
19.0 \\
19.0 \\
20.0 \\
20.0\end{array}$ & $\begin{array}{l}18.0 \\
18.0 \\
18.0 \\
18.0 \\
19.0\end{array}$ \\
\hline $\begin{array}{l}11 \\
12 \\
13 \\
14 \\
15\end{array}$ & $\begin{array}{r}11.0 \\
21.0 \\
11.0 \\
10.0 \\
9.0\end{array}$ & $\begin{array}{l}8.0 \\
7.0 \\
8.0 \\
8.0 \\
8.0\end{array}$ & \begin{tabular}{r}
11.0 \\
\hdashline-0 \\
11.0
\end{tabular} & $\begin{array}{r}9.0 \\
\hdashline-0 \\
\hdashline 10.0\end{array}$ & \begin{tabular}{l}
--- \\
\hdashline-- \\
\hdashline-- \\
---
\end{tabular} & $\begin{array}{l}--- \\
-\cdots \\
-- \\
--\end{array}$ & $\begin{array}{l}17.0 \\
18.0 \\
17.0 \\
17.0 \\
17.0\end{array}$ & $\begin{array}{l}14.0 \\
14.0 \\
14.0 \\
14.0 \\
14.0\end{array}$ & $\begin{array}{l}15.0 \\
16.0 \\
16.0 \\
16.0 \\
17.0\end{array}$ & $\begin{array}{l}14.0 \\
14.0 \\
15.0 \\
15.0 \\
16.0\end{array}$ & $\begin{array}{l}19.0 \\
21.0 \\
21.0 \\
20.0 \\
21.0\end{array}$ & $\begin{array}{l}18.0 \\
18.0 \\
18.0 \\
18.0 \\
19.0\end{array}$ \\
\hline $\begin{array}{l}16 \\
17 \\
18 \\
19 \\
20\end{array}$ & $\begin{array}{r}11.0 \\
10.0 \\
9.0 \\
9.0 \\
9.0\end{array}$ & $\begin{array}{l}7.0 \\
7.0 \\
8.0 \\
8.0 \\
8.0\end{array}$ & $\begin{array}{l}11.0 \\
11.0 \\
11.0 \\
12.0 \\
12.0\end{array}$ & $\begin{array}{l}10.0 \\
11.0 \\
11.0 \\
11.0 \\
11.0\end{array}$ & $\begin{array}{r}--- \\
17.0 \\
17.0 \\
16.0\end{array}$ & $\begin{array}{l}0 .- \\
14.0 \\
14.0 \\
14 . C\end{array}$ & $\begin{array}{l}17.0 \\
17.0 \\
18.0 \\
16.0 \\
18.0\end{array}$ & $\begin{array}{l}14.0 \\
14.0 \\
14.0 \\
14.0 \\
14.0\end{array}$ & $\begin{array}{l}17.0 \\
17.0 \\
17.0 \\
16.0 \\
18.0\end{array}$ & $\begin{array}{l}15.0 \\
15.0 \\
15.0 \\
15.0 \\
16.0\end{array}$ & $\begin{array}{l}21.0 \\
21.0 \\
21.0 \\
20.0 \\
22.0\end{array}$ & $\begin{array}{l}19.0 \\
19.0 \\
19.0 \\
19.0 \\
19.0\end{array}$ \\
\hline $\begin{array}{l}21 \\
22 \\
23 \\
24 \\
25\end{array}$ & $\begin{array}{l}5.0 \\
5.0 \\
9.0 \\
5.0 \\
8.0\end{array}$ & $\begin{array}{l}8.0 \\
8.0 \\
8.0 \\
8.0 \\
8.0\end{array}$ & $\begin{array}{l}12.0 \\
13.0 \\
12.0 \\
13.0 \\
13.0\end{array}$ & $\begin{array}{l}12 . \mathrm{C} \\
12 . \mathrm{C} \\
12.0 \\
12 . \mathrm{C} \\
13.0\end{array}$ & $\begin{array}{l}17.0 \\
18.0 \\
18.0 \\
19.0 \\
18.0\end{array}$ & $\begin{array}{l}13.0 \\
13 . \mathrm{C} \\
14 . \mathrm{C} \\
14.0 \\
14 . \mathrm{C}\end{array}$ & $\begin{array}{l}18.0 \\
17.0 \\
18.0 \\
18.0 \\
17.0\end{array}$ & $\begin{array}{l}14.0 \\
14.0 \\
14.0 \\
14.0 \\
14.0\end{array}$ & $\begin{array}{l}18.0 \\
19.0 \\
19.0 \\
18.0 \\
20.0\end{array}$ & $\begin{array}{l}16.0 \\
16.0 \\
17.0 \\
17.0 \\
17.0\end{array}$ & $\begin{array}{l}23.0 \\
23.0 \\
23.0 \\
21.0 \\
21.0\end{array}$ & $\begin{array}{l}19.0 \\
19.0 \\
19.0 \\
20.0 \\
21.0\end{array}$ \\
\hline $\begin{array}{l}26 \\
27 \\
28 \\
29 \\
30 \\
31\end{array}$ & $\begin{array}{r}10.0 \\
8.0 \\
9.0 \\
8.0 \\
9.0 \\
-0\end{array}$ & $\begin{array}{l}8.0 \\
8.0 \\
8.0 \\
8.0 \\
2.0 \\
-. .\end{array}$ & $\begin{array}{c}-- \\
\cdots \\
-\cdots \\
-\cdots\end{array}$ & $\begin{array}{r}-.- \\
-0 \\
--0 \\
13.0\end{array}$ & $\begin{array}{l}17.0 \\
19.0 \\
16.0 \\
19.0 \\
19.0 \\
-\end{array}$ & $\begin{array}{r}15.0 \\
14 . \mathrm{C} \\
13 . \mathrm{C} \\
13.0 \\
14 . \mathrm{C} \\
\ldots\end{array}$ & $\begin{array}{l}17.0 \\
17.0 \\
17.0 \\
18.0 \\
19.0 \\
17.0\end{array}$ & $\begin{array}{l}14.0 \\
14.0 \\
14.0 \\
14.0 \\
14.0 \\
14.0\end{array}$ & $\begin{array}{l}18.0 \\
18.0 \\
18.0 \\
17.0 \\
17.0 \\
17.0\end{array}$ & $\begin{array}{l}16.0 \\
16.0 \\
16.0 \\
16.0 \\
16.0 \\
16.0\end{array}$ & $\begin{array}{l}21.0 \\
21.0 \\
22.0 \\
21.0 \\
22.0 \\
\ldots .0\end{array}$ & $\begin{array}{l}21.0 \\
21.0 \\
21.0 \\
21.0 \\
21.0 \\
-\end{array}$ \\
\hline IEATH & 12.0 & 7.0 & $-\infty$ & -- & --- & -- & 19.0 & 13.0 & 20.0 & 14.0 & 23.0 & 17.0 \\
\hline
\end{tabular}
IONTINUOUS ETHYL ALCOHOL-ACTUATED THERMOGRAPH I 
03196800 ELX RIVER AT CLAY, T. VA.

LOCATION,--Lat $38^{\circ} 27^{\prime} 36^{\prime \prime}$, long $81^{\circ} 05^{\prime} 15^{\prime \prime}$, Clay County, temperature recorder at gaging station on right bank at downstream side of pler of highway bridge at clay, 0.9 mile downstream from Buffalo Creek, 2.1 miles downstream from
Lower Two Run Creek, and at mile 52.5. DRAINAGE AREA, $-994 \mathrm{sq}$ ml.

PERIOD OF RECORD.--Water temperatures: November 1960 to September 1968.

EXTREHES. $-1967-68$ : Water temperatures: Maximum, $27,0^{\circ} \mathrm{C}$ on several days in July; minimum, freezing point on several days during
January and February.

Period of record: Water temperatures: Maximum, $31,0^{\circ} \mathrm{C} J u l y ~ 23,1964$; m1nimum, freezing point on several days in February 1961 ,
January to March 1967, and January, February 1968. TEMPERATURE ( $\left.{ }^{\circ} \mathrm{C}\right)$ OF WATER, WATER YEAR OCTOBER 1967 TO SEPTEMBER 1968
(CONTINUOUS ETHYL ALCOHOL-ACTUATED THERMOGRAPH)

\begin{tabular}{|c|c|c|c|c|c|c|c|c|c|c|c|c|}
\hline \multirow[b]{2}{*}{ DAY } & \multicolumn{2}{|c|}{ OCTOBER } & \multicolumn{2}{|c|}{ NOVEMBER } & \multicolumn{2}{|c|}{ DECEMBER } & \multicolumn{2}{|c|}{ JANU ARY } & \multicolumn{2}{|c|}{ FEURUARY } & \multicolumn{2}{|c|}{ MARCH } \\
\hline & MAX & MIN & $\operatorname{MAX}$ & MIN & $M \Delta x$ & MIN & $\operatorname{MAX}$ & MIN & MAX & MI N & $\operatorname{MAX}$ & NIN \\
\hline $\begin{array}{l}1 \\
2 \\
3 \\
4 \\
5\end{array}$ & $\begin{array}{l}16.0 \\
17.0 \\
18.0 \\
18.0 \\
17.0\end{array}$ & $\begin{array}{l}15.0 \\
16.0 \\
17.0 \\
17.0 \\
17.0\end{array}$ & $\begin{array}{l}8.0 \\
8.0 \\
9.0 \\
9.0 \\
8.0\end{array}$ & $\begin{array}{l}8.0 \\
8.0 \\
8.0 \\
8.0 \\
7.0\end{array}$ & $\begin{array}{l}4.0 \\
5.0 \\
5.0 \\
5.0 \\
4.0\end{array}$ & $\begin{array}{l}4 . C \\
4 . C \\
5.0 \\
4 . c \\
4 . C\end{array}$ & $\begin{array}{l}2.0 \\
2.0 \\
2.0 \\
1.0 \\
1.0\end{array}$ & $\begin{array}{l}1.0 \\
1.0 \\
1.0 \\
1.0 \\
1.0\end{array}$ & $\begin{array}{l}3.0 \\
3.0 \\
3.0 \\
3.0 \\
3.0\end{array}$ & $\begin{array}{l}3.0 \\
3.0 \\
3.0 \\
3.0 \\
2.0\end{array}$ & $\begin{array}{l}2.0 \\
2.0 \\
2.0 \\
2.0 \\
2.0\end{array}$ & $\begin{array}{l}2.0 \\
2.0 \\
2.0 \\
2.0 \\
2.0\end{array}$ \\
\hline $\begin{array}{r}6 \\
7 \\
8 \\
9 \\
10\end{array}$ & $\begin{array}{l}17.0 \\
16.0 \\
16.0 \\
16.0 \\
16.0\end{array}$ & $\begin{array}{l}16.0 \\
16.0 \\
16.0 \\
16.0 \\
15.0\end{array}$ & $\begin{array}{l}7.0 \\
6.0 \\
6.0 \\
5.0 \\
6.0\end{array}$ & $\begin{array}{l}6 . c \\
6.0 \\
5.0 \\
5.0 \\
5.0\end{array}$ & $\begin{array}{l}4.0 \\
4.0 \\
3.0 \\
3.0 \\
3.0\end{array}$ & $\begin{array}{l}4 . c \\
3.0 \\
3.0 \\
3.0 \\
3.0\end{array}$ & $\begin{array}{l}1.0 \\
1.0 \\
0.0 \\
1.0 \\
0.0\end{array}$ & $\begin{array}{l}1.0 \\
0.0 \\
0.0 \\
0.0 \\
0.0\end{array}$ & $\begin{array}{l}2.0 \\
2.0 \\
1.0 \\
1.0 \\
1.0\end{array}$ & $\begin{array}{l}2.0 \\
1.0 \\
1.0 \\
1.0 \\
1.0\end{array}$ & $\begin{array}{l}2.0 \\
2.0 \\
2.0 \\
3.0 \\
3.0\end{array}$ & $\begin{array}{l}2.0 \\
2.0 \\
2.0 \\
2.0 \\
3.0\end{array}$ \\
\hline $\begin{array}{l}11 \\
12 \\
13 \\
14 \\
15\end{array}$ & $\begin{array}{l}15.0 \\
14.0 \\
13.0 \\
13.0 \\
13.0\end{array}$ & $\begin{array}{l}13.0 \\
13.0 \\
12.0 \\
12.0 \\
13.0\end{array}$ & $\begin{array}{l}6.0 \\
7.0 \\
7.0 \\
7.0 \\
7.0\end{array}$ & $\begin{array}{l}6.0 \\
6.0 \\
7.0 \\
7.0 \\
6.0\end{array}$ & $\begin{array}{l}4.0 \\
4.0 \\
4.0 \\
4.0 \\
5.0\end{array}$ & $\begin{array}{l}3 . c \\
4 . c \\
4 . c \\
4 . c \\
4.0\end{array}$ & $\begin{array}{l}0.0 \\
0.0 \\
0.0 \\
0.0 \\
0.0\end{array}$ & $\begin{array}{l}0 . c \\
0 . c \\
0.0 \\
0.0 \\
0.0\end{array}$ & $\begin{array}{l}1.0 \\
1.0 \\
0.0 \\
0.0 \\
0.0\end{array}$ & $\begin{array}{l}1.0 \\
0.0 \\
0.0 \\
0.0 \\
0.0\end{array}$ & $\begin{array}{l}3.0 \\
4.0 \\
4.0 \\
4.0 \\
4.0\end{array}$ & $\begin{array}{l}3.0 \\
3.0 \\
4.0 \\
4.0 \\
4.0\end{array}$ \\
\hline $\begin{array}{l}16 \\
17 \\
18 \\
19 \\
20\end{array}$ & $\begin{array}{l}13.0 \\
13.0 \\
13.0 \\
13.0 \\
12.0\end{array}$ & $\begin{array}{l}12.0 \\
13.0 \\
13.0 \\
12.0 \\
12.0\end{array}$ & $\begin{array}{l}6.0 \\
5.0 \\
5.0 \\
5.0 \\
4.0\end{array}$ & $\begin{array}{l}5.0 \\
5.0 \\
5.0 \\
4.0 \\
4.0\end{array}$ & $\begin{array}{l}5.0 \\
4.0 \\
4.0 \\
4.0 \\
4.0\end{array}$ & $\begin{array}{l}4 . c \\
3 . C \\
3 . c \\
4 . c \\
4.0\end{array}$ & $\begin{array}{l}0.0 \\
0.0 \\
0.0 \\
0.0 \\
0.0\end{array}$ & $\begin{array}{l}0 . c \\
0.0 \\
0.0 \\
0.0 \\
0.0\end{array}$ & $\begin{array}{l}1.0 \\
1.0 \\
1.0 \\
1.0 \\
0.0\end{array}$ & $\begin{array}{l}0.0 \\
1.0 \\
1.0 \\
0.0 \\
0.0\end{array}$ & $\begin{array}{l}4.0 \\
4.0 \\
6.0 \\
6.0 \\
6.0\end{array}$ & $\begin{array}{l}4.0 \\
4.0 \\
4.0 \\
6.0 \\
0.0\end{array}$ \\
\hline $\begin{array}{l}21 \\
22 \\
23 \\
24 \\
25\end{array}$ & $\begin{array}{l}12.0 \\
11.0 \\
11.0 \\
11.0 \\
11.0\end{array}$ & $\begin{array}{l}11.0 \\
11.0 \\
11.0 \\
11.0 \\
10.0\end{array}$ & $\begin{array}{l}4.0 \\
6.0 \\
6.0 \\
6.0 \\
6.0\end{array}$ & $\begin{array}{l}4.0 \\
4 . c \\
6 . c \\
6.0 \\
6 . c\end{array}$ & $\begin{array}{l}4.0 \\
5.0 \\
5.0 \\
4.0 \\
3.0\end{array}$ & $\begin{array}{l}4 . c \\
4.0 \\
4 . c \\
2.7 \\
2.0\end{array}$ & $\begin{array}{l}0.0 \\
1.0 \\
1.0 \\
1.0 \\
1.0\end{array}$ & $\begin{array}{l}0 . c \\
0.0 \\
1.0 \\
1.0 \\
1.0\end{array}$ & $\begin{array}{l}1.0 \\
1.0 \\
1.0 \\
1.0 \\
1.0\end{array}$ & $\begin{array}{l}0.0 \\
1.0 \\
1.0 \\
1.0 \\
1.0\end{array}$ & $\begin{array}{l}7.0 \\
8.0 \\
8.0 \\
8.0 \\
7.0\end{array}$ & $\begin{array}{l}6.0 \\
7.0 \\
8.0 \\
7.0 \\
0.0\end{array}$ \\
\hline $\begin{array}{l}26 \\
27 \\
28 \\
29 \\
30 \\
31\end{array}$ & $\begin{array}{r}10.0 \\
10.0 \\
9.0 \\
8.0 \\
8.0 \\
8.0\end{array}$ & $\begin{array}{r}10.0 \\
5.0 \\
8.0 \\
8.0 \\
7.0 \\
8.0\end{array}$ & $\begin{array}{l}6.0 \\
6.0 \\
5.0 \\
4.0 \\
4.0 \\
-.-\end{array}$ & $\begin{array}{l}6 . C \\
5.0 \\
4.0 \\
4.0 \\
4.0 \\
\ldots .-\end{array}$ & $\begin{array}{l}3.0 \\
3.0 \\
3.0 \\
3.0 \\
3.0 \\
2.0\end{array}$ & $\begin{array}{l}3.0 \\
3.0 \\
3 . c \\
3.5 \\
2.0 \\
2.0\end{array}$ & $\begin{array}{l}1.0 \\
1.0 \\
1.0 \\
2.0 \\
2.0 \\
3.0\end{array}$ & $\begin{array}{l}1 . c \\
1.0 \\
1.0 \\
1.0 \\
2.0 \\
2.0\end{array}$ & $\begin{array}{l}1.0 \\
1.0 \\
2.0 \\
2.0 \\
-.-\end{array}$ & \begin{tabular}{l}
1.0 \\
1.0 \\
1.0 \\
2.0 \\
\hdashline-0
\end{tabular} & $\begin{array}{r}6.0 \\
6.0 \\
8.0 \\
9.0 \\
11.0 \\
11.0\end{array}$ & $\begin{array}{r}6.0 \\
t .0 \\
7.0 \\
8.0 \\
5.0 \\
11 . c\end{array}$ \\
\hline \multirow[t]{2}{*}{ NTH } & 18.0 & 7.0 & 9.0 & $4 . C$ & 5.0 & 2.0 & 3.0 & 0.0 & 3.0 & 0.0 & 11.0 & 2.0 \\
\hline & \multicolumn{2}{|c|}{ APRIL } & \multicolumn{2}{|c|}{ MAY } & \multicolumn{2}{|c|}{ JUNE } & \multicolumn{2}{|c|}{ JULLY } & \multicolumn{2}{|c|}{ AUGUST } & \multicolumn{2}{|c|}{ SEPTEMBER } \\
\hline DAY & $\operatorname{MAX}$ & MIN & MAX & MIN & $\operatorname{Max}$ & $\mathrm{M}[\mathrm{K}$ & $\operatorname{MAx}$ & MIN & $\operatorname{MAX}$ & MIN & $\operatorname{MAx}$ & MIN \\
\hline $\begin{array}{l}1 \\
2 \\
3 \\
4 \\
5\end{array}$ & $\begin{array}{r}11.0 \\
11.0 \\
9.0 \\
5.0 \\
8.0\end{array}$ & $\begin{array}{r}11.0 \\
9.0 \\
9.0 \\
8.0 \\
8.0\end{array}$ & $\begin{array}{l}13.0 \\
14.0 \\
15.0 \\
15.0 \\
15.0\end{array}$ & $\begin{array}{l}12.0 \\
13.0 \\
14.0 \\
15.0 \\
14.0\end{array}$ & $\begin{array}{l}15.0 \\
15.0 \\
15.0 \\
10.0 \\
17.0\end{array}$ & $\begin{array}{l}14 . C \\
15.0 \\
15 . c \\
15 . c \\
16 . C\end{array}$ & $\begin{array}{l}27.0 \\
27.0 \\
27.0 \\
26.0 \\
24.0\end{array}$ & $\begin{array}{l}24.0 \\
26.0 \\
26.0 \\
24.0 \\
23.0\end{array}$ & $\begin{array}{l}26.0 \\
26.0 \\
26.0 \\
26.0 \\
26.0\end{array}$ & $\begin{array}{l}25.9 \\
24.0 \\
25.0 \\
26.0 \\
26.0\end{array}$ & $\begin{array}{l}22.0 \\
22.0 \\
21.0 \\
21.0 \\
21.0\end{array}$ & $\begin{array}{l}22.0 \\
21.0 \\
21.0 \\
21.0 \\
21.0\end{array}$ \\
\hline $\begin{array}{r}6 \\
7 \\
8 \\
9 \\
10\end{array}$ & $\begin{array}{r}8.0 \\
9.0 \\
9.0 \\
10.0 \\
10.0\end{array}$ & $\begin{array}{r}8.0 \\
8.0 \\
9.0 \\
9.0 \\
10.0\end{array}$ & $\begin{array}{l}14.0 \\
14.0 \\
14.0 \\
14.0 \\
14.0\end{array}$ & $\begin{array}{l}13.0 \\
13.0 \\
13.0 \\
14.0 \\
14.0\end{array}$ & $\begin{array}{l}17.0 \\
17.0 \\
19.0 \\
19.0 \\
19.0\end{array}$ & $\begin{array}{l}17 . c \\
17.0 \\
17.0 \\
19.0 \\
19.0\end{array}$ & $\begin{array}{l}24.0 \\
26.0 \\
26.0 \\
27.0 \\
26.0\end{array}$ & $\begin{array}{l}24.0 \\
24.0 \\
24.0 \\
26.0 \\
26.0\end{array}$ & $\begin{array}{l}26.0 \\
26.0 \\
24.0 \\
24.0 \\
23.0\end{array}$ & $\begin{array}{l}24.0 \\
24.0 \\
22.0 \\
23.0 \\
22.0\end{array}$ & $\begin{array}{l}21.0 \\
21.0 \\
22.0 \\
21.0 \\
21.0\end{array}$ & $\begin{array}{l}21.0 \\
21.0 \\
21.0 \\
21.0 \\
20.0\end{array}$ \\
\hline $\begin{array}{l}11 \\
12 \\
13 \\
14 \\
15\end{array}$ & $\begin{array}{l}11.0 \\
11.0 \\
12.0 \\
12.0 \\
12.0\end{array}$ & $\begin{array}{l}1 C .0 \\
1 c .0 \\
11.0 \\
11.0 \\
12.0\end{array}$ & $\begin{array}{l}14.0 \\
15.0 \\
15.0 \\
15.0 \\
15.0\end{array}$ & $\begin{array}{l}14.0 \\
14.0 \\
15.0 \\
15.0 \\
15.0\end{array}$ & $\begin{array}{l}22.0 \\
22.0 \\
21.0 \\
19.0 \\
20.0\end{array}$ & $\begin{array}{l}19.0 \\
21.0 \\
19.0 \\
18.0 \\
18.0\end{array}$ & $\begin{array}{l}26.0 \\
26.0 \\
27.0 \\
27.0 \\
26.0\end{array}$ & $\begin{array}{l}25.0 \\
26.0 \\
26.0 \\
26.0 \\
26.0\end{array}$ & $\begin{array}{l}22.0 \\
22.0 \\
22.0 \\
20.0 \\
20.0\end{array}$ & $\begin{array}{l}22.0 \\
22.0 \\
20.0 \\
20.0 \\
20.0\end{array}$ & $\begin{array}{l}20.0 \\
20.0 \\
19.0 \\
19.0 \\
19.0\end{array}$ & $\begin{array}{l}2 c . C \\
19.0 \\
19.0 \\
19.0 \\
19.0\end{array}$ \\
\hline $\begin{array}{l}16 \\
17 \\
18 \\
19 \\
20\end{array}$ & $\begin{array}{l}12.0 \\
12.0 \\
12.0 \\
14.0 \\
14.0\end{array}$ & $\begin{array}{l}11.0 \\
11.0 \\
12.0 \\
12.0 \\
13.0\end{array}$ & $\begin{array}{l}15.0 \\
15.0 \\
14.0 \\
14.0 \\
13.0\end{array}$ & $\begin{array}{l}15.0 \\
14.0 \\
14.0 \\
13.0 \\
13.0\end{array}$ & $\begin{array}{l}20.0 \\
20.0 \\
20.0 \\
21.0 \\
22.0\end{array}$ & $\begin{array}{l}20.0 \\
19.0 \\
19.0 \\
20.0 \\
21.0\end{array}$ & $\begin{array}{l}26.0 \\
27.0 \\
27.0 \\
27.0 \\
27.0\end{array}$ & $\begin{array}{l}26.0 \\
26.0 \\
26.0 \\
27.0 \\
26.0\end{array}$ & $\begin{array}{l}20.0 \\
21.0 \\
22.0 \\
22.0 \\
22.0\end{array}$ & $\begin{array}{l}20.0 \\
20.0 \\
21.0 \\
21.0 \\
21.0\end{array}$ & $\begin{array}{l}19.0 \\
19.0 \\
19.0 \\
19.0 \\
20.0\end{array}$ & $\begin{array}{l}19.0 \\
19.0 \\
19.0 \\
19.0 \\
19.0\end{array}$ \\
\hline $\begin{array}{l}21 \\
22 \\
23 \\
24 \\
25\end{array}$ & $\begin{array}{l}14.0 \\
14.0 \\
14.0 \\
14.0 \\
14.0\end{array}$ & $\begin{array}{l}13.0 \\
14.0 \\
14.0 \\
14.0 \\
13.0\end{array}$ & $\begin{array}{l}13.0 \\
13.0 \\
13.0 \\
13.0 \\
14.0\end{array}$ & $\begin{array}{l}13.0 \\
13.0 \\
13.0 \\
13.0 \\
13.0\end{array}$ & $\begin{array}{l}22.0 \\
22.0 \\
23.0 \\
25.0 \\
26.0\end{array}$ & $\begin{array}{l}21.0 \\
22.0 \\
22.0 \\
23.0 \\
24.0\end{array}$ & $\begin{array}{l}27.0 \\
26.0 \\
27.0 \\
27.0 \\
27.0\end{array}$ & $\begin{array}{l}25.0 \\
26.0 \\
26.0 \\
26.0 \\
26.0\end{array}$ & $\begin{array}{l}22.0 \\
21.0 \\
22.0 \\
24.0 \\
26.0\end{array}$ & $\begin{array}{l}21.0 \\
21.0 \\
21.0 \\
22.0 \\
24.0\end{array}$ & $\begin{array}{l}22.0 \\
23.0 \\
23.0 \\
23.0 \\
23.0\end{array}$ & $\begin{array}{l}20.0 \\
22.0 \\
22.0 \\
22.0 \\
22.0\end{array}$ \\
\hline $\begin{array}{l}26 \\
27 \\
28 \\
29 \\
30 \\
31\end{array}$ & $\begin{array}{r}13.0 \\
13.0 \\
13.0 \\
13.0 \\
13.0 \\
\ldots\end{array}$ & $\begin{array}{r}12.0 \\
13.0 \\
12.0 \\
13.0 \\
12.0 \\
-.-0\end{array}$ & $\begin{array}{l}15.0 \\
15.0 \\
15.0 \\
16.0 \\
16.0 \\
16.0\end{array}$ & $\begin{array}{l}14.0 \\
15.0 \\
15.0 \\
15.0 \\
16.0 \\
14.0\end{array}$ & $\begin{array}{l}26.0 \\
26.0 \\
24.0 \\
24.0 \\
26.0 \\
\ldots . .\end{array}$ & $\begin{array}{r}25.0 \\
24 . c \\
23 . c \\
23 . c \\
23 . c \\
-. .\end{array}$ & $\begin{array}{l}27.0 \\
26.0 \\
26.0 \\
27.0 \\
27.0 \\
26.0\end{array}$ & $\begin{array}{l}26.0 \\
26.0 \\
26.0 \\
24.0 \\
26.0 \\
26.0\end{array}$ & $\begin{array}{l}26.0 \\
24.0 \\
23.0 \\
22.0 \\
22.0 \\
22.0\end{array}$ & $\begin{array}{l}24.0 \\
23.0 \\
22.0 \\
22.0 \\
22.0 \\
22.0\end{array}$ & $\begin{array}{l}22.0 \\
22.0 \\
21.0 \\
20.0 \\
20.0 \\
\ldots \ldots\end{array}$ & $\begin{array}{r}22.0 \\
21.0 \\
20.0 \\
20.0 \\
20.0 \\
-. .\end{array}$ \\
\hline RTH & 14.0 & 8.0 & 16.0 & 12.0 & $26 . c$ & $14 . C$ & 27.0 & 23.0 & 26.0 & 20.0 & 23.0 & 19.0 \\
\hline
\end{tabular}


LOCATION, - Lat $38^{\circ} 28^{\prime} 20^{\prime \prime}$, long $81^{\circ} 17^{\prime} 10^{\prime \prime}$, Kanawha County, temperature recorder at gaging station on right hank 50 ft upstream from Queen Shoals Creek,

DRAINAGE AREA, - -1,145 sq mi, Including that of Queen Shoals creek.

PERIOD OF RECORD, --Water temperatures: November 1960 to Septemher 1968.

EXTREMES. - 1967-68:

Water temperatures: Maximum, $29.0^{\circ} \mathrm{C}$ July $2,3,18,19$; minimum, freezing polnt on several days during January.

period of record:

Maximum, $29.0^{\circ} \mathrm{C}$ on several days in July 1963,1964 and 1968; minimum, freezing point on many days during winter periods most years.

TEMPERATURE $\left({ }^{\circ} \mathrm{C}\right)$ OF WATER, WATER YEAR OC TOBER 1967 TO SEPTEMBER 1968 (CONTINUOUS ETHYL ALCOHOL-ACTUATED THERMOGRAPH)

\begin{tabular}{|c|c|c|c|c|c|c|c|c|c|c|c|c|}
\hline \multirow[b]{2}{*}{ DAY } & \multicolumn{2}{|c|}{ JCTOUER } & \multicolumn{2}{|c|}{ NOVEMBER } & \multicolumn{2}{|c|}{ DECEMEER } & \multicolumn{2}{|c|}{ JANUARY } & \multicolumn{2}{|c|}{ FEBRUARY } & \multicolumn{2}{|c|}{ MARCH } \\
\hline & MAX & MIN & $\operatorname{mAx}$ & MIA & $\operatorname{M\Delta X}$ & MIN & $\max$ & MIN & $\max$ & MIN & $\operatorname{MAX}$ & MIN \\
\hline $\begin{array}{l}1 \\
2 \\
3 \\
4 \\
5\end{array}$ & $\begin{array}{l}7.0 \\
16.0 \\
16.0 \\
17.0 \\
18.0\end{array}$ & $\begin{array}{l}16.0 \\
15.0 \\
15.0 \\
16.0 \\
17.0\end{array}$ & $\begin{array}{l}12.0 \\
12.0 \\
12.0 \\
12.0 \\
12.0\end{array}$ & $\begin{array}{l}12 . \mathrm{C} \\
12.0 \\
12 . \mathrm{C} \\
12 . \mathrm{C} \\
12.0\end{array}$ & $\begin{array}{l}5.0 \\
6.0 \\
6.0 \\
6.0 \\
6.0\end{array}$ & $\begin{array}{l}4 . C \\
5.0 \\
6.0 \\
6 . C \\
6 . C\end{array}$ & $\begin{array}{l}2.0 \\
1.0 \\
0.0 \\
0.0 \\
0.0\end{array}$ & $\begin{array}{l}1.0 \\
0.0 \\
0.0 \\
0.0 \\
0.0\end{array}$ & $\begin{array}{l}5.0 \\
6.0 \\
5.0 \\
6.0 \\
6.0\end{array}$ & $\begin{array}{l}4.0 \\
5.0 \\
6.0 \\
6.0 \\
4.0\end{array}$ & $\begin{array}{l}2.0 \\
2.0 \\
2.0 \\
2.0 \\
2.0\end{array}$ & $\begin{array}{l}2.0 \\
2.0 \\
2.0 \\
2.0 \\
2.0\end{array}$ \\
\hline $\begin{array}{r}6 \\
7 \\
8 \\
9 \\
10\end{array}$ & $\begin{array}{l}18.0 \\
18.0 \\
18.0 \\
17.0 \\
17.0\end{array}$ & $\begin{array}{l}18.0 \\
18.0 \\
17.0 \\
17.0 \\
17.0\end{array}$ & $\begin{array}{r}12.0 \\
11.0 \\
9.0 \\
8.0 \\
7.0\end{array}$ & $\begin{array}{r}11.0 \\
9.0 \\
8.0 \\
7.0 \\
7.0\end{array}$ & $\begin{array}{l}0.0 \\
5.0 \\
5.0 \\
5.0 \\
5.0\end{array}$ & $\begin{array}{l}5.0 \\
5.0 \\
5.0 \\
5.0 \\
5.0\end{array}$ & $\begin{array}{l}0.0 \\
0.0 \\
0.0 \\
0.0 \\
0.0\end{array}$ & $\begin{array}{l}0.0 \\
0.0 \\
0.0 \\
0.0 \\
0.0\end{array}$ & $\begin{array}{l}4.0 \\
4.0 \\
3.0 \\
3.0 \\
3.0\end{array}$ & $\begin{array}{l}4.0 \\
3.0 \\
3.0 \\
3.0 \\
3.0\end{array}$ & $\begin{array}{l}2.0 \\
2.0 \\
2.0 \\
3.0 \\
4.0\end{array}$ & $\begin{array}{l}2.0 \\
2.0 \\
2.0 \\
2.0 \\
3.0\end{array}$ \\
\hline $\begin{array}{l}11 \\
12 \\
13 \\
14 \\
15\end{array}$ & $\begin{array}{l}17.0 \\
17.0 \\
17.0 \\
16.0 \\
16.0\end{array}$ & $\begin{array}{l}17.0 \\
17.0 \\
16 . \mathrm{C} \\
16.0 \\
16 . \mathrm{C}\end{array}$ & $\begin{array}{l}8.0 \\
9.0 \\
9.0 \\
9.0 \\
9.0\end{array}$ & $\begin{array}{l}7.0 \\
8.0 \\
9.0 \\
9.0 \\
8.0\end{array}$ & $\begin{array}{l}5.0 \\
5.0 \\
5.0 \\
5.0 \\
5.0\end{array}$ & $\begin{array}{l}4.0 \\
5.0 \\
5.0 \\
5.0 \\
5.0\end{array}$ & $\begin{array}{l}1.0 \\
1.0 \\
1.0 \\
1.0 \\
1.0\end{array}$ & $\begin{array}{l}0 . c \\
1.0 \\
1.0 \\
1.0 \\
1.0\end{array}$ & $\begin{array}{l}3.0 \\
2.0 \\
2.0 \\
2.0 \\
2.0\end{array}$ & $\begin{array}{l}2.0 \\
2.0 \\
2.0 \\
2.0 \\
2.0\end{array}$ & $\begin{array}{l}4.0 \\
5.0 \\
6.0 \\
6.0 \\
6.0\end{array}$ & $\begin{array}{l}4.0 \\
4.0 \\
5.0 \\
5.0 \\
6.0\end{array}$ \\
\hline $\begin{array}{l}16 \\
17 \\
18 \\
19 \\
20\end{array}$ & $\begin{array}{l}16.0 \\
16.0 \\
16.0 \\
16.0 \\
16.0\end{array}$ & $\begin{array}{l}16.0 \\
16.0 \\
16.0 \\
16.0 \\
16.0\end{array}$ & $\begin{array}{l}8.0 \\
7.0 \\
7.0 \\
7.0 \\
7.0\end{array}$ & $\begin{array}{l}7.0 \\
7.0 \\
7.0 \\
7.0 \\
7.0\end{array}$ & $\begin{array}{l}5.0 \\
4.0 \\
3.0 \\
3.0 \\
4.0\end{array}$ & $\begin{array}{l}4 . c \\
3 . c \\
3 . c \\
3 . c \\
3.0\end{array}$ & $\begin{array}{l}1.0 \\
1.0 \\
1.0 \\
1.0 \\
1.0\end{array}$ & $\begin{array}{l}1.0 \\
1.0 \\
1.0 \\
1.0 \\
1.0\end{array}$ & $\begin{array}{l}2.0 \\
2.0 \\
2.0 \\
2.0 \\
2.0\end{array}$ & $\begin{array}{l}2.0 \\
2.0 \\
2.0 \\
2.0 \\
2.0\end{array}$ & $\begin{array}{l}6.0 \\
6.0 \\
6.0 \\
7.0 \\
7.0\end{array}$ & $\begin{array}{l}5.0 \\
5.0 \\
6.0 \\
6.0 \\
7.0\end{array}$ \\
\hline $\begin{array}{l}21 \\
22 \\
23 \\
24 \\
25\end{array}$ & $\begin{array}{l}16.0 \\
14.0 \\
14.0 \\
14.0 \\
14.0\end{array}$ & $\begin{array}{l}14.0 \\
14.0 \\
14.0 \\
14.0 \\
14.0\end{array}$ & $\begin{array}{l}7.0 \\
7.0 \\
7.0 \\
7.0 \\
6.0\end{array}$ & $\begin{array}{l}7.0 \\
7 . \mathrm{C} \\
7 . \mathrm{C} \\
6 . \mathrm{C} \\
6 . \mathrm{C}\end{array}$ & $\begin{array}{l}4.0 \\
6.0 \\
6.0 \\
4.0 \\
3.0\end{array}$ & $\begin{array}{l}4 . c \\
4.0 \\
4 . C \\
3.0 \\
2.0\end{array}$ & $\begin{array}{l}2.0 \\
3.0 \\
3.0 \\
3.0 \\
3.0\end{array}$ & $\begin{array}{l}1.0 \\
2.0 \\
3.0 \\
3.0 \\
3.0\end{array}$ & $\begin{array}{l}2.0 \\
2.0 \\
2.0 \\
2.0 \\
2.0\end{array}$ & $\begin{array}{l}2.0 \\
2.0 \\
2.0 \\
2.0 \\
2.0\end{array}$ & $\begin{array}{l}8.0 \\
9.0 \\
9.0 \\
9.0 \\
8.0\end{array}$ & $\begin{array}{l}7.0 \\
8.0 \\
9.0 \\
8.0 \\
8.0\end{array}$ \\
\hline $\begin{array}{l}26 \\
27 \\
28 \\
29 \\
30 \\
31\end{array}$ & $\begin{array}{l}14.0 \\
14.0 \\
14.0 \\
13.0 \\
13.0 \\
12.0\end{array}$ & $\begin{array}{l}14.0 \\
14.0 \\
13.0 \\
13.0 \\
12.0 \\
12.0\end{array}$ & $\begin{array}{l}6.0 \\
6.0 \\
6.0 \\
6.0 \\
5.0 \\
---\end{array}$ & $\begin{array}{l}6 . C \\
0 . C \\
6.0 \\
5.0 \\
4.0 \\
-.-\end{array}$ & $\begin{array}{l}2.0 \\
2.0 \\
2.0 \\
2.0 \\
2.0 \\
2.0\end{array}$ & $\begin{array}{l}2 . c \\
2.0 \\
2 . c \\
2.0 \\
2.0 \\
2 . c\end{array}$ & $\begin{array}{l}3.0 \\
3.0 \\
3.0 \\
4.0 \\
4.0 \\
6.0\end{array}$ & $\begin{array}{l}3.0 \\
3.0 \\
3.0 \\
3.0 \\
4.0 \\
4.0\end{array}$ & $\begin{array}{l}2.0 \\
2.0 \\
2.0 \\
2.0 \\
-\ldots \\
---\end{array}$ & $\begin{array}{l}2.0 \\
2.0 \\
2.0 \\
2.0 \\
--- \\
---\end{array}$ & $\begin{array}{r}8.0 \\
8.0 \\
9.0 \\
10.0 \\
12.0 \\
12.0\end{array}$ & $\begin{array}{r}8.0 \\
8.0 \\
8.0 \\
9.0 \\
10.0 \\
12.0\end{array}$ \\
\hline \multirow[t]{2}{*}{ MONTH } & $1 e .0$ & 12.0 & 12.0 & 4.0 & $6 . C$ & 2.0 & 6.0 & 0.0 & 6.0 & 2.0 & 12.0 & 2.0 \\
\hline & \multicolumn{2}{|c|}{ APRIL } & \multicolumn{2}{|c|}{ MAY } & \multicolumn{2}{|c|}{ JUNE } & \multicolumn{2}{|c|}{ JuL $r$} & \multicolumn{2}{|c|}{ AUGUST } & \multicolumn{2}{|c|}{ SEPTEMEER } \\
\hline CAY & $\operatorname{mAX}$ & $M 1 N$ & $\operatorname{MAX}$ & in & MAX & $\operatorname{MIN}$ & $\operatorname{mAX}$ & MIN & $\operatorname{MAx}$ & $M I N$ & $\operatorname{MAX}$ & MIN \\
\hline $\begin{array}{l}1 \\
2 \\
3 \\
4 \\
5\end{array}$ & $\begin{array}{l}\cdots \\
-- \\
-\cdots \\
--\end{array}$ & $\begin{array}{l}-- \\
-\cdots \\
--- \\
--\end{array}$ & $\begin{array}{l}13.0 \\
13.0 \\
14.0 \\
14.0 \\
14.0\end{array}$ & $\begin{array}{l}13.0 \\
13.0 \\
13.0 \\
14.0 \\
14.0\end{array}$ & \begin{tabular}{r}
15.0 \\
15.0 \\
\hdashline-0 \\
$\cdots$
\end{tabular} & $\begin{array}{r}15.0 \\
15.0 \\
0.0 \\
-0\end{array}$ & $\begin{array}{l}28.0 \\
29.0 \\
29.0 \\
28.0 \\
27.0\end{array}$ & $\begin{array}{l}28.0 \\
28.0 \\
28.0 \\
27.0 \\
27.0\end{array}$ & $\begin{array}{l}27.0 \\
27.0 \\
27.0 \\
27.0 \\
27.0\end{array}$ & $\begin{array}{l}27.0 \\
27.0 \\
27.0 \\
27.0 \\
27.0\end{array}$ & $\begin{array}{l}23.0 \\
23.0 \\
23.0 \\
22.0 \\
22.0\end{array}$ & $\begin{array}{l}23.0 \\
23.0 \\
22.0 \\
22.0 \\
22.0\end{array}$ \\
\hline $\begin{array}{r}6 \\
7 \\
8 \\
9 \\
10\end{array}$ & $\begin{array}{l}1 \overline{0.0} \\
10.0 \\
11.0 \\
11.0\end{array}$ & $\begin{array}{r}-1.0 \\
10.0 \\
10.0 \\
11.0\end{array}$ & $\begin{array}{l}14.0 \\
14.0 \\
14.0 \\
15.0 \\
15.0\end{array}$ & $\begin{array}{l}14.0 \\
14.0 \\
14.0 \\
14.0 \\
15.0\end{array}$ & $\begin{array}{l}-- \\
-\cdots \\
--\end{array}$ & $\begin{array}{l}--- \\
-\cdots \\
-\cdots \\
--\end{array}$ & $\begin{array}{l}27.0 \\
27.0 \\
27.0 \\
27.0 \\
27.0\end{array}$ & $\begin{array}{l}27.0 \\
27.0 \\
27.0 \\
27.0 \\
27.0\end{array}$ & $\begin{array}{l}27.0 \\
27.0 \\
27.0 \\
27.0 \\
27.0\end{array}$ & $\begin{array}{l}27.0 \\
27.0 \\
27.0 \\
27.0 \\
27.0\end{array}$ & $\begin{array}{l}22.0 \\
22.0 \\
22.0 \\
22.0 \\
22.0\end{array}$ & $\begin{array}{l}22.0 \\
22.0 \\
22.0 \\
22.0 \\
22.0\end{array}$ \\
\hline $\begin{array}{l}11 \\
12 \\
13 \\
14 \\
15\end{array}$ & $\begin{array}{l}11.0 \\
11.0 \\
12.0 \\
13.0 \\
13.0\end{array}$ & $\begin{array}{l}11.0 \\
11.0 \\
11.0 \\
12.0 \\
13.0\end{array}$ & $\begin{array}{l}15.0 \\
16.0 \\
16.0 \\
17.0 \\
17.0\end{array}$ & $\begin{array}{l}15.0 \\
15.0 \\
15 . \mathrm{C} \\
16.0 \\
17 . \mathrm{C}\end{array}$ & 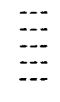 & 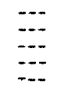 & $\begin{array}{l}27.0 \\
28.0 \\
28.0 \\
28.0 \\
28.0\end{array}$ & $\begin{array}{l}27.0 \\
27.0 \\
28.0 \\
28.0 \\
28.0\end{array}$ & $\begin{array}{l}27.0 \\
23.0 \\
22.0 \\
22.0 \\
22.0\end{array}$ & $\begin{array}{l}23.0 \\
22.0 \\
22.0 \\
22.0 \\
22.0\end{array}$ & $\begin{array}{l}22.0 \\
22.0 \\
21.0 \\
21.0 \\
20.0\end{array}$ & $\begin{array}{l}22.0 \\
21.0 \\
21.0 \\
20.0 \\
20.0\end{array}$ \\
\hline $\begin{array}{l}16 \\
17 \\
18 \\
19 \\
20\end{array}$ & $\begin{array}{l}13.0 \\
13.0 \\
13.0 \\
13.0 \\
14.0\end{array}$ & $\begin{array}{l}13.0 \\
13.0 \\
13.0 \\
13.0 \\
13.0\end{array}$ & $\begin{array}{l}17.0 \\
18.0 \\
18.0 \\
18.0 \\
15.0\end{array}$ & $\begin{array}{l}17.0 \\
17.0 \\
17.0 \\
15.0 \\
15.0\end{array}$ & $\begin{array}{c}\cdots \\
\cdots \\
\cdots 5 \\
\cdots\end{array}$ & 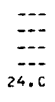 & $\begin{array}{l}28.0 \\
28.0 \\
29.0 \\
29.0 \\
28.0\end{array}$ & $\begin{array}{l}28.0 \\
28.0 \\
28.0 \\
28.0 \\
28.0\end{array}$ & $\begin{array}{l}22.0 \\
23.0 \\
24.0 \\
26.0 \\
26.0\end{array}$ & $\begin{array}{l}22.0 \\
22.0 \\
23.0 \\
24.0 \\
26.0\end{array}$ & $\begin{array}{l}21.0 \\
21.0 \\
21.0 \\
21.0 \\
21.0\end{array}$ & $\begin{array}{l}20.0 \\
21.0 \\
21.0 \\
21.0 \\
21.0\end{array}$ \\
\hline $\begin{array}{l}21 \\
22 \\
23 \\
24 \\
25\end{array}$ & $\begin{array}{l}14.0 \\
15.0 \\
15.0 \\
15.0 \\
15.0\end{array}$ & $\begin{array}{l}14.0 \\
14.0 \\
15.0 \\
15.0 \\
14.0\end{array}$ & $\begin{array}{l}15.0 \\
15.0 \\
15.0 \\
15.0 \\
15.0\end{array}$ & $\begin{array}{l}15.0 \\
15.0 \\
15.0 \\
15.0 \\
15.0\end{array}$ & $\begin{array}{l}25.0 \\
25.0 \\
20.0 \\
25.0 \\
27.0\end{array}$ & $\begin{array}{l}25.0 \\
25 . c \\
25 . c \\
26.0 \\
26.6\end{array}$ & $\begin{array}{l}28.0 \\
28.0 \\
28.0 \\
28.0 \\
28.0\end{array}$ & $\begin{array}{l}28.0 \\
28.0 \\
28.0 \\
28.0 \\
28.0\end{array}$ & $\begin{array}{l}27.0 \\
27.0 \\
27.0 \\
28.0 \\
28.0\end{array}$ & $\begin{array}{l}26.0 \\
27.0 \\
27.0 \\
27.0 \\
28.0\end{array}$ & $\begin{array}{l}21.0 \\
21.0 \\
22.0 \\
22.0 \\
22.0\end{array}$ & $\begin{array}{l}21 . \mathrm{c} \\
21.0 \\
21.0 \\
21 . \mathrm{c} \\
22 . \mathrm{c}\end{array}$ \\
\hline $\begin{array}{l}26 \\
27 \\
28 \\
29 \\
30 \\
21\end{array}$ & $\begin{array}{r}14.0 \\
14.0 \\
13.0 \\
13.0 \\
13.0 \\
\ldots-0\end{array}$ & $\begin{array}{l}14.0 \\
13.0 \\
13.0 \\
13.0 \\
13.0 \\
\ldots .0\end{array}$ & $\begin{array}{l}15.0 \\
15.0 \\
15.0 \\
15.0 \\
15.0 \\
15.0\end{array}$ & $\begin{array}{l}15 . c \\
15.0 \\
15.0 \\
15.0 \\
15.0 \\
15.0\end{array}$ & $\begin{array}{r}28.0 \\
28.0 \\
28.0 \\
28.0 \\
28.0 \\
-\ldots\end{array}$ & $\begin{array}{c}27.0 \\
28 . c \\
28.0 \\
27.0 \\
27.0 \\
\ldots . .\end{array}$ & $\begin{array}{l}28.0 \\
28.0 \\
28.0 \\
28.0 \\
27.0 \\
27.0\end{array}$ & $\begin{array}{l}28.0 \\
28.0 \\
28.0 \\
27.0 \\
27.0 \\
27.0\end{array}$ & $\begin{array}{l}28.0 \\
27.0 \\
26.0 \\
24.0 \\
24.0 \\
24.0\end{array}$ & $\begin{array}{l}27.0 \\
26.0 \\
24.0 \\
24.0 \\
24.0 \\
23.0\end{array}$ & $\begin{array}{c}22.0 \\
22.0 \\
20.0 \\
20.0 \\
20.0 \\
.-.\end{array}$ & $\begin{array}{l}22 . \mathrm{c} \\
20 . \mathrm{c} \\
20.0 \\
20 . \mathrm{c} \\
20.0 \\
. .-\end{array}$ \\
\hline MONTH & 15.0 & 5.0 & 18.0 & 13.0 & --- & --- & 29.0 & $27 . C$ & 29.0 & 22.0 & 23.0 & 20.0 \\
\hline
\end{tabular}


LOCATION. - - Lat $38^{\circ} 22^{\prime} 10^{\prime \prime}$, long $81^{\circ} 42^{\prime} 05^{\prime \prime}$, Kanawha County, temperature recorder at gaging station on 1 eft bank at old Lock 6, I mile upstream from Davis Creek, 1.5 miles downstream from Twomile Creek, 3.5 miles downstream from Elk
River, and at mile 54.3. AINAGE AREA, - -10,419 sq mi.

PERIOD OF RECORD. - - Water temperatures: March 1953 to September 1968.

EXTREMES. --1967-68:

Water temperatures: Maximum, $33.0^{\circ} \mathrm{C} \mathrm{July} 24 ;$ minimum, $1.0^{\circ} \mathrm{C}$ on several days in February.

period of record:

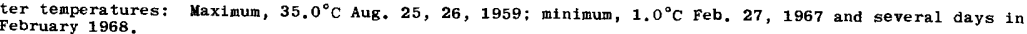
TEMPERATURE $\left.1^{\circ} \mathrm{C}\right)$ OF WATER, WATER YEAR OCTOBER 1967 TO SEPTEMBER 1968 (CONTINUOUS ETHYL ALCOHOL-ACTUATED THERMOGRAPH)

TOB

JANUARY

FEBRUARY

MARCF

DAY

1
2
4
1
1
1
15
15
17
19
20
21
22
24
25
26
27
29
30

MONTH

CAY

$\begin{array}{rr}\text { MAX } & M 1 N \\ 21.0 & 19.0 \\ 19.0 & 19.0 \\ 21.0 & 15.0 \\ 22.0 & 20.0 \\ 22.0 & 21.0 \\ 22.0 & 21.0 \\ 22.0 & 21.0 \\ 23.0 & 21.0 \\ 22.0 & 21.0 \\ 22.0 & 21.0 \\ 22.0 & 21.0 \\ 22.0 & 20.0 \\ 21.0 & 20.0 \\ 22.0 & 21.0 \\ 21.0 & 19.0 \\ 22.0 & 20.0 \\ 22.0 & 20.0 \\ 22.0 & 19.0 \\ 20.0 & 19.0 \\ 19.0 & 18.0 \\ 18.0 & 19.0 \\ 18.0 & 27.0 \\ 17.0 & 16.0 \\ 17.0 & 16.0 \\ 17.0 & 16.0 \\ 16.0 & 16.0 \\ 16.0 & 15.0 \\ 15.0 & 14.0 \\ 14.0 & 14.0 \\ 14.0 & 13.0 \\ 14.0 & 13.0 \\ 23.0 & 13.0 \\ & A P R 11 \\ & \\ M .0 & \\ 20\end{array}$

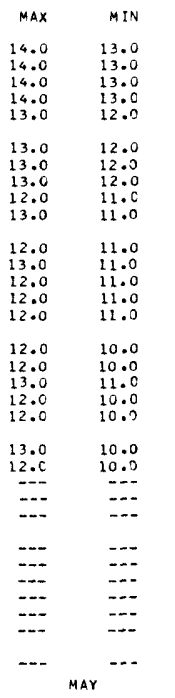

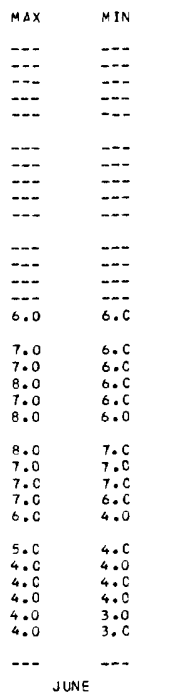

\begin{tabular}{ll} 
MAX & MIN \\
4.0 & 3.0 \\
4.0 & 3.0 \\
5.0 & 3.0 \\
5.0 & 3.0 \\
4.0 & 3.0 \\
3.0 & 2.0 \\
2.0 & 2.0 \\
-0.0 & -0.0 \\
\hline.- &..-
\end{tabular}

:

juer
MAX MIN

$\cdots$
$\cdots$
$\cdots$

...

$\cdots$

4.0

\section{--:}

3.0
3.0

3.0
4.0

$\begin{array}{ll}4.0 & 3.0 \\ 4.0 & 2.0\end{array}$

$\begin{array}{ll}4.0 & 3.0 \\ 4.0 & 2.0 \\ 3.0 & 2.0\end{array}$

3.0
3.0

2.0

$\begin{array}{lll}--. & -- & 4.0 \\ -\cdots & 3.0\end{array}$

$\begin{array}{lll}-- & -- & 3.0 \\ -- & -. & 4.0\end{array}$

1.0
1.0

1.0
1.0
1.0
1.0

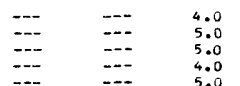

2.0
2.0
1.0
1.0
2.0

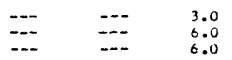

$\begin{array}{rl}6.0 & 2.0 \\ 6.0 & 2.0 \\ -0 & -0.0\end{array}$

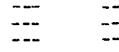

aUgusi

$\operatorname{MAX} M I N$

28.0

28.0
30.0

$30.0 \quad 28.0$

$29.0 \quad 27.0$

$\begin{array}{llll}14.0 & 13.0 & 30.0 & 28.0 \\ 14.0 & 14.0 & 29.0 & 28.0\end{array}$

$\begin{array}{llll}14.0 & 14.0 & 29.0 & 28.0 \\ 15.0 & 14.0 & 29.0 & 27.0\end{array}$

16.0

27.0

19.0

20.0
22.0

$16 . \mathrm{C}$

17.0
19.0

19.0
20.0

29.0
29.0
30.0

30.0
29.0

16.0
16.0

15.0

22.0

22,0

$$
\begin{aligned}
& 17.0 \\
& 19.0 \\
& 20.0 \\
& 19.0
\end{aligned}
$$

15.0

$15.0 \quad 23.0$

$16.0 \quad 23.0$

17.0

23.0
22.0
23.0

$22 . c$
23.0
$22 . c$

$22 . \mathrm{C}$
$22 . \mathrm{C}$
$22 . \mathrm{C}$

24.0

24.0
23.0
23.0

14.0
14.0

14.0
14.0
14.0

14.0
14.0

13.0

19.0

$\begin{array}{ll}19.0 & 18.0 \\ 18.0 & 18.0\end{array}$

$\begin{array}{lll}13.0 & 19.0 & 18.0 \\ 13.0 & 18.0 & 17.0 \\ 13.0 & 17.0 & 16.0\end{array}$

23.0
24.0

22.0
22.0

21.0
22.0

$22 . \mathrm{C}$

23.0
24.0

$\begin{array}{lll}14.0 & 16.0 & 15.0 \\ 16.0 & 16.0 & 16.0 \\ 16.0 & 16.0 & 16.0\end{array}$

17.0

$\begin{array}{lll}16.0 & 16.0 & 16.0 \\ 16.0 & 16.0 & 16.0 \\ 16.0 & 16.0 & 15 . \mathrm{C}\end{array}$

17.0

$25 . \mathrm{C}$
24.0
26.0

22.0
23.0

23.0
23.0
24.0

$\begin{array}{lll}16.0 & 16.0 & 27.0 \\ 16.0 & 14.0 & 27.0 \\ 14.0 & 14.0 & 27.0\end{array}$

$\begin{array}{cccc}16.0 & 15.0 & 14.0 & 14.0 \\ 16.0 & 14.0 & 14.0 & 14.0 \\ 14.0 & 13.0 & 14.0 & 14.0 \\ -.0 & -.0 & 14.0 & 13.0\end{array}$

$\begin{array}{rrrr}16.0 & 14.0 & 14.0 & 14.0 \\ 14.0 & 13.0 & 14.0 & 14.0 \\ -0 & -0.0 & 14.0 & 13.0\end{array}$

18.0

24.0
24.0
25.0
24.0

24.0

29.0
29.0
30.0
31.0

$27 . \mathrm{c}$

28.0
28.0

$28.0 \quad 27.0$

$\begin{array}{ll}28.0 & 26.0 \\ 28.0 & 26.0\end{array}$

$27 . \mathrm{C} \quad 28.0$

25.0

28.9
27.0

25.0

23.0

23.0
19.0

$\begin{array}{lll}24.0 & 19.0 & 19.0 \\ 27.0 & 20.0 & 19.0\end{array}$

28.0

19.0

18.0
18.0

31.0

28.0

22.0

19.0

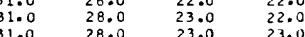

$\begin{array}{llll}31.0 & 28.0 & 23.0 & 23.0\end{array}$

30.0

26.0

23.0

32.0

29.0
29.0

26.0

24.0
25.0

$\begin{array}{ll}31.0 & 27.0 \\ 33.0 & 29.0\end{array}$

27.0
29.0
29.0

26.0
26.0
27.0

30.0

$28.0 \quad 31.0$

27.0

27.0
27.0

$\begin{array}{llll}30.0 & 28.0 & 28.0 & 27.0 \\ 27.0 & 27.0 & 26.0\end{array}$

$\begin{array}{llll}28.0 & 27.0 & 28.0 & 25.0 \\ 28.0 & 27.0 & 27.0 & 26.0\end{array}$

28.0

$27 . \mathrm{C}$

31.0

18.0

28.

$13 . \mathrm{C} \quad 33.0$ MAX MIA

$6.0 \quad 2.0$

$\begin{array}{ll}7.0 & 2.0 \\ 7.0 & 4.0 \\ 7.0 & 4.0\end{array}$

$6.0 \quad 4.0$

$8.0 \quad 4.0$

$\begin{array}{ll}7.0 & 5.0 \\ 7.0 & t .0 \\ 7.0 & 6.0\end{array}$

$8.0 \quad 7.0$

$7.0 \quad 6.0$

$6.0 \quad 4.0$

$6.0 \quad 4.0$

$5.0 \quad 4.0$

$\begin{array}{ll}5.0 & 4.0 \\ 6.0 & 5.0\end{array}$

$7.0 \quad 6.0$

$8.0 \quad T .0$

$\begin{array}{rr}9.0 & 8.0 \\ 10.0 & 9.0\end{array}$

$\begin{array}{ll}9.0 & 9.6 \\ 9.0 & 9 . \mathrm{C}\end{array}$

$9.0 \quad 9.0$

$\begin{array}{ll}10.0 & 9.0 \\ 10.0 & 9.0\end{array}$

$12.0 \quad 5.0$

$\begin{array}{ll}11.0 & 10.0 \\ 12.0 & 11.0\end{array}$

$12.0 \quad 2.0$

SEPTEMBER

MAX MIN

$\begin{array}{ll}27.0 & 25.0 \\ 28.0 & 27.0\end{array}$

$28.0 \quad 27 . \mathrm{C}$

25.0

$26.0 \quad 23.0$

$27.0 \quad 25.0$

$\begin{array}{ll}26.0 & 23.0 \\ 26.5 & 23.0\end{array}$

$4.0 \quad 22.0$

$23.0 \quad 22.0$

$22.0 \quad 2 \mathrm{C.0}$

$23.0 \quad 21.0$

$21.0 \quad 15$.

$22.0 \quad 20 . \mathrm{C}$

19.0

$\begin{array}{ll}20.0 & 18.0 \\ 21.0 & 18.0\end{array}$

$21.0 \quad 15.0$

$24.0 \quad 15.0$

$\begin{array}{ll}23.0 & 21.0 \\ 23.0 & 20.0\end{array}$

20.

$22.0 \quad 15 . \mathrm{C}$

$19.0 \quad 17.0$

$\begin{array}{ll}19.0 & 17.0 \\ 19.0 & \end{array}$

.

28.0

16.0 
03201300 KANAWHA RIVER AT WINFIELD DAM, AT WINFIELD, W. VA.

LOCATION...Lat $38^{\circ} 31^{\circ} 32^{\prime}$, long $81^{\circ} 54^{\prime} 40^{\prime}$, Putnam County, on left bank at intake line to ohio River Va11ey water Sanitation Comission (ORSANCO) monitor station at Kanawha Valley Power Co. intake at Winfield Dam, 1 mile downstream from infield Toll Bridge.

DRAINAGE AREA.--11, 809 sq mix.

PERIOD OF RECORD... Chemical analyses: October 1956 to September 1968.

Water temperatures: October 1956 to September 1968.

EXTREMES. - - 1967-68:

Specific conductance: Maximum dally, 695 micromhos July 15; minimum daily, 120 micromhos Mar. 15

water temperatures: Maximum, $31.0^{\circ} \mathrm{C}$ July $21-30 ;$ minimum, $2.0^{\circ} \mathrm{C} \mathrm{Feb,20}$

Period of record:

Speclfic conductance: Haximum dally, 2,700 micromhos Apr, 21, 1961; min mum da1ly, 77 micromhos Jan, $31,1957$. Water temperatures: Kaximum, $33.0^{\circ} \mathrm{C}$ July 24, 1964; minimum, freezing point Feb. 14, 1958, Mar. 12, 1960.

REKARKS. - - Dafly samples were collected at this station and samples were selected for analysis on the following basis: (1) Maximum daily specific conductance for each month, (2) minimum daily specific conductance for each month, and (3) median daly specific conductance for each month. Samples for iron and manganese were filtered clear when collected. No discharge records available.

CHEMICAL ANALYSES IN MILLIGRAMS PER LITER, WATER YEAR ULTOBER 1967 TO SEPTEMBER 1968

\begin{tabular}{|c|c|c|c|c|c|c|c|c|}
\hline DATE & TIME & $\begin{array}{l}\text { IRON } \\
\text { (FE) }\end{array}$ & $\begin{array}{l}\text { MAN- } \\
\text { GANESE } \\
\text { (MN) }\end{array}$ & $\begin{array}{l}\text { BICAR - } \\
\text { BONATE } \\
\text { (HCO3) }\end{array}$ & $\begin{array}{l}\text { CAR- } \\
\text { RONATE } \\
\text { (CO3) }\end{array}$ & $\begin{array}{l}\text { SULFATE } \\
\text { (SO4) }\end{array}$ & $\begin{array}{l}\text { CHLO- } \\
\text { RIDE } \\
\text { (CL) }\end{array}$ & $\begin{array}{l}\text { FLIIO } \\
\text { R[OE } \\
\text { IF] }\end{array}$ \\
\hline \multicolumn{9}{|l|}{ oct. } \\
\hline & 0700 & .19 & .13 & 82 & c & 58 & 91 & -1 \\
\hline $13 .$. & 0700 & .14 & .10 & 94 & 0 & 33 & 40 & .2 \\
\hline $30 .$. & 0800 & .23 & .04 & ค0 & c & 16 & 30 & .2 \\
\hline \multicolumn{9}{|l|}{ Nov. } \\
\hline $01 \ldots$ & 0800 & .21 & .06 & 44 & 0 & 39 & 27 & $\cdot 2$ \\
\hline $10 \ldots$ & 0800 & .23 & .08 & 28 & c & 57 & 49 & .2 \\
\hline $25 \ldots$ & 3800 & .30 & .10 & 22 & 0 & 60 & 95 & .4 \\
\hline \multicolumn{9}{|l|}{ DEC. } \\
\hline $06 \ldots$ & 0800 & .37 & .20 & 26 & 0 & 24 & 11 & 1 \\
\hline $12 \ldots$ & & & .12 & 23 & 0 & 30 & 16 & 1 \\
\hline $21 \ldots$ & 0800 & .25 & .15 & 29 & 0 & 50 & & $\cdot 2$ \\
\hline \multicolumn{9}{|l|}{ JAN. } \\
\hline $\begin{array}{l}05 \ldots \\
11 \ldots\end{array}$ & 0800 & .16 & .14 & $\begin{array}{l}42 \\
34\end{array}$ & 0 & $\begin{array}{l}52 \\
43\end{array}$ & $\begin{array}{l}38 \\
19\end{array}$ & .0 \\
\hline $\begin{array}{l}11 \ldots \\
25 \ldots\end{array}$ & $\begin{array}{l}0800 \\
0800\end{array}$ & .25 & $\begin{array}{l}.11 \\
.12\end{array}$ & $\begin{array}{l}34 \\
32\end{array}$ & $\begin{array}{l}0 \\
0\end{array}$ & $\begin{array}{l}43 \\
31\end{array}$ & $\begin{array}{r}19 \\
9.0\end{array}$ & .0 \\
\hline \multicolumn{9}{|l|}{ FEB. } \\
\hline $02 \ldots$ & OBOO & .62 & .11 & 27 & 0 & 25 & 8.0 & .0 \\
\hline $15 \ldots$ & 0800 & .19 & .09 & 34 & 0 & 42 & 29 & -2 \\
\hline $\begin{array}{l}29 . . . \\
\text { MAR. }\end{array}$ & $O B D O$ & .23 & .17 & 40 & 0 & 64 & $4 B$ & .2 \\
\hline $06 . .$. & 0800 & .35 & .16 & 70 & 0 & 79 & 65 & .2 \\
\hline $15 \ldots$ & 9600 & .21 & .09 & 24 & 0 & 22 & 6.0 & .1 \\
\hline $30 \ldots$ & 0800 & .46 & .11 & 21 & 0 & 39 & 16 & .1 \\
\hline \multicolumn{9}{|l|}{$A P R$} \\
\hline $\begin{array}{l}07 . . . \\
16 . . .\end{array}$ & $\begin{array}{l}0800 \\
0800\end{array}$ & .27 & .05 & $\begin{array}{l}28 \\
34\end{array}$ & $\begin{array}{l}0 \\
0\end{array}$ & $\begin{array}{l}28 \\
45\end{array}$ & $26^{9.0}$ & $\frac{1}{1}$ \\
\hline $\begin{array}{l}16 \ldots \\
26 . \ldots\end{array}$ & $\begin{array}{l}0800 \\
0800\end{array}$ & $\begin{array}{l}.22 \\
.13\end{array}$ & $\begin{array}{l}.14 \\
.09\end{array}$ & $\begin{array}{l}34 \\
37\end{array}$ & 0 & 53 & 44 & .12 \\
\hline \multicolumn{9}{|l|}{ MAY } \\
\hline $08 \ldots$ & 0800 & .24 & .08 & 32 & 0 & 33 & 30 & .3 \\
\hline $16 \ldots$ & 0800 & .27 & .09 & 64 & 0 & 47 & 56 & .4 \\
\hline $29 \ldots$ & OBOO & .40 & .09 & 26 & 0 & 24 & 9.0 & .3 \\
\hline \multicolumn{9}{|l|}{ JUNE } \\
\hline $\mathrm{c} 2 \ldots$ & 0800 & .46 & .12 & 34 & 0 & 21 & 7.0 & .1 \\
\hline $16 \ldots$ & 0730 & .22 & .10 & 44 & 0 & 49 & 34 & .2 \\
\hline $30 \ldots$ & 0800 & .23 & .13 & 32 & 0 & 64 & 84 & .2 \\
\hline \multirow{2}{*}{\multicolumn{9}{|c|}{ JULY }} \\
\hline $02 \ldots$ & & .12 & .11 & 31 & 0 & 70 & 64 & 2 \\
\hline $15 \ldots$ & 0730 & .24 & .16 & $3 h$ & 0 & 94 & 112 & 4 \\
\hline $31 \ldots$ & 0800 & .07 & .08 & 46 & 0 & 94 & 78 & .7 \\
\hline \multicolumn{9}{|l|}{ AUG. } \\
\hline $05 \ldots$ & 0800 & .22 & .14 & $\begin{array}{l}38 \\
14\end{array}$ & 0 & 92 & 74 & .3 \\
\hline $\begin{array}{l}16 \ldots \\
27 . . .\end{array}$ & $\begin{array}{l}0800 \\
0800\end{array}$ & .27 & .14 & 24 & 0 & $\begin{array}{l}39 \\
57\end{array}$ & 18 & .1 \\
\hline \multicolumn{9}{|l|}{ SEPT. } \\
\hline $01 \ldots$ & 0800 & .25 & .14 & 30 & 0 & 75 & 60 & .2 \\
\hline $05 \ldots$ & 0800 & .26 & .25 & 22 & 0 & 90 & 110 & 3 \\
\hline $26 . \ldots$ & OROO & .27 & .29 & 20 & 0 & 95 & 77 & \\
\hline
\end{tabular}


03201300 KANATHA RIVER AT WINFIELD DAM, AT WINFIELD, W. VA.--Cont1nued

CMEMICAL ANALYSES IN MILLIGRAMS PER LITER, WATER YEAR OCTOBER 1967 TO SEPTEMBER 1968

\begin{tabular}{|c|c|c|c|c|c|c|c|}
\hline DATE & $\begin{array}{l}\text { NITRATE } \\
\text { (NO3) }\end{array}$ & $\begin{array}{l}\text { TDTAL } \\
\text { PHOS- } \\
\text { PHORUS } \\
\text { (PO4) }\end{array}$ & $\begin{array}{l}\text { OIS- } \\
\text { SOLVED } \\
\text { SOLIDS } \\
\text { IRESI - } \\
\text { DUE AT } \\
\text { IBO CI }\end{array}$ & $\begin{array}{l}\text { MARO- } \\
\text { NESS } \\
(C A, M G)\end{array}$ & $\begin{array}{l}\text { NON- } \\
\text { CAR- } \\
\text { BONATE } \\
\text { HARD- } \\
\text { NESS }\end{array}$ & $\begin{array}{l}\text { SPECI- } \\
\text { FIC } \\
\text { COND- } \\
\text { UCTANCE } \\
\text { (MICRO- } \\
\text { MHOS) }\end{array}$ & $\mathrm{PH}$ \\
\hline $\begin{array}{r}O C T . \\
01 \ldots \\
13 \ldots \\
30 \ldots\end{array}$ & $\begin{array}{l}7.8 \\
9.4 \\
3.2\end{array}$ & $\begin{array}{l}.24 \\
.27 \\
.12\end{array}$ & $\begin{array}{l}322 \\
216 \\
188\end{array}$ & $\begin{array}{r}128 \\
94 \\
78\end{array}$ & $\begin{array}{l}61 \\
25 \\
12\end{array}$ & $\begin{array}{l}515 \\
329 \\
247\end{array}$ & $\begin{array}{l}7.5 \\
7.6 \\
7.8\end{array}$ \\
\hline $\begin{array}{l}\text { NOV. } \\
01 \ldots \ldots \\
10 \ldots \\
25 \ldots \ldots\end{array}$ & $\begin{array}{l}5.8 \\
8.0 \\
12\end{array}$ & $\begin{array}{l}.10 \\
.12 \\
.13\end{array}$ & $\begin{array}{l}142 \\
218 \\
338\end{array}$ & $\begin{array}{r}83 \\
100 \\
142\end{array}$ & $\begin{array}{r}47 \\
77 \\
124\end{array}$ & $\begin{array}{l}255 \\
365 \\
530\end{array}$ & $\begin{array}{l}7.1 \\
6.4 \\
7.2\end{array}$ \\
\hline $\begin{array}{l}\text { OEC. } \\
06 \ldots \\
12 \ldots \\
21 \ldots\end{array}$ & $\begin{array}{l}5.2 \\
4.8 \\
6.7\end{array}$ & $\begin{array}{l}.10 \\
.08 \\
.51\end{array}$ & $\begin{array}{r}80 \\
86 \\
182\end{array}$ & $\begin{array}{l}50 \\
5 t \\
90\end{array}$ & $\begin{array}{l}28 \\
33 \\
67\end{array}$ & $\begin{array}{l}144 \\
181 \\
315\end{array}$ & $\begin{array}{l}6.5 \\
6.5 \\
6.7\end{array}$ \\
\hline $\begin{array}{l}\text { JAN. } \\
05 \ldots \\
11 \ldots \\
25 \ldots \\
\text { FEB. }\end{array}$ & $\begin{array}{l}5.0 \\
5.2 \\
3.6\end{array}$ & $\begin{array}{l}.15 \\
.23 \\
.10\end{array}$ & $\begin{array}{l}192 \\
154 \\
104\end{array}$ & $\begin{array}{l}94 \\
67 \\
56\end{array}$ & $\begin{array}{l}60 \\
39 \\
30\end{array}$ & $\begin{array}{l}317 \\
277 \\
161\end{array}$ & $\begin{array}{l}7.1 \\
7.0 \\
7.4\end{array}$ \\
\hline $\begin{array}{l}02 \ldots \\
15 \ldots \\
29 \ldots \\
\text { MAR. }\end{array}$ & $\begin{array}{l}3.8 \\
6.6 \\
10\end{array}$ & $\begin{array}{l}.10 \\
.22 \\
.20\end{array}$ & $\begin{array}{r}72 \\
150 \\
218\end{array}$ & $\begin{array}{r}51 \\
84 \\
115\end{array}$ & $\begin{array}{l}29 \\
54 \\
82\end{array}$ & $\begin{array}{l}131 \\
268 \\
404\end{array}$ & $\begin{array}{l}6.8 \\
7.8 \\
7.6\end{array}$ \\
\hline $\begin{array}{r}06 \ldots \\
15 \ldots \\
30 \ldots \\
A P H .\end{array}$ & $\begin{array}{l}.1 \\
3.4 \\
4.7\end{array}$ & $\begin{array}{r}.31 \\
.18 \\
.39\end{array}$ & $\begin{array}{r}292 \\
68 \\
126\end{array}$ & $\begin{array}{r}134 \\
46 \\
60\end{array}$ & $\begin{array}{l}76 \\
26 \\
43\end{array}$ & $\begin{array}{l}493 \\
120 \\
190\end{array}$ & $\begin{array}{l}6.9 \\
7.6 \\
7.5\end{array}$ \\
\hline $\begin{array}{l}07 \ldots \\
16 \ldots \\
26 \ldots \\
\text { MAY }\end{array}$ & $\begin{array}{l}2.0 \\
3.4 \\
6.2\end{array}$ & $\begin{array}{l}.08 \\
.16 \\
.13\end{array}$ & $\begin{array}{r}92 \\
164 \\
220\end{array}$ & $\begin{array}{r}50 \\
85 \\
101\end{array}$ & $\begin{array}{l}27 \\
57 \\
70\end{array}$ & $\begin{array}{l}146 \\
248 \\
344\end{array}$ & $\begin{array}{l}7.1 \\
7.5 \\
7.4\end{array}$ \\
\hline $\begin{array}{l}08 \ldots . . \\
16 \ldots \\
29 \ldots\end{array}$ & $\begin{array}{l}7.1 \\
2.8 \\
3.2\end{array}$ & $\begin{array}{l}.14 \\
.28 \\
.15\end{array}$ & $\begin{array}{r}165 \\
242 \\
92\end{array}$ & $\begin{array}{r}76 \\
102 \\
45\end{array}$ & $\begin{array}{l}50 \\
50 \\
24\end{array}$ & $\begin{array}{l}246 \\
404 \\
134\end{array}$ & $\begin{array}{l}6.9 \\
7.9 \\
7.1\end{array}$ \\
\hline $\begin{array}{l}\text { JUNE } \\
02 \ldots \\
16 \ldots \\
30 \ldots \\
\text { JULY }\end{array}$ & $\begin{array}{l}4.4 \\
12\end{array}$ & $\begin{array}{l}.00 \\
.02 \\
.21\end{array}$ & $\begin{array}{r}88 \\
192 \\
280\end{array}$ & $\begin{array}{r}50 \\
100 \\
118\end{array}$ & $\begin{array}{l}22 \\
64 \\
92\end{array}$ & $\begin{array}{l}132 \\
314 \\
444\end{array}$ & $\begin{array}{l}7.0 \\
6.8 \\
6.4\end{array}$ \\
\hline $\begin{array}{l}02 \ldots \\
15 \ldots \\
31 \ldots\end{array}$ & $\begin{array}{l}11 \\
17 \\
12\end{array}$ & $\begin{array}{l}.36 \\
.38 \\
.23\end{array}$ & $\begin{array}{l}264 \\
406 \\
330\end{array}$ & $\begin{array}{l}123 \\
192 \\
172\end{array}$ & $\begin{array}{r}98 \\
1 E 3 \\
135\end{array}$ & $\begin{array}{l}450 \\
695 \\
581\end{array}$ & $\begin{array}{l}6.8 \\
6.7 \\
6.3\end{array}$ \\
\hline $\begin{array}{l}\triangle U G . \\
05 \ldots \\
16 \ldots \\
27 \ldots\end{array}$ & $\begin{array}{l}14 \\
6.2 \\
9.2\end{array}$ & $\begin{array}{l}.39 \\
.22 \\
.21\end{array}$ & $\begin{array}{l}330 \\
110 \\
184\end{array}$ & $\begin{array}{r}156 \\
56 \\
86\end{array}$ & $\begin{array}{r}125 \\
44 \\
66\end{array}$ & $\begin{array}{l}543 \\
184 \\
308\end{array}$ & $\begin{array}{l}6.4 \\
6.5 \\
6.3\end{array}$ \\
\hline $\begin{array}{c}\text { SEPT. } \\
01 \ldots \\
05 \ldots \\
26 \ldots\end{array}$ & $\begin{array}{l}8.7 \\
17 \\
14\end{array}$ & $\begin{array}{l}.14 \\
.25 \\
.44\end{array}$ & $\begin{array}{l}280 \\
389 \\
322\end{array}$ & $\begin{array}{l}122 \\
179 \\
155\end{array}$ & $\begin{array}{r}98 \\
1 \notin 1 \\
139\end{array}$ & $\begin{array}{l}435 \\
637 \\
544\end{array}$ & $\begin{array}{l}6.3 \\
6.6 \\
6.6\end{array}$ \\
\hline
\end{tabular}
SPECIFIC CONDUCTANCE (MICROMHOS AT $25^{\circ} \mathrm{C}$ ), WATER YEAR OCTOBER 1967 TO SEPTEMBER 1968
(DNCE-DAILY MEASUREMENT USUALLY BETWEEN O7O0 AND 0800 )

\begin{tabular}{|c|c|c|c|c|c|c|c|c|c|c|c|c|}
\hline $\begin{array}{l}1 \ldots \ldots \\
2 \ldots \ldots \\
3 \ldots \ldots \\
4 \ldots \ldots \\
5 \ldots \ldots\end{array}$ & $\begin{array}{l}515 \\
326 \\
281 \\
290 \\
302\end{array}$ & $\begin{array}{l}255 \\
276 \\
283 \\
304 \\
320\end{array}$ & $\begin{array}{l}283 \\
192 \\
197 \\
164 \\
154\end{array}$ & $\begin{array}{l}182 \\
180 \\
207 \\
247 \\
317\end{array}$ & $\begin{array}{l}144 \\
131 \\
138 \\
144 \\
152\end{array}$ & $\begin{array}{l}442 \\
442 \\
468 \\
424 \\
446\end{array}$ & $\begin{array}{l}230 \\
276 \\
180 \\
193 \\
170\end{array}$ & $\begin{array}{l}282 \\
199 \\
192 \\
197 \\
230\end{array}$ & $\begin{array}{l}134 \\
132 \\
139 \\
149 \\
168\end{array}$ & $\begin{array}{l}467 \\
450 \\
463 \\
474 \\
473\end{array}$ & $\begin{array}{l}539 \\
536 \\
515 \\
504 \\
543\end{array}$ & $\begin{array}{l}435 \\
464 \\
517 \\
552 \\
637\end{array}$ \\
\hline $\begin{array}{l}16 \ldots \ldots \\
17 \ldots \ldots \\
18 \ldots \ldots \\
19 \ldots \ldots \\
20 \ldots \ldots\end{array}$ & $\begin{array}{l}374 \\
379 \\
366 \\
374 \\
406\end{array}$ & $\begin{array}{l}361 \\
383 \\
409 \\
392 \\
431\end{array}$ & $\begin{array}{l}179 \\
190 \\
196 \\
209 \\
248\end{array}$ & $\begin{array}{l}276 \\
256 \\
258 \\
249 \\
280\end{array}$ & $\begin{array}{l}302 \\
326 \\
335 \\
354 \\
358\end{array}$ & $\begin{array}{l}122 \\
157 \\
153 \\
134 \\
149\end{array}$ & $\begin{array}{l}248 \\
290 \\
290 \\
261 \\
261\end{array}$ & $\begin{array}{l}404 \\
314 \\
266 \\
260 \\
270\end{array}$ & $\begin{array}{l}314 \\
319 \\
334 \\
357 \\
353\end{array}$ & $\begin{array}{l}682 \\
668 \\
661 \\
619 \\
566\end{array}$ & $\begin{array}{l}184 \\
206 \\
251 \\
269 \\
280\end{array}$ & $\begin{array}{l}539 \\
539 \\
533 \\
521 \\
553\end{array}$ \\
\hline $\begin{array}{l}26 \ldots \ldots \\
27 \ldots \ldots \\
28 \ldots \ldots \\
29 \ldots \ldots \\
30 \ldots \ldots \\
31 \ldots \ldots \\
\end{array}$ & $\begin{array}{l}317 \\
315 \\
294 \\
255 \\
247 \\
257\end{array}$ & $\begin{array}{l}361 \\
320 \\
283 \\
264 \\
257 \\
--\end{array}$ & $\begin{array}{l}176 \\
197 \\
198 \\
204 \\
196 \\
169\end{array}$ & $\begin{array}{l}165 \\
178 \\
184 \\
187 \\
215 \\
194\end{array}$ & $\begin{array}{r}335 \\
342 \\
385 \\
404 \\
=- \\
=-\end{array}$ & $\begin{array}{l}167 \\
170 \\
178 \\
204 \\
190 \\
199\end{array}$ & $\begin{array}{l}344 \\
259 \\
234 \\
252 \\
279 \\
--\end{array}$ & $\begin{array}{l}191 \\
175 \\
137 \\
134 \\
144 \\
179\end{array}$ & $\begin{array}{l}370 \\
388 \\
377 \\
393 \\
444 \\
--\end{array}$ & $\begin{array}{l}530 \\
605 \\
637 \\
628 \\
640 \\
581\end{array}$ & $\begin{array}{l}305 \\
308 \\
315 \\
345 \\
371 \\
370\end{array}$ & $\begin{array}{l}544 \\
557 \\
544 \\
562 \\
593 \\
--\end{array}$ \\
\hline AVERAGE & 334 & 369 & 190 & 225 & 262 & 263 & 237 & 243 & 290 & 573 & 347 & 546 \\
\hline
\end{tabular}


TEMPERATURE ( ${ }^{\circ} \mathrm{C}$ ) OF WATER, WATER YEAR DCTOBER 1967 TO SEPTEMBER 1968 (ONCE-DAILY MEASUREMENT USUALLY BETWEEN OTOO AND OBOO)

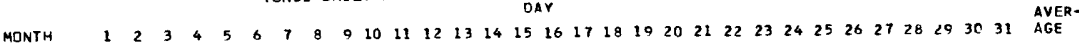
OCTOBER.. $23 \begin{array}{llllllllllllllllllllllllllllll}23 & 22 & 21 & 21 & 21 & 20 & 21 & 21 & 21 & 21 & 21 & 21 & 21 & 21 & 21 & 21 & 21 & 21 & 21 & 21 & 18 & 18 & 18 & 18 & 18 & 18 & 18 & 17 & 16 & 16\end{array}$

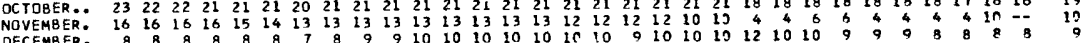
$\begin{array}{llllllllllllllllllllllllllllllllllllll}\text { JANUARY.. } & 8 & 8 & 7 & 6 & 6 & 5 & 4 & 4 & 4 & 4 & 4 & -- & - & 4 & 4 & 4 & 4 & 4 & 3 & 3 & 3 & 4 & 4 & 4 & 3 & 3 & 3 & 3 & 3 & 4 & 6 & 4\end{array}$

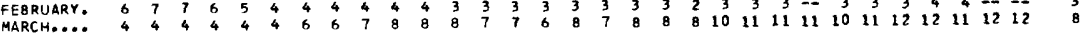

$1212101213131313131616161616171718171818191818181818-2 \quad 15$

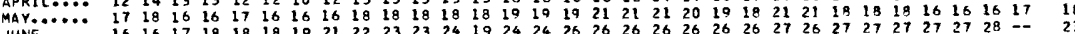

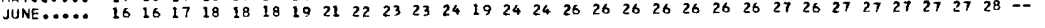

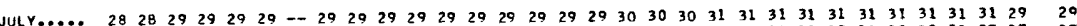
$\begin{array}{llllllllllllllllllllll}27 & 24 & 24 & 24 & 23 & 23 & 23 & 23 & 24 & 27 & 27 & 27 & 28 & 29 & 29 & 28 & 29 & 28 & 28 & 27 & 27 & 27\end{array}$ RACCOON CREEK BAS IN

03202000 RACCOON CREEK AT ADAMSVILLE, OHIO

LOCATION. --Lat $38^{\circ} 52^{\prime} 31^{\prime \prime}$, long $82^{\circ} 21^{\prime} 18^{\prime \prime}$, on line between secs, 25 and 26, T.6 N., R.16 W., Gall1a County, at gag1ng station at bridge on 'U.S. Highway 35 ' at Adamsville, 1.3 miles downstream from Indian Creek.

DRAINAGE AREA. $-\mathbf{- 5 8 5} \mathrm{sq} \mathrm{mi}$.

PERIOD OF RECORD.--Chemical analyses: October 1951 to September 1954, October 1964 to September 1968 Water temperatures: October 1951 to September 1954 , October 1964 to September 1968.

EXTREMES, - -1967-68:

Specific conductance: Maximum dally, 2,340 micromhos Nov, 2; minimum daily, 122 micromhos Hay 24

Water temperatures: Maximum, $27.0^{\circ} \mathrm{C}$ Aug. 24 ; minimum, freezing point Dec. 29, Jan. 2-15, 23, 24, 26, Feb. 28,

period of record:

Specific conductance: Maximun daily, 2,930 micromhos Nov, 20, 1964; minimum daily, 115 micromhos Mar. 23, 1952 .

water temperatures: Maximum, $29.0^{\circ} \mathrm{C}$ June 16, 1952; minimum, freezing point on many days during winter periods.

REMARKS.--Samples for 1 ron and manganese filtered clear when collected. Daily samples were collected at this station and samples were selected for analysis on the following basis: (1) Maximum daily specific conductance for each month, (2) minimum daily specific conductance for each month, (3) median daily specific conductance for each month, and (4) specific sample to further define the quality of water. Interruptions in the record of the conconductance and temperature are published here as a supplement to the data from the continuous recorder.

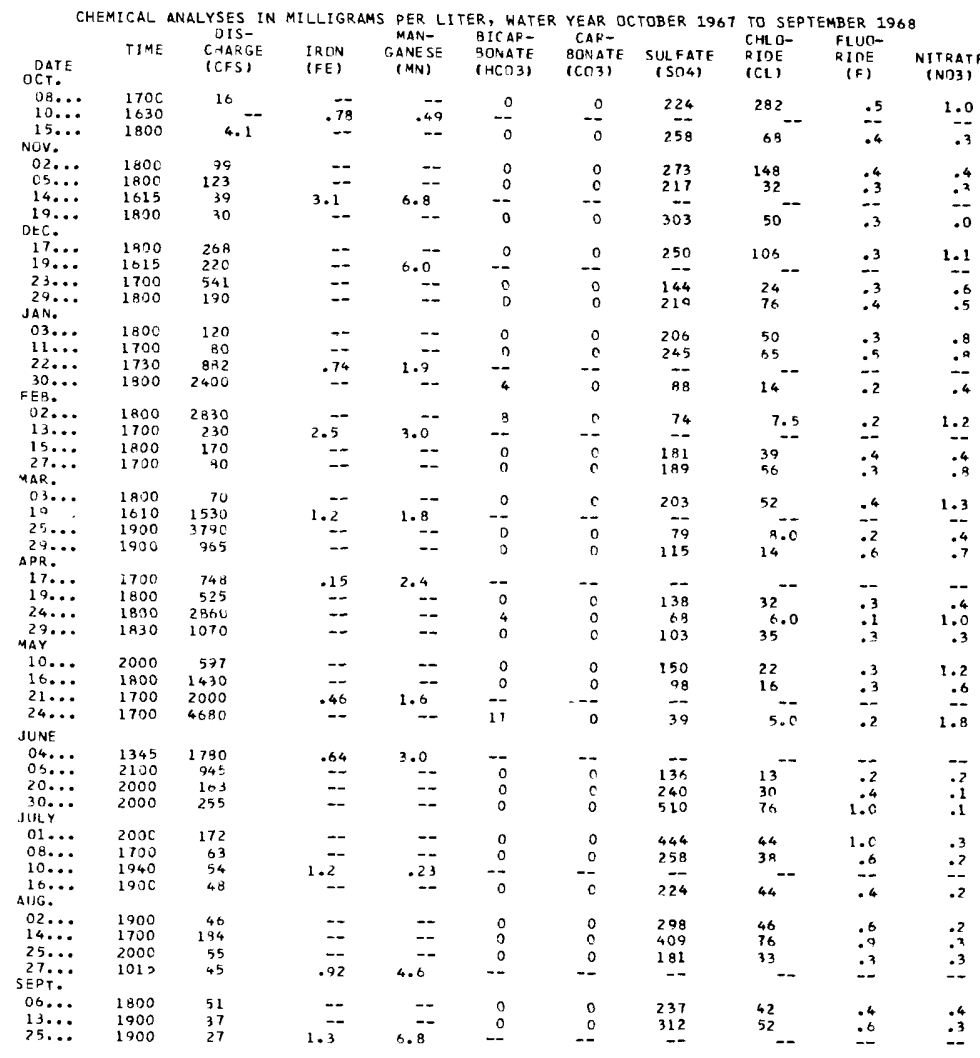


03202000 RACCON CREEK AT ADAHSVILLE, OHIO--COntinued

CHEMICAL ANALYSES IN MILLIGRAMS PER LITER, WATER YEAR OCTOBER 1967 TO SEPTEMBER 1968

\begin{tabular}{|c|c|c|c|c|c|c|c|c|c|c|}
\hline DATE & $\begin{array}{l}\text { TOTAL } \\
\text { PHOS- } \\
\text { PHDRUS } \\
\text { I POAI }\end{array}$ & $\begin{array}{l}\text { DIS- } \\
\text { SULVED } \\
\text { SULIDS } \\
\text { (XESI- } \\
\text { DUE AT } \\
\text { IPO C) }\end{array}$ & $\begin{array}{l}\text { HARO- } \\
\text { NESS } \\
\text { (CA.MG ) }\end{array}$ & $\begin{array}{l}\text { NON- } \\
\text { CAR- } \\
\text { BONATE } \\
\text { HARD- } \\
\text { NESS }\end{array}$ & $\begin{array}{c}\text { TOT AL } \\
\text { ACIOI IY } \\
\text { AS } \\
H_{+}\end{array}$ & $\begin{array}{l}\text { SPECI- } \\
\text { FIC } \\
\text { COND- } \\
\text { UCTANCE } \\
\text { IMICRO- } \\
\text { MHOSI }\end{array}$ & $\mathrm{PH}$ & $\begin{array}{l}\text { TEMP- } \\
\text { ERATURE } \\
\text { (DEG C) }\end{array}$ & $\begin{array}{l}\text { DISS- } \\
\text { OLVEn } \\
\text { OXY'BEN }\end{array}$ & $\begin{array}{l}\text { PEP- } \\
\text { CENT } \\
\text { SATUR- } \\
\text { ATICN }\end{array}$ \\
\hline $10 \ldots$ & $=$ & 808 & 238 & $\begin{array}{r}238 \\
--\end{array}$ & 1.0 & 1390 & 3.8 & 17 & 6.0 & $\overline{60}$ \\
\hline $15 \ldots$ & -- & 510 & 208 & 208 & .8 & 780 & -- & 14 & - & - \\
\hline \multicolumn{11}{|l|}{ Nov. } \\
\hline $\begin{array}{l}02 \ldots \\
05 \ldots\end{array}$ & $\begin{array}{l}.16 \\
.20\end{array}$ & $\begin{array}{l}654 \\
378\end{array}$ & $\begin{array}{l}226 \\
172\end{array}$ & $\begin{array}{l}226 \\
172\end{array}$ & $\begin{array}{l}1.4 \\
1.0\end{array}$ & $\begin{array}{r}1060 \\
613\end{array}$ & $\begin{array}{l}3.8 \\
3.8\end{array}$ & 11 & $=$ & $=$ \\
\hline $14 \ldots$ & -- & 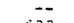 & $=$ & -- & -- & -- & $\cdots$ & -- & 10.0 & 83 \\
\hline $\begin{array}{c}13 \ldots \\
D E C .\end{array}$ & .11 & 322 & 214 & 214 & 1.6 & 858 & 3.5 & 6 & -- & -- \\
\hline $17 \ldots$ & .06 & 518 & 225 & 225 & 1.2 & 900 & 3.9 & 3 & - & -- \\
\hline $19 \ldots$ & -- & - & -- & -- & - & -- & -- & -- & 12.0 & 92 \\
\hline $\begin{array}{l}23 \ldots \\
29 . .\end{array}$ & 1.6 & $\begin{array}{l}246 \\
410\end{array}$ & 140 & 140 & .5 & 436 & $4 \cdot 4$ & 4 & - & $=$ \\
\hline \multicolumn{11}{|l|}{ JAN. } \\
\hline $\begin{array}{l}03 \ldots \\
11 \ldots\end{array}$ & $.0 D$ & 358 & 1 AO & 180 & .9 & +27 & 4.4 & 0 & -- & -- \\
\hline $\begin{array}{l}11 \ldots \\
22 \ldots\end{array}$ & $\cdot 04$ & 462 & 202 & 202 & 1.2 & $\begin{array}{r}778 \\
--\end{array}$ & 3.9 & $-\therefore$ & 13.0 & $\overline{93}$ \\
\hline $\begin{array}{l}30 \ldots \\
\text { FER. }\end{array}$ & .06 & 170 & 90 & 8.7 & -- & 275 & 5.5 & 4 & - & -- \\
\hline $02 \ldots$ & .22 & 162 & 78 & 71 & -- & 236 & 6.8 & 3 & -- & -- \\
\hline $13 \ldots$ & -- & - & -- & -- & -- & $\rightarrow$ & -- & - & 12.0 & 82 \\
\hline $\begin{array}{l}15 \ldots \\
27 \ldots\end{array}$ & $\begin{array}{l}.13 \\
.02\end{array}$ & $\begin{array}{l}352 \\
410\end{array}$ & 160 & 160 & .7 & 522 & 4.4 & 1 & -- & - \\
\hline \multicolumn{11}{|l|}{ MAK." } \\
\hline $03 \ldots$ & .04 & $30^{\circ} 8$ & 186 & 196 & 1.0 & 625 & 4.2 & 1 & -- & -- \\
\hline $19 \ldots$ & -- & - & -- & $=$ & -- & $\cdots$ & -- & -- & 11.0 & 95 \\
\hline $25 \ldots$ & .04 & $13 \mathrm{~B}$ & 74 & 74 & .2 & 210 & 4.9 & 5 & $\cdots$ & -- \\
\hline \multicolumn{11}{|l|}{ APR. } \\
\hline $17 \ldots$ & -- & $=$ & - & -- & -- & -- & -- & -- & 9.6 & 91 \\
\hline $19 \ldots$ & .05 & 260 & 128 & 128 & .7 & 430 & 4.4 & 16 & - & - \\
\hline $24 \ldots$ & .12 & 110 & 66 & 63 & $\therefore$ & 104 & $5 . h$ & 13 & -. & -- \\
\hline $29 \ldots$ & $.0 \mathrm{~A}$ & 196 & 94 & 94 & .3 & 294 & 4.9 & 13 & -- & -- \\
\hline \multicolumn{11}{|l|}{ MAY } \\
\hline $10 \ldots$ & .08 & 242 & 124 & 124 & .0 & 405 & 4.5 & 16 & -- & -- \\
\hline $16 \ldots$ & .04 & 172 & 90 & 90 & .2 & 287 & 4.9 & 19 & -- & -- \\
\hline $21 \ldots$ & -- & -- & -- & -- & -- & - & - & 14 & 9.0 & A6 \\
\hline $24 \ldots$ & .09 & 63 & 42 & 33 & -- & 122 & 6.7 & 16 & -- & -- \\
\hline \multicolumn{11}{|l|}{ JUNE } \\
\hline $04 \ldots$ & -- & -- & -- & - & - & $\cdots$ & -- & 19 & B. 0 & 84 \\
\hline $06 \ldots$ & .04 & 238 & 115 & 115 & .7 & 369 & 4.4 & 20 & -- & -- \\
\hline $20 \ldots$ & .04 & 402 & 174 & 174 & 1.4 & 648 & 4.1 & 20 & -- & $\rightarrow$ \\
\hline $30 \ldots$ & .05 & 824 & 342 & 342 & 4.0 & 1300 & 3.3 & 22 & -- & -- \\
\hline \multicolumn{11}{|l|}{ JuLY } \\
\hline $\begin{array}{l}01 \ldots \\
08 \ldots\end{array}$ & $\begin{array}{l}.07 \\
.10\end{array}$ & $\begin{array}{l}718 \\
470\end{array}$ & $\begin{array}{l}307 \\
192\end{array}$ & $\begin{array}{l}307 \\
192\end{array}$ & $\begin{array}{l}2.8 \\
1.4\end{array}$ & $\begin{array}{r}1030 \\
746\end{array}$ & 3.6 & $\begin{array}{l}24 \\
22\end{array}$ & $=$ & $=$ \\
\hline $\begin{array}{l}08 \ldots \\
10 \ldots\end{array}$ & - & $\begin{array}{l}470 \\
--\end{array}$ & 192 & 192 & 1.4 & $\begin{array}{r}746 \\
--\end{array}$ & 3.5 & 22 & 7.4 & 85 \\
\hline is... & .09 & 388 & 169 & 159 & 1.0 & 680 & 3.6 & 24 & $\cdots$ & -- \\
\hline \multicolumn{11}{|l|}{ AUS. } \\
\hline $\begin{array}{l}02 \ldots \\
14 \ldots\end{array}$ & $\begin{array}{l}.12 \\
.06\end{array}$ & $\begin{array}{l}502 \\
692\end{array}$ & $\begin{array}{l}219 \\
321\end{array}$ & 219 & 1.9 & 835 & 3.6 & 23 & -- & $=$ \\
\hline $14 \ldots$ & .06 & 692 & 321 & 321 & 2.6 & 1130 & 3.3 & 22 & -- & -- \\
\hline $25 \ldots$ & .06 & 330 & 155 & 155 & .9 & 574 & 3.9 & 26 & -- & $\overline{-}$ \\
\hline $\begin{array}{l}27 \ldots \\
\text { SEPT. }\end{array}$ & -- & - & -- & -- & - & -- & -- & 21 & 7.4 & 92 \\
\hline $06 \ldots$ & .21 & 426 & 190 & 190 & 1.2 & 716 & 3.6 & 21 & -- & -- \\
\hline $13 \ldots$ & .03 & 530 & 235 & 235 & 1.8 & B 75 & 3.6 & 18 & - & $\because$ \\
\hline $25 \ldots$ & -- & -- & -- & - & -- & -- & -- & 20 & 7.6 & 83 \\
\hline
\end{tabular}

SPECIFIC CONDUCTANCE (MICROMHOS AT $25^{\circ} \mathrm{C}$ ), WATER YEAR OCTOBER 1967 TO SEPTEMBER $196 \mathrm{~B}$ TANCE (MICROMHOS AT $25^{\circ} \mathrm{C}$ ), WATER YEAR OCTOBER 1967 TO
(ONCE-DAILY MEASUREMENT USUALLY BETWEEN 1700 AND 2200 )

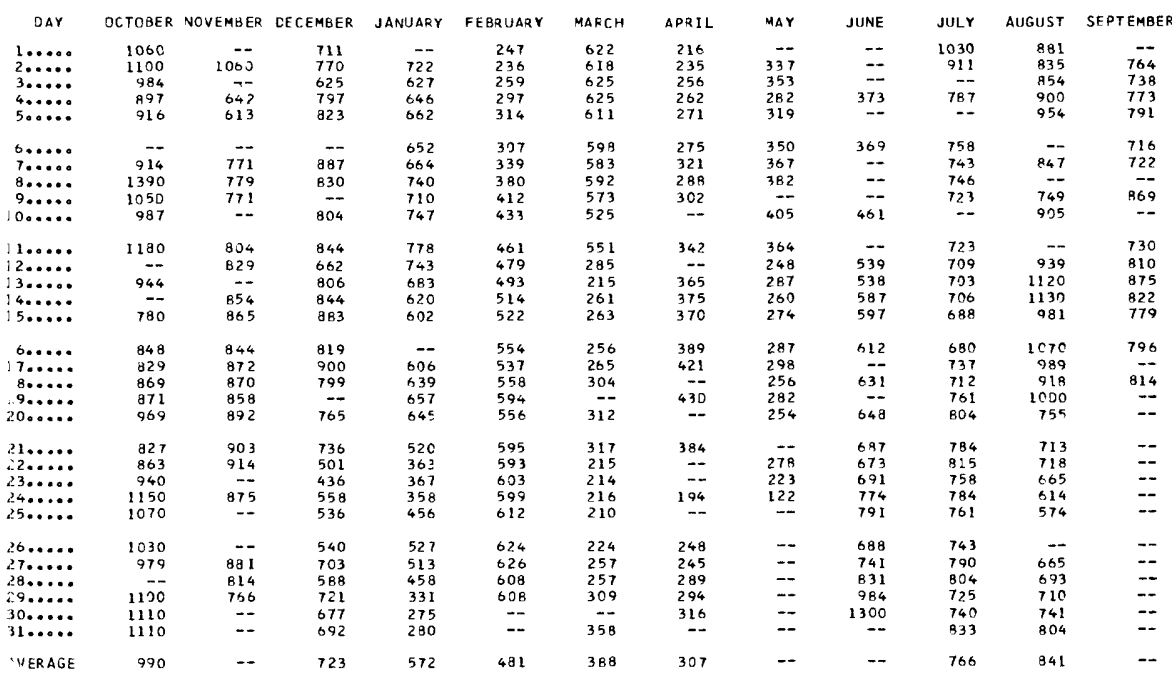


03202000 RACCOON CREEK AT ADAMSVILLE, OHIO--COntInUed

TEMPERATURE $\left({ }^{\circ} \mathrm{C}\right)$ OF WATER, WATER YEAR OCTOBER 1967 TO SEPTEMBER 1968

\begin{tabular}{|c|c|c|c|c|c|c|c|c|c|c|c|c|}
\hline DAY & $n C \top$ & NOV & DEC & JAN & FEB & MAR & $A P R$ & MAY & JUN & JUL & AUG & SEP \\
\hline $\begin{array}{l}1 \\
2 \\
3 \\
4 \\
5\end{array}$ & $\begin{array}{l}14.0 \\
16.0 \\
18.0 \\
17.0 \\
16.0\end{array}$ & $\begin{array}{r}11.0 \\
10.0 \\
10.0 \\
1.0\end{array}$ & $\begin{array}{l}2.0 \\
3.0 \\
3.0 \\
4.0 \\
3.0\end{array}$ & $\begin{array}{l}-.0 \\
0.0 \\
0.0 \\
0.0 \\
0.0\end{array}$ & $\begin{array}{l}4.0 \\
3.0 \\
4.0 \\
4.0 \\
-.-0\end{array}$ & $\begin{array}{l}1.0 \\
1.0 \\
1.0 \\
2.0 \\
2.0\end{array}$ & $\begin{array}{l}11.0 \\
11.0 \\
11.0 \\
11.0 \\
10.0\end{array}$ & $\begin{array}{l}16.0 \\
16.0 \\
16.0 \\
16.0\end{array}$ & 18.0 & $\begin{array}{r}24.0 \\
25.0 \\
22.0 \\
\end{array}$ & $\begin{array}{l}23.0 \\
23.0 \\
24.0 \\
24.0 \\
24.0\end{array}$ & $\begin{array}{r}20.0 \\
21.0 \\
21.0 \\
21.0\end{array}$ \\
\hline $\begin{array}{r}6 \\
7 \\
3 \\
9 \\
10\end{array}$ & $\begin{array}{l}-16.0 \\
17.0 \\
16.0 \\
13.0\end{array}$ & $\begin{array}{l}6.0 \\
6.0 \\
6.0 \\
-.-\end{array}$ & $\begin{array}{l}--- \\
6.0 \\
4.0 \\
5.0\end{array}$ & $\begin{array}{l}0.0 \\
0.0 \\
0.0 \\
0.0 \\
0.0\end{array}$ & $\begin{array}{l}-\rightarrow \\
--- \\
-- \\
--\end{array}$ & $\begin{array}{l}2.0 \\
3.0 \\
3.0 \\
5.0 \\
6.0\end{array}$ & $\begin{array}{l}10.0 \\
11.0 \\
11.0 \\
10.0 \\
\end{array}$ & $\begin{array}{l}15.0 \\
16.0 \\
15.0 \\
16.0\end{array}$ & $\frac{20.0}{22.0}$ & $\begin{array}{l}22.0 \\
22.0 \\
22.0 \\
24.0 \\
\end{array}$ & $\begin{array}{r}26.0 \\
24.0 \\
22.0\end{array}$ & $\begin{array}{r}21.0 \\
21.0 \\
20.0 \\
-\end{array}$ \\
\hline $\begin{array}{l}11 \\
12 \\
13 \\
14 \\
15\end{array}$ & $\begin{array}{r}13.0 \\
13.0 \\
14.0\end{array}$ & $\begin{array}{l}6.0 \\
6.0 \\
8.0 \\
6.0\end{array}$ & $\begin{array}{l}7.0 \\
7.0 \\
6.0 \\
6.0 \\
5.0\end{array}$ & $\begin{array}{l}0.0 \\
0.0 \\
0.0 \\
0.0 \\
0.0\end{array}$ & $\begin{array}{l}--- \\
--- \\
1.0 \\
1.0\end{array}$ & $\begin{array}{r}7.0 \\
5.0 \\
11.0 \\
3.0 \\
3.0\end{array}$ & $\begin{array}{l}13.0 \\
14.0 \\
14.0 \\
14.0\end{array}$ & $\begin{array}{l}16.0 \\
16.0 \\
16.0 \\
16.0 \\
17.0\end{array}$ & $\begin{array}{l}22.0 \\
20.0 \\
20.0 \\
20.0\end{array}$ & $\begin{array}{l}23.0 \\
23.0 \\
24.0 \\
24.0 \\
24.0\end{array}$ & $\begin{array}{l}22.0 \\
22.0 \\
22.0 \\
24.0\end{array}$ & $\begin{array}{l}18.0 \\
19.0 \\
18.0 \\
18.0 \\
19.0\end{array}$ \\
\hline $\begin{array}{l}16 \\
17 \\
18 \\
19 \\
20\end{array}$ & $\begin{array}{l}16.0 \\
15.0 \\
13.0 \\
14.0 \\
12.0\end{array}$ & $\begin{array}{l}4.0 \\
6.0 \\
6.0 \\
6.0 \\
5.0\end{array}$ & $\begin{array}{l}4.0 \\
3.0 \\
4.0 \\
-0\end{array}$ & $\begin{array}{l}1.0 \\
1.0 \\
1.0 \\
2.0\end{array}$ & $\begin{array}{l}2.0 \\
1.0 \\
1.0 \\
2.0 \\
1.0\end{array}$ & $\begin{array}{r}4.0 \\
6.0 \\
7.0 \\
10.0\end{array}$ & $\begin{array}{r}14.0 \\
15.0 \\
16.0 \\
\end{array}$ & $\begin{array}{l}18.0 \\
17.0 \\
17.0 \\
16.0 \\
14.0\end{array}$ & $\begin{array}{r}20.0 \\
19.0 \\
20.0\end{array}$ & $\begin{array}{l}24.0 \\
23.0 \\
26.0 \\
26.0 \\
24.0\end{array}$ & $\begin{array}{l}23.0 \\
24.0 \\
24.0 \\
25.0 \\
25.0\end{array}$ & $\begin{array}{r}19.0 \\
19.0 \\
-\end{array}$ \\
\hline $\begin{array}{l}21 \\
22 \\
23 \\
24 \\
25\end{array}$ & $\begin{array}{l}12.0 \\
12.0 \\
19.0 \\
12.0 \\
11.0\end{array}$ & $\begin{array}{l}6.0 \\
6.0 \\
4.0\end{array}$ & $\begin{array}{l}7.0 \\
7.0 \\
4.0 \\
3.0 \\
3.0\end{array}$ & $\begin{array}{l}2.0 \\
1.0 \\
0.0 \\
0.0 \\
2.0\end{array}$ & $\begin{array}{l}2.0 \\
1.0 \\
1.0 \\
1.0 \\
1.0\end{array}$ & $\begin{array}{r}11.0 \\
9.0 \\
7.0 \\
6.0 \\
5.0\end{array}$ & $\begin{array}{r}16.0 \\
16.0 \\
13.0\end{array}$ & $\begin{array}{l}-0 . \\
14.0 \\
14.0 \\
16.0 \\
-\end{array}$ & $\begin{array}{l}20.0 \\
21.0 \\
21.0 \\
22.0 \\
23.0\end{array}$ & $\begin{array}{l}24.0 \\
24.0 \\
24.0 \\
25.0 \\
24.0\end{array}$ & $\begin{array}{l}26.0 \\
26.0 \\
25.0 \\
27.0 \\
26.0\end{array}$ & $\begin{array}{l}--- \\
-- \\
--- \\
--\end{array}$ \\
\hline $\begin{array}{l}26 \\
27 \\
28 \\
29 \\
30 \\
31\end{array}$ & $\begin{array}{r}11.0 \\
10.0 \\
10.0 \\
9.0 \\
9.0 \\
13.0\end{array}$ & $\begin{array}{l}--0 \\
4.0 \\
3.0 \\
2.0 \\
-0-\end{array}$ & $\begin{array}{l}2.0 \\
1.0 \\
1.0 \\
0.0 \\
1.0 \\
2.0\end{array}$ & $\begin{array}{l}0.0 \\
1.0 \\
2.0 \\
2.0 \\
4.0 \\
4.0\end{array}$ & $\begin{array}{l}1.0 \\
1.0 \\
0.0 \\
1.0 \\
--0\end{array}$ & $\begin{array}{r}7.0 \\
9.0 \\
11.0 \\
12.0 \\
14.0\end{array}$ & $\begin{array}{r}13.0 \\
13.0 \\
13.0 \\
13.0 \\
14.0 \\
-\end{array}$ & 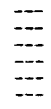 & $\begin{array}{l}23.0 \\
22.0 \\
21.0 \\
22.0 \\
22.0 \\
-.0\end{array}$ & $\begin{array}{l}24.0 \\
24.0 \\
24.0 \\
24.0 \\
23.0 \\
23.0\end{array}$ & $\begin{array}{l}-\overline{22.0} \\
21.0 \\
20.0 \\
19.0 \\
20.0\end{array}$ & $\begin{array}{l}--- \\
\because- \\
\square- \\
--\end{array}$ \\
\hline VERAGE & 13.5 & --- & 4.0 & 1.0 & -- & 6.0 & 13.0 & - & $\cdots$ & 24.0 & 23.5 & - \\
\hline
\end{tabular}

SPECIFIC CONDUCTANCE, PH, DISSOLVED OXYGEN, AND WATER TEMPERATURES, WATER YEAR OCTOBER 1967 TO SEPTEMBER 1968

OCTOBER

\begin{tabular}{|c|c|c|c|c|c|c|}
\hline \multirow[t]{2}{*}{ DAY } & \multicolumn{2}{|c|}{$\begin{array}{l}\text { SPECIFIC } \\
\text { CONDUCTANCE } \\
\text { (MICROMHOS } \\
\left.\text { AT } 25^{\circ} \mathrm{C}\right)\end{array}$} & \multicolumn{2}{|c|}{$\mathrm{pH}$} & \multicolumn{2}{|c|}{$\begin{array}{l}\text { DI SSOLVED } \\
\text { OXYGEN } \\
(\mathbf{H G} / \mathrm{L})\end{array}$} \\
\hline & $\operatorname{Max}$ & MIN & $\operatorname{cax}$ & MIN & $\operatorname{maX}$ & MIN \\
\hline $\begin{array}{l}1 \\
2 \\
3 \\
4 \\
5\end{array}$ & $\begin{array}{r}-- \\
1100 \\
960 \\
950\end{array}$ & $\begin{array}{l}-- \\
920 \\
900 \\
900\end{array}$ & $\begin{array}{l}3.8 \\
3.9 \\
3.9 \\
4.0 \\
3.9\end{array}$ & $\begin{array}{l}3.6 \\
3.6 \\
3.6 \\
3.6 \\
3.6\end{array}$ & $\begin{array}{l}6.4 \\
7.3 \\
7.0 \\
4.5 \\
5.0\end{array}$ & $\begin{array}{l}3.9 \\
4.1 \\
4.5 \\
4.0 \\
4.2\end{array}$ \\
\hline $\begin{array}{r}6 \\
7 \\
8 \\
9 \\
10\end{array}$ & $\begin{array}{r}910 \\
960 \\
1630 \\
1250 \\
1090\end{array}$ & $\begin{array}{r}850 \\
860 \\
940 \\
1050 \\
990\end{array}$ & $\begin{array}{l}4.0 \\
4.0 \\
3.8 \\
3.9 \\
3.9\end{array}$ & $\begin{array}{l}3.8 \\
3.6 \\
3.6 \\
3.8 \\
3.8\end{array}$ & $\begin{array}{l}5.9 \\
4.6 \\
4.6 \\
4.6 \\
4.7\end{array}$ & $\begin{array}{l}4.4 \\
4.4 \\
3.8 \\
4.2 \\
4.2\end{array}$ \\
\hline $\begin{array}{l}11 \\
12 \\
13 \\
14 \\
15\end{array}$ & $\begin{array}{r}1310 \\
1290 \\
1190 \\
890 \\
840\end{array}$ & $\begin{array}{r}1050 \\
1130 \\
890 \\
730 \\
730\end{array}$ & $\begin{array}{l}3.8 \\
3.7 \\
3.6 \\
3.7 \\
3.6\end{array}$ & $\begin{array}{l}3.6 \\
3.4 \\
3.4 \\
3.4 \\
3.3\end{array}$ & $\begin{array}{l}4.6 \\
4.9 \\
5.4 \\
5.7 \\
5.7\end{array}$ & $\begin{array}{l}4.2 \\
4.1 \\
3.9 \\
4.6 \\
4.8\end{array}$ \\
\hline $\begin{array}{l}16 \\
17 \\
18 \\
19 \\
20\end{array}$ & $\begin{array}{r}850 \\
900 \\
-- \\
--\end{array}$ & $\begin{array}{r}820 \\
820 \\
-- \\
--\end{array}$ & $\begin{array}{r}3.6 \\
3.6 \\
3.6 \\
-- \\
--\end{array}$ & $\begin{array}{r}3.4 \\
3.4 \\
3.5 \\
-- \\
--\end{array}$ & $\begin{array}{r}5.4 \\
4.9 \\
5.2 \\
-. \\
--\end{array}$ & $\begin{array}{r}4.5 \\
3.9 \\
3.6 \\
-- \\
--\end{array}$ \\
\hline $\begin{array}{l}21 \\
22 \\
23 \\
24 \\
25\end{array}$ & $\begin{array}{r}-- \\
1180 \\
1200\end{array}$ & $\begin{array}{r}-- \\
900 \\
1000\end{array}$ & $\begin{array}{l}-- \\
-- \\
4.0 \\
4.0\end{array}$ & $\begin{array}{r}-- \\
-- \\
3.8 \\
3.9\end{array}$ & $\begin{array}{r}-- \\
-- \\
8.1 \\
8.0\end{array}$ & $\begin{array}{r}-- \\
-- \\
7.5 \\
7.2\end{array}$ \\
\hline $\begin{array}{l}26 \\
27 \\
28 \\
29 \\
30 \\
31\end{array}$ & $\begin{array}{l}1200 \\
1200 \\
1160 \\
1250 \\
1220 \\
1110\end{array}$ & $\begin{array}{r}990 \\
930 \\
1020 \\
1100 \\
1050 \\
1050\end{array}$ & $\begin{array}{l}4.3 \\
4.5 \\
4.1 \\
4.0 \\
3.8 \\
3.6\end{array}$ & $\begin{array}{l}4.0 \\
4.1 \\
3.9 \\
3.7 \\
3.4 \\
3.5\end{array}$ & $\begin{array}{l}7.7 \\
7.4 \\
7.4 \\
8.0 \\
8.4 \\
8.1\end{array}$ & $\begin{array}{l}6.1 \\
5.9 \\
6.9 \\
7.3 \\
7.8 \\
7.4\end{array}$ \\
\hline
\end{tabular}

NOVEMBER

\begin{tabular}{|c|c|c|c|c|c|c|c|}
\hline \multicolumn{2}{|c|}{$\begin{array}{l}\text { SPECIFIC } \\
\text { CONDUCTANCE } \\
\text { (MICRONHOS } \\
\text { AT } 25^{\circ} \mathrm{C} \text { ) }\end{array}$} & \multicolumn{2}{|c|}{$\mathrm{pH}$} & \multicolumn{2}{|c|}{$\begin{array}{l}\text { DISSOLVED } \\
\text { OXYGEN } \\
(\mathbf{H G} / \mathbf{L})\end{array}$} & \multicolumn{2}{|c|}{$\begin{array}{l}\text { TEYPER- } \\
\text { ATURE } \\
\left({ }^{\circ} \mathrm{C}\right)\end{array}$} \\
\hline MAX & MIN & $\operatorname{Max}$ & MIN & $\operatorname{MAX}$ & MIN & $\operatorname{cax}$ & MIN \\
\hline $\begin{array}{l}2180 \\
2340\end{array}$ & $\begin{array}{r}1030 \\
440\end{array}$ & $\begin{array}{l}3.7 \\
4.5\end{array}$ & $\begin{array}{l}3.6 \\
3.7\end{array}$ & $\begin{array}{l}7.6 \\
7.4\end{array}$ & $\begin{array}{l}6.9 \\
5.5\end{array}$ & 11 & $\begin{array}{r}9 \\
10\end{array}$ \\
\hline 780 & 470 & 3.8 & 3.5 & 8.1 & 7.4 & 11 & 10 \\
\hline-- & -- & 3.9 & 3.6 & 8.2 & 8.0 & 11 & 9 \\
\hline- & -- & 3.9 & 3.8 & 9.0 & 8.2 & 9 & 7 \\
\hline-- & -- & 3.8 & 3.6 & 9.5 & 9.0 & 7 & 6 \\
\hline-- & -- & 3.7 & 3.6 & 10.0 & 9.5 & 6 & 5 \\
\hline -- & -- & 3.7 & 3.6 & 10.2 & 9.9 & 6 & 5 \\
\hline -- & - & 3.7 & 3.6 & 10.2 & 9.9 & 6 & 4 \\
\hline- & -- & 3.8 & 3.7 & 9.9 & 9.7 & 6 & 5 \\
\hline -- & -- & -- & -- & -- & -- & - & -- \\
\hline - & - & -- & -- & -- & -- & $=$ & - \\
\hline-- & - & - & - & -- & $\rightarrow$ & -- & - \\
\hline-- & -- & $-\bar{\pi}$ & -- & - & -- & - & $=$ \\
\hline-- & -- & 3.7 & 3.6 & 9.7 & 8.7 & 7 & 5 \\
\hline$-m$ & -- & 3.7 & 3.6 & 10.2 & 9.4 & 5 & 4 \\
\hline- & 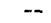 & 3.7 & 3.6 & 10.1 & 9.6 & 5 & 4 \\
\hline -- & -- & 3.7 & 3.6 & 10.2 & 9.4 & 6 & 5 \\
\hline$\rightarrow$ & $=$ & 3.7 & 3.6 & 10.2 & 9.4 & 6 & 5 \\
\hline-- & -- & 3.7 & 3.6 & 10.4 & 9.6 & 5 & 4 \\
\hline -- & -- & 3.6 & 3.6 & 10.2 & 9.7 & 5 & 4 \\
\hline- & 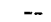 & 3.7 & 3.6 & 10.0 & 9. & 6 & 5 \\
\hline- & -- & 3.8 & 3.6 & 10.1 & 9.3 & 6 & 5 \\
\hline$=$ & -- & 3.8 & 3.7 & 10.1 & 9.4 & 5 & 4 \\
\hline-- & - & 4.0 & 3.7 & 10.3 & 9.6 & 6 & 4 \\
\hline -- & -- & 4.0 & 3.7 & 10.6 & 9. & 5 & 4 \\
\hline -- & 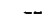 & 3.8 & 3.7 & 10.7 & 10.2 & 5 & 4 \\
\hline- & 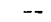 & 3.8 & 3.7 & 11.0 & 10.4 & 4 & 3 \\
\hline -- & -- & 3.8 & 3.7 & 11.2 & 10.7 & 3 & 2 \\
\hline -- & -- & 4.5 & 3.8 & - & - & 2 & 1 \\
\hline & & & & & & & \\
\hline
\end{tabular}


03202000 RACCOON CREEK AT ADAMSVILLE, OHIO--COntinued

SPECIFIC CONDUCTANCE, PH, DISSOLVED OXYGEN, AND HATER TEMPERATURES, HATER YEAR OCTOBER 1967 TO SEPTEMBER 1968

DECEMBER

\begin{tabular}{|c|c|c|c|c|c|c|c|}
\hline \multicolumn{2}{|c|}{$\begin{array}{l}\text { SPECIFIC } \\
\text { CONDUCTANCE } \\
\text { (MICROMHOS } \\
\text { AT } 25^{\circ} \mathrm{C} \text { ) }\end{array}$} & \multicolumn{2}{|c|}{ pH } & \multicolumn{2}{|c|}{$\begin{array}{l}\text { DI SSOLVED } \\
\text { OXYGEN } \\
(\mathbf{M G} / \mathrm{L})\end{array}$} & \multicolumn{2}{|c|}{$\begin{array}{l}\text { TEMPER- } \\
\text { ATURE } \\
\left({ }^{\circ} \mathrm{C}\right)\end{array}$} \\
\hline $\operatorname{san} x$ & MIN & $\cos x$ & MIN & max & MIN & MAX & MIN \\
\hline-- & -- & 4.6 & 4.2 & -- & -- & 2 & \\
\hline-- & -- & 4.3 & 3.9 & - & -- & 2 & \\
\hline- & -- & 4. & 3.9 & -- & -- & 3 & \\
\hline- & - & 4.2 & 3.9 & -- & -- & 3 & \\
\hline- & -- & 4.0 & 3.9 & -- & - & 3 & \\
\hline- & $-m$ & 4.0 & 3.9 & -- & $\infty$ & 3 & \\
\hline 910 & 820 & 3.9 & 3.7 & 9.6 & 9.0 & 4 & \\
\hline 830 & 780 & 4.0 & 3.9 & 9.1 & 8.9 & 4 & \\
\hline 810 & 740 & 4.0 & 3.9 & 9.3 & 8.9 & 4 & \\
\hline 810 & 700 & 4.2 & 3.9 & 9.1 & 8.6 & 5 & \\
\hline 890 & 680 & 4.6 & 4.2 & 8.8 & 8.4 & 6 & \\
\hline$\overline{-}$ & -- & 4.8 & 4.4 & 9.3 & 8.2 & 7 & \\
\hline 820 & 640 & 4.4 & 4.0 & 12.5 & 9.2 & 7 & \\
\hline 880 & 710 & 4. & 4. & 12.8 & 11.6 & 6 & \\
\hline 880 & 720 & 4.3 & 4.2 & 13.3 & 11.4 & 6 & \\
\hline 850 & 760 & 4.2 & 4.1 & 13.9 & 12.2 & 4 & \\
\hline 910 & 760 & 4.2 & 4.0 & 13.9 & 12.1 & 3 & \\
\hline 890 & 700 & 4.0 & 3.9 & 13.8 & 9.1 & 4 & \\
\hline 740 & 690 & 4. & 3 . & 13.2 & 11.3 & 5 & \\
\hline 760 & 680 & 4.0 & 3.8 & 13.7 & 11.7 & 4 & \\
\hline & 4 & 4.0 & 3.9 & 12.4 & 11.3 & 7 & \\
\hline -- & - & 5.1 & 4.0 & 12.4 & 11.4 & 7 & \\
\hline-- & -- & 5.0 & 4.3 & 13.2 & 9.0 & 6 & \\
\hline- & - & 4.3 & 4. & 10.9 & 8.8 & 4 & \\
\hline-- & -- & 4.4 & 4.1 & 11.6 & 9.8 & 3 & 2 \\
\hline- & - & - & - & -- & -- & -- & 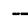 \\
\hline & & - & & - & $=$ & - & - \\
\hline$\cdots$ & - & - & - & - & -- & - & 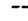 \\
\hline- & - & - & - & - & - & - & 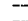 \\
\hline$\ldots$ & - & -- & - & $=$ & $\overline{-}$ & $=$ & 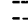 \\
\hline
\end{tabular}

\section{FEBRUARY}

SPECIFIC

CONDUCTANCE DISSOLVED TEMPER-

(MICROMHOS
AT 25 $\left.{ }^{\circ} \mathrm{C}\right)$ PH $\quad \begin{aligned} & \text { OXYGEN } \\ & (\text { MG } / \mathrm{L})\end{aligned}$

$$
\text { MiN MAX MIN MAX MIN }
$$

$\max$ uIN

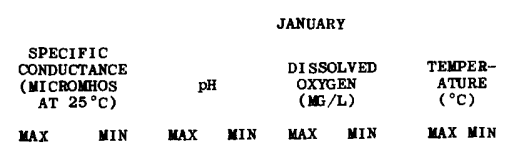

290 250 $\begin{array}{llll}5.8 & 5.5 & 12.3 & 12.0\end{array}$

MARCH

\begin{tabular}{|c|c|c|c|c|c|c|c|}
\hline $\begin{array}{r}\text { SPI } \\
\text { CONI } \\
\text { (MID } \\
\text { A] }\end{array}$ & $\begin{array}{l}\text { IC } \\
\text { ANCE } \\
\text { IOS } \\
\text { C) }\end{array}$ & & & $\begin{array}{l}\text { DISS } \\
\text { OXY } \\
\text { (IE }\end{array}$ & $\begin{array}{l}\text { LVED } \\
\text { EN } \\
\text { L) }\end{array}$ & $\begin{array}{l}\text { TEPP } \\
\text { ATU } \\
\left({ }^{\circ} \mathrm{C}\right)\end{array}$ & \\
\hline MAX & MIN & $\cos x$ & MIN & $\cos x$ & MIN & MAX & MIN \\
\hline- & - & & & -- & -- & -- & -- \\
\hline- & $=$ & & & $=$ & $\bar{z}$ & $=$ & -- \\
\hline$=$ & - & & & - & $=$ & $=$ & \\
\hline-- & -- & & & - & - & - & $\therefore$ \\
\hline -- & -- & & & -. & -- & -- & - \\
\hline$\because$ & $=$ & & & -- & -. & - & - \\
\hline 300 & 550 & & & 120 & $11 \overline{5}$ & $-\overrightarrow{6}$ & -- \\
\hline 70 & 510 & & & 11.5 & 11.2 & $\begin{array}{l}6 \\
6\end{array}$ & 5 \\
\hline 560 & 540 & & & -- & -. & 7 & 4 \\
\hline-- & -- & & & -- & - & - & - \\
\hline $\bar{z}$ & $=$ & & & $=$ & $\because$ & 11 & 9 \\
\hline-- & -- & & & $=$ & $\overline{-}$ & $\overline{4}$ & $\overline{2}$ \\
\hline-- & -- & & & -- & -- & 4 & 4 \\
\hline 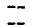 & $=$ & & & $=$ & - & 6 & 4 \\
\hline-- & $=$ & & & $=$ & $=$ & 8 & 7 \\
\hline-- & -- & & & $=$ & - & $10^{\circ}$ & 8 \\
\hline-- & -- & & & -- & - & 11 & 9 \\
\hline$=$ & $=$ & & & -- & - & 9 & 8 \\
\hline -- & - & & & $\because$ & $\overline{-}$ & $=$ & $=$ \\
\hline- & -- & & & - & - & - & $=$ \\
\hline-- & -- & & & -- & -. & -- & $\ldots$ \\
\hline$=$ & -- & & & -- & - & $\rightarrow$ & -- \\
\hline & -- & & & -- & -- & - & - \\
\hline & $\therefore$ & & & $\overline{-}$ & $=$ & $\overline{-}$ & -- \\
\hline- & 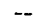 & & & $=$ & $=$ & $=$ & - \\
\hline
\end{tabular}


03202000 RACCOON CREEK AT ADAMSVILLE, OHIO--Cont1 nued

SPECIFIC CONDUCTANCE, PH, DISSOLVED OXYGEN, AND WATER TEMPERATURES, WATER YEAR OCTOBER 1967 TO SEPTEMBER 1968

\begin{tabular}{|c|c|c|c|c|c|c|c|c|c|c|c|c|c|c|c|c|}
\hline \multirow{3}{*}{ DAY } & \multicolumn{8}{|c|}{ APR IL } & & & \multicolumn{6}{|c|}{ MAY } \\
\hline & \multicolumn{2}{|c|}{$\begin{array}{l}\text { SPECIFIC } \\
\text { CONDUCTANCE } \\
\text { (MICROMHOS } \\
\left.\text { AT } 25^{\circ} \mathrm{C}\right)\end{array}$} & \multicolumn{2}{|c|}{$\mathrm{pH}$} & \multicolumn{2}{|c|}{$\begin{array}{l}\text { DISSOLVED } \\
\text { OXYGEN } \\
(\mathbf{M G} / \mathrm{L})\end{array}$} & \multicolumn{2}{|c|}{$\begin{array}{l}\text { TEMPER- } \\
\text { ATURE } \\
\left({ }^{\circ} \mathrm{C}\right)\end{array}$} & \multicolumn{2}{|c|}{$\begin{array}{l}\text { SPECIPIC } \\
\text { CONDUCTANCE } \\
\text { (MICROMFOS } \\
\text { AT } 25^{\circ} \mathrm{C} \text { ) }\end{array}$} & \multicolumn{2}{|c|}{ pH } & \multicolumn{2}{|c|}{$\begin{array}{l}\text { DI SSOLVED } \\
\text { OXYGEN } \\
(\mathbf{M G} / L)\end{array}$} & \multicolumn{2}{|c|}{$\begin{array}{l}\text { TEUPER- } \\
\text { ATURE } \\
\left({ }^{\circ} \mathrm{C}\right)\end{array}$} \\
\hline & $\operatorname{mAX}$ & MIN & MAX & MIN & WAX & MIN & $\operatorname{MAX}$ & MIN & MAX & MIN & $\ln x$ & MIN & MAX & MIN & $\operatorname{MAX}$ & MIN \\
\hline $\begin{array}{l}1 \\
2 \\
3 \\
4 \\
5\end{array}$ & $\begin{array}{l}= \\
= \\
= \\
=\end{array}$ & $\begin{array}{l}=- \\
=- \\
=-\end{array}$ & & & $\begin{array}{l}= \\
=- \\
=-\end{array}$ & $\begin{array}{l}= \\
=- \\
=\end{array}$ & $\begin{array}{l}=- \\
=- \\
=- \\
=-\end{array}$ & $\begin{array}{l}= \\
\ddot{--} \\
--\end{array}$ & $\begin{array}{l}370 \\
340 \\
360 \\
440 \\
350\end{array}$ & $\begin{array}{l}330 \\
320 \\
330 \\
220 \\
260\end{array}$ & & & $\begin{array}{l}14.3 \\
10.7 \\
11.2 \\
10.8 \\
10.0\end{array}$ & $\begin{array}{r}10.7 \\
8.8 \\
8.8 \\
8.9 \\
8.6\end{array}$ & $\begin{array}{l}15 \\
16 \\
16 \\
16 \\
17\end{array}$ & $\begin{array}{l}13 \\
14 \\
14 \\
16 \\
16\end{array}$ \\
\hline $\begin{array}{r}6 \\
7 \\
8 \\
9 \\
10\end{array}$ & $\begin{array}{l}= \\
= \\
=\end{array}$ & $\begin{array}{l}= \\
=- \\
=- \\
--\end{array}$ & & & $\begin{array}{l}\overline{-} \\
\overline{--} \\
=\end{array}$ & $\begin{array}{l}\overline{-} \\
\overline{-} \\
=\end{array}$ & $\begin{array}{l}-- \\
\ddot{--} \\
--\end{array}$ & $\begin{array}{l}\overline{-} \\
\overline{--} \\
\overline{--}\end{array}$ & $\begin{array}{l}440 \\
390 \\
390 \\
400 \\
440\end{array}$ & $\begin{array}{l}350 \\
350 \\
360 \\
380 \\
320\end{array}$ & & & $\begin{array}{l}8.9 \\
8.9 \\
8.6 \\
8.5 \\
9.0\end{array}$ & $\begin{array}{l}8.6 \\
8.6 \\
8.3 \\
8.3 \\
8.3\end{array}$ & $\begin{array}{l}16 \\
16 \\
15 \\
15 \\
16\end{array}$ & $\begin{array}{l}14 \\
14 \\
13 \\
14 \\
14\end{array}$ \\
\hline $\begin{array}{l}11 \\
12 \\
13 \\
14 \\
15\end{array}$ & $\begin{array}{l}=- \\
z- \\
z-\end{array}$ & $\begin{array}{l}\overline{-} \\
\overline{--} \\
\overline{-}\end{array}$ & & & $\begin{array}{l}= \\
= \\
=\end{array}$ & $\begin{array}{l}= \\
= \\
=\end{array}$ & $\begin{array}{l}= \\
=- \\
=\end{array}$ & $\begin{array}{l}=- \\
= \\
=\end{array}$ & $\begin{array}{l}\mathbf{5 7 0} \\
\mathbf{2 6 0} \\
310 \\
390 \\
300\end{array}$ & $\begin{array}{l}260 \\
190 \\
190 \\
240 \\
220\end{array}$ & & & $\begin{array}{l}9.6 \\
9.4 \\
8.5 \\
8.9 \\
9.5\end{array}$ & $\begin{array}{l}9.0 \\
8.4 \\
8.2 \\
8.5 \\
8.7\end{array}$ & $\begin{array}{l}16 \\
16 \\
16 \\
16 \\
18\end{array}$ & $\begin{array}{l}15 \\
16 \\
15 \\
16 \\
17\end{array}$ \\
\hline $\begin{array}{l}16 \\
17 \\
18 \\
19 \\
20\end{array}$ & $=$ & $\begin{array}{l}-- \\
-- \\
-- \\
--\end{array}$ & & & $\begin{array}{l}-- \\
-- \\
-- \\
--\end{array}$ & $\begin{array}{l}=- \\
=- \\
=-\end{array}$ & 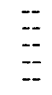 & $\begin{array}{l}= \\
= \\
= \\
=-\end{array}$ & $\begin{array}{l}310 \\
380 \\
380 \\
290 \\
310\end{array}$ & $\begin{array}{l}280 \\
290 \\
220 \\
220 \\
220\end{array}$ & & & $\begin{array}{r}10.0 \\
9.7 \\
9.4 \\
8.5 \\
8.4\end{array}$ & $\begin{array}{l}9.5 \\
9.3 \\
8.4 \\
8.2 \\
8.1\end{array}$ & $\begin{array}{l}18 \\
17 \\
18 \\
17 \\
16\end{array}$ & $\begin{array}{l}17 \\
17 \\
17 \\
16 \\
13\end{array}$ \\
\hline $\begin{array}{l}21 \\
22 \\
23 \\
24 \\
25\end{array}$ & $\begin{array}{r}430 \\
450 \\
-\end{array}$ & $\begin{array}{r}390 \\
430 \\
-- \\
--\end{array}$ & & & $\begin{array}{r}-- \\
-- \\
10.8 \\
9.4\end{array}$ & $\begin{array}{r}-- \\
-\overline{-} \\
9.3 \\
9.2\end{array}$ & $\begin{array}{l}\overline{17} \\
17 \\
16 \\
13\end{array}$ & $\begin{array}{l}-\overline{16} \\
15 \\
13 \\
13\end{array}$ & $\begin{array}{l}250 \\
300 \\
300 \\
150 \\
140\end{array}$ & $\begin{array}{l}200 \\
230 \\
140 \\
140 \\
140\end{array}$ & & & $\begin{array}{l}8.4 \\
8.4 \\
8.4 \\
8.2 \\
7.4\end{array}$ & $\begin{array}{l}8.2 \\
8.2 \\
8.1 \\
7.4 \\
7.2\end{array}$ & $\begin{array}{l}14 \\
14 \\
15 \\
16 \\
16\end{array}$ & $\begin{array}{l}14 \\
13 \\
14 \\
14 \\
15\end{array}$ \\
\hline $\begin{array}{l}26 \\
27 \\
28 \\
29 \\
30 \\
31\end{array}$ & $\begin{array}{r}260 \\
270 \\
300 \\
300 \\
330 \\
--\end{array}$ & $\begin{array}{c}210 \\
210 \\
270 \\
260 \\
260 \\
-\end{array}$ & & & $\begin{array}{c}15.0 \\
15.0 \\
15.0 \\
15.0 \\
15.0 \\
--\end{array}$ & $\begin{array}{r}9.4 \\
15.0 \\
15.0 \\
15.0 \\
14.3 \\
.\end{array}$ & $\begin{array}{l}13 \\
13 \\
13 \\
13 \\
14 \\
--\end{array}$ & $\begin{array}{l}12 \\
12 \\
12 \\
12 \\
13 \\
--\end{array}$ & $\begin{array}{r}140 \\
140 \\
-- \\
-- \\
-- \\
--\end{array}$ & $\begin{array}{r}140 \\
140 \\
-- \\
-- \\
--\end{array}$ & & & $\begin{array}{r}7.3 \\
7.3 \\
-- \\
-- \\
--\end{array}$ & $\begin{array}{c}7.0 \\
7.1 \\
=- \\
=- \\
=-\end{array}$ & $\begin{array}{l}17 \\
17 \\
-- \\
-- \\
--\end{array}$ & $\begin{array}{l}16 \\
16 \\
=- \\
=- \\
-\end{array}$ \\
\hline \multicolumn{9}{|c|}{ JUNE } & \multicolumn{8}{|c|}{ JULY } \\
\hline \multirow[t]{2}{*}{ DAY } & \multicolumn{2}{|c|}{$\begin{array}{l}\text { SPECIFIC } \\
\text { CONDUCTANCE } \\
\text { (MICROMHOS } \\
\left.\text { AT } 25^{\circ} \mathrm{C}\right)\end{array}$} & \multicolumn{2}{|c|}{$\mathrm{pH}$} & \multicolumn{2}{|c|}{$\begin{array}{l}\text { DI SSOLVED } \\
\text { OXYGEN } \\
(\mathbf{W G} / \mathrm{L})\end{array}$} & \multicolumn{2}{|c|}{$\begin{array}{l}\text { TEMPER- } \\
\text { ATURE } \\
\left({ }^{\circ} \mathrm{C}\right)\end{array}$} & \multicolumn{2}{|c|}{$\begin{array}{c}\text { SPECIPIC } \\
\text { CONDUCT ANCE } \\
\text { (MCROMHOS } \\
\left.\text { AT 25 } 25^{\circ} \mathrm{C}\right)\end{array}$} & \multicolumn{2}{|c|}{ pH } & \multicolumn{2}{|c|}{$\begin{array}{l}\text { DISSOLVED } \\
\text { OXYGEN } \\
\text { (LG/L) }\end{array}$} & \multicolumn{2}{|c|}{$\begin{array}{c}\text { TEMPER- } \\
\text { ATURE } \\
\left({ }^{\circ} \mathrm{C}\right)\end{array}$} \\
\hline & MAX & MIN & $\max$ & MIN & $\max$ & MnN & $\max$ & MIN & $\max$ & иัм & $\max$ & MIN & $\max$ & MIN & $\operatorname{MAX}$ & YIY \\
\hline $\begin{array}{l}1 \\
2 \\
3 \\
4 \\
5\end{array}$ & $\begin{array}{l}\overline{--} \\
470 \\
490 \\
400\end{array}$ & $\begin{array}{l}\overline{-} \\
430 \\
340 \\
230\end{array}$ & & & $\begin{array}{l}-- \\
7.0 \\
6.9 \\
7.5\end{array}$ & $\begin{array}{l}-- \\
6.8 \\
6.7 \\
6.7\end{array}$ & $\begin{array}{l}-- \\
18 \\
19 \\
19\end{array}$ & $\begin{array}{l}-- \\
17 \\
18 \\
18\end{array}$ & $\begin{array}{r}1180 \\
980 \\
1080 \\
960 \\
860\end{array}$ & $\begin{array}{l}980 \\
900 \\
960 \\
760 \\
780\end{array}$ & & & $\begin{array}{l}5.6 \\
5.5 \\
5.6 \\
5.7 \\
6.1\end{array}$ & $\begin{array}{l}5.4 \\
5.3 \\
5.3 \\
5.5 \\
5.7\end{array}$ & $\begin{array}{l}24 \\
26 \\
24 \\
23 \\
22\end{array}$ & $\begin{array}{l}23 \\
24 \\
22 \\
21 \\
20\end{array}$ \\
\hline $\begin{array}{r}6 \\
7 \\
8 \\
9 \\
10\end{array}$ & $\begin{array}{l}380 \\
400 \\
440 \\
490 \\
490\end{array}$ & $\begin{array}{l}310 \\
380 \\
400 \\
440 \\
\mathbf{4 4 0}\end{array}$ & & & $\begin{array}{r}9.7 \\
9.5 \\
11.5 \\
11.4 \\
11.0\end{array}$ & $\begin{array}{r}7.3 \\
7.0 \\
7.4 \\
8.2 \\
9.6\end{array}$ & $\begin{array}{l}20 \\
19 \\
20 \\
21 \\
22\end{array}$ & $\begin{array}{l}19 \\
19 \\
19 \\
19 \\
21\end{array}$ & $\begin{array}{l}780 \\
760 \\
770 \\
740 \\
730\end{array}$ & $\begin{array}{l}\mathbf{7 6 0} \\
\mathbf{7 2 0} \\
\mathbf{7 4 0} \\
\mathbf{7 2 0} \\
\mathbf{7 1 0}\end{array}$ & & & $\begin{array}{l}6.2 \\
6.2 \\
6.3 \\
6.0 \\
7.3\end{array}$ & $\begin{array}{l}5.8 \\
5.9 \\
5.9 \\
3.1 \\
5.0\end{array}$ & $\begin{array}{l}22 \\
22 \\
22 \\
24 \\
23\end{array}$ & $\begin{array}{l}20 \\
20 \\
21 \\
22 \\
22\end{array}$ \\
\hline $\begin{array}{l}11 \\
12 \\
13 \\
14 \\
15\end{array}$ & $\begin{array}{l}\mathbf{5 2 0} \\
\mathbf{5 4 0} \\
\mathbf{5 7 0} \\
600 \\
\mathbf{6 2 0}\end{array}$ & $\begin{array}{l}\mathbf{4 5 0} \\
\mathbf{5 2 0} \\
\mathbf{5 4 0} \\
\mathbf{5 7 0} \\
\mathbf{6 0 0}\end{array}$ & & & $\begin{array}{r}11.8 \\
11.3 \\
9.5 \\
8.7 \\
8.6\end{array}$ & $\begin{array}{l}\mathbf{8 . 9} \\
\mathbf{9 . 5} \\
\mathbf{8 . 3} \\
\mathbf{8 . 3} \\
\mathbf{8 . 0}\end{array}$ & $\begin{array}{l}22 \\
22 \\
22 \\
20 \\
21\end{array}$ & $\begin{array}{l}21 \\
21 \\
19 \\
19 \\
19\end{array}$ & $\begin{array}{l}\mathbf{7 4 0} \\
\mathbf{7 1 0} \\
\mathbf{7 1 0} \\
\mathbf{7 2 0} \\
\mathbf{7 2 0}\end{array}$ & $\begin{array}{l}700 \\
690 \\
680 \\
690 \\
670\end{array}$ & & & $\begin{array}{l}6.6 \\
6.7 \\
6.7 \\
6.3 \\
6.0\end{array}$ & $\begin{array}{l}6.1 \\
5.8 \\
5.8 \\
5.5 \\
5.4\end{array}$ & $\begin{array}{l}23 \\
23 \\
24 \\
24 \\
24\end{array}$ & $\begin{array}{l}22 \\
22 \\
23 \\
23 \\
23\end{array}$ \\
\hline $\begin{array}{l}16 \\
17 \\
18 \\
19 \\
20\end{array}$ & $\begin{array}{l}620 \\
620 \\
660 \\
700 \\
700\end{array}$ & $\begin{array}{l}610 \\
600 \\
610 \\
500 \\
500\end{array}$ & & & $\begin{array}{l}8.0 \\
7.4 \\
7.3 \\
7.0 \\
6.4\end{array}$ & $\begin{array}{l}7.2 \\
7.2 \\
6.9 \\
6.2 \\
6.1\end{array}$ & $\begin{array}{l}21 \\
20 \\
20 \\
20 \\
21\end{array}$ & $\begin{array}{l}20 \\
19 \\
18 \\
18 \\
18\end{array}$ & $\begin{array}{l}690 \\
740 \\
740 \\
790 \\
830\end{array}$ & $\begin{array}{l}670 \\
690 \\
720 \\
700 \\
\mathbf{7 9 0}\end{array}$ & & & $\begin{array}{l}6.2 \\
5.8 \\
5.8 \\
5.7 \\
6.0\end{array}$ & $\begin{array}{l}5.6 \\
5.5 \\
5.3 \\
5.3 \\
5.3\end{array}$ & $\begin{array}{l}24 \\
24 \\
26 \\
26 \\
25\end{array}$ & $\begin{array}{l}23 \\
22 \\
24 \\
24 \\
23\end{array}$ \\
\hline $\begin{array}{l}21 \\
22 \\
23 \\
24 \\
25\end{array}$ & $\begin{array}{l}700 \\
710 \\
690 \\
810 \\
800\end{array}$ & $\begin{array}{l}600 \\
670 \\
640 \\
690 \\
740\end{array}$ & & & $\begin{array}{l}6.3 \\
6.2 \\
6.0 \\
5.8 \\
6.6\end{array}$ & $\begin{array}{l}6.1 \\
5.8 \\
5.8 \\
5.6 \\
5.5\end{array}$ & $\begin{array}{l}20 \\
21 \\
21 \\
23 \\
23\end{array}$ & $\begin{array}{l}19 \\
18 \\
19 \\
21 \\
22\end{array}$ & $\begin{array}{l}810 \\
910 \\
920 \\
830 \\
860\end{array}$ & $\begin{array}{l}\mathbf{7 7 0} \\
\mathbf{7 9 0} \\
\mathbf{7 4 0} \\
\mathbf{7 3 0} \\
\mathbf{7 6 0}\end{array}$ & & & $\begin{array}{l}6.3 \\
5.8 \\
5.5 \\
5.2 \\
5.0\end{array}$ & $\begin{array}{l}5.6 \\
5.3 \\
5.0 \\
5.0 \\
4.9\end{array}$ & $\begin{array}{l}24 \\
24 \\
25 \\
25 \\
25\end{array}$ & $\begin{array}{l}23 \\
23 \\
23 \\
24 \\
24\end{array}$ \\
\hline $\begin{array}{l}26 \\
27 \\
28 \\
29 \\
30 \\
31\end{array}$ & $\begin{array}{r}750 \\
770 \\
900 \\
1030 \\
1400 \\
--\end{array}$ & $\begin{array}{c}630 \\
690 \\
660 \\
710 \\
720 \\
--\end{array}$ & & & $\begin{array}{l}5.7 \\
5.3 \\
5.9 \\
6.0 \\
5.9 \\
-.\end{array}$ & $\begin{array}{r}5.1 \\
5.0 \\
5.4 \\
5.7 \\
5.5 \\
--\end{array}$ & $\begin{array}{l}23 \\
23 \\
21 \\
22 \\
23 \\
--\end{array}$ & $\begin{array}{l}22 \\
21 \\
20 \\
20 \\
21 \\
--\end{array}$ & $\begin{array}{l}810 \\
890 \\
890 \\
760 \\
790 \\
850\end{array}$ & $\begin{array}{l}670 \\
710 \\
760 \\
660 \\
660 \\
760\end{array}$ & & & $\begin{array}{l}5.5 \\
5.5 \\
5.5 \\
5.8 \\
6.1 \\
5.8\end{array}$ & $\begin{array}{l}4.9 \\
5.3 \\
5.3 \\
5.4 \\
5.8 \\
5.7\end{array}$ & $\begin{array}{l}24 \\
24 \\
24 \\
24 \\
24 \\
23\end{array}$ & $\begin{array}{l}24 \\
23 \\
23 \\
23 \\
22 \\
22\end{array}$ \\
\hline
\end{tabular}


03202000 RACCOON CREEK AT ADAHSVILLE, OHIO--CONEInUed

SPECIFIC CONDUCTANCE, PH, DISSOLVED OXYGEN, AND WATER TEMPERATURES, WATER YEAR OCTOBER 1967 TO SEPTEMBER 1968 AUGUST

\begin{tabular}{|c|c|c|}
\hline \multirow[t]{2}{*}{ DAY } & \multicolumn{2}{|c|}{$\begin{array}{l}\text { SPECIFIC } \\
\text { CONDUCTANCE } \\
\text { (UICROMHOS } \\
\text { AT 25 }{ }^{\circ} \mathrm{C} \text { ) }\end{array}$} \\
\hline & MaX & MIN \\
\hline $\begin{array}{l}1 \\
2 \\
3 \\
4 \\
5\end{array}$ & $\begin{array}{l}890 \\
870 \\
870 \\
910 \\
970\end{array}$ & $\begin{array}{l}790 \\
820 \\
830 \\
840 \\
900\end{array}$ \\
\hline $\begin{array}{l}6 \\
7 \\
8\end{array}$ & $\begin{array}{r}930 \\
900 \\
1050\end{array}$ & $\begin{array}{l}770 \\
800 \\
900\end{array}$ \\
\hline $\begin{array}{r}9 \\
10\end{array}$ & $=$ & $=$ \\
\hline $\begin{array}{l}11 \\
12 \\
13 \\
14 \\
15\end{array}$ & $\begin{array}{r}800 \\
980 \\
1130 \\
1140 \\
1010\end{array}$ & $\begin{array}{l}520 \\
630 \\
800 \\
980 \\
800\end{array}$ \\
\hline $\begin{array}{l}16 \\
17 \\
18 \\
19 \\
20\end{array}$ & $\begin{array}{r}1100 \\
1160 \\
930 \\
1010 \\
980\end{array}$ & $\begin{array}{r}1010 \\
730 \\
290 \\
540 \\
740\end{array}$ \\
\hline $\begin{array}{l}21 \\
22 \\
23 \\
24 \\
25\end{array}$ & $\begin{array}{l}880 \\
730 \\
740 \\
640 \\
580\end{array}$ & $\begin{array}{l}700 \\
660 \\
640 \\
570 \\
560\end{array}$ \\
\hline $\begin{array}{l}26 \\
27 \\
28 \\
29 \\
30 \\
31\end{array}$ & $\begin{array}{l}650 \\
670 \\
700 \\
740 \\
760 \\
820\end{array}$ & $\begin{array}{l}560 \\
610 \\
640 \\
680 \\
710 \\
710\end{array}$ \\
\hline
\end{tabular}

\begin{tabular}{|c|c|c|}
\hline H & \multicolumn{2}{|c|}{$\begin{array}{l}\text { DISSOL VED } \\
\text { OXYGEN } \\
\text { (MG /L) }\end{array}$} \\
\hline MIN & $\operatorname{LAX}$ & MIN \\
\hline $\begin{array}{l}=- \\
=- \\
=-\end{array}$ & $\begin{array}{l}5.7 \\
5.6 \\
6.0 \\
5.8 \\
5.6\end{array}$ & $\begin{array}{l}5.5 \\
5.2 \\
5.5 \\
5.5 \\
5.3\end{array}$ \\
\hline$\overline{--}$ & $\begin{array}{l}5.7 \\
5.5 \\
5.6\end{array}$ & $\begin{array}{l}5.2 \\
5.1 \\
5.2\end{array}$ \\
\hline$=$ & -- & - \\
\hline $\begin{array}{l}= \\
z \\
=\end{array}$ & $\begin{array}{l}3.1 \\
3.9 \\
4.3 \\
4.2 \\
4.4\end{array}$ & $\begin{array}{l}2.6 \\
2.9 \\
3.7 \\
4.0 \\
4.0\end{array}$ \\
\hline $\begin{array}{l}\square \\
= \\
=\end{array}$ & $\begin{array}{l}4.6 \\
4.6 \\
4.7 \\
4.9 \\
4.9\end{array}$ & $\begin{array}{l}4.1 \\
4.1 \\
4.0 \\
4.6 \\
4.6\end{array}$ \\
\hline$=$ & $\begin{array}{l}4.7 \\
4.6 \\
4.6 \\
4.6 \\
4.9\end{array}$ & $\begin{array}{l}4.5 \\
4.3 \\
4.4 \\
4.2 \\
4.5\end{array}$ \\
\hline $\begin{array}{r}\overline{-} \\
\overline{3.7} \\
3.9 \\
4.0\end{array}$ & $\begin{array}{l}5.3 \\
5.9 \\
6.0 \\
6.1 \\
6.0 \\
5.8\end{array}$ & $\begin{array}{l}4.9 \\
5.4 \\
5.8 \\
5.8 \\
5.7 \\
5.3\end{array}$ \\
\hline
\end{tabular}

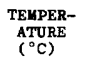

MAX MIN

$\begin{array}{ll}23 & 22 \\ 24 & 22 \\ 24 & 22 \\ 24 & 23\end{array}$

$\begin{array}{ll}24 & 23 \\ 24 & 23\end{array}$

$\begin{array}{ll}26 & 24 \\ 26 & 24\end{array}$

$\begin{array}{ll}26 & 24 \\ 26 & 24\end{array}$

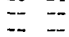

$\begin{array}{ll}23 & 23 \\ 23 & 22\end{array}$

$\begin{array}{ll}22 & 22 \\ 23 & 22\end{array}$

$24 \quad 23$

$\begin{array}{ll}23 & 22 \\ 24 & 23\end{array}$

\begin{tabular}{ll}
24 & 23 \\
25 & 23 \\
\hline
\end{tabular}

$\begin{array}{ll}25 & 23 \\ 25 & 24\end{array}$

$\begin{array}{ll}26 & 25 \\ 26 & 24\end{array}$

$\begin{array}{ll}26 & 24 \\ 26 & 24\end{array}$

$\begin{array}{ll}26 & 24 \\ 27 & 26 \\ 27 & 25\end{array}$

$\begin{array}{ll}27 & 25\end{array}$

$\begin{array}{ll}26 & 23 \\ 23 & 21 \\ 21 & 19\end{array}$

$\begin{array}{ll}21 & 19 \\ 21 & 19 \\ 20 & 18\end{array}$

$\begin{array}{ll}20 & 18 \\ 20 & 19\end{array}$

BIG SANDY RIVER BASIN

\begin{tabular}{|c|c|c|c|c|c|c|c|}
\hline \multicolumn{2}{|c|}{$\begin{array}{l}\text { SPECIFIC } \\
\text { CONDUCTANCE } \\
\text { ( UICROMHOS } \\
\text { AT } 25^{\circ} \mathrm{C} \text { ) }\end{array}$} & \multicolumn{2}{|c|}{ pH } & \multicolumn{2}{|c|}{$\begin{array}{l}\text { DISSOLVED } \\
\text { OXYGEN } \\
(\mathbf{M G} / L)\end{array}$} & \multicolumn{2}{|c|}{$\begin{array}{l}\text { TEMPER- } \\
\text { ATURE } \\
\left({ }^{\circ} \mathrm{C}\right)\end{array}$} \\
\hline MAX & MIN & KAXX & MIN & KAX & MIN & MAX & MIN \\
\hline $\begin{array}{l}820 \\
780 \\
820 \\
790 \\
830\end{array}$ & $\begin{array}{l}760 \\
730 \\
720 \\
730 \\
740\end{array}$ & $\begin{array}{l}4.0 \\
4.1 \\
4.1 \\
4.0 \\
4.0\end{array}$ & $\begin{array}{l}3.9 \\
3.5 \\
3.5 \\
3.2 \\
3.5\end{array}$ & $\begin{array}{l}5.6 \\
5.4 \\
5.5 \\
5.7 \\
5.6\end{array}$ & $\begin{array}{l}5.1 \\
5.1 \\
5.0 \\
5.1 \\
5.0\end{array}$ & $\begin{array}{l}21 \\
21 \\
21 \\
21 \\
21\end{array}$ & $\begin{array}{l}20 \\
19 \\
19 \\
21 \\
21\end{array}$ \\
\hline $\begin{array}{l}910 \\
730 \\
800 \\
900 \\
900\end{array}$ & $\begin{array}{l}690 \\
690 \\
730 \\
690 \\
700\end{array}$ & $\begin{array}{l}-- \\
\ddot{--} \\
--\end{array}$ & $\begin{array}{l}\ddot{-} \\
\ddot{-} \\
=\end{array}$ & $\begin{array}{l}5.7 \\
5.9 \\
5.8 \\
5.9 \\
5.7\end{array}$ & $\begin{array}{l}4.5 \\
5.0 \\
5.4 \\
5.5 \\
5.5\end{array}$ & $\begin{array}{l}21 \\
21 \\
21 \\
21 \\
20\end{array}$ & $\begin{array}{l}20 \\
19 \\
19 \\
19 \\
19\end{array}$ \\
\hline $\begin{array}{l}750 \\
850 \\
910 \\
930 \\
810\end{array}$ & $\begin{array}{l}670 \\
710 \\
810 \\
800 \\
760\end{array}$ & $\begin{array}{l}- \\
\bar{m} \\
-\end{array}$ & $\begin{array}{l}-- \\
=- \\
=\end{array}$ & $\begin{array}{l}6.0 \\
6.2 \\
6.4 \\
6.6 \\
6.7\end{array}$ & $\begin{array}{l}5.6 \\
5.8 \\
6.1 \\
6.2 \\
6.3\end{array}$ & $\begin{array}{l}19 \\
19 \\
18 \\
19 \\
19\end{array}$ & $\begin{array}{l}18 \\
18 \\
17 \\
17 \\
18\end{array}$ \\
\hline $\begin{array}{l}800 \\
820 \\
820 \\
920 \\
840\end{array}$ & $\begin{array}{l}\mathbf{7 7 0} \\
800 \\
790 \\
770 \\
\mathbf{5 5 0}\end{array}$ & $\begin{array}{l}-- \\
\overline{--} \\
--\end{array}$ & $\begin{array}{l}= \\
=- \\
=\end{array}$ & $\begin{array}{l}6.8 \\
6.8 \\
6.8 \\
6.8 \\
6.7\end{array}$ & $\begin{array}{l}6.4 \\
6.5 \\
6.6 \\
6.2 \\
5.8\end{array}$ & $\begin{array}{l}19 \\
19 \\
19 \\
18 \\
19\end{array}$ & $\begin{array}{l}18 \\
19 \\
18 \\
18 \\
17\end{array}$ \\
\hline $\begin{array}{l}870 \\
910 \\
900 \\
900 \\
880\end{array}$ & $\begin{array}{l}630 \\
870 \\
860 \\
840 \\
830\end{array}$ & $\begin{array}{l}\ddot{-} \\
\ddot{-} \\
-\end{array}$ & $\begin{array}{l}=- \\
=- \\
=\end{array}$ & $\begin{array}{l}6.8 \\
6.7 \\
5.0 \\
5.1 \\
5.0\end{array}$ & $\begin{array}{l}5.9 \\
4.9 \\
4.6 \\
4.8 \\
4.8\end{array}$ & $\begin{array}{l}19 \\
21 \\
21 \\
21 \\
21\end{array}$ & $\begin{array}{l}18 \\
19 \\
19 \\
20 \\
20\end{array}$ \\
\hline $\begin{array}{r}840 \\
1020 \\
910 \\
800 \\
710\end{array}$ & $\begin{array}{l}800 \\
790 \\
770 \\
700 \\
670\end{array}$ & $\begin{array}{l}\overline{-} \\
\bar{z} \\
\bar{z}\end{array}$ & $\begin{array}{l}\bar{z} \\
\bar{z} \\
\bar{z}\end{array}$ & $\begin{array}{l}5.2 \\
5.5 \\
5.7 \\
5.8 \\
5.9\end{array}$ & $\begin{array}{l}4.9 \\
5.1 \\
5.3 \\
5.7 \\
5.8\end{array}$ & $\begin{array}{l}21 \\
19 \\
18 \\
17 \\
17\end{array}$ & $\begin{array}{l}19 \\
17 \\
17 \\
17 \\
16\end{array}$ \\
\hline-- & - & $m$ & - & -- & -- & -- & - \\
\hline
\end{tabular}

03209300 RUSSELL FORK AT ELKHORN CITY, KY.

LOCATION.--Lat $37^{\circ} 18^{\prime} 14^{\prime \prime}$, long $82^{\circ} 20^{\prime} 35^{\prime \prime}$, pike County, temperature recorder at gagıng station on left bank, $10 \mathrm{ft}$ downstream from steeí highway bridge on State Highway 80 at Elkhorn City and 0.9 mile upstream from Elkhorn creek.

DRAINAGE AREA, .-554 sq mi.

PERIOD OF RECORD.--Water temperatures: July 1961 to September 1968.

EXTREMES. --1967-68:

Water temperatures: Maximum, $23.0^{\circ} \mathrm{C}$ July $12-28$; minimum, $2.0^{\circ} \mathrm{C}$ Jan. 9-23, $25-28$.

Period of record: Water temperatures: Maximum, $28.0^{\circ} \mathrm{C}$ Aug. 19-21, Sept. 3, 1962; minimum, freezing potnt Jan. 9, 22, 1962,
Jan. 11-13, 1963.

REMARKS.-.Flow regulated by North Fork Pound and John W. Flannagan Reservoirs tn Virginia. TEMPERATURE $\left({ }^{\circ} \mathrm{C}\right)$ OF WATER, WATER YEAR OCTOBER 1967 TO SEPTEMBER 1968 (CONTINUOUS ETHYL ALCOHOL-ACTUATED THERMOGRAPH)

naY

MONTH $123456978910111213141516171812202122232425202720 \Leftrightarrow 3031$ AGE

OCTOBER

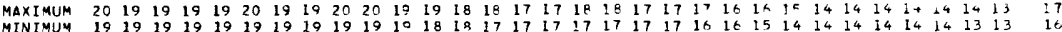
MINIMUM

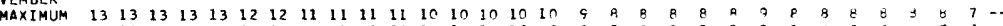

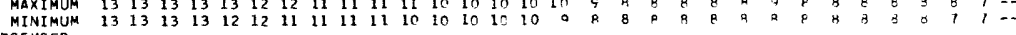
DECEMBER

$\begin{array}{llllllllllllllllllllllllllllllllllllll}\text { MAXIMUM } & 7 & 7 & 7 & 7 & 6 & 6 & 6 & 6 & 6 & 6 & 6 & 6 & 6 & 6 & 6 & 6 & 5 & 4 & 6 & 7 & 7 & 7 & 7 & 6 & 6 & 0 & 0 & 5 & 4 & 3 & 3 \\ \text { MINIMUMM } & 7 & 7 & 7 & 6 & 6 & 6 & 6 & 6 & 6 & 6 & 6 & 6 & 6 & 6 & 6 & 5 & 4 & 4 & 4 & 6 & 7 & 7 & 5 & 6 & 6 & 5 & 5 & 7 & 3 & 3 & 3\end{array}$

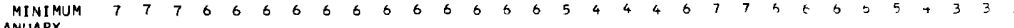
ANUARY $\begin{array}{rllllllllllllllllllllllllllllllll}\text { MAXIMUM } & 3 & 3 & 3 & 3 & 3 & 3 & 3 & 3 & 3 & 2 & 2 & 2 & 2 & 2 & 2 & 2 & 2 & 2 & 2 & 2 & 2 & 2 & 2 & 2 & 3 & 2 & 2 & 3 & 3 & 3 & 4 \\ \text { MINIMUMM } & 3 & 3 & 3 & 3 & 3 & 3 & 3 & 3 & 2 & 2 & 2 & 2 & 2 & 2 & 2 & 2 & 2 & 2 & 2 & 2 & 2 & 2 & 2 & 3 & 2 & 2 & 2 & 4 & 3 & 3 & 3\end{array}$

EBRUARY

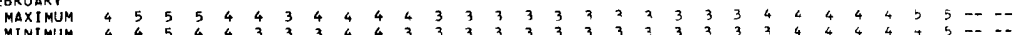

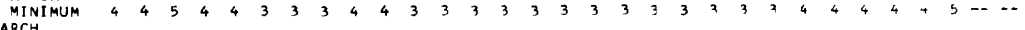

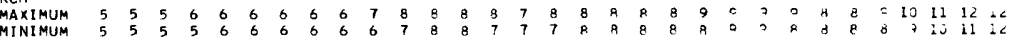

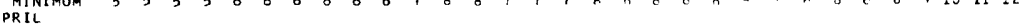

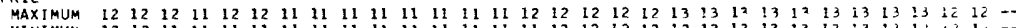

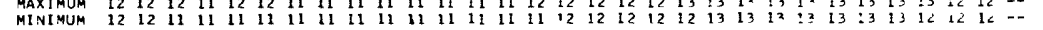

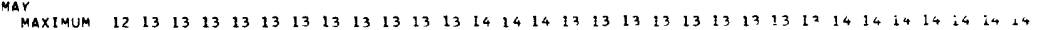

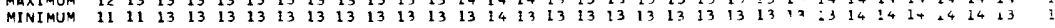

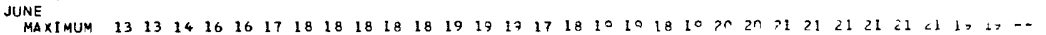

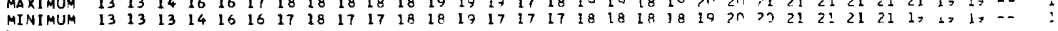

MAXIMUM \begin{tabular}{lllllllllllllllllllllllllllllllll}
\hline & 21 & 21 & 21 & 21 & 21 & 21 & 21 & 22 & 22 & 22 & 23 & 23 & 23 & 23 & 23 & 23 & 23 & 23 & 23 & 23 & 73 & 73 & 22 & 23 & 23 & 23 & 63 & 62 & 41 & 21
\end{tabular}

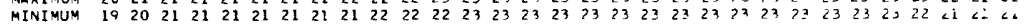
AUGUST

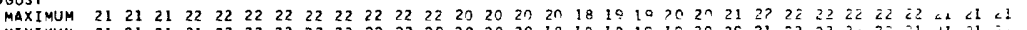

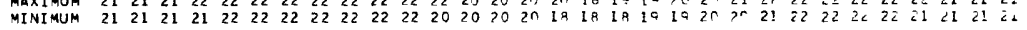
SEPTEMBER

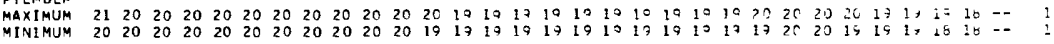


03211500 JOHNS CREEK NEAR YAN LEAR, KY.

LOCATION - $37^{\circ} 44^{\prime} 37^{\prime \prime}$, long $82^{\circ} 43^{\prime} 27^{\prime \prime}$, Johnson County, temperature recorder at gaging station on right bank

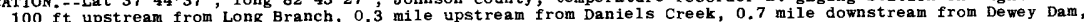
100 ft upstream from Long Branch, 0.

DRAINAGE AREA. --206 sq $m i$.

PERIOD OF RECORD... Water temperatures: APr11 1954 to September 1968.

EXTREMES, $-1967-68$ :

Water temperatures: Maximum, 28. $0^{\circ} \mathrm{C}$ Aug. 11; minimum, 1.0 ${ }^{\circ} \mathrm{C} \mathrm{Jan.} \mathrm{21-23.}$

Period of record:

Water temperatures: Maximum, $32.0^{\circ} \mathrm{C}$ July 3, 1956; minimum, freezing point on several days during December 1962 and January 1963 .

REMARKS...-Flow regulated by Dewey Reservoir.

TEMPERATURE ( $\left.{ }^{\circ} \mathrm{C}\right)$ OF WATER, WATER YEAR OCTOBER 1967 TO SEPTEMBER 1968 (CONTINUOUS ETHYL ALCOHOL-ACTUATED THERMOGRAPH)

\begin{tabular}{|c|c|c|c|c|c|c|c|c|c|c|c|c|}
\hline \multirow[b]{2}{*}{ DAY } & \multicolumn{2}{|c|}{ DCTOBER } & \multicolumn{2}{|c|}{ NOVEMBER } & \multicolumn{2}{|c|}{ DECEMBER } & \multicolumn{2}{|c|}{ JANUARY } & \multicolumn{2}{|c|}{ FEBRUARY } & \multicolumn{2}{|c|}{ MARCF } \\
\hline & MAX & $N I N$ & $\max$ & MIN & MAX & MIN & MAX & MIN & MAX & MIN & MAX & MIN \\
\hline $\begin{array}{l}1 \\
2 \\
3 \\
4 \\
5\end{array}$ & $\begin{array}{l}16.0 \\
16.0 \\
16.0 \\
16.0 \\
16.0\end{array}$ & $\begin{array}{l}16.0 \\
16.0 \\
16.0 \\
16.0 \\
16.0\end{array}$ & $\begin{array}{l}14.0 \\
14.0 \\
14.0 \\
14.0 \\
14.0\end{array}$ & $\begin{array}{l}14.0 \\
14.0 \\
14.0 \\
14.0 \\
14.0\end{array}$ & $\begin{array}{r}9.0 \\
10.0 \\
7.0 \\
8.0 \\
8.0\end{array}$ & $\begin{array}{l}8.0 \\
7.0 \\
7.0 \\
6.0 \\
6.0\end{array}$ & $\begin{array}{l}6.0 \\
5.0 \\
4.0 \\
4.0 \\
4.0\end{array}$ & $\begin{array}{l}5.0 \\
4.0 \\
4.0 \\
4.0 \\
4.0\end{array}$ & $\begin{array}{l}3.0 \\
3.0 \\
3.0 \\
6.0 \\
4.0\end{array}$ & $\begin{array}{l}3.0 \\
3.0 \\
3.0 \\
3.0 \\
4.0\end{array}$ & $\begin{array}{l}6.0 \\
7.0 \\
7.0 \\
7.0 \\
7.0\end{array}$ & $\begin{array}{l}6.0 \\
6.0 \\
7.0 \\
7.0 \\
7.0\end{array}$ \\
\hline $\begin{array}{r}6 \\
7 \\
8 \\
9 \\
10\end{array}$ & $\begin{array}{l}16.0 \\
16.0 \\
17.0 \\
17.0 \\
17.0\end{array}$ & $\begin{array}{l}16.0 \\
16.0 \\
16.0 \\
17.0 \\
16.0\end{array}$ & $\begin{array}{l}14.0 \\
14.0 \\
13.0 \\
13.0 \\
13.0\end{array}$ & $\begin{array}{l}14 . \mathrm{c} \\
13.0 \\
13 . \mathrm{c} \\
13.0 \\
13.0\end{array}$ & $\begin{array}{l}8.0 \\
6.0 \\
8.0 \\
6.0 \\
6.0\end{array}$ & $\begin{array}{l}6 . c \\
6 . c \\
6.0 \\
6 . c \\
6 . c\end{array}$ & $\begin{array}{l}4.0 \\
3.0 \\
4.0 \\
3.0 \\
2.0\end{array}$ & $\begin{array}{l}3.0 \\
3 . c \\
2.0 \\
2.0 \\
2.0\end{array}$ & $\begin{array}{l}4.0 \\
4.0 \\
4.0 \\
4.0 \\
4.0\end{array}$ & $\begin{array}{l}4.0 \\
4.0 \\
4.0 \\
4.0 \\
4.0\end{array}$ & $\begin{array}{l}7.0 \\
6.0 \\
6.0 \\
7.0 \\
7.0\end{array}$ & $\begin{array}{l}6.0 \\
6.0 \\
6.0 \\
t . c \\
7 . c\end{array}$ \\
\hline $\begin{array}{l}11 \\
12 \\
13 \\
14 \\
15\end{array}$ & $\begin{array}{l}16.0 \\
16.0 \\
16.0 \\
16.0 \\
16.0\end{array}$ & $\begin{array}{l}1 \epsilon .0 \\
16.0 \\
16.0 \\
16.0 \\
1 \epsilon .0\end{array}$ & $\begin{array}{l}13.0 \\
13.0 \\
13.0 \\
13.0 \\
13.0\end{array}$ & $\begin{array}{l}13.0 \\
13.0 \\
13.0 \\
13.0 \\
12.0\end{array}$ & $\begin{array}{l}7.0 \\
7.0 \\
8.0 \\
9.0 \\
8.0\end{array}$ & $\begin{array}{l}6 \cdot c \\
7 \cdot c \\
7 \cdot c \\
7 \cdot c \\
7 \cdot 0\end{array}$ & $\begin{array}{l}2.0 \\
4.0 \\
3.0 \\
2.0 \\
2.0\end{array}$ & $\begin{array}{l}2.0 \\
2.0 \\
2.0 \\
2.0 \\
2.0\end{array}$ & $\begin{array}{l}4.0 \\
6.0 \\
5.0 \\
5.0 \\
6.0\end{array}$ & $\begin{array}{l}4.0 \\
4.0 \\
4.0 \\
5.0 \\
5.0\end{array}$ & $\begin{array}{l}7.0 \\
6.0 \\
7.0 \\
7.0 \\
7.0\end{array}$ & $\begin{array}{l}6.0 \\
6 . c \\
6 . c \\
7.0 \\
7.0\end{array}$ \\
\hline $\begin{array}{l}16 \\
17 \\
18 \\
19 \\
20\end{array}$ & $\begin{array}{l}16.0 \\
16.0 \\
16.0 \\
16.0 \\
16.0\end{array}$ & $\begin{array}{l}16.0 \\
16.0 \\
16.0 \\
16.0 \\
16.0\end{array}$ & $\begin{array}{l}12.0 \\
12.0 \\
12.0 \\
12.0 \\
12.0\end{array}$ & $\begin{array}{l}12.0 \\
12.0 \\
12.0 \\
12.0 \\
12.0\end{array}$ & $\begin{array}{l}7.0 \\
7.0 \\
7.0 \\
8.0 \\
8.0\end{array}$ & $\begin{array}{l}7.0 \\
7.0 \\
7.0 \\
7.0 \\
7.0\end{array}$ & $\begin{array}{l}2.0 \\
3.0 \\
2.0 \\
2.0 \\
2.0\end{array}$ & $\begin{array}{l}2.0 \\
2.0 \\
2.0 \\
2.0 \\
2.0\end{array}$ & $\begin{array}{l}5.0 \\
5.0 \\
5.0 \\
5.0 \\
6.0\end{array}$ & $\begin{array}{l}5.0 \\
5.0 \\
5.0 \\
5.0 \\
6.0\end{array}$ & $\begin{array}{l}7.0 \\
7.0 \\
8.0 \\
8.0 \\
8.0\end{array}$ & $\begin{array}{l}7.0 \\
7.0 \\
7.0 \\
8.0 \\
8.0\end{array}$ \\
\hline $\begin{array}{l}21 \\
22 \\
23 \\
24 \\
25\end{array}$ & $\begin{array}{l}16.0 \\
15.0 \\
14.0 \\
14.0 \\
15.0\end{array}$ & $\begin{array}{l}15.0 \\
14.0 \\
14.0 \\
14.0 \\
14.0\end{array}$ & $\begin{array}{l}12.0 \\
11.0 \\
11.0 \\
11.0 \\
11.0\end{array}$ & $\begin{array}{l}11.0 \\
11.0 \\
11.0 \\
11.0 \\
11.0\end{array}$ & $\begin{array}{l}8.0 \\
8.0 \\
8.0 \\
8.0 \\
8.0\end{array}$ & $\begin{array}{l}7.0 \\
7.0 \\
8.0 \\
7.0 \\
7.0\end{array}$ & $\begin{array}{l}2.0 \\
1.0 \\
3.0 \\
4.0 \\
-.-\end{array}$ & $\begin{array}{l}1 . c \\
1.0 \\
1.0 \\
2.0 \\
-\cdots\end{array}$ & $\begin{array}{l}6.0 \\
6.0 \\
6.0 \\
6.0 \\
6.0\end{array}$ & $\begin{array}{l}6.0 \\
6.0 \\
6.0 \\
6.0 \\
6.0\end{array}$ & $\begin{array}{l}8.0 \\
8.0 \\
8.0 \\
8.0 \\
8.0\end{array}$ & $\begin{array}{l}8.0 \\
8.0 \\
8.0 \\
8.0 \\
8.0\end{array}$ \\
\hline $\begin{array}{l}26 \\
27 \\
28 \\
29 \\
30 \\
31\end{array}$ & $\begin{array}{l}15.0 \\
14.0 \\
14.0 \\
14.0 \\
14.0 \\
14.0\end{array}$ & $\begin{array}{l}14.0 \\
14.0 \\
14.0 \\
14.0 \\
14.0 \\
14.0\end{array}$ & $\begin{array}{l}11.0 \\
11.0 \\
10.0 \\
10.0 \\
10.0 \\
---\end{array}$ & $\begin{array}{r}11.0 \\
10.0 \\
10.0 \\
10.0 \\
9.0 \\
0.0\end{array}$ & $\begin{array}{l}8 . C \\
8.0 \\
7.0 \\
6.0 \\
6.0 \\
7.0\end{array}$ & $\begin{array}{l}7 . c \\
7.0 \\
6 . c \\
6 . C \\
6 . c \\
6 . c\end{array}$ & \begin{tabular}{l}
$-\cdots$ \\
\hdashline.- \\
\hdashline.- \\
3.0 \\
3.0
\end{tabular} & $\begin{array}{l}-.- \\
-. . \\
3.0 \\
3.0\end{array}$ & $\begin{array}{l}6.0 \\
7.0 \\
7.0 \\
6.0 \\
--- \\
-\cdots\end{array}$ & $\begin{array}{l}6.0 \\
6.0 \\
6.0 \\
6.0 \\
-. . \\
-.-\end{array}$ & $\begin{array}{r}9.0 \\
9.0 \\
9.0 \\
9.0 \\
9.0 \\
10.0\end{array}$ & $\begin{array}{l}8.0 \\
9.0 \\
9.0 \\
9.0 \\
9.0 \\
9.0\end{array}$ \\
\hline \multirow[t]{2}{*}{ MONTH } & 17.0 & 14.0 & 14.0 & s.c & 10.0 & 6.0 & 0.0 & 1.0 & 7.0 & 3.0 & 10.0 & 6.0 \\
\hline & \multicolumn{2}{|c|}{ APRIL } & \multicolumn{2}{|c|}{ MaY } & \multicolumn{2}{|c|}{ JUNE } & \multicolumn{2}{|c|}{ JuL $Y$} & \multicolumn{2}{|c|}{ AUGUST } & \multicolumn{2}{|c|}{ SEPTEMEER } \\
\hline CAY & $\operatorname{MAX}$ & $M I N$ & $\operatorname{MAx}$ & MIN & $\operatorname{Max}$ & $\operatorname{Min}$ & $\operatorname{mAx}$ & MIN & $\operatorname{MAX}$ & MIN & $\operatorname{MAX}$ & MIN \\
\hline $\begin{array}{l}1 \\
2 \\
3 \\
4 \\
5\end{array}$ & $\begin{array}{r}10.0 \\
9.0 \\
9.0 \\
11.0 \\
11.0\end{array}$ & $\begin{array}{r}9.0 \\
9.0 \\
9.0 \\
5.0 \\
11.0\end{array}$ & $\begin{array}{l}14.0 \\
14.0 \\
13.0 \\
13.0 \\
13.0\end{array}$ & $\begin{array}{l}13.0 \\
13.0 \\
13.0 \\
13.0 \\
13.0\end{array}$ & $\begin{array}{l}19.0 \\
19.0 \\
21.0 \\
21.0 \\
20.0\end{array}$ & $\begin{array}{l}19.0 \\
19.0 \\
19.0 \\
20.0 \\
19.0\end{array}$ & $\begin{array}{l}22.0 \\
27.0 \\
24.0 \\
22.0 \\
22.0\end{array}$ & $\begin{array}{l}21 . c \\
22.0 \\
22.0 \\
22.0 \\
21.0\end{array}$ & $\begin{array}{l}23.0 \\
24.0 \\
22.0 \\
22.0 \\
22.0\end{array}$ & $\begin{array}{l}22.0 \\
22.0 \\
22.0 \\
22.0 \\
22.0\end{array}$ & $\begin{array}{l}24.0 \\
24.0 \\
25.0 \\
25.0 \\
25.0\end{array}$ & $\begin{array}{l}24.0 \\
24.0 \\
24.0 \\
25.0 \\
25.0\end{array}$ \\
\hline $\begin{array}{r}6 \\
7 \\
8 \\
9 \\
10\end{array}$ & $\begin{array}{l}11.0 \\
11.0 \\
11.0 \\
11.0 \\
11.0\end{array}$ & $\begin{array}{l}11.0 \\
11.0 \\
11.0 \\
11.0 \\
11.0\end{array}$ & $\begin{array}{l}13.0 \\
13.0 \\
13.0 \\
13.0 \\
14.0\end{array}$ & $\begin{array}{l}13.0 \\
13.0 \\
13.0 \\
13.0 \\
13.0\end{array}$ & $\begin{array}{l}19.0 \\
19.0 \\
23.0 \\
21.0 \\
21.0\end{array}$ & $\begin{array}{l}19 . \mathrm{C} \\
19.0 \\
19 . \mathrm{C} \\
19 . \mathrm{C} \\
20 . \mathrm{C}\end{array}$ & $\begin{array}{l}21.0 \\
21.0 \\
21.0 \\
21.0 \\
21.0\end{array}$ & $\begin{array}{l}21.0 \\
21.0 \\
21.0 \\
21.0 \\
21.0\end{array}$ & $\begin{array}{l}26.0 \\
23.0 \\
23.0 \\
27.0 \\
25.0\end{array}$ & $\begin{array}{l}22.0 \\
23.0 \\
23.0 \\
23.0 \\
23.0\end{array}$ & $\begin{array}{l}25.0 \\
25.0 \\
25.0 \\
25.0 \\
25.0\end{array}$ & $\begin{array}{l}25.0 \\
25.0 \\
25.0 \\
23.0 \\
24.0\end{array}$ \\
\hline $\begin{array}{l}11 \\
12 \\
13 \\
14 \\
15\end{array}$ & $\begin{array}{l}11.0 \\
13.0 \\
11.0 \\
11.0 \\
11.0\end{array}$ & $\begin{array}{l}11.0 \\
11.0 \\
11.0 \\
11.0 \\
11.0\end{array}$ & $\begin{array}{l}16.0 \\
15.0 \\
14.0 \\
17.0 \\
17.0\end{array}$ & $\begin{array}{l}14.0 \\
14.0 \\
14.0 \\
14.0 \\
15.0\end{array}$ & $\begin{array}{l}20.0 \\
24.0 \\
23.0 \\
21.0 \\
22.0\end{array}$ & $\begin{array}{l}20 \cdot c \\
20.0 \\
21.0 \\
21.0 \\
21.0\end{array}$ & $\begin{array}{l}21.0 \\
21.0 \\
21.0 \\
24.0 \\
22.0\end{array}$ & $\begin{array}{l}21.0 \\
21.0 \\
21.0 \\
21.0 \\
22.0\end{array}$ & $\begin{array}{l}28.0 \\
24.0 \\
23.0 \\
24.0 \\
25.0\end{array}$ & $\begin{array}{l}23.0 \\
23.0 \\
23.0 \\
23.0 \\
22.0\end{array}$ & $\begin{array}{l}25.0 \\
25.0 \\
25.0 \\
25.0 \\
25.0\end{array}$ & $\begin{array}{l}25.0 \\
25.0 \\
25.0 \\
24.0 \\
24.0\end{array}$ \\
\hline $\begin{array}{l}16 \\
17 \\
18 \\
19 \\
20\end{array}$ & $\begin{array}{l}11.0 \\
11.0 \\
11.0 \\
12.0 \\
12.0\end{array}$ & $\begin{array}{l}11.0 \\
11.0 \\
11.0 \\
11.0 \\
12.0\end{array}$ & $\begin{array}{l}16.0 \\
17.0 \\
16.0 \\
16.0 \\
16.0\end{array}$ & $\begin{array}{l}15.0 \\
15.0 \\
15.0 \\
16.0 \\
16.0\end{array}$ & $\begin{array}{l}21.0 \\
24.0 \\
22.0 \\
21.0 \\
21.0\end{array}$ & $\begin{array}{l}21.0 \\
21.0 \\
21.0 \\
21.0 \\
21.0\end{array}$ & $\begin{array}{l}22.0 \\
22.0 \\
22.0 \\
22.0 \\
24.0\end{array}$ & $\begin{array}{l}22.0 \\
22.0 \\
22.0 \\
22.0 \\
22.0\end{array}$ & $\begin{array}{l}23.0 \\
25.0 \\
26.0 \\
26.0 \\
23.0\end{array}$ & $\begin{array}{l}22.0 \\
23.0 \\
23.0 \\
23.0 \\
23.0\end{array}$ & $\begin{array}{l}25.0 \\
26.0 \\
24.0 \\
24.0 \\
24.0\end{array}$ & $\begin{array}{l}25.0 \\
23.0 \\
24.0 \\
24.0 \\
24.0\end{array}$ \\
\hline $\begin{array}{l}21 \\
22 \\
23 \\
24 \\
25\end{array}$ & $\begin{array}{l}12.0 \\
12.0 \\
12.0 \\
12.0 \\
12.0\end{array}$ & $\begin{array}{l}12.0 \\
12.0 \\
12.0 \\
12.0 \\
12.0\end{array}$ & $\begin{array}{l}16.0 \\
16.0 \\
16.0 \\
17.0 \\
17.0\end{array}$ & $\begin{array}{l}16 . c \\
16 . c \\
16.0 \\
16 . c \\
16.0\end{array}$ & $\begin{array}{l}21.0 \\
21.0 \\
21.0 \\
21.0 \\
21.0\end{array}$ & $\begin{array}{l}21.0 \\
21.0 \\
21.0 \\
21.0 \\
21.0\end{array}$ & $\begin{array}{l}22.0 \\
24.0 \\
23.0 \\
23.0 \\
27.0\end{array}$ & $\begin{array}{l}22.0 \\
22.0 \\
23.0 \\
23.0 \\
23.0\end{array}$ & $\begin{array}{l}23.0 \\
23.0 \\
23.0 \\
24.0 \\
24.0\end{array}$ & $\begin{array}{l}23.0 \\
23.0 \\
23.0 \\
23.0 \\
24.0\end{array}$ & $\begin{array}{l}24.0 \\
24.0 \\
25.0 \\
25.0 \\
27.0\end{array}$ & $\begin{array}{l}24.0 \\
24.0 \\
24.0 \\
25.0 \\
23.0\end{array}$ \\
\hline $\begin{array}{l}26 \\
27 \\
28 \\
29 \\
30 \\
21\end{array}$ & $\begin{array}{r}12.0 \\
12.0 \\
12.0 \\
13.0 \\
14.0 \\
-\end{array}$ & $\begin{array}{r}12.0 \\
12.0 \\
12.0 \\
12.0 \\
12.0 \\
\ldots \ldots\end{array}$ & $\begin{array}{l}16.0 \\
21.0 \\
19.0 \\
19.0 \\
22.0 \\
21.0\end{array}$ & $\begin{array}{l}16.0 \\
16.0 \\
19.0 \\
18.0 \\
18.0 \\
19.0\end{array}$ & $\begin{array}{l}21.0 \\
21.0 \\
21.0 \\
21.0 \\
21.0 \\
\ldots\end{array}$ & $\begin{array}{r}21.0 \\
21.0 \\
21.0 \\
21.0 \\
21.0 \\
\ldots\end{array}$ & $\begin{array}{l}26.0 \\
23.0 \\
23.0 \\
23.0 \\
27.0 \\
24.0\end{array}$ & $\begin{array}{l}23.0 \\
23.0 \\
23.0 \\
23.0 \\
23.0 \\
23.0\end{array}$ & $\begin{array}{l}24.0 \\
24.0 \\
24.0 \\
24.0 \\
24.0 \\
24.0\end{array}$ & $\begin{array}{l}24.0 \\
24.0 \\
24.0 \\
24.0 \\
24.0 \\
24.0\end{array}$ & $\begin{array}{l}27.0 \\
26.0 \\
26.0 \\
26.0 \\
24.0 \\
\end{array}$ & $\begin{array}{l}26.0 \\
26.0 \\
26.0 \\
24.0 \\
24.0 \\
\ldots . .0\end{array}$ \\
\hline ITH & 14.0 & 5.0 & 22.0 & 13.0 & 24.0 & 1 s. C & 27.0 & 21.0 & 28.0 & 22.0 & 27.0 & 23.0 \\
\hline
\end{tabular}


03212500 LEVISA FORK AT PAINTSVILLE, KY.

LOCATION.--Lat $37^{\circ} 48^{\prime} 55^{\prime \prime}$, long $82^{\circ} 47^{\prime} 30^{\prime \prime}$, Jobnson County, at bridge on State Highway 40 at Paintsville, 200 ft downstream from paint Creek and 700 ft upstream from gaging station.

DRAINAGE AREA. $--2,143 \mathrm{sq} \mathrm{ml}$.

PERIOD OF RECORD. --Chemical analyses: October 1949 to Karch 1953, November 1960 to September 1961.

Water temperatures: October 1949 to March 1953, November 1960 to September 1968.

Sediment records: October 1952 to March 1953, October 1960 to September 1968.

EXTREMES. --1967-68:

Nater temperatures: Maximum, $29.0^{\circ} \mathrm{C}$ on several days during July and August; minimum, freezing point Jan. 21 , Feb. 23, 28.

Sediment concentrations: Maximum daily, $1,620 \mathrm{mg} / 1$ Aug. 16 ; minimum da1ly, $4 \mathrm{mg} / 1$ Feb. 18.

Sediment loads: Maximum dally, 56,800 tons Dec. 23; minimum daily, 3.0 tons Oct. 7.

Period of record:

ater temperatures: Maximum, $31.5^{\circ} \mathrm{C}$ July 21, 23, 1952, July 27, 1963; minimum, freezing point on many days

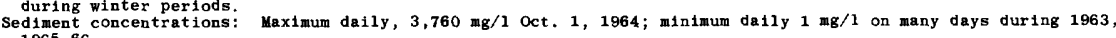

Sediment ioads: Maximum da1ly, 402,000 tons Mar. 13, 1963; minimum da11y, 0.25 ton Jan. $28,1966$.

REMARKS. --Flow slightly regulated by North Fork Pound and John $\pi$. Flannagan Reservoirs in Virginia and Dewey Reservoir.

IEMPERATURE $\left({ }^{\circ} \mathrm{C}\right)$ OF WATER, WATER YEAR OCTOBER 1967 TO SEPTEMBER 1968 (ONCE-DAILY MEASUREMEN T AT 1700 )

\begin{tabular}{|c|c|c|c|c|c|c|c|c|c|c|c|c|}
\hline DAY & CCT & NOV & DEC & JAN & FEB & MAR & $A P R$ & MAY & JUN & NL & AUG & SEP \\
\hline $\begin{array}{l}1 \\
2 \\
3 \\
4 \\
5\end{array}$ & $\begin{array}{r}18.0 \\
17.0 \\
18.0 \\
21.0 \\
-. .\end{array}$ & $\begin{array}{l}13.0 \\
14.0 \\
14.0 \\
11.0 \\
10.0\end{array}$ & $\begin{array}{l}6.0 \\
4.0 \\
4.0 \\
6.0 \\
4.0\end{array}$ & $\begin{array}{l}--- \\
--\overline{-} \\
---\end{array}$ & $\begin{array}{l}6.0 \\
5.0 \\
8.0 \\
4.0 \\
7.0\end{array}$ & $\begin{array}{l}1.0 \\
1.0 \\
1.0 \\
3.0\end{array}$ & $\begin{array}{l}10.0 \\
12.0 \\
12.0 \\
10.0 \\
10.0\end{array}$ & $\begin{array}{l}16.0 \\
16.0 \\
16.0 \\
16.0 \\
19.0\end{array}$ & $\begin{array}{l}21.0 \\
18.0 \\
10.0 \\
16.0 \\
21.0\end{array}$ & $\begin{array}{l}29.0 \\
28.0 \\
24.0 \\
24.0 \\
23.0\end{array}$ & $\begin{array}{l}23.0 \\
24.0 \\
25.0 \\
27.0 \\
27.0\end{array}$ & $\begin{array}{l}23.0 \\
23.0 \\
24.0 \\
22.0 \\
22.0\end{array}$ \\
\hline $\begin{array}{r}6 \\
7 \\
8 \\
9 \\
10\end{array}$ & $\begin{array}{l}18.0 \\
21.0 \\
21.0 \\
21.0 \\
21.0\end{array}$ & \begin{tabular}{r}
$-1-$ \\
\hdashline 9.0 \\
7.0 \\
12.0
\end{tabular} & $\begin{array}{l}5.0 \\
4.0 \\
5.0 \\
9.0\end{array}$ & $\begin{array}{l}--- \\
-\cdots \\
--- \\
--\end{array}$ & $\begin{array}{l}4.0 \\
0.0 \\
6.0 \\
4.0 \\
-. .\end{array}$ & $\begin{array}{l}4.0 \\
4.0 \\
7.0 \\
7.0 \\
6.0\end{array}$ & $\begin{array}{l}14.0 \\
14.0 \\
13.0 \\
16.0 \\
10.0\end{array}$ & $\begin{array}{l}16.0 \\
19.0 \\
19.0 \\
19.0\end{array}$ & $\begin{array}{l}17.0 \\
19.0 \\
20.0 \\
21.0 \\
22.0\end{array}$ & $\begin{array}{l}24.0 \\
26.0 \\
26.0 \\
27.0 \\
28.0\end{array}$ & $\begin{array}{l}27.0 \\
28.0 \\
29.0 \\
29.0 \\
27.0\end{array}$ & $\begin{array}{l}23.0 \\
22.0 \\
23.0 \\
23.0 \\
22.0\end{array}$ \\
\hline $\begin{array}{l}11 \\
12 \\
13 \\
14 \\
15\end{array}$ & $\begin{array}{l}16.0 \\
20.0 \\
17.0 \\
16.0 \\
19.0\end{array}$ & $\begin{array}{r}10.0 \\
11.0 \\
10.0 \\
9.0 \\
8.0\end{array}$ & $\begin{array}{l}6.0 \\
7.0 \\
5.0 \\
5.0 \\
4.0\end{array}$ & $\begin{array}{l}=- \\
--- \\
--\end{array}$ & $\begin{array}{r}11.0 \\
3.0 \\
4.0 \\
4.0 \\
3.0\end{array}$ & $\begin{array}{l}6.0 \\
2.0 \\
3.0 \\
1.0 \\
2.0\end{array}$ & $\begin{array}{l}13.0 \\
10.0 \\
10.0 \\
10.0 \\
10.0\end{array}$ & $\begin{array}{l}16.0 \\
20.0 \\
19.0 \\
16.0 \\
16.0\end{array}$ & $\begin{array}{l}24.0 \\
24.0 \\
16.0 \\
21.0 \\
21.0\end{array}$ & $\begin{array}{l}29.0 \\
29.0 \\
29.0 \\
27.0 \\
27.0\end{array}$ & $\begin{array}{l}25.0 \\
22.0 \\
22.0 \\
22.0 \\
23.0\end{array}$ & $\begin{array}{l}21.0 \\
21.0 \\
20.0 \\
21.0 \\
21.0\end{array}$ \\
\hline $\begin{array}{l}16 \\
17 \\
18 \\
19 \\
20\end{array}$ & $\begin{array}{l}19.0 \\
18.0 \\
10.0 \\
14.0 \\
21.0\end{array}$ & $\begin{array}{l}8.0 \\
9.0 \\
9.0 \\
6.0 \\
4.0\end{array}$ & $\begin{array}{l}4.0 \\
2.0 \\
1.0 \\
3.0 \\
-.\end{array}$ & $\begin{array}{l}\cdots- \\
\cdots- \\
\cdots-0\end{array}$ & $\begin{array}{l}3.0 \\
2.0 \\
2.0 \\
2.0 \\
1.0\end{array}$ & $\begin{array}{r}1.0 \\
2.0 \\
4.0 \\
7.0 \\
13.0\end{array}$ & $\begin{array}{l}10.0 \\
11.0 \\
14.0 \\
16.0 \\
16.0\end{array}$ & $\begin{array}{l}16.0 \\
16.0 \\
16.0 \\
16.0 \\
16.0\end{array}$ & $\begin{array}{l}22.0 \\
22.0 \\
21.0 \\
21.0 \\
22.0\end{array}$ & $\begin{array}{l}26.0 \\
26.0 \\
26.0 \\
26.0 \\
27.0\end{array}$ & $\begin{array}{l}24.0 \\
24.0 \\
24.0 \\
24.0 \\
27.0\end{array}$ & $\begin{array}{l}23.0 \\
23.0 \\
21.0 \\
21.0 \\
22.0\end{array}$ \\
\hline $\begin{array}{l}21 \\
22 \\
23 \\
24 \\
25\end{array}$ & $\begin{array}{r}14.0 \\
13.0 \\
14.0 \\
13.0\end{array}$ & $\begin{array}{l}5.0 \\
5.0 \\
4.0 \\
3.0 \\
8.0\end{array}$ & $\begin{array}{l}--- \\
-\cdots \\
-\square \\
--\end{array}$ & $\begin{array}{l}0.0 \\
0.0 \\
4.0 \\
1.0 \\
2.0\end{array}$ & $\begin{array}{l}2 . \mathrm{c} \\
1.0 \\
0.0 \\
1 . \mathrm{c} \\
1.0\end{array}$ & $\begin{array}{r}6.0 \\
11.0 \\
8.0 \\
9.0 \\
10.0\end{array}$ & $\begin{array}{l}16.0 \\
22.0 \\
21.0 \\
16.0 \\
13.0\end{array}$ & $\begin{array}{l}16.0 \\
16.0 \\
16.0 \\
16.0 \\
17.0\end{array}$ & $\begin{array}{l}21.0 \\
22.0 \\
24.0 \\
24.0 \\
-\end{array}$ & $\begin{array}{l}28.0 \\
29.0 \\
29.0 \\
26.0 \\
28.0\end{array}$ & $\begin{array}{l}28.0 \\
28.0 \\
29.0 \\
29.0 \\
27.0\end{array}$ & $\begin{array}{l}22.0 \\
24.0 \\
22.0 \\
24.0 \\
21.0\end{array}$ \\
\hline $\begin{array}{l}26 \\
27 \\
28 \\
29 \\
30 \\
31\end{array}$ & $\begin{array}{l}13.0 \\
14.0 \\
11.0 \\
12.0 \\
13.0 \\
13.0\end{array}$ & $\begin{array}{r}14.0 \\
4.0 \\
14.0 \\
8.0 \\
7.0 \\
-.-2\end{array}$ & $\begin{array}{l}--- \\
--- \\
--- \\
--- \\
--\end{array}$ & $\begin{array}{r}2.0 \\
6.0 \\
6.0 \\
11.0 \\
7.0 \\
6.0\end{array}$ & \begin{tabular}{l}
1.0 \\
1.0 \\
0.0 \\
1.0 \\
\hdashline.--
\end{tabular} & $\begin{array}{r}10.0 \\
9.0 \\
15.0 \\
10.0 \\
10.0 \\
9.0\end{array}$ & $\begin{array}{l}16.0 \\
16.0 \\
21.0 \\
16.0 \\
16.0 \\
-\end{array}$ & $\begin{array}{l}17.0 \\
16.0 \\
16.0 \\
16.0 \\
16.0 \\
18.0\end{array}$ & $\begin{array}{r}24.0 \\
--- \\
24.0 \\
26.0 \\
28.0 \\
---\end{array}$ & $\begin{array}{l}26.0 \\
24.0 \\
27.0 \\
26.0 \\
26.0 \\
24.0\end{array}$ & $\begin{array}{l}26.0 \\
23.0 \\
22.0 \\
22.0 \\
22.0 \\
23.0\end{array}$ & $\begin{array}{r}22.0 \\
22.0 \\
19.0 \\
21.0 \\
21.0 \\
-\end{array}$ \\
\hline VERAGE & 16.5 & 9.0 & --- & --- & 3.5 & 0.0 & 14.0 & 17.0 & 21.5 & 26.5 & 25.0 & 22.0 \\
\hline
\end{tabular}

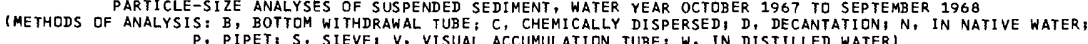
P. PIPET; S, SIEVE; $V$, VISUAL ACCUMULATION TUBE; W, IN DISTILLED WATER,

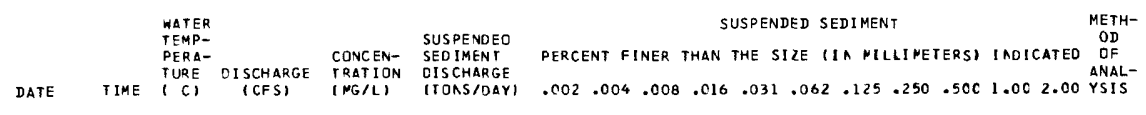


03212500 LEVISA FORK AT PAINTSVILLE, KY.--Continued

SUSPENDED SEDIMENT, WATER YEAR OCTOBER 1967 TO SEPTEMBER 1968

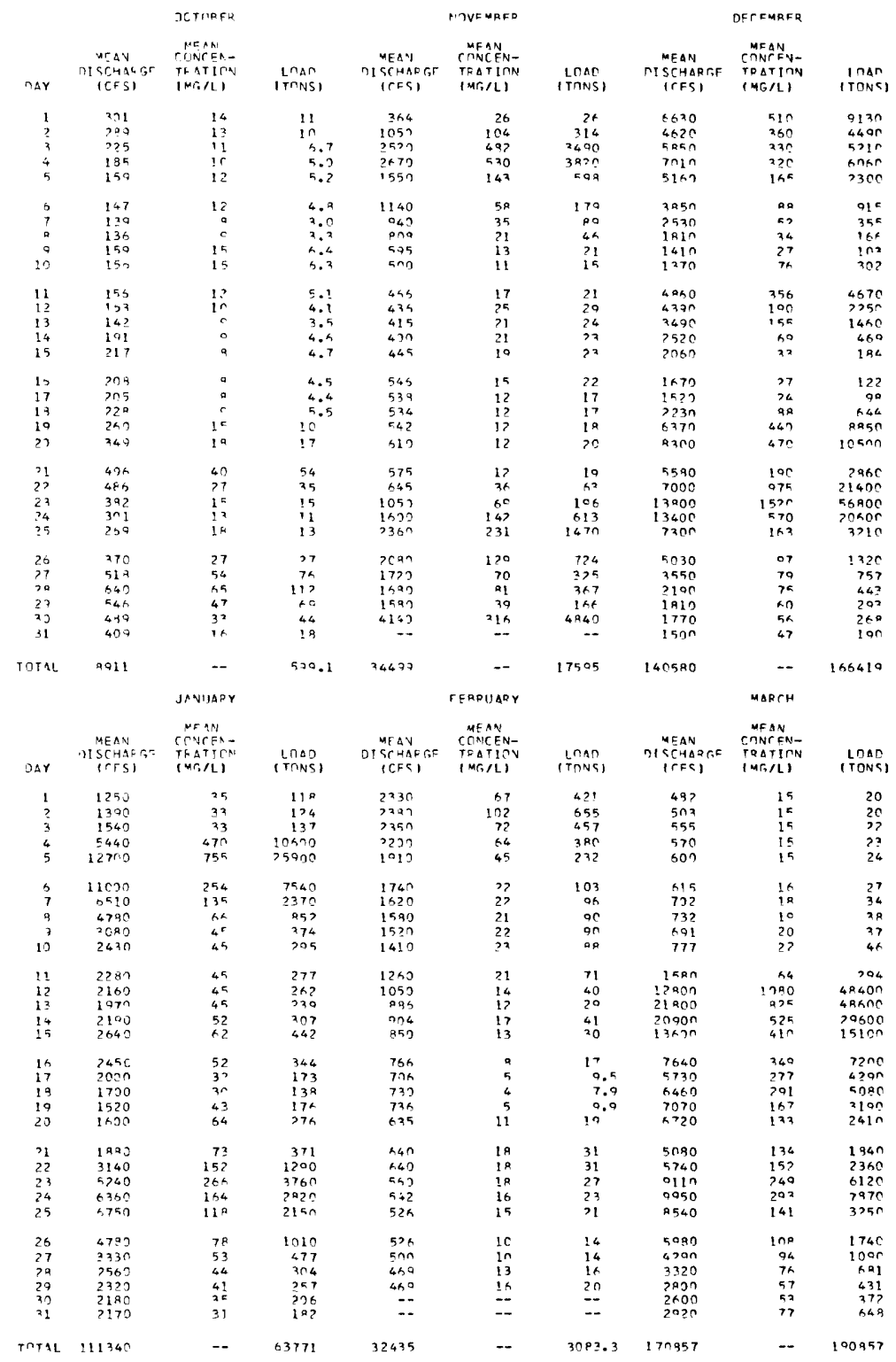


BIG SANDY RIVER BASIN

03212500 LEVISA FORK AT PAINTSVILLE, KY.--Continued

SUSPENDED SEDIMENT, WATER YEAR OCTOBER 1967 TO SEPTEMBER 1968

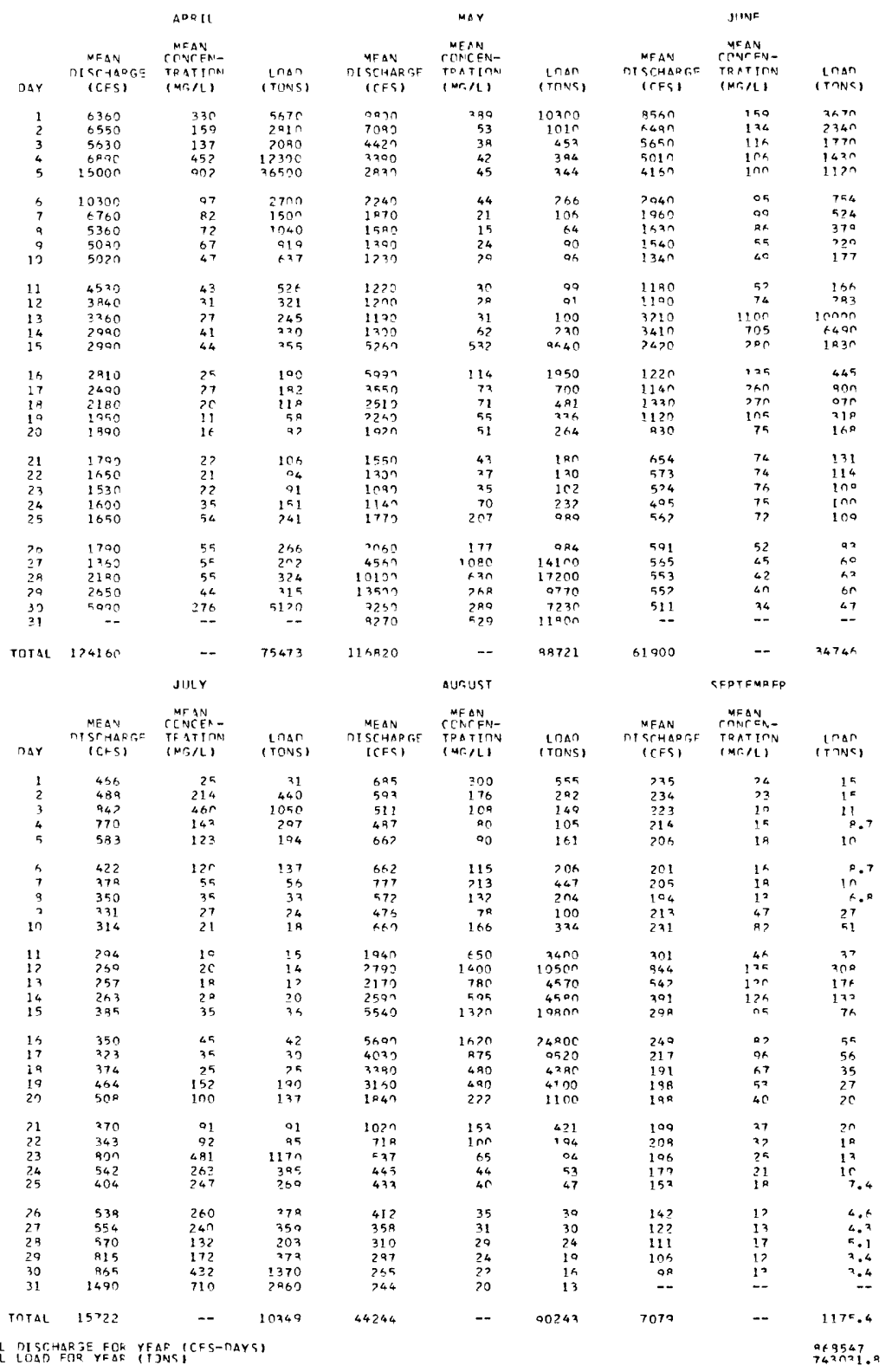


LOCATION.-- Lat $37^{\circ} 50^{\prime} 17^{\prime \prime}$, long $82^{\circ} 24^{\prime} 35^{\prime \prime}$, Mingo County, at city waterplant at Kermit, 0.8 mile downstream from Wolf Creek and 3 miles downstream from gaging station near Kermit.

DRAINAGE AREA.--1,274 sq mi at waterplant; 1,185 sq mi at gaging station.

PERIOD OF RECORD. - Water temperatures: October 1946 to September 1968.

EXTREMES. --1967-68:

Water temperatures: Maximum, $26.0^{\circ} \mathrm{C}$ Aug. 21-24; minimum, 2.0 ${ }^{\circ} \mathrm{C} \mathrm{Feb.} \mathrm{12,} \mathrm{14,} \mathrm{17,} 19$.

Period of record:

Water temperatures: Maximum, $32.0^{\circ} \mathrm{C}$ July 29, 1949 ; minimum, freezing point on several days $1 \mathrm{n} 1947$ and 1951.

\begin{tabular}{|c|c|c|c|c|c|c|c|c|c|c|c|c|}
\hline DAY & $\mathrm{OCT}$ & NuV & DEC & JAN & FEB & $\begin{array}{l}-Y \\
M A R\end{array}$ & $\begin{array}{c}\text { REMENT } \\
\text { APR }\end{array}$ & MAY & JUN & JUL & $A \cup G$ & SEP \\
\hline 1 & 16.0 & 23.0 & 3.0 & 4.0 & 9.0 & 3.3 & 18.0 & 11.0 & 11.0 & 16.0 & 20.0 & 19.0 \\
\hline 2 & 17.0 & 12.0 & 13.0 & 3.0 & 10.0 & 7.0 & 12.0 & 12.0 & 13.0 & IB. 0 & 21.0 & 18.0 \\
\hline 3 & 17.0 & 13.0 & 13.0 & 4.0 & 12.0 & 7.0 & 13.0 & 13.0 & 13.0 & 18.0 & 21.0 & 18.0 \\
\hline 4 & 18.0 & 13.0 & 7.0 & 4.0 & 10.0 & 6.0 & 14.0 & 13.0 & 13.0 & 23.0 & 24.0 & 19.0 \\
\hline 5 & 19.0 & 18.0 & 8.0 & 4.0 & 9.0 & 7.0 & 12.0 & 12.0 & 13.0 & 23.0 & 21.0 & 21.0 \\
\hline 0 & 21.0 & 12.0 & 8.0 & 4. C & $7 . \mathrm{C}$ & 8.0 & 14.0 & 12.0 & 21.0 & 22.0 & 22.0 & 21.0 \\
\hline 7 & 20.0 & 0.0 & 10.0 & 4.0 & 7.0 & 7.0 & 13.0 & 11.0 & 21.0 & 23.0 & 23.0 & 21.0 \\
\hline 8 & 16.0 & 0.0 & 10.0 & $3 . \mathrm{c}$ & 9.0 & 7.0 & 13.0 & 11.0 & 13.0 & 23.0 & 23.0 & 21.0 \\
\hline 9 & 19.0 & 7.0 & 10.0 & 8.0 & 10.0 & 11.0 & 12.0 & 12.0 & 13.0 & 24.0 & 24.0 & 21.0 \\
\hline 10 & 10.0 & 9. 0 & 12.0 & 9.0 & 5.0 & 13.0 & 13.0 & 13.0 & 14.0 & 24.0 & 22.0 & 20.0 \\
\hline 11 & 14.0 & B. 0 & 11.0 & 3.0 & 0.0 & 13.0 & 12.0 & 12.0 & 13.0 & 24.0 & 22.0 & 10.0 \\
\hline 12 & 13.0 & 16.0 & 12.0 & 4.0 & 2.0 & 11.0 & 13.0 & 13.0 & 10.0 & 25.0 & 21.0 & 18. 0 \\
\hline 11 & 12.0 & 13.0 & 10.0 & 10.0 & 3.0 & 6.0 & 16.0 & 13.0 & 13.0 & 24.0 & 21.0 & 18.0 \\
\hline 14 & 16.0 & 11.0 & 9.0 & 9.0 & 2.0 & 7.0 & 12.0 & 12.0 & 11.0 & 24.0 & 21.0 & 17.0 \\
\hline 15 & 10.0 & S. 0 & 9.0 & 8.0 & 4.0 & 9.0 & 23.0 & 13.0 & 12.0 & 24.0 & 21.0 & 21.0 \\
\hline 16 & $16 . \mathrm{C}$ & 3.0 & 10.0 & 4.0 & 3.0 & 0.0 & 13.0 & 14.0 & 13.0 & 25.0 & 21.0 & 21.0 \\
\hline 17 & 17.0 & 7.0 & 10.0 & 4. 0 & 2. c & 13.0 & 14.0 & 13.0 & 12.0 & 23.0 & 21.0 & 21.0 \\
\hline 18 & 18.0 & 7.0 & 8.0 & 3.0 & 3.0 & 12.0 & 13.0 & 13.0 & 13.0 & 24.0 & 23.0 & 21.0 \\
\hline 19 & 18.0 & 7.0 & 10.0 & 3.3 & 2.0 & 13.0 & 14.0 & 13.0 & 14.0 & 23.0 & 24.0 & 21.0 \\
\hline 20 & 18.0 & 7.0 & 10.0 & $4 \cdot C$ & 3.0 & 13.0 & 13.0 & 11.0 & 14.0 & 21.0 & 24.0 & 20.0 \\
\hline 21 & 19.0 & 10.0 & 11.0 & 9.0 & 3.0 & 13.0 & 14.0 & 10.0 & 13.0 & 23.0 & 26.0 & zl. 0 \\
\hline 22 & 18.0 & 13.0 & 12.0 & 9.0 & 3.0 & 13.0 & 14.0 & 11.0 & 13.0 & 24.0 & 26.0 & 21.0 \\
\hline 23 & 18.0 & 13.0 & 10.0 & 9.0 & 3.0 & 13.0 & 14.0 & 12.0 & 14.0 & 23.0 & 26.0 & 21.0 \\
\hline 24 & 19.0 & 13.0 & 7.0 & $7 . c$ & 3.0 & 8. 0 & 13.0 & 12.0 & 16.0 & 24.0 & 26.0 & 21.0 \\
\hline 25 & 16.0 & 12.0 & 7.0 & 4.0 & 4.0 & 11.0 & 12.0 & 10.0 & 15.0 & 24.0 & 24.0 & 21.0 \\
\hline 26 & 13.0 & 13.0 & 6.0 & 4.0 & 4. $\mathrm{C}$ & 10.0 & 12.0 & 10.0 & 14.0 & 23.0 & 21.0 & 21.0 \\
\hline 27 & 14.0 & 0.0 & 4.0 & 7.0 & 5.0 & 10.0 & 12.0 & 11.0 & 14.0 & 22.0 & 20.0 & 21.0 \\
\hline 28 & 13.0 & 7.0 & 4.0 & B. 0 & 7.0 & 16.0 & 13.0 & 12.0 & 12.0 & 22.0 & 18.0 & 20.0 \\
\hline 29 & 9.1 & 6.0 & 4.0 & 9.0 & 5.0 & 18.0 & 12.0 & 13.0 & 13.0 & 23.0 & 18.0 & 21.0 \\
\hline 30 & Q. 0 & 7.0 & 3.0 & 9.0 & $\ldots$ & 18.0 & 12.0 & 10.0 & 14.0 & 21.0 & 19.0 & 20.0 \\
\hline 31 & 12.0 & $\cdots$ & 4.0 & 9.0 & -- & 11.0 & -- & 11.0 & $\cdots$ & 21.0 & 18.0 & $\cdots$ \\
\hline RAGE & 10.0 & 10.0 & 8. 5 & 6.0 & 5.5 & 10.5 & 13.0 & 12.0 & 13.5 & 22.5 & 22.0 & 20.0 \\
\hline
\end{tabular}

LITTLE SANDY RIVER BASIN

03216350 LITTLE SANDY RIVER BELOW GRAYSON DAN, NEAR LEON, KY.

LOCATION.--Lat $38^{\circ} 15^{\prime} 18^{\prime \prime}$, long $82^{\circ} 59^{\prime} 25^{\prime \prime}$, Carter County, temperature recorder at gaging station on right bank, approximately $1,200 \mathrm{ft}$ downstream from Grayson Dam, 0.4 mile upstream from Big Sinking Creek, and 2.4 miles southwest of Leon.

DRAINAGE AREA.--196 sq mi.

PERIOD OF RECORD.--Water temperatures: October 1967 to September 1968.

EXTREMES. - - 1967-68:

Water temperatures: Maximum, $32.0^{\circ} \mathrm{C}$ July $23 ;$ minimum, $1.0^{\circ} \mathrm{C}$ on many days during January.

REMARKS. - Water-temperature records furnished by Corps of Engineers, Flow regulated by Grayson Reservoir. TEMPERATURE ( $\left.{ }^{\circ} \mathrm{C}\right)$ OF WATER, WATER YEAR OCTOBER 1967 TO SEPTEMBER 1968

\begin{tabular}{|c|c|c|c|c|c|c|c|c|c|c|c|c|}
\hline \multirow[b]{2}{*}{ CAY } & \multicolumn{2}{|c|}{ OCTUBER } & \multicolumn{2}{|c|}{ NOVEMAER } & \multicolumn{2}{|c|}{ UECEMBER } & \multicolumn{2}{|c|}{ JANUARY } & \multicolumn{2}{|c|}{ FEBRUARY } & \multicolumn{2}{|c|}{ MARCH } \\
\hline & MAX & NIN & $M \Delta x$ & $M I N$ & $\operatorname{MAX}$ & $M I N$ & $\max$ & MIN & $\operatorname{MAX}$ & $M[N$ & $\max$ & MIA \\
\hline 1 & 20.0 & 15.0 & 13.0 & 12.0 & $4 . C$ & 4. $C$ & 2.0 & 1.0 & 4.0 & 3.0 & 3.0 & 2.0 \\
\hline 2 & 21.0 & 17.0 & 13.6 & 12.0 & 5.0 & 4.0 & 2.0 & 1. $c$ & 0.0 & 4.0 & 4.0 & 3.0 \\
\hline 3 & 22.0 & 18.0 & $12 . c$ & $12 . \mathrm{C}$ & 5.0 & 5.0 & 2.0 & 1.0 & 7.0 & 6.0 & 4.0 & 2.0 \\
\hline 4 & 22.0 & 19.0 & 12.0 & $12 . c$ & 5.0 & $4 \cdot C$ & 2.0 & 1.0 & 7.0 & 6.0 & 4.0 & 3.0 \\
\hline 5 & 22.0 & I B. 0 & 12.8 & 10.0 & 6.0 & $5 . c$ & 1.0 & 1.c & 7.0 & $6 . C$ & 5.0 & 3.0 \\
\hline 6 & 21.0 & 18.0 & 10.0 & 9.0 & $6 . \mathrm{C}$ & $6 . \mathrm{C}$ & 1.0 & 1.0 & 0.0 & 5.0 & 4.0 & 4.0 \\
\hline 7 & 19.0 & 17.0 & 9.0 & 3.2 & 6.0 & $5 . c$ & 1.0 & l. C & 5.0 & 4.3 & 5.0 & $3 . \mathrm{C}$ \\
\hline 8 & 20.0 & 17.0 & 8.0 & 7.6 & $6 . C$ & 5.0 & 1.0 & 1.0 & 4.0 & 3.0 & 6.0 & 4. C \\
\hline 9 & 19.0 & 17.0 & 8.0 & 7.0 & 7.0 & $t \cdot c$ & 1.0 & $\mathrm{i}, \mathrm{C}$ & 3.0 & 3.0 & 7.0 & 4.0 \\
\hline 10 & 18.0 & $16 . \mathrm{C}$ & 9.0 & 7.0 & 7.0 & $7 . \mathrm{C}$ & 1.0 & 1.0 & 3.0 & 2.0 & 6.0 & $6 . \mathrm{C}$ \\
\hline 11 & 17.0 & 16.0 & s.o & B. 0 & 7.0 & 7.6 & 1.0 & $1 . c$ & 3.0 & 2.0 & 7.0 & 6.0 \\
\hline 12 & 19.0 & 14.0 & 21.0 & 9.0 & 7.0 & 7.6 & 1.2 & i.c & 2.0 & 2.0 & 8.0 & 6.0 \\
\hline 13 & $1 e .0$ & 13.0 & 10.0 & A. $\mathrm{C}$ & 7.0 & $7 . \mathrm{C}$ & 1.0 & 1.0 & 2.0 & 2.0 & 7.0 & 5.6 \\
\hline 14 & 19.0 & 10.0 & 9.0 & B. 0 & 7.0 & 7.6 & 1.0 & l. $c$ & 3.0 & 2.0 & 6.0 & 4.8 \\
\hline 15 & 19.0 & 14.0 & 9.0 & 7.0 & 7.0 & 7.0 & 1.0 & 1.0 & 3.0 & 2.0 & 6.0 & 5.0 \\
\hline 16 & 19.0 & 16.0 & 9.0 & 7.0 & $7 . \mathrm{C}$ & $t . C$ & 1.0 & l. $\mathrm{C}$ & 3.0 & 2.0 & 6.0 & $6 . \mathrm{C}$ \\
\hline 17 & 19.0 & 17.0 & 8.0 & 7.0 & 6.0 & 4.0 & 1.0 & 1.0 & 3.0 & 2.0 & 6.0 & $6 . C$ \\
\hline 18 & 18.0 & 14.0 & 8.0 & $7 . \mathrm{C}$ & 5. C & 4.6 & 1.0 & 1.0 & 3.0 & 2.0 & 7.0 & 5.0 \\
\hline 19 & 10.0 & 14.0 & 8.0 & 7.0 & 0.0 & 5.6 & 1.0 & $1 . c$ & 3.2 & 2.0 & 7.0 & 7.0 \\
\hline 20 & 17.0 & 13.0 & $7 . \mathrm{C}$ & 7.0 & 7.0 & 6.0 & 2.0 & 1.0 & 3.0 & 3.0 & 8,0 & $7 . \mathrm{C}$ \\
\hline 21 & 17.0 & 13.0 & 7.0 & 7.0 & 8.C & 7.6 & 1.0 & 1.0 & 3.3 & 2.2 & $8 . c$ & B.C \\
\hline 22 & 16.0 & 12.0 & 3.0 & 7.0 & 9.0 & 8.0 & 1.0 & 1.0 & 3.0 & 2.0 & 9.0 & 8.0 \\
\hline 23 & 16.0 & 12.0 & 7.0 & $7 . \mathrm{C}$ & e.o & $7 . c$ & 1.0 & 1.0 & 3.0 & 2.0 & 9.0 & $7 . c$ \\
\hline 24 & 17.0 & 13.0 & 7.0 & 6.0 & 7.0 & $4 . C$ & 1.0 & 1. $c$ & 3.0 & $2 . n$ & 7.0 & 7.0 \\
\hline 25 & 16.0 & 13.0 & 7.0 & 6.0 & 4.0 & 3.0 & 2.0 & 1.0 & 3.0 & 2.0 & 7.0 & $6 . c$ \\
\hline 26 & 15.0 & 12.0 & 7.0 & $6 . c$ & 3.0 & $3 . \mathrm{C}$ & 2.0 & 2. C & 3.0 & 2.0 & 8.0 & 6.0 \\
\hline 27 & 14.0 & 12.0 & 7.0 & 6.0 & 3.0 & 3.0 & 2.0 & 2.0 & 4.0 & 3.0 & 9.0 & 8.0 \\
\hline 28 & 14.0 & 12.0 & 6.0 & 6.0 & 3.0 & 2. C & 2.0 & 2.0 & 3.0 & 3.0 & 10.0 & 9.0 \\
\hline 29 & 14.0 & 11.0 & $6 . c$ & 5.0 & 2.0 & 2.0 & 2.0 & $2 . c$ & 3.0 & 2.0 & 12.0 & 10.0 \\
\hline 30 & 14.0 & 11.0 & 6.0 & $4 . C$ & 2.0 & 2.0 & 3.0 & 2.0 & $\cdots$ & - & 14.0 & $12 . \mathrm{C}$ \\
\hline 31 & 13.0 & 12.0 & $\cdots$ & $\cdots$ & 2.0 & $2 . c$ & 3.0 & $3 . c$ & $-\infty$ & $\cdots$ & 14.0 & 14.0 \\
\hline DIH & 22.0 & 11.0 & 23.0 & 4.0 & 9.0 & 2.0 & 3.0 & 1.0 & 7.0 & 2.0 & 14.0 & 2.0 \\
\hline
\end{tabular}


03216350 LITTLE SANDY RIVER BELON GRAYSON DAM, NEAR LEON, KY,--CONT1 nued

TEMPERATURE (' $\left.{ }^{\circ} \mathrm{C}\right)$ OF WATER, WATER YEAR OCTOBER 1967 TO SEPTEMBER 1968 CONTINUDUS ETHYL ALCOHDL-ACTUATED THERMOGRAPH)

\begin{tabular}{|c|c|c|c|c|c|c|c|c|c|c|c|c|}
\hline \multirow[b]{2}{*}{ EAY } & \multicolumn{2}{|c|}{ APKIL } & \multicolumn{2}{|c|}{ MAY } & \multicolumn{2}{|c|}{ JUNF } & \multicolumn{2}{|c|}{ JULY } & \multicolumn{2}{|c|}{ A UG UST } & \multicolumn{2}{|c|}{ SEPTEMEER } \\
\hline & $\operatorname{MAX}$ & MIN & MAX & MIN & $\max$ & $\operatorname{MIN}$ & MAX & MIN & MAX & MIN & $\operatorname{MAX}$ & MIN \\
\hline $\begin{array}{l}1 \\
2 \\
3 \\
4 \\
5\end{array}$ & $\begin{array}{l}14.0 \\
13.0 \\
12.0 \\
12.0 \\
12.0\end{array}$ & $\begin{array}{l}13.0 \\
12.0 \\
11.0 \\
11.0 \\
11.0\end{array}$ & $\begin{array}{l}18.0 \\
19.0 \\
19.0 \\
19.0 \\
19.0\end{array}$ & $\begin{array}{l}16.0 \\
16.0 \\
17.0 \\
18.0 \\
18.0\end{array}$ & $\begin{array}{l}18.0 \\
18.0 \\
18.0 \\
20.0 \\
21.0\end{array}$ & $\begin{array}{l}17 . \mathrm{C} \\
17.0 \\
17 . \mathrm{C} \\
18.0 \\
15 . \mathrm{C}\end{array}$ & $\begin{array}{l}28.0 \\
27.0 \\
26.0 \\
26.0 \\
27.0\end{array}$ & $\begin{array}{l}23.0 \\
24.0 \\
24.0 \\
24.0 \\
24.0\end{array}$ & $\begin{array}{l}25.0 \\
27.0 \\
29.0 \\
28.0 \\
30.0\end{array}$ & $\begin{array}{l}25.0 \\
25.0 \\
26.0 \\
27.0 \\
26.0\end{array}$ & $\begin{array}{l}25.0 \\
25.0 \\
26.0 \\
25.0 \\
24.0\end{array}$ & $\begin{array}{l}24.0 \\
23.0 \\
23.0 \\
24.0 \\
23.0\end{array}$ \\
\hline $\begin{array}{r}6 \\
7 \\
8 \\
9 \\
10\end{array}$ & $\begin{array}{l}11.0 \\
11.0 \\
11.0 \\
11.0 \\
11.0\end{array}$ & $\begin{array}{l}11.0 \\
11.0 \\
11.0 \\
11.0 \\
11.0\end{array}$ & $\begin{array}{l}18.0 \\
20.0 \\
20.0 \\
19.0 \\
18.0\end{array}$ & $\begin{array}{l}17.0 \\
17.0 \\
17.0 \\
18.0 \\
18.0\end{array}$ & $\begin{array}{l}22.0 \\
23.0 \\
24.0 \\
25.0 \\
26.0\end{array}$ & $\begin{array}{l}21 . c \\
22.0 \\
23.0 \\
23.0 \\
24.0\end{array}$ & $\begin{array}{l}26.0 \\
29.0 \\
28.0 \\
29.0 \\
30.0\end{array}$ & $\begin{array}{l}23.0 \\
24.0 \\
25.0 \\
26.0 \\
26.0\end{array}$ & $\begin{array}{l}31.0 \\
31.0 \\
31.0 \\
31.0 \\
29.0\end{array}$ & $\begin{array}{l}27.0 \\
28.0 \\
27.0 \\
28.0 \\
27.0\end{array}$ & $\begin{array}{l}24.0 \\
26.0 \\
26.0 \\
24.0 \\
24.0\end{array}$ & $\begin{array}{l}23.0 \\
23.0 \\
23.0 \\
23.6 \\
23.0\end{array}$ \\
\hline $\begin{array}{l}11 \\
12 \\
13 \\
14 \\
15\end{array}$ & $\begin{array}{l}13.0 \\
14.0 \\
14.0 \\
15.0 \\
15.0\end{array}$ & $\begin{array}{l}11.0 \\
13.0 \\
13.0 \\
14.0 \\
14.0\end{array}$ & $\begin{array}{l}19.0 \\
19.0 \\
20.0 \\
22.0 \\
23.0\end{array}$ & $\begin{array}{l}18.0 \\
18.0 \\
18.0 \\
19.0 \\
21.0\end{array}$ & $\begin{array}{l}29.0 \\
28.0 \\
27.0 \\
28.0 \\
28.0\end{array}$ & $\begin{array}{l}26.0 \\
27.0 \\
25.0 \\
24.0 \\
24.0\end{array}$ & $\begin{array}{l}29.0 \\
31.0 \\
31.0 \\
29.0 \\
27.0\end{array}$ & $\begin{array}{l}26.0 \\
26.0 \\
27.0 \\
27.0 \\
26.0\end{array}$ & $\begin{array}{l}27.0 \\
27.0 \\
27.0 \\
27.0 \\
27.0\end{array}$ & $\begin{array}{l}25.0 \\
25.0 \\
26.0 \\
26.0 \\
25.0\end{array}$ & $\begin{array}{l}23.0 \\
23.0 \\
24.0 \\
23.0 \\
25.0\end{array}$ & $\begin{array}{l}22.0 \\
21.0 \\
21.0 \\
21.0 \\
21.0\end{array}$ \\
\hline $\begin{array}{l}16 \\
17 \\
18 \\
19 \\
20\end{array}$ & $\begin{array}{l}16.0 \\
15.0 \\
14.0 \\
15.0 \\
16.0\end{array}$ & $\begin{array}{l}14.0 \\
13.0 \\
13.0 \\
13.0 \\
15.0\end{array}$ & $\begin{array}{l}23.0 \\
22.0 \\
22.0 \\
21.0 \\
19.0\end{array}$ & $\begin{array}{l}22.0 \\
21.0 \\
21.0 \\
19.0 \\
18.0\end{array}$ & $\begin{array}{l}27.0 \\
24.0 \\
26.0 \\
29.0 \\
20.0\end{array}$ & $\begin{array}{l}24.0 \\
23.0 \\
23.0 \\
23.0 \\
24.0\end{array}$ & $\begin{array}{l}29.0 \\
31.0 \\
31.0 \\
29.0 \\
29.0\end{array}$ & $\begin{array}{l}26.0 \\
26.0 \\
27.0 \\
27.0 \\
77.0\end{array}$ & $\begin{array}{l}27.0 \\
27.0 \\
27.0 \\
27.0 \\
27.0\end{array}$ & $\begin{array}{l}24.0 \\
25.0 \\
25.0 \\
25.0 \\
26.0\end{array}$ & $\begin{array}{l}23.0 \\
23.0 \\
22.0 \\
21.0 \\
24.0\end{array}$ & $\begin{array}{l}21.0 \\
21.0 \\
21.0 \\
21.0 \\
20.0\end{array}$ \\
\hline $\begin{array}{l}21 \\
22 \\
23 \\
24 \\
25\end{array}$ & $\begin{array}{l}17.0 \\
18.0 \\
19.0 \\
18.0 \\
17.0\end{array}$ & $\begin{array}{l}16.0 \\
17.0 \\
17.0 \\
17.0 \\
16.0\end{array}$ & $\begin{array}{l}19.0 \\
21.0 \\
19.0 \\
18.0 \\
17.0\end{array}$ & $\begin{array}{l}18 . \mathrm{C} \\
18 . \mathrm{C} \\
18.0 \\
16 . \mathrm{C} \\
16 . \mathrm{C}\end{array}$ & $\begin{array}{l}28.0 \\
28.0 \\
29.0 \\
26.0 \\
25.0\end{array}$ & $\begin{array}{l}23.0 \\
24.0 \\
25.0 \\
24.0 \\
24.0\end{array}$ & $\begin{array}{l}30.0 \\
31.0 \\
32.0 \\
31.0 \\
31.0\end{array}$ & $\begin{array}{l}27.0 \\
27.0 \\
28.0 \\
28.0 \\
28.0\end{array}$ & $\begin{array}{l}27.0 \\
27.0 \\
28.0 \\
28.0 \\
28.0\end{array}$ & $\begin{array}{l}26.0 \\
26.0 \\
26.0 \\
27.0 \\
27.0\end{array}$ & $\begin{array}{l}24.0 \\
26.0 \\
26.0 \\
26.0 \\
24.0\end{array}$ & $\begin{array}{l}22 . c \\
22.0 \\
22.0 \\
23.0 \\
23.0\end{array}$ \\
\hline $\begin{array}{l}26 \\
27 \\
28 \\
29 \\
30 \\
31\end{array}$ & $\begin{array}{l}16.0 \\
15.0 \\
16.0 \\
16.0 \\
16.0 \\
-\cdots\end{array}$ & $\begin{array}{l}15.0 \\
14.0 \\
14.0 \\
15.0 \\
15.0 \\
-.0\end{array}$ & $\begin{array}{l}17.0 \\
17.0 \\
17.0 \\
18.0 \\
17.0 \\
18.0\end{array}$ & $\begin{array}{l}10.0 \\
17.0 \\
10.0 \\
17.0 \\
17.0 \\
17.0\end{array}$ & $\begin{array}{r}24.0 \\
24.0 \\
22.0 \\
23.0 \\
26.0 \\
\ldots\end{array}$ & $\begin{array}{l}24.0 \\
22.0 \\
21.0 \\
21.0 \\
22.0 \\
\ldots\end{array}$ & $\begin{array}{l}28.0 \\
27.0 \\
27.0 \\
26.0 \\
27.0 \\
27.0\end{array}$ & $\begin{array}{l}25.0 \\
20.0 \\
26.0 \\
25.0 \\
24.0 \\
25.0\end{array}$ & $\begin{array}{l}27.0 \\
26.0 \\
26.0 \\
25.0 \\
25.0 \\
26.0\end{array}$ & $\begin{array}{l}26.0 \\
24.0 \\
24.0 \\
23.0 \\
23.0 \\
24.0\end{array}$ & $\begin{array}{r}24.0 \\
23.0 \\
24.0 \\
23.0 \\
23.0 \\
-\cdots\end{array}$ & $\begin{array}{r}21.0 \\
20.0 \\
20.0 \\
15.0 \\
19.0 \\
\ldots\end{array}$ \\
\hline MOATH & 19.0 & 11.0 & 23.0 & $16 . c$ & 29.0 & 17.6 & 32.0 & 23.0 & 31.0 & 23.0 & 26.0 & 15.0 \\
\hline
\end{tabular}

03217000 TYGARTS CREEK NEAR GREENUP, KY.

LOCATION,--Lat $38^{\circ} 33^{\prime} 51^{\prime \prime}$, long $82^{\circ} 57^{\prime} 08^{\prime \prime}$, Greenup County, at gaging station at bridge on State Highway 7 , 100 ft downstream from Lick' Run, 0.4 mile upstream from White Oak Creek and 6.5 miles west of Greenup.

DRAI NAGE AREA. - -242 sq mi.

PERIOD OF RECORD. - Water temperatures: October 1956 to September 1968.

Sediment records: October 1956 to September 1968

EXTREMES, - $1967-68$,

Water temperatures: Maximum, $29.0^{\circ} \mathrm{C}$ July 21, 23, Aug. 23; minimum, freezing point on several days during January and February.

Sediment concentrations: Maximum daily, $1,100 \mathrm{mg} / 1$ July 27; minimum daily, $1 \mathrm{mg} / 1$ on many days during

Nevember, January, February and March.

Pertod of record:

Water temperatures: Maximum, $30.5^{\circ} \mathrm{C}$ July 10,18 , 1966; minimum, freezing potat on many days during winter periods.

Sediment concentrations: Maximum daily, 1,900 mg/1 July 13, 1966; minimum daily, no flow Sept. 25, 26, 1964,

Sediment loads: Maximum dally, 31,600 tons Feb, 28, 1962; minimum daily, 0 tons on several days during 1964 and 1967 .

REMARKS. - Occastonal regulation of low flow caused by withdrawal of water for cooling purposes by gas transmission plant above station.

TEMPERATURE $\left({ }^{\circ} \mathrm{C}\right)$ OF WATER, WATER YEAR OCTOBER 1967 TO SEPTEMBER 1968 (ONCE-DAILY MEASUREMENT AT 1700 )

TAY

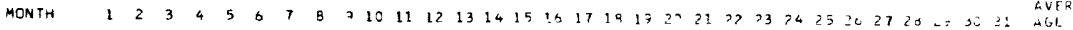

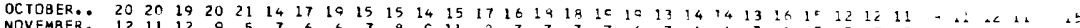

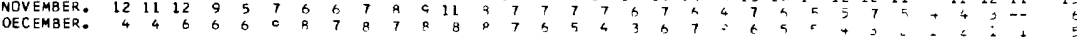

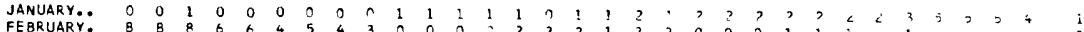

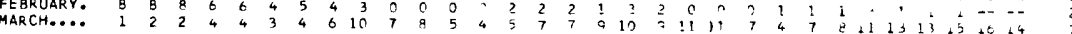

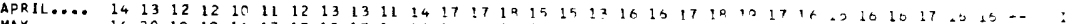

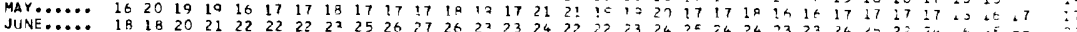

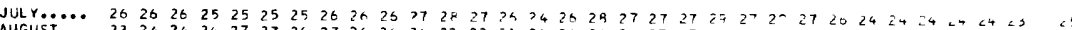

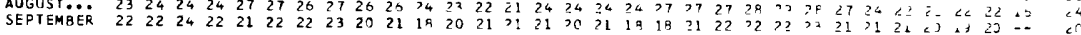
PARTICLE-SIZE ANALYSES OF SUSPENDED SEDIMENT, WATER YEAR OCTOBER 1967 TO SEPTEMBER 1968

(METHODS OF ANALYSIS: B, BOTTOM WITHDRAWAL TUBE; C, CHEMICALLY DISPERSED; D, DECANTATION; N, IN NATIVE WATER;
P, PIPET; S, SIEVE; V, VISUAL ACCUMULATION TUBE; W, IN DISTILLED WATER)

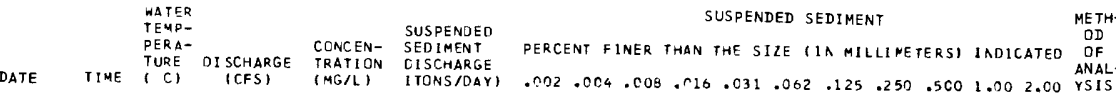


03217000 TYGARTS CREEK NEAR GREENUP, KY.--Cont1 nued

SUSPENDED SEDIMENT, WATER YEAR OCTOBER 1967 TO SEPTEMBER 1968

\begin{tabular}{|c|c|c|c|c|c|c|c|c|c|}
\hline \multirow[b]{2}{*}{ niY } & \multicolumn{3}{|c|}{ OE TORFF } & \multicolumn{3}{|c|}{ MIIVEMRED } & \multicolumn{3}{|c|}{ DECFMRFO } \\
\hline & $\begin{array}{l}\text { MEAV } \\
\text { TICHASTH } \\
\text { (rES) }\end{array}$ & $\begin{array}{l}\text { MEAN } \\
\text { CONSFN- } \\
\text { TPDTLEM } \\
\text { (NGAL) }\end{array}$ & 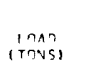 & $\begin{array}{l}\text { MFAV } \\
\text { MSCUAFFF } \\
\text { ICFSI }\end{array}$ & $\begin{array}{l}\text { MFAN } \\
\text { CONCEN- } \\
\text { TRATITN } \\
\text { (WFILI) }\end{array}$ & $\begin{array}{l}\text { (nAn } \\
\text { (TONS) }\end{array}$ & $\begin{array}{l}\text { MEAN } \\
\text { NISCHAR GF } \\
\text { (CFS) }\end{array}$ & $\begin{array}{l}\text { MFAN } \\
\text { TONCFM- } \\
\text { TRATION } \\
\text { IMFILI) }\end{array}$ & $\begin{array}{l}\text { LnAr } \\
\text { (TกNS) }\end{array}$ \\
\hline 1 & 1.4 & h & .12 & 12 & $4^{2}$ & 2.4 & $15 ? 0$ & $50 \mathrm{~h}$ & snan \\
\hline$?$ & 1.4 & 7 & .03 & 310 & 22 & 77 & 503 & 111 & 160 \\
\hline 3 & 1.2 & 12 & .94 & $\Rightarrow>7$ & 4? & 60 & 747 & 47 & कर \\
\hline 4 & 1.2 & $=$ & .92 & $2>0$ & $3^{\circ}$ & 24 & 566 & 48 & 96 \\
\hline 5 & .87 & ? & 0 & $1 ? ?$ & 35 & 12 & 21 ? & 3? & $>R$ \\
\hline$b$ & . $n$ ? & $=$ & 2 & 24 & 20 & b.4 & 204 & 2) & 12 \\
\hline 7 & . คา & 4 &.$n 1$ & 50 & 22 & $=5$ & 154 & $1^{2}$ & 4. 2 \\
\hline a & 1.4 & a & .02 & 4? & In & 1.0 & i37 & P & .0 \\
\hline$?$ & 2.8 & 4 & .03 & 37 & 13 & 1.2 & 113 & 5 & 1.5 \\
\hline 10 & 3.0 & 7 & .36 & $2 a$ & i) & .01 & 94 & 5 & 1.3 \\
\hline 11 & $2 . R$ & 9 & .07 & 25 & 11 & .74 & 174 & A & $2 . A$ \\
\hline 12 & 2.5 & $\circ$ & $.3 t$ & 22 & in & .50 & 433 & $\because$ & $1^{2}$ \\
\hline 13 & 2.2 & a & . na & 10 & 10 & .51 & 215 & in & 9.5 \\
\hline 14 & $2 . n$ & a & .n5 & !7 & A & .27 & $20 ?$ & a & 4.0 \\
\hline 15 & $1 .{ }^{2}$ & $1 c$ & .05 & is & $B$ & .26 & 165 & in & 4.5 \\
\hline$\therefore 4$ & 1.6 & 10 &.$n_{4}$ & 15 & 5 & $.2 r$ & $17 ?$ & 12 & 5.0 \\
\hline 17 & $2 . ?$ & in & .75 & 15 & 5 & .20 & is, & 7 & 2.0 \\
\hline 18 & 4.0 & 11 & .15 & 14 & 5 & .10 & 14? & 4 & 1.5 \\
\hline 10 & 5.7 & 11 & .17 & 14 & 5 & .10 & $15 n$ & 3 & 1.2 \\
\hline 20 & 4.2 & in & .11 & 12 & a &.$I^{2}$ & 154 & 2 & 1.2 \\
\hline 21 & 3.? & 1C & .09 & 12 & 5 & .18 & 127 & 4 & 1.9 \\
\hline .22 & 3.0 & 12 & .10 & 14 & 4 & .15 & $40 R$ & 34 & $3 t$ \\
\hline 23 & 4.4 & 13 & .15 & 15 & 2 & $.0 R$ & 795 & 43 & Re \\
\hline 24 & 0.0 & $1 !$ &.$? 7$ & 74 & 9 & 1.8 & $\angle 06$ & $\angle 5$ & 40 \\
\hline 25 & 7.8 & 27 & .57 & 122 & $=$ & .99 & $27 x$ & 67 & 35 \\
\hline 23 & $3 . ?$ & 19 & $.3 n$ & 104 & 1 & .20 & 207 & 2) & 17 \\
\hline 27 & 5,3 & 11 & .17 & 34 & $i$ & .23 & 152 & 6 & 3.5 \\
\hline 29 & +.3 & 9 & .15 & 53 & $i$ & .17 & 119 & a & $1 . R$ \\
\hline 20 & 17 & 33 & 1.6 & $4 R$ & 1 & .12 & 190 & $x$ & .21 \\
\hline 30 & 14 & 17 & .64 & 453 & 77 & 240 & 77 & 2 & $.5 R$ \\
\hline 31 & i) & $i^{2}$ & .42 & $=$ & -- & -- & 50 & $=$ & .50 \\
\hline TOTAL & $1 \times 2.70$ & -- & 5.40 & 2606 & -- & 435.65 & 0224 & -- & 2748.50 \\
\hline & & JANIISRY & & & FFARUARY & & & $M \triangle R C H$ & \\
\hline & $M E A N$ & $\begin{array}{l}\text { MFAN } \\
\text { CANCEN- }\end{array}$ & & MEAV & $\begin{array}{c}\text { MFAN } \\
\text { CONS EN- }\end{array}$ & & MEAN & $\begin{array}{l}\text { MEAN } \\
\text { CNNPEN- }\end{array}$ & \\
\hline & 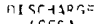 & TRATITM & inan & OISCTARS, & TPATINN & enan & TISTHARTF & TQATION & IOAn \\
\hline TAY & $(c=s)$ & $(M G / L)$ & (TANS) & (CFS) & $\left(M_{F} / L\right)$ & (TONS) & $(0 \times 5)$ & $(M r / L)$ & (TANS) \\
\hline 1 & $5 ?$ & $x^{2}+x-1$ & .47 & 575 & 23 & 37 & $3 b$ & 1 & .10 \\
\hline$?$ & $4 a$ & ? & $.2 \mathrm{~h}$ & 479 & 10 & 25 & 34 & 1 & in \\
\hline 3 & 46 & 2 & .34 & $54 ?$ & 13 & 10 & $3 t$ & : & .10 \\
\hline 4 & 63 & $?$ & $.0^{x / 4}$ & 424 & 7 & 7.7 & $3 R$ & $i$ & .10 \\
\hline 5 & 71 & $?$ & .38 & 320 & h & 5.0 & 39 & $!$ & in \\
\hline 5 & 74 & 2 & $.4 n$ & $2 \pi 0$ & 5 & 2.5 & 7t & I & $.1 n$ \\
\hline 7 & 64 & 3 & .35 & $27 \%$ & ? & i.? & 27 & 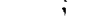 & .11 \\
\hline$a$ & 52 & ? & $.2 R$ & $2 \cap 4$ & $?$ & 1.1 & 30 & I &.+1 \\
\hline 9 & 47 & 3 & .25 & in? & $i$ & .44 & 27 & 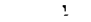 & .10 \\
\hline 10 & 40 & $?$ & .75 & 77 & 1 & .21 & 41 & 2 & .27 \\
\hline 11 & 47 & 1 & .12 & 77 & 1 & .21 & $4 x$ & 7 & I.? \\
\hline 12 & 47 & 1 & .1 & 17 & ? & .42 & 2720 & 574 & Kano \\
\hline 13 & 50 & $i$ & .14 & 17 & $?$ & .47 & GR2O & 53: & a)8n \\
\hline 14 & 54 & 2 & .15 & 77 & 3 &.$<2$ & $1+90$ & 127 & $50 n$ \\
\hline 15 & 64 & 1 & .17 & 73 & 3 & .52 & $73 n$ & 46 & 97 \\
\hline in & 54 & 1 & .15 & 63 & 3 & $.5 !$ & 977 & 93 & $28 \mathrm{Bh}$ \\
\hline 11 & 48 & 1 & $i^{x}$ & 5, & 2 & $.4 a$ & $2<50$ & ? & $130 n$ \\
\hline 13 & 49 & 1 & .13 & 41 & 3 & .32 & IORO & 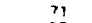 & हीर \\
\hline 10 & 5? & 1 & .17 & 27 & 3 & .23 & GAR & 27 & 40 \\
\hline $2 \pi$ & 122 & $?$ & .37 & 25 & ? & .14 & 533 & 19 & 34 \\
\hline 21 & 427 & 7 & 16 & 25 & 2 & .14 & 459 & $1 \mathrm{f}$ & $2 n$ \\
\hline 22 & 1190 & hr & 102 & $>0$ & $?$ & .15 & 1040 & $\Rightarrow 0$ & 3) \\
\hline 23 & 1220 & GE & 214 & $3 c$ & $\Rightarrow$ & $.1 k$ & $448 n$ & 210 & Phan \\
\hline 24 & 1020 & $2 a$ & +9 & 31 & 2 & .17 & 1700 & a) & $27 \mathrm{k}$ \\
\hline 25 & 579 & 14 & 27 & 36 & 2 & .10 & 044 & 40 & 102 \\
\hline $2 n$ & 325 & $=$ & 7.9 & $>0$ & 3 & .72 & 533 & 13 & $x>$ \\
\hline$? 7$ & 243 & 7 & 4.5 & 3? & 2 & .29 & 443 & is & $2 \pi$ \\
\hline$P Q$ & 10.2 & ? & $x, a$ & 32 & 3 & .26 & 257 & 14 & 12 \\
\hline 79 & 176 & 11 & 5.2 & $3 !$ & ? & i 7 & 208 & 12 & $1^{n}$ \\
\hline 39 & 798 & $2 c$ & $4 n$ & $\cdots$ & -- & - & San & 1) & 0.1 \\
\hline 31 & $\times 40$ & 50 & $9 n$ & -- & -- & - & 2? & 11 & 0.4 \\
\hline$T=11$ & 7472 & -- & KAOO.JQ & $41>7$ & -- & 105.70 & 20940 & -- & 95997.14 \\
\hline
\end{tabular}


TYGARTS CREEK BASIN

03217000 TYGARTS CREEK NEAR GREENUP, KY.--Continued

SUSPENDED SEDIMENT, WATER YEAR OCTOBER 1967 TO SEPTEMBER 1968

\begin{tabular}{|c|c|c|c|c|c|c|c|c|c|}
\hline & & $\triangle P F I I$ & & & $u_{A Y}$ & & & JUNF & \\
\hline & $\sim F A N$ & $\begin{array}{l}\text { MEAN } \\
\text { CONCEN- }\end{array}$ & & MEAN & $\begin{array}{l}\text { MFAN } \\
\text { CONCFN- }\end{array}$ & & MFAN & $\begin{array}{l}\text { MFIN } \\
\text { CONCFA- }\end{array}$ & \\
\hline & RISCHARGE & TPATICM & LIAn & DISCHARGF & TRATION & LnAN & NISCHARGF & TRATINV & $\ln A n$ \\
\hline DAY & (CFS) & $\left(N F_{3} / L\right)$ & (TINC) & (CFS) & $(M r, / L)$ & (TONS) & $(C F S)$ & $\mid 4 r / L)$ & (TONE) \\
\hline 1 & 792 & 31 & R. & 73 & 8 & 1.5 & 44 ? & is & 19 \\
\hline 2 & 745 & 43 & 127 & so & p & 1.3 & 343 & 14 & $i=$ \\
\hline 3 & 490 & 24 & 32 & 50 & 7 & .94 & 304 & 11 & $0 . n$ \\
\hline 4 & 1320 & 14? & 725 & 49 & 7 & .91 & 230 & 11 & 7.1 \\
\hline 5 & 2930 & 220 & $10 ! n$ & 47 & 6 & .76 & 204 & 11 & 8.1 \\
\hline 0 & QRR & SC & 150 & 39 & 5 & .51 & 154 & in & $4 . ?$ \\
\hline 7 & 420 & 22 & 37 & $3 n$ & 5 & .43 & $1>3$ & 0 & 3.0 \\
\hline 8 & 4Q? & 12 & 16 & $\gg$ & 5 & .36 & 104 & $1 n$ & $\because 0$ \\
\hline 9 & 511 & 11 & 15 & 27 & 5 & .75 & 93 & 7 & 1.9 \\
\hline 10 & $40 ?$ & 11 & 12 & 27 & a & .28 & 93 & 5 & 1.1 \\
\hline 11 & $2 \geq ?$ & 12 & 11 & 39 & 6 & .40 & 74 & 5 & $1 . n$ \\
\hline 12 & 200 & $1^{3}$ & 9.1 & $\ln ^{n}$ & 20 & 5.4 & 53 & 5 & .77 \\
\hline 13 & 222 & 13 & 7.9 & 187 & 12 & 6.6 & 41 & a & .AK \\
\hline 14 & 196 & $\ln$ & 5.3 & $13^{n}$ & 7 & 3.5 & 30 & a &.$\times 3$ \\
\hline 15 & $35 \mathrm{~K}$ & 10 & 6.9 & 04 & $t$ & 1.5 & 35 & a & .57 \\
\hline $1 \mathrm{~s}$ & 346 & 10 & a. 3 & A & a & .92 & 31 & a & $.5 n$ \\
\hline 37 & 203 & $a$ & 5,4 & $5>$ & 4 & $.5 \mathrm{~h}$ & 77 & h & .44 \\
\hline 13 & 226 & 8 & 4.9 & 46 & 4 & .50 & 25 & 4 & $.2^{\circ}$ \\
\hline in & 202 & a & 4.4 & 72 & 6 & $1 . ?$ & 25 & 4 & .07 \\
\hline 20 & $17 \pi$ & a & 3.7 & $\operatorname{lng} \theta$ & 5 & 1.5 & $? 4$ & 4 & .26 \\
\hline 21 & 157 & a & 2.4 & $R_{1}$ & 5 & 1.1 & 27 & 5 & $.3 n$ \\
\hline 22 & 142 & a & 3.1 & 74 & 4 &.$B C$ & 25 & 6 & .42 \\
\hline 23 & 174 & 7 & 2.3 & 40 & 20 & 6.5 & 45 & 33 & 4.0 \\
\hline 24 & 135 & 7 & 2.6 & 2020 & 409 & 4970 & 114 & 20 & if \\
\hline 25 & 202 & a & $4 . ?$ & 5150 & 355 & 5200 & 137 & $2 k$ & $i^{5}$ \\
\hline 25 & 150 & 7 & 3.0 & 1110 & 115 & 345 & 112 & 36 & 11 \\
\hline 27 & 133 & 7 & 2.5 & 3177 & 311 & 2930 & 164 & $3 n$ & 17 \\
\hline 29 & 111 & 7 & 2.1 & P1SO & $4 h$ & $3 O R$ & 123 & $3 n$ & 10 \\
\hline 27 & 79 & 7 & 1.9 & 792 & 30 & 84 & 101 & 25 & $a .8$ \\
\hline 30 & 94 & 7 & 1.6 & 655 & 25 & 44 & in & 3) & $t .0$ \\
\hline 31 & -- & -- & $\cdots$ & 594 & 22 & 35 & $\cdots$ & -- & $\cdots$ \\
\hline TOTAL & 13103 & -- & ${ }^{2} 175.2$ & 18176 & -- & $13 \times 32.00$ & 3433 & - & 157.05 \\
\hline & & JULY & & & AUCUST & & & SEPTFMPFR & \\
\hline & MEAN & $\begin{array}{l}\text { MEAN } \\
\text { CMNCEN- }\end{array}$ & & MFAV & $\begin{array}{l}\text { MEAN } \\
\text { CANCEN- }\end{array}$ & & MEAN & $\begin{array}{l}\text { MFAN } \\
\text { CONFFN- }\end{array}$ & \\
\hline & ПI SCHARGE & IFATION & $10 \mathrm{~A}^{n}$ & DISTHAOSE & TRATION & $\operatorname{LnAC}$ & NISCHARTEF & TRSTION & ח DAח \\
\hline haY & |CFSI & $\left.\mid M r_{s} / L\right)$ & ITONS) & $\mid r=s\}$ & $(M r / L)$ & ITINS) & $(C, F<)$ & {$[4 r / L)$} & (TINA) \\
\hline 1 & 54 & 25 & 3.4 & $53 \mathrm{~K}$ & $25 ?$ & 344 & 20 & 2 & .31 \\
\hline 2 & 43 & 32 & 2.5 & $7 n R$ & 204 & 290 & is & 5 &.$?$ \\
\hline 3 & 25 & it & 2.5 & 632 & 78 & 133 & 24 & 5 & .10 \\
\hline 4 & $3^{n}$ & 22 & 1.8 & 151 & 52 & 75 & 13 & 5 & .10 \\
\hline 5 & 25 & $1 \%$ & 1.1 & 113 & 55 & 17 & 17 & 5 & $.2 a$ \\
\hline b & $? ?$ & 15 & .89 & 72 & 69 & $1^{2}$ & 137 & 19 & $a .5$ \\
\hline 7 & 20 & 14 & $.7 \mathrm{k}$ & सa & 73 & 13 & $>19$ & in & 5.9 \\
\hline a & 19 & a & .44 & 41 & 45 & 7.4 & 102 & 15 & 4.1 \\
\hline 9 & 17 & 9 & .41 & 72 & 35 & $A . P^{\circ}$ & 61 & on & $3.3^{3}$ \\
\hline 10 & 12 & 14 & .45 & 154 & 64 & 27 & 92 & 15 & 2.8 \\
\hline 11 & 14 & $1+$ &. $\mathrm{AOC}$ & 1140 & 509 & 1970 & 100 & 15 & 4.4 \\
\hline 12 & 12 & 27 & .97 & 524 & 245 & 400 & 115 & 21 & h. 5 \\
\hline 13 & 11 & 20 &.$\approx 9$ & $2 \times 3$ & $=20$ & 201 & the & 10 & 2.4 \\
\hline 14 & 10 & 12 & .32 & 1427 & 574 & 3750 & 36 & 14 & 1.4 \\
\hline 15 & 11 & 11 & .32 & $31 \div 0$ & $a 3 c$ & 7010 & 26 & 12 & .21 \\
\hline is & 12 & 15 & .49 & 1390 & 397 & 22 to & 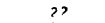 & 10 & .50 \\
\hline 17 & 21 & 11 & .52 & 474 & 79 & $\ln$ & is & $\ln$ & $.4^{2}$ \\
\hline 19 & 39 & 14 & 1.4 & 304 & 53 & 44 & 19 & 10 & .51 \\
\hline 17 & 33 & 13 & 1.2 & 357 & $10 n$ & ah & 21 & in & .57 \\
\hline 20 & 24 & 14 & .91 & 736 & 56 & 36 & 23 & in & , h? \\
\hline 21 & 19 & $1^{n}$ & .51 & 253 & 20 & 19 & 45 & 10 & 1.2 \\
\hline 72 & 16 & a & .26 & 280 & $2 \pi$ & 20 & 47 & 0 & 1.1 \\
\hline 23 & $1^{R}$ & t & .20 & 100 & 17 & a.c & 41 & 0 & $1 . n$ \\
\hline 24 & IA & 11 & .40 & 65 & 10 & 1.8 & $3 n$ & 10 & . 21 \\
\hline 25 & 19 & 34 & 2.3 & 54 & 11 & $1 . t$ & 17 & in & .46 \\
\hline 25 & 20 & 143 & 30 & 65 & 12 & 1.5 & 10 & 10 & .51 \\
\hline 27 & 1390 & 1100 & 4560 & 37 & $1^{2}$ & $1 . ?$ & is & in & .42 \\
\hline 27 & 394 & $x \geq 0$ & SE 1 & 31 & 12 & 1.0 & $1 x$ & $1^{n}$ & .35 \\
\hline 29 & 100 & $27^{\circ}$ & 142 & 30 & 7 & .53 & 12 & a & .26 \\
\hline 20 & 110 & 120 & 28 & 21 & s & .24 & in & 7 & .19 \\
\hline 31 & Ro & 87 & 17 & $2^{n}$ & A & .32 & -- & - & -- \\
\hline TרT & 2723 & $\cdots$ & $9456.7 ?$ & 12600 & -- & 16905.50 & 1392 & -- & 51.20 \\
\hline $\begin{array}{l}015 \mathrm{CH} \\
\text { LOAN }\end{array}$ & $\begin{array}{l}S E F \cap P \\
R Y F A P\end{array}$ & S1 & & & & & & & 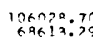 \\
\hline
\end{tabular}


03224500 WHETSTONE CREEK NEAR ASHLEY, OHIO

LOCATION,--Lat $40^{\circ} 27^{\prime} 20^{\prime \prime}$, long $82^{\circ} 57^{\prime} 25^{\prime \prime}$, in NW sec.19, T.7 N., R.18 w, Morrow County, at gaging station on left bank $800 \mathrm{ft}$ upstream from bridge on State Highway $746,0.6$ mile downstream from Shaw Creek, and 3.2 miles north bank 800 ft upstream from br
of Ashley, Delaware County.

DRAINAGE AREA. $--98.7 \mathrm{sq} \mathrm{mi}$.

PERIOD OF RECORD. --Chemical analyses (conductance recorder): October 1964 to June 1968 (discontinued).

EXTREWES, - - October 1967 to June 1968 :

Specific conductance: Maximum daily, 1,070 micromhos Oct. 15-17; minimum daily, 220 micromhos Jan. 30, 31.

Period of record:

Specific conductance: Maximum dally, >3,000 micromhos Nov. 12-25, 1964; minimum daily, 160 micromhos Feb. 21, 1965

REMARKS. --Conductance recorder is installed in gagehouse with probe in creek.

SPECIFIC CONDUCTANCE (MICROMHOS AT $25^{\circ} \mathrm{C}$ ), OCTOBER 1967 TO JUNE 1968
DCTIORER
NOVEMRER
DECEMARP
IANUAOY
FERRIIAOV
MARTH

MAXIAIIM MIVIMJM MAXIMIJM MIVIMIIM MAXIUIIN MIMIMIIU Ma

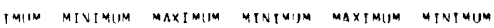

$1 \ldots$

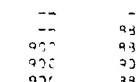

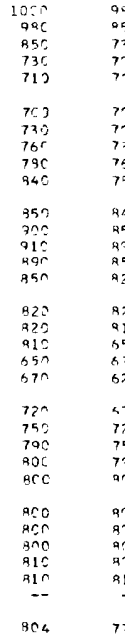

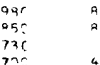

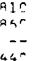

210
P1c
--

250
850

$\begin{array}{lll}215 & 270 & 332 \\ 979 & 370 & 367 \\ 255 & 460 & 360\end{array}$

$330 \quad 02 ? \quad 0 \% 0$

$5 \ldots \ldots$

$7 \ldots \ldots$

$7 \ldots \ldots$

$9 . . .$.

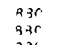

करा:
वर:

par

$5>0$

440

aic

81?

475

400

$\begin{array}{ll}5 x & 460 \\ 45 C & 459 \\ 51 r & 45 n\end{array}$

456
525

513

$\overline{--}$

- 50 an

796

$11 \ldots \ldots . \quad 85 c$

$13 \ldots \ldots$

$15 \ldots .$.

$\begin{array}{rr}956 & 730 \\ 096 & 953 \\ 1236 & 98 ? \\ 1050 & 1030\end{array}$

$\begin{array}{ll}840 & 53 \\ 25 \mathrm{C} & 53\end{array}$

728
560
536
536

$43 n$
449

443
52
50,5
$x \rightarrow 2$

1070 1055

व.2

$\begin{array}{lll}10 \ldots \ldots & 1070 & 1559 \\ 17 \ldots \ldots & 107 & 155 \\ 18 \ldots \ldots & 10 n c & 975\end{array}$

$20 . \cdots$

zar
agr

500
736
736
706

$\lim _{200}$

$\begin{array}{ll}500 & 500\end{array}$

$21 \ldots \ldots$

$22 \ldots \ldots$

$24 \ldots$

$\begin{array}{ll}\ln x & 980 \\ \ln x & 1000 \\ 10 x & 1000 \\ 10 x & 1000\end{array}$

$\begin{array}{ll}416 & 536 \\ 530 & 720 \\ 476 & 330 \\ 506 & 472\end{array}$

$26 . \ldots$.

$77 \ldots \ldots$

$20 \ldots$

si.......

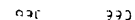

595

$\rightarrow 50$

$\begin{array}{ll}770 & 750 \\ 778 & 770 \\ 770 & 770 \\ 210 & 770 \\ 810 & 410\end{array}$

650
750
770
779
770
410
574

JiNe

574 -.

diste

AUT15T

SFOTFMAFP

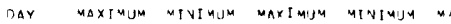

Inime mivinum wax

IMIJM MIVIMUM MAXIMIIM NTNIMIJM MaXIMIIM MINIMUM

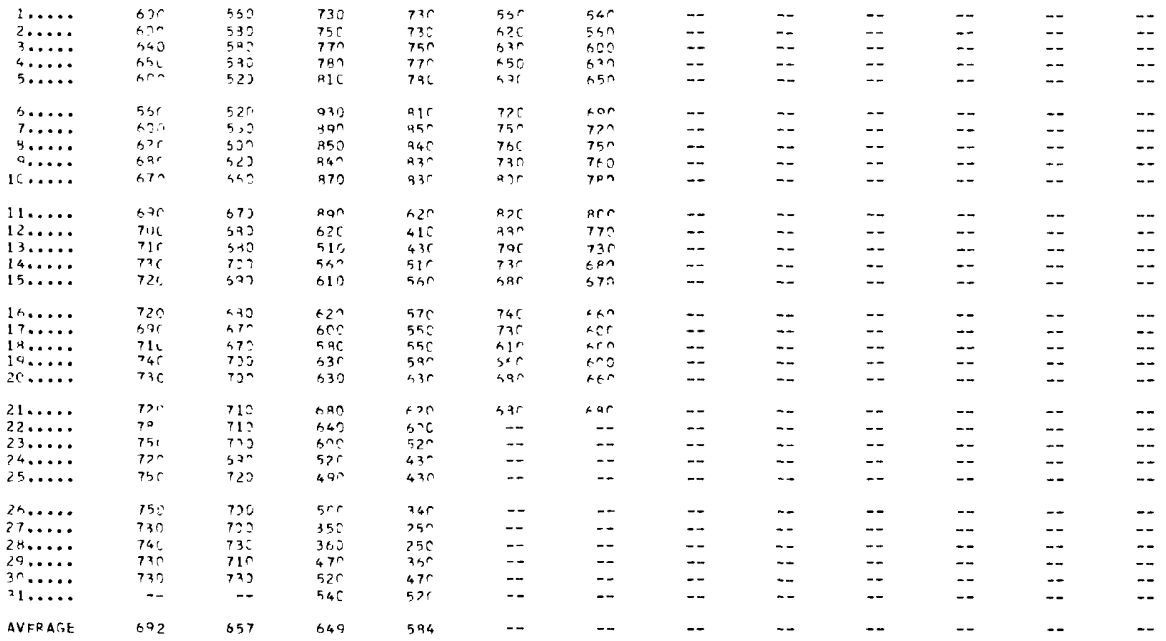


LÓCATION.--Lat $40^{\circ} 06^{\prime} 35^{\prime}$, long $83^{\circ} 01^{\prime} 55^{\prime}$, in NW $\frac{1}{4} \mathrm{~T} .2 \mathrm{~N}$, , R. $18 \mathrm{~W}$., Franklin County, temperature recorder at gaging Wilson Road Bridge, 1.5 miles northwest of Worthington, and 2.8 miles upstream from Rush Run.

DRAINAGE AREA, $--497 \mathrm{sq} \mathrm{mi}$.

PERIOD OF RECORD.--Water temperatures: October 1955 to September 1968.

EXTREMES. - - 1967-68:

Water temperatures: Maximum, $29.0^{\circ} \mathrm{C}$ Aug. 20 ; minimum, freezing point on many days during January to March.

period of record:

Water temperatures: Maximum, $31.0^{\circ} \mathrm{C}$ July 7,1962 , July $2,3,1966$; minimum, freezing point on many days during winter periods.

TEMPERATURE $\left.1{ }^{\circ} \mathrm{C}\right)$ OF WATER, WATER YEAR OCTOBER 1967 TO SEPTEMBER 1968 ICONTINUDUS ETHYL ALCOHOL-ACTUATED THERMOGRAPH)

DAY A VER-

MONTH

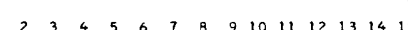

OC TOBER

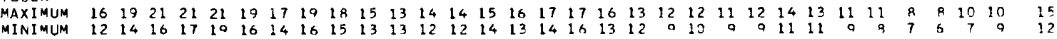
NOVFMBER

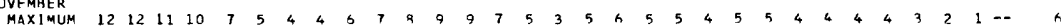

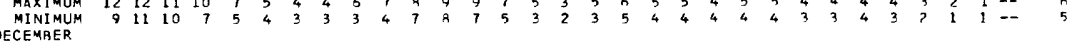

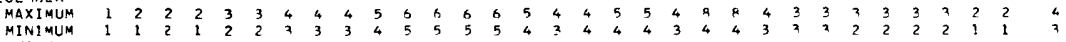
JANUARY

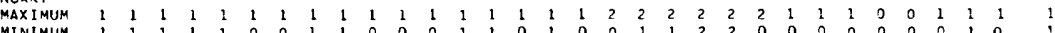

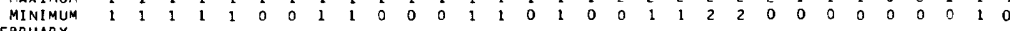
EBRUARY

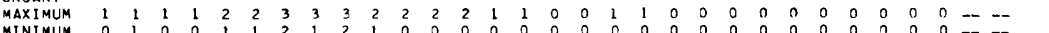
MINIMUM $00 \begin{array}{llllllllllllllllllllllllllllll} & 0 & 0 & 1 & 1 & 2 & 1 & 2 & 1 & 0 & 0 & 0 & 0 & 0 & 0 & 0 & 0 & 0 & 0 & 0 & 0 & 0 & 0 & 0 & 0 & 0 & 0 & 0 & -- & --\end{array}$ $\begin{array}{llllllllllllllllllllllllllllllll}\text { MAXIMUM } & 0 & 0 & 1 & 0 & 0 & 2 & 3 & 4 & 7 & 7 & 7 & 6 & 2 & 2 & 3 & 4 & 7 & 6 & 7 & 7 & 7 & 5 & 3 & 6 & 5 & 5 & 7 & 8 & 11 & 11 & 11 \\ \text { MINIMUM } & 0 & 0 & 0 & 0 & 0 & 0 & 1 & 2 & 4 & 6 & 5 & 2 & 1 & 0 & 2 & 3 & 3 & 2 & 3 & 6 & 5 & 2 & 2 & 3 & 3 & 3 & 4 & 5 & 7 & 8 & 9\end{array}$ APRIL

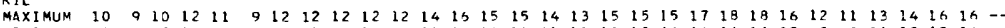

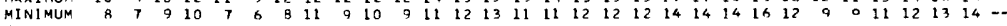

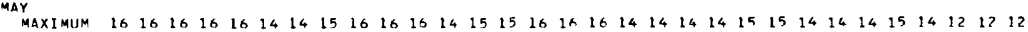

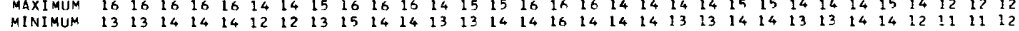
JUNE

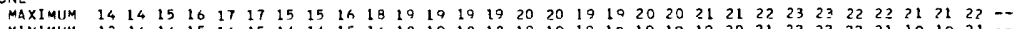
MINIMUM $121414151615141415161819181819191919191919202122 \quad 2722 \quad 21191921 \quad-$ JULY MAX1MUM $23 \begin{array}{lllllllllllllllllllllllllllllllllllll} & 23 & 22 & 21 & 21 & 22 & 22 & 22 & 23 & 23 & 23 & 24 & 24 & 24 & 23 & 24 & 24 & 25 & 24 & 23 & 23 & 23 & 24 & 24 & 24 & 24 & 23 & 22 & 23 & 22 & 21 & 23\end{array}$ AUGUST

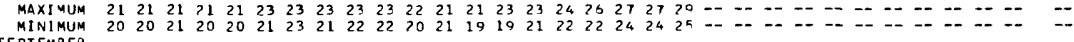
SEPTEMBER

MAXIMUM 03228805 ALUY CREEK AT AFRICA, OHIO

LOCATION.--Lat $40^{\circ} 11^{\prime} 00^{\prime \prime}$, long $82^{\circ} 57^{\prime} 45^{\prime \prime}$, in SE⿺ sec.1, T.3 N., R.16 w., Delaware County, at gaging station at bridge on Orange Township Road $109,0.3$ mile west of Africa and 4.2 miles northwest of Westerville.

DRAINAGE AREA. $--122 \mathrm{sq} \mathrm{mi}$.

PERIOD OF RECORD. --Chemical analyses: December 1964 to August 1965, periodic; October 1965 to September 1966. Water temperatures: October 1965 to September 1968.

EXTREMES. - - $1967-68$ :

Specific conductance: Maximum da1ly, 1,130 micromhos Dec. 23; minimum daily, 251 micromhos May $26,28$.

Maximum daily, 1,130 micromhos Dec. 23 ; minimum daily, 251 micromhos lay $26,28$.
Water temperatures: Maximum, $26.0^{\circ} \mathrm{C}$ Aug. 7,24 ; minimum, freezing point on several days during December to March.

Period of record:

Specific conductance: Maximum daily, 1,560 micrombos Feb. 6, 1966; minimum daily, 275 micrombos July $14,1966$. Fater temperatures: Haximum, $28.0^{\circ} \mathrm{C}$ July 3,1966 ; minimum, freezing point on many days during winter periods.

REMARKS. - Samples for iron and manganese were filtered clear when collected. Dally samples were collected at this station and samples were selected for analysis on the following basis: (1) Maximum daily specific conductance for each month, (2) minimum daily specific conductance for each month, (3) median daily specific conductance for each month, and (4) special sample each month to further define the quality of water.

CHEMICAL ANALYSES IN MILLIGRAMS PER LITER, WATER YEAR OCTOBER 1967 TO SEPTEMBER 1968

\begin{tabular}{|c|c|c|c|c|c|c|c|c|c|c|}
\hline DATE & TIME & $\begin{array}{l}\text { DIS- } \\
\text { CHARGE } \\
\text { (CFS) }\end{array}$ & $\begin{array}{l}\text { IRUN } \\
\text { (FE) }\end{array}$ & $\begin{array}{l}\text { MAN- } \\
\text { GANESE } \\
\text { (MN) }\end{array}$ & $\begin{array}{l}\text { B1CAR- } \\
\text { BONATE } \\
\text { (HCO3) }\end{array}$ & $\begin{array}{l}\text { CAR- } \\
\text { BONATE } \\
\text { (COB) }\end{array}$ & $\begin{array}{l}\text { SULFATE } \\
(\mathrm{SO4})\end{array}$ & $\begin{array}{l}\text { CHLn- } \\
\text { RIOE } \\
\text { (CL) }\end{array}$ & $\begin{array}{l}\text { FLUO- } \\
\text { RIOE } \\
\text { (F) }\end{array}$ & $\begin{array}{l}\text { NITRATE } \\
\text { (NO3) }\end{array}$ \\
\hline \multicolumn{11}{|l|}{ oct. } \\
\hline $04 \ldots$ & 1730 & 5.0 & $\cdots$ & -- & 204 & 0 & 212 & 109 & .3 & .2 \\
\hline $13 \ldots$ & 1615 & 12 & .12 & .08 & -- & -- & - & - & $=$ & $\cdots$ \\
\hline $19 \ldots$ & 1730 & 12 & -- & -- & 196 & 0 & 155 & 100 & .3 & 5.8 \\
\hline 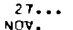 & 1730 & 26 & -- & - & 253 & 0 & 216 & 99 & .3 &.$?$ \\
\hline $05 \ldots$ & 1830 & 50 & -- & $=$ & 196 & 0 & 158 & 100 & .4 & 6.0 \\
\hline $10 \ldots$ & 1600 & 19 & .19 & .04 & -- & $\cdots$ & - & - & - & 0. \\
\hline $18 \ldots$ & 1830 & 173 & -- & -- & 138 & 0 & 112 & 74 & .3 & 18 \\
\hline $19 \ldots$ & 1930 & 12 & -- & -- & 214 & 0 & 171 & 94 & .3 & 5.7 \\
\hline \multicolumn{11}{|l|}{ OEC. } \\
\hline OH... & 1545 & 258 & .23 & .06 & -- & -- & -- & - & -- & -- \\
\hline $16 \ldots$ & 1830 & b4 & - & $\cdots$ & 260 & 0 & 184 & 80 & .4 & 5.3 \\
\hline $23 \ldots$ & 1830 & 316 & -- & -- & 324 & 0 & 318 & 29 & .4 & $? .0$ \\
\hline $31 \ldots$ & 1830 & 41 & -- & -- & $10 \mathrm{~A}$ & 0 & 57 & IA & .2 & 23 \\
\hline \multicolumn{11}{|l|}{ JAN. } \\
\hline $09 .$. & 1330 & 21 & -- & -- & 180 & 0 & 113 & 52 & .2 & 3.7 \\
\hline $12 \ldots$ & 1615 & 22 & .11 & .07 & - & -- & $=$ & $-\overline{9}$ & $\vec{z}$ & $\overline{1}$ \\
\hline $21 \ldots$ & 1830 & 28 & -- & - & 216 & 0 & 178 & $1 \mathrm{~A}$ & .2 & 1.1 \\
\hline $26 \ldots$ & 1830 & 35 & -- & -- & 110 & 0 & 54 & $1 \mathrm{~A}$ & .4 & 14 \\
\hline
\end{tabular}


CHEMICAL ANALYSES IN MILLIGRAMS PER LITER, WATER YEAR OCTOBER 1967 TO SEPTEMBER 1968

\begin{tabular}{|c|c|c|c|c|c|c|c|c|c|c|}
\hline DATE & TIME & $\begin{array}{l}\text { DIS- } \\
\text { CHARGE } \\
\text { (CFS) }\end{array}$ & $\begin{array}{l}\text { IRON } \\
\text { (FE) }\end{array}$ & $\begin{array}{l}\text { MAN- } \\
\text { GANESE } \\
\text { (MN) }\end{array}$ & $\begin{array}{l}\text { BICAR- } \\
\text { BONATE } \\
\text { (HCD3) }\end{array}$ & $\begin{array}{l}\text { CAR- } \\
\text { BONATE } \\
\text { (CO3) }\end{array}$ & $\begin{array}{l}\text { SULFATE } \\
(504)\end{array}$ & $\begin{array}{l}\text { CHLO- } \\
\text { RIDE } \\
\text { (CL) }\end{array}$ & $\begin{array}{l}\text { FLUD- } \\
\text { RIDE } \\
\text { (F) }\end{array}$ & $\begin{array}{c}\text { NI TRATE } \\
\text { (NO3) }\end{array}$ \\
\hline \multicolumn{11}{|l|}{ FEA. } \\
\hline $02 \ldots$ & 1830 & 1240 & -- & $\cdots$ & 230 & 0 & 157 & 117 & .3 & 2.1 \\
\hline $07 \ldots$ & 1 คาธ & 52 & .11 & .46 & -- & $\cdots$ & - & - & - & - \\
\hline $11 \ldots$ & 1830 & 47 & -- & -- & $>1 \mathrm{C}$ & 0 & 174 & 72 & .2 & 1.9 \\
\hline $27 \ldots$ & 1830 & 19 & -- & -- & 250 & 0 & 144 & 104 & .3 & .8 \\
\hline \multicolumn{11}{|l|}{ पAर. } \\
\hline nL... & 1830 & 21 & $=$ & -- & 248 & c & 174 & 76 & .3 & 2.8 \\
\hline $0 \times \ldots$ & Lajo & 27 & .09 & .05 & - & -- & - & - & $\cdots$ & - \\
\hline $24 \ldots$ & 1830 & 373 & -- & - & 110 & 0 & 85 & 54 & .2 & 20 \\
\hline \multicolumn{11}{|l|}{$\Delta Q k$. } \\
\hline us... & 1715 & 212 & .15 & .07 & - & -- & $-\overline{-}$ & $=$ & $=$ & $-\overline{0}$ \\
\hline $09 .$. & 1830 & $+R$ & -- & -- & $18 \mathrm{C}$ & 0 & 123 & 52 & .2 & 2.0 \\
\hline $21 \ldots$ & 1930 & 33 & -- & -- & 298 & 0 & 145 & 70 & .3 & .4 \\
\hline \multicolumn{11}{|l|}{ YAY } \\
\hline $17 \ldots$ & $\begin{array}{l}1130 \\
0 \% 30\end{array}$ & $\begin{array}{l}200 \\
245\end{array}$ & .19 & .39 & $\overline{13}$ & $\overline{0}$ & $\overline{80}$ & $\overline{4}$ & 4 & 47 \\
\hline $23 \ldots$ & $=$ & $\begin{array}{r}240 \\
50\end{array}$ & - & - & $\begin{array}{l}172 \\
198\end{array}$ & 0 & $\begin{array}{l}07 \\
117\end{array}$ & 92 & .4 & $\begin{array}{l}4.1 \\
1.3\end{array}$ \\
\hline $28 \ldots$ & 0830 & 260 & -- & -- & 64 & 0 & 35 & 12 & .2 & 14 \\
\hline \multicolumn{11}{|l|}{ JUNE } \\
\hline $03 \ldots$ & 0915 & 100 & -- & -- & 176 & 0 & 81 & 38 & .2 & 5.9 \\
\hline $13 \ldots$ & 0730 & 32 & .10 & .05 & - & -- & - & - & $\Longrightarrow$ & - \\
\hline $17 \ldots$ & 0.30 & 59 & - & - & 226 & $c$ & 131 & 68 & .3 & 1.2 \\
\hline $28 \ldots$ & $O B 30$ & 26 & - & -- & 240 & 0 & 148 & 74 & .2 & .9 \\
\hline \multicolumn{11}{|l|}{ JUL.Y } \\
\hline $11 \ldots$ & 1000 & 9.8 & .14 & .23 & -- & -- & - & -- & - & - \\
\hline $12 \ldots$ & 0830 & 6.2 & - & -- & 224 & c & 254 & 99 & .3 & .6 \\
\hline $25 \ldots$ & 0830 & 775 & -- & -- & 80 & 0 & 40 & 13 & .2 & 12 \\
\hline $31 \ldots$ & 0830 & $2 c$ & - & -- & 196 & 0 & 114 & 40 & .3 & 3.5 \\
\hline \multirow{2}{*}{\multicolumn{11}{|c|}{ Aug. }} \\
\hline & 0830 & & -- & - & $19 t$ & 0 & 104 & 47 & .4 & 3.3 \\
\hline $07 \ldots$ & 4930 & 18 & .21 & .04 & - & -- & $\ldots$ & -- & $\cdots$ & -- \\
\hline $27 \ldots$ & 0830 & 4.7 & - & - & 230 & 0 & 135 & 77 & .3 & .0 \\
\hline $30 \ldots$ & 0830 & 3.0 & - & - & 308 & 0 & 141 & 83 & .3 & .0 \\
\hline SEPT. & & & & & & & & & & \\
\hline $02 \ldots$ & $\overrightarrow{0.30}$ & $\begin{array}{l}3.7 \\
2.8\end{array}$ & .06 & .05 & 205 & 0 & 141 & 78 & -3 & $\therefore 2$ \\
\hline $\begin{array}{l}04 \ldots \\
10 \ldots\end{array}$ & 0800 & & 0 & .03 & 200 & $\bar{c}$ & $\overline{186}$ & 80 & $\overline{3}$ & $\overline{1}$ \\
\hline $\begin{array}{l}10 \ldots \\
24 \ldots\end{array}$ & 0330 & $\begin{array}{l}3.6 \\
5.0\end{array}$ & - & -- & $\begin{array}{l}220 \\
224\end{array}$ & $\begin{array}{l}\mathrm{C} \\
0\end{array}$ & $\begin{array}{l}186 \\
183\end{array}$ & $\begin{array}{l}80 \\
71\end{array}$ & .3 & $\begin{array}{l}.1 \\
.0\end{array}$ \\
\hline \multirow{2}{*}{\multicolumn{11}{|c|}{ DIS- }} \\
\hline & & & & NON- & FIC & & & & & \\
\hline & & SULIDS & & CAR- & CONO- & & & & & ER- \\
\hline & PHOS- & IRESI- & HARD- & BONATE & UCTANC & & TEMP- & niss- & & ENT \\
\hline & PHERUS & DUE AT & NESS & HARD- & (MICRD & $o_{H}$ & ERATURE & OL VED & & TUR- \\
\hline UATF & $(P J 4)$ & $180 \mathrm{Cl}$ & ICA, MG & NESS & MHOSI & & (DEG CI & OXYGEA & & NON \\
\hline
\end{tabular}

\begin{tabular}{|c|c|c|c|c|c|c|c|c|c|}
\hline $04 \ldots$ & .16 & 622 & 440 & 273 & 1040 & 7.8 & 13 & -- & - \\
\hline $13 \ldots$ & + & -- & -- & -. & . & - & -- & 9.0 & 82 \\
\hline $19 \ldots$ & .17 & 614 & 378 & 217 & 917 & 8.0 & 10 & - & $\cdots$ \\
\hline $27 \ldots$ & .09 & 724 & 470 & 260 & 1080 & 7.5 & A & -- & - \\
\hline \multicolumn{10}{|l|}{ Nov. } \\
\hline $05 \ldots$ & .55 & 626 & 382 & 221 & 926 & 7.8 & 4 & $\cdots$ & $=$ \\
\hline $10 \ldots$ & -- & - & - & -- & -- & -- & - & 12.0 & 100 \\
\hline $1+\ldots$ & .62 & 492 & 231 & 163 & 714 & 7.2 & 4 & - & $=$ \\
\hline $19 \ldots$ & .40 & 620 & 415 & 230 & 960 & 7.4 & 1 & - & $-\infty$ \\
\hline \multicolumn{10}{|l|}{ DEC. } \\
\hline $08 \ldots$ & -- & - & -- & -- & -- & -- & -- & 11.0 & 92 \\
\hline $16 \ldots$ & .62 & 596 & 445 & 232 & 992 & 7.6 & 4 & $\cdots$ & - \\
\hline $23 \ldots$ & .64 & 776 & 610 & 344 & 1130 & 7.5 & 2 & - & -- \\
\hline \multirow{2}{*}{\multicolumn{10}{|c|}{ JAN. }} \\
\hline & & & & & & & & & \\
\hline $09 \ldots$ & .09 & 424 & 290 & 142 & 677 & R.O & 1 & -- & -- \\
\hline $12 \ldots$ & -- & -- & - & -- & $\cdots$ & -- & -- & 10.0 & 31 \\
\hline $21 \ldots$ & .04 & 470 & 384 & 207 & 770 & 7.9 & 1 & -- & - \\
\hline $25 \ldots$ & .38 & 216 & 166 & 76 & 385 & 7.1 & $?$ & $\cdots$ & -- \\
\hline \multicolumn{10}{|l|}{ FEO. } \\
\hline $02 \ldots$ & .24 & $6 \% 6$ & 408 & 217 & 1030 & 7.7 & 2 & -- & - \\
\hline $09 \ldots$ & $\cdots$ & -- & $=$ & - & -- & -- & -- & 13.0 & 92 \\
\hline $11 \ldots$ & .02 & 554 & 323 & 151 & 903 & 8.2 & 1 & -- & -- \\
\hline $27 \ldots$ & .06 & $64 \pi$ & 400 & 195 & 974 & $7.0^{\circ}$ & 1 & - & $\rightarrow$ \\
\hline \multicolumn{10}{|l|}{ MAR. } \\
\hline $01 \ldots$ & .00 & 596 & $41 t$ & 213 & 958 & 8.1 & 1 & - & -- \\
\hline $38 \ldots$ & -- & -- & -- & $-\bar{x}$ & -- & - & - & 14.0 & 96 \\
\hline $24 \ldots$ & .05 & 354 & 220 & 130 & 549 & 8.2 & 3 & -- & - \\
\hline \multicolumn{10}{|l|}{$A P K$. } \\
\hline $05 \ldots$ & -- & - & -- & -- & - & $\cdots$ & -- & 12.0 & $9 ?$ \\
\hline $09 \ldots$ & .05 & 444 & 305 & 157 & 680 & 8.0 & 11 & -- & - \\
\hline \multirow{2}{*}{\multicolumn{10}{|c|}{ MAY }} \\
\hline & - & -- & & & & & & & 79 \\
\hline $17 \ldots$ & .16 & 348 & 259 & 118 & 595 & 7.3 & 16 & - & - \\
\hline $22 \ldots$ & .10 & 474 & 312 & 158 & 798 & 7.7 & 13 & -- & - \\
\hline $28 \ldots$ & .27 & 148 & 105 & 52 & 251 & 7.0 & 14 & -- & - \\
\hline \multicolumn{10}{|l|}{ JUNE } \\
\hline $03 \ldots$ & .21 & 390 & 250 & 106 & 572 & 7.1 & $1 \%$ & - & -- \\
\hline $13 \ldots$ & -- & -- & - & -- & -- & $\cdots$ & 21 & 6.4 & 71 \\
\hline $17 \ldots$ & .14 & 526 & 346 & 161 & 795 & 7.4 & 19 & -- & $\cdots$ \\
\hline $28 \ldots$ & .05 & 556 & 376 & 179 & 854 & 7.5 & 18 & - & -- \\
\hline \multicolumn{10}{|l|}{ JULY } \\
\hline $11 \ldots$ & -- & -- & - & 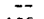 & -- & $\cdots$ & -- & 6.2 & 71 \\
\hline $12 \ldots$ & .09 & 596 & 379 & 195 & 918 & 7.7 & 23 & -- & -- \\
\hline $26 \ldots$ & .20 & 204 & 124 & 50 & 290 & 7.5 & 21 & $\cdots$ & $\cdots$ \\
\hline $31 \ldots$ & .17 & 416 & 290 & 129 & 040 & 8.2 & 24 & -- & -- \\
\hline \multicolumn{10}{|l|}{ AUGG. } \\
\hline $02 \ldots$ & .13 & 422 & 280 & 117 & 640 & 8.2 & 21 & - & -- \\
\hline $07 \ldots$ & -- & - & - & $\overline{--}$ & $\overline{-}$ & - & 26 & 6.1 & 74 \\
\hline $27 \ldots$ & .04 & 542 & 361 & $17 ?$ & 839 & A. 1 & 17 & -- & -- \\
\hline \multicolumn{10}{|l|}{ SFPT. } \\
\hline $02 \ldots$ & .05 & 514 & 346 & 178 & 842 & 8.1 & 17 & -- & - \\
\hline $04 \ldots$ & - & -- & -- & -- & - & -- & 20 & 6.3 & 69 \\
\hline $10 .$. & . C6 & $6 C 8$ & 309 & 219 & 925 & 7.9 & $-\overline{-}$ & -- & -- \\
\hline $24 \ldots$ & .09 & 590 & 390 & $20 \mathrm{~h}$ & B१ค & 7.9 & 22 & -- & 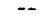 \\
\hline
\end{tabular}


03228805 ALUM CREEK AT AFRICA, OHIO--Continued

SPECIFIC CONDUCTANCE (MICROMOHS AT $25^{\circ} \mathrm{C}$ ), WATER YEAR OCTOBER 1967 TO SEPTEMBER 1968

DAY OCTOBER NOVEMBER DECEMBER JANUARY FEBRUARY MARCH APRIL MAY JUNE JULY aUGUST SEPIEMBER

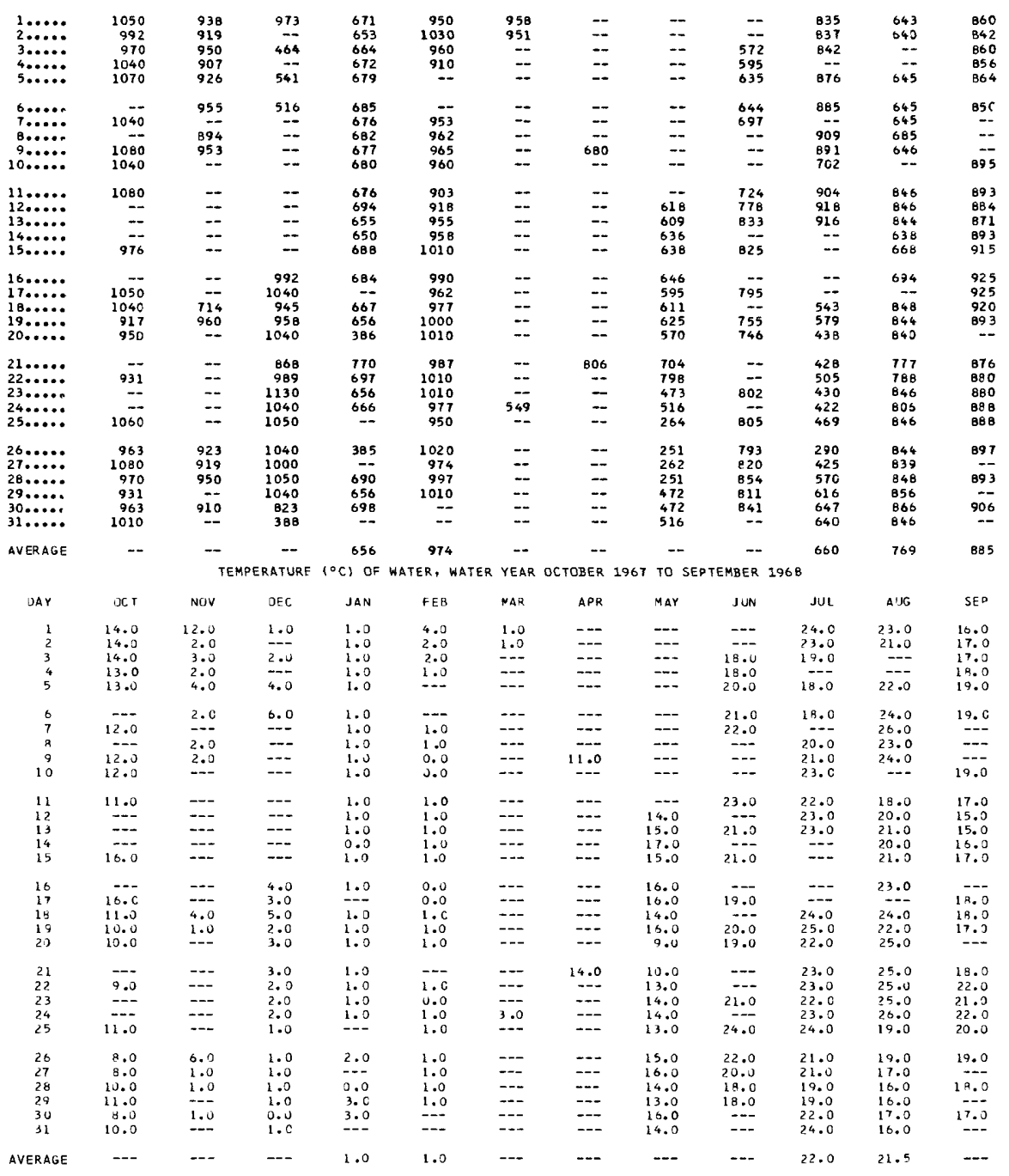


LOCATION. --Lat $39^{\circ} 47^{\circ} 37^{\prime \prime}$, long $83^{\circ} 00^{\circ} 40^{\prime \prime}$, Pickaway County, on left bank at Plcway Plant of Columbus and Southern Obio Electric Co., $0.4 \mathrm{mile}$ downstream from B1g Falnut Creek and 3.2 miles downstream from Shadeville.

DRAINAGE AREA, $-2,266 \mathrm{sq} \mathrm{mi}$.

PERIOD OF RECORD.--Chemical analyses: March 1965 to September 1968.

Water temperatures: Marcb 1965 to September 1968.

EXTREMES, - -1967-68:

Specific conductance: Maximum daily, 1,000 micromhos Jan, 20; minimum daily, 190 micromhos May 27.

Dissolved oxygen: Maximum daily, $14.6 \mathrm{mg} / 1$ Dec. $24 ;$ minimum daily, $0.0 \mathrm{mg} / 1$ on several days during June to

September.
Nater temperatures: Maximum, $32.0^{\circ} \mathrm{C}$ Aug. 20; minimum, freezing point on several days during December to March.

Period of record:

Specific conductance: Maximum datly, 1,260 micromhos Feb. 9, 1966; minimum dally, 190 micrombos May $27,1968$. Dissolved oxygen: Maximum daily, 14.6 mg/1 Dec. 24, 1967; minimum daily, $0.0 \mathrm{mg} / 1$ on many days during

Water temperatures: Maximum, 33.0 ${ }^{\circ} \mathrm{C}$ Aug. 16, 1965; minimum, freezing point on several days during December 1967 to

REHARKS. - In addition to the continuous recorder dally samples were collected by a local observer. Partial analyses were made on maximum specific conductance and minimum specific conductance of the samples collected 作

ava1 lable, CHEMICAL ANALYSES IN MILLIGRAMS PER LITER, WATER YEAR OCTOBER 1967 TO SEPTEMBER 1968

\begin{tabular}{|c|c|c|c|c|c|c|c|c|c|c|c|c|}
\hline DATE & TIME & $\begin{array}{l}\text { BICAR- } \\
\text { BONATE } \\
\text { (HCOX) }\end{array}$ & $\begin{array}{l}\text { CAR- } \\
\text { RTYATF } \\
\text { (CJ3) }\end{array}$ & $\begin{array}{l}\text { SULFATE } \\
\text { (Sח4) }\end{array}$ & $\begin{array}{l}\text { CHLO- } \\
\text { RIDE } \\
\text { (CL) }\end{array}$ & $\begin{array}{l}\text { FLIYD- } \\
\text { PITE } \\
\text { IFI) }\end{array}$ & $\begin{array}{l}\text { NITPATF } \\
\text { (NO3) }\end{array}$ & $\begin{array}{l}\text { UIS- } \\
\text { SOLVEN } \\
\text { SOLIOS } \\
\text { IRESI- } \\
\text { NUE AT } \\
\text { ISO CI }\end{array}$ & $\begin{array}{l}\text { HARD- } \\
\text { NFCS } \\
(C A . M G)\end{array}$ & $\begin{array}{l}\text { NON- } \\
\text { TAR- } \\
\text { RONATF } \\
\text { HARD- } \\
\text { NTCS }\end{array}$ & $\begin{array}{l}\text { SOFCI- } \\
\text { FIC } \\
\text { TONN- } \\
\text { UNTAVCE } \\
\text { (MICPO- } \\
\text { MHOSI }\end{array}$ & PH \\
\hline OCT. & & & & & & & & & & & & \\
\hline $\begin{array}{l}12 \ldots \\
19 . .\end{array}$ & $\begin{array}{l}3650 \\
07 C 0\end{array}$ & $\begin{array}{l}162 \\
139\end{array}$ & : & $\begin{array}{l}129 \\
176\end{array}$ & $\begin{array}{l}48 \\
6 R\end{array}$ & 1.8 & $\begin{array}{l}29 \\
6 n\end{array}$ & $\begin{array}{l}434 \\
572\end{array}$ & $\begin{array}{l}259 \\
204\end{array}$ & $\begin{array}{l}125 \\
190\end{array}$ & $\begin{array}{l}723 \\
0 \times 5\end{array}$ & $\begin{array}{l}6.8 \\
7.8\end{array}$ \\
\hline Nov. & & & & & & & & & & & & \\
\hline $\begin{array}{l}1 \\
03 \ldots\end{array}$ & $\begin{array}{l}0745 \\
09 C A\end{array}$ & $\begin{array}{l}102 \\
174\end{array}$ & $\begin{array}{r}0 \\
14\end{array}$ & $\begin{array}{l}201 \\
100\end{array}$ & $\begin{array}{l}8 C \\
44\end{array}$ & $\begin{array}{r}1.5 \\
.9\end{array}$ & 50 & $\begin{array}{l}672 \\
\operatorname{sn} 8\end{array}$ & $\begin{array}{l}204 \\
277\end{array}$ & $\begin{array}{l}319 \\
\ln 4\end{array}$ & $\begin{array}{l}971 \\
+41\end{array}$ & $\begin{array}{l}2.7 \\
9.7\end{array}$ \\
\hline $\begin{array}{l}\text { OEC. } \\
\text { D4... }\end{array}$ & noor & 182 & 0 & 118 & 65 & .5 & 2.8 & $45 n$ & 299 & 129 & $40 x$ & 7.4 \\
\hline $13 \ldots$ & 0725 & 128 & 0 & 86 & 24 & .2 & 10 & 310 & 220 & 115 & $4 \times 7$ & 9.3 \\
\hline $\begin{array}{r}\text { JAN. } \\
72 \ldots \\
31 \ldots\end{array}$ & $\begin{array}{l}1530 \\
0730\end{array}$ & $\begin{array}{r}227 \\
86\end{array}$ & $\begin{array}{l}0 \\
0\end{array}$ & $\begin{array}{r}132 \\
51\end{array}$ & $\begin{array}{l}97 \\
18\end{array}$ & .9 & $\begin{array}{l}9.5 \\
9.1\end{array}$ & $\begin{array}{l}594 \\
2^{n} 4\end{array}$ & $\begin{array}{l}343 \\
134\end{array}$ & $\begin{array}{r}157 \\
63\end{array}$ & $\begin{array}{l}014 \\
311\end{array}$ & $\begin{array}{l}7 . ? \\
9.1\end{array}$ \\
\hline FFA. & & & n & 50 & & & 15 & 209 & $13 k$ & Git & 312 & \\
\hline $\begin{array}{r}01 \ldots \\
29 . \\
M A R\end{array}$ & $\begin{array}{l}9900 \\
1415\end{array}$ & $\begin{array}{r}\text { A6 } \\
210\end{array}$ & $\hat{n}$ & 137 & $\begin{array}{l}12 \\
52\end{array}$ & $1.5^{-3}$ & 14 & 512 & 322 & 150 & 797 & 700 \\
\hline $\begin{array}{l}\text { MaR. } \\
\text { O8.... }\end{array}$ & jgc0 & 216 & 0 & 153 & 51 & I. 5 & 14 & $53 \mathrm{~A}$ & 345 & $1 \in A$ & QSR $R$ & 7.7 \\
\hline$>9 .$. & 2807 & 132 & 2 & 60 & 35 & .4 & 17 & $31 \mathrm{~A}$ & 218 & 107 & 4R5 & 9.4 \\
\hline$Q P R_{0}$ & & & & & & & & & & & & \\
\hline $\begin{array}{l}01 \ldots \\
30 \ldots\end{array}$ & $\begin{array}{l}2800 \\
0715\end{array}$ & $\begin{array}{l}146 \\
>06\end{array}$ & $\begin{array}{l}0 \\
0\end{array}$ & $\begin{array}{r}77 \\
103\end{array}$ & $\begin{array}{l}26 \\
45\end{array}$ & .3 & 30 & $\begin{array}{l}726 \\
432\end{array}$ & $\begin{array}{l}319 \\
282\end{array}$ & $11^{2}$ & $\begin{array}{l}571 \\
\text { S.95 }\end{array}$ & $\begin{array}{l}7.6 \\
7.1\end{array}$ \\
\hline MAY & & & & & & & & & & & & \\
\hline $\begin{array}{l}04 \ldots \\
28 . . .\end{array}$ & $\begin{array}{l}0860 \\
0815\end{array}$ & $\begin{array}{r}198 \\
96\end{array}$ & $\begin{array}{l}0 \\
0\end{array}$ & $\begin{array}{r}145 \\
4 C\end{array}$ & $4 h$ & 1.7 & 26 & $49 \pi$ & $31 \%$ & 154 & an1 & 5.9 \\
\hline JUNF & & & & & $1 \mathrm{C}$ & .2 & 9.1 & 172 & 132 & 44 & 271 & 7.1 \\
\hline $\begin{array}{l}03 \ldots \\
24 \ldots\end{array}$ & CROn & 144 & ? & 58 & 16 & .2 & 15 & 254 & 177 & 59 & $4 ? 7$ & 7.3 \\
\hline $\begin{array}{l}24 \ldots \\
\text { JULY }\end{array}$ & 1300 & $? 16$ & $c$ & 120 & $3 A$ & .4 & 11 & 412 & 200 & 120 & 717 & 9.2 \\
\hline $11 .$. & 1105 & 216 & 0 & 104 & 26 & .3 & 14 & $47 c$ & 294 & 117 & $74 \mathrm{~K}$ & 7.4 \\
\hline $\begin{array}{l}26 \ldots \\
\text { AlIG. }\end{array}$ & 0830 & 164 & 0 & 88 & 37 & .4 & 15 & 345 & 235 & 101 & 559 & 9.n \\
\hline $02 \ldots$ & 0720 & 149 & 0 & QR & 24 & $3^{3}$ & 10 & $3 n ?$ & 310 & 9 & & \\
\hline $29 \ldots$ & 1000 & 188 & r & 146 & 54 & 1.5 & 36 & 524 & 290 & 178 & $\begin{array}{l}517 \\
86 ?\end{array}$ & $\begin{array}{l}4.8 \\
6.8\end{array}$ \\
\hline $24 \ldots$. & Jpon & $\begin{array}{l}746 \\
174\end{array}$ & $\delta_{0}^{6}$ & $\begin{array}{l}149 \\
129\end{array}$ & $\begin{array}{l}56 \\
50\end{array}$ & $\begin{array}{r}1.9 \\
.9\end{array}$ & $25{ }^{5}$ & 510 & 302 & $\begin{array}{r}78 \\
119\end{array}$ & $\begin{array}{l}294 \\
745\end{array}$ & $\begin{array}{l}7.1 \\
2.1\end{array}$ \\
\hline
\end{tabular}

SPECIFIC CONDUCTANCE, DISSOLVED OXYGEN, AND WATER TEMPERATURES, WATER YEAR OCTOBER 1967 TO SEPTEMBER 1968 ECIFIC CONDUCTANCE, DISSOLVED OXYGEN, AND WATER TEMPERATURE,
NOVEMBER

DAY CONDUCTANCE CONDUCTANCE DISSOLVED TEMPE

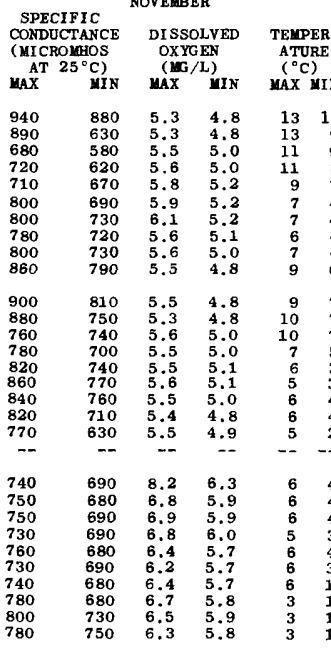

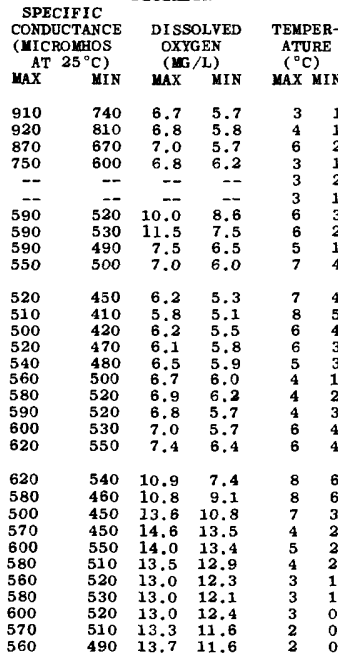


03229600 SCIOTO RIVER BELOW SHADEV ILLE, OHIO--COntinued

SPECIFIC CONDUCTANCE, DISSOLVED OXYGEN, AND WATER TEMPERATURES, WATER YEAR OCTOBER 1967 TO SEPTEMBER 1968 JANUARY

FEBRUARY

SPECIFIC

CONDUCTANCE DISSOLVED TEUPER-

$620 \quad 11.7 \quad 9.5$
DAY (MICROTANC

AT $25^{\circ} \mathrm{C}$ )

$\max$

$\begin{array}{llll}610 & 560 & 13.6 & 12.8\end{array}$

$\begin{array}{lll}550 & 13.6 & 12.6 \\ 550 & 13.0 & 10.0\end{array}$

$560 \quad 11.5 \quad 9.5$

$\begin{array}{lll}690 & 12.4 & 10.2\end{array}$

$\begin{array}{lll}680 & 12.3 & 10.0\end{array}$

$\begin{array}{lll}660 & 12.2 & 10.4\end{array}$

$\begin{array}{lll}700 & 11.3 & 9.8 \\ 730 & 11.3 & 8.7\end{array}$

$\begin{array}{lll}770 & 11.3 & 9.0 \\ 740 & 11.6 & 8.6\end{array}$

$730 \quad 10.8 \quad 7.4$

$\begin{array}{lll}750 & 12.0 & 9.0 \\ 740 & 12.0 & 9.7\end{array}$

$\begin{array}{lll}760 & 12.9 & 10.6\end{array}$

$\begin{array}{lll}760 & 14.0 & 11.9 \\ 770 & 14.0 & 12.0\end{array}$

$\begin{array}{rrr}770 & 14.0 & 12.0 \\ 790 & 12.0 & 7.6\end{array}$

$\begin{array}{lll}790 & 12.0 & 7.6 \\ 840 & 13.1 & 2.4\end{array}$

$\begin{array}{lll}890 & 8.2 & 1.3\end{array}$

$\begin{array}{lrr}880 & 11.2 & 4.5 \\ 850 & 11.6 & 3.3 \\ 860 & 7.6 & 6.9 \\ 690 & 8.9 & 6.9\end{array}$

$\begin{array}{lll}710 & 9.0 & 7.3\end{array}$

$\begin{array}{lll}\mathbf{7 1 0} & \mathbf{8 . 7} & \mathbf{7 . 5} \\ \mathbf{6 9 0} & \mathbf{8 . 6} & \mathbf{7 . 1}\end{array}$

$\begin{array}{lll}690 & 8.6 & 7.1 \\ 480 & 9.2 & 8.4 \\ 330 & 9.3 & 8.8\end{array}$

TEMPER-
ATURE
$\left({ }^{\circ} \mathrm{C}\right)$

MAX MIN

$\begin{array}{ll}\mathbf{2} & \mathbf{1} \\ \mathbf{2} & 0 \\ \mathbf{2} & 0 \\ \mathbf{3} & 0 \\ \mathbf{2} & 0\end{array}$

$\begin{array}{ll}4 & 1 \\ 3 & 1 \\ 2 & 0 \\ 2 & 1 \\ 4 & 1\end{array}$

$\begin{array}{ll}4 & 0 \\ 4 & 1 \\ 3 & 1 \\ 5 & \\ 5 & \end{array}$

$\begin{array}{ll}4 & 1 \\ 2 & 0 \\ 4 & 1 \\ 6 & 2 \\ 6 & 2\end{array}$

$\begin{array}{ll}7 & 3 \\ 4 & \\ 7 & \\ 6 & \end{array}$

$\mathbf{2}$
$\mathbf{2}$
$\mathbf{2}$
$\mathbf{2}$
$\mathbf{3}$
$\mathrm{3}$

$\begin{array}{ll}30 & 480 \\ 31 & \mathbf{3 3 0}\end{array}$

\begin{tabular}{|c|c|c|c|c|c|}
\hline \multicolumn{2}{|c|}{$\begin{array}{l}\text { SPECIFIC } \\
\text { CONDUCTANCE } \\
\text { (UI CROMHOS } \\
\text { AT } 25^{\circ} \mathrm{C} \text { ) }\end{array}$} & \multicolumn{2}{|c|}{$\begin{array}{l}\text { DI SSOLVED } \\
\text { OXYGEN } \\
(\text { HG/L) }\end{array}$} & \multicolumn{2}{|c|}{$\begin{array}{c}\text { TEMPER- } \\
\text { ATURE } \\
\left({ }^{\circ} \mathrm{C}\right)\end{array}$} \\
\hline $\max$ & MIN & YAXX & MIN & $\operatorname{MAX}$ & IIN \\
\hline $\begin{array}{l}360 \\
410 \\
390 \\
390 \\
410\end{array}$ & $\begin{array}{l}\mathbf{2 6 0} \\
\mathbf{3 4 0} \\
\mathbf{3 4 0} \\
\mathbf{3 4 0} \\
\mathbf{3 7 0}\end{array}$ & $\begin{array}{l}9.5 \\
9.3 \\
9.3 \\
9.7 \\
9.7\end{array}$ & $\begin{array}{l}9.0 \\
8.5 \\
6.7 \\
9.1 \\
9.3\end{array}$ & $\begin{array}{l}7 \\
6 \\
5 \\
4 \\
7\end{array}$ & $\begin{array}{l}3 \\
3 \\
2 \\
1 \\
4\end{array}$ \\
\hline- & -- & 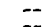 & - & $=$ & -- \\
\hline $\begin{array}{l}540 \\
560 \\
580\end{array}$ & $\begin{array}{l}480 \\
490 \\
520\end{array}$ & $\begin{array}{l}10.7 \\
10.3 \\
10.3\end{array}$ & $\begin{array}{l}9.7 \\
9.1 \\
9.3\end{array}$ & $\begin{array}{l}5 \\
4 \\
3\end{array}$ & $\begin{array}{l}3 \\
2 \\
0\end{array}$ \\
\hline $\begin{array}{l}580 \\
600 \\
650 \\
640 \\
660\end{array}$ & $\begin{array}{l}\mathbf{5 3 0} \\
\mathbf{5 5 0} \\
570 \\
\mathbf{5 7 0} \\
\mathbf{5 9 0}\end{array}$ & $\begin{array}{r}10.6 \\
10.3 \\
9.7 \\
9.7 \\
9.7\end{array}$ & $\begin{array}{l}9.6 \\
9.6 \\
8.6 \\
8.8 \\
8.5\end{array}$ & $\begin{array}{l}2 \\
2 \\
2 \\
3 \\
4\end{array}$ & $\begin{array}{l}0 \\
1 \\
0 \\
1 \\
1\end{array}$ \\
\hline $\begin{array}{l}670 \\
700 \\
700 \\
700 \\
\mathbf{7 2 0}\end{array}$ & $\begin{array}{l}620 \\
650 \\
640 \\
640 \\
650\end{array}$ & $\begin{array}{l}9.4 \\
9.6 \\
9.6 \\
9.6 \\
9.1\end{array}$ & $\begin{array}{l}8.4 \\
7.9 \\
8.9 \\
8.5 \\
7.4\end{array}$ & $\begin{array}{l}5 \\
5 \\
4 \\
4 \\
4\end{array}$ & $\begin{array}{l}2 \\
2 \\
2 \\
1 \\
1\end{array}$ \\
\hline $\begin{array}{l}780 \\
790 \\
780 \\
790 \\
780\end{array}$ & $\begin{array}{l}680 \\
760 \\
730 \\
710 \\
\mathbf{7 2 0}\end{array}$ & $\begin{array}{l}9.6 \\
9.9 \\
9.6 \\
8.8 \\
9.4\end{array}$ & $\begin{array}{l}7.9 \\
8.9 \\
7.9 \\
7.5 \\
8.7\end{array}$ & $\begin{array}{l}4 \\
4 \\
6 \\
6 \\
6\end{array}$ & $\begin{array}{l}\mathbf{1} \\
\mathbf{2} \\
\mathbf{2} \\
\mathbf{3} \\
\mathbf{2}\end{array}$ \\
\hline $\begin{array}{l}750 \\
800 \\
840 \\
800\end{array}$ & $\begin{array}{l}730 \\
720 \\
780 \\
760\end{array}$ & $\begin{array}{l}9.7 \\
9.3 \\
8.7 \\
8.3\end{array}$ & $\begin{array}{l}8.8 \\
6.8 \\
7.0 \\
7.0\end{array}$ & $\begin{array}{l}7 \\
8 \\
8 \\
6\end{array}$ & $\begin{array}{l}3 \\
4 \\
5 \\
4\end{array}$ \\
\hline$\overline{--}$ & $\overline{--}$ & $=$ & - & $\overline{-}$ & $=$ \\
\hline
\end{tabular}

MARCH

\begin{tabular}{|c|c|c|c|c|c|}
\hline \multicolumn{2}{|c|}{$\begin{array}{l}\text { SPECIF IC } \\
\text { CONDUCTANCE } \\
\text { (MICROMHOS } \\
\text { AT } 25^{\circ} \mathrm{C} \text { ) }\end{array}$} & \multicolumn{2}{|c|}{$\begin{array}{l}\text { DI SSOLVED } \\
\text { OXYGEN } \\
(\text { MG } / L)\end{array}$} & \multicolumn{2}{|c|}{$\begin{array}{l}\text { TEUPER- } \\
\text { ATURE } \\
\left({ }^{\circ} \mathrm{C}\right)\end{array}$} \\
\hline IAX & MIN & $\max$ & MIN & $\max$ & MII \\
\hline $\begin{array}{l}840 \\
870 \\
860 \\
860 \\
840\end{array}$ & $\begin{array}{l}\mathbf{7 7 0} \\
\mathbf{8 2 0} \\
810 \\
800 \\
\mathbf{7 8 0}\end{array}$ & $\begin{array}{l}7.3 \\
6.9 \\
8.8 \\
9.3 \\
8.4\end{array}$ & $\begin{array}{l}6.1 \\
5.7 \\
6.5 \\
7.7 \\
5.5\end{array}$ & $\begin{array}{l}7 \\
8 \\
7 \\
9 \\
9\end{array}$ & \\
\hline $\begin{array}{l}70 \\
190 \\
40 \\
30 \\
100\end{array}$ & $\begin{array}{l}790 \\
820 \\
860 \\
860 \\
830\end{array}$ & $\begin{array}{l}7.2 \\
7.9 \\
6.9 \\
5.8 \\
6.7\end{array}$ & $\begin{array}{l}5 . \\
7 . \\
5 . \\
4 .\end{array}$ & $\begin{array}{l}10 \\
11 \\
12 \\
14 \\
14\end{array}$ & $\begin{array}{l}10 \\
11\end{array}$ \\
\hline $\begin{array}{l}880 \\
920 \\
910 \\
890 \\
860\end{array}$ & $\begin{array}{l}810 \\
810 \\
840 \\
830 \\
780\end{array}$ & $\begin{array}{l}7.9 \\
6.4 \\
6.8 \\
7.8 \\
8.1\end{array}$ & $\begin{array}{l}4.6 \\
3.1 \\
3.5 \\
6.2 \\
5.8\end{array}$ & $\begin{array}{r}14 \\
12 \\
8 \\
10 \\
11\end{array}$ & \\
\hline $\begin{array}{l}880 \\
860 \\
840 \\
770 \\
820\end{array}$ & $\begin{array}{l}760 \\
800 \\
750 \\
690 \\
700\end{array}$ & $\begin{array}{r}6.9 \\
7.6 \\
7.3 \\
9.0 \\
10.2\end{array}$ & $\begin{array}{l}5.2 \\
4.0 \\
6.3 \\
6.9 \\
8.4\end{array}$ & $\begin{array}{l}11 \\
13 \\
12 \\
11 \\
13\end{array}$ & 11 \\
\hline $\begin{array}{l}860 \\
690 \\
590 \\
580 \\
550\end{array}$ & $\begin{array}{l}690 \\
590 \\
430 \\
460 \\
420\end{array}$ & $\begin{array}{l}10.1 \\
10.3 \\
11.1 \\
11.5 \\
11.1\end{array}$ & $\begin{array}{r}8.1 \\
8.8 \\
10.0 \\
10.7 \\
10.6\end{array}$ & $\begin{array}{r}14 \\
12 \\
6 \\
5 \\
7\end{array}$ & \\
\hline $\begin{array}{l}40 \\
40 \\
40 \\
10\end{array}$ & $\begin{array}{l}440 \\
460 \\
510 \\
450 \\
450 \\
470\end{array}$ & $\begin{array}{r}11.1 \\
11.1 \\
10.8 \\
10.4 \\
10.1 \\
9.4\end{array}$ & $\begin{array}{r}10.4 \\
10.2 \\
9.4 \\
9.0 \\
8.4\end{array}$ & $\begin{array}{r}8 \\
9 \\
9 \\
11 \\
14 \\
13\end{array}$ & $\begin{array}{r}6 \\
7 \\
9\end{array}$ \\
\hline
\end{tabular}

APRIL

MAY

SPECIFIC

CONDUCTANCE DISSOLVED TEMPE-

(MICROWHOS OXYGEN ATURE

$\begin{array}{lll}\mathbf{4 7 0} & \mathbf{8 . 6} & \mathbf{7 . 3} \\ \mathbf{5 2 0} & \mathbf{8 . 9} & \mathbf{7} .3\end{array}$

$\begin{array}{lllll}530 & 9.9 & 8.3 & 13 & 10\end{array}$

$\begin{array}{lllll}570 & 10.4 & 9.5 & 13 & 9\end{array}$

$\begin{array}{lllll}560 & 9.9 & 8.7 & 14 & 12\end{array}$

$\begin{array}{lllll}550 & 9.6 & 7.8 & 16 & 11 \\ 580 & 9.2 & 7.6 & 16 & 13\end{array}$

$\begin{array}{lllll}610 & 9.7 & 7.4 & 18 & 14 \\ 630 & 9.1 & 7.0 & 19 & 14\end{array}$

$\begin{array}{lllll}630 & 9.1 & 7.0 & 19 & 14 \\ 630 & 8.5 & 5.5 & 21 & 16\end{array}$

$\begin{array}{lllll}620 & 8.6 & 5.5 & 21 & 16 \\ 620 & 8.3 & 6.4 & 20 & 17 \\ & & & 19 & 15\end{array}$

$\begin{array}{lllll}630 & 9.5 & 6.5 & 19 & 14\end{array}$

$\begin{array}{lllll}630 & 9.5 & 6.5 & 19 & 14 \\ 620 & 8.3 & 5.5 & 18 & 13 \\ 540 & 8.6 & 5.0 & 16 & 13\end{array}$

$\begin{array}{lllll}540 & 8.6 & 5.0 & 16 & 13 \\ 600 & 8.5 & 4.3 & 19 & 14\end{array}$

$.5 \quad 3.0$

$\begin{array}{lllll}610 & 8.3 & 3.0 & 19 & 14\end{array}$

$\begin{array}{lrrrr}610 & 10.4 & 4.5 & 19 & 14\end{array}$

$\begin{array}{rrrrr}610 & 7.0 & .7 & 19 & 16 \\ 500 & 6.7 & .7 & 18 & 13 \\ 550 & 6.3 & 4.5 & 14 & 11\end{array}$

$\begin{array}{lllll}560 & 6.6 & 4.8 & 14 & 10\end{array}$

$\begin{array}{lllll}570 & 6.5 & 4.1 & 16 & 11\end{array}$

$\begin{array}{lllll}590 & 5.9 & 4.0 & 16 & 11 \\ 630 & 6.1 & 2.4 & 17 & 13\end{array}$
aX MIN maX MIN MAX MIN

73

730

730

760
850
800

\section{MIN 600}

$\begin{array}{lllll}600 & 5.8 & 2.2 & 18 & 13\end{array}$

$\begin{array}{lllll}680 & 3.9 & 1.8 & 19 & 15 \\ 750 & 3.4 & 2.0 & 19 & 16\end{array}$

$\begin{array}{lllll}670 & 6.8 & 3.0 & 17 & 12 \\ 680 & 4.9 & 3.4 & 17 & 13\end{array}$

$\begin{array}{llllll}810 & 740 & 4.8 & 3.1 & 18 & 15 \\ 840 & 740 & 4.6 & 3.2 & 19 & 16\end{array}$

790

840

650
500
590

590
660

610
490

490
510
550

550
630

670
650

650
690
360
440

510
510

330

400

450
500 $\begin{array}{lllll}740 & 4.6 & 3.2 & 19 & 16 \\ 710 & 4.7 & 3.5 & 19 & 16\end{array}$

$\begin{array}{lllll}550 & 4.0 & 1.2 & 19 & 16 \\ 280 & 7.5 & 3.9 & 19 & 13\end{array}$

$\begin{array}{lllll}\mathbf{2 8 0} & 7.5 & 3.9 & 19 & 13 \\ \mathbf{3 8 0} & \mathbf{8 . 2} & 7.4 & 18 & 15\end{array}$

$\begin{array}{lllll}500 & 7.2 & 7.4 & 18 & 15 \\ 560 & 8.1 & 6.5 & 19 & 16 \\ & & 5.3 & 21 & 16\end{array}$

$\begin{array}{lllll}370 & 5.8 & 4.5 & 22 & 18 \\ 410 & 6.4 & 5.1 & 21 & 18\end{array}$

$\begin{array}{lllll}410 & 6.4 & 5.1 & 21 & 18 \\ 410 & 6.9 & 5.9 & 19 & 16\end{array}$

$\begin{array}{lllll}450 & 7.4 & 6.2 & 18 & 16 \\ 460 & 7.2 & 5.8 & 20 & 14\end{array}$

$\begin{array}{lllll}530 & 6.3 & 5.2 & 17 & 12\end{array}$

$\begin{array}{lllll}550 & 6.6 & 4.3 & 21 & 15 \\ 360 & 6.2 & 3.7 & 19 & 14\end{array}$

$\begin{array}{lllll}360 & 6.2 & 3.7 & 19 & 14 \\ 250 & 7.1 & 5.8 & 16 & 13\end{array}$

$\begin{array}{lllll}410 & 6.8 & 6.1 & 17 & 14\end{array}$

$\begin{array}{lllll}410 & 6.8 & 6.1 & 17 & 14 \\ 190 & 7.1 & 5.9 & 18 & 16\end{array}$

$\begin{array}{lllll}240 & 7.2 & 6.4 & 18 & 14 \\ 250 & 7.4 & 6.4 & 16 & 14\end{array}$

$\begin{array}{lllll}370 & 7.7 & 6.6 & 16 & 1 \\ 400 & 7.7 & 7.0 & 17 & 13\end{array}$ $\begin{array}{lllll}650 & 4.2 & 2.3 & 18 & 15\end{array}$

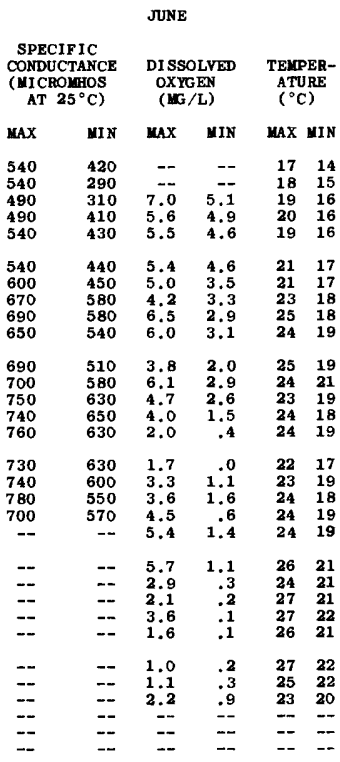


03229600 SCIOTO RIVER BELOW SHADEVILLE, OHIO--CONTInUed SPECIFIC CONDUCTANCE, DISSOLYED OXYGEN, AND FATER TEMPERATURES, TATER YEAR OCTOBER 1967 TO SEPTEIBER 1968

JULY

\begin{tabular}{|c|c|c|c|c|}
\hline \multirow[t]{2}{*}{ DAY } & \multicolumn{2}{|c|}{$\begin{array}{l}\text { SPECIFIC } \\
\text { CONDUCTANCE } \\
\text { (MICROMHOS } \\
\text { AT } 25^{\circ} \mathrm{C} \text { ) }\end{array}$} & \multicolumn{2}{|c|}{$\begin{array}{l}\text { DI SSOLVED } \\
\text { OXYGEN } \\
(\mathbf{M G} / L)\end{array}$} \\
\hline & $\max$ & MIN & MAX & MIN \\
\hline 1 & -- & -- & -- & - \\
\hline 2 & -- & -- & - & - \\
\hline $\begin{array}{l}3 \\
4\end{array}$ & $=$ & $\because$ & $\overline{--}$ & -- \\
\hline 5 & -- & -- & -- & -- \\
\hline 6 & -- & -- & -- & -- \\
\hline 7 & - & -- & $\rightarrow$ & - \\
\hline 8 & $\bar{x}$ & $\overline{0}$ & 5 & 7 \\
\hline 10 & $\begin{array}{l}810 \\
750\end{array}$ & 640 & $\begin{array}{l}5.5 \\
7.4\end{array}$ & $\begin{array}{l}4.1 \\
2.6\end{array}$ \\
\hline 1 & 770 & 690 & 7.8 & 2.7 \\
\hline 2 & 790 & 710 & 5.8 & 3.3 \\
\hline 13 & 830 & 73 & 4.2 & 1.9 \\
\hline 14 & 840 & 760 & 3.1 & 1.4 \\
\hline 15 & 810 & 740 & 3.8 & 1.7 \\
\hline 6 & 780 & 670 & 3.4 & 1.2 \\
\hline 7 & 790 & 63 & 4. & \\
\hline 18 & 730 & 620 & 6.0 & .8 \\
\hline 19 & 720 & 520 & 4.3 & .6 \\
\hline 20 & 590 & 550 & & \\
\hline $\begin{array}{l}21 \\
22\end{array}$ & 700 & $\begin{array}{l}570 \\
590\end{array}$ & 4.8 & 2.5 \\
\hline 23 & $\begin{array}{l}690 \\
680\end{array}$ & $\begin{array}{l}5 \\
5\end{array}$ & $\begin{array}{l}4.0 \\
3.0\end{array}$ & $\begin{array}{l}1.6 \\
1.0\end{array}$ \\
\hline 24 & 640 & 520 & 3.8 & 1.1 \\
\hline 95 & 690 & 540 & 2.5 & 1 \\
\hline 26 & 620 & 450 & 1.5 & .0 \\
\hline 27 & 530 & & 1. & .2 \\
\hline 28 & 520 & 42 & 1.3 & \\
\hline 29 & 610 & 480 & 1.6 & .5 \\
\hline 30 & 640 & 570 & 2.9 & 1.0 \\
\hline 31 & 680 & 560 & 1.7 & .2 \\
\hline
\end{tabular}

AUGUST

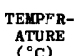

MAX MIN

$\overline{-0}$

$--$

-- --

$\overline{26} \quad \overline{22}$

$\begin{array}{ll}27 & 21\end{array}$

$\begin{array}{ll}27 & 22 \\ 28 & 24\end{array}$

$\begin{array}{ll}28 & 24 \\ 28 & 23\end{array}$

$\begin{array}{ll}27 & 23 \\ 27 & 24\end{array}$

$\begin{array}{ll}27 & 23 \\ 27 & 24\end{array}$

$\begin{array}{ll}27 & 24 \\ 29 & 22\end{array}$

$\begin{array}{ll}27 & 22 \\ 28 & 23\end{array}$

$\begin{array}{ll}29 & 23\end{array}$

2822

$\begin{array}{ll}27 & 22 \\ 28 & 24 \\ 29 & 24\end{array}$

$\begin{array}{ll}29 & 24 \\ 27 & 23 \\ 27 & 24\end{array}$

$\begin{array}{ll}27 & 24 \\ 27 & 24\end{array}$

$\begin{array}{ll}27 & 24 \\ 27 & 24 \\ 27 & 21\end{array}$

\begin{tabular}{|c|c|c|c|c|c|}
\hline \multicolumn{2}{|c|}{$\begin{array}{l}\text { SPECIFIC } \\
\text { CONDUCTANCE } \\
\text { (MICROMFOS } \\
\text { AT } 25^{\circ} \mathrm{C} \text { ) }\end{array}$} & \multicolumn{2}{|c|}{$\begin{array}{l}\text { DI SSOLVED } \\
\text { OXYGEN } \\
(\text { MG } / L)\end{array}$} & \multicolumn{2}{|c|}{$\begin{array}{l}\text { TEYPER- } \\
\text { ATURE } \\
\left({ }^{\circ} \mathrm{C}\right)\end{array}$} \\
\hline MAX & MIN & MAX & MIN & $\operatorname{MAX}$ & MIN \\
\hline $\begin{array}{l}840 \\
660 \\
700 \\
690 \\
640\end{array}$ & $\begin{array}{l}530 \\
480 \\
600 \\
620 \\
470\end{array}$ & $\begin{array}{r}2.2 \\
1.6 \\
1.2 \\
1.4 \\
.9\end{array}$ & $\begin{array}{l}.3 \\
.4 \\
.6 \\
.3 \\
.0\end{array}$ & $\begin{array}{l}27 \\
28 \\
27 \\
27 \\
27\end{array}$ & $\begin{array}{l}23 \\
22 \\
24 \\
23 \\
21\end{array}$ \\
\hline $\begin{array}{l}670 \\
700 \\
700 \\
690 \\
560\end{array}$ & $\begin{array}{l}\mathbf{5 5 0} \\
560 \\
590 \\
530 \\
470\end{array}$ & $\begin{array}{r}.5 \\
.6 \\
.7 \\
1.2 \\
1.0\end{array}$ & $\begin{array}{l}.0 \\
.0 \\
.0 \\
.0 \\
.0\end{array}$ & $\begin{array}{l}27 \\
27 \\
26 \\
27 \\
27\end{array}$ & $\begin{array}{l}22 \\
21 \\
23 \\
22 \\
22\end{array}$ \\
\hline $\begin{array}{l}600 \\
620 \\
670 \\
670 \\
720\end{array}$ & $\begin{array}{l}490 \\
540 \\
560 \\
580 \\
560\end{array}$ & $\begin{array}{r}2.0 \\
-- \\
--\end{array}$ & $\begin{array}{l}.5 \\
=- \\
--\end{array}$ & $\begin{array}{l}25 \\
25 \\
27 \\
26 \\
27\end{array}$ & $\begin{array}{l}21 \\
21 \\
22 \\
22 \\
21\end{array}$ \\
\hline $\begin{array}{l}750 \\
710 \\
730 \\
770 \\
\mathbf{7 4 0}\end{array}$ & $\begin{array}{l}630 \\
610 \\
620 \\
550 \\
640\end{array}$ & $\begin{array}{l}=- \\
=- \\
=\end{array}$ & $\begin{array}{l}= \\
=- \\
=\end{array}$ & $\begin{array}{l}26 \\
27 \\
28 \\
28 \\
32\end{array}$ & $\begin{array}{l}22 \\
22 \\
23 \\
21 \\
26\end{array}$ \\
\hline $\begin{array}{l}770 \\
790 \\
820 \\
690 \\
700\end{array}$ & $\begin{array}{l}630 \\
670 \\
610 \\
570 \\
600\end{array}$ & $\begin{array}{l}=- \\
= \\
=\end{array}$ & $\begin{array}{l}=- \\
=- \\
=\end{array}$ & $\begin{array}{l}29 \\
29 \\
31 \\
27 \\
26\end{array}$ & $\begin{array}{l}25 \\
24 \\
20 \\
21 \\
21\end{array}$ \\
\hline $\begin{array}{l}770 \\
770 \\
860 \\
870 \\
880 \\
850\end{array}$ & $\begin{array}{l}690 \\
710 \\
760 \\
720 \\
790 \\
770\end{array}$ & $\begin{array}{l}= \\
= \\
= \\
=\end{array}$ & $\begin{array}{l}=- \\
=- \\
=- \\
=-\end{array}$ & $\begin{array}{l}28 \\
24 \\
23 \\
23 \\
24 \\
24\end{array}$ & $\begin{array}{l}23 \\
20 \\
18 \\
17 \\
19 \\
19\end{array}$ \\
\hline
\end{tabular}

SEPTEMBER

03231000 DEER CREEK AT TILLIAMSPORT, OHIO

\begin{tabular}{|c|c|c|c|c|c|}
\hline \multicolumn{2}{|c|}{$\begin{array}{l}\text { SPECIFIC } \\
\text { CONDUCTANCE } \\
\text { (MICROMHOS } \\
\text { AT } 25^{\circ} \mathrm{C} \text { ) }\end{array}$} & \multicolumn{2}{|c|}{$\begin{array}{l}\text { DI SSOLVED } \\
\text { OXYG EN } \\
(\mathbb{M G} / L)\end{array}$} & \multicolumn{2}{|c|}{$\begin{array}{l}\text { TEMPPER- } \\
\text { ATURE } \\
\left({ }^{\circ} \mathrm{C}\right)\end{array}$} \\
\hline MAX & MIN & MAX & MIN & $\operatorname{MAX}$ & MIN \\
\hline $\begin{array}{l}860 \\
800 \\
790 \\
760 \\
840\end{array}$ & $\begin{array}{l}780 \\
590 \\
660 \\
660 \\
740\end{array}$ & $\begin{array}{l}=- \\
=- \\
=\end{array}$ & $\begin{array}{l}-- \\
\overline{--} \\
=-\end{array}$ & $\begin{array}{l}24 \\
23 \\
24 \\
21 \\
21\end{array}$ & $\begin{array}{l}21 \\
18 \\
19 \\
17 \\
18\end{array}$ \\
\hline $\begin{array}{l}830 \\
760 \\
810 \\
880 \\
880\end{array}$ & $\begin{array}{l}690 \\
670 \\
690 \\
750 \\
750\end{array}$ & $\begin{array}{l}-- \\
\overline{-1} \\
3.8\end{array}$ & $\begin{array}{r}-- \\
\overline{-5} \\
.0\end{array}$ & $\begin{array}{l}25 \\
24 \\
23 \\
24 \\
24\end{array}$ & $\begin{array}{l}18 \\
18 \\
19 \\
20 \\
19\end{array}$ \\
\hline $\begin{array}{l}890 \\
850 \\
890 \\
910 \\
970\end{array}$ & $\begin{array}{l}790 \\
770 \\
780 \\
820 \\
820\end{array}$ & $\begin{array}{l}.6 \\
2.0 \\
1.3 \\
1.5 \\
1.3\end{array}$ & $\begin{array}{l}.0 \\
.0 \\
.0 \\
.0 \\
.0\end{array}$ & $\begin{array}{l}23 \\
23 \\
23 \\
24 \\
26\end{array}$ & $\begin{array}{l}18 \\
19 \\
19 \\
19 \\
19\end{array}$ \\
\hline $\begin{array}{l}930 \\
890 \\
950 \\
940 \\
790\end{array}$ & $\begin{array}{l}830 \\
780 \\
820 \\
790 \\
670\end{array}$ & $\begin{array}{l}=- \\
=- \\
=-\end{array}$ & $\begin{array}{l}=- \\
=- \\
--\end{array}$ & $\begin{array}{l}28 \\
25 \\
26 \\
22 \\
23\end{array}$ & $\begin{array}{l}18 \\
18 \\
19 \\
18 \\
19\end{array}$ \\
\hline $\begin{array}{l}800 \\
870 \\
820 \\
780 \\
810\end{array}$ & $\begin{array}{l}710 \\
720 \\
680 \\
630 \\
640\end{array}$ & $\begin{array}{l}=- \\
=- \\
=-\end{array}$ & $\begin{array}{l}=- \\
=- \\
--\end{array}$ & $\begin{array}{l}23 \\
23 \\
27 \\
27 \\
24\end{array}$ & $\begin{array}{l}18 \\
19 \\
17 \\
21 \\
18\end{array}$ \\
\hline $\begin{array}{l}910 \\
930 \\
980 \\
990 \\
950\end{array}$ & $\begin{array}{r}800 \\
840 \\
870 \\
880 \\
850 \\
--\end{array}$ & $\begin{array}{l}=- \\
=- \\
=- \\
=\end{array}$ & $\begin{array}{l}=- \\
=- \\
=- \\
=-\end{array}$ & $\begin{array}{l}26 \\
24 \\
22 \\
23 \\
26 \\
--\end{array}$ & $\begin{array}{l}19 \\
19 \\
18 \\
17 \\
19\end{array}$ \\
\hline 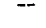 & . & $\cdots$ & - & - & $\cdots$ \\
\hline
\end{tabular}

LOCATION. --Lat $39^{\circ} 35^{\prime} 09^{\prime \prime}$, long $83^{\circ} 07^{\prime} 22^{\prime \prime}$, Pickaway County, at gaging station at bridge on U.S. Highway 22 at west edge of Williamsport, 2 miles dowstream from Dry Run.

DRAINAGE AREA. $--333 \mathrm{sq} \mathrm{m} x$.

PERIOD OF RECORD. --Chemical analyses: October 1965 to September 1968.

Water temperatures: October 1965 to September 1968.

EXTR EMES. - -1967-68:

Specific conductance: Maximum daily, 734 micrombos Jan. 4; minimum daily, 239 micrombos May 24

Water temperatures: Maximum, $31.0^{\circ} \mathrm{C}$ Aug, 6, 21-23; minimum, $1.0^{\circ} \mathrm{C}$ Jan. $2,4$.

period of record:

Specific conductance: Maximum daily, 871 micrombos Jan, 27, 1966; minimum daily, 239 micromhos May $24,1968$. Water temperatures: Maximum, $31.0^{\circ} \mathrm{C}$ June 25,1967 , Aug. 6, 21-23, 1968; minimum, freezing polnt on many days during winter periods.

REMARKS. --Samples for iron and manganese were filtered clear when collected. Daily samples were collected at this station and samples were selected for analysis on the following basis: (1) Maximum daily specific conductance for each month, (2) minimum daily specific conductance for each month, (3) median daily specific conductance for each montb, and (4) special sample each montb to furtber define the quality of water. CHEMICAL ANALYSES IN MILLIGRAMS PER LITER, WATER YEAR OCTOBER 1967 TO SEPTEMBER 1968

\begin{tabular}{|c|c|c|c|c|c|c|c|c|c|c|}
\hline DATE & TIME & $\begin{array}{l}\text { DIS- } \\
\text { CHARGE } \\
\text { ICFSI }\end{array}$ & $\begin{array}{l}\text { IRON } \\
\text { IFEI }\end{array}$ & $\begin{array}{l}\text { MAN- } \\
\text { CANE SE } \\
\text { I MNI }\end{array}$ & $\begin{array}{l}\text { BICAR- } \\
\text { BONATE } \\
\text { IHCO3I }\end{array}$ & $\begin{array}{l}\text { CAR- } \\
\text { BONATE } \\
\text { (CD 3) }\end{array}$ & $\begin{array}{l}\text { SULFATE } \\
\text { ISO4| }\end{array}$ & $\begin{array}{l}\text { CHLO- } \\
\text { RINE } \\
\text { ICLI }\end{array}$ & $\begin{array}{l}\text { FLUO- } \\
\text { RINEE } \\
\text { IFI }\end{array}$ & $\begin{array}{l}\text { NITRATE } \\
\text { INO3! }\end{array}$ \\
\hline \multicolumn{11}{|l|}{ BCT. } \\
\hline $01 \ldots$ & 1600 & 21 & -- & $\ddot{0}$ & 280 & c & 92 & 22 & .6 & 3.5 \\
\hline $10 \ldots$ & 1115 & 18 & .06 & .07 & $-\overline{-}$ & -- & -- & -- & $=$ & - \\
\hline $14 \ldots$ & $\$ 700$ & 17 & -- & -- & 398 & 0 & 86 & 18 & .6 & 2.4 \\
\hline $17 \ldots$ & 1700 & 16 & -- & -- & 194 & c & 51 & 12 & .4 & 3. 8 \\
\hline \multicolumn{11}{|l|}{ Nov. } \\
\hline $14 \ldots$ & 0950 & -- & .05 & .02 & -- & -- & $\overline{-}$ & -- & -- & -- \\
\hline $14 \ldots$ & 1730 & -- & -- & -- & 312 & c & 72 & 16 & .3 & 3.4 \\
\hline $16 \ldots$ & 1700 & -- & - & -- & 196 & 0 & 71 & 16 & .2 & 3.4 \\
\hline$\angle 5 \ldots$ & 1700 & -- & -- & -- & 316 & 0 & 76 & 18 & .2 & 5.5 \\
\hline \multicolumn{11}{|l|}{ OEC. } \\
\hline $13 \ldots$ & $170 \mathrm{c}$ & 358 & $=$ & $=$ & 276 & 0 & 64 & 18 & .4 & 24 \\
\hline $17 \ldots$ & 1700 & 214 & -- & -- & 180 & 0 & 73 & 18 & .4 & 22 \\
\hline $17 \ldots$ & 1100 & $1+3$ & $.0 B$ & .04 & $-\bar{x}$ & $=$ & $=$ & -- & $\cdots$ & - \\
\hline $\begin{array}{l}29 \ldots . . \\
\text { JAly. }\end{array}$ & -- & $15 \mathrm{H}$ & -- & -- & 328 & 0 & 74 & 18 & .5 & 22 \\
\hline $04 \ldots$ & 1700 & 138 & - & -- & 328 & 0 & 75 & 18 & .5 & 8.2 \\
\hline $27 \ldots$ & $C 8+5$ & 134 & .08 & .05 & - & -- & -- & - & -- & - \\
\hline 2 \&... & 1700 & 531 & $\rightarrow$ & -- & 236 & 0 & 56 & 16 & .5 & 6.8 \\
\hline $\begin{array}{l}30 \ldots \\
\text { FER. }\end{array}$ & 0870 & 1320 & -- & - & 168 & 0 & 36 & 14 & .4 & 20 \\
\hline $02 \ldots$ & 1700 & 1240 & -- & -- & 190 & 12 & 53 & 17 & .4 & 24 \\
\hline $13 \ldots$ & 0900 & 232 & .09 & .03 & $\overline{3}$ & $\cdots$ & -- & & 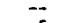 & \\
\hline $25 \ldots$ & 1730 & 94 & -- & - & 328 & c & 82 & 18 & .5 & 7.2 \\
\hline $28 \ldots$ & 1700 & 75 & - & -- & 300 & $c$ & 72 & 18 & .5 & 8.6 \\
\hline
\end{tabular}


SCIOTO RIVER BASIN

03231000 DEER CREEK AT WILLIAHSPORT, OHIO--Continued

CHEMICAL ANALYSES IN MILLIGRAMS PER LITER, WATER YEAR OCTOBER 1967 TC SEPTEMBER 1968

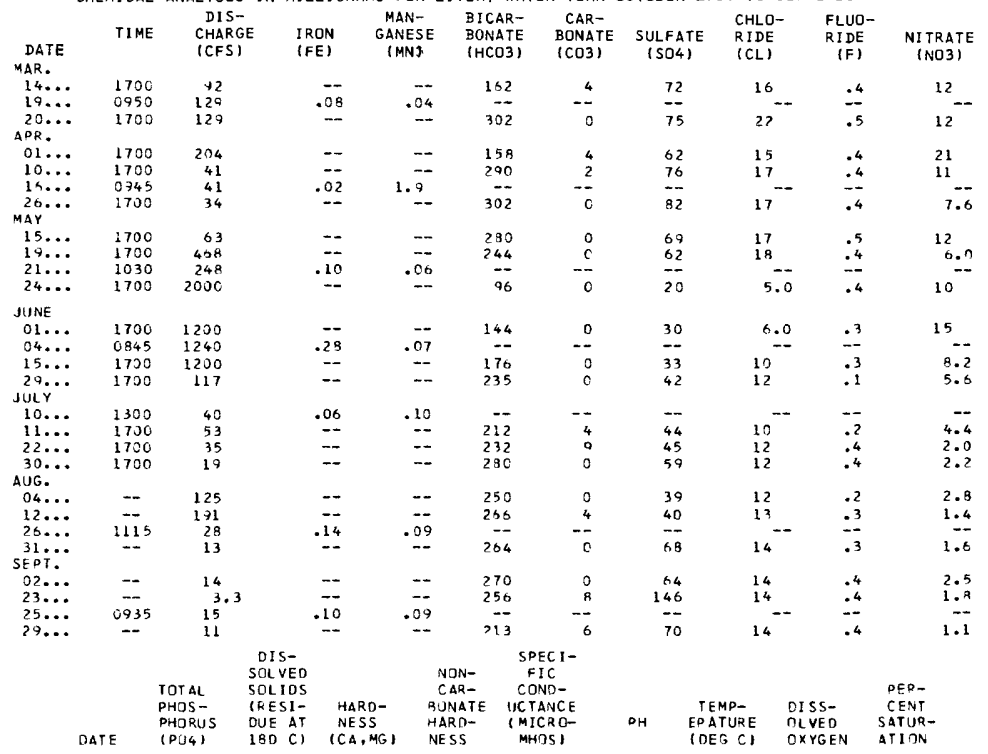

\begin{tabular}{|c|c|c|c|c|c|c|c|c|c|}
\hline $\begin{array}{l}0 C T . \\
03 . . .\end{array}$ & .44 & 404 & 322 & 92 & 656 & 7.3 & 21 & -- & -- \\
\hline $10 .$. & $\because 4$ & -- & 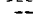 & -2 & - & - & $-\cdots$ & 7.8 & 71 \\
\hline $14 \ldots$ & .20 & 420 & 338 & 85 & 673 & 7.5 & 17 & $\because$ & - \\
\hline $17 \ldots$ & .72 & 270 & 210 & 51 & 445 & 7.0 & 18 & - & -- \\
\hline \multicolumn{10}{|l|}{ NUV." } \\
\hline $14 \ldots$ & -- & -- & - & -- & -- & -- & -- & 10.0 & 83 \\
\hline $14 \ldots$ & .50 & 414 & 338 & 82 & 646 & 7.6 & -- & -. &.- \\
\hline $16 \ldots$ & .41 & 312 & 240 & 79 & 489 & 7.9 & 4 & -- & -- \\
\hline $25 \ldots$ & .63 & 414 & 348 & 87 & 664 & 7.6 & 7 & - & $=$ \\
\hline \multicolumn{10}{|l|}{ DEC. } \\
\hline $13 \ldots$ & .88 & 362 & 322 & 96 & 605 & 8.1 & 9 & -- & -- \\
\hline $17 \ldots$ & .86 & 274 & 246 & 98 & 503 & 7.8 & 7 & -- & -- \\
\hline $19 . .$. & - & - & $\ldots$ & $\ldots$ & - & - & -- & 11.0 & 92 \\
\hline $29 \ldots$ & .85 & 396 & 376 & 107 & 703 & 7.6 & 2 & - & - \\
\hline \multicolumn{10}{|l|}{ JAN." } \\
\hline $04 \ldots$ & .06 & 374 & 300 & 91 & 734 & 7.9 & 1 & -- & $=$ \\
\hline $28 \cdots$ &.$\overline{42}$ & $\overline{284}$ & 266 & $\overline{70}$ & $52 \overline{9}$ & $8 . \overline{2}$ & $-\overline{3}$ & 13.0 & $\begin{array}{l}93 \\
--\end{array}$ \\
\hline $30 \ldots$ & .45 & 236 & 190 & 52 & 417 & 7.2 & 4 & $\therefore$ & - \\
\hline \multicolumn{10}{|l|}{ FER. } \\
\hline $02 \ldots$ & .34 & 352 & 270 & 94 & 511 & 8.6 & 7 & -- & - \\
\hline $13 \ldots$ & 10 & 462 & $3 \overline{78}$ & -- & -- & -- & $m$ & 7.2 & 49 \\
\hline $25 \ldots$ & $\begin{array}{l}.10 \\
.04\end{array}$ & & & 109 & $70^{\circ}$ & 8.1 & 2 & $\cdots$ & -- \\
\hline \multirow{2}{*}{\multicolumn{10}{|c|}{ MAK." }} \\
\hline & & & & & & & & & \\
\hline $14 \ldots$ & .00 & 278 & 230 & 90 & 455 & 8.4 & 5 & -- & - \\
\hline $19 \ldots$ & $=$ & -- & - & - & - & $=$ & -- & 11.0 & 92 \\
\hline $20 \ldots$ & .12 & 412 & 358 & 110 & 675 & 8.0 & 13 & - & - \\
\hline \multicolumn{10}{|l|}{ APR. } \\
\hline $01 \ldots$ & .14 & 284 & 225 & 89 & 480 & A. 5 & 14 & -- & -- \\
\hline $10 \ldots$ & .19 & 388 & 340 & 99 & 640 & 8.3 & 13 & -- & - \\
\hline $16 \ldots$ & - & - & - & -- & -- & - & - & 10.0 & 92 \\
\hline $20 \ldots$ & .12 & 394 & 360 & 112 & 656 & 8.1 & 18 & -- & - \\
\hline \multicolumn{10}{|l|}{ MAY } \\
\hline $15 \ldots$ & .12 & 366 & 340 & 110 & 641 & 7.7 & 23 & -- & - \\
\hline $19 \ldots$ & .22 & 324 & 302 & 102 & 583 & 7.9 & 17 & -- & $-\overline{-}$ \\
\hline $21 \ldots$ & -- & -- & - & -- & -- & -- & 16 & 8.4 & 84 \\
\hline $24 \ldots$ & .34 & 110 & 117 & 38 & 239 & 7.3 & 17 & -- & - \\
\hline \multicolumn{10}{|l|}{ JUNE } \\
\hline $01 \ldots$ & .29 & 226 & 168 & 50 & 342 & 7.2 & 17 & -- & - \\
\hline $04 \ldots$ & $\ldots$ & $\ldots$ & $\ldots$ & - & - & - & is & 8.6 & 96 \\
\hline $15 \ldots$ & .50 & 264 & 198 & 54 & 303 & 7.1 & 24 & -- & -- \\
\hline $29 .$. & .38 & 292 & 250 & $5 B$ & 494 & 7.5 & 25 & -- & -- \\
\hline \multicolumn{10}{|l|}{ suir } \\
\hline $10 \ldots$ & -- & -- & -- & -- & -- & $\cdots$ & -- & 7.4 & 90 \\
\hline $11 \ldots$ & .11 & 284 & 236 & 56 & 456 & 8.3 & 27 & $\ldots$ & - \\
\hline $22 \ldots$ & .09 & 294 & 264 & 58 & 508 & 8.5 & 29 & - & - \\
\hline $30 \ldots$ & .15 & 336 & 266 & 36 & 552 & 8.1 & 26 & -- & -- \\
\hline \multicolumn{10}{|l|}{ AUG. } \\
\hline $0_{4} \ldots$ & .03 & 282 & 254 & 48 & $4 A_{1}$ & 7.8 & 27 & -- & - \\
\hline $12 \ldots$ & .18 & 310 & 272 & 47 & 508 & 8.3 & 24 & -- & 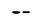 \\
\hline $26 \ldots$ & - & -- & - & $\cdots$ & - & - & 23 & 6.4 & 74 \\
\hline $31 \ldots$ & .15 & 338 & 292 & 75 & 553 & 8.0 & 24 & - & - \\
\hline \multicolumn{10}{|l|}{ SEPT. } \\
\hline$D 2 \ldots$ & .17 & 332 & $29 t$ & 74 & $55 ?$ & B. 0 & 24 & -- & - \\
\hline $23 \ldots$ & .11 & 448 & 380 & 156 & 699 & 8.4 & 25 & - & \\
\hline $25 \ldots$ & - & - & - & - & - & -- & 22 & 6.4 & 3 \\
\hline $29 \ldots$ & .06 & 318 & 272 & 87 & 519 & 8. 5 & 20 & $\because$ & \\
\hline
\end{tabular}


03231000 DEER CREEK AT WILLIAMSPORT, OHIO--Cont I nued

SPECIFIC CONDUCTANCE (MICROMHOS AT $25^{\circ} \mathrm{C}$ ), WATER YEAR OCTOBER 1967 TO SEPTEMBER 1968

DAY OCTOBER NOVEMBER DECEMBER JANUARY FEBRUARY MARCH APRIL MAY JUNE JULY AUGUST SEPTEMBER

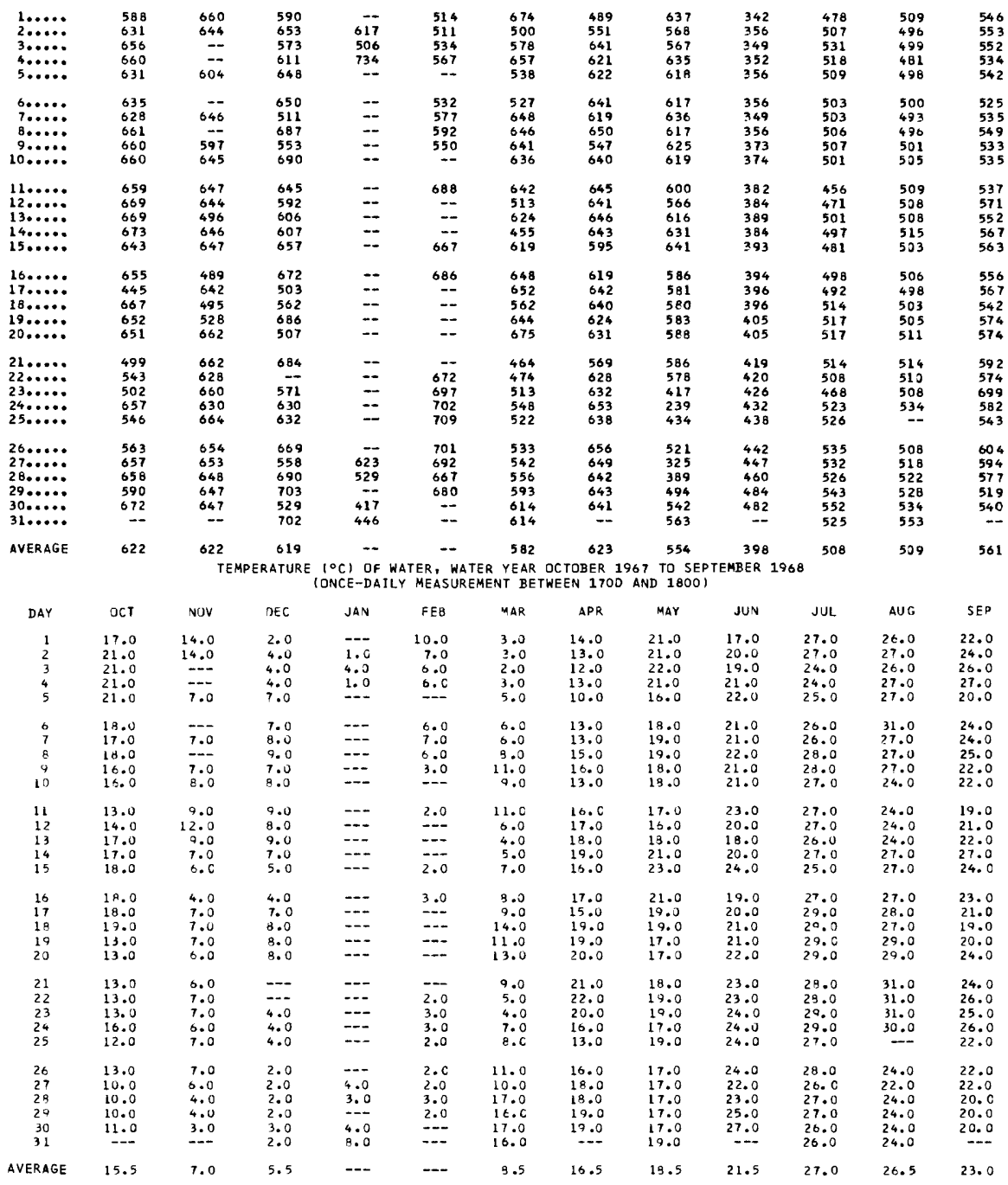


03231500 SCIOTO RIVER AT CHILLICOTHE, OHIO

LOCATION. --Lat $39^{\circ} 20^{\prime} 31^{\prime \prime}$, long $82^{\circ} 58^{\prime} 27^{\prime \prime}$, Ross County, at center of Bridge Street bridge on U.S. Highway 23 at north end of Chillicothe, $450 \mathrm{ft}$ upstream from gaging station.

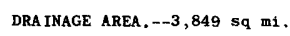

PERIOD OF RECORD, --Chemical analyses: October 1950 to September 1951, May 1965 to September 1968.

Wa ter temperatures: October 1950 to September 1951, October 1953 to September 1968.

EXTREMES, --1967-68: Water temperatures: Haximum, $29.0^{\circ} \mathrm{C}$ Aug. 22-25; minimum, freezing point on several days during December to
February.

Period of record:

Specific conductance (1950-51, 1965-66): Maximum daily, 1,040 micromhos Feb. 9, 1966; minimum daily,

245 micromhos Dec. 9, 1950.
Dissolved oxygen (1965-67): Waximum da1ly, $15.0 \mathrm{mg} / 1$ or greater on several days during June 1966 , June and July 1967; minimum daily, 0.0 mg/l Apr. 27, Aug. 12, Sept. 22, 1966 ater temperatures: Maximum, $32.0^{\circ} \mathrm{C}$ July 14, 1954, Aug. 2, 3, 1955; minimum, freezing point on many days
during winter periods.

REXARKS. - In addition to the continuous recorder, twice-weekly samples were also collected by a local observer. Partial analyses were made on the maximum specific conductance and the minimum specific conductance of the Samples collected each month. Temperature observations, Yar. 18 to Apr. 23, May 1-9, June 4-27, July 16-31, concentions of $150 \mathrm{mg} / \mathrm{l}$ or greater due to instrument limitations. to malfunctions of the instrument.

CHEMICAL ANALYSES in MiLLigRAMS PER LitTER, WATER yeAR OCTOBER 1967 TO SEPTEMBER 1968

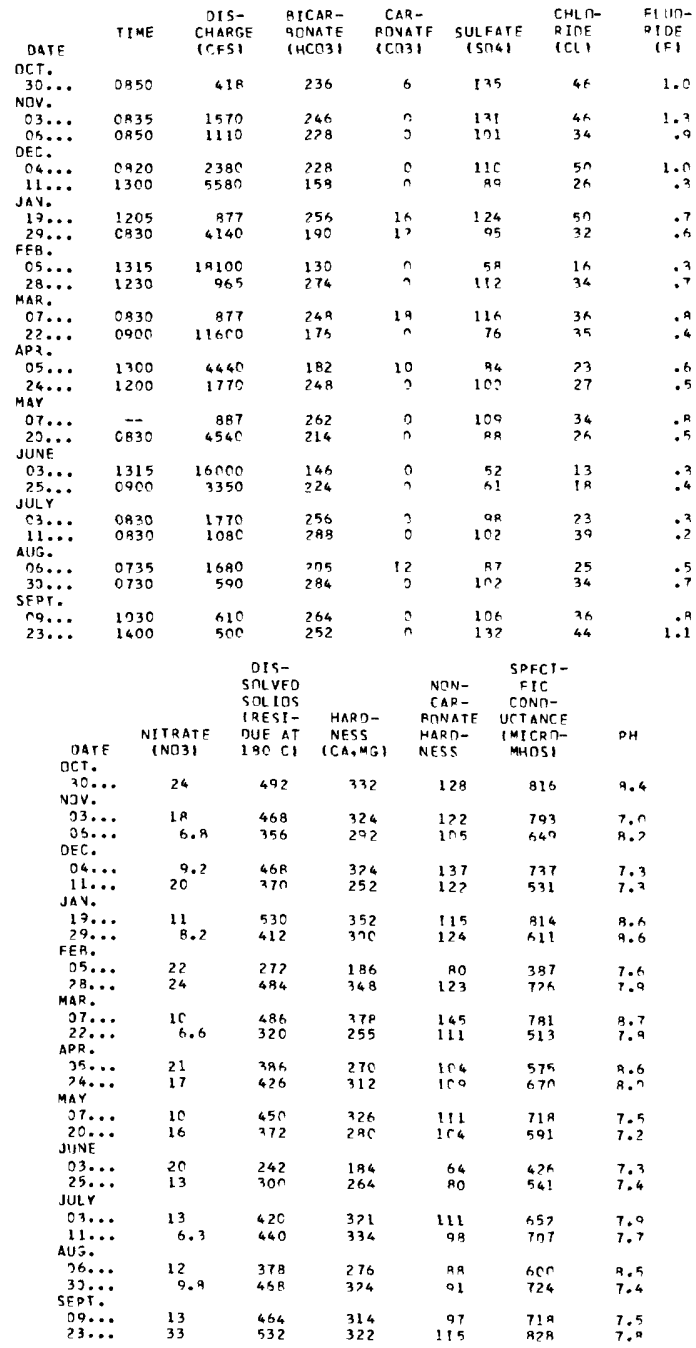


03231500 SCIOTO RIVER AT CHILLICOTHE, OHIO---Cont1 nued

SPECIFIC CONDUCTANCE, DISSOLVED OXYGEN, AND WATER TELPERATURES, WATER YEAR OCTOBER 1967 TO SEPTEUBER 1968

october

\begin{tabular}{|c|c|c|c|c|c|c|}
\hline \multirow[t]{2}{*}{ DAY } & \multicolumn{2}{|c|}{$\begin{array}{l}\text { SPECIF IC } \\
\text { CONDUCTANCE } \\
\text { (MICROMHOS } \\
\left.\text { AT } \mathbf{2 5}{ }^{\circ} \mathrm{C}\right)\end{array}$} & \multicolumn{2}{|c|}{$\begin{array}{l}\text { DISSOLVED } \\
\text { OXYGEN } \\
(\mathbf{M G} / \mathrm{L})\end{array}$} & \multicolumn{2}{|c|}{$\begin{array}{l}\text { TEMPER- } \\
\text { ATURE } \\
\left({ }^{\circ} \mathrm{C}\right)\end{array}$} \\
\hline & $\max$ & MIN & MAX & MIN & MAX & $M$ \\
\hline $\begin{array}{l}1 \\
2 \\
3 \\
4 \\
5\end{array}$ & $\begin{array}{l}680 \\
580 \\
600 \\
610 \\
640\end{array}$ & $\begin{array}{l}460 \\
560 \\
570 \\
590 \\
610\end{array}$ & $\begin{array}{l}7.4 \\
7.3 \\
7.2 \\
7.8 \\
7.6\end{array}$ & $\begin{array}{l}4.4 \\
5.2 \\
4.7 \\
4.6 \\
4.5\end{array}$ & $\begin{array}{l}16 \\
17 \\
18 \\
19 \\
19\end{array}$ & \\
\hline $\begin{array}{r}6 \\
7 \\
8 \\
9 \\
10\end{array}$ & $\begin{array}{l}660 \\
700 \\
730 \\
760 \\
810\end{array}$ & $\begin{array}{l}620 \\
660 \\
700 \\
720 \\
760\end{array}$ & $\begin{array}{l}6.0 \\
6.6 \\
7.1 \\
5.5 \\
5.7\end{array}$ & $\begin{array}{l}4.3 \\
4.2 \\
4.7 \\
4.2 \\
4.1\end{array}$ & $\begin{array}{l}18 \\
17 \\
18 \\
17 \\
16\end{array}$ & \\
\hline $\begin{array}{l}11 \\
12 \\
13 \\
14 \\
15\end{array}$ & $\begin{array}{r}830 \\
860 \\
840 \\
-- \\
--\end{array}$ & $\begin{array}{r}800 \\
830 \\
810 \\
-- \\
--\end{array}$ & $\begin{array}{r}5.9 \\
6.1 \\
7.8 \\
-- \\
--\end{array}$ & $\begin{array}{r}4.4 \\
4.6 \\
4.9 \\
-.- \\
-.\end{array}$ & $\begin{array}{l}15 \\
16 \\
15 \\
16 \\
16\end{array}$ & \\
\hline $\begin{array}{l}16 \\
17 \\
18 \\
19 \\
20\end{array}$ & $\begin{array}{l}740 \\
760 \\
780 \\
790 \\
810\end{array}$ & $\begin{array}{l}730 \\
690 \\
760 \\
780 \\
790\end{array}$ & $\begin{array}{l}8.0 \\
7.1 \\
7.8 \\
7.9 \\
8.8\end{array}$ & $\begin{array}{l}4.9 \\
4.6 \\
4.6 \\
5.3 \\
5.4\end{array}$ & $\begin{array}{l}16 \\
15 \\
15 \\
14 \\
13\end{array}$ & \\
\hline $\begin{array}{l}21 \\
22 \\
23 \\
24 \\
25\end{array}$ & $\begin{array}{l}810 \\
800 \\
810 \\
830 \\
820\end{array}$ & $\begin{array}{l}800 \\
790 \\
790 \\
810 \\
790\end{array}$ & $\begin{array}{l}9.0 \\
9.0 \\
9.3 \\
9.3 \\
8.6\end{array}$ & $\begin{array}{l}5.7 \\
5.8 \\
5.9 \\
5.7 \\
5.5\end{array}$ & $\begin{array}{l}15 \\
13 \\
12 \\
13 \\
13\end{array}$ & \\
\hline $\begin{array}{l}\mathbf{2 6} \\
\mathbf{2 7} \\
\mathbf{2 8} \\
29 \\
30 \\
\mathbf{3 1}\end{array}$ & $\begin{array}{l}790 \\
810 \\
820 \\
810 \\
810 \\
820\end{array}$ & $\begin{array}{l}770 \\
780 \\
810 \\
800 \\
800 \\
800\end{array}$ & $\begin{array}{l}8.5 \\
7.4 \\
8.0 \\
8.7 \\
8.6 \\
6.6\end{array}$ & $\begin{array}{l}5.3 \\
5.2 \\
5.6 \\
5.8 \\
6.0 \\
5.3\end{array}$ & $\begin{array}{l}12 \\
11 \\
11 \\
11 \\
11 \\
10\end{array}$ & \\
\hline
\end{tabular}

November

SPECIF IC

CONDUCTANCE DISSOLVED TEMPER-

(MICROMHOS OXYGN ATURE

AT $\left.25^{\circ} \mathrm{C}\right)(1 \mathrm{CO} / \mathrm{L}) \quad\left({ }^{\circ} \mathrm{C}\right)$

$\begin{array}{llll}810 & 750 & 6.3 & 5.0 \\ 770 & 720 & 6.4 & 4.6\end{array}$

$\begin{array}{lllllll}-- & -- & -- & -- & 12 & 12 \\ -- & -- & -- & -- & 12 & 11\end{array}$

$\begin{array}{rrrrr}650 & 640 & 7.4 & 7.2 & 9\end{array}$

$\begin{array}{llll}700 & 640 & 8.2 & 7.4 \\ 720 & 700 & 8.1 & 7.4\end{array}$

$\begin{array}{llll}720 & 700 & 8.1 & 7.4 \\ 760 & 710 & 8.1 & 7.3\end{array}$

770

750

$\begin{array}{rrrrrr}750 & 740 & 7.1 & 6.6 & 8 & 8\end{array}$

750

770
810

800

740

730
770
800
770

760
720

720
730
750

750
750

750

$\mathbf{7 5 0}$
$\mathbf{7 4 0}$
$\mathbf{7 5 0}$
$\mathbf{7 4 0}$
$\mathbf{7 4 0}$ $\begin{array}{lllll}740 & 7.5 & 6.1 & 10 & 8 \\ 770 & 6.1 & 5.7 & 10 & 9\end{array}$

$\begin{array}{lll}770 & 6.8 & 5.7\end{array}$

$\begin{array}{lll}710 & 8.6 & 7.1\end{array}$

$\begin{array}{lll}720 & 8.4 & 7.2 \\ 730 & 7.7 & 6.7\end{array}$

$\begin{array}{lll}770 & 7.5 & 6.5 \\ 720 & 7.2 & 6.3\end{array}$

$\begin{array}{lll}720 & 8.2 & 7.1 \\ 700 & 8.0 & 7.4\end{array}$

$\begin{array}{lll}700 & 8.0 & 7.4 \\ 730 & 8.1 & 7.3\end{array}$

$\begin{array}{lll}730 & 8.1 & \mathbf{7 . 2} \\ \mathbf{7 4 0} & \mathbf{8 . 9} & \mathbf{7 . 7}\end{array}$

$\begin{array}{lll}\mathbf{7 3 0} & \mathbf{8 . 9} & \mathbf{7 . 4} \\ \mathbf{7 2 0} & \mathbf{9 . 3} & \mathbf{7 . 6} \\ \mathbf{7 3 0} & \mathbf{8 . 9} & \mathbf{7 . 1}\end{array}$

$\begin{array}{lll}730 & 9.4 & \mathbf{7 . 7} \\ \mathbf{7 3 0} & \mathbf{9 . 5} & \mathbf{8 . 3}\end{array}$
December

CONDUCTANCE DISSOLVED TEMPER-

(NICROMHOS OXYGN ATURE

MIN WAX YIN MAX MIN

$\begin{array}{llll}760 & 730 & 9.0 & 8.6\end{array}$

$\begin{array}{llll}\mathbf{7 7 0} & \mathbf{7 6 0} & \mathbf{9 . 3} & \mathbf{8 . 2}\end{array}$

$\begin{array}{llll}760 & 720 & 8.3 & 7.9\end{array}$

$\begin{array}{llll}800 & 720 & 8.1 & 6.7 \\ 730 & 690 & 9.8 & 5.9\end{array}$

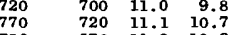

$\begin{array}{llll}750 & 570 & 11.2 & 10.8\end{array}$

$\begin{array}{llll}600 & 560 & 11.4 & 11.0\end{array}$

$540 \quad 530 \quad 11.0 \quad 9.7$

$\begin{array}{llll}\mathbf{5 4 0} & \mathbf{5 2 0} & 10.2 & \mathbf{9 . 5} \\ \mathbf{5 3 0} & \mathbf{5 2 0} & \mathbf{1 0 . 2} & \mathbf{9 . 7}\end{array}$

$\begin{array}{rrrr}530 & 520 & 10.2 & 9.7 \\ 540 & 520 & 10.6 & 10.2\end{array}$

$\begin{array}{llll}560 & 540 & 10.6 & 10.3\end{array}$

$\begin{array}{llll}580 & 560 & 10.7 & 10.5\end{array}$

$580 \quad 10.6 \quad 10.5$

$\begin{array}{lll}590 & 10.6 & 9.9\end{array}$

$590 \quad 9.9 \quad 9.3$

$\begin{array}{lll}600 & 10.0 & 9.9\end{array}$

$\begin{array}{lll}500 & 9.9 & 9.4\end{array}$

$\begin{array}{lrr}510 & 10.8 & 9.6\end{array}$

$\begin{array}{lll}520 & 12.1 & 10.8 \\ 530 & 12.2 & 11.9\end{array}$

$\begin{array}{lll}560 & 12.1 & 11.8\end{array}$

$\begin{array}{lll}550 & 12.1 & 11.8 \\ 550 & 12.0 & 11.7\end{array}$

$\begin{array}{lll}550 & 12.0 & 11.7 \\ 560 & 11.9 & 11.6\end{array}$

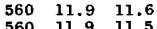

$\begin{array}{lll}560 & 11.9 & 11.5 \\ 600 & 11.7 & 11.5\end{array}$

$\begin{array}{ll}5 & 4 \\ 5 & 4 \\ 4 & 3\end{array}$

$\begin{array}{ll}4 & 3 \\ 4 & 4 \\ 5 & 4 \\ 5 & 5 \\ 5 & 5\end{array}$

$\begin{array}{ll}6 & 5 \\ 7 & 6\end{array}$

8
8

65

$\begin{array}{ll}6 & 5 \\ 7 & 6\end{array}$

87

$\begin{array}{ll}\mathbf{8} & 7 \\ 9 & 8 \\ 9 & 7 \\ 7 & 5 \\ \mathbf{5} & \mathbf{4}\end{array}$
43

$\begin{array}{rr}7 & 6 \\ 8 & 6 \\ 6 & 5 \\ 5 & 4 \\ 5 & 3 \\ -- & \end{array}$

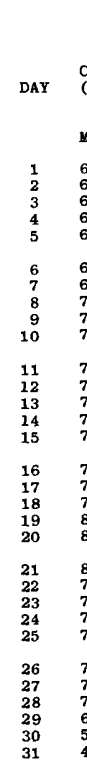

$\begin{array}{ll} & \text { January } \\ \text { SPECIFIC } & \end{array}$ (MICROMHOS

DI

I SSOLVED
OXYGEN (MG/L)

TEMPER-

ATURE
$\left({ }^{\circ} \mathrm{C}\right)$

MaX MIN MAX MIN MAX MIN

$\begin{array}{lllll}620 & 550 & 11.6 & 11.4\end{array}$

$\begin{array}{llll}620 & 550 & 11.7 & 11.3\end{array}$

$\begin{array}{llll}640 & 520 & 11.4 & 7.8\end{array}$

670

9.87 .2

$\begin{array}{llll}690 & 650 & 9.8 & 9.6 \\ 690 & 670 & 9.8 & 9.7\end{array}$

$\begin{array}{llll}720 & 660 & \mathbf{9 . 7} & \mathbf{8 . 7}\end{array}$

$\begin{array}{llll}\mathbf{7 4 0} & 680 & \mathbf{9 . 7} & \mathbf{5 . 3} \\ \mathbf{7 3 0} & 660 & \mathbf{8 . 4} & \mathbf{8 . 0}\end{array}$

$\begin{array}{llll}710 & 660 & 9.0 & 8.4 \\ 730 & 640 & 9.0 & 8.3\end{array}$

$\begin{array}{llll}\mathbf{7 8 0} & \mathbf{7 0 0} & \mathbf{8 . 3} & \mathbf{7 . 7} \\ \mathbf{7 8 0} & 710 & 8.7 & \mathbf{7 . 5}\end{array}$

760

$\begin{array}{lll}710 & \mathbf{8 . 7} & \mathbf{7 . 5} \\ \mathbf{7 5 0} & \mathbf{8 . 4} & \mathbf{8 . 1}\end{array}$

$\begin{array}{llll}\mathbf{7 6 0} & \mathbf{7 5 0} & \mathbf{8 . 2} & \mathbf{7 . 9} \\ \mathbf{7 6 0} & \mathbf{7 5 0} & \mathbf{8 . 4} & \mathbf{7 . 9}\end{array}$

$\begin{array}{llll}770 & 760 & 8.1 & 7.2 \\ 820 & 770 & 8.2 & 7.0\end{array}$

$\begin{array}{llll}820 & 790 & 8.5 & 8.2 \\ 790 & 760 & 8.5 & 8.2\end{array}$

$\begin{array}{rrrr}760 & 700 & 9.2 & 8.3 \\ 710 & 700 & 10.2 & 8.9\end{array}$

$\begin{array}{llll}710 & 700 & 10.2 & 8.9 \\ 750 & 700 & 10.3 & 9.7\end{array}$

$\begin{array}{llll}770 & 750 & 10.8 & 10.1\end{array}$

$\begin{array}{llll}760 & 720 & 11.3 & 10.5 \\ 720 & 690 & 10.9 & 10.3\end{array}$

$\begin{array}{rrrr}690 & 570 & 10.6 & 9.8\end{array}$

$\begin{array}{rrrr}570 & 420 & 10.6 & 9.6 \\ 460 & 420 & 10.9 & 10.4\end{array}$

\begin{tabular}{|c|c|c|c|c|c|}
\hline \multicolumn{6}{|c|}{ February } \\
\hline \multicolumn{2}{|c|}{$\begin{array}{l}\text { SPECIFIC } \\
\text { CONDUCTANCE } \\
\text { (MICROMHOS } \\
\text { AT 25 } 2{ }^{\circ} \mathrm{C} \text { ) }\end{array}$} & \multicolumn{2}{|c|}{$\begin{array}{l}\text { DISSOLVED } \\
\text { OXYGEN } \\
(\mathbb{K G} / L)\end{array}$} & \multicolumn{2}{|c|}{$\begin{array}{c}\text { TEMPER- } \\
\text { ATURE } \\
\left({ }^{\circ} \mathrm{C}\right)\end{array}$} \\
\hline $\max$ & MIN & MAX & MIN & MAX & IIN \\
\hline $\begin{array}{l}460 \\
410 \\
380 \\
380 \\
390\end{array}$ & $\begin{array}{l}\mathbf{4 1 0} \\
370 \\
370 \\
370 \\
\mathbf{3 8 0}\end{array}$ & $\begin{array}{l}11.1 \\
10.9 \\
12.6 \\
12.2 \\
12.7\end{array}$ & $\begin{array}{l}10.9 \\
10.4 \\
10.3 \\
10.6 \\
10.4\end{array}$ & $\begin{array}{l}2 \\
4 \\
3 \\
3 \\
3\end{array}$ & $\begin{array}{l}1 \\
2 \\
3 \\
2 \\
2\end{array}$ \\
\hline $\begin{array}{l}420 \\
480 \\
530 \\
550 \\
570\end{array}$ & $\begin{array}{l}390 \\
420 \\
480 \\
530 \\
550\end{array}$ & $\begin{array}{r}11.8 \\
10.0 \\
9.9 \\
10.0 \\
10.8\end{array}$ & $\begin{array}{l}9.0 \\
9.8 \\
9.4 \\
9.5 \\
9.6\end{array}$ & $\begin{array}{l}3 \\
3 \\
3 \\
3 \\
3\end{array}$ & $\begin{array}{l}2 \\
2 \\
2 \\
3 \\
2\end{array}$ \\
\hline $\begin{array}{l}610 \\
630 \\
640 \\
650 \\
660\end{array}$ & $\begin{array}{l}570 \\
580 \\
460 \\
610 \\
650\end{array}$ & $\begin{array}{l}11.0 \\
11.1 \\
11.1 \\
11.1 \\
11.0\end{array}$ & $\begin{array}{r}10.0 \\
10.8 \\
10.6 \\
10.8 \\
9.4\end{array}$ & $\begin{array}{l}2 \\
1 \\
1 \\
2 \\
2\end{array}$ & $\begin{array}{l}0 \\
0 \\
0 \\
0 \\
1\end{array}$ \\
\hline $\begin{array}{l}660 \\
670 \\
670 \\
680 \\
670\end{array}$ & $\begin{array}{l}660 \\
660 \\
660 \\
670 \\
670\end{array}$ & $\begin{array}{r}10.5 \\
10.1 \\
9.9 \\
10.1 \\
10.2\end{array}$ & $\begin{array}{l}8.7 \\
9.3 \\
9.3 \\
9.5 \\
9.6\end{array}$ & $\begin{array}{l}2 \\
3 \\
2 \\
2 \\
2 \\
3\end{array}$ & $\begin{array}{l}1 \\
1 \\
2 \\
1 \\
2\end{array}$ \\
\hline $\begin{array}{l}680 \\
690 \\
700 \\
720 \\
730\end{array}$ & $\begin{array}{l}670 \\
680 \\
690 \\
700 \\
720\end{array}$ & $\begin{array}{r}10.1 \\
10.2 \\
9.5 \\
9.7 \\
9.4\end{array}$ & $\begin{array}{l}9.1 \\
9.0 \\
8.9 \\
9.3 \\
8.8\end{array}$ & $\begin{array}{l}2 \\
2 \\
2 \\
3 \\
3\end{array}$ & $\begin{array}{l}1 \\
1 \\
1 \\
1 \\
2\end{array}$ \\
\hline $\begin{array}{l}730 \\
730 \\
750 \\
730\end{array}$ & $\begin{array}{l}720 \\
720 \\
730 \\
\mathbf{7 2 0}\end{array}$ & $\begin{array}{r}9.6 \\
10.0 \\
10.3 \\
10.2\end{array}$ & $\begin{array}{l}8.7 \\
8.9 \\
9.5 \\
8.6\end{array}$ & $\begin{array}{l}3 \\
4 \\
4 \\
4\end{array}$ & $\begin{array}{l}2 \\
3 \\
4 \\
4\end{array}$ \\
\hline- & -- & - & -- & -- & -- \\
\hline- & -- & - & -. & & -- \\
\hline
\end{tabular}


03231500 SCIOTO RIVER AT CHILLICOTHE, OHIO--Continued

SPECIFIC CONDUCTANCE, DISSOLVED OXYGEN, AND WATER TEMPERATURES, WATER YEAR OCTOBER 1967 TO SEPTEMBER 1968

\begin{tabular}{|c|c|c|c|c|c|c|c|c|c|c|c|c|c|c|c|c|c|c|}
\hline \multirow{3}{*}{ DAY } & \multicolumn{6}{|c|}{ April } & \multicolumn{6}{|c|}{ May } & \multicolumn{6}{|c|}{ June } \\
\hline & \multicolumn{2}{|c|}{$\begin{array}{l}\text { SPECIFIC } \\
\text { CONDUCTANCE } \\
\text { (MICROMHOS } \\
\text { AT } 25^{\circ} \mathrm{C} \text { ) }\end{array}$} & \multicolumn{2}{|c|}{$\begin{array}{l}\text { DI SSOLVED } \\
\text { OXYGEN } \\
(\text { KG/L) }\end{array}$} & \multicolumn{2}{|c|}{$\begin{array}{l}\text { TEMPER- } \\
\text { ATURE } \\
\left({ }^{\circ} \mathrm{C}\right)\end{array}$} & \multicolumn{2}{|c|}{$\begin{array}{l}\text { SPECIFIC } \\
\text { CONDUCTANCE } \\
\text { (MICROLHOS } \\
\left.\text { AT } 25^{\circ} \mathrm{C}\right)\end{array}$} & \multicolumn{2}{|c|}{$\begin{array}{l}\text { DISSOLYED } \\
\text { OXYGEN } \\
(\mathbb{K G / L )}\end{array}$} & \multicolumn{2}{|c|}{$\begin{array}{l}\text { TEMPER- } \\
\text { ATURE } \\
\left({ }^{\circ} \mathrm{C}\right)\end{array}$} & \multicolumn{2}{|c|}{$\begin{array}{l}\text { SPECIFIC } \\
\text { CONDUCTANCE } \\
\text { (MI CROMHOS } \\
\text { AT } 25^{\circ} \mathrm{C} \text { ) }\end{array}$} & \multicolumn{2}{|c|}{$\begin{array}{l}\text { DI SSOLVED } \\
\text { OXYGEN } \\
(\mathrm{WG} / \mathrm{L})\end{array}$} & \multicolumn{2}{|c|}{$\begin{array}{l}\text { TEMPER- } \\
\text { ATURE } \\
\left({ }^{\circ} \mathrm{C}\right)\end{array}$} \\
\hline & $\max$ & MIN & $\max$ & MIN & MAX & MIN & $\operatorname{yax}$ & MIN & $\operatorname{MaX}$ & MIN & $\operatorname{MAX}$ & MIN & MAAX & MIN & KAX & MIN & $\operatorname{MAX}$ & MIN \\
\hline $\begin{array}{l}1 \\
2 \\
3 \\
4 \\
5\end{array}$ & $\begin{array}{l}=- \\
=- \\
=- \\
=-\end{array}$ & $\begin{array}{l}=- \\
-- \\
-- \\
--\end{array}$ & $\begin{array}{l}-- \\
-- \\
-- \\
--\end{array}$ & $\begin{array}{l}-- \\
-- \\
-- \\
--\end{array}$ & $\begin{array}{l}12 \\
12 \\
11 \\
11 \\
11\end{array}$ & $\begin{array}{l}11 \\
11 \\
11 \\
11 \\
11\end{array}$ & $\begin{array}{l}-- \\
=- \\
=-\end{array}$ & $\begin{array}{l}-- \\
=- \\
=-\end{array}$ & $\begin{array}{l}=- \\
=- \\
=- \\
--\end{array}$ & $\begin{array}{l}=- \\
=- \\
=-\end{array}$ & $\begin{array}{l}17 \\
17 \\
18 \\
18 \\
18\end{array}$ & $\begin{array}{l}15 \\
16 \\
17 \\
17 \\
16\end{array}$ & $\begin{array}{r}480 \\
490 \\
460 \\
-- \\
--\end{array}$ & $\begin{array}{r}430 \\
460 \\
420 \\
-- \\
--\end{array}$ & $\begin{array}{l}6.8 \\
6.7 \\
6.5 \\
-- \\
--\end{array}$ & $\begin{array}{r}6.2 \\
6.2 \\
6.1 \\
-- \\
--\end{array}$ & $\begin{array}{l}19 \\
19 \\
19 \\
18 \\
19\end{array}$ & $\begin{array}{l}18 \\
18 \\
18 \\
18 \\
18\end{array}$ \\
\hline $\begin{array}{r}6 \\
7 \\
8 \\
9 \\
10\end{array}$ & $\begin{array}{l}-- \\
= \\
=-\end{array}$ & $\begin{array}{l}-- \\
=- \\
=- \\
--\end{array}$ & $\begin{array}{l}=- \\
=- \\
=\end{array}$ & $\begin{array}{l}-- \\
-- \\
--\end{array}$ & $\begin{array}{l}11 \\
11 \\
12 \\
13 \\
13\end{array}$ & $\begin{array}{l}11 \\
11 \\
11 \\
12 \\
12\end{array}$ & $\begin{array}{l}-- \\
-- \\
740\end{array}$ & $\overline{--}$ & $\begin{array}{l}-- \\
\overline{--} \\
\overline{8.6}\end{array}$ & $\begin{array}{l}-- \\
-- \\
-\overline{-} \\
5.9\end{array}$ & $\begin{array}{l}17 \\
17 \\
17 \\
17 \\
19\end{array}$ & $\begin{array}{l}15 \\
15 \\
16 \\
16 \\
17\end{array}$ & $\begin{array}{l}= \\
=- \\
= \\
=\end{array}$ & $\begin{array}{l}-- \\
=- \\
-- \\
--\end{array}$ & $\begin{array}{l}=- \\
-- \\
--\end{array}$ & $\begin{array}{l}=- \\
=- \\
=- \\
--\end{array}$ & $\begin{array}{l}19 \\
20 \\
21 \\
22 \\
22\end{array}$ & $\begin{array}{l}19 \\
19 \\
20 \\
21 \\
22\end{array}$ \\
\hline $\begin{array}{l}11 \\
12 \\
13 \\
14 \\
15\end{array}$ & $\begin{array}{l}=- \\
-- \\
=- \\
--\end{array}$ & $\begin{array}{l}-- \\
-- \\
=- \\
--\end{array}$ & $\begin{array}{l}-- \\
-- \\
-- \\
--\end{array}$ & $\begin{array}{l}-- \\
-- \\
-- \\
--\end{array}$ & $\begin{array}{l}13 \\
14 \\
16 \\
17 \\
17\end{array}$ & $\begin{array}{l}12 \\
12 \\
13 \\
16 \\
16\end{array}$ & $\begin{array}{l}740 \\
720 \\
580 \\
540 \\
620\end{array}$ & $\begin{array}{l}660 \\
600 \\
520 \\
520 \\
540\end{array}$ & $\begin{array}{l}5.9 \\
4.7 \\
5.8 \\
6.8 \\
6.7\end{array}$ & $\begin{array}{l}3.3 \\
1.8 \\
3.1 \\
6.1 \\
6.2\end{array}$ & $\begin{array}{l}19 \\
19 \\
18 \\
17 \\
20\end{array}$ & $\begin{array}{l}18 \\
18 \\
17 \\
16 \\
16\end{array}$ & $\begin{array}{l}=- \\
z- \\
z-\end{array}$ & $\begin{array}{l}-- \\
-- \\
=- \\
--\end{array}$ & $\begin{array}{l}-- \\
-- \\
--\end{array}$ & $\begin{array}{l}=- \\
=- \\
-- \\
--\end{array}$ & $\begin{array}{l}22 \\
22 \\
22 \\
20 \\
21\end{array}$ & $\begin{array}{l}21 \\
22 \\
20 \\
19 \\
19\end{array}$ \\
\hline $\begin{array}{l}16 \\
17 \\
18 \\
19 \\
20\end{array}$ & $\begin{array}{l}=- \\
=- \\
=-\end{array}$ & $\begin{array}{l}=- \\
=- \\
--\end{array}$ & $\begin{array}{l}-- \\
-- \\
-- \\
--\end{array}$ & $\begin{array}{l}= \\
=- \\
=- \\
=-\end{array}$ & $\begin{array}{l}16 \\
16 \\
17 \\
17 \\
18\end{array}$ & $\begin{array}{l}14 \\
15 \\
14 \\
16 \\
16\end{array}$ & $\begin{array}{l}630 \\
640 \\
610 \\
600 \\
620\end{array}$ & $\begin{array}{l}620 \\
610 \\
560 \\
570 \\
590\end{array}$ & $\begin{array}{l}6.0 \\
6.0 \\
6.2 \\
6.5 \\
7.2\end{array}$ & $\begin{array}{l}5.8 \\
4.9 \\
5.3 \\
6.1 \\
6.4\end{array}$ & $\begin{array}{l}22 \\
22 \\
22 \\
20 \\
19\end{array}$ & $\begin{array}{l}20 \\
21 \\
20 \\
19 \\
16\end{array}$ & $\begin{array}{l}-- \\
z- \\
-- \\
-\end{array}$ & $\begin{array}{l}= \\
=- \\
=-\end{array}$ & $\begin{array}{l}= \\
=- \\
=- \\
=-\end{array}$ & $\begin{array}{l}-- \\
=- \\
=- \\
--\end{array}$ & $\begin{array}{l}21 \\
20 \\
21 \\
21 \\
22\end{array}$ & $\begin{array}{l}20 \\
19 \\
20 \\
21 \\
21\end{array}$ \\
\hline $\begin{array}{l}21 \\
22 \\
23 \\
24 \\
25\end{array}$ & $\begin{array}{r}-- \\
\overline{--} \\
700 \\
700\end{array}$ & $\begin{array}{r}-- \\
-- \\
-- \\
660 \\
630\end{array}$ & $\begin{array}{r}-- \\
\overline{--} \\
7.2 \\
6.0\end{array}$ & $\begin{array}{r}-- \\
\overline{--} \\
5.0 \\
4.0\end{array}$ & $\begin{array}{l}18 \\
19 \\
19 \\
18 \\
16\end{array}$ & $\begin{array}{l}17 \\
17 \\
18 \\
16 \\
14\end{array}$ & $\begin{array}{l}640 \\
660 \\
670 \\
430 \\
380\end{array}$ & $\begin{array}{l}610 \\
640 \\
420 \\
180 \\
250\end{array}$ & $\begin{array}{l}7.4 \\
7.4 \\
7.6 \\
8.0 \\
7.6\end{array}$ & $\begin{array}{l}6.5 \\
6.8 \\
6.5 \\
6.3 \\
7.3\end{array}$ & $\begin{array}{l}19 \\
19 \\
19 \\
18 \\
18\end{array}$ & $\begin{array}{l}18 \\
18 \\
16 \\
16 \\
17\end{array}$ & $\begin{array}{l}-- \\
\overline{-} \\
\overline{--} \\
-\end{array}$ & $\begin{array}{l}=- \\
=- \\
=- \\
--\end{array}$ & $\begin{array}{l}=- \\
=- \\
--\end{array}$ & $\begin{array}{l}-- \\
=- \\
-- \\
--\end{array}$ & $\begin{array}{l}22 \\
22 \\
23 \\
23 \\
23\end{array}$ & $\begin{array}{l}21 \\
21 \\
22 \\
22 \\
23\end{array}$ \\
\hline $\begin{array}{l}\mathbf{2 6} \\
\mathbf{2 7} \\
\mathbf{2 8} \\
\mathbf{2 9} \\
30 \\
31\end{array}$ & $\begin{array}{r}650 \\
650 \\
680 \\
670 \\
680 \\
-\end{array}$ & $\begin{array}{l}630 \\
630 \\
650 \\
650 \\
670 \\
-\ldots\end{array}$ & $\begin{array}{l}8.2 \\
8.4 \\
8.0 \\
8.6 \\
7.9 \\
-.\end{array}$ & $\begin{array}{r}5.9 \\
6.0 \\
5.5 \\
5.3 \\
4.7 \\
.-\end{array}$ & $\begin{array}{l}14 \\
15 \\
16 \\
16 \\
17 \\
--\end{array}$ & $\begin{array}{l}13 \\
13 \\
14 \\
14 \\
15 \\
-\end{array}$ & $\begin{array}{l}420 \\
420 \\
360 \\
350 \\
390 \\
430\end{array}$ & $\begin{array}{l}380 \\
330 \\
320 \\
330 \\
340 \\
390\end{array}$ & $\begin{array}{l}7.4 \\
7.5 \\
7.2 \\
7.2 \\
7.4 \\
7.1\end{array}$ & $\begin{array}{l}7.3 \\
7.1 \\
6.9 \\
7.0 \\
7.1 \\
6.5\end{array}$ & $\begin{array}{l}18 \\
19 \\
19 \\
18 \\
18 \\
18\end{array}$ & $\begin{array}{l}18 \\
18 \\
18 \\
17 \\
17 \\
17\end{array}$ & $\begin{array}{r}-- \\
640 \\
680 \\
660 \\
--\end{array}$ & $\begin{array}{r}-- \\
610 \\
620 \\
640 \\
--\end{array}$ & $\begin{array}{r}-. \\
5.0 \\
4.7 \\
4.6 \\
-.\end{array}$ & $\begin{array}{r}-- \\
4.0 \\
3.7 \\
3.0 \\
--\end{array}$ & $\begin{array}{l}24 \\
24 \\
23 \\
23 \\
25 \\
-\end{array}$ & $\begin{array}{l}23 \\
22 \\
22 \\
22 \\
23\end{array}$ \\
\hline
\end{tabular}

July

SPECIFIC

CONDUCTANCE DISSOLYED TEUPER-

DAY (HICROYHOS

AT $25^{\circ} \mathrm{C}$ )

MAX

MIN MAX MIN MAX MIN

$\begin{array}{llllll}680 & 660 & 4.6 & 3.1 & 26 & 24 \\ 680 & 660 & 5.2 & 3.4 & 27 & 26\end{array}$

$\begin{array}{llllll}\mathbf{6 8 0} & \mathbf{6 6 0} & \mathbf{5 . 2} & \mathbf{3 . 4} & \mathbf{2 7} & \mathbf{2 6} \\ \mathbf{6 8 0} & 650 & \mathbf{6 . 6} & \mathbf{2 . 8} & \mathbf{2 6} & \mathbf{2 4}\end{array}$

$\begin{array}{llllll}680 & 650 & 6.6 & 2.8 & 26 & 24 \\ 680 & 670 & 9.2 & 4.0 & 25 & 23\end{array}$

$\begin{array}{llllll}700 & 660 & 12.7 & 4.6 & 25 & 23\end{array}$

$\begin{array}{llllll}700 & 660 & 12.7 & 4.6 & 25 & 23 \\ 690 & 650 & 11.0 & 6.5 & 25 & 23\end{array}$

$\begin{array}{rrrrrr}680 & 650 & 10.7 & 7.5 & 25 & \mathbf{2 4} \\ 700 & 660 & 8.3 & 5.1 & 26 & \mathbf{2 4}\end{array}$

$\begin{array}{lllllll}720 & 690 & 8.3 & 5.1 & 26 & 24 \\ 7.6 & 3.5 & 25 & 25\end{array}$

$\begin{array}{llllll}730 & \mathbf{7 1 0} & \mathbf{4 . 0} & 3.0 & \mathbf{2 6} & \mathbf{2 5} \\ \mathbf{7 4 0} & \mathbf{7 3 0} & 5.8 & \mathbf{2 . 5} & \mathbf{2 7} & \mathbf{2 6}\end{array}$

$\begin{array}{llllll}\mathbf{7 4 0} & \mathbf{7 3 0} & 5.8 & \mathbf{2 . 5} & \mathbf{2 7} & \mathbf{2 6} \\ \mathbf{7 3 0} & 650 & \mathbf{5 . 5} & \mathbf{3 . 7} & \mathbf{2 6} & \mathbf{2 5}\end{array}$

$\begin{array}{llllll}700 & 670 & 6.9 & 3.6 & \mathbf{2 7} & \mathbf{2 6} \\ \mathbf{7 0 0} & \mathbf{7 0 0} & 5.8 & \mathbf{3 . 8} & \mathbf{2 6} & \mathbf{2 5}\end{array}$

$\begin{array}{llllll}-- & -- & -- & -- & 25 & 24 \\ -- & -- & -- & -- & 26 & 24 \\ - & -- & - & - & 27 & 26\end{array}$

$\begin{array}{llllll}-- & -- & -- & -- & 27 & 26 \\ -- & -- & -- & -- & 27 & 27 \\ - & - & - & -- & 27 & 26\end{array}$

$\begin{array}{lllllll}-- & -- & -- & -- & 27 & 26 \\ -- & -- & -- & -- & 26 & 25\end{array}$

$\begin{array}{llllll}-z & - & -- & - & 26 & 25 \\ -- & -- & -- & -- & 26 & 24 \\ -- & -- & -- & -- & 26 & 25\end{array}$

$\begin{array}{lllllll}26 & -- & -- & -- & -- & 26 & 24 \\ 27 & -- & -- & -- & - & 26 & 25 \\ 28 & -- & -- & -- & -- & 26 & 25 \\ 29 & -- & -- & -- & -- & 25 & 24\end{array}$

$\begin{array}{lllllll}29 & -- & -- & -- & -- & 25 & 24 \\ 30 & -- & -- & -- & -- & 24 & 23\end{array}$
Augus $t$

SPECIFIC

CORCIFIC

(MICROYHOS OXYGEN

AT $25^{\circ} \mathrm{C}$ )

MAX MIN MAX MIN MAX MIN

--
$\bar{z}$
$\bar{z}$

$\bar{z}=$

$\bar{z}=$

$\begin{array}{ll}z & = \\ -- & =\end{array}$

$=\quad-$

$=\quad=$

$\begin{array}{ll}-- & = \\ -- & =\end{array}$

$=$

$\begin{array}{ll}710 & 700 \\ 720 & 680\end{array}$

$\begin{array}{ll}\mathbf{7 2 0} & 680 \\ 700 & 680 \\ \mathbf{6 8 0} & 640\end{array}$

$690 \quad 670$

700
700

$\begin{array}{ll}700 & 690 \\ 700 & 690\end{array}$

$\begin{array}{ll}700 & 690 \\ 700 & 690 \\ 710 & 700\end{array}$
September

SPECIFIC DONDUCTANCE DISSOLVED TEMPER-

$\begin{array}{ccc}\text { (MICROMAOS } & \text { OXYGEN } & \text { ATURE } \\ \left.\text { AT } 25^{\circ} \mathrm{C}\right) & (\text { (GG } / \mathrm{L}) & \left({ }^{\circ} \mathrm{C}\right)\end{array}$

MAX MIN MAX MIN MAX MIN

$\begin{array}{llllll}710 & 700 & -- & -- & 23 & 22 \\ 730 & 710 & -- & -- & 23 & 22\end{array}$

$\begin{array}{llllll}740 & 720 & -- & -- & 23 & 22 \\ 750 & 740 & -- & -- & 23 & 23 \\ 760 & 750 & -- & -- & 23 & 22\end{array}$

$\begin{array}{llllll}\mathbf{7 6 0} & \mathbf{7 3 0} & -- & -- & 23 & \mathbf{2 2} \\ \mathbf{7 6 0} & \mathbf{7 2 0} & -- & -- & 23 & 22 \\ \mathbf{7 2 0} & \mathbf{7 0 0} & -- & -- & 24 & 22\end{array}$

$\begin{array}{llllll}\mathbf{7 2 0} & \mathbf{7 0 0} & -- & -- & 24 & \mathbf{2 2} \\ \mathbf{7 1 0} & \mathbf{6 9 0} & -- & -- & 23 & \mathbf{2 2} \\ \mathbf{7 4 0} & \mathbf{7 0 0} & -- & -- & 23 & \mathbf{2 2}\end{array}$

$\begin{array}{llllll}730 & 700 & -- & -- & 22 & 20 \\ 700 & 690 & -- & -- & 23 & 20 \\ 730 & 700 & - & -- & 23 & 21\end{array}$

$\begin{array}{llllll}730 & 700 & -- & -- & 23 & 21 \\ 760 & 730 & - & -- & 22 & 21\end{array}$

$\begin{array}{llllll}760 & 740 & -- & -- & 22 & 21 \\ 760 & & -- & 23 & \end{array}$

$\begin{array}{llllllll}24 & 23 & 760 & 750 & -- & - & 23 & 22 \\ 26 & 24 & 760 & 750 & -- & -- & 22 & 21\end{array}$

$\begin{array}{llllllll}24 & 23 & 760 & 750 & -- & - & 23 & 22 \\ 26 & 24 & 760 & 750 & -- & -- & 22 & 21 \\ 26 & 24 & 760 & 730 & -- & -- & 21 & 21\end{array}$

$\begin{array}{llllllll}26 & 24 & 750 & 730 & -- & -- & 21 & 20 \\ 27 & 26 & 790 & 740 & -- & -- & 22 & 20\end{array}$

$\begin{array}{llllllll}28 & 27 & 780 & 760 & -- & -- & 23 & 22 \\ 29 & 27 & 790 & 760 & -- & -- & 25 & 23\end{array}$

$\begin{array}{llllllll}29 & 28 & 840 & 760 & 7.7 & 5.3 & 25 & 23 \\ 29 & 28 & 830 & 780 & 9.0 & 3.8 & 26 & 24\end{array}$

$\begin{array}{llllll}790 & 760 & 5.0 & 3.2 & 25 & 24\end{array}$

$\begin{array}{llllllll}27 & 25 & 770 & 760 & 5.5 & 3.1 & 24 & 23\end{array}$

$\begin{array}{llllllll}25 & 23 & 790 & 770 & 5.2 & 3.0 & 23 & 22 \\ \mathbf{2 4} & \mathbf{2 2} & \mathbf{7 8 0} & \mathbf{7 6 0} & \mathbf{6 . 6} & 3.8 & 23 & 22\end{array}$

$\begin{array}{llllllll}\mathbf{2 4} & \mathbf{2 2} & \mathbf{7 8 0} & \mathbf{7 6 0} & \mathbf{6 . 6} & \mathbf{3 . 8} & \mathbf{2 3} & \mathbf{2 2} \\ \mathbf{2 3} & \mathbf{2 2} & \mathbf{7 6 0} & \mathbf{7 5 0} & 5.6 & \mathbf{3 . 5} & \mathbf{2 3} & \mathbf{2 1}\end{array}$

$\begin{array}{llcccccc}23 & 22 & 760 & 750 & 5.6 & 3.5 & 23 & 21 \\ 23 & 22 & 760 & 750 & 5.5 & 3.6 & 22 & 21\end{array}$ 
LOCATION, --Lat $39^{\circ} 15^{\prime} 49^{\prime \prime}$, long $83^{\circ} 10^{\prime} 01^{\prime \prime}$, Ross County, at gaging station at highway bridge, 1.2 miles southwest of Bourneville and 1.2 miles upstream from Upper Trin Creek.

DRAINAGE AREA, $--807 \mathrm{sq} \mathrm{m} 1$.

PERIOD OF RECORD.--Chemical analyses: October 1965 to September 1968.

Water temperatures: October 1956 to September 1962, October 1965 to September 1968. Sediment records: October 1956 to September 1962

EXTREMES, $-1967-68$ :

Specific conductance: Maximum dally, 730 micromhos Jan. 11, 12; minimum daily, 239 micromhos May 27

Water temperatures: Maximum, 25.0 $0^{\circ} \mathrm{C}$ Sept. 3, 6, 8; minimum, $1.0^{\circ} \mathrm{C}$ on many days during December and March.

Pertod of record:

Spectflc conductance (1965-68): Maximum da1ly, 730 micromhos Jan. 11, 12, 1968; mintmum da1ly, 239 micromhos May 27,1968

Water temperatures: Maximum, $27.0^{\circ} \mathrm{C}$ June 30 , July 1, 1959; minimum, freezing point on many days during winter periods.

REMARKS.--Samples for tron and manganese were flltered clear when collected. Daily samples were collected at this station and samples were selected for analyses on the following basis: (1) Maximum daily specific

conductance for each month, (2) minimum dally specific conductance for each month, (3) median daily specific conductance for each month, and (4) special sample
slightly regulated by Rocky Fork Lake since 1952 .

CHEMICAL ANALYSES IN MILLIGRAMS PER LITER, WATER YEAR OCTOBER 1967 TO SEPTEMBER 1968

\begin{tabular}{|c|c|c|c|c|c|c|c|c|c|c|}
\hline DATE & IIME & $\begin{array}{l}\text { JIS- } \\
\text { CHARGE } \\
\text { ICFS) }\end{array}$ & $\begin{array}{l}\text { [RUN } \\
\text { (FE) }\end{array}$ & $\begin{array}{l}\text { MAN- } \\
\text { GANESE } \\
\text { ( YN) }\end{array}$ & $\begin{array}{l}\text { BICAR- } \\
\text { SONATE } \\
\text { (HCD3) }\end{array}$ & $\begin{array}{l}\text { CAP- } \\
\text { BONATE } \\
(C O B)\end{array}$ & $\begin{array}{l}\text { SULFATE } \\
\left(\mathrm{SO}_{4}\right)\end{array}$ & $\begin{array}{l}\text { CHLD- } \\
\text { RIDE } \\
\text { (CL) }\end{array}$ & $\begin{array}{l}\text { FLUOO- } \\
\text { RIDE } \\
\text { (F) }\end{array}$ & $\begin{array}{l}\text { NI TRATF } \\
\text { (NO3) }\end{array}$ \\
\hline \multicolumn{11}{|l|}{ DCT. } \\
\hline & 1340 & 41 & .07 & .07 & -- & -- & -- & -- & -- & -- \\
\hline $14 \ldots$ & 0700 & 40 & - & - & 284 & 0 & 42 & I 8 & .2 & 3.2 \\
\hline $20 \ldots$ & 0700 & 502 & -- & -- & 212 & 0 & 27 & 12 & .3 & 4.3 \\
\hline $25 \ldots$ & 0700 & 544 & -- & -- & 198 & 0 & 27 & 10 & .3 & 2.4 \\
\hline \multicolumn{11}{|l|}{ NOV. } \\
\hline $01 \ldots$ & 0800 & 490 & -- & - & 202 & 0 & 30 & 10 & .1 & 1.5 \\
\hline $12 \ldots$ & JROO & 101 & $\cdots$ & $\cdots$ & 298 & 0 & 61 & 24 & 3 & 2.9 \\
\hline $14 \ldots$ & 1150 & i15 & .06 & .05 & - & $\cdots$ & - & - & $\cdots$ & - \\
\hline $16 \ldots$ & OBOO & 89 & $\cdots$ & - & 274 & 0 & 57 & 18 & .4 & 2.5 \\
\hline \multicolumn{11}{|l|}{ DEC." } \\
\hline $12 \ldots$ & 0800 & 1500 & - & $=$ & 182 & 0 & 44 & 11 & .2 & 8.6 \\
\hline $19 . .$. & 1300 & 781 & .06 & .04 & - & $=$ & $\cdots$ & - & - & - \\
\hline $20 \ldots$ & טค0อ & 668 & -- & $\cdots$ & 248 & 0 & 55 & 15 & .2 & 8. 2 \\
\hline $29 \ldots$ & 0800 & 510 & -- & -- & 296 & $c$ & 61 & 17 & .2 & 12 \\
\hline $11 \ldots$ & 0800 & 254 & -- & \multicolumn{7}{|c|}{ JAN. } \\
\hline $15 \ldots$ & OBOO & 198 & -- & -- & 262 & $\hat{0}$ & $\begin{array}{l}52 \\
35\end{array}$ & $\begin{array}{l}19 \\
20\end{array}$ & $: 3$ & $\begin{array}{l}12 \\
10\end{array}$ \\
\hline $22 \ldots$ & 1115 & 731 & .09 & .04 & - & -- & - & - & $\because$ & $\rightarrow$ \\
\hline $31 \ldots$ & $O B O 0$ & 3910 & - & - & 156 & 0 & 39 & 14 & .2 & 20 \\
\hline \multicolumn{11}{|l|}{$\begin{array}{c}31 . \cdots \\
\text { FEA. }\end{array}$} \\
\hline $01 \ldots$ & $\begin{array}{l}08000 \\
1100\end{array}$ & $\begin{array}{l}3380 \\
1070\end{array}$ & .03 & $\overline{06}$ & 160 & 4 & $\begin{array}{l}45 \\
--\end{array}$ & 18 & $\therefore 2$ & 18 \\
\hline $\begin{array}{l}13 \ldots \\
15 \ldots\end{array}$ & 0800 & 338 & 03 & .06 & 350 & 0 & 64 & $19^{--}$ & $\overline{2}$ & 9.9 \\
\hline $\begin{array}{l}15 \ldots \\
28 \ldots\end{array}$ & 0800 & $\begin{array}{l}338 \\
170\end{array}$ & -- & - & $\begin{array}{l}350 \\
206\end{array}$ & $\begin{array}{l}0 \\
4\end{array}$ & $\begin{array}{l}64 \\
62\end{array}$ & I9 & $\begin{array}{l}.2 \\
.2\end{array}$ & $\begin{array}{l}9.9 \\
9.9\end{array}$ \\
\hline \multicolumn{11}{|l|}{ MAR. } \\
\hline $02 \ldots$ & 0800 & 154 & -- & -- & 310 & c & 59 & 19 & .3 & 7.0 \\
\hline $19 \ldots$ & $O B O 0$ & 1100 & - & -- & 220 & 0 & 51 & 22 & .3 & 8.2 \\
\hline $19 \ldots$ & 1145 & 930 & .12 & $\therefore 06$ & -- & -- & - & - & - & - \\
\hline \multirow{2}{*}{\multicolumn{11}{|c|}{$\begin{array}{l}22 \ldots \\
A P R\end{array}$}} \\
\hline & & & & & & & & & & \\
\hline $11 \ldots$ & 0800 & 508 & - & -- & 256 & 0 & 53 & 14 & .3 & 12 \\
\hline is... & 1250 & 535 & .17 & .07 & -- & -- & -- & & -- & - \\
\hline $22 \ldots$ & 0800 & 431 & - & - & 268 & 0 & 54 & 15 & .3 & 6.6 \\
\hline $25 \ldots$ & 0800 & 946 & -- & - & 178 & 0 & 40 & 0.0 & .2 & 7.6 \\
\hline \multicolumn{11}{|l|}{ MAY } \\
\hline $03 \ldots$ & C8OC & 294 & -- & -- & 240 & 0 & 55 & 16 & .3 & 13 \\
\hline $19 \ldots$ & 0900 & $135 \mathrm{C}$ & -- & -- & 246 & 0 & 49 & 14 & .4 & 22 \\
\hline $21 \ldots$ & 1315 & 866 & .15 & .12 & $\rightarrow$ & -- & -- & -- & -- & $\cdots$ \\
\hline $27 \ldots$ & 0800 & 20800 & -- & - & 122 & 0 & 17 & 4.0 & .4 & 10 \\
\hline \multicolumn{11}{|l|}{ JUNE } \\
\hline $02 \ldots$ & 0800 & 3860 & -- & -- & 212 & 0 & 38 & 9.0 & .2 & 19 \\
\hline $04 \ldots$ & 1055 & 2550 & .14 & .12 & -- & $\cdots$ & $\cdots$ & & -- & \\
\hline $14 \ldots$ & $O B O O$ & 474 & -- & -- & 291 & 0 & 46 & 13 & .2 & 16 \\
\hline $30 \ldots$ & 0800 & 212 & - & $\cdots$ & 309 & 0 & 46 & 14 & .2 & 10 \\
\hline \multicolumn{11}{|l|}{ JULY } \\
\hline $10 \ldots$ & 1510 & 114 & .09 & .15 & - & -- & $=-$ & -- & -- & -- \\
\hline $14 \ldots$ & 0800 & 257 & - & -- & 278 & 12 & 50 & 18 & .3 & 6.8 \\
\hline i ค.... & 0800 & $19 \mathrm{~A}$ & -- & - & 224 & 8 & 42 & 14 & .3 & 8.9 \\
\hline $27 \ldots$ & 0900 & 173 & $\cdots$ & -- & 248 & 8 & 44 & 16 & .3 & 7.6 \\
\hline \multicolumn{11}{|l|}{ AUG. } \\
\hline $11 \ldots$ & OBOO & 792 & $\cdots$ & $\cdots$ & 184 & 4 & 34 & 10 & .3 & 5.1 \\
\hline $15 \ldots$ & 0800 & 217 & $\cdots$ & - & 253 & 4 & 42 & 16 & .3 & 8.7 \\
\hline $26 \ldots$ & 1535 & 84 & .17 & .08 & -- & -- & $=$ & 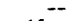 & - & - \\
\hline $\begin{array}{l}29 . \cdots \\
\text { SEPT. }\end{array}$ & ¿800 & 69 & -- & -- & 260 & 4 & 43 & 15 & .2 & 5.1 \\
\hline \multicolumn{11}{|l|}{ SEPT. } \\
\hline $\begin{array}{l}09 \ldots \\
24 \ldots\end{array}$ & 0800 & 58 & $=$ & $=$ & $\begin{array}{l}192 \\
334\end{array}$ & 4 & $\begin{array}{l}44 \\
43\end{array}$ & $\begin{array}{l}15 \\
14\end{array}$ & .2 & $\begin{array}{l}3.8 \\
4.8\end{array}$ \\
\hline $\begin{array}{l}24 \ldots \\
25 \ldots\end{array}$ & $\begin{array}{l}0900 \\
1115\end{array}$ & $\begin{array}{l}43 \\
39\end{array}$ &.$\overline{06}$ & .14 & $\begin{array}{r}334 \\
---\end{array}$ & $\therefore$ & -3 & 14 & $\therefore$ & 4.8 \\
\hline $29 \ldots$ & $O B O C$ & 28 & $\ldots$ & $\therefore$ & 289 & 0 & 43 & 16 & .2 & 3. \\
\hline
\end{tabular}


03234000 PAINT CREEK NEAR BOURNEVILLE. OHIO--Cont 1 nued

CHEMICAL ANALYSES IN MILLIGRAMS PER LITER, WATER YEAR OCTOBER 1967 TO SEPTEMBER 1968

\begin{tabular}{|c|c|c|c|c|c|c|c|c|c|}
\hline DATE & $\begin{array}{l}\text { FOTAL } \\
\text { PHOS- } \\
\text { PHORUS } \\
\text { (PO4) }\end{array}$ & $\begin{array}{l}\text { CIS- } \\
\text { SULVED } \\
\text { SULIDS } \\
\text { IHESI- } \\
\text { DUE AT } \\
180 \mathrm{CI}\end{array}$ & $\begin{array}{l}\text { HARO- } \\
\text { NFSS } \\
\text { (CA,MG) }\end{array}$ & $\begin{array}{l}\text { NON- } \\
\text { CAR- } \\
\text { RONATE } \\
\text { HARD- } \\
\text { NESS }\end{array}$ & $\begin{array}{l}\text { SPECI- } \\
\text { FIC } \\
\text { CDND- } \\
\text { UCF ANCE } \\
\text { (MICRD- } \\
\text { MHISS ) }\end{array}$ & $\mathrm{PH}$ & $\begin{array}{l}\text { TEMP- } \\
\text { ERATLIRE } \\
\text { IDES C) }\end{array}$ & $\begin{array}{l}\text { DISS- } \\
\text { DLVED } \\
\text { OXYGFN }\end{array}$ & $\begin{array}{l}\text { PER- } \\
\text { CENT } \\
\text { SATUR- } \\
\text { ATION }\end{array}$ \\
\hline $\begin{array}{l}\text { UCT. } \\
10 . . .\end{array}$ & -- & -- & -- & -- & -- & $-\infty$ & -- & 8.4 & 84 \\
\hline $24 \ldots$ & $\begin{array}{l}.52 \\
.98\end{array}$ & $\begin{array}{l}324 \\
238\end{array}$ & $\begin{array}{l}280 \\
208\end{array}$ & $\begin{array}{l}47 \\
34\end{array}$ & $\begin{array}{l}617 \\
435\end{array}$ & $\begin{array}{l}7.7 \\
7.3\end{array}$ & $\begin{array}{l}13 \\
10\end{array}$ & $=$ & $=$ \\
\hline $\begin{array}{l}25 . \cdots \\
\text { NDV. }\end{array}$ & .57 & 230 & 190 & 28 & 386 & 7.5 & 13 & -- & -- \\
\hline $\begin{array}{l}01 \ldots \\
12 \ldots\end{array}$ & $\begin{array}{l}1.0 \\
1.9\end{array}$ & $\begin{array}{l}240 \\
392\end{array}$ & $\begin{array}{l}200 \\
304\end{array}$ & $\begin{array}{l}34 \\
68\end{array}$ & $\begin{array}{l}406 \\
631\end{array}$ & $\begin{array}{l}7.4 \\
7.8\end{array}$ & $\begin{array}{l}13 \\
13\end{array}$ & $=$ & $=$ \\
\hline $\begin{array}{l}14 \ldots . \\
14 \ldots\end{array}$ & $1.3^{--}$ & 354 & $\overline{20}$ & 85 & $\overrightarrow{582}$ & $\overrightarrow{7.4}$ & - & 10.0 & 23 \\
\hline $\begin{array}{l}\text { DEC. } \\
12 \ldots\end{array}$ & 103 & & & 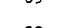 & & & & & \\
\hline $\begin{array}{l}12 \ldots . . \\
19 . .\end{array}$ & .76 & 238 & & 59 & 422 & 7.0 & A & -- & -- \\
\hline $20 \ldots$ & .32 & 306 & 277 & 74 & 531 & $R .2$ & 6 & 11.0 & 92 \\
\hline $29 \ldots$ & .77 & 350 & 332 & 89 & 630 & 7.7 & 1 & -- & - \\
\hline JAN. & & & & & & & & & \\
\hline $\begin{array}{l}12 \ldots \\
15 . .\end{array}$ & $\begin{array}{r}.50 \\
.12\end{array}$ & $\begin{array}{l}418 \\
334\end{array}$ & $\begin{array}{l}374 \\
295\end{array}$ & $\begin{array}{l}82 \\
80\end{array}$ & 730 & 3.0 & 1 & $=$ & - \\
\hline $22 \ldots$ & $\ldots$ & - & $\begin{array}{l}295 \\
---\end{array}$ & 80 & 616 & $\begin{array}{c}8.1 \\
-.-\end{array}$ & -1 & 14.0 & 100 \\
\hline $31 \ldots$ & .64 & 236 & 188 & 60 & 417 & 7.5 & 4 & -- & -- \\
\hline $\begin{array}{l}\text { FER. } \\
\text { O1.... }\end{array}$ & & & & & & & & - & \\
\hline $13 .$. & .54 & 288 & 226 & $\begin{array}{l}38 \\
--\end{array}$ & 445 & $\begin{array}{r}8.3 \\
---\end{array}$ & -- & $10 . \overline{0}$ & 68 \\
\hline $15 \ldots$ & .56 & 426 & 372 & 85 & 678 & 8.1 & 1 & -- & $\ldots$ \\
\hline $28 \ldots$ & .14 & 382 & 265 & 89 & 622 & 8.4 & 1 & -- & -- \\
\hline $\begin{array}{l}\text { MAR. } \\
02 . . .\end{array}$ & .38 & 398 & 342 & 88 & 638 & 8.2 & 1 & -- & $\cdots$ \\
\hline $18 \ldots$ & .22 & 324 & 254 & 74 & 518 & 7.6 & 7 & -- & - \\
\hline $19 \ldots$ & -- & -- & - & -- & $=$ & -- & -- & 12.0 & 103 \\
\hline$\underset{A P R}{22 \ldots}$ & .39 & 240 & 181 & 04 & 350 & 7.3 & 4 & -- & -- \\
\hline $11 \ldots$ & .26 & 334 & 294 & 84 & 591 & 7.8 & 10 & -- & -- \\
\hline $18 \ldots$ & -- & -- & - & - & $\because$ & -- & - & 9.6 & 91 \\
\hline $22 \ldots$ & .34 & 358 & 287 & 67 & $55 \mathrm{~A}$ & 7.5 & 16 & -- & -- \\
\hline$\underset{\text { MAY }}{25} \cdots$ & .43 & 240 & 194 & 48 & 392 & 7.9 & 13 & -- & -- \\
\hline $03 \ldots$ & .19 & 346 & 270 & 73 & $58 C$ & A. 1 & 17 & -- & -- \\
\hline $19 \ldots$ & .37 & 318 & 276 & 74 & 541 & 7.5 & 16 & -- & - \\
\hline $21 \ldots$ & 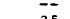 & -- & -- & - & -- & $\cdots$ & 16 & 9.0 & 90 \\
\hline $27 \ldots$ & .25 & 138 & 123 & 23 & 239 & 7.1 & 17 & -- & $\cdots$ \\
\hline JUNE & & & & & & & & & \\
\hline $02 \ldots$ & .32 & 288 & 228 & 54 & 446 & 7.9 & 17 & -- & -- \\
\hline $04 \ldots$ & $=$ & -- & -- & -- & -- & -- & 19 & 7.8 & 83 \\
\hline $14 \ldots$ & .32 & 360 & 298 & 59 & 570 & 7.5 & 21 & $-\infty$ & 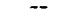 \\
\hline $30 \ldots$ & .44 & 376 & 301 & 49 & 578 & 7.9 & 22 & -- & - \\
\hline $10 \ldots$ & -- & - & -- & -- & $m$ & -- & -- & 8.4 & $\Delta 9$ \\
\hline $14 \ldots$ & .62 & 348 & 303 & 54 & 590 & 8.4 & 24 & -- & -- \\
\hline $18 \ldots$ & .57 & 326 & 250 & 53 & 491 & B. 5 & 23 & -- & -- \\
\hline $\begin{array}{l}27 \ldots \\
\text { AUG. }\end{array}$ & .60 & 328 & 293 & $6 h$ & 534 & 8.4 & $2^{3}$ & $=$ & $\cdots$ \\
\hline AUG... & .54 & 224 & 196 & 38 & 396 & R. 4 & 23 & -- & -- \\
\hline $15 \ldots$ & .54 & 300 & 264 & 50 & 512 & 8.3 & 22 & -- & -- \\
\hline $26 \ldots$ & -- & -- & -- & -- & - & - & 23 & 8.4 & 96 \\
\hline SEPT. & .18 & 344 & 265 & 45 & 573 & 8.4 & 22 & - & - \\
\hline $\begin{array}{l}09 \ldots \\
24 \ldots\end{array}$ & $\begin{array}{l}.11 \\
.15\end{array}$ & $\begin{array}{l}228 \\
352\end{array}$ & $\begin{array}{l}214 \\
322\end{array}$ & $\begin{array}{l}50 \\
49\end{array}$ & $\begin{array}{l}501 \\
605\end{array}$ & $\begin{array}{l}8.4 \\
7.3\end{array}$ & $\begin{array}{l}24 \\
22\end{array}$ & $=$ & $=$ \\
\hline $25 \ldots$ & -- & - & -- & -- & -- & -- & 21 & 5.0 & 56 \\
\hline $29 \ldots$ & .13 & 332 & 290 & 52 & 559 & 7.6 & 18 & -- & -- \\
\hline
\end{tabular}


03234000 PAINT CREEK NEAR BOURNEVILLE, OHIO--Continued

SPECIFIC CONDUCTANCE (MICROMHOS AT 25\% ), WATER YEAR OCTOBER 1967 TO SEPTEMBER 1968 ONCE-DAILY MEASUREMENT BETWEEN 0700 AND 0900)

DAY OCTOBER NOVEMBER DECEMBER JANUARY FEBRUARY MARCH APRIL MAY JUNE JULY AJGUST SEPTEMBER

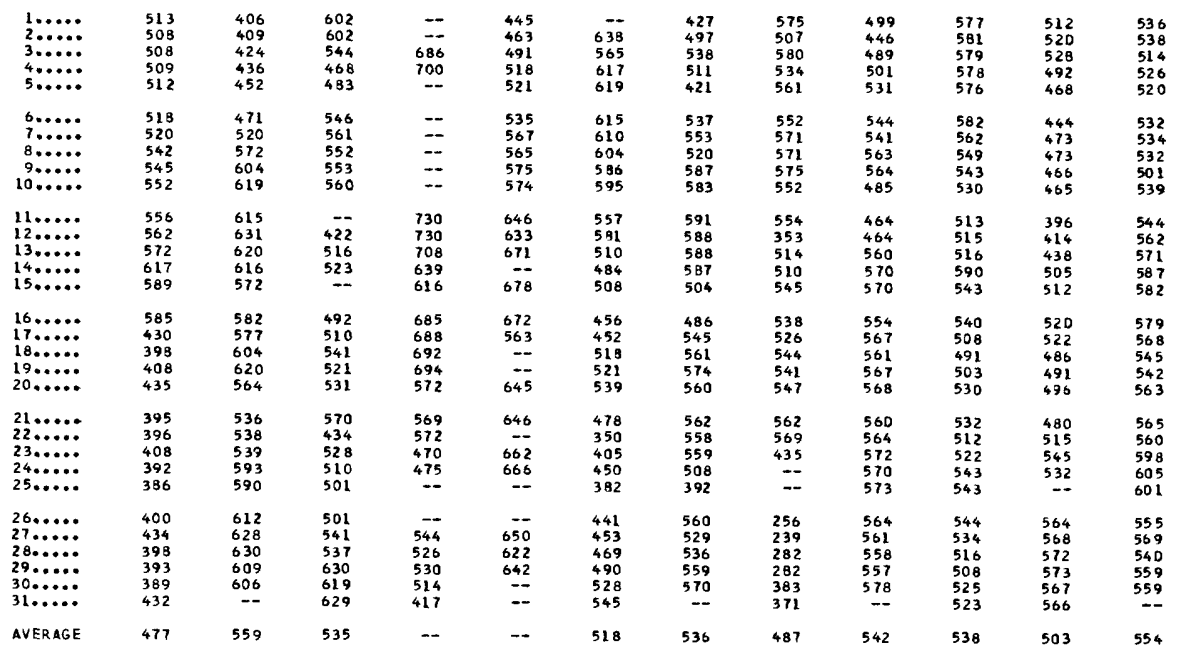

TEMPERATURE $1{ }^{\circ} \mathrm{C}$ ) OF WATER, WATER YEAR OCTOBER 1967 TO SEPTEMBER 1968 ( ${ }^{\circ}$ ) OF WATER, WATER YEAR OCTOBER 1967 TO SEPTEMB
(ONCE-DAILY MEASUREMENT BETWEEN O700 AND O800)

\begin{tabular}{|c|c|c|c|c|c|c|c|c|c|c|c|c|}
\hline AY & UCT & NOV & DEC & JAN & FEB & NAR & $\triangle P R$ & MAY & JUN & JUL & $A \cup G$ & SEP \\
\hline 1 & 12.0 & 13.0 & 3.0 & $\cdots$ & 4.0 & -- & 14.0 & 17.0 & 17.0 & 23.0 & 23.0 & 24.0 \\
\hline 2 & 14.0 & 13.0 & 4.0 & $\cdots$ & 7.0 & 1.0 & 9.0 & 15.0 & 17.0 & 24.0 & 23.0 & $24 . C$ \\
\hline 1 & 16.0 & 12.0 & 3.0 & 1.0 & 5.0 & 1.0 & 11.0 & 17.0 & $1 R \cdot 0$ & 22.0 & 23.0 & 25.0 \\
\hline 4 & 10.0 & 10.0 & 3.0 & 1.0 & 3.0 & 1.0 & 12.0 & 16.0 & 18.0 & 21.0 & 23.0 & 24.0 \\
\hline 5 & 15.0 & 7.0 & 3.0 & --- & 3.0 & 1.0 & 11.0 & 16.0 & 18.0 & 21.0 & 23.0 & 24.0 \\
\hline 6 & 18.0 & 7.0 & 4.0 & -- & 2.0 & 4.0 & 10.0 & 13.0 & 19.0 & 21.0 & 23.0 & $25 . c$ \\
\hline 7 & 14.0 & 7.0 & 7.0 & $\cdots$ & 3.0 & 2.0 & 9.0 & 13.0 & 21.0 & 21.0 & 23.0 & 24.0 \\
\hline$B$ & 14.0 & 7.0 & 7.0 & $\cdots$ & 3.0 & 3.0 & 11.0 & 14.0 & 19.0 & 21.0 & 23.0 & 25.0 \\
\hline 9 & 15.0 & 7.0 & 4.0 & $\cdots$ & 3.0 & 4. C & 13.0 & 17.0 & 21.0 & 21.0 & 26.0 & 24.0 \\
\hline 10 & 15.0 & 7.0 & 7.0 & --- & 1.0 & 8.0 & 12.0 & 16.0 & 22.0 & 21.0 & 24.0 & 24.0 \\
\hline 11 & 14.0 & 7.0 & -- & 1.0 & 1.0 & 4.0 & 10.0 & 14.0 & 22.0 & 21.0 & 23.0 & 22.0 \\
\hline 12 & 13.0 & 13.0 & R.O & 1.0 & 1.0 & 7.0 & 14.0 & 16.0 & 22.0 & 23.0 & 21.0 & 20.0 \\
\hline 13 & 13.0 & 7.0 & 7.0 & 1.0 & 1.0 & 3.0 & 16.0 & 16.0 & 21.0 & 22.0 & 22.0 & 20.0 \\
\hline 14 & 13.0 & 7.0 & 7.0 & 1.0 & -- & 2.0 & 15.0 & 17.0 & 21.0 & 24.0 & 22.0 & 20.0 \\
\hline 15 & 14.0 & 7.0 & -- & 1.0 & 1.0 & 2.0 & 13.0 & 17.0 & 20.0 & 23.0 & 22.0 & 22.0 \\
\hline 16 & 16.0 & 6.0 & 6.0 & 1.0 & 1.0 & 7.0 & 12.0 & 17.0 & 21.0 & 23.0 & 22.0 & 20.0 \\
\hline 17 & 16.0 & 7.0 & 3.0 & 1.0 & 1.0 & 7.0 & 15.0 & 17.0 & 20.0 & 23.0 & 22.0 & 20.0 \\
\hline 19 & 16.0 & 7.0 & 7.0 & 2.0 & $\cdots$ & 7.0 & 13.0 & 17.0 & 20.0 & 23.0 & 23.0 & 20.0 \\
\hline 19 & 13.0 & 4.0 & 4.0 & 4.0 & $\cdots$ & 7.0 & 15.0 & 16.0 & 21.0 & 24.0 & 23.0 & 20.0 \\
\hline 20 & 10.0 & 5.0 & 6.0 & 1.0 & 1.0 & 9.0 & 16.0 & 14.0 & 20.0 & 24.0 & 23.0 & 20.0 \\
\hline 21 & 13.0 & 7.0 & B. 0 & 2.0 & 1.0 & 0.0 & $1 \mathrm{~h} .0$ & 14.0 & 20.0 & 24.0 & 23.0 & 20.0 \\
\hline 22 & 13.0 & 7.0 & 7.0 & 3.0 & $\cdots$ & 4.0 & 16.0 & 14.0 & 20.0 & 24.0 & 23.0 & 22.0 \\
\hline 23 & 12.0 & 6.0 & 3.0 & 2.0 & 1.0 & 3.0 & 16.0 & 14.0 & 21.0 & 24.0 & 23.0 & 22.0 \\
\hline 24 & 13.0 & 4.0 & 3.0 & 2.0 & 1.0 & 3.0 & 15.0 & --- & 22.0 & 24.0 & 23.0 & 22.0 \\
\hline 25 & 13.0 & 7.3 & 3.0 & -- & -- & $4 . c$ & 13.0 & -- & 23.0 & 24.0 & 22.0 & 22.0 \\
\hline 26 & 13.0 & 7.0 & 1.0 & $\cdots$ & --- & 7.0 & 11.0 & $1 d .0$ & 23.0 & 24.0 & 22.0 & 20.0 \\
\hline 27 & ii. 0 & 7.0 & 1.0 & 1.0 & 1.0 & 9.0 & 12.0 & 17.0 & 22.0 & 23.0 & 21.0 & 19.0 \\
\hline 28 & 11.0 & 4.0 & 1.0 & 2.0 & 1.0 & 10.0 & 12.0 & 16.0 & 19.0 & 23.0 & 21.0 & 19.6 \\
\hline 29 & 10.0 & $x .0$ & 1.0 & $3 . C$ & 1.0 & 12.0 & 11.0 & 16.0 & 20.0 & 23.0 & 22.0 & 18.0 \\
\hline 30 & $10 . n$ & 3.0 & 1.0 & 4.0 & -- & 21.0 & 14.0 & 16.0 & 22.0 & 23.0 & 20.0 & 17.0 \\
\hline 31 & 12.0 & -- & 1.0 & 4.0 & --- & 14.0 & $m$ & 16.0 & -- & 23.0 & 21.0 & $\cdots$ \\
\hline $\mathrm{TH}$ & 13.5 & 7.0 & 4.0 & --- & 2.0 & 6.0 & 13.0 & 15.5 & 20.5 & 22.5 & 22.5 & 21.5 \\
\hline
\end{tabular}


03234500 SCIOTO RIVER AT HIGBY, OHIO

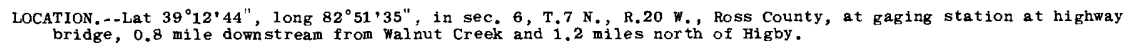

DRAINAGE AREA. - - 5,131 sq mi.

PERIOD OF RECORD.--Chemical analyses: March 1967 to September 1968.

Water temperatures: October 1953 to September 1968.
Sediment records: October 1953 to September 1968 .

EXTREMES, - -1967-68:

Sediment concentrations: Maximum daily, 2,020 mg/1 May 24; minimum daily, $8 \mathrm{mg} / 1$ Nov, 6 .

Sediment loads: Maximum daily, 294,000 tons May 25; minimum daily, 19 tons oct. 14.

period of record:

Water temperatures: Maximum, $34.0^{\circ} \mathrm{C}$ June 29,1966 ; minimum, freezing point on many days during winter periods.

dment concentrations: Maximum daily, 2,130 mg/1 July 21, 1954; minimum dally, $1 \mathrm{mg} / 1$ on several days

Sediment loads: Maximum daily, 550,000 tons Jan. 23, 1959; minimum daily, 0.82 ton Sept. 8, 1955 (revised).

REMARKS.--In addition to the continuous recorder, twice-weekly samples were collected by a local observer.

partial analyses were made on maximum and minimum specific conductance of samples collected each month.

Interruptions in the record were due to malfunctions of the instrument. Flow slightly regulated by

O'Shaughnessy, Griggs, Delaware, Hoover, Rocky Fork and Deer Creek Reservoirs. Daily sediment loads were computed by subdi

CHEMICAL ANALYSES IN MILLIGRAMS PER LITER, WATER YEAR OCTOBER 1967 TO SEPTEMBER 1968

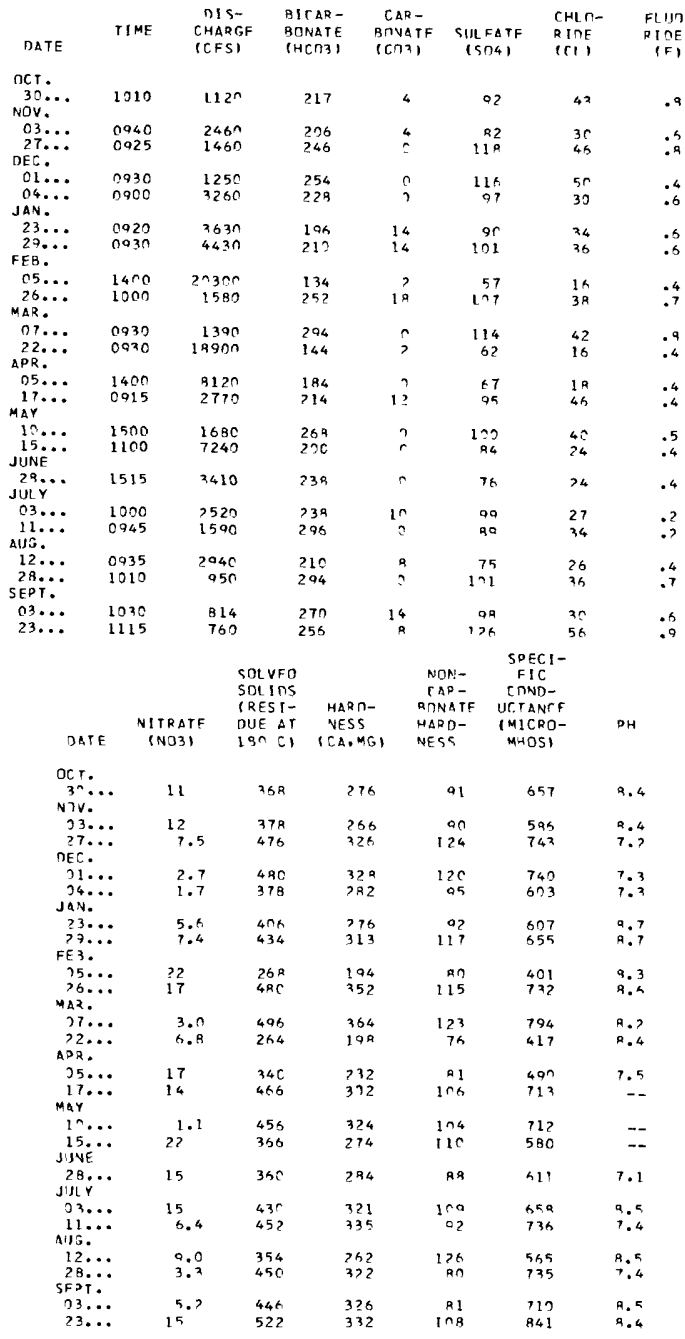


03234500 SCIOTO RIVER AT HIGBY, OHIO--Continued

SPECIFIC CONDUCTANCE, PH, DISSOLVED OXYGEN, AND WATER TEMPERATURES, WATER YEAR OCTOBER 1967 TO SEPTEMBER 1968 OCTOBER

NOVEMBER

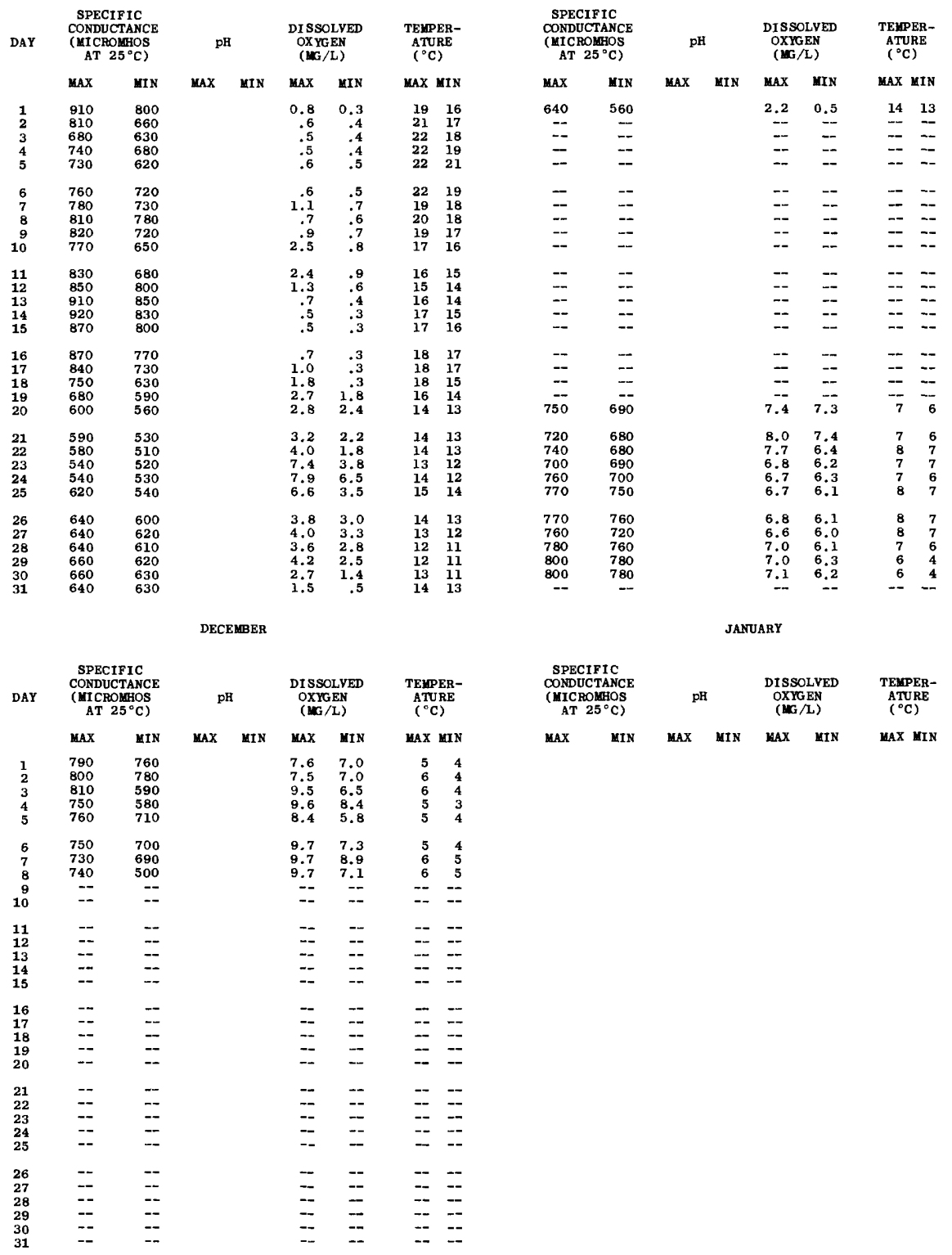


03234500 SCIOTO RIVER AT HIGBY, OHIO--Continued

SPECIFIC CONDUCTANCE, pH, DISSOLVED OXYGEN, AND WATER TEMPERATURES, WATER YEAR OCTOBER 1967 TO SEPTEMBER 1968 FEBRUARY

MARCH

\begin{tabular}{|c|c|c|}
\hline \multirow[t]{2}{*}{ DAY } & \multicolumn{2}{|c|}{$\begin{array}{l}\text { SPECIFIC } \\
\text { CONDUCTANCE } \\
\text { (עICROMOHOS } \\
\text { AT } 25^{\circ} \mathrm{C} \text { ) }\end{array}$} \\
\hline & YAX & uIN \\
\hline 1 & -- & -- \\
\hline 2 & - & - \\
\hline 3 & -- & - \\
\hline 4 & -- & -- \\
\hline 5 & & \\
\hline 6 & -- & - \\
\hline 7 & -- & 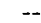 \\
\hline 8 & -- & - \\
\hline 9 & -- & -- \\
\hline 10 & $\cdots$ & - \\
\hline 11 & -- & -- \\
\hline 12 & -- & - \\
\hline 13 & -- & - \\
\hline 14 & 670 & 650 \\
\hline 15 & 690 & 660 \\
\hline 16 & 680 & 660 \\
\hline 17 & 700 & 670 \\
\hline 18 & 710 & 670 \\
\hline 19 & 700 & 680 \\
\hline 20 & 710 & 690 \\
\hline 21 & 710 & 670 \\
\hline 22 & 730 & 670 \\
\hline 23 & 720 & 680 \\
\hline 24 & 720 & 700 \\
\hline 25 & 740 & 700 \\
\hline 26 & 740 & 720 \\
\hline 27 & 720 & 690 \\
\hline 28 & 730 & 720 \\
\hline 29 & 730 & 690 \\
\hline 30 & -- & - \\
\hline 31 & 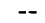 & -- \\
\hline
\end{tabular}

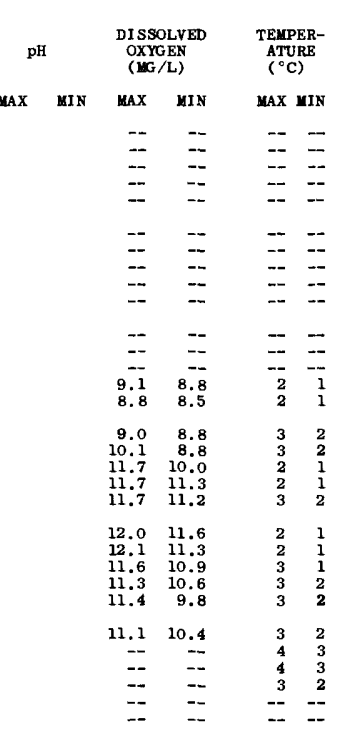

\begin{tabular}{|c|c|}
\hline MAX & MIN \\
\hline $\begin{array}{l}\mathbf{7 3 0} \\
\mathbf{7 4 0} \\
\mathbf{7 8 0} \\
\mathbf{7 8 0} \\
\mathbf{7 9 0}\end{array}$ & $\begin{array}{l}\mathbf{7 2 0} \\
\mathbf{7 1 0} \\
\mathbf{7 4 0} \\
730 \\
\mathbf{7 2 0}\end{array}$ \\
\hline $\begin{array}{l}740 \\
800 \\
770 \\
710 \\
660\end{array}$ & $\begin{array}{l}710 \\
740 \\
710 \\
580 \\
600\end{array}$ \\
\hline $\begin{array}{l}660 \\
690 \\
680 \\
\mathbf{7 5 0} \\
\mathbf{7 2 0}\end{array}$ & $\begin{array}{l}610 \\
500 \\
500 \\
650 \\
680\end{array}$ \\
\hline $\begin{array}{l}740 \\
610 \\
650 \\
690 \\
740\end{array}$ & $\begin{array}{l}520 \\
510 \\
610 \\
610 \\
680\end{array}$ \\
\hline $\begin{array}{l}690 \\
450 \\
470 \\
520 \\
530\end{array}$ & $\begin{array}{l}430 \\
380 \\
380 \\
470 \\
500\end{array}$ \\
\hline $\begin{array}{l}\mathbf{5 4 0} \\
\mathbf{5 5 0} \\
\mathbf{5 3 0} \\
\mathbf{5 5 0} \\
\mathbf{5 3 0} \\
\mathbf{5 0 0}\end{array}$ & $\begin{array}{l}510 \\
510 \\
510 \\
520 \\
490 \\
480\end{array}$ \\
\hline
\end{tabular}

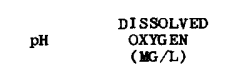

TEMPER-
ATURE

(MG/L) ( $\left.{ }^{\circ} \mathrm{C}\right)$

APRI L

MIN MAX MIN

9.18 .8

$\begin{array}{ll}8.8 & 8.1 \\ 8.6 & 8.0 \\ 9.0 & 8.1\end{array}$

MAX MIN

$\begin{array}{ll}4 & 2 \\ 4 & 3 \\ 4 & 2 \\ 5 & 3 \\ 6 & 4\end{array}$

710

$8.5 \quad 7.9$

$\begin{array}{ll}7.9 & 7.2 \\ 8.1 & 7.3\end{array}$

$\begin{array}{ll}6 & 6 \\ 7 & 5\end{array}$

$\begin{array}{rrrr}8.0 & 6.5 & 8 & 6 \\ 7.6 & 5.7 & 11 & 8\end{array}$

$\begin{array}{llll}8.6 & 6.4 & 11 & 9 \\ 9.5 & 7.6 & 11 & 6\end{array}$

$\begin{array}{rrrr}9.5 & 7.6 & 11 & 6 \\ 10.6 & 9.2 & 6 & 4 \\ 10.6 & 9.3 & 7 & 5 \\ 10.6 & 9.7 & 8 & 6\end{array}$

$9.9 \quad 8.7$

$\begin{array}{rrrr}9.9 & 9.0 & 9 & 6 \\ 9.0 & 8.3 & 10 & 8 \\ 8.8 & 8.0 & 11 & 8\end{array}$

$\begin{array}{llll}6.6 & 12 & 11\end{array}$

$\begin{array}{rrrr}8.3 & 7.0 & 11 & 10 \\ 9.7 & 8.2 & 10 & 6\end{array}$

$\begin{array}{rrrr}10.6 & 9.6 & 6 & 3 \\ 10.6 & 10.1 & 4 & 3 \\ 10.5 & 9.9 & 5 & 3\end{array}$

$\begin{array}{rrrr}11.4 & 9.8 & 3 & 2\end{array}$

$\begin{array}{rrrr}.1 & 10.4 & 3 & 2 \\ -- & -- & 4 & 3 \\ -- & -- & 4 & 3 \\ -- & -- & 3 & 2 \\ -- & -- & -- & -- \\ -- & -- & --\end{array}$

$\begin{array}{rrrr}10.2 & 9.7 & 7 & 5 \\ 9.8 & 9.3 & 8 & 7\end{array}$

$\begin{array}{llll}9.5 & 9.1 & \text { 11 } & 7 \\ 9.1 & 8.6 & \text { 11 } & 9\end{array}$

$\begin{array}{rrrr}9.6 & 8.0 & 11 & 10 \\ 8.0 & 7.6 & 12 & 11\end{array}$

MAY

\begin{tabular}{|c|c|c|c|c|c|c|c|c|c|c|c|c|c|c|c|c|}
\hline \multirow[t]{2}{*}{ DAY } & \multicolumn{2}{|c|}{$\begin{array}{l}\text { SPECIFIC } \\
\text { OONDUCTANCE } \\
\text { (MICROMHOS } \\
\left.\text { AT } 25^{\circ} \mathrm{C}\right)\end{array}$} & \multicolumn{2}{|c|}{ pH } & \multicolumn{2}{|c|}{$\begin{array}{l}\text { DI SSOLVED } \\
\text { OXYGEN } \\
(\text { MG } / L)\end{array}$} & \multicolumn{2}{|c|}{$\begin{array}{l}\text { TEMPER- } \\
\text { ATURE } \\
\left({ }^{\circ} \mathrm{C}\right)\end{array}$} & \multicolumn{2}{|c|}{$\begin{array}{l}\text { SPECIFIC } \\
\text { CONDUCTANCE } \\
\text { (MICRONHOS } \\
\left.\text { AT } 25^{\circ} \mathrm{C}\right)\end{array}$} & \multicolumn{2}{|c|}{ pH } & \multicolumn{2}{|c|}{$\begin{array}{l}\text { DI SSOLVED } \\
\text { OXYGEN } \\
(\text { WG } / L)\end{array}$} & \multicolumn{2}{|c|}{$\begin{array}{c}\text { TEMPER- } \\
\text { ATURE } \\
\left({ }^{\circ} \mathrm{C}\right)\end{array}$} \\
\hline & MAX & UIN & $\max$ & UIN & MAX & MIN & MAX & MIN & MAX & MIN & MAX & MIN & LAX & MIN & $\max$ & MIN \\
\hline $\begin{array}{l}1 \\
2 \\
3 \\
4 \\
5\end{array}$ & $\begin{array}{l}480 \\
540 \\
580 \\
580 \\
560\end{array}$ & $\begin{array}{l}450 \\
470 \\
540 \\
410 \\
420\end{array}$ & $\begin{array}{l}-- \\
-- \\
=- \\
--\end{array}$ & $\begin{array}{l}=- \\
=- \\
=- \\
--\end{array}$ & $\begin{array}{l}8.0 \\
8.1 \\
7.2 \\
8.6 \\
9.3\end{array}$ & $\begin{array}{l}7.6 \\
7.0 \\
6.5 \\
6.3 \\
7.6\end{array}$ & $\begin{array}{l}12 \\
11 \\
11 \\
11 \\
11\end{array}$ & $\begin{array}{l}11 \\
10 \\
11 \\
11 \\
10\end{array}$ & $\begin{array}{c}670 \\
-- \\
-- \\
--\end{array}$ & $\begin{array}{c}660 \\
-- \\
=- \\
-\end{array}$ & $\begin{array}{l}7.7 \\
-- \\
-- \\
--\end{array}$ & $\begin{array}{l}7.7 \\
-- \\
-- \\
--\end{array}$ & $\begin{array}{l}5.2 \\
\overline{--} \\
\overline{--}\end{array}$ & $\begin{array}{l}4.6 \\
=- \\
=- \\
--\end{array}$ & $\begin{array}{l}16 \\
-- \\
=- \\
--\end{array}$ & $\begin{array}{l}16 \\
=- \\
=- \\
--\end{array}$ \\
\hline $\begin{array}{r}6 \\
7 \\
8 \\
9 \\
10\end{array}$ & $\begin{array}{l}640 \\
600 \\
610 \\
640 \\
640\end{array}$ & $\begin{array}{l}\mathbf{5 6 0} \\
580 \\
\mathbf{5 7 0} \\
\mathbf{5 8 0} \\
\mathbf{6 2 0}\end{array}$ & $\begin{array}{l}=- \\
=- \\
=-\end{array}$ & $\begin{array}{l}=- \\
-- \\
--\end{array}$ & $\begin{array}{l}8.6 \\
8.8 \\
8.6 \\
8.6 \\
8.2\end{array}$ & $\begin{array}{l}7.5 \\
8.5 \\
8.1 \\
8.1 \\
7.0\end{array}$ & $\begin{array}{l}11 \\
12 \\
13 \\
13 \\
14\end{array}$ & $\begin{array}{r}9 \\
10 \\
12 \\
12 \\
13\end{array}$ & $\begin{array}{r}-- \\
\overline{--} \\
7 \overrightarrow{710} \\
720\end{array}$ & $\begin{array}{r}-- \\
\overline{--} \\
700 \\
700\end{array}$ & $\begin{array}{r}-- \\
-- \\
7.7 \\
7.7\end{array}$ & $\begin{array}{r}-- \\
\overline{--} \\
7.5 \\
7.4\end{array}$ & $\begin{array}{r}-- \\
\overline{--} \\
3.4 \\
4.6\end{array}$ & $\begin{array}{r}\overline{--} \\
\overline{--} \\
2.9 \\
2.3\end{array}$ & $\begin{array}{l}-- \\
\overline{--} \\
19 \\
19\end{array}$ & $\begin{array}{l}-- \\
\overline{--} \\
18 \\
17\end{array}$ \\
\hline $\begin{array}{l}11 \\
12 \\
13 \\
14 \\
15\end{array}$ & $\begin{array}{l}640 \\
650 \\
670 \\
670 \\
660\end{array}$ & $\begin{array}{l}620 \\
610 \\
630 \\
650 \\
560\end{array}$ & $\begin{array}{l}7 .-8 \\
7.8 \\
7.6 \\
7.7\end{array}$ & $\begin{array}{l}-- \\
7.8 \\
7.5 \\
7.5 \\
7.5\end{array}$ & $\begin{array}{l}7.5 \\
7.3 \\
6.4 \\
6.3 \\
6.8\end{array}$ & $\begin{array}{l}7.0 \\
6.4 \\
5.7 \\
5.4 \\
5.7\end{array}$ & $\begin{array}{l}14 \\
15 \\
16 \\
17 \\
16\end{array}$ & $\begin{array}{l}12 \\
12 \\
14 \\
15 \\
14\end{array}$ & $\begin{array}{l}730 \\
600 \\
620 \\
540 \\
620\end{array}$ & $\begin{array}{l}450 \\
390 \\
490 \\
490 \\
540\end{array}$ & $\begin{array}{l}7.8 \\
7.7 \\
7.8 \\
7.7 \\
7.8\end{array}$ & $\begin{array}{l}7.6 \\
7.6 \\
7.6 \\
7.6 \\
7.6\end{array}$ & $\begin{array}{l}5.3 \\
6.1 \\
6.1 \\
6.5 \\
6.0\end{array}$ & $\begin{array}{l}3.8 \\
5.3 \\
4.0 \\
6.0 \\
5.7\end{array}$ & $\begin{array}{l}19 \\
17 \\
19 \\
19 \\
20\end{array}$ & $\begin{array}{l}16 \\
16 \\
16 \\
16 \\
18\end{array}$ \\
\hline $\begin{array}{l}16 \\
17 \\
18 \\
19 \\
20\end{array}$ & $\begin{array}{l}670 \\
\mathbf{7 1 0} \\
\mathbf{7 2 0} \\
\mathbf{7 2 0} \\
\mathbf{7 1 0}\end{array}$ & $\begin{array}{l}590 \\
660 \\
690 \\
650 \\
650\end{array}$ & $\begin{array}{l}7.7 \\
7.7 \\
7.7 \\
7.7 \\
7.7\end{array}$ & $\begin{array}{l}7.7 \\
7.7 \\
7.6 \\
7.6 \\
7.7\end{array}$ & $\begin{array}{l}6.8 \\
6.7 \\
6.2 \\
8.9 \\
8.2\end{array}$ & $\begin{array}{l}6.2 \\
5.7 \\
5.7 \\
5.5 \\
6.0\end{array}$ & $\begin{array}{l}15 \\
15 \\
16 \\
17 \\
17\end{array}$ & $\begin{array}{l}13 \\
14 \\
14 \\
12 \\
16\end{array}$ & $\begin{array}{l}640 \\
650 \\
640 \\
600 \\
610\end{array}$ & $\begin{array}{l}620 \\
600 \\
560 \\
560 \\
600\end{array}$ & $\begin{array}{l}7.7 \\
7.6 \\
7.6 \\
7.7 \\
7.7\end{array}$ & $\begin{array}{l}7.6 \\
7.4 \\
7.6 \\
7.6 \\
7.6\end{array}$ & $\begin{array}{l}5.7 \\
5.3 \\
5.2 \\
5.6 \\
5.9\end{array}$ & $\begin{array}{l}4.8 \\
4.4 \\
4.7 \\
5.2 \\
5.3\end{array}$ & $\begin{array}{l}22 \\
21 \\
21 \\
19 \\
18\end{array}$ & $\begin{array}{l}20 \\
20 \\
19 \\
18 \\
17\end{array}$ \\
\hline $\begin{array}{l}21 \\
22 \\
23 \\
24 \\
25\end{array}$ & $\begin{array}{l}690 \\
690 \\
650 \\
600 \\
610\end{array}$ & $\begin{array}{l}650 \\
660 \\
400 \\
\mathbf{4 5 0} \\
\mathbf{5 4 0}\end{array}$ & $\begin{array}{l}7.7 \\
7.7 \\
7.7 \\
7.8 \\
7.7\end{array}$ & $\begin{array}{l}7.6 \\
7.6 \\
7.7 \\
7.7 \\
7.7\end{array}$ & $\begin{array}{l}7.9 \\
9.1 \\
7.6 \\
7.3 \\
7.3\end{array}$ & $\begin{array}{l}5.7 \\
6.2 \\
5.5 \\
4.9 \\
5.2\end{array}$ & $\begin{array}{l}19 \\
20 \\
19 \\
17 \\
15\end{array}$ & $\begin{array}{l}16 \\
17 \\
16 \\
15 \\
13\end{array}$ & $\begin{array}{c}630 \\
670 \\
670 \\
-- \\
--\end{array}$ & $\begin{array}{r}610 \\
630 \\
640 \\
-- \\
-\end{array}$ & $\begin{array}{r}7.6 \\
7.6 \\
7.6 \\
-- \\
-\end{array}$ & $\begin{array}{r}7.5 \\
7.5 \\
7.6 \\
-- \\
--\end{array}$ & $\begin{array}{r}6.0 \\
6.5 \\
5.5 \\
-- \\
--\end{array}$ & $\begin{array}{r}5.1 \\
5.3 \\
5.1 \\
-- \\
--\end{array}$ & $\begin{array}{l}18 \\
19 \\
19 \\
-- \\
--\end{array}$ & $\begin{array}{l}17 \\
17 \\
17 \\
-- \\
--\end{array}$ \\
\hline $\begin{array}{l}26 \\
27 \\
28 \\
29 \\
30 \\
31\end{array}$ & $\begin{array}{r}600 \\
640 \\
650 \\
660 \\
670 \\
--\end{array}$ & $\begin{array}{r}540 \\
590 \\
620 \\
640 \\
640 \\
--\end{array}$ & $\begin{array}{r}7.7 \\
7.7 \\
7.7 \\
7.7 \\
7.7 \\
-.\end{array}$ & $\begin{array}{r}7.7 \\
7.7 \\
7.7 \\
7.7 \\
7.7 \\
--\end{array}$ & $\begin{array}{l}7.2 \\
7.3 \\
6.8 \\
6.3 \\
6.3 \\
--.\end{array}$ & $\begin{array}{l}5.8 \\
5.9 \\
6.0 \\
5.2 \\
4.8 \\
--\end{array}$ & $\begin{array}{l}14 \\
15 \\
16 \\
17 \\
17 \\
-\end{array}$ & $\begin{array}{l}13 \\
13 \\
14 \\
14 \\
15 \\
-\end{array}$ & $\begin{array}{l}= \\
= \\
= \\
=\end{array}$ & $\begin{array}{l}= \\
= \\
= \\
=\end{array}$ & $\begin{array}{l}= \\
= \\
= \\
=\end{array}$ & $\begin{array}{l}= \\
=- \\
=- \\
=\end{array}$ & $\begin{array}{l}\overline{-} \\
\bar{z} \\
\overline{-} \\
\overline{-}\end{array}$ & $\begin{array}{l}=- \\
=- \\
=- \\
=-\end{array}$ & $\begin{array}{l}-- \\
-- \\
-- \\
--\end{array}$ & $\begin{array}{l}= \\
= \\
= \\
=\end{array}$ \\
\hline
\end{tabular}


03234500 SCIOTO RIVER AT HIGBY, OHIO--Cont1nued

SPECIF IC CONDUCTANCE, PH, DISSOLVED OXYGEN, AND WATER TEMPERATURES, WATER YEAR OCTOBER 1967 TO SEPTEIBER 1968 JUNE

JULY

\begin{tabular}{|c|c|c|c|c|c|c|c|c|c|c|c|c|c|c|c|c|}
\hline \multirow[t]{2}{*}{ DAY } & \multicolumn{2}{|c|}{$\begin{array}{l}\text { SPECIFIC } \\
\text { CONDUCTANCE } \\
\text { (MICROMHOS } \\
\text { AT } 25^{\circ} \mathrm{C} \text { ) }\end{array}$} & \multicolumn{2}{|c|}{$\mathrm{pH}$} & \multicolumn{2}{|c|}{$\begin{array}{l}\text { DI SSOLVED } \\
\text { OXYGEN } \\
(\mathbf{H G} / L)\end{array}$} & \multicolumn{2}{|c|}{$\begin{array}{l}\text { TEMPER- } \\
\text { ATURE } \\
\left({ }^{\circ} \mathrm{C}\right)\end{array}$} & \multicolumn{2}{|c|}{$\begin{array}{l}\text { SPECIFIC } \\
\text { CONDUCTANCE } \\
\text { (MICROMHOS } \\
\text { AT } 25^{\circ} \mathrm{C} \text { ) }\end{array}$} & \multicolumn{2}{|c|}{ pH } & \multicolumn{2}{|c|}{$\begin{array}{l}\text { DISSOLVED } \\
\text { OXYG EN } \\
(\mathbf{H G} / \mathrm{L})\end{array}$} & \multicolumn{2}{|c|}{$\begin{array}{l}\text { TEKPER- } \\
\text { ATURE } \\
\left({ }^{\circ} \mathrm{C}\right)\end{array}$} \\
\hline & MAX & UIN & MAX & MIN & $\operatorname{MAX}$ & MIN & MAX & MIN & MAX & MIN & MAX & MIN & $\operatorname{lax}$ & MIN & yax & MIN \\
\hline $\begin{array}{l}1 \\
2 \\
3 \\
4 \\
5\end{array}$ & $\begin{array}{l}=- \\
=- \\
=\end{array}$ & $\begin{array}{l}\overline{-} \\
\bar{z} \\
\overline{-}\end{array}$ & & & $\begin{array}{l}= \\
\overline{--} \\
--\end{array}$ & $=$ & $\begin{array}{l}=- \\
=- \\
=-\end{array}$ & $\begin{array}{l}= \\
\overline{-} \\
=- \\
--\end{array}$ & $\begin{array}{l}730 \\
730 \\
730 \\
700 \\
700\end{array}$ & $\begin{array}{l}620 \\
540 \\
650 \\
610 \\
630\end{array}$ & & & $\begin{array}{r}4.1 \\
4.6 \\
5.0 \\
8.4 \\
12.0\end{array}$ & $\begin{array}{l}3.3 \\
3.1 \\
3.5 \\
4.7 \\
7.6\end{array}$ & $\begin{array}{l}27 \\
27 \\
26 \\
24 \\
24\end{array}$ & $\begin{array}{l}24 \\
25 \\
24 \\
23 \\
22\end{array}$ \\
\hline $\begin{array}{l}11 \\
12 \\
13 \\
14 \\
15\end{array}$ & $\begin{array}{l}-- \\
\overline{--} \\
= \\
-\end{array}$ & $\begin{array}{l}= \\
\bar{z} \\
=\end{array}$ & & & $\begin{array}{l}-- \\
-- \\
--\end{array}$ & $\begin{array}{l}\ddot{-} \\
\ddot{--} \\
--\end{array}$ & $\begin{array}{l}=- \\
\overline{--} \\
\overline{--}\end{array}$ & $\begin{array}{l}-- \\
\overline{--} \\
--\end{array}$ & $\begin{array}{l}740 \\
800 \\
820 \\
770 \\
690\end{array}$ & $\begin{array}{l}670 \\
670 \\
770 \\
690 \\
660\end{array}$ & & & $\begin{array}{l}1.7 \\
2.8 \\
3.1 \\
3.8 \\
5.3\end{array}$ & $\begin{array}{l}1.3 \\
1.3 \\
2.1 \\
1.4 \\
2.7\end{array}$ & $\begin{array}{l}27 \\
27 \\
27 \\
27 \\
27\end{array}$ & $\begin{array}{l}25 \\
26 \\
26 \\
26 \\
25\end{array}$ \\
\hline $\begin{array}{l}21 \\
22 \\
23 \\
24 \\
25\end{array}$ & $\begin{array}{l}-- \\
\overline{--} \\
--\end{array}$ & $\begin{array}{l}\overline{-} \\
\overline{--} \\
\overline{-}\end{array}$ & & & $\begin{array}{l}-- \\
-- \\
=- \\
--\end{array}$ & $\begin{array}{l}\overline{-} \\
\overline{--} \\
--\end{array}$ & $\begin{array}{l}=- \\
=- \\
--\end{array}$ & $\begin{array}{l}-- \\
=- \\
=- \\
=\end{array}$ & $\begin{array}{r}740 \\
700 \\
-- \\
--\end{array}$ & $\begin{array}{r}700 \\
650 \\
-- \\
- \\
-\end{array}$ & & & $\begin{array}{r}2.6 \\
2.8 \\
-- \\
--\end{array}$ & $\begin{array}{r}1.3 \\
1.2 \\
-= \\
-\end{array}$ & $\begin{array}{l}29 \\
29 \\
-- \\
--\end{array}$ & $\begin{array}{l}27 \\
25 \\
-- \\
--\end{array}$ \\
\hline $\begin{array}{l}26 \\
27 \\
28 \\
29 \\
30 \\
31\end{array}$ & $\begin{array}{r}-- \\
670 \\
690 \\
740 \\
--\end{array}$ & $\begin{array}{l}-\square \\
610 \\
670 \\
680 \\
-\end{array}$ & & & $\begin{array}{r}-- \\
4.4 \\
4.7 \\
3.9 \\
--\end{array}$ & $\begin{array}{l}-- \\
3.9 \\
3.3 \\
2.7 \\
-2\end{array}$ & $\begin{array}{l}-- \\
-- \\
22 \\
28 \\
--\end{array}$ & $\begin{array}{l}-- \\
\overline{21} \\
21 \\
23 \\
--\end{array}$ & $\begin{array}{l}=- \\
=- \\
\overline{-} \\
=\end{array}$ & $\begin{array}{l}\bar{z} \\
\bar{z} \\
\bar{z}\end{array}$ & & & $\begin{array}{l}=- \\
=- \\
=- \\
=-\end{array}$ & $\begin{array}{l}=- \\
\overline{-} \\
=- \\
-=\end{array}$ & $\begin{array}{l}=- \\
=- \\
=- \\
=\end{array}$ & $\begin{array}{l}\bar{z} \\
\bar{z} \\
\bar{z} \\
\bar{z}\end{array}$ \\
\hline \multicolumn{9}{|c|}{ AUGUST } & \multicolumn{8}{|c|}{ SEPTEMBER } \\
\hline \multirow[t]{2}{*}{ DAY } & \multicolumn{2}{|c|}{$\begin{array}{l}\text { SPECIFIC } \\
\text { CONDUCTANCE } \\
\text { ( HICROMHOS } \\
\text { AT } 25^{\circ} \mathrm{C} \text { ) }\end{array}$} & \multicolumn{2}{|c|}{$\mathrm{pH}$} & \multicolumn{2}{|c|}{$\begin{array}{l}\text { DI SSOLVED } \\
\text { OXYG EN } \\
(\mathbf{H G} / \mathrm{L})\end{array}$} & \multicolumn{2}{|c|}{$\begin{array}{l}\text { TEMPER- } \\
\text { ATURE } \\
\left({ }^{\circ} \mathrm{C}\right)\end{array}$} & \multicolumn{2}{|c|}{$\begin{array}{l}\text { SPECIFIC } \\
\text { CONDUCTANCE } \\
\text { (MICROMHOS } \\
\left.\text { AT } 25^{\circ} \mathrm{C}\right)\end{array}$} & \multicolumn{2}{|c|}{ pH } & \multicolumn{2}{|c|}{$\begin{array}{l}\text { DISSOLVED } \\
\text { OXYGEN } \\
\text { (UG/L) }\end{array}$} & \multicolumn{2}{|c|}{$\begin{array}{l}\text { TEIPER } \\
\text { ATURE } \\
\left({ }^{\circ} \mathrm{C}\right)\end{array}$} \\
\hline & MAX & MIN & $\operatorname{MAX}$ & MIN & MAX & MIN & $\operatorname{MAX}$ & MIN & $\operatorname{MAX}$ & MIN & MAX & MIN & $\operatorname{MAX}$ & MIN & MAX & MIN \\
\hline $\begin{array}{l}1 \\
2 \\
3 \\
4 \\
5\end{array}$ & $\begin{array}{l}=- \\
=- \\
=\end{array}$ & $\begin{array}{l}= \\
=- \\
=\end{array}$ & & & $\begin{array}{l}=- \\
=- \\
=-\end{array}$ & $\begin{array}{l}=- \\
=- \\
=-\end{array}$ & $\begin{array}{l}= \\
=- \\
= \\
--\end{array}$ & $\begin{array}{l}- \\
= \\
-- \\
--\end{array}$ & $\begin{array}{l}700 \\
700 \\
710 \\
710 \\
780\end{array}$ & $\begin{array}{l}680 \\
650 \\
620 \\
600 \\
710\end{array}$ & & & $\begin{array}{r}9.7 \\
11.0 \\
13.0 \\
12.0 \\
5.5\end{array}$ & $\begin{array}{l}5.6 \\
5.6 \\
5.3 \\
5.5 \\
2.1\end{array}$ & $\begin{array}{l}24 \\
24 \\
24 \\
24 \\
24\end{array}$ & $\begin{array}{l}23 \\
22 \\
22 \\
23 \\
23\end{array}$ \\
\hline $\begin{array}{r}6 \\
7 \\
8 \\
9 \\
10\end{array}$ & $\begin{array}{l}-- \\
\overline{--} \\
--\end{array}$ & $\begin{array}{l}-- \\
=- \\
=\end{array}$ & & & $\begin{array}{l}=- \\
=- \\
=-\end{array}$ & $\begin{array}{l}=- \\
=- \\
=\end{array}$ & $\begin{array}{l}= \\
\ddot{-} \\
=\end{array}$ & $\begin{array}{l}-- \\
-- \\
--\end{array}$ & $\begin{array}{l}790 \\
780 \\
790 \\
780 \\
770\end{array}$ & $\begin{array}{l}\mathbf{7 5 0} \\
740 \\
760 \\
760 \\
\mathbf{7 2 0}\end{array}$ & & & $\begin{array}{r}6.9 \\
6.5 \\
2.3 \\
.6 \\
4.5\end{array}$ & $\begin{array}{l}.7 \\
.8 \\
.0 \\
.0 \\
.0\end{array}$ & $\begin{array}{l}24 \\
23 \\
24 \\
24 \\
23\end{array}$ & $\begin{array}{l}22 \\
22 \\
23 \\
23 \\
22\end{array}$ \\
\hline $\begin{array}{l}11 \\
12 \\
13 \\
14 \\
15\end{array}$ & $\begin{array}{l}=- \\
=- \\
z- \\
z-\end{array}$ & $\begin{array}{l}= \\
=- \\
=\end{array}$ & & & $\begin{array}{l}=- \\
=- \\
=-\end{array}$ & $\begin{array}{l}=- \\
=- \\
=-\end{array}$ & $\begin{array}{l}=- \\
=- \\
=-\end{array}$ & $\begin{array}{l}-- \\
=- \\
-- \\
--\end{array}$ & $\begin{array}{l}790 \\
800 \\
800 \\
850 \\
820\end{array}$ & $\begin{array}{l}730 \\
780 \\
780 \\
800 \\
800\end{array}$ & & & $\begin{array}{r}.6 \\
1.5 \\
5.5 \\
6.4 \\
1.7\end{array}$ & $\begin{array}{l}.0 \\
.0 \\
.0 \\
.2 \\
.0\end{array}$ & $\begin{array}{l}23 \\
23 \\
22 \\
23 \\
23\end{array}$ & $\begin{array}{l}21 \\
20 \\
21 \\
21 \\
22\end{array}$ \\
\hline $\begin{array}{l}16 \\
17 \\
18 \\
19 \\
20\end{array}$ & $\begin{array}{c}-- \\
\overline{-} \\
\overline{-} \\
90\end{array}$ & $\begin{array}{l}-- \\
\overline{-} \\
670\end{array}$ & & & $\overline{-}$ & $\begin{array}{l}z \\
\overline{-} \\
\overline{0 . \overline{7}}\end{array}$ & $\begin{array}{l}-- \\
-- \\
29\end{array}$ & $\begin{array}{l}-- \\
=- \\
=- \\
28\end{array}$ & $\begin{array}{l}810 \\
840 \\
840 \\
830 \\
820\end{array}$ & $\begin{array}{l}800 \\
790 \\
830 \\
\mathbf{8 0 0} \\
\mathbf{8 0 0}\end{array}$ & & & $\begin{array}{l}1.6 \\
3.3 \\
1.7 \\
3.2 \\
3.4\end{array}$ & $\begin{array}{l}1.1 \\
1.2 \\
1.5 \\
1.6 \\
1.6\end{array}$ & $\begin{array}{l}23 \\
23 \\
22 \\
21 \\
22\end{array}$ & $\begin{array}{l}22 \\
22 \\
21 \\
20 \\
20\end{array}$ \\
\hline $\begin{array}{l}21 \\
22 \\
23 \\
24 \\
25\end{array}$ & $\begin{array}{l}710 \\
730 \\
740 \\
740 \\
750\end{array}$ & $\begin{array}{l}670 \\
680 \\
700 \\
710 \\
720\end{array}$ & & & $\begin{array}{l}4.1 \\
4.0 \\
6.5 \\
2.3 \\
4.2\end{array}$ & $\begin{array}{l}.5 \\
.7 \\
.5 \\
.7 \\
.6\end{array}$ & $\begin{array}{l}29 \\
29 \\
29 \\
29 \\
29\end{array}$ & $\begin{array}{l}28 \\
28 \\
28 \\
28 \\
28\end{array}$ & $\begin{array}{l}800 \\
840 \\
860 \\
880 \\
880\end{array}$ & $\begin{array}{l}760 \\
780 \\
840 \\
860 \\
840\end{array}$ & & & $\begin{array}{l}5.0 \\
1.9 \\
2.6 \\
3.2 \\
1.6\end{array}$ & $\begin{array}{r}1.4 \\
1.2 \\
.7 \\
1.2 \\
.9\end{array}$ & $\begin{array}{l}24 \\
25 \\
26 \\
26 \\
26\end{array}$ & $\begin{array}{l}22 \\
23 \\
24 \\
25 \\
24\end{array}$ \\
\hline $\begin{array}{l}26 \\
27 \\
28 \\
29 \\
30 \\
31\end{array}$ & $\begin{array}{l}\mathbf{7 6 0} \\
770 \\
750 \\
770 \\
770 \\
760\end{array}$ & $\begin{array}{l}710 \\
750 \\
720 \\
730 \\
730 \\
680\end{array}$ & & & $\begin{array}{r}3.4 \\
2.1 \\
3.6 \\
5.1 \\
9.7 \\
11.0\end{array}$ & $\begin{array}{r}.5 \\
.7 \\
.8 \\
.6 \\
2.6 \\
4.7\end{array}$ & $\begin{array}{l}28 \\
25 \\
24 \\
24 \\
24 \\
24\end{array}$ & $\begin{array}{l}25 \\
23 \\
22 \\
22 \\
22 \\
23\end{array}$ & $\begin{array}{r}840 \\
810 \\
840 \\
840 \\
830 \\
--\end{array}$ & $\begin{array}{r}\mathbf{7 4 0} \\
\mathbf{7 5 0} \\
\mathbf{8 1 0} \\
\mathbf{8 3 0} \\
\mathbf{7 9 0} \\
---\end{array}$ & & & $\begin{array}{l}5.0 \\
2.9 \\
1.1 \\
2.1 \\
2.2 \\
--\end{array}$ & $\begin{array}{r}1.0 \\
.9 \\
.9 \\
.9 \\
.6 \\
-.\end{array}$ & $\begin{array}{l}24 \\
23 \\
23 \\
22 \\
22 \\
--\end{array}$ & $\begin{array}{l}22 \\
22 \\
21 \\
21 \\
21 \\
-2\end{array}$ \\
\hline
\end{tabular}


SCIOTO RIVER BASIN

03234500 SCIOTO RIVER HIGBY, OHIO--Continued

SUSPENDEC SEOIMENT, WATER YEAR OCTOBER 1967 TO SEPTEMBER 1968

\begin{tabular}{|c|c|c|c|c|c|c|c|c|c|}
\hline & & OCTOBER & & & NOVEMBER & & & DCCEMBER & \\
\hline DAY & $\begin{array}{l}\text { MEAN } \\
\text { DISCHARGE } \\
\text { (CFS I }\end{array}$ & $\begin{array}{l}\text { MEAN } \\
\text { CONCEN- } \\
\text { TRATION } \\
\text { IMG/LI }\end{array}$ & $\begin{array}{l}\text { LOAD } \\
\text { (FONS) }\end{array}$ & $\begin{array}{l}\text { MEAN } \\
\text { OISCHARGE } \\
\text { (CFS) }\end{array}$ & $\begin{array}{l}\text { MEAN } \\
\text { CONCEN- } \\
\text { TRATION } \\
\text { IMG/LI }\end{array}$ & $\begin{array}{l}\text { LOAD } \\
\text { (TONS) }\end{array}$ & $\begin{array}{l}\text { MEAN } \\
\text { OISCHARGE } \\
\text { (CFS) }\end{array}$ & $\begin{array}{l}\text { MEAN } \\
\text { CUNCEN- } \\
\text { TRATIUN } \\
\text { (MG/L) }\end{array}$ & $\begin{array}{l}\text { LDAD } \\
\text { ITUNSI }\end{array}$ \\
\hline $\begin{array}{l}1 \\
2 \\
3 \\
4 \\
5\end{array}$ & $\begin{array}{r}1150 \\
841 \\
706 \\
643 \\
607\end{array}$ & $\begin{array}{l}20 \\
18 \\
18 \\
18 \\
18\end{array}$ & $\begin{array}{l}62 \\
41 \\
34 \\
31 \\
30\end{array}$ & $\begin{array}{l}1170 \\
1690 \\
2490 \\
2280 \\
1850\end{array}$ & $\begin{array}{r}21 \\
81 \\
211 \\
104 \\
22\end{array}$ & $\begin{array}{r}66 \\
404 \\
1420 \\
640 \\
110\end{array}$ & $\begin{array}{l}1240 \\
1270 \\
2010 \\
3370 \\
5770\end{array}$ & $\begin{array}{r}11 \\
46 \\
53 \\
78 \\
554\end{array}$ & $\begin{array}{l}57 \\
156 \\
288 \\
710 \\
0030\end{array}$ \\
\hline $\begin{array}{r}6 \\
7 \\
8 \\
9 \\
10\end{array}$ & $\begin{array}{l}634 \\
652 \\
661 \\
625 \\
661\end{array}$ & $\begin{array}{l}18 \\
19 \\
18 \\
15 \\
13\end{array}$ & $\begin{array}{l}31 \\
33 \\
32 \\
25 \\
23\end{array}$ & $\begin{array}{l}1480 \\
1260 \\
1476 \\
1380 \\
1190\end{array}$ & $\begin{array}{l}83 \\
13 \\
18 \\
20 \\
12\end{array}$ & $\begin{array}{l}32 \\
44 \\
71 \\
75 \\
39\end{array}$ & $\begin{array}{l}7480 \\
7320 \\
7890 \\
7800 \\
6700\end{array}$ & $\begin{array}{r}253 \\
130 \\
128 \\
82 \\
82\end{array}$ & $\begin{array}{l}5120 \\
2576 \\
2730 \\
1730 \\
1480\end{array}$ \\
\hline $\begin{array}{l}11 \\
12 \\
13 \\
14 \\
15\end{array}$ & $\begin{array}{l}706 \\
652 \\
607 \\
589 \\
571\end{array}$ & $\begin{array}{l}13 \\
12 \\
12 \\
12 \\
13\end{array}$ & $\begin{array}{l}25 \\
21 \\
25 \\
19 \\
20\end{array}$ & $\begin{array}{l}1100 \\
1110 \\
1440 \\
1390 \\
1236\end{array}$ & $\begin{array}{l}15 \\
18 \\
20 \\
18 \\
11\end{array}$ & $\begin{array}{l}45 \\
54 \\
78 \\
68 \\
37\end{array}$ & $\begin{array}{r}6150 \\
9030 \\
10600 \\
9022 \\
8060\end{array}$ & $\begin{array}{r}93 \\
272 \\
227 \\
97 \\
110\end{array}$ & $\begin{array}{l}1540 \\
0630 \\
6506 \\
2300 \\
2520\end{array}$ \\
\hline $\begin{array}{l}16 \\
17 \\
18 \\
19 \\
20\end{array}$ & $\begin{array}{r}562 \\
715 \\
960 \\
1000 \\
1140\end{array}$ & $\begin{array}{l}15 \\
15 \\
20 \\
22 \\
23\end{array}$ & $\begin{array}{l}23 \\
29 \\
52 \\
59 \\
71\end{array}$ & $\begin{array}{l}1130 \\
1110 \\
1450 \\
1880 \\
1860\end{array}$ & $\begin{array}{l}18 \\
22 \\
11 \\
23 \\
23\end{array}$ & $\begin{array}{r}55 \\
66 \\
43 \\
117 \\
116\end{array}$ & $\begin{array}{l}6220 \\
4750 \\
4010 \\
3910 \\
4010\end{array}$ & $\begin{array}{l}58 \\
28 \\
38 \\
46 \\
60\end{array}$ & $\begin{array}{l}474 \\
355 \\
411 \\
486 \\
656\end{array}$ \\
\hline $\begin{array}{l}21 \\
22 \\
23 \\
24 \\
25\end{array}$ & $\begin{array}{l}1200 \\
1170 \\
1140 \\
1120 \\
1190\end{array}$ & $\begin{array}{l}26 \\
13 \\
14 \\
16 \\
12\end{array}$ & $\begin{array}{l}84 \\
41 \\
43 \\
48 \\
39\end{array}$ & $\begin{array}{l}1780 \\
1800 \\
1710 \\
1620 \\
1540\end{array}$ & $\begin{array}{l}11 \\
12 \\
13 \\
13 \\
13\end{array}$ & $\begin{array}{l}53 \\
58 \\
60 \\
57 \\
54\end{array}$ & $\begin{array}{r}4450 \\
7450 \\
10600 \\
12430 \\
10100\end{array}$ & $\begin{array}{l}77 \\
490 \\
330 \\
208 \\
120\end{array}$ & $\begin{array}{r}\$ 25 \\
+1406 \\
9620 \\
6900 \\
3440\end{array}$ \\
\hline $\begin{array}{l}26 \\
27 \\
28 \\
29 \\
30 \\
31\end{array}$ & $\begin{array}{l}1210 \\
1280 \\
1210 \\
1200 \\
1160 \\
1140\end{array}$ & $\begin{array}{l}20 \\
25 \\
24 \\
23 \\
22 \\
21\end{array}$ & $\begin{array}{l}65 \\
86 \\
78 \\
75 \\
69 \\
65\end{array}$ & $\begin{array}{r}1530 \\
1450 \\
1410 \\
1280 \\
1260 \\
=\end{array}$ & $\begin{array}{r}12 \\
9 \\
12 \\
22 \\
17 \\
--\end{array}$ & $\begin{array}{l}50 \\
35 \\
46 \\
76 \\
58 \\
--\end{array}$ & $\begin{array}{l}7770 \\
5880 \\
4200 \\
3430 \\
2981 \\
2740\end{array}$ & $\begin{array}{l}84 \\
76 \\
72 \\
68 \\
05 \\
00\end{array}$ & $\begin{array}{r}1760 \\
1210 \\
816 \\
030 \\
523 \\
486\end{array}$ \\
\hline TOTAL & $2770 ?$ & -- & 1374 & 45340 & -- & 4127 & 188610 & $=-$ & 83045 \\
\hline DAY & $\begin{array}{l}\text { MEAN } \\
\text { DISCHARGE } \\
\text { (CFS) }\end{array}$ & $\begin{array}{l}\text { JANUARY } \\
\text { MEAN } \\
\text { CONCEN- } \\
\text { TRATION } \\
\text { (MG ILI) }\end{array}$ & $\begin{array}{l}\text { LOAD } \\
\text { (TONS) }\end{array}$ & $\begin{array}{l}\text { MEAN } \\
\text { Ot SCHARGE } \\
\text { (CFS) }\end{array}$ & $\begin{array}{l}\text { FEBRUARY } \\
\text { MEAN } \\
\text { CONCEN- } \\
\text { TRATIION } \\
\text { (MGLL) }\end{array}$ & $\begin{array}{l}\text { LOAD } \\
\text { (TONS) }\end{array}$ & $\begin{array}{l}\text { MEAN } \\
\text { OISCHARGE } \\
\text { (CFS) }\end{array}$ & $\begin{array}{l}\text { MARCH } \\
\text { MLAN } \\
\text { CUNCEN- } \\
\text { TRATION } \\
\text { (MGIL) }\end{array}$ & $\begin{array}{l}\text { LOAE } \\
\text { (TONS) }\end{array}$ \\
\hline $\begin{array}{l}1 \\
2 \\
3 \\
4 \\
5\end{array}$ & $\begin{array}{l}2560 \\
2080 \\
2050 \\
2110 \\
1740\end{array}$ & $\begin{array}{l}48 \\
5 C \\
54 \\
6 C \\
68\end{array}$ & $\begin{array}{l}332 \\
281 \\
305 \\
342 \\
319\end{array}$ & $\begin{array}{l}24500 \\
26800 \\
26200 \\
237 C C \\
20500\end{array}$ & $\begin{array}{r}276 \\
170 \\
133 \\
129 \\
96\end{array}$ & $\begin{array}{r}18300 \\
12300 \\
9410 \\
8250 \\
5310\end{array}$ & $\begin{array}{l}1510 \\
1470 \\
1430 \\
1350 \\
1320\end{array}$ & $\begin{array}{l}12 \\
10 \\
10 \\
13 \\
15\end{array}$ & $\begin{array}{l}45 \\
46 \\
39 \\
47 \\
53\end{array}$ \\
\hline $\begin{array}{r}6 \\
7 \\
8 \\
9 \\
10\end{array}$ & $\begin{array}{l}1760 \\
1670 \\
137 C \\
145 C \\
1500\end{array}$ & $\begin{array}{l}44 \\
37 \\
43 \\
42 \\
48\end{array}$ & $\begin{array}{l}209 \\
167 \\
159 \\
164 \\
194\end{array}$ & $\begin{array}{r}15700 \\
10900 \\
7060 \\
5470 \\
4400\end{array}$ & $\begin{array}{l}77 \\
62 \\
47 \\
42 \\
33\end{array}$ & $\begin{array}{r}3260 \\
1820 \\
896 \\
620 \\
392\end{array}$ & $\begin{array}{l}1360 \\
1380 \\
1370 \\
1350 \\
1370\end{array}$ & $\begin{array}{l}10 \\
15 \\
15 \\
17 \\
20\end{array}$ & $\begin{array}{l}59 \\
56 \\
55 \\
6< \\
74\end{array}$ \\
\hline $\begin{array}{l}11 \\
12 \\
13 \\
14 \\
15\end{array}$ & $\begin{array}{l}143 C \\
141 C \\
145 C \\
1470 \\
1496\end{array}$ & $\begin{array}{l}35 \\
34 \\
28 \\
26 \\
38\end{array}$ & $\begin{array}{l}135 \\
129 \\
110 \\
103 \\
153\end{array}$ & $\begin{array}{l}3500 \\
3010 \\
2790 \\
2630 \\
2520\end{array}$ & $\begin{array}{l}26 \\
27 \\
28 \\
30 \\
23\end{array}$ & $\begin{array}{l}246 \\
219 \\
211 \\
213 \\
156\end{array}$ & $\begin{array}{l}1380 \\
1850 \\
2430 \\
2350 \\
2130\end{array}$ & $\begin{array}{l}17 \\
49 \\
98 \\
47 \\
28\end{array}$ & $\begin{array}{l}69 \\
245 \\
643 \\
296 \\
161\end{array}$ \\
\hline $\begin{array}{l}16 \\
17 \\
18 \\
19 \\
20\end{array}$ & $\begin{array}{l}1410 \\
1330 \\
1350 \\
1370 \\
1390\end{array}$ & $\begin{array}{l}36 \\
25 \\
26 \\
22 \\
22\end{array}$ & $\begin{array}{r}137 \\
90 \\
95 \\
81 \\
83\end{array}$ & $\begin{array}{l}2400 \\
2330 \\
2140 \\
1960 \\
1940\end{array}$ & $\begin{array}{l}20 \\
15 \\
15 \\
13 \\
10\end{array}$ & $\begin{array}{r}130 \\
94 \\
87 \\
69 \\
52\end{array}$ & $\begin{array}{l}2710 \\
4150 \\
3460 \\
3620 \\
4230\end{array}$ & $\begin{array}{r}4 b \\
272 \\
126 \\
75 \\
78\end{array}$ & $\begin{array}{r}389 \\
3450 \\
1180 \\
733 \\
891\end{array}$ \\
\hline $\begin{array}{l}21 \\
22 \\
23 \\
24 \\
25\end{array}$ & $\begin{array}{l}161 C \\
2530 \\
378 C \\
3970 \\
348 C\end{array}$ & $\begin{array}{r}25 \\
88 \\
176 \\
84 \\
29\end{array}$ & $\begin{array}{r}109 \\
601 \\
1800 \\
900 \\
272\end{array}$ & $\begin{array}{l}1920 \\
1770 \\
1680 \\
1700 \\
1650\end{array}$ & $\begin{array}{l}10 \\
10 \\
11 \\
13 \\
18\end{array}$ & $\begin{array}{l}52 \\
48 \\
50 \\
60 \\
80\end{array}$ & $\begin{array}{r}8650 \\
21100 \\
26700 \\
20900 \\
18200\end{array}$ & $\begin{array}{r}1270 \\
1310 \\
530 \\
416 \\
272\end{array}$ & $\begin{array}{l}41000 \\
74000 \\
38<00 \\
\angle 3500 \\
13400\end{array}$ \\
\hline $\begin{array}{l}20 \\
27 \\
28 \\
29 \\
30 \\
31\end{array}$ & $\begin{array}{r}3400 \\
3140 \\
2880 \\
4850 \\
13800 \\
24500\end{array}$ & $\begin{array}{r}20 \\
24 \\
26 \\
102 \\
433 \\
580\end{array}$ & $\begin{array}{r}184 \\
203 \\
202 \\
1450 \\
19000 \\
38400\end{array}$ & $\begin{array}{r}1570 \\
1540 \\
1550 \\
1540 \\
=-\end{array}$ & $\begin{array}{l}27 \\
18 \\
13 \\
12 \\
-- \\
--\end{array}$ & $\begin{array}{r}114 \\
75 \\
54 \\
50 \\
-- \\
=-\end{array}$ & $\begin{array}{l}16500 \\
17700 \\
18160 \\
16800 \\
14400 \\
10600\end{array}$ & $\begin{array}{l}178 \\
163 \\
132 \\
106 \\
117 \\
117\end{array}$ & $\begin{array}{l}7 \times 30 \\
7790 \\
0450 \\
4810 \\
4550 \\
3350\end{array}$ \\
\hline TOTAL & 100370 & -- & 66709 & 205370 & -- & 62618 & 231870 & -- & 233813 \\
\hline
\end{tabular}


03234500 SCIOTO RIVER HIGBY, OHIO--ContInued

SUSPENDED SEDIMENT, WATER YEAR OCTOBER 1967 TO SEPTEMBER 1968

\begin{tabular}{|c|c|c|c|c|c|c|c|c|c|}
\hline & & APRIL & & & MAY & & & JUNE & \\
\hline DAY & $\begin{array}{l}\text { MEAN } \\
\text { DI SCHARGE } \\
\text { (CFS) }\end{array}$ & $\begin{array}{l}\text { MEAN } \\
\text { CONCEN- } \\
\text { TRATION } \\
\text { (MG/LI) }\end{array}$ & $\begin{array}{l}\text { LOAD } \\
\text { (TONS) }\end{array}$ & $\begin{array}{l}\text { MEAN } \\
\text { DISCHARGE } \\
\text { ICFSI }\end{array}$ & $\begin{array}{l}\text { MEAN } \\
\text { CONCEN- } \\
\text { TRATION } \\
(M G / L)\end{array}$ & $\begin{array}{l}\text { LOAD } \\
\text { (TONS) }\end{array}$ & $\begin{array}{l}\text { MEAN } \\
\text { DISCHARGE } \\
\text { (CFS) }\end{array}$ & $\begin{array}{l}\text { MEAN } \\
\text { CONCEN- } \\
\text { TRATION } \\
\text { (MG/L) }\end{array}$ & $\begin{array}{l}\text { LUAD } \\
\text { (TONS) }\end{array}$ \\
\hline $\begin{array}{l}1 \\
2 \\
3 \\
4 \\
5\end{array}$ & $\begin{array}{r}10400 \\
7660 \\
6330 \\
7740 \\
8710\end{array}$ & $\begin{array}{l}264 \\
114 \\
150 \\
215 \\
172\end{array}$ & $\begin{array}{l}7410 \\
2360 \\
2560 \\
4490 \\
404 C\end{array}$ & $\begin{array}{l}2120 \\
2060 \\
1960 \\
1890 \\
1800\end{array}$ & $\begin{array}{l}50 \\
41 \\
30 \\
38 \\
39\end{array}$ & $\begin{array}{l}286 \\
228 \\
159 \\
194 \\
190\end{array}$ & $\begin{array}{l}24100 \\
18900 \\
19500 \\
18100 \\
14200\end{array}$ & $\begin{array}{l}196 \\
539 \\
428 \\
198 \\
138\end{array}$ & $\begin{array}{r}12800 \\
27500 \\
22500 \\
9600 \\
5290\end{array}$ \\
\hline $\begin{array}{r}6 \\
7 \\
8 \\
9 \\
10\end{array}$ & $\begin{array}{l}6640 \\
6410 \\
5580 \\
4710 \\
3870\end{array}$ & $\begin{array}{r}113 \\
81 \\
62 \\
65 \\
58\end{array}$ & $\begin{array}{r}2030 \\
1400 \\
934 \\
827 \\
606\end{array}$ & $\begin{array}{l}1670 \\
1620 \\
1560 \\
1520 \\
1670\end{array}$ & $\begin{array}{l}33 \\
29 \\
24 \\
22 \\
28\end{array}$ & $\begin{array}{r}149 \\
127 \\
101 \\
90 \\
126\end{array}$ & $\begin{array}{r}12100 \\
10600 \\
7840 \\
6320 \\
5680\end{array}$ & $\begin{array}{l}138 \\
152 \\
140 \\
127 \\
128\end{array}$ & $\begin{array}{l}4510 \\
4350 \\
2900 \\
2170 \\
1900\end{array}$ \\
\hline $\begin{array}{l}11 \\
12 \\
13 \\
14 \\
15\end{array}$ & $\begin{array}{l}3450 \\
307 C \\
281 C \\
264 C \\
3400\end{array}$ & $\begin{array}{r}42 \\
47 \\
47 \\
42 \\
295\end{array}$ & $\begin{array}{r}391 \\
390 \\
357 \\
299 \\
1790\end{array}$ & $\begin{array}{l}2740 \\
6000 \\
9080 \\
8580 \\
7110\end{array}$ & $\begin{array}{l}134 \\
428 \\
220 \\
142 \\
109\end{array}$ & $\begin{array}{l}1489 \\
6930 \\
5390 \\
3290 \\
2090\end{array}$ & $\begin{array}{l}5740 \\
5560 \\
4700 \\
4280 \\
4000\end{array}$ & $\begin{array}{r}165 \\
196 \\
168 \\
110 \\
72\end{array}$ & $\begin{array}{l}2560 \\
2940 \\
2130 \\
1270 \\
778\end{array}$ \\
\hline $\begin{array}{l}16 \\
17 \\
18 \\
19 \\
20\end{array}$ & $\begin{array}{l}3150 \\
2770 \\
2760 \\
2680 \\
2540\end{array}$ & $\begin{array}{l}89 \\
52 \\
50 \\
38 \\
28\end{array}$ & $\begin{array}{l}757 \\
389 \\
373 \\
275 \\
192\end{array}$ & $\begin{array}{l}5650 \\
6390 \\
6950 \\
7000 \\
5890\end{array}$ & $\begin{array}{l}102 \\
128 \\
143 \\
108 \\
106\end{array}$ & $\begin{array}{l}1560 \\
2210 \\
2680 \\
2040 \\
1690\end{array}$ & $\begin{array}{l}3920 \\
4200 \\
4140 \\
4420 \\
4760\end{array}$ & $\begin{array}{r}05 \\
81 \\
107 \\
127 \\
128\end{array}$ & $\begin{array}{r}688 \\
\quad 119 \\
1200 \\
1520 \\
1050\end{array}$ \\
\hline $\begin{array}{l}21 \\
22 \\
23 \\
24 \\
25\end{array}$ & $\begin{array}{l}254 C \\
2410 \\
248 C \\
3790 \\
4160\end{array}$ & $\begin{array}{r}30 \\
42 \\
234 \\
294 \\
243\end{array}$ & $\begin{array}{r}206 \\
273 \\
1060 \\
3010 \\
2730\end{array}$ & $\begin{array}{r}4510 \\
3730 \\
11000 \\
46700 \\
83700\end{array}$ & $\begin{array}{r}92 \\
70 \\
957 \\
2020 \\
1300\end{array}$ & $\begin{array}{r}1120 \\
705 \\
45000 \\
271000 \\
294000\end{array}$ & $\begin{array}{l}4360 \\
4660 \\
7720 \\
5300 \\
4340\end{array}$ & $\begin{array}{r}108 \\
135 \\
2320 \\
548 \\
356\end{array}$ & $\begin{array}{r}1270 \\
1906 \\
32200 \\
7840 \\
4170\end{array}$ \\
\hline $\begin{array}{l}26 \\
27 \\
28 \\
29 \\
30 \\
31\end{array}$ & $\begin{array}{c}3420 \\
2960 \\
2980 \\
2560 \\
2300 \\
-0\end{array}$ & $\begin{array}{r}100 \\
56 \\
42 \\
32 \\
18 \\
--\end{array}$ & $\begin{array}{r}923 \\
448 \\
338 \\
221 \\
112 \\
-2\end{array}$ & $\begin{array}{l}65500 \\
57800 \\
63000 \\
57300 \\
57000 \\
42200\end{array}$ & $\begin{array}{l}542 \\
575 \\
500 \\
394 \\
324 \\
200\end{array}$ & $\begin{array}{l}95900 \\
85700 \\
85000 \\
61000 \\
49900 \\
22800\end{array}$ & $\begin{array}{c}4600 \\
4420 \\
3680 \\
3300 \\
3250 \\
--\end{array}$ & $\begin{array}{l}230 \\
457 \\
194 \\
133 \\
110 \\
--\end{array}$ & $\begin{array}{r}2800 \\
5456 \\
1>30 \\
1490 \\
965 \\
--\end{array}$ \\
\hline TOTAL & 126920 & -- & 41191 & 575700 & - & 1047135 & 228690 & -- & 109210 \\
\hline DAY & $\begin{array}{l}\text { MEAN } \\
\text { OI SCHARGE } \\
\text { (CFS) }\end{array}$ & $\begin{array}{l}\text { JULY } \\
\text { MEAN } \\
\text { COACEN- } \\
\text { TRATION } \\
\text { (MG/L) }\end{array}$ & $\begin{array}{l}\text { LOAD } \\
\text { (TONS) }\end{array}$ & $\begin{array}{l}\text { MEAN } \\
\text { OISCHARGE } \\
\text { (CFS) }\end{array}$ & $\begin{array}{l}\text { AUGUST } \\
\text { MEAN } \\
\text { CONCEN- } \\
\text { TRATION } \\
\text { (MG LL) }\end{array}$ & $\begin{array}{l}\text { LOAD } \\
\text { (TONS) }\end{array}$ & $\begin{array}{l}\text { MEAN } \\
\text { DISCHARGE } \\
\text { (CFS) }\end{array}$ & $\begin{array}{l}\text { SEPTEMBER } \\
\text { MEAN } \\
\text { CONCEN- } \\
\text { TRATION } \\
\text { IMG /LI }\end{array}$ & $\begin{array}{l}\text { LOAL } \\
\text { (TUNS) }\end{array}$ \\
\hline $\begin{array}{l}1 \\
2 \\
3 \\
4 \\
5\end{array}$ & $\begin{array}{l}3160 \\
291 C \\
249 C \\
2220 \\
2020\end{array}$ & $\begin{array}{l}90 \\
50 \\
46 \\
60 \\
52\end{array}$ & $\begin{array}{l}768 \\
393 \\
309 \\
360 \\
284\end{array}$ & $\begin{array}{l}1580 \\
2150 \\
1920 \\
1680 \\
1950\end{array}$ & $\begin{array}{l}57 \\
83 \\
55 \\
21 \\
33\end{array}$ & $\begin{array}{r}243 \\
482 \\
285 \\
95 \\
174\end{array}$ & $\begin{array}{l}844 \\
843 \\
835 \\
881 \\
856\end{array}$ & $\begin{array}{l}89 \\
97 \\
95 \\
98 \\
45\end{array}$ & $\begin{array}{l}203 \\
221 \\
214 \\
233 \\
i 04\end{array}$ \\
\hline $\begin{array}{r}6 \\
7 \\
8 \\
9 \\
10\end{array}$ & $\begin{array}{l}1880 \\
1790 \\
1700 \\
1590 \\
1540\end{array}$ & $\begin{array}{l}45 \\
78 \\
98 \\
42 \\
20\end{array}$ & $\begin{array}{r}228 \\
377 \\
450 \\
180 \\
83\end{array}$ & $\begin{array}{l}2020 \\
1920 \\
1840 \\
2896 \\
3180\end{array}$ & $\begin{array}{r}39 \\
25 \\
18 \\
119 \\
237\end{array}$ & $\begin{array}{r}213 \\
130 \\
89 \\
1280 \\
2030\end{array}$ & $\begin{array}{l}875 \\
895 \\
876 \\
843 \\
837\end{array}$ & $\begin{array}{l}42 \\
70 \\
38 \\
11 \\
12\end{array}$ & $\begin{array}{r}99 \\
169 \\
90 \\
25 \\
27\end{array}$ \\
\hline $\begin{array}{l}11 \\
12 \\
13 \\
14 \\
15\end{array}$ & $\begin{array}{l}1590 \\
1720 \\
1610 \\
1650 \\
1600\end{array}$ & $\begin{array}{l}15 \\
15 \\
13 \\
20 \\
25\end{array}$ & $\begin{array}{r}64 \\
70 \\
57 \\
90 \\
108\end{array}$ & $\begin{array}{l}3410 \\
2910 \\
2770 \\
2130 \\
1790\end{array}$ & $\begin{array}{r}312 \\
264 \\
175 \\
85 \\
49\end{array}$ & $\begin{array}{r}2870 \\
2070 \\
1310 \\
489 \\
237\end{array}$ & $\begin{array}{l}834 \\
831 \\
823 \\
810 \\
789\end{array}$ & $\begin{array}{l}14 \\
13 \\
15 \\
52 \\
40\end{array}$ & $\begin{array}{r}32 \\
24 \\
33 \\
114 \\
45\end{array}$ \\
\hline $\begin{array}{l}16 \\
17 \\
18 \\
19 \\
20\end{array}$ & $\begin{array}{l}1590 \\
1670 \\
1840 \\
1770 \\
2080\end{array}$ & $\begin{array}{l}23 \\
21 \\
33 \\
50 \\
59\end{array}$ & $\begin{array}{r}99 \\
95 \\
164 \\
239 \\
331\end{array}$ & $\begin{array}{l}1650 \\
1590 \\
1670 \\
1720 \\
1500\end{array}$ & $\begin{array}{r}30 \\
23 \\
102 \\
126 \\
30\end{array}$ & $\begin{array}{r}134 \\
99 \\
545 \\
585 \\
122\end{array}$ & $\begin{array}{l}770 \\
759 \\
773 \\
784 \\
855\end{array}$ & $\begin{array}{l}17 \\
17 \\
18 \\
17 \\
15\end{array}$ & $\begin{array}{l}35 \\
35 \\
38 \\
30 \\
35\end{array}$ \\
\hline $\begin{array}{l}21 \\
22 \\
23 \\
24 \\
25\end{array}$ & $\begin{array}{l}1920 \\
1730 \\
1550 \\
1430 \\
148 C\end{array}$ & $\begin{array}{l}55 \\
5 C \\
43 \\
46 \\
45\end{array}$ & $\begin{array}{l}285 \\
234 \\
180 \\
178 \\
180\end{array}$ & $\begin{array}{l}1480 \\
1370 \\
1270 \\
1200 \\
1130\end{array}$ & $\begin{array}{l}32 \\
30 \\
32 \\
23 \\
18\end{array}$ & $\begin{array}{r}128 \\
111 \\
110 \\
75 \\
55\end{array}$ & $\begin{array}{l}843 \\
796 \\
752 \\
718 \\
743\end{array}$ & $\begin{array}{l}12 \\
13 \\
23 \\
25 \\
18\end{array}$ & $\begin{array}{l}27 \\
28 \\
47 \\
48 \\
30\end{array}$ \\
\hline $\begin{array}{l}26 \\
27 \\
28 \\
29 \\
30 \\
31\end{array}$ & $\begin{array}{l}1650 \\
2060 \\
2380 \\
2320 \\
2020 \\
1720\end{array}$ & $\begin{array}{l}24 \\
52 \\
72 \\
85 \\
55 \\
36\end{array}$ & $\begin{array}{l}107 \\
289 \\
463 \\
532 \\
300 \\
167\end{array}$ & $\begin{array}{r}1050 \\
971 \\
947 \\
904 \\
870 \\
851\end{array}$ & $\begin{array}{l}20 \\
27 \\
23 \\
26 \\
73 \\
88\end{array}$ & $\begin{array}{r}57 \\
71 \\
57 \\
63 \\
171 \\
202\end{array}$ & $\begin{array}{l}784 \\
750 \\
722 \\
707 \\
689 \\
--\end{array}$ & $\begin{array}{l}18 \\
12 \\
15 \\
27 \\
43 \\
--\end{array}$ & $\begin{array}{l}30 \\
24 \\
29 \\
52 \\
80 \\
--\end{array}$ \\
\hline TOTAL & $5869 \mathrm{C}$ & - & 7664 & 54313 & - & 14584 & 24117 & - & $<<06$ \\
\hline $\begin{array}{l}\text { TOTAL } \\
\text { TDTAL }\end{array}$ & $\begin{array}{l}\text { DI SCHARGE FOR } \\
\text { LDAD FOR YEAR }\end{array}$ & $\begin{array}{l}\text { R YEAR IC } \\
\text { R (TONS) }\end{array}$ & DAYS! & & & & & & $\begin{array}{l}1867694 \\
1734336\end{array}$ \\
\hline
\end{tabular}


03234500 SCIOTO RIVER HIGBY, OHIO---CONTInUEd

PERIODIC DETERMINATIONS OF SUSPENDED-SEDIMENT DISCHARGE AND PARTICLE SIIE, WATER YEAR OCTOBER 1967 TO SEPTEMBER 1968
IMETHODS DF AVALYSIS: B, ROTTOM WITHORAWAL TISE; C, CHENICALIY DISDERSFD; N, IN NATIVE WATFO V. VISUAL ACCIJUIJLATION TURE: W. IN TISTILLED WATERI

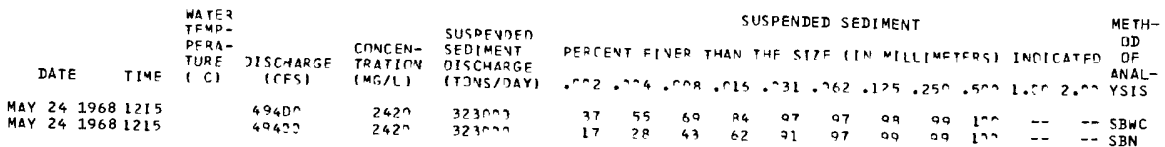

\section{SCIOTO RIVER AT LUCASVILLE, OHIO}

LOCATION. --Lat $38^{\circ} 52^{\prime} 32^{\prime \prime}$, long $83^{\circ} 00^{\prime} 52^{\prime \prime}$, Scioto County, at bridge on State Highway 348 at Lucasville, 0.4 mile downstream from Miller Run, and 4.9 miles upstream from Scioto Brush Creek.

DRA INAGE AREA. $--6,178 \mathrm{sq} \mathrm{m} 1$.

PER IOD OF RECORD. --Chemical analyses: October 1956 to September 1968.

Water temperatures: October 1956 to September 1968.

EXTR EMES. - -1967-68:

Specific conductance: Maximum daily, 827 micromhos Oct. 17; minimum daily, 240 mtcromhos May 24. ater temperatures: Maximum, 28.0 $\mathrm{C}$ Aug. 23, 24; minimum, freezing point on several days during January and
February.

Period of record:

Specific conductance: Maximum daily, 1,020 micromhos Dec, 22, 1963; minimum daily, 207 micramhas May 8, 1961 , Water temperatures: Maximum, $29.0^{\circ} \mathrm{C}$ Juiy 22, 1957; minimum, freezing point on many days during winter periods.

REMARKS. --Samples for iron and manganese were filtered clear when collected. Daily samples were collected at this station and samples were selected for analysis as follows: (1) Maximur daily specific conductance for each month, (2) minimum daily specific conductance for each month, (3) median daily specific conductance for each month,

(4) spectal sample each month to further define the quality of water. No discharge records available.

CHEMICAL ANALYSES IN MILLIGRAMS PER LITER, WATER YEAR OCTOBER 1967 TO SEPTEMBER 1968

\begin{tabular}{|c|c|c|c|c|c|c|c|c|c|}
\hline DATE & TIME & $\begin{array}{l}\text { IRON } \\
\text { (FE) }\end{array}$ & $\begin{array}{l}\text { MAN- } \\
\text { GANESE } \\
\text { (MN) }\end{array}$ & $\begin{array}{l}\text { BICAR- } \\
\text { PONATE } \\
\text { (HCC } 3 \text { ) }\end{array}$ & $\begin{array}{l}\text { CAR - } \\
\text { BONATE } \\
\text { (CO3) }\end{array}$ & $\begin{array}{l}\text { SULFATE } \\
\text { (SD4) }\end{array}$ & $\begin{array}{l}\text { CHLN- } \\
\text { RIDE } \\
\text { |CLI }\end{array}$ & $\begin{array}{l}\text { FLUO- } \\
\text { RINE } \\
\text { (F) }\end{array}$ & $\begin{array}{l}\text { NITRATE } \\
\text { IND3) }\end{array}$ \\
\hline \multicolumn{10}{|l|}{ OCT. } \\
\hline $\begin{array}{l}10 \ldots \\
17 \ldots\end{array}$ & $\begin{array}{l}0830 \\
0830\end{array}$ & $\overline{--}$ & $\overline{-}$ & $\begin{array}{l}250 \\
260\end{array}$ & $\begin{array}{l}0 \\
0\end{array}$ & $\begin{array}{r}98 \\
125\end{array}$ & 55 & .6 & $10^{209}$ \\
\hline $20 . .$. & 0930 & .24 & .17 & - & -- & -- & -- & -- & . \\
\hline $27 \ldots$ & 0630 & -- & -- & 230 & 0 & 73 & 28 & .3 & 11 \\
\hline \multicolumn{10}{|l|}{ NuV. } \\
\hline $\begin{array}{l}04 \ldots \\
15 \ldots\end{array}$ & $\begin{array}{l}0930 \\
1750\end{array}$ & .28 & .30 & $\begin{array}{r}196 \\
---\end{array}$ & $\begin{array}{l}0 \\
-\end{array}$ & $\begin{array}{l}74 \\
-\ldots\end{array}$ & $30 \ldots$ & $\because 4$ & $\begin{array}{r}3.3 \\
+.\end{array}$ \\
\hline $16 \ldots$ & 0930 & - & - & 224 & 0 & 135 & 46 & .8 & 7.0 \\
\hline $23 \ldots$ & 0930 & -- & -- & 230 & 0 & 114 & 38 & .6 & 4.4 \\
\hline \multicolumn{10}{|l|}{ DEC. } \\
\hline $\begin{array}{l}08 . . . \\
19 . .\end{array}$ & $\begin{array}{l}0930 \\
0900\end{array}$ & $\cdots$ & - & 210 & 0 & 138 & 34 & .4 & 7.5 \\
\hline $\begin{array}{l}19 \ldots \\
20 . \ldots\end{array}$ & 1400 & $\overline{3}$ & $\overline{35}$ & 200 & 0 & 88 & 74 & $\because 3$ & \\
\hline $24 \ldots$ & $\begin{array}{l}1430 \\
0900\end{array}$ & .18 & $\cdot-35$ & 166 & $\overline{0}$ & $\overline{74}$ & $19^{-2}$ & .3 & 12 \\
\hline \multicolumn{10}{|l|}{ JAN. } \\
\hline $05 .$. & 0900 & -- & - & 240 & 0 & 90 & 28 & .4 & 10 \\
\hline $\begin{array}{l}12 \ldots \\
23 . .\end{array}$ & 0930 & - & $\overline{3}$ & 276 & 0 & 108 & 40 & .5 & 7.0 \\
\hline $\begin{array}{l}23 \ldots \\
31 \ldots\end{array}$ & 1315 & .48 & .20 & -- & -- & -- & 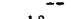 & $=$ & \\
\hline$\underset{\text { FEB. }}{31 \ldots}$ & 0900 & -- & -- & 132 & 0 & 60 & 18 & $\cdot 2$ & 11 \\
\hline $04 \ldots$ & 0900 & -- & -- & 130 & 0 & 55 & 15 & .4 & 17 \\
\hline $14 \ldots$ & 1520 & .28 & .12 & -- & -- & -- & -- & - & - \\
\hline $15 \ldots$ & 0900 & -- & $-\infty$ & 218 & 15 & 96 & 27 & .5 & 12 \\
\hline $28 \ldots$ & 0900 & -- & - & 280 & 0 & 100 & 36 & .0 & 7.3 \\
\hline \multicolumn{10}{|l|}{ MAR. } \\
\hline $20 \ldots$ & $\begin{array}{l}0915 \\
1320\end{array}$ &.$\overline{12}$ & $\overline{10}$ & $\begin{array}{r}282 \\
--\end{array}$ & -0 & 101 & 37 & $\begin{array}{l}-7 \\
--\end{array}$ & 11. \\
\hline $23 \ldots$ & 0900 & - & $\ldots$ & 98 & 0 & 43 & 10 & .3 & ค. 1 \\
\hline $28 \ldots$ & 0900 & -- & $-\infty$ & 174 & 0 & 72 & 24 & .4 & 12 \\
\hline \multicolumn{10}{|l|}{ APR. } \\
\hline $18 \ldots$ & - & .09 & .14 & -- & -- & -- & & $=$ & 0.0 \\
\hline $24 \ldots$ & 0930 & -- & -- & 84 & 0 & 46 & 10 & .4 & 3.6 \\
\hline$\underset{M A Y}{29} \ldots$ & 0930 & -- & -- & 183 & 0 & 71 & 22 & .4 & 4.7 \\
\hline $01 \ldots$ & 0930 & -- & -- & 182 & B & 14 & 24 & .4 & 8,8 \\
\hline$\underset{\text { JUNE }}{24 \ldots}$ & 0930 & -- & -- & 108 & 0 & 30 & 5.0 & $\cdot 2$ & 6.2 \\
\hline $\begin{array}{l}\text { JUNE } \\
04 \ldots .\end{array}$ & 1500 & & & -- & -- & - & -- & -- & \\
\hline $10 \ldots$ & 0930 & - & 12 & 244 & 0 & 61 & $16^{--}$ & .3 & 16 \\
\hline $19 .$. & $093 \mathrm{C}$ & -- & - & 244 & 10 & 12 & 32 & .3 & $\begin{array}{l}16 \\
13\end{array}$ \\
\hline $24 \ldots$ & 0930 & -- & -- & 148 & 0 & 40 & 10 & .2 & 7.5 \\
\hline \multicolumn{10}{|l|}{ JULY } \\
\hline $06 \ldots$ & 0930 & -- & -- & 280 & 0 & 84 & 23 & .4 & 3.4 \\
\hline $13 \ldots$ & 0930 & $\overline{-}$ & - & 300 & 0 & 90 & 32 & .4 & 2.6 \\
\hline $17 \ldots$ & 1705 & .26 & .19 & -- & -- & -- & -- & - & - \\
\hline $20 \ldots$ & 0930 & - & - & 208 & 0 & 69 & 28 & .4 & 1,8 \\
\hline \multicolumn{10}{|l|}{ AUG. } \\
\hline $04 \ldots$ & 0930 & $=$ & $\overline{-}$ & 236 & 0 & 87 & 28 & .4 & 2.3 \\
\hline $20 \ldots$ & 0930 & - & - & 192 & 4 & 64 & 24 & .4 & 6.2 \\
\hline $28 \ldots$ & 1000 & .49 & .30 & -- & -- & -- & -- & $\cdots$ & -- \\
\hline $30 \ldots$ & $093 \mathrm{C}$ & $\rightarrow$ & $\cdots$ & 290 & 0 & 91 & 38 & .6 & 4.8 \\
\hline $02 \ldots$ & 0930 & -- & $\cdots$ & 272 & 12 & 91 & 28 & .6 & 6.8 \\
\hline $1<\ldots$ & 0930 & $\because$ & -- & 280 & 0 & 96 & 42 & .5 & 71 \\
\hline $26 \ldots$ & - & .27 & .39 & $\ddot{-}$ & -- & $=$ & -- & - & \\
\hline $28 \ldots$ & 0930 & $-\rightarrow$ & $\cdots$ & 308 & 8 & 112 & 52 & .7 & 9.0 \\
\hline
\end{tabular}


03237100 SCIOTO RIVER AT LUCASVILLE, OHIO--COntInUE

CHEMICAL ANALYSES IN MILLIGRAMS PER LITER, WATER YEAR OCTOBER 1967 TO SEPTEMBER 1968

\begin{tabular}{|c|c|c|c|c|c|c|c|c|c|}
\hline DATE & $\begin{array}{l}\text { TOTAL } \\
\text { PHOS- } \\
\text { PHORUS } \\
(\text { PO4) }\end{array}$ & $\begin{array}{l}\text { DIS- } \\
\text { SOLVED } \\
\text { SOLIDS } \\
\text { IRESI- } \\
\text { DUE AT } \\
\text { IBO CI }\end{array}$ & $\begin{array}{l}\text { HARD- } \\
\text { NESS } \\
\text { (CA,MG) }\end{array}$ & $\begin{array}{l}\text { NON- } \\
\text { CAR- } \\
\text { BUNATE } \\
\text { HARD- } \\
\text { NESS }\end{array}$ & $\begin{array}{l}\text { SPECI- } \\
\text { FIC } \\
\text { COND- } \\
\text { UCTANCE } \\
\text { (MICRD- } \\
\text { MHOS) }\end{array}$ & PH & $\begin{array}{l}\text { TEMP- } \\
\text { ERATURE } \\
\text { IOEG CI }\end{array}$ & $\begin{array}{l}\text { OISS- } \\
\text { OL VEO } \\
\text { OXYGEN }\end{array}$ & $\begin{array}{l}\text { PER- } \\
\text { CFNT } \\
\text { SATUR- } \\
\text { ATION }\end{array}$ \\
\hline \multicolumn{10}{|l|}{ OCT. } \\
\hline $10 \ldots$ & 2.1 & 442 & 300 & 95 & 733 & 7.1 & 14 & -- & $\cdots$ \\
\hline $17 \ldots$ & 4.0 & 540 & 329 & 116 & 827 & 7.2 & 17 & $\because$ & -- \\
\hline $26 \ldots$ & 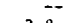 & $=$ & $-\pi$ & $\overline{-}$ & - & -- & - & 7.6 & 69 \\
\hline $27 \ldots$ & 2.8 & 346 & 261 & 72 & 600 & 7.2 & 12 & -- & -- \\
\hline \multicolumn{10}{|l|}{ NDV. } \\
\hline $04 \ldots$ & 1.7 & 342 & 234 & $\begin{array}{l}73 \\
--\end{array}$ & 563 & 7.5 & 11 & - & $-\overline{-}$ \\
\hline $15 \ldots$ & 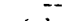 & $\overrightarrow{0}$ & - & -- & $-\overline{-}$ & -- & - & 7.6 & 63 \\
\hline $18 \ldots$ & 6.1 & 510 & 318 & 134 & 765 & 7.9 & 7 & -- & -- \\
\hline $\begin{array}{l}23 \ldots \\
\text { DEC. }\end{array}$ & 1.6 & 466 & 308 & 119 & 715 & 7.2 & 6 & $\cdots$ & - \\
\hline $08 \ldots$ & $1 . c$ & 414 & 310 & 133 & 697 & 8.2 & 5 & - & $\cdots$ \\
\hline $19 \ldots$ & 1.0 & 368 & 268 & 104 & 577 & 7.4 & 4 & $\overline{-}$ & $\overline{-}$ \\
\hline $20 \ldots$ & -- & 3 & $\overline{20}$ & $\overline{0}$ & $=-$ & - & - & 9.2 & 77 \\
\hline \multirow{2}{*}{\multicolumn{3}{|c|}{ JAN. }} & 226 & 90 & 492 & 8.0 & 3 & & \\
\hline & 1.0 & 384 & 302 & 105 & 655 & 7.3 & 0 & -- & - \\
\hline $12 \ldots$ & 1.4 & 442 & 334 & 108 & 774 & 7.5 & 0 & - & $m$ \\
\hline $23 \ldots$ & - & - & 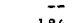 & $\overline{-}$ & - & -- & $\overline{-}$ & 10.0 & 71 \\
\hline $\begin{array}{l}31 \ldots \\
\text { FEB. }\end{array}$ & .82 & 230 & 184 & 76 & 415 & 6.9 & 4 & - & -- \\
\hline $04 \ldots$ & .64 & 258 & 196 & 89 & 388 & 8.3 & 3 & $\cdots$ & - \\
\hline $14 \ldots$ & $\overline{-}$ & $\cdots$ & $-\bar{x}$ & $\overline{-}$ & $\overline{-}$ & -- & -- & 11.0 & 77 \\
\hline $15 \ldots$ & .96 & 402 & 316 & 110 & 628 & 8.7 & 1 & $\cdots$ & $\rightarrow$ \\
\hline \multirow{2}{*}{\multicolumn{10}{|c|}{ MAR. }} \\
\hline & & & & & & & & & \\
\hline $20 \ldots$ & - & - & - & - & - & $\because$ & -2 & 8.8 & $R_{1}$ \\
\hline $23 \ldots$ & .32 & 196 & 141 & 61 & 299 & 7.8 & 4 & - & $\therefore$ \\
\hline $\begin{array}{l}28 \ldots \\
A P R .\end{array}$ & .44 & 366 & 254 & 111 & 521 & 7.5 & 7 & -- & - \\
\hline $14 \ldots$ & .78 & 326 & 280 & 109 & 580 & 7.9 & 14 & -- & $=$ \\
\hline $18 \ldots$ & $\tilde{z}$ & - & $\cdots$ & -- & $\because$ & -- & $\because$ & 7.6 & 72 \\
\hline $24 \ldots$ & .35 & 148 & 116 & 47 & 269 & 7.0 & 15 & -- & $\cdots$ \\
\hline \multicolumn{10}{|l|}{ MAY } \\
\hline $01 .$. & .85 & 362 & 246 & 84 & 535 & 8.5 & 16 & $\cdots$ & -- \\
\hline \multicolumn{10}{|l|}{ JUNE } \\
\hline $04 \ldots$ & -- & -- & - & -- & - & -- & 21 & 6.0 & 67 \\
\hline $10 \ldots$ & .47 & 374 & 272 & 72 & 545 & A. 0 & 33 & - & -- \\
\hline $19 \ldots$ & .80 & 400 & 296 & 70 & 592 & R. 4 & 21 & - & -. \\
\hline $24 \ldots$ & .31 & 230 & 160 & 39 & 351 & 7.2 & 22 & $\cdots$ & -- \\
\hline \multicolumn{10}{|l|}{ JULY } \\
\hline $06 \ldots$ & .73 & 382 & 316 & 86 & 650 & 7.5 & 22 & 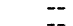 & -- \\
\hline $13 \ldots$ & 1.1 & 434 & $\begin{array}{l}330 \\
--\end{array}$ & 84 & $\begin{array}{l}704 \\
-\end{array}$ & 7.7 & 25 & 6 & $\overline{70}$ \\
\hline $\begin{array}{l}17 \ldots \\
26 .\end{array}$ & $=$ & $3 \overline{26}$ & 250 & 80 & $5 \overline{30}$ & $-\overline{5}$ & $\ddot{a}$ & 6.4 & 79 \\
\hline $\begin{array}{l}26 . . \\
\text { AUG. }\end{array}$ & .95 & \multicolumn{8}{|c|}{ AUG. } \\
\hline $04 \ldots$ & .84 & 366 & 290 & 96 & 620 & 7.4 & 24 & -- & - \\
\hline $20 \ldots$ & .78 & 290 & 225 & 61 & 503 & 8.4 & 26 & -- & - \\
\hline $28 \ldots$ & $\overline{7}$ & $\overline{-1}$ & $\overrightarrow{0}$ & $=-$ & -- & - & 23 & 13.0 & 149 \\
\hline $\begin{array}{l}30 . \ldots \\
\text { SEPT. }\end{array}$ & 1.7 & 422 & 325 & 82 & 714 & 7.8 & 21 & \multicolumn{2}{|c|}{ SEPT. } \\
\hline $\begin{array}{l}\text { SEPT. } \\
02 \ldots\end{array}$ & 1.6 & 334 & 325 & 82 & 579 & 8.5 & $2 \mathbf{I}$ & $-\cdots$ & -- \\
\hline $12 \ldots$ & 2.4 & 434 & 320 & 90 & 729 & 8.1 & 19 & -- & $\cdots$ \\
\hline $26 \ldots$ & $=$ & -- & $=$ & -- & -- & - & 2? & 10.2 & 116 \\
\hline $28 \ldots$ & 4.2 & 492 & 335 & 68 & 792 & 8.3 & 18 & - & - \\
\hline
\end{tabular}

SPECIFIC CONDUCTANCE (MICROMHOS AT $25^{\circ} \mathrm{C}$ ), WATER YEAR OCTOBER 1967 TO SEPTEMBER 1968 (ONCE-DAILY MEASUREMENT BETHEEN D830 AND D930)

DAY OCTOBER NOVEMBER DECEMBER JANUARY FEBRUARY MARCH APRIL MAY JUNE JULY AUGUST SEPTEMBER

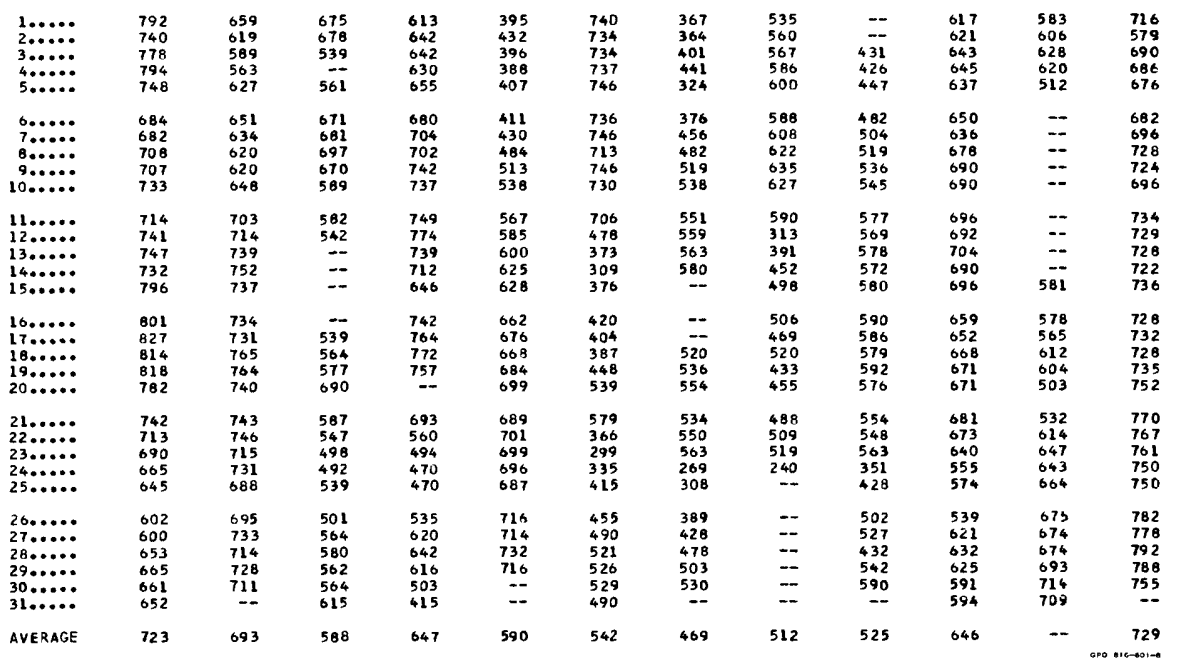


03237100 SCIOTO RIVER AT LUCASVILLE, OHIO--Continued

TEMPERATURE ( $\left.{ }^{\circ} \mathrm{C}\right)$ OF WATER, WATER YEAR OCTOBER 1967 TO SEPTEMBER 1968 (ONCE-DAILY MEASUREMENT BETWEEN 0830 AND 09301

\begin{tabular}{|c|c|c|c|c|c|c|c|c|c|c|c|c|}
\hline DAY & OCT & NOV & DEC & JAN & FEB & NAR & $A P R$ & MAY & JUN & JUL & AUG & SEP \\
\hline $\begin{array}{l}1 \\
2 \\
3 \\
4 \\
5\end{array}$ & $\begin{array}{l}14.0 \\
15.0 \\
17.0 \\
20.0 \\
19.0\end{array}$ & $\begin{array}{r}11.0 \\
12.0 \\
12.0 \\
11.0 \\
9.0\end{array}$ & $\begin{array}{r}3.0 \\
3.0 \\
4.0 \\
3.0\end{array}$ & $\begin{array}{l}1.0 \\
1.0 \\
2.0 \\
1.0 \\
0.0\end{array}$ & $\begin{array}{l}4.0 \\
4.0 \\
4.0 \\
3.0 \\
4.0\end{array}$ & $\begin{array}{l}2.0 \\
2.0 \\
2.0 \\
2.0 \\
3.0\end{array}$ & $\begin{array}{l}12.0 \\
11.0 \\
11.0 \\
12.0 \\
11.0\end{array}$ & $\begin{array}{l}16.0 \\
16.0 \\
17.0 \\
18.0 \\
17.0\end{array}$ & $\begin{array}{r}-1 . \\
18.0 \\
18.0 \\
19.0\end{array}$ & $\begin{array}{l}24.0 \\
24.0 \\
23.0 \\
22.0 \\
21.0\end{array}$ & $\begin{array}{l}24.0 \\
24.0 \\
24.0 \\
24.0 \\
24.0\end{array}$ & $\begin{array}{l}22.0 \\
21.0 \\
21.0 \\
22.0 \\
22.0\end{array}$ \\
\hline $\begin{array}{r}6 \\
7 \\
2 \\
9 \\
10\end{array}$ & $\begin{array}{l}19.0 \\
18.0 \\
17.0 \\
17.0 \\
14.0\end{array}$ & $\begin{array}{l}7.0 \\
6.0 \\
6.0 \\
0.0 \\
7.0\end{array}$ & $\begin{array}{l}3.0 \\
4.0 \\
5.0 \\
4.0 \\
5.0\end{array}$ & $\begin{array}{l}1.0 \\
0.0 \\
0.0 \\
0.0 \\
0.0\end{array}$ & $\begin{array}{l}4.0 \\
3.0 \\
4.0 \\
3.0 \\
2.0\end{array}$ & $\begin{array}{l}4.0 \\
4.0 \\
4.0 \\
4.0 \\
7.0\end{array}$ & $\begin{array}{r}9.0 \\
9.0 \\
11.0 \\
12.0 \\
12.0\end{array}$ & $\begin{array}{l}15.0 \\
15.0 \\
16.0 \\
17.0 \\
17.0\end{array}$ & $\begin{array}{l}20.0 \\
21.0 \\
21.0 \\
21.0 \\
23.0\end{array}$ & $\begin{array}{l}22.0 \\
22.0 \\
22.0 \\
23.0 \\
24.0\end{array}$ & $\begin{array}{l}-\cdots \\
-- \\
--- \\
--\end{array}$ & $\begin{array}{l}22.0 \\
21.0 \\
21.0 \\
22.0 \\
21.0\end{array}$ \\
\hline $\begin{array}{l}11 \\
12 \\
13 \\
14 \\
15\end{array}$ & $\begin{array}{l}14.0 \\
12.0 \\
12.0 \\
14.0 \\
14.0\end{array}$ & $\begin{array}{l}8.0 \\
9.0 \\
0.0 \\
7.0 \\
7.0\end{array}$ & \begin{tabular}{l}
6.0 \\
7.0 \\
7.0 \\
\hdashline- \\
--
\end{tabular} & $\begin{array}{l}0.0 \\
0.0 \\
0.0 \\
0.0 \\
0.0\end{array}$ & $\begin{array}{l}1.0 \\
0.0 \\
0.0 \\
0.0 \\
1.0\end{array}$ & $\begin{array}{l}7.0 \\
7.0 \\
6.0 \\
4.0 \\
4.0\end{array}$ & $\begin{array}{l}12.0 \\
12.0 \\
13.0 \\
14.0 \\
\ldots-\end{array}$ & $\begin{array}{l}17.0 \\
16.0 \\
15.0 \\
16.0 \\
17.0\end{array}$ & $\begin{array}{l}23.0 \\
23.0 \\
21.0 \\
18.0 \\
20.0\end{array}$ & $\begin{array}{l}24.0 \\
25.0 \\
25.0 \\
24.0 \\
24.0\end{array}$ & $\begin{array}{c}0- \\
\overline{0} \\
\overline{23.0}\end{array}$ & $\begin{array}{r}20.0 \\
19.0 \\
18.0 \\
19.0 \\
21.0\end{array}$ \\
\hline $\begin{array}{l}16 \\
17 \\
18 \\
19 \\
20\end{array}$ & $\begin{array}{l}16.0 \\
17.0 \\
16.0 \\
14.0 \\
12.0\end{array}$ & $\begin{array}{l}6.0 \\
6.0 \\
7.0 \\
6.0 \\
6.0\end{array}$ & $\begin{array}{l}2.0 \\
4.0 \\
4.0 \\
3.0\end{array}$ & $\begin{array}{l}0.0 \\
2.0 \\
3.0 \\
3.0 \\
-.-\end{array}$ & $\begin{array}{l}1.0 \\
1.0 \\
1.0 \\
1.0 \\
2.0\end{array}$ & $\begin{array}{l}4.0 \\
6.0 \\
6.0 \\
6.0 \\
8.0\end{array}$ & $\begin{array}{l}13.0 \\
15.0 \\
16.0\end{array}$ & $\begin{array}{l}18.0 \\
18.0 \\
18.0 \\
17.0 \\
15.0\end{array}$ & $\begin{array}{l}21.0 \\
20.0 \\
20.0 \\
21.0 \\
20.0\end{array}$ & $\begin{array}{l}24.0 \\
24.0 \\
26.0 \\
26.0 \\
26.0\end{array}$ & $\begin{array}{l}24.0 \\
24.0 \\
26.0 \\
26.0 \\
26.0\end{array}$ & $\begin{array}{l}21.0 \\
21.0 \\
21.0 \\
21.0 \\
19.0\end{array}$ \\
\hline $\begin{array}{l}21 \\
22 \\
21 \\
24 \\
25\end{array}$ & $\begin{array}{l}12.0 \\
11.0 \\
11.0 \\
12.0 \\
12.0\end{array}$ & $\begin{array}{l}6.0 \\
7.0 \\
6.0 \\
6.0 \\
6.0\end{array}$ & $\begin{array}{l}6.0 \\
3.0 \\
3.0 \\
3.0 \\
3.0\end{array}$ & $\begin{array}{l}3.0 \\
3.0 \\
2.0 \\
1.0 \\
2.0\end{array}$ & $\begin{array}{l}0.0 \\
0 . c \\
1.0 \\
2.0 \\
1.0\end{array}$ & $\begin{array}{r}10.0 \\
7.0 \\
4.0 \\
3.0 \\
4.0\end{array}$ & $\begin{array}{l}17.0 \\
18.0 \\
17.0 \\
15.0 \\
13.0\end{array}$ & $\begin{array}{r}15.0 \\
15.0 \\
16.0 \\
14.0 \\
-\ldots .0\end{array}$ & $\begin{array}{l}21.0 \\
21.0 \\
22.0 \\
22.0 \\
23.0\end{array}$ & $\begin{array}{l}26.0 \\
26.0 \\
26.0 \\
26.0 \\
26.0\end{array}$ & $\begin{array}{l}26.0 \\
27.0 \\
2 R .0 \\
28.0 \\
27.0\end{array}$ & $\begin{array}{l}21.0 \\
22.0 \\
22.0 \\
23.0 \\
23.0\end{array}$ \\
\hline $\begin{array}{l}26 \\
27 \\
28 \\
29 \\
30 \\
31\end{array}$ & $\begin{array}{r}11.0 \\
12.0 \\
10.0 \\
9.0 \\
9.0 \\
9.0\end{array}$ & $\begin{array}{l}6.0 \\
7.0 \\
4.0 \\
3.0 \\
3.0 \\
-\end{array}$ & $\begin{array}{l}2.0 \\
2.0 \\
2.0 \\
2.0 \\
1.0 \\
2.0\end{array}$ & $\begin{array}{l}2.0 \\
4.0 \\
3.0 \\
4.0 \\
4.0 \\
4.0\end{array}$ & \begin{tabular}{l}
2.0 \\
2.0 \\
2.0 \\
2.0 \\
\hdashline-0
\end{tabular} & $\begin{array}{r}6.0 \\
6.0 \\
7.0 \\
9.0 \\
19.0 \\
11.0\end{array}$ & $\begin{array}{r}12.0 \\
12.0 \\
13.0 \\
13.0 \\
15.0 \\
-\end{array}$ & 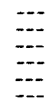 & $\begin{array}{r}23.0 \\
22.0 \\
22.0 \\
21.0 \\
22.0 \\
-.-0\end{array}$ & $\begin{array}{l}24.0 \\
24.0 \\
25.0 \\
24.0 \\
23.0 \\
24.0\end{array}$ & $\begin{array}{l}24.0 \\
23.0 \\
21.0 \\
21.0 \\
21.0 \\
20.0\end{array}$ & $\begin{array}{r}21.0 \\
19.0 \\
18.0 \\
19.0 \\
19.0 \\
-.0\end{array}$ \\
\hline IVERAGE & 14.0 & 7.0 & 3.5 & 0323 & $\begin{array}{l}2.0 \\
\text { JPPER }\end{array}$ & $\begin{array}{l}5.5 \\
\text { CREF }\end{array}$ & $\begin{array}{l}13.0 \\
\text { IASIN }\end{array}$ & -- & 21.0 & 24.0 & -- & 20.5 \\
\hline
\end{tabular}

LOCATION.--Lat $38^{\circ} 38^{\prime} 15^{\prime \prime}$, long $83^{\circ} 13^{\prime} 30^{\prime \prime}$, Scioto County, at gaging station at bridge on U.S. Highway 52 at MeGaw, 2 miles northeast of Buena Vista and' 2.8 miles upstream from nouth.

DRAINAGE AREA, $--12.8 \mathrm{sq} \mathrm{mi}$.

PERIOD OF RECORD.--Chemical analyses: October 1963 to May 1967, periodic; August 1967 to September 1968, monthly.

Water temperatures: October 1963 to September 1966, October 1967 to September 1968.

Sediment records: October 1963 to september 1968 (intermittent).

EXTRENES. - 1967-68:

Water temperatures: Minimum, freezing point on many days during January and February,

Period of record:

Water temperatures: Maximum, $30.0^{\circ} \mathrm{C} \mathrm{July} \mathrm{27,} \mathrm{1964;} \mathrm{minimum,} \mathrm{freezing} \mathrm{point} \mathrm{on} \mathrm{many} \mathrm{days} \mathrm{during} \mathrm{January} \mathrm{and}$ February 1968 .

REMARKs. - No temperature record Nov, 17 to Dec, 26, Feb. 18 to Mar. 20, May 1-9, May 31 to June 6 , July 16 to

Aug. 28. No flow Oct. 16, 20-24.

CHEMICAL ANALYSES IN MILLIGRAMS PER LITER, WATER YEAR OCTOBER 1967 TO SEPTEMBER 1968

\begin{tabular}{|c|c|c|c|c|c|c|c|c|c|c|c|c|}
\hline DATE & TIME & $\begin{array}{l}\text { OIS- } \\
\text { CHARGE } \\
\text { (CFS) }\end{array}$ & $\begin{array}{l}\text { SILICA } \\
\text { IS1021 }\end{array}$ & $\begin{array}{l}\text { (RON } \\
\text { (FE) }\end{array}$ & $\begin{array}{l}\text { MAN- } \\
\text { GANESE } \\
\text { (MN) }\end{array}$ & $\begin{array}{l}\text { CAL- } \\
\text { CIUM } \\
\text { (CA) }\end{array}$ & $\begin{array}{l}\text { MAG- } \\
\text { NE- } \\
\text { SIUM } \\
\text { IMGI }\end{array}$ & $\begin{array}{l}\text { SOOIUM } \\
\text { (NA) }\end{array}$ & $\begin{array}{l}\text { PO- } \\
\text { TAS- } \\
\text { SIUM } \\
\text { (K) }\end{array}$ & $\begin{array}{l}\text { BICAR - } \\
\text { ARNATE } \\
\text { (HCOA) }\end{array}$ & $\begin{array}{l}\text { CAR- } \\
\text { BONATE } \\
\text { (CO3) }\end{array}$ & $\begin{array}{l}\text { SULFAT } \\
\text { [SO4] }\end{array}$ \\
\hline ocr. & 1200 & .09 & 9.2 & .06 & .01 & 7.9 & 6.2 & 4.6 & 3.0 & 20 & 0 & 34 \\
\hline $\begin{array}{l}\text { NOV. } \\
16 . . . \\
\text { DEC. }\end{array}$ & 1200 & .41 & 8.4 & .02 & .02 & 7.0 & 5.2 & 4.0 & 2.6 & 18 & 0 & 28 \\
\hline${ }_{J A N}^{21}:$ & 0915 & 2.2 & 9.2 & .02 & .04 & 6.5 & 3.8 & 3.4 & 1.7 & 15 & 0 & 25 \\
\hline $\begin{array}{l}23 \ldots \\
F F 8 .\end{array}$ & 1640 & 30 & 8.0 & .08 & .05 & 4.0 & 3.2 & 2.4 & 1.6 & 10 & 0 & 20 \\
\hline${ }_{\text {MAR. }}^{14 \ldots}$ & 1825 & 2.1 & -- & .01 & .27 & 4.9 & 3.7 & $2 \cdot \mathrm{B}$ & 1.4 & 11 & 0 & 22 \\
\hline APR... & 1430 & 17 & 8.9 & .02 & .05 & 3.6 & 3.0 & 2.2 & 1.6 & 9 & 0 & 20 \\
\hline$\underset{\operatorname{MAY}}{18} \cdot$. & 1215 & II & II & .00 & .07 & 3.3 & 3.3 & 2.3 & 1.8 & 10 & 0 & 10 \\
\hline$\underset{\text { JUNE }}{28 . .}$ & 1130 & 66 & 9.5 & .05 & .00 & 2.9 & 3.0 & 1.9 & 1.6 & 10 & 0 & 17 \\
\hline Juty & 1305 & 4.2 & 9.5 & .31 & .06 & 4.1 & 3.3 & 2.5 & 1.9 & 11 & 0 & 21 \\
\hline$\underset{A U G .}{17}$ & 1600 & .17 & 11 & .09 & .05 & 9.0 & 5.2 & 4.1 & 2.7 & 24 & 0 & 31 \\
\hline SEPT. & 1140 & .33 & 10 & .15 & .11 & 7.6 & 5.0 & 3.8 & 2.2 & 20 & 0 & 27 \\
\hline $26 \ldots$ & 1130 & .33 & 9.3 & .28 & .06 & 7.9 & 4.9 & 3.8 & 2.2 & 19 & 0 & 27 \\
\hline
\end{tabular}


03237280 UPPER TWIN CREEK AT MCGAW, OHIO--Continued

CHEMICAL ANALYSES IN MILLIGRAMS PER LITER, WATER YEAR OCTOBER 1967 TO SEPTEMBER 1968

\begin{tabular}{|c|c|c|c|c|c|c|c|c|c|c|c|c|}
\hline DATE & $\begin{array}{l}\text { CHLU- } \\
\text { RIDE } \\
(\mathrm{CL})\end{array}$ & $\begin{array}{l}\text { FLUUO- } \\
\text { RIOE } \\
\text { (F) }\end{array}$ & $\begin{array}{l}\text { NITRATE } \\
\text { (N03) }\end{array}$ & $\begin{array}{l}\text { TOTAL } \\
\text { PHOS- } \\
\text { PHDRUS } \\
\text { (PO4) }\end{array}$ & $\begin{array}{l}\text { OIS- } \\
\text { SOLVED } \\
\text { SOLIOS } \\
\text { (RESI- } \\
\text { OUE AT } \\
180 \text { C) }\end{array}$ & $\begin{array}{l}\text { DIS- } \\
\text { SOL VED } \\
\text { SOLIDS } \\
\text { ISIJM DF } \\
\text { CONSTI- } \\
\text { TUENTSI }\end{array}$ & $\begin{array}{l}\text { HARD- } \\
\text { NESS } \\
\text { (CA,MG) }\end{array}$ & $\begin{array}{l}\text { NDN- } \\
\text { CAR- } \\
\text { BONATE } \\
\text { HARD- } \\
\text { NESS }\end{array}$ & $\begin{array}{l}\text { SPECI- } \\
\text { FIC } \\
\text { COND- } \\
\text { UCTANCE } \\
\text { (MICRO- } \\
\text { MHOS) }\end{array}$ & $\mathrm{PH}$ & $\begin{array}{l}\text { TEMP- } \\
\text { EPATURE } \\
\text { (NEG C) }\end{array}$ & CDLOR \\
\hline $\begin{array}{l}\text { nct. } \\
26 . .\end{array}$ & 6.0 & $\cdot 1$ & .7 & .62 & 72 & 82 & 45 & 29 & 130 & 7.3 & 9 & 5 \\
\hline $\begin{array}{l}16 . . \\
\text { DEC. }\end{array}$ & 4.0 & .2 & 1.6 & .34 & 63 & 70 & 39 & 24 & 113 & 7.0 & 7 & 2 \\
\hline $\begin{array}{l}21 \ldots \\
\text { JAN. }\end{array}$ & 3.5 & .2 & 1.4 & .51 & 54 & 63 & 32 & 20 & 96 & 7.3 & 8 & 5 \\
\hline FEB. & 3.0 & .1 & 1.0 & .06 & 56 & 48 & 23 & 15 & 70 & 6.9 & 3 & 5 \\
\hline $\begin{array}{l}14 \ldots . \\
\text { MAK. }\end{array}$ & 3.0 & .0 & .8 & .02 & 57 & 53 & 27 & 18 & 81 & 6.9 & 0 & 2 \\
\hline $\begin{array}{c}20 \ldots . . \\
\text { APR. }\end{array}$ & 2.0 & .1 & .8 & .06 & 52 & 47 & 22 & 15 & 68 & 6.9 & 11 & 5 \\
\hline MAY 18 & 3.0 & .0 & .2 & .02 & 49 & 49 & 22 & 14 & 68 & 7.0 & 14 & 2 \\
\hline$\underset{\text { JUAF }}{28}$ & 2.0 & .1 & .5 & .04 & 46 & 43 & 20 & 12 & 61 & 6.8 & 13 & 7 \\
\hline $\begin{array}{l}\text { Do... } \\
\text { JULY }\end{array}$ & 2.0 & . 1 & .4 & .04 & 52 & 50 & 24 & 15 & 75 & 7.1 & 20 & $?$ \\
\hline $\begin{array}{l}17 \ldots \\
\text { AUG. }\end{array}$ & 6.0 & .0 & 2.2 & .11 & 89 & 82 & 44 & 24 & 126 & 7.3 & 30 & 5 \\
\hline $\begin{array}{l}29 . . . \\
\text { SEPT. }\end{array}$ & 4.0 & .2 & 1.6 & .06 & 78 & 71 & 40 & 23 & 113 & 7.2 & 22 & 7 \\
\hline $26 \ldots$ & 4.5 & .1 & 1.3 & .07 & 81 & 70 & 40 & 24 & 112 & 7.1 & 19 & 7 \\
\hline
\end{tabular}

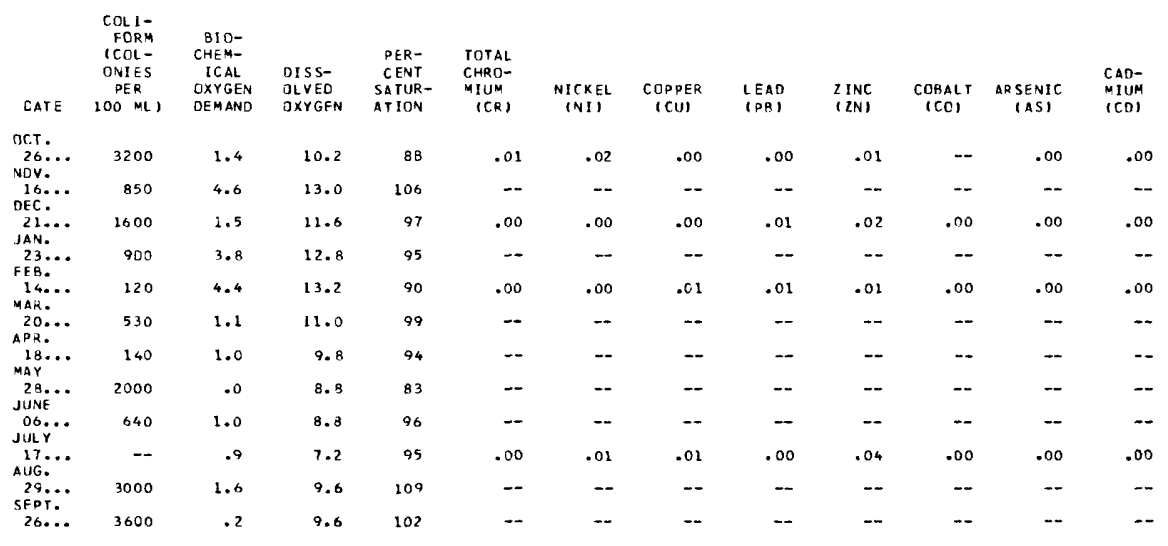

TEMPERATURE $\left({ }^{\circ} \mathrm{C}\right)$ DF HATER, WATER YEAR OCTDBER 1967 TO SEPTEMBER 1968 (THERMOGRAPH RECDRDER)

DAY

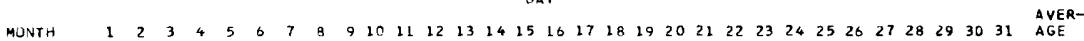

UCTOBER $\begin{array}{lllllllllllllllllllllllllllllllllllll}\text { MAXIMUM } & 15 & 28 & 19 & 21 & 21 & 21 & 21 & 17 & 20 & 20 & 16 & 12 & 12 & 16 & 16 & - & 19 & 18 & 17 & - & - & - & -- & -- & 17 & 8 & 7 & 5 & 3 & 9 & 8 & 15 \\ \text { MINIMUM } & 12 & 13 & 14 & 15 & 16 & 17 & 17 & 14 & 16 & 16 & 12 & 12 & 11 & 10 & 10 & - & 12 & 15 & 16 & - & - & -- & - & -- & 8 & 0 & 5 & 4 & 2 & 2 & 7 & 11\end{array}$

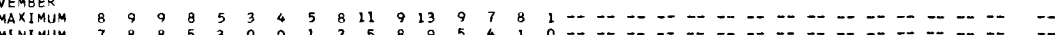
MI NI MUM

MAXIMUM
MINIMUM

MINIMUM

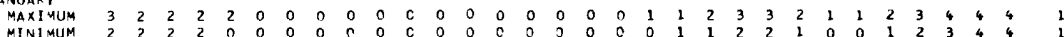

MINIMUM
FEBRUARY

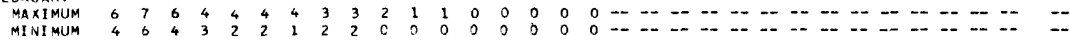

MARCH

MAXIMUM MINIMU

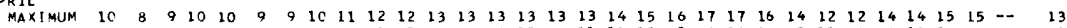

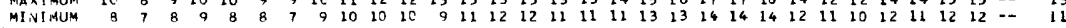
MAY MAXIMUM MAX

MAXIMUM -

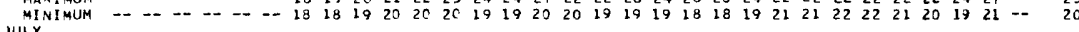

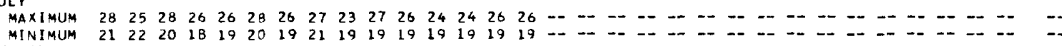
AUGUST

MAXIMUM SEPTEMUER

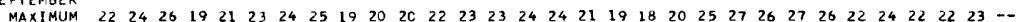

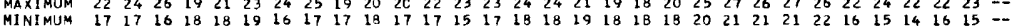


03237280 UPPER TWIN CREEK AT MCGAW, OHIO--Continued

PERIODIC DETERMINATIONS OF SUSPENDED-SEDIMENT DISCHARge, WATER YEAR OCTOBER 1967 TO SEPTEMBER 1968

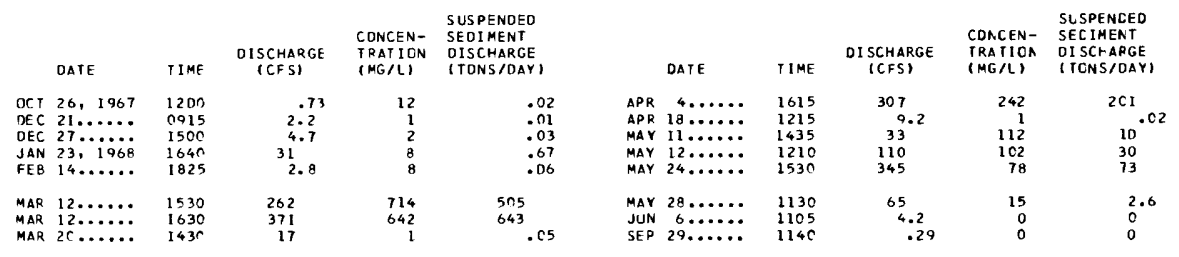

LITTLE MIAMI RIVER BASIN

03247500 EAST FORK LITTLE MIAMI RIVER AT PERINTONN, OHIO

LOCATION.--Lat $39^{\circ} 08^{\prime} 13^{\prime \prime}$, long $84^{\circ} 14^{\prime} 17^{\prime \prime}$, Clermont County, at gaging station at highway bridge at Perintown

5 miles upstream from mouth.

DRA INAGE AREA. $--476 \mathrm{sq} \mathrm{mi}$.

PER IOD OF RECORD. --Chemical analyses: October 1965 to September 1968

Water temperatures: October 1965 to September 1968.

EXTREMES. -1967-68:

Speciflc conductance: Maximura da11y, 631 micromhos Feb. 25, 27; mintmum da11y, 175 micromhos May 27.

Water temperatures: Maximum, 28.0 $\mathrm{C}$ Aug. 21-24; minimum, freezing point on several days during December and February.

Pertod of record:

Specific conductance: Maximum daily, 641 micromhos Mar. 1, 1967; minimum daily, 172 micromhos Jan. 7, 1966 . pater temperatures: Maximum, 28. $0^{\circ} \mathrm{C}$ Aug. 21-24, 1968; minimum, freezing point on several days during winter
periods in 1966-68.

REMARKS. --Samples for iron and manganese were filtered clear when collected. Daily samples were collected at this station and samples were selected for analysis on the following basis: (1) Maximum daily specific conductance for each month, (2) minimum daily specific conductance for each month, (3) median daily specific conductance for each month, and (4) special sample each month to further define the quality of water. Occa-

CHEMICAL ANALYSES IN MILLigRAMS PER Liter, WATER YEAR OCTOBER 1967 TO SEPTEMBER 1968

\begin{tabular}{|c|c|c|c|c|c|c|c|c|c|c|}
\hline DATE & $T I A E$ & $\begin{array}{l}\text { DIS- } \\
\text { CHARGE } \\
\text { (CFS) }\end{array}$ & $\begin{array}{l}\text { IRON } \\
\text { (FE) }\end{array}$ & $\begin{array}{l}\text { MAN- } \\
\text { GANESE } \\
\text { (MN) }\end{array}$ & $\begin{array}{l}\text { BICAR- } \\
\text { BDNATE } \\
\text { (HCD 3) }\end{array}$ & $\begin{array}{l}\text { CAR- } \\
\text { BDNATE } \\
\text { (CO3) }\end{array}$ & $\begin{array}{l}\text { SULFATE } \\
\text { (SD4) }\end{array}$ & $\begin{array}{l}\text { CHLO- } \\
\text { RIDE } \\
\text { (CL) }\end{array}$ & $\begin{array}{l}\text { FLUO- } \\
\text { RINE } \\
\text { IF }\end{array}$ & $\begin{array}{l}\text { NITRATE } \\
\text { (ND3) }\end{array}$ \\
\hline \multicolumn{11}{|l|}{ DCT. } \\
\hline $04 \ldots$ & 0700 & 1.5 & $\because$ & $=-$ & 264 & 0 & 59 & 26 & .2 & 1.4 \\
\hline $09 .$. & 0700 & 3.8 & -- & $\overline{0}$ & 148 & 0 & 54 & 18 & .2 & 1.5 \\
\hline $\begin{array}{l}17 \ldots \\
20 \ldots\end{array}$ & 1300 & 4.8 & .06 & .02 & $\cdots$ & - & $-\bar{c}$ & +- & -- & - \\
\hline $\begin{array}{c}20 . . . \\
\text { vov. }\end{array}$ & 0700 & 6.0 & -- & - & 276 & c & 57 & 24 & .2 & .8 \\
\hline \multicolumn{11}{|l|}{ vov. } \\
\hline $01 \ldots$ & 0800 & 23 & -- & -- & 240 & c & 69 & 36 & .2 & 2.2 \\
\hline $\begin{array}{l}04 \ldots . . \\
06 . .\end{array}$ & $\begin{array}{l}0800 \\
1045\end{array}$ & $\begin{array}{l}268 \\
109\end{array}$ & -- & - & 132 & 0 & 49 & 12 & .2 & 2.0 \\
\hline $06 \ldots$ & 1045 & 109 & .19 & .10 & -- & - & $=$ & - & -- & - \\
\hline $\begin{array}{l}19 . . \\
\text { DEC. }\end{array}$ & 0800 & 73 & - & -- & 194 & 0 & 58 & 20 & .1 & 1.0 \\
\hline $12 \ldots$ & -- & 1980 & - & - & 94 & 0 & 37 & 10 & .2 & 7.6 \\
\hline $19 .$. & 1245 & 663 & .40 & .06 & - & - & - & -- & -- & -- \\
\hline $20 \ldots$ & -- & 468 & - & -- & $12 B$ & 0 & 48 & 12 & .2 & 9.7 \\
\hline $31 \ldots$ & - & so & -- & $-\infty$ & 202 & 0 & 57 & 18 & .2 & 11 \\
\hline $\begin{array}{l}\text { JAN. } \\
\text { 31.... }\end{array}$ & 0800 & 4830 & -- & -- & 88 & 0 & 32 & 12 & .3 & 12 \\
\hline \multicolumn{11}{|l|}{ FEB. } \\
\hline 0 LL... & 0800 & 1330 & -- & -- & 86 & 0 & 38 & 14 & .4 & 12 \\
\hline $17 \ldots$ & 0800 & 55 & -- & -- & 218 & 12 & 65 & 23 & .3 & 6.3 \\
\hline $2 L \ldots$ & 0930 & 38 & .04 & .04 & - & - & - & -- & -- & -- \\
\hline $\begin{array}{r}25 . . \\
M A R .\end{array}$ & & .2 & 5. R \\
\hline $\begin{array}{l}\text { MAR. } \\
01 . . .\end{array}$ & 0800 & 34 & -. & -- & 240 & 16 & 69 & 28 & .2 & 7.3 \\
\hline $17 \ldots$ & $0 B 00$ & 1200 & -- & $=$ & 150 & 0 & 53 & 22 & .2 & 5.5 \\
\hline 1 в... & 1100 & 673 & .15 & .02 & - & $\cdots$ & -- & -- & -- & - \\
\hline $\begin{array}{l}26 \ldots \\
A P R .\end{array}$ & 0800 & 3710 & -- & - & 78 & 0 & 26 & 10 & .2 & B.2 \\
\hline $05 \ldots$ & 0800 & 3200 & -- & - & 102 & 0 & 31 & 8.0 & .2 & 6.6 \\
\hline $13 \ldots$ & OA90 & 174 & -- & -- & 232 & D & 50 & 16 &.$?$ & $3 . B$ \\
\hline $22 \ldots$ & 0930 & 360 & .13 & .03 & - & - & $\cdots$ & -- & -- & - \\
\hline $27 \ldots$ & 0800 & 346 & - & - & 176 & 0 & 42 & 13 & .2 & 3.3 \\
\hline \multicolumn{11}{|l|}{ MAY } \\
\hline $06 \ldots$ & 0800 & 65 & $=$ & 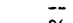 & 219 & 0 & 49 & 16 & -1 & 4.0 \\
\hline $08 \ldots$ & 1000 & 64 & .17 & .06 & $-\overline{-}$ & -- & -- & -- & -- & $\cdots$ \\
\hline $10 \ldots$ & 0800 & 835 & -- & - & 169 & 0 & 41 & 12 & .3 & 3.8 \\
\hline$\underset{\text { JUNE }}{27 . .}$ & 0800 & 23600 & - & -- & 78 & 0 & 16 & 3.0 &.$^{2}$ & 4.4 \\
\hline \multicolumn{7}{|l|}{ JUNE } & & & & \\
\hline $10 \ldots$ & 1045 & 115 & .12 & .02 & 132 & $\ldots$ & 28 & $\begin{array}{l}3.0 \\
-.\end{array}$ & $\because 4$ & 3.4 \\
\hline $17 \ldots$ & $0 B O O$ & 69 & - & - & 220 & 0 & 45 & 16 & .2 & 2.3 \\
\hline $28 \ldots$ & 0800 & 34 & -- & - & 250 & 0 & 47 & 18 & .2 & 1.5 \\
\hline \multicolumn{11}{|l|}{ JULY } \\
\hline $12 \ldots$ & 0800 & 21 & $\ddot{n}$ & $\bar{a}$ & 260 & 0 & 56 & 22 & $\therefore 1$ & 1.1 \\
\hline $23 \ldots$ & c915 & 32 & .08 & .06 & & $-\overline{6}$ & $\ddot{3}$ & $12^{--}$ & & 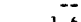 \\
\hline $24 \ldots$ & OROO & 27 & $\cdots$ & $-\infty$ & 178 & 6 & 37 & 12 & .2 & 1.6 \\
\hline \multicolumn{8}{|l|}{ AUG. } & & & \\
\hline $11 \ldots$ & 0800 & 2400 & -- & -- & 88 & 0 & 18 & 4.0 & .2 & 3.4 \\
\hline $12 \ldots$ & 1030 & 367 & .29 & .04 & $\cdots$ & $\cdots$ & 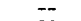 & - & -- & - \\
\hline $19 \ldots$ & 0800 & 120 & - & - & 164 & 6 & 30 & 12 & .2 & 4.1 \\
\hline $\begin{array}{l}30 \ldots . . \\
\text { SEPT. }\end{array}$ & 0800 & 14 & $=$ & - & 218 & 12 & 39 & 14 & .2 & 2.5 \\
\hline $04 \ldots$ & 0800 & 11 & - & - & 200 & 8 & 42 & 16 & .2 & 1.9 \\
\hline $17 \ldots$ & 0800 & 9.0 & $-\overline{0}$ & $-\overline{0}$ & 242 & 0 & 44 & 18 & .2 & 1.1 \\
\hline $17 \ldots$ & 1000 & $\ddot{0}$ & .02 & .06 & $\overline{202}$ & $\overline{0}$ & -- & $20^{-}$ & .2 & .8 \\
\hline & 0800 & 7.0 & - & - & 262 & 0 & 44 & & & \\
\hline
\end{tabular}


03247500 EAST FORK LITTLE MIAMI RIVER AT PERINTONN, OHIO--Continued

CHEMICAL ANALYSES IN MILLIGRAMS PER LITER, WATER YEAR OCTOBER 1967 TO SEPTEMBER 1968

\begin{tabular}{|c|c|c|c|c|c|c|c|c|c|}
\hline OATE & $\begin{array}{l}\text { TOTAL } \\
\text { PHOS- } \\
\text { PHORUS } \\
(P D) 4\}\end{array}$ & $\begin{array}{l}\text { OIS- } \\
\text { SOLVEO } \\
\text { SOLIDS } \\
\text { IRESI- } \\
\text { DUE AT } \\
180 \mathrm{CI}\end{array}$ & $\begin{array}{l}\text { HARO- } \\
\text { NFSS } \\
\text { CA.MGI }\end{array}$ & $\begin{array}{l}\text { NON- } \\
\text { CAR- } \\
\text { BONATE } \\
\text { HARO- } \\
\text { NES'S }\end{array}$ & $\begin{array}{l}\text { SPECI- } \\
\text { FIC } \\
\text { COND- } \\
\text { UCTANCE } \\
\text { IMICRO- } \\
\text { MHOSI }\end{array}$ & PH & $\begin{array}{l}\text { TEMP- } \\
\text { ERATURE } \\
\text { IDEG CI }\end{array}$ & $\begin{array}{l}\text { DISS- } \\
\text { OLVED } \\
\text { OXYGEN }\end{array}$ & $\begin{array}{l}\text { PER- } \\
\text { CENT } \\
\text { SATUR- } \\
\text { ATION }\end{array}$ \\
\hline \multicolumn{10}{|l|}{ OCT. } \\
\hline $\begin{array}{l}04 \ldots . . . \\
04 . .\end{array}$ & .47 & 382 & 276 & 59 & 575 & 8.1 & 16 & -- & -- \\
\hline $17 \ldots$ & -10 & 240 & 177 & 56 & 412 & $\begin{array}{l}7.8 \\
---\end{array}$ & 16 & 7.0 & $\overline{71}$ \\
\hline $\begin{array}{l}20 \ldots . . \\
\text { Nov. }\end{array}$ & .41 & 374 & 286 & 60 & 599 & 7.5 & 13 & -- & -- \\
\hline $01 \ldots$ & 2.2 & 400 & 270 & 73 & 526 & 8.1 & 12 & $=$ & -- \\
\hline $\begin{array}{l}04 \ldots \\
06 \ldots\end{array}$ & 1.2 & 226 & 144 & 36 & $\begin{array}{l}345 \\
--\end{array}$ & 7.2 & 10 & 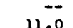 & 92 \\
\hline $\begin{array}{c}19 . . \\
\text { UEC. }\end{array}$ & 1.2 & $31 \mathrm{C}$ & 216 & 57 & 479 & 7.8 & 5 & 11 & -19 \\
\hline${ }_{19}^{12} \ldots$ & 1.0 & 158 & 118 & 41 & 272 & 7.4 & 9 & -- & -- \\
\hline $20 \ldots$ & .60 & 200 & 158 & 53 & $\overline{348}$ & 7.2 & $\overline{5}$ & 11.0 & 92 \\
\hline $31 \ldots$ & 1.2 & 272 & 234 & 68 & 491 & 7.7 & 0 & - & - \\
\hline $\begin{array}{l}31 \ldots . . \\
F E B .\end{array}$ & .43 & 152 & 116 & 44 & 277 & 7.0 & 4 & - & -- \\
\hline $01 \ldots$ & .45 & 200 & 123 & 52 & 276 & 7.9 & 4 & - & -- \\
\hline $17 \ldots$ & .42 & $\begin{array}{l}386 \\
--\end{array}$ & 284 & 85 & 574 & 8.t & 1 & - & -7 \\
\hline${ }_{25}^{21} \ldots$ &.$\overline{58}$ & 423 & $3 \overline{15}$ & $\overline{85}$ & $6 \overrightarrow{3 i}$ & 8.1 & $\overline{1}$ & 14.0 & 98 \\
\hline MAR." & & & & & & & & & \\
\hline $\begin{array}{l}01 \ldots . . \\
17 . .\end{array}$ & $\begin{array}{l}.50 \\
.26\end{array}$ & $\begin{array}{l}394 \\
264\end{array}$ & $\begin{array}{l}310 \\
188\end{array}$ & 86 & 622 & $\begin{array}{l}8.5 \\
8.2\end{array}$ & $\begin{array}{l}1 \\
6\end{array}$ & $=$ & $=$ \\
\hline $18 \ldots$ & $\because$ & & -- & - & -- & $\because$ & $\therefore$ & 11.0 & 90 \\
\hline $26 \ldots$ & .25 & 143 & 99 & 35 & 225 & 7.9 & 4 & - & -- \\
\hline $05 .$. & .48 & 158 & 116 & 32 & 257 & 7.3 & 11 & 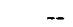 & -- \\
\hline $13 \ldots$ & .40 & 296 & 248 & 58 & 504 & 7.6 & 14 & $\because$ & 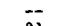 \\
\hline $27 \ldots$ & .51 & 232 & 203 & 59 & 398 & 7.5 & 13 & -- & -- \\
\hline $\begin{array}{c}\text { MAY } \\
\text { OS. }\end{array}$ & .46 & 268 & 240 & 60 & 499 & 7.5 & 14 & -- & -- \\
\hline $08 \ldots$ & -- & -- & $\because$ & -- & - & - & 17 & 9.4 & 97 \\
\hline${ }_{27}^{11} \ldots$ & .54 & $\begin{aligned} 240 \\
98\end{aligned}$ & $\begin{array}{l}184 \\
82\end{array}$ & 46 & 391 & 7.9 & 16 & $\overline{-}$ & $=$ \\
\hline JUNE & & & & & & & 17 & - & - \\
\hline $\begin{array}{l}04 \ldots . \\
10 \ldots\end{array}$ & . 35. & 212 & 158 & 34 & 328 & 7.1 & $\begin{array}{l}19 \\
25\end{array}$ & $\overline{2}$ & $\bar{a}$ \\
\hline $17 \ldots$ & .38 & 304 & 230 & 50 & 467 & 8.0 & 22 & - & $\because$ \\
\hline $28 \ldots$ & .45 & 330 & 257 & 52 & 521 & 7.6 & -- & -- & -- \\
\hline JULY & & & & & & & & & \\
\hline $12 \ldots$ & .80 & 328 & 272 & 58 & 556 & 8.0 & 25 & - & -- \\
\hline $23 \ldots$ & & $\overline{30}$ & $\vec{a}$ & 37 & $39 \overline{9}$ & $\ddot{s}$ & 37 & 6.6 & 80 \\
\hline $26 \ldots$ & .32 & $\begin{array}{l}236 \\
134\end{array}$ & 193 & 37 & 396 & $\begin{array}{l}8.5 \\
7.8\end{array}$ & $\begin{array}{l}27 \\
24\end{array}$ & $\overline{-}$ & $=$ \\
\hline AUG." & .39 & & & & & & & - & -- \\
\hline $11 \ldots$ & .31 & 116 & $7 P$ & 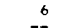 & 191 & 7.2 & 24 & - & - \\
\hline $12 \ldots$ & .29 & 206 & $1 \overline{74}$ & 30 & & 8.4 & 21 & 6.6 & 73 \\
\hline $30 \ldots$ & .22 & 286 & $\begin{array}{l}214 \\
214\end{array}$ & $\begin{array}{l}0 \\
10\end{array}$ & $4 \mathrm{B3}$ & 8.6 & $\begin{array}{l}26 \\
20\end{array}$ & $=$ & - \\
\hline SEPT. & & & & & & & & & \\
\hline $\begin{array}{l}04 \ldots \\
17 \ldots\end{array}$ & $\begin{array}{l}.10 \\
.15\end{array}$ & $\begin{array}{l}258 \\
284\end{array}$ & $\begin{array}{l}220 \\
244\end{array}$ & $\begin{array}{l}42 \\
46\end{array}$ & $\begin{array}{l}449 \\
503\end{array}$ & $\begin{array}{l}8.5 \\
7.8\end{array}$ & $? 2$ & $=$ & $=$ \\
\hline $17 \ldots$ & - & -1 & -76 & - & -- & $\cdots$ & 20 & 8.2 & 89 \\
\hline $30 \ldots$ & .18 & 298 & 260 & 45 & 535 & 8.0 & & $=$ & -- \\
\hline
\end{tabular}

SPECIFIC CONDUCTANCE (MICROMHOS AT $25^{\circ} \mathrm{C}$ ), WATER YEAR OCTOBER 1967 TO SEPTEMBER 1968 IONCE-DAILY MEASUREMENT BETWEEN 0700 AND 08001

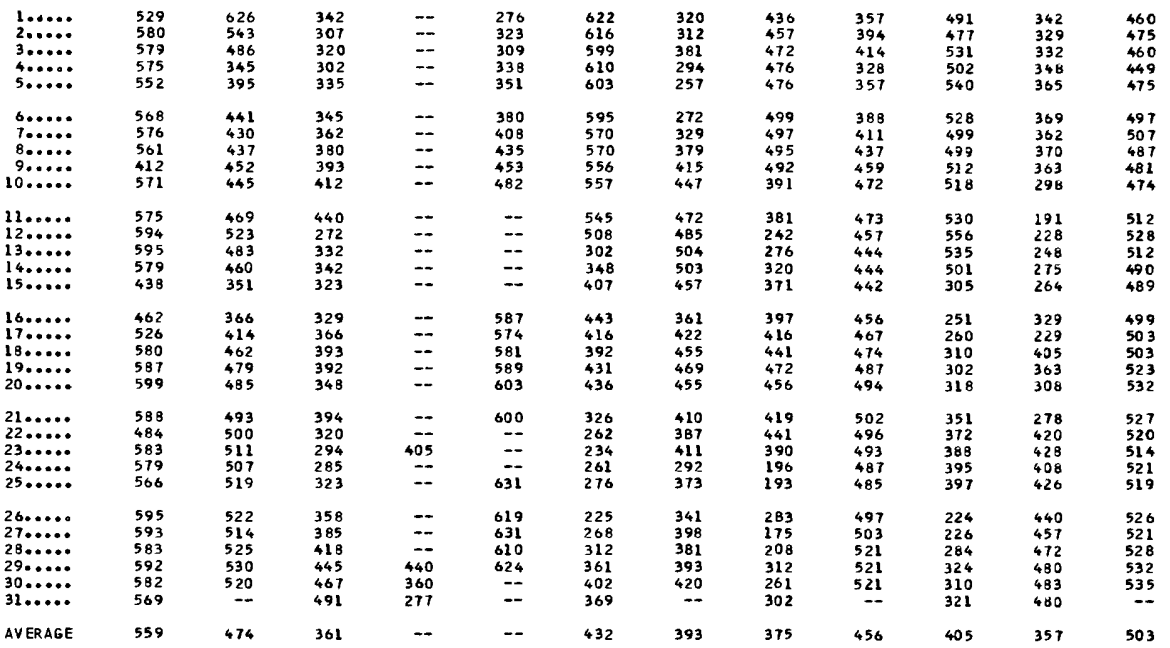


03247500 EAST FORK LITTLE YIAMI RIVER AT PERINTOWN, OHIO--Continued

TEMPERATURE (OC) OF WATER, WATER YEAR OCTOBER 1967 TO SEPTEMBER 1968

\begin{tabular}{|c|c|c|c|c|c|c|c|c|c|c|c|c|}
\hline \multirow{2}{*}{ DAY } & \multicolumn{12}{|c|}{$E-D A$} \\
\hline & $O C T$ & NOV & DEC & JAN & FEB & $M A R$ & $A P R$ & MAY & juin & Jut & AUG & SEP \\
\hline 1 & 13.0 & 12.0 & 2.0 & -- & 4.0 & 1.0 & 12.0 & 16.0 & 16.0 & 23.0 & 24.0 & 22.0 \\
\hline 2 & 14.0 & 12.0 & 2.0 & -- & 7.0 & 2.0 & $i_{1.0}$ & 16.0 & 17.0 & 26.0 & 24.0 & 21.0 \\
\hline 3 & 16.0 & 12.0 & 4.0 & --- & 4.0 & 1.0 & 11.0 & 18.0 & 19.0 & 24.0 & 24.0 & 21.0 \\
\hline 4 & $16 . \mathrm{C}$ & 10.0 & 3.0 & -- & 3.0 & 1.0 & 13.0 & 19.0 & 19.0 & 22.0 & 24.0 & 22.0 \\
\hline 5 & 18.0 & 3.0 & 3.0 & $m$ & 3. C & 2.0 & 11.0 & 18.0 & 20.0 & 22.0 & 24.0 & 21.0 \\
\hline 6 & 18.0 & 6.0 & 4.0 & -- & 3.0 & 4.0 & 9.0 & 14.0 & 22.0 & 22.0 & 26.0 & 20.0 \\
\hline 7 & 14.0 & 6.0 & 5.0 & --- & 3.0 & 3.0 & 8.0 & 15.0 & $22 \cdot 0$ & 23.0 & 27.0 & 20.0 \\
\hline 8 & 16.0 & 4.0 & 6.0 & -- & 3.0 & 3.0 & 12.0 & 17.0 & 23.0 & 24.0 & $>7.0$ & 20.0 \\
\hline 9 & 16.0 & 0.0 & 5.0 & --- & 2.0 & 6.0 & 12.0 & 19.0 & 23.0 & 24.0 & 27.0 & 20.0 \\
\hline 10 & 14.0 & 7.0 & 3.0 & -- & 0.0 & 9.0 & 12.0 & 16.0 & 24.0 & 24.0 & 27.0 & 20.0 \\
\hline 11 & 13.0 & 7.0 & 7.0 & -- & $-\cdots$ & 8.0 & 11.0 & 16.0 & 25.0 & 24.0 & 24.0 & $19 . \mathrm{C}$ \\
\hline 12 & 9.0 & 10.0 & 9.0 & $\ldots$ & --- & 7.0 & 12.0 & 10.0 & 26.0 & 25.0 & 22.0 & 19.0 \\
\hline 13 & 11.0 & 9.0 & 7.0 & --- & -- & 7.0 & 14.0 & 15.0 & 20.0 & 26.0 & 23.0 & 18.0 \\
\hline 14 & 13.0 & 7.0 & 8.0 & -- & -- & 1.0 & 16.0 & 120 & 22.0 & 25.0 & 23.0 & 18.0 \\
\hline is & 13.0 & 0.0 & 0.0 & --- & -- & 3.0 & 13.0 & 19.0 & 22.0 & 24.0 & 23.0 & 19.0 \\
\hline 16 & 15.0 & 4.0 & 3.0 & --- & 1.0 & 6.0 & 12.0 & 21.0 & 23.0 & 22.0 & 24.0 & 19.0 \\
\hline 17 & $16 . \mathrm{C}$ & 7.0 & 2.0 & --- & 1.0 & 6.0 & 14.0 & 20.0 & 22.0 & 23.0 & 25.0 & 20.0 \\
\hline 18 & $1 b .0$ & $\forall .0$ & 4.0 & --- & 1.0 & 7.0 & 13.0 & 18.0 & 22.0 & 24.0 & 26.0 & 19.0 \\
\hline 19 & 13.0 & 5.0 & 5.0 & $\rightarrow$ & 1.0 & 8.0 & 16.0 & 10.0 & 22.0 & 26.0 & 26.0 & 18.0 \\
\hline$? 0$ & 13.0 & 5.0 & 5.0 & $\cdots$ & 2.0 & 11.0 & 17.0 & 16.0 & 22.0 & 27.0 & 27.0 & 19.0 \\
\hline 11 & 11.0 & 5.0 & 7.0 & -- & 0.0 & 9.0 & 13.0 & 16.0 & 22.0 & 26.0 & 28.0 & 20.0 \\
\hline$\because 2$ & 9.0 & 7.0 & 9.0 & --- & -- & 8.0 & 17.0 & 16.0 & 22.0 & 26.0 & 28.0 & 20.0 \\
\hline$\because 3$ & 9.0 & 6.0 & 6.0 & 1.0 & --- & 2.0 & 18.0 & 16.0 & 24.0 & 26.0 & 28.0 & 21.0 \\
\hline 14 & 11.0 & 7.0 & 3.0 & -- & -- & 2.0 & 16.0 & 16.0 & 24.0 & 27.0 & 28.0 & 22.0 \\
\hline is & 12.0 & 6.0 & 3.0 & --- & 1.0 & 3.0 & 16.0 & 16.0 & 24.0 & 27.0 & 27.0 & 25.0 \\
\hline ?6 & 10.0 & 6.0 & 2.0 & --- & 1.0 & 4.0 & 12.0 & 17.0 & 24.0 & 24.0 & 25.0 & 19.0 \\
\hline$i 7$ & 11.0 & 5.0 & 0.0 & --- & 2.0 & 8. C & 13.0 & 17.0 & 22.0 & 24.0 & 22.0 & 17.0 \\
\hline$\therefore 0$ & 9.0 & 4.0 & 0.0 & -- & 2.0 & 11.0 & 13.0 & 17.0 & $-\cdots$ & $26 . \mathrm{C}$ & 21.0 & 17.0 \\
\hline :9 & 8.0 & 3.0 & 0.0 & 1.0 & 2.0 & 12.0 & 15.0 & 16.0 & 21.0 & 24.0 & 19.0 & $17 . \mathrm{C}$ \\
\hline 10 & $\forall .0$ & 3.0 & 0.0 & 3.0 & -- & 13.0 & $16 . \mathrm{C}$ & 15.0 & 23.0 & 23.0 & 20.0 & 17.0 \\
\hline 31 & 11.0 & -- & 0.0 & 4.0 & -- & 14.0 & -- & 15.0 & $\cdots$ & 24.0 & 22.0 & 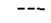 \\
\hline VERAGE & 12.5 & 7.0 & 4.0 &.- & $-\ldots$ & 6.0 & 13.5 & 17.0 & 22.0 & 24.5 & 24.5 & 19.5 \\
\hline
\end{tabular}

\section{LICKING RIVER BASIN}

03249500 LICKING RIVER AT FARMERS, KY.

LOCATION, --Lat $38^{\circ} 08^{\prime} 24^{\prime \prime}$, long $83^{\circ} 33^{\prime} 26^{\prime \prime}$, Rowan County, at auxiliary gaging station near right bank at bridge on S. Highway $60,300 \mathrm{ft}$ upstream from Chesapeake and Oh10 Railway bridge, $.8 \mathrm{mile}$ west of Farmers, $1.1 \mathrm{mile}$ upstream from Triplett Creek, 3.4 .

DRAINAGE AREA. --831 sq mi.

PERIOD OF RECORD.--Chemical analyses: September 1949 to August 1950.

Water temperatures: October 1949 to September 1968

EXTREUES. - -1967-68:

Water temperatures: Maximum, $26.0^{\circ} \mathrm{C}$ Aug. $7,24,25$; minimum, freezing point on many days during December to March.

Period of record:

Water temperatures: Maximum, $33.5^{\circ} \mathrm{C}$ July 19, 1951 ; minimum, freezing point on many days during winter periods. TEMPERATURE $\left({ }^{\circ} \mathrm{C}\right)$ OF WATER, WATER YEAR OCTOBER 1967 TO SEPTEMBER 1968 (ONCE-DAILY MEASUREMENT AT 0700)

\begin{tabular}{|c|c|c|c|c|c|c|c|c|c|c|c|c|}
\hline DAY & $\mathrm{SCT}$ & NCV & DEC & JAA & FEB & $M A R$ & $\triangle P R$ & MAY & JUN & Jut & AUG & SEP \\
\hline $\begin{array}{l}1 \\
2 \\
3 \\
4 \\
5\end{array}$ & $\begin{array}{r}19.0 \\
20.0 \\
-- \\
-- \\
--\end{array}$ & $\begin{array}{l}--- \\
-- \\
--- \\
---\end{array}$ & $\begin{array}{l}=- \\
=- \\
=- \\
=-\end{array}$ & \begin{tabular}{l}
--- \\
0.0 \\
\hdashline-- \\
---
\end{tabular} & $\begin{array}{l}7.0 \\
7.0 \\
6.0 \\
3.0 \\
2.0\end{array}$ & $\begin{array}{l}0.0 \\
1.0 \\
0.0 \\
1.0 \\
1.0\end{array}$ & $\begin{array}{l}12.0 \\
10.0 \\
11.0 \\
11.0 \\
10.0\end{array}$ & $\begin{array}{l}13.0 \\
13.0 \\
16.0 \\
16.0 \\
16.0\end{array}$ & $\begin{array}{l}16.0 \\
16.0 \\
16.0 \\
17.0 \\
17.0\end{array}$ & $\begin{array}{l}22.0 \\
22.0 \\
22.0 \\
21.0 \\
21.0\end{array}$ & $\begin{array}{l}23.0 \\
23.0 \\
24.0 \\
24.0 \\
24.0\end{array}$ & $\begin{array}{l}20.0 \\
20.0 \\
20.0 \\
21.0 \\
21.0\end{array}$ \\
\hline $\begin{array}{r}6 \\
8 \\
8 \\
0 \\
: 0\end{array}$ & $\begin{array}{l}-- \\
-- \\
--\end{array}$ & \begin{tabular}{c}
-- \\
6.0 \\
\hdashline- \\
---
\end{tabular} & $\begin{array}{r}14.0 \\
7.0 \\
5.0\end{array}$ & $\begin{array}{l}--- \\
--- \\
--- \\
---\end{array}$ & $\begin{array}{l}2.0 \\
1.0 \\
2.0 \\
2.0 \\
1.0\end{array}$ & $\begin{array}{l}3.0 \\
2.0 \\
3.0 \\
1.0 \\
3.0\end{array}$ & $\begin{array}{r}10.0 \\
9.0 \\
9.0 \\
10.0 \\
9.0\end{array}$ & $\begin{array}{l}14.0 \\
14.0 \\
15.0 \\
10.0 \\
16.0\end{array}$ & $\begin{array}{l}19.0 \\
18.0 \\
19.0 \\
20.0 \\
22.0\end{array}$ & $\begin{array}{l}21.0 \\
21.0 \\
22.0 \\
23.0 \\
23.0\end{array}$ & $\begin{array}{l}24.0 \\
26.0 \\
25.0 \\
25.0 \\
? 4.0\end{array}$ & $\begin{array}{l}20.0 \\
19.0 \\
10.0 \\
19.0 \\
21.0\end{array}$ \\
\hline $\begin{array}{r}+1 \\
2 \\
.3 \\
\vdots 4 \\
5\end{array}$ & $\begin{array}{l}-- \\
-- \\
-- \\
--\end{array}$ & $\ddot{--}$ & $\begin{array}{l}6.0 \\
7.0 \\
7.0 \\
5.0 \\
6.0\end{array}$ & $\begin{array}{l}-- \\
\cdots- \\
\cdots- \\
--\end{array}$ & $\begin{array}{l}0.0 \\
0.0 \\
0.0 \\
0.0 \\
0.0\end{array}$ & $\begin{array}{l}7.0 \\
5.0 \\
3.0 \\
2.0 \\
3.0\end{array}$ & $\begin{array}{r}9.0 \\
11.0 \\
13.0 \\
12.0 \\
12.0\end{array}$ & $\begin{array}{l}17.0 \\
16.0 \\
18.0 \\
18.0 \\
18.0\end{array}$ & $\begin{array}{l}22.0 \\
23.0 \\
22.0 \\
21.0 \\
22.0\end{array}$ & $\begin{array}{l}24.0 \\
24.0 \\
24.0 \\
24.0 \\
24.0\end{array}$ & $\begin{array}{l}24.0 \\
22.0 \\
21.0 \\
21.0 \\
21.0\end{array}$ & $\begin{array}{l}20.0 \\
18.0 \\
18.0 \\
18.0 \\
18.0\end{array}$ \\
\hline $\begin{array}{r}6 \\
7 \\
-8 \\
: 9 \\
? 0\end{array}$ & $\begin{array}{l}-- \\
-- \\
-- \\
--\end{array}$ & 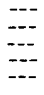 & $\begin{array}{l}3.0 \\
2.0 \\
5.0 \\
-0.0\end{array}$ & $\begin{array}{l}-\cdots \\
--- \\
-\cdots \\
\cdots-\end{array}$ & $\begin{array}{l}0.0 \\
0.0 \\
0.0 \\
0.0 \\
0.0\end{array}$ & $\begin{array}{l}6.0 \\
6.0 \\
5.0 \\
7.0 \\
8.0\end{array}$ & $\begin{array}{l}13.0 \\
13.0 \\
14.0 \\
15.0 \\
15.0\end{array}$ & $\begin{array}{l}18.0 \\
18.0 \\
17.0 \\
17.0 \\
17.0\end{array}$ & $\begin{array}{l}22.0 \\
22.0 \\
20.0 \\
21.0 \\
22.0\end{array}$ & $\begin{array}{l}23.0 \\
23.0 \\
24.0 \\
25.0 \\
24.0\end{array}$ & $\begin{array}{l}22.0 \\
22.0 \\
23.0 \\
23.0 \\
24.0\end{array}$ & $\begin{array}{l}19.0 \\
19.0 \\
18.0 \\
18.0 \\
18.0\end{array}$ \\
\hline $\begin{array}{l}1 \\
! 2 \\
\vdots 3 \\
: 4 \\
? 5\end{array}$ & $\overline{--}$ & $\begin{array}{l}--- \\
--- \\
--- \\
---\end{array}$ & $\begin{array}{l}4.0 \\
4.0 \\
5.0 \\
4.0 \\
4.0\end{array}$ & $\begin{array}{l}--- \\
--- \\
-- \\
2.0 \\
0.0\end{array}$ & $\begin{array}{l}0.0 \\
0.0 \\
1.0 \\
0.0 \\
0.0\end{array}$ & $\begin{array}{l}9.0 \\
9.0 \\
6.0 \\
4.0 \\
4.0\end{array}$ & $\begin{array}{l}15.0 \\
15.0 \\
14.0 \\
15.0 \\
13.0\end{array}$ & $\begin{array}{l}15.0 \\
15.0 \\
16.0 \\
16.0 \\
16.0\end{array}$ & $\begin{array}{l}22.0 \\
21.0 \\
22.0 \\
23.0 \\
22.0\end{array}$ & $\begin{array}{l}24.0 \\
24.0 \\
23.0 \\
24.0 \\
24.0\end{array}$ & $\begin{array}{l}24.0 \\
24.0 \\
24.0 \\
26.0 \\
26.0\end{array}$ & $\begin{array}{l}19.0 \\
20.0 \\
21.0 \\
21.0 \\
19.0\end{array}$ \\
\hline $\begin{array}{l}! 6 \\
\vdots 7 \\
\vdots 8 \\
99 \\
60 \\
31\end{array}$ & $\begin{array}{l}-\cdots \\
\cdots- \\
--- \\
-\cdots\end{array}$ & $\begin{array}{l}--- \\
--- \\
--- \\
--- \\
--\end{array}$ & \begin{tabular}{c}
3.0 \\
4.0 \\
\hdashline 0. \\
0.0 \\
0.0
\end{tabular} & $\begin{array}{l}0.0 \\
0.0 \\
1.0 \\
3.0 \\
4.0 \\
4.0\end{array}$ & \begin{tabular}{l}
0.0 \\
0.0 \\
0.0 \\
0.0 \\
\hdashline- \\
-
\end{tabular} & $\begin{array}{r}6.0 \\
7.0 \\
8.0 \\
10.0 \\
11.0 \\
13.0\end{array}$ & $\begin{array}{c}14.0 \\
12.0 \\
13.0 \\
13.0 \\
13.0 \\
-.-0\end{array}$ & $\begin{array}{l}10.0 \\
16.0 \\
15.0 \\
15.0 \\
15.0 \\
15.0\end{array}$ & $\begin{array}{l}22.0 \\
21.0 \\
10.0 \\
20.0 \\
21.0 \\
-\end{array}$ & $\begin{array}{l}24.0 \\
23.0 \\
23.0 \\
22.0 \\
22.0 \\
23.0\end{array}$ & $\begin{array}{l}23.0 \\
21.0 \\
20.0 \\
19.0 \\
19.0 \\
19.0\end{array}$ & $\begin{array}{r}18.0 \\
18.0 \\
17.0 \\
16.0 \\
17.0 \\
\end{array}$ \\
\hline ERAGE & --- & -- & $\cdots$ & --- & 1.0 & 5.0 & 12.0 & 16.0 & 20.5 & $23 . \mathrm{C}$ & 23.0 & 19.0 \\
\hline
\end{tabular}


LOCATION.--Lat $38^{\circ} 35^{\prime} 52^{\prime \prime}$, long $84^{\circ} 16^{\prime} 00^{\prime \prime}$, Pendleton County, at gaging station at county highway bridge at McKinneysburg, 6.5 miles southeast of Falmouth, 9.0 miles upstream from Blanket Creek, and 12.8 miles upstream from

DRAI NAGE AREA. - -2,326 sq mi.

PERIOD OF RECORD. - Chemical analyses: October 1952 to September 1968.

Water temperatures: October 1952 to September 1968 .

Sediment records: October 1952 to September 1968.

EXTREMES, - -1967-68:

Specific conductance: Maximum dally, 425 micromhos Nov. 25; minimum daily, 110 micromhos Apr, 8

Water temperatures: Maximum, $30.0^{\circ} \mathrm{C}$ Aug. 22, 23; minimum, freezing point on several days during January and

February.

Sediment loads: Maximum daily, 56,200 tons Mar. 13; minimum daily, 1.0 ton Feb. 27,28 .

period of record:

Specific conductance: Maximum daily, 674 micromhos Nov, 20, 1961; minimum daily, 83 micromhos Mar. 4, 1962. Water temperatures: Maximum, $32.0^{\circ} \mathrm{C}$ July 3,1964 ; minimum, freezing point on many days during winter periods. Sediment concentrations: Maximum dally, 4,230 mg/1 Feb. 25, 1956; minimum daily, $1 \mathrm{mg} / 1$ on many days during

Sediment loads: Kaximum da11y, 223,000 tons Feb. 25, 1956; minimum daily, 0.04 ton Nov. 14, 15, 1953.

REMARKS. .-Daily samples were collected for maximum and minimum specific conductance for each month. CHEMICAL ANALYSES IN MILLIGRAMS PER LITER, WATER YEAR OCTOBER 1967 TO SEPTEMBER 1968

\begin{tabular}{|c|c|c|c|c|c|c|c|c|c|c|c|c|}
\hline DATE & $\begin{array}{l}\text { DIS- } \\
\text { CHARGE } \\
\text { (CFS) }\end{array}$ & $\begin{array}{l}\text { BICAR - } \\
\text { BDNATE } \\
\text { (HCD3) }\end{array}$ & $\begin{array}{l}\text { CAR- } \\
\text { BONATE } \\
\text { (CD3) }\end{array}$ & $\begin{array}{l}\text { SULFATE } \\
(504)\end{array}$ & $\begin{array}{l}\text { CHL D- } \\
\text { RIDE } \\
\text { I CL I }\end{array}$ & $\begin{array}{l}\text { NITRATE } \\
\text { (NO3) }\end{array}$ & $\begin{array}{l}\text { OIS- } \\
\text { SOLVED } \\
\text { SOLIDS } \\
\text { IRESI- } \\
\text { DUE AT } \\
\text { IBO CI }\end{array}$ & $\begin{array}{l}\text { HARD- } \\
\text { NESS } \\
\text { (CA,MG) }\end{array}$ & $\begin{array}{l}\text { NON- } \\
\text { CAR- } \\
\text { BONATF } \\
\text { HARD- } \\
\text { NECS }\end{array}$ & $\begin{array}{l}\text { SPECI- } \\
\text { EIC } \\
\text { COND- } \\
\text { UCTANCE } \\
\text { (MICRC- } \\
\text { MMNS) }\end{array}$ & $\mathrm{PH}$ & $\begin{array}{l}\text { TEMP- } \\
\text { CRATURF } \\
\text { (DFG C) }\end{array}$ \\
\hline $\begin{array}{l}\text { OCT. } \\
01 \ldots . . \\
23 . . . \\
\text { NOV. }\end{array}$ & $\begin{array}{r}159 \\
42\end{array}$ & $\begin{array}{l}104 \\
142\end{array}$ & $\begin{array}{l}0 \\
0\end{array}$ & $\begin{array}{l}22 \\
22\end{array}$ & $21^{3.0}$ & $\begin{array}{r}1.8 \\
.4\end{array}$ & $\begin{array}{l}142 \\
216\end{array}$ & $\begin{array}{l}106 \\
140\end{array}$ & $\begin{array}{l}21 \\
24\end{array}$ & $\begin{array}{l}223 \\
327\end{array}$ & $\begin{array}{l}72 \\
75\end{array}$ & $\begin{array}{l}13 \\
12\end{array}$ \\
\hline $\begin{array}{l}24 \ldots . . \\
30 . . \\
\text { DEC. }\end{array}$ & $\begin{array}{r}440 \\
6840\end{array}$ & $\begin{array}{r}144 \\
87\end{array}$ & 0 & $\begin{array}{l}37 \\
21\end{array}$ & $\begin{array}{l}39 \\
5.0\end{array}$ & $\begin{array}{l}1.1 \\
4.5\end{array}$ & $\begin{array}{l}278 \\
154\end{array}$ & $\begin{array}{r}171 \\
96\end{array}$ & $\begin{array}{l}53 \\
25\end{array}$ & $\begin{array}{l}424 \\
210\end{array}$ & $\begin{array}{l}79 \\
78\end{array}$ & $\begin{array}{l}4 \\
3\end{array}$ \\
\hline $\begin{array}{l}15 \ldots . . \\
26 \ldots \\
\text { JAN. }\end{array}$ & $\begin{array}{l}2440 \\
4220\end{array}$ & $\begin{array}{r}132 \\
72\end{array}$ & $\begin{array}{l}0 \\
0\end{array}$ & $\begin{array}{l}34 \\
25\end{array}$ & $\begin{array}{l}6.0 \\
6.0\end{array}$ & $\begin{array}{l}2.3 \\
2.0\end{array}$ & $\begin{array}{r}198 \\
96\end{array}$ & $\begin{array}{r}146 \\
78\end{array}$ & $\begin{array}{l}38 \\
10\end{array}$ & $\begin{array}{l}301 \\
176\end{array}$ & $\begin{array}{ll}7 & 4 \\
7 & 0\end{array}$ & $\begin{array}{l}6 \\
7\end{array}$ \\
\hline $\begin{array}{l}23 . \ldots \\
26 . . . \\
\text { FEB. }\end{array}$ & $\begin{array}{l}5200 \\
4950\end{array}$ & $\begin{array}{r}122 \\
72\end{array}$ & $\begin{array}{l}0 \\
0\end{array}$ & $\begin{array}{l}28 \\
24\end{array}$ & $\begin{array}{l}8.0 \\
6.0\end{array}$ & $\begin{array}{l}4.1 \\
2.8\end{array}$ & $\begin{array}{r}152 \\
98\end{array}$ & $\begin{array}{r}134 \\
84\end{array}$ & $\begin{array}{l}34 \\
25\end{array}$ & $\begin{array}{l}280 \\
194\end{array}$ & $\begin{array}{ll}7 & 6 \\
7 & 0\end{array}$ & $\begin{array}{l}1 \\
2\end{array}$ \\
\hline $\begin{array}{l}01 \ldots . . \\
28 . . \\
\text { MAR. }\end{array}$ & $\begin{array}{r}6350 \\
370\end{array}$ & $\begin{array}{l}108 \\
117\end{array}$ & $\begin{array}{l}0 \\
0\end{array}$ & $\begin{array}{l}28 \\
33\end{array}$ & $12^{2.0}$ & $\begin{array}{l}4.2 \\
1.6\end{array}$ & $\begin{array}{l}168 \\
194\end{array}$ & $\begin{array}{l}120 \\
134\end{array}$ & $\begin{array}{l}31 \\
38\end{array}$ & $\begin{array}{l}252 \\
299\end{array}$ & $\begin{array}{l}82 \\
79\end{array}$ & $\begin{array}{l}6 \\
1\end{array}$ \\
\hline $\begin{array}{l}110 . . \\
16 \ldots . . \\
A P R_{0}\end{array}$ & $\begin{array}{r}1930 \\
17100\end{array}$ & $\begin{array}{r}128 \\
38\end{array}$ & $\begin{array}{l}0 \\
0\end{array}$ & $\begin{array}{l}33 \\
19\end{array}$ & $\begin{array}{l}9.0 \\
4.0\end{array}$ & $\begin{array}{l}3.7 \\
2.2\end{array}$ & $\begin{array}{r}188 \\
80\end{array}$ & $\begin{array}{r}148 \\
50\end{array}$ & $\begin{array}{l}43 \\
19\end{array}$ & $\begin{array}{l}311 \\
120\end{array}$ & $\begin{array}{ll}7 & 7 \\
6 & 6\end{array}$ & $\begin{array}{l}8 \\
7\end{array}$ \\
\hline $\begin{array}{l}02 . . . \\
08 . . . \\
\text { MAY }\end{array}$ & $\begin{array}{r}6930 \\
14900\end{array}$ & $\begin{array}{r}112 \\
42\end{array}$ & $\begin{array}{l}0 \\
0\end{array}$ & $\begin{array}{l}26 \\
14\end{array}$ & $\begin{array}{l}5.0 \\
2.0\end{array}$ & $\begin{array}{l}2.0 \\
1.4\end{array}$ & $\begin{array}{r}164 \\
62\end{array}$ & $\begin{array}{r}120 \\
4 \mathrm{R}\end{array}$ & $\begin{array}{l}28 \\
14\end{array}$ & $\begin{array}{l}250 \\
110\end{array}$ & $\begin{array}{l}73 \\
67\end{array}$ & $\begin{array}{l}12 \\
12\end{array}$ \\
\hline $\begin{array}{l}13 \ldots . . \\
27 \ldots \\
\text { JUNE }\end{array}$ & $\begin{array}{r}1270 \\
26100\end{array}$ & $\begin{array}{r}140 \\
70\end{array}$ & $\begin{array}{l}0 \\
0\end{array}$ & $\begin{array}{l}29 \\
13\end{array}$ & $\begin{array}{l}4.0 \\
1.5\end{array}$ & $\begin{array}{l}1.7 \\
3.6\end{array}$ & $\begin{array}{l}174 \\
100\end{array}$ & $\begin{array}{r}142 \\
72\end{array}$ & $\begin{array}{l}28 \\
14\end{array}$ & $\begin{array}{l}298 \\
151\end{array}$ & $\begin{array}{ll}7 & 6 \\
8 & 0\end{array}$ & $\begin{array}{l}18 \\
17\end{array}$ \\
\hline $\begin{array}{l}03 \ldots . . \\
25 \ldots . \\
\text { JuL. }\end{array}$ & $\begin{array}{l}4340 \\
1740\end{array}$ & $\begin{array}{r}110 \\
76\end{array}$ & $\begin{array}{l}0 \\
0\end{array}$ & $\begin{array}{l}23 \\
19\end{array}$ & $\begin{array}{l}4.0 \\
4.5\end{array}$ & $\begin{array}{l}2.4 \\
3.0\end{array}$ & $\begin{array}{l}130 \\
124\end{array}$ & $\begin{array}{r}111 \\
79\end{array}$ & $\begin{array}{l}21 \\
17\end{array}$ & $\begin{array}{l}239 \\
183\end{array}$ & $\begin{array}{l}75 \\
72\end{array}$ & $\begin{array}{l}17 \\
24\end{array}$ \\
\hline $\begin{array}{l}17 \ldots . . \\
28 . \\
\text { AUG. }\end{array}$ & $\begin{array}{r}448 \\
6640\end{array}$ & $\begin{array}{r}138 \\
80\end{array}$ & $\begin{array}{l}0 \\
0\end{array}$ & $\begin{array}{l}23 \\
12\end{array}$ & $\begin{array}{l}4.5 \\
1.5\end{array}$ & $\begin{array}{l}2.7 \\
6.2\end{array}$ & $\begin{array}{l}192 \\
134\end{array}$ & $\begin{array}{r}136 \\
80\end{array}$ & $\begin{array}{l}23 \\
14\end{array}$ & $\begin{array}{l}289 \\
175\end{array}$ & $\begin{array}{ll}8 & 0 \\
7 & 0\end{array}$ & $\begin{array}{l}28 \\
23\end{array}$ \\
\hline $\begin{array}{l}05 \ldots . . \\
12 \ldots . \\
\text { SEOT. }\end{array}$ & $\begin{array}{r}12100 \\
4530\end{array}$ & $\begin{array}{r}72 \\
120\end{array}$ & $\begin{array}{l}0 \\
0\end{array}$ & $\begin{array}{l}11 \\
23\end{array}$ & $12^{.5}$ & $\begin{array}{l}4.0 \\
3.4\end{array}$ & $\begin{array}{l}128 \\
186\end{array}$ & $\begin{array}{r}70 \\
126\end{array}$ & $\begin{array}{l}11 \\
28\end{array}$ & $\begin{array}{l}150 \\
285\end{array}$ & $\begin{array}{ll}7 & 6 \\
7 & 1\end{array}$ & $\begin{array}{l}23 \\
24\end{array}$ \\
\hline $25 \ldots$ & 87 & 122 & 0 & 22 & 14 & 1.0 & 184 & 122 & 22 & 282 & 77 & 23 \\
\hline
\end{tabular}

PARTICLE-SIZE ANALYSES OF SUSPENDED SEDIMENT, WATER YEAR OCTOBER 1967 TO SEPTEMBER 1968 (METHODS OF ANALYSIS: B, BOTTOM WITHDRAWAL TUBE; C, CHEMICALLY DISPERSED; D, DECANTATION; N, IN NATIVE WATER;
P, PIPET; S. SIEVE; V, VISUAL ACCUMULATION TUBE; $W$, IN DISTILLED WATER)

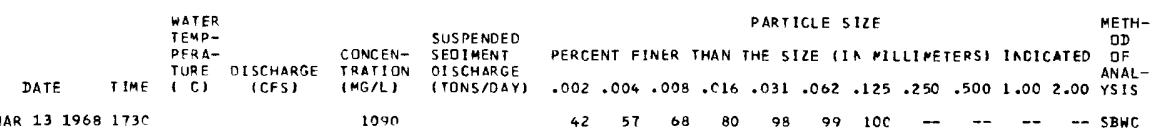


03251500 LICKING RIVER AT MCKINNEYSBURG, KY. --Cont1 nued

SPECIFIC CONDUCTANCE (MICROMHOS AT $25^{\circ} \mathrm{C}$ ), WATER YEAR OCTOBER 1967 TO SEPTEMBER 1968

OCTOBER NOVEMBER OECEMBE

\begin{tabular}{|c|c|c|c|c|c|c|c|c|c|c|c|c|}
\hline $\begin{array}{l}1 \ldots \ldots \\
2 \ldots \ldots \\
3 \ldots \ldots \\
4 \ldots \ldots \\
5 \ldots \ldots\end{array}$ & $\begin{array}{l}223 \\
228 \\
237 \\
244 \\
253\end{array}$ & $\begin{array}{l}270 \\
215 \\
290 \\
315 \\
302\end{array}$ & $\begin{array}{l}251 \\
269 \\
187 \\
206 \\
215\end{array}$ & $\begin{array}{l}= \\
=- \\
=-\end{array}$ & $\begin{array}{l}252 \\
252 \\
281 \\
-\overline{272}\end{array}$ & $\begin{array}{l}301 \\
296 \\
20 \\
206\end{array}$ & $\begin{array}{l}196 \\
250 \\
186 \\
162 \\
159\end{array}$ & $\begin{array}{l}231 \\
225 \\
220 \\
221 \\
223\end{array}$ & $\begin{array}{l}212 \\
230 \\
223 \\
221\end{array}$ & $\begin{array}{l}242 \\
234 \\
210 \\
226 \\
226\end{array}$ & $\begin{array}{l}230 \\
274 \\
260 \\
259 \\
150\end{array}$ & $\begin{array}{l}243 \\
262 \\
264 \\
276 \\
272\end{array}$ \\
\hline $\begin{array}{r}6 \ldots . . \\
7 \ldots \ldots \\
8 \ldots . . \\
10 . \ldots .\end{array}$ & $\begin{array}{l}240 \\
264 \\
264 \\
274\end{array}$ & $\begin{array}{l}272 \\
287 \\
287 \\
281\end{array}$ & $\begin{array}{l}203 \\
195 \\
202 \\
221 \\
210\end{array}$ & $\begin{array}{r}251 \\
-- \\
\because- \\
--\end{array}$ & $\begin{array}{l}257 \\
255 \\
259 \\
262 \\
261\end{array}$ & $\begin{array}{l}293 \\
291 \\
\ddot{301}\end{array}$ & $\begin{array}{l}159 \\
122 \\
110 \\
115 \\
144\end{array}$ & $\begin{array}{l}223 \\
223 \\
220 \\
228 \\
228\end{array}$ & $\begin{array}{l}215 \\
209 \\
214 \\
219 \\
218\end{array}$ & $\begin{array}{l}227 \\
226 \\
216 \\
216 \\
218\end{array}$ & $\begin{array}{l}257 \\
276 \\
210 \\
224 \\
264\end{array}$ & $\begin{array}{l}276 \\
270 \\
247 \\
224 \\
220\end{array}$ \\
\hline $\begin{array}{l}11 \ldots \ldots \\
12 \ldots \ldots . \\
13 \ldots \ldots \\
14 \ldots . . . \\
15 \ldots\end{array}$ & $\begin{array}{l}281 \\
285 \\
-2 \\
290 \\
298\end{array}$ & $\begin{array}{l}281 \\
294 \\
309 \\
292 \\
292\end{array}$ & $\begin{array}{l}220 \\
249 \\
276 \\
301\end{array}$ & $\begin{array}{l}=- \\
=- \\
z\end{array}$ & $\begin{array}{r}261 \\
253 \\
- \\
=-\end{array}$ & $\begin{array}{l}311 \\
238 \\
244 \\
158 \\
126\end{array}$ & $\begin{array}{l}141 \\
188 \\
189 \\
194 \\
234\end{array}$ & $\begin{array}{l}244 \\
281 \\
298 \\
289 \\
277\end{array}$ & $\begin{array}{l}221 \\
219 \\
218 \\
218 \\
218\end{array}$ & $\begin{array}{l}219 \\
222 \\
214 \\
214 \\
215\end{array}$ & $\begin{array}{l}268 \\
285 \\
233 \\
203 \\
234\end{array}$ & $\begin{array}{l}230 \\
240 \\
243 \\
253 \\
255\end{array}$ \\
\hline $\begin{array}{l}16 \ldots . . \\
17 \% \ldots . \\
18 \ldots . . \\
20 . \ldots .\end{array}$ & $\begin{array}{l}302 \\
302 \\
305 \\
313 \\
316\end{array}$ & $\begin{array}{l}307 \\
329 \\
387 \\
388 \\
400\end{array}$ & $\begin{array}{l}276 \\
284 \\
282 \\
289 \\
291\end{array}$ & $\begin{array}{l}=- \\
=- \\
z \\
z\end{array}$ & $\begin{array}{l}279 \\
276 \\
276 \\
276 \\
--\end{array}$ & $\begin{array}{r}120 \\
140 \\
262 \\
158 \\
--\end{array}$ & $\begin{array}{r}220 \\
222 \\
203 \\
197\end{array}$ & $\begin{array}{l}261 \\
250 \\
256 \\
256 \\
259\end{array}$ & $\begin{array}{l}217 \\
221 \\
229 \\
230\end{array}$ & $\begin{array}{l}240 \\
280 \\
248 \\
250 \\
236\end{array}$ & $\begin{array}{l}194 \\
191 \\
224 \\
222 \\
223\end{array}$ & $\begin{array}{l}247 \\
236 \\
239 \\
251 \\
263\end{array}$ \\
\hline $\begin{array}{l}21 \ldots \ldots . \\
222 . \ldots . \\
23 \ldots \ldots . \\
24 \ldots . . .\end{array}$ & $\begin{array}{l}318 \\
321 \\
327 \\
326 \\
318\end{array}$ & $\begin{array}{r}400 \\
378 \\
-424 \\
425\end{array}$ & $\begin{array}{l}264 \\
264 \\
228 \\
223 \\
191\end{array}$ & $\begin{array}{l}=- \\
280 \\
229 \\
195\end{array}$ & $\begin{array}{l}=- \\
=- \\
294 \\
292\end{array}$ & $\begin{array}{l}210 \\
199 \\
217 \\
185 \\
160\end{array}$ & $\begin{array}{l}198 \\
208 \\
208 \\
188 \\
228\end{array}$ & $\begin{array}{l}259 \\
239 \\
244 \\
174 \\
210\end{array}$ & $\begin{array}{l}229 \\
229 \\
217 \\
223 \\
183\end{array}$ & $\begin{array}{l}240 \\
237 \\
253 \\
250 \\
243\end{array}$ & $\begin{array}{l}236 \\
247 \\
257 \\
231 \\
222\end{array}$ & $\begin{array}{l}267 \\
268 \\
270 \\
278 \\
282\end{array}$ \\
\hline $\begin{array}{l}26 \ldots . . . \\
27 \ldots . . \\
28 . \ldots . \\
29 . \ldots . \\
30 \ldots \\
31 \ldots . . .\end{array}$ & $\begin{array}{l}3 \overline{3} \\
312 \\
315 \\
312 \\
312\end{array}$ & $\begin{array}{l}355 \\
355 \\
348 \\
362 \\
210\end{array}$ & $\begin{array}{l}176 \\
177 \\
177 \\
198 \\
199\end{array}$ & $\begin{array}{l}194 \\
296 \\
197 \\
226 \\
229\end{array}$ & $\begin{array}{l}292 \\
292 \\
299 \\
297 \\
-- \\
--\end{array}$ & $\begin{array}{l}156 \\
150 \\
162 \\
195 \\
210 \\
215\end{array}$ & $\begin{array}{r}210 \\
228 \\
230 \\
227 \\
227 \\
--\end{array}$ & $\begin{array}{l}190 \\
151 \\
211 \\
156 \\
160 \\
195\end{array}$ & $\begin{array}{l}229 \\
238 \\
219 \\
218 \\
235 \\
---\end{array}$ & $\begin{array}{l}206 \\
194 \\
175 \\
228 \\
-728\end{array}$ & $\begin{array}{l}222 \\
228 \\
228 \\
236 \\
240 \\
241\end{array}$ & $\begin{array}{l}282 \\
282 \\
278 \\
27 n \\
264 \\
--\end{array}$ \\
\hline$A V$ & 289 & 323 & 231 & -- & -- & 211 & 191 & 229 & 220 & 228 & 234 & 258 \\
\hline
\end{tabular}

TEMPERATURE ( $\left.{ }^{\circ} \mathrm{C}\right)$ OF WATER, WATER YEAR OCTOBER 1967 TO SEPTEMBER 1968

\begin{tabular}{|c|c|c|c|c|c|c|c|c|c|c|c|c|}
\hline DAY & $\mathrm{OCT}$ & nuv & OEC & JAN & FEB & MAR & $A P R$ & MAY & $J \cup N$ & JUL & $A \cup G$ & SEP \\
\hline $\begin{array}{l}1 \\
2 \\
3 \\
4 \\
5\end{array}$ & $\begin{array}{l}13.0 \\
14.0 \\
15.0 \\
16.0 \\
17.0\end{array}$ & $\begin{array}{r}13.0 \\
13.0 \\
14.0 \\
11.0 \\
8.0\end{array}$ & $\begin{array}{l}4.0 \\
3.0 \\
4.0 \\
5.0 \\
5.0\end{array}$ & $\begin{array}{l}\cdots- \\
\cdots \\
\cdots-\end{array}$ & $\begin{array}{l}6.0 \\
7.0 \\
8.0 \\
7.0 \\
6.0\end{array}$ & $\begin{array}{l}-. . \\
1.0 \\
3.0 \\
2.0\end{array}$ & $\begin{array}{l}12.0 \\
12.0 \\
12.0 \\
13.0 \\
11.0\end{array}$ & $\begin{array}{l}18.0 \\
19.0 \\
20.0 \\
15.0 \\
18.0\end{array}$ & $\begin{array}{l}16.0 \\
17.0 \\
17.0 \\
21.0 \\
21.0\end{array}$ & $\begin{array}{l}27.0 \\
26.0 \\
24.0 \\
24.0 \\
25.0\end{array}$ & $\begin{array}{l}23.0 \\
24.0 \\
23.0 \\
24.0 \\
23.0\end{array}$ & $\begin{array}{l}23.0 \\
23.0 \\
24.0 \\
23.0 \\
23.0\end{array}$ \\
\hline $\begin{array}{r}6 \\
7 \\
8 \\
9 \\
.0\end{array}$ & $\begin{array}{l}-15.0 \\
17.0 \\
16.0 \\
14.0\end{array}$ & $\begin{array}{l}--. \\
8.0 \\
9.0 \\
9.0 \\
8.0\end{array}$ & $\begin{array}{l}6.0 \\
8.0 \\
8.0 \\
6.0 \\
8.0\end{array}$ & \begin{tabular}{c}
0.0 \\
\hdashline- \\
\hdashline- \\
\hdashline-
\end{tabular} & $\begin{array}{l}0.0 \\
0.0 \\
4.0 \\
1.0 \\
0.0\end{array}$ & $\begin{array}{l}4.0 \\
4.0 \\
4.0 \\
7.0\end{array}$ & $\begin{array}{l}12.0 \\
11.0 \\
12.0 \\
12.0 \\
12.0\end{array}$ & $\begin{array}{l}18.0 \\
18.0 \\
18.0 \\
18.0 \\
18.0\end{array}$ & $\begin{array}{l}22.0 \\
22.0 \\
23.0 \\
23.0 \\
23.0\end{array}$ & $\begin{array}{l}26.0 \\
25.0 \\
25.0 \\
27.0 \\
29.0\end{array}$ & $\begin{array}{l}26.0 \\
26.0 \\
26.0 \\
24.0 \\
26.0\end{array}$ & $\begin{array}{l}22.0 \\
22.0 \\
22.0 \\
22.0 \\
10.0\end{array}$ \\
\hline $\begin{array}{l}11 \\
12 \\
13 \\
14 \\
15\end{array}$ & $\begin{array}{r}12.0 \\
12.0 \\
12.0 \\
13.0\end{array}$ & $\begin{array}{r}11.0 \\
0.0 \\
8.0 \\
7.0 \\
6.0\end{array}$ & $\begin{array}{l}-1.0 \\
8.0 \\
7.0 \\
6.0\end{array}$ & $\begin{array}{l}\cdots \\
\cdots \\
\cdots \\
\cdots\end{array}$ & $\begin{array}{l}0.0 \\
0.0 \\
0.0 \\
0.0 \\
0.0\end{array}$ & $\begin{array}{l}8.0 \\
6.0 \\
3.0 \\
5.0 \\
6.0\end{array}$ & $\begin{array}{l}11.0 \\
13.0 \\
13.0 \\
14.0 \\
11.0\end{array}$ & $\begin{array}{l}18.0 \\
19.0 \\
19.0 \\
21.0 \\
21.0\end{array}$ & $\begin{array}{l}23.0 \\
26.0 \\
26.0 \\
24.0 \\
23.0\end{array}$ & $\begin{array}{l}28.0 \\
28.0 \\
28.0 \\
27.0 \\
24.0\end{array}$ & $\begin{array}{l}24.0 \\
24.0 \\
23.0 \\
23.0 \\
23.0\end{array}$ & $\begin{array}{l}20.0 \\
21.0 \\
21.0 \\
22.0 \\
21.0\end{array}$ \\
\hline $\begin{array}{l}16 \\
17 \\
18 \\
19 \\
10\end{array}$ & $\begin{array}{l}17.0 \\
16.0 \\
16.0 \\
15.0 \\
12.0\end{array}$ & $\begin{array}{l}6.0 \\
6.0 \\
6.0 \\
6.0 \\
5.0\end{array}$ & $\begin{array}{l}4.0 \\
4.0 \\
4.0 \\
4.0 \\
4.0\end{array}$ & 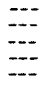 & $\begin{array}{l}1.0 \\
0.0 \\
2.0 \\
1.0 \\
3.0\end{array}$ & $\begin{array}{l}7.0 \\
7.0 \\
7.0 \\
7.0 \\
9.0\end{array}$ & $\begin{array}{l}13.0 \\
14.0 \\
16.0 \\
15.0 \\
16.0\end{array}$ & $\begin{array}{l}22.0 \\
22.0 \\
18.0 \\
18.0 \\
17.0\end{array}$ & $\begin{array}{l}24.0 \\
24.0 \\
22.0 \\
25.0 \\
26.0\end{array}$ & $\begin{array}{l}24.0 \\
26.0 \\
27.0 \\
27.0 \\
27.0\end{array}$ & $\begin{array}{l}23.0 \\
24.0 \\
23.0 \\
26.0 \\
28.0\end{array}$ & $\begin{array}{r}21.0 \\
21.0 \\
21.0 \\
21.0 \\
22.0\end{array}$ \\
\hline $\begin{array}{l}? 1 \\
? 2 \\
? 3 \\
? 4 \\
: 5\end{array}$ & $\begin{array}{l}13.0 \\
12.0 \\
12.0 \\
11.0 \\
12.0\end{array}$ & $\begin{array}{l}6.0 \\
7.0 \\
4.0 \\
5.0\end{array}$ & $\begin{array}{l}7.0 \\
7.0 \\
6.0 \\
5.0 \\
4.0\end{array}$ & $\begin{array}{l}-1- \\
1.0 \\
1.0 \\
1.0\end{array}$ & $\begin{array}{l}\cdots- \\
\overline{-0} \\
1.0 \\
2.0\end{array}$ & $\begin{array}{l}9.0 \\
7.0 \\
7.0 \\
4.0 \\
6.0\end{array}$ & $\begin{array}{l}16.0 \\
17.0 \\
16.0 \\
15.0 \\
14.0\end{array}$ & $\begin{array}{l}18.0 \\
18.0 \\
18.0 \\
16.0 \\
17.0\end{array}$ & $\begin{array}{l}26.0 \\
26.0 \\
27.0 \\
26.0 \\
24.0\end{array}$ & $\begin{array}{l}28.0 \\
28.0 \\
28.0 \\
28.0 \\
28.0\end{array}$ & $\begin{array}{l}29.0 \\
30.0 \\
30.0 \\
29.0 \\
29.0\end{array}$ & $\begin{array}{l}23.0 \\
24.0 \\
24.0 \\
24.0 \\
23.0\end{array}$ \\
\hline $\begin{array}{l}16 \\
: 7 \\
: 8 \\
19 \\
10 \\
11\end{array}$ & $\begin{array}{r}11.0 \\
9.0 \\
5.0 \\
9.0 \\
10.0\end{array}$ & $\begin{array}{l}6.0 \\
6.0 \\
4.0 \\
3.0 \\
3.0 \\
--.\end{array}$ & $\begin{array}{l}7.0 \\
3.0 \\
3.0 \\
-2.0 \\
1.0\end{array}$ & $\begin{array}{l}2.0 \\
2.0 \\
2.0 \\
0.0 \\
4.0\end{array}$ & $\begin{array}{l}2.0 \\
1.0 \\
1.0 \\
1.0 \\
--0 \\
---\end{array}$ & $\begin{array}{r}7.0 \\
7.0 \\
9.0 \\
10.0 \\
13.0 \\
13.0\end{array}$ & $\begin{array}{c}16.0 \\
16.0 \\
17.0 \\
17.0 \\
18.0 \\
-\end{array}$ & $\begin{array}{l}17.0 \\
17.0 \\
17.0 \\
17.0 \\
16.0 \\
16.0\end{array}$ & $\begin{array}{r}25.0 \\
26.0 \\
23.0 \\
24.0 \\
24.0 \\
-.0\end{array}$ & $\begin{array}{l}24.0 \\
23.0 \\
23.0 \\
24.0 \\
24.0 \\
24.0\end{array}$ & $\begin{array}{l}25.0 \\
24.0 \\
23.0 \\
23.0 \\
23.0 \\
24.0\end{array}$ & $\begin{array}{l}22.0 \\
21.0 \\
21.0 \\
26.0 \\
21.0 \\
. .-0\end{array}$ \\
\hline ERAGE & 13.0 & 7.5 & 5.0 & -- & 2.5 & 6.5 & 14.0 & 18.0 & 23.5 & 26.0 & 25.0 & 22.0 \\
\hline
\end{tabular}


LICKI NG RIVER BASIN

03251500 LICKI NAG RIVER AT YCKINNEYSBURG, KY, --Cont1nued

SUSPENDED SEDIMENT, WATER YEAR OCTOBER 1967 TO SEPTEMBER 1968

\begin{tabular}{|c|c|c|c|c|c|c|c|c|c|}
\hline & & OC TORER & & & NOVEMBER & & & NECEMBER & \\
\hline & MFAN & $\begin{array}{l}\text { MEAN } \\
\text { CCNEFN- }\end{array}$ & & MFAN & MEFAN & & MFAM & $\begin{array}{l}\text { MEAN } \\
\text { CINCFN- }\end{array}$ & \\
\hline & $n I S T+A O F_{3}=$ & TRATTINA & 1547 & $\cap S C+A P G F$ & TRATION & 1040 & DISCHARGE & TRATION & $\tan$ \\
\hline DAY & $(C+5)$ & (Mr, IL) & (TITS) & (CFS) & $(45 / 1)$ & (TกNS) & $(C F()$ & $(4,12)$ & (TONS) \\
\hline 1 & 159 & 50 & 25 & 2050 & 357 & 3310 & RR20 & 795 & 19000 \\
\hline 2 & 34 & 27 & 0.4 & 5800 & 397 & 6270 & 9170 & 410 & $15: 00$ \\
\hline 3 & 70 & 31 & $s . h$ & 3 3าตก & 270 & 1420 & 9950 & $35 n$ & 0310 \\
\hline 4 & Th & 30 & 4.? & 2690 & $1 ? h$ & 012 & 7260 & 250 & 4900 \\
\hline 5 & 73 & 35 & $h .0$ & las? & 95 & 475 & 5000 & 165 & 2400 \\
\hline 5 & 205 & 48 & 37 & 1370 & 66 & 244 & 3570 & $\ln x$ & 902 \\
\hline 7 & 375 & $10 x$ & on & 1050 & 44 & $12 t$ & 2070 & 73 & SOH \\
\hline q & 130 & 44 & 15 & 780 & $2 f$ & 55 & 2380 & 55 & 353 \\
\hline 9 & on & 42 & in & 614 & 17 & 78 & $1 F O C$ & 44 & 214 \\
\hline 10 & $7 x$ & 20 & 5.5 & 505 & is & 20 & $177 n$ & S: & 301 \\
\hline 11 & 69 & 74 & 4.4 & 426 & 22 & 25 & 4720 & 371 & 5960 \\
\hline 12 & 63 & 20 & 3.4 & कRी & 35 & 64 & 5960 & 413 & R.50 \\
\hline 13 & 57 & $>0$ & 2.1 & 475 & 24 & 31 & 2400 & $20 n$ & 2nor \\
\hline 14 & 55 & 21 & 3.1 & 325 & $1 *$ & 14 & 2310 & 104 & $\$ 40$ \\
\hline 15 & 51 & 31 & 4.3 & 289 & is & 12 & 2440 & 57 & 374 \\
\hline 16 & 42 & $2 r$ & 2.6 & 249 & 15 & 10 & 2360 & 27 & 236 \\
\hline 17 & 45 & in & 2.4 & 224 & 14 & 0.5 & 2160 & 29 & 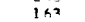 \\
\hline is & 42 & $2^{r}$ & 2.3 & 201 & 13 & 7.1 & 2030 & 35 & 137 \\
\hline is & 43 & 17 & 2.0 & IR7 & 10 & 5.1 & 1940 & 20 & 147 \\
\hline 20 & 43 & 17 & $2 . n$ & 173 & in & .4 .7 & 1790 & $>0$ & 130 \\
\hline$? 1$ & 4? & 13 & 1.5 & 154 & in & 4.4 & 2080 & 29 & $16 !$ \\
\hline 27 & $4 ?$ & i? & 1.4 & 173 & 12 & 5.6 & 7280 & 473 & $06 \geqslant 0$ \\
\hline 23 & 4? & 12 & 1.4 & $z^{2} \mathbf{l}$ & 1 ? & 0.1 & Gono & 192 & 3110 \\
\hline 24 & 41 & 13 & 1.4 & 443 & $1 ?$ & 14 & $\$ 450$ & 351 & 4270 \\
\hline 25 & 245 & $4 t$ & 5.3 & 750 & 15 & 30 & a! 00 & tan & 2100 \\
\hline $2 \mathrm{~h}$ & 207 & 29 & $10 K$ & Ras & 10 & 41 & 4220 & 87 & 901 \\
\hline 27 & $1 \div 6$ & 31 & 12 & $R Q D$ & 17 & 41 & 3170 & 64 & 548 \\
\hline$\geqslant 9$ & log & 19 & a.h & 830 & 13 & >0 & ग30 & 44 & 71 \\
\hline 29 & $\angle 0$ & 15 & 2.9 & 775 & 10 & 21 & 1760 & $\dddot{7}$ & 170 \\
\hline $3 n$ & 41 & in & 2.3 & Sagn & $54 x$ & 14400 & 1410 & is & 57 \\
\hline 31 & 182 & $3 t$ & $2 n$ & -- & - & - & 1270 & in & 34 \\
\hline TAPAL & 3295 & -- & $4 K A . K$ & 34070 & - & 27736.5 & 123270 & -- & 91594 \\
\hline & & JANIJARY & & & FERRIIARY & & & MARCH & \\
\hline & NEAN & $\begin{array}{l}\text { MEAN } \\
\text { COMAREN- }\end{array}$ & & NEAY & $\begin{array}{l}\text { ME } \triangle N \\
\text { CONC FN- }\end{array}$ & & MFAN & $\begin{array}{l}\text { ME AN } \\
\text { CONSFN- }\end{array}$ & \\
\hline & DT 5 C HAF $=$ & TPATI IN & LIAn & DISC TAFGF & TRATION & LnAD & ПTिCHADE & TRATINN & $\ln 80$ \\
\hline DAY & (CFS) & $(M E / L)$ & (TONS) & (CFS) & $\left(M_{F} / L\right)$ & (TONS) & (CFS) & (MFIL) & (TOMle) \\
\hline 1 & 1150 & $n$ & TR & 6350 & 120 & 2210 & $39 n$ & ? & 2.1 \\
\hline 2 & lish & 9 & $2 R$ & 5872 & 205 & 3,250 & 200 & ? & 2.1 \\
\hline 3 & $\ln 30$ & c & is & 4430 & $10 ?$ & 2000 & 414 & 2 & $? . ?$ \\
\hline 4 & 1512 & 10 & 41 & 3630 & RO & दRQ & $400^{\circ}$ & 2 & 3.2 \\
\hline 5 & 2200 & $2 n$ & 110 & 2asn & 45 & 347 & 422 & ? & 2.7 \\
\hline , & 32700 & 150 & 1740 & 2250 & 3? & 194 & 420 & 1 & 1.1 \\
\hline 7 & 3200 & ar & GO 1 & IRAS & $2^{5}$ & 127 & $44 \pi$ & 1 & $\because 7$ \\
\hline 9 & 2700 & $5 n$ & $3 \times 4$ & 1540 & 17 & 75 & 425 & 1 & $\therefore 1$ \\
\hline a & 2039 & 30 & 152 & 1443 & 14 & 54 & 400 & 2 & 3.3 \\
\hline 10 & 1900 & $\rightarrow a$ & $1>9$ & $12 \mathrm{ho}$ & 0 & 31 & on? & 54 & 227 \\
\hline 11 & 2A51) & $2 n$ & $\operatorname{lnn}$ & 1070 & 7 & 20 & 1030 & lan & $78 ?$ \\
\hline 12 & 1750 & 15 & 71 & 1030 & 4 & il & InaOAn & 1530 & $50 \times n 0$ \\
\hline 13 & 23 no & 15 & RI & 725 & 4 & 8.6 & 16000 & dxon & aROAC \\
\hline 14 & 1750 & ic & 47 & 919 & 4 & 8.8 & 17000 & oon & $435 \mathrm{~nm}$ \\
\hline 15 & 1223 & $\therefore$ & 23 & $\sin x$ & 4 & 9.7 & ipron & oln & 29200 \\
\hline If & $12 n 0$ & 0 & 20 & 720 & a & 0.0 & 17100 & 515 & 232000 \\
\hline 17 & $1 \times 09$ & 0 & 34 & 713 & 4 & 7.7 & 17400 & $42 n$ & $1970 n$ \\
\hline 19 & L290 & 。 & $2 n$ & 655 & 4 & 7.2 & ISACO & 355 & 1510 r \\
\hline 17 & 1250 & ค & $\gg$ & Al1 & 3 & 4.0 & 12200 & $24 n$ & $112 \mathrm{cn}$ \\
\hline 20 & 11 in & a & 24 & $5 k h$ & 2 & 3.1 & a उA? & 210 & Tnin \\
\hline$? 1$ & 1003 & 15 & 77 & 52.3 & 2 & 2.9 & 10 ano & $R_{2} R$ & $2270 n$ \\
\hline 22 & 2200 & $7 n$ & $6>4$ & 559 & 2 & 2.2 & 15400 & 045 & zGann \\
\hline 23 & 5200 & $\angle \cap 0$ & 2810 & 559 & ? & $3 . c$ & 20302 & $3 B C$ & 20000 \\
\hline 24 & $4>47$ & $35 n$ & t7on & $=59$ & 3 & 4.5 & zogon & $35 ?$ & $10 R C O$ \\
\hline 25 & 7500 & $15 ?$ & $3 n \times 0$ & $53 n$ & ? & 7.9 & 20800 & $24^{\circ}$ & 14000 \\
\hline 26 & 4050 & 37 & 1390 & $41 n$ & l & 1.1 & $12 \times 000$ & 200 & ORRC \\
\hline 27 & 7300 & 57 & 5?? & $3 \times 3$ & I & 1.0 & 14000 & 159 & 5070 \\
\hline$\rightarrow 9$ & 2500 & 45 & 211 & 370 & 1 & 1.0 & RGBO & 121 & $\rightarrow 240$ \\
\hline 27 & 2470 & 42 & 200 & 3R3 & 2 & 2.1 & $42 \times 0$ & 05 & $12 \mathrm{kn}$ \\
\hline an & $58: 0$ & 234 & 7020 & -- & -- & $\ldots$ & 3330 & an & pron \\
\hline 31 & $704 \pi$ & $x \rightarrow n$ & $7 C 3 n$ & -- & -- & - & 3090 & 102 & 955 \\
\hline & $374 \leq 9$ & -- & 24254 & $4^{7} 644$ & -- & 9277.5 & Torno & -- & 2QXR5ก.? \\
\hline
\end{tabular}


LICKING RIVER BASIN

03251500 LICKING RIVER AT MCKINNEYSBURG, KY.--ContI nued

SUSPENDED SEDIMENT, WATER YEAR OCTOBER 1967 TO SEPTEMBER 1968

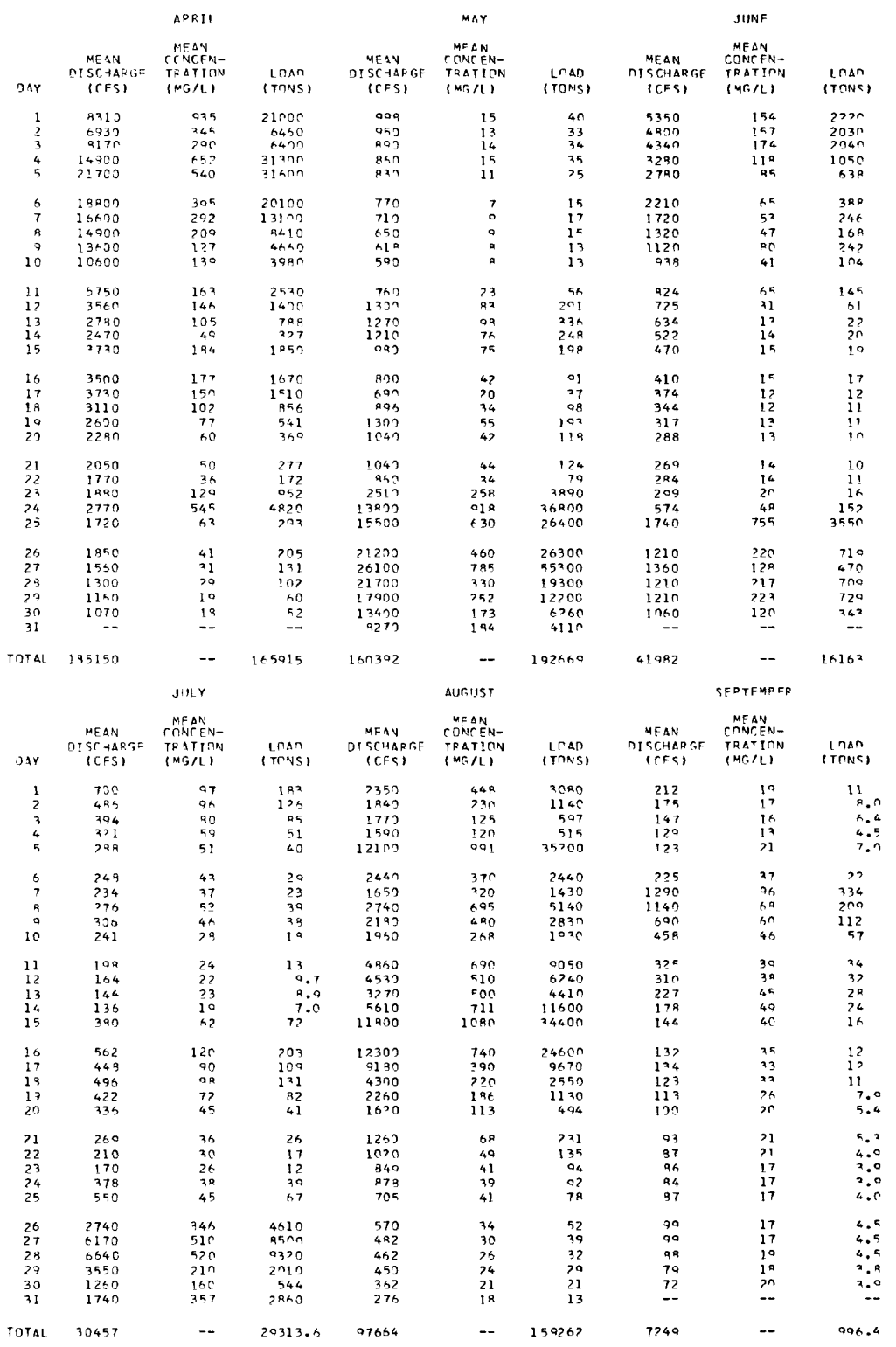

TOTAL DISCHARGE FOR YEAR (CFS-DAYS)

1095342. 
LOCATION, - Lat $38^{\circ} 23^{\prime} 27^{\prime \prime}$, long $84^{\circ} 18^{\prime} 11^{\prime \prime}$, Harrison County, at gaging station at bridge on State Highway 356 and 36 at Cynthiana, 0.4 mile downstream from Grays Run and in pool formed by old milldam 2.6 miles downstream.

DRAINAGE AREA. --621 sq $\mathrm{m} 1$.

PERTOD OF RECORD.--Chemical analyses: October 1950 to August 1951.

Water temperatures: October 1949 to September 1968 .

EXTREMES. - -1967-68:

Water temperatures: Maximum, $30.0^{\circ} \mathrm{C}$ Aug. 23 ; minimum, freezing point on many days during December to March.

Pertod of record:

ater temperatures: Maximum, $30.5^{\circ} \mathrm{C}$ June 30,1952 , July 14, 1954; minimum, freezing point on many days during winter periods.

REMARKS, --Small diversion by Cynthiana municipal waterplant.

TEMPERATURE $\left({ }^{\circ} \mathrm{C}\right)$ OF WATER, WATER YEAR OCTOBER 1967 TO SEPTEMBER 1968 (TWICE-DAILY MEASUREMENTS, AT APPROXIMATELY OTOO AND 1800)

\begin{tabular}{|c|c|c|c|c|c|c|c|c|c|c|c|c|}
\hline \multirow[b]{2}{*}{ DAY } & \multicolumn{2}{|c|}{ OCTOBER } & \multicolumn{2}{|c|}{ NOVEMBER } & \multicolumn{2}{|c|}{ DEC EM BER R } & \multicolumn{2}{|c|}{ JANUARY } & \multicolumn{2}{|c|}{ FEBRUARY } & \multicolumn{2}{|c|}{ MARCH } \\
\hline & $A M$ & PM & AM & $P M$ & AM & PM & $A M$ & PM & AM & PM & AM & $P M$ \\
\hline $\begin{array}{l}1 \\
2 \\
3 \\
4 \\
5\end{array}$ & $\begin{array}{l}13.0 \\
13.0 \\
16.0 \\
16.0 \\
17.0\end{array}$ & $\begin{array}{l}17.0 \\
18.0 \\
19.0 \\
19.0 \\
20.0\end{array}$ & $\begin{array}{r}13.0 \\
12.0 \\
12.0 \\
11.0 \\
8.0\end{array}$ & $\begin{array}{r}13.0 \\
13.0 \\
12.0 \\
10.0 \\
8.0\end{array}$ & $\begin{array}{l}4.0 \\
4.0 \\
6.0 \\
4.0 \\
5.0\end{array}$ & $\begin{array}{l}4.0 \\
6.0 \\
6.0 \\
6.0 \\
7.0\end{array}$ & $\begin{array}{l}0.0 \\
0.0 \\
0.0 \\
0.0 \\
0.0\end{array}$ & $\begin{array}{l}0.0 \\
0.0 \\
0.0 \\
0.0 \\
0.0\end{array}$ & $\begin{array}{l}7.0 \\
8.0 \\
7.0 \\
5.0 \\
4.0\end{array}$ & $\begin{array}{l}9.0 \\
8.0 \\
7.0 \\
6.0 \\
6.0\end{array}$ & $\begin{array}{l}0.0 \\
1.0 \\
0.0 \\
0.0 \\
1.0\end{array}$ & $\begin{array}{l}2.0 \\
1.0 \\
1.0 \\
4.0 \\
5.0\end{array}$ \\
\hline $\begin{array}{r}6 \\
7 \\
8 \\
9 \\
10\end{array}$ & $\begin{array}{l}19.0 \\
16.0 \\
17.0 \\
17.0 \\
14.0\end{array}$ & $\begin{array}{l}18.0 \\
18.0 \\
19.0 \\
18.0 \\
15.0\end{array}$ & $\begin{array}{l}7.0 \\
4.0 \\
4.0 \\
6.0 \\
6.0\end{array}$ & $\begin{array}{l}7.0 \\
7.0 \\
7.0 \\
8.0 \\
8.0\end{array}$ & $\begin{array}{l}6.0 \\
7.0 \\
7.0 \\
6.0 \\
7.0\end{array}$ & $\begin{array}{l}7.0 \\
8.0 \\
8.0 \\
7.0 \\
8.0\end{array}$ & \begin{tabular}{l}
0.0 \\
0.0 \\
\hdashline- \\
\hdashline- \\
$-\square$
\end{tabular} & $\begin{array}{l}0.0 \\
0.0 \\
0.0 \\
0.0\end{array}$ & $\begin{array}{l}4.0 \\
3.0 \\
3.0 \\
3.0 \\
1.0\end{array}$ & $\begin{array}{l}5.0 \\
4.0 \\
3.0 \\
3.0 \\
2.0\end{array}$ & $\begin{array}{l}3.0 \\
1.0 \\
3.0 \\
6.0 \\
8.0\end{array}$ & $\begin{array}{l}4.0 \\
6.0 \\
7.0 \\
8.0 \\
8.0\end{array}$ \\
\hline $\begin{array}{l}11 \\
12 \\
13 \\
14 \\
15\end{array}$ & $\begin{array}{l}13.0 \\
12.0 \\
12.0 \\
14.0 \\
15.0\end{array}$ & $\begin{array}{l}14.0 \\
15.0 \\
16.0 \\
17.0 \\
18.0\end{array}$ & $\begin{array}{l}8.0 \\
8.0 \\
8.0 \\
8.0 \\
7.0\end{array}$ & $\begin{array}{r}8.0 \\
11.0 \\
8.0 \\
8.0 \\
7.0\end{array}$ & $\begin{array}{l}8.0 \\
9.0 \\
8.0 \\
8.0 \\
7.0\end{array}$ & $\begin{array}{r}10.0 \\
9.0 \\
9.0 \\
8.0 \\
7.0\end{array}$ & $\overline{0.0}$ & $\begin{array}{l}0.0 \\
0.0 \\
0.0 \\
0.0 \\
0.0\end{array}$ & $\begin{array}{l}0.0 \\
0.0 \\
0.0 \\
0.0 \\
0.0\end{array}$ & $\begin{array}{l}1.0 \\
1.0 \\
1.0 \\
1.0 \\
1.0\end{array}$ & $\begin{array}{l}8.0 \\
7.0 \\
3.0 \\
2.0 \\
4.0\end{array}$ & $\begin{array}{l}9.0 \\
5.0 \\
4.0 \\
5.0 \\
7.0\end{array}$ \\
\hline $\begin{array}{l}16 \\
17 \\
18 \\
19 \\
20\end{array}$ & $\begin{array}{l}17.0 \\
17.0 \\
16.0 \\
14.0 \\
12.0\end{array}$ & $\begin{array}{l}19.0 \\
19.0 \\
16.0 \\
14.0 \\
15.0\end{array}$ & $\begin{array}{l}4.0 \\
6.0 \\
6.0 \\
4.0 \\
5.0\end{array}$ & $\begin{array}{l}7.0 \\
7.0 \\
7.0 \\
7.0 \\
6.0\end{array}$ & $\begin{array}{l}3.0 \\
3.0 \\
6.0 \\
7.0 \\
6.0\end{array}$ & $\begin{array}{l}5.0 \\
4.0 \\
8.0 \\
7.0 \\
8.0\end{array}$ & $\begin{array}{l}0.0 \\
0.0 \\
0.0 \\
0.0\end{array}$ & $\begin{array}{l}0.0 \\
0.0 \\
1.0 \\
1.0 \\
1.0\end{array}$ & $\begin{array}{l}0.0 \\
1.0 \\
0.0 \\
0.0 \\
---\end{array}$ & $\begin{array}{l}2.0 \\
1.0 \\
1.0 \\
2.0 \\
-\end{array}$ & $\begin{array}{l}6.0 \\
6.0 \\
7.0 \\
8.0 \\
9.0\end{array}$ & $\begin{array}{r}7.0 \\
8.0 \\
9.0 \\
11.0 \\
11.0\end{array}$ \\
\hline $\begin{array}{l}21 \\
22 \\
23 \\
24 \\
25\end{array}$ & $\begin{array}{l}12.0 \\
12.0 \\
11.0 \\
13.0 \\
13.0\end{array}$ & $\begin{array}{l}14.0 \\
15.0 \\
15.0 \\
16.0 \\
13.0\end{array}$ & $\begin{array}{l}4.0 \\
5.0 \\
5.0 \\
3.0 \\
4.0\end{array}$ & $\begin{array}{l}6.0 \\
7.0 \\
6.0 \\
6.0 \\
6.0\end{array}$ & $\begin{array}{l}8.0 \\
9.0 \\
4.0 \\
3.0 \\
--\end{array}$ & $\begin{array}{r}10.0 \\
7.0 \\
4.0 \\
5.0 \\
6.0\end{array}$ & $\begin{array}{l}1.0 \\
1.0 \\
1.0 \\
1.0 \\
1.0\end{array}$ & $\begin{array}{l}1.0 \\
1.0 \\
1.0 \\
2.0 \\
2.0\end{array}$ & $\begin{array}{l}0.0 \\
0.0 \\
0.0 \\
0.0 \\
0.0\end{array}$ & $\begin{array}{l}0.0 \\
0.0 \\
0.0 \\
0.0 \\
1.0\end{array}$ & $\begin{array}{r}11.0 \\
9.0 \\
5.0 \\
2.0 \\
4.0\end{array}$ & $\begin{array}{r}10.0 \\
7.0 \\
4.0 \\
5.0 \\
7.0\end{array}$ \\
\hline $\begin{array}{l}26 \\
27 \\
28 \\
29 \\
30 \\
31\end{array}$ & $\begin{array}{r}11.0 \\
12.0 \\
10.0 \\
9.0 \\
11.0 \\
12.0\end{array}$ & $\begin{array}{l}13.0 \\
11.0 \\
11.0 \\
12.0 \\
13.0 \\
13.0\end{array}$ & $\begin{array}{l}6.0 \\
6.0 \\
3.0 \\
2.0 \\
3.0 \\
\end{array}$ & $\begin{array}{l}7.0 \\
6.0 \\
5.0 \\
4.0 \\
4.0 \\
-. .\end{array}$ & $\begin{array}{l}3.0 \\
2.0 \\
1.0 \\
1.0 \\
0.0 \\
1.0\end{array}$ & $\begin{array}{l}3.0 \\
1.0 \\
1.0 \\
1.0 \\
1.0 \\
1.0\end{array}$ & $\begin{array}{l}1.0 \\
2.0 \\
3.0 \\
4.0 \\
6.0 \\
6.0\end{array}$ & $\begin{array}{l}3.0 \\
3.0 \\
5.0 \\
6.0 \\
7.0 \\
7.0\end{array}$ & $\begin{array}{l}0.0 \\
1.0 \\
1.0 \\
1.0 \\
--\end{array}$ & $\begin{array}{l}2.0 \\
1.0 \\
2.0 \\
1.0 \\
-0\end{array}$ & $\begin{array}{r}6.0 \\
8.0 \\
10.0 \\
12.0 \\
14.0 \\
15.0\end{array}$ & $\begin{array}{l}10.0 \\
12.0 \\
13.0 \\
15.0 \\
16.0 \\
15.0\end{array}$ \\
\hline
\end{tabular}

\begin{tabular}{|c|c|c|c|c|c|c|c|c|c|c|c|c|}
\hline \multirow[b]{2}{*}{ DAY } & \multicolumn{2}{|c|}{ APRIL } & \multicolumn{2}{|c|}{ MAY } & \multicolumn{2}{|c|}{ JUNE } & \multicolumn{2}{|c|}{ JULY } & \multicolumn{2}{|c|}{ AUGUST } & \multicolumn{2}{|c|}{ SEPTEMBER } \\
\hline & $A M$ & PM & $A M$ & $P M$ & $A M$ & PM & $A M$ & PM & $A M$ & PM & AM & PM \\
\hline $\begin{array}{l}1 \\
2 \\
3 \\
4 \\
5\end{array}$ & $\begin{array}{l}12.0 \\
12.0 \\
12.0 \\
12.0 \\
11.0\end{array}$ & $\begin{array}{l}13.0 \\
12.0 \\
12.0 \\
13.0 \\
10.0\end{array}$ & $\begin{array}{l}16.0 \\
17.0 \\
19.0 \\
19.0 \\
19.0\end{array}$ & $\begin{array}{l}21.0 \\
22.0 \\
23.0 \\
22.0 \\
19.0\end{array}$ & $\begin{array}{l}16.0 \\
16.0 \\
18.0 \\
18.0 \\
20.0\end{array}$ & $\begin{array}{l}17.0 \\
19.0 \\
20.0 \\
22.0 \\
23.0\end{array}$ & $\begin{array}{l}24.0 \\
25.0 \\
24.0 \\
22.0 \\
22.0\end{array}$ & $\begin{array}{l}28.0 \\
27.0 \\
27.0 \\
27.0 \\
27.0\end{array}$ & $\begin{array}{l}24.0 \\
23.0 \\
23.0 \\
25.0 \\
23.0\end{array}$ & $\begin{array}{l}26.0 \\
26.0 \\
26.0 \\
27.0 \\
25.0\end{array}$ & $\begin{array}{l}21.0 \\
21.0 \\
22.0 \\
22.0 \\
22.0\end{array}$ & $\begin{array}{l}23.0 \\
24.0 \\
25.0 \\
23.0 \\
23.0\end{array}$ \\
\hline $\begin{array}{r}6 \\
7 \\
8 \\
9 \\
10\end{array}$ & $\begin{array}{r}9.0 \\
9.0 \\
12.0 \\
11.0 \\
12.0\end{array}$ & $\begin{array}{l}11.0 \\
12.0 \\
13.0 \\
13.0 \\
14.0\end{array}$ & $\begin{array}{l}16.0 \\
16.0 \\
18.0 \\
18.0 \\
17.0\end{array}$ & $\begin{array}{l}19.0 \\
19.0 \\
19.0 \\
19.0 \\
18.0\end{array}$ & $\begin{array}{l}21.0 \\
22.0 \\
23.0 \\
23.0 \\
24.0\end{array}$ & $\begin{array}{l}24.0 \\
24.0 \\
24.0 \\
26.0 \\
28.0\end{array}$ & $\begin{array}{l}23.0 \\
22.0 \\
24.0 \\
24.0 \\
25.0\end{array}$ & $\begin{array}{l}27.0 \\
26.0 \\
26.0 \\
29.0 \\
28.0\end{array}$ & $\begin{array}{l}25.0 \\
26.0 \\
23.0 \\
26.0 \\
26.0\end{array}$ & $\begin{array}{l}28.0 \\
28.0 \\
29.0 \\
27.0 \\
27.0\end{array}$ & $\begin{array}{l}21.0 \\
21.0 \\
20.0 \\
21.0 \\
21.0\end{array}$ & $\begin{array}{l}24.0 \\
24.0 \\
23.0 \\
23.0 \\
21.0\end{array}$ \\
\hline $\begin{array}{l}11 \\
12 \\
13 \\
14 \\
15\end{array}$ & $\begin{array}{l}12.0 \\
13.0 \\
14.0 \\
16.0 \\
14.0\end{array}$ & $\begin{array}{l}14.0 \\
15.0 \\
16.0 \\
17.0 \\
16.0\end{array}$ & $\begin{array}{l}18.0 \\
18.0 \\
17.0 \\
19.0 \\
21.0\end{array}$ & $\begin{array}{l}19.0 \\
21.0 \\
21.0 \\
23.0 \\
24.0\end{array}$ & $\begin{array}{l}26.0 \\
26.0 \\
23.0 \\
22.0 \\
23.0\end{array}$ & $\begin{array}{l}29.0 \\
28.0 \\
27.0 \\
26.0 \\
26.0\end{array}$ & $\begin{array}{l}26.0 \\
26.0 \\
25.0 \\
24.0 \\
23.0\end{array}$ & $\begin{array}{l}29.0 \\
29.0 \\
27.0 \\
26.0 \\
25.0\end{array}$ & $\begin{array}{l}23.0 \\
22.0 \\
23.0 \\
23.0 \\
22.0\end{array}$ & $\begin{array}{l}26.0 \\
24.0 \\
24.0 \\
24.0 \\
23.0\end{array}$ & $\begin{array}{l}20.0 \\
19.0 \\
18.0 \\
19.0 \\
19.0\end{array}$ & $\begin{array}{l}20.0 \\
22.0 \\
22.0 \\
22.0 \\
23.0\end{array}$ \\
\hline $\begin{array}{l}16 \\
17 \\
18 \\
19 \\
20\end{array}$ & $\begin{array}{l}13.0 \\
14.0 \\
14.0 \\
15.0 \\
17.0\end{array}$ & $\begin{array}{l}16.0 \\
14.0 \\
17.0 \\
18.0 \\
19.0\end{array}$ & $\begin{array}{l}22.0 \\
21.0 \\
19.0 \\
19.0 \\
17.0\end{array}$ & $\begin{array}{l}24.0 \\
22.0 \\
22.0 \\
19.0 \\
21.0\end{array}$ & $\begin{array}{l}23.0 \\
22.0 \\
22.0 \\
23.0 \\
23.0\end{array}$ & $\begin{array}{l}26.0 \\
25.0 \\
26.0 \\
26.0 \\
26.0\end{array}$ & $\begin{array}{l}23.0 \\
24.0 \\
25.0 \\
26.0 \\
26.0\end{array}$ & $\begin{array}{l}26.0 \\
29.0 \\
29.0 \\
29.0 \\
29.0\end{array}$ & $\begin{array}{l}22.0 \\
23.0 \\
24.0 \\
25.0 \\
26.0\end{array}$ & $\begin{array}{l}24.0 \\
26.0 \\
26.0 \\
27.0 \\
28.0\end{array}$ & $\begin{array}{l}20.0 \\
20.0 \\
20.0 \\
19.0 \\
19.0\end{array}$ & $\begin{array}{l}21.0 \\
22.0 \\
20.0 \\
21.0 \\
23.0\end{array}$ \\
\hline $\begin{array}{l}21 \\
22 \\
23 \\
24 \\
25\end{array}$ & $\begin{array}{l}18.0 \\
18.0 \\
19.0 \\
19.0 \\
14.0\end{array}$ & $\begin{array}{l}20.0 \\
20.0 \\
19.0 \\
17.0 \\
17.0\end{array}$ & $\begin{array}{l}17.0 \\
16.0 \\
18.0 \\
17.0 \\
17.0\end{array}$ & $\begin{array}{l}19.0 \\
20.0 \\
18.0 \\
17.0 \\
18.0\end{array}$ & $\begin{array}{l}22.0 \\
23.0 \\
24.0 \\
24.0 \\
25.0\end{array}$ & $\begin{array}{l}27.0 \\
27.0 \\
27.0 \\
26.0 \\
26.0\end{array}$ & $\begin{array}{l}26.0 \\
27.0 \\
26.0 \\
27.0 \\
27.0\end{array}$ & $\begin{array}{l}29.0 \\
27.0 \\
28.0 \\
29.0 \\
28.0\end{array}$ & $\begin{array}{l}27.0 \\
27.0 \\
27.0 \\
27.0 \\
26.0\end{array}$ & $\begin{array}{l}29.0 \\
29.0 \\
30.0 \\
29.0 \\
28.0\end{array}$ & $\begin{array}{l}20.0 \\
21.0 \\
22.0 \\
22.0 \\
23.0\end{array}$ & $\begin{array}{l}24.0 \\
26.0 \\
26.0 \\
25.0 \\
22.0\end{array}$ \\
\hline $\begin{array}{l}26 \\
27 \\
28 \\
29 \\
30 \\
31\end{array}$ & $\begin{array}{l}13.0 \\
14.0 \\
15.0 \\
16.0 \\
16.0 \\
\end{array}$ & $\begin{array}{r}19.0 \\
17.0 \\
18.0 \\
19.0 \\
19.0 \\
\end{array}$ & $\begin{array}{l}17.0 \\
17.0 \\
16.0 \\
15.0 \\
16.0 \\
15.0\end{array}$ & $\begin{array}{l}18.0 \\
17.0 \\
17.0 \\
16.0 \\
16.0 \\
18.0\end{array}$ & $\begin{array}{l}24.0 \\
23.0 \\
21.0 \\
23.0 \\
23.0\end{array}$ & $\begin{array}{l}26.0 \\
23.0 \\
24.0 \\
25.0 \\
27.0 \\
-\end{array}$ & $\begin{array}{l}26.0 \\
24.0 \\
24.0 \\
23.0 \\
23.0 \\
24.0\end{array}$ & $\begin{array}{l}26.0 \\
25.0 \\
26.0 \\
27.0 \\
27.0 \\
25.0\end{array}$ & $\begin{array}{l}25.0 \\
22.0 \\
21.0 \\
21.0 \\
21.0 \\
21.0\end{array}$ & $\begin{array}{l}25.0 \\
24.0 \\
25.0 \\
24.0 \\
24.0 \\
24.0\end{array}$ & $\begin{array}{l}20.0 \\
21.0 \\
19.0 \\
19.0 \\
19.0\end{array}$ & $\begin{array}{l}23.0 \\
23.0 \\
23.0 \\
23.0 \\
22.0 \\
\end{array}$ \\
\hline
\end{tabular}


LOCATION,--Lat $40^{\circ} 17^{\prime} 14^{\prime \prime}$, long $84^{\circ} 08^{\prime} 57^{\prime \prime}$, Shelby County, at gaging station at North Street Bridge in Sidney, $100 \mathrm{ft}$ downstream from gage and 0.5 mile downstream from Tawawa Creek.

DRAINAGE AREA. -2541 sq $m 1$.

PERIOD OF RECORD. --Chemical analyses: October 1967 to September 1968.

Water temperatures: October 1967 to September 1968.

Sediment records: October 1967 to September 1968.

EXTREMES, $-1967-68$

Water temperatures: Maximum, 29.0 $\mathrm{C}$ Aug. 24; minimum, freezing point on several days during December, January

to March.
Sediment concentrations: Maximum da1ly, $704 \mathrm{mg} / 1$ July 25 ; minimum da1ly, $8 \mathrm{mg} / 1$ Jan. 26,27, Mar 6.

Sediment loads: Maximum dally, 5,300 tons Dec, 22; minimum da11y, 2.5 tons Oct. 30.

REMARKS.--Samples for iron and manganese were filtered clear when collected. Samples were collected weekly october, July to September and monthly November to June. Flow affected by ice Dec. 27 to Jan. 8, Jan. 24-27, Feb. 8 to Mar. 5, Mar 14, 15 .

CHEMICAL ANALYSES IN MILLIGRAMS PER LITER, WATER YEAR OCTOBER 1967 TO SEPTEMBER 1968

\begin{tabular}{|c|c|c|c|c|c|c|c|c|c|c|c|c|}
\hline$\cap A T F$ & TIMF & 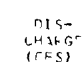 & $\begin{array}{l}\text { SILICA } \\
\text { (sine }\end{array}$ & $\begin{array}{l}\text { IRUN } \\
\text { (FE) }\end{array}$ & $\begin{array}{l}\text { WAN- } \\
\text { GANESE } \\
\text { (MA) }\end{array}$ & $\begin{array}{l}\text { CAL- } \\
\text { crim } \\
\text { iral }\end{array}$ & $\begin{array}{l}\text { MAF- } \\
\text { NIF- } \\
\text { SIIIN } \\
\text { IMES }\end{array}$ & $\begin{array}{l}\text { SODIUM } \\
\text { (NA) }\end{array}$ & $\begin{array}{l}D C- \\
T A C- \\
\text { SIII: } \\
(K)\end{array}$ & $\begin{array}{l}\text { BICAD- } \\
\text { ANAIATF } \\
\text { (HCOA) }\end{array}$ & $\begin{array}{l}\text { CAR- } \\
\text { AONATF } \\
\text { (COA) }\end{array}$ & $\begin{array}{l}\text { SILFATF } \\
\text { (Sn4) }\end{array}$ \\
\hline \multicolumn{13}{|l|}{ DCT. } \\
\hline $3 \ldots$ & 1945 & 47 & $\ldots$ & .16 & .14 & -. & -- & -- & -- & 724 & $x$ & 87 \\
\hline $1 \ldots$ & 745 & $6 R$ & -- & .20 & . 2 & -- & -- & -- & -- & $33^{n}$ & - & 78 \\
\hline $17 \ldots$ & $1 \times 43$ & 57 & -- & $\therefore 9$ & $\therefore a$ & - & -- & -- & -- & $2 x k$ & . & RO \\
\hline $24 \ldots$ & $1-2$ & $6^{-}$ & -- & .1 &.$^{2}$ & -- & -- & -- & -- & 212 & $r$ & ga \\
\hline Nov... & 111 & 7 & -- & .14 & $\cdot 3$ & -- & - & -- & -- & $24^{2}$ & n & 94 \\
\hline $7 \ldots$ & 73 & 245 & -- &. .5 &. & -- & -- & -- & -- & $15 !$ & 12 & \\
\hline $\begin{array}{l}15 . . \\
\text { DEC. }\end{array}$ & 123 & 243 & h. & i1? & : 7 & 90 & 27 & 0.4 & 2.3 & 258 & $n$ & in \\
\hline JAN. & $131^{\circ}$ & 253 & 3.1 & . คR & $\therefore 6$ & 58 & 17 & $4 . "$ & 2.9 & 156 & $"$ & or \\
\hline $\begin{array}{l}17 \ldots . . \\
\text { FFR. }\end{array}$ & $1 \leqslant 3$ & 17, & 9.7 & .2 & .7 & 99 & 34 & 1 r & 2.1 & 215 & ' & 105 \\
\hline $\begin{array}{l}13 \ldots \\
\text { MAK. }\end{array}$ & 145 & 22 & 9.1 & .12 & .25 & 25 & 36 & 8.6 & 1.9 & 218 & n & 121 \\
\hline $\begin{array}{l}19 \ldots . . \\
A D R:\end{array}$ & 915 & $5 \geq 2$ & B. 1 & .12 &.+1 & 73 & 24 & R.R & $2 . r$ & $22^{-}$ & ' & Q 4 \\
\hline${ }_{V_{A Y}}^{22} \ldots$ & 163 & 241 & 2.7 & . 9 & .14 & 92 & 22 & R. $\mathrm{k}$ & 1.5 & 204 & 1 & I $?$ \\
\hline $\begin{array}{l}14 \ldots . . \\
\text { JuNif }\end{array}$ & $121^{\circ}$ & $2 \mathrm{~h} 2$ & 4.6 & .12 & .15 & \& 7 & 31 & $1^{n}$ & 2.1 & $P R Q$ & ? & Q9 \\
\hline${ }_{w L Y}^{11 \ldots}$ & 1115 & 191 & 5.7 & $.1 r$ & .44 & 84 & 34 & 0.2 & 2.1 & $3 \div 2$ & $?$ & 29 \\
\hline $1 \ldots$ & $114^{-}$ & 245 & -- & .15 & .12 & -- & -- & -- & -- & 254 & m & AQ \\
\hline$q \ldots$ & 13 . & 87 & -- & $\cdots^{h}$ & $\ldots 4$ & -- & $-\infty$ & -- & -- & $27 k$ & R & 118 \\
\hline $16 \ldots$ & $111^{5}$ & 274 & -- & . 3 & .4 & -- & -- & $\cdots$ & -. & 299 & $\therefore$ & RA \\
\hline $24 \ldots$ & 141 & 115 & -- & .14 & . 3 & -- & -- & -- & -- & 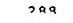 & 4 & 74 \\
\hline $\begin{array}{l}3 n \ldots . . \\
\text { Altr. }\end{array}$ & 1.3 & $3+3$ & $\cdots$ & .14 & .15 & -- & -- & - & -- & $3+A$ & $r$ & 76 \\
\hline $6 \ldots$ & 1245 & 6., & - & .18 & $\therefore \Leftrightarrow$ & -- & -- & -- & -. & $26^{-}$ & r & hR \\
\hline $13 \ldots$ & $2 \cdot 15$ & $42 a$ & -- & .31 & $\therefore 2$ & -- & -- & -- & - & $2 t t$ & 0 & 74 \\
\hline $2 . \ldots$ & 1,4, & 195 & -- & $\therefore$ & - 2 & -- & -- & -- & - & $2 R^{-}$ & 0 & 91 \\
\hline SEPT. & 12 & 141 & -- & $.1^{-}$ & .1 & -- & -- & -- & -- & $x x^{2}$ & 4 & $9 t$ \\
\hline r $4 \ldots$ & 13 & 76 & -- & .17 & .3 & -- & -- & -- & -- & $25 ?$ & ᄃ & 02 \\
\hline $11 \ldots$ & $2 \dddot{15}$ & 71 & -- & .3? & .46 & -- & -- & - & -- & $24^{\circ}$ & ? & $\$ 4$ \\
\hline $17 \ldots$ & 1' 1 & 59 & -- & . $?$ & .1 & -. & -- & -- & - & 272 & 12 & $7 R$ \\
\hline $74 \ldots$ & 573 & \&? & -- & .17 & .17 & -- & -- & -- & $\cdots$ & 252 & 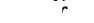 & 78 \\
\hline DATF & $\begin{array}{l}\text { CHLCO- } \\
\text { IPEE } \\
\text { ICLI }\end{array}$ & 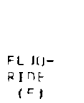 & $\begin{array}{l}\text { NITRATE } \\
\text { (N]3) }\end{array}$ & $\begin{array}{l}\text { TMTAL } \\
\text { DHRS- } \\
\text { OHIRIIS } \\
\text { POCAI }\end{array}$ & $\begin{array}{l}\text { DIS- } \\
\text { SNLVFD } \\
\text { SOLINS } \\
\text { IFFSI- } \\
\text { DIIF AT } \\
\text { I }^{\circ} \text { C C }\end{array}$ & 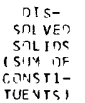 & $\begin{array}{l}H A F \cap)- \\
A F S S \\
(C A, M C, I\end{array}$ & $\begin{array}{l}\text { NON- } \\
\text { CAD- } \\
\text { PNNATE } \\
\text { HARD- } \\
\text { NESS }\end{array}$ & $\begin{array}{l}\text { SDECI- } \\
\text { FIC } \\
\text { CINA- } \\
\text { UCTANCF } \\
\text { INITPN- } \\
\text { WHOSI }\end{array}$ & ${ }^{2} H$ & $\begin{array}{l}\text { TFMP- } \\
\text { FDATHRE } \\
\text { (DFC, CI }\end{array}$ & CrLER \\
\hline
\end{tabular}

\begin{tabular}{|c|c|c|c|c|c|c|c|c|c|c|c|c|}
\hline $3 . \ldots$ & $2 c$ & +- & $3 . x$ & 1. & $44 ?$ & -- & $4^{e-}$ & 134 & $7 \times 5$ & 8,1 & 16 & -- \\
\hline $1 \ldots$ & 23 & -- & 2.3 & 1.9 & 434 & -- & $=h E$ & 04 & CQR 5 & 9.8 & $I^{3}$ & $=$ \\
\hline $17 \ldots$ & 2 & -- & 2.5 & .29 & $44 \mathrm{R}$ & -- & $4 r a$ & $1>0$ & KOP & $\therefore, 3$ & 16 & - \\
\hline$>4, \ldots$ & $1^{\circ}$ & -- & $2 . r$ & 1.2 & 444 & -- & 285 & 129 & hah & $a .1$ & 11 & -. \\
\hline $31 \ldots$ & 22 & - & $\cdot$ & 19 & $45 ?$ & -- & $42^{\prime}$ & 141 & 712 & 9.2 & 9 & -- \\
\hline vov. & & & & & & & & & & & & \\
\hline $7 \ldots$ & 18 & $\cdots$ & 14 & .10 & $3+1$ & $\cdots$ & $2 n$ & 157 & $5 k t$ & A. 7 & 4 & $=$ \\
\hline $\begin{array}{c}15 \ldots . \\
\text { DEFr. }\end{array}$ & 18 & .4 & 2.1 & .25 & $42 h$ & 415 & 240 & 124 & 2.34 & 2.4 & 5 & $2^{2}$ \\
\hline $12 \ldots$ & 11 & .3 & 13 & 2.4 & 25 & $2 \leq 1$ & ?15 & go & 413 & $7 . R$ & 7 & $5 r$ \\
\hline $\begin{array}{l}17 \ldots \\
\text { FER. }\end{array}$ & 18 & .4 & 6.8 & 1 & 4.64 & 449 & 287 & $12 \mathrm{~B}$ & $7 \sim 9$ & a. $r$ & 1 & $1^{r}$ \\
\hline $\begin{array}{l}13 . . \\
\text { MAR. }\end{array}$ & 16. & .3 & 1. & . 3R & 47 & 463 & $41^{\circ}$ & 140 & $72 k$ & R. & 1 & $1^{n}$ \\
\hline$\underset{\triangle P F}{19 .}$ & 16. & .3 & 15 & .29 & 384 & 330 & 220 & 1.0 & 5.42 & 7.0 & 7 & 15 \\
\hline${ }_{M A Y} 2 \cdot \cdots$ & 1t & .5 & 2.3 & .35 & $42^{\circ}$ & $4 \times 2$ & $2 \times I$ & $12^{\circ}$ & RAI & a.? & 10 & 7 \\
\hline $\begin{array}{l}14 \ldots \\
\text { JINF }\end{array}$ & It & .3 & 11 & .39 & $x c h$ & 303 & $\times 45$ & $1: 9$ & 625 & R. & 17 & 16 \\
\hline $\operatorname{Ju}_{\operatorname{Ju}} 11 \ldots$ & 16 & .5 & 3.5 & .29 & 426 & 413 & 275 & 124 & 354 & 9.2 & 25 & $4^{n}$ \\
\hline$-1 \ldots$ & 16 & -- & 12 & .49 & 382 & -- & $33 r$ & 122 & 590 & R.r & $>3$ & - \\
\hline $.9 \ldots$ & I A & $\cdots$ &. & .12 & 424 & -- & 250 & $11^{\circ}$ & $65 ?$ & 0.4 & $2 A$ & - \\
\hline $16 \ldots$ & 2. & -- & 3.5 & . Ahs & 378 & -- & 34 & $1<4$ & $B>A$ & A.? & 23 & - \\
\hline $24 \ldots$ & 16 & -- & 4.5 & .38 & 369 & -- & 228 & of & $B=2$ & R. 2 & $2 h$ & -- \\
\hline$\cdots$ & 12 & -- & 5.9 & . 31 & 374 & -- & ${ }^{2} 1^{2}$ & $1^{\cdots}$ & 572 & R. 1 & sn & -- \\
\hline Aus, & & & & & & & & & & & & \\
\hline $6 \ldots$ & 1. & -- & 6.0 & the & 362 & -- & 298 & $g a$ & $a<4$ & a.r & 23 & -- \\
\hline $13 \ldots$ & 14 & -- & 2.7 & .35 & $3+4$ & -- & 314 & 96 & 5.53 & 7.9 & $2^{r}$ & - \\
\hline $20 \ldots$ & lt & -- & 2. & .31 & 30 & -- & 32 & $1 n r$ & KA7 & R.? & 25 & -. \\
\hline $27 \ldots$ & 22 & -- & 1.5 & .46 & $4 t h$ & -- & $20 R$ & 121 & $74 t$ & 2.3 & 19 & -- \\
\hline SFPT. & & & & & & & & & & & & \\
\hline $5 . \ldots$ & 24 & -- & 3.5 & .35 & 454 & -- & 412 & $11 ?$ & 722 & จ.2 & 21 & -- \\
\hline $11 \ldots$ & I 8 & -- & 3.2 & .37 & $4 A B$ & -- & 20 of & 1.7 & 712 & $R .2$ & 19 & -- \\
\hline $17 \ldots$ & 24 & $=$ & 1.5 & .41 & 392 & - & 357 & $1 \div 0$ & $n \geqslant 0$ & $D . a$ & 19 & -- \\
\hline $24 \ldots$ & 22 & $\cdots$ & 2.5 & .72 & 422 & -- & 291 & $1{ }_{1}$ & $+0 / 6$ & 3.2 & ?? & - \\
\hline
\end{tabular}


03261500 GREAT MIAMI RIVER AT SIDNEY, OHIO--Continued

CHEMICAL ANALYSES IN MILLIGRAMS PER LITER, WATER YEAR OCTOBER 1967 TO SEPTEMBER 1968

\begin{tabular}{|c|c|c|c|c|c|c|c|c|}
\hline DATE & $\begin{array}{l}\text { AMMONI A } \\
(\mathrm{NH} 4)\end{array}$ & $\begin{array}{c}\text { NITRITE } \\
\text { (NO2) }\end{array}$ & $\begin{array}{l}\text { DIS- } \\
\text { SOLVED } \\
\text { OXYGEN }\end{array}$ & $\begin{array}{l}\text { PER- } \\
\text { CENT } \\
\text { SATUR- } \\
\text { ATION }\end{array}$ & PHENOLS & $\begin{array}{l}\text { METHV- } \\
\text { LENE } \\
\text { BLUE } \\
\text { ACTIVE } \\
\text { SUB- } \\
\text { STANCE }\end{array}$ & $\begin{array}{l}\text { TUR- } \\
\text { BI D- } \\
\text { I TY }\end{array}$ & ODOR \\
\hline \multicolumn{9}{|l|}{ OCT. } \\
\hline $03 \ldots$ & .22 & .00 & 9.2 & 93 & .008 & .04 & 20 & 0 \\
\hline $10 \ldots$ & .30 & .00 & 7.8 & 74 & .008 & .05 & 35 & 0 \\
\hline $17 \ldots$ & .07 & .05 & 8.2 & 82 & - & .05 & 30 & 0 \\
\hline $24 \ldots$ & .22 & .00 & 11.0 & 98 & .001 & .04 & 20 & 0 \\
\hline $31 \ldots$ & .07 & .00 & 10.0 & 87 & .000 & .05 & 20 & 0 \\
\hline \multicolumn{9}{|l|}{ NOV. } \\
\hline $07 \ldots$ & .22 & .05 & 6.0 & 46 & .002 & .13 & 4400 & 2 \\
\hline & \multicolumn{8}{|c|}{ DEC. } \\
\hline $\begin{array}{l}12 \ldots . . \\
\text { JAN. }\end{array}$ & .07 & .05 & 9.8 & 80 & .004 & .04 & 138 & 2 \\
\hline $\begin{array}{l}17 . . \\
\text { FEB. }\end{array}$ & .37 & .05 & 12.0 & 84 & .006 & .20 & 20 & 0 \\
\hline $\begin{array}{l}33 . . \\
\text { MAR. }\end{array}$ & .22 & - & 12.0 & 84 & .003 & .13 & 7.0 & 0 \\
\hline $\begin{array}{l}19 . . \\
\text { APR. }\end{array}$ & 1.1 & .05 & 11.0 & 90 & .001 & .22 & 50 & 0 \\
\hline MAY $22 \ldots$ & .22 & .05 & 13.0 & 138 & .000 & .04 & 8.0 & 4 \\
\hline JUNE & .07 & .05 & 8.8 & 91 & .004 & .06 & 28 & 2 \\
\hline \multicolumn{5}{|l|}{ JULY } & .007 & .04 & 45 & 2 \\
\hline $01 \ldots$ & .15 & .05 & 7.8 & 90 & .001 & .06 & 40 & 8 \\
\hline $09 \ldots$ & .00 & .05 & 10.8 & 132 & .003 & .18 & 45 & \\
\hline $16 \ldots$ & .00 & .05 & 7.4 & 85 & .001 & .04 & 60 & \\
\hline $24 \ldots$ & .15 & .05 & 8.0 & 98 & .003 & .14 & 50 & \\
\hline $\begin{array}{l}30 . . \\
\text { AUG. }\end{array}$ & .07 & .05 & 7.6 & 83 & .005 & .22 & 70 & 4 \\
\hline $06 \ldots$ & .15 & .05 & 6.8 & 78 & .008 & .11 & 85 & \\
\hline $13 \ldots$ & .22 & .05 & 7.2 & 78 & .000 & .05 & 70 & \\
\hline $20 \ldots$ & .00 & .05 & 7.2 & 86 & .006 & .29 & 49 & \\
\hline $\begin{array}{l}27 . . \\
\text { SEPT. }\end{array}$ & .15 & .00 & 8.2 & 87 & .000 & .20 & 30 & \\
\hline $04 \ldots$ & .07 & .05 & 8.5 & 94 & .023 & .05 & 35 & 2 \\
\hline $11 \ldots$ & .07 & .05 & 7.8 & 82 & .006 & .13 & 25 & \\
\hline $17 \ldots$ & .00 & .00 & 9.1 & 97 & .011 & .16 & 22 & 2 \\
\hline $24 \ldots$ & .15 & .00 & 7.2 & 82 & .001 & .10 & 50 & \\
\hline
\end{tabular}

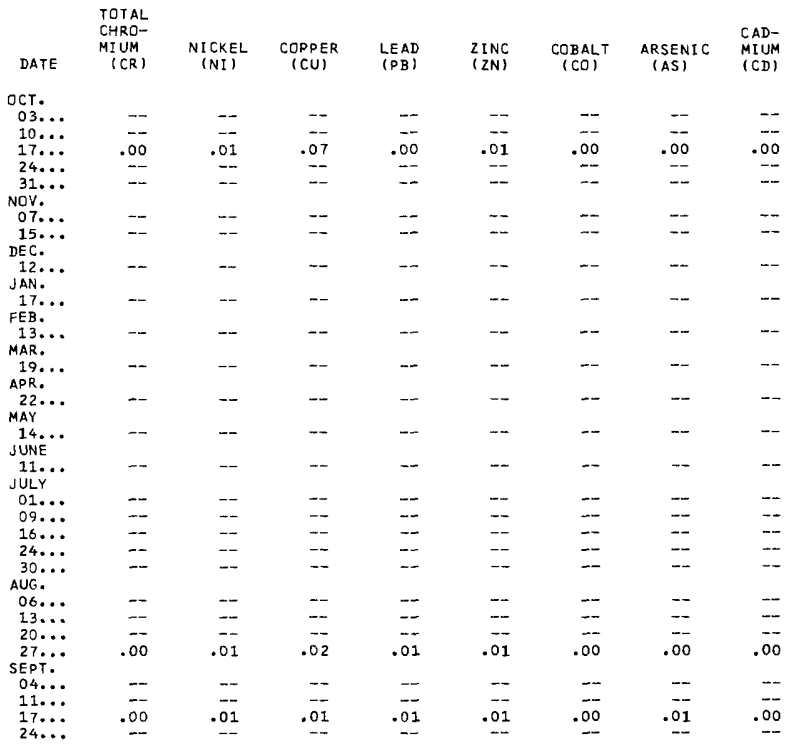


03261500 GREAT MIAMI RIVER AT SIDNEY, OHIO--COntinued

TEMPERATURE ( $\left.{ }^{\circ} \mathrm{C}\right)$ OF WATER, WATER YEAR OCTOBER 1967 TO SEPTEMBER 1968

\begin{tabular}{|c|c|c|c|c|c|c|c|c|c|c|c|}
\hline DAY & OCT & NOV & $D E C$ & JAN & FEB & NAR & $A P R$ & MAY & JUN & JUL & AUG \\
\hline 1 & - & $\cdots$ & 1.0 & $\cdots$ & 6.0 & --- & 11.0 & 12.0 & 17.0 & $27 . c$ & 26.0 \\
\hline 2 & 18.0 & 11.0 & 0.0 & 0.0 & - & --- & 11.0 & 17.0 & $=-$ & 23.0 & 23.0 \\
\hline 3 & 18.0 & - & $=-$ & 0.0 & 3.0 & --- & 11.0 & 20.0 & $\cdots$ & 22.0 & 23.0 \\
\hline 4 & $\cdots$ & $\cdots$ & 0.0 & 0.0 & -- & 4.0 & 12.0 & 18.0 & 22.0 & -- & -- \\
\hline 5 & $1 B .0$ & --- & 4.0 & 0.0 & 4.0 & 2.0 & B. 0 & 16.0 & 23.0 & 24.0 & 24.0 \\
\hline 6 & --- & --- & 4.0 & 0.0 & 5.0 & 3.0 & 9.0 & --- & 24.0 & 25.0 & 25.0 \\
\hline 7 & 18.0 & -- & 6.0 & $\ldots$ & 4.0 & 4.0 & $\cdots$ & 18.0 & 24.0 & $\cdots$ & 25.0 \\
\hline 8 & $\ldots$ & -.- & -- & 0.0 & 3.0 & 0.0 & 13.0 & is. 0 & 25.0 & 25.0 & 25.0 \\
\hline 9 & -- & -- & 6.0 & 0.0 & -- & 8.0 & 14.0 & 18.0 & -- & 26.0 & 26.0 \\
\hline .0 & -- & --- & $\cdots$ & 1.0 & -- & $=-$ & 12.0 & 17.0 & 27.0 & -- & - \\
\hline 1 & --- & $\ldots$ & 7.0 & 1.0 & --- & 7.0 & 13.0 & 15.0 & -- & 27.0 & --- \\
\hline 2 & --- & --- & 7.0 & 1.0 & -- & -- & 16.0 & -- & 26.0 & -- & 22.0 \\
\hline 3 & $=$ & --- & 6.0 & 1.0 & --- & 0.0 & 16.0 & 19.0 & 23.0 & $\ldots$ & 22.0 \\
\hline 14 & 13.0 & $\cdots$ & 6.0 & -- & --- & 0.0 & $\cdots$ & 20.0 & $\cdots$ & --- & - \\
\hline .5 & $\ldots$ & 3.0 & 4.0 & --- & 1.0 & 4.0 & 14.0 & $\cdots-$ & 24.0 & 23.0 & 23.0 \\
\hline Lo & -- & 2.0 & --- & --- & 1.0 & 4.0 & -. & 20.0 & -- & 25.0 & -- \\
\hline .7 & --- & 4.0 & --- & 1.0 & - & -- & 12.0 & 17.0 & 22.0 & $\ldots$ & 25.0 \\
\hline 8 & $\cdots$ & -- & b.o & -- & -- & 8. 0 & 14.0 & $16 . \mathrm{C}$ & 22.0 & 27.0 & $\cdots$ \\
\hline .9 & -- & --- & 0.0 & 1.0 &.- & 10.0 & - & $\ldots$ & 24.0 & 27.0 & 26.0 \\
\hline 0 & -- & 3.0 & 6.0 & --- & $\cdots$ & 10.0 & 17.0 & 16.0 & 24.0 & 26.0 & - \\
\hline 1 & 12.0 & 3.0 & 9.0 & -- & --- & 4.0 & --- & --- & 24.0 & -- & -- \\
\hline 2 & 13.0 & 4.0 & -- & 1.0 & 0.0 & -- & -- & 17.0 & 25.0 & 25.0 & $\cdots$ \\
\hline 3 & 13.0 & 4.0 & 2.0 & -- & 2.0 & 2.0 & 19.0 & 15.0 & $\cdots$ & $2 a .0$ & $\cdots$ \\
\hline$: 4$ & 14.0 & 4.0 & -- & -- & 0.0 & $\because$ & 13.0 & 13.0 & - & -- & 29.0 \\
\hline 75 & & 5.0 & $\cdots$ & 0.0 & -- & 7.0 & 12.0 & 16.0 & 21.0 & 22.0 & -- \\
\hline 'b & -- & -- &.-- & --- & --- & 6.0 & 12.0 & -- & 23.0 & 24.0 & -.- \\
\hline$: 7$ & $\forall .0$ & 3.0 & -- & --- & -- & 13.0 & 15.0 & 16.0 & 19.0 & 23.0 & --- \\
\hline :A & $\cdots$ & 2.0 & -- & - & -- & 12.0 & - & 15.0 & 19.0 & -- & -- \\
\hline 9 & --- & 1.0 & -- & 3.0 & $\cdots$ & 11.0 & 18.0 & 16.0 & 22.0 & 23.0 & --- \\
\hline .0 & -- & 1.0 & 0.0 & --- & -- & 15.0 & 16.0 & -- & - & 23.0 & --- \\
\hline 11 & -- & -- & -- & 3.0 & -- & --- & -- & -.. & -- & 22.0 & $\cdots$ \\
\hline ERAGE & -- & -- & --- & -- & -.. & -- & + & -- & -- & -- & -- \\
\hline
\end{tabular}

PERIODIC DETERMINATIONS OF SUSPENDED-SEDIMENT DISCHARGE AND PARTICLE SIZE, WATER YEAR OCTOBER 1967 TO SEPTEMBER 1968 IMETHODS OF ANALYSIS: B, BOTTOM HITHDRAWAL TUBE; C, CHEMICALLY OISPERSEO; N, IN NATIVE WATER; P. PIPET; S, SIEVE:

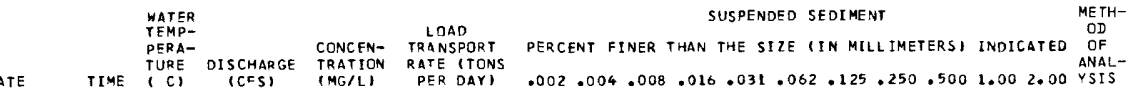

DEC 1119672040

JAN 3019681935

MAY $27 \ldots . .11710$

$\begin{array}{lllllllllllllll}2730 & 112 & 826 & 85 & 91 & 92 & 98 & 99 & 99 & 100 & - & - & -Z & - & \text { SBWC } \\ 5260 & 161 & 2290 & 67 & 76 & 82 & 89 & 94 & 95 & 100 & - & - & - & - & \text { SBWC } \\ 4200 & 626 & 7100 & 60 & 6 B & 81 & 98 & 95 & 96 & 98 & 99 & 100 & - & - & \text { SBWC } \\ 4200 & 626 & 7100 & 23 & 38 & 58 & 90 & 94 & 95 & 97 & 98 & 100 & -- & - & \text { SBN }\end{array}$

SUSPENDED SEDIMENT, WATER YEAR OCTOBER 1967 TO SEPTEMBER 1968

OCTOBER

NOVE MBER

DECEMBER̈

AY MEAN
CONCEN-
TRATION MEAN
CISCHARGE
(CFS)

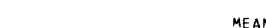
MEAN
CONCENN$\begin{array}{ccl}\text { MEAN } & \text { MEAN } & \text { CONCEN- } \\ \text { LOAD } & \text { DISCHARGE } & \text { TRATION } \\ \text { ITONSI } & \text { (CFS) } & \text { (HG/LI) }\end{array}$ LOAD
(TCNSI

TOTAL 2086

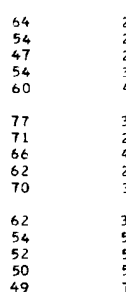

28
22
23
38
40
36
36
27
43
28
30
38
56
55
52
70
56
56
42
55
80
41
30
37
27
23
32
32
21
21
18
15
14
21 $\begin{array}{lcc}\text { LOAD } & \text { DISCHARGE } & \text { TRATI } \\ \text { (TONS) } & \text { (CFS) } & \text { (MG/L) }\end{array}$

$$
\begin{array}{rr}
4.8 & 89 \\
3.2 & 300 \\
2.9 & 425 \\
5.5 & 419
\end{array}
$$$$
7.9 \quad 439
$$

$\begin{array}{ll}7.5 & 298 \\ 5.2 & 236\end{array}$

$\begin{array}{ll}7.7 & 195 \\ 4.7 & 161\end{array}$

6.4143

6.4
8.2
7.7

7.7
7.0
9.3

143
132
179
159

159
226

$7.4 \quad 293$

$\begin{array}{ll}7.0 & 340 \\ 11 & 527 \\ 29 & 535 \\ 14 & \end{array}$

132
122

88
72
64
62

86

65
67

67
68
67
$6 E$

67

23
75
62
51
38
25
18
32
17
13
22
24
27
19
19
12
13
22
22
16
15
12
20
17
17
20
15
15
12
10
--
--

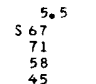

158
507
4270
3880
3200

10
107
298
102
52

$\begin{array}{ll}20 & 2920 \\ 11 & 2570 \\ 17 & 2130 \\ 7.4 & 1660\end{array}$

$\begin{array}{rr}8.5 & 2790 \\ 8.6 & 2550 \\ 13 & 2020 \\ 8.2 & 1480\end{array}$

$\begin{array}{ll}\mathrm{B}^{2} 2 & 1480 \\ 12 & 1120\end{array}$

$\begin{array}{rr}9.5 & 845 \\ 12 & 624 \\ 31 & 742 \\ 32 & 1100 \\ 20 & 958\end{array}$

$\begin{array}{rr}17 & 1120 \\ 11 & 4150 \\ 9.9 & 3080 \\ 7.6 & 1920\end{array}$

$8.1 \quad 1240$

10
6.6
6.0
4.4
3.9

958
600
450
400
320
270

$546.6 \quad 51942$
$5477^{4.3}$

$5<77$

1070

331
518

518
215
5580

5580

1020

620
340

248

60
37
44

44
122
124

$\begin{array}{rr}06 & 5292 \\ 473 & 5300 \\ 234 & 1950\end{array}$

487
148

487
198

10

62
43
37

22

18597.3 
3-2615. GREAT MIAUI RIVER AT SIDNEY, OHIO--CONTINUEd

SUSPENDED SEDIMENT , WATER YEAR OCTOBER 1967 TO SEPTEMBER 1968

\begin{tabular}{|c|c|c|c|c|c|c|c|c|c|}
\hline & & JANUARY & & & FEBRUARY & & & MARCH & \\
\hline DAY & $\begin{array}{l}\text { MEAN } \\
\text { DISCHARGE } \\
\text { (CFS) }\end{array}$ & $\begin{array}{l}\text { MEAN } \\
\text { CONCEN- } \\
\text { TRATION } \\
\text { (MG L) }\end{array}$ & $\begin{array}{l}\text { LOAD } \\
\text { ITONSI }\end{array}$ & $\begin{array}{l}\text { MEAN } \\
\text { DISCHARGE } \\
\text { (CFS) }\end{array}$ & $\begin{array}{l}\text { MEAN } \\
\text { CONCEN- } \\
\text { TRATION } \\
\text { (MG IL) }\end{array}$ & $\begin{array}{l}\text { LOAD } \\
\text { (TONS) }\end{array}$ & $\begin{array}{l}\text { MEAN } \\
\text { OISCHARGE } \\
\text { (CFS) }\end{array}$ & $\begin{array}{l}\text { MEAN } \\
\text { CONCEN- } \\
\text { TRATION } \\
\text { TMG/LI }\end{array}$ & $\begin{array}{l}\text { LUAL } \\
\text { (TONS) }\end{array}$ \\
\hline 1 & 230 & 28 & 17 & 3940 & 62 & 660 & 120 & 9 & 2.9 \\
\hline 2 & 220 & 27 & 16 & 3480 & 52 & 489 & 120 & q & 2.9 \\
\hline 3 & 230 & 33 & 20 & 2790 & 43 & 324 & 110 & 9 & 2.7 \\
\hline 4 & 200 & 35 & 19 & 2060 & 34 & 189 & 110 & 10 & 3.0 \\
\hline 5 & 200 & 32 & 17 & 1510 & 31 & 126 & 120 & 11 & 3.6 \\
\hline 6 & 210 & 49 & 28 & 1050 & 28 & 79 & 130 & B & 2.8 \\
\hline 7 & 190 & 30 & 15 & 778 & 27 & 57 & 125 & 11 & 3.7 \\
\hline g & 170 & 23 & 11 & 500 & 22 & 30 & 122 & 19 & 6.3 \\
\hline 9 & 170 & 18 & 8.3 & 400 & 16 & 17 & 125 & 20 & 6.8 \\
\hline 10 & 190 & 22 & 11 & 300 & 10 & 8.1 & 139 & 19 & 7.1 \\
\hline 11 & 180 & 13 & 6.3 & 240 & 10 & 6.5 & 137 & 22 & $\mathrm{~B}_{0} 1$ \\
\hline 12 & 170 & 16 & 7.3 & 230 & 10 & 6.2 & 141 & 22 & 8.4 \\
\hline 13 & 160 & 23 & 9.9 & 220 & 10 & 5.9 & 262 & 18 & 13 \\
\hline 14 & 170 & 22 & 10 & 210 & 10 & 5.7 & 140 & 20 & 7.6 \\
\hline 15 & 170 & 21 & 9.6 & 200 & 10 & 5.4 & 120 & 27 & 8.7 \\
\hline 10 & 170 & 20 & 9.2 & 190 & 15 & 7.7 & 181 & 27 & 13 \\
\hline 17 & 170 & 18 & 8.3 & 170 & 22 & 10 & 647 & 28 & 47 \\
\hline 18 & 170 & 10 & 4.6 & 160 & 25 & 11 & 683 & 35 & 65 \\
\hline 10 & 177 & 10 & 4.8 & 150 & 28 & 11 & 624 & 34 & 57 \\
\hline 20 & 175 & 13 & 6.1 & 140 & $2 B$ & 11 & 551 & 29 & 43 \\
\hline 21 & 195 & 13 & 6.8 & 140 & 28 & 11 & 555 & 29 & 43 \\
\hline 22 & 312 & 10 & 8.4 & 140 & $2 B$ & 11 & 692 & 28 & 52 \\
\hline 23 & 634 & 28 & 48 & 130 & 24 & 8.4 & 755 & 24 & 49 \\
\hline 24 & 600 & 25 & 40 & 130 & 14 & 4.9 & 647 & 22 & 38 \\
\hline 25 & 430 & 12 & 14 & 130 & 12 & 4.2 & 890 & 45 & $\$ 123$ \\
\hline 26 & 320 & 8 & 6.9 & 130 & 18 & 6.3 & 2170 & 131 & 708 \\
\hline 27 & 260 & 8 & 5.6 & 120 & 33 & 11 & 2570 & 144 & 997 \\
\hline 28 & 650 & 61 & 5131 & 120 & 21 & 6.8 & 2030 & 72 & 395 \\
\hline 29 & 2260 & 195 & 1190 & 120 & 12 & 3.9 & 1460 & 68 & 268 \\
\hline 30 & 4560 & 205 & 2520 & -- & -- & -- & 1020 & 72 & 198 \\
\hline 31 & 4710 & 108 & 1370 & - & - & -- & 728 & 68 & 134 \\
\hline TCTAL & 18653 & -- & 5579.1 & 19878 & - & 2127.0 & 18224 & - & 3381.6 \\
\hline & & APRIL & & & MAY & & & JUNE & \\
\hline & MEAN & $\begin{array}{l}\text { MEAN } \\
\text { CONCEN- }\end{array}$ & & MEAN & $\begin{array}{l}\text { MEAN } \\
\text { CONCEN- }\end{array}$ & & MEAN & $\begin{array}{l}\text { MEAN } \\
\text { CONCEN- }\end{array}$ & \\
\hline & DI SCHAKGE & TKATION & $\angle O A O$ & DISCHARGE & TRATION & LOAD & DISCHARGE & TRATION & $\angle O A D$ \\
\hline DAY & (CFS) & (MG/L) & (TONS) & (CFS) & $(M G / L)$ & (TONS) & (CFS) & $(M G / L)$ & (TONS) \\
\hline 1 & 1130 & 92 & 281 & 179 & 47 & 23 & 1340 & 68 & 246 \\
\hline 2 & 922 & 54 & 134 & 159 & 46 & 20 & 1020 & 53 & 140 \\
\hline 3 & 647 & 36 & 63 & 134 & 27 & 9.8 & 760 & 46 & 94 \\
\hline 4 & 1620 & 250 & 51330 & 144 & 27 & 10 & 539 & 35 & 51 \\
\hline 5 & 2010 & $1 B 8$ & 1020 & 146 & 27 & 11 & 412 & 33 & 37 \\
\hline 6 & 1400 & 70 & 265 & 163 & 28 & 12 & 334 & 85 & 77 \\
\hline 7 & 944 & 59 & 150 & 120 & 30 & 9.7 & 290 & 110 & 86 \\
\hline 8 & 678 & 48 & 88 & 114 & 42 & 13 & 245 & 102 & 67 \\
\hline s & 519 & 47 & 66 & 124 & 37 & 12 & 236 & 92 & 59 \\
\hline 10 & 439 & 42 & 50 & 132 & 38 & 14 & 217 & 75 & 44 \\
\hline 11 & 403 & 36 & 39 & 171 & 45 & 21 & 191 & 82 & 42 \\
\hline 12 & 320 & 34 & 29 & 409 & BI & 89 & 171 & B2 & 38 \\
\hline 13 & $27 \mathrm{C}$ & 37 & 27 & 357 & 30 & 29 & 198 & 82 & 44 \\
\hline 14 & 272 & 26 & 19 & 262 & 22 & 16 & 181 & 107 & 52 \\
\hline 15 & 331 & 41 & 37 & 222 & 27 & 16 & 144 & 82 & 32 \\
\hline 16 & 334 & 33 & 30 & 262 & 30 & 21 & 222 & 84 & 50 \\
\hline 17 & 262 & 33 & 23 & 303 & 30 & 25 & 306 & 123 & 102 \\
\hline 18 & 258 & 22 & 15 & 231 & 22 & 14 & 229 & 88 & 54 \\
\hline 19 & 265 & 29 & 21 & 229 & 30 & 19 & 179 & 90 & 43 \\
\hline 20 & 245 & 24 & 16 & 204 & 30 & 17 & 161 & 103 & 45 \\
\hline 21 & 245 & 26 & 17 & 189 & 33 & 17 & 152 & 103 & 42 \\
\hline 22 & 243 & 28 & 18 & 169 & 27 & 12 & 124 & 113 & 38 \\
\hline 23 & 213 & 25 & 14 & 372 & 74 & 597 & 117 & 107 & 34 \\
\hline 24 & 195 & 25 & 15 & 1660 & 156 & 699 & 130 & 81 & 28 \\
\hline 25 & 198 & 22 & 12 & 1770 & 94 & 449 & 187 & 116 & $5 \%$ \\
\hline 26 & 187 & 16 & 8.1 & 1170 & 56 & 177 & 492 & 120 & 159 \\
\hline 27 & 177 & 20 & 9.6 & 3190 & 433 & 54010 & 755 & so & 183 \\
\hline 28 & 158 & 23 & S. 8 & 4050 & 246 & 2690 & 800 & 122 & 264 \\
\hline 29 & 143 & 22 & 8.5 & 3080 & 156 & 1300 & 563 & Bo & 122 \\
\hline 30 & 137 & $2 \mathrm{~B}$ & 10 & 2380 & 98 & 630 & 387 & 68 & 71 \\
\hline 31 & - & -- & -- & 1850 & 82 & 410 & -- & -- & - \\
\hline TOTAL & 15165 & 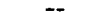 & 3825.0 & 23945 & - & 10892.5 & 11082 & $\rightarrow$ & 2409 \\
\hline
\end{tabular}


03261500 GREAT MIAMI RIVER AT SIDNEY, OHIO--Cont1nued SUSPENDED SEDIMENT, WATER YEAR OCTOBER 1967 TO SEPTEMBER 1968 JULY

AUG UST

SEPTEMBER

$\begin{array}{rr} & \\ \text { OAY DIS } & \\ 1 & \\ 2 & \\ 3 & \\ 4 & \\ 5 & \\ 6 & \\ 7 \\ 8 \\ 9 \\ 10 \\ 11 \\ 12 \\ 13 \\ 14 \\ 15 \\ 16 \\ 17 \\ 18 \\ 19 \\ 20 \\ 21 \\ 22 \\ 23 \\ 24 \\ 25 & \\ 26 & \\ 27 & \\ 28 & \\ 29 & \\ 30 & \\ 31 & \\ & \end{array}$

\section{MEAN}

TRATION

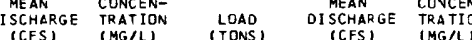

MEAN

MEAN
CONCEN-

TRATION

LOAD

MEAN
DISCHARGE

MEAN

(TONS)

TRATIUN LOAL

$\begin{array}{ll}283 & 48 \\ 241 & 5 \\ 204 & 70 \\ 189 & 73 \\ 143 & 70\end{array}$

$\begin{array}{ll}37 & 241 \\ 34 & 403 \\ 39 & 334\end{array}$

334
355
791

62
73
72
94

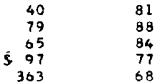

$\begin{array}{ll}81 & 63 \\ 88 & 60 \\ 84 & 46 \\ 77 & 52 \\ 68 & 82\end{array}$

$\begin{array}{ll}63 & 14 \\ 60 & 14 \\ 46 & 10 \\ 52 & 11 \\ 82 & 15\end{array}$

19

120
105

92
84

$\begin{array}{rrr}56 & 18 & 611 \\ 50 & 16 & 499 \\ 58 & 16 & 742 \\ 58 & 14 & 1080 \\ 42 & 905 & 1320\end{array}$

98
93
106
142

162
125
212
414

73

73
76
72

$\begin{array}{ccccc}14 & 1080 & 142 & 414 & 68 \\ 9.5 & 1320 & 172 & 613 & 71\end{array}$

68

87

$\begin{array}{ll}87 & 17 \\ 32 & 27\end{array}$

$\begin{array}{rl}92 & 53 \\ 89 & 38 \\ 78 & 4 \\ 102 & 57 \\ 172 & 82\end{array}$

$13 \quad 1140$

$\begin{array}{lll}38 & 9.1 & 728 \\ 42 & 8.8 & 422 \\ 57 & 16 & 303 \\ 82 & 38 & 250\end{array}$

99
62 $\quad 12$

58
88
105

122
66
72

72
81

80
67

$\begin{array}{ll}33 & 217 \\ 14 & 222 \\ 9.4 & 272 \\ 54 & 245\end{array}$

$\begin{array}{ll}\$ 54 & 245 \\ 42 & 181\end{array}$

106
101
94
62
52

62
61
69
41

64

104
84

34

$256-57$

21
17
18
5184

5184

$15 \epsilon$
130
122
119
120

68
81
68
88

41
25

62
80
96
93

82
50
110
86

16
20

24
16

8515

$\begin{array}{ll}93 & 15 \\ 68 & 11 \\ 93 & 20 \\ 58 & 15 \\ 58 & 15\end{array}$

$\begin{array}{ll}29 & 76 \\ 30 & 72 \\ 22 & 77 \\ 28 & 86 \\ 25 & 76\end{array}$

$704 \times \quad 4580$

222
118

$\begin{array}{ll}136 & 275 \\ 136 & 317\end{array}$

317
181
63

130
134

134
105

$\begin{array}{rrr}863 & 136 & 317 \\ 638 & 105 & 181 \\ 357 & 65 & 63 \\ 245 & 67 & 44\end{array}$

28
25

56
55
59
56

11
11
12
11

- $\quad 7173.8 \quad 11623$

TOTAL DISCHARGE FOR YEAR (CFS-DAYS)

TOTAL LOAD FOR VEAR (TONS)

$S$ COMPUTED BY SUBDIVIDING DAY.

D3261950 LORAMIE CREEK NEAR NEWPORT, OHIO

LOCATION,--Lat $40^{\circ} 18^{\prime} 25^{\prime \prime}$, long $84^{\circ} 23^{\prime} 02^{\prime \prime}$, In SEł sec.24, T.11 N., R.4 E., Shelby County, at gaging station at bridge on Cardo Roman Road, 1 .1 miles northiest of Nemport, 3 mlles south of Fort Loramie and 3 miles downtream from Creek.

DRA INAGE AREA.--152 sq mi.

PERIOD OF RECORD.--water temperatures: October 1967 to September 1968.

Sediment records: Octoher 1967 to September 1968 .

EXTREMES. $-1967-68$ :

Sediment concentrations: Maximum da11y, 548 mg/1 July $25 ;$ minimum daily, 4 mg/1 Mar. $3,4$.
Sed1ment loads: Maximum dally, 1,320 tons Dec, 4; m1n1mum daily, 0.04 ton Oct. 3.

TEMPERATURE ('O) OF WATER, WATER YEAR OCTOBER 1967 TO SEPTEMBER 1968 IONCE-DAILY MEASUREMENT BETWEEN O700 AND 09001

raY

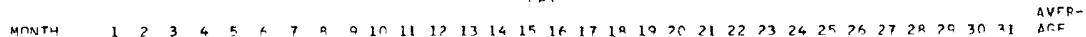
JAAMIPY.. - -

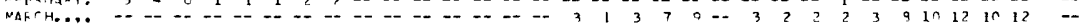

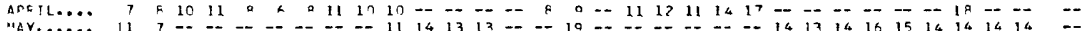

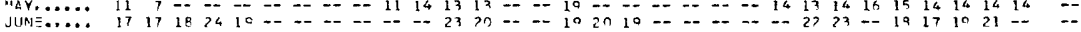

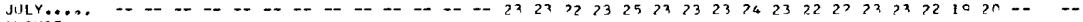
AITIJS UE,

PERIODIC DETERMINATIONS OF SUSPENDED-SEDIMENT DISCHARGE AND PARTICLE SIZE, WATER YEAR OCTOBER 1967 TO SEPTEMBER 1968 (METHOOS OF ANALYSIS: B, BOTTOM WITHDRAHAL TUBE; C, CHEMICALLY DISPER SED; N, IN NATIVE HATER: P, PIPEI; S, SIEVE;
V, VISUAL ACCUMULATION TUAE: H, IN DISTILLED WATER)

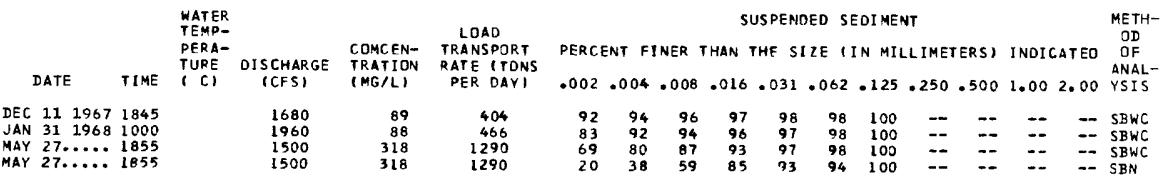


03261950 LORAMIE CREEK NEAR NEWPORT, OHIO--CONTINUED

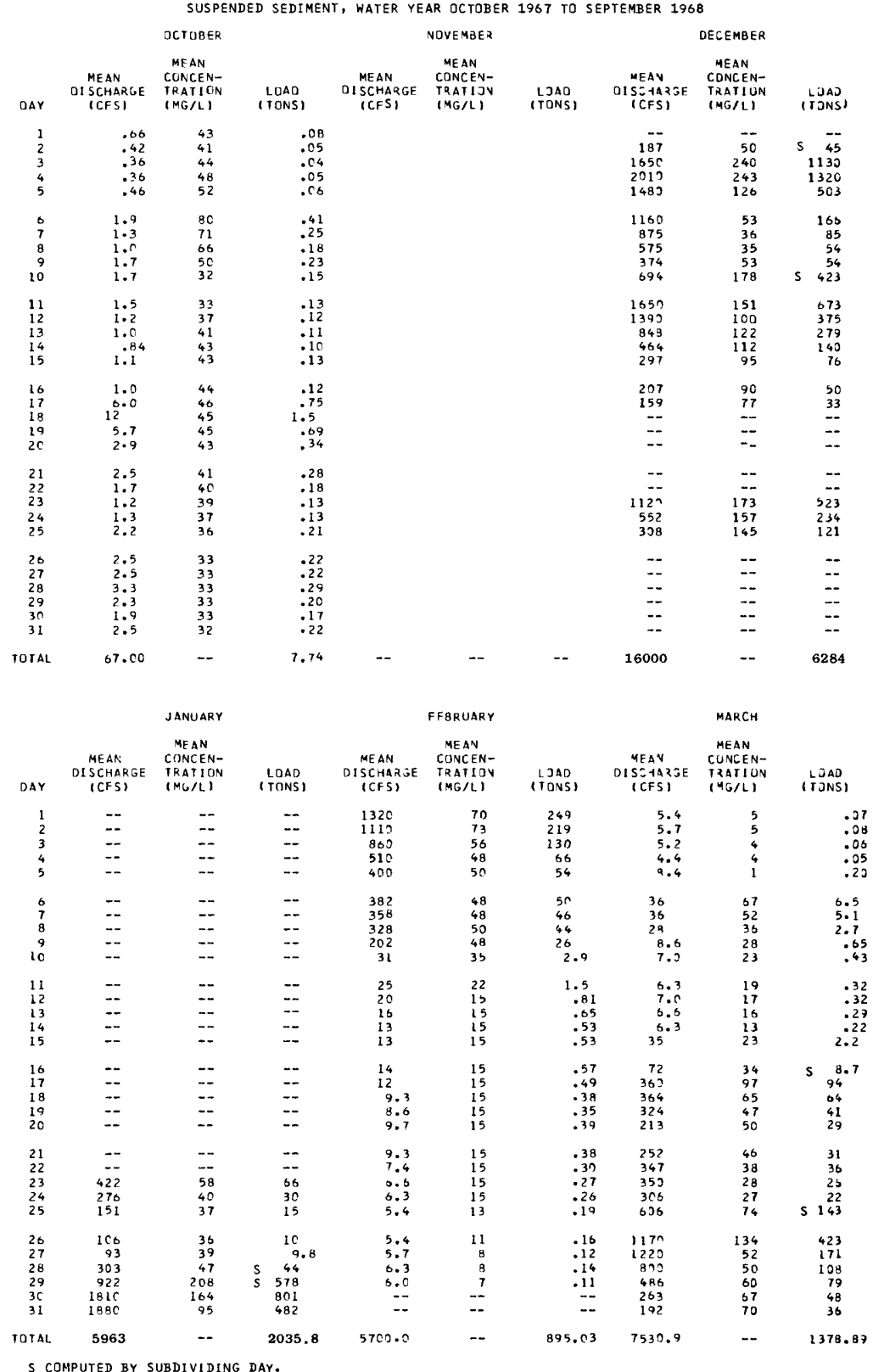


GREAT MIAMI RIVER BASIN

03261950 LORAMIE CREEK NEAR NEWPORT, OHIO--Cont1 nued

SUSPENDED SEDIMENT, WATER YEAR OCTOBER 1967 TO SEPTEMBER 1968

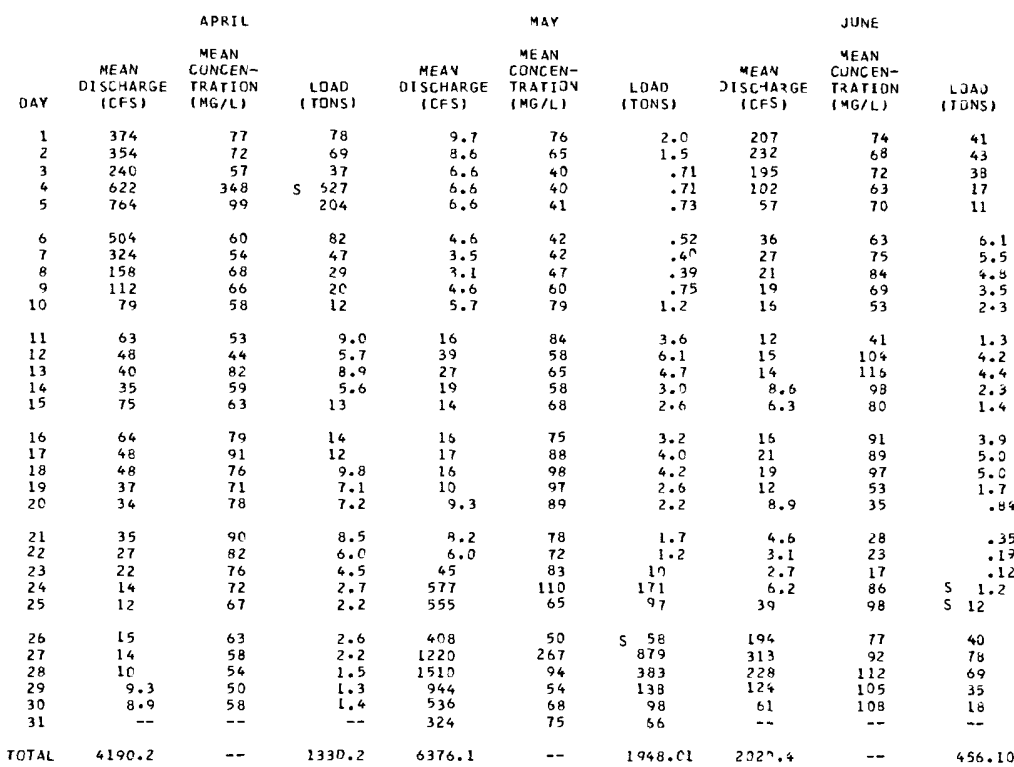

\begin{tabular}{|c|c|c|c|c|c|c|c|c|c|}
\hline \multirow[b]{2}{*}{ DAY } & \multicolumn{3}{|c|}{ JULY } & \multicolumn{3}{|c|}{ AJGUST } & \multicolumn{3}{|c|}{ SEPTEMBER } \\
\hline & $\begin{array}{l}\text { MEAN } \\
\text { OI SCHARGE } \\
\text { (CFS) }\end{array}$ & $\begin{array}{l}\text { MEAN } \\
\text { CONCEN- } \\
\text { TRATI IN } \\
\text { (MGIL) }\end{array}$ & $\begin{array}{l}\text { LOAO } \\
\text { (TONS) }\end{array}$ & $\begin{array}{l}\text { MEAN } \\
\text { OISCHARGE } \\
\text { (CFS) }\end{array}$ & $\begin{array}{l}\text { MEAN } \\
\text { CONCEN- } \\
\text { TRATIOV } \\
\text { (MG/L) }\end{array}$ & $\begin{array}{l}\text { LOAD } \\
\text { ITONSI }\end{array}$ & $\begin{array}{l}\text { MEAN } \\
\text { DISCHASGE } \\
\text { (CFS) }\end{array}$ & $\begin{array}{l}\text { MEAN } \\
\text { CONEEN- } \\
\text { IRAIION } \\
\text { \{MGIL\} }\end{array}$ & (TUNS) \\
\hline 1 & 31 & 92 & 7.7 & 31 & 160 & 515 & 1.7 & 48 & .22 \\
\hline 2 & 22 & 82 & 4.6 & 85 & 234 & 54 & 2.7 & 50 & .35 \\
\hline 3 & & 75 & $3 . n$ & 51 & 201 & 28 & 2.5 & 47 & .32 \\
\hline 4 & 9.3 & 71 & 1.8 & 30 & 155 & 13 & 1.9 & 42 & .22 \\
\hline 5 & 6.3 & 65 & 1.1 & 49 & 152 & 20 & 1.5 & 42 & .17 \\
\hline 6 & 4.9 & $6 c$ & .79 & 24 & 139 & 9.0 & 1.7 & 42 & .22 \\
\hline 7 & 4.2 & 55 & .62 & 14 & 127 & 4.8 & 1.7 & 40 & .15 \\
\hline 8 & 3.3 & 52 & .46 & 110 & 233 & 5166 & 1.6 & 41 & .18 \\
\hline 9 & 2.9 & 47 & .37 & 887 & 397 & 5951 & 1.2 & 40 & .13 \\
\hline 10 & 2.5 & 48 & .32 & 658 & 146 & 259 & 5.5 & 58 & . Bs \\
\hline 11 & 2.3 & 55 & .34 & 366 & 138 & 136 & 4.7 & 47 & .62 \\
\hline 12 & 2.3 & $6 C$ & .37 & 178 & 122 & 59 & 4.9 & 37 & .49 \\
\hline 13 & 2.2 & 68 & .40 & 83 & 103 & 23 & 3.3 & 38 & .34 \\
\hline 14 & 1.9 & 86 & .44 & 43 & 87 & 10 & 2.7 & 41 & $.3 j$ \\
\hline 15 & 2.7 & 89 & .65 & 25 & 75 & 5.1 & $2 \cdot 3$ & 40 & .25 \\
\hline 16 & 14 & 78 & 2.9 & 26 & 75 & 5.3 & 2.2 & 42 & .25 \\
\hline 17 & 41 & 80 & 8.9 & 80 & 141 & $S \quad 38$ & 2.7 & 51 & .37 \\
\hline 18 & 22 & 111 & 6.6 & 129 & 200 & 70 & 6.4 & $10 i$ & 1.7 \\
\hline 19 & $3 c$ & 138 & 11 & 48 & 113 & 15 & 12 & 103 & 3.3 \\
\hline 20 & 42 & 112 & 13 & 17 & 73 & 3.7 & 12 & 70 & 2.3 \\
\hline 21 & 20 & 137 & 7.4 & 12, & 65 & 2.1 & 5.7 & 57 & .83 \\
\hline 22 & 12 & 137 & 4.4 & 8.2 & 66 & 1.5 & 3.9 & 54 & .57 \\
\hline 23 & 22 & 126 & 7.5 & 7.4 & 62 & 1.2 & 3.1 & 54 & .45 \\
\hline 24 & 115 & 222 & 5147 & 4.9 & 68 & $.9 n$ & 2.9 & 52 & .41 \\
\hline 25 & 548 & 548 & 811 & 10 & 109 & 2.9 & 3.1 & 53 & .44 \\
\hline 26 & 480 & 213 & 276 & 8.6 & 76 & 1.8 & 3.1 & 52 & .44 \\
\hline 27 & 273 & 171 & 126 & 5.2 & 61 & .86 & 2.3 & 52 & .32 \\
\hline 28 & 161 & 177 & 77 & 3.1 & 57 & .48 & 2.3 & 54 & .34 \\
\hline 29 & 86 & 170 & 39 & 2.0 & 53 & .29 & 2.0 & 53 & .29 \\
\hline 30 & 36 & 165 & 16 & 1.9 & 52 & .27 & 1.5 & 52 &.$<1$ \\
\hline 31 & 16 & 120 & 5.2 & 1.6 & 48 & .21 & -- & $\cdots$ & - \\
\hline TOTAL & $2 \mathrm{C} 29.8$ & -- & 1581.86 & 2999.9 & -- & 1897.41 & 105.5 & -- & 67.13 \\
\hline $\begin{array}{l}\text { TOTAL } \\
\text { TOTAL }\end{array}$ & $\begin{array}{l}\text { I SCHARGE F } \\
\text { OAD FOR PE }\end{array}$ & $\begin{array}{l}\text { PERIOD } \\
\text { D (TON }\end{array}$ & S) & & & & & & $\begin{array}{l}52982.80 \\
17832.17\end{array}$ \\
\hline
\end{tabular}

$\$$ COMPUTED BY SUBDIVIDING DAY. 
LOCATION.--Lat $39^{\circ} 51^{\prime} 17^{\prime \prime}$, long $84^{\circ} 10^{\prime} 09^{\prime \prime}$, Montgomery County, at highway bridge on Little York Road, 0.8 mile downstream from Poplar Creek, 0.8 mile south of Taylorsville, 1.3 miles downstream from gaging station and 1.5 miles downstream from Taylorsville Dam.

DRA INAGE AREA. $--1,149 \mathrm{sq} \mathrm{mi}$ (at gaging station).

PERIOD OF RECORD, --Chemical analyses: November 1961 to July 1963, July 1966 to September 1968.

REMARKS.-Samples for iron and manganese were flltered clear when collected. Samples were collected weekly at this station october, July to September and monthly November to June. Records of discharge are given for Great

CHEMICAL ANALYSES IN MILLIGRAMS PER LITER, WATER YEAR OCTOBER 1967 TO SEPTEMBER 1968

\begin{tabular}{|c|c|c|c|c|c|c|c|c|c|c|}
\hline DATE & $T I M E$ & $\begin{array}{l}\text { OIS- } \\
\text { CHAFGE } \\
\text { ICFSI }\end{array}$ & $\begin{array}{l}\text { SILICA } \\
\text { (Sice) }\end{array}$ & $\begin{array}{l}\text { IRnN } \\
\text { IFEI }\end{array}$ & $\begin{array}{l}\text { MAN- } \\
\text { GANE SE } \\
\text { ( } M N)\end{array}$ & $\begin{array}{l}C A L- \\
C I U M \\
(C A)\end{array}$ & $\begin{array}{l}\text { MAG- } \\
\text { NF- } \\
\text { CIUM } \\
(M G \mid\end{array}$ & $\begin{array}{l}\text { SCDI UNe } \\
\text { (NA) }\end{array}$ & $\begin{array}{l}\text { Pח- } \\
\text { TAS- } \\
\text { SIIJM } \\
(K)\end{array}$ & $\begin{array}{l}\text { RICAR } \\
\text { RTNAT } \\
\text { IHC } T_{1} \text { ? }\end{array}$ \\
\hline \multicolumn{11}{|l|}{$n \subset \mathrm{T}}$. \\
\hline$\therefore 3 \ldots$ & 1130 & $1+1$ & -- & .00 & $\therefore \hat{n}$ & -- & -- & - & -- & \\
\hline $10 \ldots$ & $14: 5$ & 125 & -- & .11 & .13 & -- & -- & -- & -- & \\
\hline $17 \ldots$ & 181 . & 112 & $\cdots$ & ico & .12 & -- & -- & -- & -- & \\
\hline $24 \ldots$ & 1315 & 114 & $\cdots$ & .11 & .03 & -- & -- & - & -- & \\
\hline \multirow{2}{*}{\multicolumn{11}{|c|}{ Juv. }} \\
\hline & & & & & & & & & & \\
\hline \multicolumn{11}{|l|}{ nEc. } \\
\hline $\begin{array}{l}\text { IZn. } \\
\text { JAA. }\end{array}$ & 1115 & a71i & 0.5 & .75 & $\because$ & 54 & 16 & $=.5$ & 3.2 & \\
\hline $\begin{array}{c}17 \ldots \\
F F R .\end{array}$ & $1+13$ & 333 & 8.1 & .21 & .66 & 79 & 25 & 22 & 2.5 & \\
\hline $\begin{array}{l}13 \ldots . . \\
4 k\end{array}$ & +315 & $35 c$ & 7.2 &.$c^{2}$ & .14 & $o_{6}$ & 31 & 12 & 2.1 & M $4 k$. \\
\hline $\begin{array}{c}19 . . \\
\triangle P K_{0}\end{array}$ & $11 \times$ & 113 & $b . C^{\circ}$ & .19 & .43 & 14 & 24 & i) & 7.8 & 22 \\
\hline \multicolumn{11}{|l|}{$\begin{array}{l}23 \ldots \\
\text { WaY }\end{array}$} \\
\hline \multicolumn{11}{|l|}{$\operatorname{sinF}^{14 \ldots}$} \\
\hline \multicolumn{10}{|l|}{ JULY } & \\
\hline $01 \ldots$ & I He & 532 & -- & . $\mathrm{ra}$ &.$i 2$ & -- & -- & -. & - & \\
\hline $9 .$. & 1030 & 297 & - & .17 & $\therefore 5$ & -- & -- & - & $\ldots$ & 24 \\
\hline $16 \ldots$ & 1435 & $124 r$ & -- & i. & .84 & -- & -- & -- & - & \\
\hline $74 \ldots$ & 1225 & 298 & -- & .12 & .22 & -- & -- & -- & -- & \\
\hline $36 \ldots$ & 1315 & WIR & -- & $.2 r$ & .14 & -- & -- & -- & -- & 2 \\
\hline \multicolumn{11}{|l|}{ AUG. } \\
\hline $13 \ldots$ & 126 & $37 t$ & -- & .19 & $\therefore i$ & -- & $=$ & 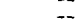 & - & \\
\hline $23 \ldots$ & $133 \%$ & $4 \pi 6$ & -- & $\therefore 2$ & . & - & -- & $\cdots$ & $\sim$ & \\
\hline $\begin{array}{l}27 . \\
\text { SEPT. }\end{array}$ & 232 & 237 & - & .07 & . 3 & -- & -- & - & -- & \\
\hline$-4 \ldots$ & $170:$ & 169 & -- & .14 & $\because 7$ & - & - & -- & - & \\
\hline $11 \ldots$ & 1315 & 159 & - & .26 & .54 & -- & $=$ & $\because$ & - & $31^{\circ}$ \\
\hline \multirow{24}{*}{$74 \ldots$} & $\begin{array}{l}1311 \\
1=45\end{array}$ & $\begin{array}{l}151 \\
149\end{array}$ & $\begin{array}{l}-- \\
--\end{array}$ &. $.1 k$ & $\begin{array}{l}.24 \\
.25\end{array}$ & $=-$ & -- & $\because$ & $\because$ & $\begin{array}{l}292 \\
29 r\end{array}$ \\
\hline & & BATE & $\begin{array}{l}\text { A } 4(1) \text { (1) } \\
\text { (vH4) }\end{array}$ & $\begin{array}{c}\text { NITR1TE } \\
\text { (NO2) }\end{array}$ & $\begin{array}{l}\text { OISS- } \\
\text { OLVEN } \\
\text { OXYSEN }\end{array}$ & $\begin{array}{l}\text { PER- } \\
\text { CFNT } \\
\text { SAT JP- } \\
A T I \cap N\end{array}$ & PHENGLS & $\begin{array}{l}\text { MF THY- } \\
\text { LFVF } \\
\text { RLUF } \\
\text { AT TIVF } \\
\text { SUR- } \\
\text { STANCE }\end{array}$ & $\begin{array}{l}\text { TUR- } \\
\text { BIn- } \\
\text { ITY }\end{array}$ & ONgR \\
\hline & & 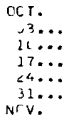 & $\begin{array}{l}.37 \\
.57 \\
.37 \\
.37 \\
.36\end{array}$ & $\begin{array}{l}.65 \\
11 \\
12 \\
110 \\
.16\end{array}$ & $\begin{array}{r}13.9 \\
5.4 \\
6.0 \\
12.2 \\
7.2\end{array}$ & $\begin{array}{r}139 \\
51 \\
61 \\
77 \\
67\end{array}$ & 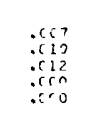 & $\begin{array}{l}.00 \\
.11 \\
112 \\
112 \\
.15\end{array}$ & $\begin{array}{l}25 \\
15 \\
6.5 \\
7.6 \\
45\end{array}$ & $\begin{array}{l}2 \\
2 \\
2 \\
4 \\
2\end{array}$ \\
\hline & & $\begin{array}{l}i 5 \ldots \\
15 \in C .\end{array}$ & $\begin{array}{r}.44 \\
.44\end{array}$ & $\begin{array}{l}.15 \\
.<5\end{array}$ & $\begin{array}{r}16.2 \\
9.8\end{array}$ & $\begin{array}{l}32 \\
75\end{array}$ & $\begin{array}{l}: C r 4 \\
: 2 L C\end{array}$ & $\begin{array}{l}.29 \\
.09\end{array}$ & 20 & ${ }^{2}$ \\
\hline & & JAN. & .67 & .55 & 12.0 & 92 & era & .04 & 132 & c \\
\hline & & $\begin{array}{l}17 \ldots \\
\text { FEg. }\end{array}$ & 1.? & .15 & 12.0 & RB & $.8 C 7$ & $.2 r$ & 7.0 & 2 \\
\hline & & $\begin{array}{l}13 \ldots \\
415 .\end{array}$ & .07 & .05 & 13.5 & 94 & err & .16 & 7.0 & 0 \\
\hline & & $\begin{array}{c}19 \ldots \\
\triangle P R\end{array}$ & 3.0 & .05 & $11 .^{-}$ & $\$ 2$ & - iro & .99 & $2^{-}$ & 4 \\
\hline & & $\underset{N A Y}{23} \cdots$ & .22 & .05 & 7.2 & 72 & .017 & .60 & 7.ค & 2 \\
\hline & & JINE & .15 & .10 & 9.2 & 98 & ero & .9 & b.r & 4 \\
\hline & & $\sin _{\sin }^{11 \ldots}$ &.$x$ & .25 & 13.0 & 157 & .161 & .05 & 36 & 2 \\
\hline & & $-1 \ldots$ & .15 & .5 & 21.0 & 132 & $15 ?$ & .77 & 75 & 4 \\
\hline & & $-9 \ldots$ & $-e^{4}$ & .05 & $111=$ & 132 & $.0 \div 3$ & .27 & 35 & ? \\
\hline & & $2 h \ldots$ & .37 & .65 & 7.2 & 47 & cor 1 & .25 & $5 n$ & 4 \\
\hline & & $24 \ldots$ & .15 & .15 & 9.5 & $1=a$ & .162 & .87 & $4 \%$ & 2 \\
\hline & & AUG. & $\therefore 7$ & $\cdots$ & \multicolumn{5}{|c|}{ AUG. } & \\
\hline & & je... & .67 & .05 & 7.4 & : &.$r r_{b}$ & .19 & se & 2 \\
\hline & & $23 \ldots$ & $\therefore 7$ & $\cdot-5$ & 6.4 & $7 t$ & erer & .13 & an & 4 \\
\hline & & $21 \ldots$ & $\ldots 0$ & .05 & R. 4 & 122 & $\therefore i 2$ & . $\sim 4$ & 35 & $r$ \\
\hline & & $\begin{array}{l}27 . \cdots \\
\text { SEPT. }\end{array}$ & .22 & .05 & 9.6 & $i: 7$ & 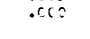 & .23 & 43 & 2 \\
\hline & & $44 \ldots$ & .20 & .65 & 21.7 & 132 & .05 & .04 & 35 & 4 \\
\hline & & $11 \cdots$ & .27 & .65 & R. 5 & 96 &. $\operatorname{sen}$ & .19 & 40 & 2 \\
\hline & & $\begin{array}{l}17 \ldots \\
24 \ldots\end{array}$ & $\because 47$ & $\begin{array}{r}.55 \\
.65\end{array}$ & $\begin{array}{r}3.6 \\
15\end{array}$ & $\begin{array}{r}93 \\
3\end{array}$ & $-1<2$ & .19 & 50 & ? \\
\hline & & $24 \cdots$ & .15 & .65 & $1 \% .4$ & 120 & ort? & $\cdot 1^{n}$ & $5^{\wedge}$ & 2 \\
\hline
\end{tabular}


03263110 GREAT MIAMI RIVER NEAR TAYLORSVILLE DAM, AT TAYLORSVILLE, OHIO--Continued

CHEMICAL ANALYSES IN MILLIGRAMS PER LITER, WATER YEAR OCTOBER 1967 TO SEPTEMBER 1968

\begin{tabular}{|c|c|c|c|c|c|c|c|c|c|c|c|c|}
\hline $03, \ldots$ & 42 & -- & 6.0 & 3.6 & 442 & -- & 345 & 101 & 729 & 7.8 & 19 & - \\
\hline $10 . .$. & 42 & $\cdots$ & 5.7 & 3.4 & 458 & -- & 345 & 101 & 720 & 7.6 & 13 & -- \\
\hline $17 \ldots$ & 40 & -- & 8.0 & 2.8 & 452 & -- & 330 & 77 & 734 & 7.7 & 17 & -- \\
\hline $24 \ldots$ & 40 & -- & 8.0 & 3.9 & 482 & -- & 365 & 99 & 771 & 8.0 & 14 & - \\
\hline $31 \ldots$ & 38 & -- & 3.7 & 3.4 & 460 & - & 335 & 92 & 722 & 8.0 & 12 & - \\
\hline \\
\hline & 24 & $\therefore$ & 16 & 1.4 & 496 & $=$ & 375 & 155 & 729 & 8.1 & 6 & - \\
\hline $\begin{array}{c}15 \ldots . . \\
\text { DEC. }\end{array}$ & 28 & .3 & 7.1 & 2.7 & 496 & 458 & 373 & 130 & 734 & 8.1 & 6 & 15 \\
\hline \multicolumn{13}{|l|}{$\begin{array}{l}\text { DEC. } \\
12 \ldots\end{array}$} \\
\hline \multicolumn{13}{|l|}{$\begin{array}{l}\text { JAN. } \\
17 . . . \\
\text { FEB. }\end{array}$} \\
\hline \multirow{2}{*}{\multicolumn{13}{|c|}{$\begin{array}{l}13 . . . \\
\text { MAR. }\end{array}$}} \\
\hline & & & & & & & & & & & & \\
\hline \multicolumn{13}{|l|}{$\begin{array}{l}19 . . \\
\text { APR. }\end{array}$} \\
\hline \multicolumn{13}{|l|}{ MAY $23 . \cdots$} \\
\hline \multicolumn{13}{|l|}{ JUNE } \\
\hline \multicolumn{13}{|l|}{${ }_{\text {JULY }}^{11 . . .}$} \\
\hline \multicolumn{13}{|l|}{$01 . .}$. \\
\hline $09 .$. & 28 & -- & 1.2 & .76 & 396 & -- & 308 & 89 & 605 & 8.7 & 25 & 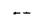 \\
\hline $16 \ldots$ & 26 & - & .0 & 1.9 & 378 & -- & 319 & 96 & 636 & 8.3 & 25 & -- \\
\hline $24 \ldots$ & 28 & -- & 5.8 & 1.4 & 380 & -- & 324 & 87 & 616 & 8.7 & 26 & -- \\
\hline $30 \ldots$ & 16 & -- & B.1 & .90 & 348 & -- & 286 & 81 & 542 & 8.1 & 21 & -- \\
\hline \multicolumn{13}{|l|}{ AUG. } \\
\hline $06 \ldots$ & 20 & - & 7.1 & 1.5 & 400 & -- & 320 & 85 & 605 & 8.2 & 26 & - \\
\hline 13. & 14 & - & 4.0 & .82 & 326 & -- & 276 & 81 & 529 & 7.9 & 21 & $\cdots$ \\
\hline 20. & 24 & -- & 2.2 & 1.2 & 428 & -- & 346 & 96 & 653 & 8.4 & 26 & -- \\
\hline 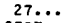 & 28 & -- & 1.5 & 1.9 & 420 & -- & 360 & 110 & 647 & 8.6 & 21 & -- \\
\hline \multicolumn{13}{|l|}{ SEPT. } \\
\hline $04 \ldots$ & 30 & -- & 3.0 & 1.9 & 412 & -- & 336 & 89 & 661 & 8.6 & 22 & 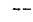 \\
\hline 11. & 40 & -- & 5.0 & 1.6 & 462 & -- & 352 & 91 & 734 & 8.2 & 19 & \\
\hline 17. & 40 & -- & .7 & 1.7 & 420 & -- & 350 & 88 & 696 & 8.6 & 20 & \\
\hline 24. & 36 & -- & 1.7 & 2.9 & 414 & -- & 346 & 82 & 700 & 8.6 & 23 & \\
\hline
\end{tabular}

\begin{tabular}{|c|c|c|c|c|c|c|c|c|}
\hline DATE & $\begin{array}{l}\text { TOTAL } \\
\text { CHRD- } \\
\text { MIUM } \\
\text { ICR) }\end{array}$ & $\begin{array}{l}\text { NICKEL } \\
\text { (NI) }\end{array}$ & $\begin{array}{l}\text { COPPER R } \\
\text { (CU) }\end{array}$ & $\begin{array}{l}\text { LEAD } \\
(P B)\end{array}$ & $\begin{array}{l}\text { ZINC } \\
(Z N)\end{array}$ & $\begin{array}{c}\text { COBALT } \\
(\operatorname{CO})\end{array}$ & $\begin{array}{c}\text { ARSENIC } \\
(A S)(1)\end{array}$ & $\begin{array}{l}\text { CAD } \\
\text { MLIM } \\
\text { (CDD) }\end{array}$ \\
\hline $\begin{array}{c}\text { ocr. } \\
{ }_{03} \ldots 3 .\end{array}$ & -- & $=$ & -- & $=-$ & -- & -- & $=$ & $=-$ \\
\hline${ }_{17}^{10} \ldots$ & .00 & .01 & .04 & .00 & .00 & .01 & .00 & .00 \\
\hline 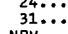 & $\bar{z}$ & -- & -- & $\overline{--}$ & $\overline{-}$ & $\bar{z}$ & $=$ & $\overline{-}$ \\
\hline $\begin{array}{c}\text { NOV. } \\
07 \ldots \\
15\end{array}$ & 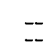 & $=$ & $=$ & $=$ & $z$ & $\overline{-}$ & $=$ & $=$ \\
\hline $\begin{array}{l}\text { DEC... } \\
12 \ldots\end{array}$ & -- & $\ldots$ & .- & -_. & .- & _- & _- & -- \\
\hline $\begin{array}{l}\text { JAN. } \\
17 \ldots\end{array}$ & _. & - & -- & -- & -- & -- & -- & -- \\
\hline FEB. & -- & _- & .- & -- & -- & -- & $\ldots$ & -- \\
\hline MAR. & $\ldots$ & $\ldots$ & .- & $\ldots$ & .- & -- & _- & -- \\
\hline $\begin{array}{c}\text { APR. } \\
\text { APR. }\end{array}$ & -- & _. & $\ldots$ & _- & .- & $\ldots$ & $\ldots$ & -- \\
\hline Mar & $\ldots$ & _. & $\ldots$ & -- & -- & -. & -- & -- \\
\hline SUNE & $\ldots$ & -- & _- & -- & ..- & -- & -.. & -- \\
\hline $\begin{array}{l}11 \ldots \\
\text { JuL }\end{array}$ & -. & - & -. & -. & .- & _- & $\ldots$ & -- \\
\hline 09. & -- & - & -- & - & $=-$ & - & $z$ & $=$ \\
\hline $\begin{array}{l}10 \cdots \\
240\end{array}$ & - & $\ddot{z}$ & - & $=$ & - & $=$ & -- & -- \\
\hline $\begin{array}{l}30 . . \\
\text { AUG: }\end{array}$ & -- & -- & - & 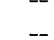 & ... & -- & .. & $\ldots$ \\
\hline 年 130. & $=$ & $=$ & $\bar{z}$ & $=$ & - & - & - & $=$ \\
\hline &.$\overline{00}$ & .01 &.$\overline{03}$ &.$\overline{00}$ &.$\overline{01}$ &.$\overline{00}$ &.$\overline{01}$ &.$\overline{00}$ \\
\hline & -- & -- & -- & - & -- & -- & -- & - \\
\hline &.$\overline{01}$ & .01 & .01 &.$\overline{00}$ & .01 & .00 & .00 & .00 \\
\hline
\end{tabular}


LOCATION,--Lat $40^{\circ} 03^{\prime} 28^{\prime \prime}, 84^{\circ} 21^{\prime} 22^{\prime \prime}$, in Swi sec.18, T.7 N, R.5 E., uiami County, at gaging station at highway bridge 0,8 mile northwest of pleasant Hill and 2 miles downstream from Painter Creek.

DRA INAGE AREA. - -503 $\mathrm{sq} \mathbf{m i}$.

PERIOD OF RECORD, - Tater tejneratures: October 1964 to September 1966.

Sediment records: October 1963 to September 1968 .

EXTREMES . --1967-68:

Sediment concentrations: Maximum daily, $559 \mathrm{mg} / 1 \mathrm{Dec}, 22 ;$ minimum dally, $5 \mathrm{mg} / 1$ on many days during October, February and March.

Sediment loads: Maximum daily, 8,080 tons May 27 ; miniram da1ly, 0.78 ton Nov. 15 .

Period of record:

Sediment concentrations: Max1mum daily, 1,300 mg/l Apr. 9, 1965; minlmum dally, $1 \mathrm{mg} / 1$ on several days during

Sediment loads: Maximum da11y, 21,400 tons Apr. 21, 1964; minimum da11y, 0.07 ton Aug. 21, 1965.

REUARKS. -Diurnal fluctuation caused by mills above station.

SUSPENDED SEDIMENT, WATER YEAR OCTOBER 1967 TO SEPTEMBER 1968 DC TOBER NOVEMBER

DECEMBFR $\begin{array}{ll}\text { MEAN } & \text { CONCEN } \\ \text { OISCHARGE } & \text { TRATION } \\ \text { (CFS) } & \text { IMG/LI }\end{array}$ 34
32
33
34
36

52
52
28
18
14
13
14
15
15
14

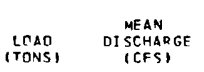

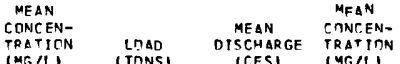$$
\begin{aligned}
& 11 \\
& 12 \\
& 13 \\
& 14 \\
& 15
\end{aligned}
$$$$
\begin{aligned}
& 13 \\
& 13 \\
& 12 \\
& 12 \\
& 10
\end{aligned}
$$

95
39
55
24
32
83
73
64
59
54

$\begin{array}{ll}192 & 16 \\ 203 & 13 \\ 220 & 12 \\ 176 & 10 \\ 150 & 10\end{array}$

$\begin{array}{ll}170 & 10 \\ 147 & 10 \\ 128 & 10 \\ 144 & 10 \\ 150 & 10\end{array}$

$142 \quad 10$

136

139

144
144

128
123
123
123
128

173
390

173
390
728
544
305

$\begin{array}{rr}38 & 154 \\ 116 & 151\end{array}$

$\begin{array}{ll}57 & 146 \\ 24 & 133\end{array}$
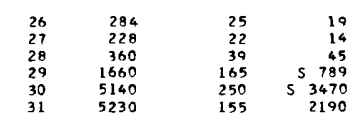

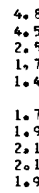$$
\begin{array}{rr}
4.8 & 95 \\
4.5 & 139 \\
2.5 & 155 \\
1.7 & 124 \\
1.4 & 132
\end{array}
$$$$
\text { 1. } 7 \quad 85
$$$$
\begin{array}{ll}
1.9 & 73 \\
2.1 & 64 \\
2.1 & 59 \\
1.9 & 54
\end{array}
$$$$
\begin{aligned}
& 1.6 \\
& 1.5 \\
& 1.3
\end{aligned}
$$$$
\begin{aligned}
& 1.3 \\
& 1.2 \\
& 1.0
\end{aligned}
$$$$
1.27
$$$$
\begin{aligned}
& 1.2 \\
& 1.5 \\
& 1.6 \\
& 1.6
\end{aligned}
$$

7
15
19
14
10
7
6
6
6

54

$$
\begin{array}{cc}
8.3 & 2550 \\
7.1 & 2709 \\
7.1 & 2250 \\
4.8 & 1170 \\
4.0 & 834
\end{array}
$$

$\begin{array}{ll}4,6 & 684 \\ 4.0 & 59 ?\end{array}$

$\begin{array}{ll}4.0 & 592 \\ 3.5 & 502 \\ 3.9 & 445\end{array}$

3.9
4.0

345

$3.8 \quad 284$

$\begin{array}{ll}3.8 & 284 \\ 3.7 & 292 \\ 3.8 & 260 \\ 3.5 & 249\end{array}$

$\begin{array}{ll}3.8 & 260 \\ 3.5 & 249 \\ 3.5 & 233\end{array}$

$\begin{array}{ll}2.8 & 224 \\ 2.7 & 200\end{array}$

$\begin{array}{ll}2.7 & 200 \\ 2.7 & 167 \\ 2.7 & 199 \\ 2.8 & 189\end{array}$

6
38
116
57
24

$381 \quad 143$

$$
\begin{aligned}
& 1.8 \\
& 5.6 \\
& 7.5 \\
& 4.7 \\
& 2 . \\
& 11 \\
& 1,2 \\
& 1.0 \\
& 0.87
\end{aligned}
$$

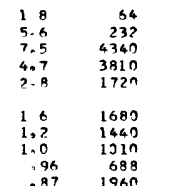

$$
\begin{array}{r}
.87 \\
-84 \\
.87 \\
.84
\end{array}
$$$$
\begin{array}{r}
.84 \\
.78
\end{array}
$$

79

79
.84
1.0
1.0

1.0

1.0
.96
.99

$: 96$
$: 96$
$i 0$

1.0

1.0
.99

1.0
.99
.96

.91

4250
2680
1590
966
840
658
538
670
854

854
640

938
4740
2340
950
576

522

522
436
380

380
315

315
298
260

$46.58 \quad 42575$

$\begin{array}{rr}54 & 37 \\ 78 & 56 \\ 110 & 66 \\ 42 & 13 \\ 22 & 50\end{array}$

$\begin{array}{rl}372 & 121 \\ 569 & 121 \\ 668 & 111 \\ 133 & 111 \\ 50 & 117\end{array}$

26

14.5
6.5

$\begin{array}{ll}6.5 & 106 \\ 4.7 & 117\end{array}$

3. 8

3.8
3.9
3.5

3.3
3.1

3.0
2.7
2.3
2.5

IDAT
MFILI ITONES

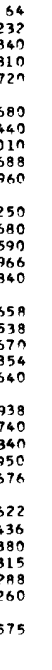

$\begin{array}{rr}4 ? & 569 \\ 274 & 3210 \\ 87 & 995 \\ 45 & 209 \\ 39 & 177 \\ 32 & 124 \\ 34 & 93 \\ 3 n & 54 \\ 177 & 51250 \\ 250 & 2870 \\ 108 & 781 \\ 62 & 264 \\ 36 & 94 \\ 22 & 50 \\ 11 & 20 \\ 9 & 12 \\ 8 & 14 \\ 9 & 18 \\ 9 & 14\end{array}$

$S 21 \mathrm{R}$

$715 n$
$S 19$ an

767
107

1ก2

35
27

$\begin{array}{ll}27 & 32 \\ 25 & 26 \\ 23 & 21 \\ 21 & 16 \\ 10 & 13\end{array}$

MARCH

2.0
2.1
2.0
2.0

115
117
113
111
115

115

138
496
604
526
460

520
719
684
634

684
634
1100

2830

$\begin{array}{ll}1,7 & 2830 \\ 18 & 2220 \\ 1,7 & 1120\end{array}$

1.7
1.6
-0

1120
719
532
490

$6 B 51.4 \quad 15593 \quad--\quad 1899.5$

15510

$S$ CONPUTED BY SUBDIVIDING DAY, 
GREAT MIAMI RIVER BASIN

03265000 STILLWATER RIVER AT PLEASANT HILL, OHIO-Continued

SUSPENDEO SEOIMENT, WATER YFAR OCTIBFR 1967 TO SFPTEMRER 196A APRIL MEAN

Jume

DAY MEAN
OI SCHARGE
ICFSI

MEAN MEAN DI SCHARGE

MEAN TONCEN-

LOAD DISCHABG TRATON LOAD MISCHARGF TRATITN
(CFSI TMGILI

1530
1070
705
2460
2750

150
91
33
413

620
263
$6 \quad 63$
$S \quad 3420$
$S \quad 2300$

136
131
124
124
119

8
8
8
8
8

2.9
2.8
2.7
2.7

826
882
789
569
450

$1180 \quad 76$

$242 \quad 113$

$\begin{array}{rr}242 & 113 \\ 82 & 109 \\ 47 & 106 \\ 25 & 119\end{array}$

504
455
380

$\begin{array}{ll}25 & 119 \\ 15 & 126\end{array}$

$\begin{array}{rr}11 & 176 \\ 8.0 & 355 \\ 6.5 & 276 \\ 7.1 & 218 \\ 16 & 191\end{array}$

16

$\begin{array}{ll}19 & 209 \\ 14 & 280 \\ 12 & 245 \\ 9.7 & 206\end{array}$

$\begin{array}{ll}9.7 & 206 \\ 8.2 & 185\end{array}$

$\begin{array}{ll}7.9 & 167 \\ 5.7 & 157\end{array}$

$\begin{array}{ll}5.7 & 157 \\ 5.5 & 520 \\ 5.3 & 4780 \\ 4.5 & 4730\end{array}$

$4.2 \quad 2500$

$\begin{array}{ll}4.0 & 6270 \\ 3.7 & 7490\end{array}$

$\begin{array}{ll}3.4 & 3690 \\ 3.3 & 1660\end{array}$

138
136

TCTAL 16483

1110

JuL

jutr

(2)

36722

MEAN
CONCENMEAN CONCEN-
DISCHARGE TRATION MEAN
LOAO OISCHARGE
ITONSI
ICFSI

ME AN

CONCENTRATION
(MG/L)

$$
\begin{array}{ll}
41 & 164 \\
29 & 375 \\
23 & 268 \\
19 & 181 \\
16 & 178
\end{array}
$$

58
110
88
83

$\begin{array}{ll}2.4 & 375 \\ 2.1 & 324 \\ 2.0 & 284\end{array}$

$\begin{array}{ll}2.0 & 284 \\ 2.2 & 257 \\ 2.4 & 236\end{array}$

53
57
79
67

(TINS)

DAY

65
55

$\begin{array}{rl}14 & 179 \\ 12 & 140 \\ 11 & 151 \\ 9.7 & 819 \\ 8.5 & 700\end{array}$

$\begin{array}{rrrrr}11 & 98 & 29 & 7.7 & 606 \\ 12 & 94 & 28 & 7.1 & 430 \\ 13 & 102 & 28 & 7.7 & 260 \\ 14 & 92 & 27 & 6.7 & 274 \\ 15 & 104 & 28 & 7.9 & 167\end{array}$

$\begin{array}{rrrrr}16 & 325 & 74 & 65 & 218 \\ 17 & 325 & 177 & 155 & 246\end{array}$

$\begin{array}{rrrrr}17 & 325 & 177 & 155 & 246 \\ 18 & 178 & 86 & 41 & 264 \\ 19 & 243 & 93 & 61 & 305 \\ 20 & 365 & 154 & 152 & 225\end{array}$

$\begin{array}{llr}21 & 194 & 98 \\ 22 & 135 & 63 \\ 23 & 120 & 51 \\ 24 & 153 & 54 \\ 25 & 360 & 131\end{array}$

$\begin{array}{rr}51 & 164 \\ 23 & 131 \\ 17 & 113 \\ 22 & 102 \\ 5168 & 92\end{array}$

$\begin{array}{llr}26 & 516 & 259 \\ 27 & 288 & 189 \\ 28 & 204 & 110 \\ 29 & 176 & 93 \\ 30 & 143 & 67 \\ 31 & 115 & 53\end{array}$

361

89
84
80
75
72
70

TOTAL 5807

--

61
44
26

$630.3 \quad 7102$

TOTAL DISCHARGE FOR YEAR (CFS-DAYS)

TOTAL LOAD FDR YEAR (TONS)

$S$ COMPUTED BY SUBDIVIDING DAY. 
03265000 STILLWATER RIVER AT PLEASANT HILL, OHIO--ContInued

PERIODIC DETERMINATIONS OF SUSPENDED-SEDIMENT DISCHARGE AND PARTICLE SIZE, WATER YEAR OCTOBER 1967 TO SEPTEMBER 1968 (METHODS OF ANALYSIS: 8, BOTTOM HITHDRAWAL TUBE; C, CHEMICALLY DISPERSED; N, IN NATIVE WATER; P, PIPET; S, SIEVE;

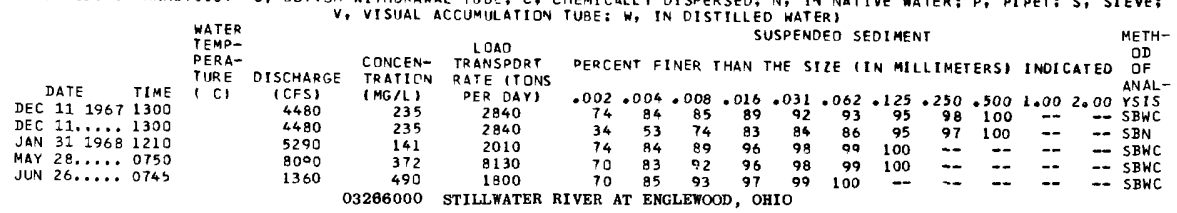

LOCATION.--Lat $39^{\circ} 52^{\prime} 10^{\prime \prime}$, long $84^{\circ} 16^{\prime} 57^{\prime \prime}$, in NWt sec.23, T.5 N., R.5 E., Montgomery County, at bridge on Interstate

Highway 70 , about $0.8 \mathrm{mile}$ downstream from gaging station, about 1 mile downstream from Englewood Dan and

1.8 miles southeast of Englewood.

DRA INAGE AREA. - $-650 \mathrm{sq} \mathrm{mi}$.

PER IOD OF RECORD, --Chemical analyses: November 1961 to July 1963, July 1966 to September 1968.

REMARKS.--Samples were collected weekly October, July to September and monthly November to June. Samples for 1ron and manganese were filtered clear when collected.

\begin{tabular}{|c|c|c|c|c|c|c|c|c|c|c|c|c|}
\hline $\begin{array}{l}\text { DATE } \\
\text { OCT. }\end{array}$ & TIME & $\begin{array}{l}\text { OIS- } \\
\text { CHARGE } \\
\text { ICFSI }\end{array}$ & $\begin{array}{l}\text { SILICA } \\
\text { (SIOL2) }\end{array}$ & $\begin{array}{l}\text { IRON } \\
\text { IFEI }\end{array}$ & $\begin{array}{l}\text { MAN- } \\
\text { GANESE } \\
\text { (MN) }\end{array}$ & $\begin{array}{l}\text { CAL- } \\
\text { CIUM } \\
\text { (CA) }\end{array}$ & $\begin{array}{l}\text { MAG- } \\
\text { NF- } \\
\text { SIUM } \\
(\text { YG) }\end{array}$ & $\begin{array}{l}\text { SODIUM } \\
\text { (NA) }\end{array}$ & $\begin{array}{l}\text { PO- } \\
\text { TAS- } \\
\text { SIUM } \\
\text { (K) }\end{array}$ & $\begin{array}{l}\text { BICAR- } \\
\text { BJNATE } \\
\text { IHCOUI }\end{array}$ & $\begin{array}{c}\text { CAR- } \\
\text { BONAIE } \\
\text { (CO3) }\end{array}$ & $\begin{array}{l}\text { SULFAIE } \\
\text { ISJ4I }\end{array}$ \\
\hline $\begin{array}{l}\text { OCT. } \\
03 . . .\end{array}$ & 1215 & 33 & $\cdots$ & .04 & .02 & - & -- & -- & -- & 308 & 0 & 59 \\
\hline $10 \ldots$ & 1230 & 52 & -- & .10 & .03 & $\cdots$ & -- & - & - & 320 & 0 & 66 \\
\hline $18 \ldots$ & 0800 & 55 & -- & .15 & .13 & - & -- & -- & -- & 319 & 0 & 58 \\
\hline $24 \ldots$ & 1230 & 48 & - & .19 & .18 & - & -- & -- & -- & 326 & 0 & 58 \\
\hline $31 \ldots$ & 1300 & 63 & -- & .10 & .03 & - & -- & -- & -- & 314 & 0 & 67 \\
\hline $\begin{array}{l}\text { NOV. } \\
07 . . .\end{array}$ & & & & & & & & & & & & \\
\hline $\begin{array}{l}07 \ldots \\
15 \ldots\end{array}$ & $\begin{array}{l}1230 \\
1100\end{array}$ & $\begin{array}{r}105 \\
68\end{array}$ & $\overline{6.2}$ & $\begin{array}{l}.14 \\
.12\end{array}$ & $\begin{array}{l}.03 \\
.06\end{array}$ & 93 & 34 & $19^{--}$ & $3 . \overline{8}$ & $\begin{array}{l}310 \\
326\end{array}$ & $\begin{array}{l}0 \\
0\end{array}$ & $\begin{array}{l}72 \\
95\end{array}$ \\
\hline $\begin{array}{l}\text { DEC. } \\
12 . .\end{array}$ & 1500 & 4120 & 6.9 & - & .03 & 56 & 17 & 4.7 & 2.8 & 146 & 0 & 50 \\
\hline JAN. & 1345 & 176 & 8.5 & .07 & .02 & 99 & 36 & 15 & 1.8 & 346 & 0 & 85 \\
\hline $\begin{array}{c}\text { FEB. } \\
13 \ldots \\
\text { MAR.. }\end{array}$ & 1230 & 278 & 7.4 & .10 & .08 & 98 & 34 & 9.5 & 1.6 & 314 & 0 & 82 \\
\hline $\begin{array}{l}19 . . . \\
\triangle P R .\end{array}$ & 1045 & 627 & 5.8 & .13 & .03 & 83 & 29 & 14 & 2.3 & 268 & 0 & 82 \\
\hline MAY $23 \cdots$ & osno & 272 & .8 & .06 & .04 & 82 & 36 & 11 & 1.5 & 292 & 0 & 79 \\
\hline$\underset{\text { JUNE }}{14 \ldots}$ & 1345 & 368 & 4.9 & .14 &.$r^{3}$ & 82 & 32 & 12 & 1.7 & 288 & 0 & 71 \\
\hline${ }_{\text {JULY }}^{11 \ldots}$ & 0930 & 311 & 7.4 & .04 & .04 & 89 & 34 & 9.5 & 1.7 & 306 & 2 & 72 \\
\hline $01 \ldots$ & 1300 & 304 & -- & .42 & .03 & -- & - & - & -- & 264 & 0 & 55 \\
\hline $09 .$. & 1115 & 152 & -- & .22 & .02 & -- & $\rightarrow$ & -- & - & 306 & 10 & 71 \\
\hline $16 \ldots$ & 1345 & 152 & -- &.$O B$ & .02 & -- & -- & -- & -- & 290 & 2 & 13 \\
\hline $24 \ldots$ & 1015 & 172 & -- & .17 & .04 & $\rightarrow$ & -- & -- & $\cdots$ & 256 & 0 & 53 \\
\hline $\begin{array}{l}30 \ldots . . \\
\text { Auc. }\end{array}$ & 1230 & 200 & - & .06 & .02 & -- & -- & -- & -- & 244 & 0 & 49 \\
\hline $\begin{array}{l}\text { AUG. } \\
\text { O6... }\end{array}$ & 1415 & 236 & -- & .09 & .04 & $\cdots$ & -- & -- & -- & 292 & 0 & 51 \\
\hline $13 \ldots$ & 1200 & 384 & - & .43 & .02 & -- & -- & -- & $\ldots$ & 262 & 0 & 51 \\
\hline $\begin{array}{l}20 \ldots \\
27 \ldots\end{array}$ & 1245 & 325 & -- & .27 & .03 & - & -- & -- & $\cdots$ & 300 & 0 & 54 \\
\hline $\begin{array}{l}27 . \cdots \\
\text { SEPT. }\end{array}$ & 1210 & 115 & -- & .00 & .02 & - & - & -- & - & 270 & $2 b$ & 52 \\
\hline $\begin{array}{l}\text { SEPT. } \\
\text { O4... }\end{array}$ & 1615 & 96 & -- & .38 & .05 & -- & -- & -- & $\ldots$ & 312 & 14 & 71 \\
\hline $11 \ldots$ & 1230 & 109 & $-\infty$ & .11 & .44 & -- & -- & -. & -- & 313 & 4 & 59 \\
\hline $17 \ldots$ & 1220 & 86 & -. & .28 & .08 & -- & -- & $\cdots$ & -- & 318 & 4 & 70 \\
\hline $24 \cdots$ & 0415 & 82 & -- & .18 & .04 & -- & - & -- & -- & 316 & 2 & 70 \\
\hline & & & & & SOL VED & SOLVEO & & NON- & $\begin{array}{l}\text { SPEC I- } \\
\text { FIC }\end{array}$ & & & \\
\hline & $\mathrm{CHLO}-$ & FLUO- & & $\begin{array}{l}\text { TOTAL } \\
\text { PHOS- }\end{array}$ & $\begin{array}{l}\text { SOLIOS } \\
\text { IRESI- }\end{array}$ & $\begin{array}{l}\text { SOLIOS } \\
15 \mathrm{UM}^{2} \mathrm{DF}\end{array}$ & & CAR- & COND- & & & \\
\hline & RIDE & RIDE & NITRATE & PHORUS & OUE AT & $\begin{array}{l}15 U M \text { DF } \\
\text { CONST I- }\end{array}$ & NESS & $\begin{array}{l}\text { BONATE } \\
\text { HARD- }\end{array}$ & $\begin{array}{l}\text { UC I INCE } \\
\text { (MICP) - }\end{array}$ & $\mathrm{PH}$ & $\begin{array}{l}\text { TEMP- } \\
\text { ERATURE }\end{array}$ & โכЬЈर \\
\hline DATE & $(C L)$ & $(F)$ & (N03) & $(004)$ & 180 C) & TUEVTSI & $(C A, M O)$ & NESS & M-10si & & (DES $=1$ & \\
\hline $03 \ldots$ & 32 & -- & 3.7 & 2.3 & 426 & -- & 360 & 107 & 679 & 7.9 & 18 & -- \\
\hline $10 \ldots$ & 33 & -- & 2.0 & $2 . n$ & 418 & -- & 335 & 72 & 695 & 7.7 & 14 & -- \\
\hline $18 \ldots$ & 30 & -- & 3.5 & .88 & 408 & -- & 340 & 77 & 690 & 7.8 & 14 & $\cdots$ \\
\hline $24 \ldots$ & 32 & -- & 4.0 & 2.0 & 438 & -- & 355 & 88 & 705 & 8.0 & 12 & -- \\
\hline $31 \ldots$ & 32 & -- & .7 & 3.1 & 416 & $\rightarrow$ & 330 & 72 & $67 n$ & 8.1 & 10 & $\cdots$ \\
\hline Nov. & & & & & & & & & & & & \\
\hline $07 \ldots$ & 34 & -- & 3.0 & 1.8 & 446 & -- & 330 & 76 & 689 & 8.2 & 6 & $\cdots$ \\
\hline $15 \ldots$ & 26 & .2 & 5.5 & 1.4 & 486 & 444 & 372 & 105 & 722 & 8.2 & 5 & 15 \\
\hline $\begin{array}{l}\text { DEC. } \\
12 . .\end{array}$ & 15 & .2 & 26 & .55 & $25 \mathrm{R}$ & 251 & 210 & 90 & 475 & 7.9 & 7 & 43 \\
\hline $\begin{array}{l}\text { JAN. } \\
17 \ldots\end{array}$ & 26 & 2 & & & & & 395 & 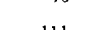 & 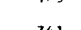 & $r^{*}$ & & 40 \\
\hline FEB. & 26 & .2 & 15 & 1.6 & 478 & 458 & 395 & 111 & 741 & 8.2 & 1 & 7 \\
\hline $\begin{array}{l}13 \ldots . \\
\text { MAR: }\end{array}$ & 23 & .2 & 22 & .50 & 434 & 432 & 385 & 127 & 891 & 8.2 & 1 & 5 \\
\hline $\begin{array}{l}19 . . \\
A P R .\end{array}$ & 28 & .3 & 16 & .55 & 410 & 393 & 326 & 106 & 635 & 8.2 & 7 & 15 \\
\hline$\underset{\text { MAY }}{23} \cdots$ & 22 & $\cdot 3$ & 10 & .28 & $40 B$ & 387 & 353 & 113 & 649 & 8.2 & 17 & 13 \\
\hline JUNE & 22 & $\cdot 3$ & 20 & $.7 ?$ & 392 & 389 & 335 & 100 & 650 & 8.2 & 18 & 15 \\
\hline JuLr & 18 & .3 & 17 & .43 & $4 C 2$ & 401 & 362 & 108 & 659 & 8.4 & 24 & 15 \\
\hline $01 \ldots$ & 14 & -- & 22 & .66 & 372 & $\cdots$ & 312 & 95 & 584 & g. & 24 & -- \\
\hline $09 . .$. & 20 & -- & 12 & .72 & 432 & - & 362 & 94 & 664 & 8. & 25 & $\cdots$ \\
\hline $16 \ldots$ & 20 & -- & 3.2 & .71 & 364 & -- & 340 & 97 & 622 & 8. & 26 & -- \\
\hline $24 \ldots$ & 18 & -- & 10 & .95 & 318 & -- & 282 & 72 & 540 & 8. & 25 & - \\
\hline $30 \ldots$ & 14 & -- & 11 & .85 & 326 & -- & 269 & 69 & 513 & 0.1 1 & 22 & -- \\
\hline AUG. & & & & & & & & & & & & \\
\hline $06 \ldots$ & 18 & -- & 10 & 1.4 & 392 & -- & 319 & 79 & 597 & 8.2 & 25 & -- \\
\hline $13 \ldots$ & 12 & - & 11 & .58 & 348 & - & 298 & 83 & 542 & 8. & 20 & -- \\
\hline $20 \ldots$ & 16 & -- & 7.8 & 1.2 & 392 & -- & 332 & 86 & 612 & 8.2 & 27 & $\cdots$ \\
\hline $\begin{array}{r}27 . . . \\
\text { SEPT. }\end{array}$ & 20 & -- & 2.7 & .68 & 402 & -- & 340 & 78 & 610 & Q.8 & 21 & - \\
\hline $04 \ldots$ & 24 & -- & 5.0 & .85 & 410 & - & 368 & 88 & 676 & 8. 5 & 21 & -- \\
\hline $11 \ldots$ & 26 & -- & $4 \cdot 5$ & .72 & 418 & -- & 360 & 92 & 870 & 8.3 & 18 & - \\
\hline $17 \ldots$ & 26 & -- & 2.7 & 1.2 & 398 & -- & 352 & 84 & 674 & 8.3 & 19 & -- \\
\hline $24 \ldots$ & 26 & -- & 3.5 & 1.4 & 386 & -- & 352 & A9 & 651 & 8.3 & 21 & -- \\
\hline
\end{tabular}


03266000 STILLWATER RIVER AT ENGLEWOOD, OHIO--CONTINUEd CHEMICAL ANALYSES IN MILLIGRAMS PER LITER, WATER YEAR OCTOBER 1967 TO SEPTEMBER 1968

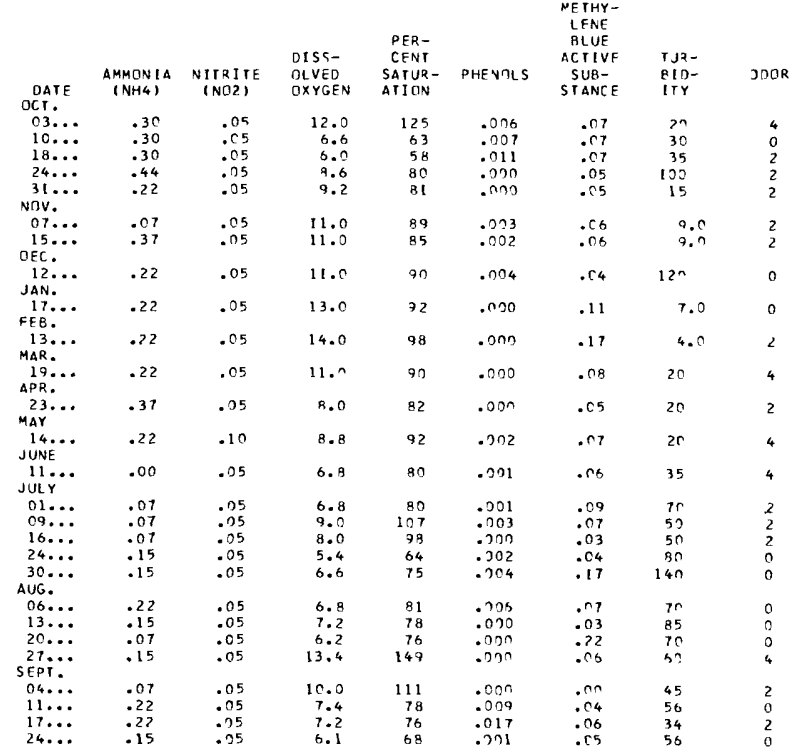

03267800 MAD RIVER AT EAGLE CITY, OHIO

LOCATION, --Lat $39^{\circ} 58^{\prime} 36^{\prime \prime}$, long $83^{\circ} 49^{\prime} 21^{\prime \prime}$, in center sec. 2 , R.10, T.4, Clark County, at gaging station at bridge on Eagle City Road, 0.2 mile downtream from Hoore Run, 0.7 mile east of Eagle City, and 2.4 miles south of Tremont
City.

DRA INAGE AREA. ---307 sq $\mathrm{mi}$.

PERIOD OF RECORD.--Water temperatures: October 1965 to September 1968

Sediment records: October 1965 to September 1968 .

EXTREMES, --1967-68:

Water temperatures: Maximum, $21.0^{\circ} \mathrm{C}$ July 25 , Aug. $7,20,23$; minimum, freezing point Jan. $5,8$.

Sediment concentrations: Haximun daily, $1,020 \mathrm{mg} / 1$ May 27 ; minimum dally, $3 \mathrm{mg} / 1$ Nov. 28 .

Sediment loads: Maximum daily, 10,400 tons May 27 ; minimum daily, 1.2 tons Nov. 28.

Period of record:

Water temperatures: Maximum, $21.0^{\circ} \mathrm{C}$ July 2, 3, 1966, July 25, Aug. 7, 20, 23, 1968; minimum, freezing point

Jan. $24,31,1966$, Feb. $25,26,1967$, Jan. $5,8,1968$.

Sediment lads: Maximum daily, 10,400 i $1,080 \mathrm{mg} / 1$ May 7,1967 ; minimum dally, $1 \mathrm{mg} / 1$ Dec. 29,1965

TEMPERATURE $1^{\circ} \mathrm{C}$ I OF WATER, WATER YEAR OCTOBER 1967 TO SEPTEMBER 1968 TEMPERATURE $1{ }^{\circ} \mathrm{C}$ ) OF WATER, WATER YEAR OCTOBER 1967 TO SEPTEM
(ONCE-DAJLY MEASUREMENT BETWEEN OBO0 AND 1000)

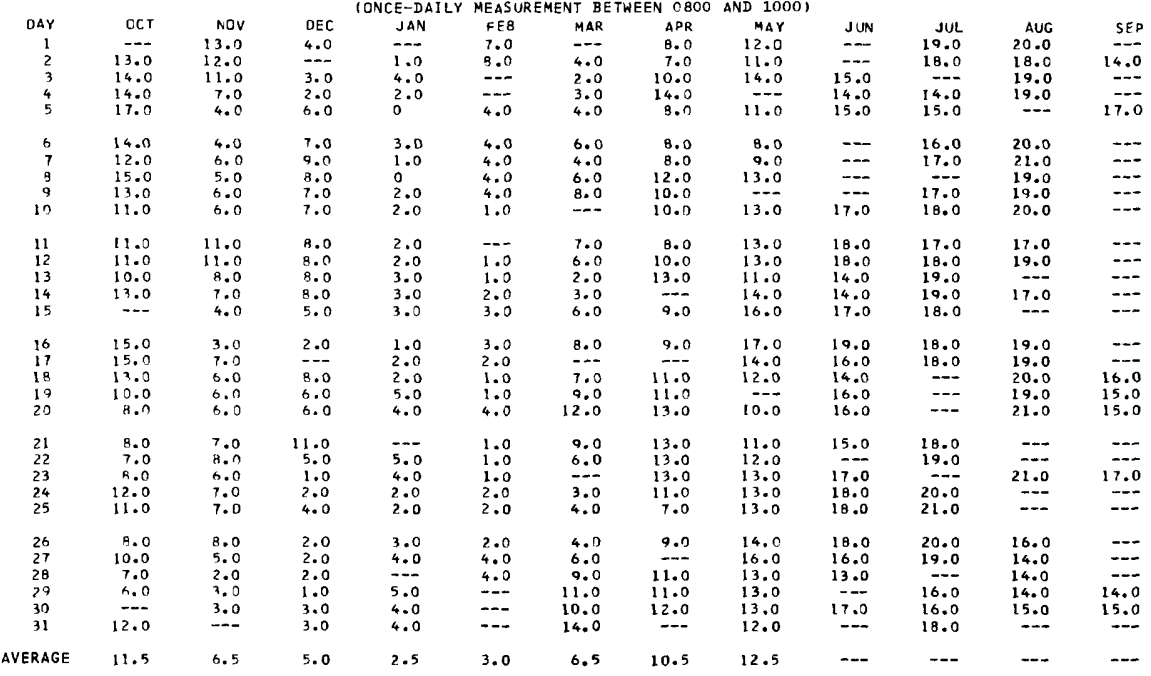


03267800 MAD RIVER AT EAGLE CITY, OHIO--COntinued

SUSPENDED SEDIMENT, WATER YEAR OCTOBER 1967 TO SEPTEMBER 1968

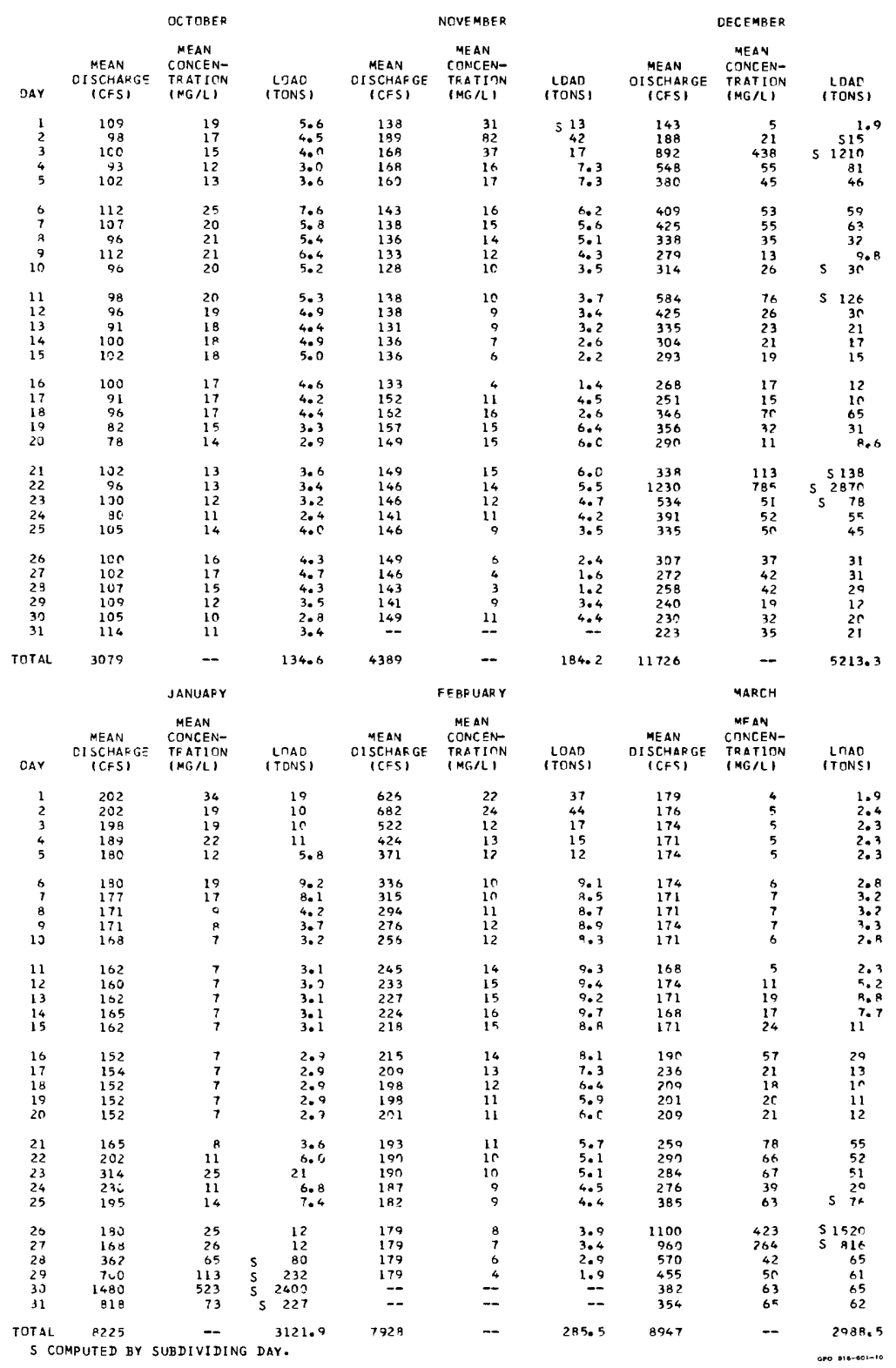


03267800 MAD RIVER AT EAGLE CITY, OHIO--COntinued

SUSPENDED SEDIMENT, WATER YEAR OCTOBER 1967 TO SEPTEMBER 1968

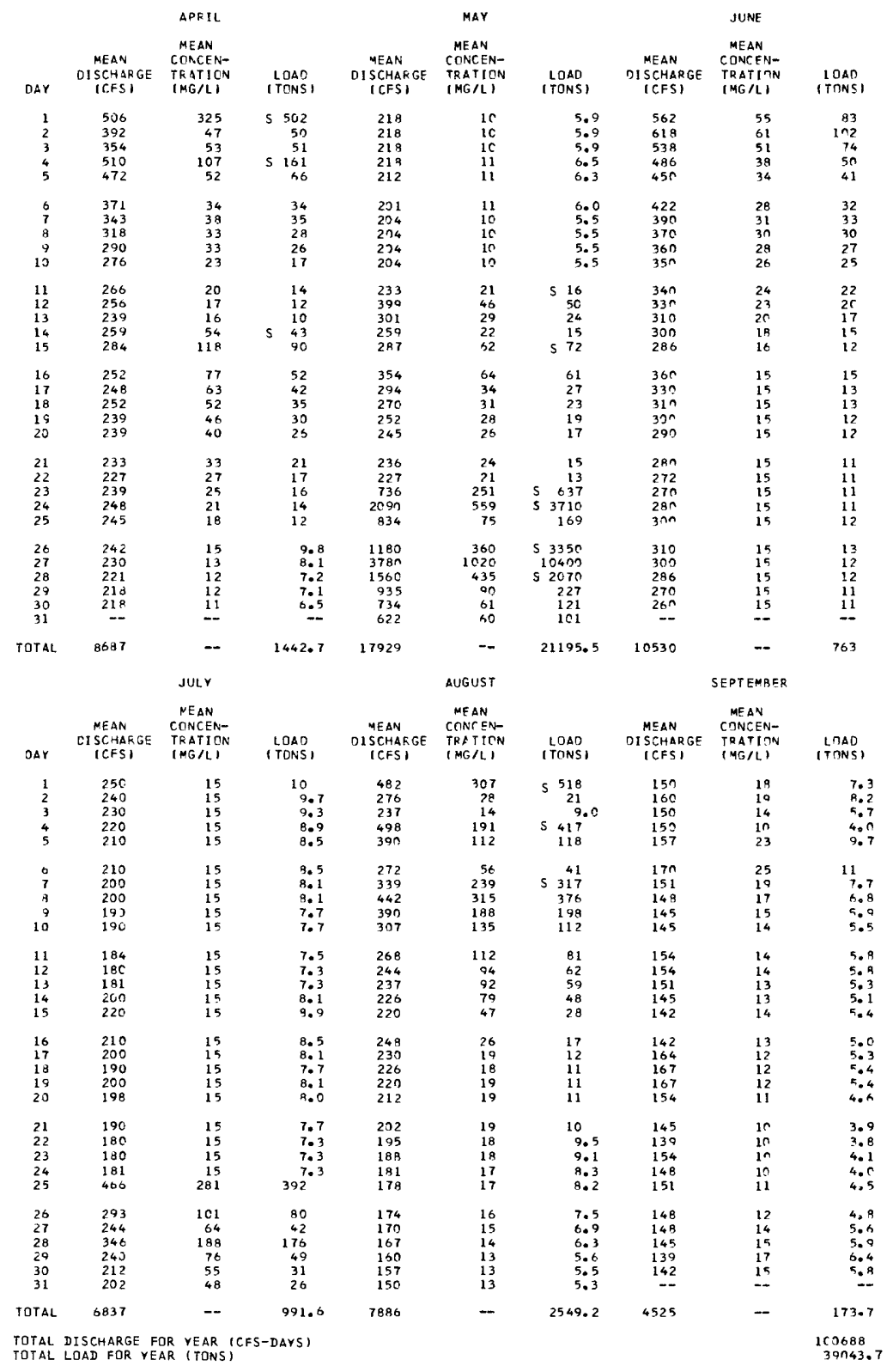

$S$ COMPUTED BY SUBDIVIDING DAY. 
03267800 MAD RIVER AT EAGLE CITY, OHIO--CONTINUEd

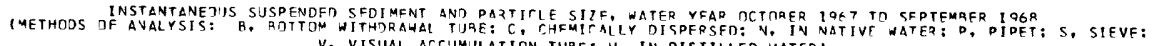

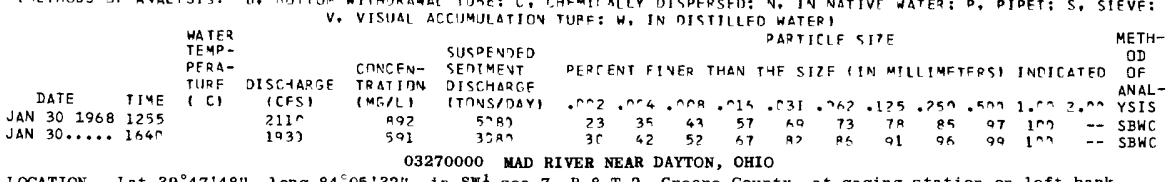
LOCATION.-.Lat $39^{\circ} 47^{\prime} 48^{\prime \prime}$, long $84^{\circ} 05^{\prime} 32^{\prime \prime}$, In SWl sec.7, R.8 T.2, Greene County, at gaging station on left bank about $600 \mathrm{ft}$ downstream from Huffman Dam, 2.5 miles downstream from Mud Run, and 6 miles northeast of Dayton, DRA INAGE AREA. -635 sq $\mathrm{mi}$.

PER IOD OF RECORD, --Chemical analyses: November I961 to July 1963, July 1966 to September 1968.

Water temperatures: June to September 1968.

REMARKS. - Samples for iron and manganese were filtered clear when collected. Samples were collected weekly October, July to September and nonthly November to June. A continuous recorder was installed at this site June 18, (he instrument.

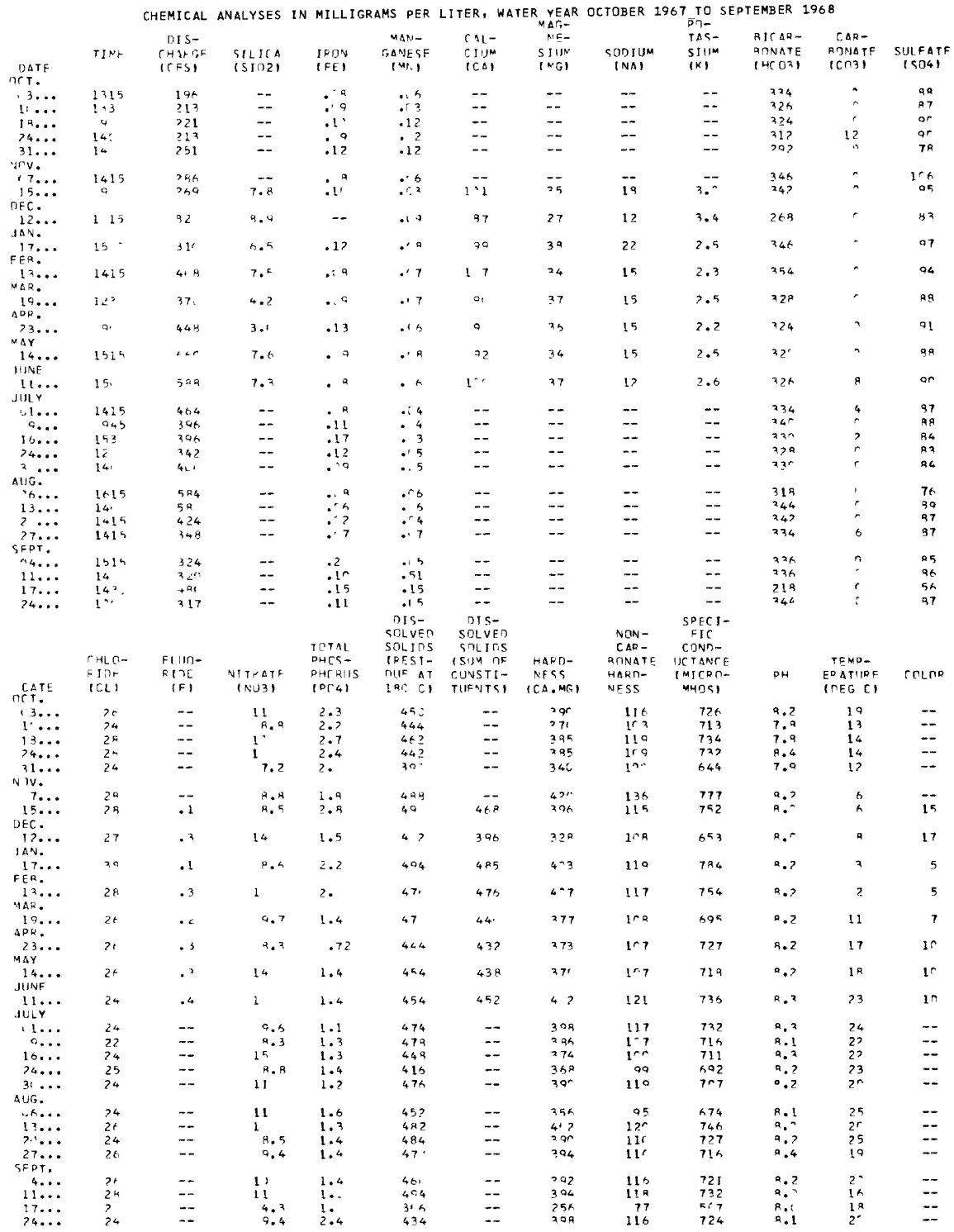


CHEMICAL ANALYSES IN MILLIGRAMS PER LITER, WATER YEAR OCTOBER 1967 TO SEPTEMBER 1968

\begin{tabular}{|c|c|c|c|c|c|c|c|c|}
\hline LATF & $\begin{array}{l}\text { A44तVIA } \\
\left(\mathrm{NH}_{4}\right)\end{array}$ & $\begin{array}{l}\text { NITKITE } \\
\text { (NDPI }\end{array}$ & $\begin{array}{l}\text { nISS- } \\
\text { nLV }=\sqcap \\
\text { UXYTEN }\end{array}$ & $\begin{array}{l}\text { PFR- } \\
\text { CFNT } \\
\text { SATIIR- } \\
\text { ATION }\end{array}$ & PHEF RLS & $\begin{array}{l}\text { MFTHY- } \\
\text { I ENF } \\
\text { QLUEF } \\
\text { ACTIVF } \\
\text { SUR- } \\
\text { STANCF }\end{array}$ & $\begin{array}{l}\text { TIJP- } \\
\text { BIn- } \\
\text { ITy }\end{array}$ & anTR \\
\hline DCT. & & & & & & & & \\
\hline${ }^{3} \cdots$ & .15 & $.1^{-}$ & 13. & 139 & $\therefore 6$ & . in $R$ & 9.1 & 2 \\
\hline 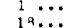 & - 7 & - 5 & 7.5 & 72 & .6 & . no & 15 & $?$ \\
\hline $24 \ldots$ & $: 77$ & 1 & 14. & $\begin{array}{r}52 \\
136\end{array}$ & $\because 9$ & $\therefore$ & h. & $?$ \\
\hline $31 \ldots$ & $\therefore$ & .1 & . . & 21 & ite & $\therefore n$ & 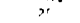 & 2 \\
\hline NOV. & & & & & & & & \\
\hline $7 .$. & .44 & $.1^{\prime}$ & $1 ? \cdot ?$ & $7 \mathrm{R}$ & .114 & .9 & a. & ? \\
\hline $\ln _{n \in C} \ldots$ & .37 & 1 & 0.2 & 71 & $\because r$ & 11 & $+:$ & 2 \\
\hline IAN. & .2 & .5 & a. & 76 & $\cdots$ & .05 & 7 & 4 \\
\hline $\begin{array}{l}17 \ldots \\
f \in R .\end{array}$ & .74 & .5 & 14. & 14 & .64 & .10 & R. & 4 \\
\hline $\begin{array}{l}13 \ldots \\
M A F_{0}\end{array}$ & 1.5 &.+5 & 14. & $1 \cdot 1$ & .183 & .23 & 2.5 & ' \\
\hline $\begin{array}{l}10 . \cdots \\
A P H\end{array}$ & 4.5 & .15 & 11. & 1'. & .4 & .09 & 2.5 & 4 \\
\hline${ }_{M A Y}^{23} \cdots$ & .22 & $\therefore 5$ & 5.' & 52 & .0 &.$A_{B}$ & 6.5 & 4 \\
\hline JUNE & $\cdot 3$ & $.1^{r}$ & 9.9 & $1 \cdot 2$ & $.6+2$ & .77 & 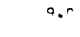 & 4 \\
\hline JuLY. & .7 & $.1^{\circ}$ & 2.2 & $I-\alpha$ &. & . a & $=-$ & $?$ \\
\hline$\because 1 \ldots$ &.$r$ & .5 & 9.4 & 111 & .22 & .96 & 6.1 & 2 \\
\hline $4 \ldots$ &. .7 & .1 & 5.7 & 65 & .14 & .16 & 13 & 4 \\
\hline $16 \ldots$ & $\therefore$ & $\therefore F$ & ०.? & 14 & $\therefore 1$ & .15 & 17 & ? \\
\hline $24 \ldots$ & $\because 7$ & .5 & n.h & 76 & .12 & $\therefore 7$ & Q. & 4 \\
\hline AUG $\because$ & ..17 & $\cdot 1$ & 9.5 & 72 & $\therefore 3$ & $\therefore 9$ & $4 \Gamma$ & 2 \\
\hline n... & .3. & . 1 & q. & an & .0 & .26 & $h^{\wedge}$ & n \\
\hline $13 \ldots$ & .15 & .1 & 7.2 & $7 \mathrm{~F}$ & iren & $\because \because \frac{\pi}{4}$ & $5^{-}$ & $\underline{2}$ \\
\hline $2, \cdots$ & $\cdots$ &. Ir $^{2}$ & 4.5 & 11 & $.1 \times 1$ & $.2 n$ & 2 & 2 \\
\hline $\begin{array}{l}27 \ldots \\
\text { SEPT. }\end{array}$ & .15 & .5 & $11 . ?$ & $i_{1} \mathrm{c}$ & $\therefore p_{p}$ & .67 & 3.6 & $i$ \\
\hline $4 \ldots$ &.$r$ & .1 & 9.5 & 1.4 & $\therefore 2$ &.$\Gamma$ & 7. $r$ & 2 \\
\hline $11 \ldots$ & . ir & $\because 5$ & 3.2 & 22 &.$r r^{\circ}$ & $\mathrm{I}^{r}$ & 0.1 & $i$ \\
\hline $17 \ldots$ & .22 & . 5 & 5.2 & 55 & $\therefore 25$ & .7 & ar & ? \\
\hline $24 \ldots$ & .15 & $\therefore 5$ & 5.1 & 59 & $.1>1$ & .07 & 7 & . \\
\hline & $\begin{array}{l}\text { TNTAL } \\
\text { CHRD- }\end{array}$ & & & & & & & $\Gamma A D-$ \\
\hline & $M[1+M$ & NICKEI & CODPFR & LEAT & 7 INC & CIRAL T & AR SFNIS & MIIIM \\
\hline TATE & $(C R)$ & (ขI) & (c11) & $(D R)$ & $(7 N)$ & $(r n)$ & issi & irni \\
\hline пCT. & & & & & & & & \\
\hline $3 \ldots$ & -- & - & $\rightarrow$ & -- & -. & -- & -- & - \\
\hline $1 \ldots$ & -- & -- & -- & -- & $=$ & $=-$ & $\because$ & $=$ \\
\hline $\begin{array}{l}19 \ldots \\
24 \ldots\end{array}$ & 1 & $\because-1$ & $\because 4$ & 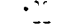 & $\because$ & $\because 1$ & $\because$ & ... \\
\hline$+1 \ldots$ & -- & -- & - & -- & - & -- & - & - \\
\hline Nitv. & -- & -- & -- & -- & -- & -- & - & $=$ \\
\hline $15 \ldots$ & -- & - & -- & -- & -- & - & - & - \\
\hline DEC. & & & & & & & & \\
\hline $\begin{array}{l}12 \ldots \\
\text { JAN. }\end{array}$ & -- & -- & -- & -- & -- & -- & -- & -- \\
\hline $17 \ldots$ & -- & -- & -- & -- & -- & -- & -- & - \\
\hline $\begin{array}{l}13 . . \\
M \triangle E_{0} .\end{array}$ & $=-$ & -- & -- & -- & -- & -- & -- & - \\
\hline $19 .$. & -- & -- & -- & -- & -- & -- & $\cdots$ & $=$ \\
\hline${ }^{A P D}: .$. & -. & -- & -- & $\ldots$ & -- & -- & -- & $\ldots$ \\
\hline MAY & & & & & & & & \\
\hline$\underset{\text { JUNF }}{14 . .}$ & -- & -- & -- & -- & -- & -- & - & - \\
\hline נik. & -- & -- & -- & -- & - & -- & -- & - \\
\hline $1 \ldots$ & -- & -- & -- & -- & -- & -- & - & - \\
\hline $9 \ldots$ & -- & -- & -- & - & -- & -- & $=$ & - \\
\hline $16 \ldots$ & -- & -- & -- & -- & - & $=$ & - & -- \\
\hline $24 \ldots$ & -- & -- & -- & -- & -- & -- & -- & -- \\
\hline $3 r \ldots$ & -- & -- & -- & -- & -- & $\cdots$ & -- & -- \\
\hline AUG. & & & & & & & & \\
\hline $6 \ldots$ & -- & -- & -- & -- & -- & -2 & -- & -- \\
\hline $13 \ldots$ & $=-$ & -- & -- & -- & $=$ & -- & -- & -- \\
\hline $2 . \ldots$ & -- & -- & $\overline{-}$ & $\cdots$ & $\because$ & 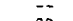 & -- & -- \\
\hline $\begin{array}{l}27 . . . \\
\text { SEDT. }\end{array}$ & . & - 1 & .12 & . I & $\cdot 1$ & $\cdot n$ &.$?$ & $\because$ \\
\hline $4 \ldots$ & -- & -- & $-\cdots$ & - & -- & -- & -- & -- \\
\hline $11 \ldots$ & $\overline{-i}$ & $\overline{-i}$ & $\bar{x}$ & $\bar{u}$ & $\overline{1}$ & $\bar{r}$ & $\overline{1}$ & $\because$ \\
\hline $\begin{array}{l}17 \ldots \\
24 \ldots\end{array}$ & $\because$ & 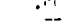 & 31 & $\cdot ? 1$ & $\because 1$ & -2 & $\because 1$ & $\because$ \\
\hline
\end{tabular}


03270000 MAD RIVER NEAR DAYTON, OHIO--COntInued

SPECIF IC CONDUCTANCE, PH, DISSOLVED OXYGEN, AND WATER TEMPERATURES, JUNE TO SEPTEMBER 1968 JUNE

JULY

\begin{tabular}{|c|c|c|c|c|c|c|c|c|}
\hline \multirow[t]{2}{*}{ DAY } & \multicolumn{2}{|c|}{$\begin{array}{l}\text { SPECIFIC } \\
\text { CONDUCTANCE } \\
\text { (MI CROMHOS } \\
\mathbf{A T} 25^{\circ} \mathrm{C} \text { ) }\end{array}$} & \multicolumn{2}{|c|}{$\mathrm{pH}$} & \multicolumn{2}{|c|}{$\begin{array}{l}\text { DI SSOLVED } \\
\text { OXYG EN } \\
(\mathbf{M G} / \mathrm{L})\end{array}$} & \multicolumn{2}{|c|}{$\begin{array}{l}\text { TEMPER- } \\
\text { ATURE } \\
\left({ }^{\circ} \mathrm{C}\right)\end{array}$} \\
\hline & $\max$ & MI N & MAX & MIN & MAX & MIN & $\operatorname{MAX}$ & II \\
\hline 1 & - & - & -- & - & & & -- & -- \\
\hline 2 & -- & $\rightarrow$ & - & $\cdots$ & & & -- & - \\
\hline 3 & -- & - & - & $\cdots$ & & & - & - \\
\hline 4 & - & -- & -- & -- & & & -- & - \\
\hline 5 & - & - & -- & - & & & $\rightarrow$ & - \\
\hline 6 & - & - & -- & 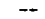 & & & -- & -- \\
\hline 7 & - & - & - & -- & & & -- & - \\
\hline 8 & - & -- & - & - & & & - & -- \\
\hline 9 & -- & -- & -- & - & & & -- & - \\
\hline 10 & -- & - & - & -- & & & - & -- \\
\hline 11 & - & -- & -- & $\sim$ & & & - & -- \\
\hline 12 & -- & -- & -- & - & & & -- & -- \\
\hline 13 & - & - & - & - & & & $\cdots$ & $\cdots$ \\
\hline 14 & -- & - & - & - & & & -- & - \\
\hline 15 & - & - & $\cdots$ & -- & & & -- & \\
\hline 16 & -- & -- & - & -- & & & - & -- \\
\hline 17 & - & - & - & -- & & & $-\infty$ & -- \\
\hline 18 & 720 & 680 & 8.3 & 8.1 & 9.0 & 6.7 & 24 & 23 \\
\hline 19 & 730 & 710 & 8.1 & 8.0 & & & 23 & \\
\hline 20 & -- & -- & - & -- & & & $=$ & -- \\
\hline 21 & -- & -- & - & -- & & & -- & -- \\
\hline 22 & -- & $\cdots$ & 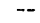 & $\cdots$ & & & - & -- \\
\hline 23 & -- & - & - & - & & & - & - \\
\hline 24 & -- & -- & - & -- & & & -- & -- \\
\hline 25 & - & - & - & -- & & & -- & $\cdots$ \\
\hline 26 & -- & -- & - & - & & & -- & -- \\
\hline 27 & -- & - & - & - & & & - & - \\
\hline 28 & -- & -- & - & -- & & & -- & -- \\
\hline 29 & -- & - & -- & -- & & & -- & -- \\
\hline 30 & -- & -- & -- & - & & & -- & - \\
\hline 31 & -- & -- & - & -- & & & -- & -- \\
\hline
\end{tabular}

\begin{tabular}{|c|c|c|c|c|c|c|c|}
\hline \multicolumn{2}{|c|}{$\begin{array}{l}\text { SPECIFIC } \\
\text { CONDUCTANCE } \\
\text { (1ICROMHOS } \\
\text { AT } 25^{\circ} \mathrm{C} \text { ) }\end{array}$} & \multicolumn{2}{|c|}{$\mathrm{pH}$} & \multicolumn{2}{|c|}{$\begin{array}{l}\text { DISSOLVED } \\
\text { OXYGEN } \\
(\mathbf{M G} / \mathrm{L})\end{array}$} & \multicolumn{2}{|c|}{$\begin{array}{l}\text { TEUPER- } \\
\text { ATURE } \\
\left({ }^{\circ} \mathrm{C}\right)\end{array}$} \\
\hline $\max$ & MIN & $\operatorname{sax}$ & MIN & MAXX & nIN & MAXX & MI N \\
\hline -- & -- & - & -- & & & - & - \\
\hline -- & -- & -- & -- & & & - & -- \\
\hline- & - & -- & -- & & & - & - \\
\hline-- & -- & - & -- & & & - & -- \\
\hline- & - & -- & -- & & & -- & -- \\
\hline -- & - & $=$ & -- & & & -- & -- \\
\hline -- & - & -- & -- & & & - & - \\
\hline$\cdots$ & - & -- & - & & & - & -- \\
\hline- & $\bar{z}$ & -- & -- & & & $=$ & $\overline{-}$ \\
\hline-- & -- & -- & -- & & & - & -- \\
\hline $\begin{array}{l}760 \\
770\end{array}$ & $\begin{array}{l}730 \\
690\end{array}$ & $\begin{array}{l}8.3 \\
8.2\end{array}$ & $\begin{array}{l}8.0 \\
7.9\end{array}$ & & & $\begin{array}{l}25 \\
25\end{array}$ & $\begin{array}{l}22 \\
22\end{array}$ \\
\hline$\overline{-}$ & - & - & - & & & $\overline{25}$ & $\overline{0}$ \\
\hline $\begin{array}{l}\mathbf{7 4 0} \\
\mathbf{7 4 0}\end{array}$ & $\begin{array}{l}710 \\
690\end{array}$ & $\begin{array}{l}8.3 \\
8.3\end{array}$ & $\begin{array}{l}7.7 \\
7.9\end{array}$ & & & $\begin{array}{l}25 \\
24\end{array}$ & $\begin{array}{l}\mathbf{2 3} \\
\mathbf{2 2}\end{array}$ \\
\hline 730 & 700 & 8.5 & 8.0 & & & 24 & 22 \\
\hline 730 & 690 & 8.6 & 8.1 & & & 26 & 22 \\
\hline 760 & 710 & 8.6 & 8.2 & & & 26 & 23 \\
\hline 750 & 670 & 8.4 & 8.0 & & & 28 & 24 \\
\hline 730 & 650 & 8.4 & 7.9 & & & 27 & 23 \\
\hline 730 & 710 & 8.5 & 7.9 & & & 26 & 23 \\
\hline 750 & 710 & 8,4 & 8.0 & & & 26 & 23 \\
\hline 740 & 670 & 8.3 & 8.0 & & & 27 & 23 \\
\hline 720 & 700 & 8.1 & 7.9 & & & 25 & 24 \\
\hline 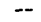 & - & - & -- & & & -- & - \\
\hline$\ldots$ & -- & -- & -- & & & -- & -- \\
\hline-- & - & -- & -- & & & -- & -- \\
\hline- & - & -- & -- & & & -- & - \\
\hline$\cdots$ & -- & - & - & & & - & -- \\
\hline $7 \overline{80}$ & $7 \overline{40}$ & $\overline{8.0}$ & $\overline{7.8}$ & & & $\overline{22}$ & $\overline{21}$ \\
\hline
\end{tabular}

\begin{tabular}{|c|c|c|c|c|c|c|}
\hline \multirow[t]{2}{*}{ DAY } & \multicolumn{2}{|c|}{$\begin{array}{l}\text { SPECIFIC } \\
\text { CONDUCTANCE } \\
\text { ( } \mathbf{M I C R O M I O S} \\
\left.\text { AT } 25^{\circ} \mathrm{C}\right)\end{array}$} & \multicolumn{2}{|c|}{$\mathrm{pH}$} & \multicolumn{2}{|c|}{$\begin{array}{l}\text { DISSOLVED } \\
\text { OXYGEN } \\
\text { (HG/L) }\end{array}$} \\
\hline & LAXX & MIN & $\max$ & MIN & MAXX & IIN \\
\hline $\begin{array}{l}1 \\
2 \\
3 \\
4 \\
5\end{array}$ & $\begin{array}{r}780 \\
580 \\
-- \\
-- \\
--\end{array}$ & $\begin{array}{r}420 \\
490 \\
-- \\
--\end{array}$ & $\begin{array}{r}7.9 \\
7.7 \\
-- \\
--\end{array}$ & $\begin{array}{r}7.5 \\
7.6 \\
-- \\
--\end{array}$ & & \\
\hline $\begin{array}{r}6 \\
7 \\
8 \\
9 \\
10\end{array}$ & $\begin{array}{r}710 \\
800 \\
700 \\
-- \\
--\end{array}$ & $\begin{array}{r}550 \\
690 \\
420 \\
- \\
--\end{array}$ & $\begin{array}{l}-- \\
8.3 \\
--\end{array}$ & $\begin{array}{r}-- \\
7.1 \\
--\end{array}$ & & \\
\hline $\begin{array}{l}11 \\
12 \\
13 \\
13 \\
14 \\
15\end{array}$ & $\begin{array}{l}= \\
= \\
=\end{array}$ & $\begin{array}{l}= \\
=- \\
= \\
=\end{array}$ & $\begin{array}{l}=- \\
=- \\
=-\end{array}$ & $\begin{array}{l}= \\
= \\
=\end{array}$ & & \\
\hline $\begin{array}{l}16 \\
17 \\
18 \\
19 \\
20\end{array}$ & $\begin{array}{l}=- \\
\because- \\
=\end{array}$ & $\begin{array}{l}-- \\
-- \\
--\end{array}$ & $\begin{array}{l}= \\
-- \\
-- \\
--\end{array}$ & $\begin{array}{l}=- \\
\bar{z} \\
z-\end{array}$ & & \\
\hline $\begin{array}{l}21 \\
22 \\
23 \\
24 \\
25\end{array}$ & $\begin{array}{l}= \\
=- \\
=\end{array}$ & $\begin{array}{l}= \\
=- \\
=-\end{array}$ & $\begin{array}{l}= \\
-- \\
--\end{array}$ & $\begin{array}{l}= \\
=- \\
=-\end{array}$ & & \\
\hline $\begin{array}{l}26 \\
27 \\
28 \\
29 \\
30 \\
31\end{array}$ & $\begin{array}{l}\overline{--} \\
\overline{-} \\
810 \\
820\end{array}$ & $\begin{array}{l}-- \\
\overline{-} \\
730 \\
720\end{array}$ & $\begin{array}{c}-- \\
\overline{--} \\
8.3 \\
--\end{array}$ & $\begin{array}{l}-- \\
\overline{-} \\
7.1\end{array}$ & & \\
\hline
\end{tabular}

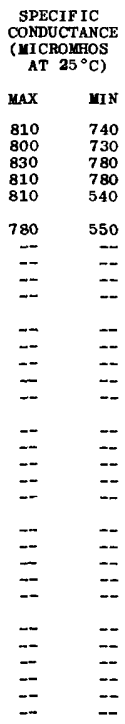

TELPERATU RE

MAX MIN

$\begin{array}{ll}20 & 19 \\ 21 & 18\end{array}$ 2218 $\begin{array}{ll}22 & 18 \\ 21 & 19 \\ 21 & 19\end{array}$

$22 \quad 19$

$=\quad-$

$=$

$=$

$=$

$--$

--

$--$

$--$

$=$

$=$

$-$

$=$

$=-$ 
03271350 GREAT MIAMI RIVER AT WEST CARROLLTON, OHIO

LOCATYON, --Lat 39 $40^{\prime} 28^{\prime \prime}$, long $84^{\circ} 15^{\prime} 42^{\prime \prime}$, Hontgomery County, at bridge on Farmersville-West Carrollton Road at West Carrolition.

DRA INAGE AREA, $--2,647 \mathrm{sq} \mathrm{mi}$.

PERIOD OF RECORD. $\rightarrow$ Chemical analyses: April 1965 to September 1968.

REMARKS, --Samples collected weekly October, July to September and monthly November to June. Samples for iron and manganese filtered clear when collected. No discharge records available.

CHEMICAL ANALYSES IN MILLIGRAMS PER LITER, WATER YEAR OCTOBER 1967 TO SEPTEMBER 1968

\begin{tabular}{|c|c|c|c|c|c|c|c|c|c|c|c|c|}
\hline DATF & TIMF & $\begin{array}{l}\text { SILICA } \\
\text { (SI0?) }\end{array}$ & $\begin{array}{l}\text { IRON } \\
\text { (FE) }\end{array}$ & $\begin{array}{l}\text { MAN- } \\
\text { GANESE } \\
\text { (MN) }\end{array}$ & $\begin{array}{l}\text { CAL- } \\
\text { CIUM } \\
\text { (CA) }\end{array}$ & $\begin{array}{l}\text { MAG- } \\
\text { NF- } \\
\text { SIUM } \\
\text { (MG) }\end{array}$ & $\begin{array}{l}\text { SODIUM } \\
\text { (NA) }\end{array}$ & $\begin{array}{l}\text { PO- } \\
\text { TAS- } \\
\text { SIIUM } \\
\text { (K) }\end{array}$ & $\begin{array}{l}\text { BICAR - } \\
\text { RONATE } \\
\text { (HCD3) }\end{array}$ & $\begin{array}{l}\text { CAR- } \\
\text { BONATF } \\
\text { ICD3) }\end{array}$ & $\begin{array}{l}\text { SIULATE } \\
\text { (SO4) }\end{array}$ & $\begin{array}{l}\text { CHLn- } \\
\text { RIDE } \\
\text { (CLI) }\end{array}$ \\
\hline \multicolumn{13}{|l|}{ CCT. } \\
\hline & 1530 & -- & .11 & .03 & -- & - & -- & -- & 272 & 0 & 97 & 56 \\
\hline $11 \ldots$ & 0800 & -- & .10 & .03 & $\cdots$ & 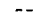 & -- & -- & 290 & 0 & 95 & 56 \\
\hline$I \nLeftarrow \ldots$ & 1000 & -- & .09 & .12 & -- & -- & - & -- & 302 & c & 97 & 56 \\
\hline $24 \ldots$ & 1530 & -- & . C & .00 & -- & -- & -- & -- & 300 & 0 & 97 & 56 \\
\hline $31 \ldots$ & 1630 & -- & .25 & .06 & -- & - & -- & -- & 314 & 0 & 97 & 54 \\
\hline Nuv. & & & & & & & & & & & & \\
\hline $07 \ldots$ & 1515 & -- & .15 & .09 & -- & - & -- & -- & $30 t$ & c & 107 & 40 \\
\hline $\begin{array}{l}14 \ldots \\
\text { UEC. }\end{array}$ & 1615 & 8.4 & .13 & .39 & 83 & 33 & 37 & 5.1 & $3 n 0$ & $c$ & 104 & 48 \\
\hline $\begin{array}{l}12 \ldots \\
\text { JAN. }\end{array}$ & 1615 & 6.4 & -- & .03 & 56 & 17 & 7.1 & 3.1 & 154 & c & 55 & 17 \\
\hline $18 \ldots$ & 0845 & 8.7 & .11 & .04 & 93 & 35 & 38 & 3.3 & 334 & c & 90 & 56 \\
\hline $\begin{array}{l}13 \ldots . \\
4 \Delta K .\end{array}$ & 1515 & 7.6 & .08 & .05 & 95 & 31 & 19 & 2.5 & 318 & c & 90 & 33 \\
\hline $\begin{array}{l}20 \ldots \\
A P R\end{array}$ & 0845 & 4.4 & .13 & .03 & 82 & 27 & 21 & 3.0 & 262 & 0 & 85 & 34 \\
\hline${ }_{M \Delta Y}^{23 \ldots}$ & 1030 & 2.5 & .07 & .03 & 85 & 34 & 25 & 2.9 & 302 & 0 & 91 & 34 \\
\hline $\begin{array}{l}\text { I } 2 \ldots . . \\
\text { JIINE }\end{array}$ & 0845 & 5.8 &. $\mathrm{Ca}$ & .05 & 85 & 35 & 27 & 3.0 & 304 & $c$ & 84 & 36 \\
\hline$\underset{\text { JuLY }}{11 \ldots}$ & 1630 & 3.7 & .07 & .08 & 86 & 73 & 20 & 2.7 & 288 & e & 83 & 32 \\
\hline $02 \ldots$ & 0900 & -- & .08 & .08 & - & -- & -- & -- & 276 & 0 & Rl & 32 \\
\hline $10 \ldots$ & 0915 & -- & .09 & .04 & -- & -- & -- & -- & 300 & 0 & 94 & 42 \\
\hline $16 \ldots$ & 1630 & -. & .09 & .04 & -- & $\cdots$ & $=$ & -- & 296 & 0 & RQ & $4 ?$ \\
\hline $24 \ldots$ & 0915 & -- & .23 & .03 & -- & - & -- & -- & 294 & 0 & B5 & 41 \\
\hline $30 \ldots$ & 1530 & $-\infty$ & .63 & .06 & -- & - & -- & - & 258 & 0 & 68 & 24 \\
\hline AUG. & & & & & & & & & & & & \\
\hline c7... & 1000 & - & .10 & .04 & -- & -- & -- & $=$ & 290 & 0 & 76 & 28 \\
\hline $13 \ldots$ & 1900 & - & .14 & .03 & -- & - & -- & - & 272 & c & 71 & 26 \\
\hline $20 \ldots$ & 1530 & -- & .04 & .07 & -- & - & -- & -- & 310 & 6 & 36 & 34 \\
\hline $\begin{array}{l}28 . . \\
\text { SFDT. }\end{array}$ & 0800 & -- & .09 & .05 & -- & $=$ & -- & - & 318 & 2 & 89 & 42 \\
\hline $05 \ldots$ & 1030 & -- & .16 & .05 & -- & - & -- & -- & 304 & 0 & 92 & 48 \\
\hline $1 \mathrm{I} \ldots$ & 1500 & -- & .18 & .49 & -- & - & -- & -- & $29 ?$ & 0 & 97 & 46 \\
\hline $18 \ldots$ & 3915 & -- & $.2 \mathrm{I}$ & .08 & -- & $\cdots$ & -- & -- & 232 & a & 70 & $3 R$ \\
\hline $24 \ldots$ & 1130 & -- & - $c 9$ & .06 & -- & -- & - & -- & 320 & $c$ & 95 & 48 \\
\hline
\end{tabular}

\begin{tabular}{|c|c|c|c|c|c|c|c|c|}
\hline DATE & $\begin{array}{l}\triangle M M O N F A \\
\text { (NH4) }\end{array}$ & $\begin{array}{l}\text { NITRITE } \\
\text { (NOZ) }\end{array}$ & $\begin{array}{l}\text { DISS- } \\
\text { OLVED } \\
\text { OXYGEN }\end{array}$ & $\begin{array}{l}\text { PER- } \\
\text { CENT } \\
\text { SATUR- } \\
\text { ATION }\end{array}$ & PHENOLS & $\begin{array}{l}\text { ME THY - } \\
\text { LENE } \\
\text { RLUE } \\
\text { ACTIVE } \\
\text { SUR- } \\
\text { STANCE }\end{array}$ & $\begin{array}{l}\text { TUR- } \\
\text { AID- } \\
1+Y\end{array}$ & OTOR \\
\hline OCT. & & & & & & & & \\
\hline $03 \ldots$ & 2.5 & .50 & 7.4 & AB & $.0 \mathrm{cs}$ & .15 & 9.0 & 4 \\
\hline $11 \ldots$ & 2.4 & .10 & 4.4 & 46 & .009 & .15 & 50 & B \\
\hline $18 \ldots$ & 2.7 & .15 & 4.0 & 44 & .010 & .15 & 20 & 4 \\
\hline $24 \ldots$ & 3.0 & .20 & 6.4 & 70 & .001 & . 14 & 20 & 4 \\
\hline $31 \ldots$ & 3.0 & .15 & 5.8 & bo & .004 & .16 & 30 & 4 \\
\hline Nov. & & & & & & & & \\
\hline $07 \ldots$ & 1.7 & .10 & 3.8 & 78 & .013 & .16 & 20 & 4 \\
\hline $\begin{array}{ll}14 \ldots & \\
D E C .\end{array}$ & 2.7 & .20 & 7.2 & 65 & .001 & .15 & 50 & 2 \\
\hline $\begin{array}{l}12 \ldots \\
J \Delta N .\end{array}$ & .15 & .05 & 11.0 & 03 & .004 & .08 & 200 & 2 \\
\hline $\begin{array}{l}18 . . \\
\text { FES. }\end{array}$ & 2.4 & .05 & 11.0 & 86 & .007 & .11 & 20 & 8 \\
\hline MAR... & 1.2 & .05 & 12.0 & 89 & .005 & .40 & 25 & 4 \\
\hline $\begin{array}{l}20 \ldots . . \\
A P R .\end{array}$ & .81 & .05 & 9.4 & 87 & .000 & .12 & 17 & 2 \\
\hline$\underset{\text { MAY }}{23} \cdots$ & $\cdot R 1$ & .05 & 7.4 & 94 & .000 & .17 & 28 & 4 \\
\hline $\begin{array}{l}15 \ldots . . \\
\text { JUNE }\end{array}$ & $\theta_{1}$ & .10 & 6.4 & 73 & .003 & .09 & 13 & 8 \\
\hline JuLY... & .15 & .05 & 9.8 & 120 & .000 & .10 & 45 & 4 \\
\hline $02 \ldots$ & $1: 74$ & $\begin{array}{l}.05 \\
.10\end{array}$ & $\begin{array}{l}5.0 \\
4.6\end{array}$ & $\begin{array}{l}62 \\
57\end{array}$ & $\begin{array}{l}.002 \\
.004\end{array}$ & .31 & $\begin{array}{l}35 \\
20\end{array}$ & $\stackrel{4}{8}$ \\
\hline $16 \ldots$ & .89 & .10 & 5.0 & 83 & .000 & .13 & 50 & 4 \\
\hline $24 \ldots$ & 1.2 & .05 & 4.4 & 56 & .003 & .29 & 35 & 4 \\
\hline $\begin{array}{l}30 \ldots \\
\text { AUG. }\end{array}$ & .37 & .05 & 6.6 & 78 & .003 & .36 & Bo & 4 \\
\hline 07... & .37 & .05 & 5.6 & 71 & .007 & .20 & 60 & 4 \\
\hline $13 \ldots$ & .59 & .05 & 7.1 & 32 & .001 & .08 & 60 & 4 \\
\hline $20 \ldots$ & .22 & .05 & 8.6 & 110 & $.0 \cap 1$ & .25 & 40 & 4 \\
\hline $\begin{array}{l}\text { 2R... } \\
\text { SEPT. }\end{array}$ & 1.3 & .10 & 5.0 & 57 & .000 & .17 & 40 & 4 \\
\hline 05... & 1.9 & .10 & 4.0 & 48 & .003 & .12 & 35 & 4 \\
\hline $11 \ldots$ & 2.0 & .10 & 4.7 & 55 & .000 & .18 & 35 & 4 \\
\hline $18 \ldots$ & I. 3 & .10 & 4.6 & 53 & . $\mathrm{Cl}_{4}$ & .14 & 35 & 4 \\
\hline $24 \ldots$ & 2.4 & .10 & 4.6 & 53 & .005 & .17 & 35 & A \\
\hline
\end{tabular}


GREAT MIAMI RIVER BASIN

03271350 GREAT MIAHI RIVER AT WEST CARROLLTON, OHIO--COntInued CHEMICAL ANALYSES IN MILLIGRAMS PER LITER, WATER YEAR OCTOBER 1967 TO SEPTEMBER 1968

\begin{tabular}{|c|c|c|c|c|c|c|c|c|c|c|c|}
\hline DATE & $\begin{array}{l}\text { FLUUD- } \\
\text { RIDE } \\
\text { (F) }\end{array}$ & $\begin{array}{l}\text { NITRATE } \\
\text { INU3I }\end{array}$ & $\begin{array}{l}\text { TOTAL } \\
\text { PHOS- } \\
\text { PHOKUS } \\
\text { (PO4) }\end{array}$ & $\begin{array}{l}\text { DIS- } \\
\text { SOLVED } \\
\text { SOLIDS } \\
\text { IRESI- } \\
\text { DUE AT } \\
\text { LBO CI }\end{array}$ & $\begin{array}{l}\text { DIS- } \\
\text { SOLVED } \\
\text { SOLIOS } \\
\text { ISUM OF } \\
\text { CONSTI- } \\
\text { TUENTSI }\end{array}$ & $\begin{array}{l}\text { HARO- } \\
\text { NESS } \\
\text { (CA,MG) }\end{array}$ & $\begin{array}{l}\text { NON- } \\
\text { CAR- } \\
\text { BONATE } \\
\text { HARO- } \\
\text { MESS }\end{array}$ & $\begin{array}{l}\text { SPECI - } \\
\text { FIC } \\
\text { COND- } \\
\text { UCTANCE } \\
\text { (MICRD- } \\
\text { MHOS) }\end{array}$ & PH & $\begin{array}{l}\text { TEMP- } \\
\text { ERATURE } \\
\text { IOEG CI }\end{array}$ & COLOP \\
\hline $\begin{array}{c}\mathrm{CC}_{\mathrm{T}} \cdot \\
33 \ldots\end{array}$ & -- & 10 & & & & & & & & & \\
\hline $11 \ldots$ & - & 0.5 & 9.0 & 502 & - & 335 & $\begin{array}{r}107 \\
97\end{array}$ & $\begin{array}{l}796 \\
797\end{array}$ & $\begin{array}{l}7.4 \\
7.4\end{array}$ & 24 & $\begin{array}{l}-- \\
--\end{array}$ \\
\hline $18 \ldots$ & -- & 8.7 & 4.2 & 508 & -- & 345 & a) & A25 & 7.4 & $2 \hat{1}$ & $=-$ \\
\hline $24 \ldots$ & 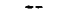 & 11 & 7.8 & 512 & -- & 350 & 104 & 838 & 7.5 & 20 & -- \\
\hline nנืv. & -- & 7.4 & 9.5 & 490 & -- & 335 & 77 & 809 & 7.8 & $1 \mathrm{~A}$ & -- \\
\hline c7... & - & 8.0 & 4.5 & 504 & $=-$ & 365 & 114 & 781 & 8.1 & 11 & -- \\
\hline $\begin{array}{c}14 \ldots \\
\text { OEC. }\end{array}$ & .4 & 9.0 & 5.5 & 506 & 485 & 343 & 97 & 780 & 7.9 & 13 & 20 \\
\hline JAN. & $\cdot 3$ & 20 & .92 & $2 A B$ & 259 & 210 & 84 & 438 & 7.9 & 8 & 40 \\
\hline $\begin{array}{c}12 \ldots . . \\
F E R .\end{array}$ & .5 & 9.6 & 4.0 & 540 & 514 & 376 & 102 & 848 & 7.8 & 5 & 5 \\
\hline $\begin{array}{l}13 \ldots \\
\text { MAR.. }\end{array}$ & $\cdot 3$ & 15 & 2.5 & 448 & 453 & 265 & 104 & 727 & 8.1 & 3 & 5 \\
\hline $\begin{array}{l}P 0 \ldots \\
A P R\end{array}$ & .4 & 25 & 2.0 & 444 & 404 & 316 & 101 & 656 & 8.1 & 12 & 18 \\
\hline$\underset{\text { MAY }}{23} \cdots$ & .6 & 7.3 & 1.6 & 458 & 433 & 352 & 104 & 739 & 7.8 & 22 & 12 \\
\hline J5... & .5 & 10 & 2.8 & 446 & 439 & 356 & 107 & 731 & 8.0 & 22 & 10 \\
\hline$\underset{J \| L L Y}{1 L}$ & .4 & 8.3 & 1.8 & 422 & 421 & 350 & 100 & 698 & 8.5 & 26 & 22 \\
\hline $02 \ldots$ & -- & 17 & 3.6 & 428 & $-\cdots$ & 328 & 102 & 686 & 8.0 & 27 & -- \\
\hline $\begin{array}{l}10 \ldots \\
16 \ldots\end{array}$ & $=$ & $\begin{array}{l}5.3 \\
5.2\end{array}$ & $\begin{array}{l}3.6 \\
3.4\end{array}$ & $\begin{array}{l}462 \\
420\end{array}$ & $\because$ & 345 & $\because 9$ & 746 & $R .1$ & 27 & $=$ \\
\hline $34 \ldots$ & -- & 6.3 & $\begin{array}{l}3.4 \\
4.0\end{array}$ & $\begin{array}{l}420 \\
420\end{array}$ & $=$ & $\begin{array}{l}338 \\
774\end{array}$ & $\begin{array}{l}95 \\
83\end{array}$ & $\begin{array}{l}722 \\
710\end{array}$ & $\begin{array}{l}8.1 \\
8.1\end{array}$ & $\begin{array}{l}28 \\
>8\end{array}$ & $\overline{--}$ \\
\hline $30 \ldots$ & -- & 7.6 & 1.7 & 378 & -- & 290 & 78 & 598 & 8.2 & 24 & $\cdots$ \\
\hline $\begin{array}{l}\text { AliG. } \\
07 . . .\end{array}$ & -- & & & & & & & & & & \\
\hline $87 \ldots$ & $-\infty$ & $\begin{array}{l}8.6 \\
3.6\end{array}$ & $\begin{array}{l}3.0 \\
1.8\end{array}$ & $\begin{array}{l}416 \\
382\end{array}$ & -- & $\begin{array}{l}318 \\
306\end{array}$ & $\begin{array}{l}80 \\
83\end{array}$ & $\begin{array}{l}652 \\
616\end{array}$ & $\begin{array}{l}7.2 \\
7.9\end{array}$ & $\begin{array}{l}28 \\
73\end{array}$ & $\overline{-}$ \\
\hline $20 \ldots$ & -- & 5.5 & 2.6 & 470 & -- & 360 & 96 & 717 & 8.4 & 70 & -- \\
\hline $\begin{array}{l}28 . . \\
\text { SEPT. }\end{array}$ & -- & 5.0 & 3.0 & 468 & -- & 362 & 98 & $74 B$ & 8.3 & 22 & -- \\
\hline $05 \ldots$ & -- & 6.5 & 3.7 & 460 & -- & 346 & 96 & 767 & 7.7 & 25 & -- \\
\hline $\begin{array}{l}11 \ldots \\
18, \ldots\end{array}$ & $\overline{--}$ & $\begin{array}{l}6.2 \\
6.5\end{array}$ & $\begin{array}{l}2.4 \\
? .8\end{array}$ & 462 & $\because$ & 328 & 88 & 741 & $7 \cdot 8$ & 24 & $=$ \\
\hline $34 \ldots$ & - & $\begin{array}{l}6.5 \\
7.0\end{array}$ & $\begin{array}{l}7.8 \\
5.6\end{array}$ & $\begin{array}{l}346 \\
464\end{array}$ & - & $\begin{array}{l}256 \\
352\end{array}$ & $\begin{array}{l}66 \\
00\end{array}$ & $\begin{array}{l}598 \\
786\end{array}$ & $\begin{array}{l}7.8 \\
8.0\end{array}$ & $\begin{array}{l}23 \\
23\end{array}$ & \\
\hline
\end{tabular}

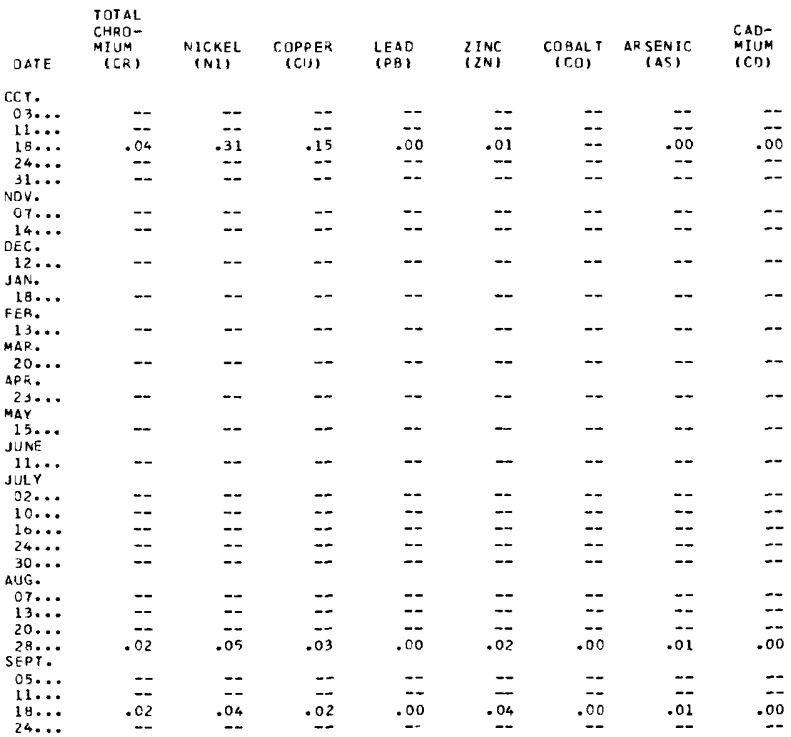


03271600 GREAT MIAMI RIVER NEAR MIAMISBURG, OHIO

LOCATION.--Lat $39^{\circ} 36^{\prime} 39^{\prime \prime}$, long $84^{\circ} 17^{\prime} 28^{\prime \prime}$, Moncgomery County, at Chautauqua Road bridge about 2 miles south of Miamisburg, off Old U.S. Highway 25 , and 2.6 miles downstream from gaging station at milamisburg.

DRA INAGE AREA. $--2,715$ sq mi.

PERIOD OF RECORD, --Chemical analyses: November 1961 to September 1968.

Nater temperatures: March 1964 to September 1968.

EXTREMES, --1967-68:

Speciftc conductance: Maximum daily, 980 micromhos Dec. 2; minimum daily, 320 micromhos May 24

pH: Haximum datly, 8.7 July 6,8; minimum dally, 7.5 July 20 .

Dissolved oxygen: Maximum daily, 15.0 mg/1 July 6-8; mintmum da1ly, $1.1 \mathrm{mg} / 1$ Oct. 19 ,

Water temperatures: Maximum, $33.0^{\circ} \mathrm{C}$ Aug. 22-25; mintmum, 4.0 ${ }^{\circ} \mathrm{C}$ Dec. 27 . Jan. 2

Period of record:

Spectfic conductance: Maximum datly, 1,110 micromhos Dec. 29, 1966; minimum daily, 270 micromhos Apr. 22, 1964

pH: Maximum datly, 9.0 June 8, 1964, Feb, 25, June 12, 1967; mintmum da11y, 6.8 July 6, 7, Nov, 4, 1965 . D1ssolved oxygen: Maximum da1ly, 15.0 mg/l June 8, 1964, Nov. 26, 30, 1966, July 6-8, 1968; min1mum da1iy, $0.0 \mathrm{mg} / 1$ on many days during $1964-66$.

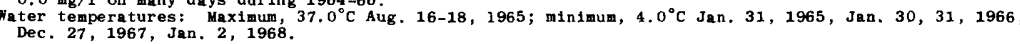

REAars. --Continuous recorder is installed in the basement of 0 . H. Hutchings power station, $400 \mathrm{ft}$ downstream from Chautauqua Road bridge, and takes water from channel under builing. In addition to the continuous recorder, dally samples were collected by a local observer. partial analyses were made on maximum specific conductance and minimum specific conductance of the samples collected for each month. Dissolved oxygen concentrations listed as $15.0 \mathrm{mg} / 1$ represent concentrations of $15.0 \mathrm{mg} / 1$ or greater, due to instrument ilmitations. Interruptions tn the record were due to malfunctions of the instrument. Discharge records are given for gaging
station at Miamisburg (drainage area $2,711 \mathrm{sq}$ ). Samples were collected at the bridge for pestictde analyse
to determine the extent and magnitude of CHEMICAL ANALYSES IN MILLIGRAMS PER LITER, WATER YEAR OCTOBER 1967 TO SEPTEMBER 1968

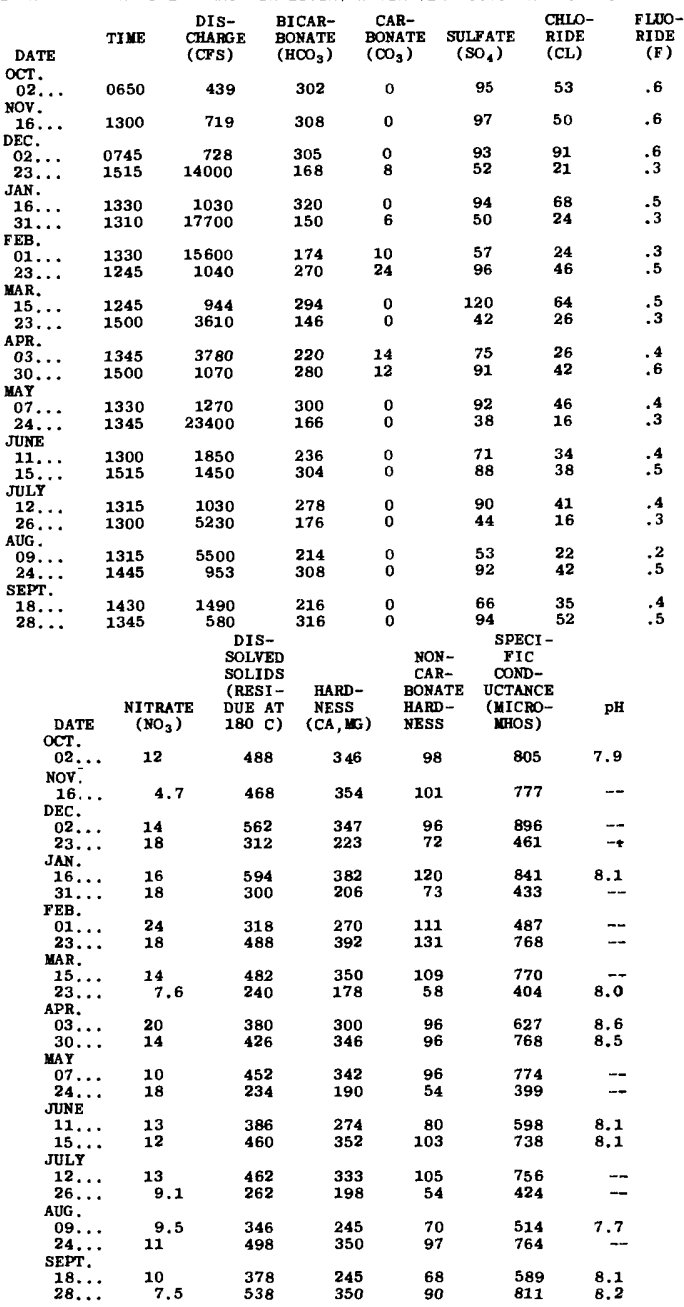


O3271600 GREAT MIAMI RIVER NEAR YIAYISBURG, OHIO--ContInued

\begin{tabular}{|c|c|c|c|c|c|c|c|}
\hline DATE & ALDRIN & DDD & DDE & DDT & $\begin{array}{c}\text { DI- } \\
\text { ELDRIN }\end{array}$ & ERDRIN & $\begin{array}{l}\text { HEPTA- } \\
\text { CHLOR }\end{array}$ \\
\hline OCT. & .00 & .00 & .00 & .00 & .01 & .00 & .00 \\
\hline $\begin{array}{l}14-18 \\
\text { APR. }\end{array}$ & .01 & .00 & .02 & .07 & .00 & .00 & .00 \\
\hline $\begin{array}{l}24-29 \\
\text { HAY }\end{array}$ & .00 & .00 & .03 & .00 & .00 & .00 & .00 \\
\hline $\begin{array}{l}13-17 \\
\text { JUNE }\end{array}$ & .00 & .00 & .04 & .06 & .00 & .00 & .00 \\
\hline $\begin{array}{l}25-29 \\
\text { JULY }\end{array}$ & .00 & .00 & .11 & .00 & .00 & .00 & .00 \\
\hline $\begin{array}{l}24-29 \\
\text { AUG }\end{array}$ & .00 & .00 & .00 & .00 & .04 & .00 & .00 \\
\hline $\begin{array}{c}08-14 \\
\text { SEPT. } \\
16-21\end{array}$ & .00 & .00 & .00 & .00 & .06 & .00 & .00 \\
\hline & .00 & .00 & .00 & .00 & .00 & .00 & .00 \\
\hline DATE & $\begin{array}{l}\text { HEPTA- } \\
\text { CHLOR } \\
\text { EPOXIDE }\end{array}$ & $\begin{array}{l}\text { METH- } \\
\text { OXY- } \\
\text { CHLOR }\end{array}$ & LINDANE & $\begin{array}{l}\text { CHLOR- } \\
\text { DANE }\end{array}$ & $\begin{array}{l}\text { YALA- } \\
\text { THION }\end{array}$ & $\begin{array}{l}\text { METHYL } \\
\text { PARA- } \\
\text { THION }\end{array}$ & $\begin{array}{l}\text { PARA- } \\
\text { THION }\end{array}$ \\
\hline $\begin{array}{l}\text { OCT. } \\
16-20\end{array}$ & .00 & .00 & .00 & .00 & .00 & .00 & .00 \\
\hline $\begin{array}{l}\text { NOV. } \\
\text { 14-18 } \\
\text { APR. }\end{array}$ & .00 & .00 & .00 & .00 & .00 & .00 & .00 \\
\hline$\underset{\text { MAY }}{24-29}$ & .00 & .00 & .00 & .00 & .00 & .00 & .00 \\
\hline $\begin{array}{l}\text { 13-17 } \\
\text { JUNE }\end{array}$ & .00 & .00 & .00 & .00 & .00 & .00 & .00 \\
\hline $\begin{array}{l}25-29 \\
\text { JULY }\end{array}$ & .00 & .00 & .00 & .00 & .00 & .00 & .00 \\
\hline $\begin{array}{l}\text { 24-29 } \\
\text { AUG. }\end{array}$ & .00 & .00 & .00 & .00 & .00 & .00 & .00 \\
\hline $\begin{array}{l}\text { 08-14 } \\
\text { SEPT. }\end{array}$ & .00 & .00 & .00 & .00 & .00 & .00 & .00 \\
\hline $16-21$ & .00 & .00 & .00 & .00 & .00 & .00 & .00 \\
\hline
\end{tabular}

SPECIFIC CONDUCTANCE, PH, DISSOLVED OXYGEN, AND WATER TEMPERATURES, TATER YEAR OCTOBER 1967 TO SEPTEMBER 1968 OCTOBER

NOVELBER

\begin{tabular}{|c|c|c|c|c|c|c|c|c|c|c|c|c|c|c|c|c|}
\hline \multirow[t]{2}{*}{ DAY } & \multicolumn{2}{|c|}{$\begin{array}{l}\text { SPECIFIC } \\
\text { CONDUCTANCE } \\
\text { (YICROMHOS } \\
\text { AT 25 }{ }^{\circ} \mathrm{C} \text { ) }\end{array}$} & \multicolumn{2}{|c|}{ pH } & \multicolumn{2}{|c|}{$\begin{array}{l}\text { DISSOLVED } \\
\text { OXYGEM } \\
(\mathbf{M G} / L)\end{array}$} & \multicolumn{2}{|c|}{$\begin{array}{l}\text { TEMPER- } \\
\text { ATURE } \\
\left({ }^{\circ} \mathrm{C}\right)\end{array}$} & \multicolumn{2}{|c|}{$\begin{array}{l}\text { SPECIFIC } \\
\text { CONDUCTANCE } \\
\text { (YICROMHOS } \\
\text { AT } 25^{\circ} \mathrm{C} \text { ) }\end{array}$} & \multicolumn{2}{|c|}{ pH } & \multicolumn{2}{|c|}{$\begin{array}{l}\text { DI SSOLVED } \\
\text { OXYGEN } \\
(\mathbf{M G} / \mathbf{L})\end{array}$} & \multicolumn{2}{|c|}{$\begin{array}{c}\text { TEKPER- } \\
\text { ATURE } \\
\left({ }^{\circ} \mathrm{C}\right)\end{array}$} \\
\hline & $\operatorname{Max}$ & UIN & Kax & YIN & Max & YIN & $\operatorname{sax}$ & IIIN & MAX & IIIN & MAX & MIN & $\operatorname{LAX}$ & MIN & MAX & MIN \\
\hline $\begin{array}{l}1 \\
2 \\
3 \\
4 \\
5\end{array}$ & $\begin{array}{l}\overline{-} \\
\bar{z} \\
\bar{m}\end{array}$ & $\begin{array}{l}=- \\
=- \\
=- \\
=\end{array}$ & $\begin{array}{l}8.1 \\
8.1 \\
8.1 \\
8.0 \\
8.0\end{array}$ & $\begin{array}{l}8.1 \\
7.8 \\
7.9 \\
7.6 \\
7.6\end{array}$ & $\begin{array}{l}4.6 \\
4.9 \\
4.2 \\
4.6 \\
3.8\end{array}$ & $\begin{array}{l}3.9 \\
2.8 \\
3.2 \\
3.2 \\
2.6\end{array}$ & $\begin{array}{l}=- \\
=- \\
=- \\
=-\end{array}$ & $\begin{array}{l}=- \\
=- \\
=-\end{array}$ & $\begin{array}{l}7 \overline{-} \\
720 \\
740 \\
730\end{array}$ & $\begin{array}{l}650 \\
660 \\
700 \\
700\end{array}$ & $\begin{array}{l}6.1 \\
6.0 \\
6.0 \\
8.0 \\
8.0\end{array}$ & $\begin{array}{l}7.9 \\
7.8 \\
7.8 \\
7.9 \\
8.0\end{array}$ & $\begin{array}{l}5 . \overline{.2} \\
5.5 \\
6.8 \\
7.3\end{array}$ & $\begin{array}{l}-\overline{-} \\
4.9 \\
5.1 \\
5.3 \\
6.6\end{array}$ & $\begin{array}{l}-- \\
21 \\
19 \\
17\end{array}$ & $\begin{array}{l}-- \\
19 \\
17 \\
15\end{array}$ \\
\hline $\begin{array}{r}6 \\
7 \\
8 \\
9 \\
10\end{array}$ & $\begin{array}{l}= \\
=- \\
= \\
=\end{array}$ & $\begin{array}{l}=- \\
=- \\
=-\end{array}$ & $\begin{array}{l}7.9 \\
8.0 \\
6.1 \\
8.1 \\
. .\end{array}$ & $\begin{array}{l}7.8 \\
7.8 \\
7.8 \\
7.7 \\
--\end{array}$ & $\begin{array}{r}-- \\
3 . \overline{4} \\
4.2 \\
--\end{array}$ & $\begin{array}{r}-- \\
2.9 \\
3.1 \\
--\end{array}$ & $\begin{array}{l}-- \\
-- \\
--\end{array}$ & $\begin{array}{l}=- \\
=- \\
=-\end{array}$ & $\begin{array}{l}790 \\
780 \\
780 \\
780 \\
780\end{array}$ & $\begin{array}{l}\mathbf{7 2 0} \\
\mathbf{7 4 0} \\
\mathbf{7 5 0} \\
\mathbf{7 4 0} \\
\mathbf{7 5 0}\end{array}$ & $\begin{array}{l}8.1 \\
8.1 \\
8.2 \\
6.2 \\
8.2\end{array}$ & $\begin{array}{l}7.9 \\
7.9 \\
8.0 \\
8.0 \\
8.1\end{array}$ & $\begin{array}{l}7.9 \\
7.8 \\
7.8 \\
7.2 \\
6.8\end{array}$ & $\begin{array}{l}7.2 \\
7.1 \\
7.0 \\
6.6 \\
6.4\end{array}$ & $\begin{array}{l}17 \\
18 \\
19 \\
18 \\
19\end{array}$ & $\begin{array}{l}16 \\
16 \\
17 \\
17 \\
18\end{array}$ \\
\hline $\begin{array}{l}11 \\
12 \\
13 \\
14 \\
15\end{array}$ & $\begin{array}{l}7 \overrightarrow{90} \\
790 \\
800 \\
600\end{array}$ & $\begin{array}{l}7 \overline{740} \\
740 \\
750 \\
780\end{array}$ & $\begin{array}{l}=- \\
=- \\
=-\end{array}$ & $\begin{array}{l}=- \\
=- \\
=- \\
-\end{array}$ & $\begin{array}{l}5 . \overline{2} \\
4.9 \\
6.5 \\
4.7\end{array}$ & $\begin{array}{l}-- \\
4.0 \\
3.7 \\
4.0 \\
3.6\end{array}$ & $\begin{array}{l}-\overline{23} \\
24 \\
25 \\
24\end{array}$ & $\begin{array}{l}-\overline{21} \\
22 \\
23 \\
23\end{array}$ & $\begin{array}{l}780 \\
770 \\
760 \\
790 \\
800\end{array}$ & $\begin{array}{l}\mathbf{7 4 0} \\
\mathbf{7 3 0} \\
\mathbf{7 0 0} \\
\mathbf{7 4 0} \\
\mathbf{7 7 0}\end{array}$ & $\begin{array}{l}8.1 \\
8.1 \\
8.1 \\
8.1 \\
8.0\end{array}$ & $\begin{array}{l}8.0 \\
8.0 \\
8.0 \\
8.0 \\
7.9\end{array}$ & $\begin{array}{l}7.5 \\
6.7 \\
6.3 \\
6.2 \\
6.4\end{array}$ & $\begin{array}{l}6.5 \\
6.1 \\
5.7 \\
5.5 \\
5.4\end{array}$ & $\begin{array}{l}21 \\
21 \\
20 \\
19 \\
18\end{array}$ & $\begin{array}{l}19 \\
20 \\
16 \\
18 \\
17\end{array}$ \\
\hline $\begin{array}{l}16 \\
17 \\
18 \\
19 \\
20\end{array}$ & $\begin{array}{r}810 \\
-700 \\
810 \\
810\end{array}$ & $\begin{array}{r}750 \\
-- \\
760 \\
790 \\
750\end{array}$ & $\begin{array}{l}= \\
=- \\
=-\end{array}$ & $\begin{array}{l}=- \\
=- \\
=-\end{array}$ & $\begin{array}{r}5.1 \\
-\overline{1} \\
3.8 \\
4.2 \\
2.0\end{array}$ & $\begin{array}{r}3.3 \\
-2 \\
2.4 \\
1.1 \\
1.3\end{array}$ & $\begin{array}{l}26 \\
-- \\
24 \\
23 \\
22\end{array}$ & $\begin{array}{l}23 \\
-- \\
23 \\
22 \\
20\end{array}$ & $\begin{array}{r}800 \\
800 \\
810 \\
7 \overline{760}\end{array}$ & $\begin{array}{r}780 \\
770 \\
760 \\
-720\end{array}$ & $\begin{array}{l}8.1 \\
8.1 \\
6.1 \\
-1 \\
6.2\end{array}$ & $\begin{array}{r}7.9 \\
8.0 \\
8.0 \\
8.1\end{array}$ & $\begin{array}{r}6.4 \\
6.4 \\
6.5 \\
8.0\end{array}$ & $\begin{array}{r}5.8 \\
5.6 \\
5.8 \\
7.8\end{array}$ & $\begin{array}{l}17 \\
19 \\
18 \\
-16 \\
16\end{array}$ & $\begin{array}{l}16 \\
16 \\
17 \\
-15\end{array}$ \\
\hline $\begin{array}{l}21 \\
22 \\
23 \\
24 \\
25\end{array}$ & $\begin{array}{l}800 \\
810 \\
820 \\
810 \\
820\end{array}$ & $\begin{array}{l}770 \\
790 \\
780 \\
790 \\
\mathbf{7 8 0}\end{array}$ & $\begin{array}{r}-- \\
\overline{8.2} \\
8.2 \\
8.2\end{array}$ & $\begin{array}{l}-- \\
8.1 \\
8.1 \\
8.0\end{array}$ & $\begin{array}{l}2.8 \\
3.6 \\
4.7 \\
5.3 \\
4.5\end{array}$ & $\begin{array}{l}1.7 \\
2.8 \\
3.7 \\
4.1 \\
3.3\end{array}$ & $\begin{array}{l}21 \\
21 \\
22 \\
23 \\
22\end{array}$ & $\begin{array}{l}20 \\
19 \\
21 \\
22 \\
19\end{array}$ & $\begin{array}{l}760 \\
740 \\
750 \\
750 \\
780\end{array}$ & $\begin{array}{l}700 \\
700 \\
710 \\
700 \\
\mathbf{7 2 0}\end{array}$ & $\begin{array}{l}8.1 \\
8.0 \\
8.0 \\
8.0 \\
7.9\end{array}$ & $\begin{array}{l}8.0 \\
7.8 \\
7.7 \\
7.6 \\
7.8\end{array}$ & $\begin{array}{l}7.9 \\
7.4 \\
7.4 \\
7.0 \\
7.0\end{array}$ & $\begin{array}{l}7.3 \\
6.7 \\
6.4 \\
6.7 \\
6.0\end{array}$ & $\begin{array}{l}15 \\
13 \\
12 \\
12 \\
10\end{array}$ & $\begin{array}{l}10 \\
10 \\
11 \\
10 \\
10\end{array}$ \\
\hline $\begin{array}{l}26 \\
27 \\
28 \\
29 \\
30 \\
31\end{array}$ & $\begin{array}{l}780 \\
790 \\
800 \\
800 \\
800 \\
780\end{array}$ & $\begin{array}{l}760 \\
750 \\
730 \\
760 \\
760 \\
700\end{array}$ & $\begin{array}{l}8.1 \\
8.1 \\
8.1 \\
8.1 \\
8.1 \\
8.2\end{array}$ & $\begin{array}{r}8.0 \\
7.9 \\
8.0 \\
8.0 \\
7.9 \\
8.0\end{array}$ & $\begin{array}{l}4.2 \\
4.3 \\
5.2 \\
4.2 \\
4.3 \\
4.2\end{array}$ & $\begin{array}{l}3.6 \\
3.3 \\
3.7 \\
3.4 \\
3.4 \\
3.5\end{array}$ & $\begin{array}{l}22 \\
22 \\
21 \\
20 \\
23 \\
22\end{array}$ & $\begin{array}{l}20 \\
20 \\
19 \\
19 \\
19 \\
21\end{array}$ & $\begin{array}{r}780 \\
770 \\
780 \\
770 \\
800 \\
-\end{array}$ & $\begin{array}{r}740 \\
740 \\
760 \\
770 \\
\mathbf{6 5 0} \\
--\end{array}$ & $\begin{array}{l}7.9 \\
8.1 \\
6.1 \\
6.1 \\
8.2 \\
-\end{array}$ & $\begin{array}{r}7.7 \\
7.9 \\
7.9 \\
7.9 \\
7.7 \\
--\end{array}$ & $\begin{array}{r}6.9 \\
7.4 \\
7.3 \\
7.3 \\
7.0 \\
-\end{array}$ & $\begin{array}{r}6.2 \\
6.5 \\
6.7 \\
6.5 \\
6.6 \\
--\end{array}$ & $\begin{array}{r}10 \\
12 \\
10 \\
10 \\
9 \\
--\end{array}$ & $\begin{array}{r}10 \\
10 \\
9 \\
9 \\
8 \\
--\end{array}$ \\
\hline
\end{tabular}


GREAT UIAMI RIVER BASIN

03271600 GREAT MIAMI RIVER NEAR MIAMISBURG, OH10--Continued

SPECIFIC CONDUCTANCE, PH, DISSOLVED OXYGEN, AND WATER TEMPERATURES, TATER YEAR OCTOBER 1967 TO SEPTEMIBER 1968 DECEMBER

JANUARY

\begin{tabular}{|c|c|c|}
\hline \multirow[t]{2}{*}{ DAY } & \multicolumn{2}{|c|}{$\begin{array}{r}\text { SPECIFIC } \\
\text { CONDUCTANC } \\
\text { (MICROMHOS } \\
\left.\text { AT } 25^{\circ} \mathrm{C}\right)\end{array}$} \\
\hline & $\operatorname{MAX}$ & 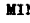 \\
\hline $\begin{array}{l}1 \\
2 \\
3 \\
4 \\
5\end{array}$ & $\begin{array}{l}810 \\
980 \\
780 \\
590 \\
520\end{array}$ & $\begin{array}{l}78 \\
78 \\
59 \\
46 \\
48\end{array}$ \\
\hline $\begin{array}{r}6 \\
7 \\
8 \\
9 \\
10\end{array}$ & $\begin{array}{l}580 \\
570 \\
590 \\
600 \\
640\end{array}$ & $\begin{array}{l}52 \\
52 \\
54 \\
54 \\
52\end{array}$ \\
\hline $\begin{array}{l}11 \\
12 \\
13 \\
14 \\
15\end{array}$ & $\begin{array}{l}620 \\
500 \\
540 \\
570 \\
610\end{array}$ & 5 \\
\hline $\begin{array}{l}16 \\
17 \\
18 \\
19 \\
20\end{array}$ & $\begin{array}{l}650 \\
640 \\
660 \\
680 \\
670\end{array}$ & $\begin{array}{l}6 \\
6\end{array}$ \\
\hline $\begin{array}{l}21 \\
22 \\
23 \\
24 \\
25\end{array}$ & $\begin{array}{l}680 \\
640 \\
470 \\
550 \\
600\end{array}$ & \\
\hline $\begin{array}{l}26 \\
27 \\
28 \\
29 \\
30 \\
31\end{array}$ & $\begin{array}{l}610 \\
650 \\
680 \\
\mathbf{7 7 0} \\
\mathbf{7 4 0} \\
\mathbf{7 6 0}\end{array}$ & \\
\hline
\end{tabular}

pH $\begin{array}{cc}\text { DISSOLVED } \\ \text { OXYGEN } \\ (\mathbf{M G} / \mathrm{L})\end{array}$

TEMPER-
ATURE
$\left({ }^{\circ} \mathrm{C}\right)$

\begin{tabular}{|c|c|}
\hline \multicolumn{2}{|c|}{$\begin{array}{l}\text { SPECIFIC } \\
\text { CONDUCTANCE } \\
\text { (MICRONBOS } \\
\text { AT } 25^{\circ} \mathrm{C} \text { ) }\end{array}$} \\
\hline MAX & MIN \\
\hline $\begin{array}{l}750 \\
750 \\
770 \\
780 \\
780\end{array}$ & $\begin{array}{l}710 \\
720 \\
740 \\
750 \\
750\end{array}$ \\
\hline $\begin{array}{l}800 \\
800 \\
800 \\
810 \\
820\end{array}$ & $\begin{array}{l}\mathbf{7 6 0} \\
\mathbf{7 6 0} \\
\mathbf{7 7 0} \\
\mathbf{7 8 0} \\
\mathbf{7 8 0}\end{array}$ \\
\hline $\begin{array}{l}830 \\
810 \\
810 \\
920 \\
900\end{array}$ & $\begin{array}{l}780 \\
780 \\
690 \\
680 \\
730\end{array}$ \\
\hline $\begin{array}{l}880 \\
880 \\
830 \\
880 \\
880\end{array}$ & $\begin{array}{l}\mathbf{8 3 0} \\
790 \\
780 \\
800 \\
\mathbf{8 4 0}\end{array}$ \\
\hline $\begin{array}{l}860 \\
830 \\
790 \\
720 \\
660\end{array}$ & $\begin{array}{l}810 \\
780 \\
720 \\
640 \\
590\end{array}$ \\
\hline $\begin{array}{l}640 \\
680 \\
690 \\
700 \\
640 \\
480\end{array}$ & $\begin{array}{l}620 \\
640 \\
660 \\
640 \\
440 \\
410\end{array}$ \\
\hline
\end{tabular}

pH $\begin{gathered}\text { DISSOLVED } \\ \text { OXYGEN } \\ (\text { MG } / L)\end{gathered}$

TEMPER-

MAX MIN

8.0 $7.9 \quad 7.2 \quad 6.5$

$\begin{array}{lr}11 & 8 \\ -- & 11 \\ -- & 6\end{array}$

$8.17 .9 \quad 9.0 \quad 7.9$

$\begin{array}{rrrr}\text { B.2 } & 8.0 & 9.8 & 9.0 \\ 8.3 & 8.0 & 10.1 & 9.7\end{array}$

$\begin{array}{llll}8.1 & 8.0 & 9.9 & 9.7\end{array}$

$\begin{array}{lrrr}8.1 & 8.0 & 9.8 & 9.4 \\ 8.0 & 7.9 & 10.0 & 9.4\end{array}$

$\begin{array}{llll}\mathbf{8 . 0} & 7.8 & 9.8 & 9.5 \\ \mathbf{8 . 0} & \mathbf{7 . 9} & 9.9 & 9.4\end{array}$

$--$

10 10

$\begin{array}{llll}8.1 & 7.9 & 9.9 & 8.2 \\ 8.1 & 7.8 & 9.9 & 8.8\end{array}$

$\begin{array}{llll}8.1 & 7.8 & 9.9 & 8.8 \\ 8.2 & 8.0 & 9.8 & 9.5\end{array}$

$\begin{array}{rrrr}\mathbf{8 . 2} & \mathbf{8 . 0} & 9.8 & 9.5 \\ \mathbf{8 . 2} & \mathbf{8 . 0} & 9.9 & 9.5 \\ \mathbf{8 . 2} & \mathbf{8 . 0} & 10.1 & 9.6\end{array}$

1210

$11 \quad 10$

$\begin{array}{rr}10 & 10 \\ 11 & 9 \\ 10 & 8\end{array}$

$\begin{array}{llll}8.3 & 8.0 & 10.3 & 9.8\end{array}$

$\begin{array}{llll}8.3 & 8.0 & 10.3 & 9.8 \\ 8.4 & 8.1 & 10.3 & 9.9\end{array}$

$\begin{array}{rrrr}8.4 & 8.0 & 10.0 & 9.1 \\ 8.3 & 8.1 & 9.8 & 9.2 \\ 8.3 & 8.1 & 9.7 & 9.4\end{array}$

$\begin{array}{ll}9 & 7 \\ 9 & 7\end{array}$

$\begin{array}{rr}9 & 7 \\ 10 & 9 \\ 10 & 9 \\ 10 & 8\end{array}$

$\begin{array}{llll}\mathbf{8 . 1} & \mathbf{8 . 0} & 9.4 & \mathbf{8 . 8} \\ \mathbf{8 . 1} & \mathbf{7 . 9} & 9.6 & \mathbf{8 . 8}\end{array}$

$\begin{array}{rrrr}8.1 & 7.9 & 9.6 & 8.8 \\ 8.1 & 8.0 & 10.4 & 9.5 \\ 8.2 & 7.9 & 10.8 & 10.2\end{array}$

1210

$\begin{array}{llll}8.2 & 7.9 & 10.8 & 10.2 \\ 8.2 & 8.0 & 10.5 & 10.2\end{array}$

$\begin{array}{rr}10 & 6 \\ 7 & 5\end{array}$

$\begin{array}{llll}8.2 & 8.1 & 11.5 & 10.4\end{array}$

$\begin{array}{llll}8.3 & 8.0 & 11.0 & 10.7 \\ 8.3 & 8.0 & 11.0 & 10.7\end{array}$

$\begin{array}{llll}8.3 & 8.0 & 11.0 & 10.7 \\ 8.2 & 8.1 & 10.8 & 10.7\end{array}$

$\begin{array}{llll}8.2 & 8.1 & 10.8 & 10.7 \\ \mathbf{8 . 4} & 8.2 & 10.8 & 10.4 \\ \mathbf{8 . 4} & 7.9 & 10.7 & 10.2\end{array}$

$\begin{array}{rr}7 & 5 \\ 8 & 4 \\ 8 & 6 \\ 7 & 6 \\ 10 & 5 \\ 15 & 5\end{array}$

FEBRUARY

410

$\begin{array}{llllll}8.4 & 7.9 & 10.9 & 10.2 & 11 & 5\end{array}$

$\begin{array}{llllll}8.6 & 8.1 & 10.5 & 10.1 & 9 & 4\end{array}$

$\begin{array}{rrrrrr}8.3 & 8.1 & 10.2 & 9.0 & 12 & 5 \\ 8.3 & 8.1 & 10.4 & 10.0 & 10 & 5\end{array}$

$\begin{array}{rrrrrr}8.3 & 8.1 & 10.4 & 10.0 & 10 & 5\end{array}$

$\begin{array}{llllll}8.3 & 8.0 & 10.1 & 9.5 & 12 & 6\end{array}$

$\begin{array}{llllll}8.3 & \mathbf{7 . 9} & 9.9 & 9.5 & 11 & 5 \\ \mathbf{8 . 3} & \mathbf{8 . 1} & 9.7 & 9.4 & 11 & 7 \\ \mathbf{8 . 4} & \mathbf{7 . 9} & 9.5 & \mathbf{8 . 4} & 11 & 6 \\ \mathbf{8 . 4} & \mathbf{7 . 9} & 9.6 & \mathbf{9 . 3} & 10 & \mathbf{5}\end{array}$

$\begin{array}{llllll}8.3 & 7.9 & 9.4 & 8.9 & 12 & 5 \\ 8.2 & 8.0 & 9.8 & 9.0 & 10 & 5\end{array}$

$\begin{array}{llllll}8.2 & 8.0 & 9.8 & 9.0 & 10 & 5 \\ 8.3 & 7.9 & 9.0 & 8.1 & 12 & 6 \\ 8.3 & 7.9 & 9.2 & 8.1 & 12 & 7\end{array}$

$\begin{array}{rrrrrr}8.3 & 7.9 & 9.2 & 8.1 & 12 & 7 \\ 8.3 & 8.0 & 11.3 & 8.2 & 11 & 6\end{array}$

$\begin{array}{rrrrrr}8.2 & 8.0 & 11.2 & 10.1 & 11 & 7 \\ 8.3 & 7.9 & 10.2 & 9.1 & 12 & 6\end{array}$

$\begin{array}{rrrrrr}8.3 & 7.9 & 10.2 & 9.1 & 12 & 6 \\ 8.1 & 7.9 & -- & -- & 13 & 9 \\ 8.1 & 7.9 & - & - & 11 & 9\end{array}$

$8.2 \quad 8.1 \quad-2 \quad--\quad 11 \quad 8$

$\begin{array}{rrrrrr}\mathbf{8 . 2} & \mathbf{8 . 0} & - & -- & 12 & \mathbf{8} \\ \mathbf{8 . 1} & \mathbf{8 . 0} & \mathbf{9 . 4} & \mathbf{8 . 2} & 11 & 8 \\ 8.3 & \mathbf{7 . 9} & 9.6 & \mathbf{8 . 8} & 11 & \mathbf{8} \\ \mathbf{8 . 2} & \mathbf{8 . 0} & 10.0 & \mathbf{9 . 5} & 10 & 6\end{array}$

$\begin{array}{llllll}8.2 & 8.0 & 10.0 & 9.5 & 10 & 6 \\ 8.3 & 7.9 & 10.6 & 9.5 & 12 & 6\end{array}$

$\begin{array}{llllll}\mathbf{8 . 3} & \mathbf{7 . 7} & 10.7 & \mathbf{8 . 9} & 12 & \mathbf{7} \\ \mathbf{8 . 2} & \mathbf{8 . 0} & 10.5 & \mathbf{8 . 9} & 12 & \mathbf{7}\end{array}$

$\begin{array}{rrrrrr}8.2 & 8.0 & 10.5 & 8.9 & 12 & 7 \\ 8.1 & 7.8 & 9.5 & 8.8 & 13 & 8 \\ 8.1 & 7.9 & 10.1 & 8.3 & 12 & 10 \\ 8.1 & 8.0 & 10.5 & 8.7 & 7 & 6\end{array}$

MARCH

\begin{tabular}{|c|c|c|c|c|c|c|c|c|c|c|c|c|c|c|c|c|}
\hline \multirow[t]{2}{*}{ DAY } & \multicolumn{2}{|c|}{$\begin{array}{c}\text { SPECIFIC } \\
\text { CONDUCTANCE } \\
\text { (HICROMHOS } \\
\left.\text { AT } 25^{\circ} \mathrm{C}\right)\end{array}$} & \multicolumn{2}{|c|}{$\mathrm{pH}$} & \multicolumn{2}{|c|}{$\begin{array}{l}\text { DISSOLVED } \\
\text { OXYGEN } \\
(\text { MG } / L)\end{array}$} & \multicolumn{2}{|c|}{$\begin{array}{l}\text { TEMPER- } \\
\text { ATURE } \\
\left({ }^{\circ} \mathrm{C}\right)\end{array}$} & \multicolumn{2}{|c|}{$\begin{array}{l}\text { SPECIFIC } \\
\text { CONDUCTANCE } \\
\text { (MICROMHOS } \\
\text { AT } 25^{\circ} \mathrm{C} \text { ) }\end{array}$} & \multicolumn{2}{|c|}{$\mathrm{pH}$} & \multicolumn{2}{|c|}{$\begin{array}{l}\text { DISSOLVED } \\
\text { OXYG EN } \\
\text { (MG /L) }\end{array}$} & \multicolumn{2}{|c|}{$\begin{array}{l}\text { TEAPRR- } \\
\text { ATURE } \\
\left({ }^{\circ} \mathrm{C}\right)\end{array}$} \\
\hline & $\max$ & MIN & $\operatorname{MAX}$ & MIN & MAX & MIN & MAX & MIN & MAX & MIN & $\operatorname{LAX}$ & MIN & MAX & MIN & $\operatorname{MAX}$ & MIN \\
\hline $\begin{array}{l}1 \\
2 \\
3 \\
4 \\
5\end{array}$ & $\begin{array}{l}500 \\
520 \\
540 \\
570 \\
600\end{array}$ & $\begin{array}{l}\mathbf{4 4 0} \\
490 \\
500 \\
530 \\
540\end{array}$ & $\begin{array}{l}8.1 \\
8.1 \\
8.1 \\
8.2 \\
8.2\end{array}$ & $\begin{array}{l}8.0 \\
7.9 \\
7.9 \\
7.9 \\
\mathbf{8 . 0}\end{array}$ & $\begin{array}{l}10.7 \\
10.3 \\
10.9 \\
11.4 \\
11.5\end{array}$ & $\begin{array}{l}10.2 \\
10.0 \\
10.1 \\
10.3 \\
11.0\end{array}$ & $\begin{array}{l}9 \\
9 \\
9 \\
9 \\
\mathbf{B}\end{array}$ & $\begin{array}{l}6 \\
7 \\
7 \\
7 \\
6\end{array}$ & $\begin{array}{l}\mathbf{7 5 0} \\
\mathbf{7 7 0} \\
\mathbf{7 7 0} \\
\mathbf{7 4 0} \\
\mathbf{7 6 0}\end{array}$ & $\begin{array}{l}730 \\
740 \\
740 \\
710 \\
730\end{array}$ & $\begin{array}{l}8.3 \\
8.2 \\
8.2 \\
8.2 \\
8.2\end{array}$ & $\begin{array}{l}8.0 \\
8.0 \\
7.8 \\
7.8 \\
7.9\end{array}$ & $\begin{array}{r}10.1 \\
9.8 \\
10.6 \\
10.3 \\
9.8\end{array}$ & $\begin{array}{l}9.3 \\
9.3 \\
9.6 \\
9.3 \\
8.8\end{array}$ & $\begin{array}{r}9 \\
11 \\
9 \\
9 \\
11\end{array}$ & $\begin{array}{l}7 \\
7 \\
6 \\
6 \\
7\end{array}$ \\
\hline $\begin{array}{r}6 \\
7 \\
8 \\
9 \\
10\end{array}$ & $\begin{array}{l}630 \\
650 \\
660 \\
660 \\
690\end{array}$ & $\begin{array}{l}580 \\
600 \\
620 \\
630 \\
640\end{array}$ & $\begin{array}{l}8.2 \\
8.2 \\
8.1 \\
8.3 \\
8.2\end{array}$ & $\begin{array}{l}7.9 \\
7.9 \\
8.0 \\
8.0 \\
7.8\end{array}$ & $\begin{array}{l}11.2 \\
10.6 \\
10.7 \\
10.7 \\
10.4\end{array}$ & $\begin{array}{r}10.6 \\
10.2 \\
10.4 \\
9.5 \\
9.7\end{array}$ & $\begin{array}{r}8 \\
9 \\
8 \\
12 \\
11\end{array}$ & $\begin{array}{l}6 \\
7 \\
7 \\
6 \\
6\end{array}$ & $\begin{array}{l}\mathbf{7 7 0} \\
\mathbf{7 6 0} \\
\mathbf{7 6 0} \\
\mathbf{7 6 0} \\
\mathbf{7 7 0}\end{array}$ & $\begin{array}{l}\mathbf{7 4 0} \\
\mathbf{7 4 0} \\
\mathbf{7 4 0} \\
\mathbf{7 4 0} \\
\mathbf{7 6 0}\end{array}$ & $\begin{array}{l}8.2 \\
8.2 \\
8.2 \\
8.2 \\
8.2\end{array}$ & $\begin{array}{l}8.0 \\
7.9 \\
8.0 \\
8.0 \\
8.0\end{array}$ & $\begin{array}{l}9.8 \\
9.7 \\
9.4 \\
8.6 \\
8.4\end{array}$ & $\begin{array}{l}7.5 \\
7.0 \\
7.2 \\
6.7 \\
5.5\end{array}$ & $\begin{array}{l}11 \\
12 \\
13 \\
15 \\
15\end{array}$ & $\begin{array}{l}10 \\
10 \\
10 \\
12 \\
13\end{array}$ \\
\hline $\begin{array}{l}11 \\
12 \\
13 \\
14 \\
15\end{array}$ & $\begin{array}{l}710 \\
740 \\
740 \\
730 \\
730\end{array}$ & $\begin{array}{l}660 \\
680 \\
690 \\
700 \\
700\end{array}$ & $\begin{array}{l}8.2 \\
8.1 \\
8.0 \\
8.1 \\
8.2\end{array}$ & $\begin{array}{l}7.8 \\
7.8 \\
7.8 \\
7.8 \\
7.9\end{array}$ & $\begin{array}{l}10.6 \\
10.7 \\
10.6 \\
10.8 \\
10.4\end{array}$ & $\begin{array}{r}9.9 \\
10.3 \\
10.0 \\
10.0 \\
9.5\end{array}$ & $\begin{array}{l}11 \\
15 \\
15 \\
15 \\
11\end{array}$ & $\begin{array}{l}6 \\
6 \\
5 \\
5 \\
6\end{array}$ & $\begin{array}{l}\mathbf{7 7 0} \\
\mathbf{7 5 0} \\
\mathbf{7 8 0} \\
830 \\
830\end{array}$ & $\begin{array}{l}\mathbf{7 4 0} \\
630 \\
690 \\
\mathbf{7 7 0} \\
\mathbf{7 5 0}\end{array}$ & $\begin{array}{l}8.2 \\
8.2 \\
8.3 \\
8.4 \\
8.3\end{array}$ & $\begin{array}{l}7.9 \\
7.9 \\
8.0 \\
7.8 \\
8.0\end{array}$ & $\begin{array}{r}10.2 \\
9.6 \\
9.8 \\
10.2 \\
9.7\end{array}$ & $\begin{array}{l}6.6 \\
6.8 \\
7.2 \\
\text { 8.6 } \\
7.8\end{array}$ & $\begin{array}{l}14 \\
12 \\
11 \\
12 \\
13\end{array}$ & $\begin{array}{r}12 \\
9 \\
8 \\
8 \\
10\end{array}$ \\
\hline $\begin{array}{l}16 \\
17 \\
18 \\
19 \\
20\end{array}$ & $\begin{array}{l}740 \\
760 \\
760 \\
750 \\
750\end{array}$ & $\begin{array}{l}710 \\
720 \\
720 \\
720 \\
720\end{array}$ & $\begin{array}{l}8.3 \\
8.3 \\
8.3 \\
8.2 \\
8.3\end{array}$ & $\begin{array}{l}8.0 \\
8.0 \\
7.9 \\
7.9 \\
8.0\end{array}$ & $\begin{array}{r}10.4 \\
10.1 \\
10.2 \\
10.4 \\
9.2\end{array}$ & $\begin{array}{l}9.4 \\
9.2 \\
9.6 \\
8.9 \\
8.6\end{array}$ & $\begin{array}{l}12 \\
11 \\
15 \\
12 \\
10\end{array}$ & $\begin{array}{l}6 \\
6 \\
6 \\
6 \\
6\end{array}$ & $\begin{array}{l}780 \\
800 \\
770 \\
710 \\
730\end{array}$ & $\begin{array}{l}750 \\
760 \\
690 \\
670 \\
640\end{array}$ & $\begin{array}{l}8.2 \\
8.2 \\
8.2 \\
8.3 \\
8.3\end{array}$ & $\begin{array}{l}7.9 \\
7.8 \\
7.8 \\
7.8 \\
7.8\end{array}$ & $\begin{array}{l}8.5 \\
9.4 \\
9.9 \\
9.7 \\
8.5\end{array}$ & $\begin{array}{l}7.1 \\
7.1 \\
8.0 \\
8.3 \\
7.5\end{array}$ & $\begin{array}{l}14 \\
15 \\
14 \\
14 \\
15\end{array}$ & $\begin{array}{l}12 \\
12 \\
12 \\
12 \\
13\end{array}$ \\
\hline $\begin{array}{l}21 \\
22 \\
23 \\
24 \\
25\end{array}$ & $\begin{array}{l}780 \\
780 \\
780 \\
780 \\
780\end{array}$ & $\begin{array}{l}730 \\
750 \\
740 \\
750 \\
750\end{array}$ & $\begin{array}{l}8.2 \\
8.3 \\
8.2 \\
8.2 \\
8.2\end{array}$ & $\begin{array}{l}8.0 \\
7.9 \\
8.0 \\
7.9 \\
7.9\end{array}$ & $\begin{array}{r}9.7 \\
9.9 \\
9.8 \\
9.8 \\
10.2\end{array}$ & $\begin{array}{l}9.1 \\
9.3 \\
9.3 \\
9.2 \\
9.4\end{array}$ & $\begin{array}{r}9 \\
10 \\
10 \\
12 \\
11\end{array}$ & $\begin{array}{l}\mathbf{5} \\
\mathbf{5} \\
5 \\
6 \\
6\end{array}$ & $\begin{array}{l}680 \\
660 \\
740 \\
780 \\
760\end{array}$ & $\begin{array}{l}550 \\
440 \\
370 \\
600 \\
650\end{array}$ & $\begin{array}{l}8.2 \\
8.2 \\
8.6 \\
8.6 \\
8.5\end{array}$ & $\begin{array}{l}7.9 \\
7.8 \\
8.0 \\
7.9 \\
8.0\end{array}$ & $\begin{array}{r}8.4 \\
10.1 \\
11.3 \\
10.2 \\
9.8\end{array}$ & $\begin{array}{r}7.3 \\
7.9 \\
10.1 \\
9.4 \\
8.5\end{array}$ & $\begin{array}{l}15 \\
15 \\
10 \\
11 \\
11\end{array}$ & $\begin{array}{r}12 \\
9 \\
6 \\
8 \\
7\end{array}$ \\
\hline $\begin{array}{l}26 \\
27 \\
28 \\
29 \\
30 \\
31\end{array}$ & $\begin{array}{r}760 \\
780 \\
770 \\
770 \\
-- \\
--\end{array}$ & $\begin{array}{r}750 \\
750 \\
750 \\
740 \\
-- \\
--\end{array}$ & $\begin{array}{r}8.2 \\
8.2 \\
8.3 \\
8.2 \\
-- \\
--\end{array}$ & $\begin{array}{r}7.9 \\
8.0 \\
7.9 \\
7.9 \\
= \\
-\end{array}$ & $\begin{array}{r}10.2 \\
10.1 \\
10.0 \\
9.6 \\
- \\
.-\end{array}$ & $\begin{array}{r}9.8 \\
9.1 \\
9.1 \\
8.8 \\
-- \\
-\end{array}$ & $\begin{array}{r}10 \\
10 \\
10 \\
9 \\
-- \\
--\end{array}$ & $\begin{array}{r}6 \\
7 \\
7 \\
7 \\
-- \\
--\end{array}$ & $\begin{array}{l}670 \\
610 \\
590 \\
610 \\
640 \\
660\end{array}$ & $\begin{array}{l}600 \\
520 \\
520 \\
570 \\
600 \\
620\end{array}$ & $\begin{array}{l}8.5 \\
8.3 \\
8.4 \\
8.2 \\
8.2 \\
8.2\end{array}$ & $\begin{array}{l}8.0 \\
8.1 \\
8.0 \\
8.0 \\
8.1 \\
8.0\end{array}$ & $\begin{array}{l}9.7 \\
9.8 \\
9.8 \\
7.5 \\
6.9 \\
6.4\end{array}$ & $\begin{array}{l}8.8 \\
8.3 \\
7.5 \\
6.5 \\
6.1 \\
5.8\end{array}$ & $\begin{array}{l}11 \\
13 \\
14 \\
16 \\
16 \\
16\end{array}$ & $\begin{array}{r}9 \\
9 \\
10 \\
13 \\
14 \\
15\end{array}$ \\
\hline
\end{tabular}


03271600 GREAT MIAMI RIVER NEAR MIAMISBURG, OHIO--CONtInUEd

SPECIFIC CONDUCTANCE, PH, DISSOLVED OXYGEN, AND WATER TEMPERATURES, WATER YEAR OCTOBER 1967 TO SEPTEMBER 1968 APRI 2

MAY

\begin{tabular}{|c|c|c|c|c|c|c|c|c|c|c|c|c|c|c|c|c|}
\hline \multirow[t]{2}{*}{ DAY } & \multicolumn{2}{|c|}{$\begin{array}{l}\text { SPECIFIC } \\
\text { CONDUCTANCE } \\
\text { (MICROMHOS } \\
\text { AT } 25^{\circ} \mathrm{C} \text { ) }\end{array}$} & \multicolumn{2}{|c|}{$\mathrm{pH}$} & \multicolumn{2}{|c|}{$\begin{array}{l}\text { DISSOLVED } \\
\text { OXYGEN } \\
(\mathbb{M G} / \mathbf{L})\end{array}$} & \multicolumn{2}{|c|}{$\begin{array}{l}\text { TEIPERR- } \\
\text { ATURE } \\
\left({ }^{\circ} \mathrm{C}\right)\end{array}$} & \multicolumn{2}{|c|}{$\begin{array}{l}\text { SPECIF IC } \\
\text { CONDUCTANCE } \\
\text { (YICROMHOS } \\
\text { AT 25. } \\
\text { ( ) }\end{array}$} & \multicolumn{2}{|l|}{ pH } & \multicolumn{2}{|c|}{$\begin{array}{l}\text { DISSOLVED } \\
\text { OXYGEN } \\
(\mathbf{M G} / L)\end{array}$} & \multicolumn{2}{|c|}{$\begin{array}{l}\text { TEMPER- } \\
\text { ATURE } \\
\left({ }^{\circ} \mathrm{C}\right)\end{array}$} \\
\hline & $\operatorname{MAx}$ & MIN & $\max$ & MIN & $\max$ & MIN & MAX & MIN & MAX & MIN & עAX & MIN & $\max$ & WIN & $\operatorname{Max}$ & MIN \\
\hline $\begin{array}{l}1 \\
2 \\
3 \\
4 \\
5\end{array}$ & $\begin{array}{l}680 \\
630 \\
650 \\
660 \\
660\end{array}$ & $\begin{array}{l}630 \\
610 \\
620 \\
620 \\
540\end{array}$ & $\begin{array}{l}8.4 \\
8.4 \\
8.4 \\
8.2 \\
8.2\end{array}$ & $\begin{array}{l}7.9 \\
8.2 \\
8.1 \\
8.1 \\
8.1\end{array}$ & $\begin{array}{l}6.1 \\
-.- \\
8.8 \\
8.4 \\
8.7\end{array}$ & $\begin{array}{l}5.6 \\
-.4 \\
8.4 \\
8.1 \\
8.4\end{array}$ & $\begin{array}{l}15 \\
14 \\
14 \\
15 \\
14\end{array}$ & $\begin{array}{l}13 \\
12 \\
13 \\
14 \\
11\end{array}$ & $\begin{array}{l}790 \\
800 \\
790 \\
790 \\
780\end{array}$ & $\begin{array}{l}720 \\
760 \\
740 \\
750 \\
760\end{array}$ & $\begin{array}{l}8.4 \\
8.4 \\
8.4 \\
8.4 \\
8.5\end{array}$ & $\begin{array}{l}8.0 \\
8.0 \\
8.0 \\
8.1 \\
8.1\end{array}$ & $\begin{array}{l}8.1 \\
7.9 \\
7.3 \\
7.5 \\
8.0\end{array}$ & $\begin{array}{l}4.9 \\
4.4 \\
4.2 \\
4.3 \\
4.6\end{array}$ & $\begin{array}{l}22 \\
23 \\
23 \\
22 \\
21\end{array}$ & $\begin{array}{l}19 \\
19 \\
21 \\
20 \\
18\end{array}$ \\
\hline $\begin{array}{r}6 \\
7 \\
8 \\
9 \\
10\end{array}$ & $\begin{array}{l}590 \\
640 \\
670 \\
690 \\
710\end{array}$ & $\begin{array}{l}540 \\
590 \\
620 \\
650 \\
670\end{array}$ & $\begin{array}{l}8.4 \\
8.4 \\
8.3 \\
8.3 \\
8.2\end{array}$ & $\begin{array}{l}8.2 \\
8.2 \\
8.1 \\
8.1 \\
8.0\end{array}$ & $\begin{array}{l}9.0 \\
9.1 \\
8.7 \\
8.8 \\
8.4\end{array}$ & $\begin{array}{l}8.7 \\
8.7 \\
8.2 \\
8.3 \\
7.8\end{array}$ & $\begin{array}{l}12 \\
13 \\
15 \\
16 \\
16\end{array}$ & $\begin{array}{l}10 \\
11 \\
13 \\
14 \\
15\end{array}$ & $\begin{array}{l}780 \\
780 \\
780 \\
780 \\
\mathbf{7 4 0}\end{array}$ & $\begin{array}{l}760 \\
770 \\
760 \\
720 \\
680\end{array}$ & $\begin{array}{l}8.5 \\
8.4 \\
8.3 \\
8.3 \\
7.9\end{array}$ & $\begin{array}{l}8.1 \\
8.1 \\
8.1 \\
7.9 \\
7.8\end{array}$ & $\begin{array}{l}9.4 \\
8.4 \\
6.6 \\
5.9 \\
5.3\end{array}$ & $\begin{array}{l}5.0 \\
4.9 \\
4.1 \\
3.9 \\
4.0\end{array}$ & $\begin{array}{l}20 \\
21 \\
22 \\
21 \\
21\end{array}$ & $\begin{array}{l}17 \\
18 \\
19 \\
20 \\
19\end{array}$ \\
\hline $\begin{array}{l}11 \\
12 \\
13 \\
14 \\
15\end{array}$ & $\begin{array}{r}710 \\
-- \\
- \\
--\end{array}$ & $\begin{array}{r}690 \\
-- \\
=- \\
--\end{array}$ & $\begin{array}{c}8.2 \\
-- \\
-- \\
--\end{array}$ & $\begin{array}{r}8.0 \\
-- \\
-- \\
--\end{array}$ & $\begin{array}{r}7.9 \\
-- \\
-- \\
--\end{array}$ & $\begin{array}{l}7.5 \\
-- \\
-- \\
--\end{array}$ & $\begin{array}{l}16 \\
-- \\
-- \\
--\end{array}$ & $\begin{array}{l}15 \\
-\square \\
=-\end{array}$ & $\begin{array}{l}720 \\
660 \\
700 \\
720 \\
730\end{array}$ & $\begin{array}{l}540 \\
580 \\
630 \\
690 \\
680\end{array}$ & $\begin{array}{l}8.1 \\
8.1 \\
8.1 \\
8.1 \\
8.2\end{array}$ & $\begin{array}{l}7.8 \\
7.9 \\
8.0 \\
8.0 \\
8.0\end{array}$ & $\begin{array}{l}6.4 \\
6.8 \\
7.2 \\
6.6 \\
6.2\end{array}$ & $\begin{array}{l}4.8 \\
6.4 \\
6.6 \\
6.0 \\
5.7\end{array}$ & $\begin{array}{l}21 \\
19 \\
19 \\
21 \\
23\end{array}$ & $\begin{array}{l}18 \\
17 \\
17 \\
19 \\
21\end{array}$ \\
\hline $\begin{array}{l}16 \\
17 \\
18 \\
19 \\
20\end{array}$ & $\begin{array}{l}=- \\
=- \\
=- \\
=-\end{array}$ & $\begin{array}{l}=- \\
=- \\
=-\end{array}$ & $\begin{array}{l}= \\
= \\
=\end{array}$ & $\begin{array}{l}= \\
= \\
=\end{array}$ & $\begin{array}{l}=- \\
=- \\
=-\end{array}$ & $\begin{array}{l}-- \\
=- \\
-\end{array}$ & $\begin{array}{l}=- \\
\therefore- \\
\therefore-\end{array}$ & $\begin{array}{l}\ddot{-} \\
\ddot{-} \\
--\end{array}$ & $\begin{array}{l}710 \\
\mathbf{7 1 0} \\
\mathbf{7 2 0} \\
\mathbf{7 4 0} \\
\mathbf{7 4 0}\end{array}$ & $\begin{array}{l}650 \\
660 \\
680 \\
700 \\
710\end{array}$ & $\begin{array}{l}8.1 \\
8.1 \\
8.2 \\
8.2 \\
8.2\end{array}$ & $\begin{array}{l}8.0 \\
8.0 \\
8.0 \\
8.1 \\
8.1\end{array}$ & $\begin{array}{l}6.7 \\
6.6 \\
6.9 \\
8.0 \\
8.0\end{array}$ & $\begin{array}{l}5.7 \\
6.2 \\
6.1 \\
5.9 \\
7.2\end{array}$ & $\begin{array}{l}22 \\
22 \\
21 \\
20 \\
19\end{array}$ & $\begin{array}{l}22 \\
20 \\
19 \\
18 \\
17\end{array}$ \\
\hline $\begin{array}{l}21 \\
22 \\
23 \\
24 \\
25\end{array}$ & $\begin{array}{l}=- \\
\overline{-} \\
\overline{750}\end{array}$ & $\begin{array}{l}\overline{-} \\
\overline{-} \\
7 \overline{30}\end{array}$ & $\begin{array}{l}= \\
= \\
8.5\end{array}$ & $\begin{array}{l}\overline{-} \\
\overline{-} \\
\overline{-} \\
8.1\end{array}$ & $\begin{array}{r}\overline{-} \\
\overline{-} \\
8 . \overline{2}\end{array}$ & $\begin{array}{c}-- \\
\overline{-} \\
\overline{-} \\
.3\end{array}$ & $\begin{array}{l}=- \\
\ddot{-2} \\
\overline{16}\end{array}$ & $\begin{array}{l}-- \\
\overline{--} \\
\overline{15}\end{array}$ & $\begin{array}{l}750 \\
770 \\
770 \\
470 \\
560\end{array}$ & $\begin{array}{l}720 \\
730 \\
400 \\
320 \\
460\end{array}$ & $\begin{array}{l}8.2 \\
8.3 \\
8.2 \\
8.0 \\
8.0\end{array}$ & $\begin{array}{l}8.1 \\
8.0 \\
8.0 \\
7.9 \\
8.0\end{array}$ & $\begin{array}{l}7.7 \\
7.7 \\
7.8 \\
8.1 \\
8.3\end{array}$ & $\begin{array}{l}6.7 \\
6.3 \\
6.3 \\
7.8 \\
8.1\end{array}$ & $\begin{array}{l}20 \\
21 \\
20 \\
18 \\
17\end{array}$ & $\begin{array}{l}18 \\
19 \\
16 \\
16 \\
15\end{array}$ \\
\hline $\begin{array}{l}26 \\
27 \\
28 \\
29 \\
30 \\
31\end{array}$ & $\begin{array}{r}\mathbf{7 6 0} \\
\mathbf{7 7 0} \\
\mathbf{7 8 0} \\
\mathbf{7 6 0} \\
\mathbf{7 8 0} \\
--\end{array}$ & $\begin{array}{r}640 \\
730 \\
740 \\
\mathbf{7 3 0} \\
\mathbf{7 5 0} \\
--\end{array}$ & $\begin{array}{c}8.4 \\
8.4 \\
8.5 \\
8.5 \\
8.5 \\
--\end{array}$ & $\begin{array}{r}8.1 \\
7.9 \\
8.0 \\
8.1 \\
8.1 \\
-\end{array}$ & $\begin{array}{r}7.6 \\
7.7 \\
9.2 \\
10.6 \\
8.3 \\
--\end{array}$ & $\begin{array}{r}6.0 \\
5.7 \\
5.7 \\
6.1 \\
5.2 \\
--\end{array}$ & $\begin{array}{l}17 \\
19 \\
20 \\
21 \\
21 \\
--\end{array}$ & $\begin{array}{l}15 \\
15 \\
16 \\
17 \\
19 \\
--\end{array}$ & $\begin{array}{l}570 \\
530 \\
500 \\
520 \\
620 \\
630\end{array}$ & $\begin{array}{l}500 \\
500 \\
480 \\
490 \\
520 \\
570\end{array}$ & $\begin{array}{l}8.1 \\
8.1 \\
8.0 \\
8.1 \\
8.1 \\
8.1\end{array}$ & $\begin{array}{l}7.9 \\
8.0 \\
7.9 \\
7.9 \\
8.0 \\
8.0\end{array}$ & $\begin{array}{l}8.3 \\
8.3 \\
8.3 \\
8.5 \\
8.4 \\
8.4\end{array}$ & $\begin{array}{l}7.9 \\
7.9 \\
8.1 \\
8.3 \\
7.9 \\
7.8\end{array}$ & $\begin{array}{l}17 \\
18 \\
17 \\
17 \\
18 \\
18\end{array}$ & $\begin{array}{l}16 \\
17 \\
15 \\
16 \\
16 \\
15\end{array}$ \\
\hline \multicolumn{9}{|c|}{ JUNE } & \multicolumn{8}{|c|}{ JULY } \\
\hline \multirow[t]{2}{*}{ DAY } & \multicolumn{2}{|c|}{$\begin{array}{l}\text { SPECIFIC } \\
\text { CONDUCTAMCB } \\
\text { (IICROMHOS } \\
\text { AT } 25^{\circ} \mathrm{C} \text { ) }\end{array}$} & \multicolumn{2}{|c|}{$\mathrm{pH}$} & \multicolumn{2}{|c|}{$\begin{array}{l}\text { DISSOLVED } \\
\text { OXYGEN } \\
(\mathbf{K G} / L)\end{array}$} & \multicolumn{2}{|c|}{$\begin{array}{l}\text { TEMPER- } \\
\text { ATURB } \\
\left({ }^{\circ} \mathrm{C}\right)\end{array}$} & \multicolumn{2}{|c|}{$\begin{array}{l}\text { SPECIFIC } \\
\text { CONDUCTANCE } \\
\text { (MICROMHOS } \\
\text { AT } 25^{\circ} \mathrm{C} \text { ) }\end{array}$} & \multicolumn{2}{|c|}{ pH } & \multicolumn{2}{|c|}{$\begin{array}{l}\text { DI SSOLVED } \\
\text { OXYGEN } \\
(\mathbf{M G} / \mathrm{L})\end{array}$} & \multicolumn{2}{|c|}{$\begin{array}{l}\text { TEMPER- } \\
\text { ATURE } \\
\left({ }^{\circ} \mathrm{C}\right)\end{array}$} \\
\hline & MAX & MIN & $\operatorname{MAX}$ & MIN & $\operatorname{MAX}$ & MIN & MAX & $X$ yIN & $\max$ & MIN & MAX & MIN & $\max$ & IIN & $\max$ & ( MIN \\
\hline $\begin{array}{l}\mathbf{1} \\
2 \\
3 \\
\mathbf{4} \\
\mathbf{5}\end{array}$ & $\begin{array}{l}660 \\
660 \\
680 \\
710 \\
710\end{array}$ & $\begin{array}{l}620 \\
620 \\
650 \\
670 \\
680\end{array}$ & $\begin{array}{l}8.1 \\
-.5 \\
8.3 \\
8.1 \\
8.1\end{array}$ & $\begin{array}{l}7.9 \\
8 . \overline{1} \\
8.0 \\
8.0\end{array}$ & $\begin{array}{l}8.0 \\
8.1 \\
8.1 \\
8.1 \\
8.6\end{array}$ & $\begin{array}{l}7.6 \\
7.7 \\
7.3 \\
7.2 \\
7.2\end{array}$ & $\begin{array}{l}19 \\
20 \\
22 \\
23 \\
24\end{array}$ & $\begin{array}{ll}9 & 17 \\
0 & 19 \\
2 & 19 \\
3 & 21 \\
4 & 22\end{array}$ & $\begin{array}{l}670 \\
\mathbf{7 0 0} \\
\mathbf{7 2 0} \\
\mathbf{7 5 0} \\
\mathbf{7 4 0}\end{array}$ & $\begin{array}{l}650 \\
670 \\
680 \\
710 \\
680\end{array}$ & $\begin{array}{l}-\overline{2} \\
8.3 \\
8.4 \\
8.6\end{array}$ & $\begin{array}{l}8.0 \\
7.9 \\
8.0 \\
8.2\end{array}$ & $\begin{array}{r}--.5 \\
7.0 \\
8.6 \\
11.2\end{array}$ & $\begin{array}{l}-\overline{-1} \\
4.7 \\
4.8 \\
5.7\end{array}$ & $\begin{array}{l}28 \\
28 \\
27 \\
27 \\
27\end{array}$ & $\begin{array}{l}26 \\
27 \\
25 \\
24 \\
24\end{array}$ \\
\hline $\begin{array}{r}6 \\
7 \\
8 \\
9 \\
10\end{array}$ & $\begin{array}{l}710 \\
720 \\
720 \\
710 \\
720\end{array}$ & $\begin{array}{l}690 \\
700 \\
580 \\
680 \\
640\end{array}$ & $\begin{array}{r}8.1 \\
8.1 \\
-2 \\
--\end{array}$ & $\begin{array}{r}8.0 \\
8.0 \\
-- \\
--\end{array}$ & $\begin{array}{r}10.0 \\
9.5 \\
10.8 \\
11.8 \\
12.7\end{array}$ & $\begin{array}{l}6.9 \\
6.5 \\
6.4 \\
6.5 \\
7.3\end{array}$ & $\begin{array}{l}25 \\
25 \\
26 \\
27 \\
28\end{array}$ & $\begin{array}{ll}5 & 23 \\
5 & 24 \\
6 & 25 \\
7 & 25 \\
8 & 26\end{array}$ & $\begin{array}{l}750 \\
760 \\
730 \\
750 \\
760\end{array}$ & $\begin{array}{l}700 \\
680 \\
670 \\
690 \\
720\end{array}$ & $\begin{array}{l}8.7 \\
-.7 \\
8.7 \\
8.5 \\
8.4\end{array}$ & $\begin{array}{l}8.2 \\
-\overline{.2} \\
8.2 \\
8.1\end{array}$ & $\begin{array}{r}15.0 \\
15.0 \\
15.0 \\
7.2 \\
5.9\end{array}$ & $\begin{array}{l}6.3 \\
6.5 \\
6.1 \\
5.2 \\
3.3\end{array}$ & $\begin{array}{l}28 \\
28 \\
28 \\
28 \\
30\end{array}$ & $\begin{array}{l}25 \\
25 \\
26 \\
26 \\
27\end{array}$ \\
\hline $\begin{array}{l}11 \\
12 \\
13 \\
14 \\
15\end{array}$ & $\begin{array}{l}680 \\
720 \\
730 \\
740 \\
\mathbf{7 4 0}\end{array}$ & $\begin{array}{l}600 \\
640 \\
690 \\
700 \\
690\end{array}$ & $\begin{array}{l}=- \\
=- \\
--\end{array}$ & $\begin{array}{l}= \\
= \\
-\end{array}$ & $\begin{array}{l}10.6 \\
10.6 \\
10.7 \\
11.2 \\
10.7\end{array}$ & $\begin{array}{l}5.1 \\
6.0 \\
5.7 \\
5.8 \\
6.0\end{array}$ & $\begin{array}{l}28 \\
28 \\
26 \\
25 \\
26\end{array}$ & $\begin{array}{ll}8 & 25 \\
8 & 26 \\
6 & 24 \\
5 & 23 \\
6 & 24\end{array}$ & $\begin{array}{r}770 \\
770 \\
770 \\
760 \\
--\end{array}$ & $\begin{array}{r}740 \\
740 \\
740 \\
\mathbf{7 5 0} \\
--\end{array}$ & $\begin{array}{r}8.3 \\
8.3 \\
8.2 \\
8.1 \\
--\end{array}$ & $\begin{array}{r}8.0 \\
8.0 \\
7.9 \\
7.8 \\
--\end{array}$ & $\begin{array}{r}6.9 \\
6.5 \\
6.1 \\
5.3 \\
-.\end{array}$ & $\begin{array}{r}1.4 \\
2.3 \\
1.9 \\
2.0 \\
--\end{array}$ & $\begin{array}{l}30 \\
31 \\
30 \\
30 \\
--\end{array}$ & $\begin{array}{l}28 \\
28 \\
28 \\
28 \\
\end{array}$ \\
\hline $\begin{array}{l}16 \\
17 \\
18 \\
19 \\
20\end{array}$ & $\begin{array}{l}\mathbf{7 2 0} \\
\mathbf{6 7 0} \\
\mathbf{7 1 0} \\
\mathbf{7 3 0} \\
\mathbf{7 4 0}\end{array}$ & $\begin{array}{l}530 \\
590 \\
670 \\
700 \\
710\end{array}$ & $\begin{array}{l}= \\
= \\
=\end{array}$ & $\begin{array}{l}= \\
z \\
z\end{array}$ & $\begin{array}{l}7.2 \\
7.3 \\
9.2 \\
9.0 \\
9.3\end{array}$ & $\begin{array}{l}5.9 \\
6.2 \\
6.0 \\
5.9 \\
5.7\end{array}$ & $\begin{array}{l}25 \\
24 \\
24 \\
25 \\
26\end{array}$ & $\begin{array}{l}23 \\
22 \\
23 \\
24 \\
24\end{array}$ & $\begin{array}{r}\overline{-} \\
\overline{--} \\
670 \\
680\end{array}$ & $\begin{array}{r}\overline{-} \\
\overline{-} \\
600 \\
600\end{array}$ & $\begin{array}{r}\overline{--} \\
\overline{-\overline{8}} \\
7.8 \\
7.8\end{array}$ & $\begin{array}{r}-- \\
-- \\
7.6 \\
7.5\end{array}$ & $\begin{array}{r}\overline{--} \\
\bar{z} \\
5.9\end{array}$ & $\begin{array}{r}-- \\
\overline{--} \\
2.3 \\
2.3\end{array}$ & $\begin{array}{l}=- \\
\overline{31} \\
31\end{array}$ & $\begin{array}{l}- \\
- \\
29 \\
28\end{array}$ \\
\hline $\begin{array}{l}21 \\
22 \\
223 \\
24 \\
25\end{array}$ & $\begin{array}{l}740 \\
740 \\
750 \\
740 \\
720\end{array}$ & $\begin{array}{l}710 \\
690 \\
690 \\
690 \\
680\end{array}$ & $\begin{array}{r}\overline{-} \\
8.6 \\
8.3\end{array}$ & $\begin{array}{r}-- \\
\overline{-} \\
8 . \overline{3} \\
8.0\end{array}$ & $\begin{array}{r}10.0 \\
9.1 \\
12.0 \\
10.2 \\
5.5\end{array}$ & $\begin{array}{l}5.5 \\
5.1 \\
4.9 \\
4.8 \\
3.9\end{array}$ & $\begin{array}{l}27 \\
27 \\
29 \\
29 \\
28\end{array}$ & $\begin{array}{ll}7 & \mathbf{2 4} \\
7 & 25 \\
& 25 \\
& 26 \\
3 & \mathbf{2 6}\end{array}$ & $\begin{array}{l}700 \\
670 \\
710 \\
730 \\
710\end{array}$ & $\begin{array}{l}620 \\
640 \\
620 \\
700 \\
570\end{array}$ & $\begin{array}{l}8.4 \\
8.6 \\
8.4 \\
8.2 \\
8.2\end{array}$ & $\begin{array}{l}7.7 \\
8.0 \\
7.8 \\
7.8 \\
7.8\end{array}$ & $\begin{array}{r}11.3 \\
12.9 \\
9.8 \\
7.2 \\
6.8\end{array}$ & $\begin{array}{l}2.0 \\
4.2 \\
2.1 \\
4.0 \\
4.4\end{array}$ & $\begin{array}{l}30 \\
31 \\
31 \\
31 \\
31\end{array}$ & $\begin{array}{l}28 \\
28 \\
28 \\
29 \\
27\end{array}$ \\
\hline $\begin{array}{l}26 \\
27 \\
28 \\
29 \\
30\end{array}$ & $\begin{array}{r}700 \\
700 \\
660 \\
660 \\
--\end{array}$ & $\begin{array}{r}650 \\
630 \\
620 \\
630 \\
--\end{array}$ & $\begin{array}{l}8.1 \\
8.1 \\
8.1 \\
8.1 \\
-.\end{array}$ & $\begin{array}{r}7.9 \\
8.0 \\
8.0 \\
7.9 \\
-.-\end{array}$ & $\begin{array}{r}6.0 \\
6.5 \\
7.2 \\
7.0 \\
-=\end{array}$ & $\begin{array}{r}4.0 \\
5.5 \\
6.5 \\
5.0 \\
--\end{array}$ & $\begin{array}{l}26 \\
24 \\
22 \\
24 \\
--\end{array}$ & $\begin{array}{l}24 \\
21 \\
21 \\
22 \\
-\end{array}$ & $\begin{array}{l}620 \\
550 \\
600 \\
640 \\
640\end{array}$ & $\begin{array}{l}430 \\
480 \\
550 \\
600 \\
610\end{array}$ & $\begin{array}{l}7.9 \\
7.8 \\
7.8 \\
7.8 \\
7.9\end{array}$ & $\begin{array}{l}7.6 \\
7.7 \\
7.7 \\
7.8 \\
7.8\end{array}$ & $\begin{array}{r}8.2 \\
-- \\
-\because \\
5.5\end{array}$ & $\begin{array}{r}6.7 \\
=- \\
=- \\
5.0\end{array}$ & $\begin{array}{l}27 \\
26 \\
27 \\
26 \\
26\end{array}$ & $\begin{array}{l}25 \\
25 \\
26 \\
25 \\
25\end{array}$ \\
\hline 31 & -- & -- & - & - & -- & -- & -- & - -- & 670 & 640 & 7.9 & 7.8 & 5.2 & 4.6 & 27 & 25 \\
\hline
\end{tabular}


03271600 GREAT MIAMI RIVER NEAR MIAMISBURG, OHIO--CONTINUE

SPECIFIC CONDUCTANCE, PH, DISSOLVED OXYGEN, AND WATER TEMPERATURES, WATER YEAR OCTOBER 1967 TO SEPTEMBER 1968

\begin{tabular}{|c|c|c|c|c|c|c|c|c|c|c|c|c|c|c|c|c|}
\hline \multirow{3}{*}{ DAY } & \multicolumn{8}{|c|}{ AUGUST } & \multicolumn{8}{|c|}{ SEPTEMBER } \\
\hline & \multicolumn{2}{|c|}{$\begin{array}{l}\text { SPECIFIC } \\
\text { CONDUCTANCE } \\
\text { (MICROMHOS } \\
\text { AT 25 }{ }^{\circ} \mathrm{C} \text { ) }\end{array}$} & \multicolumn{2}{|c|}{$\mathrm{pH}$} & \multicolumn{2}{|c|}{$\begin{array}{l}\text { DISSOLVED } \\
\text { OXYGEN } \\
(\text { HG } / L)\end{array}$} & \multicolumn{2}{|c|}{$\begin{array}{l}\text { TEMPER- } \\
\text { ATURE } \\
\left({ }^{\circ} \mathrm{C}\right)\end{array}$} & \multicolumn{2}{|c|}{$\begin{array}{l}\text { SPECIFIC } \\
\text { OONDUCTANCE } \\
\text { (MICROMHOS } \\
\text { AT 25 }{ }^{\circ} \text { C) }\end{array}$} & \multicolumn{2}{|c|}{ pH } & \multicolumn{2}{|c|}{$\begin{array}{l}\text { DISSOLVED } \\
\text { OXYGEN } \\
(\mathbf{M G} / \mathrm{L})\end{array}$} & \multicolumn{2}{|c|}{$\begin{array}{l}\text { TEMPER- } \\
\text { ATURE } \\
\left({ }^{\circ} \mathrm{C}\right)\end{array}$} \\
\hline & yAX & MIN & $\max$ & MIN & $\operatorname{LAX}$ & MIN & MAX & MIN & $\max$ & MIN & $\operatorname{MAX}$ & MIN & $\max$ & MIN & $\max$ & MIN \\
\hline $\begin{array}{l}1 \\
2 \\
3 \\
4 \\
5\end{array}$ & $\begin{array}{r}690 \\
630 \\
660 \\
-- \\
--\end{array}$ & $\begin{array}{r}620 \\
560 \\
590 \\
-- \\
--\end{array}$ & $\begin{array}{r}7.9 \\
7.9 \\
8.0 \\
-- \\
--\end{array}$ & $\begin{array}{r}7.8 \\
7.8 \\
7.7 \\
-- \\
--\end{array}$ & $\begin{array}{r}5.3 \\
5.6 \\
5.6 \\
---\end{array}$ & $\begin{array}{r}4.6 \\
5.1 \\
4.8 \\
-2 \\
--\end{array}$ & $\begin{array}{l}28 \\
27 \\
27 \\
-- \\
--\end{array}$ & $\begin{array}{l}26 \\
25 \\
26 \\
=- \\
--\end{array}$ & $\begin{array}{l}810 \\
810 \\
750 \\
810 \\
810\end{array}$ & $\begin{array}{l}780 \\
750 \\
710 \\
750 \\
770\end{array}$ & $\begin{array}{r}8.1 \\
8.1 \\
8.2 \\
-- \\
--\end{array}$ & $\begin{array}{r}8.0 \\
8.0 \\
7.8 \\
-- \\
--\end{array}$ & $\begin{array}{l}4.4 \\
5.5 \\
5.8 \\
5.9 \\
4.0\end{array}$ & $\begin{array}{l}2.6 \\
3.1 \\
2.7 \\
2.7 \\
2.2\end{array}$ & $\begin{array}{l}28 \\
26 \\
27 \\
27 \\
27\end{array}$ & $\begin{array}{l}25 \\
25 \\
25 \\
25 \\
26\end{array}$ \\
\hline $\begin{array}{r}6 \\
7 \\
8 \\
9 \\
10\end{array}$ & $\begin{array}{l}680 \\
700 \\
710 \\
600 \\
620\end{array}$ & $\begin{array}{l}640 \\
660 \\
600 \\
510 \\
560\end{array}$ & $\begin{array}{l}8.1 \\
8.0 \\
8.0 \\
7.9 \\
7.9\end{array}$ & $\begin{array}{l}7.9 \\
7.9 \\
7.9 \\
7.8 \\
7.8\end{array}$ & $\begin{array}{l}6.0 \\
6.2 \\
6.9 \\
6.1 \\
5.9\end{array}$ & $\begin{array}{l}5.0 \\
5.1 \\
5.7 \\
5.8 \\
5.7\end{array}$ & $\begin{array}{l}29 \\
30 \\
29 \\
27 \\
27\end{array}$ & $\begin{array}{l}27 \\
28 \\
28 \\
26 \\
26\end{array}$ & $\begin{array}{l}\mathbf{7 7 0} \\
\mathbf{7 4 0} \\
790 \\
750 \\
780\end{array}$ & $\begin{array}{l}620 \\
600 \\
730 \\
720 \\
730\end{array}$ & $\begin{array}{l}-- \\
-- \\
--\end{array}$ & $\begin{array}{l}=- \\
=- \\
=\end{array}$ & $\begin{array}{r}6.5 \\
5.0 \\
-2 \\
-. .8\end{array}$ & $\begin{array}{r}3.0 \\
3.1 \\
-- \\
-\overline{3.0}\end{array}$ & $\begin{array}{l}27 \\
27 \\
27 \\
27 \\
25\end{array}$ & $\begin{array}{l}26 \\
24 \\
25 \\
25 \\
24\end{array}$ \\
\hline $\begin{array}{l}11 \\
12 \\
13 \\
14 \\
15\end{array}$ & $\begin{array}{l}620 \\
640 \\
780 \\
690 \\
710\end{array}$ & $\begin{array}{l}590 \\
600 \\
530 \\
660 \\
680\end{array}$ & $\begin{array}{l}8.0 \\
7.9 \\
8.0 \\
8.0 \\
8.0\end{array}$ & $\begin{array}{l}7.9 \\
7.8 \\
7.9 \\
7.9 \\
7.9\end{array}$ & $\begin{array}{l}6.0 \\
5.9 \\
6.6 \\
5.5 \\
5.3\end{array}$ & $\begin{array}{l}5.2 \\
5.7 \\
5.0 \\
5.0 \\
4.8\end{array}$ & $\begin{array}{l}26 \\
25 \\
26 \\
27 \\
28\end{array}$ & $\begin{array}{l}25 \\
24 \\
25 \\
25 \\
26\end{array}$ & $\begin{array}{l}780 \\
770 \\
800 \\
810 \\
820\end{array}$ & $\begin{array}{l}690 \\
740 \\
770 \\
790 \\
800\end{array}$ & $\begin{array}{l}-- \\
-- \\
--\end{array}$ & $\begin{array}{l}-- \\
=- \\
=- \\
=-\end{array}$ & $\begin{array}{l}3.6 \\
3.9 \\
4.0 \\
5.0 \\
5.4\end{array}$ & $\begin{array}{l}2.3 \\
2.5 \\
2.9 \\
3.0 \\
2.8\end{array}$ & $\begin{array}{l}25 \\
25 \\
25 \\
26 \\
26\end{array}$ & $\begin{array}{l}23 \\
22 \\
23 \\
24 \\
25\end{array}$ \\
\hline $\begin{array}{l}16 \\
17 \\
18 \\
19 \\
20\end{array}$ & $\begin{array}{l}\mathbf{7 2 0} \\
\mathbf{7 5 0} \\
\mathbf{7 5 0} \\
\mathbf{7 4 0} \\
\mathbf{7 4 0}\end{array}$ & $\begin{array}{l}690 \\
720 \\
710 \\
710 \\
720\end{array}$ & $\begin{array}{l}8.0 \\
8.1 \\
8.2 \\
8.3 \\
8.4\end{array}$ & $\begin{array}{l}7.9 \\
7.9 \\
8.0 \\
8.0 \\
8.0\end{array}$ & $\begin{array}{l}5.2 \\
5.6 \\
6.0 \\
6.3 \\
6.4\end{array}$ & $\begin{array}{l}4.5 \\
4.2 \\
4.4 \\
4.4 \\
4.1\end{array}$ & $\begin{array}{l}29 \\
30 \\
30 \\
31 \\
32\end{array}$ & $\begin{array}{l}27 \\
28 \\
27 \\
26 \\
29\end{array}$ & $\begin{array}{l}810 \\
790 \\
760 \\
670 \\
720\end{array}$ & $\begin{array}{l}780 \\
750 \\
570 \\
600 \\
620\end{array}$ & $\begin{array}{r}-- \\
-- \\
8.0 \\
8.3\end{array}$ & $\begin{array}{r}-- \\
\overline{--} \\
7.9 \\
7.9\end{array}$ & $\begin{array}{l}5.8 \\
5.5 \\
4.4 \\
4.4 \\
5.4\end{array}$ & $\begin{array}{l}3.8 \\
3.9 \\
3.5 \\
3.8 \\
3.3\end{array}$ & $\begin{array}{l}26 \\
26 \\
26 \\
23 \\
25\end{array}$ & $\begin{array}{l}25 \\
25 \\
23 \\
22 \\
22\end{array}$ \\
\hline $\begin{array}{l}21 \\
22 \\
23 \\
24 \\
25\end{array}$ & $\begin{array}{l}740 \\
750 \\
770 \\
780 \\
780\end{array}$ & $\begin{array}{l}710 \\
720 \\
740 \\
760 \\
750\end{array}$ & $\begin{array}{l}8.3 \\
8.2 \\
8.1 \\
8.1 \\
8.1\end{array}$ & $\begin{array}{l}8.0 \\
7.9 \\
7.9 \\
7.9 \\
7.9\end{array}$ & $\begin{array}{l}5.7 \\
5.6 \\
6.1 \\
5.0 \\
4.9\end{array}$ & $\begin{array}{l}3.9 \\
3.4 \\
4.0 \\
3.4 \\
2.9\end{array}$ & $\begin{array}{l}32 \\
33 \\
33 \\
33 \\
33\end{array}$ & $\begin{array}{l}30 \\
30 \\
30 \\
31 \\
30\end{array}$ & $\begin{array}{l}740 \\
760 \\
760 \\
770 \\
800\end{array}$ & $\begin{array}{l}720 \\
740 \\
740 \\
720 \\
710\end{array}$ & $\begin{array}{l}8.3 \\
8.1 \\
8.3 \\
8.2 \\
8.3\end{array}$ & $\begin{array}{l}8.0 \\
8.0 \\
8.0 \\
8.0 \\
7.9\end{array}$ & $\begin{array}{l}5.1 \\
4.7 \\
5.1 \\
5.1 \\
3.7\end{array}$ & $\begin{array}{l}3.7 \\
2.8 \\
2.7 \\
2.6 \\
2.3\end{array}$ & $\begin{array}{l}26 \\
27 \\
27 \\
28 \\
28\end{array}$ & $\begin{array}{l}23 \\
25 \\
26 \\
27 \\
27\end{array}$ \\
\hline $\begin{array}{l}26 \\
27 \\
28 \\
29 \\
30 \\
31\end{array}$ & $\begin{array}{l}750 \\
750 \\
770 \\
770 \\
790 \\
610\end{array}$ & $\begin{array}{l}\mathbf{7 3 0} \\
\mathbf{7 4 0} \\
\mathbf{7 5 0} \\
\mathbf{7 5 0} \\
\mathbf{7 6 0} \\
\mathbf{7 8 0}\end{array}$ & $\begin{array}{l}8.1 \\
8.3 \\
8.4 \\
8.4 \\
8.2 \\
8.2\end{array}$ & $\begin{array}{l}7.9 \\
8.0 \\
8.0 \\
8.1 \\
8.1 \\
8.0\end{array}$ & $\begin{array}{l}4.8 \\
4.5 \\
5.2 \\
5.7 \\
6.3 \\
6.2\end{array}$ & $\begin{array}{l}3.0 \\
3.5 \\
3.5 \\
3.6 \\
3.0 \\
3.3\end{array}$ & $\begin{array}{l}30 \\
27 \\
27 \\
27 \\
27 \\
28\end{array}$ & $\begin{array}{l}27 \\
25 \\
24 \\
25 \\
25 \\
25\end{array}$ & $\begin{array}{l}810 \\
810 \\
810 \\
830 \\
820 \\
--\end{array}$ & $\begin{array}{r}790 \\
780 \\
790 \\
810 \\
800 \\
--\end{array}$ & $\begin{array}{l}8.1 \\
8.1 \\
8.2 \\
8.1 \\
8.1 \\
.-\end{array}$ & $\begin{array}{l}7.8 \\
7.9 \\
7.7 \\
7.8 \\
7.9 \\
--\end{array}$ & $\begin{array}{r}4.0 \\
4.6 \\
4.5 \\
-- \\
-- \\
--\end{array}$ & $\begin{array}{r}2.4 \\
1.9 \\
-- \\
-- \\
--\end{array}$ & $\begin{array}{l}27 \\
26 \\
25 \\
25 \\
25 \\
-2\end{array}$ & $\begin{array}{l}25 \\
25 \\
24 \\
24 \\
24 \\
--\end{array}$ \\
\hline
\end{tabular}

03272010 TWIN CREEK AT GERMANTONN, OHIO

LOCATION. --Lat $39^{\circ} 37^{\prime} 22^{\prime \prime}$, long $84^{\circ} 23^{\prime} 33^{\prime \prime}$, Montgomery County, at bridge on State Highway 725,1 mile downstream from gaging station, approximately 0.1 mile west of Germantown.

DRA INAGE AREA, $--275 \mathrm{sq}$ m1.

PERIOD OF RECORD, --Chemical analyses: August 1967 to September 1968.

REMARKS.--Samples were collected weekly October and November, July to September, and monthly December to June.

Samples for iron and manganese were filtered clear when collected. Records of discharge are given for gaging station near Germantown.

CHEMICAL ANALYSES IN MILLIGRAMS PER LITER, WATER YEAR OCTOBER 1967 TO SEPTEMBER 1968

\begin{tabular}{|c|c|c|c|c|c|c|c|c|c|c|c|c|}
\hline DATE & TIME & $\begin{array}{l}\text { DIS- } \\
\text { CHARGE } \\
\text { (CFS) }\end{array}$ & $\begin{array}{l}\text { SILICA } \\
\text { (SIO2) }\end{array}$ & $\begin{array}{l}\text { IRON } \\
\text { (FE) }\end{array}$ & $\begin{array}{l}\text { MAN- } \\
\text { GANESE } \\
(\text { MN) }\end{array}$ & $\begin{array}{l}\text { CAL- } \\
\text { CIUM } \\
\text { (CA) }\end{array}$ & $\begin{array}{l}\text { MAG- } \\
\text { NE- } \\
\text { SIUM } \\
\text { (MG) }\end{array}$ & $\begin{array}{l}\text { SODIUM } \\
\text { (NA) }\end{array}$ & $\begin{array}{l}\text { PO- } \\
\text { TAS- } \\
\text { SIUH } \\
\text { (K) }\end{array}$ & $\begin{array}{l}\text { BICAR- } \\
\text { BONATE } \\
\text { (HCO3) }\end{array}$ & $\begin{array}{l}\text { CAR- } \\
\text { BONATE } \\
\text { (CO3) }\end{array}$ & $\begin{array}{l}\text { SULF AT } \\
\left.(53)^{4}\right)\end{array}$ \\
\hline OCT. & & & & & & & & & & & & \\
\hline $\begin{array}{l}03 \ldots \\
10 . . .\end{array}$ & $\begin{array}{l}1630 \\
1530\end{array}$ & $\begin{array}{l}13 \\
18\end{array}$ & $\overrightarrow{-}$ & $\begin{array}{l}.02 \\
.06\end{array}$ & $\begin{array}{l}.02 \\
.02\end{array}$ & $=$ & $\overrightarrow{-}$ & -- & $=$ & 310 & 0 & $\begin{array}{l}53 \\
56\end{array}$ \\
\hline $10 \ldots$ & 1100 & 21 & - & .04 & .03 & -- & -- & -- & -- & 312 & 0 & 55 \\
\hline $24 \ldots$ & 1630 & 22 & -- & .02 & .00 & -- & -- & -- & -- & 320 & 0 & 55 \\
\hline nov... & 1730 & 28 & -- & .07 & .09 & -- & -- & -- & - & 310 & 0 & 58 \\
\hline $\begin{array}{l}\text { NOV. } \\
07 . . .\end{array}$ & & & & & & & & -- & -- & & & \\
\hline $\begin{array}{l}07 \ldots . . \\
14 \ldots \\
\text { OEC. }\end{array}$ & $\begin{array}{l}1600 \\
1530\end{array}$ & $\begin{array}{l}43 \\
33\end{array}$ & 4.4 & .05 & .06 & $\overline{87}$ & 29 & $10^{--}$ & 2.5 & 312 & 0 & $\begin{array}{l}38 \\
32\end{array}$ \\
\hline $\begin{array}{l}\text { DEC. } \\
12 \ldots .\end{array}$ & & & & -- & & & & & 2.2 & 186 & 0 & 48 \\
\hline $\begin{array}{l}12 \ldots \\
\text { JAN. } \\
17 \ldots\end{array}$ & $2 T 15$ & 1090 & 1.0 & -- & .04 & $0<$ & 14 & 3.0 & 202 & 200 & & 40 \\
\hline $\begin{array}{l}17 \ldots \\
\text { FEB. }\end{array}$ & 1700 & 60 & 7.8 & .02 & .03 & 89 & 35 & 9.2 & 1.6 & 344 & 0 & 53 \\
\hline $\begin{array}{l}13 . . . \\
\text { MAR. }\end{array}$ & 1600 & 110 & 6.6 & .04 & .02 & 94 & 32 & a. 2 & 1.5 & 33.4 & 0 & 63 \\
\hline $\begin{array}{l}19 \ldots \\
{ }_{A P R} . .\end{array}$ & 1715 & 166 & 3.0 & .04 & .02 & 75 & 29 & 17 & 2.1 & 248 & 8 & b1 \\
\hline MAY $23 .$. & 1145 & 102 & 3.3 & .10 & .00 & 73 & 34 & 8.8 & 1.5 & 288 & 0 & 58 \\
\hline $\begin{array}{l}14 \ldots . \\
\text { JUNE }\end{array}$ & 1630 & 249 & 5.8 & .05 & .01 & 82 & 31 & 8.5 & 1.9 & 272 & 2 & 57 \\
\hline JULY & 1730 & 136 & 3.2 & .02 & .02 & 79 & 33 & 7.8 & 1.8 & 298 & 2 & 34 \\
\hline $02 \ldots$ & 0950 & 92 & $\overline{--}$ & .07 & .02 & $=$ & $=-$ & -- & -- & 294 & 4 & 54 \\
\hline $\begin{array}{l}10 \ldots \\
16 \ldots\end{array}$ & $\begin{array}{l}1000 \\
1730\end{array}$ & $\begin{array}{l}54 \\
65\end{array}$ & $=-$ & $\begin{array}{l}.07 \\
.07\end{array}$ & $\begin{array}{l}.03 \\
.03\end{array}$ & - & -- & $=$ & - & $\begin{array}{l}280 \\
270\end{array}$ & $\begin{array}{l}0 \\
2\end{array}$ & $\begin{array}{l}54 \\
53\end{array}$ \\
\hline $23 \ldots$ & 2000 & 130 & - & .11 & .03 & -- & -- & - & -- & 182 & 0 & 34 \\
\hline $\begin{array}{l}30 \ldots . . \\
\text { AUG. }\end{array}$ & 1700 & $5 T$ & -- & .02 & .12 & -- & -- & -- & -- & 294 & 4 & 52 \\
\hline $\begin{array}{l}\text { AUG. } \\
\text { O6.... }\end{array}$ & & & & & & -- & - & $\cdots$ & -- & & 4 & \\
\hline $13, \ldots$ & 1630 & $\begin{array}{l}114 \\
315\end{array}$ & - & $\begin{array}{l}.06 \\
.14\end{array}$ & .02 & - & - & -- & -- & 298 & 0 & $\begin{array}{l}41 \\
44\end{array}$ \\
\hline $20 \ldots$ & 1630 & 87 & -- & .02 & .03 & -- & -- & -- & -- & 320 & 4 & 52 \\
\hline $28 \ldots$ & 0900 & 43 & -- & .03 & .04 & + & -- & -- & -- & 320 & 0 & 54 \\
\hline $\begin{array}{l}\text { SEPT. } \\
05 . .\end{array}$ & & & $\cdots$ & .01 & .01 & -- & -- & $\cdots$ & -- & 316 & 0 & 54 \\
\hline $11 \ldots$ & 1600 & 65 & -- & .07 & .13 & - & -- & -- & -- & 288 & 0 & 51 \\
\hline $18 \ldots$ & 1000 & 34 & -- & .11 & .03 & -- & -- & $\cdots$ & $=$ & 298 & 0 & 51 \\
\hline $24 \ldots$ & 1215 & 34 & -- & .04 & .02 & -- & -- & -- & -- & 316 & 0 & 53 \\
\hline
\end{tabular}


03272010 TTIN CREEK AT GERMANTOWN, OHIO--Continued

CHEMICAL ANALYSES IN MILLIGRAMS PER LITER, WATER YEAR OCTOBER 1967 TO SEPTEMBER 1968

\begin{tabular}{|c|c|c|c|c|c|c|c|c|c|c|c|c|}
\hline DATE & $\begin{array}{l}\text { CHLO- } \\
\text { RIDE } \\
\text { ICLI }\end{array}$ & $\begin{array}{l}\text { FLUO- } \\
\text { RIOE } \\
\text { IF I }\end{array}$ & $\begin{array}{l}\text { NI TRATE } \\
\text { (NO3) }\end{array}$ & $\begin{array}{l}\text { TOTAL } \\
\text { PHOS- } \\
\text { PHORUS } \\
\text { (PO4) }\end{array}$ & $\begin{array}{l}\text { DIS- } \\
\text { SOLVEO } \\
\text { SOLIDS } \\
\text { IRESI- } \\
\text { DUE AT } \\
180 \text { CI }\end{array}$ & $\begin{array}{l}\text { DIS- } \\
\text { SOLVES } \\
\text { SOLIDS } \\
\text { ISUM DF } \\
\text { CONSTI- } \\
\text { TUEVTSI }\end{array}$ & $\begin{array}{l}\text { HARJ- } \\
\text { NESS } \\
(E A, M S)\end{array}$ & $\begin{array}{l}\text { NON- } \\
\text { CAR- } \\
\text { RINATE } \\
\text { HARO- } \\
\text { NESS }\end{array}$ & $\begin{array}{l}\text { SPFCI- } \\
\text { FIC } \\
\text { COND- } \\
\text { UCTANLF } \\
\text { (NICRD- } \\
\text { M-OOSI }\end{array}$ & $\mathrm{PH}$ & $\begin{array}{l}\text { TEMP- } \\
\text { ERATURE } \\
\text { IOES }=1\end{array}$ & גכנד \\
\hline \multicolumn{13}{|l|}{ DCF. } \\
\hline$n 3 \ldots$ & 18 & -- & 6.1 & .10 & 366 & -- & 345 & 89 & 616 & 8.0 & 18 & -- \\
\hline $\begin{array}{l}10 \ldots \\
18 \ldots\end{array}$ & $\begin{array}{l}17 \\
18\end{array}$ & $=$ & $\begin{array}{l}4.8 \\
5.1\end{array}$ & $\begin{array}{l}.20 \\
.17\end{array}$ & $\begin{array}{l}376 \\
364\end{array}$ & -- & $\begin{array}{l}325 \\
325\end{array}$ & $\begin{array}{l}66 \\
64\end{array}$ & $\begin{array}{l}617 \\
6 \cap 8\end{array}$ & $\begin{array}{l}8.0 \\
8.0\end{array}$ & 12 & $=$ \\
\hline $24 \ldots$ & 18 & -- & 6.3 & .21 & 366 & -- & 250 & 87 & 630 & 8.1 & $\begin{array}{l}14 \\
13\end{array}$ & - \\
\hline \multirow{2}{*}{\multicolumn{4}{|c|}{ NOV. }} & .25 & 348 & -- & 320 & 65 & 605 & 8.1 & 12 & -- \\
\hline & & & 3.8 & .27 & $37 C$ & -- & 325 & 71 & 619 & 8.3 & 6 & \\
\hline $\begin{array}{l}14 . . \\
\text { DEC. }\end{array}$ & 20 & .1 & 5.3 & 3.8 & 394 & 377 & 336 & 80 & 623 & 8.2 & 6 & 10 \\
\hline $\begin{array}{l}12 \ldots \\
\text { JAN. }\end{array}$ & 17 & .3 & 29 & .36 & 306 & 272 & $2 \times 3$ & RO & 462 & 8.1 & 8 & 35 \\
\hline $\begin{array}{c}17 \ldots \\
\text { FEB. }\end{array}$ & 18 & .2 & 11 & .33 & 436 & $4 \cap 4$ & 366 & 84 & 672 & 8.2 & 1 & 10 \\
\hline $\begin{array}{l}13 \ldots \\
\text { MAR. }\end{array}$ & 21 & .1 & 17 & .20 & 406 & 409 & 366 & 92 & 663 & 8.2 & 1 & 5 \\
\hline $\begin{array}{c}19 \ldots . . \\
\triangle P R .\end{array}$ & 36 & .2 & 14 & .11 & 398 & 359 & 306 & 89 & 603 & 8.4 & 13 & 5 \\
\hline${ }_{M A Y}^{23} \cdots$ & 20 & .3 & 6.6 & .04 & 366 & 348 & $32 ?$ & 86 & 598 & 8.2 & 19 & 5 \\
\hline JUNE & 22 & .3 & 24 & .14 & 396 & 368 & 332 & 106 & $6 ? 5$ & 8.3 & 18 & 15 \\
\hline${ }_{\text {JULY }}^{11}$ & 16 & .5 & 12 & .06 & 362 & 355 & 333 & 85 & 605 & 8.3 & 25 & 5 \\
\hline $02 \ldots$ & 20 & -- & 19 & .14 & 412 & $=$ & 332 & 84 & 619 & 8.3 & 23 & $\because$ \\
\hline $\begin{array}{l}10 \ldots \\
16 \ldots\end{array}$ & $\begin{array}{l}19 \\
16\end{array}$ & -- & $\begin{array}{l}7.8 \\
5.3\end{array}$ & $\begin{array}{l}.06 \\
.05\end{array}$ & $\begin{array}{l}362 \\
320\end{array}$ & $=$ & $\begin{array}{l}308 \\
300\end{array}$ & $\begin{array}{l}78 \\
75\end{array}$ & $\begin{array}{l}572 \\
554\end{array}$ & $\begin{array}{l}8.1 \\
8.3\end{array}$ & $\begin{array}{l}22 \\
25\end{array}$ & $=$ \\
\hline $23 \ldots$ & 11 & $=-$ & 8.1 & .36 & $24 B$ & -- & 200 & 51 & $\begin{array}{l}534 \\
392\end{array}$ & $\begin{array}{l}8.3 \\
8.0\end{array}$ & $\begin{array}{l}25 \\
25\end{array}$ & - \\
\hline $\begin{array}{l}30 . . . \\
\text { AUG. }\end{array}$ & I B & -- & 10 & .12 & 388 & - & 322 & 74 & $5 B 8$ & 8.3 & 22 & -- \\
\hline $06 \ldots$ & 16 & - & 12 & .32 & 392 & -- & 314 & 69 & 579 & 8.3 & 26 & - \\
\hline $13 \ldots$ & 14 & $=$ & 10 & .23 & 364 & -- & 314 & 70 & 562 & 8.2 & 20 & -- \\
\hline $20 \ldots$ & 18 & -- & 8.1 & .08 & 404 & -- & 350 & 81 & 620 & 8.3 & 26 & -- \\
\hline $28 \ldots$ & 18 & -- & 7.8 & .05 & 384 & -- & 340 & 78 & 616 & 8.1 & II & - \\
\hline $\begin{array}{c}\text { SEPT. } \\
05 . . .\end{array}$ & 16 & -- & 8.3 & .06 & 372 & -- & 332 & 72 & 608 & 8.1 & 19 & \\
\hline $\begin{array}{l}05 \ldots \\
11 \ldots\end{array}$ & 16 & -- & 6.6 & .12 & 368 & -- & 314 & 78 & 568 & 8.1 & 17 & $=$ \\
\hline $19 .$. & is & -- & 5.8 & .04 & 362 & -- & 314 & 70 & 580 & 8.1 & 18 & $=$ \\
\hline $24 \ldots$ & 18 & -- & 6.3 & .16 & 340 & -- & 328 & 63 & $60 ?$ & 8.2 & 21 & -- \\
\hline
\end{tabular}

\begin{tabular}{|c|c|c|c|c|c|c|c|c|}
\hline DATE & $\begin{array}{l}\text { AMMON IA } \\
\text { (NH4) }\end{array}$ & $\begin{array}{c}\text { N1 IR I IE } \\
\text { (Nח2) }\end{array}$ & $\begin{array}{l}\text { DISS- } \\
\text { OLVED } \\
\text { OXYGEN }\end{array}$ & $\begin{array}{l}\text { PER- } \\
\text { CENT } \\
\text { SATUR- } \\
\text { ATION }\end{array}$ & PHENULS & $\begin{array}{l}\text { METHY- } \\
\text { LENE } \\
\text { BLUF } \\
\text { ACTIVF } \\
\text { SUB- } \\
\text { STANCE }\end{array}$ & $\begin{array}{l}\text { T JR- } \\
\text { BIO- } \\
\text { ITY }\end{array}$ & JDOR \\
\hline OCT. & & & & & & & & \\
\hline $03 \ldots$ & .30 & .00 & 9.4 & 99 & .206 & .03 & 0.0 & 0 \\
\hline $10 \ldots$ & .07 &. no & 3. 8 & 81 & $.02 \mathrm{~A}$ & .05 & 9.0 & 0 \\
\hline $18 . .$. & .00 & .00 & 7.6 & 74 & .010 & .04 & $5 . ?$ & 0 \\
\hline $24 \ldots$ & .15 & .05 & 10.0 & 95 & . 010 & .03 & 2.3 & 0 \\
\hline $31 \ldots$ & .07 & .00 & 9.4 & 86 & .000 & .03 & $3 . ?$ & 0 \\
\hline $\begin{array}{l}\text { Nov. } \\
07 . . .\end{array}$ & .00 & & 12.0 & 93 & .003 & & & \\
\hline $\begin{array}{l}07 \ldots \\
14 \ldots\end{array}$ & .07 & $\begin{array}{l}.00 \\
.00\end{array}$ & 12.0 & 100 & .701 & $\begin{array}{l}.04 \\
.03\end{array}$ & $\begin{array}{l}6.0 \\
5.0\end{array}$ & $\begin{array}{l}0 \\
0\end{array}$ \\
\hline $\begin{array}{l}\text { DEC. } \\
12 . . .\end{array}$ & .07 & & 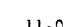 & & & & & \\
\hline JAN." & $0 r$ & .05 & 11.0 & 93 & .010 & .06 & 104 & 0 \\
\hline$\underset{F \in B .}{17 . . .}$ & .15 & .00 & 13.0 & 72 & .900 & .04 & 6.0 & 0 \\
\hline $\begin{array}{l}13 \ldots \\
\text { MAR. }\end{array}$ & .07 & .05 & 13.0 & 92 & .392 & .10 & 6.9 & 0 \\
\hline $\begin{array}{l}19 . . . \\
\text { APR. }\end{array}$ & .00 & .05 & 12.0 & 114 & .000 & .07 & 55 & 0 \\
\hline$\underset{M A Y}{23} \cdots$ & .07 & .05 & 10.0 & $10 \mathrm{~s}$ & .001 & .04 & 8.0 & 2 \\
\hline $\begin{array}{l}14 \ldots \\
\text { JUNF }\end{array}$ & .00 & .05 & 9.4 & 98 & -.000 & .07 & 9.0 & 4 \\
\hline JuLy & .00 & .05 & 11.0 & 132 & .000 & .04 & 6.0 & 0 \\
\hline $02 \ldots$ & .15 & .05 & 7.0 & 80 & .001 & .10 & 9.0 & 2 \\
\hline $\begin{array}{l}10 \ldots \\
16 \ldots\end{array}$ & .00 & .05 & $8 . n$ & 91 & .003 & .05 & 9.7 & 4 \\
\hline $\begin{array}{l}16 \ldots \\
23 . . .\end{array}$ & .15 & .05 & 10.4 & 125 & .000 & .03 & 20 & 2 \\
\hline $30 \ldots$ & $\begin{array}{l}.07 \\
.00\end{array}$ & $\begin{array}{l}.05 \\
.05\end{array}$ & $\begin{array}{l}6.4 \\
9.2\end{array}$ & $\begin{array}{r}76 \\
104\end{array}$ & $\begin{array}{l}.0 n 0 \\
.004\end{array}$ & $\begin{array}{r}.15 \\
.29\end{array}$ & $27 ?$ & $\begin{array}{l}2 \\
0\end{array}$ \\
\hline AUG. & & & & & & & & 0 \\
\hline $06 \ldots$ & .30 & .05 & 7.2 & 88 & $.0 \cap 3$ & .10 & 27 & 2 \\
\hline $13 \ldots$ & .00 & .05 & 8.0 & 87 & .000 &.$n 2$ & 50 & 2 \\
\hline $20 \ldots$ & .00 & .05 & 9.4 & 115 & .000 & .04 & 2.0 & 0 \\
\hline $\begin{array}{l}28 \ldots \\
S E P T .\end{array}$ & .00 & .05 & 7.8 & 87 & .000 & .02 & 3.6 & 2 \\
\hline $\begin{array}{r}\text { SEPT. } \\
05 . .\end{array}$ & .00 & .05 & 7.4 & 79 &.$n \cap 1$ & .00 & 3,8 & 0 \\
\hline $11 \ldots$ & .15 & .05 & 10.6 & 109 & .000 & .05 & 8.0 & 2 \\
\hline $18 \ldots$ & .15 & .05 & 7.9 & 83 & .711 & .04 & 9.0 & 0 \\
\hline $24 \ldots$ & .15 & .05 & 8.2 & 91 & .001 & .04 & 9.7 & 2 \\
\hline
\end{tabular}


LOCATION, --Lat $39^{\circ} 32^{\prime} 31^{\prime \prime}$, long $84^{\circ} 21^{\prime} 27^{\prime \prime}$, Butler County, on left bank at County Park dock at Middletown, about 0.6 mile downstream from New York Central Railroad bridge and 0.3 mile downtream from Twin Creek.

DRA INAGE AREA. $--3,134 \mathrm{sq} m i$, approximately .

PERIOD OF RECORD.--Chemical analyses: July 1963 to September 1968.

REMARKS.--Samples were collected weekly October, July to September, and monthly November to June. Samples for iron and manganese were flltered clear when collected. No discharge records available.

$$
\text { CHEMICAL ANALYSES IN MILLIGRAMS PER LITER, WATER YEAR OCTOBER } 1967 \text { TO SEPTEMBER } 1968
$$

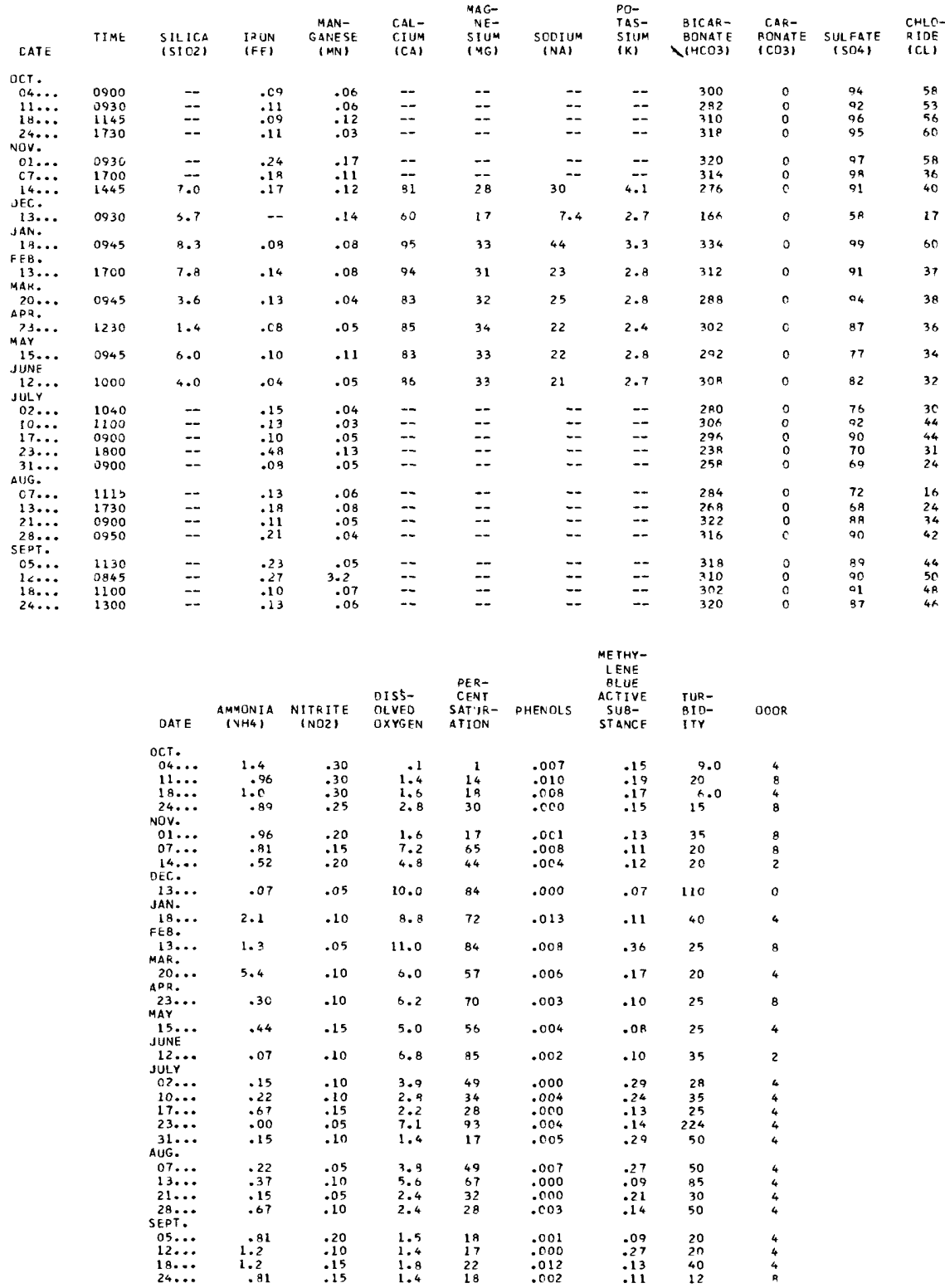


03272100 GREAT MIAMI RIVER AT MIDDLETOWN, OHIO--Continued CHEMICAL ANALYSES IN MILLIGRAMS PER LITER, WATER YEAR OCTOBER 1967 TO SEPTEMBER 1968

\begin{tabular}{|c|c|c|c|c|c|c|c|c|c|c|c|}
\hline DATE & $\begin{array}{l}\text { FLUn- } \\
\text { KIDE } \\
|F|\end{array}$ & $\begin{array}{l}\text { NITRATE } \\
\text { (NOS) }\end{array}$ & $\begin{array}{l}\text { TOTAL } \\
\text { PHUS- } \\
\text { PHORUS } \\
\text { (PD4) }\end{array}$ & $\begin{array}{l}\text { DIS- } \\
\text { SOLVED } \\
\text { SOLIDS } \\
\text { IRESI- } \\
\text { DUE AT } \\
\text { ISO CI }\end{array}$ & $\begin{array}{l}\text { DIS- } \\
\text { SOLVED } \\
\text { SOLIDS } \\
\text { ISUM DF } \\
\text { CDNSTI- } \\
\text { TUENTSI }\end{array}$ & $\begin{array}{l}\text { HARD- } \\
\text { NESS } \\
\text { (CA, MG) }\end{array}$ & $\begin{array}{l}\text { NON- } \\
\text { CAR- } \\
\text { RONATE } \\
\text { HARD- } \\
\text { NESS }\end{array}$ & $\begin{array}{l}\text { SPECI- } \\
\text { FIC } \\
\text { COND- } \\
\text { UCTANCE } \\
\text { (MICRN- } \\
\text { MHOSI }\end{array}$ & $\mathrm{PH}$ & $\begin{array}{l}\text { TEMP- } \\
\text { ERATURE } \\
\text { (DEG C) }\end{array}$ & CDLOR \\
\hline \multicolumn{12}{|l|}{ CCT. } \\
\hline $04 \ldots$. & - & 9.3 & 6.0 & 476 & -- & 345 & 99 & 818 & 7.4 & 24 & - \\
\hline $11 \ldots$ & -- & 6.0 & 5. 0 & 478 & -- & 325 & 94 & $77 t$ & 7.4 & 17 & -- \\
\hline $19 \ldots$ & $\cdots$ & 6.7 & 3.4 & 510 & -- & 345 & 91 & B25 & 7.6 & 21 & -- \\
\hline $24 \ldots$ & -- & 8.3 & 5.4 & 512 & - & 360 & 09 & 846 & 7.6 & 20 & -- \\
\hline \multicolumn{12}{|l|}{ NOV. } \\
\hline $01 . .$. & -- & 6.1 & 5.8 & 514 & -- & 345 & 82 & 824 & 7.7 & 18 & $\cdots$ \\
\hline $07 \ldots$ & -- & 4.9 & 3.1 & 492 & - & 365 & 107 & 767 & 7.8 & ii & -- \\
\hline DEC... & .3 & 7.6 & 4.8 & 460 & 430 & 317 & 91 & 711 & 7.7 & 13 & 20 \\
\hline $\begin{array}{l}\text { DEC. } \\
13 . . .\end{array}$ & .3 & 19 & BB & 298 & 271 & 220 & 84 & 462 & 7.9 & $B$ & 35 \\
\hline \\
\hline $\begin{array}{c}18 . . . \\
\text { FER. }\end{array}$ & .6 & 8.3 & 3.9 & 548 & 522 & 373 & 99 & 860 & 7.5 & 7 & 20 \\
\hline $\begin{array}{l}13 \ldots . . \\
\text { MAK. }\end{array}$ & .3 & 15 & 2.4 & 460 & 459 & 362 & 106 & 737 & 7.9 & 4 & 10 \\
\hline \multicolumn{11}{|l|}{$A P R$} & 15 \\
\hline $\begin{array}{r}23 \\
\text { MAY }\end{array}$ & .4 & 7.5 & .95 & 448 & 425 & 352 & 104 & 728 & 7.7 & 22 & 10 \\
\hline \multicolumn{12}{|l|}{$\begin{array}{l}15 \ldots . . \\
\text { JUNE }\end{array}$} \\
\hline $12 \ldots$ & .2 & 8.5 & 1.6 & 428 & 422 & 350 & 97 & 710 & 8.2 & 27 & 23 \\
\hline \multicolumn{12}{|l|}{ JULY } \\
\hline $07 \ldots$ & -- & 18 & 1.9 & 450 & -- & 332 & 102 & 682 & 7.7 & $2 B$ & -- \\
\hline $10 \ldots$ & -- & 5.8 & 3.3 & 474 & -- & 348 & 97 & 754 & 8.0 & 27 & -- \\
\hline $17 \ldots$ & -- & 4.6 & 3.6 & 442 & - & 332 & 89 & 741 & 7.8 & 29 & -- \\
\hline $23 \ldots$ & -- & 6.0 & 1.6 & 346 & -- & 274 & 79 & 576 & 8.1 & 30 & -- \\
\hline $31 \ldots$ & - & 7.5 & 1.8 & 392 & -- & 292 & 80 & $59 t$ & 7.9 & 26 & -- \\
\hline \multicolumn{12}{|l|}{ Aug. } \\
\hline $07 \ldots$ & - & 6.0 & 2.0 & 424 & -- & 312 & 79 & 640 & 8.0 & 29 & -- \\
\hline $13 \ldots$ & -- & 7.5 & 2.0 & 392 & -- & 302 & 92 & 606 & 7.7 & 25 & -- \\
\hline $21 \ldots$ & -- & 5.3 & 2.8 & 482 & -- & 362 & 98 & 729 & 8.1 & 31 & - \\
\hline $28 \ldots$ & -- & 4.2 & 2.9 & 482 & -- & 356 & 96 & 750 & 7.9 & 25 & $\cdots$ \\
\hline \multicolumn{12}{|l|}{ SEPT. } \\
\hline $05 \ldots$ & -- & 9.2 & 3.4 & 470 & $\cdots$ & 360 & 99 & 764 & 7.8 & 27 & - \\
\hline $12 \ldots$ & -- & 5.0 & 2.2 & 480 & -- & 348 & 94 & 770 & 7.6 & 25 & $\cdots$ \\
\hline $18 \ldots$ & -- & 6.2 & 3.3 & 450 & -- & 342 & 94 & 763 & 7.8 & $2 \mathrm{k}$ & -- \\
\hline $24 \ldots$ & -- & 6.4 & 4.3 & 454 & -- & 352 & 90 & 763 & 7.8 & 29 & -- \\
\hline
\end{tabular}

\begin{tabular}{|c|c|c|c|c|c|c|c|c|}
\hline DATE & 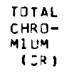 & $\begin{array}{l}\text { NICKEL } \\
\text { INII) }\end{array}$ & $\begin{array}{c}\text { CDPPER } \\
\text { (CUI) }\end{array}$ & $\begin{array}{l}\text { LEAD } \\
(P B)\end{array}$ & $\begin{array}{l}\text { IINC } \\
\text { IIVI }\end{array}$ & $\begin{array}{c}\text { CDBALT } \\
(C D)^{2}\end{array}$ & $\begin{array}{c}\text { ARSENIC } \\
\text { (ASI }\end{array}$ & $\begin{array}{l}\text { CAD- } \\
\text { MIUM } \\
\text { irDI }\end{array}$ \\
\hline $\begin{array}{c}c \text { C. } \\
04 . .\end{array}$ & & & & & & & & \\
\hline $\begin{array}{l}11 \ldots \\
18 \ldots \\
18 \ldots\end{array}$ & $\begin{array}{l}.00 \\
.01\end{array}$ & $\begin{array}{r}.22 \\
.23\end{array}$ & .02 & $\begin{array}{l}.00 \\
.00\end{array}$ & .01 & .00 & $\begin{array}{l}.00 \\
.00\end{array}$ & $\begin{array}{l}.00 \\
.00\end{array}$ \\
\hline $24: \ldots$ & & .30 & .03 & $\because 00$ & .01 & -- & .00 & .00 \\
\hline $01 . \cdots$ & -- & .22 & .02 & .00 & .01 & -- & .00 & .00 \\
\hline $\begin{array}{l}07 \ldots . \\
14\end{array}$ &.$\overline{02}$ & $\begin{array}{l}.14 \\
.08\end{array}$ & .02 & .001 & $\begin{array}{l}01 \\
.04\end{array}$ & . & $: 02$ & .00 \\
\hline $13 \ldots$ & -- & -- & -- & -- & -- & -. & -- & - \\
\hline 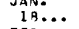 & .02 & .00 & .07 & .01 & .07 & .00 & .00 & .01 \\
\hline $13 \ldots$ & -- & -- & -- & -- & - & -- & - & -- \\
\hline $20 \ldots$ & .01 & .03 & .02 & .05 & .20 & .00 & .00 & .10 \\
\hline $23 . \cdots$ & -- & -- & -- & -- & -- & -. & -- & - \\
\hline $15 \ldots$ & .01 & .02 & .02 & .02 & .03 & .00 & סD. & .00 \\
\hline $12 \ldots$ & -- & -- & -- & -- & - & -- & -- & -- \\
\hline $02 \ldots$ & - & & $\cdots$ & - & - & - & - & \\
\hline${ }_{17}^{10} \ldots$ & .01 & .02 & .01 & .00 & .01 & .00 & .01 & . \\
\hline $23 \cdots$ & .01 & .01 & .01 & .00 & .00 & .co & .02 & .00 \\
\hline AUG. & & & & & & & & \\
\hline $13 \ldots$ & .01 & .02 & .03 & .00 & .01 & .01 & .01 & $\begin{array}{l}.00 \\
.00\end{array}$ \\
\hline $\begin{array}{l}21 \ldots . \\
28\end{array}$ & $\begin{array}{l}: 01 \\
.01 \\
01\end{array}$ & $\begin{array}{l}.02 \\
.03\end{array}$ & $\begin{array}{l}.03 \\
.02\end{array}$ & $\begin{array}{l}.01 \\
01 \\
01\end{array}$ & $\begin{array}{l}.02 \\
.02\end{array}$ & $\begin{array}{l}.00 \\
: 00\end{array}$ & 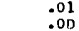 & $\begin{array}{l}: 00 \\
: 00 \\
.00\end{array}$ \\
\hline & & .01 & .00 & .00 & .00 & .00 & .01 & \\
\hline & .01 & .03 & .02 & .01 & .04 & .00 & .01 & .00 \\
\hline$\because:$ & $0_{01}^{01}$ & .01 & .01 & $\begin{array}{l}.00 \\
: 00\end{array}$ & $\begin{array}{l}.02 \\
.01\end{array}$ & .00 & $\begin{array}{l}0101 \\
.01\end{array}$ & $\begin{array}{l}.00 \\
.00\end{array}$ \\
\hline
\end{tabular}


LOCATION. - Lat $39^{\circ} 25^{\prime} 45^{\prime \prime}$, long $84^{\circ} 28^{\prime} 05^{\prime \prime}$, Butler County, at brldge on Liberty-Falrfield Road, southwest of Middletown, 0.7 mile upstream from Baltimore and Ohio Rajiroad bridge.

DRAINAGE AREA, $--3,280 \mathrm{sq} \mathrm{m} 1$.

PERIOD OF RECORD.--Chemical analyses: July 1963 to September 1968.

REMARKS. --Samples were collected weekly October, July to September, and monthly November to June. Samples for ron and manganese were filtered clear when collected. No discharge records available.

CHEMICAL ANALYSES IN MILLIGRAMS PER LITER, WATER YEAR OCTOBER 1967 TO SEPTEMBER 1968

\begin{tabular}{|c|c|c|c|c|c|c|c|c|c|c|c|c|}
\hline RATE & $T: t$ & $\begin{array}{l}\text { SILICA } \\
\text { (SInZ) }\end{array}$ & $\begin{array}{l}1 \times 0,0 \\
(t \in t)\end{array}$ & $\begin{array}{c}\text { YAV- } \\
\text { TAPJFSE } \\
\text { (MN) }\end{array}$ & $\begin{array}{l}C A != \\
\text { CIIUA } \\
(C A)\end{array}$ & $\begin{array}{l}M \Delta G= \\
V F- \\
S I(I M) \\
(M[S)\end{array}$ & $\begin{array}{l}\text { senium } \\
\text { (NA) }\end{array}$ & $\begin{array}{l}\text { DO- } \\
\text { TAS- } \\
\text { SII14 } \\
\text { (k) }\end{array}$ & $\begin{array}{l}\text { BICAR - } \\
\text { HONATE } \\
\text { (HROB) }\end{array}$ & 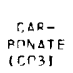 & $\begin{array}{l}\text { SIILFATF } \\
(S \cap 4)\end{array}$ & $\begin{array}{l}\text { CHLO- } \\
\text { RINE } \\
\text { (CL) }\end{array}$ \\
\hline \multicolumn{13}{|l|}{ irt. } \\
\hline & 3945 & -- & .07 & .16 & -- & -- & $=$ & - & 2 rh & $s$ & 167 & $5 C$ \\
\hline $11 \ldots$ & $\begin{array}{l}1745 \\
1245\end{array}$ & -- & 1.4 & .83 & -- & -- & -- & - & 178 & 5 & 172 & 58 \\
\hline $18 \ldots$ & 1245 & $=$ & $\therefore 56$ & $.2 ?$ & -- & $\because$ & -- & -- & $? 34$ & $i$ & 165 & SC \\
\hline \multicolumn{13}{|l|}{ vuv." } \\
\hline $51 \ldots$ & 1115 & -- &.$x$ & $.2^{r}$ & -- & - & -- & -- & $2 k ?$ & $c$ & 134 & $5 \mathrm{R}$ \\
\hline $28 \ldots$ & 113 & -- & 1.4 & .cs & -- & -- & $\cdots$ & -- & $26:$ & $i$ & 141 & 38 \\
\hline \multicolumn{13}{|l|}{$\begin{array}{l}14 \ldots \\
D \in C\end{array}$} \\
\hline JAN." & 1031 & 6.7 & -- & $\therefore 0$ & be & 17 & 7.2 & 7.7 & 152 & $c$ & 62 & 10 \\
\hline $\begin{array}{l}18 \ldots \\
F E A .\end{array}$ & 1.45 & a. 2 & .45 & .14 & $a_{5}$ & 33 & 51 & 3.1 & $3 \div 2$ & $c$ & 125 & 74 \\
\hline \multicolumn{13}{|l|}{$14 \ldots$} \\
\hline $\begin{array}{l}20 \\
A P R\end{array}$ & $11 \mathrm{~L}=$ & 2.7 & 1.5 & .69 & 15 & 27 & 25 & 2.7 & $2 h A$ & $r$ & 105 & 38 \\
\hline \multicolumn{13}{|l|}{$23 \ldots$} \\
\hline JUNE & 16.45 & 5.7 & .75 & .11 & 91 & 32 & 22 & 2.4 & 258 & $c$ & $a_{2}$ & a? \\
\hline \multicolumn{13}{|l|}{ JUL $12 \ldots$} \\
\hline $52 \ldots$ & $122^{-}$ & -- & .07 & $\therefore 4$ & -- & - & -- & -- & $25 r$ & $c$ & 90 & $3 C$ \\
\hline $11 \ldots$ & 126, & -- & .42 & $.1=$ & $\cdots$ & -- & -- & -- & $33 t$ & 6 & 135 & 39 \\
\hline $17 \ldots$ & LL. & -- & .62 & $\therefore A$ & -- & -- & -- & -- & 270 & $\therefore$ & 11 & 42 \\
\hline $23 \ldots$ & 1645 & -- & $1 .:$ & $C A$ & -- & -- & -- & -- & $25 a$ & $r$ & 93 & 35 \\
\hline \multicolumn{13}{|l|}{ ALG. } \\
\hline $07 \ldots$ & 1215 & -- & .17 &.$\therefore 6$ & -- & -. & -- & -- & 248 & $\therefore$ & an & $3 r$ \\
\hline $1+\ldots$ & $30 \pm 1$ & -- & .23 & . 况 & -- & -- & -- & -- & ?he & $\mathrm{r}$ & RE & 24 \\
\hline $21 \ldots$ & $1: 0$. & -- & $.4 R$ & $w^{2}$ & -- & -- & -- & -- & $20 k$ & c & $1<4$ & 34 \\
\hline \multicolumn{13}{|l|}{$\begin{array}{l}23 \ldots . \\
\text { SFPT. }\end{array}$} \\
\hline $03 \ldots$ & $12 \mathrm{sr}$ & -- & . bu & .17 & -- & - & - & -- & $2 f, 4$ & 1 & $1 C 3$ & 42 \\
\hline $12 \ldots$ & iasb & - & .37 & 1.5 & - & -- & -- & -- & 284 & $i$ & 115 & 46 \\
\hline $18 \ldots$ & 126 & -- & 1. & .12 & -- & -- & - & -- & Tar & . & 119 & 49 \\
\hline \multirow[t]{34}{*}{$24 \ldots$} & $14 t^{\prime}$ & -- & .53 & .15 & -- & -- & -- & -- & $24 \mathrm{~B}$ & ' & 145 & 48 \\
\hline & \multicolumn{12}{|c|}{$\begin{array}{l}\text { ML. THY - } \\
\text { T FMF }\end{array}$} \\
\hline & & & & & & PF Z- & & DLIIE & & & & \\
\hline & & & А МपEI IIA & NITRITE & $\begin{array}{l}\text { OISS- } \\
\text { JVEO }\end{array}$ & $\begin{array}{l}\text { CENT } \\
\text { SAT'IR- }\end{array}$ & PHENIOS & ACTIVF & TUR - & Onger & & \\
\hline & & JATE & $\left(\mathrm{NH}_{4}\right)$ & (N112) & JXYSEY & AT IOR. & PHE & ST ANEF & jTr & Drmothe & & \\
\hline & \multicolumn{12}{|c|}{ OCT. } \\
\hline & & $+\cdots$ & 1.7 & .15 & 1.2 & $?:$ & . $c 1$ & $.1=$ & 35 & 4 & & \\
\hline & & $11 \ldots$ & 1.4 & .15 & 2.8 & 23 & $\therefore 1^{2}$ &.$i^{7}$ & 72 & \& & & \\
\hline & & +3... & 1.7 & . In & 2.8 & 3 & .57 & .17 & 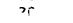 & $\therefore$ & & \\
\hline & \multicolumn{12}{|c|}{${ }_{N}^{25} \ldots$} \\
\hline & & - $2 .$. & 1.4 & $.2^{r}$ & 3.2 & 23 & in & .17 & $G^{r}$ & a & & \\
\hline & & G.... & 1.1 & .05 & $h . h$ & ba & $\therefore 1^{n}$ & $.1 ?$ & 65 & R & & \\
\hline & & $14 \ldots$ & .21 & .15 & 5.4 & 44 & . $r_{4}$ & .14 & $7 r$ & 4 & & \\
\hline & & $\begin{array}{l}\text { OEC. } \\
13 \ldots\end{array}$ & .52 & $\ldots 5$ & $110^{\circ}$ & a) & $\therefore ? 4$ & $\therefore 7$ & 150 & 4 & & \\
\hline & & JAV. & & & & & & & & & & \\
\hline & & $\begin{array}{c}14 . \ldots \\
F=0\end{array}$ & 1.3 & .15 & 7.6 & 75 & $\cdot[7$ & $.1^{\prime}$ & $19 n$ & 4 & & \\
\hline & & $14 \ldots$ & 1.3 & .5 & lt. & $7 \mathrm{~m}$ &.$(1)$ & .59 & $7 r$ & क & & \\
\hline & & ${ }_{\Delta P,}^{2 r} \ldots$ & .44 & .5 & 7.6 & 73 & (n) & $.1^{2}$ & or & a & & \\
\hline & & ${ }_{M A Y}^{23} \cdots$ & .37 & in & 6.6 & 75 & .019 & .15 & 54 & 4 & & \\
\hline & & JUNE & .67 & .10 & 5.0 & 6.4 & CP? &.$^{\wedge H}$ & 50 & 4 & & \\
\hline & & JuLY &.+4 & .15 & $50^{-}$ & $\mathrm{S} 2$ & ir? & $.1 r$ & ar & 4 & & \\
\hline & & $-2 \ldots$ & .37 & $.1 t$ & 5. & $\theta ?$ & ar & .19 & 5? & 4 & & \\
\hline & & $i^{r} \ldots$ & .15 & .25 & 4.2 & 53 & $\because{ }^{\prime} 4$ & .11 & $5 h$ & 4 & & \\
\hline & & $17 \ldots$ & .59 & .16 & $3.0^{\circ}$ & 37 & $\therefore-n$ & $\because 92$ & $4 ?$ & 4 & & \\
\hline & & $23 \ldots$ & .57 & .15 & 7.4 & 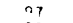 & $\therefore \div 4$ & $\therefore 9$ & $5^{n}$ & 4 & & \\
\hline & & $31 \ldots$ & .54 & .25 & 4.4 & 52 & .113 & .15 & s1 & 4 & & \\
\hline & & 67 & .37 & .5 & 4.3 & +1 & $.2 C_{5}$ & $.2 r$ & 72 & 4 & & \\
\hline & & $14 \ldots$ & .22 & .15 & 5. & 53 & $\therefore 2$ & $.3 x$ & $3 r$ & 4 & & \\
\hline & & $21 \ldots$ & .37 & .05 & 3. & 32 & $r+i^{2}$ & .17 & 51 & 4 & & \\
\hline & & SEPT. & .44 & .16 & 4.4 & $\Rightarrow$ & $\therefore-0$ & $\because 7$ & 45 & 4 & & \\
\hline & & $=5 \ldots$ & $\because \because 7$ & .05 & 2.0 & 42 & $\therefore: 2$ & .18 & 45 & 4 & & \\
\hline & & $12 \ldots$ & 1.5 & .15 & 3.4 & 37 & -lui & .32 & 25 & 4 & & \\
\hline & & $19 \ldots$ & .97 & $.1 \mathrm{C}$ & 3.5 & 35 & .rr & $.1 r$ & Sc & 4 & & \\
\hline & & $24 \ldots$ & .31 & .16 & 1.4 & 43 & $\therefore-13$ & $.1^{5}$ & 25 & a & & \\
\hline
\end{tabular}


GREAT MIAMI RIVER BASIN

03272400 GREAT YIANI RIVER NEAR MIDDLETOWN, OHIO--CONT InUed

CHEMICAL ANALYSES IN MILLIGRAMS PER LITER, HATER YEAR OCTOBER 1967 TO SEPTEMBER 1968

\begin{tabular}{|c|c|c|c|c|c|c|c|c|c|c|c|}
\hline 1) ATE & 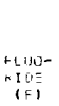 & $\begin{array}{l}V I T H \text { ITE } \\
(V 13)\end{array}$ & $\begin{array}{l}\text { ICTAL } \\
\text { PHIS- } \\
\text { PHIFIIS } \\
(P \cap 4)\end{array}$ & $\begin{array}{l}\text { DIS- } \\
\text { SIIVET } \\
\text { SHLIOS } \\
\text { IFESI- } \\
\text { DUE AT } \\
\text { IRC CI }\end{array}$ & $\begin{array}{l}\text { DIS- } \\
\text { SNLVF? } \\
5 \mathrm{LIOS} \\
\text { ISIM JF } \\
\text { CFISTI- } \\
\text { TUFNTSI }\end{array}$ & $\begin{array}{l}\text { HAPT- } \\
\triangle E S S \\
(C A . M G)\end{array}$ & $\begin{array}{l}\text { NAP - } \\
\text { CAP- } \\
\text { RNNATE } \\
\text { HADS- } \\
\text { NESS }\end{array}$ & $\begin{array}{l}\text { SDFCI- } \\
\text { FIS } \\
\text { CTINID- } \\
\text { METANCE } \\
\text { IMICEC- } \\
\text { MHOSI }\end{array}$ & PH & $\begin{array}{l}\text { TFMP- } \\
\text { FEATURE } \\
\text { IDEG CI }\end{array}$ & $\operatorname{COL} \cap \mathrm{P}$ \\
\hline \multicolumn{12}{|l|}{ UCT. } \\
\hline ra... & -- & 7.7 & .22 & 542 & -- & $3 \in 5$ & $1 \subset A$ & $84 C$ & 7. C & $2 \mathrm{I}$ & -- \\
\hline $11 \ldots$ & -- & $7 . ?$ & .33 & $5 ? \%$ & -- & 321 & 174 & $P C^{2}$ & h. 0 & 17 & -- \\
\hline $12 \ldots$ & -- & a.s & .22 & $58 ?$ & -- & 35 : & 16.8 & $8+3$ & 7.? & 19 & -- \\
\hline$>5 \ldots$ & -- & 9.8 & $\therefore 29$ & 578 & -- & $39 c$ & 178 & 596 & 7.1 & I 7 & $\cdots$ \\
\hline \multicolumn{12}{|l|}{ Nive. } \\
\hline$\therefore 1 \ldots$ & -- & 4.8 & .47 & 524 & -- & 245 & $1^{2}$ & 927 & 7.4 & 17 & -- \\
\hline $19 \ldots$ & -- & 0.3 & .21 & 514 & -- & 365 & 152 & $78 \bar{L}$ & 7.4 & 16 & -- \\
\hline $14 \ldots$ & .4 & 9.3 & .17 & 520 & 432 & $34 \times$ & $1+4$ & $T P R$ & 7.2 & 12 & $4^{9}$ \\
\hline $\begin{array}{l}\text { oer. } \\
1 ; \ldots .\end{array}$ & $\cdot 3$ & 10 & . & 316 & 275 & 224 & +7 & 403 & 7.7 & B & 25 \\
\hline $\begin{array}{l}\text { JAIN. } \\
14 . . .\end{array}$ & & & & $50 ?$ & & & & & 7.4 & & 75 \\
\hline rEA." & .4 & 8.3 & - -2 & 34 & 540 & 273 & lish & of 2 & 7.4 & b & h \\
\hline $\begin{array}{l}14 \ldots . . \\
\text { MAR. }\end{array}$ & $\bullet$ & 14 & .25 & 484 & 472 & 342 & 128 & 740 & 7.6 & 4 & 25 \\
\hline $\begin{array}{l}21 \\
A P\end{array}$ & .4 & 7. B & .25 & $45 \pi$ & 425 & 330 & 121 & +01 & $7 . t$ & $1^{2}$ & 15 \\
\hline MAY & .3 & R. 1 & .12 & $45^{\circ}$ & $42 ?$ & 345 & $1 \times 7$ & 716 & 7.4 & 22 & 15 \\
\hline $\begin{array}{l}15 \ldots . \\
\text { jivt }\end{array}$ & $\cdot+$ & 14 & .14 & $4 \times n$ & 411 & $3 \times 4$ & $1>2$ & $\{0\rangle$ & T. & $\gg$ & 25 \\
\hline JuLY $1<$. & .4 & 7.3 & .15 & 322 & 372 & 203 & $1: 2$ & $+3 I$ & 7.5 & 77 & 3 \\
\hline $12 \ldots$ & -- & 19 & .20 & 459 & -- & 222 & $1=7$ & G.R. & 7.5 & 2.7 & - \\
\hline $19 \ldots$ & -- & 5.3 & .20 & 476 & -- & 341 & $14 \%$ & $7 ? 1$ & 7.4 & 29 & -- \\
\hline $17 \ldots$ & -- & 3.5 & $.4 t$ & 454 & -- & 138 & 117 & 741 & 7.6 & 20 & -- \\
\hline $2 \$ \ldots$ & -- & 5.6 & $.4 v$ & $41 t$ & -- & $31 \vec{c}$ & ifi & 150 & 7.0 & $3^{r}$ & -- \\
\hline$\$ 1 \ldots$ & -- & 7.0 & .17 & $41 z$ & -- & 244 & 114 & 611 & 7.5 & 25 & -- \\
\hline A'lis. & & & & & & & & & & & \\
\hline $27 \ldots$ & - & 7.4 & .20 & 442 & -- & $31 t$ & 153 & +20 & 7.4 & 30 & -- \\
\hline $14 \ldots$ & -- & 8.3 & .31 & $4 \geq r$ & -- & $31 r$ & \& 7 & 6ito & 7.4 & 24 & - \\
\hline $21 \ldots$ & -- & 7.5 & . $a_{1}$ & 49 & -- & $3 \in t$ & $12=$ & 732 & 7.7 & 29 & -- \\
\hline$? 2 \ldots$ & -- & h. 2 & .29 & 491 & -- & $2+6$ & $L^{2 r}$ & $7 b C$ & 7.7 & 24 & -- \\
\hline SFPT. & & & & & & & & & & & \\
\hline $35 \ldots$ & -- & $\ldots l$ & $.4 C$ & 452 & -- & $33+4$ & $11^{\circ}$ & 721 & 7.5 & $? 4$ & -- \\
\hline $12 \ldots$ & -- & 2.2 & .67 & $5: 2$ & -- & $25 c$ & 127 & $77=$ & 7.5 & $? 2$ & -- \\
\hline $18 \ldots$ & -- & 0.5 & $.2 t$ & 494 & -- & 357 & 127 & $7 \mu_{1}$ & 7.5 & 25 & -- \\
\hline $24 \ldots$ & - & 7.2 & .16 & $49 r$ & -- & $25 t$ & 153 & 770 & 7.4 & 79 & -- \\
\hline
\end{tabular}

\begin{tabular}{|c|c|c|c|c|c|c|c|}
\hline 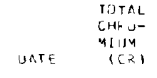 & 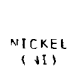 & $\begin{array}{c}\text { capofe- } \\
\text { (culis) }\end{array}$ & $\begin{array}{ll}\operatorname{lr} 10 \\
x \rightarrow 21\end{array}$ & $711 \%$ & 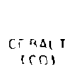 & $\begin{array}{l}\text { ARSENSC } \\
\text { TASS }\end{array}$ & $\begin{array}{l}\text { cAn- } \\
\text { mllu" } \\
\text { inn }\end{array}$ \\
\hline $\begin{array}{c}0 \mathrm{cr} . \\
r_{4}^{4} \ldots\end{array}$ & -- & -- & :- & I & $=$ & $\because$ & $=$ \\
\hline $\begin{array}{l}12 \ldots \ldots \\
<5 \ldots\end{array}$ & ${ }_{-12}$ & .16 & ." &.$r^{2}$ & $=$ & $\because r$ & ن \\
\hline -- & -. & -- & -- & -. & -. & -- & - \\
\hline$\because$ & $=$ & $\because$ & $\because$ & $\because$ & $\because$ & $\because-$ & -- \\
\hline -- & -- & -- & -- & -. & -- & -- & - \\
\hline$\therefore$ & -- & -- & -- & -- & -- & -- & -- \\
\hline$\therefore$ & -- & -- & -- & -- & -- & -. & -- \\
\hline -- & -- & -- & -- & -. & -- & -- & -- \\
\hline .- & .. & -- & .- & .. & --. & .- & - \\
\hline .. & -- & .. & -.- & -.. & -- & .. & - \\
\hline -- & -- & -- & .. & .. & -. & -- & -1 \\
\hline -- & -- & -- & -- & -- & -- & -. & \\
\hline$\because$ & $\because$ & $\because$ & $\because$ & $\because$ & $\ddot{z}$ & - & \\
\hline $31 \ldots$ & -- & -- & $\because$ & $\because$ & -- & -- & - \\
\hline -- & $=$ & $=-$ & $\because$ & $\because$ & 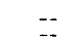 & $=$ & \\
\hline$\cdots$ & $\therefore$ & $\because$ & - & $\because$ & $\therefore$ & $\overline{-\pi}$ & \\
\hline -- & $\ldots$ & -- & ._- & .. & -- & -- & \\
\hline$\cdots$ & -- & -- & - & - & --- & $\because$ & \\
\hline$\cdots$ & $\because 2$ & $\because 1$ & $\because$ & $\because$ & $\because$ & $\because$ & \\
\hline
\end{tabular}


LOCATION, --Lat $39^{\circ} 23^{\prime} 28^{\prime \prime}$, long $84^{\circ} 34^{\prime} 20^{\prime \prime}$, in NEł sec.6, T.1 N., R.3 E., Butler County, temperature recorder at gaging station on right bank, 1,000 ft downstream from Columbia Bridge at Hamilton, and 3 miles downstream from Four Mile creek.

DRA INAGE AREA. $--3,630 \mathrm{sq} \mathrm{m} 1$

PERIOD OF RECORD. --Chemical analyses: October 1950 to September 1951.

Water temperatures: October 1950 to September 1951, October 1957 to September 1968.

EXTREMES. - -1967-68:

Fater temperatures: Maximum, $28.0^{\circ} \mathrm{C}$ July $18-20,22,23$, Aug, 21-26; minimum, $1.0^{\circ} \mathrm{C} \mathrm{Jan}, 2,3,5-7$.

Period of record:

Water temperatures: Maximum, $34.0^{\circ} \mathrm{C}$ Aug. 16,1965 ; minimum, freezing point on several days during December 1950, January to February 1951.

REMARKS.--Some regulation at low flow by industrial plants above station.

TEMPERATURE $\left.1{ }^{\circ} \mathrm{C}\right)$ OF WATER, WATER YEAR OCTOBER 1967 TO SEPTEMBER 29681 ( CONT INUDUS ETHYL-ALCOHOL ACTUATED THERMOGRAPH)

$\begin{array}{llllllllllllllllllllllllllllllllllllllllll}\text { MUNH } & 1 & 2 & 3 & 4 & 5 & 6 & 7 & 8 & 0 & 10 & 11 & 12 & 13 & 14 & 15 & 16 & 17 & 18 & 19 & 20 & 21 & 22 & 23 & 24 & 25 & 26 & 27 & 28 & 29 & 30 & 31 & \text { AVER }\end{array}$

$\begin{array}{llllllllllllllllllllllllllllllllllllll}\text { MAXIMUM } & 17 & 18 & 20 & 21 & 21 & 21 & 20 & 19 & 19 & 19 & 18 & 17 & 17 & 18 & 18 & 19 & 19 & 19 & 19 & 18 & 18 & 17 & 17 & 17 & 17 & 17 & 17 & 16 & 15 & 15 & 15 & 18 \\ \text { MINIMUM } & 16 & 17 & 18 & 20 & 21 & 20 & 19 & 19 & 18 & 18 & 17 & 17 & 17 & 17 & 18 & 18 & 19 & 19 & 18 & 17 & 17 & 17 & 17 & 17 & 17 & 17 & 16 & 15 & 14 & 14 & 15 & 17\end{array}$ MINIMUM

NOVEMBER

$\begin{array}{lllllllllllllllllllllllllllllllllll}\text { MAXIMUM } & 16 & 16 & 16 & 16 & 14 & 13 & 12 & 11 & 11 & 11 & 12 & 12 & 12 & 12 & 11 & 10 & 10 & 10 & 10 & 9 & 9 & 9 & 9 & 9 & 8 & 8 & 8 & 7 & 7 & 7 & -- & 11\end{array}$

$\begin{array}{lllllllllllllllllllllllllllllllll}\text { MINIMUM } & 15 & 16 & 16 & 14 & 13 & 12 & 11 & 11 & 10 & 10 & 11 & 12 & 12 & 11 & 10 & 10 & 10 & 10 & 9 & 9 & 9 & 9 & 9 & 8 & 8 & 8 & 7 & 7 & 7 & 7 & - & 10\end{array}$

$\begin{array}{llllllllllllllllllllllllllllllllllllll}\text { MAXIMUM } & 7 & 7 & 5 & 3 & 2 & 3 & 4 & 4 & 4 & 5 & 5 & 5 & 5 & 5 & 5 & 5 & 4 & 4 & 4 & 4 & 6 & 5 & 6 & 3 & 2 & 2 & 2 & 2 & 2 & 2 & 2 & 4\end{array}$

$\begin{array}{lllllllllllllllllllllllllllllllllllll}\text { MINI MUM } & 7 & 5 & 3 & 2 & 2 & 2 & 3 & 4 & 4 & 4 & 5 & 5 & 5 & 5 & 5 & 4 & 3 & 3 & 4 & 4 & 4 & 6 & 3 & 2 & 2 & 2 & 2 & 2 & 2 & 2 & 2 & 3 & \end{array}$

MAXIMUM
INAMUM

FEBROARY

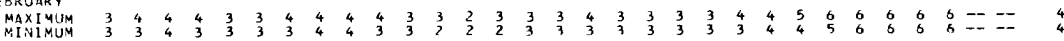

MAKCH

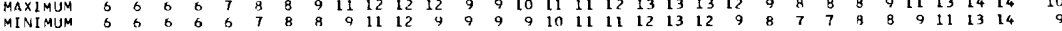

$\begin{array}{llllllllllllllllllllllllllllllllllll}\text { MAXIMUM } & 14 & 14 & 13 & 13 & 13 & 12 & 11 & 12 & 13 & 14 & 15 & 16 & 17 & 17 & 17 & 17 & 17 & 18 & 18 & 19 & 19 & 20 & 20 & 20 & 18 & 17 & 17 & 18 & 19 & 19 & -- & 16 \\ \text { MINIMUM } & 13 & 13 & 13 & 13 & 12 & 11 & 11 & 11 & 12 & 13 & 14 & 15 & 16 & 17 & 16 & 16 & 17 & 17 & 18 & 18 & 19 & 19 & 20 & 18 & 17 & 17 & 17 & 17 & 18 & 19 & -- & 16\end{array}$

MAY

$\begin{array}{lllllllllllllllllllllllllllllllllllllll}\text { MAXIMUM } & 20 & 21 & 21 & 21 & 21 & 20 & 19 & 19 & 19 & 19 & 19 & 17 & 17 & 18 & 20 & 20 & 20 & 19 & 18 & 18 & 17 & 17 & 17 & 14 & 14 & 15 & 15 & 15 & 15 & 14 & 15 & 18 \\ \text { MINIMUM } & 19 & 20 & 21 & 21 & 20 & 19 & 19 & 19 & 19 & 19 & 17 & 17 & 17 & 17 & 18 & 20 & 19 & 18 & 18 & 17 & 17 & 17 & 14 & 14 & 14 & 14 & 15 & 15 & 14 & 14 & 14 & 17\end{array}$

$\begin{array}{llllllllllllllllllllllllllllllllllll}\text { MAXIMUM } & 16 & 17 & 18 & 19 & 20 & 21 & 22 & 23 & 24 & 24 & 24 & 24 & 24 & 24 & 23 & 23 & 23 & 22 & 22 & 23 & 23 & 23 & 24 & 25 & 25 & 24 & 24 & 22 & 22 & 23 & -- & 22 \\ \text { MINIMUM } & 15 & 16 & 17 & 18 & 19 & 20 & 21 & 22 & 23 & 24 & 24 & 24 & 24 & 23 & 23 & 23 & 22 & 22 & 22 & 22 & 23 & 23 & 23 & 24 & 24 & 24 & 22 & 21 & 21 & 22 & -- & 22\end{array}$ JULY

$\begin{array}{llllllllllllllllllllllllllllllllllll}\text { MAXIXUM } & 24 & 24 & 24 & 24 & 24 & 24 & 24 & 24 & 24 & 25 & 26 & 27 & 27 & 27 & 27 & 27 & 27 & 28 & 28 & 28 & 27 & 28 & 28 & 27 & 27 & 26 & 26 & 24 & 24 & 24 & 24 & 26 \\ \text { MINIMUM } & 23 & 24 & 24 & 23 & 23 & 24 & 24 & 24 & 24 & 24 & 25 & 26 & 27 & 27 & 27 & 26 & 26 & 27 & 28 & 27 & 27 & 27 & 27 & 27 & 25 & 25 & 24 & 24 & 24 & 24 & 24 & 25\end{array}$ AUGUST

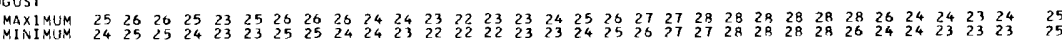
SEPTEMBER $\begin{array}{lllllllllllllllllllllllllllllllllllllll}\text { MAXIMUM } & 24 & 24 & 24 & 24 & 24 & 24 & 24 & 24 & 24 & 24 & 22 & 22 & 23 & 23 & 24 & 24 & 24 & 23 & 23 & 23 & 23 & 25 & 26 & 26 & 26 & 26 & 24 & 24 & 23 & 23 & -2 & 24 \\ \text { MINIMUM } & 24 & 24 & 24 & 24 & 24 & 24 & 24 & 24 & 24 & 22 & 21 & 21 & 22 & 23 & 23 & 24 & 23 & 23 & 23 & 23 & 23 & 23 & 25 & 26 & 26 & 24 & 24 & 23 & 23 & 23 & -- & 23\end{array}$ 03274050 GREAT MIAMI RIVER NEAR HAMILTON, OHIO LOCATION. - - Lat $39^{\circ} 20^{\prime} 00^{\prime \prime}, 1$ long $84^{\circ} 36^{\prime} 42^{\prime \prime}$, Butler County, at American Materials Company private bridge near Hamilton,
about 5.5 miles below gaging station.

DRAINAGE AREA. $--3,667 \mathrm{sq} \mathrm{mi}$.

PERIOD OF RECORD, --Chemical analyses: July 1963 to September 1966.

REMARKS. --Samples were collected weekly October, July to September, and monthly November to June. Samples for iron and manganese were filtered clear when collected. Records of discharge are given for Great Mrami River at Hamilton (drainage area $3,630 \mathrm{sq} \mathrm{mi}$ )

CHEMICAL ANALYSES IN MILLIGRAMS PER LITER, WATER YEAR OCTOBER 1967 TO SEPTEMBER 1968

\begin{tabular}{|c|c|c|c|c|c|c|c|c|c|c|c|c|}
\hline $\begin{array}{l}\text { CATE } \\
\text { חCT. }\end{array}$ & TIME & $\begin{array}{l}\text { DIS- } \\
\text { CHARGE } \\
\text { (CFS) }\end{array}$ & $\begin{array}{l}\text { SILICA } \\
\text { ISI02I }\end{array}$ & $\begin{array}{l}\text { IRON } \\
\text { (FE) }\end{array}$ & $\begin{array}{l}\text { MAN- } \\
\text { GANESE } \\
\text { (MN) }\end{array}$ & $\begin{array}{l}\text { CAL- } \\
\text { CIUM } \\
\text { ICAI }\end{array}$ & $\begin{array}{l}\text { MAG- } \\
\text { NE- } \\
\text { SIUM } \\
\text { I MGI }\end{array}$ & $\begin{array}{c}\text { SחDIUM } \\
\text { (NA) }\end{array}$ & $\begin{array}{l}\text { TAS- } \\
\text { SIUM } \\
\text { (K) }\end{array}$ & $\begin{array}{l}\text { BICAR- } \\
\text { BONATE } \\
\text { (HCO3) }\end{array}$ & $\begin{array}{l}\text { CAR- } \\
\text { BONATE } \\
\text { (CO3) }\end{array}$ & $\begin{array}{l}\text { SUEFAT } \\
\text { (SO4) }\end{array}$ \\
\hline $04 \ldots$ & 1100 & 479 & -- & .15 & .15 & -- & -- & -- & -- & 210 & 0 & 171 \\
\hline $11 \ldots$ & 1200 & 531 & $\cdots$ & .41 & .15 & - & - & -- & $\cdots$ & 224 & 0 & 152 \\
\hline $18 \ldots$ & 1400 & 572 & -- & .22 & .15 & - & -- & $\cdots$ & $\cdots$ & 226 & 0 & 184 \\
\hline $25 \ldots$ & 0900 & 2850 & - & .40 & .17 & -- & -- & -- & -- & 224 & 0 & 159 \\
\hline Nov. & & & & & & & & & & & & \\
\hline $01 \ldots$ & 1130 & 926 & -- & .49 & .28 & -- & -- & -- & -- & 218 & 0 & 181 \\
\hline ов... & 1015 & 1020 & $=$ & .98 & .12 & -- & -- & -- & -- & 274 & c & 127 \\
\hline $14 \ldots$ & 1230 & 808 & 7.9 & 1.0 & .11 & 89 & 32 & 36 & 4.8 & 748 & 0 & 149 \\
\hline $\begin{array}{l}13 \ldots \\
11 \mathrm{~N} .\end{array}$ & 1130 & 11700 & 6.7 & -- & .00 & 62 & 19 & 7.7 & 2.9 & 104 & 0 & 60 \\
\hline $\begin{array}{l}18 . . \\
\text { FEA. }\end{array}$ & 1145 & 1250 & 8.6 & .38 & .18 & 99 & 32 & 42 & 3.3 & 289 & 0 & 135 \\
\hline $\begin{array}{l}14 \ldots \\
\text { MAR. }\end{array}$ & 1015 & 1930 & 7.0 & .34 & $.0 B$ & 92 & ${ }^{2} 1$ & 21 & 2.7 & 284 & 0 & 106 \\
\hline $\begin{array}{l}20 \ldots . . \\
A P R .\end{array}$ & 1200 & 2620 & 2.4 & .81 & .07 & 79 & 35 & 27 & 2.7 & 276 & 0 & 102 \\
\hline MAY $23 \cdots$ & 1400 & 1820 & $\cdot B$ & .21 & .06 & 81 & 33 & 22 & 4.2 & 258 & 0 & 106 \\
\hline JUNE & 1200 & 2760 & 6.0 & .54 & .09 & 79 & 31 & 20 & 3.0 & 262 & 0 & 36 \\
\hline $\begin{array}{l}12 \ldots \\
\text { JuLY }\end{array}$ & 1215 & 2250 & 2.3 & .28 & .05 & 82 & 30 & 18 & 2.8 & 274 & 0 & $8 ?$ \\
\hline $02 \ldots$ & 1300 & 1760 & -- & .48 & .05 & -- & -- & -- & - & 252 & 0 & 96 \\
\hline $10 \ldots$ & 1315 & 1160 & $\cdots$ & .37 & .07 & -- & -- & -- & -- & 262 & 0 & 127 \\
\hline $17 \ldots$ & 1100 & 2000 & -- & .38 & .06 & -- & -- & -- & -- & 262 & 0 & 93 \\
\hline $23 \ldots$ & 1530 & 2830 & - & .17 & .07 & -- & -- & -- & -- & 206 & 0 & 90 \\
\hline $31 \ldots$ & 1100 & 1740 & -- & .17 & .07 & -- & -- & -- & -- & 234 & $c$ & 94 \\
\hline$A L: G$. & & & & & & & & & & & & \\
\hline $07 \ldots$ & 1400 & 2380 & -- & .18 & .07 & -- & -- & -- & -- & 264 & 0 & 81 \\
\hline $14 \ldots$ & 1130 & 2700 & $\cdots$ & .14 & .10 & -- & - & $\cdots$ & $\cdots$ & 250 & 0 & 80 \\
\hline $21 \ldots$ & 1115 & 1620 & - & .16 & .09 & -- & -- & -- & -- & 290 & 0 & 103 \\
\hline $28 \ldots$ & 1240 & 969 & -- & .35 & .18 & -- & -- & -- & $\cdots$ & 277 & 0 & 137 \\
\hline SEPT * & & 850 & - & 37 & 19 & -- & -- & $\ldots$ & -- & & & \\
\hline $12 \ldots$ & $\begin{array}{l}1343 \\
1100\end{array}$ & $\begin{array}{l}850 \\
952\end{array}$ & 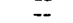 & $: 34$ & $1: 39$ & $=$ & $\ldots$ & $\therefore$ & $=$ & $\begin{array}{l}262 \\
284\end{array}$ & c & $\begin{array}{r}125 \\
91\end{array}$ \\
\hline $18 \ldots$ & 1300 & 1280 & -- & .52 & .19 & -- & -- & -- & -- & 248 & 0 & 137 \\
\hline $24 \ldots$ & 1500 & 833 & - & .25 & .14 & -- & -- & -- & -- & 270 & 0 & 115 \\
\hline
\end{tabular}


03274050 GREAT MIAMI RIVER NEAR HAMILTON, OHIO--Continued

CHEMICAL ANALYSES IN MILLIGRAMS PER LITER, WATER YEAR OCTOBER 1967 TO SEPTEMBER 1968

\begin{tabular}{|c|c|c|c|c|c|c|c|c|c|c|c|c|}
\hline CATE & $\begin{array}{l}\text { CHLO- } \\
\text { KIOE } \\
(\mathrm{CL})\end{array}$ & $\begin{array}{l}\text { FLUO- } \\
\text { RIDE } \\
\text { (F) }\end{array}$ & $\begin{array}{l}\text { NITRATE } \\
\text { (NO3) }\end{array}$ & $\begin{array}{l}\text { TOTAL } \\
\text { PHOS- } \\
\text { PHORUS } \\
\text { (PO4) }\end{array}$ & $\begin{array}{l}\text { DIS- } \\
\text { SOLVED } \\
\text { SOLIOS } \\
\text { IRESI- } \\
\text { DUE AT } \\
\text { IBO CI }\end{array}$ & $\begin{array}{l}\text { DIS- } \\
\text { SOLVED } \\
\text { SOL IOS } \\
\text { ISUM OF } \\
\text { CUNSTI- } \\
\text { TUENTSI }\end{array}$ & $\begin{array}{l}\text { HAPD- } \\
\text { NESS } \\
\text { (CA, MCI) }\end{array}$ & $\begin{array}{l}\text { NON- } \\
\text { CAR- } \\
\text { BONAIE } \\
\text { HARD- } \\
\text { NESS }\end{array}$ & $\begin{array}{l}\text { SPECI- } \\
\text { FIC } \\
\text { COND- } \\
\text { UC TANCE } \\
\text { IMICRD- } \\
\text { MHOSI }\end{array}$ & PH & $\begin{array}{l}\text { TEMD- } \\
\text { ERATURE } \\
\text { IOEG CI }\end{array}$ & COLnR \\
\hline \multicolumn{13}{|l|}{ OCT. } \\
\hline $\begin{array}{l}04 \ldots . \\
11 . . .\end{array}$ & $\begin{array}{l}60 \\
58\end{array}$ & -- & $\begin{array}{l}5.2 \\
5.4\end{array}$ & .50 & 554 & -- & 345 & 173 & 850 & 7.2 & 21 & $=$ \\
\hline $18 \ldots$ & 58 & -- & $\begin{array}{l}5.4 \\
5.4\end{array}$ & .12 & $\begin{array}{l}344 \\
578\end{array}$ & $=$ & $\begin{array}{l}330 \\
350\end{array}$ & $\begin{array}{l}146 \\
165\end{array}$ & $\begin{array}{l}830 \\
891\end{array}$ & $\begin{array}{l}7.7 \\
7.4\end{array}$ & $\begin{array}{l}17 \\
19\end{array}$ & $=$ \\
\hline $25 . .$. & 58 & -- & 7.2 & .90 & 540 & - & 365 & 181 & 856 & 7.3 & 14 & -- \\
\hline \multicolumn{13}{|l|}{ Nov. } \\
\hline $\begin{array}{l}01 . . . \\
08 . . .\end{array}$ & $\begin{array}{l}60 \\
44\end{array}$ & $=$ & $\begin{array}{l}6.2 \\
6.2\end{array}$ & .32 & $\begin{array}{l}556 \\
508\end{array}$ & $\because$ & $\begin{array}{l}345 \\
345\end{array}$ & $\begin{array}{l}166 \\
120\end{array}$ & $\begin{array}{l}856 \\
782\end{array}$ & $\begin{array}{l}7.3 \\
7.7\end{array}$ & $\begin{array}{r}17 \\
9\end{array}$ & $=$ \\
\hline $14 \ldots$ & 48 & .4 & 7.7 & .24 & 530 & 498 & 354 & 151 & 800 & 7.5 & 10 & 20 \\
\hline \multicolumn{13}{|l|}{ OEC. } \\
\hline $\begin{array}{l}13 \ldots \\
\text { JAN. }\end{array}$ & 20 & .4 & 18 & .47 & 300 & 278 & 233 & 98 & 463 & 7.8 & a & 25 \\
\hline $\begin{array}{l}18 . . \\
F \in 8 .\end{array}$ & 66 & .3 & 9.3 & .31 & 586 & 540 & 379 & 143 & 881 & 7.7 & 6 & 25 \\
\hline$\underset{M A R}{14 \ldots}$ & 34 & .2 & 13 & .28 & 456 & 449 & 357 & 124 & 726 & 7.7 & 3 & 10 \\
\hline $\begin{array}{l}20 \ldots \\
\triangle P R .\end{array}$ & 40 & .4 & 7.1 & .33 & 462 & 433 & 341 & 115 & 705 & 7.8 & 14 & 15 \\
\hline${ }_{M \Delta Y}^{23} \cdots$ & 36 & .3 & 7.1 & .31 & 442 & 418 & 338 & 126 & 708 & 7.6 & 22 & 10 \\
\hline$\underset{\text { JUNE }}{15 \ldots}$ & 32 & .4 & 13 & .40 & 422 & 400 & 325 & 110 & 672 & 7.8 & 22 & 15 \\
\hline $\begin{array}{l}12 \ldots \\
\text { Juty }\end{array}$ & \multicolumn{12}{|c|}{ Juty } \\
\hline $02 \ldots$ & 30 & -- & 19 & .56 & 476 & -- & 326 & 119 & 684 & 7.6 & 27 & -- \\
\hline $10 \ldots$ & $4 \mathrm{C}$ & $\cdots$ & 4.5 & .57 & 490 & -- & 350 & 135 & 760 & 7.7 & 29 & $=$ \\
\hline $17 \ldots$ & 40 & -- & 8.3 & .92 & 418 & -- & 314 & 99 & 696 & 7.8 & 29 & -- \\
\hline $23 \ldots$ & 28 & -- & 6.8 & .39 & 338 & -- & 264 & 95 & 554 & 7.7 & 29 & - \\
\hline $31 \ldots$ & 28 & -- & 5.7 & .23 & 434 & -- & 299 & 106 & 621 & 7.7 & 24 & -- \\
\hline \multicolumn{13}{|l|}{ AIIG. } \\
\hline $07 \ldots$ & 28 & -- & 10 & .58 & 452 & $\cdots$ & 310 & 93 & 635 & 7.9 & 28 & -- \\
\hline $14 \ldots$ & 24 & -- & 9.1 & .46 & 404 & -- & 300 & 05 & 600 & 7.6 & 24 & -- \\
\hline $21 \ldots$ & 34 & $\cdots$ & 9.0 & .79 & 494 & -- & 364 & 126 & 727 & 7.8 & 30 & -- \\
\hline $\begin{array}{l}28 . . . \\
\text { SEPT. }\end{array}$ & 42 & - & 6.4 & .31 & 509 & -. & 366 & 143 & 772 & 7.7 & 23 & - \\
\hline $05 \ldots$ & 44 & $\because$ & 8.5 & .46 & 488 & $=$ & 352 & 137 & 759 & 7.5 & 24 & $=$ \\
\hline $\begin{array}{l}12 \ldots \\
18 . . .\end{array}$ & $\begin{array}{l}42 \\
48\end{array}$ & - & $\begin{array}{l}7.0 \\
5.9\end{array}$ & $\begin{array}{r}.99 \\
.35\end{array}$ & $\begin{array}{l}458 \\
514\end{array}$ & - & $\begin{array}{l}330 \\
340\end{array}$ & $\begin{array}{r}97 \\
137\end{array}$ & $\begin{array}{l}726 \\
783\end{array}$ & $\begin{array}{l}7.7 \\
7.5\end{array}$ & $\begin{array}{l}21 \\
23\end{array}$ & -- \\
\hline $24 \ldots$ & 46 & -- & 9.2 & .88 & 456 & - & 344 & 123 & 760 & 7.6 & 27 & - \\
\hline
\end{tabular}

\begin{tabular}{|c|c|c|c|c|c|c|c|c|}
\hline DATE & $\begin{array}{l}\text { TOTAL } \\
\text { CHRO- } \\
M I J M \\
\text { (CR) }\end{array}$ & $\begin{array}{l}\text { NICKEL } \\
\text { (NI) }\end{array}$ & $\begin{array}{l}\text { COPOER } \\
\text { (CU) }\end{array}$ & $\begin{array}{l}\text { LEAD } \\
\text { (PB) }\end{array}$ & $\begin{array}{l}\text { ZINC } \\
\text { I } Z \text { N) }\end{array}$ & $\begin{array}{c}\text { CORALT } \\
\text { (CD) }\end{array}$ & $\begin{array}{c}\text { AR SENIC } \\
\text { IASI }\end{array}$ & $\begin{array}{l}\text { CAD- } \\
\text { MIUM } \\
\text { ICDI }\end{array}$ \\
\hline \multicolumn{9}{|l|}{ OCT. } \\
\hline $04 \ldots$ & .06 & .00 & .02 & .00 & .02 & .00 & .00 & $\begin{array}{l}.00 \\
.00\end{array}$ \\
\hline $11 \ldots$ & .00 & $\begin{array}{l}.07 \\
.08\end{array}$ & $\begin{array}{l}.03 \\
.00\end{array}$ & $\begin{array}{l}.00 \\
.00\end{array}$ & .02 & .00 & $\begin{array}{l}.00 \\
.00\end{array}$ & $\begin{array}{l}.00 \\
.00\end{array}$ \\
\hline $\begin{array}{l}2 \mathrm{~B} \ldots \\
25 \ldots\end{array}$ & $\begin{array}{l}.00 \\
.01\end{array}$ & $\begin{array}{l}.08 \\
.16\end{array}$ & $\begin{array}{l}.00 \\
.01\end{array}$ & .00 & .02 & .00 & .00 & .00 \\
\hline \multicolumn{9}{|l|}{ Nov. } \\
\hline $01 \ldots$ & -- & .19 & .01 & .00 & .07 & $=$ & .00 & .00 \\
\hline $\begin{array}{l}08 \ldots \\
14 \ldots\end{array}$ & .00 & $\begin{array}{l}.13 \\
.07\end{array}$ & $\begin{array}{l}.01 \\
.01\end{array}$ & $\begin{array}{l}.00 \\
.00\end{array}$ & $\begin{array}{l}.03 \\
.05\end{array}$ &.$\overline{O C}$ & .01 & $\begin{array}{l}.00 \\
.00\end{array}$ \\
\hline \multicolumn{9}{|l|}{ OEC. } \\
\hline $13 \ldots$ & -- & -- & -- & -- & -- & -- & -- & - \\
\hline JAN. & - & -- & -- & & 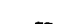 & & & \\
\hline FE8. & - & -- & - & -- & - & -- & - & -- \\
\hline$\underset{M A R}{14 \ldots}$ & -- & -- & -- & -- & - & -- & -- & -- \\
\hline $20 \ldots$ & .01 & .00 & .02 & .03 & .25 & .00 & .00 & .00 \\
\hline $\begin{array}{l}\text { APR : } \\
23 . . .\end{array}$ & & & & & & & & \\
\hline \multirow{2}{*}{\multicolumn{8}{|c|}{ MAY }} & - \\
\hline $15 \ldots$ & .01 & .01 & .02 & .02 & .06 & .00 & .00 & \\
\hline JUNE & & & & & & & & \\
\hline${ }_{\text {JuLY }}^{12 \ldots}$ & - & -- & -- & -- & -- & -- & -- & -- \\
\hline $02 \ldots$ & -. & + & -- & -- & -- & -- & -- & \\
\hline $10 \ldots$ & .00 & .01 & .01 & .00 & .01 & .00 & .00 & .00 \\
\hline $17 \ldots$ & $m$ & -- & $-\overline{-}$ & $\cdots$ & -- & -- & -- & 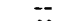 \\
\hline $23 \ldots$ & .01 & .01 & .01 & .00 & .01 & .00 & .02 & .00 \\
\hline $31 \ldots$ & -- & -- & -- & -- & -- & -- & -- & -- \\
\hline \multicolumn{9}{|l|}{ AUG. } \\
\hline $14 \ldots$ & .01 & .02 & .03 & .00 & .02 & .01 & .01 & .00 \\
\hline $21 \ldots$ & .00 & .02 & .03 & .01 & .02 & .00 & .01 & .00 \\
\hline $28, \ldots$ & .00 & .02 & .02 & .01 & .02 & .00 & .00 & .00 \\
\hline SEPT. & & & & & & & & \\
\hline $\begin{array}{l}05 \ldots \\
12 \ldots\end{array}$ & .00 & .01 & .01 & .00 & .06 & .00 & .01 & .00 \\
\hline $18 \ldots$ & .00 & .02 & .01 & .00 & .04 & .00 & .00 & .00 \\
\hline $24 \ldots$ & .01 & .01 & .01 & .00 & .02 & .00 & .01 & .00 \\
\hline
\end{tabular}


03274050 GREAT YIAKI RIVER NEAR HAYILTON, OHIO--Cont 1 nued CHEMICAL ANALYSES IN MILLIGRAMS PER LITER, WATER YEAR OCTOBER 1967 TO SEPTEMBER 1968

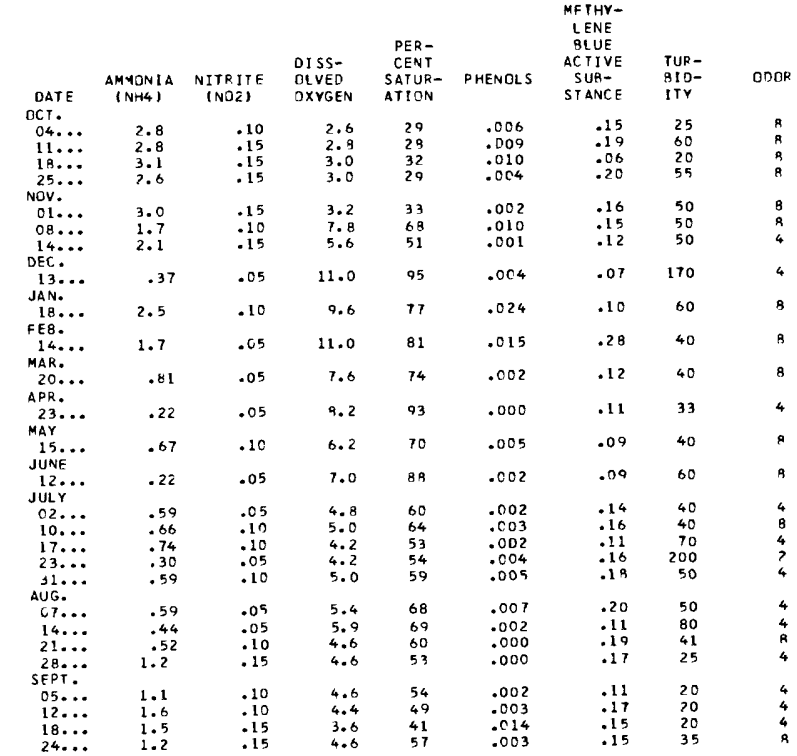

LOCATION,--Let $39^{\circ} 15^{\prime} 47^{\prime \prime}$, long $84^{\circ} 40^{\circ} 00^{\prime \prime}$, Hamilton County, at Blue Rock Road bridge at New Baltimore about 6.5 miles downtream from Indian Creek and $14 \mathrm{miles}$ downstream from gaging station at Hamilton, Butler County.

DRA INAGE AREA, $--3,814 \mathrm{sq} \mathrm{mi}$.

PER IOD OF RECORD.--Chemical analyses: July 1966 to September 1968

Water temperatures: July 1966 to september 1968 .

EXTR EMES. --1967-68:

Specific conductance: Maximum dally, 930 micromos Oct. 1, Nov. 3; minimum daily, 230 micromhos May 24.

Dissolved oxygen: Maximum daily, $12.4 \mathrm{mg} / 1 \mathrm{Dec}, 20$; minimum daily, $1.9 \mathrm{mg} / 1 \mathrm{Ju} 1 \mathrm{y} 20$, Sept. 25.

Water temperatures: Maximum, $32.0^{\circ} \mathrm{C}$ Aug. $21,23,24$; minimum, not determined.

Period of record:

Specific conductance (1967-68): Maximum dai1y, 930 micromhos Oct. 1, Nov, 3, 1967; minimum da11y, 230 micro-

mhos Yay 24,1968 .

D1ssolved oxygen (1967-68): Maximur daily, $12.4 \mathrm{mg} / 1 \mathrm{Dec} .20,1967$; minimum daily, $1.9 \mathrm{mg} / 1 \mathrm{July} 20$, Sept. 25 1968 .

water temperatures: Maximum, $32.0^{\circ} \mathrm{C}$ Aug. $21,23,24,1968$; minimum, not determined.

REMARKs. - In addition to the continuous recorder Installed on right bank at Blue Rock Road bridge, twice-weekly samples were collected by a local observer. Partial analyses were made on the maximum specific conductance and the minimum specific conductance of the samples collected each month. Jan, 1-20, 23-31 no data recorded due to frozen intake. All other interruptions in the record were due to malfunctions of the instrument. Records of discharge are given for Great Mani River at Hamilton (drainage area 3,630 sq Ini).

CHFMICAL ANALYSES IN MILLIGRAMS PER LITER, WATER YEAR OCTOBER 1967 TO SEPTEMBER 1968

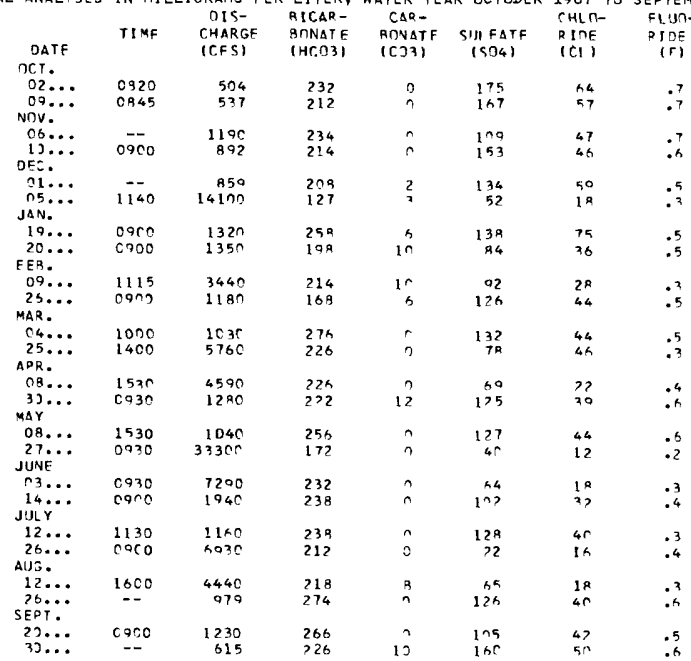




\begin{tabular}{|c|c|c|c|c|c|c|}
\hline DATE & $\begin{array}{l}\text { NITRATE } \\
\text { (NO3) }\end{array}$ & $\begin{array}{l}\text { NIS- } \\
\text { SOLVED } \\
\text { SOLINS } \\
\text { IRFSI- } \\
\text { DUE AT } \\
1 \text { SC CI }\end{array}$ & $\begin{array}{l}\text { HARD- } \\
\text { NESS } \\
(C A, M(B)\end{array}$ & $\begin{array}{l}\text { NNN- } \\
\text { CAP- } \\
\text { ANMATF } \\
\text { HARD- } \\
\text { NFSE }\end{array}$ & $\begin{array}{l}\text { SOERI } \\
\text { FIC } \\
\text { CNND- } \\
\text { UCTANCE } \\
\text { I MICRT- } \\
\text { NHOSI }\end{array}$ & PH \\
\hline $\begin{array}{c}\text { חст. } \\
{ }_{32} \ldots . .\end{array}$ & 13 & 596 & $37 c$ & 190 & 912 & 7.5 \\
\hline $\begin{array}{c}09 . . . \\
\text { vav. }\end{array}$ & 12 & 572 & 344 & $17 n$ & 849 & 7.0 \\
\hline & $11^{8.7}$ & $\begin{array}{l}438 \\
506\end{array}$ & $\begin{array}{l}73 A \\
342\end{array}$ & $\begin{array}{l}116 \\
165\end{array}$ & $\begin{array}{l}727 \\
819\end{array}$ & $\begin{array}{l}\text { T.h } \\
\text { R.n }\end{array}$ \\
\hline $\begin{array}{l}\text { DEC. } \\
21 \ldots . . \\
35 . . .\end{array}$ & $\begin{array}{l}2 n \\
26\end{array}$ & $\begin{array}{l}530 \\
277\end{array}$ & $\begin{array}{l}346 \\
196\end{array}$ & $\begin{array}{r}177 \\
91\end{array}$ & $\begin{array}{l}7 A B \\
40 h\end{array}$ & $\begin{array}{l}9.7 \\
0.4\end{array}$ \\
\hline $\begin{array}{l}\text { J14. } \\
17 \ldots \\
21 . . .\end{array}$ & 11 & $\begin{array}{l}594 \\
39 \mathrm{C}\end{array}$ & $\begin{array}{l}372 \\
286\end{array}$ & $\begin{array}{l}150 \\
107\end{array}$ & $\begin{array}{l}\text { RQK } \\
\text { 600 }\end{array}$ & $\begin{array}{l}8.4 \\
9.7\end{array}$ \\
\hline $\begin{array}{l}\text { FER. } \\
\text { O7... } \\
26 . .\end{array}$ & $\begin{array}{l}22 \\
? 2\end{array}$ & $\begin{array}{l}41 R \\
442\end{array}$ & $\begin{array}{l}3 \times 2 \\
3 \times 4\end{array}$ & $\begin{array}{l}140 \\
I \times 4\end{array}$ & $\begin{array}{l}434 \\
\text { P19 }\end{array}$ & $\begin{array}{l}2.5 \\
R .5\end{array}$ \\
\hline $\begin{array}{l}42 . \\
24 \ldots \\
25 \ldots\end{array}$ & $\begin{array}{l}19 \\
18\end{array}$ & $\begin{array}{l}510 \\
416\end{array}$ & $\begin{array}{l}974 \\
392\end{array}$ & $\begin{array}{l}149 \\
107\end{array}$ & $\begin{array}{l}\text { R32 } \\
\text { on? }\end{array}$ & $\begin{array}{l}7.3 \\
7.5\end{array}$ \\
\hline $\begin{array}{l}\text { AD } 2 . \\
29 . \ldots \\
35 . . .\end{array}$ & $\begin{array}{l}20 \\
17\end{array}$ & $\begin{array}{l}778 \\
456\end{array}$ & $\begin{array}{l}290 \\
336\end{array}$ & $\begin{array}{l}165 \\
124\end{array}$ & $\begin{array}{l}599 \\
754\end{array}$ & $\begin{array}{l}7.5 \\
8.5\end{array}$ \\
\hline $\begin{array}{l}44 r \\
29 . . . \\
77 \ldots\end{array}$ & $\begin{array}{l}22 \\
25\end{array}$ & $\begin{array}{l}464 \\
765\end{array}$ & $\begin{array}{l}34 \% \\
206\end{array}$ & $\begin{array}{r}132 \\
6,5\end{array}$ & $\begin{array}{l}780 \\
4 ? 8\end{array}$ & $\begin{array}{l}\text { A. } 1 \\
7.8\end{array}$ \\
\hline MUNE & & & & & & \\
\hline $14 \ldots$ & $\begin{array}{l}18 \\
16\end{array}$ & $\begin{array}{l}360 \\
436\end{array}$ & $\begin{array}{l}280 \\
314\end{array}$ & ar & $\begin{array}{l}554 \\
710\end{array}$ & $\begin{array}{l}7 . ? \\
9.1\end{array}$ \\
\hline $\begin{array}{l}J \| y \\
12 \ldots \\
25 \ldots\end{array}$ & 22.5 & $\begin{array}{l}482 \\
288\end{array}$ & $\begin{array}{l}34 h \\
23 r\end{array}$ & $\begin{array}{r}151 \\
56\end{array}$ & $\begin{array}{l}764 \\
473\end{array}$ & 7.4 \\
\hline $\begin{array}{l}\text { Alto. } \\
12 \ldots \\
25 \ldots .\end{array}$ & $\begin{array}{l}16 \\
21\end{array}$ & $\begin{array}{l}358 \\
514\end{array}$ & $\begin{array}{l}268 \\
398\end{array}$ & $\begin{array}{r}74 \\
113\end{array}$ & $\begin{array}{l}546 \\
770\end{array}$ & $\begin{array}{l}8.5 \\
7.5\end{array}$ \\
\hline $\begin{array}{l}\text { SFPT. } \\
\text { गJ... }\end{array}$ & & 472 & 318 & 103 & $73^{n}$ & \\
\hline $35 \ldots$ & 15 & 556 & $36 r$ & 1 व9 & 825 & 9.5 \\
\hline
\end{tabular}

SPECIF IC CONDUCTANCE, DISSOLVED OXYGEN, AND WATER TEMPERATURES, WATER YEAR OCTOBER 1967 TO SEPTEMBER 1968

OCTOBER

\begin{tabular}{|c|c|c|c|c|c|c|}
\hline \multirow[t]{2}{*}{ DAY } & \multicolumn{2}{|c|}{$\begin{array}{c}\text { SPECIFIC } \\
\text { CONDUCTANCE } \\
\text { (MICROMHOS } \\
\text { AT } 25^{\circ} \mathrm{C} \text { ) }\end{array}$} & \multicolumn{2}{|c|}{$\begin{array}{l}\text { DI SSOLVED } \\
\text { OXYGEN } \\
(\mathrm{MG} / \mathrm{L})\end{array}$} & \multicolumn{2}{|c|}{$\begin{array}{l}\text { TEMPER- } \\
\text { ATURE } \\
\left({ }^{\circ} \mathrm{C}\right)\end{array}$} \\
\hline & $\operatorname{MAX}$ & MIN & MAX & MIN & MAX & MIN \\
\hline $\begin{array}{l}\mathbf{1} \\
\mathbf{2} \\
3 \\
\mathbf{4} \\
5\end{array}$ & $\begin{array}{l}930 \\
920 \\
920 \\
890 \\
840\end{array}$ & $\begin{array}{l}920 \\
900 \\
880 \\
830 \\
820\end{array}$ & $\begin{array}{l}7.5 \\
6.9 \\
7.6 \\
7.1 \\
5.9\end{array}$ & $\begin{array}{l}5.6 \\
3.9 \\
4.8 \\
4.3 \\
4.3\end{array}$ & $\begin{array}{l}20 \\
22 \\
23 \\
24 \\
24\end{array}$ & $\begin{array}{l}16 \\
18 \\
19 \\
21 \\
22\end{array}$ \\
\hline $\begin{array}{r}6 \\
7 \\
8 \\
9 \\
10\end{array}$ & $\begin{array}{l}860 \\
860 \\
860 \\
860 \\
870\end{array}$ & $\begin{array}{l}790 \\
700 \\
760 \\
800 \\
840\end{array}$ & $\begin{array}{l}5.0 \\
6.5 \\
6.4 \\
5.1 \\
5.1\end{array}$ & $\begin{array}{l}3.5 \\
3.4 \\
3.7 \\
3.6 \\
4.0\end{array}$ & $\begin{array}{l}23 \\
21 \\
22 \\
20 \\
18\end{array}$ & $\begin{array}{l}21 \\
18 \\
20 \\
18 \\
17\end{array}$ \\
\hline $\begin{array}{l}11 \\
12 \\
13 \\
14 \\
15\end{array}$ & $\begin{array}{l}890 \\
840 \\
820 \\
870 \\
860\end{array}$ & $\begin{array}{l}840 \\
810 \\
790 \\
820 \\
830\end{array}$ & $\begin{array}{l}5.2 \\
5.8 \\
5.6 \\
5.2 \\
5.8\end{array}$ & $\begin{array}{l}4.5 \\
3.4 \\
3.2 \\
3.1 \\
3.2\end{array}$ & $\begin{array}{l}17 \\
18 \\
18 \\
20 \\
21\end{array}$ & $\begin{array}{l}16 \\
15 \\
15 \\
16 \\
17\end{array}$ \\
\hline $\begin{array}{l}16 \\
17 \\
18 \\
19 \\
20\end{array}$ & $\begin{array}{l}860 \\
870 \\
900 \\
920 \\
890\end{array}$ & $\begin{array}{l}\mathbf{8 4 0} \\
840 \\
850 \\
890 \\
860\end{array}$ & $\begin{array}{l}5.1 \\
4.5 \\
5.6 \\
5.8 \\
7.6\end{array}$ & $\begin{array}{l}3.2 \\
3.0 \\
3.1 \\
3.7 \\
4.3\end{array}$ & $\begin{array}{l}21 \\
21 \\
20 \\
18 \\
17\end{array}$ & $\begin{array}{l}19 \\
19 \\
18 \\
15 \\
15\end{array}$ \\
\hline $\begin{array}{l}21 \\
22 \\
23 \\
24 \\
25\end{array}$ & $\begin{array}{l}900 \\
880 \\
890 \\
910 \\
880\end{array}$ & $\begin{array}{l}850 \\
860 \\
870 \\
850 \\
850\end{array}$ & $\begin{array}{l}8.3 \\
8.5 \\
8.9 \\
8.2 \\
5.7\end{array}$ & $\begin{array}{l}4.9 \\
5.1 \\
5.5 \\
4.0 \\
3.5\end{array}$ & $\begin{array}{l}17 \\
17 \\
18 \\
19 \\
17\end{array}$ & $\begin{array}{l}14 \\
14 \\
14 \\
16 \\
14\end{array}$ \\
\hline $\begin{array}{l}26 \\
27 \\
28 \\
29 \\
30 \\
31\end{array}$ & $\begin{array}{l}880 \\
880 \\
890 \\
910 \\
890 \\
880\end{array}$ & $\begin{array}{l}850 \\
860 \\
880 \\
890 \\
880 \\
\mathbf{8 4 0}\end{array}$ & $\begin{array}{l}7.6 \\
5.8 \\
6.9 \\
7.2 \\
6.7 \\
4.7\end{array}$ & $\begin{array}{l}3.5 \\
4.1 \\
4.5 \\
4.3 \\
3.6 \\
2.8\end{array}$ & $\begin{array}{l}15 \\
14 \\
13 \\
14 \\
15 \\
16\end{array}$ & $\begin{array}{l}13 \\
13 \\
12 \\
12 \\
12 \\
13\end{array}$ \\
\hline
\end{tabular}

\section{NOVEIBER}

SPECIFIC
CONDUCTANCE DISSOLVED TEMPER-

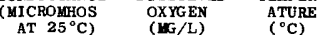

MAX MIN MAX MIN MAX MIN

$\begin{array}{lllllll}860 & 810 & 4.8 & 2.4 & 17 & 16\end{array}$ $\begin{array}{llllll}860 & 770 & 5.2 & 4.3 & 17 & 16 \\ 930 & 780 & 5.2 & 4.7 & 17 & 16\end{array}$ $\begin{array}{rrrrrr}930 & 780 & 5.2 & 4.7 & 17 & 16 \\ 870 & 710 & -- & -- & 16 & 14\end{array}$ 720

$\begin{array}{rrrrrr}760 & 700 & 6.8 & -- & 12 & 11 \\ 780 & 740 & 7.2 & 6.4 & 11 & 10\end{array}$

$\begin{array}{rrrrrr}770 & 720 & 7.8 & \mathbf{7 . 1} & 11 & 9 \\ 820 & 770 & 8.1 & 7.0 & 11 & 10\end{array}$

$\begin{array}{llllll}820 & 770 & 8.1 & 7.0 & 11 & 10 \\ 830 & 800 & 7.6 & 5.5 & 13 & 11\end{array}$

$\begin{array}{llllll}830 & 790 & 5.5 & 4.8 & 13 & 13\end{array}$

$\begin{array}{llllll}820 & 790 & 5.8 & 5.1 & 13 & 13\end{array}$

$\begin{array}{rrrrrr}830 & 810 & 6.0 & 5.8 & 14 & 12 \\ 830 & 810 & 6.0 & 5.7 & 12 & 11 \\ 830 & 800 & 6.4 & 5.7 & 11 & 9\end{array}$

$810 \quad 780$

$810 \quad 780$

$\begin{array}{rrrrr}800 & 5.7 & 5.0 & \mathbf{1 1} & 9\end{array}$

$\begin{array}{llllll}810 & 800 & 5.6 & 4.9 & 11 & 11\end{array}$

$\begin{array}{llllll}790 & 780 & 6.4 & 6.0 & 11 & 10\end{array}$

$\begin{array}{llllll}790 & 780 & 6.4 & 6.0 & 11 & 10 \\ 790 & 760 & 6.4 & 5.8 & 11 & 11\end{array}$

$\begin{array}{rrrrrr}770 & 730 & 6.4 & 5.6 & 11 & 10 \\ 740 & 710 & 6.3 & 5.7 & 10 & 9\end{array}$

750

$800 \quad 750$

$\begin{array}{ll}750 & 730 \\ \mathbf{7 4 0} & \mathbf{7 2 0}\end{array}$

$\begin{array}{ll}\mathbf{7 4 0} & \mathbf{7 2} \\ \mathbf{7 9 0} & \mathbf{7 4} \\ \mathbf{8 1 0} & \mathbf{7 6}\end{array}$
DECEMER

SPECIFIC

CONDUCTANCE DISSOLVED TEMPER-

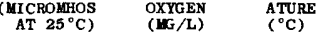

MAX MIN MAX MIN MAX MIN

$\begin{array}{llllll}800 & 760 & 6.8 & 6.3 & 8 & 7\end{array}$

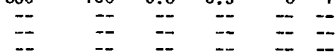
$\begin{array}{llllll}600 & \overline{110} & 12.0 & 11 . \overline{3} & \overline{4} & \overline{3}\end{array}$

$\begin{array}{rrrrrr}660 & 600 & 11.3 & 8.9 & 6 & 4 \\ 630 & 570 & - & -. & 8 & 6\end{array}$ $\begin{array}{llllll}630 & 570 & -\overline{7} & -5 & 8 & 6 \\ 570 & 520 & 7.7 & 6.7 & 8 & 7 \\ \overline{570} & 5 \overline{-70} & -\overline{-0} & -\overline{7.4} & 8 & 7\end{array}$

$\begin{array}{llllll}570 & 510 & -- & -- & 9 & 8\end{array}$ $\begin{array}{rrrrrr}550 & 480 & 10.0 & 7.2 & 9 & 8 \\ 560 & 520 & 9.5 & 8.3 & 9 & 8\end{array}$ $\begin{array}{rrrrrr}520 & 470 & 12.0 & 9.5 & 8 & 8 \\ 560 & 520 & 11.7 & 10.9 & 8 & 6\end{array}$ $\begin{array}{llllll}600 & 560 & 10.9 & 8.6 & 8 & 4\end{array}$ $\begin{array}{llllll}700 & 590 & -- & -- & \overline{10} & \overline{8}\end{array}$ $\begin{array}{rrrrrr}680 & 660 & -- & -- & 9 & 7 \\ 720 & 680 & 12.4 & -- & 10 & 7\end{array}$

$\begin{array}{rrrrrr}720 & 660 & 9.5 & 8.7 & 12 & 10\end{array}$ $\begin{array}{rrrrrr}660 & 510 & 10.9 & 8.6 & 10 & 4\end{array}$ $\begin{array}{rrrrrr}530 & 420 & 9.8 & -- & 6 & 3 \\ - & -- & - & -. & -- & -\end{array}$ $\begin{array}{llllll}-- & -- & -- & -- & - & -\end{array}$

$=\quad=\quad--\quad=\quad z=$

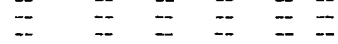


03274600 GREAT MIAMI RIVER AT NEW BALTIMORE, OHIO--CONTI IUE

SPECIFIC CONDUCTANCE, DISSOLVED OXYGEN, AND NATER TEMPERATURES, NATER YEAR OCTOBER 1967 TO SEPTEMBER 1968

JANUARY

$\mathrm{D} A$



1
1
12
1
15
1
1
1
29
21
2
23
24
25
26
27
28
29
39
31

CONDUCTANC

(MICROMHOS

MIN

460

490

$\mathbf{5 3 0}$
$\mathbf{5 9 0}$

$\begin{array}{lllll}440 & 9.1 & 8.2 & 15 & 13\end{array}$

$\begin{array}{lllll}460 & 9.1 & 8.1 & 14 & 13 \\ 470 & 8.1 & 7.5 & 13 & 13\end{array}$

$\begin{array}{lllll}490 & 8.9 & 8.1 & 14 & 13 \\ 530 & 9.5 & 8.9 & 13 & 10\end{array}$

610

$\begin{array}{rrrrr}590 & 10.0 & 8.9 & 11 & 8 \\ 570 & 10.2 & 9.6 & 12 & 10\end{array}$

$\begin{array}{rrrrr}570 & 10.2 & 9.6 & 12 & 10 \\ 590 & 9.6 & 8.9 & 13 & 12\end{array}$

$\begin{array}{llllll}660 & 620 & 8.9 & 7.8 & 15 & 13 \\ 670 & 660 & 8.7 & 8.4 & 16 & 14\end{array}$

9
10

2

$\begin{array}{llllll}690 & 670 & 8.7 & 7.5 & 16 & 14 \\ 710 & 680 & 8.7 & 7.2 & 17 & 14\end{array}$

$\begin{array}{llllll}720 & 680 & 8.7 & 7.2 & 17 & 14 \\ 700 & 7.7 & 6.2 & 18 & 16\end{array}$

$\begin{array}{lllllll}\mathbf{7 2 0} & \mathbf{7 1 0} & \mathbf{7 . 4} & 6.1 & \mathbf{1 7} & 16 \\ \mathbf{7 2 0} & \mathbf{6 8 0} & \mathbf{8 . 1} & 6.2 & 17 & 15\end{array}$

760

$\begin{array}{lllll}\mathbf{7 1 0} & \mathbf{8 . 6} & \mathbf{6 . 7} & \mathbf{1 7} & \mathbf{1 5} \\ 700 & \mathbf{7 . 4} & 6.2 & 17 & 16\end{array}$

$\begin{array}{lllll}700 & 7.5 & 5.6 & 18 & 16\end{array}$

$\begin{array}{lllll}720 & 8.4 & 6.5 & 19 & 17 \\ 710 & 7.4 & 5.9 & 20 & 18\end{array}$

$\begin{array}{lllllll}21 & 730 & 710 & 8.0 & \mathbf{5 . 7} & \mathbf{2 1} & \mathbf{1 9} \\ \mathbf{2 2} & \mathbf{7 3 0} & \mathbf{7 0 0} & \mathbf{8 . 4} & \mathbf{5 . 8} & \mathbf{2 1} & \mathbf{1 9}\end{array}$

$\begin{array}{llllll}700 & 650 & 6.5 & 4.9 & 21 & 18\end{array}$

$\begin{array}{lllllll}24 & 720 & 650 & 5.7 & 5.0 & 18 & 16 \\ 25 & 730 & 670 & 7.3 & 5.7 & 16 & 14\end{array}$

$\begin{array}{lllllll}\mathbf{2 6} & \mathbf{7 5 0} & \mathbf{7 1 0} & \mathbf{7 . 0} & \mathbf{6 . 2} & \mathbf{1 7} & \mathbf{1 4} \\ \mathbf{2 7} & \mathbf{7 4 0} & \mathbf{7 2 0} & \mathbf{7 . 1} & \mathbf{6 . 1} & \mathbf{1 8} & \mathbf{1 4}\end{array}$

$\begin{array}{lllllll}28 & 760 & 720 & 7.1 & 6.1 & 18 & 14 \\ 29 & 750 & 730 & 7.3 & 6.0 & 18 & 16\end{array}$

$\begin{array}{lllllll}29 & 750 & 730 & \mathbf{7 . 4} & \mathbf{5 . 7} & 19 & 17 \\ 30 & 770 & \mathbf{7 4 0} & \mathbf{9 . 0} & \mathbf{6 . 4} & \mathbf{1 9} & 17\end{array}$

FEBRUARY

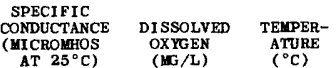

$\begin{array}{llllll}-- & -- & - & -- & -- & - \\ -- & -- & -- & -- & -- & - \\ -- & -- & -- & -- & - & -\end{array}$

$\begin{array}{llllll}- & - & -- & - & -- & - \\ -- & - & -- & - & -- & -\end{array}$

$\begin{array}{rrrrrr}\overline{590} & \overline{540} & 12 . \overline{0} & \mathbf{1 1 . 3} & \overline{10} & \overline{5} \\ 580 & 560 & 11.5 & 10.8 & 8 & 6\end{array}$

$\begin{array}{rrrrrr}580 & 560 & 11.5 & 10.8 & 8 & 6 \\ 630 & 580 & 10.9 & 9.7 & 6 & 4\end{array}$

$\begin{array}{llllll}-- & -- & -- & -- & -- & - \\ -- & -- & - & -- & - & -\end{array}$

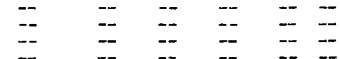

$\begin{array}{llllll}7 \overline{9} 0 & 7 \overline{70} & -- & -- & -\overline{6} & --\end{array}$

$\begin{array}{rrrrrr}\mathbf{7 9 0} & \mathbf{7 7 0} & -- & -- & 6 & \mathbf{4} \\ \mathbf{8 0 0} & \mathbf{7 9 0} & -- & -- & \mathbf{5} & 3 \\ 820 & 800 & -\overline{-} & -\overline{5} & 3 \\ 840 & 800 & \mathbf{1 0 . 6} & \mathbf{1 0 . 2} & \mathbf{5} & \mathbf{4}\end{array}$

$\begin{array}{lrrrrr}820 & 800 & 10.9 & 10.3 & 4 & 3 \\ 830 & 800 & 10.5 & 10.0 & 4 & 3 \\ 850 & 830 & 10.1 & \mathbf{9 . 5} & 6 & 3 \\ 860 & 840 & \mathbf{9 . 9} & \mathbf{9 . 0} & 6 & 4 \\ 840 & 800 & \mathbf{9 . 8} & \mathbf{9 . 4} & \mathbf{7} & \mathbf{5}\end{array}$

$\begin{array}{lllllll}830 & 810 & 9.9 & 8.6 & 7 & 5\end{array}$

$\begin{array}{llllll}830 & 810 & 9.9 & 8.6 & 7 & 5 \\ 830 & 800 & \mathbf{8 . 9} & \mathbf{8 . 4} & 7 & 6 \\ 830 & 810 & 8.4 & \mathbf{7 . 7} & \mathbf{7} & 6\end{array}$

$\begin{array}{rrrrrr}\mathbf{8 3 0} & \mathbf{8 1 0} & \mathbf{8 . 4} & \mathbf{8 . 4} & \mathbf{7} & 6 \\ -- & -- & -- & -- & -- & --\end{array}$

\begin{tabular}{|c|c|c|c|c|c|}
\hline \multirow{2}{*}{\multicolumn{2}{|c|}{$\begin{array}{l}\text { SPECIFIC } \\
\text { CONDUCTANCE } \\
\text { (MICROMBOS } \\
\left.\text { AT } 25^{\circ} \mathrm{C}\right)\end{array}$}} & \multicolumn{4}{|l|}{ MAY } \\
\hline & & $\begin{array}{l}\text { DISS } \\
\text { OXY } \\
\text { (WC }\end{array}$ & $\begin{array}{l}\text { LVED } \\
\text { EN } \\
\text { L) }\end{array}$ & $\begin{array}{l}\text { TEMP } \\
\text { ATU } \\
\left(^{\circ} \mathrm{C}\right.\end{array}$ & $\begin{array}{l}\text { PR- } \\
\text { RE } \\
\text { c) }\end{array}$ \\
\hline MaX & MIN & $\operatorname{MaX}$ & MIN & MAX & YIN \\
\hline $\begin{array}{l}760 \\
760 \\
770 \\
760 \\
780\end{array}$ & $\begin{array}{l}740 \\
740 \\
730 \\
730 \\
760\end{array}$ & $\begin{array}{l}8.7 \\
7.7 \\
7.0 \\
7.8 \\
7.5\end{array}$ & $\begin{array}{l}6.7 \\
6.4 \\
5.4 \\
5.6 \\
5.7\end{array}$ & $\begin{array}{l}21 \\
21 \\
22 \\
21 \\
21\end{array}$ & $\begin{array}{l}18 \\
18 \\
20 \\
20 \\
18\end{array}$ \\
\hline $\begin{array}{l}790 \\
780 \\
800 \\
780 \\
760\end{array}$ & $\begin{array}{r}770 \\
-- \\
780 \\
700 \\
700\end{array}$ & $\begin{array}{r}8.4 \\
9.2 \\
9.8 \\
7.0 \\
6.2\end{array}$ & $\begin{array}{l}6.3 \\
6.1 \\
6.5 \\
6.0 \\
6.0\end{array}$ & $\begin{array}{l}19 \\
19 \\
20 \\
20 \\
19\end{array}$ & $\begin{array}{l}17 \\
17 \\
18 \\
18 \\
18\end{array}$ \\
\hline $\begin{array}{l}740 \\
520 \\
600 \\
650 \\
670\end{array}$ & $\begin{array}{l}420 \\
490 \\
520 \\
570 \\
640\end{array}$ & $\begin{array}{l}6.9 \\
8.0 \\
8.0 \\
8.4 \\
7.6\end{array}$ & $\begin{array}{l}5.5 \\
5.6 \\
7.8 \\
7.6 \\
6.5\end{array}$ & $\begin{array}{l}19 \\
16 \\
17 \\
19 \\
21\end{array}$ & $\begin{array}{l}16 \\
16 \\
15 \\
17 \\
19\end{array}$ \\
\hline $\begin{array}{l}680 \\
590 \\
620 \\
660 \\
680\end{array}$ & $\begin{array}{l}510 \\
510 \\
590 \\
620 \\
660\end{array}$ & $\begin{array}{l}7.6 \\
7.9 \\
7.8 \\
7.9 \\
7.5\end{array}$ & $\begin{array}{l}6.4 \\
7.3 \\
7.3 \\
7.2 \\
7.2\end{array}$ & $\begin{array}{l}22 \\
19 \\
19 \\
19 \\
17\end{array}$ & $\begin{array}{l}19 \\
18 \\
17 \\
17 \\
16\end{array}$ \\
\hline $\begin{array}{l}700 \\
710 \\
710 \\
360 \\
370\end{array}$ & $\begin{array}{l}680 \\
680 \\
280 \\
230 \\
290\end{array}$ & $\begin{array}{l}7.8 \\
7.4 \\
7.9 \\
8.2 \\
8.6\end{array}$ & $\begin{array}{l}6.9 \\
6.5 \\
6.6 \\
7.4 \\
7.7\end{array}$ & $\begin{array}{l}18 \\
19 \\
19 \\
16 \\
16\end{array}$ & $\begin{array}{l}17 \\
17 \\
14 \\
14 \\
15\end{array}$ \\
\hline$\ldots$ & -- & 9.0 & 6.6 & 18 & 16 \\
\hline- & 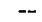 & - & & 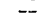 & - \\
\hline$\overline{-r}$ & $=$ & $\overline{-}$ & -- & -- & -- \\
\hline $\begin{array}{l}530 \\
610\end{array}$ & $\begin{array}{l}500 \\
520\end{array}$ & $\begin{array}{l}7.4 \\
7.2\end{array}$ & $\begin{array}{l}6.5 \\
6.5\end{array}$ & $\begin{array}{l}17 \\
18\end{array}$ & $\begin{array}{l}15 \\
15\end{array}$ \\
\hline
\end{tabular}

MARCH

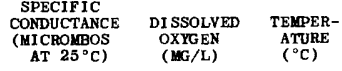

MAX MIN MAX MIN MAX MIN

$\begin{array}{llllll}830 & 800 & 8.3 & 8.1 & 7 & 6 \\ 850 & 830 & 8.9 & 8.3 & 7 & 6\end{array}$

$\begin{array}{llllll}850 & 830 & 8.9 & 8.3 & 7 & 6 \\ 850 & 830 & \mathbf{9 . 2} & \mathbf{8 . 9} & 7 & 6\end{array}$

$\begin{array}{llllll}\mathbf{8 4 0} & \mathbf{8 2 0} & \mathbf{9 . 3} & \mathbf{8 . 5} & \mathbf{8} & 6 \\ \mathbf{8 4 0} & \mathbf{8 1 0} & \mathbf{9 . 6} & \mathbf{8 . 8} & \mathbf{8} & \mathbf{7}\end{array}$

$\begin{array}{lllllll}840 & 810 & 8.8 & 8.0 & 8 & 8\end{array}$

$\begin{array}{llllrr}840 & 810 & 8.2 & 7.5 & 9 & 8 \\ 830 & 810 & 8.0 & 7.0 & 11 & 8\end{array}$

$\begin{array}{llllll}850 & 810 & 8.0 & 7.0 & 11 & 8 \\ 840 & 820 & 8.0 & 7.3 & 13 & 11\end{array}$

$\begin{array}{rrrrrr}840 & 770 & 8.2 & 7.6 & 13 & 11 \\ 860 & 810 & 8.7 & 8.0 & 12 & 8\end{array}$

$\begin{array}{rrrrrr}840 & 820 & 8.8 & 8.3 & 8 & 7 \\ 850 & 810 & 9.5 & 8.8 & 9 & 7\end{array}$

$\begin{array}{llllll}870 & 830 & 8.8 & 8.2 & 10 & 8\end{array}$

$\begin{array}{llllll}890 & 840 & 8.3 & 7.2 & 12 & 10 \\ 870 & 850 & 7.4 & 6.7 & 13 & 10\end{array}$

$\begin{array}{lllllll}860 & 820 & \mathbf{8 . 1} & 6.9 & 13 & 11 \\ 830 & \mathbf{7 9 0} & \mathbf{7 . 7} & \mathbf{7 . 0} & \mathbf{1 5} & \mathbf{1 2}\end{array}$

$\begin{array}{llllll}830 & 790 & 7.7 & 7.0 & 15 & 12 \\ 790 & 750 & 7.8 & 7.2 & 14 & 14\end{array}$

$\begin{array}{llllll}830 & 740 & 8.1 & 7.6 & 14 & 12\end{array}$

$\begin{array}{rrrrrr}750 & 730 & 8.5 & 7.9 & 14 & 7 \\ 840 & 740 & 11.2 & 8.5 & 7 & 7\end{array}$

$\begin{array}{rrrrrr}840 & 740 & 11.2 & 8.5 & 7 & 6 \\ 850 & 640 & 12.0 & 11.2 & 7 & 5\end{array}$

$\begin{array}{lllll}670 & - & 12.2 & 11.6 & 8\end{array}$

$\begin{array}{rrrrrr}-- & -- & 11.6 & 11.1 & 9 & 7\end{array}$

$\begin{array}{rrrrrr}580 & 460 & 11.4 & 9.9 & 10 & 8 \\ 460 & 440 & 9.9 & 9.5 & 12 & 9\end{array}$

$\begin{array}{rrrrrr}470 & 440 & 9.9 & 9.5 & 12 & 9 \\ 460 & 460 & 9.5 & 8.5 & 14 & 12\end{array}$

$\begin{array}{llllll}\mathbf{4 6 0} & \mathbf{4 5 0} & \mathbf{8 . 5} & \mathbf{8 . 0} & \mathbf{1 6} & \mathbf{1 4} \\ \mathbf{4 5 0} & \mathbf{4 4 0} & \mathbf{8 . 2} & \mathbf{8 . 0} & \mathbf{1 6} & \mathbf{1 4}\end{array}$

JUNE

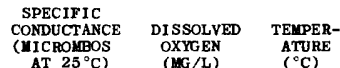

MAX MIN MAX MIN MAX MIN

$\begin{array}{llllll}610 & 560 & 6.9 & 5.3 & 17 & 17\end{array}$

$\begin{array}{llllll}560 & 350 & 6.0 & \mathbf{5 . 5} & 19 & 17\end{array}$

$\begin{array}{llllll}580 & 510 & 5.6 & \mathbf{5 . 3} & \mathbf{2 1} & 18 \\ 620 & \mathbf{5 8 0} & \mathbf{5 . 5} & \mathbf{5 . 2} & \mathbf{2 2} & \mathbf{1 9}\end{array}$

$\begin{array}{llllll}650 & 620 & 5.5 & 5.0 & 23 & 21\end{array}$

$\begin{array}{llllll}660 & 650 & 5.1 & 4.8 & 24 & 22 \\ 680 & 660 & 4.9 & 4.5 & 24 & 22\end{array}$

$\begin{array}{llllll}690 & 670 & 4.9 & 4.5 & -- & 23\end{array}$

$\begin{array}{llllll}710 & 670 & -- & -- & 26 & -- \\ 700 & 690 & -- & -- & 26 & 24\end{array}$

$\begin{array}{llllll}690 & 670 & 9.4 & 6.4 & 27 & 25\end{array}$

$\begin{array}{llllll}700 & 640 & 8.4 & 6.2 & 27 & 25\end{array}$

$\begin{array}{llllll}700 & 640 & 8.3 & 5.6 & 25 & 23 \\ 730 & 700 & 9.6 & 7.8 & 24 & 22\end{array}$

$\begin{array}{llllll}730 & 700 & 9.6 & 7.8 & 24 & 22 \\ 780 & 670 & 9.1 & 6.4 & 24 & 22\end{array}$

$\begin{array}{llllll}760 & 650 & 7.0 & 5.5 & 23 & 23\end{array}$

$\begin{array}{llllll}650 & 560 & 7.6 & 6.6 & 23 & 22 \\ 610 & 530 & 6.6 & 5.8 & 24 & 22\end{array}$

$\begin{array}{llllll}610 & 530 & 6.6 & 5.8 & 24 & 22 \\ 610 & 590 & 7.9 & 6.6 & 24 & 23 \\ 630 & 610 & 7.3 & 6.2 & 25 & 23\end{array}$

$\begin{array}{llllll}670 & 630 & 8.6 & 6.3 & 24 & 23\end{array}$

$\begin{array}{llllll}690 & 630 & 8.6 & 6.3 & 24 & 23 \\ 690 & 660 & 7.8 & 6.2 & 25 & 23\end{array}$

$\begin{array}{rrrrrr}\mathbf{7 3 0} & 660 & 7.8 & 6.2 & 25 & \mathbf{2 3} \\ \mathbf{7 5 0} & \mathbf{7 0 0} & \mathbf{6 . 2} & \mathbf{4 . 3} & \mathbf{2 7} & \mathbf{2 4} \\ - & -- & -- & \mathbf{2 7} & --\end{array}$

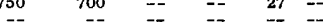

$\begin{array}{llllll}-- & -- & -- & -- & -- & -- \\ -- & -- & -- & -- & -- & \cdots \\ -- & -- & -- & -- & -- & -\end{array}$

$\begin{array}{llllll}-- & -- & -- & -- & -- & -- \\ -- & -- & -- & -- & -- & -\end{array}$ 
03274600 GREAT MIAKI RIVER AT NEN BALTIMORE, OHIO-_Cont1 nued SPECIFIC CONDUCTANCE, DISSOLVED OXYGEN, AND WATER TEMPERATURES, WATER YEAR OCTOBER 1967 TO SEPTEMBER 1968 JULY

AUGUST

SPECIFIC

CONDUCTANCE

(MICROMHOS
AT $25^{\circ} \mathrm{C}$ )

MAX MY

1
10
1
13
1
1
15
18
19
2
22
24
25
26
27
29
30
31

1
2
3
4
5
6
7
8
9
0
1
2
3
5
6
7
9
9
4
4
4
4
6

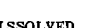

DISSOLVED TEUPEROXYGEN

TEMPER-

ATURE

SPECIFIC

CONDUCTANCE

(MI CROMHOS
AT $25^{\circ} \mathrm{C}$ )

MAX

$\begin{array}{lllll}-- & -- & = & -- & = \\ z- & = & = & = & =\end{array}$

590

$630 \quad 590$

$620 \quad 580$

510

610

610
650
660

660

600

$-$

600

610

$7 \overline{710}$

$\mathbf{7 1 0}$

710

$\mathbf{7 1 0}$

740
750
760

760
760

780

780
770
780
770
780

$\mathbf{7 7 0}$
$\mathbf{7 8 0}$
$\mathbf{7 9 0}$
(0)

DISSOLVED

OXYGEN TEMPER-

ATURE

MAX MIN MAX MIN

$\begin{array}{ll}4.4 & 3.9 \\ 4.6 & 4.4\end{array}$

$\begin{array}{ll}4.6 & 4.4 \\ 5.2 & 3.9 \\ 4.9 & 4.0\end{array}$

$\begin{array}{lllll}450 & 5.4 & 5.0 & 29 & 26\end{array}$

$\begin{array}{lllll}610 & 5.9 & 4.5 & 29 & 28\end{array}$

$\begin{array}{lllll}410 & -2 & -2 & 29 & 27\end{array}$

$\begin{array}{lllll}410 & -- & -- & 29 & 26 \\ 510 & -- & -- & 28 & 26\end{array}$

$\begin{array}{lllll}- & - & - & - & -\end{array}$

$\begin{array}{lllll}\bar{z} & \overline{-} & \overline{-} & \overline{-} & \overline{-} \\ 570 & 5.9 & 51 & \overline{27} & \overline{25}\end{array}$

$\begin{array}{llllll}590 & 6.3 & 5.3 & 28 & 36\end{array}$

$\begin{array}{rrrrr}5 .- & -- & \overline{-} & -- & \overline{--} \\ \overline{700} & 5.8 & \overline{-} & \overline{30} & \overline{38}\end{array}$

$\begin{array}{lllll}700 & 5.8 & -5 & 30 & 38 \\ 700 & 6.6 & 4.6 & 31 & 29\end{array}$

$\begin{array}{lllll}700 & 5.9 & 4.4 & 32 & 29 \\ 710 & 6.0 & 4.0 & 31 & 30\end{array}$

$\begin{array}{lllll}710 & 6.0 & 4.0 & 31 & 30 \\ 720 & 4.2 & 2.5 & 32 & 29\end{array}$

$\begin{array}{lllll}720 & 5.0 & 3.0 & 32 & 29 \\ 740 & 5.6 & 3.0 & 31 & 30\end{array}$

$\begin{array}{lllll}750 & 4.5 & 3.7 & 29 & 27 \\ 760 & 4.4 & 3.1 & 27 & 25\end{array}$

$\begin{array}{lllll}760 & 4.4 & 3.1 & 29 & 27 \\ 760 & 5.4 & 4.4 & 26 & 23 \\ 750 & 5.7 & 4.0 & 25 & 23 \\ 760 & -. & -. & 28 & 24\end{array}$
SEPTEMEER

\begin{tabular}{|c|c|c|c|c|c|}
\hline \multicolumn{2}{|c|}{$\begin{array}{l}\text { SPECIF IC } \\
\text { CONDUCTANCE } \\
\text { (UICROMHOS } \\
\left.\text { AT } 25^{\circ} \mathrm{C}\right)\end{array}$} & \multicolumn{2}{|c|}{$\begin{array}{l}\text { DISSOLVED } \\
\text { OXYYGEN } \\
(\mathbf{M G} / \mathrm{L})\end{array}$} & \multicolumn{2}{|c|}{$\begin{array}{l}\text { TEMPER- } \\
\text { ATURE } \\
\left({ }^{\circ} \mathrm{C}\right)\end{array}$} \\
\hline MAX & MIN & $\max$ & MIN & $\operatorname{MAX}$ & MIN \\
\hline $\begin{array}{l}790 \\
770 \\
770 \\
780 \\
790\end{array}$ & $\begin{array}{l}750 \\
750 \\
760 \\
760 \\
760\end{array}$ & $\begin{array}{l}5.2 \\
4.9 \\
5.4 \\
5.1 \\
4.9\end{array}$ & $\begin{array}{l}4.5 \\
4.5 \\
4.8 \\
4.6 \\
4.5\end{array}$ & $\begin{array}{l}26 \\
25 \\
26 \\
26 \\
25\end{array}$ & $\begin{array}{l}24 \\
23 \\
23 \\
24 \\
24\end{array}$ \\
\hline $\begin{array}{l}760 \\
790 \\
800 \\
770 \\
700\end{array}$ & $\begin{array}{l}740 \\
760 \\
770 \\
580 \\
610\end{array}$ & $\begin{array}{r}-- \\
5.2 \\
5.1 \\
5.1\end{array}$ & $\begin{array}{l}-- \\
4.5 \\
4.5 \\
4.6\end{array}$ & $\begin{array}{l}24 \\
25 \\
26 \\
26 \\
24\end{array}$ & $\begin{array}{l}24 \\
23 \\
24 \\
23 \\
21\end{array}$ \\
\hline $\begin{array}{l}720 \\
750 \\
760 \\
790 \\
780\end{array}$ & $\begin{array}{l}610 \\
710 \\
740 \\
750 \\
770\end{array}$ & $\begin{array}{l}5.2 \\
5.0 \\
4.8 \\
4.6 \\
4.4\end{array}$ & $\begin{array}{l}4.8 \\
4.7 \\
4.5 \\
4.3 \\
4.1\end{array}$ & $\begin{array}{l}21 \\
23 \\
23 \\
24 \\
25\end{array}$ & $\begin{array}{l}21 \\
21 \\
22 \\
23 \\
23\end{array}$ \\
\hline $\begin{array}{l}790 \\
790 \\
790 \\
770 \\
740\end{array}$ & $\begin{array}{l}780 \\
700 \\
700 \\
740 \\
680\end{array}$ & $\begin{array}{l}4.4 \\
3.9 \\
3.3 \\
3.1 \\
3.3\end{array}$ & $\begin{array}{l}3.9 \\
3.0 \\
3.0 \\
2.9 \\
3.0\end{array}$ & $\begin{array}{l}25 \\
25 \\
24 \\
23 \\
25\end{array}$ & $\begin{array}{l}24 \\
23 \\
22 \\
23 \\
23\end{array}$ \\
\hline $\begin{array}{l}700 \\
700 \\
730 \\
750 \\
770\end{array}$ & $\begin{array}{l}670 \\
680 \\
690 \\
730 \\
700\end{array}$ & $\begin{array}{l}3.2 \\
3.4 \\
3.6 \\
2.9 \\
2.6\end{array}$ & $\begin{array}{l}2.9 \\
2.8 \\
2.9 \\
2.6 \\
1.9\end{array}$ & $\begin{array}{l}26 \\
27 \\
27 \\
27 \\
26\end{array}$ & $\begin{array}{l}23 \\
25 \\
26 \\
26 \\
24\end{array}$ \\
\hline $\begin{array}{l}790 \\
800 \\
810 \\
820 \\
830\end{array}$ & $\begin{array}{l}770 \\
780 \\
790 \\
800 \\
800\end{array}$ & $\begin{array}{l}2.7 \\
3.1 \\
4.3 \\
3.1 \\
3.0\end{array}$ & $\begin{array}{l}2.4 \\
2.7 \\
3.1 \\
2.4 \\
2.7\end{array}$ & $\begin{array}{l}24 \\
24 \\
23 \\
24 \\
24\end{array}$ & $\begin{array}{l}23 \\
23 \\
22 \\
22 \\
22\end{array}$ \\
\hline & & & 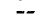 & & \\
\hline
\end{tabular}

03276600 GRAT NIAKI RIVER AT ELYZABETHTONN, OHIO

LOCATION.--Lat $39^{\circ} 09^{\prime} 11^{\prime \prime}$, long $84^{\circ} 4^{\prime} 38^{\prime \prime}$, Hamilton County, at Lost Bridge on Lawrenceburg Road 0.6 mile southeast of Eilizabethtown, 0.9 mile downstream from whitewater Rdver, and 5.4 miles upstream from mouth.

DRAINAGE AREA. $-5,356 \mathrm{sq} \mathrm{m} 1$.

PER IOD OF RECORD. --Chemical anal yses: October 1956 to September 1968.

Water temperatures: October 1956 to September 1968

EXTREMES. - 1967-68:

Specific conductance: Maxtmum datly, 943 micromhos Oct. $3 ;$ minimum datly, 350 mtcromhos May 24.

Vater temper

Period of record: Water temperatures: Maximum, 32.0

REMARKS. --Samples for iron and manganese were flltered clear when collected. Datly samples were collected at thts station and samples were selected for analysis as follows: (1) Maximum daily specific conductance for each month, (2) minimum dally spectefc conductance for each month, (3) median daily specific conductance for each
month, and (4) special samples each month to further deftne the quality of water. No discharge records available CHEMICAL ANALYSES IN MILLIGRAMS PER LITER, WATER YeAR OCTOBER 1967 TO SEPTEMBER 1968

\begin{tabular}{|c|c|c|c|c|c|c|c|c|c|}
\hline DATE & TIME & $\begin{array}{l}\text { IRON } \\
\text { \{FE\} }\end{array}$ & $\begin{array}{l}\text { MAN- } \\
\text { GANESE } \\
\text { (MN) }\end{array}$ & $\begin{array}{l}\text { AICAR- } \\
\text { BONATF } \\
\text { (HCO3) }\end{array}$ & $\begin{array}{l}\text { CAR- } \\
\text { BONATE } \\
\text { (CO3) }\end{array}$ & $\begin{array}{l}\text { SULFATE } \\
\text { (SO4) }\end{array}$ & $\begin{array}{l}\text { CHLO- } \\
\text { RIOE } \\
\text { (CI) }\end{array}$ & $\begin{array}{l}\text { FLUO- } \\
\text { RIOE } \\
\text { (F) }\end{array}$ & $\begin{array}{l}\text { NITRATE } \\
\text { (NO3) }\end{array}$ \\
\hline \multicolumn{10}{|l|}{ UCT. } \\
\hline $03 \ldots$ & -- & -- & - & 240 & 0 & 169 & 62 & .7 & 31 \\
\hline$O B \ldots$ & -- & -- & -- & 196 & 0 & 149 & 52 & . 8 & $2 i$ \\
\hline $17 \ldots$ & 1130 & .10 & .10 & - & -- & - & $\cdots$ & - & \\
\hline $21 \ldots$ & -- & -- & - & 234 & 0 & 168 & 60 & .8 & 16 \\
\hline \multicolumn{10}{|l|}{ NOSV. } \\
\hline $02 \ldots$ & -. & -- & - & 226 & 0 & 161 & 58 & .7 & 11 \\
\hline $00 \ldots$ & - & - & -- & 220 & 0 & 106 & 43 & .6 & 7.9 \\
\hline $14 \ldots$ & 1045 & .52 & .16 & - & - & - & - & - & - \\
\hline $17 \ldots$ & - & $\cdots$ & -- & 216 & 0 & 155 & 44 & .6 & 5.0 \\
\hline LEC. & & & & & & & & & \\
\hline $02 \ldots$ & -- & - & -- & 234 & 0 & 139 & 54 & .4 & 10 \\
\hline $10 \ldots$ & -- & -- & -- & 202 & 0 & 80 & 23 & .2 & 25 \\
\hline $19 \ldots$ & 1515 & .37 & .05 & - & -- & -- & - & -- & - \\
\hline $24 \ldots$ & $\cdots$ & $-\infty$ & -- & 164 & 0 & 53 & 13 & .2 & 18 \\
\hline \multicolumn{10}{|l|}{ JAN. } \\
\hline $06 \ldots$ & -- & $=$ & -- & 296 & 0 & $10 \mathrm{~s}$ & 36 & .3 & 19 \\
\hline $16 \ldots$ & 1115 & .42 & .13 & $\cdots$ & -- & -- & - & - & \\
\hline $18 \ldots$ & -- & - & - & 286 & 0 & 136 & 62 & .4 & 15 \\
\hline $31 \ldots$ & -- & -- & -- & 108 & 0 & 48 & 21 & .2 & 20 \\
\hline \multicolumn{10}{|l|}{ FER. } \\
\hline $01 \ldots$ & -- & -- & -- & 152 & 0 & 47 & 13 & .2 & 17 \\
\hline $13 \ldots$ & $\cdots$ & - & $=$ & 228 & 12 & 102 & 32 & .3 & it \\
\hline $21 \ldots$ & 1445 & .61 & .09 & - & $=$ & -- & -- & -- & 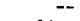 \\
\hline MAR... & \multicolumn{5}{|c|}{ MAR. } & 138 & $4 ?$ & .4 & I 6 \\
\hline $07 \ldots$ & $=$ & - & -- & 228 & 14 & 129 & 40 & .5 & 19 \\
\hline $17 \ldots$ & - & -- & -- & 214 & A & 133 & 68 & .6 & A. 2 \\
\hline 18. & 1515 & .70 & .14 & - & -- & - & $=$ & -- & \\
\hline $29 \ldots$ & - & 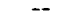 & - & 172 & 6 & 68 & 22 & .3 & 26 \\
\hline
\end{tabular}


O3276600 GREAT MIAMI RIVER AT ELIZABETHTOWN, OHIO--COnTInUEd

CHEMICAL ANALYSES IN MILLIGRAMS PER LITER, WATER YEAR OCTOBER 1967 TO SEPTEMBER 1968

\begin{tabular}{|c|c|c|c|c|c|c|c|c|c|}
\hline DATE & TIME & $\begin{array}{l}\text { IRON } \\
\text { (FE) }\end{array}$ & $\begin{array}{l}\text { MAN- } \\
\text { GANESE } \\
\text { (MN) }\end{array}$ & $\begin{array}{l}\text { BICAR- } \\
\text { BONATE } \\
\text { (HCO3) }\end{array}$ & $\begin{array}{l}\text { CAR- } \\
\text { BONATE } \\
\text { (CO3) }\end{array}$ & $\begin{array}{l}\text { SULFATE } \\
\text { (S04) }\end{array}$ & $\begin{array}{l}\text { CHLO- } \\
\text { RIDE } \\
\text { (CL) }\end{array}$ & $\begin{array}{l}\text { FLUO- } \\
\text { RIDE } \\
\text { (F) }\end{array}$ & $\begin{array}{l}\text { NI TRATE } \\
\text { (NO3) }\end{array}$ \\
\hline \multicolumn{10}{|l|}{$\triangle P R$. } \\
\hline $06 \ldots$ & - & -- & -- & 195 & 0 & 66 & 18 & .3 & 25 \\
\hline $22 \ldots$ & 1100 & .20 & .04 & 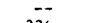 & -- & $\overline{0}$ & - & - & - \\
\hline $24 \ldots$ & -- & -- & -- & 236 & 0 & 100 & 32 & .4 & 8. 2 \\
\hline $30 \ldots$ & -- & -- & -- & 266 & 0 & 120 & 38 & .5 & 7.0 \\
\hline & 1415 & .09 & 13 & & & & & & \\
\hline $\begin{array}{l}0 . \ldots \\
22 \ldots\end{array}$ & $\begin{array}{c}1415 \\
--\end{array}$ & .09 & .13 & 207 & 0 & 133 & 42 & .5 & 18 \\
\hline $\begin{array}{l}22 \ldots \\
24 \ldots\end{array}$ & $=$ & $=$ & $=$ & 220 & 0 & 61 & 19 & .3 & 20 \\
\hline JUNE & 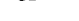 & $\cdots$ & $\cdots$ & 152 & 0 & 28 & ค. 0 & .3 & 17 \\
\hline JUNE & & & & & & & & & \\
\hline $02 \ldots$ & 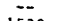 & -- & -- & 208 & 0 & 56 & 16 & .3 & 8.8 \\
\hline $10 \ldots$ & 1530 & .06 & .04 & -- & - & $=-$ & -- & - & -- \\
\hline $15 \ldots$ & - & $\cdots$ & - & 284 & 0 & 96 & 28 & .3 & 5.6 \\
\hline $27 \ldots$ & -- & - & -- & 254 & 0 & 88 & 30 & .3 & 7.6 \\
\hline JULY & & & & & & & & & \\
\hline $13 \ldots$ & $\cdots$ & -- & - & 254 & 0 & 110 & 34 & .4 & 10 \\
\hline $15 \ldots$ & - & -- & -- & 226 & 16 & 101 & 34 & .4 & 11 \\
\hline $23 \ldots$ & 1400 & .15 & .05 & - & -- & 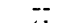 & -- & $=$ & -- \\
\hline $28 \ldots$ & -- & -- & - & 190 & 0 & 61 & 18 & .3 & 14 \\
\hline AUG. & & & & & & & & & \\
\hline $03 \ldots$ & -- & -- & $=$ & 230 & 12 & 87 & 30 & .4 & 14 \\
\hline $05 \ldots$ & -- & $\ddot{z}$ & $=$ & 160 & 4 & 47 & 14 & .3 & 10 \\
\hline $12 \ldots$ & 1500 & .15 & .02 & -- & -- & -- & -- & $\cdots$ & . -- \\
\hline $26 \ldots$ & -- & $\cdots$ & - & 264 & 0 & 130 & 39 & .6 & 22 \\
\hline $\begin{array}{l}\text { SEPT. } \\
11 . .\end{array}$ & -- & -- & -- & 188 & 8 & 87 & 36 & .4 & 18 \\
\hline $17 . .$. & 1500 & .18 & .12 & -2 & -2 & 21 & -. & - & $\ldots$ \\
\hline $20 \ldots$ & $\cdots$ & -- & -- & 244 & c & 121 & 46 & .4 & 17 \\
\hline $30 \ldots$ & -- & $\sim$ & -- & 228 & 12 & 147 & 48 & .5 & 10 \\
\hline & & $\begin{array}{l}\text { DIS- } \\
\text { SOL VED }\end{array}$ & & NON- & $\begin{array}{l}\text { SPECI I - } \\
\text { FIC }\end{array}$ & & & & \\
\hline & TOTAL & SOLIDS & & CAR - & CONO- & & & & PER - \\
\hline & PHOS- & IRESI- & HARD- & BONATE & UCTANCE & & & DISS- & CENT \\
\hline DATE & $\begin{array}{l}\text { PHJRUS } \\
\text { (PO4) }\end{array}$ & $\begin{array}{l}\text { DUE AT } \\
\text { IBO C }\end{array}$ & $\begin{array}{l}\text { NESS } \\
(C A, M G)\end{array}$ & $\begin{array}{l}\text { HARD- } \\
\text { NESS }\end{array}$ & $\begin{array}{l}\text { (MICRC- } \\
\text { MHOS) }\end{array}$ & PH & $\begin{array}{l}\text { ERATURE } \\
\text { (DEG C) }\end{array}$ & $\begin{array}{l}\text { OLVED } \\
\text { OXYGEN }\end{array}$ & SATUR \\
\hline & & & & & & & & & \\
\hline OCT. & & & & & & & & & \\
\hline $03 \ldots$ & .54 & $\begin{array}{l}628 \\
514\end{array}$ & 374 & 177 & 943 & 7.6 & 21 & 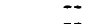 & $=$ \\
\hline $13 \ldots$ & 34 & 514 & 314 & 153 & $\begin{array}{r}792 \\
--\end{array}$ & ?.1 & 20 & 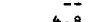 & $\overline{5 n}$ \\
\hline $21 \ldots$ & .41 & 592 & 360 & 168 & 894 & 7.4 & $\overline{14}$ & 4.8 & 50 \\
\hline NOV. & & & & & & & 14 & & - \\
\hline $02 \ldots$ & 1.1 & 578 & 350 & 160 & 878 & 7.2 & 16 & -- & -- \\
\hline $08 . .$. & .86 & 474 & 290 & 110 & 702 & 8.0 & II & - & $\cdots$ \\
\hline $14 \ldots$ & -- & - & -- & - & -- & $\cdots$ & $\because$ & 7.2 & 65 \\
\hline DEC... & .36 & 470 & 338 & 161 & 782 & 8.2 & 10 & - & -- \\
\hline $02 \ldots$ & 1.0 & $\begin{array}{l}494 \\
334\end{array}$ & 344 & 152 & 830 & 7.6 & $?$ & $=-$ & $=$ \\
\hline $19 \ldots$ & - & 334 & 277 & 111 & 538 & $\begin{array}{l}7.4 \\
--\end{array}$ & $\begin{array}{r}8 \\
--\end{array}$ & $11 . \overline{0}$ & $\overline{92}$ \\
\hline $24 \ldots$ & .92 & 248 & 209 & 74 & 440 & 7.3 & 4 & 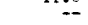 & 92 \\
\hline JAN. & & & & & & & & & \\
\hline $10 \ldots$ & $\cdot-80$ & 466 & $\begin{array}{r}372 \\
-2\end{array}$ & 129 & 801 & $\begin{array}{l}7.6 \\
-.\end{array}$ & -2 & $11 . \overline{0}$ & $\overline{78}$ \\
\hline $18 \ldots$ & .33 & 522 & 366 & 131 & 898 & 7.3 & 4 & 110 & -1 \\
\hline $31 \ldots$ & .90 & 260 & 208 & 70 & $46 \mathrm{~A}$ & 7.3 & 4 & -- & - \\
\hline $01 . .$. & .68 & 276 & 200 & 75 & 420 & 8.1 & 6 & -- & \\
\hline $13 \ldots$ & .91 & 442 & 239 & 32 & 718 & 8.6 & 2 & -- & - \\
\hline $21 \ldots$ & -- & -- & -- & -- & -- & $\ldots$ & -- & 10.0 & 74 \\
\hline $28 \ldots$ & .39 & 522 & 369 & 154 & 820 & 8.4 & 6 & -- & -- \\
\hline MAR. & & & & & & & & & \\
\hline $07 \ldots$ & .30 & 506 & 352 & 141 & 780 & 8.6 & 8 & -- & -- \\
\hline $17 \ldots$ & .30 & 522 & 335 & 146 & 847 & 8.5 & 12 & $\cdots$ & -- \\
\hline $18 \ldots$ & -- & -- & -- & -- & $=$ & $\cdots$ & - & B. 2 & 60 \\
\hline $\begin{array}{l}29 . . . \\
\text { APR. }\end{array}$ & .42 & 366 & 254 & 103 & 518 & 3.5 & 14 & - & -- \\
\hline $06 \ldots$ & 1.1 & 336 & 260 & 100 & 524 & 7.7 & 12 & -- & -- \\
\hline $22 \ldots$ & $=$ & - & - & -- & 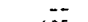 & -- & -- & 11.0 & 122 \\
\hline $24 \ldots$ & .78 & 408 & 307 & 113 & 685 & 7.9 & 16 & -- & -- \\
\hline $30 \ldots$ & .51 & 448 & 348 & 130 & 757 & 7.4 & 20 & -- & -- \\
\hline MaY & & & & & & & & & \\
\hline $08 \ldots$ & .34 & 428 & 314 & 144 & 773 & 7.8 & 20 & 11.0 & 120 \\
\hline $22 \ldots$ & .72 & 312 & 262 & 82 & 521 & 8.0 & 17 & -- & -- \\
\hline $24 \ldots$ & .66 & 190 & 164 & 40 & 350 & ค. 0 & 16 & -- & -- \\
\hline JUNE & & & & & & & & & \\
\hline $02 \ldots$ & .76 & 332 & 245 & 74 & 503 & 7.9 & 19 & -- & - \\
\hline $10 \ldots$ & -- & $\cdots$ & $\cdots$ & $\cdots$ & - & -- & 26 & 11.0 & 134 \\
\hline $15 \ldots$ & .90 & 464 & 349 & 116 & 713 & 7.3 & 25 & -- & $\cdots$ \\
\hline $27 \ldots$ & 1.0 & 446 & 310 & 102 & 655 & 7. & 23 & -- & $\ldots$ \\
\hline JULY & & & & & & & & & \\
\hline $13 \ldots$ & .48 & 432 & 326 & 118 & 714 & 8.1 & 27 & -- & -- \\
\hline $15 \ldots$ & .47 & 404 & 320 & 108 & 68 & 6. & 26 & -- & $\overline{0}$ \\
\hline $23 \ldots$ & - & -- & -- & 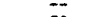 & $=$ & 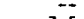 & $-\bar{x}$ & 8.6 & 109 \\
\hline $28 \ldots$ & .46 & 292 & 226 & 70 & 480 & 7.5 & 26 & $\cdots$ & 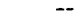 \\
\hline AUG. & & & & & & & & & \\
\hline $03 \ldots$ & .90 & 394 & 304 & 95 & 645 & 8.5 & 27 & - & $\cdots$ \\
\hline $05 \ldots$ & .72 & 244 & 192 & 54 & 405 & 8. & 27 & $\cdots$ & -- \\
\hline $12 \ldots$ & $=$ & - & - & $\rightarrow$ & $\overline{-}$ & $\cdots$ & 24 & 0.2 & 73 \\
\hline $26 \ldots$ & .46 & 496 & 360 & 143 & 780 & 7.7 & 27 & -- & -- \\
\hline SEPT. & & & & & & & & & \\
\hline - & .88 & 398 & 267 & 99 & 601 & 8.3 & 20 & $\because$ & $\cdots$ \\
\hline $17 \ldots$ & -- & -- & - & - & -- & $=$ & 23 & 5.6 & 64 \\
\hline $20 \ldots$ & .65 & 454 & 330 & 130 & 761 & 7.5 & 22 & -- & $=$ \\
\hline $30 \ldots$ & .74 & 540 & 355 & 148 & 816 & 8.5 & 73 & -- & \\
\hline
\end{tabular}


03276600 GREAT MIAMI RIVER AT ELIZABETHTOWN, OHIO--COntinued

SPECIFIC CONDUCTANCE (MICROMHOS AT $25^{\circ} \mathrm{C}$ ), HATER YEAR OCTOBER 1967 TO SEPTEMBER 1968

oAY OCTOBER NIVEMBER DECEMBER JANUARY FEBRUARY MARCH APRIL MAY

JUNE JULY AUGUST SEPTEMBFR

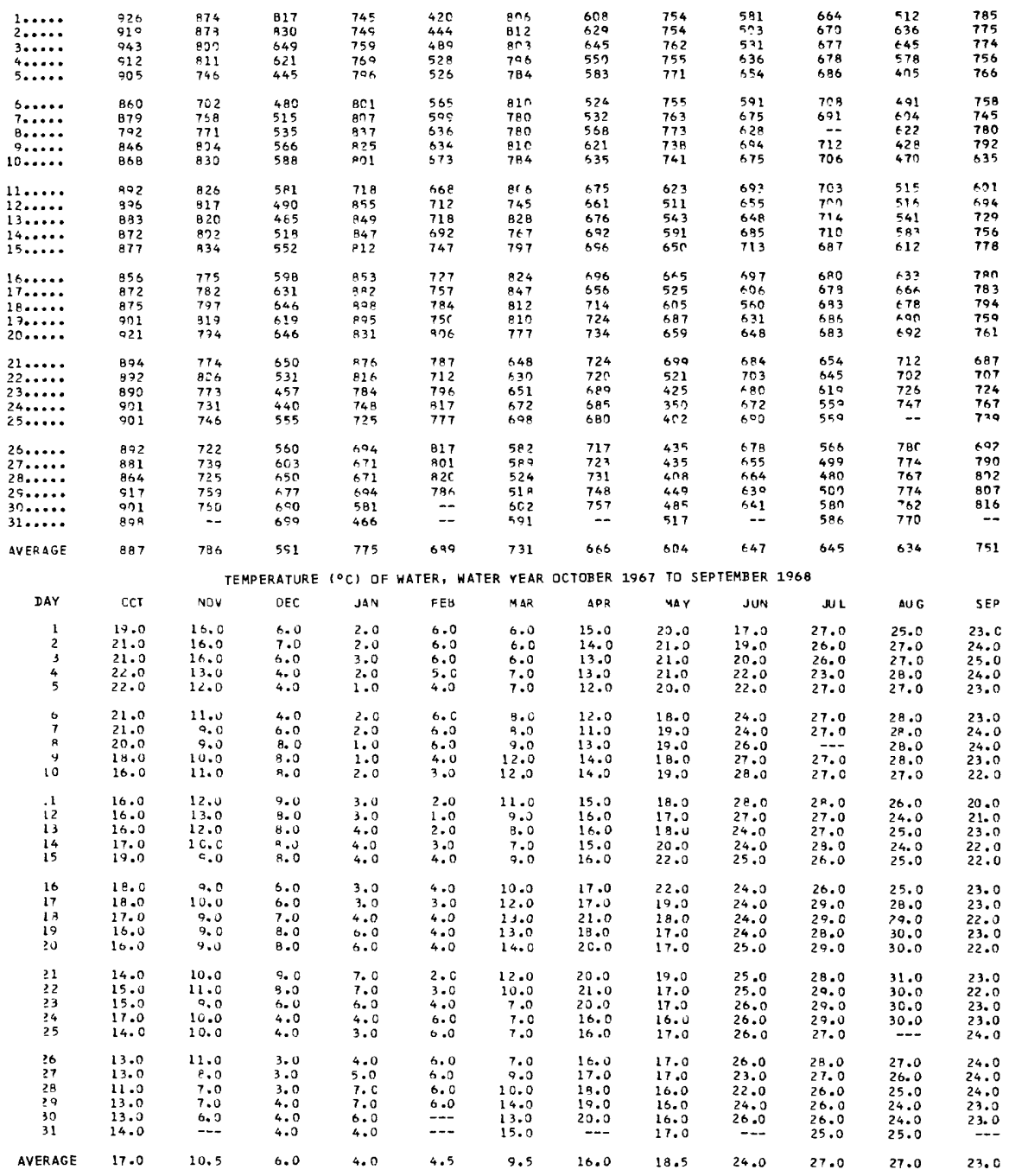


03277200 OHIO RIVER AT MARKLAND DAM, NEAR WARSAW, KY.

LOCATION. --Lat $38^{\circ} 46^{\prime} 27^{\prime \prime}$, long $84^{\circ} 57^{\prime} 39^{\prime \prime}$, Gallatin County, about 1,000 ft upstream from dam, 0.7 mile upstrean from Stevens Creek, 1.4 miles downtream from Craigs Creek, 3.3 miles west of Warsaw, and at mile 531.3 .

DRA INAGE AREA. $--83,170 \mathrm{sq} \mathrm{mi}$.

PERIOD OF RECORD. --Chemical analyses: October 1959 to September 1968.

Hater temperatures: October 1959 to September 1968.

EXTREMES, $--1967-68$ :

Specific conductance: Maximum daily, 613 micromhos oct, 12; minimum da1ly, 230 micromhos June 1.

Water tenperatures: Maximum, 29.0 ${ }^{\circ} \mathrm{C}$ Aug. 7, 8, 23-26; minimum, 1.0 $0^{\circ} \mathrm{C} \mathrm{Feb.'23.}$

Period of record:

Specific conductance: Maximum da1ly, 810 micromhos oct. 21, 1962; minimum da1ly, 167 micromhos Mar. 3, 1962. Water temperatures: Maximum, $31.0^{\circ} \mathrm{C}$ July 14, 1962; minimum, freezing point on many days during winter periods.

REMARKS. --Dally samples were collected at this station and samples were selected for analysis on the following basis: (1) Maximum daily specific conductance for each month, (2) minimum daily specific conductance for each month, (3) mediandally spectfic conductance for each month, and (4) a composite analysis each month to deter-

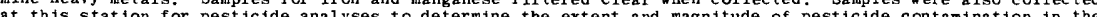
stream. No discharge records available.

CHEMICAL ANALYSES IN MILLIGRAMS PER LITER, WATER YEAR OCTOBER 1967 TO SEPTEMBER 1968

\begin{tabular}{|c|c|c|c|c|c|c|c|}
\hline DATE & $\begin{array}{l}\text { IRON } \\
\text { (FE) }\end{array}$ & $\begin{array}{l}\text { MAN- } \\
\text { GANESE } \\
\text { (MN) }\end{array}$ & $\begin{array}{l}\text { BICAR- } \\
\text { BONATE } \\
\text { (HCO3) }\end{array}$ & $\begin{array}{l}\text { CAR- } \\
\text { BONATE } \\
\text { (CO3) }\end{array}$ & $\begin{array}{c}\text { SULFATE } \\
\left(\mathrm{SO}_{4}\right)\end{array}$ & $\begin{array}{l}\text { CHLO- } \\
\text { RIDE } \\
\text { (CL) }\end{array}$ & $\begin{array}{l}\text { FLUO- } \\
\text { RIDE } \\
\text { (F) }\end{array}$ \\
\hline \multicolumn{8}{|l|}{ ост. } \\
\hline $12 \ldots$ & .20 & .26 & 34 & 0 & 148 & 66 & \\
\hline $\begin{array}{l}23 \ldots \\
30 . .\end{array}$ & .09 & .51 & 44 & 0 & 143 & 53 & $: 6$ \\
\hline $30 \ldots$ & .15 & .40 & 42 & 0 & 86 & 37 & .4 \\
\hline \multicolumn{8}{|l|}{ NOV. } \\
\hline $11 \ldots$ & .13 & .18 & 54 & 0 & 103 & 30 & $\cdot 3$ \\
\hline $17 \ldots$ & .24 & .31 & 58 & 0 & 88 & 29 & $\cdot 2$ \\
\hline $24 \ldots$ & .21 & .21 & 52 & 0 & 104 & 51 & .2 \\
\hline \multicolumn{8}{|l|}{ DEC. } \\
\hline $02 \ldots$ & .30 & .26 & 44 & 0 & 94 & 38 & .5 \\
\hline $11 .$. & .28 & .17 & 52 & 0 & 60 & 20 & .3 \\
\hline $25 \ldots$ & .95 & .25 & 72 & 0 & 63 & 19 & .3 \\
\hline \multicolumn{8}{|l|}{ JAN. } \\
\hline $04 \ldots$ & .26 & .23 & 60 & 0 & 63 & 20 & .3 \\
\hline $16 \ldots$ & .78 & .26 & 58 & 0 & 72 & 26 & .3 \\
\hline $25 \ldots$ & .51 & .40 & 60 & 0 & 82 & 30 & $\cdot 3$ \\
\hline \multicolumn{8}{|l|}{ FEB, } \\
\hline $08 \ldots$ & .14 & .17 & 52 & 0 & 64 & 19 & .2 \\
\hline $13 \ldots$ & .11 & .15 & 46 & 0 & 63 & 40 & .2 \\
\hline $26 \ldots$ & .62 & .27 & 70 & 0 & 78 & 32 & .2 \\
\hline \multicolumn{8}{|l|}{ MAR. } \\
\hline $02 \ldots$ & .36 & .42 & 66 & 0 & 77 & 27 & .1 \\
\hline $14 \ldots$ & - & -- & 62 & 0 & 92 & 38 & .1 \\
\hline $17 \ldots$ & 1.6 & .42 & 28 & 0 & 61 & 16 & .1 \\
\hline \multicolumn{8}{|l|}{ APR. } \\
\hline $01 \ldots$ & .14 & .11 & 62 & 0 & 67 & 22 & .2 \\
\hline $09 . .$. & .25 & .03 & 52 & 0 & 47 & 14 & .2 \\
\hline \multirow{2}{*}{\multicolumn{8}{|c|}{ MAY }} \\
\hline & & & & & & & \\
\hline $03 .$. & .07 & . 11 & 72 & 0 & 84 & 28 & .3 \\
\hline $19 \ldots$ & .06 & .09 & 70 & 0 & 113 & 34 & .4 \\
\hline 31 & .12 & .07 & 56 & 0 & 48 & 10 & .2 \\
\hline \multicolumn{8}{|l|}{ JUNE } \\
\hline $01 .$. & .36 & .05 & 58 & 0 & 50 & 7.0 & .2 \\
\hline $14 \ldots$ & .09 & .05 & 70 & 0 & 84 & 18 & .3 \\
\hline $29 \ldots$ & .71 & .04 & 97 & 0 & 91 & 25 & .3 \\
\hline \multicolumn{8}{|l|}{ JULY } \\
\hline $07 \ldots$ & .16 & .03 & 100 & 0 & 85 & 24 & .3 \\
\hline $14 \ldots$ & .17 & .02 & 106 & 0 & 93 & 30 & .2 \\
\hline \multirow{2}{*}{\multicolumn{8}{|c|}{ AUG. }} \\
\hline & & & & & & & \\
\hline $02 \ldots$ & .44 & .16 & 85 & 0 & 96 & 36 & .3 \\
\hline $17 \ldots$ & .54 & .08 & 86 & 0 & 117 & 62 & .4 \\
\hline $22 \ldots$ & .53 & .15 & 84 & 0 & 86 & 38 & .3 \\
\hline \multicolumn{8}{|l|}{ SEPT. } \\
\hline $06 \ldots$ & .15 & .19 & 84 & 0 & 77 & 28 & $\cdot 3$ \\
\hline $11 \ldots$ & .19 & .12 & 88 & 0 & 91 & 34 & .4 \\
\hline $30 \ldots$ & .09 & .14 & 88 & 0 & 101 & 40 & .3 \\
\hline
\end{tabular}


OHIO RIVER YAIN STEM

03277200 OHIO RIVER AT MARKLAND DAM, NEAR WARSAW, KY,--Continued

CHEMICAL ANALYSES IN MILLIGRAMS PER LITER, WATER YEAR OCTOBER 1967 TO SEPTEMBER 1968

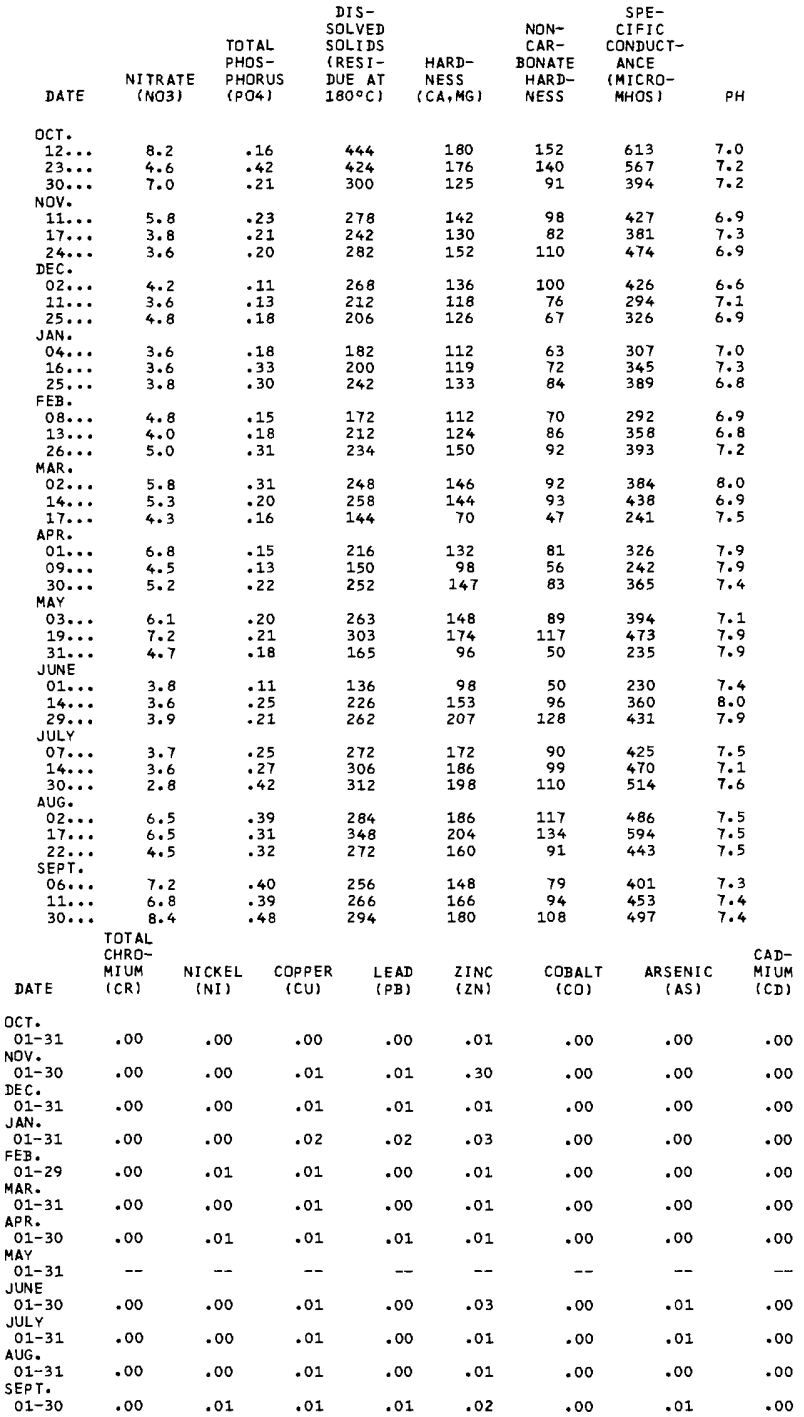

PESTICIDE ANALYSES IN MICROGRAMS PER LITER, WATER YEAR OCTOBER 1967 TO SEPTEMBER 1968

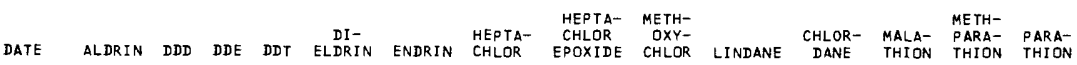
$\begin{array}{llllllllllllllllll}\text { AUG. } & 00 & .00 & .00 & .00 & .00 & .00 & .00 & .00 & .00 & .00 & .00 & .00 & .00 & .00\end{array}$

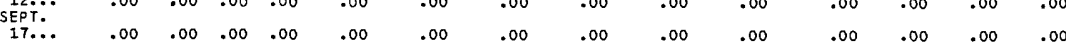


03277200 OHIO RIVER AT MARKLAND DAM, NEAR WARSAF, KY.--Continued

RADIOISOTOPES IN FATER, WATER YEAR OCTOBER 1967 TO SEPTEMBER 1968

Units of measurement: Uraniun, micrograms per liter of water; radium, as radium-226, in picocuries per 11 ter of water; gross beta radiation as strontium-90-yttrium-90, in picocuries per liter of water; gross alpha radiation, as micrograms of uranium equivalent per liter of water; tritium as tritium units (approximately equal to 3.2 plcocuries per liter). A picocurie is one millionth of the amount of radiosctivity representicocurie of radium which is the quantity of radiation represented by one milition equal to one tritium atom in $10^{+15}$ protium (ording in hydrogen) atoms.

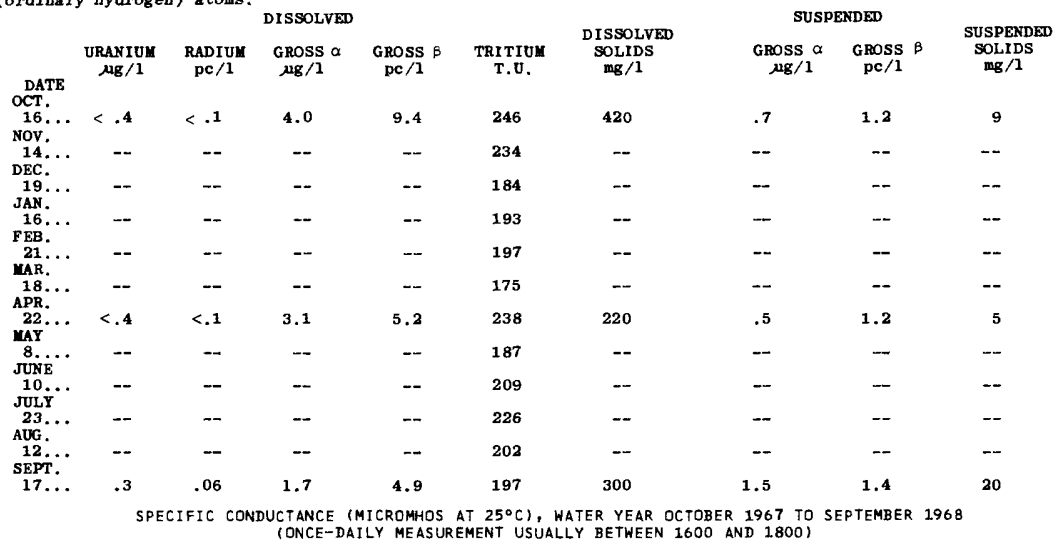

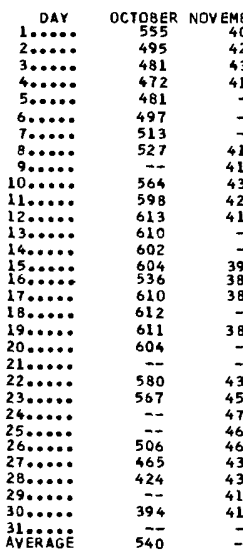

IONCE-DAILY MEASUREMENT USUALLY BETHEEN 1600 AND 1800$)$

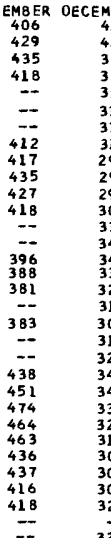

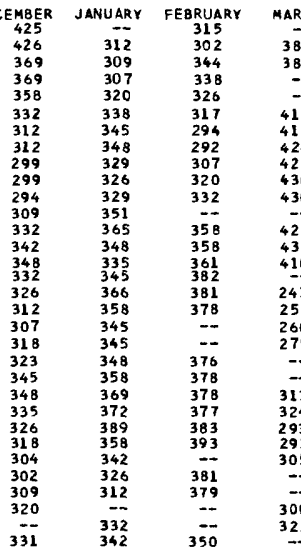

APRIL
326
329
323
--1
302
276
276
262
242
248
248
284
283
292
312
317
323
335
334
341
348
348
354
348
341
348
341
361
365
365
316

\begin{tabular}{lr} 
MAY & JUNE \\
343 & 230 \\
375 & 258 \\
394 & 276 \\
410 & 287 \\
421 & 291 \\
423 & 291 \\
$39 B$ & 308 \\
398 & -- \\
410 & - \\
415 & - \\
397 & -7 \\
365 & 331 \\
350 & 350 \\
360 & 360 \\
388 & 360 \\
411 & 360 \\
407 & -- \\
441 & 382 \\
473 & 400 \\
464 & 402 \\
456 & 404 \\
430 & -7 \\
456 & 404 \\
325 & 416 \\
303 & 416 \\
301 & 422 \\
308 & 425 \\
244 & 430 \\
243 & 431 \\
246 & -2 \\
235 & -- \\
373 & -9 \\
\hline &
\end{tabular}

\begin{tabular}{|c|c|c|}
\hline JULY & AUGUST & SEPI EMBER \\
\hline 438 & 504 & -- \\
\hline 447 & 486 & 442 \\
\hline 444 & 477 & 436 \\
\hline 444 & 515 & - \\
\hline 433 & 501 & 409 \\
\hline & 534 & 401 \\
\hline 425 & 547 & 418 \\
\hline 430 & 536 & 418 \\
\hline 438 & 478 & 442 \\
\hline 449 & 456 & 452 \\
\hline 455 & 526 & 453 \\
\hline 466 & 525 & 436 \\
\hline-- & 539 & 430 \\
\hline 470 & 539 & 442 \\
\hline $\begin{array}{l}468 \\
472\end{array}$ & $\begin{array}{l}570 \\
587\end{array}$ & 444 \\
\hline 472 & 594 & 457 \\
\hline 477 & 571 & 460 \\
\hline 484 & 508 & 457 \\
\hline 490 & 482 & 457 \\
\hline 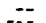 & 471 & 470 \\
\hline 505 & 443 & 466 \\
\hline 491 & 445 & 462 \\
\hline 486 & 451 & 464 \\
\hline 511 & 460 & 462 \\
\hline- & $\begin{array}{l}460 \\
454\end{array}$ & $\begin{array}{l}460 \\
472\end{array}$ \\
\hline 491 & 461 & 482 \\
\hline 460 & 461 & - \\
\hline 514 & 458 & 497 \\
\hline 511 & $\begin{array}{r}451 \\
499\end{array}$ & $\overline{4}$ \\
\hline 468 & 499 & 449 \\
\hline
\end{tabular}

TEMPERATURE $\left({ }^{\circ} \mathrm{C}\right)$ OF WATER, WATER YEAR OCTOBER I967 TO SEPTEMBER 1968 CCT NOV DEC (ONCE-DAILY MEASUREMENT USUALLY BETWEEN 1600 AND 1800)

\begin{tabular}{|c|c|}
\hline $\begin{array}{l}21.0 \\
22.0 \\
22.0 \\
20.0 \\
20.0\end{array}$ & $\begin{array}{l}14.0 \\
16.0 \\
15.0 \\
15.0 \\
\end{array}$ \\
\hline 20.0 & $=$ \\
\hline 21.0 & -- \\
\hline 21.0 & 13.0 \\
\hline & 12.0 \\
\hline 21.0 & 12.0 \\
\hline 21.0 & 13.0 \\
\hline 19.0 & 12.0 \\
\hline 19.0 & $\cdots$ \\
\hline 19.0 & $\overline{0}$ \\
\hline${ }_{21: 0}^{21: 0}$ & $11: 0$ \\
\hline 20.0 & 11.0 \\
\hline 20.0 & 11.0 \\
\hline 19.0 & 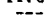 \\
\hline 19.0 & 9.0 \\
\hline 17.0 & 9.0 \\
\hline-- & 9.0 \\
\hline 17.0 & $\begin{array}{l}9.0 \\
9.0\end{array}$ \\
\hline 17.0 & 9.0 \\
\hline 17.0 & 9.0 \\
\hline & 8.0 \\
\hline 15.0 & 8.0 \\
\hline & \\
\hline
\end{tabular}

8.0
8.0
8.0
7.0
7.0
7.0
7.0
7.0
6.0
7.0
7.0
7.0
7.0
7.0
7.0
7.0
7.0
7.0
7.0
8.0
8.0
8.0
7.0
7.0
7.0
6.0
6.0
6.0
6.0
6.0
7.0
7.0

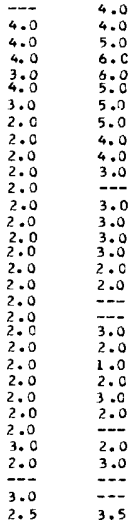

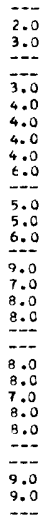

$\begin{array}{ll}11.0 & 17.0 \\ 11.0 & 18.0 \\ 12.0 & 18.0 \\ 12.0 & 18.0 \\ 12.0 & 19.0 \\ 13.0 & 19.0 \\ 13.0 & 18.0 \\ 12.0 & 18.0 \\ 13.0 & 18.0 \\ 13.0 & 19.0 \\ 13.0 & 18.0 \\ 14.0 & 18.0 \\ 1-.0 & 18.0 \\ 13.0 & 19.0 \\ 13.0 & 20.0 \\ 13.0 & 20.0 \\ 14.0 & 20.0 \\ 14.0 & 20.0 \\ 16.0 & 19.0 \\ 17.0 & 19.0 \\ 17.0 & 19.0 \\ 17.0 & 18.0 \\ 17.0 & 17.0 \\ 17.0 & 17.0 \\ 17.0 & 17.0 \\ 17.0 & 17.0 \\ 17.0 & 17.0 \\ 17.0 & 17.0 \\ 17.0 & 17.0 \\ 14.0 & 17.0 \\ 14.5 & 18.0\end{array}$

17.0
17.0
17.0
18.0
18.0
19.0
18.0
0.0
-0.
22.0
23.0
23.0
22.0
23.0
23.0
22.0
25.0
24.0
26.0
26.0
26.0
26.0
24.0
25.0
25.0
0.0
-0.
-1.

\begin{tabular}{|c|c|c|}
\hline $\mathrm{NL}$ & AUG & SEP \\
\hline 26.0 & $2 B .0$ & $\cdots$ \\
\hline 25.0 & 28.0 & -- \\
\hline 25.0 & $27 . \mathrm{C}$ & 27.0 \\
\hline 25.0 & 27.0 & $\cdots$ \\
\hline 24.0 & 27.0 & 27.0 \\
\hline 24.0 & 29.0 & - \\
\hline 27.0 & 29.0 & 26.0 \\
\hline 27.0 & 28.0 & 27.0 \\
\hline $\begin{array}{l}26.0 \\
26.0\end{array}$ & 28.0 & 25.0 \\
\hline 26.0 & 27.0 & 21.0 \\
\hline$\cdots$ & 27.0 & 24.0 \\
\hline 26.0 & 28.0 & 24.0 \\
\hline 27.0 & 28.0 & 24.0 \\
\hline 28.0 & 28.0 & \\
\hline 27.0 & 28.0 & 24.0 \\
\hline 27.0 & 28.0 & $24.1]$ \\
\hline 23.0 & 28.0 & 23.0 \\
\hline 28.0 & 28.0 & 23.0 \\
\hline 28.0 & $\begin{array}{r}28.0 \\
-\end{array}$ & 23.0 \\
\hline 28.0 & 29.0 & 25.0 \\
\hline 28.0 & 29.0 & 25.0 \\
\hline $2 \mathrm{~B} . \mathrm{O}$ & 29.0 & 25.0 \\
\hline & 29.0 & 23.0 \\
\hline-- & 28.0 & $-\cdots$ \\
\hline 28.0 & 28.0 & 23.0 \\
\hline 28.0 & 28.0 & \\
\hline 27.0 & 28.0 & 23.0 \\
\hline 28.0 & 28.0 & \\
\hline & 28 & - \\
\hline
\end{tabular}


LOCATION.--Lat $37^{\circ} 13^{\prime} 52^{\prime \prime}$, long $83^{\circ} 02^{\prime} 10^{\prime \prime}$, Knott County, temperature recorder at gaging station on loft bank, $0.3 \mathrm{mil}$ downstream from bridge on State Highway 1089 and Sassafras Creek, 0.5 mile downstream from Carr Fork Dam (under DRAINAGE AREA. $--60.6 \mathrm{sq} \mathrm{m} \pm$.

PERIOD OF RECORD. - Hater temperatures: July 1966 to September 1968.

EXTREMES, --1967-68:

Water temperatures: Maximum, $31.0^{\circ} \mathrm{C}$ Aug. 7,9 ; minimum, freezing point on several days during December to eriod of record: Water temperatures: Maximum, $31.0^{\circ} \mathrm{C}$ Aug, $7,9,1968$; minimum, freezing point on several days during December
1967 to March 1968 .

TEMPERATURE $\left({ }^{\circ} \mathrm{C}\right)$ OF WATER, WATER YEAR OCTOBER 1967 TO SEPTEMBER 1968 (CONTINUOUS ETHYL. ALCOHOL-ACTUATED THERMOGRAPH)

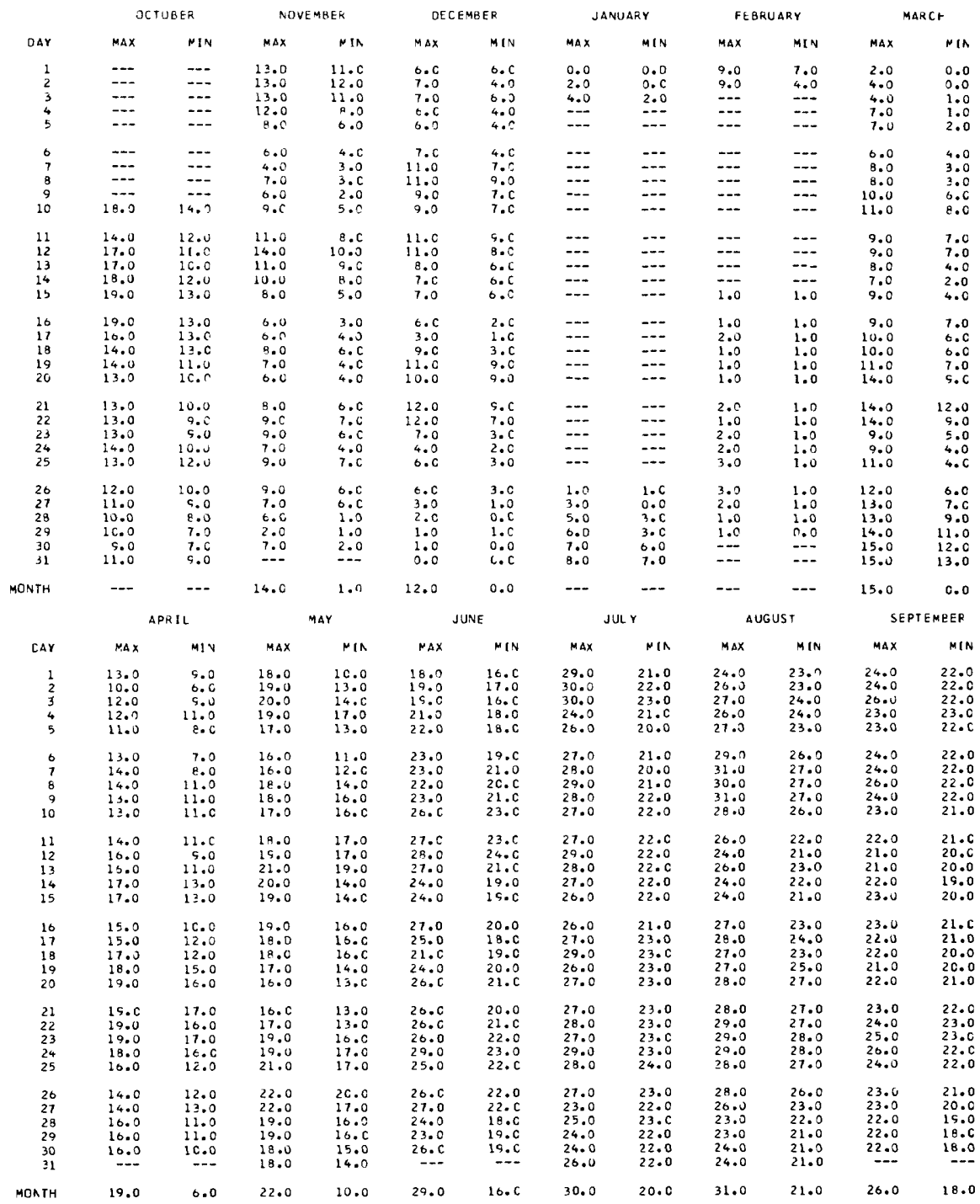


03277500 NORTH FORK KENTUCKY RIVER AT HAZARD, KY.

LOCATION,--Lat $37^{\circ} 14^{\prime} 45^{\prime \prime}$, long $83^{\circ} 11^{\prime} 00^{\prime \prime}$, Perry County, at Foodland Park bridge at eastern 1 inits of Hazard, 150 ft upstream from city waterworks dam, $300 \mathrm{ft}$ downtream from gaging station, and 4.0 miles upstream from Lotts

DRAINAGE AREA. $--466 \mathrm{sq} \mathrm{m} 1$.

PERIOD OF RECORD. --Chemical analyses: November 1949 to August 1950, August 1957 to September 1959 (periodic); October 1962 to September 1968 .

Water temperatures: October 1949 to September 1968 .

EXTREMES. --1967-68:

Specific conductance: Maximum daily, 740 micromhos Sept. 29; minimum daily, 127 micromhos Mar. 17.

Water temperatures: Maximum, 33.0 $\mathrm{C}$ Aug. 9, 22; minimum, freezing point on several days during January to March.

Period of record:

Specific conductance (1962-68): Maximum daily, 1,720 micromhos Dec. 19, 20, 1962; minimum daily, 118 micromhos

Dec. 13, 1966 .
Water temperatures: Maximum, $34.0^{\circ} \mathrm{C}$ Aug. 1,1953 ; minimum, freezing point on many days during winter periods.

REMARKS.--Daily samples were collected at this station and samples were selected for analysis on the following basis: (1) Maximum daily specific conductance for each month, and (2) minimum daily specific conductance for each month. Temperature recorder at gaging station $300 \mathrm{ft}$ upstream from sampling site. Small diversion by city of Hazard waterworks and electric plant above station.

CHEMICAL ANALYSES IN MILLIGRAMS PER LITER, WATER YEAR OCTOBER 1967 TO SEPTEMBER 1968

\begin{tabular}{|c|c|c|c|c|c|c|c|c|c|c|c|c|}
\hline DATE & $\begin{array}{l}\text { DIS- } \\
\text { CHARGE } \\
\text { (CFS) }\end{array}$ & $\begin{array}{l}\text { BICAR- } \\
\text { BONATE } \\
\text { (HCO3) }\end{array}$ & $\begin{array}{l}\text { CAR- } \\
\text { BONATE } \\
\text { (CO3) }\end{array}$ & $\begin{array}{l}\text { SUL FATE } \\
\text { (SO4) }\end{array}$ & $\begin{array}{l}\text { CHLO- } \\
\text { RIDE } \\
\text { (CL) }\end{array}$ & $\begin{array}{l}\text { NITRATE } \\
\text { (NO3) }\end{array}$ & $\begin{array}{l}\text { DIS- } \\
\text { SOLVED } \\
\text { SOLIDS } \\
\text { IRESI- } \\
\text { DUE AT } \\
\text { I8OCI }\end{array}$ & $\begin{array}{l}\text { HARD- } \\
\text { NFSS } \\
(C A, M G)\end{array}$ & $\begin{array}{l}\text { NON- } \\
\text { CAR- } \\
\text { BONATE } \\
\text { HARO- } \\
\text { N=SS }\end{array}$ & $\begin{array}{l}\text { SPECI- } \\
\text { FIC } \\
\text { COND- } \\
\text { UCTANCF } \\
\text { CMICRA- } \\
\text { MHOSI }\end{array}$ & $\mathrm{PH}$ & $\begin{array}{l}\text { TFMP- } \\
\text { ERATUPF } \\
\text { (DFF C I }\end{array}$ \\
\hline OCT. & & & & & & & & & & & & \\
\hline $19 .$. & 179 & 132 & 0 & 21 ค & 13 & .4 & 448 & 234 & 126 & 666 & 75 & 13 \\
\hline $\begin{array}{l}29 . . . \\
\text { NOV. }\end{array}$ & 54 & 60 & 0 & 117 & 6,0 & .6 & 242 & 132 & 83 & 366 & 73 & i1 \\
\hline $\begin{array}{l}03 . . . \\
23 . .\end{array}$ & $\begin{array}{r}1360 \\
254\end{array}$ & $\begin{array}{l}25 \\
44\end{array}$ & $\begin{array}{l}D \\
0\end{array}$ & $\begin{array}{r}55 \\
144\end{array}$ & $10^{3.0}$ & 28.2 & $\begin{array}{l}136 \\
332\end{array}$ & $\begin{array}{r}68 \\
171\end{array}$ & $\begin{array}{r}47 \\
135\end{array}$ & $\begin{array}{l}184 \\
457\end{array}$ & $\begin{array}{l}72 \\
7\end{array}$ & $\begin{array}{r}10 \\
6\end{array}$ \\
\hline 11... & 693 & 58 & 0 & 145 & 30 & . $\mathrm{A}$ & 294 & 57 & 9 & 513 & 72 & 8 \\
\hline $\begin{array}{l}19 . . \\
\text { JAN. }\end{array}$ & 3400 & 16 & 0 & 48 & 3.0 & 1.6 & 74 & 48 & 35 & 130 & 68 & 7 \\
\hline $\begin{array}{l}05 \ldots . . \\
15 \ldots \\
F \in B .\end{array}$ & $\begin{array}{l}2530 \\
1250\end{array}$ & $\begin{array}{l}29 \\
24\end{array}$ & $\begin{array}{l}0 \\
0\end{array}$ & $\begin{array}{r}110 \\
60\end{array}$ & $\begin{array}{l}8.0 \\
3.5\end{array}$ & $\begin{array}{r}1,3 \\
.8\end{array}$ & $\begin{array}{l}174 \\
104\end{array}$ & $\begin{array}{r}114 \\
66\end{array}$ & $\begin{array}{l}91 \\
46\end{array}$ & $\begin{array}{l}323 \\
188\end{array}$ & $\begin{array}{l}71 \\
69\end{array}$ & i \\
\hline $\begin{array}{l}01 \ldots . . \\
28 . . \\
\text { MAR. }\end{array}$ & $\begin{array}{r}506 \\
92\end{array}$ & $\begin{array}{l}33 \\
61\end{array}$ & $\begin{array}{l}0 \\
0\end{array}$ & $\begin{array}{r}83 \\
145\end{array}$ & $\begin{array}{l}2.0 \\
5.0\end{array}$ & $\begin{array}{l}1.7 \\
1.5\end{array}$ & $\begin{array}{l}160 \\
246\end{array}$ & $\begin{array}{r}93 \\
153\end{array}$ & $\begin{array}{r}66 \\
103\end{array}$ & $\begin{array}{l}256 \\
431\end{array}$ & $\begin{array}{l}76 \\
72\end{array}$ & 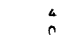 \\
\hline $01 . .$. & 102 & 64 & 0 & 139 & 6.0 & . $B$ & $26 B$ & 152 & 100 & 430 & 72 & 0 \\
\hline $\begin{array}{l}\text { 17... } \\
\text { APR. }\end{array}$ & 1320 & 16 & 0 & 39 & 3.0 & 2.0 & 70 & 46 & 33 & 127 & A 4 & 6 \\
\hline $\begin{array}{l}23 \ldots \ldots \\
25 \ldots \ldots\end{array}$ & $\begin{array}{l}371 \\
326\end{array}$ & $\begin{array}{l}26 \\
60\end{array}$ & $\begin{array}{l}0 \\
0\end{array}$ & $\begin{array}{r}56 \\
107\end{array}$ & $\begin{array}{l}3.0 \\
4.5\end{array}$ & $\begin{array}{r}1.2 \\
.5\end{array}$ & $\begin{array}{l}116 \\
230\end{array}$ & $\begin{array}{r}63 \\
122\end{array}$ & $\begin{array}{l}42 \\
73\end{array}$ & $\begin{array}{l}178 \\
330\end{array}$ & $\begin{array}{l}71 \\
7\end{array}$ & $\begin{array}{l}17 \\
17\end{array}$ \\
\hline $\begin{array}{l}15 \ldots \\
25 \ldots\end{array}$ & $\begin{array}{r}2540 \\
630\end{array}$ & $\begin{array}{l}34 \\
52\end{array}$ & $\begin{array}{l}0 \\
0\end{array}$ & $\begin{array}{r}55 \\
128\end{array}$ & $\begin{array}{l}2.5 \\
4.0\end{array}$ & $\begin{array}{l}2.3 \\
2.5\end{array}$ & $\begin{array}{r}97 \\
226\end{array}$ & $\begin{array}{r}69 \\
134\end{array}$ & $\begin{array}{l}41 \\
92\end{array}$ & $\begin{array}{l}165 \\
378\end{array}$ & 78 & $\begin{array}{l}19 \\
17\end{array}$ \\
\hline JUNE & & & & & & & & & & & & \\
\hline $\begin{array}{l}09 \ldots . . \\
26 \ldots . .\end{array}$ & $\begin{array}{r}209 \\
92\end{array}$ & $\begin{array}{r}36 \\
100\end{array}$ & $\begin{array}{l}0 \\
0\end{array}$ & $\begin{array}{r}58 \\
204\end{array}$ & $10^{3.0}$ & $\begin{aligned} 2 & =1 \\
& =4\end{aligned}$ & $\begin{array}{l}124 \\
388\end{array}$ & $\begin{array}{r}73 \\
208\end{array}$ & $\begin{array}{r}44 \\
126\end{array}$ & $\begin{array}{l}204 \\
602\end{array}$ & $\begin{array}{l}66 \\
72\end{array}$ & $\begin{array}{l}22 \\
26\end{array}$ \\
\hline $\begin{array}{l}13 \ldots . . \\
25 \ldots \\
A \cup G .\end{array}$ & $\begin{array}{l}43 \\
54\end{array}$ & ${ }_{50}^{4}$ & 0 & $\begin{array}{r}334 \\
95\end{array}$ & $\begin{array}{l}6.0 \\
2.0\end{array}$ & $\begin{array}{l}1.8 \\
1.8\end{array}$ & $\begin{array}{l}522 \\
216\end{array}$ & $\begin{array}{l}288 \\
108\end{array}$ & $\begin{array}{r}285 \\
67\end{array}$ & $\begin{array}{l}726 \\
305\end{array}$ & 65 & $\begin{array}{l}26 \\
27\end{array}$ \\
\hline $\begin{array}{l}01 \ldots . . \\
18 . . \\
\text { SFP. }\end{array}$ & $\begin{array}{l}124 \\
830\end{array}$ & $\begin{array}{l}42 \\
29\end{array}$ & $\begin{array}{l}0 \\
0\end{array}$ & $\begin{array}{r}237 \\
78\end{array}$ & $\begin{array}{l}8.0 \\
4.0\end{array}$ & $\begin{array}{l}2.0 \\
2.0\end{array}$ & $\begin{array}{l}414 \\
172\end{array}$ & $\begin{array}{r}214 \\
36\end{array}$ & $\begin{array}{r}180 \\
63\end{array}$ & $\begin{array}{l}582 \\
240\end{array}$ & $\begin{array}{l}7 . \\
7.3\end{array}$ & $\begin{array}{l}2 k \\
23\end{array}$ \\
\hline $01 \ldots$ & 39 & 88 & 0 & 189 & 10 & .6 & 390 & 204 & 132 & 555 & 7 & 21 \\
\hline 29 & 21 & 124 & 0 & 248 & 16 & .2 & 516 & 248 & 147 & 740 & 7 & 21 \\
\hline
\end{tabular}

SPECIFIC CONDUCTANCE (MICROMHOS AT $25^{\circ} \mathrm{C}$ ), WATER YEAR OCTOBER 1967 TO SEPTEMBER 1968

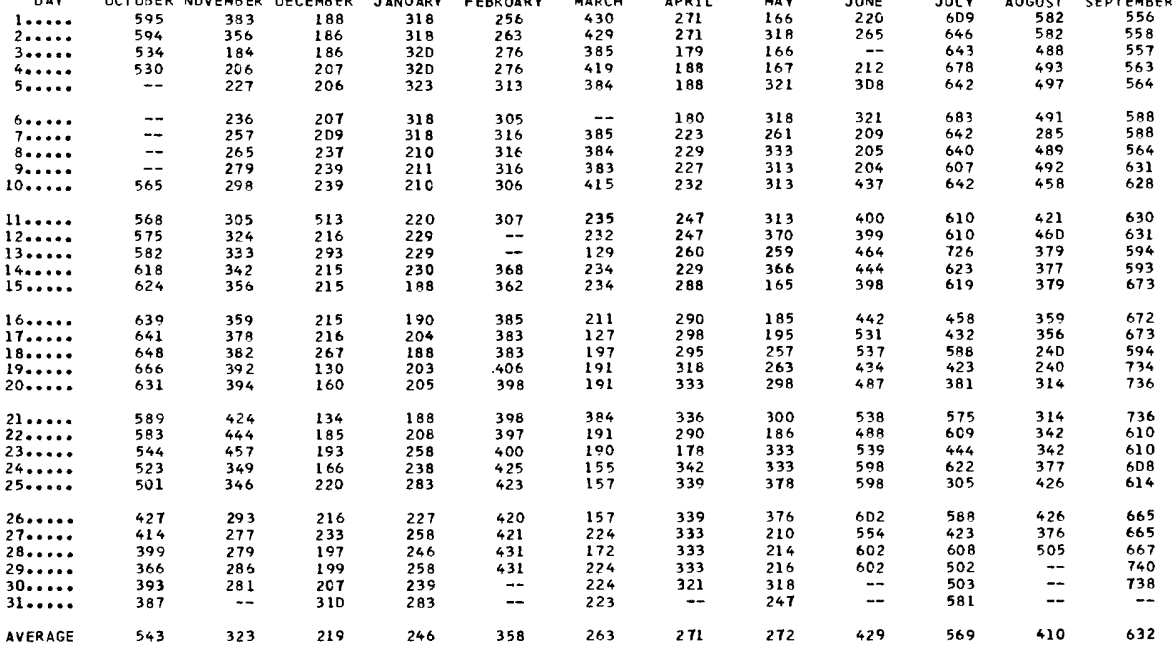


UCTOUE

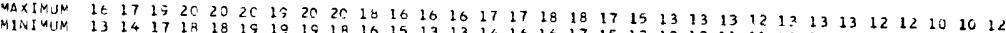

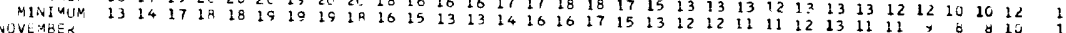

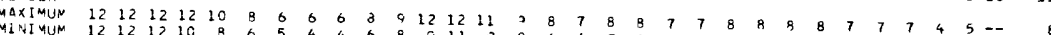
DECEYBER

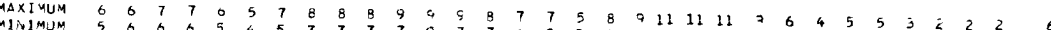

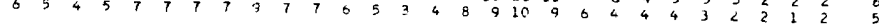

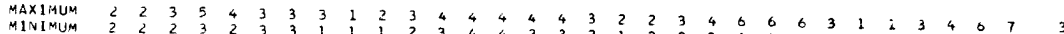
$\begin{array}{llllllllllllllllllllllllllllllllllll}\text { MINIMUM } & 2 & 2 & 2 & 3 & 2 & 3 & 3 & 1 & 1 & 1 & 2 & 3 & 4 & 4 & 3 & 3 & 2 & 1 & 2 & 2 & 3 & 4 & 6 & 3 & 1 & 0 & 1 & 1 & 3 & 4 & 6 & 3\end{array}$

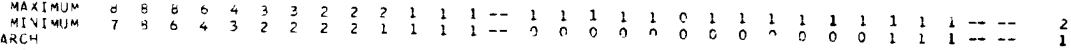
ARCH

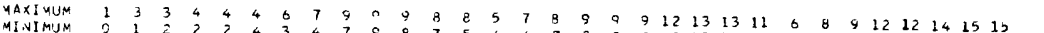
APKIL

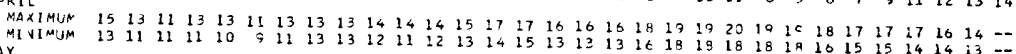
MAY

YAXIMUM

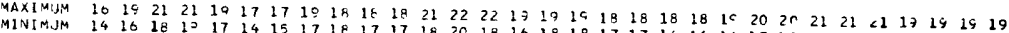
JINE

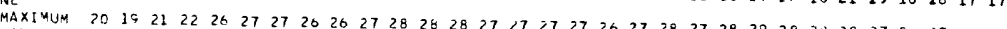
$\begin{array}{lllllllllllllllllllllllllllllllll}\text { MINIMUM } & 18 & 19 & 19 & 21 & 22 & 23 & 24 & 20 & 26 & 27 & 28 & 28 & 28 & 27 & 27 & 27 & 27 & 26 & 27 & 28 & 27 & 28 & 29 & 28 & 28 & 28 & 27 & 20 & 27 & 31 & --\end{array}$ ULI $Y$

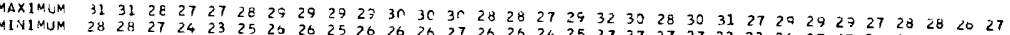
MUGUST

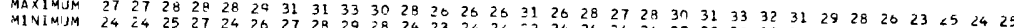
SEPTEMGEN

$\begin{array}{lllllllllllllllllllllllllllllllllllll}\text { MAXIMUM } & 24 & 25 & 26 & 24 & 23 & 25 & 24 & 26 & 24 & 23 & 23 & 21 & 22 & 23 & 25 & 23 & 23 & 22 & 21 & 23 & 24 & 26 & 26 & 27 & 25 & 24 & 22 & 22 & 21 & 42 & -- \\ \text { MINIMUM } & 22 & 23 & 22 & 23 & 22 & 22 & 22 & 22 & 22 & 22 & 21 & 19 & 16 & 26 & 21 & 21 & 21 & 26 & 19 & 19 & 22 & 23 & 24 & 24 & 23 & 22 & 19 & 19 & 18 & 18 & --\end{array}$ 15
8
7
6
5
3
2
2
1
8
6
5
3
15
7
6
3
8
5
5
5
3 03286200 DIX RIVER AT DIX DAM, NEAR BURGIN, KY,

LOCATION.--Lat $37^{\circ} 47^{\prime} 35^{\prime \prime}$, long $84^{\circ} 42^{\prime} 22^{\prime \prime}$, Mercer County, temperature recorder at stage station on left bank, $400 \mathrm{ft}$ upstream from Dix Dam spillway outlet, 0.6 mile downstream from powerhouse (at toe of dam), 2.4 miles upstream from mouth and $4,4 \mathrm{miles}$ nor theast of Burgin.

DRAINAGE AREA. $--439 \mathrm{sq} \mathrm{mi}$.

PERIOD OF RECORD.--Water temperatures: November 1962 to September 1968.

EXTREMES. --1967-68:

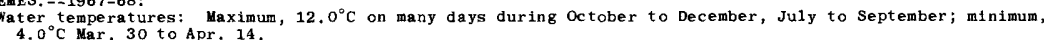

period of record

Water temperatures: Maximum, $15.5^{\circ} \mathrm{C}$ June $23,24,26-28,1967$; minimum, $4.0^{\circ} \mathrm{C}$ Mar. 30 to Apr. $14,1968$. REMARKS...-No discharge records available. Flow regulated by Herrington Lake.

TEMPERATURE $\left({ }^{\circ} \mathrm{C}\right)$ DF WATER, WATER YEAR OCTOBER 1967 TO SEPTEMBER 1968 $\left({ }^{\circ} \mathrm{C}\right)$ OF WATER, WATER YEAR OCTOBER 1967 TO SEP

$\operatorname{CTOBER}$

$$
\text { NOVEMBER OECEMBER }
$$

\begin{tabular}{|c|c|c|c|}
\hline MAX & NIA & $\operatorname{MAx}$ & $M I N$ \\
\hline $\begin{array}{l}12.0 \\
12.0 \\
12.0 \\
12.0 \\
12.0\end{array}$ & $\begin{array}{l}12.0 \\
12.0 \\
12.6 \\
12.0 \\
12.0\end{array}$ & $\begin{array}{l}12.0 \\
12.0 \\
12.0 \\
12.0 \\
12.0\end{array}$ & $\begin{array}{l}12.0 \\
12.0 \\
12.0 \\
12.0 \\
12.0\end{array}$ \\
\hline $\begin{array}{l}12.0 \\
12.0 \\
12.0 \\
12.0 \\
12.0\end{array}$ & $\begin{array}{l}12.0 \\
12.0 \\
12.0 \\
12.0 \\
11.0\end{array}$ & $\begin{array}{l}12.0 \\
12.0 \\
12.0 \\
12.0 \\
1200\end{array}$ & $\begin{array}{l}12.0 \\
12.0 \\
12.0 \\
12.0 \\
12.0\end{array}$ \\
\hline $\begin{array}{l}12.0 \\
11.0 \\
11.0 \\
11.0 \\
12.0\end{array}$ & $\begin{array}{l}11.0 \\
1 \mathrm{c} .0 \\
11.0 \\
11.0 \\
11.0\end{array}$ & $\begin{array}{l}12.0 \\
12.0 \\
12.0 \\
12.0 \\
12.0\end{array}$ & $\begin{array}{l}12.0 \\
12.0 \\
12.0 \\
12.0 \\
12.0\end{array}$ \\
\hline $\begin{array}{l}12.0 \\
11.0 \\
11.0 \\
11.0 \\
11.0\end{array}$ & $\begin{array}{l}11.0 \\
11.0 \\
11.0 \\
11.0 \\
11.0\end{array}$ & $\begin{array}{l}12.0 \\
12.0 \\
12.0 \\
12.0 \\
12.0\end{array}$ & $\begin{array}{l}11.0 \\
11.0 \\
12.0 \\
12.0 \\
12.0\end{array}$ \\
\hline $\begin{array}{l}12.0 \\
12.0 \\
12.0 \\
12.0 \\
12.0\end{array}$ & $\begin{array}{l}11.0 \\
12.0 \\
11.0 \\
11.0 \\
11.0\end{array}$ & $\begin{array}{l}12.0 \\
12.0 \\
12.0 \\
12.0 \\
12.0\end{array}$ & $\begin{array}{l}12.0 \\
12.0 \\
12.0 \\
12.0 \\
12.0\end{array}$ \\
\hline $\begin{array}{l}11.0 \\
11.0 \\
11.0 \\
11.0 \\
12.0 \\
12.0\end{array}$ & $\begin{array}{l}11.0 \\
11.0 \\
11.0 \\
11.0 \\
11.0 \\
12.0\end{array}$ & $\begin{array}{r}12.0 \\
12.0 \\
12.0 \\
12.0 \\
12.0 \\
\ldots .0\end{array}$ & $\begin{array}{l}12.0 \\
12.0 \\
12.0 \\
12.0 \\
12.0 \\
-\end{array}$ \\
\hline
\end{tabular}

DAY

MOATH 12.0

$1 \mathrm{c.} 0$

12.0

MAX
12.0
12.0
12.0
12.0
12.0
12.0
11.0
11.0
10.0
10.2
10.0
9.0
8.0
8.0
8.0
$8 . C$
8.0
8.0
8.0
8.0
$8 . C$
8.0
$8 . C$
9.0
$B .0$
8.0
8.0
8.0
8.0
8.0
$8 . C$
12.0
12.0

$M 1 N$
$12 . C$
12.0
12.0
$12 . \mathrm{C}$
$12 . \mathrm{C}$
$11 . \mathrm{C}$
11.0
10.0
$10 . \mathrm{C}$
$9 . \mathrm{C}$
$9 . \mathrm{C}$
$8 . \mathrm{C}$
$8 . \mathrm{C}$
8.0
8.0
8.0
8.0
8.0
8.0
8.0
$8 . C$
8.0
$8 . \mathrm{C}$
$8 . \mathrm{C}$
8.0
8.0
8.0
$8 . C$
8.0
$8 . C$
8.0
8.0
JANUARY

FEBRUARY

MARCH

5.0

5.0

5.0

8.0

B. C

8.0

8.0
8.0

8.0
8.0

8.0
8.0

8.0

6.0

6.0

$\begin{array}{ll}6.0 & 0.0 \\ 6.0 & 6.0\end{array}$

$\begin{array}{ll}6.0 & 6.0 \\ 6.0 & 6.0\end{array}$

6.0

8. C

. C 3.

$8 . \mathrm{C} \quad 8.0$

$\begin{array}{ll}.0 & 8.0 \\ .0 & 8.0\end{array}$

8.0

6.0

5.0
5.0

0.0
6.0
5.0

5.0
5.0

5.0

8.0

5.0

$\begin{array}{ll}8 . C & 8.0 \\ 3.0 & 8.0 \\ 8.0 & 7.0 \\ 8.0 & 7.0\end{array}$

8.0
7.0
7.0

7.0

5.0
5.0

5.2
5.0

5.0
5.0

5.0

$8.0 \quad 7.0$

7. $C$

7.0

7.0

5.0

7.0
7.0

5.0

$7.0 \quad 5.0$

5.0
5.0
5.0

5.0

7.0
7.0
7.0

7.2

$\begin{array}{ll}8.0 & 7.0 \\ 8.0 & 7.0\end{array}$

7.0
0.0

0.0

7.0
6.0
6.0

5.0

5.?

5.0

5.0

8. 0

8.0

0.0

…

5.0
5.0

5.0

6.0

6.0

6.0

5.0

$5.0 \quad 5.0$

5.0

5.0
5.0

5.0

5.0
5.0

5.0

5.0

5.0
5.0

5.0

5.0

4.0

IN

5.0 
03286200 DIX RIVER AT DIX DAH, NEAR BURGIN, KY.--Continued

TEMPERATURE $\left({ }^{\circ} \mathrm{C}\right)$ OF WATER, WATER YEAR OCTOBER 1967 TO SEPTEMBER 1968

\begin{tabular}{|c|c|c|c|c|c|c|c|c|c|c|c|c|}
\hline \multirow{4}{*}{ CAY } & \multirow{2}{*}{\multicolumn{2}{|c|}{ AQKIL }} & \multirow{2}{*}{\multicolumn{2}{|c|}{ MAY }} & \multicolumn{3}{|r|}{. } & KMUGR A & \multirow{2}{*}{\multicolumn{2}{|c|}{ AUGUST }} & \multirow{2}{*}{\multicolumn{2}{|c|}{ SEPTEMRER }} \\
\hline & & & & & & & & & & & & \\
\hline & $\operatorname{MAX}$ & MIN & $\operatorname{Max}$ & MIN & $\operatorname{MAX}$ & MIN & $\operatorname{Nax}$ & $M[N$ & MAX & MIN & $\operatorname{Max}$ & MIN \\
\hline & 4.0 & 4.0 & 7.0 & 6.0 & 7.0 & $7 \cdot c$ & 10.0 & 9.0 & 11.0 & 11.0 & 12.0 & 12.0 \\
\hline 3 & 4.0 & 4.0 & 7.0 & 7.0 & 7.0 & 7.0 & 11.0 & 9.0 & 11.0 & 11.0 & 12.0 & $12 . \mathrm{C}$ \\
\hline 4 & 4.0 & 4.0 & 7.0 & 7.5 & 7.0 & $7 . \mathrm{C}$ & 11.0 & 11.0 & 12.0 & 11.0 & 12.0 & $22 . c$ \\
\hline $\begin{array}{l}4 \\
5\end{array}$ & 4.0 & 4.5 & $e \cdot 0$ & 7.0 & a. 0 & $7 . \mathrm{c}$ & 11.0 & $11 \cdot c$ & 12.3 & 12.0 & 12.0 & $12 \cdot 0$ \\
\hline 6 & $4 \cdot 0$ & 4.0 & 8.0 & 8.0 & 9.0 & a.c & 11.0 & 11.0 & 12.0 & 11.0 & 12.0 & 12.0 \\
\hline 7 & 4.0 & 4.0 & 8.0 & 8.0 & 8.0 & $8 . c$ & 11.0 & $11 . c$ & 11.0 & 11.0 & 12.0 & $12 . \mathrm{C}$ \\
\hline 8 & 4.0 & $4 \cdot C$ & 8.0 & 8.0 & 9.0 & B.C & 11.0 & 11.0 & 11.0 & 11.0 & 12.0 & $12 \cdot c$ \\
\hline 9 & $\begin{array}{l}4.0 \\
4.0\end{array}$ & 4.0 & 8.0 & 8.0 & 9.0 & 9.6 & 11.0 & 11.0 & 11.0 & 11.0 & 12.0 & 12.0 \\
\hline 10 & $\begin{array}{l}4.0 \\
4.0\end{array}$ & 4.0 & 8.0 & B. 0 & 9.0 & $\because \cdot c$ & 11.0 & 11.0 & 11.0 & 11.0 & 12.0 & 12.0 \\
\hline 11 & $\begin{array}{l}4.0 \\
4.0\end{array}$ & 4.0 & 8.0 & R.c & 9.0 & $8 \cdot c$ & 11.0 & 11.0 & 11.0 & 11.0 & 12.0 & $\begin{array}{l}12.0 \\
12.0\end{array}$ \\
\hline 12 & 4.0 & 4.0 & $\begin{array}{l}9.0 \\
9.0\end{array}$ & $\begin{array}{l}8.0 \\
9.0\end{array}$ & $\begin{array}{r}9.0 \\
10.0\end{array}$ & $\begin{array}{l}8 . C \\
9.0\end{array}$ & $\begin{array}{l}12.0 \\
11.0\end{array}$ & $\begin{array}{l}11.0 \\
11.0\end{array}$ & 12.0 & 11.0 & 12.0 & $\begin{array}{l}12.0 \\
12.0\end{array}$ \\
\hline 13 & 4.0 & 4.0 & 9.0 & 9.0 & $10 . \mathrm{c}$ & $1 \mathrm{C} . \mathrm{C}$ & 11.0 & 11.0 & $\begin{array}{l}12.0 \\
12.0\end{array}$ & 12.0 & $\begin{array}{l}12.0 \\
12.0\end{array}$ & 12.0 \\
\hline 14 & 5.0 & 4.0 & 9.0 & $8 . \mathrm{c}$ & 10.0 & 10.0 & 11.0 & 11.0 & 12.0 & 11.0 & 12.0 & 12.0 \\
\hline 15 & 5.0 & 5.0 & 8.0 & 8. $\mathrm{c}$ & 10.0 & 10. C & 12.0 & 11.0 & 11.0 & 10.0 & 12.0 & 12.0 \\
\hline 16 & 5.0 & 5.0 & 8.0 & 8.0 & 10.0 & 10.0 & 12.0 & $11 . \mathrm{C}$ & 10.0 & 10.0 & 12.0 & 12.0 \\
\hline 17 & 5.0 & 5.0 & 8.0 & 8.0 & 10.0 & 9.0 & 11.0 & 12.0 & 10.0 & 10.0 & 12.0 & 12.0 \\
\hline 18 & 5.0 & 5.0 & 8.0 & 8.0 & $11 . c$ & 9.0 & 11.0 & $11 . c$ & 12.3 & $1 \mathrm{C.} C$ & 12.0 & 12.0 \\
\hline 19 & 5.0 & 5.0 & 8.0 & $B \cdot C$ & 9.0 & 9.0 & 11.0 & 11.0 & 11.0 & 11.0 & 12.0 & $12 . c$ \\
\hline 20 & 5.0 & 5.0 & 8.0 & $8 \cdot C$ & 10.0 & 9. C & 11.0 & 10.0 & 11.0 & 11.0 & 12.0 & 12.0 \\
\hline 21 & 5.2 & 5.6 & 8.0 & 8.c & 9.0 & 9.0 & 11.0 & 10.0 & 11.0 & 11.0 & 12.0 & $12 . c$ \\
\hline 22 & 5.0 & 5.0 & 8.0 & $8 \cdot C$ & 9.0 & 9. C & 11.0 & 11.0 & 12.0 & 11.0 & 12.0 & 12.0 \\
\hline 23 & 5.0 & 5.0 & 8.0 & 8.0 & 12.0 & 9.6 & 11.0 & $11 . c$ & 11.0 & $11 . c$ & 12.0 & 12.0 \\
\hline 24 & 5.0 & 5.0 & 8.0 & $e \cdot c$ & 10.0 & 9.0 & 11.0 & 11.0 & 11.0 & 11.0 & 12.0 & $12 . \mathrm{c}$ \\
\hline 25 & 5.0 & 5.0 & 8.0 & 8.0 & 11.0 & $10 . c$ & 11.0 & 11.0 & 12.0 & 11.0 & 12.0 & 12.0 \\
\hline 26 & 5.0 & $5 \cdot 0$ & 8.0 & 7.0 & 11.0 & 9.0 & 11.0 & 11.0 & 12.0 & 12.0 & 12.0 & $12 . c$ \\
\hline 27 & 5.0 & 5.0 & 7.0 & $7 . c$ & 9.0 & 9. $c$ & 12.0 & 11.0 & 12.0 & 12.0 & 12.0 & 12.0 \\
\hline 28 & 6.0 & 5.0 & 7.0 & 7.0 & 9.0 & 9.6 & 12.9 & $12 . c$ & 12.0 & 12.0 & 12.0 & $12 . c$ \\
\hline 29 & 6.0 & 6.0 & 7.0 & 7.6 & 10.0 & 9.0 & 12.0 & 11.0 & 12.0 & 12.0 & 12.0 & $12 . c$ \\
\hline 30 & 6.0 & 6.0 & 7.0 & 7.0 & 10.0 & G. $c$ & 11.0 & $11 . c$ & 12.0 & 12.0 & 12.0 & 12.0 \\
\hline 31 & --- & $\cdots$ & 7.0 & 7.0 & $\cdots$ & --- & 11.0 & 11.0 & 12.0 & 12.0 & $\cdots$ & \\
\hline ATH & 6.0 & 4.0 & 9.0 & $6 . c$ & 11.0 & 7.6 & 12.0 & 9.0 & 12.0 & 10.0 & 12.0 & 12.0 \\
\hline
\end{tabular}

LOCATION,--Lat $38^{\circ} 12^{\prime} 06^{\prime \prime}$, long $84^{\circ} 52^{\prime} 54^{\prime \prime}$, Franklin County, at gaging station at Broadway Street bridge at Frankfort, $300 \mathrm{ft}$ upstream from Benson Creek, 0.9 m1le upstream from lock 4 and at mile 65.9 .

DRAINAGE AREA.--5,412 sq mi (Including that of Benson Creek), of which about 120 sq mi does not contribute.directly to surface runoff.

PERIOD OF RECORD.--Chemical analyses: October 1949 to September 1968

Water temperatures: October 1949 to September 1968.

Sediment records: October 1952 to September 1968.

EXTREMES. --1967-68:

Specific conductance: Maximum da11y, 536 micromhos Nov, 21; minimum da11y, 121 micromhos Mar. 15

Water temperatures: Maximum, $29.0^{\circ} \mathrm{C}$ July 10,11 , Aug. $7-11$; minimum, $1.0^{\circ} \mathrm{C}$ Jan. $7-18$.

Sediment concentrations: Maximum daliy, $1,270 \mathrm{mg} / 1$ Mar. 14 ; mintmum daily, $3 \mathrm{mg} / 1$ Sept. $24,26$.

Period of record:

Specific conductance (1949-68): Maximum dally, 635 micronhos July 26, 1965; minimum daily, 71 micromhos

Dec. $30,1961$.

Water temperatur

Naximum, $31.0^{\circ} \mathrm{C}$ July 22, 1957; minimum, freezing point on several days during January an

diment concentration

Sediment loads: Maximum daily, 420,000 tons Feb, 28, 1962; minimum daily, 0.53 ton Nov, 17, 1953.

REMARKS. - Daily samples were collected for maximum and minimum specific conductance for each month. Flow partiy regulated by Buckhorn Reservo1r, Herrington Lake and hydroelectric plant at lock 7 .

CHEMICAL ANALYSES IN MILLIGRAMS PER LITER, WATER YEAR OCTOBER 1967 TO SEPTEMBER 1968

\begin{tabular}{|c|c|c|c|c|c|c|c|c|c|c|c|c|}
\hline DATE & $\begin{array}{l}\text { DIS- } \\
\text { CHARGE } \\
\text { (CFS) }\end{array}$ & $\begin{array}{l}\text { BICAR- } \\
\text { BONATE } \\
\text { IHCO3) }\end{array}$ & $\begin{array}{l}\text { CAR- } \\
\text { BDNATE } \\
\text { (CD3) }\end{array}$ & $\begin{array}{l}\text { SULFATE } \\
\text { (SO4) }\end{array}$ & $\begin{array}{l}\text { CHLO- } \\
\text { RIDE } \\
|\mathrm{CL}|\end{array}$ & $\begin{array}{l}\text { NITRATE } \\
\text { INO3\} }\end{array}$ & $\begin{array}{l}\text { OIS- } \\
\text { SOLVEO } \\
\text { SOL INS } \\
\text { (RESI- } \\
\text { OUE AT } \\
180 \mathrm{C} \text { ) }\end{array}$ & $\begin{array}{l}\text { HARD- } \\
\text { NFSS } \\
\text { (CA,ME) }\end{array}$ & $\begin{array}{l}\text { NINN- } \\
\text { CAR- } \\
\text { BONATE } \\
\text { HARN- } \\
\text { NESS }\end{array}$ & $\begin{array}{l}\text { SPFCI- } \\
\text { FIC } \\
\text { COND- } \\
\text { UTTANCE } \\
\text { IMICRN- } \\
\text { MHOSI }\end{array}$ & $\mathrm{PH}$ & $\begin{array}{l}\text { TEMP- } \\
\text { SRATINPF } \\
\text { INFG CI }\end{array}$ \\
\hline $\begin{array}{l}\text { OCT. } \\
24 \ldots \ldots \\
31 \ldots\end{array}$ & $\begin{array}{r}350 \\
1290\end{array}$ & $\begin{array}{l}126 \\
100\end{array}$ & $\begin{array}{l}0 \\
0\end{array}$ & $\begin{array}{l}25 \\
30\end{array}$ & $12^{5.0}$ & $\begin{array}{l}2.4 \\
1.1\end{array}$ & $\begin{array}{l}202 \\
184\end{array}$ & $\begin{array}{l}125 \\
107\end{array}$ & $\begin{array}{l}22 \\
25\end{array}$ & $\begin{array}{l}268 \\
253\end{array}$ & $\begin{array}{ll}7 & 3 \\
7 & 2\end{array}$ & $\begin{array}{l}16 \\
14\end{array}$ \\
\hline $\begin{array}{l}\text { NOV. } \\
21 . . . \\
29 . . .\end{array}$ & $\begin{array}{l}1130 \\
3880\end{array}$ & $\begin{array}{l}96 \\
68\end{array}$ & $\begin{array}{l}0 \\
0\end{array}$ & $\begin{array}{l}53 \\
41\end{array}$ & $\begin{array}{l}87 \\
10\end{array}$ & $\begin{array}{l}.2 \\
.8\end{array}$ & $\begin{array}{l}324 \\
180\end{array}$ & $\begin{array}{r}160 \\
92\end{array}$ & $\begin{array}{l}81 \\
36\end{array}$ & $\begin{array}{l}536 \\
234\end{array}$ & $\begin{array}{ll}7 & 1 \\
7 & 1\end{array}$ & $?$ \\
\hline $\begin{array}{l}\text { OEC. } \\
02 \ldots \\
27 \ldots \\
\text { JAN. }\end{array}$ & $\begin{array}{l}19700 \\
12700\end{array}$ & $\begin{array}{l}84 \\
42\end{array}$ & $\begin{array}{l}0 \\
0\end{array}$ & $\begin{array}{l}32 \\
22\end{array}$ & $\begin{array}{r}59 \\
6.0\end{array}$ & $\begin{array}{l}1.0 \\
1.9 \\
1.3\end{array}$ & $\begin{array}{r}236 \\
74\end{array}$ & $\begin{array}{r}128 \\
54\end{array}$ & $\begin{array}{l}59 \\
20\end{array}$ & $\begin{array}{l}40 n \\
132\end{array}$ & $\begin{array}{ll}7 & 1 \\
7 & 2\end{array}$ & t \\
\hline $\begin{array}{l}02 \ldots \\
25 \ldots \\
F E B .\end{array}$ & $\begin{array}{r}4050 \\
14100\end{array}$ & $\begin{array}{r}56 \\
100\end{array}$ & $\begin{array}{l}0 \\
0\end{array}$ & $\begin{array}{l}27 \\
33\end{array}$ & $13^{6.0}$ & $\begin{array}{l}1.3 \\
2.3\end{array}$ & $\begin{array}{l}100 \\
164\end{array}$ & $\begin{array}{r}52 \\
118\end{array}$ & $\begin{array}{r}6 \\
36\end{array}$ & $\begin{array}{l}175 \\
276\end{array}$ & $\begin{array}{ll}7 & 9 \\
7 & 3\end{array}$ & $\begin{array}{l}3 \\
3\end{array}$ \\
\hline $\begin{array}{l}01 \ldots \\
12 \ldots . . . \\
\text { MAR. }\end{array}$ & $\begin{array}{l}6760 \\
3040\end{array}$ & $\begin{array}{r}89 \\
100\end{array}$ & $\begin{array}{l}1 \\
2\end{array}$ & $\begin{array}{l}32 \\
35\end{array}$ & $\begin{array}{l}8.0 \\
9.0\end{array}$ & $\begin{array}{l}3.1 \\
3.2\end{array}$ & $\begin{array}{l}146 \\
176\end{array}$ & $\begin{array}{l}11 n \\
123\end{array}$ & $\begin{array}{l}35 \\
3 \mathrm{~B}\end{array}$ & $\begin{array}{l}252 \\
283\end{array}$ & $\begin{array}{ll}9 & 3 \\
8 & 3\end{array}$ & i \\
\hline $\begin{array}{l}13 \ldots \ldots \\
15 \ldots \\
\triangle P R_{4}\end{array}$ & $\begin{array}{l}43900 \\
53000\end{array}$ & $\begin{array}{l}92 \\
34\end{array}$ & $\begin{array}{l}0 \\
0\end{array}$ & $\begin{array}{l}36 \\
21\end{array}$ & 14.0 & $\begin{array}{l}3.7 \\
3.3\end{array}$ & $\begin{array}{r}172 \\
86\end{array}$ & $\begin{array}{r}118 \\
48\end{array}$ & $\begin{array}{l}42 \\
29\end{array}$ & $\begin{array}{l}281 \\
121\end{array}$ & $\begin{array}{ll}6 & 0 \\
6 & 9\end{array}$ & $\frac{6}{7}$ \\
\hline $\begin{array}{l}08 . . . \\
29 . . . \\
\text { MAY }\end{array}$ & $\begin{array}{r}30900 \\
4840\end{array}$ & $\begin{array}{l}52 \\
84\end{array}$ & $\begin{array}{l}0 \\
0\end{array}$ & $\begin{array}{l}22 \\
33\end{array}$ & $\begin{array}{l}5.5 \\
6.0\end{array}$ & $\begin{array}{l}2.0 \\
2.0\end{array}$ & $\begin{array}{r}96 \\
154\end{array}$ & $\begin{array}{r}63 \\
104\end{array}$ & $\begin{array}{l}20 \\
35\end{array}$ & $\begin{array}{l}149 \\
240\end{array}$ & $\begin{array}{ll}7 & 2 \\
7 & 2\end{array}$ & $\begin{array}{l}17 \\
14\end{array}$ \\
\hline $\begin{array}{l}25 \ldots . . \\
\text { J0... } \\
\text { JUNE }\end{array}$ & $\begin{array}{r}3600 \\
13100\end{array}$ & $\begin{array}{r}45 \\
103\end{array}$ & $\begin{array}{l}0 \\
0\end{array}$ & $\begin{array}{l}25 \\
26\end{array}$ & $12^{6.0}$ & $\begin{array}{l}1.4 \\
4.8\end{array}$ & $\begin{array}{r}96 \\
154\end{array}$ & $\begin{array}{r}58 \\
112\end{array}$ & $\begin{array}{l}21 \\
29\end{array}$ & $\begin{array}{l}147 \\
257\end{array}$ & $\begin{array}{ll}7 & 4 \\
7 & 4\end{array}$ & $\begin{array}{l}19 \\
16\end{array}$ \\
\hline $\begin{array}{l}13 \ldots . . \\
\text { JULY }\end{array}$ & $\begin{array}{l}1570 \\
1130\end{array}$ & $\begin{array}{l}86 \\
84\end{array}$ & $\begin{array}{l}0 \\
0\end{array}$ & $\begin{array}{l}41 \\
26\end{array}$ & $\begin{array}{l}7.0 \\
8.0\end{array}$ & $\begin{array}{r}1.5 \\
.7\end{array}$ & $\begin{array}{l}142 \\
126\end{array}$ & $\begin{array}{r}107 \\
93\end{array}$ & $\begin{array}{l}36 \\
24\end{array}$ & $\begin{array}{l}240 \\
217\end{array}$ & $\begin{array}{ll}7 & 1 \\
7 & 3\end{array}$ & $\begin{array}{l}23 \\
26\end{array}$ \\
\hline $\begin{array}{l}13 . . . \\
22 . . .\end{array}$ & $\begin{array}{r}654 \\
1850\end{array}$ & $\begin{array}{r}86 \\
104\end{array}$ & $\begin{array}{l}0 \\
0\end{array}$ & $\begin{array}{l}24 \\
25\end{array}$ & $\begin{array}{l}7.0 \\
8.0\end{array}$ & $\begin{array}{l}1.6 \\
2.2\end{array}$ & $\begin{array}{l}136 \\
148\end{array}$ & $\begin{array}{r}95 \\
110\end{array}$ & $\begin{array}{l}24 \\
25\end{array}$ & $\begin{array}{l}221 \\
250\end{array}$ & $\begin{array}{l}77 \\
77\end{array}$ & $\begin{array}{l}27 \\
28\end{array}$ \\
\hline $\begin{array}{l}15 \ldots . . \\
19 \ldots . . \\
\text { SEPT. }\end{array}$ & $\begin{array}{r}29100 \\
4550\end{array}$ & $\begin{array}{l}92 \\
72\end{array}$ & $\begin{array}{l}0 \\
0\end{array}$ & $\begin{array}{l}59 \\
30\end{array}$ & $\begin{array}{l}40 \\
8.0\end{array}$ & $\begin{array}{l}2.9 \\
2.4\end{array}$ & $\begin{array}{l}266 \\
150\end{array}$ & $\begin{array}{r}142 \\
87\end{array}$ & $\begin{array}{l}66 \\
29\end{array}$ & $\begin{array}{l}415 \\
215\end{array}$ & $\begin{array}{ll}6 & 9 \\
7 & 5\end{array}$ & $\begin{array}{l}24 \\
25\end{array}$ \\
\hline $\begin{array}{l}02 . \ldots \\
16 \ldots\end{array}$ & $\begin{array}{l}855 \\
393\end{array}$ & $\begin{array}{l}80 \\
92\end{array}$ & $\begin{array}{l}0 \\
0\end{array}$ & $\begin{array}{l}21 \\
26\end{array}$ & $\begin{array}{l}10 \\
10\end{array}$ & $\begin{array}{l}2.7 \\
2.9\end{array}$ & $\begin{array}{l}152 \\
148\end{array}$ & $\begin{array}{r}89 \\
102\end{array}$ & $\begin{array}{l}24 \\
26\end{array}$ & $\begin{array}{l}219 \\
238\end{array}$ & $\begin{array}{ll}70 \\
7 & 1\end{array}$ & $\begin{array}{l}24 \\
23\end{array}$ \\
\hline
\end{tabular}


03287500 KENTUCKY RIVER AT LOCK 4, AT FRANKFORT, KY.--Continued

SPECIFIC CONDUCTANCE (MICROMHOS AT 250 C), WATER YEAR OCTOBER 1967 TO SEPTEMBER 1968 (ONCE-DAII Y MEASUREMENT BETWEEN 1200 AND 1500)

DAY

\begin{tabular}{|c|c|c|}
\hline $\begin{array}{l}1 \ldots \ldots \\
2 \ldots \ldots \\
3 \ldots \ldots \\
4 \ldots \ldots \\
5 \ldots \ldots\end{array}$ & $\begin{array}{l}266 \\
264 \\
264 \\
264 \\
264\end{array}$ & $\begin{array}{l}247 \\
259 \\
257 \\
259 \\
333\end{array}$ \\
\hline $\begin{array}{c}6 \ldots \ldots \\
7 \ldots \ldots \\
8 \ldots \ldots \\
10 \ldots \ldots\end{array}$ & $\begin{array}{l}266 \\
264 \\
260 \\
258\end{array}$ & $\begin{array}{l}413 \\
485 \\
474 \\
436 \\
501\end{array}$ \\
\hline $\begin{array}{l}11 \ldots \ldots \\
12 \ldots \ldots \\
13 \ldots \ldots \\
14 \ldots \ldots \\
15 \ldots \ldots\end{array}$ & $\begin{array}{l}262 \\
262 \\
262 \\
257 \\
258\end{array}$ & $\begin{array}{c}531 \\
-- \\
- \\
-\end{array}$ \\
\hline $\begin{array}{l}16 \ldots \ldots \\
17 \ldots \ldots \\
18 \ldots \ldots \\
19 \ldots \ldots \\
20 \ldots \ldots\end{array}$ & $\begin{array}{l}260 \\
264 \\
266 \\
264\end{array}$ & $\begin{array}{l}=- \\
\because- \\
=-\end{array}$ \\
\hline $\begin{array}{l}21 \ldots \ldots \\
22 \ldots \ldots \\
23 \ldots \ldots \\
24 \ldots \ldots \\
25 \ldots \ldots\end{array}$ & $\begin{array}{l}266 \\
262 \\
264 \\
268 \\
266\end{array}$ & $\begin{array}{l}536 \\
480 \\
349 \\
342 \\
330\end{array}$ \\
\hline $\begin{array}{l}26 \ldots \ldots \\
27 \ldots \ldots \ldots \\
28 \ldots \ldots \ldots \\
29 \ldots \ldots \\
30 \ldots \ldots \\
31 \ldots \ldots\end{array}$ & $\begin{array}{r}264 \\
264 \\
--5 \\
252 \\
253\end{array}$ & $\begin{array}{l}302 \\
242 \\
236 \\
234 \\
259 \\
-7\end{array}$ \\
\hline AVERAGE & 262 & -- \\
\hline
\end{tabular}

$\begin{array}{rr}256 & 1 \\ 400 & 1 \\ 247 & 1 \\ 231 & 194 \\ -- & 206 \\ 212 & 1 \\ -5 & 1 \\ 205 & 1 \\ 214 & 2 \\ 200 & 1 \\ 193 & 1 \\ 196 & 1 \\ 196 & 2 \\ 211 & 1 \\ 210 & 1\end{array}$

177
175
189
194
206
185
180
191
226
193
180
184
214
199
197

181

178

179

188
199

262

276

$262-268$

$\begin{array}{ll}262 & 268 \\ 276 & 270\end{array}$

276
272
274

256
248

210

274
274

274
274

265

267
264

270
271
--

267

\begin{abstract}
FEBRUARY
\end{abstract}
252
256
256
253
255
255
263
274
276
276
277
280
274
272
272

MARCH

APRIL

268
270

$270 \quad 196$

$\begin{array}{ll}270 & 184 \\ 266 & 191\end{array}$

266

264
260

149
157

270
276

276
281
264
121

186
190
195

128
171
202

171
202
184

212
212
212

193
203
218
197

218
197
156

221
230

230
$22 \mathrm{~B}$

228

169

199

206

206
206
198
191
200

--

157
182

183

195
198

203

MAY

$\begin{array}{ll}239 & 23 \\ 235 & 235 \\ 234 & 244 \\ 221 & 2 \\ 220 & 236 \\ 219 & 236 \\ 223 & 239 \\ 210 & 2 \\ 211 & 2 \\ 212 & 24\end{array}$

204

204
202
187
184

206

189
199
252
231

185
172
159
155

155
147

238
237

237
235
240

240
$23 \mathrm{~B}$
--

206

170

232
228
253

253
257
255

209
JUNE

JULY AUGUST SEPTEMBER

$\begin{array}{lll}236 & -- & 219 \\ 239 & -- & 218 \\ 239 & -- & 223 \\ 238 & -- & 223 \\ 236 & 256 & 222 \\ 236 & 254 & 224 \\ 234 & 257 & 226 \\ 233 & 259 & 22 B \\ 233 & 261 & -7 \\ 233 & 257 & 228\end{array}$

$\begin{array}{lll}241 & 233 & 259 \\ 241 & 233 & 261 \\ 241 & 233 & 257\end{array}$

239
243

243

234
227

227
221
222

256
263

263
277
293

231

234

238
237

236
230
222

230
222
$21 \mathrm{~B}$

233

415

238
235

244
222
215

231

$\begin{array}{ll}219 & 250 \\ 218 & 250 \\ 218 & --\end{array}$

25

236
219

235

$\begin{array}{lll}217 & -- & 21\end{array}$

222
222
218
225
233
-

220

220
222
218

218

219
219

231

251

TEMPERATURE $\left({ }^{\circ} \mathrm{C}\right)$ DF WATER, WATER YEAR OCTOBER 1967 TO SEPTEMBER 1968

OAY

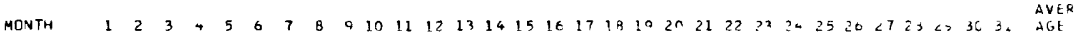

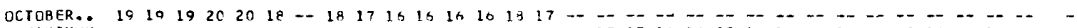
MAXIMUM -- - -

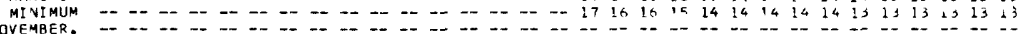

\begin{tabular}{l} 
MAXIMUMA \\
\hline M
\end{tabular}

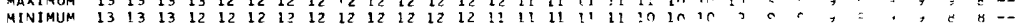

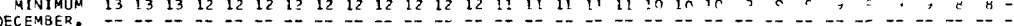

MAXIMUM

JANUARY.. -

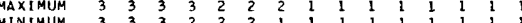

FEBRUARY. --

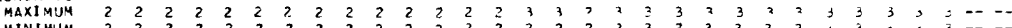

$3,3,3,3,3--$

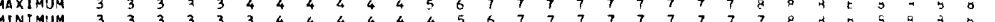

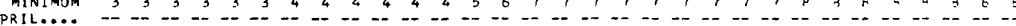

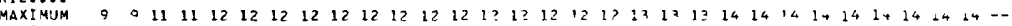

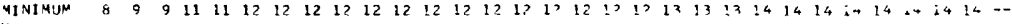

MAXIMUM

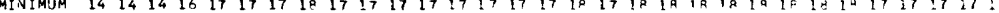

UAXIMUM

MAXIMUM $17 \begin{array}{llllllllllllllllllllllllllllllll}7 & 17 & 18 & 19 & 17 & 10 & 20 & 21 & 22 & 22 & 23 & 23 & 23 & 24 & 24 & 25 & 75 & 25 & 25 & 25 & 26 & 24 & 25 & 25 & 25 & 25 & 25 & 45 & 25 & -1\end{array}$

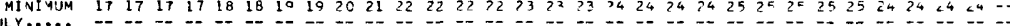

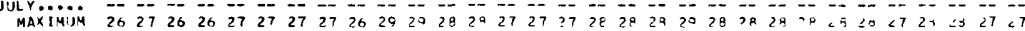

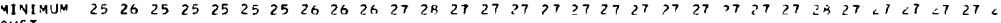
MAxigui 27 - 28 28

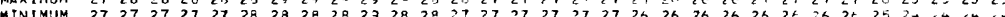
SEPTEMBER -

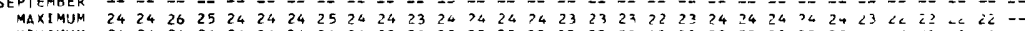

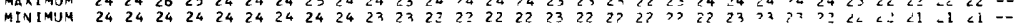


KENTUCKY RIVER BASIN

03287500 KENTUCKY RIVER AT LOCK 4, AT FRANKFORT, KY.--Continued

SUSPENDED SEDIMENT, WATER YEAR OCTOBER 1967 TO SEPTEMBER 1968

OCTPRER NOUFMRER BETFMAFR

\begin{tabular}{|c|c|c|c|c|c|c|c|c|c|}
\hline JAY & $\begin{array}{l}\text { MFAN } \\
\text { PISCHAPS, } \\
\text { (IFS) }\end{array}$ & $\begin{array}{l}\text { MESN } \\
\text { CCNCEN- } \\
\text { TRATICM } \\
\text { (MCIL) }\end{array}$ & $\begin{array}{l}\text { (IIAN } \\
\text { (TONS) }\end{array}$ & $\begin{array}{l}\text { MEAV } \\
\text { DISCHARGF } \\
\text { (CFS) }\end{array}$ & $\begin{array}{l}\text { MEAN } \\
\text { PCNPEN- } \\
\text { TPATION } \\
\text { PMEAII) }\end{array}$ & $\begin{array}{l}\text { InAT } \\
\text { (TONS) }\end{array}$ & $\begin{array}{l}\text { MEAN } \\
\text { MICCHARGE } \\
\text { (CFS) }\end{array}$ & $\begin{array}{l}\text { MEAN } \\
\text { PONCEN- } \\
\text { PPATI INA } \\
\text { (MP./L) }\end{array}$ & $\begin{array}{l}\ln \Delta C \\
(Y \cap N \&)\end{array}$ \\
\hline 1 & RRO & $1 n$ & 24 & 1247 & R & 27 & 19700 & $23 n$ & 12 गח \\
\hline 2 & 108n & in & 20 & $241 \pi$ & $\circ$ & 50 & 19700 & 365 & 14100 \\
\hline 3 & QRO & 7 & 17 & 5650 & IR & $27 a$ & 22600 & $26 n$ & ikann \\
\hline 4 & 785 & 7 & is & 10770 & so & $1>70$ & 19930 & 275 & $1400 n$ \\
\hline 5 & 459 & 。 & 11 & 10970 & $5 R$ & 1710 & 10300 & 279 & 14200 \\
\hline 6 & 1030 & 。 & 76 & 7120 & 32 & 634 & 17800 & 135 & $642 \mathrm{C}$ \\
\hline 7 & QR? & a & 10 & 4750 & 18 & 206 & 11000 & lok & 5700 \\
\hline क & 510 & 。 & i2 & 3690 & 17 & 119 & ด>90 & IBn & 4270 \\
\hline 9 & 510 & 6 & 2.3 & .090 & 12 & inn & sano & 143 & $58 \times n$ \\
\hline 10 & 636 & 7 & 12 & $25 ? \pi$ & 17 & 8) & 5290 & 97 & 1280 \\
\hline 11 & 8.30 & 10 & 74 & 2200 & a & 53 & 6580 & aK & $117 n$ \\
\hline 12 & 600 & $\because$ & 13 & $1 \times 75$ & 。 & 33 & 8740 & BK & 2030 \\
\hline 13 & 471 & 7 & 9.9 & 1293 & 。 & 31 & 11400 & 122 & 3770 \\
\hline 14 & 380 & a & h. 2 & 1340 & ? & $2^{\circ}$ & II & so & xก?n \\
\hline 15 & 350 & t. & 5.9 & 1213 & a & $2 k$ & $a_{460}$ & 75 & 1 Q२ก \\
\hline is & 310 & 5 & $4 . ?$ & 1127 & a & 24 & 8160 & 52 & 1150 \\
\hline 17 & 390 & 5 & 5.1 & 1211 & $?$ & $2^{\mathrm{H}}$ & 7250 & 36 & $7 n a$ \\
\hline 19 & 390 & 6 & h., & $9 \mathrm{C}_{4}$ & 7 & 15 & 6750 & 2n & 542 \\
\hline is & 330 & 5 & 4.5 & 993 & 7 & 10 & 7200 & Pt & $50=$ \\
\hline 20 & 432 & h & $7 . n$ & 924 & $\rightarrow$ & 15 & 12800 & 37 & LaAn \\
\hline 21 & 200 & 7 & 5.3 & $11^{2 n}$ & t & $1 R$ & 10000 & inn & 5120 \\
\hline 22 & 240 & a & 5.8 & 705 & 5 & 11 & 21000 & $10^{\circ}$ & axnn \\
\hline 23 & $33 n$ & 2 & 7.1 & 1579 & 7 & 30 & 73700 & 125 & Rann \\
\hline 24 & 350 & 5 & 4.7 & 1577 & 7 & 30 & 26700 & 263 & 19000 \\
\hline 25 & 629 & 7 & 12 & 3040 & 7 & 57 & 25200 & $44 \mathrm{t}$ & $30 \times 0$ n \\
\hline 26 & $100 C$ & a & 74 & $4 a c n$ & 9 & 117 & $19 \times 00$ & $2 n n$ & 15000 \\
\hline 27 & 1130 & 9 & $? 7$ & KR9? & 13 & 242 & 12700 & $? ?$ & $761 n$ \\
\hline 29 & 1400 & $1^{n}$ & 28 & 5मR० & 1) & 191 & 10500 & $21 \mathrm{~h}$ & 6.1 an \\
\hline 20 & 1340 & 10 & 26 & 3890 & 15 & 157 & RRQก & 203 & 4870 \\
\hline 30 & 1790 & a & $2 R$ & 0795 & Gr & 2220 & 7020 & 175 & $7 \times 2 n$ \\
\hline 31 & 1290 & a & 29 & $\cdots$ & -- & -- & 4 ค9ก & 155 & $205 n$ \\
\hline \multirow[t]{4}{*}{ TOTAL } & 21510 & $\cdots$ & 474.1 & 103733 & $\cdots$ & $92 A B$ & 421100 & -- & 215359 \\
\hline & & JANIIARY & & & FERELIARY & & & MAPCH & \\
\hline & "FAN & $\begin{array}{l}\text { MFAN } \\
\text { CFNCEN:- }\end{array}$ & & MEAV & $\begin{array}{l}\text { MEAN } \\
\text { CCNCFN- }\end{array}$ & & & $\begin{array}{l}\text { MEAN } \\
\text { CONCFN- }\end{array}$ & \\
\hline & $M I S C+A R F_{F} F$ & TRATION & Lnan & חISCHAKGE & YRATINN & LIIAC & MISCHARGF & TRATIONN & Lon \\
\hline$n \Delta Y$ & (CFS) & $(N G / L)$ & (TחMS) & $(C F S)$ & $\left(M r_{3} / L\right)$ & (TONS) & I(FS) & $(M r, / L)$ & (TONS) \\
\hline 1 & 4420 & 142 & $171 n$ & 5750 & 13 & 227 & $94 n$ & A & $2^{n}$ \\
\hline 2 & 4050 & $13 r$ & $14 ? 0$ & $66 ? n$ & 14 & 250 & QRח & 0 & 24 \\
\hline 3 & 3020 & of & $101 n$ & 6403 & 15 & 263 & 1020 & 10 & 29 \\
\hline 4 & 4130 & 53 & 591 & 4170 & 15 & 247 & 1110 & a & $2^{4}$ \\
\hline 5 & $S A+C$ & 4? & 774 & 5701 & 14 & 215 & $96 n$ & 7 & 19 \\
\hline 6 & $1+00 n$ & in & $302 \pi$ & $523 n$ & 16 & 226 & 980 & 7 & $1^{\circ}$ \\
\hline 7 & $1680=$ & 120 & 5440 & 4630 & 17 & 213 & $36 n$ & 7 & 10 \\
\hline a & $124 n 0$ & 95 & $285 n$ & 4340 & 15 & 176 & $134 n$ & 11 & $4 n$ \\
\hline 9 & 9360 & +2 & 1570 & 3720 & if & $\mid 6 I$ & 10 n & in & 20 \\
\hline 10 & 7770 & $4 n$ & 841 & 3600 & 18 & 175 & 118 ก & 0 & 20 \\
\hline 11 & 6450 & 40 & 497 & 2440 & 10 & 167 & 1970 & 23 & 122 \\
\hline 12 & 0230 & ho & $114 n$ & 2043 & in & 131 & 1GAOS & 181 & lotno \\
\hline 12 & $5+70$ & 117 & lann & 2530 & 13 & 98 & 42010 & 1090 & 1)onne \\
\hline 14 & 6140 & 113 & 10Tn & 2170 & i3 & $7 t$ & 21520 & $1>>0$ & 177ngen \\
\hline 15 & 0050 & 00 & $16>0$ & 1542 & 13 & 54 & 52000 & $100 ?$ & $1560 n$ \\
\hline 16 & 0360 & $7 c$ & 1360 & 1950 & 15 & 75 & $4440^{n}$ & Qan & $11 a n o r$ \\
\hline 17 & 4490 & 50 & $\ln 30$ & (5)5 & 14 & 67 & 25500 & $67 n$ & $4 k 10 n$ \\
\hline 13 & 0140 & 30 & 867 & $17>0$ & in & $4 k$ & 27800 & 423 & $250 \mathrm{rn}$ \\
\hline 10 & $505 n$ & 27 & 301 & 1450 & in & 30 & 10000 & 355 & $135 \mathrm{nn}$ \\
\hline 20 & 4500 & 10 & 221 & 1540 & in & 42 & 16407 & 175 & 7750 \\
\hline 21 & 5230 & 15 & $P 12$ & $11 \times 0$ & 11 & 34 & $20^{2} 00$ & 165 & anar \\
\hline $2 ?$ & 9740 & 17 & 401 & 1400 & 11 & 42 & 31200 & 192 & I a ann \\
\hline $2^{2}$ & 14400 & 5. & 2140 & $g k n$ & 10 & $2+$ & 42600 & 205 & $3240 ?$ \\
\hline 24 & 20000 & 50 & $215 n$ & 920 & 10 & 26 & 45000 & 200 & 35000 \\
\hline 25 & 14100 & 26 & 1370 & $113 n$ & $\circ$ & 37 & 45600 & 275 & 33900 \\
\hline 26 & 10600 & 34 & 972 & 930 & 10 & 26 & 25600 & 1A5 & 17900 \\
\hline 27 & 8993 & 74 & 779 & $9>0$ & in & 25 & 22500 & ins & $042 n$ \\
\hline 29 & 7480 & 25 & 505 & 990 & in & 26 & 17100 & 120 & 5540 \\
\hline 29 & $662 \pi$ & 19 & $34 n$ & $10 \times 1$ & 9 & 25 & 14800 & $\operatorname{lon}$ & 4000 \\
\hline 30 & 7200 & 17 & 220 & -. & $\ldots$ & - & $1203 n$ & a & xn? \\
\hline 31 & 7150 & $1 \geq$ & 251 & - & - & -- & 11000 & aR & $212^{n}$ \\
\hline InTaL & 250050 & -- & 30205 & 936.70 & $\cdots$ & 3201 & 605070 & -- & 256210 \\
\hline
\end{tabular}


03287500 KENTUCKY RIVER AT LOCK 4, AT FRANKFORT, KY.--Continued

SUSPENDED SEDIMENT, WATER YEAR OCTOBER 1967 TO SEPTEMBER 1968

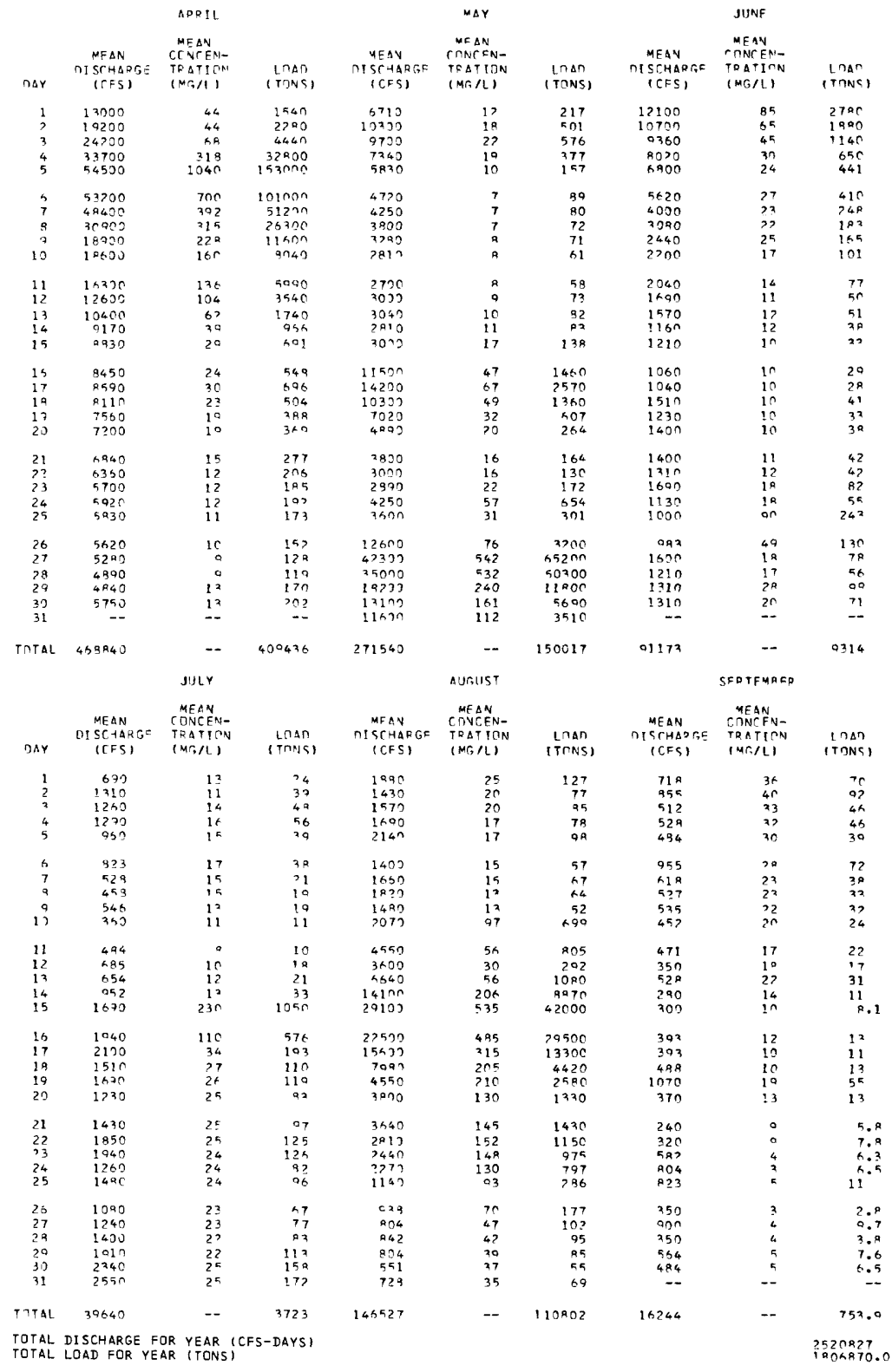


03287500 KENTUCKY RIVER AT LOCK 4, AT FRANKFORT, KY. --Continued

PARTICLE-SIZE ANALYSES OF SUSPENDED SEDIMENT, WATER YEAR OCTOBER 1967 TO SEPTEMBER 1968

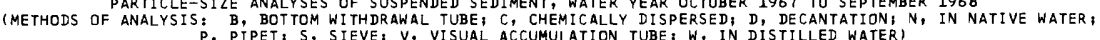

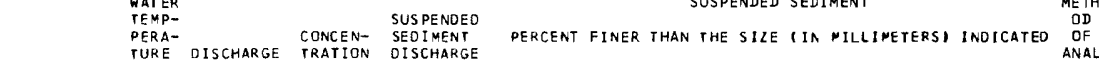

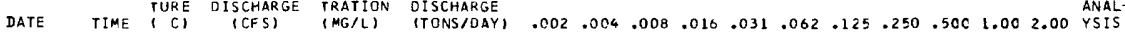

03291500 EAGLE CREEK AT GLENCOE, KY.

LOCATION, --Lat $38^{\circ} 42^{\prime} 18^{\prime \prime}$, long $84^{\circ} 49^{\prime} 26^{\prime \prime}$, Gallatin County, at gaging station on left bank 600 ft upstream from bridge on U.S. Highway $127,0.6 \mathrm{mile}$ south of Glencoe, 5.8 miles downstream from Tenmile Creek, and 22 miles upstream from mouth.

DRA INAGE AREA. $--437 \mathrm{sq} \mathrm{mi}$.

PER IOD OF RECORD. --Water temperatures: October 1949 to September 1968.

Sediment records: November 1961 to September 1968 (discontinued).

EXTREMES, $--1967-68$ :

Water temperatures: Maximum, $29.0^{\circ} \mathrm{C}$ on many days during June to August; minimum, freezing point Jan. 4

(Maximum daily, 2,210 mg/1 May 27; minimum daily, $4 \mathrm{mg} / 1$ Feb. $28,29$.

(a) $22-24$

Period of record:

Water temperatures: Maximum, $34.0^{\circ} \mathrm{C}$ Sept. 1, 2, 1953; minimum, freezing point on many days during winter periods.

1963-66 concentrations: Maximum daily, 3,890 mg/1 Mar. 29, 1965; minimum daily, no flow on many days during Sediment ioads: Maximum daily, 231,000 tons Mar. 5, 1964; minimum daily, 0 tons on many days during 1963-66.

REMARKS.--Sediment samples are collected at bridge on U.S., Highway 127, $600 \mathrm{ft}$ downstream from gage.

TEMPERATURE $\left.11^{\circ} \mathrm{C}\right)$ OF WATER, WATER YEAR OCTOBER 1967 TO SEPTEMBER 1968 (TWICE-DAILY MEASUREMENT AT APPROXIMATELY O8O0 AND 1900)

OCTOBER

NOVEMBER

OECEMBER

JANUARY

FEBRUARY

MARCH

\begin{tabular}{|c|c|c|c|c|}
\hline AM & PM & $A M$ & PM & AM \\
\hline $\begin{array}{l}14.0 \\
14.0 \\
16.0 \\
16.0 \\
17.0\end{array}$ & $\begin{array}{l}16.0 \\
16.0 \\
17.0 \\
18.0 \\
18.0\end{array}$ & $\begin{array}{r}10.0 \\
9.0 \\
8.0 \\
7.0\end{array}$ & $\begin{array}{r}10.0 \\
10.0 \\
10.0 \\
8.0 \\
7.0\end{array}$ & $\begin{array}{l}4.0 \\
4.0 \\
4.0 \\
4.0\end{array}$ \\
\hline $\begin{array}{l}17.0 \\
16.0 \\
16.0 \\
16.0 \\
14.0\end{array}$ & $\begin{array}{l}18.0 \\
18.0 \\
17.0 \\
16.0 \\
14.0\end{array}$ & $\begin{array}{l}6.0 \\
6.0 \\
6.0 \\
7.0 \\
7.0\end{array}$ & $\begin{array}{l}7.0 \\
7.0 \\
8.0 \\
8.0 \\
9.0\end{array}$ & $\begin{array}{l}4.0 \\
4.0 \\
5.0 \\
5.0 \\
6.0\end{array}$ \\
\hline $\begin{array}{l}13.0 \\
13.0 \\
12.0 \\
12.0 \\
12.0\end{array}$ & $\begin{array}{l}14.0 \\
13.0 \\
13.0 \\
13.0 \\
14.0\end{array}$ & $\begin{array}{l}8.0 \\
7.0 \\
8.0 \\
7.0 \\
6.0\end{array}$ & $\begin{array}{l}8.0 \\
9.0 \\
8.0 \\
7.0 \\
7.0\end{array}$ & $\frac{\frac{6.0}{6.0}}{6.0}$ \\
\hline $\begin{array}{l}14.0 \\
16.0 \\
16.0 \\
14.0 \\
12.0\end{array}$ & $\begin{array}{l}17.0 \\
17.0 \\
16.0 \\
14.0 \\
12.0\end{array}$ & $\begin{array}{l}5.0 \\
4.0 \\
5.0 \\
6.0 \\
5.0\end{array}$ & $\begin{array}{l}6.0 \\
6.0 \\
8.0 \\
7.0 \\
6.0\end{array}$ & $\begin{array}{l}4.0 \\
4.0 \\
6.0 \\
6.0 \\
5.0\end{array}$ \\
\hline $\begin{array}{l}11.0 \\
10.0 \\
10.0 \\
11.0 \\
11.0\end{array}$ & $\begin{array}{l}12.0 \\
11.0 \\
12.0 \\
13.0 \\
11.0\end{array}$ & $\begin{array}{l}4.0 \\
4.0 \\
4.0 \\
4.0 \\
5.0\end{array}$ & $\begin{array}{l}4.0 \\
5.0 \\
5.0 \\
6.0 \\
6.0\end{array}$ & $\begin{array}{l}7.0 \\
7.0 \\
4.0 \\
4.0 \\
4.0\end{array}$ \\
\hline $\begin{array}{r}9.0 \\
10.0 \\
-0 \\
8.0 \\
9.0\end{array}$ & $\begin{array}{r}11.0 \\
10.0 \\
9.0 \\
9.0 \\
10.0 \\
11.0\end{array}$ & $\begin{array}{l}.0 \\
4.0 \\
3.0 \\
4.0 \\
\end{array}$ & $\begin{array}{l}5.0 \\
4.0 \\
4.0 \\
4.0 \\
4.0 \\
\end{array}$ & $\begin{array}{l}4.0 \\
4.0 \\
4.0 \\
4.0 \\
4.0 \\
4.0\end{array}$ \\
\hline
\end{tabular}

4.0
5.0
6.0
5.0
6.0
6.0
6.0
6.0
7.0
7.0
7.0
7.0
6.0
7.0
6.0
5.0
4.0
6.0
6.0
7.0

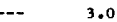

$6.0 \quad 7.0$

$6.0 \quad 6.0$

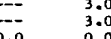

3.0
$\mathbf{3 . 0} 0$

4.0

6.0
5.0

$--$

2.0

2.0
2.0

3.0

$\begin{array}{ll}4.0 & 5.0 \\ 4.0 & 6.0\end{array}$

2. 0

2.0

3.0

2.0

3.0

3.0

4.0

3.0

4.0
4.0

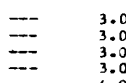

$\begin{array}{ll}3.0 & 3.0\end{array}$

$3.0 \quad 3.0$

$3.0 \quad 3.0$

4.0

3.0

$--$

4.0

4.0

-

\begin{tabular}{rr}
3.0 & 3.0 \\
3.0 & 3.0 \\
- & 3.0 \\
\hline
\end{tabular}

$\begin{array}{llll}-- & 3.0 & 3.0 & 3.0 \\ -- & 3.0 & -- & 3.0\end{array}$

4.0
5.0

$\begin{array}{ll}5.0 & 8.0 \\ 6.0 & 8.0 \\ 7.0 & 8.0\end{array}$

$7.0 \quad 8.0$

$\begin{array}{llll}4.0 & 4.0 & - & 3.0 \\ 4.0 & 4.0 & - & 2.0\end{array}$

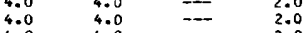

$\begin{array}{llll}4.0 & 4.0 & - & 2.0\end{array}$

7.0

6.0

3.0

9.0

7.0
4.0

4.0

$\begin{array}{llll}4.0 & 4.0 & -- & 2.0 \\ 4.0 & 4.0 & -- & 2.0\end{array}$

$\begin{array}{llll}4.0 & 5.0 & -- & 2.0\end{array}$

$\begin{array}{ll}4.0 & 5.0 \\ 5.0 & 7.00\end{array}$

$\begin{array}{ll}5.0 & 7.0 \\ 6.0 & \end{array}$ 
03291500 EAGLE CREEK AT GLENCOE, KY.--Continued

TEMPERATURE (' $\mathrm{C}$ ) OF WATER, WATER YEAR OCTOBER 1967 TO SEPTEMBER 1968

(TWICE-DAILY MEASUREMENT AT APPROXIMATELY D8DO AND 1900)

\begin{tabular}{|c|c|c|c|c|c|c|c|c|c|c|c|c|}
\hline \multirow[b]{2}{*}{ DAY } & \multicolumn{2}{|c|}{ APRIL } & \multicolumn{2}{|c|}{ MAY } & \multicolumn{2}{|c|}{ JUNE } & \multicolumn{2}{|c|}{ juLr } & \multicolumn{2}{|c|}{ AUGUST } & \multicolumn{2}{|c|}{ SEPTEMBER } \\
\hline & $A M$ & $p 4$ & $A M$ & $P M$ & AM & $P M$ & $A M$ & $P M$ & AM & $P M$ & $A M$ & PM \\
\hline $\begin{array}{l}1 \\
2 \\
2 \\
4 \\
5\end{array}$ & $\begin{array}{l}13.0 \\
11.0 \\
12.0 \\
12.0 \\
11.0\end{array}$ & $\begin{array}{l}14.0 \\
13.0 \\
13.0 \\
13.0 \\
12.0\end{array}$ & $\begin{array}{l}16.0 \\
17.0 \\
18.0 \\
17.0 \\
16.0\end{array}$ & $\begin{array}{l}19.0 \\
20.0 \\
19.0 \\
19.0 \\
18.0\end{array}$ & $\begin{array}{l}14.0 \\
17.0 \\
18.0 \\
20.0 \\
20.0\end{array}$ & $\begin{array}{l}18.0 \\
19.0 \\
21.0 \\
22.0 \\
23.0\end{array}$ & $\begin{array}{l}27.0 \\
27.0 \\
27.0 \\
27.0 \\
27.0\end{array}$ & $\begin{array}{l}29.0 \\
28.0 \\
28.0 \\
29.0 \\
29.0\end{array}$ & $\begin{array}{r}24.0 \\
23.0 \\
-0 \\
26.0\end{array}$ & $\frac{26.0}{28.0}$ & $\begin{array}{l}20.0 \\
21.0 \\
21.0 \\
21.0 \\
21.0\end{array}$ & $\begin{array}{l}22.0 \\
22.0 \\
22.0 \\
22.0 \\
21.0\end{array}$ \\
\hline $\begin{array}{r}6 \\
7 \\
8 \\
9 \\
10\end{array}$ & $\begin{array}{l}10.0 \\
10.0 \\
12.0 \\
13.0 \\
12.0\end{array}$ & $\begin{array}{l}12.0 \\
12.0 \\
14.0 \\
13.0 \\
14.0\end{array}$ & $\begin{array}{l}16.0 \\
18.0 \\
18.0 \\
19.0 \\
18.0\end{array}$ & $\begin{array}{l}19.0 \\
19.0 \\
20.0 \\
20.0 \\
20.0\end{array}$ & $\begin{array}{l}21.0 \\
22.0 \\
23.0 \\
26.0 \\
27.0\end{array}$ & $\begin{array}{l}23.0 \\
24.0 \\
27.0 \\
28.0 \\
29.0\end{array}$ & $\begin{array}{l}27.0 \\
27.0 \\
27.0 \\
27.0 \\
27.0\end{array}$ & $\begin{array}{l}29.0 \\
29.0 \\
28.0 \\
29.0 \\
29.0\end{array}$ & $\begin{array}{l}27.0 \\
27.0 \\
27.0 \\
27.0 \\
27.0\end{array}$ & $\begin{array}{l}28.0 \\
28.0 \\
28.0 \\
27.0 \\
27.0\end{array}$ & $\begin{array}{l}20.0 \\
20.0 \\
20.0 \\
20.0 \\
\end{array}$ & $\begin{array}{l}21.0 \\
21.0 \\
21.0 \\
20.0 \\
20.0\end{array}$ \\
\hline $\begin{array}{l}11 \\
12 \\
13 \\
14 \\
15\end{array}$ & $\begin{array}{l}13.0 \\
13.0 \\
14.0 \\
14.0 \\
13.0\end{array}$ & $\begin{array}{l}14.0 \\
15.0 \\
16.0 \\
16.0 \\
14.0\end{array}$ & $\begin{array}{r}18.0 \\
-18.0 \\
19.0 \\
19.0\end{array}$ & $\begin{array}{l}20.0 \\
19.0 \\
19.0 \\
21.0 \\
22.0\end{array}$ & $\begin{array}{l}27.0 \\
27.0 \\
27.0 \\
26.0 \\
25.0\end{array}$ & $\begin{array}{l}29.0 \\
29.0 \\
28.0 \\
27.0 \\
27.0\end{array}$ & $\begin{array}{l}28.0 \\
28.0 \\
28.0 \\
27.0 \\
27.0\end{array}$ & $\begin{array}{l}29.0 \\
29.0 \\
28.0 \\
28.0 \\
29.0\end{array}$ & $\begin{array}{l}26.0 \\
24.0 \\
24.0 \\
24.0 \\
27.0\end{array}$ & $\begin{array}{l}27.0 \\
27.0 \\
26.0 \\
27.0 \\
28.0\end{array}$ & $\begin{array}{l}19.0 \\
21.0 \\
19.0 \\
19.0 \\
19.0\end{array}$ & $\begin{array}{l}20.0 \\
20.0 \\
20.0 \\
20.0 \\
20.0\end{array}$ \\
\hline $\begin{array}{l}16 \\
17 \\
18 \\
19 \\
20\end{array}$ & $\begin{array}{l}13.0 \\
13.0 \\
13.0 \\
14.0 \\
14.0\end{array}$ & $\begin{array}{l}14.0 \\
16.0 \\
16.0 \\
16.0 \\
17.0\end{array}$ & $\begin{array}{l}20.0 \\
20.0 \\
20.0 \\
20.0\end{array}$ & $\begin{array}{l}22.0 \\
22.0 \\
22.0 \\
21.0 \\
20.0\end{array}$ & $\begin{array}{l}24.0 \\
24.0 \\
25.0 \\
24.0 \\
23.0\end{array}$ & $\begin{array}{l}26.0 \\
26.0 \\
27.0 \\
26.0 \\
26.0\end{array}$ & $\begin{array}{l}28.0 \\
28.0 \\
28.0 \\
28.0 \\
27.0\end{array}$ & $\begin{array}{l}29.0 \\
29.0 \\
29.0 \\
29.0 \\
28.0\end{array}$ & $\begin{array}{l}27.0 \\
27.0 \\
28.0 \\
28.0 \\
28.0\end{array}$ & $\begin{array}{l}28.0 \\
28.0 \\
29.0 \\
29.0 \\
29.0\end{array}$ & $\begin{array}{l}19.0 \\
20.0 \\
20.0 \\
20.0 \\
20.0\end{array}$ & $\begin{array}{l}21.0 \\
21.0 \\
21.0 \\
21.0 \\
21.0\end{array}$ \\
\hline $\begin{array}{l}21 \\
22 \\
23 \\
24 \\
25\end{array}$ & $\begin{array}{l}-16.0 \\
18.0 \\
18.0 \\
17.0\end{array}$ & $\begin{array}{l}17.0 \\
19.0 \\
19.0 \\
18.0 \\
18.0\end{array}$ & $\begin{array}{l}19.0 \\
20.0 \\
20.0 \\
20.0 \\
20.0\end{array}$ & $\begin{array}{l}21.0 \\
21.0 \\
21.0 \\
22.0 \\
21.0\end{array}$ & $\begin{array}{l}24.0 \\
26.0 \\
27.0 \\
26.0 \\
26.0\end{array}$ & $\begin{array}{l}27.0 \\
28.0 \\
28.0 \\
28.0 \\
27.0\end{array}$ & $\begin{array}{l}27.0 \\
27.0 \\
27.0 \\
27.0 \\
27.0\end{array}$ & $\begin{array}{l}28.0 \\
28.0 \\
28.0 \\
28.0 \\
28.0\end{array}$ & $\begin{array}{l}28.0 \\
28.0 \\
28.0 \\
28.0 \\
27.0\end{array}$ & $\begin{array}{l}29.0 \\
29.0 \\
29.0 \\
28.0 \\
27.0\end{array}$ & $\begin{array}{l}21.0 \\
21.0 \\
21.0 \\
24.0 \\
21.0\end{array}$ & $\begin{array}{l}22.0 \\
22.0 \\
22.0 \\
22.0 \\
21.0\end{array}$ \\
\hline $\begin{array}{l}26 \\
27 \\
28 \\
29 \\
30 \\
31\end{array}$ & $\begin{array}{l}17.0 \\
15.0 \\
16.0 \\
16.0 \\
15.0 \\
\end{array}$ & $\begin{array}{l}18.0 \\
17.0 \\
18.0 \\
18.0 \\
18.0\end{array}$ & $\begin{array}{l}- \\
18.0 \\
17.0 \\
16.0 \\
16.0 \\
14.0\end{array}$ & $\begin{array}{l}22.0 \\
19.0 \\
18.0 \\
17.0 \\
17.0 \\
16.0\end{array}$ & $\begin{array}{l}26.0 \\
22.0 \\
26.0 \\
27.0 \\
28.0\end{array}$ & $\begin{array}{r}27.0 \\
28.0 \\
28.0 \\
29.0 \\
29.0 \\
=\end{array}$ & $\begin{array}{r}27.0 \\
26.0 \\
26.0 \\
23.0 \\
26.0\end{array}$ & $\begin{array}{l}28.0 \\
27.0 \\
27.0 \\
26.0 \\
27.0 \\
26.0\end{array}$ & $\begin{array}{r}26.0 \\
26.0 \\
-12.0 \\
22.0 \\
21.0 \\
20.0\end{array}$ & $\begin{array}{r}27.0 \\
26.0 \\
23.0 \\
22.0 \\
21.0\end{array}$ & $\begin{array}{l}20.0 \\
20.0 \\
20.0 \\
20.0 \\
20.0 \\
\end{array}$ & $\begin{array}{l}21.0 \\
21.0 \\
21.0 \\
21.0 \\
20.0\end{array}$ \\
\hline
\end{tabular}

SUSPENDED SEDIMENT, WATER YEAR OCTOBER 1967 TO SEPTEMBER 1968

OCTHAER NOVFMAER DECEMBER

\begin{tabular}{|c|c|c|c|c|c|c|c|c|c|}
\hline & & MFAN & & & MF AN & & & MEAN & \\
\hline & MEAN & CONCEN- & & MEAN & CONCEN- & & MEAN & CONCEN- & \\
\hline & DISCHARGE & TRATION & $\ln \Delta 0$ & DISCHARGE & TRATION & LOAO & DISCHARGE & TRATION & LDAD \\
\hline DAY & (CFS) & $(M G / L)$ & (TONS) & (CFS) & (MG/L) & (TONS) & (CFS) & $(M G / L)$ & (TONS) \\
\hline 1 & 3.6 & 22 & .21 & 4.0 & $1^{n}$ & .11 & $42 \mathrm{cn}^{2}$ & 512 & 6100 \\
\hline 2 & 3.2 & 19 & .16 & 1512 & 214 & 1010 & 1600 & 373 & $255 n$ \\
\hline$=$ & 3.7 & 14 & .12 & $14 \geqslant 0$ & 111 & 426 & 4573 & 5n 5 & 6230 \\
\hline 4 & 2.8 & $i^{n}$ & . 1 & 242 & 58 & $3 A$ & $15 \mathrm{nn}$ & 256 & $112 n$ \\
\hline 5 & 2.4 & 6 & .14 & 117 & 32 & $\ln ^{n}$ & 478 & 119 & 154 \\
\hline 6 & 2.7 & 11 & .07 & 67 & 26 & 4.7 & 269 & 88 & 64 \\
\hline 7 & 1.7 & 12 & . $\mathrm{A}$ & 41 & 23 & 2.5 & $2 n ?$ & 77 & 42 \\
\hline 8 & 1.5 & 12 & .05 & 27 & 19 & 1.4 & 167 & 73 & 33 \\
\hline a & 1.9 & 15 & . $\cap \mathrm{R}$ & ?n & 16 & . 96 & 135 & $7 n$ & 26 \\
\hline $3^{n}$ & 1.8 & 16 & . & 15 & 17 & .60 & 120 & 69 & 24 \\
\hline 11 & 1.9 & 15 & .07 & 15 & 32 & 1.3 & 189 & 114 & 58 \\
\hline 12 & 1.6 & 13 & . Cs & $4 r 1$ & 196 & 347 & 189 & 90 & 46 \\
\hline 13 & 1.4 & 12 & .05 & $6 \cap 8$ & 142 & 274 & 211 & 75 & 43 \\
\hline 14 & 1.6 & 9 & .04 & 151 & $4 n$ & 15 & 299 & 56 & 45 \\
\hline 15 & 1.5 & 6 &.$\times 3$ & 33 & $2^{n}$ & 4. 5 & 809 & 136 & 297 \\
\hline 16 & 1.4 & 7 & .03 & 64 & 19 & 3.3 & 654 & 111 & 196 \\
\hline 17 & 1.4 & 12 & .05 & 50 & 21 & 3.2 & 394 & 107 & 114 \\
\hline 18 & 1.4 & 15 & .56 & 52 & 25 & 3.5 & 305 & $\ln ^{n}$ & 82 \\
\hline 19 & 1.3 & 12 & .24 & $5 n$ & 23 & 3.1 & 673 & 112 & $2 \sqrt{4}$ \\
\hline $2 n$ & $1 . n$ & in & .13 & 46 & 27 & 3.4 & 517 & 84 & 117 \\
\hline 21 & .95 & $1^{n}$ & .03 & 54 & 33 & 4.8 & 354 & 114 & 128 \\
\hline 22 & $.9 n$ & $?$ &.$\cap 2$ & $1 n g$ & 56 & 27 & 6620 & 778 & $139 \mathrm{cn}$ \\
\hline 23 & .90 & 8 &.+12 & 335 & 71 & 64 & 2900 & 102 & 1630 \\
\hline 24 & 1.1 & я & $\cdot{ }^{n}$ & 163 & 44 & 19 & 634 & 124 & 212 \\
\hline 25 & 1.6 & ir & .04 & 163 & 45 & $2^{n}$ & 317 & 103 & 88 \\
\hline 26 & 1.7 & $1 r$ & .05 & 211 & 52 & $3 n$ & 226 & 90 & 55 \\
\hline 27 & 1.7 & in & .05 & 179 & 56 & 21 & 135 & 61 & 22 \\
\hline 28 & 1.9 & 11 & .05 & 105 & 63 & 18 & 99 & 50 & 13 \\
\hline 20 & 4.6 & in & .12 & 87 & 51 & 12 & 79 & 43 & 9.2 \\
\hline $3 n$ & 4.7 & 7 & .08 & 3660 & $7^{n g}$ & $9 n 3 C$ & 56 & 36 & 5.4 \\
\hline 31 & 3.6 & 7 & .97 & -- & -- & -- & 47 & 28 & 3.6 \\
\hline TOTAL & 61.65 & -- & 1.95 & 1 n015.n & - & 11398.46 & 29047 & -- & 33621.2 \\
\hline
\end{tabular}


KENTUCKY RIVER BASIN

03291500 EAGLE CREEK AT GLENCOE, KY,--Continued

SUSPENDED SEDIMENT, WATER YEAR OCTOBER 1967 TO SEPTEMBER 1968

JANUARY

MARCH

DAY MFAN MFAN DI SCHARGE TRATION

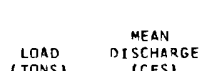

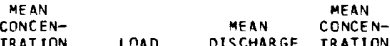

(CFS) (MGIL) (TONS) C (CFS) (MGIL)

LOAD

$\begin{array}{lrrrrrrr}2 n & 1.8 & 10 n n & 258 & 777 & 13 & 5 & .18 \\ 2 n & 2.1 & 1710 & 184 & 85 n & 13 & 7 & .25 \\ 26 & 2.6 & 173 r & 199 & 930 & 13 & 12 & .42 \\ 37 & 3.7 & 543 & 118 & 173 & 13 & 20 & .70 \\ 37 & 4.7 & 253 & 75 & 51 & 13 & 13 & .46\end{array}$

$\begin{array}{lll}36 & 4.2 & 151 \\ 22 & 3.4 & 108\end{array}$

$\begin{array}{rr}7.9 & 87 \\ 2.7 & 71 \\ 2.4 & 56\end{array}$

$\begin{array}{ll}67 & 27 \\ 52 & 15 \\ 40 & 9 \\ 30 & 5\end{array}$

$\begin{array}{ll}7 & 15 \\ 5 & 16 \\ 9.4 & 16 \\ 5.8 & 16\end{array}$

$\begin{array}{lll}26 & 2.2 & 5 r \\ 4 n & 3.5 & 39 \\ 32 & 2.6 & 35 \\ 39 & 3.1 & 3 n \\ 3 n & 2.4 & 28\end{array}$

28
25
22
22
23

$\begin{array}{lllll}6 & 30 & 25 & 2.8 & 26 \\ 7 & 19 & 37 & 1.6 & 23 \\ 8 & 10 & 33 & 1.7 & 21 \\ 9 & 19 & 74 & 1.2 & 19\end{array}$

$\begin{array}{ll}21 & 173 \\ 72 & 2120\end{array}$

2020
2090

53

$102 n$

34
467

281
114

18
16
15
15
13

$\begin{array}{ll}26 & 499 \\ 27 & 248 \\ 28 & 155 \\ 29 & 162 \\ 30 & 2730\end{array}$

$\begin{array}{ll}45 & \text { or } \\ 52 & 35 \\ 37 & 15 \\ 45 & 25\end{array}$

15
$2 \pi$
9720
10690

12
12
$1 ?$
12

TOTAL 16289

$22417.5 \quad 6123$

$\begin{array}{lr}3.8 & 883 \\ 2.6 & 467 \mathrm{C}\end{array}$

$\begin{array}{rr}2.6 & 4670 \\ 2.1 & 3360 \\ 1.8 & 858 \\ 1.7 & 494\end{array}$

$\begin{array}{rr}1.5 & 579 \\ 1.1 & 155 n \\ 1.1 & 844 \\ 1.1 & 462\end{array}$

$\begin{array}{ll}1.1 & 462 \\ .87 & 429\end{array}$

$.97 \quad 806$

$\begin{array}{ll}.95 & 7880 \\ .65 & 465 C \\ .61 & 248 C \\ .49 & 3840\end{array}$

23
$3 n$
25
22

23
$3 n$
25
22
23

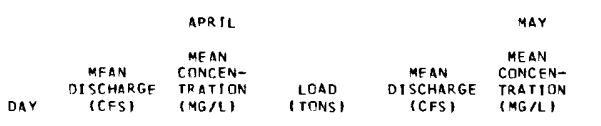

$\begin{array}{rr}.13 & 599 \\ -- & 455 \\ -- & 494 \\ 2864.95 & 50242\end{array}$

1.1

1310
828

$250 \quad 579$

$\begin{array}{ll}153 & 239 \\ 236 & 989\end{array}$

$\begin{array}{ll}145 & 330 \\ 112 & 14 C \\ 150 & 174\end{array}$

198C 43100

$\begin{array}{rr}72 n & 153 n c \\ 31 C & 3 A 50\end{array}$

$\begin{array}{ll}.26 & 4230 \\ .19 & 226 n \\ .13 & 102 n\end{array}$

$.13 \quad 599$

$10 n \quad 114 n$

$\begin{array}{rr}82 & 500 \\ 57 & 157 \\ 45 & 73\end{array}$

$\begin{array}{rr}45 & 73 \\ 175 & 698\end{array}$

-- 96191.39

$1 \quad 532 n \quad 13$

$\begin{array}{rl}1310 & 2 n 10 n \\ 43 n & 380 n\end{array}$

$\begin{array}{rrrr}1790 & 43 n & 278 n & 1 n \\ 711 & 1 n 5 & 25 ? & 99 \\ 964 n & 147 n & 473 n n & 92 \\ 916 n & 823 & 2160 r & 84\end{array}$

13
in 6
92
84

2

$\begin{array}{lll}29 & 8.8 & 488 \\ 26 & 7.4 & 429 \\ 24 & 6.4 & 455 \\ 25 & 6.2 & 390 \\ 25 & 5.7 & 233\end{array}$

JUNE

$\begin{array}{cccc} & \text { MEAN } \\ \text { LOAD } & \text { MEAN } & \text { CONCEN- } \\ \text { (TONS) } & \text { (CFARGE } & \text { TRATILN } & \text { LOAD } \\ \text { (MG/L) } & \text { (TONS) }\end{array}$

$\begin{array}{cccc}\text { MEAN } & \text { MEAN } \\ \text { CONCEN- } & \\ \text { LOAD } & \text { DISCHARGE } & \text { TRATILN } & \text { LOAD } \\ \text { (TONS) } & \text { (CFS) } & \text { (MG/L) } & \text { (TONS) }\end{array}$

$\begin{array}{ll}8.8 & 488 \\ 7.4 & 429 \\ 6.4 & 455 \\ 6.2 & 390 \\ 5.7 & 233\end{array}$

$\begin{array}{ll}55 & 72 \\ 38 & 44 \\ 87 & 98 \\ 77 & 81 \\ 69 & 43\end{array}$

$\begin{array}{rrrr}158^{n} & 144 & 7 n n & 75 \\ 725 & 98 & 192 & 73 \\ 57 n & 71 & 10 n & 89 \\ 377 & 45 & 46 & 93\end{array}$

27
27
27
$3 ?$
55

$\begin{array}{ll}5.5 & 152 \\ 5.3 & 130 \\ 5.0 & 118 \\ 8.0 & 104\end{array}$

$\begin{array}{ll}54 & 22 \\ 39 & 14 \\ 38 & 12 \\ 35 & 9.8 \\ 75 & 5.5\end{array}$

297

$\begin{array}{llll}233 & 44 & 28 & 104 n\end{array}$

$\begin{array}{rrr}44 & 28 & 194 n \\ 46 & 23 & 151 n \\ 57 & 22 & 429 \\ 95 & 77 & 232\end{array}$

513$$
\begin{array}{r}
4520 \\
871 \\
51 \\
2 ? \\
14
\end{array}
$$

192
$198^{n}$

649

$347 n$

161

44
35

921
379
282
217

$\begin{array}{rrr}127 & 344 & 123 \\ 61 & 62 & 101 \\ 56 & 43 & 1 n 9\end{array}$

$\begin{array}{rrr}56 & 43 & 179 \\ 49 & 29 & 166 \\ 73 & 174 & 277\end{array}$

33
27
27
25
24

474

$29 ?$

638
386

$\begin{array}{rrr}35 & 45 & 143 \\ 35 & 27 & 99 \\ 65 & 196 & 207 n \\ 57 & 136 & 137 m n \\ 4 B & 57 & 4890\end{array}$

25
75
561
2190
682

$\begin{array}{ll}32 & 3230 \\ 18 & 7780 \\ 13 & 2240 \\ 8.8 & 1650 \\ 8.4 & 1810\end{array}$

277
273
217
156

125

44
$3 n$
23
21
25
--

848
221 1
495
187

$21^{n} \quad 1010 n$

$495 \quad 367 n$

$\begin{array}{rr}187 & 833 \\ 212 & \operatorname{In} 4 n\end{array}$

$\begin{array}{rr}130 & 321 \\ --\quad 169719.0\end{array}$

TOTAL 38922

- $97300.2 \quad 44559$

- $169719.0 \quad 3323$

$\begin{array}{ll}25 & 4.8 \\ 21 & 3.4 \\ 21 & 2.8 \\ 25 & 2.8 \\ 2 C & 1.8\end{array}$

$\begin{array}{llll}11 & 31 & 19 & 1.6 \\ 7.4 & 25 & 37 & 2.2 \\ 7.9 & 24 & 37 & 2.4 \\ 11 & 21 & 37 & 1.7 \\ 19 & 17 & 25 & 1.1\end{array}$

$\begin{array}{rr}9.7 & 16 \\ 6.7 & 14 \\ 6590 & 14 \\ 85600 & 65 \\ 9530 & 154\end{array}$

$\begin{array}{rr}24 & 1.0 \\ 24 & .91 \\ 24 & .91\end{array}$

15

$\begin{array}{ll}62 & 6.4 \\ 35 & 2.3 \\ 42 & 1.9 \\ 34 & 1.3 \\ 35 & 1.1 \\ -- & -- \\ -- & 454.72\end{array}$ 
03291500 EAGLE CREEK AT GLENCOE, KY.--Continued

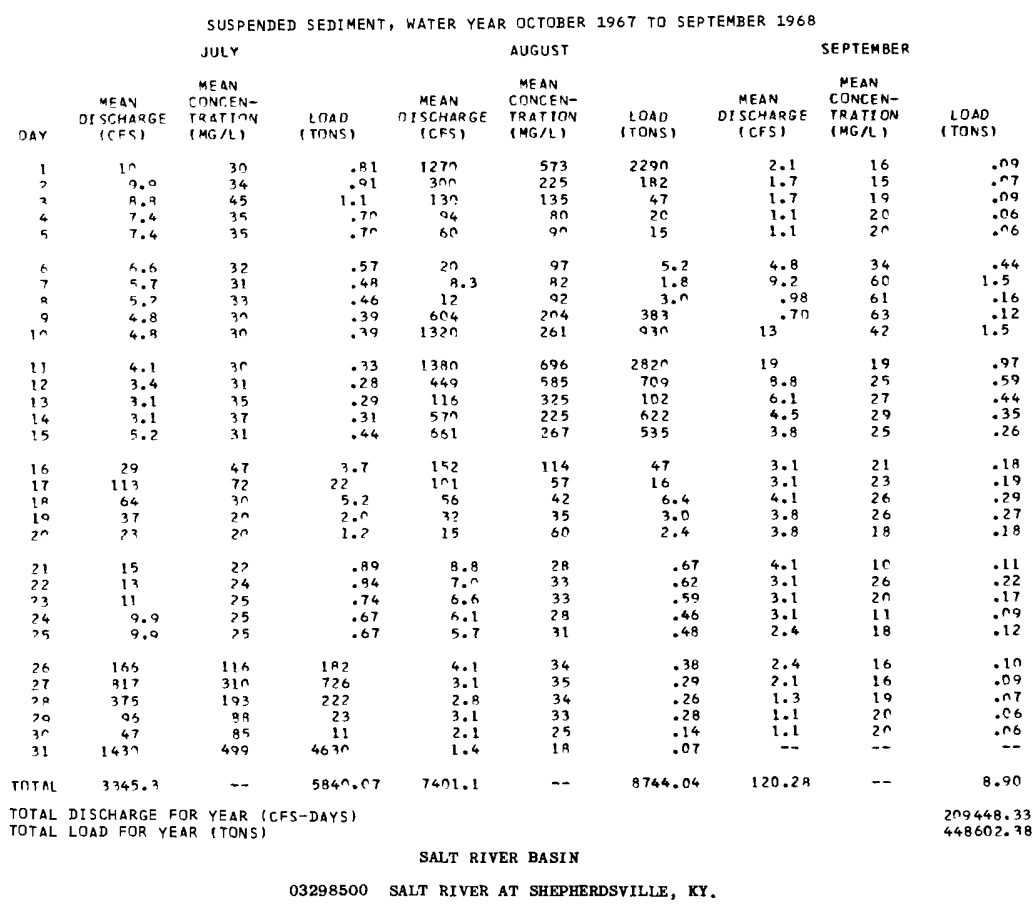

LOCATION,..-Lat $37^{\circ} 59^{\prime} 06$, long $85^{\circ} 43^{\circ} 03$, Bullitt County, at gaging station at bridge on state Highway 61 at Shepherdsville, $500 \mathrm{ft}$ downstream from Louisville and Nashville Railroad bridge and 2.5 miles downstream from
Floyds Fork.

DRAINAGE AREA. $--1,197 \mathrm{sq} \mathrm{mi}$.

PERIOD OF RECORD.--Chemical analyses: October 1949 to September 1950, October 1952 to September 1959, November 1965 to September 1968.

Water temperatures: October 1949 to September 1968, unpublished.

Sediment records: October 1952 to September 1961 .

REMARKS.--Samples for iron and manganese filtered clear when collected.

CHEMICAL ANALYSES IN MILLIGRAMS PER LITER, WATER YEAR OCTOBER 1967 TO SEPTEMBER 1968

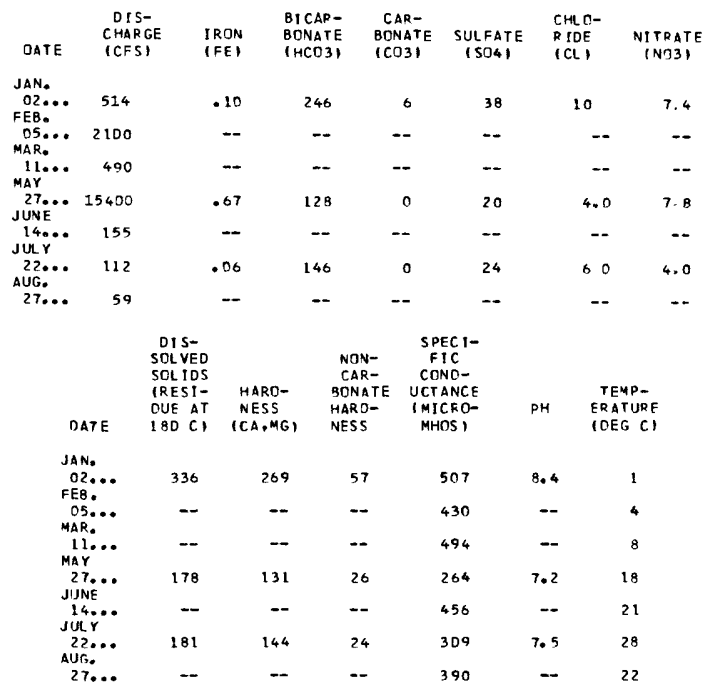


03301500 ROLLING FORK NEAR BOSTON, KY.

LOCATION,--Lat $37^{\circ} 46^{\prime} 02^{\prime \prime}$, long $85^{\circ} 42^{\prime} 14^{\prime \prime}$, Nelson County, at gaging station at bridge on U.S. Highway 62 and State Highway $61,0.4$ mile downstream from Beech Fork and 2.3 miles southwest of Boston.

DRA INAGE AREA. --1, $299 \mathrm{sq} \mathrm{m} 1$.

PER IOD OF RECORD. --Chemical analyses: OC tober 1950 to September 1952.

Water temperatures: October 1949 to September 1968.

EXTREMES. - -1967-68:

Water temperatures: Maximum, $29.0^{\circ} \mathrm{C}$ July 4 ; minimum, freezing point on many days during January to March.

Period of record:

Water temperatures: Maximum, $30.5^{\circ} \mathrm{C}$ July 4, 1950, June 22, 25, 28, 1954 ; mintmum, freezing point on many days during winter periods.

TEMPERATURE $1{ }^{\circ} \mathrm{CI}$ OF WATER, WATER YEAR OCTOBER 1967 TO SEPTEMBER 1968 (TWICE-DAILY MEASUREMENT AT APPROXIMATELY 0730 AND 1800)

\begin{tabular}{|c|c|c|c|c|c|c|c|c|c|c|c|c|}
\hline \multirow[b]{2}{*}{ DAY } & \multicolumn{2}{|c|}{ OC TOBER } & \multicolumn{2}{|c|}{ NOVEMBER } & \multicolumn{2}{|c|}{ OECEMBER } & \multicolumn{2}{|c|}{ JANUARY } & \multicolumn{2}{|c|}{ FEBRUARY } & \multicolumn{2}{|c|}{ MARCH } \\
\hline & $A M$ & $P M$ & $\mathbf{A M}$ & $P M$ & $A M$ & $P M$ & $A M$ & $P M$ & $A M$ & PM & $A M$ & $P M$ \\
\hline $\begin{array}{l}1 \\
2 \\
3 \\
4 \\
5\end{array}$ & $\begin{array}{l}14.0 \\
14.0 \\
16.0 \\
18.0\end{array}$ & $\begin{array}{l}13.0 \\
14.0 \\
16.0 \\
17.0 \\
18.0\end{array}$ & $\begin{array}{r}13.0 \\
13.0 \\
11.0 \\
10.0 \\
-\end{array}$ & $\begin{array}{r}13.0 \\
12.0 \\
11.0 \\
9.0 \\
8.0\end{array}$ & $\begin{array}{l}6.0 \\
7.0 \\
7.0 \\
7.0 \\
6.0\end{array}$ & $\begin{array}{l}0.0 \\
7.0 \\
7.0 \\
7.0 \\
6.0\end{array}$ & $\begin{array}{l}-7.0 \\
0.0 \\
1.0 \\
0.0\end{array}$ & $\begin{array}{l}-1.0 \\
1.0 \\
0.0 \\
1.0\end{array}$ & $\begin{array}{l}7.0 \\
7.0 \\
6.0 \\
5.0\end{array}$ & $\begin{array}{l}8.0 \\
7.0 \\
6.0 \\
6.0 \\
5.0\end{array}$ & $\overline{-}$ & 2.0 \\
\hline $\begin{array}{r}6 \\
7 \\
8 \\
9 \\
10\end{array}$ & $\begin{array}{r}18.0 \\
16.0 \\
16.0 \\
16.0\end{array}$ & $\begin{array}{l}17.0 \\
17.0 \\
16.0 \\
16.0 \\
13.0\end{array}$ & $\begin{array}{l}7.0 \\
7.0 \\
6.0 \\
7.0 \\
7.0\end{array}$ & $\begin{array}{l}7.0 \\
7.0 \\
7.0 \\
7.0 \\
7.0\end{array}$ & $\begin{array}{l}6.0 \\
6.0 \\
6.0 \\
7.0 \\
\end{array}$ & $\begin{array}{l}6.0 \\
8.0 \\
7.0 \\
7.0 \\
7.0\end{array}$ & $\begin{array}{l}1.0 \\
1.0 \\
1.0 \\
0.0\end{array}$ & $\begin{array}{l}1.0 \\
1.0 \\
1.0 \\
0.0 \\
0.0\end{array}$ & $\begin{array}{l}5.0 \\
5.0 \\
4.0 \\
3.0 \\
2.0\end{array}$ & $\begin{array}{l}5.0 \\
4.0 \\
3.0 \\
3.0 \\
1.0\end{array}$ & $\begin{array}{l}0.0 \\
0.0 \\
0.0 \\
0.0 \\
-\end{array}$ & $\begin{array}{l}0.0 \\
0.0 \\
1.0 \\
1.0 \\
4.0\end{array}$ \\
\hline $\begin{array}{l}11 \\
12 \\
13 \\
14 \\
15\end{array}$ & $\begin{array}{r}10.0 \\
9.0 \\
9.0 \\
11.0 \\
-0.0\end{array}$ & $\begin{array}{r}9.0 \\
9.0 \\
11.0 \\
11.0 \\
16.0\end{array}$ & $\begin{array}{l}8.0 \\
8.0 \\
8.0 \\
7.0\end{array}$ & $\begin{array}{l}8.0 \\
9.0 \\
9.0 \\
7.0 \\
4.0\end{array}$ & $\begin{array}{l}8.0 \\
7.0 \\
7.0 \\
7.0 \\
7.0\end{array}$ & $\begin{array}{l}8.0 \\
7.0 \\
7.0 \\
7.0 \\
6.0\end{array}$ & $\begin{array}{l}0.0 \\
0.0 \\
0.0 \\
-\end{array}$ & $\begin{array}{l}0.0 \\
0.0 \\
0.0 \\
0.0 \\
0.0\end{array}$ & $\begin{array}{l}-1.0 \\
0.0 \\
0.0 \\
0.0\end{array}$ & $\begin{array}{l}0.0 \\
0.0 \\
0.0 \\
0.0 \\
1.0\end{array}$ & $\begin{array}{l}4.0 \\
3.0 \\
0.0 \\
0.0 \\
0.0\end{array}$ & $\begin{array}{l}4.0 \\
2.0 \\
0.0 \\
0.0 \\
0.0\end{array}$ \\
\hline $\begin{array}{l}16 \\
17 \\
18 \\
19 \\
20\end{array}$ & $\begin{array}{l}16.0 \\
15.0 \\
15.0 \\
16.0 \\
11.0\end{array}$ & $\begin{array}{l}16.0 \\
15.0 \\
15.0 \\
14.0 \\
11.0\end{array}$ & $\begin{array}{l}3.0 \\
4.0 \\
3.0 \\
6.0\end{array}$ & $\begin{array}{l}4.0 \\
3.0 \\
4.0 \\
7.0 \\
7.0\end{array}$ & $\begin{array}{l}4.0 \\
7.0 \\
6.0 \\
6.0\end{array}$ & $\begin{array}{l}6.0 \\
7.0 \\
7.0 \\
7.0 \\
6.0\end{array}$ & $\begin{array}{l}0.0 \\
0.0 \\
0.0 \\
1.0 \\
2.0\end{array}$ & $\begin{array}{l}0.0 \\
0.0 \\
0.0 \\
2.0 \\
2.0\end{array}$ & $\begin{array}{l}0.0 \\
0.0 \\
0.0 \\
0.0\end{array}$ & $\begin{array}{l}0.0 \\
0.0 \\
0.0 \\
1.0 \\
0.0\end{array}$ & $\begin{array}{l}0.0 \\
4.0 \\
4.0 \\
6.0\end{array}$ & $\begin{array}{l}1.0 \\
4.0 \\
4.0 \\
6.0 \\
6.0\end{array}$ \\
\hline $\begin{array}{l}21 \\
22 \\
23 \\
24 \\
25\end{array}$ & $\begin{array}{l}11.0 \\
12.0 \\
13.0 \\
13.0\end{array}$ & $\begin{array}{l}12.0 \\
13.0 \\
13.0 \\
13.0 \\
12.0\end{array}$ & $\begin{array}{l}6.0 \\
7.0 \\
6.0 \\
7.0 \\
8.0\end{array}$ & $\begin{array}{l}7.0 \\
7.0 \\
7.0 \\
7.0 \\
8.0\end{array}$ & $\begin{array}{l}7.0 \\
5.0 \\
4.0 \\
4.0\end{array}$ & $\begin{array}{l}7.0 \\
4.0 \\
3.0 \\
3.0 \\
3.0\end{array}$ & $\begin{array}{l}-0- \\
1.0 \\
2.0 \\
1.0 \\
0.0\end{array}$ & $\begin{array}{l}1.0 \\
1.0 \\
2.0 \\
0.0 \\
1.0\end{array}$ & $\begin{array}{l}0.0 \\
0.0 \\
0.0 \\
0.0 \\
-. .\end{array}$ & $\begin{array}{l}0.0 \\
0.0 \\
0.0 \\
0.0 \\
1.0\end{array}$ & $\begin{array}{r}6.0 \\
4.0 \\
3.0 \\
3.0\end{array}$ & $\begin{array}{l}5.0 \\
4.0 \\
3.0 \\
3.0 \\
2.0\end{array}$ \\
\hline $\begin{array}{l}26 \\
27 \\
28 \\
29 \\
30 \\
31\end{array}$ & $\begin{array}{r}11.0 \\
12.0 \\
15.0 \\
10.0 \\
12.0\end{array}$ & $\begin{array}{l}12.0 \\
14.0 \\
15.0 \\
11.0 \\
12.0 \\
13.0\end{array}$ & $\begin{array}{l}\overline{7.0} \\
3.0 \\
1.0 \\
6.0 \\
\end{array}$ & $\begin{array}{l}8.0 \\
4.0 \\
2.0 \\
4.0 \\
5.0 \\
\end{array}$ & $\begin{array}{l}3.0 \\
3.0 \\
2.0 \\
1.0 \\
1.0 \\
\end{array}$ & $\begin{array}{l}4.0 \\
3.0 \\
2.0 \\
1.0 \\
1.0 \\
-\end{array}$ & $\begin{array}{l}0.0 \\
1.0 \\
7.0 \\
7.0 \\
7.0\end{array}$ & $\begin{array}{l}1.0 \\
2.0 \\
7.0 \\
7.0 \\
7.0 \\
7.0\end{array}$ & $\begin{array}{l}0.0 \\
1.0 \\
0.0 \\
=- \\
-\infty\end{array}$ & $\begin{array}{l}1.0 \\
0.0 \\
0.0 \\
-0 \\
-\square\end{array}$ & $\begin{array}{l}1.0 \\
0.0 \\
2.0 \\
2.0 \\
2.0 \\
-\end{array}$ & $\begin{array}{l}1.0 \\
2.0 \\
2.0 \\
2.0 \\
2.0 \\
2.0\end{array}$ \\
\hline
\end{tabular}

\begin{tabular}{|c|c|c|c|c|c|c|c|c|c|c|c|c|}
\hline \multirow[b]{2}{*}{ DAY } & \multicolumn{2}{|c|}{ APRIL } & \multicolumn{2}{|c|}{ MAY } & \multicolumn{2}{|c|}{ JUNE } & \multicolumn{2}{|c|}{ JULY } & \multicolumn{2}{|c|}{ AUGUST } & \multicolumn{2}{|c|}{ SEPTEMBER } \\
\hline & $A M$ & PM & $A M$ & PM & $A M$ & PM & $A M$ & PM & $A M$ & $P M$ & $A M$ & PM \\
\hline $\begin{array}{l}1 \\
2 \\
3 \\
4 \\
5\end{array}$ & $\begin{array}{r}3.0 \\
5.0 \\
8.0 \\
10.0 \\
12.0\end{array}$ & $\begin{array}{r}4.0 \\
7.0 \\
9.0 \\
12.0 \\
12.0\end{array}$ & $\begin{array}{r}17.0 \\
17.0 \\
17.0 \\
17.0 \\
-0\end{array}$ & $\begin{array}{l}17.0 \\
17.0 \\
17.0 \\
17.0 \\
16.0\end{array}$ & $\begin{array}{r}17.0 \\
17.0 \\
18.0 \\
18.0\end{array}$ & $\begin{array}{l}17.0 \\
17.0 \\
18.0 \\
18.0 \\
18.0\end{array}$ & $\begin{array}{r}26.0 \\
26.0 \\
29.0 \\
28.0\end{array}$ & $\begin{array}{l}26.0 \\
27.0 \\
28.0 \\
29.0 \\
29.0\end{array}$ & $\begin{array}{l}24.0 \\
24.0 \\
24.0 \\
24.0\end{array}$ & $\begin{array}{l}24.0 \\
24.0 \\
24.0 \\
26.0 \\
24.0\end{array}$ & $\begin{array}{l}26.0 \\
24.0 \\
24.0 \\
22.0\end{array}$ & $\begin{array}{l}26.0 \\
26.0 \\
24.0 \\
23.0 \\
22.0\end{array}$ \\
\hline $\begin{array}{r}6 \\
7 \\
8 \\
9 \\
10\end{array}$ & $\begin{array}{r}12.0 \\
10.0 \\
11.0 \\
12.0\end{array}$ & $\begin{array}{l}12.0 \\
10.0 \\
11.0 \\
12.0 \\
12.0\end{array}$ & $\begin{array}{l}16.0 \\
16.0 \\
16.0 \\
16.0 \\
16.0\end{array}$ & $\begin{array}{l}16.0 \\
16.0 \\
16.0 \\
16.0 \\
16.0\end{array}$ & $\begin{array}{r}19.0 \\
17.0 \\
18.0 \\
21.0\end{array}$ & $\begin{array}{l}18.0 \\
18.0 \\
19.0 \\
20.0 \\
22.0\end{array}$ & $\begin{array}{r}27.0 \\
27.0 \\
24.0 \\
24.0\end{array}$ & $\begin{array}{l}28.0 \\
23.0 \\
27.0 \\
24.0 \\
24.0\end{array}$ & $\begin{array}{r}24.0 \\
24.0 \\
-0 \\
-- \\
-\end{array}$ & 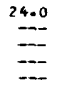 & $\begin{array}{r}22.0 \\
22.0 \\
22.0 \\
21.0\end{array}$ & $\begin{array}{l}22.0 \\
23.0 \\
23.0 \\
21.0 \\
20.0\end{array}$ \\
\hline $\begin{array}{l}11 \\
12 \\
13 \\
14 \\
15\end{array}$ & $\begin{array}{l}11.0 \\
11.0 \\
13.0 \\
12.0\end{array}$ & $\begin{array}{l}11.0 \\
12.0 \\
13.0 \\
13.0 \\
11.0\end{array}$ & $\begin{array}{l}16.0 \\
18.0 \\
17.0 \\
18.0\end{array}$ & $\begin{array}{l}16.0 \\
18.0 \\
17.0 \\
18.0 \\
17.0\end{array}$ & $\begin{array}{l}22.0 \\
22.0 \\
21.0 \\
21.0 \\
21.0\end{array}$ & $\begin{array}{r}22.0 \\
22.0 \\
21.0 \\
21.0\end{array}$ & $\begin{array}{r}24.0 \\
24.0 \\
24.0 \\
26.0\end{array}$ & $\begin{array}{l}24.0 \\
24.0 \\
24.0 \\
26.0 \\
26.0\end{array}$ & $\begin{array}{l}\overline{-} \\
\overline{-} \\
\square\end{array}$ & $\overline{-}$ & $\begin{array}{l}21.0 \\
21.0 \\
20.0 \\
21.0 \\
\end{array}$ & $\begin{array}{l}21.0 \\
21.0 \\
21.0 \\
21.0 \\
21.0\end{array}$ \\
\hline $\begin{array}{l}16 \\
17 \\
18 \\
19 \\
20\end{array}$ & $\begin{array}{l}11.0 \\
12.0 \\
14.0 \\
16.0 \\
17.0\end{array}$ & $\begin{array}{l}14.0 \\
13.0 \\
16.0 \\
16.0 \\
17.0\end{array}$ & $\begin{array}{r}17.0 \\
19.0 \\
19.0 \\
17.0\end{array}$ & $\begin{array}{l}18.0 \\
19.0 \\
18.0 \\
17.0 \\
17.0\end{array}$ & $\begin{array}{l}21.0 \\
21.0 \\
21.0 \\
22.0\end{array}$ & $\begin{array}{l}21.0 \\
21.0 \\
21.0 \\
21.0 \\
22.0\end{array}$ & $\begin{array}{l}24.0 \\
24.0 \\
26.0 \\
26.0 \\
26.0\end{array}$ & $\begin{array}{l}26.0 \\
26.0 \\
26.0 \\
26.0 \\
26.0\end{array}$ & $\begin{array}{r}-- \\
--0 \\
27.0 \\
26.0\end{array}$ & $\begin{array}{l}28.0 \\
28.0 \\
27.0 \\
26.0\end{array}$ & $\begin{array}{l}21.0 \\
21.0 \\
22.0 \\
21.0 \\
21.0\end{array}$ & $\begin{array}{l}21.0 \\
21.0 \\
21.0 \\
21.0 \\
21.0\end{array}$ \\
\hline $\begin{array}{l}21 \\
22 \\
23 \\
24 \\
25\end{array}$ & $\begin{array}{l}2 \overline{21.0} \\
20.0 \\
18.0 \\
16.0\end{array}$ & $\begin{array}{r}18.0 \\
20.0 \\
20.0 \\
17.0 \\
\end{array}$ & $\begin{array}{l}17.0 \\
14.0 \\
27.0 \\
17.0 \\
18.0\end{array}$ & $\begin{array}{l}16.0 \\
16.0 \\
17.0 \\
18.0 \\
18.0\end{array}$ & $\begin{array}{r}22.0 \\
22.0 \\
25.0 \\
26.0\end{array}$ & $\begin{array}{l}22.0 \\
23.0 \\
24.0 \\
26.0 \\
26.0\end{array}$ & $\begin{array}{l}26.0 \\
26.0 \\
24.0 \\
26.0\end{array}$ & $\begin{array}{l}26.0 \\
27.0 \\
26.0 \\
26.0 \\
26.0\end{array}$ & $\begin{array}{l}27.0 \\
27.0 \\
27.0 \\
27.0 \\
-\end{array}$ & $\begin{array}{l}27.0 \\
27.0 \\
26.0 \\
27.0 \\
26.0\end{array}$ & $\begin{array}{r}21.0 \\
22.0 \\
22.0 \\
21.0\end{array}$ & $\begin{array}{l}22.0 \\
22.0 \\
22.0 \\
21.0 \\
21.0\end{array}$ \\
\hline $\begin{array}{l}26 \\
27 \\
28 \\
29 \\
30 \\
31\end{array}$ & $\begin{array}{r}16.0 \\
16.0 \\
17.0 \\
17.0 \\
\end{array}$ & $\begin{array}{l}16.0 \\
16.0 \\
17.0 \\
17.0 \\
17.0 \\
\end{array}$ & $\begin{array}{l}-0- \\
17.0 \\
18.0 \\
17.0 \\
17.0 \\
17.0\end{array}$ & $\begin{array}{l}18.0 \\
18.0 \\
18.0 \\
17.0 \\
17.0 \\
17.0\end{array}$ & $\begin{array}{l}26.0 \\
24.0 \\
23.0 \\
24.0 \\
- \\
\end{array}$ & $\begin{array}{r}26.0 \\
24.0 \\
24.0 \\
26.0 \\
26.0 \\
\end{array}$ & $\begin{array}{r}24.0 \\
24.0 \\
24.0 \\
24.0 \\
24.0\end{array}$ & $\begin{array}{l}26.0 \\
24.0 \\
24.0 \\
24.0 \\
24.0 \\
24.0\end{array}$ & $\begin{array}{l}26.0 \\
26.0 \\
26.0 \\
26.0 \\
26.0 \\
26.0\end{array}$ & $\begin{array}{l}26.0 \\
26.0 \\
26.0 \\
26.0 \\
26.0 \\
27.0\end{array}$ & $\begin{array}{r}21.0 \\
21.0 \\
21.0 \\
18.0 \\
\end{array}$ & $\begin{array}{l}21.0 \\
21.0 \\
21.0 \\
19.0 \\
19.0 \\
-0.0\end{array}$ \\
\hline
\end{tabular}


03306000 GREEN RIVER NEAR CAMPBELLSVILLE, KY.

LOCATION,-Lat $37^{\circ} 14^{\prime} 25^{\prime \prime}$, long $85^{\circ} 20^{\prime} 25^{\prime \prime}$, Taylor County, temperature recorder at gaging station on right bank at $\begin{array}{ll} & \end{array}$ bridge on State Highway $55,0.6 \mathrm{mi}$
6.9 miles south of Camphelisville.

DRA INAGE AREA. - $-682 \mathrm{sq} \mathrm{ml}$.

PER IOD OF RECORD. -- Water temperatures: October 1963 to September 1968.

EXTREMES. - - 1967-68:

Water temperatures: Maximum, $22.0^{\circ} \mathrm{C}$ Aug. 20-28; minimum, $1.0^{\circ} \mathrm{C}$ on several days during January.

Period of record:

Water temperatures: Maximum, 31.0 ${ }^{\circ} \mathrm{C}$ Aug. 3-5, 1964: minimum, freezing point on many days during $1963-66$. TEMPERATURE $\left({ }^{\circ} \mathrm{C}\right)$ OF WATER, WATER YEAR OCTOBER 1967 TO SEPTEMBER 1968 (CONTINUDUS ETHYL AL COHOL-ACTUATED THERMOGRAPH)

OCFOBER

MAX MIN

$\begin{array}{ll}21.0 & 19.0 \\ 19.0 & 19.0 \\ 19.0 & 15.0 \\ 19.0 & 19.0\end{array}$

MONTH

$17.0-17.0$

$\begin{array}{lll}17.0 & 17.0 & 10.0 \\ 17.0 & 17.0 & 10.0 \\ 17.0 & 17.0 & 9.0\end{array}$

$\begin{array}{rrr}17.0 & 17.0 & 9.0 \\ 17.0 & 17.0 & 9.0\end{array}$

$17.0 \quad 16 . \mathrm{C} \quad 9.0$

$16.0 \quad 16.0$

$16 . \mathrm{C} \quad 15.0$

$15.0 \quad 14.0$

$\begin{array}{ll}14.0 & 14.0 \\ 14.0 & 14.0\end{array}$

$14.0 \quad 14.0$

14.0

$14.0 \quad 14.0$

$\begin{array}{ll}14.0 & 13.0 \\ 13.0 & 13.0\end{array}$

13.0

21.0

9.0
9.0
9.0
9.0

9.0

9.0
8.0

8.0

8.0
3.0

13.0
NOVEMBER

OECEMBEF

$\begin{array}{llll}\text { MAX } & \text { MIN } & \text { MAX } & \text { MIN } \\ 8 . C & 7 . C & 3.0 & 3.0 \\ 7.0 & 7 . C & 3.0 & 1.0 \\ 7.0 & 7.0 & 1.0 & 1.0 \\ 7.0 & 7.0 & 1.0 & 1.0 \\ 7.0 & 6.5 & 1.0 & 1 . C \\ 6 . C & 6 . C & 2.0 & 1.0 \\ 6.0 & 6 . C & 2.0 & 2.0 \\ 6.0 & 6.0 & 2.0 & 1.0 \\ 7.0 & 6 . C & 1.0 & 1.0 \\ 7.0 & 7 . C & 1.0 & 1.0 \\ 9.0 & 7 . C & 1.0 & 1.0 \\ 8.0 & 8 . C & 2.0 & 1 . C \\ 8.0 & 7 . C & 2.0 & 2.0 \\ 7.0 & 7 . C & 2.0 & 2.0 \\ 7.0 & 7.0 & 2.0 & 1.0\end{array}$

yar

MAX MIN

13.0
14.0
14.0

14.0
14.0

14.0

14.0
14.0

14.0

14.0

14.0

15.0
15.0

15.0
16.0

16.0

16.0

16.0
16.0

16.0

17.0

$17 . \mathrm{C}$

18.0

18.0
18.0

18.0

17.0
17.0
17.
17.0
17.

18.0

17.0
17.0

$$
\begin{aligned}
& 17.0 \\
& 17.0
\end{aligned}
$$

$\begin{array}{ll}18.0 & 17.0 \\ 18.0 & 18.0\end{array}$

$\begin{array}{ll}18.0 & 18.0 \\ 18.0 & 18.0\end{array}$

$\begin{array}{lll}18.0 & 18.0 & 16.0\end{array}$

$\begin{array}{lll}18.0 & 18.0 & 16.0 \\ 18.0 & 18.0 & 16.0\end{array}$

14.0
14.0

14.0
15.0
15.0

$\begin{array}{ll}17.0 & 17.0 \\ 17.0 & 17.0\end{array}$

$\begin{array}{ll}17.0 & 17.0 \\ 17.0 & 17.0 \\ 17.0 & 17.0\end{array}$

$16 . \mathrm{C}$

$$
\begin{aligned}
& 16.0 \\
& 16.0 \\
& 16.0 \\
& 16.0
\end{aligned}
$$

18.0

$$
\begin{aligned}
& 19.0 \\
& 19.0 \\
& 18.0
\end{aligned}
$$

16.0

18.0
18.0

17.0

17.0

$$
\begin{aligned}
& 17.0 \\
& 16.0 \\
& 16.0 \\
& 16.0
\end{aligned}
$$

17.0
16.0
16.0
16.0

17.0

16.

$\begin{array}{ll}16.0 & 16.0 \\ 16.0 & 16.0\end{array}$

$\begin{array}{ll}16.0 & 16.0 \\ 16.0 & 16.0\end{array}$

$\begin{array}{ll}16.0 & 16.0 \\ 16.0 & 16.0 \\ 16.0 & 16.0 \\ 16.0 & 16.0\end{array}$

$\begin{array}{ccc}16.0 & 16.0 & 16.0 \\ 16.3 & 16.0 & 16.0 \\ \cdots & 16.0 & 16.0\end{array}$

$13.0 \quad 19.0$

$16 . c$

7.0

7.0
7.0
6.0

7.0
7.0
6.0
6.0
6.0

$\begin{array}{ll}1.0 & 1.0 \\ 2.0 & 1.0 \\ 2.0 & 2.0 \\ 2.0 & 2.0 \\ 2.0 & 2.0\end{array}$

2.0

2.0

6. C
$6 . C$

t. 6

2.0
2.0

2.0
2.0
2.0

2.0
2.0
2.0
2.0

0.0
4.0

4. C

2.0

$\begin{array}{ll}3.0 & 4.0 \\ 8.0 & 4.0\end{array}$

3.0

. 3.0

4.0
3.0

2.0
2.0
2.0

3.0

3.0

8.0

3.

3.0
4.0

4.0

2.0
2.0
2.0
2.0
3.0
3.0

JUNE

MAX

16.0

16.0
15.0

$\begin{array}{ll}15.0 & 15.0 \\ 16.0 & 15.0\end{array}$

$16.0 \quad 15 . c$

16.0
16.0
16.0
16.0
16.0

16.0

16.0
16.6
16.0

16.0

16.0

17.0

$16 . \mathrm{C}$

$16 . \mathrm{C}$

16.0
16.0
17.0

17.0
17.0

$\begin{array}{ll}18.0 & 17.0 \\ 18.0 & 17.0 \\ 18.0 & 17.0\end{array}$

17.0

$\begin{array}{ll}18.0 & 17.0 \\ 18.0 & 17.0\end{array}$

17.0
$17 . \mathrm{C}$
$17 . \mathrm{C}$
17.0
$17 . \mathrm{C}$

18.0
18.0
18.0

17.

$16 . C$
$16 . C$

$18.0 \quad 18.0$

18.0
18.0

19.0

19.0
18.0

18.0
18.0
18.0

18.0
18.0
.- .5

18.0

18.0
18.0

18.0
18.0
-2.0

18.0

15.6

MAX JULY

$19.0 \quad 18 . \mathrm{C}$

$\begin{array}{ll}19.0 & 19.0 \\ 19.0 & 19.0\end{array}$

$19.0 \quad 19.0$

$19.0 \quad 19.0$

$19.0 \quad 19.0$

19.0

19.0

19.0

20.0

20.0
20.0
20.0
19.0

20.0
20.0

20.0
21.0
21.0

21.0
21.0

21.0

21.0

21.0
21.0

21.0

21.0

21.0
21.0

21.0

21.0

$$
\begin{aligned}
& 19.0 \\
& 19.0
\end{aligned}
$$

19.0
19.0

$$
\begin{aligned}
& 19.0 \\
& 20.0 \\
& 19.0
\end{aligned}
$$

19.0

19.0

$2 \mathrm{C} .0$
20.0
21.0

21.

21.0
21.0
21.0
21.0

21.0
21.0

21.0

$$
\begin{aligned}
& 21.0 \\
& 21.0 \\
& 21.0
\end{aligned}
$$

\begin{tabular}{|c|c|c|c|}
\hline & \\
\hline $\max$ & MIN & max & NIN \\
\hline $\begin{array}{l}5.0 \\
5.0 \\
6.0 \\
6.0 \\
6.0\end{array}$ & $\begin{array}{l}4.0 \\
5.0 \\
5.0 \\
6.0 \\
6.0\end{array}$ & $\begin{array}{l}4.0 \\
4.0 \\
4.0 \\
4.0 \\
4.0\end{array}$ & $\begin{array}{r}4.0 \\
4.0 \\
4.0 \\
+4.0 \\
4.0\end{array}$ \\
\hline $\begin{array}{l}6.0 \\
6.0 \\
6.0 \\
6.0 \\
6.0\end{array}$ & $\begin{array}{l}6.0 \\
6.0 \\
6.0 \\
6.0 \\
5.0\end{array}$ & $\begin{array}{l}4.0 \\
4.0 \\
4.0 \\
6.0 \\
6.0\end{array}$ & $\begin{array}{l}4.0 \\
4.0 \\
4.0 \\
4.0 \\
6.0\end{array}$ \\
\hline $\begin{array}{l}5.0 \\
4.0 \\
4.0 \\
4.0 \\
4.0\end{array}$ & $\begin{array}{l}4.0 \\
4.0 \\
4.0 \\
4.0 \\
4.0\end{array}$ & $\begin{array}{l}7.0 \\
7.0 \\
7.0 \\
6.0 \\
6.0\end{array}$ & $\begin{array}{l}6.0 \\
7.0 \\
6.0 \\
6.0 \\
5.0\end{array}$ \\
\hline $\begin{array}{l}4.0 \\
4.0 \\
4.0 \\
4.0 \\
4.0\end{array}$ & $\begin{array}{l}4.0 \\
4.0 \\
4.0 \\
4.0 \\
4.0\end{array}$ & $\begin{array}{l}6.0 \\
7.0 \\
8.0 \\
7.0 \\
9.0\end{array}$ & $\begin{array}{l}6.0 \\
6.0 \\
7.0 \\
7.0 \\
7.0\end{array}$ \\
\hline $\begin{array}{l}4.0 \\
4.0 \\
4.0 \\
4.0 \\
4.0\end{array}$ & $\begin{array}{l}4.0 \\
4.0 \\
4.0 \\
4.0 \\
4.0\end{array}$ & $\begin{array}{l}11.0 \\
11.0 \\
11.0 \\
11.0 \\
10.0\end{array}$ & $\begin{array}{r}9.0 \\
11.0 \\
11.0 \\
10.0 \\
1 c . c\end{array}$ \\
\hline $\begin{array}{l}4.0 \\
4.0 \\
4.0 \\
4.0 \\
-0.0\end{array}$ & $\begin{array}{l}4.0 \\
4.0 \\
4.0 \\
4.0 \\
\ldots . .\end{array}$ & $\begin{array}{l}10.0 \\
10.0 \\
11.0 \\
11.0 \\
12.0 \\
13.0\end{array}$ & $\begin{array}{l}10.0 \\
1 c .0 \\
10.0 \\
11.0 \\
12.0 \\
12.0\end{array}$ \\
\hline & & & \\
\hline
\end{tabular}

21.0
21.0
21.0

21.0

$1 \mathrm{B.C}$

MCATH

FEBRUARY

A UGUST

MAX MIN

$21.0 \quad 21.0$

21.0

21.0
21.0
21.0

21.0

$21.0 \quad 21.0$

$21.0 \quad 21.0$

21.0

21.0

$21.0 \quad 21.0$

21.0
21.0

$\begin{array}{ll}21.0 & 21.0 \\ 21.0 & 21.0\end{array}$

$\begin{array}{ll}21.0 & 21.0 \\ 21.0 & 21.0\end{array}$

22.0

$22.0 \quad 22.0$

$22.0 \quad 21.0$

$\begin{array}{ll}22.0 & 22.0 \\ 22.0 & 22.0\end{array}$

22.0

$22.0 \quad 22.0$

$22.0 \quad 22.0$

$\begin{array}{ll}22.0 & 21.0 \\ 21.0 & 21.0\end{array}$

$\begin{array}{ll}21.0 & 21.0 \\ 21.0 & 21.0\end{array}$

$22.0 \quad 21.0$

SEPTEMBER

MAX MIN

$21 . C$

21.0

$20.0 \quad 20.0$

$\begin{array}{ll}21.0 & 20.0 \\ 21.0 & 21.0\end{array}$

$\begin{array}{ll}21.0 & 21.0 \\ 21.0 & 21.0\end{array}$

$21.0 \quad 21.0$

$\begin{array}{ll}21.0 & 21.0 \\ 21.0 & 21.0\end{array}$

$21.0 \quad 21.0$

$21.0 \quad 21.0$

$21.0 \quad 21.0$

$21.0 \quad 21.0$

$21.0 \quad 21.0$

$21.0 \quad 21.0$

21.0

$21 . \mathrm{C}$

21.0

21.0

21.0

21.0

20.0

20.0
20.0

21.0 
GREEN R IVER BASIN

03306490 GREEN RIVER NEAR GREENSBURG, KY.

LOCATION,--Lat $37^{\circ} 14^{\prime} 43^{\prime \prime}$, long $85^{\circ} 28^{\prime} 47^{\prime \prime}$, Green County, at auxiliary gaging station at Sardins Ford bridge on State Highway $487,1.4$ miles east of Greensburg and 2 miles upstream from gaging station.

DRAINAGE AREA.--736 sq mi (at gaging station).

PERIOD OF RECORD.--Chemical analyses: October 1959 to September 1968.

REMARKS. --Samples for iron and manganese filtered clear when collected. Records of discharge are given for gaging station at Greensburg.

CHEMICAL ANALYSES IN MILLIGRAMS PER LITER, WATER YEAR DCTOBER 1967 TO SEPTEMBER 1968

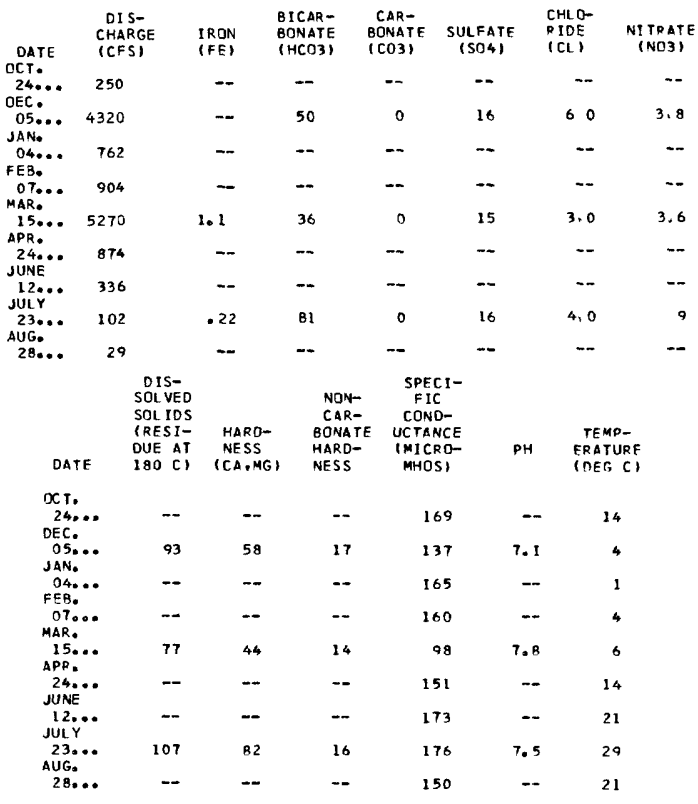

03307800 LITTLE BARREN RIVER NEAR MONROE, KY.

LOCATION,-Lat $37^{\circ} 13^{\prime} 35^{\prime \prime}$, long $85^{\circ} 40^{\prime} 40^{\prime \prime}$, Hart County, at bridge on state Highway $88,1.2$ miles east of Monroe and 6.3 miles upstream from mouth.

DRAINAGE AREA, -244 sq $\mathrm{m} 1$.

PERIOD OF RECORD.--Chemical analyses: December 1960 to September 1968.

REMARKS.--Samples for iron and manganese filtered clear when collected. No discharge records available. CHEMICAL ANALYSES IN MILLIGRAMS PER LITER, WATER YEAR OCTOBER 1967 TO SEPTEMBER 1968

\begin{tabular}{|c|c|c|c|c|c|c|c|c|c|c|}
\hline DATE & $\begin{array}{l}\text { SIL ICA } \\
151021\end{array}$ & $\begin{array}{l}\text { IRUN } \\
\text { IFE) }\end{array}$ & $\begin{array}{l}\text { MAN- } \\
\text { GANESE } \\
\text { (MN) }\end{array}$ & $\begin{array}{l}\text { CAL- } \\
\text { CIUM } \\
\text { ICA) }\end{array}$ & $\begin{array}{l}\text { MAE- } \\
\text { NE- } \\
\text { SIUM } \\
\text { IMG) }\end{array}$ & $\begin{array}{l}\text { SOD I UM } \\
\text { (NA) }\end{array}$ & $\begin{array}{l}P O- \\
\text { TAS- } \\
\text { SIUM } \\
(K)\end{array}$ & $\begin{array}{l}\text { BICAR- } \\
\text { PONATE } \\
\text { (HCO3) }\end{array}$ & $\begin{array}{l}\text { CAR- } \\
\text { BONATE } \\
\text { CCC3I }\end{array}$ & $\begin{array}{l}\text { SULFATE } \\
\text { (SO4) }\end{array}$ \\
\hline $\begin{array}{l}\text { DCT. } \\
25 \ldots . . \\
D E C .\end{array}$ & 11 & .13 & .02 & 72 & 16 & 76 & 3.0 & 184 & 0 & 45 \\
\hline $\begin{array}{l}\text { O6... } \\
\text { JAN. }\end{array}$ & - & $\cdots$ & $\cdots$ & -- & -- & -- & -- & -- & $\cdots$ & -- \\
\hline $\begin{array}{l}04 \ldots \\
F E B .\end{array}$ & - & .06 & $\cdots$ & $\cdots$ & $\cdots$ & -- & - & 110 & 6 & 24 \\
\hline & - & - & - & - & -- & -- & - & -- & -- & - \\
\hline $\begin{array}{l}15 \ldots \\
\text { APR. }\end{array}$ & $=-$ & $\cdots$ & -- & -- & -- & -- & - & -- & -- & -- \\
\hline$\underset{J U N F}{24 \ldots .}$ & -- & - & $\cdots$ & -- & - & - & -- & -- & +- & - \\
\hline $\sin _{13}$ & 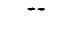 & .00 & - & -- & -- & - & - & 174 & 0 & 24 \\
\hline $\begin{array}{l}23 \ldots \\
\text { AUG. }\end{array}$ & - & .24 & - & - & - & -- & - & 104 & 0 & 35 \\
\hline $29 \ldots$ & -- & - & - & -. & -- & -- & $m$ & -- & -- & -- \\
\hline
\end{tabular}


03307800 LITTLE BARREN RIYER NEAR YONROE, KY.--CONt1nUed

CHEMICAL ANALYSES IN MILLIGRAMS PER LITER, WATER YEAR OCTOBER 1967 TO SEPTEMBER 1968

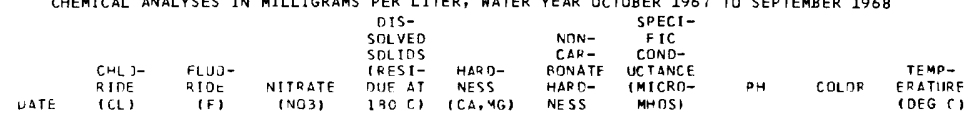

OCT.

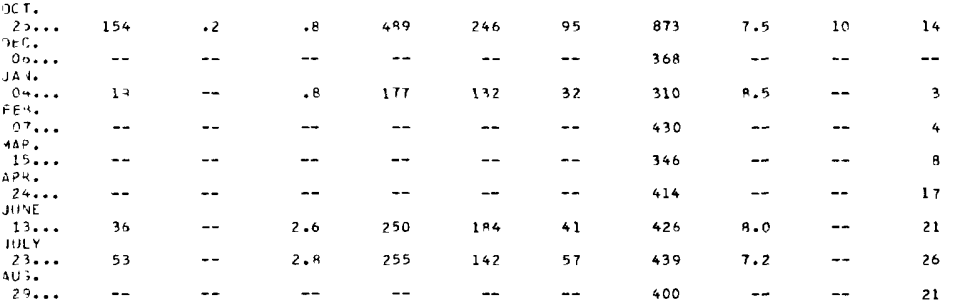

03308500 GREEN RIVER AT MUNFORDVILLE, KY.

LOCATION,--Lat $37^{\circ} 16^{\circ} 05^{\prime}$, long $85^{\circ} 53^{\prime} 10^{\prime \prime}$, Hart County, at gaging station at bridge on U.S. Highway 31 W at Munfordville.

DRAINAGE AREA.--1,673 sq $\mathrm{mi}$, of which about $180 \mathrm{sq} \mathrm{mi}$ does not contribute directly to surface runoff.

PERIOD OF RECORD.--Chemical analyses: October 1949 to September 1968.

Kater temperatures: October 1950 to September 1968

sediment records:

Specific conductance: Maximum datly, 668 micromhos Sept. $30 ;$ minimum daily, 134 micromhos Apr. 5 .
Water temperatures: Maximum, $26.0^{\circ} \mathrm{C}$ on several days during August; minimum, $1.0^{\circ} \mathrm{C}$ on many days during JanWater temperatures:
uary and February.

Sediment concentrations: Maximum daily, $1,130 \mathrm{mg} / 1$ May 26 ; minimum daily, $1 \mathrm{mg} / 1$ Nov, 16, 17, Feb. 18-22.

Sediment loads: Yaximum da1ly, 58,000 tons Apr. 6; minimum da1ly, 1.6 tons Nov. 17.

Period of record:

Specific conductance: Maximum dally, 9,420 micromhos oct. 10, 1959; minimum daily, 59 micromhos Mar. 25, 1952.

Water temperatures: Maximum, $28.0^{\circ} \mathrm{C}$ July 20, 1957; minimum, freezing point on many days during 1957-66.

Sediment concentrations: Maximur daily, 3,180 mg/1 June 14, 1952; minimum daily, 1 mg/1 on many days during

$1952-57,1960-64,1966-68$

Sediment loads: Maximum daily, 157,000 tons Mar. 1, 1962; minimum dal1y, 0,22 (revised) ton Oct, 4-7, 1963,

REMARKS,--Da1ly samples were collected for maximum and minimum specific conductance for each month.

CHEMICAL ANALYSES IN MILLIGRAMS PER LITER, WATER YEAR OCTOBER 1967 TO SEPTEMBER 1968

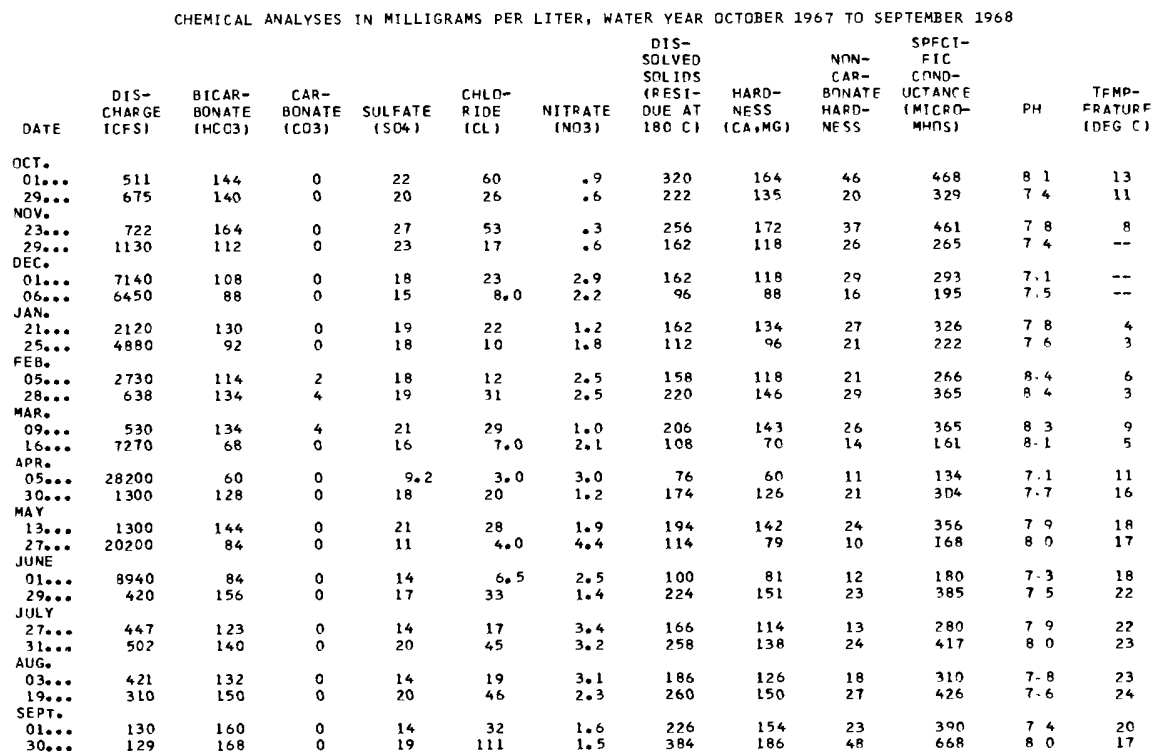


GREEN RIVER BASIN

191

03308500 GREEN RIVER AT MUNFORDVILLE, KY.--Cont1nued

SPECIFIC CONDUCTANCE (MICROMHOS AT 25ㅇ), HATER YEAR OCTOBER 1967 TO SEPTEMBER 1968 (ONCE-DAILY MEASUREMENT AT APPROXIMATELY 0700 ;

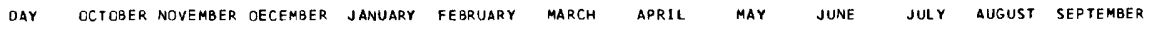

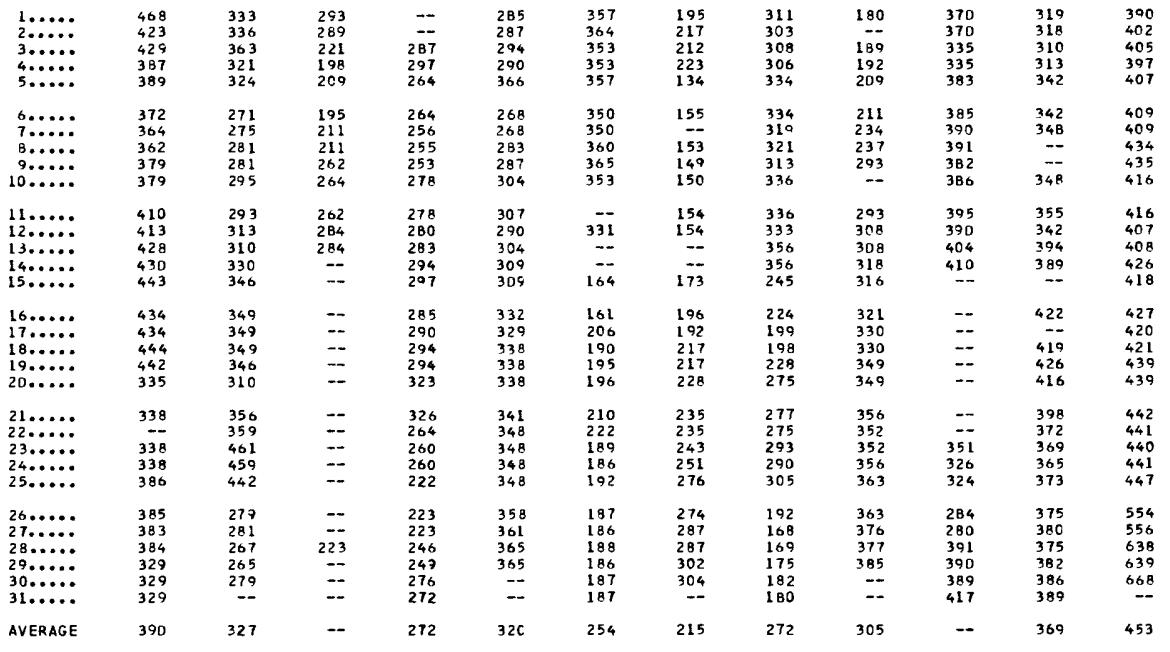

TEMPERATURE $\left({ }^{\circ} \mathrm{C}\right)$ OF WATER, WATER YEAR OCTOBER 1967 TO SEPTEMBER $196 \mathrm{~B}$ (ONCE-DAILY MEASUREMENT AT APPROXIMATELY OTOO)

\begin{tabular}{|c|c|c|c|c|c|c|c|c|c|c|c|c|}
\hline DAY & $\triangle \mathrm{CT}$ & NOV & DEC & JAN & FEB & $M A R$ & $A P R$ & MAY & JUN & JUL & $A \cup G$ & SEP \\
\hline $\begin{array}{l}1 \\
2 \\
3 \\
4 \\
5\end{array}$ & $\begin{array}{l}13.0 \\
14.0 \\
14.0 \\
16.0 \\
16.0\end{array}$ & $\begin{array}{r}11.0 \\
12.0 \\
11.0 \\
10.0 \\
8.0\end{array}$ & $\begin{array}{l}\cdots .0 \\
7.0 \\
7.0\end{array}$ & $\begin{array}{l}1.0 \\
1.0 \\
2.0 \\
1.0 \\
1.0\end{array}$ & $\begin{array}{l}9.0 \\
8.0 \\
7.0 \\
6.0 \\
6.0\end{array}$ & $\begin{array}{l}4.0 \\
4.0 \\
4.0 \\
4.0 \\
5.0\end{array}$ & $\begin{array}{l}12.0 \\
12.0 \\
13.0 \\
13.0 \\
11.0\end{array}$ & $\begin{array}{l}16.0 \\
17.0 \\
18.0 \\
18.0 \\
16.0\end{array}$ & $\begin{array}{l}18.0 \\
18.0 \\
18.0 \\
18.0 \\
18.0\end{array}$ & $\begin{array}{l}23.0 \\
23.0 \\
22.0 \\
21.0 \\
21.0\end{array}$ & $\begin{array}{l}23.0 \\
23.0 \\
23.0 \\
24.0 \\
24.0\end{array}$ & $\begin{array}{l}20.0 \\
19.0 \\
21.0 \\
20.0 \\
20.0\end{array}$ \\
\hline $\begin{array}{r}6 \\
7 \\
8 \\
9 \\
10\end{array}$ & $\begin{array}{l}18.0 \\
18.0 \\
18.0 \\
16.0 \\
14.0\end{array}$ & $\begin{array}{l}7.0 \\
7.0 \\
7.0 \\
5.0 \\
8.0\end{array}$ & $\begin{array}{l}--- \\
--- \\
--- \\
--\end{array}$ & $\begin{array}{l}1.0 \\
1.0 \\
1.0 \\
1.0 \\
1.0\end{array}$ & $\begin{array}{l}6.0 \\
4.0 \\
5.0 \\
4.0 \\
3.0\end{array}$ & $\begin{array}{l}4.0 \\
5.0 \\
7.0 \\
9.0 \\
9.0\end{array}$ & $\begin{array}{l}11.0 \\
12.0 \\
13.0 \\
13.0 \\
12.0\end{array}$ & $\begin{array}{l}14.0 \\
14.0 \\
16.0 \\
17.0 \\
17.0\end{array}$ & $\begin{array}{l}19.0 \\
20.0 \\
21.0 \\
21.0 \\
21.0\end{array}$ & $\begin{array}{l}21.0 \\
21.0 \\
22.0 \\
21.0 \\
22.0\end{array}$ & $\begin{array}{l}24.0 \\
26.0 \\
25.0 \\
25.0 \\
25.0\end{array}$ & $\begin{array}{l}20.0 \\
19.0 \\
20.0 \\
20.0 \\
19.0\end{array}$ \\
\hline $\begin{array}{l}11 \\
12 \\
13 \\
14 \\
15\end{array}$ & $\begin{array}{l}13.0 \\
12.0 \\
12.0 \\
14.0 \\
14.0\end{array}$ & $\begin{array}{l}8.0 \\
8.0 \\
9.0 \\
8.0 \\
7.0\end{array}$ & $\overline{--}$ & $\begin{array}{l}1.0 \\
2.0 \\
2.0 \\
1.0 \\
2.0\end{array}$ & $\begin{array}{l}2.0 \\
1.0 \\
1.0 \\
1.0 \\
1.0\end{array}$ & $\begin{array}{l}9.0 \\
8.0 \\
5.0 \\
6.0 \\
6.0\end{array}$ & $\begin{array}{r}13.0 \\
13.0 \\
13.0 \\
13.0\end{array}$ & $\begin{array}{l}17.0 \\
18.0 \\
18.0 \\
18.0 \\
19.0\end{array}$ & $\begin{array}{l}22.0 \\
22.0 \\
21.0 \\
21.0 \\
21.0\end{array}$ & $\begin{array}{l}22.0 \\
22.0 \\
22.0 \\
23.0 \\
24.0\end{array}$ & $\begin{array}{l}26.0 \\
23.0 \\
23.0 \\
24.0 \\
24.0\end{array}$ & $\begin{array}{l}20.0 \\
20.0 \\
19.0 \\
10.0 \\
18.0\end{array}$ \\
\hline $\begin{array}{l}16 \\
17 \\
18 \\
19 \\
20\end{array}$ & $\begin{array}{l}16.0 \\
17.0 \\
14.0 \\
14.0 \\
13.0\end{array}$ & $\begin{array}{l}7.0 \\
8.0 \\
8.0 \\
7.0 \\
6.0\end{array}$ & 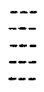 & $\begin{array}{l}1.0 \\
1.0 \\
1.0 \\
2.0 \\
2.0\end{array}$ & $\begin{array}{l}2.0 \\
3.0 \\
3.0 \\
3.0 \\
3.0\end{array}$ & $\begin{array}{r}5.0 \\
8.0 \\
9.0 \\
10.0 \\
11.0\end{array}$ & $\begin{array}{l}14.0 \\
14.0 \\
15.0 \\
16.0 \\
17.0\end{array}$ & $\begin{array}{l}19.0 \\
17.0 \\
18.0 \\
18.0 \\
18.0\end{array}$ & $\begin{array}{l}22.0 \\
21.0 \\
21.0 \\
21.0 \\
20.0\end{array}$ & $\begin{array}{r}24.0 \\
23.0 \\
23.0 \\
23.0 \\
\end{array}$ & $\begin{array}{l}24.0 \\
24.0 \\
24.0 \\
24.0 \\
25.0\end{array}$ & $\begin{array}{l}18.0 \\
18.0 \\
19.0 \\
18.0 \\
18.0\end{array}$ \\
\hline $\begin{array}{l}21 \\
22 \\
23 \\
24 \\
25\end{array}$ & $\begin{array}{l}13.0 \\
13.0 \\
13.0 \\
13.0 \\
12.0\end{array}$ & $\begin{array}{l}7.0 \\
8.0 \\
8.0 \\
7.0 \\
7.0\end{array}$ & $\overline{-}$ & $\begin{array}{l}4.0 \\
4.0 \\
3.0 \\
3.0 \\
3.0\end{array}$ & $\begin{array}{l}1.0 \\
1.0 \\
1.0 \\
1.0 \\
4.0\end{array}$ & $\begin{array}{r}11.0 \\
9.0 \\
7.0 \\
6.0 \\
8.0\end{array}$ & $\begin{array}{l}17.0 \\
18.0 \\
18.0 \\
17.0 \\
17.0\end{array}$ & $\begin{array}{l}17.0 \\
17.0 \\
18.0 \\
18.0 \\
18.0\end{array}$ & $\begin{array}{l}20.0 \\
21.0 \\
23.0 \\
23.0 \\
23.0\end{array}$ & 21.0 & $\begin{array}{l}26.0 \\
26.0 \\
26.0 \\
26.0 \\
26.0\end{array}$ & $\begin{array}{l}16.0 \\
19.0 \\
19.0 \\
20.0 \\
21.0\end{array}$ \\
\hline $\begin{array}{l}26 \\
27 \\
28 \\
29 \\
30 \\
31\end{array}$ & $\begin{array}{l}11.0 \\
11.0 \\
11.0 \\
11.0 \\
11.0 \\
11.0\end{array}$ & \begin{tabular}{l}
.-- \\
-- \\
\hdashline- \\
$-\cdots$ \\
$-\cdots$
\end{tabular} & $\begin{array}{c}--- \\
\overline{3.0} \\
--- \\
--\end{array}$ & $\begin{array}{l}3.0 \\
3.0 \\
4.0 \\
6.0 \\
7.0 \\
7.0\end{array}$ & $\begin{array}{l}3.0 \\
3.0 \\
3.0 \\
2.0 \\
-0- \\
--\end{array}$ & $\begin{array}{r}7.0 \\
9.0 \\
10.0 \\
11.0 \\
12.0 \\
13.0\end{array}$ & $\begin{array}{l}16.0 \\
16.0 \\
14.0 \\
15.0 \\
16.0 \\
\end{array}$ & $\begin{array}{l}18.0 \\
17.0 \\
17.0 \\
17.0 \\
17.0 \\
17.0\end{array}$ & $\begin{array}{r}23.0 \\
22.0 \\
20.0 \\
22.0 \\
--- \\
---\end{array}$ & $\begin{array}{l}23.0 \\
22.0 \\
23.0 \\
24.0 \\
24.0 \\
23.0\end{array}$ & $\begin{array}{l}24.0 \\
23.0 \\
22.0 \\
21.0 \\
21.0 \\
20.0\end{array}$ & $\begin{array}{l}20.0 \\
18.0 \\
17.0 \\
17.0 \\
17.0 \\
\end{array}$ \\
\hline RAGE & 13.5 & 8.0 & -- & 2.5 & 3.5 & 7.5 & 14.5 & 17.5 & 20.5 & 22.5 & 24.0 & 19.0 \\
\hline
\end{tabular}


GREEN RIYER BASIN

03308500 GREEN RIYER AT MUNFORDVILLE, KY.--Cont1 nued

SUSPENDED SEDIMENT, WATER YEAR OCTOBER 1967 TO SEPTEMBER 1968

\begin{tabular}{|c|c|c|c|c|c|c|c|c|c|}
\hline \multirow[b]{4}{*}{ 1) $\Delta Y$} & \multicolumn{3}{|c|}{ OCTחAEF } & \multicolumn{3}{|c|}{ NOVFMAED } & \multicolumn{3}{|c|}{ DECEMBFR } \\
\hline & MFAN & $\begin{array}{l}\text { MFAN } \\
\text { CUNCES- }\end{array}$ & & MEAV & $\begin{array}{c}\text { MEAN } \\
\text { rOMECFV- }\end{array}$ & & MFAN & $\begin{array}{l}\text { MFAN } \\
\text { CINAEEA- }\end{array}$ & \\
\hline & NISCAADCF & FRATINN & Lnan & NTSCHAFGE & TRATITN & $\ln \Delta n$ & NISCHARGF & TRATION & $\ln A \pi$ \\
\hline & (CFS) & $(N \div / L)$ & (ITNS) & $(C F)$ & $(M \cap, / L)$ & (TONS) & (CFS) & $(m c, / L)$ & (TกNS) \\
\hline 1 & 511 & Ir & 14 & 584 & 13 & 21 & 7140 & 506 & $07 a n$ \\
\hline$?$ & 441 & in & 12 & 944 & 17 & 30 & 6335 & 457 & $7 R_{1 C}$ \\
\hline 3 & 450 & 10 & 12 & 1510 & 37 & 151 & 11700 & $24 ?$ & 1OROR \\
\hline 4 & 445 & 9 & 11 & 1610 & 26 & 113 & 11200 & 170 & 4200 \\
\hline 5 & 415 & $1^{n}$ & 11 & 1742 & 20 & $a_{4}$ & 7920 & sn & 1710 \\
\hline a & 398 & 10 & $1 n$ & 1740 & 17 & an & 6450 & 73 & $127 \mathrm{C}$ \\
\hline ? & $2 \times 5$ & If & 0.0 & 1450 & 12 & 47 & 5440 & 50 & 724 \\
\hline 9 & 345 & a & 7.5 & 1213 & 9 & 20 & 4470 & 43 & $51^{\circ}$ \\
\hline$?$ & $31 \mathrm{~h}$ & $\ln ^{n}$ & 8.5 & 1070 & R & $2 \pi$ & 2459 & 41 & 322 \\
\hline 12 & 204 & 10 & 9.2 & nats & 7 & 18 & 2630 & an & 284 \\
\hline 11 & 201 & 10 & 9.1 & R7S & 7 & 17 & 2Ron & 52 & 303 \\
\hline 12 & 301 & 7 & 5.7 & 013 & 7 & 15 & 5010 & R5 & 1150 \\
\hline 13 & $30 \mathrm{P}$ & 7 & 5.9 & 740 & h & 12 & $x 700$ & 75 & $74^{\circ}$ \\
\hline 14 & 321 & 7 & 5.7 & 754 & 4 & R. 1 & 2070 & 60 & 407 \\
\hline 15 & 207 & 5 & 4.0 & 694 & 2 & 2.9 & 2890 & 45 & 251 \\
\hline is & 203 & $=$ & 4.0 & 673 & 1 & 1.7 & 2000 & 37 & 200 \\
\hline 17 & 301 & F & 4.1 & 501 & 1 & 1.6 & $>960$ & ${ }^{x} 1$ & 340 \\
\hline 18 & 32. & 4 & 3.5 & 553 & 2 & 3.0 & 3040 & $3 n$ & 246 \\
\hline 19 & 377 & 5 & 5.1 & 513 & 2 & 2.8 & 4740 & $7 p$ & Q9A \\
\hline 22 & 487 & 5 & $h .6$ & 497 & ? & 2.6 & 4470 & 66 & 707 \\
\hline 21 & $55 ?$ & t & $0 . n$ & 473 & 3 & 3.9 & 4770 & 79 & rone \\
\hline 22 & sก5 & 7 & 11 & 501 & 4 & 5.4 & R0 40 & 322 & 6900 \\
\hline 23 & 572 & 7 & 11 & $72 ?$ & $\circ$ & 19 & 0030 & $23 \mathrm{~h}$ & 0010 \\
\hline 24 & 524 & 11 & 16 & $10 \times 0$ & 15 & 4? & 7770 & 101 & 4010 \\
\hline 25 & 536 & 55 & $9 a$ & $12 \times 2$ & 27 & on & $664 n$ & 56 & 1000 \\
\hline 26 & 1050 & 50 & 169 & 1542 & 26 & 109 & 5670 & 33 & 505 \\
\hline 27 & 897 & 0 & 32 & 1410 & $>0$ & 76 & 4640 & $1 n$ & son \\
\hline 28 & 744 & 7 & 14 & 1350 & A & $2 R$ & 2600 & 10 & 100 \\
\hline 29 & 675 & 6 & 11 & 1130 & t & IR & $292 n$ & 0 & 71 \\
\hline 30 & 633 & h & in & $\rightarrow 960$ & $3 n c$ & 2770 & $231 n$ & b & 37 \\
\hline 31 & 591 & B & $1 *$ & $\cdots$ & -- & -- & 1970 & 6 & $3 ?$ \\
\hline TOTAL & 14808 & - & 541.7 & 31680 & -- & $3 R 41.8$ & 160760 & - & 64142 \\
\hline & & JANUARY & & & FEBRUARY & & & MAPTH & \\
\hline & MEA W & $\begin{array}{c}\text { MEAN } \\
\text { CONCEN- }\end{array}$ & & MEAV & $\begin{array}{l}\text { NEAN } \\
\text { CONTEN- }\end{array}$ & & MEAN & $\begin{array}{l}\text { MFAN } \\
\text { CONCEN- }\end{array}$ & \\
\hline & MISCHAFG & reArice & $\operatorname{lnan}$ & NISCHARGF & TFATION & LOAD & IISCHARGF & TRATINN & $10 A 0$ \\
\hline nar & (CFS) & (Mr,L) & (TINS) & (CFS) & (MG/L) & (TONS) & (CFS) & $(M G / L)$ & (TONC) \\
\hline 1 & 1920 & $=$ & 25 & 2013 & 10 & 54 & 610 & 4 & 6.7 \\
\hline 2 & 1640 & 4 & 18 & 2190 & $2 k$ & 153 & $\sin 5$ & 4 & $t .5$ \\
\hline 3 & 1310 & 4 & 17 & 7750 & 22 & $16 x$ & 591 & 2 & 4.8 \\
\hline 4 & $24 n \pi$ & 37 & 240 & 3809 & 18 & 140 & 577 & 3 & 4.7 \\
\hline 5 & 3050 & $2 n$ & 165 & 2737 & 15 & 111 & 583 & 4 & $A=1$ \\
\hline 6 & 289त & 15 & 117 & 2400 & 12 & 21 & 548 & 4 & 5.0 \\
\hline 7 & 2730 & a & 71 & $22 \mathrm{kn}$ & a & 40 & 544 & , & 2.0 \\
\hline \& & 2000 & 10 & 70 & 2053 & 6 & 23 & 524 & 2 & 2.0 \\
\hline a & $245 n$ & 10 & sh & 1240 & 4 & 20 & 530 & 6 & A. 6 \\
\hline 10 & 2300 & 7 & $4 \pi$ & 1670 & 4 & 18 & 552 & 14 & ? \\
\hline 11 & 2100 & A & 34 & 1510 & 4 & 16 & 694 & 25 & 47 \\
\hline 12 & 2000 & $t$ & $\because 2$ & 1340 & 4 & 14 & 3640 & 555 & GRBO \\
\hline 13 & 1000 & A & 31 & 1210 & 4 & 13 & 11100 & 400 & $1200 \mathrm{n}$ \\
\hline 14 & 1920 & h & 32 & $112 n$ & 3 & 0.1 & 10000 & 215 & 590n \\
\hline 15 & 1990 & $=$ & 27 & 1073 & 2 & 5.8 & 7730 & $30 n$ & $6 \geqslant<0$ \\
\hline 18 & 1870 & 5 & 25 & 1040 & ? & 5.5 & 7270 & 255 & $5 n 00$ \\
\hline 17 & 1720 & 5 & 3 & Q9? & , & 5.3 & 8500 & 203 & $\angle 56 C$ \\
\hline 18 & 1590 & $=$ & $? 1$ & 034 & 1 & 2.5 & 9050 & 123 & $\rightarrow x>c$ \\
\hline 10 & 1580 & $=$ & $\because 1$ & 897 & 1 & 2.4 & 6060 & QP & 1940 \\
\hline 20 & 1730 & 4 & 10 & 929 & $i$ & 2.3 & 6130 & 120 & 1990 \\
\hline 21 & 2120 & 13 & 74 & 829 & 1 & 2.2 & 7720 & 230 & 7070 \\
\hline 22 & $\approx 070$ & 42 & 348 & $79 !$ & i & 2.2 & 12890 & 220 & 7910 \\
\hline 23 & 4050 & 57 & 623 & 701 & 2 & 3.2 & legor & 178 & onar \\
\hline 24 & 4750 & 47 & $\mathrm{AO}_{3}$ & $A \rightarrow 1$ & 2 & 2.7 & 10500 & 98 & 5160 \\
\hline 25 & $\triangle P 9 C$ & 32 & 425 & 67 & 2 & $3 . t$ & $163 \mathrm{~nm}$ & $n$ & 4000 \\
\hline 24 & 4460 & 27 & $=25$ & 657 & 2 & 3.5 & 14900 & 70 & \\
\hline 27 & 3750 & 26 & $2 \times 4$ & 64 ? & $?$ & 3.5 & $1 \times 600$ & 69 & 3390 \\
\hline 29 & 3120 & 10 & 150 & 639 & 3 & 5.2 & 10000 & 75 & $? 210$ \\
\hline 27 & 2540 & 14 & 96 & 633 & 3 & 5.1 & 2320 & 73 & $174 \mathrm{C}$ \\
\hline 20 & 2200 & 13 & 77 & -- & - & - & $7 \in, 20$ & 73 & $\lcm{500}$ \\
\hline 31 & 2040 & 10 & 55 & $\cdots$ & -- & -- & 6760 & $7 n$ & 1280 \\
\hline TOTAL & 70140 & -- & 4157 & 40051 & -- & 930.7 & 213565 & -- & 92737.1 \\
\hline
\end{tabular}


GREEN RIVER BASIN

03308500 GREEN RIVER AT MUNFORDVILLE, KY.--Continued

SUSPENDED SEDIMENT, WATER YEAR OCTOBER 1967 TO SEPTEMBER 1968

\begin{tabular}{|c|c|c|c|c|c|c|c|c|c|}
\hline & & APRIL & & & MAY & & & JUNF & \\
\hline & MFAN & $\begin{array}{l}\text { MEAN } \\
\text { CONCEN- }\end{array}$ & & MEAN & $\begin{array}{l}\text { MEAN } \\
\text { PONFEN- }\end{array}$ & & MEAN & $\begin{array}{l}\text { MEAN } \\
\text { rONCEN- }\end{array}$ & \\
\hline & $D T S C+\triangle P G E$ & TRATINN & LIAD & IISCHAPGE & TRATION & $\operatorname{tn} A n$ & DISCHARGF & TRATIIN & L nan \\
\hline DAY & (CFS) & $(M G / L)$ & (TกNS) & (CFS) & $(M G / L)$ & (TONS) & $(r F s)$ & $(W[, L])$ & (TONS) \\
\hline 1 & 6700 & 54 & 077 & 1240 & 13 & 44 & R94ก & $14 \mathrm{~F}$ & 3500 \\
\hline$?$ & 6670 & 75 & 1350 & $11<0$ & 12 & 39 & 9170 & 174 & $>74 n$ \\
\hline 3 & 6060 & B4 & 1050 & ican & 13 & 38 & 8870 & $1 \cap 7$ & P5an \\
\hline 4 & 11400 & 758 & 27000 & 1013 & $1^{2}$ & 25 & 7400 & 114 & $\supset>20$ \\
\hline 5 & 28200 & 770 & $556 n 0$ & Q9. & 12 & 32 & 5840 & 04 & 1480 \\
\hline s & $3+400$ & $59 n$ & 58000 & 919 & 11 & 27 & $4+60$ & 74 & Qhet \\
\hline 7 & 29000 & 143 & 11200 & R59 & 8 & 19 & 3510 & 34 & 424 \\
\hline q & 20600 & 25? & 14000 & 83) & h & 13 & 2770 & 54 & 404 \\
\hline 9 & $16 n 00$ & 261 & 11300 & 827 & ศ & is & $>120$ & 34 & 195 \\
\hline 10 & 13700 & 224 & $820 \mathrm{C}$ & 809 & 10 & 24 & 1610 & 27 & $\ln r$ \\
\hline 11 & 11330 & 183 & 5590 & 005 & 12 & 20 & $124 n$ & $2 ?$ & an \\
\hline 12 & 9810 & 157 & 4160 & 1197 & 72 & 229 & 1160 & 30 & 63 \\
\hline 13 & 2610 & $13 t$ & $31 \circ 0$ & 1303 & 34 & 225 & $104 n$ & 19 & 52 \\
\hline 14 & 7400 & ino & 2000 & 2180 & $12 \mathrm{n}$ & 1240 & 950 & 10 & $4 \mathrm{~h}$ \\
\hline 15 & 7330 & 76 & 1500 & S880 & 460 & 3690 & 987 & 17 & 41 \\
\hline 16 & 6940 & h2 & 1170 & 4530 & 217 & 2470 & 906 & is & 35 \\
\hline 17 & 5000 & 52 & $82 \mathrm{~A}$ & उ०31 & 130 & 1440 & 761 & 15 & 31 \\
\hline is & 5200 & 53 & 744 & $30 n 0$ & 132 & 1070 & 736 & 14 & 28 \\
\hline 19 & 4550 & 59 & 714 & 2579 & $11^{a}$ & 708 & 696 & 13 & 24 \\
\hline 20 & 7790 & 71 & 727 & 2070 & 72 & 389 & 642 & 1) & $2 !$ \\
\hline 21 & 3410 & 61 & $56 ?$ & 1639 & 43 & 199 & 578 & 11 & 17 \\
\hline 22 & 2930 & 56 & 442 & 1410 & 43 & $1 \in 4$ & 532 & $1 n$ & 14 \\
\hline 23 & 2510 & 54 & 366 & $1>2 n$ & 35 & 115 & 488 & ic & 13 \\
\hline 24 & 2150 & 48 & 279 & 1090 & 27 & $7 n$ & 453 & 10 & 12 \\
\hline 25 & 1940 & 34 & 180 & 3320 & 214 & 2780 & 431 & 0 & in \\
\hline 26 & 1700 & 23 & $1 \mathrm{cs}$ & 9720 & 1130 & 31300 & $42 !$ & ? & 0.1 \\
\hline 27 & $154 \mathrm{C}$ & 17 & 71 & $2020 n$ & 400 & $21 \times 00$ & 415 & $\because 1$ & 17 \\
\hline 29 & 1440 & 14 & 54 & 24300 & 143 & $938 n$ & 424 & 1) & 14 \\
\hline 29 & 1370 & 14 & 52 & 20003 & 112 & $62>0$ & 470 & $\because 1$ & 12 \\
\hline 30 & 1300 & 14 & 49 & 15200 & 116 & 4760 & 300 & in & 11 \\
\hline 31 & -- & $\because$ & -. & 11930 & 142 & $45>0$ & -. & - & $=$ \\
\hline TOTAL & 765980 & -- & 211521 & 148994 & -- & 98075 & 67566 & -- & 15385.1 \\
\hline & & JIJLY & & & AUGUST & & & SFPTE YQER & \\
\hline & & MEAN & & & MEAN & & $M E A N$ & MEAN & \\
\hline & $\begin{array}{l}\text { MISCAR } \\
\text { MIARSE }\end{array}$ & TRATINN & LOAn & DISCHAPGE & TRATION & losn & nISCHADGF & TRATION & tTAR \\
\hline DAY & (CFS) & $(M G / L)$ & (TONS) & (CFS) & $\left(M S_{S} / L\right)$ & (TONS) & (CFS) & $(4 r, L)$ & (TONS) \\
\hline 1 & 374 & 11 & 11 & 449 & 42 & 51 & 130 & $1 \mathrm{~A}$ & $5 . t$ \\
\hline 2 & 360 & 15 & 15 & 424 & 36 & 41 & 127 & la & 5.5 \\
\hline 3 & $4 \geq 8$ & 25 & 29 & $4 \geqslant 1$ & 29 & 43 & 127 & ? & t.o \\
\hline 4 & 420 & 21 & 24 & 400 & 41 & 44 & 129 & $2 \pi$ & 8.0 \\
\hline 5 & 399 & 21 & 22 & 335 & 24 & 22 & 135 & 19 & $n .6$ \\
\hline 3 & 336 & 21 & 19 & 315 & 21 & 1 A & 136 & 17 & 6.? \\
\hline 7 & $29 \%$ & $\because$ & 17 & $20)$ & 10 & 15 & 294 & 42 & $3 \geqslant$ \\
\hline 3 & 275 & 20 & 15 & 287 & 26 & pn & 340 & 37 & 34 \\
\hline 9 & 250 & 21 & 15 & 302 & 30 & 24 & 267 & 28 & $>7$ \\
\hline 10 & 250 & 20 & 14 & 276 & 75 & 10 & 247 & $3 \mathrm{~h}$ & 24 \\
\hline 11 & 246 & 15 & 10 & 499 & 75 & 9o & 349 & 50 & 47 \\
\hline 12 & 240 & 15 & 9.7 & 529 & 92 & 131 & 290 & 30 & 30 \\
\hline 13 & 233 & 15 & 9.4 & 424 & 87 & inc & 254 & $4 n$ & 27 \\
\hline 14 & 243 & 12 & 7.0 & 375 & 50 & 60 & 737 & 32 & 21 \\
\hline 15 & 257 & is & 10 & 444 & 41 & 49 & 216 & $2^{\circ}$ & 17 \\
\hline 15 & 279 & 28 & ?.1 & 474 & 36 & 41 & 103 & 31 & $1 *$ \\
\hline 17 & $2 \notin 4$ & 23 & 16 & 398 & 14 & 37 & 192 & ?o & 14 \\
\hline 19 & 250 & 10 & 13 & $x \neq 6$ & 33 & 31 & 108 & 32 & is \\
\hline 17 & 279 & $1 \mathrm{~A}$ & 12 & 310 & 30 & ?5 & 208 & ?क & 14 \\
\hline$? 0$ & 288 & 13 & in & 279 & $2 h$ & 20 & 202 & 25 & 14 \\
\hline 21 & 277 & 13 & 0.7 & $2+1$ & 26 & 18 & 193 & $3 x$ & 16 \\
\hline 22 & 264 & 17 & 1? & 249 & 25 & 17 & 177 & 37 & 13 \\
\hline 23 & 557 & 47 & 100 & 240 & 24 & 16 & 172 & 24 & 12 \\
\hline 24 & S13 & 47 & 78 & 225 & 23 & 14 & $16 ?$ & 33 & 12 \\
\hline 25 & 359 & 52 & $5 n$ & 205 & 22 & 12 & 155 & 25 & ic \\
\hline 26 & 300 & $5 t$ & 45 & 123 & 23 & 11 & 145 & 19 & 7.4 \\
\hline 27 & 447 & 66 & $\mathrm{Ax}^{2}$ & 150 & 22 & 10 & 138 & $2 \mathrm{I}$ & 7.9 \\
\hline 29 & 210 & 102 & 223 & 157 & 19 & 9.1 & 135 & $2 n$ & 7.7 \\
\hline 29 & 84? & R1 & 184 & 145 & 18 & 7.1 & 132 & 19 & h. $R$ \\
\hline 30 & 509 & 02 & 149 & 139 & 17 & 6.4 & 129 & 10 & t.h \\
\hline 31 & 502 & 75 & $10 ?$ & 134 & 17 & S.? & -- & - & -- \\
\hline TDTAL & $1154 \mathrm{~s}$ & $\cdots$ & 1335.7 & 9621 & -- & 1015.8 & 5789 & -- & $47^{2} .7$ \\
\hline $\begin{array}{l}\text { OISCH } \\
\text { LOAD }\end{array}$ & $\begin{array}{l}\text { SE FOR } \\
\text { R YEAR }\end{array}$ & (15) & & & & & & & $\begin{array}{c}1049411 \\
406157.6\end{array}$ \\
\hline
\end{tabular}


PERIODIC DETERMINATIONS OF SUSPENDED SEDIMENT AND PARTICLE SIZE, WATER YEAR OCTOBER 1967 TO SEPTEMBER 1968 (METHOD OF ANALYIS: B, BOTTOM WITHDRAWAL TUBE; C, CHEMICALLY DISPERSED; D, DECANTATION; N, IN NATIVE WATER;
P, PIPET; S, SIEVE; V, VISUAL ACCUMULATION TUBE; W, IN DISTILLED WATER)

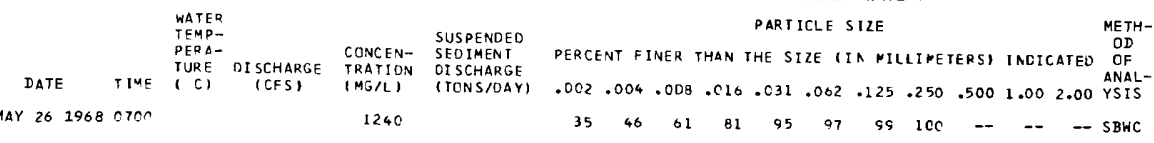

03309000 GREEN RIVER AT MAMMOTH CAVE, KY.

LOCATION, --Lat $37^{\circ} 10^{\prime} 46^{\prime \prime}$, long $86^{\circ} 06^{\prime} 46^{\prime \prime}$ (revised), Edmonton County, at Mammoth Cave Ferry crossing, 350 ft upstream from stage station, which is 0.2 mile downstream from Echo River and 0.8 mile southwest of Mamroth Cave.

DRAINAGE AREA,-1,983 sq mi, of which $444 \mathrm{sq}$ mi does not contribute directly to surface runoff.

PER IOD OF RECORD.--Chemical analyses: September 1959 to September 1968.

Water temperatures: October 1959 to June 1961.

REMARKS.--Samples for Iron and manganese filtered clear when collected, No discharge records available. CHEMICAL ANALYSES IN MILLIGRAMS PER LITER, WATER YEAR OCTOBER 1967 TO SEPTEMBER 1968

\begin{tabular}{|c|c|c|c|c|c|c|c|c|c|c|c|c|}
\hline DATE & $\begin{array}{l}\text { IRON } \\
\text { (FE) }\end{array}$ & $\begin{array}{l}\text { BICAR- } \\
\text { B ONATE } \\
\text { (HCO3) }\end{array}$ & $\begin{array}{l}\text { CAR- } \\
\text { BONATE } \\
\text { (CO3) }\end{array}$ & $\begin{array}{c}\text { SULFATE } \\
\text { (SO4) }\end{array}$ & $\begin{array}{l}\text { CHLO- } \\
\text { RIDE } \\
\text { (CL) }\end{array}$ & $\begin{array}{l}\text { NITRATE } \\
\text { (NO3) }\end{array}$ & $\begin{array}{l}\text { DIS- } \\
\text { SOL VED } \\
\text { SOL IDS } \\
\text { (RESI- } \\
\text { OUE AT } \\
\text { IBO C) }\end{array}$ & $\begin{array}{l}\text { HARD- } \\
\text { NESS } \\
\text { (CA,MG) }\end{array}$ & $\begin{array}{l}\text { NON- } \\
\text { CAR- } \\
\text { BONATE } \\
\text { HARD- } \\
\text { NESS }\end{array}$ & $\begin{array}{l}\text { SPECI- } \\
\text { FIC } \\
\text { COND- } \\
\text { UCTANCE } \\
\text { IMICRA- } \\
\text { MHOSI }\end{array}$ & PH & $\begin{array}{l}\text { TFMP- } \\
\text { ERATURE } \\
\text { (DFF C) }\end{array}$ \\
\hline $\begin{array}{l}\text { NOV. } \\
\text { Ol... } \\
\text { OEC.. }\end{array}$ & .10 & 142 & 0 & 20 & 25 & 3.7 & 199 & 146 & 30 & 339 & 77 & 13 \\
\hline JAN... & -- & -- & -- & -- & -- & -- & - & 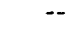 & - & 277 & - & 11 \\
\hline $\begin{array}{l}10 \ldots . . \\
\text { FEB. }\end{array}$ & .07 & 112 & 2 & 18 & 15 & 3,3 & 159 & 122 & 27 & 262 & 83 & 3 \\
\hline${ }_{M A R .}^{13 \ldots}$ & -- & -- & -- & -- & $\rightarrow$ & $\cdots$ & - & -- & -- & 304 & - & 6 \\
\hline APR... & $=$ & - & -- & - & - & - & - & -- & -- & 233 & -- & 12 \\
\hline${ }_{\text {MAY }}^{30 \ldots . .}$ & - & -- & - & -- & -- & - & -- & -- & -- & 303 & - & 12 \\
\hline juir... & -- & -- & -- & - & -- & -- & $\cdots$ & -. & -. & 179 & -- & 18 \\
\hline AUG... & -- & -- & -- & - & - & $=$ & - & -- & -- & 440 & - & 22 \\
\hline $28, \ldots$ & .21 & 164 & 0 & 21 & 28 & 1.6 & 225 & 160 & 26 & 393 & 79 & 19 \\
\hline
\end{tabular}

03311000 NOLIN RIVER AT KYROCK, KY.

LOCATION, --Lat $37^{\circ} 16^{\prime} 27^{\prime \prime}$, long $86^{\circ} 15^{\prime} 03^{\prime \prime}$, Edmonson County, at gaging station on right bank 470 ft downstream from Disma Creek, 0.3 mile downstream from Nolin River Dam, 1.2 miles upstream from pigeon Creek, 0.9 mile northeast of Kyrock, and 7.5 miles upstream from mouth.

DRAINAGE AREA, -707 sq mi (including that of Dismal Creek), of which about 223 sq mi does not contribute directly to surface runoff.

PERIOD OF RECORD. -.Chenical analyses: October 1964 to September 1968.

Water temperatures: October 1949 to September 1950, September 1962, unpublished; October 1962 to september 1968.

EXTREMES, --1967-68:

Water temperatures: Maximum, $29.0^{\circ} \mathrm{C}$ Aug. $23-26$; minimum, $2.0^{\circ} \mathrm{C}$ Mar. $2-5$.

period of record:

Water temperatures: Maximum, $25.5^{\circ} \mathrm{C}$ Aug. $20-23,1965$, Aug. 27 to Sept, 1,1966 ; minimum, $1.0^{\circ} \mathrm{C}$ Dec. $19-21,1962$ Jan. 31 to Feb. 6, 1963.

REMARKS. --Samples for 1 ron and manganese fil tered clear when collected. Flow regulated by Nolin River Reservoir. CHEMICAL ANALYSES IN MILLIGRAMS PER LITER, WATER YEAR OCTOBER 1967 TO SEPTEMBER 1968

\begin{tabular}{|c|c|c|c|c|c|c|c|c|c|c|c|}
\hline DATE & $\begin{array}{l}\text { OTS- } \\
\text { CHARGE } \\
\text { (C.FS) }\end{array}$ & $\begin{array}{l}\text { SILICA } \\
\text { ISIOZ) }\end{array}$ & $\begin{array}{l}\text { IRON } \\
\text { IFEI }\end{array}$ & $\begin{array}{l}\text { MAN- } \\
\text { GANESE } \\
\text { (MN) }\end{array}$ & $\begin{array}{l}\text { CAL- } \\
\text { CIUM } \\
\text { ITAI }\end{array}$ & $\begin{array}{l}\text { MAG- } \\
\text { NE- } \\
\text { SIUM } \\
\text { (MG) }\end{array}$ & $\begin{array}{l}\text { SODI UM } \\
\text { (NA) }\end{array}$ & $\begin{array}{l}\text { PO- } \\
\text { TAS- } \\
\text { SIUM } \\
\text { (K) }\end{array}$ & $\begin{array}{l}\text { AICAR- } \\
\text { RONATE } \\
\text { (HCO3) }\end{array}$ & $\begin{array}{l}\text { CAR- } \\
\text { BONAIE } \\
\left(C D^{2}\right)\end{array}$ & $\begin{array}{l}\text { SIILFATE } \\
\text { (Sn4) }\end{array}$ \\
\hline $\begin{array}{c}\text { uc } T . \\
03 . .\end{array}$ & 272 & 7.0 & .38 & .05 & 52 & 4.8 & $2 \cdot 8$ & 1.4 & 168 & 0 & 1? \\
\hline NOV. & 1930 & - & .03 & .02 & - & -- & - & - & 122 & 0 & 11 \\
\hline OER. & 2370 & -- & -- & -- & - & -- & -- & -- & $\cdots$ & $\cdots$ & $\cdots$ \\
\hline $\begin{array}{l}J A N . \\
O^{2} \cdots \\
F E+.\end{array}$ & 596 & - & .35 & .21 & -- & -- & - & -- & 116 & 4 & 26 \\
\hline${ }_{M A R}^{O 1 . . .}$ & 867 & -- & -- & $\cdots$ & -- & - & -- & $\cdots$ & -- & -- & -- \\
\hline $\begin{array}{c}05 \ldots \\
\triangle P 4 .\end{array}$ & 330 & -- & -- & -- & -- & -- & - & -- & -- & - & -- \\
\hline${ }_{\text {MAY }}^{O 2} \cdots$ & 3700 & -- & $=-$ & -- & -- & - & - & - & -- & $\cdots$ & $\cdots$ \\
\hline W' & 479 & -- & -- & -- & - & - & - & -- & $\cdots$ & -- & - \\
\hline${ }_{\text {Jijly }}^{11}$ & 5200 & -- & .08 & .02 & -- & -- & $\sim$ & -- & 126 & 0 & 13 \\
\hline SFPT: & 262 & -- & -- & $\cdots$ & -- & - & $\cdots$ & 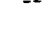 & 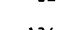 & 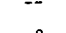 & $=-$ \\
\hline $10 \ldots$ & 270 & -- & .27 & .06 & -- & $\cdots$ & $\cdots$ & - & 134 & 0 & 14 \\
\hline
\end{tabular}


03311000 NOLIN RIVER AT KYROCK, KY.--Cont1nued

CHEMICAL ANALYSES IN MILLIGRAMS PER LITER, WATER YEAR OCTOBER 1967 TO SEPTEMBER 1968

\begin{tabular}{|c|c|c|c|c|c|c|c|c|c|c|}
\hline DATE & $\begin{array}{l}\text { CHLI)- } \\
\text { R IDF } \\
\text { (CLI }\end{array}$ & $\begin{array}{l}\text { FLUD- } \\
\text { RIDE } \\
\text { (F) }\end{array}$ & $\begin{array}{l}\text { N]TRATF } \\
(N D 3)\end{array}$ & $\begin{array}{l}\text { DIS- } \\
\text { SOLVED } \\
\text { SOLIOS } \\
\text { IRESI- } \\
\text { DUE AT } \\
\text { I RO CI }\end{array}$ & $\begin{array}{l}\text { HARD- } \\
\text { NESS } \\
\text { ICA.MG) }\end{array}$ & $\begin{array}{l}\text { NON- } \\
\text { CAF- } \\
\text { RONATE } \\
\text { HARD- } \\
\text { NESS }\end{array}$ & $\begin{array}{l}\text { SPECI- } \\
\text { FIC } \\
\text { COND- } \\
\text { UCTANCE } \\
\text { (MIC,RO- } \\
\text { MHOSI }\end{array}$ & ${ }^{\mathrm{PH}}$ & COLOF & $\begin{array}{l}\text { TFMP- } \\
\text { ERATURE } \\
\text { IOFG CI }\end{array}$ \\
\hline. & & & & & & & & & & \\
\hline $\begin{array}{l}03 . . \\
\text { Nov. }\end{array}$ & 4.0 & .2 & 3.6 & 171 & 150 & 12 & 299 & 7.6 & 6 & 19 \\
\hline $\begin{array}{l}07 . . \\
\text { DEC. }\end{array}$ & 4.0 & -- & 1.8 & 134 & 112 & 12 & 226 & 7.7 & -- & 11 \\
\hline $\begin{array}{l}05 . . . \\
114 .\end{array}$ & -- & -- & -- & -- & -- & -- & 267 & -- & -- & 7 \\
\hline FEP. & 5.0 & -- & 1.0 & 156 & 134 & 32 & 275 & 8.4 & - & 6 \\
\hline $\begin{array}{l}01 \ldots \\
\text { MA2. }\end{array}$ & -- & -- & - & -- & -- & -- & 310 & -- & -- & 4 \\
\hline $05 \ldots$ & -- & -- & -- & -- & -- & - & 288 & -- & -- & 2 \\
\hline पav $\cdots$ & -- & -- & -- & -- & -- & -- & 226 & -- & -- & 11 \\
\hline Jü. & -- & -- & -- & -- & -- & -- & 210 & -- & -- & 18 \\
\hline $\operatorname{Mu}_{y}$ & 4.0 & -- & $4 . \mathrm{D}$ & 153 & 126 & 23 & 236 & 7.9 & $\cdots$ & 19 \\
\hline $\begin{array}{c}2+\ldots \\
\text { SEPT. }\end{array}$ & -- & -- & -- & -- & -- & - & 255 & -- & -- & 28 \\
\hline $30 \ldots$ & 3.5 & -- & .8 & 153 & 122 & 12 & 253 & 8.0 & -- & 23 \\
\hline
\end{tabular}
(CONTINUOUS ETHYL ALCOHOL-ACTUATED THERMOGRAPH)
(COCSER 1968

OAY

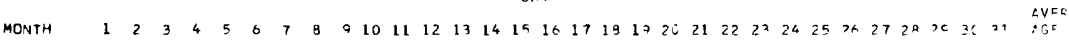

OC TOBER.: - - - -

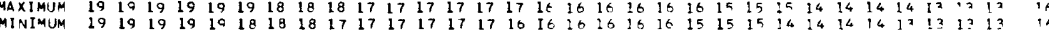

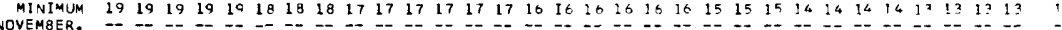

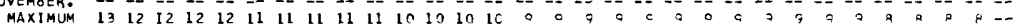

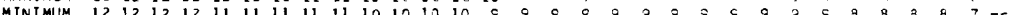

DECEMBER.

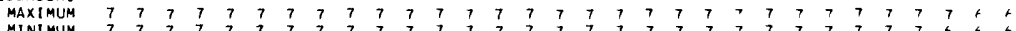

JANUARY.. -

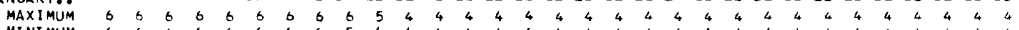

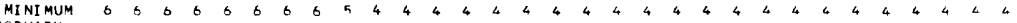

FEBRUARY. - -

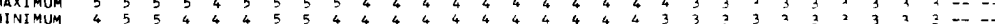

MARCH... - -

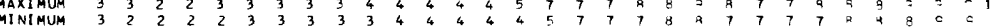

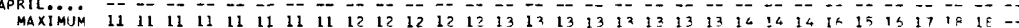

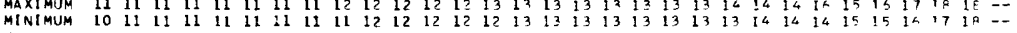

MAXIMUM 18 18

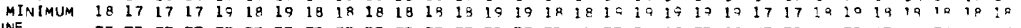
JUNE.1̈̈0

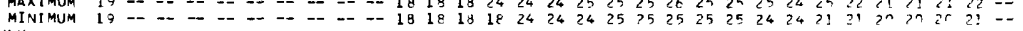

MAXIXï - - - - - - -

MINIMUM $22 \begin{array}{llllllllllllllllllllllll}24 & 25 & 25 & 26 & 26 & 26 & 26 & 26 & 26 & 27 & 27 & 26 & 26 & 27 & 27 & 27 & 27 & 27 & 20 & 28 & 28 & 29 & 29 & 3\end{array}$

MAXIMUM 27 27 27 27 $2727 \quad 27282928$

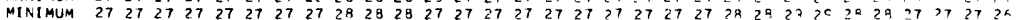

SEPTEMBER -- - - - - - - - - - -

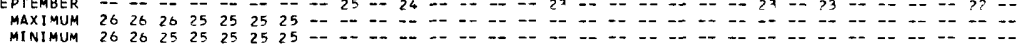

0331300D BARREN RIVER NEAR FINNEY, KY.

LOCATION,-Lat $36^{\circ} 53^{\prime} 42^{\prime \prime}$, long $86^{\circ} 08^{\prime} 02^{\prime \prime}$, Allen County, temperature recorder at gaging station on 1 eft bank, $1,200 \mathrm{ft}$ upstream from Fort O11ver Ford, 2,500 ft upstream from Difficult Creek, 0.5 mile downstream from Barren River Dam, 2.1 miles southwest of Finney, and at mile 78.7 .

DRAINAGE AREA,- $-940 \mathrm{sq} \mathrm{m} 1$, of which about $77 \mathrm{sq} \mathrm{ml}$ does not contribute directly to surface runoff.

PER IOD OP RECORD. - Water temperatures: August 1961 to June 1962, unpublished; November 1962 to September 1968.

EXTREMES. --1967-68:

Water temperatures: Haximum, $23.0^{\circ} \mathrm{C}$ Sept. $30 ;$ minimum, $2.0^{\circ} \mathrm{C} \mathrm{Jan} .9$.

Pertod of record:

Nater temperatures: Maximum, $33.0^{\circ} \mathrm{C}$ July $3,4,8,9,1963$; minimum recorded, $0.5^{\circ} \mathrm{C}$ during period Nov. 24,1963 to Jan. 7,1964 .

REMARKS. --Recorder stopped during the following periods: Nov, 7 to Dec. 5 , range $8.0^{\circ} \mathrm{C}$ to $16.0^{\circ} \mathrm{C} ;$ Dec. 17 to

$\mathrm{Jan} .8$, range $2.0^{\circ} \mathrm{C}$ to $9.0^{\circ} \mathrm{C}$; Feb, 1 to Mar. 4 , range $5.0^{\circ} \mathrm{C}$ to $9.0^{\circ} \mathrm{C}$. Flow regulated by Barren River Reservoir, 
TEMPERATURE $\left({ }^{\circ} \mathrm{C}\right)$ OF WATER, WATER YEAR OCTOBER 1967 TO SEPTEMBER 1968 (CONTINUOUS ETHYL ALCOHOL-ACTUATED THERMOGRAPH)

DAY

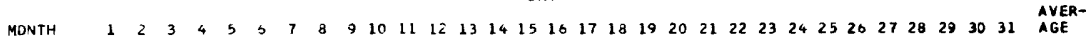

OCTOBER

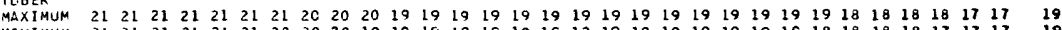

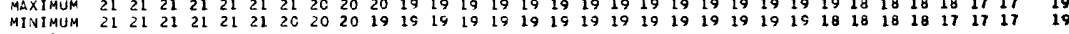
NOVEYBER

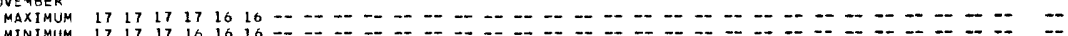
MAXIMUM MINIMUM JANUARY

MAXIMUM MINIMUM -- - - - - - - - - - - - -

MAXIMUM MARCH

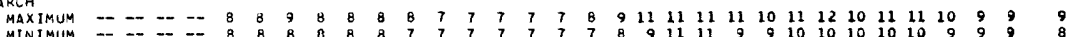
MINIMUM PRIL MAXIMUM MAY INIMUM

MAXIMJM MINIMU
JUNE

MAXIMUM MINI MUM JULY

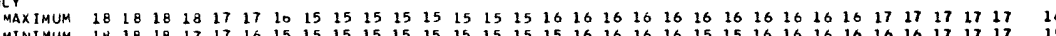
MINIMUM AUGUST

MAXIMUM
MINIMUM SEPTEMBER MAXIMUM MINIMUM $\begin{array}{lllllrlllllllllllllllllllllllllllllll}9 & 11 & 11 & 11 & 10 & 11 & 11 & 11 & 11 & 11 & 11 & 11 & 11 & 11 & 12 & 12 & 12 & 12 & 12 & 12 & 12 & 12 & 12 & 12 & 12 & 12 & 13 & 13 & 13 & 13 & -2 & 11 \\ 9 & 9 & 10 & 9 & 10 & 12 & 11 & 11 & 11 & 11 & 11 & 11 & 11 & 11 & 12 & 12 & 12 & 12 & 12 & 12 & 12 & 12 & 12 & 12 & 12 & 12 & 13 & 13 & 13 & -- & 11\end{array}$ $\begin{array}{llllllllllllllllllllllllllllllllllllll}13 & 13 & 13 & 12 & 12 & 12 & 12 & 12 & 12 & 12 & 12 & 13 & 13 & 14 & 14 & 14 & 15 & 15 & 14 & 14 & 14 & 13 & 13 & 13 & 14 & 15 & 14 & 14 & 13 & 13 & 13 & 13\end{array}$ $\begin{array}{lllllllllllllllllllllllllllllllllll}14 & 14 & 16 & 16 & 16 & 16 & 16 & 16 & 16 & 16 & 16 & 16 & 16 & 16 & 16 & 16 & 16 & 16 & 16 & 16 & 17 & 17 & 17 & 17 & 17 & 18 & 18 & 18 & 16 & \cdots & 16\end{array}$ $\begin{array}{llllllllllllllllllllllllllllllll}17 & 17 & 17 & 17 & 17 & 17 & 17 & 16 & 16 & 16 & 17 & 17 & 19 & 18 & 18 & 18 & 18 & 18 & 17 & 17 & 17 & 17 & 17 & 18 & 18 & 18 & 18 & 18 & 18 & 18 & 18 & 17\end{array}$

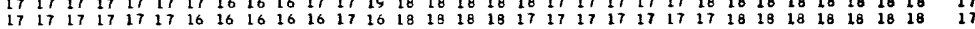
$\begin{array}{lllllllllllllllllllllllllllllllll}18 & 18 & 18 & 18 & 18 & 18 & 18 & 18 & 18 & 18 & 18 & 18 & 18 & 18 & 18 & 18 & 18 & 18 & 18 & 19 & 19 & 19 & 19 & 19 & 19 & 19 & 19 & 19 & 19 & 23 & -\end{array}$

O3314500 BARREN RIVER AT BOWL ING GREEN, KY

LOCATION.--Lat $37^{\circ} 00^{\prime} 04^{\prime \prime}$, long $86^{\circ} 25^{\prime} 51^{\prime \prime}$, Warren County, at gaging station on College Street bridge, 600 ft downstream from bridge on U.S. Highways 31 and 68 at Bow1ing Green, $800 \mathrm{ft}$ upstream from Louisville and Nashville
Railroad bridge, 6 miles downtream from Drakes Creek, 8.9 miles upstream from Jennings Creek and at mile 37,6 .

DRA INAGE AREA. - $1,848 \mathrm{sq} \mathrm{mi}$, of which about $490 \mathrm{sq} \mathrm{mi}$ does not contribute directly to surface runoff.

PERIOD OF RECORD. --Chemical analyses: October 1949 to September 1950, October 1959 to September 1960 , October 1965 to September 1968

Water temperatures: October 1949 to September 1968.

Sediment records: November 1952 to September 1960.

EXTREMES, --1967-68:

Water temperatures: Maximum, $29.0^{\circ} \mathrm{C}$ on July 23, 24, Aug. 23-27; minimum, 3. $0^{\circ} \mathrm{C}$ Jan. 8-18,

Period of record: Water temperatures: Haximum, $30.5^{\circ} \mathrm{C}$ July 1, 2, 22, 29, 1952, July 13, 14, 1966; minimum, freezing point on many
days during 1951, 1958-67.

REMARKS.--Samples for 1ron and manganese filtered clear when collected. Recorder stopped during the following periods: Aug. $3-4$, range $26.0^{\circ} \mathrm{C}$ to $27.0^{\circ} \mathrm{C}$; Sept. $5-7$, range $23.0^{\circ} \mathrm{C}$ to $24.0^{\circ} \mathrm{C}$. Flow partly regulated by

CHEMICAL ANALYSES IN MILLIGRAMS PER LITER, WATER YEAR OCTOBER 1967 TO SEPTEMBER 1968

\begin{tabular}{|c|c|c|c|c|c|c|c|c|c|c|c|}
\hline กATE & $\begin{array}{l}\text { DIS- } \\
\text { CHARGE } \\
\text { (CFS) }\end{array}$ & $\begin{array}{l}\text { SILICA } \\
\text { (SI J2) }\end{array}$ & $\begin{array}{l}\text { IRCN } \\
\text { IFFI }\end{array}$ & $\begin{array}{l}\text { MAN- } \\
\text { GANESE } \\
\text { (MN) }\end{array}$ & $\begin{array}{l}\text { CAL- } \\
\text { CIUY } \\
\text { (CA) }\end{array}$ & $\begin{array}{l}\text { MAC:- } \\
\text { NE- } \\
\text { SIUM } \\
\text { I } \Psi G I\end{array}$ & $\begin{array}{l}\text { SNOIUM } \\
\text { (NA) }\end{array}$ & $\begin{array}{l}\text { PR- } \\
\text { TAS- } \\
\text { SIIUM } \\
(K)\end{array}$ & $\begin{array}{l}\text { PICAR- } \\
\text { ANNATE } \\
\text { (HCO } 3 \text { ) }\end{array}$ & $\begin{array}{l}\text { CAR- } \\
\text { ANNATE } \\
\left(C O^{2}\right)\end{array}$ & $\begin{array}{l}\text { SULFATE } \\
\text { (Sn4) }\end{array}$ \\
\hline oct. & & & & & & & & & & & \\
\hline $3 x \ldots$ & 905 & $=$ & .60 & .21 & $=$ & $=$ & -- & $=$ & 12 ด & 0 & 15 \\
\hline DFF. & & & & & & & & & - & & \\
\hline$\underset{N A N .}{05 .}$ & 5220 & 7.1 & .12 & .19 & 44 & 0.0 & 4.5 & 1.3 & 130 & 0 & 36 \\
\hline $\begin{array}{l}03 . . . \\
\text { प15. }\end{array}$ & 4630 & -- & .11 & .11 & - & -- & -- & -- & 124 & 0 & $2 B$ \\
\hline ADE. & 707 & -. & -- & - & -- & -- & -- & - & $\ldots$ & -- & -- \\
\hline $\operatorname{OI}_{M Y Y} \ldots$ & 5070 & -- & - & -- & -- & -- & -- & - & -- & -- & - \\
\hline duvr & 3500 & -- & .08 & .05 & -- & -- & - & -- & 94 & 0 & 13 \\
\hline$\underset{J \| L Y}{05}$ & 4700 & -- & - & -- & - & $-\infty$ & - & -- & -- & -- & -- \\
\hline 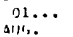 & 3490 & -- & - & -- & $\cdots$ & -- & -- & -- & - & -- & - \\
\hline $\begin{array}{l}96 . . . \\
\text { SFPF. }\end{array}$ & 440 & - & .03 & .02 & -- & -- & -- & -- & 126 & 0 & 16 \\
\hline$n 3 . .$. & 396 & -- & - & -- & -- & -- & -- & -- & -- & -- & -- \\
\hline
\end{tabular}


03314500 BARREN RIVER AT BOWLING GREEN, KY.--Continued

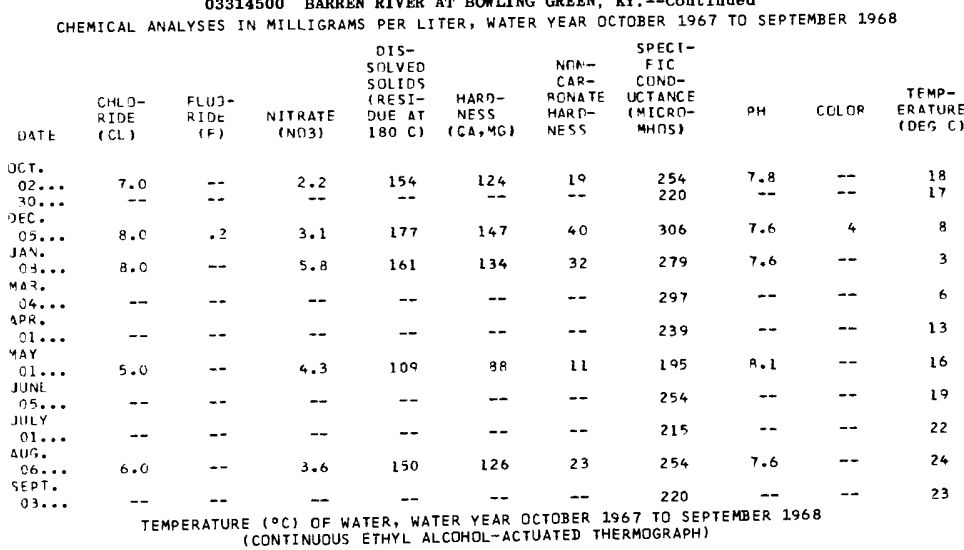

DAY

MONTH

OCTO8ER

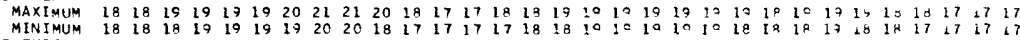
NOVEMBER

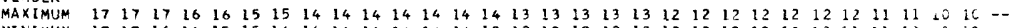

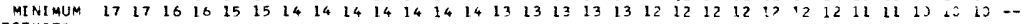
DECEMBER

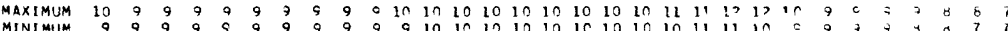

MINI MUEM

ANUARY

MAKIMUA $7 \begin{array}{lllllllllllllllllllllllllllllll} & 6 & 6 & 6 & 6 & 5 & 4 & 4 & 3 & 3 & 3 & 3 & 3 & 3 & 3 & 3 & 3 & 4 & 4 & 4 & 6 & 6 & 7 & 7 & 7 & 6 & 0 & 7 & 7 & 0\end{array}$

MINIMUM

FEBRUARY

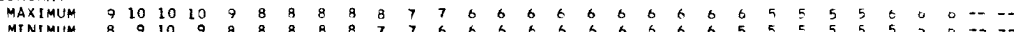

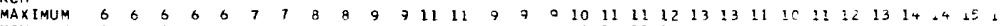

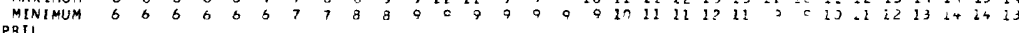

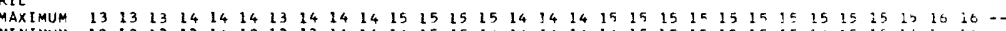

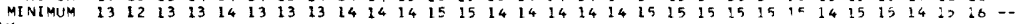

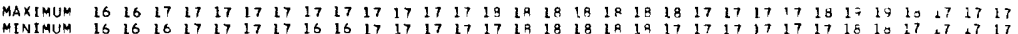

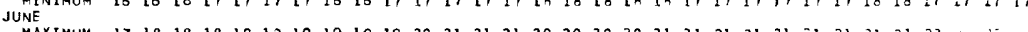

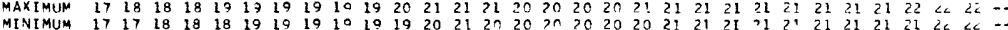

JULY $Y$ Maxi

MAXIMUM $\begin{array}{llllllllllllllllllllllllllllllll}22 & 22 & 22 & 22 & 22 & 22 & 23 & 23 & 22 & 23 & 24 & 24 & 24 & 26 & 26 & 27 & 27 & 27 & 27 & 28 & 2 R & 2 B & 26 & 26 & 28 & 28 & 28 & 20 & 20 & 27 & 47\end{array}$

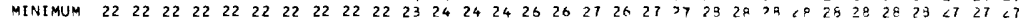
AUGUST

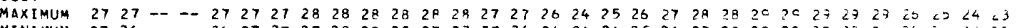

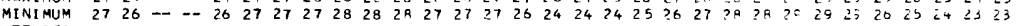
SEPTEMBER

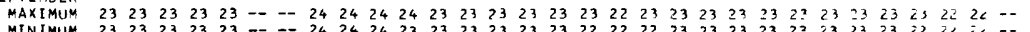
03318010 ROUGH RIVER AT ROUGH RIVER DAI, NEAR FALLS OF ROUGH, KY.

LOCATION.--Lat $37^{\circ} 37^{\prime} 19^{\prime \prime}$, Iong $86^{\circ} 30^{\prime} 15^{\prime \prime}$, Grayson County, temperature recorder at stage station on left bank, $800 \mathrm{ft}$ downstream from centerline of Rough River Dam, 1.5 miles upstream from Cane Run, 3.1 miles upstream from Rock Lick Creek, 3.5 miles northeast of Falls of Rough, and at mile 89.2.

DRAINAGE AREA. - -454 sq mi, of which about $110 \mathrm{sq}$ mi does not contribute directly to surface runoff.

PER IOD OF RECORD. --Water temperatures: July 1962 to September 1968.

EXTREMES. --1967-68:

Water temperatures: Maximum, $24.0^{\circ} \mathrm{C}$ Oct, $3-5$; minimum, $2.0^{\circ} \mathrm{C} \mathrm{Jan.} \mathrm{4-6.}$

Period of record:

Water temperatures: Maximum, $24.0^{\circ} \mathrm{C}$ Oct. 3-5, 1967; minimum, $0.5^{\circ} \mathrm{C}$ Jan. $6,7,1967$.

REMARKS, --Recorder stopped during the following periods: Mar, 4-6, range $6.0^{\circ} \mathrm{C}$ to $7.0^{\circ} \mathrm{C} ; \mathrm{Apr} .11-29$, range $9.0^{\circ} \mathrm{C}$

to $13.0^{\circ} \mathrm{C}$; May 8 to June $12,11.0^{\circ} \mathrm{C}$ to $17.0^{\circ} \mathrm{C}$. No discharge records available. Flow regulated by Rough
River Reservoir. 
TEMPERATURE (ㅇ) OF WATER, WATER YEAR OCTOBER 1967 TO SEPTEMBER 1968 ( $)$ C) OF WATER, WATER YEAR OCTOBER 1967 TO SEPTEMB
(CONTINUOUS ETHYL ALCOHOL-ACTUATED THERMOGRAPH)

\begin{tabular}{|c|c|c|c|c|c|c|c|c|c|c|c|c|}
\hline \multirow[b]{2}{*}{ OAY } & \multicolumn{2}{|c|}{ OCTOВER } & \multicolumn{2}{|c|}{ NOVEMBER } & \multicolumn{2}{|c|}{ DECEMBER } & \multicolumn{2}{|c|}{ JANUARY } & \multicolumn{2}{|c|}{ FEBRUARY } & \multicolumn{2}{|c|}{ MARCL } \\
\hline & $\max$ & MIN & $\operatorname{MAx}$ & Min & $\operatorname{M\Delta x}$ & MIN & MAX & MIN & $\operatorname{MAX}$ & MIN & $\operatorname{Max}$ & Min \\
\hline $\begin{array}{l}1 \\
2 \\
3 \\
4 \\
5\end{array}$ & $\begin{array}{l}23.0 \\
23.0 \\
24.0 \\
24.0 \\
24.0\end{array}$ & $\begin{array}{l}22.0 \\
23.0 \\
23.0 \\
23.0 \\
22.0\end{array}$ & $\begin{array}{l}16.0 \\
16.0 \\
16.0 \\
15.0 \\
14.0\end{array}$ & $\begin{array}{l}16.0 \\
16.0 \\
15.0 \\
14.0 \\
14.0\end{array}$ & $\begin{array}{l}8.0 \\
8.0 \\
7.0 \\
7.0 \\
6.0\end{array}$ & $\begin{array}{l}8.0 \\
7.0 \\
6.0 \\
6.0 \\
6.0\end{array}$ & $\begin{array}{l}5.0 \\
3.0 \\
3.0 \\
3.0 \\
4.0\end{array}$ & $\begin{array}{l}3.0 \\
3.0 \\
3.0 \\
2.0 \\
2.0\end{array}$ & $\begin{array}{l}6.0 \\
7.0 \\
7.0 \\
7.0 \\
8.0\end{array}$ & $\begin{array}{l}5.0 \\
6.0 \\
7.0 \\
7.0 \\
7.0\end{array}$ & $\begin{array}{l}6.0 \\
6.0 \\
7.0 \\
-2 . \\
--.\end{array}$ & $\begin{array}{l}6.0 \\
6.0 \\
6.0 \\
-. .\end{array}$ \\
\hline $\begin{array}{r}6 \\
7 \\
8 \\
9 \\
10\end{array}$ & $\begin{array}{l}22.0 \\
22.0 \\
22.0 \\
22.0 \\
22.0\end{array}$ & $\begin{array}{l}22.0 \\
22.0 \\
22.0 \\
22.0 \\
21.0\end{array}$ & $\begin{array}{l}14.0 \\
13.0 \\
12.0 \\
12.0 \\
12.0\end{array}$ & $\begin{array}{l}13.0 \\
12.0 \\
12.0 \\
12.0 \\
12.0\end{array}$ & $\begin{array}{l}6.0 \\
6.0 \\
6.0 \\
7.0 \\
7.0\end{array}$ & $\begin{array}{l}6 . C \\
6.0 \\
6.0 \\
6.0 \\
\epsilon . C\end{array}$ & $\begin{array}{l}3.0 \\
4.0 \\
5.0 \\
3.0 \\
3.0\end{array}$ & $\begin{array}{l}2.0 \\
3.0 \\
3.0 \\
3.0 \\
3.0\end{array}$ & $\begin{array}{l}9.0 \\
9.0 \\
7.0 \\
7.0 \\
7.0\end{array}$ & $\begin{array}{l}8.0 \\
7.0 \\
6.0 \\
6.0 \\
6.0\end{array}$ & $\begin{array}{l}-1 .- \\
7.0 \\
7.0 \\
7.0 \\
7.0\end{array}$ & $\begin{array}{l}-. . \\
7.0 \\
\epsilon .0 \\
7.0 \\
7.0\end{array}$ \\
\hline $\begin{array}{l}11 \\
12 \\
13 \\
14 \\
15\end{array}$ & $\begin{array}{l}21.0 \\
21.0 \\
21.0 \\
21.0 \\
21.0\end{array}$ & $\begin{array}{l}21.0 \\
21.0 \\
21.0 \\
21.0 \\
21.0\end{array}$ & $\begin{array}{l}12.0 \\
12.0 \\
12.0 \\
12.0 \\
11.0\end{array}$ & $\begin{array}{l}12.0 \\
12.0 \\
12.0 \\
11.0 \\
11.0\end{array}$ & $\begin{array}{l}7.0 \\
7.0 \\
7.0 \\
7.0 \\
5.0\end{array}$ & $\begin{array}{l}7.0 \\
7.0 \\
7.0 \\
6.0 \\
6.0\end{array}$ & $\begin{array}{l}4.0 \\
3.0 \\
3.0 \\
4.0 \\
4.0\end{array}$ & $\begin{array}{l}3 . c \\
3 . C \\
3.0 \\
3 . C \\
4.0\end{array}$ & $\begin{array}{l}6.0 \\
7.0 \\
5.0 \\
7.0 \\
7.0\end{array}$ & $\begin{array}{l}0.0 \\
6.0 \\
6.0 \\
6.0 \\
6.0\end{array}$ & $\begin{array}{l}7.0 \\
7.0 \\
7.0 \\
7.0 \\
7.0\end{array}$ & $\begin{array}{l}0.6 \\
6.0 \\
7.6 \\
7.0 \\
7.0\end{array}$ \\
\hline $\begin{array}{l}16 \\
17 \\
18 \\
19 \\
20\end{array}$ & $\begin{array}{l}21.0 \\
21.0 \\
21.0 \\
21.0 \\
20.0\end{array}$ & $\begin{array}{l}21.0 \\
21.0 \\
21.0 \\
20.0 \\
20.0\end{array}$ & $\begin{array}{l}11.0 \\
11.0 \\
10.0 \\
10.0 \\
10.0\end{array}$ & $\begin{array}{l}11.0 \\
10.0 \\
10.0 \\
10.0 \\
10.0\end{array}$ & $\begin{array}{l}7 . c \\
6.0 \\
6 . c \\
6 . c \\
7.0\end{array}$ & $\begin{array}{l}t . c \\
6.0 \\
6 . c \\
6.0 \\
6 . c\end{array}$ & $\begin{array}{l}5.0 \\
6.0 \\
5.0 \\
5.0 \\
5.0\end{array}$ & $\begin{array}{l}4.0 \\
4.0 \\
4.0 \\
4.0 \\
4.0\end{array}$ & $\begin{array}{l}6.0 \\
7.0 \\
7.0 \\
7.0 \\
7.0\end{array}$ & $\begin{array}{l}6.0 \\
6.0 \\
5.0 \\
5.0 \\
5.0\end{array}$ & $\begin{array}{l}7.0 \\
8.0 \\
8.0 \\
8.0 \\
8.0\end{array}$ & $\begin{array}{l}7.0 \\
7.0 \\
8.0 \\
8.0 \\
8.0\end{array}$ \\
\hline $\begin{array}{l}21 \\
22 \\
23 \\
24 \\
25\end{array}$ & $\begin{array}{l}20.0 \\
15.0 \\
19.0 \\
19.0 \\
18.0\end{array}$ & $\begin{array}{l}19.0 \\
15.0 \\
19.0 \\
18.0 \\
18.0\end{array}$ & $\begin{array}{r}10.0 \\
10.0 \\
10.0 \\
9.0 \\
9.0\end{array}$ & $\begin{array}{r}10.0 \\
10.0 \\
9.0 \\
9.0 \\
9.0\end{array}$ & $\begin{array}{l}7.0 \\
7.0 \\
7.0 \\
6.0 \\
6.0\end{array}$ & $\begin{array}{l}7 . c \\
7.0 \\
6.6 \\
6.0 \\
6.0\end{array}$ & $\begin{array}{l}5.0 \\
5.0 \\
4.0 \\
6.0 \\
6.0\end{array}$ & $\begin{array}{l}4 . C \\
4.0 \\
4.0 \\
4 . C \\
4.0\end{array}$ & $\begin{array}{l}6.0 \\
7.0 \\
5.0 \\
5.0 \\
6.0\end{array}$ & $\begin{array}{l}5.0 \\
5.0 \\
5.0 \\
5.0 \\
5.0\end{array}$ & $\begin{array}{l}9.5 \\
9.0 \\
9.0 \\
9.0 \\
9.0\end{array}$ & $\begin{array}{l}8.0 \\
9.0 \\
9.0 \\
8.0 \\
8.0\end{array}$ \\
\hline $\begin{array}{l}26 \\
27 \\
28 \\
29 \\
30 \\
31\end{array}$ & $\begin{array}{l}18.0 \\
18.0 \\
17.0 \\
17.0 \\
16.0 \\
16.0\end{array}$ & $\begin{array}{l}18.0 \\
17.0 \\
17.0 \\
16.0 \\
16.0 \\
16.0\end{array}$ & $\begin{array}{l}9.0 \\
9.0 \\
9.0 \\
8.0 \\
8.0 \\
-.-\end{array}$ & $\begin{array}{l}8.0 \\
8.0 \\
8.0 \\
8.0 \\
8.0 \\
-. .\end{array}$ & $\begin{array}{l}6.0 \\
6.0 \\
6.0 \\
4.0 \\
4.0 \\
4.0\end{array}$ & $\begin{array}{l}6 . c \\
6.0 \\
4 . c \\
3.0 \\
3.0 \\
3 . c\end{array}$ & $\begin{array}{l}5.0 \\
4.0 \\
4.0 \\
4.0 \\
4.0 \\
5.0\end{array}$ & $\begin{array}{l}4.0 \\
4.0 \\
4.0 \\
4.0 \\
4.0 \\
4.0\end{array}$ & $\begin{array}{l}6.0 \\
5.0 \\
6.0 \\
6.0 \\
-.-\end{array}$ & $\begin{array}{l}5.0 \\
5.0 \\
5.0 \\
5.0 \\
\cdots .-\end{array}$ & $\begin{array}{r}8.0 \\
9.0 \\
9.0 \\
9.0 \\
9.0 \\
10.0\end{array}$ & $\begin{array}{l}8.0 \\
8.0 \\
8.0 \\
8.0 \\
8.0 \\
9.0\end{array}$ \\
\hline \multirow[t]{2}{*}{ MONYH } & 24.0 & 16.0 & 16.0 & 8.0 & 8.0 & 3.0 & 6.0 & 2.0 & 9.0 & 5.0 & 10.0 & 6.0 \\
\hline & \multicolumn{2}{|c|}{$\triangle P R 1 L$} & \multicolumn{2}{|c|}{ MaY } & \multicolumn{2}{|c|}{ JUNE } & \multicolumn{2}{|c|}{ JUL Y } & \multicolumn{2}{|c|}{ AUGUST } & \multicolumn{2}{|c|}{ SEPIEMEER } \\
\hline CAY & $\operatorname{MAX}$ & $\operatorname{MIN}$ & $\operatorname{MAX}$ & MIN & $\max$ & MIN & $\operatorname{MAX}$ & MIN & $\operatorname{MAX}$ & $M 1 N$ & MAX & MIN \\
\hline $\begin{array}{l}1 \\
2 \\
3 \\
4 \\
5\end{array}$ & $\begin{array}{r}10.0 \\
11.0 \\
11.0 \\
12.0 \\
5.0\end{array}$ & $\begin{array}{r}9.0 \\
10.0 \\
11.0 \\
9.0 \\
5.0\end{array}$ & $\begin{array}{l}11.0 \\
11.0 \\
11.0 \\
11.0 \\
11.0\end{array}$ & $\begin{array}{l}11.0 \\
11.0 \\
11.0 \\
11.0 \\
11.0\end{array}$ & $\begin{array}{l}--- \\
--- \\
--- \\
--\end{array}$ & $\begin{array}{l}--- \\
-\cdots \\
\cdots- \\
\cdots-\end{array}$ & $\begin{array}{l}19.0 \\
18.0 \\
18.0 \\
18.0 \\
18.0\end{array}$ & $\begin{array}{l}18.0 \\
18.0 \\
18.0 \\
18.0 \\
18.0\end{array}$ & $\begin{array}{l}18.0 \\
18.0 \\
18.0 \\
18.0 \\
18.0\end{array}$ & $\begin{array}{l}18.0 \\
18.0 \\
18.0 \\
18.0 \\
18.0\end{array}$ & $\begin{array}{l}19.0 \\
18.0 \\
18.0 \\
18.0 \\
18.0\end{array}$ & $\begin{array}{l}18.0 \\
18.0 \\
18.0 \\
18.0 \\
18.0\end{array}$ \\
\hline $\begin{array}{r}6 \\
7 \\
8 \\
9 \\
10\end{array}$ & $\begin{array}{l}5.0 \\
5.0 \\
9.0 \\
9.0 \\
5.0\end{array}$ & $\begin{array}{l}9.0 \\
5.0 \\
9.0 \\
5.0 \\
5.0\end{array}$ & \begin{tabular}{r}
11.0 \\
11.0 \\
\hdashline-- \\
---
\end{tabular} & $\begin{array}{r}11.0 \\
11.0 \\
\cdots \\
\cdots-\end{array}$ & $\begin{array}{c}--- \\
\cdots- \\
\cdots- \\
\cdots-\end{array}$ & $\begin{array}{l}-\ldots \\
-\cdots \\
-\cdots\end{array}$ & $\begin{array}{l}18.0 \\
18.0 \\
18.0 \\
18.0 \\
18.0\end{array}$ & $\begin{array}{l}18.0 \\
18.0 \\
18.0 \\
18.0 \\
18.0\end{array}$ & $\begin{array}{l}18.0 \\
18.0 \\
18.0 \\
18.0 \\
18.0\end{array}$ & $\begin{array}{l}18.0 \\
18.0 \\
18.0 \\
18.0 \\
18.0\end{array}$ & $\begin{array}{l}19.0 \\
19.0 \\
19.0 \\
19.0 \\
18.0\end{array}$ & $\begin{array}{l}18.0 \\
18.0 \\
18.0 \\
18.0 \\
18.0\end{array}$ \\
\hline $\begin{array}{l}11 \\
12 \\
13 \\
14 \\
15\end{array}$ & $\begin{array}{l}\cdots- \\
-- \\
\cdots- \\
\cdots-\end{array}$ & $\begin{array}{l}=- \\
=- \\
--- \\
---\end{array}$ & $\begin{array}{l}--- \\
-- \\
\cdots- \\
---\end{array}$ & $\begin{array}{l}m- \\
\cdots \\
\cdots- \\
-- \\
--\end{array}$ & $\begin{array}{l}\ldots . \\
17.0 \\
17.0 \\
17.0\end{array}$ & $\begin{array}{r}-0 . \\
17.0 \\
17.0 \\
17.0\end{array}$ & $\begin{array}{l}18.0 \\
18.0 \\
18.0 \\
19.0 \\
19.0\end{array}$ & $\begin{array}{l}18.0 \\
18.0 \\
18.0 \\
18.0 \\
18.0\end{array}$ & $\begin{array}{l}18.0 \\
18.0 \\
18.0 \\
18.0 \\
18.0\end{array}$ & $\begin{array}{l}18.0 \\
18.0 \\
18.0 \\
18.0 \\
18.0\end{array}$ & $\begin{array}{l}19.0 \\
18.0 \\
18.0 \\
18.0 \\
18.0\end{array}$ & $\begin{array}{l}18.0 \\
18.0 \\
18.0 \\
18.0 \\
18.0\end{array}$ \\
\hline $\begin{array}{l}16 \\
17 \\
18 \\
19 \\
20\end{array}$ & $\begin{array}{l}--- \\
\cdots- \\
\cdots-\end{array}$ & \begin{tabular}{l}
-- \\
\hdashline- \\
--- \\
---
\end{tabular} & $\begin{array}{l}\cdots- \\
\cdots- \\
\cdots- \\
\cdots-\end{array}$ & $\begin{array}{l}m- \\
\cdots- \\
\cdots- \\
--\end{array}$ & $\begin{array}{l}17.0 \\
17.0 \\
18.0 \\
18.0 \\
18.0\end{array}$ & $\begin{array}{l}17.0 \\
17.0 \\
17.0 \\
18.0 \\
18.0\end{array}$ & $\begin{array}{l}19.0 \\
19.0 \\
18.0 \\
19.0 \\
19.0\end{array}$ & $\begin{array}{l}18.0 \\
19.0 \\
18.0 \\
18.0 \\
19.0\end{array}$ & $\begin{array}{l}18.0 \\
18.0 \\
18.0 \\
18.0 \\
18.0\end{array}$ & $\begin{array}{l}18.0 \\
18.0 \\
18.0 \\
18.0 \\
18.0\end{array}$ & $\begin{array}{l}18.0 \\
18.0 \\
18.0 \\
18.0 \\
18.0\end{array}$ & $\begin{array}{l}18 . c \\
18.0 \\
18.0 \\
18.0 \\
18.0\end{array}$ \\
\hline $\begin{array}{l}21 \\
22 \\
23 \\
24 \\
25\end{array}$ & 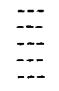 & $\begin{array}{l}--- \\
--- \\
--- \\
---\end{array}$ & $\begin{array}{l}a- \\
\cdots \\
\cdots- \\
---\end{array}$ & \begin{tabular}{l}
--- \\
\hdashline- \\
$\cdots-$ \\
$\cdots-$
\end{tabular} & $\begin{array}{l}18.0 \\
18.0 \\
18.0 \\
17.0 \\
17.0\end{array}$ & $\begin{array}{l}18.0 \\
18.0 \\
17.0 \\
17.0 \\
17.0\end{array}$ & $\begin{array}{l}19.0 \\
19.0 \\
18.0 \\
18.0 \\
18.0\end{array}$ & $\begin{array}{l}19.0 \\
18.0 \\
18.0 \\
19.0 \\
18.0\end{array}$ & $\begin{array}{l}18.0 \\
18.0 \\
18.0 \\
19.0 \\
19.0\end{array}$ & $\begin{array}{l}18.0 \\
18.0 \\
18.0 \\
18.0 \\
18.0\end{array}$ & $\begin{array}{l}18.0 \\
18.0 \\
18.0 \\
18.0 \\
18.0\end{array}$ & $\begin{array}{l}18.0 \\
18.0 \\
18.0 \\
18.0 \\
18.0\end{array}$ \\
\hline $\begin{array}{l}26 \\
27 \\
28 \\
29 \\
30 \\
31\end{array}$ & \begin{tabular}{r}
-- \\
\hdashline-- \\
\hdashline-- \\
11.0 \\
$-2-$
\end{tabular} & 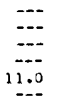 & 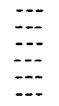 & \begin{tabular}{l}
$-\cdots$ \\
\hdashline-- \\
\hdashline-- \\
\hdashline- \\
$\cdots-$
\end{tabular} & $\begin{array}{r}17.0 \\
17.0 \\
18.0 \\
18.0 \\
18.0 \\
\ldots\end{array}$ & $\begin{array}{l}17.0 \\
17.0 \\
17.0 \\
18.0 \\
18.0 \\
\ldots\end{array}$ & $\begin{array}{l}18.0 \\
19.0 \\
18.0 \\
18.0 \\
18.0 \\
18.0\end{array}$ & $\begin{array}{l}18.0 \\
18.0 \\
18.0 \\
18.0 \\
18.0 \\
18.0\end{array}$ & $\begin{array}{l}18.0 \\
18.0 \\
18.0 \\
18.0 \\
18.0 \\
18.0\end{array}$ & $\begin{array}{l}18.0 \\
18.0 \\
18.0 \\
18.0 \\
18.0 \\
18.0\end{array}$ & $\begin{array}{r}18.0 \\
18.0 \\
18.0 \\
18.0 \\
18.0 \\
.\end{array}$ & $\begin{array}{r}17.0 \\
18.0 \\
18.0 \\
18.0 \\
18.0 \\
\ldots .-\end{array}$ \\
\hline MON YH & -- & -- & -- & -- & -- & -- & 19.0 & 18.0 & 19.0 & 18.0 & 19.0 & 17.0 \\
\hline
\end{tabular}


03319500 ROUGH RIVER AT DUNDEE, KY.

LOCATION.--Lat $37^{\circ} 33^{\prime} 46^{\prime \prime}$, long $86^{\circ} 46^{\prime} 16^{\prime \prime}$, Ohio County, at auxiliary gaging station at bridge on State Highway 69 at Dundee, 5.6 miles downstream from gaging station near Dundee, 7.1 miles downstream from Caney Creek, and at mile 56.9.

DRAINAGE AREA.--770 sq $\mathrm{mi}$, of which about $122 \mathrm{sq}$ mi does not contribute directly to surface runoff.

PER IOD OF RECORD.--Tater temperatures: October 1949 to September 1968.

EXTREMES, --1967-68:

Fater temperatures: Maximum, $28.0^{\circ} \mathrm{C}$ July 20; minimum, freezing point on several days during January to March.

Period of record:

Water temperatures: Maximum, $31.5^{\circ} \mathrm{C}$ Aug. 3,1955 ; minimum, freezing point on many days during winter periods. REMARKS.--Records of discharge are given for gaging station near Dundee. Flow regulated by Rough River Reservoir. TEMPERATURE ('O) OF WATER, WATER YEAR OCTOBER 1967 TO SEPTEMBER 1968

OCTOBER

\begin{tabular}{|c|c|c|c|}
\hline \multicolumn{2}{|c|}{ OCTOBER } & \multicolumn{2}{|c|}{ NOVEMBER } \\
\hline$\Delta M$ & PM & AM & $\mathbf{P M}$ \\
\hline 19.0 & - & -- & \\
\hline 20.0 & $=$ & $=$ & \\
\hline 20.0 & - & $\ldots$ & \\
\hline-- & --- & - & \\
\hline --- & -- & $\ldots$ & \\
\hline-- & -- & - & \\
\hline $\bar{z}$ & $\overline{-}$ & $=$ & \\
\hline-- & -- & 10.0 & \\
\hline-- & -- & 12.0 & \\
\hline-- & $\cdots$ & 12.0 & \\
\hline- & -- & 11.0 & \\
\hline$=$ & $=$ & 11.0 & 12 \\
\hline & & & \\
\hline-- & $\cdots$ & 9.0 & 11 \\
\hline-- & $\cdots$ & 11.0 & \\
\hline-- & -- & 10.0 & 11 \\
\hline-- & - & 9.0 & \\
\hline-- & -- & 9.0 & \\
\hline-- & - & 9.0 & \\
\hline-- & $\cdots$ & 11.0 & \\
\hline- & $\rightarrow$ & 9.0 & \\
\hline$\overline{-}$ & $=$ & $\begin{array}{l}9.0 \\
8.0\end{array}$ & \\
\hline-- & - & 9.0 & \\
\hline-- & -- & 8.0 & \\
\hline$\cdots$ & $\cdots$ & 7.0 & \\
\hline-- & -- & 7.0 & \\
\hline$-\infty$ & $-\infty$ & 6.0 & \\
\hline
\end{tabular}

$$
\text { DECEMBER }
$$

$$
\text { JANUARY }
$$$$
\text { AM } P
$$$$
\begin{aligned}
& 5.0 \\
& 7.0 \\
& 7.0 \\
& 6.0 \\
& 4.0 \\
& 6.0 \\
& 7.0 \\
& 6.0 \\
& 8.0 \\
& 8.0 \\
& 8.0 \\
& 8.0 \\
& 7.0 \\
& 6.0 \\
& 7.0 \\
& 7.0 \\
& 7.0 \\
& 11.0 \\
& 9.0 \\
& 4.0 \\
& 6.0 \\
& 5.0 \\
& 5.0 \\
& 4.0 \\
& 3.0 \\
& 2.0
\end{aligned}
$$

$\begin{array}{ll}6.0 & 1 . \\ 7.0 & 1.0 \\ 7.0 & 1.0 \\ 6.0 & 1.0 \\ 5.0 & 1.0 \\ 7.0 & 1.0 \\ 8.0 & 0.0 \\ 7.0 & 0.0 \\ 7.0 & 2.0 \\ 8.0 & 0.0 \\ 8.0 & 0.0 \\ 9.0 & 1.0 \\ 8.0 & 1.0 \\ 7.0 & 0.0 \\ 7.0 & 1.0 \\ 7.0 & 1.0 \\ 7.0 & 1.0 \\ 7.0 & 1.0 \\ 8.0 & 2.0 \\ 8.0 & 1 \\ 2.0 & 2.0 \\ 8.0 & 0.0 \\ 6.0 & 0.0 \\ 6.0 & 0.0 \\ 6.0 & 1.0 \\ 6.0 & 1.0 \\ 5.0 & 0.0 \\ 4.0 & 3.0 \\ 4.0 & 4.0 \\ 3.0 & 6.0 \\ 2.0 & 6.0 \\ & \end{array}$

1.0
1.0
1.0
1.0
1.0
1.0
0.0
0.0
2.0
0.0
0.0
1.0
1.0
0.0
1.0
1.0
1.0
1.0
2.0
-.0
2.0
0.0
0.0
0.0
1.0
1.0
0.0
3.0
4.0
6.0
6.0

\section{PM}

1.0
2.0
2.0
2.0

2.0
1.0

1.0
0.0

1.0
0.0
0.0
2.0

0.0

0.0
1.0
1.0
1.0

1.0

1.0

2.0

1.0

1.0

0.0
0.0

0.0
0.0
1.0
0.0

0.0
2.0

0.0
0.0
1.0

1.0
6.0

\begin{tabular}{|c|c|c|c|}
\hline \multicolumn{2}{|c|}{ FEBRUARY } & \multicolumn{2}{|c|}{ MARCH } \\
\hline AM & PM & $A M$ & $P M$ \\
\hline $\begin{array}{l}7.0 \\
6.0 \\
7.0 \\
6.0 \\
4.0\end{array}$ & $\begin{array}{l}6.0 \\
8.0 \\
8.0 \\
6.0 \\
6.0\end{array}$ & $\begin{array}{l}0.0 \\
1.0 \\
1.0 \\
1.0 \\
1.0\end{array}$ & $\begin{array}{l}1.0 \\
1.0 \\
1.0 \\
2.0 \\
1.0\end{array}$ \\
\hline $\begin{array}{l}4.0 \\
6.0 \\
6.0 \\
4.0 \\
5.0\end{array}$ & $\begin{array}{l}6.0 \\
6.0 \\
6.0 \\
6.0 \\
5.0\end{array}$ & $\begin{array}{l}1.0 \\
1.0 \\
3.0 \\
6.0 \\
7.0\end{array}$ & $\begin{array}{l}1.0 \\
4.0 \\
4.0 \\
6.0 \\
7.0\end{array}$ \\
\hline $\begin{array}{l}4.0 \\
3.0 \\
2.0 \\
1.0 \\
1.0\end{array}$ & $\begin{array}{l}4.0 \\
3.0 \\
3.0 \\
2.0 \\
1.0\end{array}$ & $\begin{array}{l}7.0 \\
6.0 \\
1.0 \\
4.0 \\
4.0\end{array}$ & $\begin{array}{l}1.0 \\
4.0 \\
3.0 \\
5.0\end{array}$ \\
\hline $\begin{array}{l}1.0 \\
1.0 \\
1.0 \\
0.0 \\
1.0\end{array}$ & $\begin{array}{l}2.0 \\
0.0 \\
2.0 \\
1.0 \\
1.0\end{array}$ & $\begin{array}{l}6.0 \\
6.0 \\
7.0 \\
7.0 \\
7.0\end{array}$ & $\begin{array}{r}7.0 \\
7.0 \\
10.0 \\
10.0 \\
10.0\end{array}$ \\
\hline $\begin{array}{l}1.0 \\
1.0 \\
0.0 \\
0.0 \\
1.0\end{array}$ & $\begin{array}{l}1.0 \\
1.0 \\
1.0 \\
1.0 \\
1.0\end{array}$ & $\begin{array}{l}9.0 \\
4.0 \\
0.0 \\
2.0 \\
1.0\end{array}$ & $\begin{array}{l}8.0 \\
9.0 \\
1.0 \\
3.0 \\
7.0\end{array}$ \\
\hline $\begin{array}{l}1.0 \\
0.0 \\
1.0 \\
0.0 \\
-.0 \\
-.\end{array}$ & $\begin{array}{l}1.0 \\
1.0 \\
1.0 \\
1.0 \\
-1 \\
--\end{array}$ & $\begin{array}{r}6.0 \\
10.0 \\
10.0 \\
12.0 \\
13.0 \\
12.0\end{array}$ & $\begin{array}{r}8.0 \\
12.0 \\
13.0 \\
14.0 \\
14.0 \\
13.0\end{array}$ \\
\hline
\end{tabular}

7.0
6.0

\begin{tabular}{|c|c|c|c|c|c|c|c|c|c|c|c|c|}
\hline \multirow[b]{2}{*}{ OAY } & \multicolumn{2}{|c|}{ APRIL } & \multicolumn{2}{|c|}{ MAY } & \multicolumn{2}{|c|}{ JUNE } & \multicolumn{2}{|c|}{ JuLr } & \multicolumn{2}{|c|}{ AUGUST } & \multicolumn{2}{|c|}{ SEPTEMBER } \\
\hline & $A M$ & PM & $A M$ & $P M$ & $A M$ & PM & $A M$ & PM & $A M$ & $P M$ & $A M$ & $P M$ \\
\hline $\begin{array}{l}1 \\
2 \\
3 \\
4 \\
5\end{array}$ & $\begin{array}{r}10.0 \\
9.0 \\
10.0 \\
11.0 \\
11.0\end{array}$ & $\begin{array}{r}9.0 \\
10.0 \\
11.0 \\
12.0 \\
10.0\end{array}$ & $\begin{array}{l}14.0 \\
16.0 \\
17.0 \\
16.0 \\
15.0\end{array}$ & $\begin{array}{l}17.0 \\
17.0 \\
17.0 \\
16.0\end{array}$ & $\begin{array}{l}16.0 \\
17.0 \\
17.0 \\
18.0 \\
18.0\end{array}$ & $\begin{array}{l}17.0 \\
18.0 \\
18.0 \\
21.0 \\
19.0\end{array}$ & $\begin{array}{l}22.0 \\
23.0 \\
21.0 \\
19.0 \\
20.0\end{array}$ & $\begin{array}{l}23.0 \\
24.0 \\
24.0 \\
22.0 \\
24.0\end{array}$ & $\begin{array}{l}-- \\
20.0 \\
20.0 \\
21.0 \\
21.0\end{array}$ & $\begin{array}{l}21.0 \\
23.0 \\
21.0 \\
22.0 \\
21.0\end{array}$ & $\begin{array}{l}20.0 \\
20.0 \\
20.0 \\
19.0 \\
20.0\end{array}$ & $\begin{array}{l}22.0 \\
22.0 \\
23.0 \\
22.0 \\
21.0\end{array}$ \\
\hline $\begin{array}{r}6 \\
7 \\
8 \\
9 \\
10\end{array}$ & $\begin{array}{r}9.0 \\
9.0 \\
12.0 \\
11.0 \\
11.0\end{array}$ & $\begin{array}{l}10.0 \\
10.0 \\
12.0 \\
12.0 \\
12.0\end{array}$ & $\begin{array}{l}16.0 \\
16.0 \\
14.0 \\
14.0 \\
16.0\end{array}$ & $\begin{array}{l}16.0 \\
16.0 \\
16.0 \\
17.0 \\
16.0\end{array}$ & $\begin{array}{l}17.0 \\
16.0 \\
16.0 \\
16.0 \\
16.0\end{array}$ & $\begin{array}{l}17.0 \\
17.0 \\
17.0 \\
18.0 \\
18.0\end{array}$ & $\begin{array}{l}21.0 \\
22.0 \\
24.0 \\
21.0 \\
21.0\end{array}$ & $\begin{array}{l}26.0 \\
25.0 \\
21.0 \\
24.0 \\
24.0\end{array}$ & $\begin{array}{l}22.0 \\
22.0 \\
23.0 \\
23.0 \\
23.0\end{array}$ & $\begin{array}{l}25.0 \\
24.0 \\
24.0 \\
22.0 \\
24.0\end{array}$ & $\begin{array}{l}21.0 \\
18.0 \\
18.0 \\
21.0 \\
18.0\end{array}$ & $\begin{array}{l}22.0 \\
23.0 \\
21.0 \\
21.0 \\
20.0\end{array}$ \\
\hline $\begin{array}{l}11 \\
12 \\
13 \\
14 \\
15\end{array}$ & $\begin{array}{l}11.0 \\
12.0 \\
12.0 \\
12.0 \\
10.0\end{array}$ & $\begin{array}{l}13.0 \\
14.0 \\
12.0 \\
12.0 \\
12.0\end{array}$ & $\begin{array}{l}14.0 \\
16.0 \\
14.0 \\
14.0 \\
16.0\end{array}$ & $\begin{array}{l}16.0 \\
16.0 \\
16.0 \\
16.0 \\
18.0\end{array}$ & $\begin{array}{l}16.0 \\
16.0 \\
16.0 \\
15.0 \\
16.0\end{array}$ & $\begin{array}{l}17.0 \\
17.0 \\
17.0 \\
17.0\end{array}$ & $\begin{array}{l}22.0 \\
23.0 \\
22.0 \\
24.0 \\
24.0\end{array}$ & $\begin{array}{l}24.0 \\
25.0 \\
27.0 \\
26.0 \\
27.0\end{array}$ & $\begin{array}{l}23.0 \\
22.0 \\
22.0 \\
21.0 \\
21.0\end{array}$ & $\begin{array}{l}25.0 \\
26.0 \\
26.0 \\
23.0 \\
24.0\end{array}$ & $\begin{array}{l}17.0 \\
17.0 \\
18.0 \\
18.0 \\
18.0\end{array}$ & $\begin{array}{l}19.0 \\
19.0 \\
20.0 \\
21.0 \\
20.0\end{array}$ \\
\hline $\begin{array}{l}16 \\
17 \\
18 \\
19 \\
20\end{array}$ & $\begin{array}{l}10.0 \\
11.0 \\
13.0 \\
13.0 \\
12.0\end{array}$ & $\begin{array}{l}12.0 \\
12.0 \\
13.0 \\
13.0 \\
13.0\end{array}$ & $\begin{array}{l}17.0 \\
17.0 \\
16.0 \\
14.0 \\
13.0\end{array}$ & $\begin{array}{l}18.0 \\
18.0 \\
17.0 \\
14.0 \\
14.0\end{array}$ & $\begin{array}{l}17.0 \\
16.0 \\
16.0 \\
16.0 \\
16.0\end{array}$ & $\begin{array}{l}18.0 \\
17.0 \\
18.0 \\
18.0 \\
17.0\end{array}$ & $\begin{array}{l}23.0 \\
23.0 \\
24.0 \\
24.0 \\
24.0\end{array}$ & $\begin{array}{l}26.0 \\
26.0 \\
27.0 \\
27.0 \\
28.0\end{array}$ & $\begin{array}{l}26.0 \\
20.0 \\
20.0 \\
20.0 \\
19.0\end{array}$ & $\begin{array}{r}23.0 \\
23.0 \\
22.0 \\
22.0 \\
-0 .\end{array}$ & $\begin{array}{l}18.0 \\
17.0 \\
17.0 \\
17.0 \\
17.0\end{array}$ & $\begin{array}{l}18.0 \\
18.0 \\
19.0 \\
18.0 \\
\end{array}$ \\
\hline $\begin{array}{l}21 \\
22 \\
23 \\
24 \\
25\end{array}$ & $\begin{array}{l}13.0 \\
13.0 \\
12.0 \\
12.0 \\
13.0\end{array}$ & $\begin{array}{l}14.0 \\
13.0 \\
12.0 \\
13.0 \\
13.0\end{array}$ & $\begin{array}{l}14.0 \\
14.0 \\
13.0 \\
14.0 \\
16.0\end{array}$ & $\begin{array}{l}14.0 \\
14.0 \\
15.0 \\
14.0 \\
17.0\end{array}$ & $\begin{array}{l}16.0 \\
17.0 \\
19.0 \\
18.0 \\
19.0\end{array}$ & $\begin{array}{l}19.0 \\
18.0 \\
18.0 \\
20.0 \\
21.0\end{array}$ & $\begin{array}{l}26.0 \\
24.0 \\
24.0 \\
25.0 \\
26.0\end{array}$ & $\begin{array}{l}26.0 \\
27.0 \\
27.0 \\
27.0 \\
26.0\end{array}$ & $\begin{array}{l}21.0 \\
22.0 \\
22.0 \\
24.0 \\
22.0\end{array}$ & $\begin{array}{l}23.0 \\
25.0 \\
26.0 \\
27.0 \\
26.0\end{array}$ & $\begin{array}{r}18.0 \\
20.0 \\
18.0 \\
19.0 \\
-\end{array}$ & $\begin{array}{l}21.0 \\
20.0 \\
20.0 \\
20.0 \\
-\end{array}$ \\
\hline $\begin{array}{l}26 \\
27 \\
28 \\
29 \\
30 \\
31\end{array}$ & $\begin{array}{r}13.0 \\
13.0 \\
13.0 \\
13.0 \\
13.0 \\
-\end{array}$ & $\begin{array}{r}14.0 \\
13.0 \\
14.0 \\
14.0 \\
14.0 \\
\end{array}$ & $\begin{array}{l}16.0 \\
17.0 \\
16.0 \\
16.0 \\
16.0 \\
15.0\end{array}$ & $\begin{array}{l}16.0 \\
17.0 \\
17.0 \\
17.0 \\
16.0 \\
16.0\end{array}$ & $\begin{array}{r}21.0 \\
18.0 \\
18.0 \\
20.0 \\
21.0 \\
-\end{array}$ & $\begin{array}{l}21.0 \\
19.0 \\
22.0 \\
22.0 \\
22.0 \\
-0.0\end{array}$ & $\begin{array}{l}23.0 \\
23.0 \\
23.0 \\
22.0 \\
21.0 \\
20.0\end{array}$ & $\begin{array}{r}24.0 \\
24.0 \\
-1.0 \\
24.0 \\
21.0\end{array}$ & $\begin{array}{l}22.0 \\
21.0 \\
21.0 \\
20.0 \\
21.0 \\
19.0\end{array}$ & $\begin{array}{l}22.0 \\
23.0 \\
22.0 \\
21.0 \\
21.0 \\
21.0\end{array}$ & $\begin{array}{l}-- \\
\square \\
-\infty \\
-\infty\end{array}$ & $=$ \\
\hline
\end{tabular}


LOCATION,--Lat $37^{\circ} 32^{\prime} 05^{\prime \prime}$, 1ong $87^{\circ} 15^{\prime} 40^{\prime \prime}$, HcLean County, temperature recorder at bridge on State Highway 81 at Calhoun, 0.2 mile upstream from gaging station, 0.3 mile upstream from $10 \mathrm{ck}$ and dam 2 and at mile 64.4 . DRAINAGE AREA. - 7,564 $\mathrm{sq} \mathrm{mi}$, of which about $1,540 \mathrm{sq} \mathrm{mi}$ does not contribute directly to surface runoff.

PERIOD OF RECORD. -Chemical analyses: October 1949 to September 1951

Water temperatures: October 1949 to September 1951, October 1951 to June 1953, unpublished; July 1953 to EXTREMES. - 1967-68:

Water temperatures: Maximum, not determined; manimum, $3.0^{\circ} \mathrm{C}$ on several days during January.

Period of record:

Water temperatures: Maximum, $31.0^{\circ} \mathrm{C}$ July 6, 11-13, Aug. 4-6, 15, 22, 23, 1954; minimum, 1.5 ${ }^{\circ} \mathrm{C}$ Jan. 19-21,

REMARKS.--Sampling site formerly located 7.8 miles upstream. Recorder stopped Mar. 8 to Apr. 1; range in temperature $9.0^{\circ} \mathrm{C}$ to $13^{\circ} \mathrm{C}$. Flow regulated by Barren, Nolin, and Rough River Reservoirs.

TEMPERATURE $1{ }^{\circ} \mathrm{C}$ ) OF WATER, WATER YEAR OCTOBER 1967 TO SEPTEMBER 1968 (CONTINUOUS ETHYL ALCOHOL-ACTUATED THERMOGRAPH)

DAY

MONTH

MAXIMUM

MINIMUM

NOVEMBER.

MAXIMUM

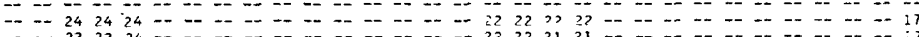

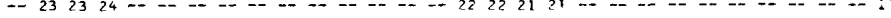

$\begin{array}{llllllllllllllllllllllllllllllllllll}\text { MINIMUM } & 17 & 17 & 17 & 16 & 15 & 14 & 14 & 14 & 13 & 13 & 13 & 13 & 13 & 13 & 13 & 13 & 13 & 13 & 12 & 12 & 13 & 12 & 12 & 12 & 12 & 12 & 12 & 11 & 11 & 0 & \cdots\end{array}$

MAXIMUM

MINIMUM

JANUARY.:

MAXIMUM

MINIMUM

FE BRUARY.
MAXIMUM

MAXIMUM

MARCH.....

MAXIMIJM

MINIMUM

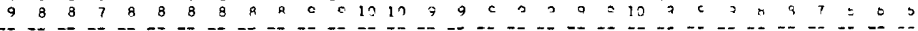

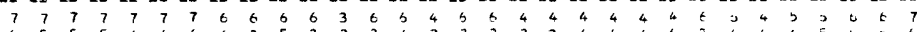

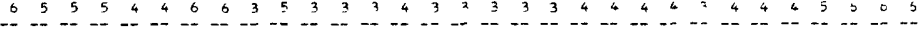

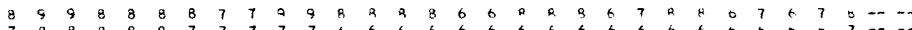

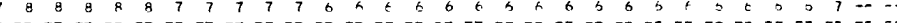
8

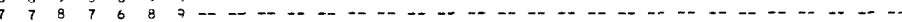
чахімй -MI VI MUM MAY...... махімӥ -. MINIMUM JUNE. OMUP MINIMUM - MAXIMUM

MINIMUM

AUGUSI...

MAXI MUN

MINIMUM

SEPTEMBEF

MAXIMUM

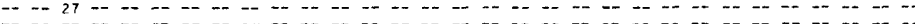

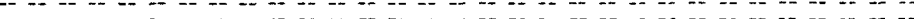

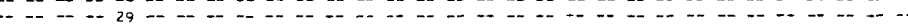

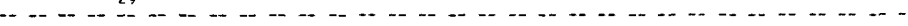

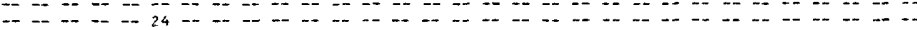


LOCATION.--Lat $40^{\circ} 51^{\prime} 20^{\prime \prime}$, long $85^{\circ} 29^{\prime} 53^{\prime \prime}$, Huntington County, temperature recorder at gaging station on right bank at the Huntington water and Light Co. Plant, 2 miles south of courthouse in Huntington, 3.2 miles upstream
from mouth of Little River, and at mile 409 .

DRA INAGE AREA, - $-710 \mathrm{sq} \mathrm{m} 1$.

PERIOD OF RECORD. --Water temperatures: October 1963 to September 1968.

EXTR EUES. - -1967-68:

Water temperatures: Maximum not recorded; minimum, 1.0 $0^{\circ} \mathrm{C}$ Dec. 25-27, Jan, 23-30.

Period of record:

Water temperatures: Maximum, $32.0^{\circ} \mathrm{C}$ July 27, 1964; min1mum, freezing point on several days during winter periods.

TEMPERATURE ( $\left.{ }^{\circ} \mathrm{C}\right)$ OF WATER, WATER YEAR OCTOBER 1967 TO SEPTEMBER 1968 (CONTINUOUS ETHYL ALCOHOL-ACTUATED THERMOGRAPH)

DAY

$\begin{array}{llllllllllllllllllllllllllllllllllllllllllll}\text { MONIH } & 1 & 2 & 3 & 4 & 5 & 6 & 7 & 8 & 9 & 10 & 11 & 12 & 13 & 14 & 15 & 16 & 17 & 19 & 19 & 20 & 21 & 22 & 23 & 24 & 25 & 26 & 27 & 28 & 29 & 30 & 31 & \text { AGER }\end{array}$

OCTOBER

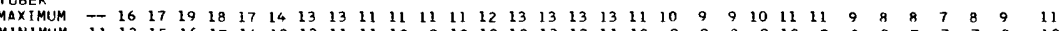

$\begin{array}{llllllllllllllllllllllllllllllllllllll}\text { MINIMUM } & 11 & 13 & 15 & 16 & 17 & 14 & 12 & 13 & 11 & 11 & 10 & 9 & 10 & 10 & 12 & 13 & 13 & 11 & 10 & 9 & 9 & 9 & 9 & 10 & 9 & 8 & 8 & 7 & 7 & 7 & 8 & 10\end{array}$

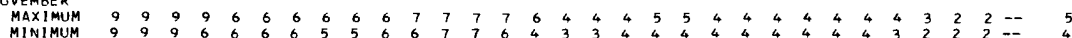

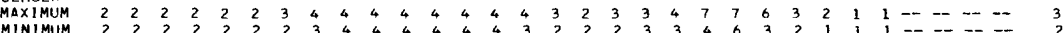

MINIMUM

MAXIMUM -

MAXIMUM
MINIMUM
FEBRUARY

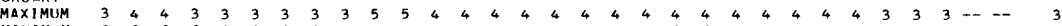

ARCH

$\begin{array}{lllllllllllllllllllllllllllllllllllll}\text { MAXINUM } & 3 & 3 & 4 & 3 & 3 & 3 & 3 & 4 & 6 & 6 & 7 & 6 & 4 & 4 & 5 & 7 & 7 & 6 & 7 & 8 & 8 & 7 & 4 & 5 & 6 & 7 & 9 & 11 & 13 & 13 & 12 & 6\end{array}$

RIL

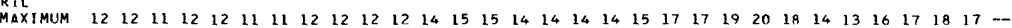
MINIMUM MAY MAXIMUM $19 \quad 191918 \quad 18 \quad 18 \quad 191921 \quad 19 \quad 18 \quad 17 \quad 921 \quad 22 \quad 21 \quad 16 \quad 16 \quad 16 \quad 14 \quad 15 \quad 16 \quad 16 \quad 16 \quad 16 \quad 16 \quad 16 \quad 16 \quad 16 \quad 16 \quad 17$

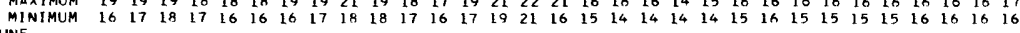
JUNE

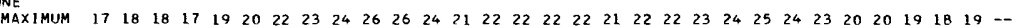

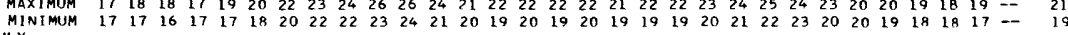
JULY

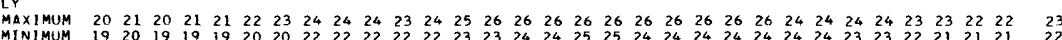
MINIMUH

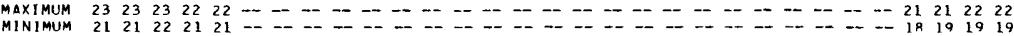

MAXIMUM $222 \begin{array}{lllllllllllllllllllllllllllllll} & 22 & 23 & 23 & 22 & 21 & 21 & 23 & 22 & 22 & 19 & 19 & 20 & 21 & 22 & 22 & 22 & 20 & 18 & 21 & 27 & 22 & 23 & 23 & 22 & 19 & 18 & 18 & 19 & 18 & -1\end{array}$

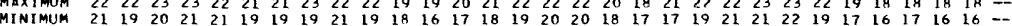


LOCATION.--Lat $40^{\circ} 25^{\prime} 19^{\prime \prime}$, long $86^{\circ} 53^{\prime} 49^{\prime \prime}$, Tippecanoe County, temperature recorder at gaging station on $r i g h t$ bank $20 \mathrm{ft}$ downstream from Brown Street Bridge in Lafayette, 5.1 miles downstream from wildcat Creek and at mile 311.9 .

DRA INAGE AREA. $--7,247 \mathrm{sq} \mathrm{mi}$.

PERIOD OF RECORD, --Water temperatures: July 1954 to September 1964, August 1967 to September 1968.

EXTREMES. - -1967-68:

Water temperatures: Maximum, $25.0^{\circ} \mathrm{C}$ (recorded) July 16-31; minimum, freezing point Jan. 2-20.

Period of record:

Water temperatures: Maximum, $32.0^{\circ} \mathrm{C}$ July $30,31,1954$; minimum, freezing point on many days during winter periods.

REMARKS. --Some regulation at low stages caused by powerplants above station.

TEMPERATURE ('0) DF WATER, WATER YEAR OCTOBER 1967 TO SEPTEMBER 1968 (CONTINUOUS ETHYL ALCOHOL-ACTUATED THERMOGRAPH)

DAY

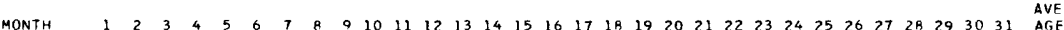

OCTOBER

MAXIMUM $17 \begin{array}{llllllllllllllllllllllllllllllll} & 19 & 20 & 21 & 21 & 20 & 19 & 1 B & 17 & 16 & 14 & 14 & 14 & 15 & 16 & 16 & 16 & 16 & 14 & 14 & 14 & 13 & 14 & 14 & 14 & 13 & 12 & 12 & 11 & 12 & 12\end{array}$

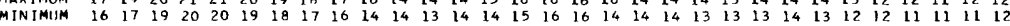
NOVEMBER

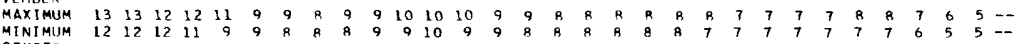

DECEMBER

$\begin{array}{lllllllllllllllllllllllllllllllll}\text { MAXIMUM } & 5 & 5 & 5 & 4 & 4 & 5 & 5 & 5 & 5 & 5 & 5 & 5 & 6 & 6 & 6 & 4 & 4 & 4 & 4 & 4 & 6 & 6 & 6 & 4 & 3 & 3 & 2 & 1 & 1 & 1 & 1 \\ \text { MINIMUM } & 5 & 5 & 4 & 4 & 4 & 4 & 5 & 5 & 5 & 5 & 5 & 5 & 5 & 6 & 4 & 4 & 4 & 4 & 4 & 4 & 4 & 6 & 4 & 3 & 3 & 2 & 1 & 1 & 1 & 1 & 1\end{array}$

JANUARY

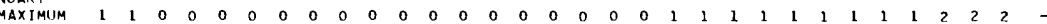

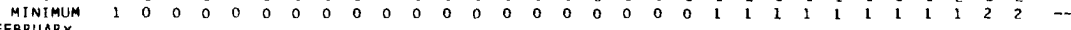

FEBRUARY

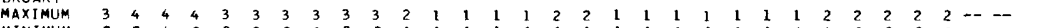

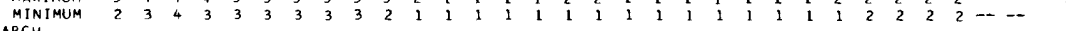

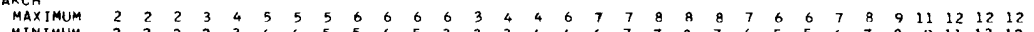

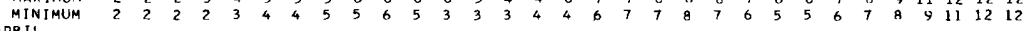

PRIL

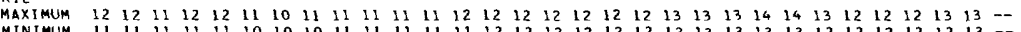

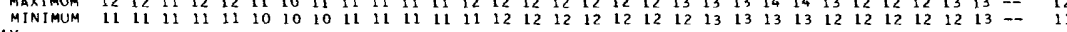

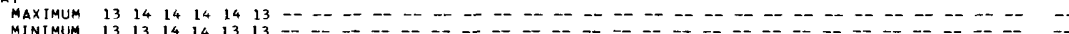

MAXIMUM

JULY

MAXIMUM -- - - - - - - - - - - - - - - - - MINIMUM -- - - - - - - - - - - - - - - - - AUGUST

MAXIMUM $24 \begin{array}{llllllllllllllllllllllllllllllllllll}24 & 23 & 23 & 23 & 23 & 24 & 24 & 24 & 24 & 24 & 24 & 23 & 23 & 23 & 23 & 23 & 23 & 23 & 23 & 23 & 23 & 23 & 24 & 24 & 24 & 24 & 23 & 22 & 22 & 21\end{array}$ MINIMUM $24 \begin{array}{lllllllllllllllllllllllllllllllllll}23 & 23 & 23 & 23 & 23 & 23 & 24 & 24 & 24 & 24 & 23 & 23 & 23 & 23 & 23 & 23 & 23 & 23 & 23 & 23 & 23 & 23 & 23 & 24 & 24 & 23 & 22 & 22 & 21 & 21\end{array}$

SFPTEMBER

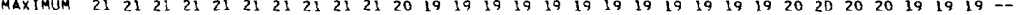

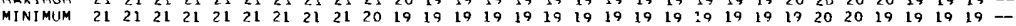
6

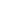
.

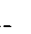


03340800 BIG RACCOON CREEK NEAR FINCASTLE, IND,

LOCATION, - Lat $39^{\circ} 48^{\prime} 45^{\prime \prime}$, long $86^{\circ} 57^{\prime} 14^{\prime \prime}$, in SW sec, 22, T. $16 \mathrm{~N}$, , R, 5 W., Putnam County, at gaging station at county road bridge, 8,350 feet upstream from Ramp Creek and 3.1 miles northwest of fincastie.

DRAINAGE AREA. - -132 sq m1.

PERIOD OF RECORD... Water temperatures: July 1965 to September 1968

Sediment records: August 1959 to September 1968

EXTREMES, - $1967-68$ :

Water temperatures: Maximum, $30.0^{\circ} \mathrm{C}$ Aug. $10,13,15 ;$ min1mum, freezing point Jan. $11-20$.

Sediment loads: Maximum da11y, 295,000 tons Dec. 22; minimum da11y, 0.05 ton Oct. 3.

period of record:

Water temperatures: Max 1 mum, $31.0^{\circ} \mathrm{C}$ July 16,$1966 ;$ minlmum, freezing point on many days during winter periods. Sediment concentrations: Kaximum da1ly, 19,100 mg/1 Mar. 21, 1962; minimum da1ly, 2 mg/1 on several days during

1965,1967 and 1968 .
Sediment loads: Maximum dat1y, 295,000 tons Dec. 22, 1967; min1mum dat1y, 0.03 ton Sept. $15,1964$.

REMARKS. - Flow affected by 1ce Jan. 2-19, Feb, 11-23, Da1ly loads were computed by subdivision on oct. 16, 17, Dec. 1, 3, 10-12, 21-23, Jan. 21, 22, 29, 31, Feb. 1, 3, Apr. 3-5, 20, hay 9, 15-17, 23, June 22, 24-26, Aug. $4,10,11,17-19$.

TEMPERATURE $\left({ }^{\circ} \mathrm{C}\right)$ OF WATER, WATER YEAR OCTOBER 1967 TO SEPTEMBER 1968 (ONCE-DAILY MEASUREMENT BETWEEN I600 AND 19001

\begin{tabular}{|c|c|c|c|c|c|c|c|c|c|c|c|c|}
\hline DAY & DCT & NOV & $\mathrm{DEC}$ & JAN & $F \in B$ & NAR & $\triangle P R$ & MAY & JUN & JUL & $A \cup G$ & StP \\
\hline 1 & -- & -- & 4.0 & 1.0 & 4.0 & 3.0 & -- & $\cdots$ & $-\cdots$ & -- & -- & - \\
\hline 2 & 18.0 & $\cdots$ & $\cdots-$ & 1. 0 & -- & 4.0 & 6.0 & -- & -- & $\cdots$ & - & 20.0 \\
\hline 3 & 18.0 & -- & 6.0 & 1.0 & -- & 3.0 & -5 & -- & -- & $=0$ & $\cdots$ & $\overline{0}$ \\
\hline 4 & 21.0 & 12.0 & $\cdots$ & 1.0 & -- & 4.0 & 13.0 & $\cdots$ & - & 22.0 & $\rightarrow$ & 20.0 \\
\hline 5 & 21.0 & 12.0 & 4.0 & 1.0 & 4.0 & 4.0 & --- & --- & 17.0 & - & 29.0 & -- \\
\hline 6 & 21.0 & 13.0 & 3.0 & 1.0 & 3.0 & 4.0 & -- & --- & 16.0 & -- & --- & -- \\
\hline 7 & 21.0 & 12.0 & 3.0 & 1.0 & 3.0 & 4.0 & --. & -- & 18.0 & - & $\cdots$ & 21.0 \\
\hline B & - & 12.0 & 4.0 & 1.0 & 3.0 & 4.0 & -.. & $-\infty$ & - & 26.0 & 29.0 & --- \\
\hline 9 & 20.0 & $=-$ & 4.0 & 1.0 & 4. $\mathrm{C}$ & -- & --- & -- & -- & -- & $=$ & 23.0 \\
\hline 10 & 21.0 & --- & $\cdots$ & 1.0 & 3.0 & --- & -- & $\cdots$ & 21.0 & $\cdots$ & 30.0 & $\cdots$ \\
\hline 11 & 21.0 & 12.0 & $\cdots$ & 0.0 & 4.0 & -- & -- & -- & 21.0 & -- & $\cdots$ & $=-$ \\
\hline 12 & 20.0 & $\cdots$ & - & 0.0 & 4.0 & -.- & $\cdots$ & $\cdots$ & 22.0 & $\cdots$ & $\cdots$ & $\cdots$ \\
\hline 13 & I8.0 & 11.0 & 7.0 & 0.0 & 5.0 & -- & -- & +- & $\cdots$ & $\cdots$ & 30.0 & $\cdots$ \\
\hline 14 & -- & - & 4.0 & 0.0 & 4.0 & $\cdots$ & $\cdots$ & $\cdots$ & 19.0 & $\cdots$ & $\overline{0}$ & $\cdots$ \\
\hline 15 & $\cdots$ & 11.0 & 3.0 & 0.0 & 4.0 & $\cdots$ & -- & $\cdots$ & 21.0 & $\cdots$ & 30.0 & $\cdots$ \\
\hline 16 & 16.0 & 9.0 & 3.0 & 0.0 & 3.0 & -- & $\cdots$ & 14.0 & -- & $\ldots$ & $-\infty$ & -.. \\
\hline 17 & -- & 9.0 & 3.0 & 0.0 & 4.0 & -- & -- & 11.0 & 23.0 & -- & 27.0 & $\cdots$ \\
\hline 18 & 15.0 & 9.0 & 4.0 & 0.0 & 4.0 &.- &.- & -- & 24.0 & --- & $\cdots$ & $\overline{7}$ \\
\hline 19 & 14.0 & --- & 4.0 & 0.0 & 4.0 & -- & -. & -- & 26.0 & $\cdots$ & $\cdots$ & 17.0 \\
\hline 20 & 16.0 & 6.0 & -- & 0.0 & 3.0 & $\cdots$ & $\cdots$ & -- & -- & -- & $\cdots$ & $\cdots$ \\
\hline 21 & 14.0 & 7.0 & $\cdots$ & 3.0 & 3.0 & -- & - & -- & --- & -- & $\cdots$ & --- \\
\hline 22 & 15.0 & 7.0 & $--\overline{0}$ & -- & 3.0 & $\cdots$ & -- & --- & 22.0 & $\cdots$ & -- & --- \\
\hline 23 & 16.0 & -- & 3.0 & 3.0 & 3.0 & $\cdots$ & $\cdots$ & $\cdots$ & - & $\cdots$ & -- & \\
\hline 24 & 14.0 & 6.0 & 4.0 & 3.0 & 3.0 & -- & -- & 14.0 & 24.0 & -- & -- & $20 . c$ \\
\hline 25 & 13.0 & 0.0 & $\cdots$ & 3.0 & -- & $\cdots$ & $\cdots$ & -- & $\cdots$ & $\cdots$ & $\cdots$ & \\
\hline 26 & 13.0 & $=-$ & $\ldots$ & 2.0 & -- & $\cdots$ & -- & -- & -- & $\cdots$ & 25.0 & 21.0 \\
\hline 27 & 12.0 & 5.0 & -- & $\cdots$ & -- & --- & -- & 11.0 & -- & $\cdots$ & 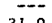 & $\cdots$ \\
\hline 28 & 13.0 & 4.0 & 1.0 & $=--$ & -- & $\cdots$ & $\cdots$ & 16.0 & -- & --- & 21.0 & --- \\
\hline 29 & 13.0 & 4.0 & -.. & 4.0 & $\cdots$ & --- & -.- & $\cdots$ & -- & $\cdots$ & -- & \\
\hline 30 & 13.0 & 5.0 & -- & 5.0 & $\ldots$ & $\cdots$ & $\cdots$ & 16.0 & $\cdots$ & $\cdots$ & $\cdots$ & $\cdots$ \\
\hline 31 & 13.0 & -- & -- & 6.0 & $-\cdots$ & $\cdots$ & $\cdots$ & 16.0 & -- & $\cdots$ & $\cdots$ & . \\
\hline IERAGE & 16.5 & -- & -- & 1.5 & -- & -- & $=-$ & -- & --- & -- & --- & - \\
\hline
\end{tabular}

PERIODIC DETERMINATIONS OF SUSPENDED SEDIMENT AND PARTICLE SIZE, WATER YEAR OCTOBER 1967 TO SEPTEMBER 1968

INSTANTANEOUS SUSPENDEO SEOIMENT ANO PARTICLE SILE, WATER YEAR OC TOBER 1967 TO SEPTEMBER I968
IMETHOOS OF ANALYSIS: 8, BOTTOM WITHDRAWAL TUBE; C, CHEMICALLY OISPERSED: N, IN NATIVE WATER; P, PIPET: S, SIEVE;

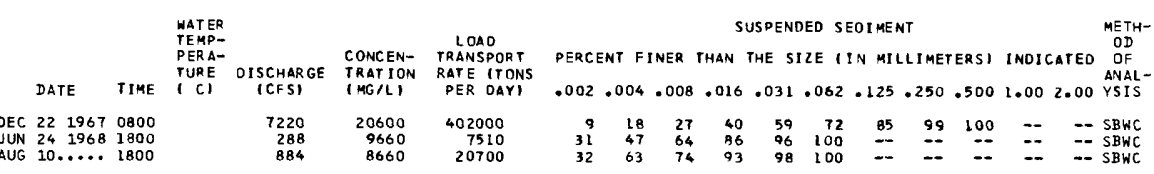


03340800 BIG RACCOON CREEK NEAR FINCASTLE, IND, --Continued SUSPENDED SEDIMENT, WATER YEAR OCTOBER 1967 TO SEPTEMBER 1968

\begin{tabular}{|c|c|c|c|c|c|c|c|c|c|}
\hline \multirow[b]{2}{*}{ DAY } & \multirow{2}{*}{\multicolumn{2}{|c|}{$\begin{array}{l}\text { OCTOBER } \\
\text { MEAN } \\
\text { CONCEN- } \\
\text { TRATION } \\
\text { (MG/L) }\end{array}$}} & \multicolumn{4}{|c|}{ NOVEMBER } & \multicolumn{3}{|c|}{ OECEMBER } \\
\hline & & & $\begin{array}{l}\text { LOAO } \\
\text { (TONS) }\end{array}$ & $\begin{array}{l}\text { MEAN } \\
\text { DI SCHARGE } \\
\text { (CFS) }\end{array}$ & $\begin{array}{l}\text { MEAN } \\
\text { CONCEN- } \\
\text { TRATION } \\
\text { (MG/L) }\end{array}$ & $\begin{array}{l}\text { LOAD } \\
\text { (TONS) }\end{array}$ & $\begin{array}{c}\text { MEAN } \\
\text { DISCHARGE } \\
\text { (CFS) }\end{array}$ & $\begin{array}{l}\text { MEAN } \\
\text { CONCEN- } \\
\text { TRAT ION } \\
\text { (MG /L) }\end{array}$ & $\begin{array}{l}\text { LOAC } \\
\text { (TONS) }\end{array}$ \\
\hline $\begin{array}{l}1 \\
2 \\
3 \\
4 \\
5\end{array}$ & $\begin{array}{l}3.4 \\
3.4 \\
3.3 \\
3.4 \\
3.7\end{array}$ & $\begin{array}{r}8 \\
7 \\
6 \\
13 \\
5\end{array}$ & $\begin{array}{l}.01 \\
.06 \\
.05 \\
.12 \\
.09\end{array}$ & $\begin{array}{l}12 \\
14 \\
20 \\
61 \\
10\end{array}$ & $\begin{array}{r}7 \\
8 \\
9 \\
10 \\
112\end{array}$ & $\begin{array}{r}.23 \\
.30 \\
. .49 \\
21.6\end{array}$ & $\begin{array}{r}17 \\
338 \\
1970 \\
799 \\
513\end{array}$ & $\begin{array}{r}20 \\
3190 \\
7730 \\
1530 \\
830\end{array}$ & $\begin{array}{l}1.2 \\
7510 \\
39000 \\
3530 \\
1150\end{array}$ \\
\hline $\begin{array}{r}0 \\
7 \\
8 \\
0 \\
10\end{array}$ & $\begin{array}{l}5.1 \\
8.0 \\
8.3 \\
7.8 \\
6.6\end{array}$ & $\begin{array}{r}8 \\
12 \\
36 \\
41 \\
34\end{array}$ & $\begin{array}{l}.11 \\
.26 \\
.81 \\
.86 \\
.61\end{array}$ & $\begin{array}{l}50 \\
37 \\
29 \\
24 \\
21\end{array}$ & $\begin{array}{r}98 \\
59 \\
58 \\
56 \\
6\end{array}$ & $\begin{array}{c}13 \\
5.9 \\
4.5 \\
3.6 \\
.34\end{array}$ & $\begin{array}{l}410 \\
355 \\
268 \\
210 \\
298\end{array}$ & $\begin{array}{l}690 \\
429 \\
266 \\
198 \\
179\end{array}$ & $\begin{array}{l}764 \\
411 \\
192 \\
112 \\
170\end{array}$ \\
\hline $\begin{array}{l}11 \\
12 \\
13 \\
14 \\
15\end{array}$ & $\begin{array}{l}5.9 \\
5.5 \\
5.8 \\
6.5 \\
7.0\end{array}$ & $\begin{array}{r}33 \\
32 \\
30 \\
128 \\
152\end{array}$ & $\begin{array}{l}.53 \\
.48 \\
.47 \\
2.2 \\
2.9\end{array}$ & $\begin{array}{l}20 \\
20 \\
19 \\
17 \\
16\end{array}$ & $\begin{array}{r}4 \\
7 \\
10 \\
8 \\
18\end{array}$ & $\begin{array}{r}.22 \\
.38 \\
.51 \\
.37 \\
.78\end{array}$ & $\begin{array}{r}640 \\
1710 \\
637 \\
493 \\
440\end{array}$ & $\begin{array}{r}492 \\
2930 \\
278 \\
235 \\
185\end{array}$ & $\begin{array}{r}450 \\
25100 \\
478 \\
313 \\
220\end{array}$ \\
\hline $\begin{array}{l}16 \\
17 \\
18 \\
19 \\
20\end{array}$ & $\begin{array}{l}1 c \\
42 \\
74 \\
42 \\
22\end{array}$ & $\begin{array}{l}312 \\
466 \\
478 \\
458 \\
160\end{array}$ & $\begin{array}{l}9.2 \\
49 \\
96 \\
52 \\
9.5\end{array}$ & $\begin{array}{l}15 \\
15 \\
16 \\
15 \\
15\end{array}$ & $\begin{array}{r}23 \\
11 \\
7 \\
7 \\
12\end{array}$ & $\begin{array}{l}.93 \\
.45 \\
.39 \\
.28 \\
.49\end{array}$ & $\begin{array}{l}295 \\
240 \\
475 \\
413 \\
283\end{array}$ & $\begin{array}{l}153 \\
182 \\
243 \\
283 \\
208\end{array}$ & $\begin{array}{l}122 \\
118 \\
312 \\
310 \\
159\end{array}$ \\
\hline $\begin{array}{l}21 \\
22 \\
23 \\
24 \\
25\end{array}$ & $\begin{array}{l}14 \\
11 \\
9.2 \\
8.8 \\
11\end{array}$ & $\begin{array}{r}82 \\
65 \\
21 \\
8 \\
16\end{array}$ & $\begin{array}{l}3.1 \\
1.9 \\
.52 \\
.19 \\
.48\end{array}$ & $\begin{array}{l}15 \\
16 \\
18 \\
19 \\
20\end{array}$ & $\begin{array}{r}14 \\
6 \\
5 \\
21 \\
26\end{array}$ & $\begin{array}{l}.57 \\
.26 \\
.24 \\
1.1 \\
1.4\end{array}$ & $\begin{array}{r}3000 \\
5690 \\
808 \\
443 \\
338\end{array}$ & $\begin{array}{r}13000 \\
15000 \\
1220 \\
760 \\
314\end{array}$ & $\begin{array}{r}204460 \\
295000 \\
3470 \\
837 \\
287\end{array}$ \\
\hline $\begin{array}{l}26 \\
27 \\
28 \\
29 \\
30 \\
31\end{array}$ & $\begin{array}{l}12 \\
15 \\
15 \\
13 \\
11 \\
11\end{array}$ & $\begin{array}{r}12 \\
7 \\
13 \\
13 \\
7 \\
6\end{array}$ & $\begin{array}{l}.39 \\
.28 \\
.53 \\
.46 \\
.21 \\
.18\end{array}$ & $\begin{array}{l}19 \\
17 \\
15 \\
14 \\
15 \\
-\end{array}$ & $\begin{array}{l}13 \\
26 \\
37 \\
37 \\
37 \\
--\end{array}$ & $\begin{array}{l}.67 \\
1.2 \\
1.5 \\
1.4 \\
1.5 \\
-.\end{array}$ & $\begin{array}{l}252 \\
182 \\
150 \\
121 \\
110 \\
100\end{array}$ & $\begin{array}{r}227 \\
199 \\
40 \\
7 \\
7 \\
8\end{array}$ & $\begin{array}{c}154 \\
98 \\
10 \\
2.3 \\
2.12 \\
c .2\end{array}$ \\
\hline TOTAL & 404.7 & - & 233.56 & 674 & - & 65.51 & 21998 & -- & 574396.6 \\
\hline DAY & $\begin{array}{l}\text { MEAN } \\
\text { DI SCHARGE } \\
\text { (CFS) }\end{array}$ & $\begin{array}{l}\text { JANUARY } \\
\text { MEAN } \\
\text { CONCEN- } \\
\text { TRATION } \\
\text { (MG/L) }\end{array}$ & $\begin{array}{l}\text { LOAC } \\
\text { (TONS) }\end{array}$ & $\begin{array}{l}\text { MEAN } \\
\text { DISCHARGE } \\
\text { (CFS) }\end{array}$ & $\begin{array}{l}\text { FEBRUARY } \\
\text { MEAN } \\
\text { CONCEN- } \\
\text { TRATION } \\
\text { (MG/L) }\end{array}$ & $\begin{array}{l}\text { LOAO } \\
\text { ITONSI }\end{array}$ & $\begin{array}{l}\text { MEAN } \\
\text { DISCHARGE } \\
\text { (CFS) }\end{array}$ & $\begin{array}{l}\text { MAKCH } \\
\text { MEAN } \\
\text { CONCEN- } \\
\text { TRATION } \\
\text { (MGILI) }\end{array}$ & $\begin{array}{l}\text { LOAO } \\
\text { (TONS) }\end{array}$ \\
\hline $\begin{array}{l}1 \\
2 \\
3 \\
4 \\
5\end{array}$ & $\begin{array}{l}8 C \\
74 \\
68 \\
63 \\
58\end{array}$ & $\begin{array}{r}8 \\
8 \\
8 \\
22 \\
19\end{array}$ & $\begin{array}{l}1.7 \\
1.6 \\
1.5 \\
3.7 \\
3.0\end{array}$ & $\begin{array}{r}997 \\
2590 \\
930 \\
523 \\
392\end{array}$ & $\begin{array}{r}975 \\
7620 \\
2830 \\
1080 \\
1660\end{array}$ & $\begin{array}{r}3660 \\
53300 \\
7370 \\
1530 \\
1760\end{array}$ & $\begin{array}{l}41 \\
43 \\
38 \\
39 \\
40\end{array}$ & $\begin{array}{l}8 \\
7 \\
6 \\
5 \\
7\end{array}$ & $\begin{array}{l}.69 \\
.81 \\
.62 \\
.53 \\
.76\end{array}$ \\
\hline $\begin{array}{r}6 \\
7 \\
8 \\
9 \\
10\end{array}$ & $\begin{array}{l}55 \\
51 \\
50 \\
52 \\
54\end{array}$ & $\begin{array}{r}22 \\
17 \\
8 \\
7 \\
3\end{array}$ & $\begin{array}{l}3.3 \\
2.3 \\
1.1 \\
.98 \\
.44\end{array}$ & $\begin{array}{l}306 \\
262 \\
223 \\
196 \\
127\end{array}$ & $\begin{array}{r}1540 \\
1070 \\
990 \\
372 \\
38\end{array}$ & $\begin{array}{r}1270 \\
757 \\
596 \\
191 \\
13\end{array}$ & $\begin{array}{l}42 \\
40 \\
39 \\
43 \\
46\end{array}$ & $\begin{array}{r}7 \\
3 \\
6 \\
37 \\
50\end{array}$ & $\begin{array}{l}.75 \\
.32 \\
.63 \\
4.3 \\
0.2\end{array}$ \\
\hline $\begin{array}{l}11 \\
12 \\
13 \\
14 \\
15\end{array}$ & $\begin{array}{l}48 \\
45 \\
47 \\
48 \\
45\end{array}$ & $\begin{array}{l}2 \\
2 \\
2 \\
2 \\
2\end{array}$ & $\begin{array}{l}.26 \\
.24 \\
.25 \\
.26 \\
.24\end{array}$ & $\begin{array}{r}110 \\
90 \\
80 \\
70 \\
66\end{array}$ & $\begin{array}{l}18 \\
26 \\
60 \\
86 \\
82\end{array}$ & $\begin{array}{l}5.3 \\
4.9 \\
13 \\
16 \\
15\end{array}$ & $\begin{array}{l}43 \\
42 \\
40 \\
39 \\
43\end{array}$ & $\begin{array}{l}46 \\
36 \\
30 \\
30 \\
30\end{array}$ & $\begin{array}{l}5.3 \\
4.1 \\
3.2 \\
3.2 \\
3.5\end{array}$ \\
\hline $\begin{array}{l}16 \\
17 \\
18 \\
19 \\
26\end{array}$ & $\begin{array}{l}48 \\
35 \\
33 \\
33 \\
57\end{array}$ & $\begin{array}{l}2 \\
2 \\
2 \\
2 \\
2\end{array}$ & $\begin{array}{l}.22 \\
.19 \\
.18 \\
.18 \\
.31\end{array}$ & $\begin{array}{l}61 \\
57 \\
54 \\
52 \\
50\end{array}$ & $\begin{array}{l}51 \\
33 \\
52 \\
45 \\
20\end{array}$ & $\begin{array}{l}8.4 \\
5.1 \\
7.6 \\
6.3 \\
2.7\end{array}$ & $\begin{array}{l}105 \\
223 \\
182 \\
151 \\
204\end{array}$ & $\begin{array}{l}141 \\
561 \\
467 \\
294 \\
508\end{array}$ & $\begin{array}{l}40 \\
350 \\
200 \\
120 \\
200\end{array}$ \\
\hline $\begin{array}{l}21 \\
22 \\
23 \\
24 \\
25\end{array}$ & $\begin{array}{l}329 \\
516 \\
54 C \\
284 \\
200\end{array}$ & $\begin{array}{r}87 \\
145 \\
229 \\
202 \\
211\end{array}$ & $\begin{array}{l}115 \\
212 \\
334 \\
155 \\
114\end{array}$ & $\begin{array}{l}48 \\
46 \\
45 \\
44 \\
44\end{array}$ & $\begin{array}{r}13 \\
8 \\
5 \\
4 \\
6\end{array}$ & $\begin{array}{l}1.7 \\
.99 \\
.61 \\
.48 \\
.71\end{array}$ & $\begin{array}{l}231 \\
233 \\
193 \\
182 \\
343\end{array}$ & $\begin{array}{l}609 \\
620 \\
461 \\
427 \\
134\end{array}$ & $\begin{array}{l}360 \\
3>0 \\
240 \\
220 \\
124\end{array}$ \\
\hline $\begin{array}{l}26 \\
27 \\
28 \\
29 \\
30 \\
31\end{array}$ & $\begin{array}{l}145 \\
131 \\
402 \\
820 \\
2180 \\
1006\end{array}$ & $\begin{array}{r}158 \\
174 \\
141 \\
990 \\
4250 \\
1570\end{array}$ & $\begin{array}{r}62 \\
62 \\
153 \\
2720 \\
25000 \\
4460\end{array}$ & $\begin{array}{l}43 \\
44 \\
44 \\
43 \\
-- \\
--\end{array}$ & $\begin{array}{l}13 \\
17 \\
10 \\
10 \\
-0 \\
--\end{array}$ & $\begin{array}{l}1.5 \\
2.0 \\
1.2 \\
1.2 \\
\therefore-\end{array}$ & $\begin{array}{l}267 \\
183 \\
137 \\
113 \\
97 \\
140\end{array}$ & $\begin{array}{l}82 \\
85 \\
83 \\
84 \\
78 \\
78\end{array}$ & $\begin{array}{l}59 \\
42 \\
31 \\
24 \\
26 \\
25\end{array}$ \\
\hline TOTAL & 7583 & -- & 33408.95 & 7631 & - & 70541.69 & 3602 & - & 2574.15 \\
\hline
\end{tabular}


03340800 BIG RACCOON CREEK NEAR FINCASTLE, IND, --Cont1nued

SUSPENDED SEDIMENT, WATER VEAR OCTOBER 1967 TO SEPTEMBER 1960 MEAN
OI SCHARGE
(CFS) APRIL MEAN
CONCEN-
TRATION TRATION LOAO MEAN CONCENMGRL) (TONSI

$\begin{array}{r}78 \\ 76 \\ 121 \\ 7750 \\ \hline\end{array}$

56
39
67
55700
8260 (CFS)

47
45
43
42
39
77
37
36
35
66
69
78
94
72
54
256

450
364
312

1230

1230
395
229

229
134

92

72
59

248
228
215
207

59
51
51
54

256

42
41
37
23
75

682
290
195
153
144

72

$\begin{array}{rr}117 & 125 \\ 43 & 107\end{array}$

$\begin{array}{cc}117 & 125 \\ 12 & 1580 \\ 3.6 & 3050 \\ 2.5 & 1050 \\ 2.9 & 694\end{array}$

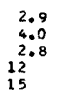

694
757
535
444
415
324

66921.8

11568

JULY $\begin{array}{ll}\text { MEAN } & \text { CONCEN- } \\ \text { DISCHARGE } & \text { TRATION } \\ \text { (CFS) } & \text { (MG/L) }\end{array}$

MEAN
LOAD
(TONS) DISCHARGE
(CFS)

$$
\begin{array}{cc}
9.0 & 18 \\
21 & 14 \\
10 & 13 \\
4.8 & 109 \\
3.9 & 102
\end{array}
$$

5.1
5.8
5.4
3.9

50
28
24
20
368

$1.8 \quad 309$

1.6
1.6
1.4

143
84
57
43

$\begin{array}{rr}1.4 & 36 \\ 1.2 & 91 \\ 1.2 & 261 \\ 1.1 & 143 \\ 1.0 & 80\end{array}$

.94
$: 81$
$: 81$
$: 74$

53
40
31
25
22

4.14

117.5

7.5
6.2
7.9

126.18

TOTAL $78 \mathrm{C}$

TOTAL DISCHARGE FOR YEAR (CFS-DAYS)
MEAN

CONCENTRATION
(MGIL)

172
126
73
1150
023

JUNE

MEAN

TRATION LUAU $\begin{array}{ccc}\text { LOAD } & \text { OISCHARGE } & \text { TRATION } \\ \text { (TONS) } & \text { (CFS) } & \text { (MG/L) }\end{array}$

(TONS)

$\begin{array}{rr}8.6 & 309 \\ 2.2 & 3 \\ 2.7 & 2 \\ 2.7 & 2 \\ 2.4 & 1 \\ 3.6 & 1 \\ 8.1 & 1 \\ 2.8 & 1 \\ 39 & 1 \\ 50 & \end{array}$

$50 \quad 95$

$\begin{array}{rr}336 & 280 \\ 427 & 386 \\ 292 & 207 \\ 237 & 155 \\ 358 & 178 \\ 384 & 155 \\ 308 & 206 \\ 208 & 64 \\ 67 & 19 \\ 20 & 5\end{array}$

$\begin{array}{cc}51 & 88 \\ 88 & 79 \\ 14 & 71 \\ 5.5 & 64 \\ 2760 & 62\end{array}$

$\begin{array}{ll}22 & 5.2 \\ 38 & 8.2 \\ 57 & 11 \\ 50 & 4.06\end{array}$

5130

5130
641

641
68
34
26

76
70
56
49
43

5.6

3.1
1.9

1.17

57
51
2780
6140
1650

19
15
14600
50600
4680

38
128

328
128
169

8.9

$\begin{array}{rr}1000 & 340 \\ 3360 & 2316 \\ 0750 & 11800\end{array}$

1100

2060

394

394
220

220
159
119

2050

2580
896

896
295

88614.6

--

$\begin{array}{rr}1050 & 1210 \\ 426 & 253\end{array}$

1210
253
132

132
67
29

$1837204 y$

SEPTEMUEN

MEAN
MEAN DON DONEN-
IOSCHARGE TRATION

(OAD) OISCHARGE
(TDNS)

TRATION LOAO

8.4
4.8
2.6
478
227

15
14
13
12
12

27
28
51
98

$\begin{array}{cc}30 & 12 \\ 3.6 & 11 \\ 1.6 & 11 \\ 1.3 & 10\end{array}$

12
11
11
10
10

27
28
51
98
132
143
145
111
35
37

25
24
3200

1480

1480
400
160
78
45

1390

154
36
12
5.2

10

9.9
9.8
9.6
9.4

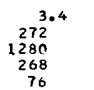

9.0
9.6
12
14
14

35
468
1730
623
352

$\begin{array}{cc}43 & 12 \\ 27 & 11 \\ 16 & 11 \\ 8.6 & 9 .\end{array}$

12

1.1

3.2
4.3

4.00

4.3
3.3
.94

1.04

1.5

$\frac{.96}{87}$

$: 7_{12}$

$: 060$

$1: 70$

3.0

2.4
1.8
1.3

. .73

$\begin{array}{llll}.97 & 9.7 & 62 & 1.6 \\ .30 & 8.9 & 78 & 1.4 \\ .53 & 8.4 & 75 & 1.7 \\ .72 & 9.4 & 63 & 1.3\end{array}$

1.3

$54 .<2$

68163.2 
LOCATION,--Lat $39^{\circ} 08^{\circ} 03^{\prime \prime}$, long $87^{\circ} 39^{\prime} 30^{\prime \prime}$, Crawford County, at intake line to Ohio River Valley Fater Sanitation Commission (ORSANCO) monitor station at Central Illinols Public Service Co. In Hutsonville.

DRA INAGE AREA, --12,600 sq mi, approximately.

PERIOD OF RECORD. --Chemical analyses: November 1964 to December 1985, October 1967 to September 1968. Water temperatures: November 1964 to December 1965 , October 1967 to September 1968.

EXTREMES. --1967-68:

Specific conductance: Maximum daily, 712 micromhos Dec. 1; minimum da1ly, 233 micromhos Jan. 30 Water temperatures: Maximum, $30.0^{\circ} \mathrm{C}$ July $22-24,27$; minimum, $1.0^{\circ} \mathrm{C}$ Dec, 28 to Jan. $2, \mathrm{Jan} .4-12$, Feb. $11-16,20$.

Period of record:

Specific conductance: Maximum daily, 784 micromhos Jan. 24, 1965; minimum daily, 233 micromhos Jan. 30,1968 . Fater temperatures: Maximum, $31.0^{\circ} \mathrm{C}$ Aug. 19, 1965; minimum, 1.0 $0^{\circ} \mathrm{C}$ Jan. 29, 30, Feb. 2, 1965, Dec. $28-31,1967$, Jan. 1, 2, 4-12, Feb. 11-16, 20, 1968 .

REMARKS, --Daily samples were collected at this station and samples were selected for analysis on the following basis: (1) Maximum daily specific conductance for each month, (2) minimum daily specific conductance for each month, and (3) median dally specific conductance for each month. Samples for 1ron and manganese were area 13,100 sq mi approximately)

CHEMICAL ANALYSES IN MILLIGRAMS PER LITER, WATER YEAR OCTOBER 1967 TO SEPTEMBER 1968

\begin{tabular}{|c|c|c|c|c|c|c|c|c|}
\hline DATE & TIME & $\begin{array}{l}\text { DIS- } \\
\text { CHARGE } \\
\text { (CFS) }\end{array}$ & $\begin{array}{l}\text { I RON } \\
(F E)\end{array}$ & $\begin{array}{c}\text { MAN- } \\
\text { GANESE } \\
(\text { WN })\end{array}$ & $\begin{array}{l}\text { BICAR- } \\
\text { BONATE } \\
\left(\mathrm{HOO}_{3}\right)\end{array}$ & $\begin{array}{c}\text { CAR- } \\
\text { BONATE } \\
\left(\infty_{3}\right)\end{array}$ & $\begin{array}{c}\text { SULFATE } \\
\left(\mathrm{SO}_{4}\right)\end{array}$ & $\begin{array}{l}\text { CHLO- } \\
\text { RIDE } \\
\text { (CL) }\end{array}$ \\
\hline \multicolumn{9}{|l|}{ OCT. } \\
\hline $08 \ldots$ & 0700 & 1970 & .52 & .25 & 242 & 12 & 90 & 26 \\
\hline $19 \ldots$ & 0710 & 2980 & .24 & .02 & 243 & 0 & 102 & 27 \\
\hline $24 \ldots$ & 0730 & 2520 & .54 & .18 & 248 & 0 & 83 & 22 \\
\hline \multicolumn{9}{|l|}{ Nov. } \\
\hline $02 \ldots$ & 0815 & 2440 & .10 & .03 & 260 & 0 & 84 & 28 \\
\hline $15 \ldots$ & 0800 & 2790 & .21 & .03 & 274 & 0 & 93 & 29 \\
\hline $27 \ldots$ & 0800 & 2730 & .16 & .04 & 282 & 0 & 95 & 27 \\
\hline \multicolumn{9}{|l|}{$D E C}$. \\
\hline $01 \ldots$ & 0820 & 2690 & .16 & .10 & 270 & 0 & 106 & 32 \\
\hline $12 \ldots$ & 0800 & 22600 & .43 & .08 & 168 & 0 & 69 & 16 \\
\hline $23 \ldots$ & 0830 & 43200 & - & - & 90 & 0 & 35 & 6.5 \\
\hline \multicolumn{9}{|l|}{ JAN. } \\
\hline $08 \ldots$ & 0800 & 9560 & .80 & .04 & 240 & 0 & 85 & 18 \\
\hline $21 \ldots$ & 0800 & 7240 & .32 & .10 & 276 & 0 & 103 & 21 \\
\hline $30 \ldots$ & 0800 & 30900 & .96 & .14 & 84 & 0 & 28 & 6.0 \\
\hline \multicolumn{9}{|l|}{ FEF. } \\
\hline $02 \ldots$ & 0800 & 49600 & .84 & .07 & 106 & 1 & 37 & 9.0 \\
\hline $\begin{array}{l}16 \ldots \\
28\end{array}$ & 0815 & 38600 & .64 & .03 & 156 & 6 & 56 & 13 \\
\hline $28 \ldots$ & 0830 & 8300 & .24 & .07 & 258 & 10 & 93 & 19 \\
\hline \multicolumn{9}{|l|}{ MAR. } \\
\hline $01 \ldots$ & 0830 & 7860 & .44 & .07 & 172 & 10 & 90 & 18 \\
\hline $10 \ldots$ & 0830 & 6640 & .42 & .07 & 278 & 4 & 99 & 20 \\
\hline \multirow{2}{*}{\multicolumn{9}{|c|}{ APR. }} \\
\hline & & & & & & & & \\
\hline $04 \ldots$ & 0800 & 21000 & - & -- & 100 & 0 & 35 & 9.0 \\
\hline $15 \ldots$ & 0830 & 13800 & .64 & .07 & 228 & 0 & 79 & 16 \\
\hline $29 \ldots$ & 0825 & 7510 & .15 & .04 & 230 & 17 & 86 & 20 \\
\hline \multicolumn{9}{|l|}{ MAY } \\
\hline $06 \ldots$ & 0825 & 5820 & .04 & .03 & 248 & 0 & 89 & 19 \\
\hline $13 \ldots$ & 0815 & 7400 & .21 & .04 & 190 & 10 & 90 & 19 \\
\hline \multirow{2}{*}{\multicolumn{9}{|c|}{ JUNE }} \\
\hline & & & & & & & & \\
\hline $06 \ldots$ & 0800 & 23800 & .20 & .03 & 220 & 0 & 65 & 16 \\
\hline $24 \ldots$ & 0800 & 7560 & .20 & .02 & 256 & 0 & 81 & 20 \\
\hline $27 \ldots$ & 0800 & 12700 & .34 & .04 & 176 & 4 & 65 & 14 \\
\hline \multicolumn{9}{|l|}{ JUL $\ddot{Y}^{\prime}$} \\
\hline $14 \ldots$ & 0800 & 6610 & .36 & .06 & 226 & 0 & 75 & 18 \\
\hline $23 \ldots$ & 0800 & 4780 & .08 & .06 & 256 & 0 & 77 & 20 \\
\hline $28 \ldots$ & - & 9460 & .38 & .15 & 191 & 0 & 66 & 16 \\
\hline \multicolumn{9}{|l|}{ AUG. } \\
\hline $07 \ldots$ & 0800 & 24600 & - & .11 & 116 & 0 & 30 & 6.0 \\
\hline $12 \ldots$ & 0930 & 10300 & -- & .16 & 228 & 0 & 63 & 16 \\
\hline $30 \ldots$ & 0800 & 4390 & .24 & .06 & 272 & 0 & 72 & 20 \\
\hline \multicolumn{9}{|l|}{ SEPT. } \\
\hline $07 \ldots$ & 0800 & 3570 & .06 & .03 & 236 & 0 & 79 & 20 \\
\hline $16 \ldots$ & 0835 & 3050 & .26 & .06 & 212 & 0 & 81 & 20 \\
\hline $25 \ldots$ & 0800 & 4130 & .20 & .02 & 262 & 0 & 85 & 22 \\
\hline
\end{tabular}


03341910 WABASH RIVER AT HUTSONYILLE, ILL..--Cont1 Inued

CHEMICAL ANALYSES IN MILLIGRAMS PER LITER, WATER YEAR OCTOBER 1967 TO SEPTEMBER 1968

\begin{tabular}{|c|c|c|c|c|c|c|c|c|}
\hline DATE & $\begin{array}{l}\text { FLUO- } \\
\text { RIDE } \\
\text { (F) }\end{array}$ & $\begin{array}{c}\text { NITRATE } \\
\left(\mathrm{NO}_{3}\right)\end{array}$ & $\begin{array}{l}\text { TOTAL } \\
\text { PHOS- } \\
\text { PHORUS } \\
\left(\mathrm{PO}_{4}\right)\end{array}$ & $\begin{array}{l}\text { DIS- } \\
\text { SOLVED } \\
\text { SOLIDS } \\
\text { (RESI- } \\
\text { DUE AT } \\
180 \text { C) }\end{array}$ & $\begin{array}{l}\text { HARD- } \\
\text { NESS } \\
(\mathrm{CA}, \mathbf{M G})\end{array}$ & $\begin{array}{l}\text { NON- } \\
\text { CAR- } \\
\text { BONATE } \\
\text { HARD- } \\
\text { NESS }\end{array}$ & $\begin{array}{l}\text { SPECI- } \\
\text { FIC } \\
\text { COND- } \\
\text { UCTANCE } \\
\text { (MICRO- } \\
\text { MHOS) }\end{array}$ & pH \\
\hline $\begin{array}{l}\text { OCT. } \\
\text { O8... } \\
19 . \ldots \\
24 \ldots\end{array}$ & $\begin{array}{l}.4 \\
.4 \\
.4\end{array}$ & $\begin{array}{l}1.6 \\
2.4 \\
4.2\end{array}$ & $\begin{array}{r}.90 \\
.60 \\
1.1\end{array}$ & $\begin{array}{l}430 \\
398 \\
372\end{array}$ & $\begin{array}{l}288 \\
276 \\
273\end{array}$ & $\begin{array}{l}69 \\
76 \\
70\end{array}$ & $\begin{array}{l}637 \\
628 \\
595\end{array}$ & $\begin{array}{l}8.4 \\
8.0 \\
8.2\end{array}$ \\
\hline $\begin{array}{l}\text { Nov. } \\
02 . . \\
15 \ldots \\
27 . .\end{array}$ & $\begin{array}{l}.4 \\
.4 \\
.4\end{array}$ & $\begin{array}{l}3.0 \\
3.6 \\
2.8\end{array}$ & $\begin{array}{l}.56 \\
.50 \\
.47\end{array}$ & $\begin{array}{l}412 \\
444 \\
452\end{array}$ & $\begin{array}{l}300 \\
\mathbf{3 3 0} \\
\mathbf{3 4 4}\end{array}$ & $\begin{array}{r}86 \\
105 \\
113\end{array}$ & $\begin{array}{l}640 \\
686 \\
705\end{array}$ & $\begin{array}{l}7.6 \\
8.1 \\
8.2\end{array}$ \\
\hline $\begin{array}{c}\text { DEC. } \\
01 \ldots \\
12 \ldots \\
23 . .\end{array}$ & $\begin{array}{l}.4 \\
.3 \\
.2\end{array}$ & $\begin{array}{c}8.0 \\
24 \\
9.2\end{array}$ & $\begin{array}{l}.72 \\
.64 \\
.34\end{array}$ & $\begin{array}{l}426 \\
306 \\
136\end{array}$ & $\begin{array}{l}336 \\
232 \\
116\end{array}$ & $\begin{array}{r}115 \\
94 \\
42\end{array}$ & $\begin{array}{l}712 \\
479 \\
255\end{array}$ & $\begin{array}{l}8.0 \\
7.9 \\
7.4\end{array}$ \\
\hline $\begin{array}{l}\text { JAN. } \\
08 . . \\
21 \ldots \\
30 . .\end{array}$ & $\begin{array}{l}.0 \\
.1 \\
.0\end{array}$ & $\begin{array}{r}12 \\
7.4 \\
8.0\end{array}$ & $\begin{array}{l}.33 \\
.26 \\
.58\end{array}$ & $\begin{array}{l}380 \\
428 \\
128\end{array}$ & $\begin{array}{l}300 \\
342 \\
102\end{array}$ & $\begin{array}{r}103 \\
116 \\
33\end{array}$ & $\begin{array}{l}614 \\
701 \\
233\end{array}$ & $\begin{array}{l}7.5 \\
7.4 \\
7.5\end{array}$ \\
\hline $\begin{array}{l}\text { FEB. } \\
02 \ldots \\
16 \ldots \\
28 . . \\
\text { YAR. }\end{array}$ & $\begin{array}{l}.1 \\
.2 \\
.2\end{array}$ & $\begin{array}{l}14 \\
19 \\
9.4\end{array}$ & $\begin{array}{l}.51 \\
.40 \\
.42\end{array}$ & $\begin{array}{l}200 \\
280 \\
422\end{array}$ & $\begin{array}{l}144 \\
230 \\
338\end{array}$ & $\begin{array}{r}57 \\
92 \\
110\end{array}$ & $\begin{array}{l}302 \\
442 \\
664\end{array}$ & $\begin{array}{l}8.3 \\
8.5 \\
8.5\end{array}$ \\
\hline $\begin{array}{l}01 \ldots \\
10 \ldots \\
20 \ldots\end{array}$ & $\begin{array}{l}.2 \\
.2 \\
.3\end{array}$ & $\begin{array}{r}9.9 \\
11.7\end{array}$ & $\begin{array}{l}.18 \\
.34 \\
.58\end{array}$ & $\begin{array}{l}360 \\
438 \\
342\end{array}$ & $\begin{array}{l}269 \\
342 \\
252\end{array}$ & $\begin{array}{r}111 \\
107 \\
92\end{array}$ & $\begin{array}{l}602 \\
684 \\
514\end{array}$ & $\begin{array}{l}8.6 \\
8.3 \\
8.6\end{array}$ \\
\hline $\begin{array}{c}\text { APR. } \\
04 \ldots \\
15 \ldots \\
29 . .\end{array}$ & $\begin{array}{l}.3 \\
.2 \\
.4\end{array}$ & $\begin{array}{r}8.5 \\
12 \\
6.8\end{array}$ & $\begin{array}{l}.63 \\
.48 \\
.44\end{array}$ & $\begin{array}{l}182 \\
360 \\
392\end{array}$ & $\begin{array}{l}129 \\
300 \\
324\end{array}$ & $\begin{array}{r}47 \\
113 \\
107\end{array}$ & $\begin{array}{l}281 \\
574 \\
644\end{array}$ & $\begin{array}{l}8.2 \\
7.9 \\
8.7\end{array}$ \\
\hline $\begin{array}{l}\text { MAY } \\
06 . . . \\
13 \ldots \\
24 \ldots \\
\operatorname{JNE}\end{array}$ & $\begin{array}{l}.3 \\
.3 \\
.3\end{array}$ & $\begin{array}{l}11 \\
8.8 \\
16\end{array}$ & $\begin{array}{l}.43 \\
.34 \\
.40\end{array}$ & $\begin{array}{l}401 \\
366 \\
187\end{array}$ & $\begin{array}{l}310 \\
276 \\
120\end{array}$ & $\begin{array}{r}107 \\
104 \\
44\end{array}$ & $\begin{array}{l}614 \\
551 \\
263\end{array}$ & $\begin{array}{l}7.6 \\
8.5 \\
8.0\end{array}$ \\
\hline $\begin{array}{l}06 \ldots \\
24 \ldots \\
27 \ldots \\
\text { JULY }\end{array}$ & $\begin{array}{l}.3 \\
.3 \\
.3\end{array}$ & $\begin{array}{l}27 \\
20 \\
17\end{array}$ & $\begin{array}{l}.28 \\
.36 \\
.31\end{array}$ & $\begin{array}{l}360 \\
392 \\
302\end{array}$ & $\begin{array}{l}279 \\
313 \\
235\end{array}$ & $\begin{array}{r}98 \\
103 \\
84\end{array}$ & $\begin{array}{l}542 \\
610 \\
476\end{array}$ & $\begin{array}{l}7.7 \\
7.9 \\
8.3\end{array}$ \\
\hline $\begin{array}{c}14 \ldots \\
23 \ldots \\
28 \ldots \\
\text { AUG. }\end{array}$ & $\begin{array}{l}.3 \\
.3 \\
.3\end{array}$ & $\begin{array}{r}10 \\
8.0 \\
8.2\end{array}$ & $\begin{array}{l}.50 \\
.50 \\
.50\end{array}$ & $\begin{array}{l}342 \\
368 \\
286\end{array}$ & $\begin{array}{l}275 \\
303 \\
227\end{array}$ & $\begin{array}{l}90 \\
92 \\
71\end{array}$ & $\begin{array}{l}557 \\
611 \\
480\end{array}$ & $\begin{array}{l}7.2 \\
8.2 \\
7.2\end{array}$ \\
\hline $\begin{array}{r}07 \ldots \\
12 \ldots \\
30 \ldots \\
\text { SEPT }\end{array}$ & $\begin{array}{l}.2 \\
.3 \\
.3\end{array}$ & $\begin{array}{c}9.5 \\
12 \\
8.0\end{array}$ & $\begin{array}{l}.64 \\
.62 \\
.63\end{array}$ & $\begin{array}{l}166 \\
322 \\
388\end{array}$ & $\begin{array}{l}136 \\
262 \\
306\end{array}$ & $\begin{array}{l}41 \\
74 \\
82\end{array}$ & $\begin{array}{l}274 \\
512 \\
612\end{array}$ & $\begin{array}{l}7.6 \\
8.1 \\
8.0\end{array}$ \\
\hline $\begin{array}{r}07 \ldots \\
16 \ldots \\
25 \ldots\end{array}$ & $\begin{array}{r}.2 \\
.2 \\
.3\end{array}$ & $\begin{array}{l}6.5 \\
5.1 \\
6.4\end{array}$ & $\begin{array}{l}.46 \\
.42 \\
.68\end{array}$ & $\begin{array}{l}346 \\
320 \\
388\end{array}$ & $\begin{array}{l}276 \\
256 \\
304\end{array}$ & $\begin{array}{l}82 \\
82 \\
89\end{array}$ & $\begin{array}{l}575 \\
545 \\
631\end{array}$ & $\begin{array}{l}7.7 \\
7.3 \\
7.2\end{array}$ \\
\hline
\end{tabular}

\begin{tabular}{|c|c|c|c|c|c|c|c|c|c|c|c|c|}
\hline DAY & CCT & NOV & DEC & JAN & FEB & MAR & $\triangle P R$ & MAY & JUN & $N \mathrm{~L}$ & AUG & SEP \\
\hline $\begin{array}{l}1 \\
2 \\
3 \\
4 \\
5\end{array}$ & $\begin{array}{r}=-- \\
20.0 \\
23.0 \\
24.0\end{array}$ & $\begin{array}{r}-10 \\
13.0 \\
13.0 \\
12.0 \\
11.0\end{array}$ & $\begin{array}{l}7.0 \\
7.0 \\
6.0 \\
6.0 \\
5.0\end{array}$ & $\begin{array}{l}1.0 \\
1.0 \\
4.0 \\
1.0 \\
1.0\end{array}$ & $\begin{array}{l}-=- \\
7.0 \\
5.0 \\
4.0 \\
4.0\end{array}$ & $\begin{array}{l}6.0 \\
5.0 \\
4.0 \\
4.0 \\
6.0\end{array}$ & $\begin{array}{l}13.0 \\
13.0 \\
13.0 \\
13.0 \\
13.0\end{array}$ & $\begin{array}{l}17.0 \\
18.0 \\
20.0 \\
19.0 \\
19.0\end{array}$ & $\begin{array}{l}19.0 \\
18.0 \\
22.0 \\
22.0 \\
22.0\end{array}$ & $\begin{array}{l}24.0 \\
24.0 \\
24.0 \\
24.0 \\
24.0\end{array}$ & $\begin{array}{l}25.0 \\
25.0 \\
24.0 \\
25.0 \\
26.0\end{array}$ & $\begin{array}{l}24.0 \\
23.0 \\
23.0 \\
24.0 \\
24.0\end{array}$ \\
\hline $\begin{array}{r}6 \\
7 \\
8 \\
9 \\
10\end{array}$ & $\begin{array}{l}23.0 \\
22.0 \\
22.0 \\
18.0 \\
17.0\end{array}$ & $\begin{array}{r}10.0 \\
9.0 \\
8.0 \\
8.0 \\
10.0\end{array}$ & $\begin{array}{l}6.0 \\
6.0 \\
6.0 \\
7.0 \\
7.0\end{array}$ & $\begin{array}{l}1.0 \\
1.0 \\
1.0 \\
1.0 \\
1.0\end{array}$ & $\begin{array}{l}4.0 \\
4.0 \\
3.0 \\
3.0 \\
2.0\end{array}$ & $\begin{array}{r}7.0 \\
8.0 \\
9.0 \\
10.0 \\
11.0\end{array}$ & $\begin{array}{l}12.0 \\
12.0 \\
13.0 \\
13.0 \\
14.0\end{array}$ & $\begin{array}{l}18.0 \\
17.0 \\
19.0 \\
19.0 \\
19.0\end{array}$ & $\begin{array}{l}22.0 \\
22.0 \\
23.0 \\
24.0 \\
25.0\end{array}$ & $\begin{array}{l}24.0 \\
25.0 \\
26.0 \\
26.0 \\
27.0\end{array}$ & $\begin{array}{l}24.0 \\
27.0 \\
27.0 \\
27.0 \\
28.0\end{array}$ & $\begin{array}{l}23.0 \\
24.0 \\
24.0 \\
24.0 \\
24.0\end{array}$ \\
\hline $\begin{array}{l}11 \\
12 \\
13 \\
14 \\
15\end{array}$ & $\begin{array}{l}16.0 \\
16.0 \\
17.0 \\
18.0 \\
18.0\end{array}$ & $\begin{array}{l}11.0 \\
11.0 \\
12.0 \\
10.0 \\
10.0\end{array}$ & $\begin{array}{l}7.0 \\
4.0 \\
8.0 \\
9.0\end{array}$ & $\begin{array}{l}1.0 \\
1.0 \\
3.0 \\
3.0 \\
3.0\end{array}$ & $\begin{array}{l}1.0 \\
1.0 \\
1.0 \\
1.0 \\
1.0\end{array}$ & $\begin{array}{r}11.0 \\
9.0 \\
7.0 \\
8.0 \\
9.0\end{array}$ & $\begin{array}{l}14.0 \\
15.0 \\
16.0 \\
16.0 \\
16.0\end{array}$ & $\begin{array}{l}19.0 \\
18.0 \\
18.0 \\
18.0 \\
21.0\end{array}$ & $\begin{array}{l}26.0 \\
27.0 \\
26.0 \\
24.0 \\
23.0\end{array}$ & $\begin{array}{l}27.0 \\
27.0 \\
27.0 \\
27.0 \\
27.0\end{array}$ & $\begin{array}{r}27.0 \\
26.0 \\
26.0 \\
26.0\end{array}$ & $\begin{array}{l}23.0 \\
22.0 \\
23.0 \\
23.0 \\
24.0\end{array}$ \\
\hline $\begin{array}{l}16 \\
17 \\
18 \\
19 \\
20\end{array}$ & $\begin{array}{r}19.0 \\
19.0 \\
18.0 \\
16.0 \\
-\end{array}$ & $\begin{array}{r}9.0 \\
10.0 \\
10.0 \\
9.0 \\
9.0\end{array}$ & $\begin{array}{l}8.0 \\
7.0 \\
9.0 \\
6.0 \\
6.0\end{array}$ & $\begin{array}{l}3.0 \\
3.0 \\
4.0 \\
4.0 \\
4.0\end{array}$ & $\begin{array}{l}1.0 \\
2.0 \\
2.0 \\
2.0 \\
1.0\end{array}$ & $\begin{array}{r}10.0 \\
8.0 \\
9.0 \\
11.0 \\
11.0\end{array}$ & $\begin{array}{l}16.0 \\
16.0 \\
16.0 \\
16.0 \\
16.0\end{array}$ & $\begin{array}{l}22.0 \\
22.0 \\
19.0 \\
17.0 \\
18.0\end{array}$ & $\begin{array}{l}23.0 \\
23.0 \\
22.0 \\
23.0 \\
23.0\end{array}$ & $\begin{array}{l}27.0 \\
28.0 \\
28.0 \\
28.0 \\
29.0\end{array}$ & $\begin{array}{l}27.0 \\
28.0 \\
29.0 \\
28.0 \\
28.0\end{array}$ & $\begin{array}{l}24.0 \\
23.0 \\
23.0 \\
22.0 \\
21.0\end{array}$ \\
\hline $\begin{array}{l}21 \\
22 \\
23 \\
24 \\
25\end{array}$ & $\begin{array}{l}18.0 \\
18.0 \\
17.0 \\
16.0 \\
16.0\end{array}$ & $\begin{array}{r}11.0 \\
8.0 \\
8.0 \\
9.0 \\
7.0\end{array}$ & $\begin{array}{r}10.0 \\
7.0 \\
6.0 \\
4.0\end{array}$ & $\begin{array}{l}6.0 \\
4.0 \\
5.0 \\
3.0 \\
3.0\end{array}$ & $\begin{array}{l}2.0 \\
2.0 \\
3.0 \\
4.0 \\
4.0\end{array}$ & $\begin{array}{r}9.0 \\
11.0 \\
8.0 \\
8.0 \\
7.0\end{array}$ & $\begin{array}{l}17.0 \\
17.0 \\
18.0 \\
18.0 \\
18.0\end{array}$ & $\begin{array}{l}17.0 \\
17.0 \\
17.0 \\
16.0 \\
16.0\end{array}$ & $\begin{array}{l}24.0 \\
26.0 \\
25.0 \\
27.0 \\
27.0\end{array}$ & $\begin{array}{l}29.0 \\
30.0 \\
30.0 \\
30.0 \\
29.0\end{array}$ & $\begin{array}{l}28.0 \\
28.0 \\
29.0 \\
29.0 \\
28.0\end{array}$ & $\begin{array}{l}22.0 \\
23.0 \\
24.0 \\
24.0 \\
23.0\end{array}$ \\
\hline $\begin{array}{l}26 \\
27 \\
28 \\
29 \\
30 \\
31\end{array}$ & $\begin{array}{l}13.0 \\
14.0 \\
13.0 \\
13.0 \\
13.0 \\
-\end{array}$ & $\begin{array}{l}8.0 \\
7.0 \\
6.0 \\
6.0 \\
5.0 \\
-\end{array}$ & $\begin{array}{l}2.0 \\
1.0 \\
1.0 \\
1.0 \\
1.0\end{array}$ & $\begin{array}{l}3.0 \\
3.0 \\
3.0 \\
3.0 \\
6.0 \\
4.0\end{array}$ & $\begin{array}{l}4.0 \\
6.0 \\
6.0 \\
--0\end{array}$ & $\begin{array}{r}8.0 \\
10.0 \\
11.0 \\
13.0 \\
13.0 \\
14.0\end{array}$ & $\begin{array}{l}16.0 \\
16.0 \\
16.0 \\
16.0 \\
16.0 \\
\end{array}$ & $\begin{array}{l}16.0 \\
16.0 \\
16.0 \\
16.0 \\
16.0 \\
17.0\end{array}$ & $\begin{array}{l}26.0 \\
24.0 \\
23.0 \\
23.0 \\
23.0 \\
\end{array}$ & $\begin{array}{l}28.0 \\
30.0 \\
27.0 \\
27.0 \\
27.0 \\
26.0\end{array}$ & $\begin{array}{l}29.0 \\
27.0 \\
26.0 \\
26.0 \\
25.0 \\
24.0\end{array}$ & $\begin{array}{r}22.0 \\
22.0 \\
22.0 \\
22.0 \\
22.0 \\
\ldots\end{array}$ \\
\hline ERAGE & 17.5 & 9.5 & 5.5 & 2.5 & 3.0 & 9.0 & 15.0 & 18.0 & 23.5 & 27.0 & 26.5 & 23.0 \\
\hline
\end{tabular}


03341910 WABASH RIVER AT HUTSONILLE, ILL.--COntinued

SPECIFIC CONDUCTANCE (MICROMHOS AT $25^{\circ} \mathrm{C}$ ), WATER YEAR OCTOBER 1967 TO SEPTEMBER 1968 (ONCE-DAILY MEASUREMENT USUALLY AT O800)

\begin{tabular}{|c|c|c|}
\hline $\begin{array}{l}1 \ldots \ldots \\
2 \ldots \ldots \\
3 \ldots \ldots \\
4 \ldots \ldots \\
5 \ldots \ldots\end{array}$ & $\begin{array}{l}\overline{-} \\
616 \\
611 \\
616\end{array}$ & $\begin{array}{l}640 \\
648 \\
667 \\
653\end{array}$ \\
\hline $\begin{array}{r}6 \ldots \ldots \\
7 \ldots \ldots \\
8 \ldots \ldots \\
9 \ldots \ldots \\
10 \ldots \ldots\end{array}$ & $\begin{array}{l}630 \\
636 \\
637 \\
626 \\
627\end{array}$ & $\begin{array}{l}659 \\
658 \\
664 \\
671 \\
665\end{array}$ \\
\hline $\begin{array}{l}11 \ldots \ldots \\
12 \ldots \ldots \\
13 \ldots \ldots \\
14 \ldots \ldots \\
15 \ldots \ldots\end{array}$ & $\begin{array}{l}636 \\
630 \\
630 \\
632 \\
634\end{array}$ & $\begin{array}{l}677 \\
680 \\
673 \\
688 \\
686\end{array}$ \\
\hline $\begin{array}{l}16 \ldots \ldots \\
17 \ldots \ldots \\
18 \ldots \ldots \\
19 \ldots \ldots \\
20 \ldots \ldots\end{array}$ & $\begin{array}{l}631 \\
614 \\
609 \\
628 \\
618\end{array}$ & $\begin{array}{l}693 \\
681 \\
688 \\
689 \\
691\end{array}$ \\
\hline $\begin{array}{l}21 \ldots \ldots \\
22 \ldots \ldots \\
23 \ldots \ldots \\
24 \ldots \ldots \\
25 \ldots \ldots\end{array}$ & $\begin{array}{r}613 \\
598 \\
-- \\
595 \\
611\end{array}$ & $\begin{array}{l}686 \\
689 \\
684 \\
693 \\
682\end{array}$ \\
\hline $\begin{array}{l}26 \ldots \ldots \\
27 \ldots \ldots \\
28 \ldots \ldots \\
29 \ldots \ldots \\
30 \ldots \ldots \\
31 \ldots \ldots\end{array}$ & $\begin{array}{l}626 \\
629 \\
609 \\
616 \\
630 \\
629\end{array}$ & $\begin{array}{r}693 \\
705 \\
703 \\
698 \\
693 \\
-\end{array}$ \\
\hline
\end{tabular}

\begin{tabular}{|c|c|}
\hline $\begin{array}{l}712 \\
695 \\
358 \\
397 \\
427\end{array}$ & $\begin{array}{l}453 \\
475 \\
491 \\
542 \\
575\end{array}$ \\
\hline $\begin{array}{l}554 \\
599 \\
556 \\
537 \\
522\end{array}$ & $\begin{array}{l}588 \\
600 \\
614 \\
606 \\
614\end{array}$ \\
\hline $\begin{array}{r}510 \\
479 \\
508 \\
-482\end{array}$ & $\begin{array}{l}604 \\
639 \\
645 \\
686 \\
670\end{array}$ \\
\hline $\begin{array}{l}490 \\
501 \\
473 \\
491 \\
522\end{array}$ & $\begin{array}{l}693 \\
682 \\
686 \\
674 \\
697\end{array}$ \\
\hline $\begin{array}{l}546 \\
276 \\
255 \\
283 \\
309\end{array}$ & $\begin{array}{l}701 \\
658 \\
645 \\
628 \\
590\end{array}$ \\
\hline $\begin{array}{l}348 \\
351 \\
338 \\
345 \\
375 \\
411\end{array}$ & $\begin{array}{l}606 \\
618 \\
617 \\
519 \\
233 \\
325\end{array}$ \\
\hline
\end{tabular}

\begin{tabular}{ll}
344 & 602 \\
302 & 667 \\
344 & 627 \\
344 & 674 \\
335 & 661 \\
326 & 678 \\
317 & 663 \\
329 & 681 \\
341 & 607 \\
370 & 684 \\
400 & 679 \\
427 & 664 \\
441 & 672 \\
438 & 642 \\
443 & 620 \\
442 & 586 \\
457 & 575 \\
483 & 606 \\
499 & 622 \\
521 & 514 \\
561 & 523 \\
572 & 546 \\
618 & 557 \\
619 & 563 \\
638 & 579 \\
658 & 586 \\
-1 & 555 \\
664 & 592 \\
606 & 554 \\
-- & 564 \\
- & 552 \\
458 & 611 \\
\hline &
\end{tabular}

$\begin{array}{ll}602 & 538 \\ 667 & 5 \\ 627 & 5 \\ 674 & 2 \\ 661 & 4 \\ 678 & 4 \\ 663 & 4 \\ 681 & 4 \\ 607 & 467 \\ 684 & 467 \\ 679 & 475 \\ 664 & 4 \\ 672 & 5 \\ 642 & 5 \\ 620 & 5 \\ 586 & 5 \\ 575 & 5 \\ 606 & 607 \\ 622 & 605 \\ 514 & 5 \\ 523 & 5 \\ 546 & 6 \\ 557 & 610 \\ 563 & 619 \\ 579 & 635 \\ 586 & 636 \\ 585 & 628 \\ 592 & 632 \\ 594 & 644 \\ 564 & 630 \\ 552 & \\ 611 & 552 \\ & \end{array}$

\begin{tabular}{|c|c|}
\hline $\begin{array}{l}538 \\
538 \\
548 \\
281 \\
472\end{array}$ & $\begin{array}{l}603 \\
600 \\
605 \\
604 \\
606\end{array}$ \\
\hline $\begin{array}{l}476 \\
489 \\
483 \\
467 \\
467\end{array}$ & $\begin{array}{l}614 \\
611 \\
609 \\
597 \\
565\end{array}$ \\
\hline $\begin{array}{l}475 \\
498 \\
524 \\
546 \\
574\end{array}$ & $\begin{array}{l}574 \\
532 \\
551 \\
582 \\
514\end{array}$ \\
\hline $\begin{array}{l}582 \\
598 \\
607 \\
605 \\
585\end{array}$ & $\begin{array}{l}603 \\
610 \\
429 \\
264 \\
288\end{array}$ \\
\hline $\begin{array}{l}570 \\
605 \\
610 \\
619 \\
635\end{array}$ & $\begin{array}{l}331 \\
376 \\
366 \\
263 \\
317\end{array}$ \\
\hline $\begin{array}{r}636 \\
628 \\
632 \\
644 \\
630 \\
--\end{array}$ & $\begin{array}{l}304 \\
352 \\
415 \\
464 \\
505 \\
529\end{array}$ \\
\hline 552 & 493 \\
\hline
\end{tabular}

504
496
503
516
523
534
542
564
571
581
578
546
582
557
534
535
556
565
577
571
508
602
611
610
529
570
567
480
515
517
533
550
56

03342000 TABASH RIVER AT RIVERTON, IND.

LOCATION.--Lat $39^{\circ} 01^{\prime} 13^{\prime \prime}$, long $87^{\circ} 34^{\prime} 07^{\prime \prime}$, Sullivan County, temperature recorder at center pier of Illinols Central Railroad bridge at Riverton, 0.6 mile downstream from Turtle Creek, and at mile 162.0 .

DRA INAGE AREA. --13,100 sq mi, approximately. PERIOD OF RECORD,--Mater temperatures: July 1954 to September 1961, October 1962 to September 1965, October 1967 to
September 1968.

EXTREMES. --1967-68: Mater temperatures: Maximum, $31.0^{\circ} \mathrm{C}$ July $21,22,25$; minimum, freezing point Dec. 18 to Jan. 5, Jan. 15, 25-29,
Feb. 10-18.

period of record:

Water temperatures: Maximum, $33.0^{\circ} \mathrm{C} \mathrm{July} 20$ and Aug. 29, 1954; minimum, freezing point on many days during REMARKS. --Temperature affected by powerplant upstream.

TEMPERATURE $\left({ }^{\circ} \mathrm{C}\right)$ OF WATER, HATER YEAR OCTOBER 1967 TO SEPTEMBER 1968 (CONTINUOUS ETHYL ALCOHOL-ACTUATED THERMOGRAPH)

DAY

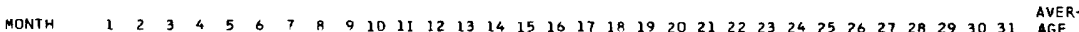

OCTOBER

MAXIMUM - MINIMUM

NOVEMBER

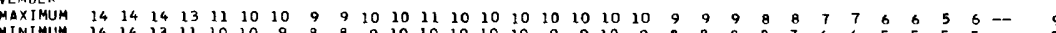

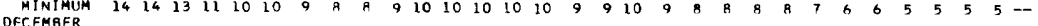

MAXIMUM $6 \begin{array}{llllllllllllllllllllllllllllllllllllll} & 6 & 6 & 4 & 3 & 4 & 4 & 4 & 5 & 5 & 6 & 6 & 6 & 5 & 7 & 8 & 4 & 4 & 2 & 0 & 0 & 0 & 0 & 0 & 0 & 0 & 0 & 0 & 0 & 0 & 0 & 0 & 2\end{array}$

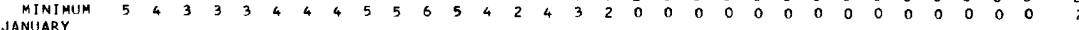

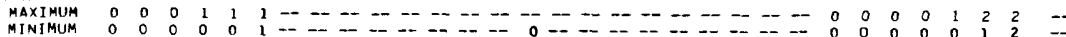

MINIMUM

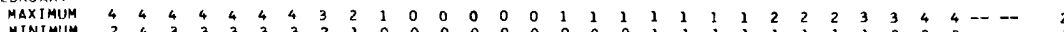

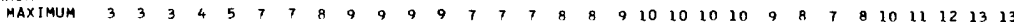

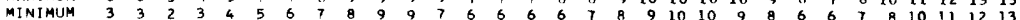

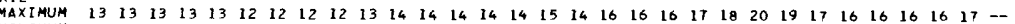
$M$ MANIMUH

$\begin{array}{lllllllllllllllllllllllllllllllllll}13 & 13 & 13 & 13 & 13 & 12 & 12 & 12 & 12 & 13 & 14 & 14 & 14 & 14 & 14 & 15 & 14 & 16 & 16 & 16 & 17 & 18 & 20 & 19 & 17 & 16 & 16 & 16 & 16 & 17 & \cdots\end{array}$

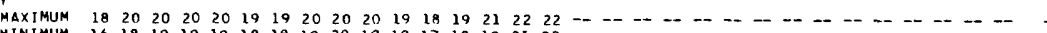

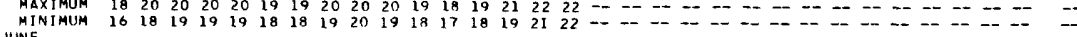

MAXIMUA -- -- --

MINIMUA

MAXIMUM --

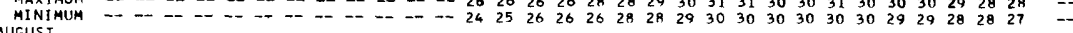

AUGST

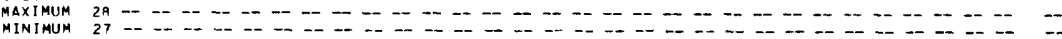

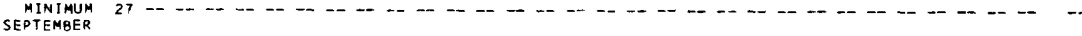

MAXIMUM 
03348500 WHITE RIVER NEAR NOBLESVILLE, IND.

LOCATION. --Lat $40^{\circ} 07^{\prime} 46^{\prime \prime}$, long $85^{\circ} 57^{\prime} 46^{\prime \prime}$, Hamilton County, temperature recorder at gaging station on downstream side of center pier of highway bridge, 1 mile west of Strawtown, 7 miles northeast of Noblesville, $9.5 \mathrm{mtles}$ upstream
from Cicero Creek, and at m1le $277^{4}$.

DRAINAGE AREA, $--828 \mathrm{sq} \mathrm{mi}$ (revised).

PERIOD OF RECORD, -- Water temperatures: October 1953 to July 1957, October 1962 to September 1968.

EXTREMES. --1967-68:

Water temperatures: Kaximum, $27,0^{\circ} \mathrm{C}$ Aug. 21-25; freezing potnt, Jan, 15, 16, 18-21, 26.

Period of record:

Water temperatures: Maximum, $31.0^{\circ} \mathrm{C} J u 1 y 14,1954 ;$ m1nimum, freezing point many days during winter periods. TEMPERATURE $\left({ }^{\circ} \mathrm{C}\right)$ OF WATER, WATER YEAR OCTOBER 1967 TO SEPTEMBER 1968 (CONTINUOUS ETHYL ALCOHOL-ACTUATED THERMOGRAPH)

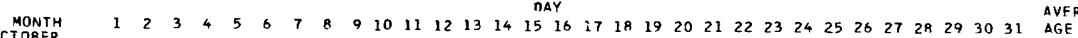

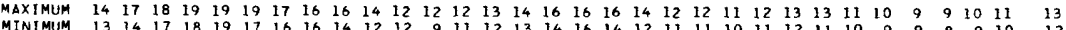

$\begin{array}{llllllllllllllllllllllllllllllllll}\text { MINIMUM } & 13 & 14 & 17 & 18 & 19 & 17 & 16 & 16 & 14 & 12 & 12 & 9 & 11 & 12 & 13 & 14 & 16 & 14 & 12 & 11 & 11 & 10 & 11 & 12 & 11 & 10 & 9 & 9 & 9 & 9 & 10 & 12\end{array}$

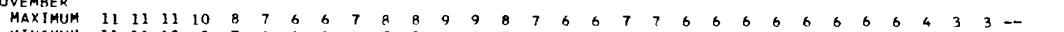

$\begin{array}{lllllllllllllllllllllllllllllllllllll}\text { HINIMUM } & 11 & 11 & 10 & 8 & 7 & 6 & 6 & 6 & 6 & 7 & 8 & 8 & 8 & 7 & 6 & 5 & 5 & 6 & 6 & 6 & 6 & 6 & 6 & 5 & 5 & 6 & 4 & 3 & 3 & 2 & -- & 5 & 6\end{array}$

$\begin{array}{lllllllllllllllllllllllllllllllllll}\text { OECEMBER } & \text { MAXIMUM } & 3 & 3 & 4 & 4 & 5 & 6 & 7 & 8 & 8 & 8 & 8 & 8 & 8 & 8 & 7 & 6 & 4 & 6 & 6 & 6 & 10 & 10 & 6 & 4 & 4 & 4 & 3 & 2 & 2 & 2 & 2 & 5\end{array}$

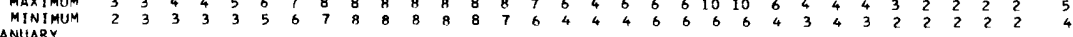

SANUARY

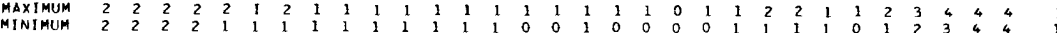

FERRUARY

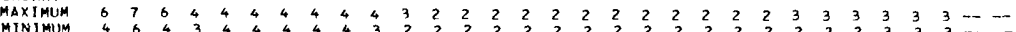

MINIMUM

MAXIMUM
MINIMUM

APR IL

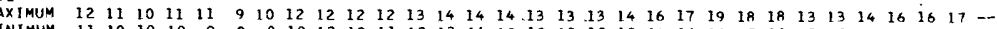

MAY

MAXIMUM $18 \quad 19 \quad 18 \quad 18 \quad 17 \quad 16 \quad 16 \quad 17 \quad 17 \quad 17 \quad 17 \quad 16 \quad 17 \quad 19 \quad 19 \quad 19 \quad 19 \quad 17 \quad 17 \quad 14 \quad 16 \quad 17 \quad 17 \quad 14 \quad 14 \quad 14 \quad 14 \quad 14 \quad 14 \quad 13 \quad 15$

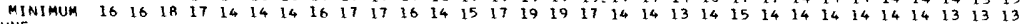

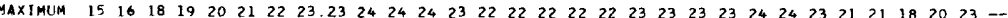

JULY

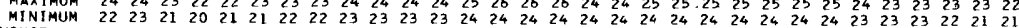

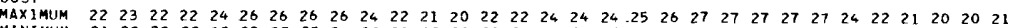

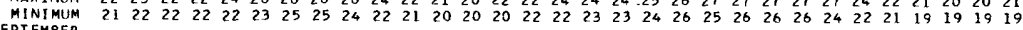

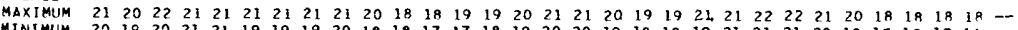

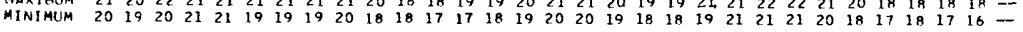
0334900 WHITE RIVER AT NOBLESVILLE, IND.

LOCATION, --Lat $40^{\circ} 02^{\prime} 50^{\prime \prime}$, long $86^{\circ} 01^{\prime} 00^{\prime \prime}$, Ham1lton County, temperature recorder at gaging stat1on on right bank at

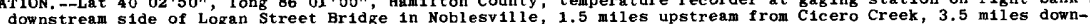
downstream side of Logan Street Bridge in No

DRA INAGE AREA. --858 sq mi (revised).

PERIOD OF RECORD, -- water temperatures: November 1952 to Septembər 1968.

EXTRELES, - - 1967 -68:

Water temperatures: Maximum, 30. $0^{\circ} \mathrm{C}$ July 14-16; minimum, freezing point Jan. 25, 26, Feb, 13-16, 18-20.

Period of record:

Rater temperatures: Maximum, $34.0^{\circ} \mathrm{C}$ Aug. 1, 1953; minimum, freezing point on many days during winter periods,

TEMPERATURE ('OC) OF WATER, WATER YEAR OCTOBER 1967 TO SEPTEMBER 1968 (CONTINUOUS ETHYL ALCOHOL-ACTUATED THERMOGRAPH)

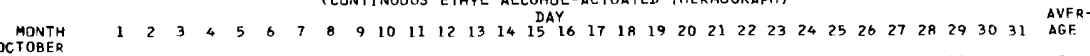

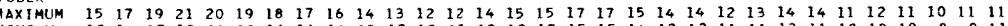

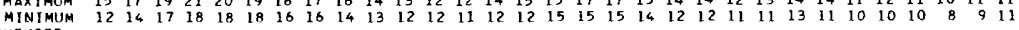

NOVEMBER

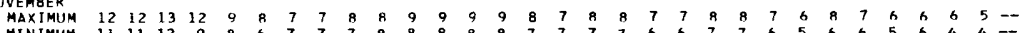

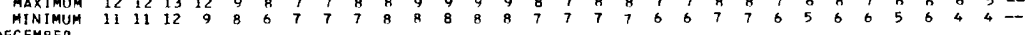

DECEMRER

MAXIMUM $66 \begin{array}{lllllllllllllllllllllllllllllll} & 5 & 5 & 5 & 6 & 7 & 8 & 8 & 8 & 8 & 8 & 8 & 8 & 8 & 8 & 7 & 5 & 6 & 7 & 7 & 11 & 11 & 7 & 4 & 4 & 4 & 3 & 2 & 2 & 2 & 1\end{array}$

MINIMUH

MAXIMUM

MINIMUM

FEBRUARY

MAXIMUM $4 \begin{array}{lllllllllllllllllllllllllllllll}4 & 6 & 6 & 3 & 3 & 3 & 4 & 4 & 4 & 3 & 1 & 1 & 1 & 2 & 1 & 1 & 1 & 1 & 1 & 2 & 3 & 3 & 4 & 3 & 3 & 6 & 6 & 5 & 5 & -- & --\end{array}$

MINIMUH

MAXIMUA

MAXIMUM

APRIL

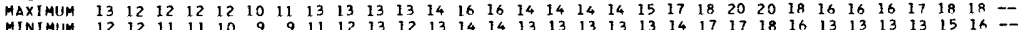

MAXIMUM $19 \quad 21 \quad 19 \quad 19 \quad 17 \quad 18 \quad 17 \quad 18 \quad 18 \quad 18 \quad 18 \quad 16 \quad 18 \quad 21 \quad 22 \quad 22 \quad 19 \quad 17 \quad 16 \quad 16 \quad 17 \quad 17 \quad 17 \quad 16 \quad 14 \quad 14 \quad 14 \quad 14 \quad 14 \quad 14 \quad 16$

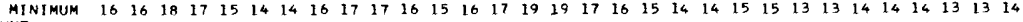

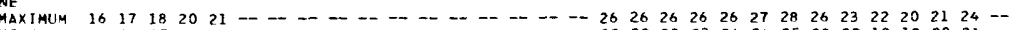

MINIMUM 16 16 16 17 17 19 JULY

MAXIMUA $27 \begin{array}{llllllllllllllllllllllllllllll}27 & 26 & 24 & 24 & 26 & 26 & 27 & 28 & 28 & 28 & 29 & 29 & 30 & 30 & 30 & 29 & 28 & 29 & 29 & 28 & 29 & 29 & 29 & 28 & 27 & 26 & 26 & 24 & 24 & 24\end{array}$

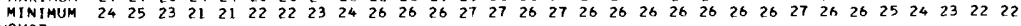
AUGUST

$\begin{array}{lllllllllllllllllllllllllllllllll}\text { MAXIMUM } & 23 & 23 & 23 & 22 & 25 & 27 & 28 & 28 & 27 & 24 & 21 & 19 & 19 & 22 & 21 & 23 & 23 & 23 & 26 & 26 & 27 & 27 & 28 & 28 & 27 & 22 & 19 & 1 \text { A } & 18 & 19 & 19\end{array}$

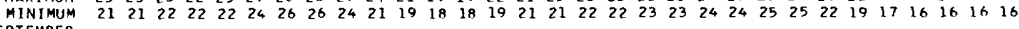
SEPTEMBER

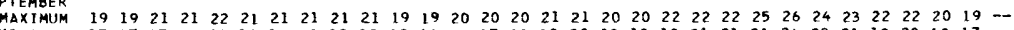

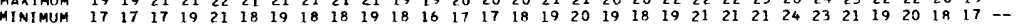


LOCATION. - Lat $39^{\circ} 54^{\prime} 35^{\prime \prime}$, long $86^{\circ} 06^{\prime} 20^{\prime \prime}$, Marion County, temperature recorder at gaging station on downstream side of center pier of bridge on State Hihgway 100, 2 miles east of Nora, 14 miles upstream from Fall Creek, and at
mile 253.4.

DRA INAGE AREA, --1,219 sq $\mathrm{mi}$ (revised).

PERIOD OF RECORD.--Water temperatures: June 1954 to May 1960, October 1962 to September 1968.

EXTREMES. $--1967-68$ :

Water temperatures: Maximum, $27.0^{\circ} \mathrm{C}$ Aug. 24 ; minimum, freezing point Jan. 5-21, 25-27.

Period of record:

Water temperatures: Maximum, $32.0^{\circ} \mathrm{C}$ July 14, 1954; minimum, freezing point on many days during winter periods. REMARKS. .-Flow regulated by powerplant above station.

TEMPERATURE (OO) OF WATER, WATER YEAR OCTOBER 1967 TO SEPTEMBER 1968 (CONTINUOUS ETHYL ALCOHOL-ACTUATED THERMOGRAPH)

DAY

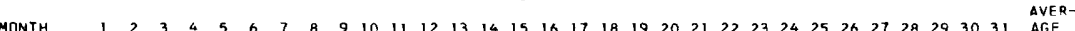

OCTOBER

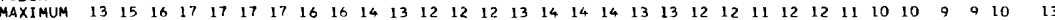

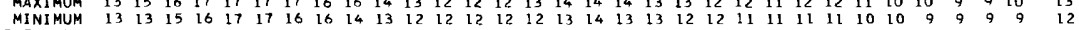

NOVEMBER

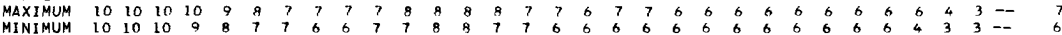

DECEMBER

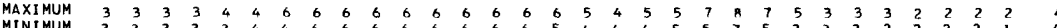

JANUARY

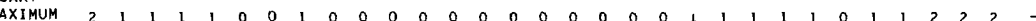

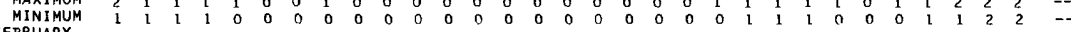

FEBRUARY

$\begin{array}{lllllllllllllllllllllllllllllllllllll}M A X I M U M & 3 & 3 & 3 & 3 & 2 & 2 & 3 & 3 & 3 & 3 & 2 & 1 & 1 & 1 & 1 & 1 & 1 & 1 & 1 & 1 & 1 & 1 & 1 & 2 & 2 & 2 & 3 & 3 & 3 & -- & -- & -\end{array}$

MARCH

MINIMUM

$\begin{array}{llllllllllllllllllllllllllllllllllllllllllllllllllllllllll}2 & 3 & 3 & 2 & 2 & 2 & 2 & 3 & 3 & 2 & 1 & 1 & 1 & 1 & 1 & 1 & 1 & 1 & 1 & 1 & 1 & 1 & 1 & 1 & 2 & 2 & 2 & 3 & 3 & \cdots & \cdots\end{array}$

$\begin{array}{llllllllllllllllllllllllllllllll}3 & 3 & 3 & 3 & 4 & 4 & 5 & 6 & 6 & 6 & 6 & 6 & 4 & 3 & 4 & 5 & 6 & 6 & 6 & 7 & 7 & 7 & 6 & 5 & 4 & 6 & 8 & 9 & 10 & 11 & 11 \\ 3 & 3 & 3 & 3 & 3 & 4 & 4 & 5 & 6 & 6 & 6 & 4 & 3 & 3 & 3 & 4 & 5 & 5 & 6 & 6 & 7 & 6 & 5 & 4 & 4 & 4 & 6 & 8 & 9 & 10 & 11\end{array}$

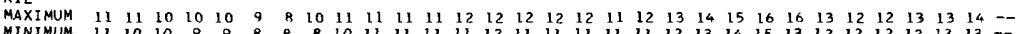

MAY

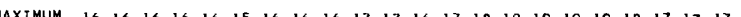

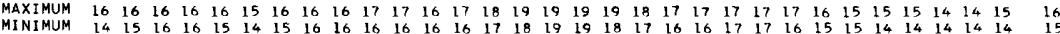

JUNE

$\begin{array}{llllllllllllllllllllllllllllllllll}\text { MAXIMUM } & 16 & 16 & 17 & 18 & 19 & 20 & 21 & 22 & 23 & 23 & 25 & 25 & 24 & 23 & 22 & 22 & 22 & 22 & 23 & 23 & 23 & 23 & 23 & 22 & 23 & 22 & 21 & 19 & 19 & 21 & -- & 21 \\ \text { MINIMUM } & 15 & 15 & 16 & 17 & 19 & 19 & 20 & 21 & 22 & 23 & 23 & 24 & 22 & 22 & 22 & 22 & 22 & 21 & 22 & 23 & 22 & 23 & 21 & 21 & 22 & 21 & 19 & 18 & 18 & 19 & -- & 20\end{array}$

JULY

$\begin{array}{lllllllllllllllllllllllllllllllll}\text { MAXIMUM } & 22 & 22 & 22 & 21 & 21 & 21 & 21 & 22 & 22 & 22 & 23 & 23 & 23 & 24 & 24 & 24 & 24 & 24 & 24 & 24 & 24 & 24 & 24 & 24 & 24 & 24 & 23 & 23 & 23 & 22 & 22 \\ \text { MINIMUM } & 21 & 22 & 21 & 21 & 21 & 21 & 21 & 21 & 22 & 22 & 22 & 23 & 23 & 23 & 24 & 24 & 24 & 24 & 24 & 24 & 24 & 24 & 23 & 23 & 24 & 23 & 23 & 23 & 22 & 22 & 22\end{array}$ MINIMUM

$\begin{array}{llllllllllllllllllllllllllllllllll}\text { MAXIMUM } & 22 & 22 & 22 & 22 & 23 & 24 & 24 & 24 & 24 & 24 & 23 & 22 & 21 & 22 & 22 & 23 & 23 & 23 & 24 & 26 & 26 & 26 & 26 & 27 & 26 & 26 & 24 & 22 & 22 & 22 & 22 & 23 \\ \text { MINIMUM } & 22 & 22 & 22 & 22 & 22 & 23 & 24 & 24 & 24 & 23 & 22 & 21 & 21 & 21 & 22 & 22 & 23 & 23 & 23 & 24 & 25 & 26 & 26 & 26 & 24 & 24 & 22 & 22 & 22 & 22 & 22 & 22\end{array}$

SEPTEMBER

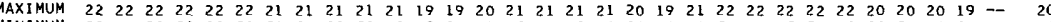

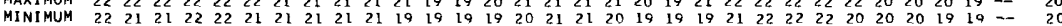


LOCATION,--Lat $38^{\circ} 58^{\prime} 57^{\prime \prime}$, long $85^{\circ} 53^{\circ} 57^{\prime \prime}$, Jackson County, at gaging station on left bank 1,700 ft downstream from highway bridge, 1 mile north of Seymour, 9.6 miles downstream from Sand Creek and at mile 219.2 .

DRAINAGE AREA. --2,341 sq mi (revised).

PERIOD OF RECORD. .- Water temperatures: October 1954 to September 1968.

sediment records: July 1966 to September 1968

EXTREMES. $-1967-68$ :

Water temperatures: Maximum, $27.0^{\circ} \mathrm{C}$ July 21-25, Aug. 21-25; minimum, freezing point Jan, 7-12, 26 Sediment concentrations: Maximum daily, $1,200 \mathrm{mg} / 1$ May 25, June 25 ; minimum daily, $9 \mathrm{mg} / 1 \mathrm{oct}$. 6, Nov. 13,

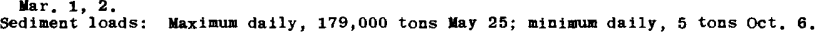

period of record:

water temperatures: Maximum, $31.0^{\circ} \mathrm{C}$ July $13,14,1966$; minimum, freezing point on many days duriag winter periods. Maximum temperature known, $32.0^{\circ} \mathrm{C}$ July 19,1954 . periods. Maximum temperature known, 32,0 C July 19, 1954.
sediment concentrations: Maximum daily, i,200 mg/1 May 25, June 25, 1968; minimum daily, $4 \mathrm{mg} / 1 \mathrm{Nov} .5,1966$.
Sediment loads: Maximum daily, 179,000 tons May 25, 1968; minimum dai1y, 3 tons Nov. 5, 1966.

REMARKS.--Regulation at low flow by pumping plant 1,200 ft upstream from recorder. Sediment sanples collected at highway bridge, $1,700 \mathrm{ft}$ upstream from gaging station. Intermit tent operation of dredge upstream is be lieved to affect low-water loads. Sediment loads were computed from subdivided days on Dec. 2, 3, 22, 23, Jan. 30, Apr. 4, May $11,16,17,23$, June 16,24 , July 25.

TEMPERATURE $\left({ }^{\circ} \mathrm{C}\right)$ DF WATER, WATER YEAR OCTOBER 1967 TO SEPTEMBER 1968 (CONTINUDUS ETHYL ALCOHOL-ACTUATED THERMOGRAPH)

DAY

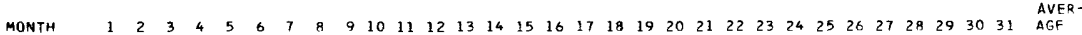

OCTOBER

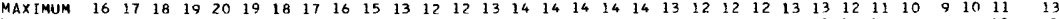
MINIMUM 14 16 $17 \begin{array}{llllllllllllllllllllllllllll}18 & 18 & 17 & 16 & 15 & 13 & 12 & 12 & 12 & 12 & 13 & 14 & 14 & 14 & 13 & 12 & 12 & 12 & 12 & 12 & 12 & 11 & 10 & 9 & 9 & 9 & 10 & 13\end{array}$

NOVEMBER

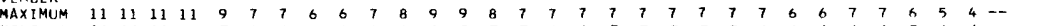

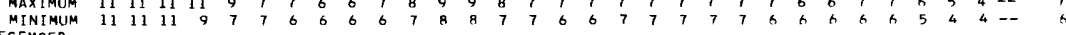

DECEMRER

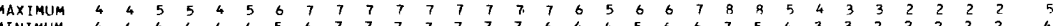

JANUIARY

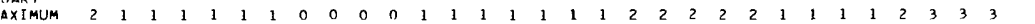

$\begin{array}{lllllllllllllllllllllllllllllllllll}\text { MINIMUM } & 1 & 1 & 1 & 1 & 1 & 1 & 0 & 0 & 0 & 0 & 0 & 0 & 1 & 1 & 1 & 1 & 1 & 1 & 1 & 2 & 2 & 2 & 1 & 1 & 1 & 0 & 1 & 1 & 2 & 3 & 3\end{array}$

FEBRUARY

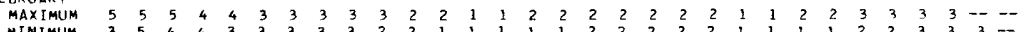

MINIMUM

$\begin{array}{lllllllllllllllllllllllllllllllllll}\text { MAX IMUM } & 3 & 3 & 3 & 3 & 4 & 5 & 5 & 6 & 7 & 7 & 7 & 7 & 6 & 5 & 5 & 7 & 8 & 8 & 9 & 10 & 10 & 9 & 7 & 6 & 6 & 7 & 9 & 11 & 12 & 13 & 13\end{array}$

APRINIMLA

MAXIMUM

MAY

$\begin{array}{llllllllllllllllllllllllllllllllllllllll}13 & 12 & 11 & 12 & 12 & 10 & 9 & 11 & 12 & 12 & 12 & 13 & 14 & 14 & 13 & 13 & 13 & 13 & 14 & 16 & 17 & 17 & 18 & 17 & 16 & 14 & 14 & 15 & 16 & 16 & -1\end{array}$

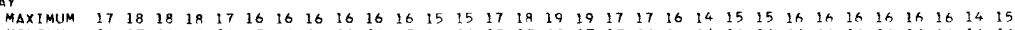

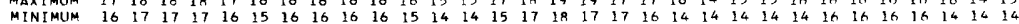
JUNE $\begin{array}{llllllllllllllllllllllllllllllllllllll}\text { MAXIMUM } & 16 & 17 & 18 & 19 & 19 & 20 & 21 & 21 & 22 & 23 & 23 & 23 & 23 & 22 & 21 & 21 & 21 & 21 & 21 & 22 & 22 & 22 & 22 & 23 & 22 & 22 & 22 & 20 & 21 & 22 & --\end{array}$ JULY

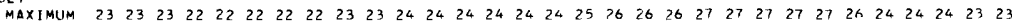
MINIMUM $\begin{array}{lllllllllllllllllllllllllllllllll}22 & 23 & 22 & 21 & 21 & 22 & 22 & 22 & 22 & 23 & 23 & 24 & 24 & 24 & 24 & 24 & 24 & 25 & 25 & 25 & 26 & 26 & 27 & 27 & 26 & 24 & 24 & 24 & 23 & 24 & 22\end{array}$ AUGUST

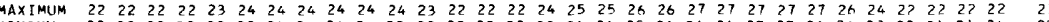

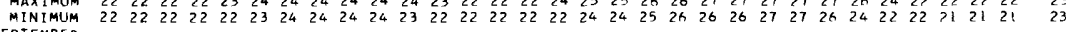

SEPTEMBER $\begin{array}{llllllllllllllllllllllllllllllll}\text { MAXIMUM } & 22 & 22 & 22 & 22 & 22 & 22 & 22 & 22 & 22 & 22 & 20 & 19 & 20 & 20 & 21 & 21 & 21 & 21 & 20 & 20 & 21 & 22 & 22 & 23 & 23 & 22 & 20 & 20 & 19 & 19 & -- \\ \text { MINIMUM } & 22 & 21 & 22 & 22 & 22 & 21 & 21 & 21 & 22 & 20 & 19 & 19 & 19 & 20 & 20 & 21 & 21 & 20 & 19 & 19 & 20 & 21 & 22 & 22 & 22 & 20 & 20 & 19 & 19 & 19 & --\end{array}$ 
TABASH RIVER BASIN

03365500 EAST FORE WHITE RIVER AT SEYMOUR, IND.--Cont1nued

SUSPENDED SEDIMENT, WATER YEAR OCTOBER 1967 TO SEPTEMBER 1968 OCTOBER

NOVEMBER

DECEMBER

MEAN

DEA MEA

LOAD DISCHARGE CONCEN-

MEAN CDEAN

MEAN
DISCHARGE (TONS)

DISCHARG

CDNCEN(CFS)

15
15
15
14
12
9
10
12
15
16
18
18
17
15
14
13
14
14
15
16
16
17
17
16
16
15
15
14
13
12
13

$$
\begin{aligned}
& 9 \\
& 9 \\
& 9 \\
& 8 \\
& 7
\end{aligned}
$$

326
338
360
450
483

$\begin{array}{ll}14 & 12 \\ 14 & 13 \\ 16 & 16 \\ 16 & 19 \\ 10 & 13 \\ & \\ 10 & 13 \\ 14 & 18 \\ 11 & 13 \\ 11 & 12 \\ 15 & 16\end{array}$

$\begin{array}{rr}12 & 659 \\ 13 & 940 \\ 16 & 5080\end{array}$

$\begin{array}{ll}19 & 6220 \\ 13 & 5980\end{array}$

3
8 $\quad 35800$

$\begin{array}{rl}5 & 473 \\ 6 & 466 \\ 8 & 440 \\ 10 & 417 \\ 11 & 396\end{array}$

18
13
12
16

3560
2980

2580

$14 \quad 3150$

$\begin{array}{ll}12 & 397 \\ 12 & 395\end{array}$

397
395
375
380

13
10
9
15
20

11
9
15
20

3150
5230
6490

6490
5990

5990
5420

249

291
317
315

$\begin{array}{rl}9 & 367 \\ 11 & 367 \\ 12 & 363 \\ 13 & 358 \\ 15 & 358\end{array}$

22
23 $\quad 3750$

4750
3900
3960

4410

4030

$\begin{array}{rr}45 & 80 \\ 112 & 460 \\ 775 & 11000 \\ 265 & 4450\end{array}$

144

2330

$\begin{array}{rr}93 & 1180 \\ 68 & 654 \\ 56 & 451 \\ 48 & 334\end{array}$

$\begin{array}{ll}48 & 334\end{array}$

$\begin{array}{lllll}21 & 342 & 16 & 15 & 370 \\ 22 & 313 & 17 & 14 & 374 \\ 23 & 296 & 17 & 14 & 372\end{array}$

$\begin{array}{ll}24 & 29 \\ 25 & 311\end{array}$

370
377

$\begin{array}{ll}26 & 292 \\ 27 & 296 \\ 28 & 309 \\ 29 & 300 \\ 30 & 295 \\ 31 & 306\end{array}$

378
380

380
378
371

TOTAL $\quad 8397$

486

11736

JANUARY

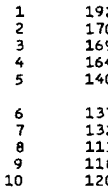

1920
1700
1690
1640
1400
1370
1320
1130
1180
1200

78
70
60
68
71
71
60
49
41
37

$\begin{array}{rr}404 & 15500 \\ 321 & 17000 \\ 274 & 21100 \\ 301 & 21500 \\ 260 & 19800 \\ & \\ 263 & 12200 \\ 214 & 7160 \\ 150 & 5610 \\ 130 & 4660 \\ 120 & 3930\end{array}$

198
152
193
250
136
86
76
59
42
33
37
24
32
26
20

$\begin{array}{rl}8290 & 1160 \\ 7300 & 1140 \\ 11000 & 1120 \\ 14500 & 1000 \\ 7270 & 1060 \\ 2830 & 1050 \\ 1470 & 1040 \\ 894 & 104 \\ 528 & 1020 \\ 350 & 1020\end{array}$

$\begin{array}{rr}40 & 3600 \\ 46 & 7130 \\ 52 & 11200\end{array}$

11200
9380

9380
6110

$\begin{array}{rr}84 & 714 \\ 148 & 2090 \\ 152 & 2660 \\ 100 & 1620\end{array}$

$100 \quad 1620$

$\begin{array}{rrrrr}11 & 1160 & 32 & 100 & 3270 \\ 12 & 1130 & 26 & 80 & 2800 \\ 13 & 1120 & 25 & 76 & 2550 \\ 14 & 1100 & 15 & 45 & 2340\end{array}$

$\begin{array}{llll}1100 & 15 & 45 & 2340 \\ 1090 & 11 & 32 & 2150\end{array}$

$\begin{array}{rrr}28 & 81 & 2020 \\ 33 & 89 & 1910 \\ 67 & 178 & 1760 \\ 37 & 98 & 1610\end{array}$

995

984
984

67
37
52

1910
1760
1610
1420

135

1420

978
1530
2380

2380
2600

$\begin{array}{rrr}33 & 87 & 1280 \\ 58 & 240 & 1300 \\ 53 & 341 & 1380\end{array}$

$\begin{array}{lll}53 & 341 & 1380 \\ 52 & 365 & 1350\end{array}$

1300
1350
1320

21
18
15
50
295
298

301

$\begin{array}{rr}114 & 1260 \\ 87 & 1240 \\ 66 & 1220\end{array}$

2010
1800
1640
2140
5000

66
289

TOTAL $\quad 59646$

$17389 \quad 162640$

$327 \quad 1040$

$\begin{array}{ll}327 & 1040 \\ 101 & 1000\end{array}$

$\begin{array}{ll}220 & 1100 \\ 164 & 1060\end{array}$

1060
1060

56

56
40

$\begin{array}{ll}40 & 421 \\ 67 & 716\end{array}$

$\begin{array}{ll}67 & 798 \\ 62 & 675\end{array}$

$\begin{array}{rr}86 & 836 \\ 443 & 9590 \\ 486 & 14500 \\ 213 & 5390\end{array}$

213
132

$\begin{array}{ll}57 & 4510 \\ 57 & 3870 \\ 58 & 3210\end{array}$

71

740

2190

75
83
84
75
86

90

MARCH

$\begin{array}{rr}9 & 28 \\ 9 & 28 \\ 10 & 30 \\ 21 & 61 \\ 20 & 57 \\ 34 & 96 \\ 40 & 112 \\ 30 & 84 \\ 28 & 77 \\ 27 & 74\end{array}$

$\begin{array}{ll}24 & 67 \\ 33 & 96\end{array}$

$\begin{array}{rr}35 & 104 \\ 36 & 103 \\ 32 & 92\end{array}$

$\begin{array}{lll}30 & 164 & 1240 \\ 24 & 124 & 1770\end{array}$

$\begin{array}{rrr}24 & 124 & 1770 \\ 25 & 119 & 2130 \\ 20 & 87 & 2150\end{array}$

$32 \quad 107$

$\begin{array}{ll}32 & 153 \\ 32 & 184 \\ 28 & 163\end{array}$

$21 \quad 01 \quad 2100$

913
867

555
560
532

69455

28
28
30
61

61
57

96
12
77

96
92
07
53
84
63
23

$\begin{array}{lll}15 & 52 & 3020 \\ 21 & 74 & 4120 \\ 24 & 89 & 4150 \\ 12 & 44 & 3920\end{array}$

174
67
57
58

1420

745
639

614
3370

$\begin{array}{lll}20 & 68 & 6470 \\ 1.2 & 40 & 6370 \\ 11 & 36 & 5380\end{array}$

$\begin{array}{lll}11 & 36 & 5370 \\ 12 & 39 & 4180 \\ -- & -- & 3700 \\ -- & -- & 3510\end{array}$

$\begin{array}{rr}11 \theta & 2060 \\ 82 & 1410 \\ 65 & 944 \\ 58 & 655 \\ 107 & 1070 \\ 80 & 758\end{array}$

$56521 \quad 75730$

15724 
TABASH RIVER BASIN

03365500 EAST FORK WHITE RIVER AT SEYMOUR, IND.--Continued

SUSPENDED SEDIMENT, WATER YEAR OCTOBER 1967 TO SEPTEMBER 1968

\begin{tabular}{|c|c|c|c|c|c|c|c|c|c|}
\hline & \multicolumn{3}{|c|}{ APRIL } & \multicolumn{3}{|c|}{ MAY } & \multicolumn{3}{|c|}{ JUNE } \\
\hline DAY & $\begin{array}{l}\text { MEAN } \\
\text { DISCHARGE } \\
\text { (CFS) }\end{array}$ & $\begin{array}{l}\text { MEAN } \\
\text { CONCEN- } \\
\text { TRATION } \\
\text { (MG/L) }\end{array}$ & $\begin{array}{l}\text { LOAD } \\
\text { (TONS) }\end{array}$ & $\begin{array}{c}\text { MEAN } \\
\text { DI SCHARGE } \\
\text { (CFS) }\end{array}$ & $\begin{array}{l}\text { MEAN } \\
\text { CONCEN- } \\
\text { TRATION } \\
\text { (MG/L) }\end{array}$ & $\begin{array}{l}\text { LOAD } \\
\text { (TONS) }\end{array}$ & $\begin{array}{c}\text { MEAN } \\
\text { DISCHARGE } \\
\text { (CFS) }\end{array}$ & $\begin{array}{l}\text { MEAN } \\
\text { CONCEN- } \\
\text { TRATION } \\
\text { (MG/L) }\end{array}$ & $\begin{array}{l}\text { LOAD } \\
\text { (TONS) }\end{array}$ \\
\hline $\begin{array}{l}1 \\
2 \\
3 \\
4 \\
5\end{array}$ & $\begin{array}{r}5400 \\
4690 \\
4780 \\
6650 \\
12100\end{array}$ & $\begin{array}{l}258 \\
120 \\
118 \\
483 \\
400\end{array}$ & $\begin{array}{r}3760 \\
1520 \\
1520 \\
9520 \\
13100\end{array}$ & $\begin{array}{l}1210 \\
1160 \\
1120 \\
1080 \\
1030\end{array}$ & $\begin{array}{l}81 \\
57 \\
40 \\
52 \\
47\end{array}$ & $\begin{array}{l}265 \\
179 \\
121 \\
152 \\
131\end{array}$ & $\begin{array}{l}8790 \\
8000 \\
7320 \\
6490 \\
5730\end{array}$ & $\begin{array}{r}98 \\
130 \\
134 \\
108 \\
94\end{array}$ & $\begin{array}{l}2330 \\
2810 \\
2650 \\
1890 \\
1450\end{array}$ \\
\hline $\begin{array}{r}6 \\
7 \\
8 \\
9 \\
10\end{array}$ & $\begin{array}{r}10700 \\
9820 \\
6760 \\
4920 \\
3840\end{array}$ & $\begin{array}{r}240 \\
122 \\
89 \\
90 \\
92\end{array}$ & $\begin{array}{r}6930 \\
3230 \\
1620 \\
1200 \\
954\end{array}$ & $\begin{array}{r}985 \\
949 \\
924 \\
1080 \\
1250\end{array}$ & $\begin{array}{l}76 \\
46 \\
53 \\
54 \\
55\end{array}$ & $\begin{array}{l}202 \\
118 \\
132 \\
157 \\
186\end{array}$ & $\begin{array}{l}4630 \\
3840 \\
3300 \\
2880 \\
2540\end{array}$ & $\begin{array}{r}95 \\
102 \\
96 \\
92 \\
107\end{array}$ & $\begin{array}{r}1190 \\
1060 \\
855 \\
715 \\
734\end{array}$ \\
\hline $\begin{array}{l}11 \\
12 \\
13 \\
14 \\
15\end{array}$ & $\begin{array}{l}3190 \\
2780 \\
2470 \\
2290 \\
2710\end{array}$ & $\begin{array}{r}85 \\
73 \\
55 \\
90 \\
108\end{array}$ & $\begin{array}{l}732 \\
548 \\
367 \\
556 \\
790\end{array}$ & $\begin{array}{l}1950 \\
6020 \\
5360 \\
3800 \\
2880\end{array}$ & $\begin{array}{l}125 \\
404 \\
145 \\
132 \\
136\end{array}$ & $\begin{array}{r}750 \\
6570 \\
2100 \\
1350 \\
1060\end{array}$ & $\begin{array}{l}2290 \\
2090 \\
1890 \\
1710 \\
1590\end{array}$ & $\begin{array}{r}112 \\
84 \\
86 \\
97 \\
80\end{array}$ & $\begin{array}{l}692 \\
474 \\
439 \\
448 \\
343\end{array}$ \\
\hline $\begin{array}{l}16 \\
17 \\
18 \\
19 \\
20\end{array}$ & $\begin{array}{l}2790 \\
2480 \\
2270 \\
2130 \\
2150\end{array}$ & $\begin{array}{l}93 \\
81 \\
57 \\
47 \\
38\end{array}$ & $\begin{array}{l}701 \\
542 \\
349 \\
270 \\
221\end{array}$ & $\begin{array}{l}2870 \\
5110 \\
4610 \\
3950 \\
3240\end{array}$ & $\begin{array}{r}190 \\
469 \\
214 \\
106 \\
94\end{array}$ & $\begin{array}{r}1500 \\
6670 \\
2660 \\
1130 \\
822\end{array}$ & $\begin{array}{l}1780 \\
4170 \\
3720 \\
2630 \\
2110\end{array}$ & $\begin{array}{l}113 \\
496 \\
382 \\
306 \\
153\end{array}$ & $\begin{array}{r}699 \\
5580 \\
3840 \\
2170 \\
872\end{array}$ \\
\hline $\begin{array}{l}21 \\
22 \\
23 \\
24 \\
25\end{array}$ & $\begin{array}{l}2650 \\
2400 \\
2070 \\
1850 \\
1680\end{array}$ & $\begin{array}{r}76 \\
77 \\
82 \\
85 \\
103\end{array}$ & $\begin{array}{l}544 \\
499 \\
458 \\
425 \\
467\end{array}$ & $\begin{array}{r}2720 \\
2380 \\
3480 \\
28300 \\
55200\end{array}$ & $\begin{array}{r}78 \\
112 \\
153 \\
781 \\
1200\end{array}$ & $\begin{array}{r}573 \\
720 \\
1700 \\
59700 \\
179000\end{array}$ & $\begin{array}{l}1790 \\
1580 \\
1490 \\
2420 \\
6080\end{array}$ & $\begin{array}{r}128 \\
102 \\
160 \\
354 \\
1200\end{array}$ & $\begin{array}{r}619 \\
435 \\
644 \\
3000 \\
19700\end{array}$ \\
\hline $\begin{array}{l}26 \\
27 \\
28 \\
29 \\
30 \\
31\end{array}$ & $\begin{array}{r}1550 \\
1470 \\
1390 \\
1320 \\
1250 \\
--\end{array}$ & $\begin{array}{l}99 \\
76 \\
67 \\
77 \\
63 \\
--\end{array}$ & $\begin{array}{r}414 \\
302 \\
251 \\
274 \\
213 \\
--\end{array}$ & $\begin{array}{l}44500 \\
32600 \\
25400 \\
18700 \\
15500 \\
11400\end{array}$ & $\begin{array}{l}871 \\
355 \\
248 \\
162 \\
128 \\
107\end{array}$ & $\begin{array}{r}105000 \\
31200 \\
17000 \\
8180 \\
5360 \\
3290\end{array}$ & $\begin{array}{r}5800 \\
4430 \\
3260 \\
2530 \\
2090 \\
--\end{array}$ & $\begin{array}{l}600 \\
278 \\
211 \\
176 \\
157 \\
--\end{array}$ & $\begin{array}{r}9400 \\
3330 \\
1860 \\
1200 \\
886 \\
--\end{array}$ \\
\hline \multirow[t]{2}{*}{ TOTAL } & 112550 & -- & 52277 & 290758 & -- & 437978 & 108970 & -- & 72315 \\
\hline & & JULY & & & AUGUST & & & SEPTEMBER & \\
\hline $\begin{array}{l}1 \\
2 \\
3 \\
4 \\
5\end{array}$ & $\begin{array}{l}1790 \\
1580 \\
1430 \\
1320 \\
1230\end{array}$ & $\begin{array}{l}152 \\
164 \\
158 \\
148 \\
145\end{array}$ & $\begin{array}{l}735 \\
700 \\
610 \\
527 \\
482\end{array}$ & $\begin{array}{r}2300 \\
7820 \\
10600 \\
5320 \\
3650\end{array}$ & $\begin{array}{l}239 \\
504 \\
130 \\
120 \\
165\end{array}$ & $\begin{array}{r}1480 \\
10600 \\
3720 \\
1720 \\
1630\end{array}$ & $\begin{array}{l}731 \\
728 \\
709 \\
695 \\
690\end{array}$ & $\begin{array}{l}66 \\
62 \\
58 \\
62 \\
62\end{array}$ & $\begin{array}{l}130 \\
122 \\
111 \\
116 \\
116\end{array}$ \\
\hline $\begin{array}{r}6 \\
7 \\
8 \\
9 \\
10\end{array}$ & $\begin{array}{r}1150 \\
1090 \\
1050 \\
1020 \\
987\end{array}$ & $\begin{array}{r}148 \\
112 \\
73 \\
71 \\
60\end{array}$ & $\begin{array}{l}460 \\
330 \\
207 \\
196 \\
160\end{array}$ & $\begin{array}{l}2850 \\
2410 \\
2490 \\
2400 \\
2680\end{array}$ & $\begin{array}{l}122 \\
112 \\
120 \\
160 \\
173\end{array}$ & $\begin{array}{r}939 \\
729 \\
807 \\
1040 \\
1250\end{array}$ & $\begin{array}{l}674 \\
658 \\
637 \\
621 \\
597\end{array}$ & $\begin{array}{l}55 \\
62 \\
52 \\
41 \\
46\end{array}$ & $\begin{array}{r}100 \\
110 \\
89 \\
69 \\
74\end{array}$ \\
\hline $\begin{array}{l}11 \\
12 \\
13 \\
14 \\
15\end{array}$ & $\begin{array}{r}1000 \\
982 \\
944 \\
996 \\
898\end{array}$ & $\begin{array}{r}67 \\
73 \\
64 \\
84 \\
103\end{array}$ & $\begin{array}{l}181 \\
194 \\
163 \\
226 \\
250\end{array}$ & $\begin{array}{l}3990 \\
5110 \\
4520 \\
2960 \\
2410\end{array}$ & $\begin{array}{l}135 \\
191 \\
112 \\
114 \\
112\end{array}$ & $\begin{array}{r}1450 \\
2640 \\
1370 \\
911 \\
729\end{array}$ & $\begin{array}{l}585 \\
569 \\
553 \\
545 \\
529\end{array}$ & $\begin{array}{l}44 \\
51 \\
52 \\
31 \\
31\end{array}$ & $\begin{array}{l}69 \\
78 \\
78 \\
46 \\
44\end{array}$ \\
\hline $\begin{array}{l}16 \\
17 \\
18 \\
19 \\
20\end{array}$ & $\begin{array}{r}943 \\
957 \\
866 \\
1100 \\
1400\end{array}$ & $\begin{array}{r}82 \\
77 \\
90 \\
105 \\
208\end{array}$ & $\begin{array}{l}209 \\
199 \\
210 \\
312 \\
786\end{array}$ & $\begin{array}{l}2070 \\
1870 \\
1910 \\
1800 \\
1580\end{array}$ & $\begin{array}{l}112 \\
105 \\
142 \\
175 \\
107\end{array}$ & $\begin{array}{l}626 \\
530 \\
732 \\
850 \\
456\end{array}$ & $\begin{array}{l}521 \\
513 \\
509 \\
525 \\
529\end{array}$ & $\begin{array}{l}33 \\
30 \\
30 \\
29 \\
38\end{array}$ & $\begin{array}{l}46 \\
42 \\
41 \\
41 \\
54\end{array}$ \\
\hline $\begin{array}{l}21 \\
22 \\
23 \\
24 \\
25\end{array}$ & $\begin{array}{l}1530 \\
1290 \\
1220 \\
2140 \\
2240\end{array}$ & $\begin{array}{l}171 \\
123 \\
156 \\
188 \\
222\end{array}$ & $\begin{array}{r}706 \\
428 \\
514 \\
1090 \\
1490\end{array}$ & $\begin{array}{l}1410 \\
1280 \\
1180 \\
1090 \\
1040\end{array}$ & $\begin{array}{l}74 \\
63 \\
52 \\
50 \\
43\end{array}$ & $\begin{array}{l}282 \\
218 \\
166 \\
147 \\
121\end{array}$ & $\begin{array}{l}533 \\
529 \\
525 \\
505 \\
497\end{array}$ & $\begin{array}{l}28 \\
30 \\
45 \\
46 \\
43\end{array}$ & $\begin{array}{l}40 \\
43 \\
64 \\
63 \\
58\end{array}$ \\
\hline $\begin{array}{l}26 \\
27 \\
28 \\
29 \\
30 \\
31\end{array}$ & $\begin{array}{l}7810 \\
8200 \\
5150 \\
3430 \\
2430 \\
1920\end{array}$ & $\begin{array}{r}1150 \\
459 \\
225 \\
162 \\
150 \\
170\end{array}$ & $\begin{array}{r}24200 \\
10200 \\
3130 \\
1500 \\
984 \\
881\end{array}$ & $\begin{array}{l}975 \\
914 \\
857 \\
815 \\
778 \\
752\end{array}$ & $\begin{array}{l}48 \\
53 \\
62 \\
64 \\
61 \\
58\end{array}$ & $\begin{array}{l}126 \\
131 \\
143 \\
141 \\
128 \\
118\end{array}$ & $\begin{array}{r}489 \\
481 \\
481 \\
473 \\
461 \\
--\end{array}$ & $\begin{array}{l}43 \\
53 \\
65 \\
60 \\
50 \\
--\end{array}$ & $\begin{array}{l}57 \\
69 \\
84 \\
77 \\
62 \\
-\end{array}$ \\
\hline TOTAL & 60093 & -- & 52260 & 81831 & -- & 35930 & 17092 & -- & 21930 \\
\hline $\begin{array}{l}\text { TOTAL } \\
\text { TOTAL }\end{array}$ & $\begin{array}{l}\text { I SCHARGE F } \\
\text { DAD FOR YE }\end{array}$ & $\begin{array}{l}\text { YEAR } \\
\text { (TONS) }\end{array}$ & AYSI & & & & & & $\begin{array}{r}1128082 \\
835006\end{array}$ \\
\hline
\end{tabular}




\section{EAST FORK WHITE RIVER AT SEYMOUR, IND. --ContInued}

PARTICLE-SIZE ANALYSIS OF SUDPENDED SEDIMENT, WATER YEAR OCTOBER 1967 TO SEPTEMBER 1968 IMETHOD OF ANALYSIS: B, BOTTOM WI THDRAWAL TUBE; C, CHEMICALLY DISPERSED; D, DECANTATION; N, IN NATIVE WATER;
P, PIPET; S, SIEVE; $V$, VISUAL ACCUMULATION TUBE; W, IN DISTILLED WATER)

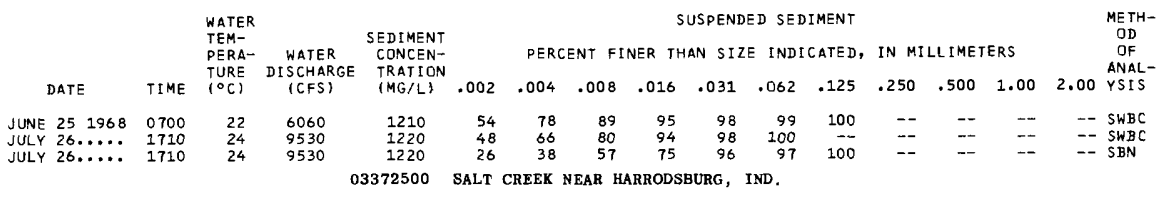

LOCATION.-Lat $39^{\circ} 00^{\prime} 16^{\prime \prime}$, long $86^{\circ} 30^{\prime} 31^{\prime \prime}$, Monroe County, temperature recorder at gaging station on $r i g h t$ bank, $1,300 \mathrm{ft}$ downs tream from Monroe Reservoir dam, 0.9 mile upstream from Clear Creek, 2.2 miles southeast of Harrodsburg, and 25.1 miles upstream from mouth.

DRA INAGE AREA, $-\mathbf{4 3 2} \mathrm{sq}$ mi (revised).

PER IOD OF RECORD. - Water temperatures: August 1966 to September 1968.

EXTREMES. --1967-68:

Water temperatures: Waximum, $26.0^{\circ} \mathrm{C}$ Aug. $21,26,27$; minisnum, $1.0^{\circ} \mathrm{C} \mathrm{Jan}, 4,5,8-13$.

Period of record:

Water temperatures: Maximum, $26.0^{\circ} \mathrm{C}$ Aug. $21,26,27,1968$; minimum, $1.0^{\circ} \mathrm{C} \mathrm{Jan.} \mathrm{4,} 5,8-13,1968$.

REMARKS. --Flow regulated by Monroe Reservoir (capacity, 418,700 acre-ft).

TEMPERATURE $\left({ }^{\circ} \mathrm{C}\right)$ OF WATER, WATER YEAR OCTOBER 1967 TO SEPTEMBER 1968 (CONTINUOUS ETHYL ALCOHOL-ACTUATED THERMOGRAPH)

$D \overline{A Y}$

$\begin{array}{lllllllllllllllllllllllllllllllllllll}\text { MUNTH } & 1 & 2 & 3 & 4 & 5 & 6 & 7 & 8 & 9 & 10 & 11 & 12 & 13 & 14 & 15 & 16 & 17 & 18 & 19 & 20 & 21 & 22 & 23 & 24 & 25 & 26 & 27 & 29 & 29 & 30 & 31 & \text { AGF }\end{array}$

OCTOBER

MAXIMUM - - - - - - - - - - - -

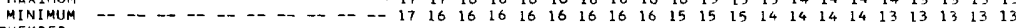

NOVEMBER

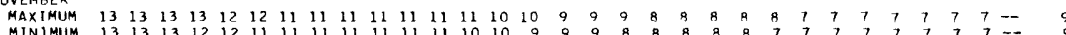

$\begin{array}{lllllllllllllllllllllllllllllllll}\text { MINIMUM } & 13 & 13 & 13 & 12 & 12 & 11 & 11 & 11 & 11 & 11 & 11 & 11 & 10 & 10 & 9 & 9 & 9 & 8 & 8 & 8 & 8 & 8 & 7 & 7 & 7 & 7 & 7 & 7 & 7 & 7 & -5\end{array}$

DEEMBER

$\begin{array}{lllllllllllllllllllllllllllllllllll}\text { MAXIMUM } & 7 & 7 & 7 & 6 & 6 & 6 & 6 & 6 & 6 & 6 & 6 & 6 & 6 & 6 & 6 & 6 & 6 & 6 & 5 & 5 & 5 & 5 & 4 & 4 & 4 & 4 & 4 & 4 & 3 & 3 & 3 & 5\end{array}$

MINIMUM
JANUARY

$\begin{array}{rlllllllllllllllllllllllllllllllll}\text { MAXIMUM } & 3 & 2 & 2 & 2 & 2 & 2 & 2 & 2 & 1 & 1 & 1 & 1 & 2 & 2 & 2 & 2 & 2 & 2 & 2 & 2 & 2 & 2 & 2 & 2 & 2 & 2 & 2 & 2 & 3 & 3 & 3 & 2 \\ \text { MINIMUM } & 2 & 2 & 2 & 1 & 1 & 2 & 2 & 1 & 1 & 1 & 1 & 1 & 1 & 2 & 2 & 2 & 2 & 2 & 2 & 2 & 2 & 2 & 2 & 2 & 2 & 2 & 2 & 2 & 2 & 3 & 3 & 1\end{array}$

$\begin{array}{llllllllllllllllllllllllllllllllll}M A X I M U M & 3 & 4 & 3 & 3 & 3 & 3 & 3 & 3 & 3 & 3 & 2 & 2 & 2 & 2 & 2 & 2 & 2 & 2 & 2 & 2 & 2 & 2 & 2 & 2 & 2 & 2 & 2 & 2 & 2 & -- & --\end{array}$

MINIMUM

$\begin{array}{lllllllllllllllllllllllllllllllll}\text { MARCH } \\ \text { MAXIMUM } & 2 & 2 & 2 & 2 & 3 & 3 & 3 & 3 & 3 & 3 & 3 & 3 & 3 & 3 & 3 & 4 & 4 & 4 & 4 & 5 & 6 & 6 & 6 & 6 & 6 & 6 & 6 & 7 & 7 & 7 & 9 & 4\end{array}$

APRIL

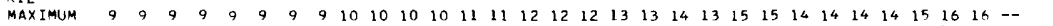

MAY

MAXIMUM $16 \quad 16 \quad 16 \quad 16 \quad 17 \quad 16 \quad 17 \quad 17 \quad 16 \quad 15 \quad 16 \quad 16 \quad 17 \quad 17 \quad 18 \quad 18 \quad 17 \quad 17 \quad 17 \quad 17 \quad 17 \quad 17 \quad 17 \quad 16 \quad 17 \quad 17 \quad 17 \quad 16 \quad 16 \quad 16 \quad 16 \quad 16$

MINIMUM $14 \quad 14 \begin{array}{llllllllllllllllllllllllllllllll}16 & 15 & 15 & 15 & 16 & 16 & 14 & 14 & 15 & 16 & 16 & 17 & 17 & 16 & 16 & 17 & 17 & 16 & 16 & 16 & 16 & 16 & 16 & 16 & 16 & 16 & 16 & 16 & 15 & 16\end{array}$

JUNE

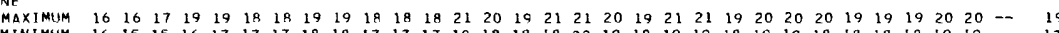

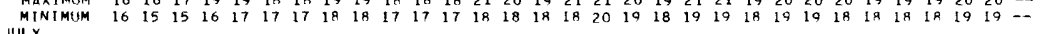
JutY

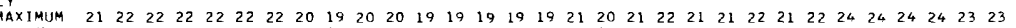

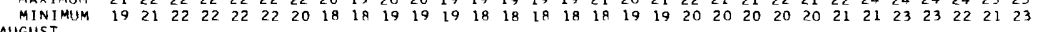
AUGUST

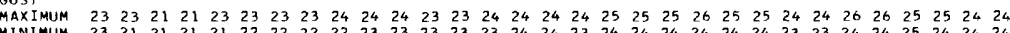
SEPTEMAUER

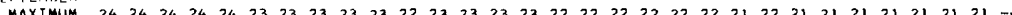

$\begin{array}{llllllllllllllllllllllllllllllllll}\text { MAXIMUM } & 24 & 24 & 24 & 24 & 24 & 23 & 23 & 23 & 23 & 23 & 22 & 23 & 23 & 23 & 23 & 22 & 22 & 22 & 22 & 22 & 22 & 21 & 22 & 21 & 21 & 21 & 21 & 21 & 21 & 21 & - \\ \text { MINIMUM } & 23 & 23 & 23 & 23 & 23 & 23 & 23 & 23 & 22 & 22 & 22 & 22 & 22 & 22 & 22 & 22 & 22 & 22 & 22 & 21 & 21 & 21 & 21 & 21 & 21 & 21 & 21 & 21 & 21 & 21 & -\end{array}$ 
LOCATION,--Lat $38^{\circ} 30^{\prime} 39^{\prime \prime}$, long $87^{\circ} 17^{\prime} 22^{\prime \prime}$, temperature recorder at gaging station on left bank, $300 \mathrm{ft}$ downstream from bridge on State Highway 61,0.4 mile upstream from Prides Creek, 1 mile north of Petersburg, and at mile 47.7.

DRAINAGE AREA. $--11,125 \mathrm{sq}$ mi (revised).

PER IOD OF RECORD. --Water temperatures: June 1964 to September 1968.

EXTREMES, --1967-68:

Water temperatures: Maximum, $29.0^{\circ} \mathrm{C}$ July 21-27, Aug. 9, 10, 21-26; minimum, 2.0 $0^{\circ} \mathrm{C}$ Jan. 2-15, 24-28, Feb. 10-24.

Period of record: Water temperatures: Maximum, $31.0^{\circ} \mathrm{C}$ July 14, 15, 1966; minimum, freezing point on many days during winter
periods.

REMARKS. --Flow slightly regulated by reservoirs.

TEMPERATURE $\left.1{ }^{\circ} \mathrm{C}\right)$ OF WATER, WATER YEAR OCTOBER 1967 TO SEPTEMBER 1968 (CONTINUDUS ETHYL ALCDHOL-ACTUATED THERMOGRAPHI

OCTDBER

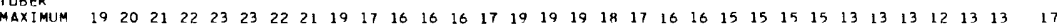
MINIMUM $17 \begin{array}{llllllllllllllllllllllllllllllll}19 & 20 & 22 & 23 & 23 & 22 & 21 & 19 & 17 & 16 & 16 & 16 & 17 & 19 & 19 & 19 & 18 & 17 & 16 & 16 & 15 & 15 & 15 & 15 & 13 & 13 & 13 & 12 & 13 & 13 & 17 \\ & 17 & 21 & 19 & 17 & 16 & 15 & 14 & 15 & 16 & 17 & 19 & 18 & 17 & 16 & 15 & 14 & 14 & 14 & 14 & 13 & 13 & 13 & 12 & 12 & 12 & 13 & 16\end{array}$

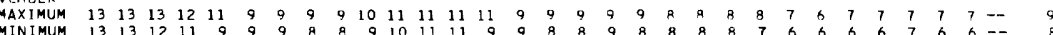
MINIMUM $13 \begin{array}{llllllllllllllllllllllllllllllllll}3 & 12 & 11 & 9 & 9 & 9 & 8 & 8 & 9 & 10 & 11 & 11 & 9 & 9 & 8 & 8 & 9 & 8 & 8 & 8 & 8 & 7 & 6 & 6 & 6 & 6 & 7 & 6 & 6 & -\end{array}$

$\begin{array}{lllllllllllllllllllllllllllllllllllll}\text { MAXIMUM } & 6 & 6 & 7 & 7 & 7 & 7 & 7 & 7 & 7 & 7 & 9 & 8 & 8 & 8 & 8 & 7 & 7 & 6 & 6 & 6 & 7 & 7 & 7 & 7 & 7 & 6 & 4 & 3 & 3 & 3 & 3 & 6 \\ \text { MINIMUM } & 6 & 6 & 6 & 7 & 7 & 7 & 7 & 7 & 7 & 7 & 7 & 8 & 8 & 8 & 7 & 7 & 6 & 6 & 6 & 6 & 6 & 7 & 7 & 7 & 6 & 4 & 3 & 3 & 3 & 3 & 3 & 4\end{array}$ MTNTMUM

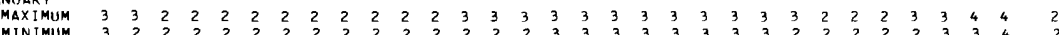
$\begin{array}{llllllllllllllllllllllllllllllllllll}\text { MINIMUM } & 3 & 2 & 2 & 2 & 2 & 2 & 2 & 2 & 2 & 2 & 2 & 2 & 2 & 2 & 2 & 3 & 3 & 3 & 3 & 3 & 3 & 3 & 3 & 2 & 2 & 2 & 2 & 2 & 3 & 3 & 4 & 2\end{array}$

$\begin{array}{lllllllllllllllllllllllllllllllllll}\text { MAXIMUM } & 6 & 7 & 6 & 6 & 6 & 5 & 4 & 4 & 4 & 3 & 2 & 2 & 2 & 2 & 2 & 2 & 2 & 2 & 2 & 2 & 2 & 2 & 2 & 3 & 3 & 4 & 4 & 4 & 4 & -- & -- & 3 \\ \text { MINIMUM } & 4 & 6 & 6 & 6 & 5 & 4 & 4 & 4 & 3 & 2 & 2 & 2 & 2 & 2 & 2 & 2 & 2 & 2 & 2 & 2 & 2 & 2 & 2 & 2 & 3 & 3 & 4 & 4 & 4 & -- & -- & 3 & 3\end{array}$

MARCH

$\begin{array}{llllllllllllllllllllllllllllllllllll}\text { MAXIMUM } & 4 & 4 & 3 & 5 & 6 & 6 & 6 & 7 & 8 & 8 & 8 & 8 & 6 & 5 & 6 & 6 & 6 & 7 & 8 & 8 & 8 & 8 & 7 & 6 & 6 & 6 & 7 & 8 & 10 & 12 & 12 & 6 \\ \text { MINIMUM } & 4 & 3 & 3 & 3 & 5 & 6 & 6 & 6 & 7 & 8 & 8 & 6 & 4 & 4 & 5 & 6 & 6 & 6 & 7 & 8 & 8 & 7 & 6 & 6 & 6 & 6 & 6 & 7 & 8 & 10 & 12 & 6\end{array}$ APRIL

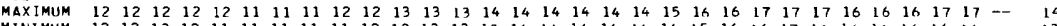

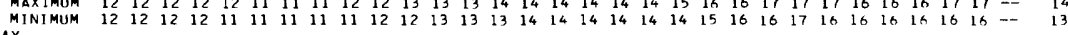
$\begin{array}{lllllllllllllllllllllllllllllllllllll}\text { MAXIMUM } & 18 & 19 & 19 & 19 & 19 & 19 & 18 & 19 & 19 & 19 & 19 & 18 & 18 & 18 & 19 & 19 & 19 & 19 & 19 & 19 & 18 & 18 & 18 & 18 & 17 & 17 & 17 & 18 & 18 & 17 & 17 & 18 \\ \text { MINIMUM } & 17 & 18 & 19 & 19 & 18 & 18 & 18 & 18 & 19 & 19 & 18 & 18 & 18 & 18 & 18 & 18 & 19 & 19 & 19 & 18 & 19 & 18 & 18 & 17 & 17 & 17 & 17 & 17 & 17 & 17 & 17 & 17\end{array}$

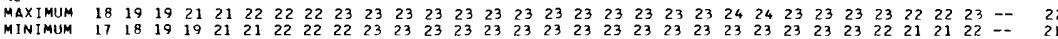

JULY

MAXIMUM $\begin{array}{lllllllllllllllllllllllllllllllllll}23 & 23 & 23 & 23 & 24 & 24 & 24 & 24 & 25 & 25 & 26 & 26 & 27 & 27 & 27 & 27 & 27 & 27 & 28 & 28 & 29 & 29 & 29 & 29 & 29 & 29 & 29 & 28 & 28 & 28 & 27 & 24\end{array}$ AUGUIST

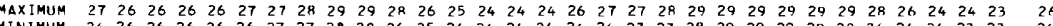
MINIMUM $26 \begin{array}{lllllllllllllllllllllllllllllllllllllll}26 & 26 & 26 & 26 & 26 & 27 & 27 & 28 & 28 & 26 & 25 & 24 & 24 & 24 & 24 & 24 & 26 & 27 & 27 & 28 & 29 & 29 & 29 & 29 & 28 & 26 & 24 & 24 & 23 & 23\end{array}$

$\begin{array}{llllllllllllllllllllllllllllllllllllllllll}\text { MAXIMUM } & 23 & 23 & 23 & 23 & 23 & 23 & 23 & 23 & 23 & 23 & 22 & 21 & 21 & 22 & 22 & 22 & 22 & 21 & 21 & 22 & 22 & 23 & 24 & 24 & 24 & 23 & 22 & 22 & 22 & 22 & -1\end{array}$

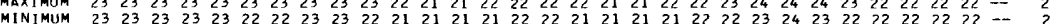
TRADEWATER RIVER BASIN

03382720 BUfFalo CREEK AT STATE hIGHWAY 1338, NEAR DAWSON SPRINGS, $\mathrm{KY}$.

LOCATION.--Lat $37^{\circ} 08^{\prime} 29^{\prime \prime}$, long $87^{\circ} 36^{\prime} 54^{\prime \prime}$, Hopkins County, at hridge on State Highway $1338,3.0 \mathrm{miles}$ upstream from mouth, 4.1 miles southwest of St. Charles and 4.6 miles southeast of Dawson Springs.

DRAINAGE AREA. - - 12.7 sq $\mathrm{mi}$.

PERIOD OF RECORD.--Chemical analyses: November 1965 to September 1968.

EXTREMES, --April to September 1968:

Specific conductance: Maximum daily, 3100 micrombos Aug. 30, to Sept. 1; minimum daily, 160 micromhos June 2 SPECIFIC CONDUCTANCE (MICROMHOS AT $25^{\circ} \mathrm{C}$ ), APRIL TO SEPTEMBER 1968 MAPRIL

$1 \ldots$

$5 \ldots \ldots$

6.......

$8 \ldots . . .0$

$10 \ldots . .$.

$11, \ldots$

$12 . . .$.

$14 \ldots .$.

$15 \ldots \ldots$

$17 \ldots . .$.

$18 \ldots . .$.

180.00

$20 \ldots . .$.

$22 \ldots \ldots$

$23 \ldots \ldots$

$24 \ldots \ldots$

$25 \ldots . .$.

$27 \ldots \ldots$

$28 \ldots \ldots$

$30 \ldots . .$.

$31 \ldots . .$.

AVER AGE

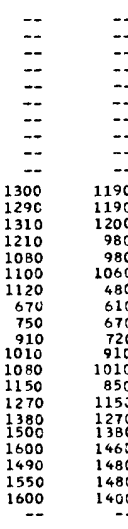

1500
1760
1680
1800
1650
1540
1540
1700
1150
--
--
--
--
--
670
720
780
940
1150
1150
1120
1250
1310
1350
1180
1120
1580
1580
1090
1480

1400
1420
1410
1450
1500
1520
1520
750
740
--
--
--
-
-
250
670
550
750
940
1050
1070
1170
$108 C$
1080
950
1080
1650
550
880
1090
1040

1310
JUNE

\begin{tabular}{|c|c|}
\hline $152 \mathrm{C}$ & 1090 \\
\hline 1090 & 160 \\
\hline 820 & 570 \\
\hline 990 & $82 C$ \\
\hline 1130 & 980 \\
\hline 1230 & 1130 \\
\hline 1250 & 1200 \\
\hline 1490 & 1250 \\
\hline $145 \mathrm{C}$ & 1380 \\
\hline 1520 & 1380 \\
\hline 1650 & 1490 \\
\hline 1750 & 1570 \\
\hline 1900 & 1620 \\
\hline 2000 & 1800 \\
\hline 2100 & 1860 \\
\hline$-\alpha$ & $\ldots$ \\
\hline- & \\
\hline- & \\
\hline$=$ & \\
\hline-- & \\
\hline$\cdots$ & \\
\hline 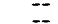 & - \\
\hline $230 \mathrm{C}$ & 2000 \\
\hline 2500 & 2300 \\
\hline 2500 & 2300 \\
\hline 2600 & 2500 \\
\hline 2600 & 2000 \\
\hline & \\
\hline
\end{tabular}

JuLY

$\begin{array}{lr}2600 & 2000 \\ 2700 & 2200 \\ 2800 & 2400 \\ 2600 & 2400 \\ 2600 & 2500 \\ 2500 & 2500 \\ 2600 & 2500 \\ 2800 & 270 \\ 1250 & 600 \\ 1750 & 1250 \\ 1850 & 1700 \\ 2100 & 1850 \\ 2100 & 1950 \\ 2600 & 2100 \\ 2400 & 2400 \\ 2600 & 2400 \\ 2700 & 2500 \\ 2500 & 2200 \\ 2200 & 21100 \\ 2200 & 2100 \\ 2700 & 2100 \\ 2700 & 2400 \\ 2600 & 2600 \\ 2900 & 2600 \\ 2900 & 2400 \\ 2800 & 1450 \\ 1900 & 1750 \\ 2200 & 1900 \\ 2200 & 2100 \\ 2100 & 2000 \\ 2600 & 2100 \\ & \\ 2420 & 2040\end{array}$

AUGUST

\begin{tabular}{|c|c|c|c|}
\hline $\begin{array}{l}2700 \\
2500\end{array}$ & $\begin{array}{l}1600 \\
1700\end{array}$ & $\begin{array}{l}3100 \\
2900\end{array}$ & $\begin{array}{l}2800 \\
2600\end{array}$ \\
\hline 2500 & 2200 & $260 n$ & 2600 \\
\hline 2400 & 2100 & 2600 & 2100 \\
\hline 2500 & 2300 & $230 n$ & 21 no \\
\hline 2500 & $24 \mathrm{CO}$ & 2200 & 2100 \\
\hline 2500 & 2500 & $240 ?$ & 2200 \\
\hline 2700 & 2500 & 2400 & 2400 \\
\hline 2700 & 2600 & 2500 & 2400 \\
\hline 2700 & 2600 & 2600 & 2400 \\
\hline 2700 & 2700 & 2600 & 2100 \\
\hline $270 \mathrm{C}$ & $>700$ & -- & -- \\
\hline 2900 & 2700 & -- & 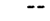 \\
\hline 2800 & 2600 & -- & - \\
\hline 2600 & 2300 & 3000 & 2900 \\
\hline 2400 & 2100 & 2000 & 2800 \\
\hline 2600 & 2400 & 2900 & 2800 \\
\hline 2600 & 2600 & 2900 & 2200 \\
\hline 2600 & 2600 & $240 n$ & 2200 \\
\hline 2600 & 2300 & 2800 & 2300 \\
\hline $23 n 0$ & $22 n c$ & 2300 & 2300 \\
\hline 2300 & 2200 & $23 \mathrm{nn}$ & 2300 \\
\hline- & -- & $240 C$ & 2300 \\
\hline- & - & 2800 & 2400 \\
\hline-- & - & 2600 & 2500 \\
\hline$\overline{-}$ & (3) & 2600 & 2600 \\
\hline 2000 & 2300 & $270 \mathrm{C}$ & 2600 \\
\hline 2660 & 2600 & 2800 & 2700 \\
\hline 2900 & 2600 & 2 ROC & 2800 \\
\hline 3100 & 2800 & 2000 & 2800 \\
\hline 3100 & 3100 & $\cdots$ & - \\
\hline
\end{tabular}

$2640-2420 \quad 2630-2460$ 
LOCATION. --Lat $37^{\circ} 13^{\prime} 26^{\prime \prime}$, long $87^{\circ} 46^{\circ} 53^{\prime \prime}$, Hopkins County, at gaging station at bighway bridge at Olney, 1.1 miles upstream from Cave Creek, 5.1 miles downstream from Flynn Creek and 9.5 ailes northeast of Princeton.

DRAINAGE AREA.--255 sq mi, of which about $9.0 \mathrm{sg} \mathrm{mi} \mathrm{does} \mathrm{not} \mathrm{contribute} \mathrm{directly} \mathrm{to} \mathrm{surface} \mathrm{runoff.}$

PERIOD OF RECORD.--Chemical analyses: October 1949 to August 1950, October 1951 to September 1968. Water temperatures: October 1951 to September 1968

EXTREMES, $-1967-68$ :

Specific conductance: Maximum, 1,650 micrombos oct. 23, 24; min1mum daily, 114 micromhos Mar. 22. Water temperatures: Maximum, $28,0^{\circ} \mathrm{C}$ Aug $22-24$; minimum, freezing point on many days during January and

Cediment concentrations: Maximum da1ly, $377 \mathrm{mg} / 1$ Mar. $21 ;$ minimum daily, $0 \mathrm{mg} / 1$ Sept. 8-10, 28-30.

Sediment loads: Maximum daily, 1,710 tons Mar. 21; min1mum da11y, 0 tons Aug. 26 to Sept. 4

Sept. $8-10,28-30$.

CHEMICAL ANALYSES IN MILLIGRAMS PER LITER, WATER YEAR OCTOBER 1967 TO SEPTEMBER 1968

\begin{tabular}{|c|c|c|c|c|c|c|c|c|}
\hline DATE & $\begin{array}{l}\text { OIS- } \\
\text { CHARGE } \\
\text { (CFS) }\end{array}$ & $\begin{array}{l}\text { DIS- } \\
\text { SOLVEC } \\
\text { ALUM- } \\
\text { IN IUM } \\
\text { (AL) }\end{array}$ & $\begin{array}{l}\text { DIS- } \\
\text { SOLVED } \\
\text { IRON } \\
\text { (FE) }\end{array}$ & $\begin{array}{l}\text { DISS- } \\
\text { DL VEO } \\
\text { MAN- } \\
\text { GANESE } \\
\text { (MN) }\end{array}$ & $\begin{array}{l}\text { BICAR- } \\
\text { BONATE } \\
\text { (HCO3) }\end{array}$ & $\begin{array}{l}\text { CAR- } \\
\text { BCNATE } \\
\text { (CO3) }\end{array}$ & $\begin{array}{l}\text { SULFATE } \\
\text { (SO4) }\end{array}$ & $\begin{array}{l}\text { CHLE- } \\
\text { RINE } \\
\text { ICLI }\end{array}$ \\
\hline OCT. & & & & & & & & \\
\hline $\begin{array}{l}19 . . . \\
24 . . \\
\text { Nov. }\end{array}$ & $\begin{array}{l}91 \\
11\end{array}$ & $1^{5.2}$ & $\begin{array}{l}.02 \\
.31\end{array}$ & $\begin{array}{l}13 \\
21\end{array}$ & $\begin{array}{l}2 \\
0\end{array}$ & $\begin{array}{l}0 \\
0\end{array}$ & $\begin{array}{l}528 \\
952\end{array}$ & $\begin{array}{l}6.0 \\
5.0\end{array}$ \\
\hline $\begin{array}{l}04 \ldots \\
22 . \ldots\end{array}$ & $\begin{array}{l}29 \\
35\end{array}$ & ${ }^{13} .5$ & $\begin{array}{l}.18 \\
.01\end{array}$ & ${ }^{15} .47$ & $\begin{array}{l}0 \\
2\end{array}$ & $\begin{array}{l}0 \\
0\end{array}$ & $\begin{array}{r}640 \\
99\end{array}$ & $\begin{array}{l}5.0 \\
3,0\end{array}$ \\
\hline $\begin{array}{l}\text { DEC. } \\
\text { ol.... }\end{array}$ & 676 & 1.7 & .01 & 5.3 & 2 & 0 & 237 & 40 \\
\hline JAN. & 1060 & $\cdot 3$ & .08 & .02 & 30 & 0 & 37 & 20 \\
\hline $\begin{array}{l}07 \ldots \\
24 \ldots \ldots \\
F E B, \ldots\end{array}$ & $\begin{array}{r}93 \\
943\end{array}$ & $0^{.1}$ & $\begin{array}{l}.01 \\
.01\end{array}$ & $\begin{array}{l}4.7 \\
.47\end{array}$ & $\begin{array}{r}8 \\
15\end{array}$ & $\begin{array}{l}0 \\
0\end{array}$ & $\begin{array}{r}229 \\
\text { nO }\end{array}$ & $\begin{array}{ll}40 \\
6 & 0\end{array}$ \\
\hline $\begin{array}{l}04 \ldots . . \\
26 . . .\end{array}$ & $\begin{array}{r}1810 \\
49\end{array}$ & .2 & $\begin{array}{l}.62 \\
.02\end{array}$ & $\begin{array}{c}.01 \\
5.8\end{array}$ & $\begin{array}{r}14 \\
4\end{array}$ & $\begin{array}{l}0 \\
0\end{array}$ & $\begin{array}{r}43 \\
288\end{array}$ & $\begin{array}{ll}1 & 0 \\
3 & 0\end{array}$ \\
\hline $\begin{array}{l}0 T \ldots . . \\
22 \ldots \\
\triangle P R .\end{array}$ & $\begin{array}{r}40 \\
1950\end{array}$ & .9 & ${ }^{0} .15$ & $\begin{array}{l}5.8 \\
.01\end{array}$ & $\begin{array}{r}3 \\
20\end{array}$ & 0 & $\begin{array}{r}306 \\
32\end{array}$ & $\begin{array}{ll}7 & 0 \\
3 & 0\end{array}$ \\
\hline $\begin{array}{l}05 \ldots . . \\
28 . \ldots\end{array}$ & $\begin{array}{r}2220 \\
147\end{array}$ & .2 & $0^{.09}$ & $\begin{array}{l}0 \\
3.2\end{array}$ & $\begin{array}{r}20 \\
8\end{array}$ & $\begin{array}{l}0 \\
0\end{array}$ & $\begin{array}{r}51 \\
233\end{array}$ & $\begin{array}{ll}2 & 5 \\
5 & 0\end{array}$ \\
\hline $\begin{array}{l}10 \ldots . . \\
15 . . . \\
\text { JUNE }\end{array}$ & $\begin{array}{r}90 \\
1310\end{array}$ & .1 & ${ }^{0} .02$ & $0^{5.0}$ & $\begin{array}{r}8 \\
20\end{array}$ & $\begin{array}{l}0 \\
0\end{array}$ & $\begin{array}{r}320 \\
69\end{array}$ & $\begin{array}{ll}5 & 0 \\
3 & 0\end{array}$ \\
\hline $\begin{array}{l}03 \ldots . . . \\
\text { Jut } \%\end{array}$ & $\begin{array}{r}846 \\
9.5\end{array}$ & .1 & .03 & 5.02 & $\begin{array}{l}14 \\
12\end{array}$ & $\begin{array}{l}0 \\
0\end{array}$ & $\begin{array}{r}97 \\
308\end{array}$ & $\begin{array}{ll}2 & 5 \\
4 . & 5\end{array}$ \\
\hline $\begin{array}{l}10 . . . \\
11 \ldots . . \\
\text { AUG. }\end{array}$ & $\begin{array}{l}313 \\
160\end{array}$ & $\begin{array}{l}8.0 \\
0^{\circ}\end{array}$ & $\begin{array}{l}.08 \\
.04\end{array}$ & ${ }^{10} .03$ & $\begin{array}{r}0 \\
12\end{array}$ & : & $\begin{array}{l}614 \\
109\end{array}$ & $\begin{array}{l}6.0 \\
20\end{array}$ \\
\hline $\begin{array}{l}01 \ldots . . \\
\text { SEPT. }\end{array}$ & $\begin{array}{l}26 \\
8.6\end{array}$ & $22^{. B}$ & $\begin{array}{l}.02 \\
.26\end{array}$ & $15^{7.2}$ & $\begin{array}{l}0 \\
0\end{array}$ & $\begin{array}{l}0 \\
0\end{array}$ & $\begin{array}{l}310 \\
796\end{array}$ & $\begin{array}{l}5.0 \\
60\end{array}$ \\
\hline $22 . .$. & $17^{.15}$ & $\begin{array}{l}5 \cdot 8 \\
0\end{array}$ & $\begin{array}{l}.16 \\
.01\end{array}$ & 11 & 12 & $\begin{array}{l}0 \\
0\end{array}$ & $\begin{array}{l}469 \\
166\end{array}$ & $\begin{array}{ll}40 \\
40\end{array}$ \\
\hline
\end{tabular}

SPECIFIC CONDUCTANCE (MICROMHOS AT $25^{\circ} \mathrm{C}$ ), WATER YEAR OCTOBER 1967 TO SEPTEMBER 1968 (ONCE-DAILY MEASUREMENT AT APPROXIMATELY O7O0)

DAY

\begin{tabular}{|c|c|c|}
\hline $\begin{array}{l}1 \ldots \ldots \\
2 \ldots \ldots \\
3 \ldots \ldots \\
4 \ldots \ldots\end{array}$ & $\begin{array}{l}104 C \\
1060 \\
1050 \\
1060 \\
1070\end{array}$ & $\begin{array}{r}1010 \\
1640 \\
1070 \\
1170 \\
B C 9\end{array}$ \\
\hline $\begin{array}{r}6 \ldots \ldots \\
7 \ldots \ldots \\
9 \ldots \ldots \\
10 \ldots \ldots\end{array}$ & $\begin{array}{l}1080 \\
1070 \\
1090 \\
1090 \\
1110\end{array}$ & $\begin{array}{l}714 \\
700 \\
770 \\
774 \\
827\end{array}$ \\
\hline $\begin{array}{l}11 \ldots \ldots \\
12 \ldots \ldots \\
13 \ldots \ldots \\
14 \ldots \ldots \\
15 \ldots \ldots\end{array}$ & $\begin{array}{l}1120 \\
1120 \\
1140 \\
1140 \\
1150\end{array}$ & $\begin{array}{r}910 \\
1040 \\
700 \\
714 \\
846\end{array}$ \\
\hline $\begin{array}{l}16 \ldots \ldots \\
17 \ldots \ldots \\
18 \ldots \ldots \\
19 \ldots \ldots \\
20 \ldots \ldots\end{array}$ & $\begin{array}{r}1140 \\
1130 \\
1230 \\
966 \\
1030\end{array}$ & $\begin{array}{l}750 \\
597 \\
560 \\
587 \\
617\end{array}$ \\
\hline $\begin{array}{l}21 \ldots \ldots \\
22 \ldots \ldots \\
23 \ldots \ldots \\
24 \ldots \ldots \\
25 \ldots \ldots\end{array}$ & $\begin{array}{l}1060 \\
1350 \\
1570 \\
1610 \\
1550\end{array}$ & $\begin{array}{l}597 \\
251 \\
587 \\
597 \\
597\end{array}$ \\
\hline $\begin{array}{l}26 \ldots \ldots \\
27 \ldots \ldots \\
28 \ldots \ldots \\
29 \ldots \ldots \\
30 \ldots \ldots \\
31 \ldots \ldots\end{array}$ & $\begin{array}{r}1580 \\
1270 \\
992 \\
1130 \\
1050 \\
1010\end{array}$ & $\begin{array}{l}628 \\
587 \\
674 \\
674 \\
674 \\
-\end{array}$ \\
\hline AVERAGE & 1160 & 735 \\
\hline
\end{tabular}

$\begin{array}{lll}390 & 300 & 5 \\ 410 & 180 & 566 \\ 439 & 13 C & 564 \\ 453 & 134 & 5 \\ 454 & 154 & 631 \\ 471 & 189 & 6 \\ 511 & 238 & 636 \\ 460 & 227 & 5 \\ 440 & 256 & 5 \\ 450 & 295 & 5 \\ 460 & 321 & 5 \\ 460 & 345 & 5 \\ 420 & 366 & 3 \\ 440 & 377 & 174 \\ 46 C & 386 & 3 \\ 440 & 408 & 274 \\ 450 & 395 & 2 \\ 440 & 408 & 2 \\ 436 & 466 & 3 \\ 410 & 492 & 307 \\ 390 & 502 & 1 \\ 376 & 521 & 1 \\ 249 & 520 & 1 \\ 238 & 497 & 1 \\ 249 & 532 & 167 \\ 274 & 605 & 1 \\ 277 & 589 & 1 \\ 302 & 532 & 1 \\ 332 & 554 & 204 \\ 329 & -2 & 262 \\ 280 & -0 & 261 \\ 393 & 376 & 365 \\ & & \end{array}$

\begin{tabular}{|c|c|}
\hline 541 & 229 \\
\hline 566 & 186 \\
\hline 564 & 191 \\
\hline 585 & 212 \\
\hline 631 & 156 \\
\hline 629 & 163 \\
\hline 636 & 166 \\
\hline 590 & 170 \\
\hline 556 & 212 \\
\hline 599 & 274 \\
\hline 598 & 282 \\
\hline 538 & 298 \\
\hline 351 & 330 \\
\hline 174 & 382 \\
\hline $3 \mathrm{C} 9$ & 388 \\
\hline $\begin{array}{l}274 \\
272\end{array}$ & $\begin{array}{l}392 \\
345\end{array}$ \\
\hline 294 & 256 \\
\hline 309 & 184 \\
\hline 307 & 239 \\
\hline 137 & 298 \\
\hline 114 & 288 \\
\hline 136 & -- \\
\hline 148 & 327 \\
\hline 167 & 355 \\
\hline 191 & 423 \\
\hline 193 & 407 \\
\hline 192 & 507 \\
\hline 204 & 464 \\
\hline 262 & -- \\
\hline 261 & - \\
\hline
\end{tabular}

JUNE

350
252
281
314
31
338
344
364
375
38
415
434
446
439
454
462
484
516
506
529
56
575
602
612
62
62
626
629
634
-
464

JULY AUGUST SEPTEMBER

$\begin{array}{rrr}653 & 659 & 886 \\ 640 & 762 & 88 B \\ 645 & 1050 & 878 \\ 662 & 1130 & 866 \\ 667 & 1200 & 844 \\ 670 & 1140 & 773 \\ 678 & 1190 & 664 \\ 681 & 1270 & 643 \\ 696 & 1330 & 615 \\ 1120 & 1360 & 574 \\ 269 & 1360 & 542 \\ 284 & 1360 & 499 \\ 293 & 134 C & 472 \\ 326 & 1200 & 449 \\ 355 & 1140 & 436 \\ 384 & 1070 & 424 \\ 398 & 1080 & 413 \\ 402 & 1180 & 406 \\ 401 & 1180 & 402 \\ 403 & 1200 & 404 \\ 401 & 1360 & 407 \\ 407 & 1240 & 398 \\ 416 & 1090 & 408 \\ 440 & 1000 & 582 \\ 452 & 1030 & 726 \\ 464 & 958 & 745 \\ 547 & 954 & 748 \\ 391 & 937 & 729 \\ 447 & 932 & 728 \\ 515 & 927 & 722 \\ 724 & 920 & -9 \\ 510 & 1110 & 609 \\ & & \\ 510 & & \end{array}$


03383000 TRADEWATER RIVER AT OLNEY, KY.--Continued

Period of record:

Specific conductance: Maximum dally, 2,480 micromhos Dec. 3, 1965; minimum da11y, 51 micromhos Mar. $23,1952$. water temperatures: Maximum, $30.5^{\circ} \mathrm{C}$ July 26, 29, 1952; minimum, freezing point on many days during winter

Sediment concentrations (1952-68): Kaximum daily, $764 \mathrm{mg} / 1$ June 5,1954 ; minimum daily, no flow on many days during 1952-57, 1960, 1963-64, 1966 . Sediment loads (1952-68): Maximum daily, 5,100 tons Mar. 10, 1964; minimum daily, 0 tons on many days during
1952-58, 1960-61, 1963-64, 1966, 1968.

RELARKS. - Values reported for iron and manganese are in solution when analyzed. Total acidity values determined to $\mathrm{pH} 7.0$. Dally samples were collected at this station and samples were selected for analysis on the

following basis: (1) Maximum dally specific conductance for each month, and (2) minimum daily specific February 16, 1968 and the data from this montor are included with the records for this station.

CHEMICAL ANALYSES IN MILLIGRAMS PER LITER, WATER YEAR OCtOBER 1967 TO SEPTEMBER 1968

\begin{tabular}{|c|c|c|c|c|c|c|c|c|}
\hline DATE & $\begin{array}{c}\text { NITRATE } \\
\text { INO3I }\end{array}$ & $\begin{array}{l}\text { DIS- } \\
\text { SOLVED } \\
\text { SOLIDS } \\
\text { TPESI- } \\
\text { OUE AT } \\
180 \mathrm{CI}\end{array}$ & $\begin{array}{l}\text { HARD- } \\
\text { NESS } \\
\text { ICA,MGI I }\end{array}$ & $\begin{array}{l}\text { NON- } \\
\text { CAR- } \\
\text { BDNATE } \\
\text { HARD- } \\
\text { NESS }\end{array}$ & $\begin{array}{c}\text { TOTAL } \\
\text { ACIDITY } \\
\text { AS } \\
H^{+}\end{array}$ & $\begin{array}{l}\text { SPFCI- } \\
\text { FIC } \\
\text { CDND } \\
\text { UCTANE } \\
\text { IMICRD- } \\
\text { MHOSI }\end{array}$ & $\mathrm{DH}_{\mathrm{H}}$ & $\begin{array}{l}\text { TEMP- } \\
\text { ERATURE } \\
\text { INEG CI }\end{array}$ \\
\hline & & & & & & & & \\
\hline $\begin{array}{l}29 \ldots . . \\
24 \ldots\end{array}$ & $\begin{array}{r}1.1 \\
.4\end{array}$ & $\begin{array}{r}822 \\
1440\end{array}$ & $\begin{array}{l}504 \\
824\end{array}$ & $\begin{array}{l}502 \\
824\end{array}$ & $3 . \overline{0}$ & $\begin{array}{r}956 \\
1610\end{array}$ & $\begin{array}{ll}46 \\
3 & 7\end{array}$ & $\begin{array}{l}13 \\
13\end{array}$ \\
\hline $\begin{array}{l}\text { Nov. } \\
04 \ldots . . .\end{array}$ & & 984 & & 560 & 2.2 & 1170 & 37 & \\
\hline $22 . .$. & 1.2 & 182 & 96 & 94 & & 251 & 47 & $T$ \\
\hline $\begin{array}{l}\text { OEC. } \\
\text { O1.... }\end{array}$ & 1.6 & 390 & 230 & 228 & -- & & & \\
\hline${ }_{\text {JANo }}^{12 \ldots . .}$ & 1.2 & 100 & 56 & 31 & 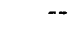 & 138 & 66 & $\stackrel{4}{9}$ \\
\hline $\begin{array}{l}07 \ldots . . \\
240 . .\end{array}$ & 1.4 & 336 & 239 & 232 & - & 511 & 69 & 0 \\
\hline${ }_{\text {FEB. }}^{240.0}$ & & 156 & & 80 & & 238 & & 1 \\
\hline $\begin{array}{r}04 \ldots . . \\
26 .: \\
\text { MAR. }\end{array}$ & 1.2 & $\begin{array}{r}68 \\
430\end{array}$ & $\begin{array}{r}52 \\
294\end{array}$ & $\begin{array}{r}41 \\
291\end{array}$ & $=$ & $\begin{array}{l}134 \\
605\end{array}$ & $\begin{array}{l}7,2 \\
6,4\end{array}$ & $\vec{l}$ \\
\hline $\begin{array}{l}07 \ldots . . \\
22 \ldots\end{array}$ & $2: 2$ & $\begin{array}{r}472 \\
88\end{array}$ & $\begin{array}{r}298 \\
44\end{array}$ & $\begin{array}{r}295 \\
28\end{array}$ & $\therefore 2$ & $\begin{array}{l}636 \\
114\end{array}$ & $\begin{array}{l}5.0 \\
7.2\end{array}$ & 4 \\
\hline $\begin{array}{r}05 \ldots \\
28 \ldots \\
M A Y\end{array}$ & 1.1 & $\begin{array}{l}108 \\
362\end{array}$ & $\begin{array}{r}62 \\
238\end{array}$ & $\begin{array}{r}46 \\
232\end{array}$ & $=1$ & $\begin{array}{l}156 \\
507\end{array}$ & $\begin{array}{l}7,3 \\
6 \quad 2\end{array}$ & $\begin{array}{l}14 \\
16\end{array}$ \\
\hline $\begin{array}{l}10 . . . \\
15 . . . \\
\text { JUNE }\end{array}$ & $\because 8$ & $\begin{array}{l}504 \\
134\end{array}$ & $\begin{array}{r}330 \\
81\end{array}$ & $\begin{array}{r}323 \\
64\end{array}$ & $=$ & $\begin{array}{l}662 \\
198\end{array}$ & $\begin{array}{l}7.3 \\
7.2\end{array}$ & $\begin{array}{l}17 \\
19\end{array}$ \\
\hline $\begin{array}{l}03 \ldots \\
30 . .\end{array}$ & $\begin{array}{r}1.2 \\
.3\end{array}$ & $\begin{array}{l}158 \\
452\end{array}$ & $\begin{array}{l}106 \\
315\end{array}$ & $\begin{array}{r}94 \\
305\end{array}$ & $: 1$ & $\begin{array}{l}252 \\
634\end{array}$ & $\begin{array}{l}6.8 \\
6.4\end{array}$ & $\begin{array}{l}19 \\
23\end{array}$ \\
\hline 1 & 1.2 & 890 & 575 & 575 & 1.0 & 1120 & & 22 \\
\hline AUG... & .4 & 164 & 114 & 104 & - & 269 & 7.6 & 21 \\
\hline $\begin{array}{l}01 . . . \\
11 . . \\
\text { SEPT. }\end{array}$ & $: 6$ & $\begin{array}{r}450 \\
1160\end{array}$ & $\begin{array}{l}300 \\
650\end{array}$ & $\begin{array}{l}300 \\
650\end{array}$ & $2: 2$ & $\begin{array}{r}659 \\
1360\end{array}$ & $\begin{array}{l}44 \\
38\end{array}$ & 26 \\
\hline $\begin{array}{l}02 . . . \\
22 . . .\end{array}$ & .6 & $\begin{array}{l}670 \\
248\end{array}$ & $\begin{array}{l}445 \\
170\end{array}$ & $\begin{array}{l}445 \\
160\end{array}$ & $\therefore 8$ & 888 & $\begin{array}{l}4.0 \\
7.5\end{array}$ & 21 \\
\hline
\end{tabular}

SPECIFIC CONDUCTANCE (MICROMHOS AT $25^{\circ} \mathrm{C}$ ), OCTOBER 1967 TO FEBRUARY 1968

\begin{abstract}
OCTOBER
\end{abstract}
NOVEMBER

DECEMBER

JANUARY

FEBRUARY

MARCH

MaXimum MINIMUM MaXiMUM MINIMUM

MAXIMUM MINIMUM ML

XIMUM MINimuM Maximum Mintmum

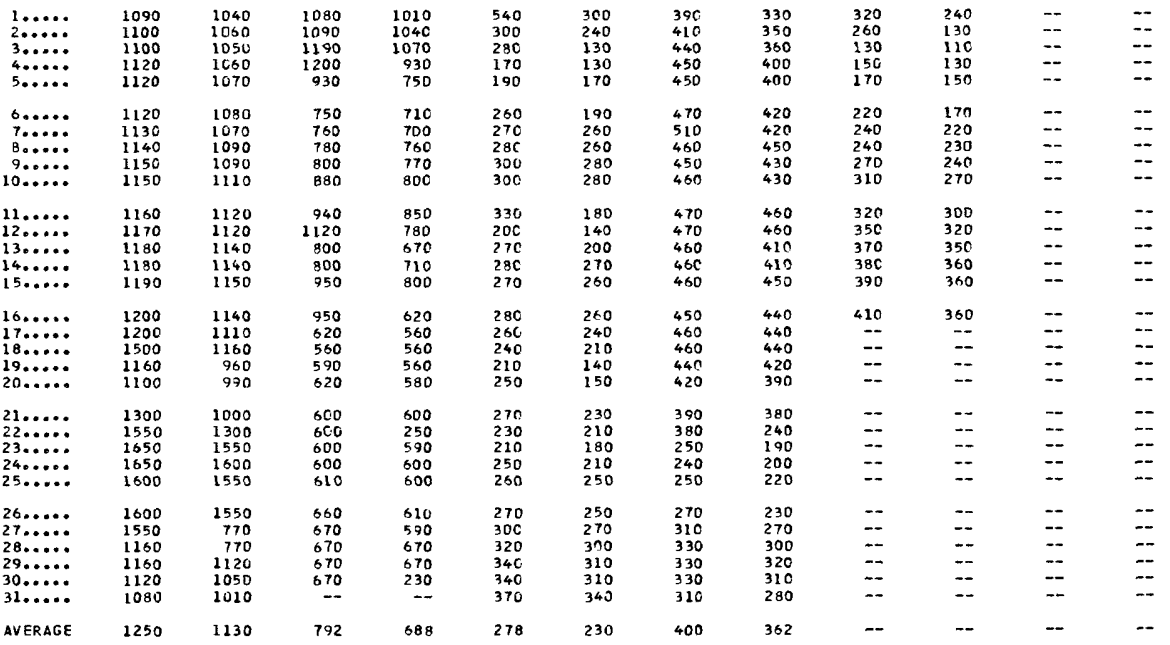


03383000 TRADEWATER RIVER AT OLNEY, KY, --Cont inued

TEMPERATURE $\left({ }^{\circ} \mathrm{C}\right)$ OF WATER, WATER YEAR OCTOBER 1967 TO SEPTEMBER 1968 (TWICE-DAILY MEASUREMENT AT APPROXIMATELY 0700 AND 1700 )

OCTOBER

NOVEMBER

DECEMBER

JANUARY

FEBRUARY

MARCH

\begin{tabular}{|c|c|c|c|c|c|c|c|c|c|c|c|c|}
\hline \multirow[b]{2}{*}{ DAY } & \multicolumn{2}{|c|}{ NCTOBER } & \multicolumn{2}{|c|}{ NOVEMBER } & \multicolumn{2}{|c|}{ DECEMBER } & \multicolumn{2}{|c|}{ JANUARY } & \multicolumn{2}{|c|}{ FEBRUARY } & \multicolumn{2}{|c|}{ MARCH } \\
\hline & $A M$ & $P H$ & $A M$ & $P M$ & $A M$ & PM & AM & PM & AM & $P M$ & AM & PM \\
\hline $\begin{array}{l}1 \\
2 \\
3 \\
4 \\
5\end{array}$ & $\begin{array}{l}14.0 \\
15.0 \\
14.0 \\
14.0 \\
15.0\end{array}$ & $\begin{array}{l}15.0 \\
15.0 \\
15.0 \\
16.0 \\
17.0\end{array}$ & $\begin{array}{r}12.0 \\
12.0 \\
12.0 \\
10.0 \\
8.0\end{array}$ & $\begin{array}{r}12.0 \\
12.0 \\
12.0 \\
10.0 \\
8.0\end{array}$ & $\begin{array}{l}4.0 \\
6.0 \\
7.0 \\
4.0 \\
6.0\end{array}$ & $\begin{array}{l}5.0 \\
4.0 \\
7.0 \\
6.0 \\
6.0\end{array}$ & $\begin{array}{l}1.0 \\
1.0 \\
1.0 \\
0.0 \\
0.0\end{array}$ & $\begin{array}{l}1.0 \\
1.0 \\
1.0 \\
1.0 \\
0.0\end{array}$ & $\begin{array}{l}7.0 \\
8.0 \\
7.0 \\
7.0 \\
6.0\end{array}$ & $\begin{array}{l}9.0 \\
9.0 \\
B .0 \\
7.0 \\
7.0\end{array}$ & $\begin{array}{l}1.0 \\
2.0 \\
2.0 \\
1.0 \\
3.0\end{array}$ & $\begin{array}{l}2.0 \\
3.0 \\
3.0 \\
2.0 \\
4.0\end{array}$ \\
\hline $\begin{array}{r}6 \\
7 \\
8 \\
9 \\
10\end{array}$ & $\begin{array}{l}16.0 \\
16.0 \\
16.0 \\
16.0 \\
14.0\end{array}$ & $\begin{array}{l}16.0 \\
17.0 \\
17.0 \\
16.0 \\
14.0\end{array}$ & $\begin{array}{l}7.0 \\
6.0 \\
6.0 \\
6.0 \\
6.0\end{array}$ & $\begin{array}{l}8.0 \\
7.0 \\
6.0 \\
7.0 \\
7.0\end{array}$ & $\begin{array}{l}7.0 \\
7.0 \\
7.0 \\
7.0 \\
8.0\end{array}$ & $\begin{array}{l}7.0 \\
8.0 \\
7.0 \\
8.0 \\
8.0\end{array}$ & $\begin{array}{l}0.0 \\
0.0 \\
0.0 \\
0.0 \\
0.0\end{array}$ & $\begin{array}{l}0.0 \\
0.0 \\
-- \\
--\end{array}$ & $\begin{array}{l}6.0 \\
6.0 \\
4.0 \\
3.0 \\
3.0\end{array}$ & $\begin{array}{l}6.0 \\
5.0 \\
4.0 \\
3.0 \\
3.0\end{array}$ & $\begin{array}{l}4.0 \\
4.0 \\
4.0 \\
7.0 \\
8.0\end{array}$ & $\begin{array}{l}4.0 \\
4.0 \\
5.0 \\
7.0 \\
8.0\end{array}$ \\
\hline $\begin{array}{l}11 \\
12 \\
13 \\
14 \\
15\end{array}$ & $\begin{array}{l}14.0 \\
13.0 \\
13.0 \\
13.0 \\
14.0\end{array}$ & $\begin{array}{l}14.0 \\
13.0 \\
14.0 \\
14.0 \\
15.0\end{array}$ & $\begin{array}{l}7.0 \\
9.0 \\
9.0 \\
9.0 \\
7.0\end{array}$ & $\begin{array}{r}9.0 \\
10.0 \\
9.0 \\
8.0 \\
8.0\end{array}$ & $\begin{array}{l}9.0 \\
9.0 \\
9.0 \\
9.0 \\
8.0\end{array}$ & $\begin{array}{r}9.0 \\
10.0 \\
11.0 \\
9.0 \\
9.0\end{array}$ & $\begin{array}{l}0.0 \\
0.0 \\
0.0 \\
0.0 \\
0.0\end{array}$ & $\bar{\square}$ & $\begin{array}{l}2.0 \\
1.0 \\
1.0 \\
1.0 \\
0.0\end{array}$ & $\begin{array}{l}1.0 \\
1.0 \\
1.0 \\
1.0 \\
2.0\end{array}$ & $\begin{array}{l}7.0 \\
7.0 \\
4.0 \\
4.0 \\
4.0\end{array}$ & $\begin{array}{l}8.0 \\
4.0 \\
5.0 \\
5.0 \\
6.0\end{array}$ \\
\hline $\begin{array}{l}16 \\
17 \\
18 \\
19 \\
20\end{array}$ & $\begin{array}{l}14.0 \\
14.0 \\
13.0 \\
13.0 \\
13.0\end{array}$ & $\begin{array}{l}14.0 \\
15.0 \\
14.0 \\
14.0 \\
14.0\end{array}$ & $\begin{array}{l}7.0 \\
7.0 \\
8.0 \\
7.0 \\
7.0\end{array}$ & $\begin{array}{l}7.0 \\
8.0 \\
8.0 \\
8.0 \\
7.0\end{array}$ & $\begin{array}{l}6.0 \\
6.0 \\
7.0 \\
7.0 \\
8.0\end{array}$ & $\begin{array}{l}6.0 \\
6.0 \\
8.0 \\
8.0 \\
8.0\end{array}$ & $\begin{array}{l}0.0 \\
0.0 \\
0.0 \\
0.0 \\
0.0\end{array}$ & $\overline{-}$ & $\begin{array}{l}1.0 \\
1.0 \\
1.0 \\
0.0 \\
1.0\end{array}$ & $\begin{array}{l}2.0 \\
2.0 \\
1.0 \\
1.0 \\
1.0\end{array}$ & $\begin{array}{r}6.0 \\
7.0 \\
8.0 \\
9.0 \\
11.0\end{array}$ & $\begin{array}{r}7.0 \\
8.0 \\
9.0 \\
9.0 \\
12.0\end{array}$ \\
\hline $\begin{array}{l}21 \\
22 \\
23 \\
24 \\
25\end{array}$ & $\begin{array}{l}12.0 \\
11.0 \\
11.0 \\
13.0 \\
12.0\end{array}$ & $\begin{array}{l}13.0 \\
12.0 \\
12.0 \\
13.0 \\
12.0\end{array}$ & $\begin{array}{l}7.0 \\
7.0 \\
7.0 \\
7.0 \\
6.0\end{array}$ & $\begin{array}{l}7.0 \\
8.0 \\
7.0 \\
7.0 \\
7.0\end{array}$ & $\begin{array}{l}9.0 \\
9.0 \\
7.0 \\
5.0 \\
4.0\end{array}$ & $\begin{array}{r}10.0 \\
9.0 \\
7.0 \\
5.0 \\
5.0\end{array}$ & $\begin{array}{l}0.0 \\
0.0 \\
2.0 \\
1.0 \\
1.0\end{array}$ & $\begin{array}{l}1.0 \\
1.0 \\
2.0 \\
2.0 \\
1.0\end{array}$ & $\begin{array}{l}1.0 \\
0.0 \\
0.0 \\
0.0 \\
1.0\end{array}$ & $\begin{array}{l}1.0 \\
1.0 \\
1.0 \\
1.0 \\
1.0\end{array}$ & $\begin{array}{l}8.0 \\
4.0 \\
2.0 \\
3.0 \\
4.0\end{array}$ & $\begin{array}{l}7.0 \\
4.0 \\
3.0 \\
5.0 \\
7.0\end{array}$ \\
\hline $\begin{array}{l}26 \\
27 \\
28 \\
29 \\
30 \\
31\end{array}$ & $\begin{array}{l}11.0 \\
11.0 \\
10.0 \\
11.0 \\
11.0 \\
12.0\end{array}$ & $\begin{array}{l}12.0 \\
12.0 \\
11.0 \\
12.0 \\
12.0 \\
13.0\end{array}$ & $\begin{array}{l}6.0 \\
6.0 \\
4.0 \\
4.0 \\
5.0 \\
\end{array}$ & $\begin{array}{l}7.0 \\
7.0 \\
5.0 \\
4.0 \\
4.0 \\
-.-\end{array}$ & $\begin{array}{l}4.0 \\
2.0 \\
1.0 \\
1.0 \\
1.0 \\
1.0\end{array}$ & $\begin{array}{l}4.0 \\
1.0 \\
1.0 \\
1.0 \\
1.0 \\
1.0\end{array}$ & $\begin{array}{l}1.0 \\
2.0 \\
4.0 \\
5.0 \\
6.0 \\
4.0\end{array}$ & $\begin{array}{l}2.0 \\
3.0 \\
5.0 \\
6.0 \\
7.0 \\
6.0\end{array}$ & $\begin{array}{l}1.0 \\
1.0 \\
1.0 \\
1.0 \\
-\end{array}$ & $\begin{array}{l}1.0 \\
1.0 \\
1.0 \\
2.0 \\
-\square\end{array}$ & $\begin{array}{r}7.0 \\
8.0 \\
11.0 \\
13.0 \\
14.0 \\
16.0\end{array}$ & $\begin{array}{r}9.0 \\
11.0 \\
12.0 \\
14.0 \\
16.0 \\
16.0\end{array}$ \\
\hline
\end{tabular}

PRIL

JULr

AUGUST

SEPTEMBER

DAY $\begin{array}{ll}13.0 & 13.0 \\ 12.0 & 12.0 \\ 12.0 & 13.0 \\ 13.0 & 14.0 \\ 14.0 & 12.0\end{array}$ AM PM

$11.0 \quad 12.0$

$\begin{array}{ll}11.0 & 12.0 \\ 12.0 & 12.0\end{array}$

12.0
13.0
13.0

17.0
18.0

\section{0}

18.0 PM

A4

$\begin{array}{lll}19.0 & 19.0 & 21.0 \\ 19.0 & 20.0 & 21.0\end{array}$

$\begin{array}{ll}20.0 & 21.0 \\ 21.0 & 21.0\end{array}$

24.0

P.:

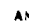

$\begin{array}{ll}23.0 & 23.0 \\ 22.0 & 23.0\end{array}$

22.0

23.0

$\begin{array}{llll}16.0 & 17.0 & 21.0 & 22.0 \\ 16.0 & 17.0 & 21.0 & 22.0\end{array}$

$\begin{array}{ll}22.0 & 23.0 \\ 23.0 & 22.0\end{array}$

$\begin{array}{ll}22.0 & 23.0 \\ 22.0 & 23.0\end{array}$

$\begin{array}{ll}22.0 & 23.0 \\ 24.0 & 24.0\end{array}$

13.0

13.0

$\begin{array}{ll}16.0 & 17.0 \\ 17.0 & 17.0\end{array}$

23.0

22.0

23.0
21.0

13.0
13.0
14.0
14.0
13.0

14.0
14.0
15.0

17.0
17.0
17.0

17.0
17.0
18.0

$\begin{array}{ll}24.0 & 25.0 \\ 24.0 & 25.0\end{array}$

$15.0 \quad 19.0 \quad 18.0 \quad 23.0 \quad 24.0$

$13.0 \quad 14.0$

19.0

20.

23.0

24.0
24.0

$\begin{array}{ll}13.0 & 14.0 \\ 13.0 & 14.0\end{array}$

21.0

$\begin{array}{llllll}14.0 & 16.0 & 18.0 & 18.0 & 22.0 & 24.0 \\ 16.0 & 16.0 & 17.0 & 17.0 & 23.0 & 24.0\end{array}$

$\begin{array}{llll}17.0 & 17.0 & 23.0 & 24.0 \\ 16.0 & 17.0 & 23.0 & 24.0\end{array}$

$17.0 \quad 17.0$

17.0

24.0

$\begin{array}{llll}16.0 & 16.0 & 23.0 & 24.0 \\ 16.0 & 16.0 & 23.0 & 24.0 \\ 16.0 & 17.0 & 24.0 & 26.0 \\ 18.0 & 18.0 & 24.0 & 25.0\end{array}$

$\begin{array}{lllll}17.0 & 18.0 & 16.0 & 17.0 & 24.0 \\ 18.0 & 18.0 & 18.0 & 18.0 & 24.0 \\ 14.0 & 16.0 & 17.0 & 18.0 & 25.0\end{array}$

25.0
26.0

$\begin{array}{lllll}15.0 & 16.0 & 18.0 & 19.0 & 24.0 \\ 14.0 & 16.0 & 18.0 & 19.0 & 23.0 \\ 16.0 & 16.0 & 18.0 & 18.0 & 21.0 \\ 15.0 & 16.0 & 17.0 & 18.0 & 22.0\end{array}$

24.0

$23.0 \quad 26.0$

$\begin{array}{ll}21.0 & 22.0 \\ 22.0 & 22.0\end{array}$

$\begin{array}{ll}22.0 & 22.0 \\ 23.0 & 23.0\end{array}$

24.0

24.0

26.0

25.026 .0

26.0

26.0

$26.0 \quad 27.0$

27.0
27.0

26.026 .0

26.0

$\begin{array}{ll}25.0 & 26.0 \\ 25.0 & 25.0\end{array}$

$\begin{array}{ll}15.0 & 16.0 \\ 16.0 & 17.0\end{array}$

$\begin{array}{llll}17.0 & 18.0 & 23.0 & 24.0\end{array}$

$\begin{array}{ll}24.0 & 25.0 \\ 24.0 & 26.0\end{array}$

22.0

$\begin{array}{llll}23.0 & 24.0 & 21.0 & 22.0\end{array}$

$24.0 \quad 26.0 \quad 21.0 \quad 22.0$

$\begin{array}{llll}24.0 & 26.0 & 22.0 & 22.0\end{array}$

$26.0 \quad 27.0 \quad 21.0 \quad 22.0$

$26.0 \quad 27.0 \quad 21.0 \quad 22.0$

$\begin{array}{llll}26.0 & 27.0 & 21.0 & 22.0 \\ 26.0 & 27.0 & 21.0 & 21.0\end{array}$

27.0 21.0

21.0

$26.0 \quad 26.0 \quad 19.0 \quad 20.0$

$24.0 \quad 26.0 \quad 18.0 \quad 19.0$

$\begin{array}{llll}24.0 & 25.0 & 18.0 & 19.0 \\ 24.0 & 25.0 & 18.0 & 19.0\end{array}$

$24.0 \quad 26.0 \quad 19.0 \quad 19.0$

$26.0 \quad 27.0 \quad 19.0 \quad 20.0$

$\begin{array}{llll}26.0 & 27.0 & 19.0 & 19.0 \\ 26.0 & 27.0 & 19.0 & 21.0\end{array}$

$\begin{array}{llll}27.0 & 27.0 & 19.0 & 21.0\end{array}$

$27.0 \quad 28.0 \quad 19.0 \quad 21.0$

$\begin{array}{llll}27.0 & 28.0 & 19.0 & 21.0\end{array}$

$\begin{array}{llll}27.0 & 28.0 & 19.0 & 21.0 \\ 27.0 & 27.0 & 19.0 & 20.0\end{array}$

$\begin{array}{llll}26.0 & 26.0 & 19.0 & 19.0\end{array}$

$\begin{array}{llll}22.0 & 23.0 & 18.0 & 19.0\end{array}$

$\begin{array}{llll}22.0 & 22.0 & 18.0 & 19.0\end{array}$

23.0

$18.0 \quad 19.0$


TRADEW ATER RIVER BASIN

03383000 TRADEWATER RIVER AT OLNEY, KY, --Continued

SUSPENDED SEDIMENT, WATER YEAR OCTOBER 1967 TO SEPTEMBER 1968

DCTOREP

N'TVEMAER

DECEMAF?

MEAN
DISCHARGF
ICFSI

MEAN
CONCEN-

MEAY TONCEN-

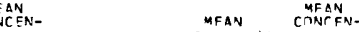
DISTHARAE TRATION
(CFS)

2.7
3.0
2.2
2.5
2.0

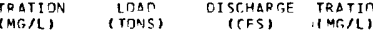
(TONS)

$$
\begin{array}{r}
1 \\
2 \\
3 \\
4 \\
5 \\
5 \\
5 \\
7 \\
9 \\
9 \\
10 \\
11 \\
12 \\
13 \\
14 \\
15 \\
16 \\
17 \\
19 \\
19 \\
20 \\
21 \\
22 \\
23 \\
24 \\
25 \\
26 \\
27 \\
28 \\
29 \\
30 \\
31 \\
\end{array}
$$$$
\begin{aligned}
& 2.7 \\
& 3.0 \\
& 2.2 \\
& 2.5 \\
& 2.0
\end{aligned}
$$$$
\begin{array}{ll}
.02 & 15 \\
.04 & 17 \\
.03 & 72 \\
.04 & 29 \\
.04 & 30
\end{array}
$$$$
\begin{array}{rr}
.22 & 676 \\
.23 & 1010 \\
.3 n & 1360 \\
.30 & 1420
\end{array}
$$

$47 \quad 12$

.29
$.40 \quad 1420$

$\begin{array}{ll}45 & 317 \\ 67 & 257 \\ 52 & 197\end{array}$

3.1
2.2
1.9
1.9
1.7

.06
.04
.04
.04

$\begin{array}{ll}.42 & 1430 \\ .39 & 1250\end{array}$

.35
.32 $\quad 596$

547
507

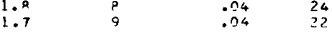

2.6
3.4
3.9
5.0

5.0

.06

.08
.09
.11
.10

73
94
150
143

$\begin{array}{cr}.53 & 874 \\ 1.6 & 1060 \\ 2.8 & 1060 \\ 2.3 & 098\end{array}$

$2.3 \quad 992$

$\begin{array}{ll}.10 & 74 \\ .99 & 50\end{array}$

5.3
$47^{3}$
104
91
52

$\begin{array}{ll}.99 & 50 \\ 2.0 & 53 \\ 1.7 & 57 \\ 1.1 & 43\end{array}$

$\begin{array}{ll}1.2 & 840 \\ .96 & 787\end{array}$

$\begin{array}{rr}.96 & 767 \\ .72 & 1747 \\ .70 & 1340\end{array}$

$27 \quad 104$

$\begin{array}{ll}15 & 51 \\ 15 & 36 \\ 13 & 10 \\ 15 & 21\end{array}$

$\begin{array}{lllll}-50 & 39 & 4 & .41 & 1260\end{array}$

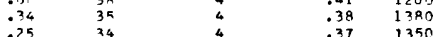

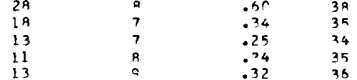

$\begin{array}{rr}.37 & 1350 \\ .39 & 1130\end{array}$

$54 \quad 127$

$3 \mathrm{C} \quad 3 \mathrm{~s}$

$\begin{array}{rr}52 \\ 32 & 50 \\ 52 & 58\end{array}$

$\begin{array}{ll}51 & 171 \\ 42 & 152 \\ 24 & 87\end{array}$

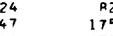

$\begin{array}{rr}48 & 176 \\ 30 & 110 \\ 34 & 58\end{array}$

26
27
28
29
30
31

TOTAL

635.0

$\begin{array}{rr}.21 & 33 \\ 1.4 & 29 \\ .94 & 24 \\ .50 & 24 \\ .30 & 296\end{array}$

$\begin{array}{rr}.50 & 24 \\ .30 & 226\end{array}$

$\begin{array}{ll}.45 & 585 \\ .30 & 420 \\ .70 & 295\end{array}$

\begin{tabular}{rr}
.30 & 420 \\
1.70 & 295 \\
27 & 214 \\
\hline
\end{tabular}

17
$--\quad 157$
-

$48.78 \quad 28675$

$12.61 \quad 1554$

FERRUARY
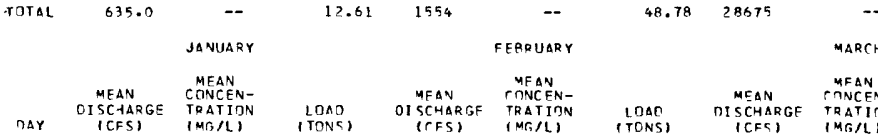

LONO OISCHARGF
LONES

MEAN

TONCEN-
TRATIINN LOAO MISCHARGF

MFAN
TINCEN-

TONCEN(CFS) (MFIL) (TONE) (TFS) (MFI)

$\begin{array}{rrr}45 & 77 & 50 \\ 178 & 602 & 47 \\ 104 & 480 & 45 \\ 34 & 313 & 44 \\ 47 & 255 & 47 \\ 72 & 117 & 41 \\ 11 & 47 & 40 \\ 10 & 29 & 38 \\ 8 & 14 & 37 \\ 9 & 5.7 & 47\end{array}$

50
47
45
44
47
41
40
38
37
47

ITOAE,

$\begin{array}{rr}2.6 & 627 \\ 2.3 & 1443 \\ 2.3 & 1710 \\ 2.2 & 1819 \\ 1.9 & 2010 \\ 1.9 & 1970 \\ 1.9 & 1525 \\ 1.4 & 1090 \\ 1.3 & 657 \\ 1.2 & 426\end{array}$

$\begin{array}{ll}11 & 80 \\ 12 & 78 \\ 13 & 79 \\ 14 & 88\end{array}$

$1.3 \quad 277$

277
197
$1<5$
127

$$
\begin{aligned}
& 5 \\
& 5 \\
& 5 \\
& 5 \\
& 5
\end{aligned}
$$

2.7
2.5
$? .0$
1.7
1.6

73
554
926
978
971

$\begin{array}{rrr}5 & 1.4 & 110 \\ 5 & 1.4 & 103 \\ 6 & 1.7 & 95 \\ 9 & 2.9 & 94 \\ 15 & 9.8 & 79\end{array}$

$\begin{array}{ll}16 & 103 \\ 17 & 104 \\ 18 & 104 \\ 19 & 114 \\ 20 & 157\end{array}$

$\begin{array}{ll}21 & 311 \\ 22 & 602\end{array}$

$\begin{array}{ll}22 & 682 \\ 23 & 914 \\ 24 & 043 \\ 25 & 713\end{array}$

$\begin{array}{ll}25 & 31 \\ 55 & 08 \\ 54 & 152\end{array}$

31
08
162
92

$26 \quad 491$

$\begin{array}{ll}27 & 396 \\ 23 & 325 \\ 29 & 304 \\ 30 & 354\end{array}$

TOTAL 8023

75
70
50
57
53
49
49
47
51
--
--

5
5
4
4
4

$\begin{array}{cc}1.5 & 694 \\ 1.4 & 498 \\ 1.0 & 401 \\ .91 & 308\end{array}$

$\begin{array}{ll}.82 & 1690 \\ .75 & 1950\end{array}$

$\begin{array}{ll}.75 & 1950 \\ .40 & 2060\end{array}$

$\begin{array}{rr}.40 & 2060 \\ .45 & 2300\end{array}$

$.43 \quad 2420$

$\begin{array}{rr}.40 & 2470 \\ .40 & 2270\end{array}$

$\begin{array}{r}.40 \\ .20 \\ .20 \\ \hline\end{array}$

$\begin{array}{rr}.2 & 15 R 0 \\ -- & 1500\end{array}$

$2051.20 \quad 28536$

.27
.25
.24
.12
.11
.11
.11
.10
.10
.19

1.7

242
547
2.7

यखก

ac

34
27
17

123

$377 \quad 1710$

$\begin{array}{rl}112 & 421 \\ 62 & 350\end{array}$

350
272
121

tis

tid

36
23
40

$8023--$

HO1.4 15156

. 
03383000 TRADEWATER RIVER AT OLNEY, KY.--Continued

SUSPENDED SEDIMENT, WATER YEAR OCTOBER 1967 TO SEPTEMBER 1968 AOPII MaY

JUNE

\begin{tabular}{|c|c|c|c|c|c|c|c|c|c|}
\hline nay & $\begin{array}{l}\text { MEAN } \\
\text { DISCHARGF } \\
\text { (CF\&) }\end{array}$ & $\begin{array}{l}\text { MEAN } \\
\text { CONCEN- } \\
\text { TRATIDN } \\
\text { (MG/L) }\end{array}$ & $\begin{array}{l}\text { IIIAN } \\
\text { (TONS) }\end{array}$ & $\begin{array}{l}\text { MEAV } \\
\text { DISCHARGE } \\
\text { (CFS) }\end{array}$ & $\begin{array}{l}\text { MEAN } \\
\text { CONCEN- } \\
\text { TRATIMN } \\
\text { (MG/L) }\end{array}$ & $\begin{array}{l}\text { LOAD } \\
\text { (TחNS) }\end{array}$ & $\begin{array}{l}\text { MEAN } \\
\text { MISCHARGF } \\
\text { (CFS) }\end{array}$ & $\begin{array}{l}\text { MFAN } \\
\text { CONCEN- } \\
\text { TRATION } \\
(M C / L)\end{array}$ & $\begin{array}{l}\text { LOAn } \\
\text { (TONS) }\end{array}$ \\
\hline 1 & 1520 & 29 & 119 & 95 & 6 & 1.5 & 130 & 5 & .8 \\
\hline$?$ & 1510 & 32 & 130 & R3 & 6 & 1.3 & 311 & 41 & 40 \\
\hline 3 & 1470 & $>5$ & 99 & 75 & 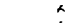 & 1.2 & 846 & $7 f$ & 174 \\
\hline 4 & 2080 & 47 & 264 & 59 & 6 & 1.1 & $73 n$ & 21 & $4 !$ \\
\hline 5 & 2720 & 72 & 432 & 31 & 6 & .99 & 458 & 9 & 11 \\
\hline B & 2070 & $5 n$ & 279 & 54 & 7 & 1.0 & 291 & क & $=0$ \\
\hline 7 & 2090 & 42 & 237 & 49 & 7 & .91 & 164 & 6 & 2.7 \\
\hline 8 & 2090 & $2 \mathrm{~A}$ & $1=7$ & 41 & 7 & .77 & 111 & $\therefore$ & 2.4 \\
\hline 9 & IRSO & 14 & 70 & 57 & 7 & .98 & 90 & 0 & 2.2 \\
\hline 10 & 1500 & p & 37 & 90 & 10 & 2.4 & 79 & 10 & $? .1$ \\
\hline 11 & 1990 & R & 23 & 417 & 4R & 67 & 60 & in & 1.9 \\
\hline 12 & +29 & a & 14 & 879 & 67 & 159 & 50 & is & l.t \\
\hline 13 & 394 & 7 & 7.4 & 039 & 40 & 124 & 47 & 10 & 1.2 \\
\hline 14 & 294 & h & 4.9 & $12 \mathrm{an}$ & 71 & 245 & $2 R$ & 13 & 1.3 \\
\hline 15 & 304 & R & 6.6 & 1310 & 39 & 138 & 31 & 16 & 1.2 \\
\hline 16 & 374 & $2 r$ & 20 & 1270 & $2 R$ & 96 & 26 & 19 & 1.3 \\
\hline 17 & 529 & 30 & 42 & 1280 & 40 & 138 & 23 & 23 & l.t. \\
\hline 18 & 903 & A? & 200 & 1110 & 31 & 93 & 30 & 22 & 1.0 \\
\hline 19 & $9 \geq 5$ & 73 & 192 & B26 & 16 & 36 & 30 & $2 \pi$ & 1.9 \\
\hline 20 & 949 & 22 & 97 & 520 & $a$ & 13 & 27 & $\Rightarrow$ & 1.6 \\
\hline 21 & 835 & 24 & 54 & 360 & 3 & 2.9 & 22 & 22 & 1.3 \\
\hline 22 & $53 n$ & 16 & 25 & 254 & 2 & 2.1 & 1 व & 20 & .97 \\
\hline 23 & 305 & ir & 11 & $R_{1}$ & $x$ & 1.5 & is & 20 & .26 \\
\hline 24 & 315 & 9 & 7.7 & 147 & 3 & 1.2 & 13 & 17 & . $S O$ \\
\hline 25 & 274 & 9 & 6.7 & 131 & 3 & 1.1 & i1 & if & .49 \\
\hline 26 & 211 & a & 4.6 & 273 & 23 & 19 & 7.2 & 15 & .29 \\
\hline 27 & 173 & + & 2.8 & 309 & 12 & 10 & A. 4 & 14 & .22 \\
\hline 29 & 147 & a & 2.4 & 259 & 0 & 6.5 & a. 0 & 13 & .71 \\
\hline 29 & $12^{a}$ & 6 & 2.1 & 210 & 6 & 3.4 & 10 & 17 & .22 \\
\hline 30 & 109 & a & 1.8 & 163 & 6 & 2.6 & 0.5 & 13 & .28 \\
\hline 31 & -. & - & -. & 154 & 5 & 2.1 & -- & 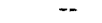 & -- \\
\hline \multirow[t]{4}{*}{ TOTAL } & 27947 & -- & 2534.9 & 12955 & - & 1273.55 & 3716.0 & -- & 302.53 \\
\hline & & JULY & & & AUCIIST & & & SFDTEMPFQ & \\
\hline & MEAN & $\begin{array}{l}\text { MEAN } \\
\text { CONCEN- }\end{array}$ & & MEAN & $\begin{array}{l}\text { MEAN } \\
\text { CONCEN- }\end{array}$ & & MESN & $\begin{array}{l}\text { MEAN } \\
\text { CONCEN- }\end{array}$ & \\
\hline & CISCTARTEF & TEATION & $10 \times n$ & DISCHARTEF & TRATINN & LOAD & DISCHARGF & TRATION & LnAT \\
\hline TAY & (CFS) & $\left(M S_{1}, L\right)$ & (T) & (CFS) & $\left(M R_{1} / \mathrm{I}\right)$ & (TONS) & (CFC) & $(M r, f L)$ & (TONS) \\
\hline 1 & 9.4 & 10 & .23 & $2 x$ & 17 & .84 & .17 & 2 & c \\
\hline 2 & 8. 3 & 11 & .25 & 20 & IC & .79 & .19 & ? & c \\
\hline 3 & 7.5 & $1 ?$ & .74 & 31 & 9 & .67 & .14 & 2 & c \\
\hline 4 & 6.0 & 1? & .10 & 20 & s & .47 & .57 & 2 & 0 \\
\hline 5 & 4.9 & 13 & .17 & $?$ & 5 & $.3^{n}$ & 2.5 & $i$ & .01 \\
\hline 6 & 4.5 & 13 & .16 & 19 & 5 & .20 & 19 & 1 & .05 \\
\hline 7 & 6.1 & $i^{2}$ & .21 & 15 & 5 & .30 & 7.2 & $\vdots$ & .02 \\
\hline 8 & 6.9 & is & .30 & 12 & a & .19 & 3.7 & $c$ & $n$ \\
\hline 9 & 70 & 52 & 12 & i1 & 5 & .15 & $x .7$ & $n$ & 0 \\
\hline 10 & 313 & 110 & 93 & 9.9 & 5 & $.1^{x}$ & 4.8 & 0 & $n$ \\
\hline 11 & 160 & Ro & $3 R$ & 9.6 & a & .14 & 5.4 & 1 & $.0 t$ \\
\hline 12 & 72 & 80 & is & 5.5 & 10 & .25 & 5.1 & $i$ & .01 \\
\hline 13 & 45 & 67 & R. 1 & 23 & 20 & 2.5 & 4.9 & $i$ & .01 \\
\hline 14 & 29 & 56 & 4.4 & 39 & 27 & 2.8 & 3.5 & 1 & .01 \\
\hline 15 & $2 ?$ & 42 & 2.5 & $? 4$ & 23 & 1.5 & 3.1 & $i$ & .01 \\
\hline 16 & 17 & 37 & 1.7 & 17 & 17 & $.7 R$ & 3.2 & 1 & .01 \\
\hline 17 & 15 & 31 & 1.2 & $1 \mathrm{~s}$ & 12 & .52 & 2.7 & 1 & . \\
\hline 19 & 0.9 & 26 & .50 & 23 & 5 & .31 & 3.4 & ? & .07 \\
\hline 19 & 8.5 & 21 & .48 & 23 & 1 & .ct & 5.0 & $?$ & .03 \\
\hline 20 & $A, t$ & 19 & .42 & 17 & 1 & .05 & 8.4 & , & .07 \\
\hline 21 & h. 0 & 15 & .24 & 13 & ? & . & 16 & 3 & .13 \\
\hline 22 & 9.0 & 10 & .34 & 9.7 & ? & .05 & 17 & 2 & .14 \\
\hline 23 & 22 & 15 & .90 & 7.7 & ? & .04 & 17 & 7 & .14 \\
\hline 24 & 16 & 12 & .52 & 3.3 & 2 & .02 & in & 2 & $\cdot 1^{2}$ \\
\hline 25 & 15 & $1^{n}$ & .40 & 1.3 & , & .01 & 10 & 2 & .05 \\
\hline 26 & 48 & 9 & 1.? & .01 & 2 & $n$ & R.I & , & .04 \\
\hline 27 & 51 & $a$ & 1.7 & .54 & 2 & c & 9.7 & : & .02 \\
\hline $2 a$ & 51 & 10 & 1.4 & .24 & ? & $i$ & 6.2 & $n$ & $n$ \\
\hline 27 & 51 & 13 & 1.9 & .17 & 2 & 0 & 4.1 & 0 & c \\
\hline 30 & 42 & 12 & 1.4 & .17 & ? & $n$ & 3.4 & n & ก \\
\hline 31 & 29 & 12 & .94 & .10 & 2 & 0 & -- & -- & -- \\
\hline TาTAL & 1152.5 & -- & 100.57 & 447.12 & -- & 12.08 & 192.02 & + & .92 \\
\hline $\begin{array}{l}\text { TOTAL } \\
\text { TOTAL }\end{array}$ & $\begin{array}{l}\text { DISCHARGE F } \\
\text { LOAD FOR YE }\end{array}$ & $\begin{array}{l}\text { OR YEAR I } \\
\text { AR (TONS) }\end{array}$ & DAYSI & & & & & & $\begin{array}{r}128998.65 \\
14645.22\end{array}$ \\
\hline
\end{tabular}


03402000 YELLOW CREEK NEAR YIDDLESBORO, KY.

LOCATION. --Lat $36^{\circ} 39^{\circ} 02^{\prime \prime}$, long $83^{\circ} 42^{\circ} 04^{\prime \prime}$, Bell County, at gaging station on right bank on U.S. Highway $25 \mathrm{E}$, 0.4 mile upstream from Low Ash Hollow, 3 miles north of piddlesboro and 6.0 miles upstream from Clear Fork.

DRAINAGE AREA. - - $58.2 \mathrm{sq} \mathrm{ml}$.

PERIOD OF RECORD. --Chemtcal anal yses: May 1964 to September 1968.

Water temperatures: October 1949 to September 1963, unpublished; October 1963 to September 1968.

REMARKS, --Samples for iron and manganese filtered clear when collected. Water-temperature measurements generally are made one day each week, twice a day, at approximately 1100 and 1800 . Occasional regulation from Fern Lake, CHEMICAL ANALYSES IN MILLIGRAMS PER LITER, WATER YEAR OCTOBER 1967 TO SEPTEMBER 1968

\begin{tabular}{|c|c|c|c|c|c|c|c|c|c|c|c|}
\hline WATE & $\begin{array}{l}\text { NIS- } \\
\text { CHARGE } \\
\text { (CFS) }\end{array}$ & $\begin{array}{l}\text { SILICA } \\
\text { (SIOZ) }\end{array}$ & $\begin{array}{l}\text { IR UN } \\
\text { (FE) }\end{array}$ & $\begin{array}{l}\text { MAN- } \\
\text { GANESE } \\
\text { (MN) }\end{array}$ & $\begin{array}{l}\text { CAL- } \\
\text { CIUM } \\
\text { (CA) }\end{array}$ & $\begin{array}{l}\text { MAG- } \\
\text { NE- } \\
\text { SIUM } \\
\text { (MG) }\end{array}$ & $\begin{array}{l}\text { SODIUM } \\
\text { (NA) }\end{array}$ & $\begin{array}{l}\text { P(i- } \\
\text { TAS- } \\
\text { SIUM } \\
(K)\end{array}$ & $\begin{array}{l}\text { RICAR- } \\
\text { ATNATE } \\
\text { (HCO3) }\end{array}$ & $\begin{array}{l}\text { CAR- } \\
\text { RONATE } \\
\text { (CO3) }\end{array}$ & $\begin{array}{l}\text { SULFATE } \\
\text { (SN4) }\end{array}$ \\
\hline $\begin{array}{l}\text { oct. } \\
\text { O2.... } \\
\text { NijV. }\end{array}$ & 19 & 7.1 & .88 & .58 & 51 & 17 & 33 & 3.2 & 110 & 0 & 134 \\
\hline DEC... & 712 & -- & - & -- & - & -- & -- & - & -- & - & -- \\
\hline $\begin{array}{l}05 . . \\
\text { JAN. }\end{array}$ & 185 & -- & .18 & .22 & -- & -. & -- & -- & 34 & 0 & 54 \\
\hline $\begin{array}{l}7 \ldots \\
31 \ldots\end{array}$ & $\begin{array}{r}153 \\
74\end{array}$ & -- & -- & $=$ & $\overline{-}$ & $\because$ & $=$ & -- & $=$ & -- & -- \\
\hline $\begin{array}{l}\text { MAR. } \\
14 \ldots . \\
\text { APR. }\end{array}$ & 239 & - & -- & -- & -- & -. & -- & -. & -- & -- & - \\
\hline${ }_{\text {MAY }}^{23} \cdots$ & 69 & -- & 1.0 & .37 & -- & -- & -- & - & 76 & 0 & 97 \\
\hline$\underset{\operatorname{dHLY}}{27 . .}$ & 54 & -- & -- & -- & -- & -- & -- & -- & -- & -- & -- \\
\hline $21 \ldots$ & 9.7 & - & 1.2 & .41 & $\cdots$ & $\cdots$ & - & $\cdots$ & 126 & 0 & 160 \\
\hline $\begin{array}{l}25 \ldots \\
\text { SFDT. }\end{array}$ & 8.5 & -- & - & & -- & -- & & & -- & -- & -- \\
\hline ob... & 23 & -- & 1.0 & .43 & -- & -- & -- & -- & 116 & 0 & 164 \\
\hline
\end{tabular}

NITRATE
(NO3)


LOCATION,--Lat $36^{\circ} 51^{\prime} 45^{\prime \prime}$, Iong $83^{\circ} 53^{\prime} 13^{\prime \prime}$, Knox County, at gaging station at bridge on State Highway 11 at Barbourville, 0.4 mile upstream from Richland Creek.

DRA INAGE AREA. --960 sq mi.

PERIOD OF RECORD. --Chemical analyses: October 1949 to August 1950.

Water temperatures: October 1949 to September 1968 .

EXTREMES. - -1967-68:

Water temperatures: Maximum, $31.0^{\circ} \mathrm{C}$ June 26 , Aug. 20 ; minimum, $1.0^{\circ} \mathrm{C}$ on several days during January and February.

Period of record: Water temperatures: Maximum, $33.0^{\circ} \mathrm{C}$ June 28,1952 ; minimum, freezing point on many days during 1950-51, 1953-56,
$1958-60,1962-67$.

REMARKS. --Diversion above station by city of Barbourville for municipal water supply.

TEMPERATURE $\left({ }^{\circ} \mathrm{C}\right.$ ) OF WATER, WATER YEAR OCTOBER 1967 TO SEPTEMBER 1968

$$
\text { (TWICE-DAILY MEASUREMENTS AT APPROXIMATELY OBOO AND 1700) }
$$

OCTOBER

$$
\text { NOVEMBER }
$$

$$
\text { DEC EMBER }
$$$$
\text { JANUARY }
$$$$
\text { FEBRUARY }
$$

MARCH

$$
\begin{aligned}
& 14 \\
& 13.0 \\
& 13.0 \\
& 14.0 \\
& 14.0 \\
& 16.0 \\
& 17.0 \\
& 18.0 \\
& 19.0 \\
& 17.0 \\
& 16 \\
& 16.0 \\
& 14.0 \\
& 13.0 \\
& 15.0 \\
& 17.0 \\
& 17.0 \\
& 17.0 \\
& 16.0 \\
& 15.0 \\
& 14.0 \\
& 13.0 \\
& 11.0 \\
& 12.0 \\
& 12.0 \\
& 13.0 \\
& 12.0 \\
& 12.0 \\
& 10.0 \\
& 11.0 \\
& 9.0 \\
& 10.0 \\
&
\end{aligned}
$$

$\begin{array}{ll}13.0 & 14.0 \\ 13.0 & 16.0 \\ 14.0 & 17.0 \\ 14.0 & 18.0 \\ 16.0 & 19.0 \\ 17.0 & 19.0 \\ 18.0 & 19.0 \\ 19.0 & 21.0 \\ 17.0 & 19.0 \\ 16.0 & 17.0 \\ 16.0 & 17.0 \\ 14.0 & 16.0 \\ 13.0 & 17.0 \\ 15.0 & 18.0 \\ 17.0 & 19.0 \\ 17.0 & 18.0 \\ 17.0 & 18.0 \\ 16.0 & 17.0 \\ 15.0 & 16.0 \\ 14.0 & 14.0 \\ 13.0 & 14.0 \\ 11.0 & 12.0 \\ 12.0 & 13.0 \\ 12.0 & 14.0 \\ 13.0 & 14.0 \\ 12.0 & 12.0 \\ 12.0 & 12.0 \\ 10.0 & 11.0 \\ 11.0 & 14.0 \\ 9.0 & 11.0 \\ 10.0 & 12.0 \\ & \\ & \end{array}$

AM
11.0
13.0
12.0
9.0
7.0
7.0
6.0
5.0
4.0
5.0
6.0
8.0
9.0
8.0
7.0
6.0
7.0
6.0
6.0
5.0
6.0
6.0
8.0
6.0
5.0
6.0
6.0
6.0
4.0
6.0
6

$$
\text { AM } P M
$$$$
\begin{aligned}
& 12.0 \\
& 13.0
\end{aligned}
$$$$
12.0
$$$$
\begin{array}{r}
10.0 \\
8.0
\end{array}
$$$$
\begin{array}{ll}
7.0 & 8.0 \\
6.0 & 8.0
\end{array}
$$$$
\begin{array}{ll}
5.0 & 7.0 \\
4.0 & 8.0
\end{array}
$$$$
\begin{array}{ll}
4.0 & 8.0 \\
5.0 & 8.0
\end{array}
$$$$
\begin{aligned}
& 6.0 \\
& 8.0
\end{aligned}
$$$$
\begin{array}{r}
8.0 \\
11.0 \\
10.0
\end{array}
$$$$
\begin{array}{r}
10.0 \\
10.0
\end{array}
$$$$
8.0
$$

9.0
8.0

8.0
7.0
7.0

7.0

7.0
8.0

7.0
8.0
8.0
7.0

8.0
7.0
7.0

8.0

8.0
7.0
6.0 6.0
7.0

\begin{tabular}{rr}
\multicolumn{1}{l}{} & \multicolumn{1}{r}{ PM } \\
6.0 & 7.0 \\
6.0 & 6.0 \\
6.0 & 7.0 \\
6.0 & 6.0 \\
5.0 & 7.0 \\
6.0 & 7.0 \\
6.0 & 8.0 \\
7.0 & 8.0 \\
7.0 & 9.0 \\
9.0 & 9.0 \\
8.0 & 9.0 \\
7.0 & 10.0 \\
8.0 & 9.0 \\
8.0 & 9.0 \\
8.0 & 9.0 \\
6.0 & 7.0 \\
4.0 & 5.0 \\
6.0 & 8.0 \\
9.0 & 11.0 \\
9.0 & 12.0 \\
11.0 & 12.0 \\
11.0 & 10.0 \\
8.0 & 7.0 \\
6.0 & 9.0 \\
-1.0 & -1.0 \\
5.0 & 5.0 \\
4.0 & 4.0 \\
3.0 & 3.0 \\
2.0 & 3.0 \\
2.0 & 3.0 \\
3.0 & 3.0
\end{tabular}

AM PM

3.0

2.0

2.0
4.0
5.0

$\underline{-10}$

$\bar{z}=$

2.0
3.0
3.0
2.0

2.0

1.0

1.0
1.0
2.0

2.0
2.0

4.0

4.0
4.0
2.0

2.0

2.0

2.0
4.0

4.0

3.0

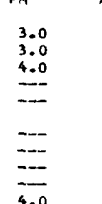

4.0
4.0
4.0
3.0
3.0

2.0
2.0
3.0

3.0
3.0
3.0

6.0
6.0
3.0
2.0

2.0
3.0

\begin{tabular}{|c|c|}
\hline AM & $P M$ \\
\hline $\begin{array}{l}2.0 \\
3.0 \\
4.0 \\
3.0 \\
4.0\end{array}$ & $\begin{array}{l}3.0 \\
5.0 \\
6.0 \\
5.0 \\
5.0\end{array}$ \\
\hline $\begin{array}{l}4.0 \\
3.0 \\
3.0 \\
4.0 \\
6.0\end{array}$ & $\begin{array}{l}3.0 \\
4.0 \\
6.0 \\
6.0 \\
9.0\end{array}$ \\
\hline $\begin{array}{l}7.0 \\
7.0\end{array}$ & $\begin{array}{r}5.0 \\
10.0 \\
7.0\end{array}$ \\
\hline $\begin{array}{l}5.0 \\
6.0\end{array}$ & $\begin{array}{l}7.0 \\
7.0\end{array}$ \\
\hline $\begin{array}{r}6.0 \\
7.0 \\
7.0 \\
9.0 \\
11.0\end{array}$ & $\begin{array}{r}7.0 \\
9.0 \\
10.0 \\
12.0 \\
12.0\end{array}$ \\
\hline 11.0 & $\overline{0}$ \\
\hline $\begin{array}{l}8.0 \\
8.0 \\
8.0\end{array}$ & $\begin{array}{r}10.0 \\
7.0 \\
10.0 \\
9.0\end{array}$ \\
\hline $\begin{array}{r}7.0 \\
9.0 \\
10.0 \\
11.0 \\
12.0 \\
13.0\end{array}$ & $\begin{array}{l}11.0 \\
12.0 \\
13.0 \\
13.0 \\
14.0 \\
14.0\end{array}$ \\
\hline
\end{tabular}

3.0
2.0
6.0

\begin{tabular}{|c|c|c|c|c|c|c|c|c|c|c|c|c|}
\hline \multirow[b]{2}{*}{ DAY } & \multicolumn{2}{|c|}{ APRIL } & \multicolumn{2}{|c|}{ MAY } & \multicolumn{2}{|c|}{ JUNE } & \multicolumn{2}{|c|}{ JULY } & \multicolumn{2}{|c|}{ AUGUST } & \multicolumn{2}{|c|}{ SEPTEMBER } \\
\hline & $A M$ & PM & $A M$ & PM & $A M$ & PM & $A M$ & PM & $A M$ & PM & $A M$ & PM \\
\hline $\begin{array}{l}1 \\
2 \\
3 \\
4 \\
5\end{array}$ & $\begin{array}{l}11.0 \\
10.0 \\
11.0 \\
11.0 \\
10.0\end{array}$ & $\begin{array}{l}12.0 \\
11.0 \\
12.0 \\
11.0 \\
11.0\end{array}$ & $\begin{array}{l}14.0 \\
16.0 \\
17.0 \\
17.0 \\
17.0\end{array}$ & $\begin{array}{l}16.0 \\
16.0 \\
18.0 \\
19.0 \\
17.0\end{array}$ & $\begin{array}{l}18.0 \\
17.0 \\
18.0 \\
18.0 \\
19.0\end{array}$ & $\begin{array}{l}21.0 \\
19.0 \\
20.0 \\
22.0 \\
22.0\end{array}$ & $\begin{array}{l}26.0 \\
27.0 \\
26.0 \\
24.0 \\
23.0\end{array}$ & $\begin{array}{l}29.0 \\
28.0 \\
29.0 \\
26.0 \\
26.0\end{array}$ & $\begin{array}{l}24.0 \\
23.0 \\
24.0 \\
25.0 \\
24.0\end{array}$ & $\begin{array}{l}26.0 \\
26.0 \\
25.0 \\
26.0 \\
27.0\end{array}$ & $\begin{array}{l}22.0 \\
22.0 \\
21.0 \\
21.0 \\
20.0\end{array}$ & $\begin{array}{l}23.0 \\
23.0 \\
23.0 \\
23.0 \\
23.0\end{array}$ \\
\hline $\begin{array}{r}6 \\
7 \\
8 \\
9 \\
10\end{array}$ & $\begin{array}{l}10.0 \\
11.0 \\
12.0 \\
12.0 \\
13.0\end{array}$ & $\begin{array}{l}11.0 \\
13.0 \\
13.0 \\
13.0 \\
14.0\end{array}$ & $\begin{array}{l}16.0 \\
16.0 \\
16.0 \\
16.0 \\
17.0\end{array}$ & $\begin{array}{l}17.0 \\
17.0 \\
17.0 \\
18.0 \\
18.0\end{array}$ & $\begin{array}{l}17.0 \\
21.0 \\
22.0 \\
21.0 \\
20.0\end{array}$ & $\begin{array}{l}23.0 \\
24.0 \\
25.0 \\
23.0 \\
23.0\end{array}$ & $\begin{array}{l}24.0 \\
26.0 \\
26.0 \\
24.0 \\
26.0\end{array}$ & $\begin{array}{l}26.0 \\
28.0 \\
27.0 \\
27.0 \\
28.0\end{array}$ & $\begin{array}{l}26.0 \\
26.0 \\
26.0 \\
27.0 \\
27.0\end{array}$ & $\begin{array}{l}28.0 \\
28.0 \\
29.0 \\
30.0 \\
28.0\end{array}$ & $\begin{array}{l}21.0 \\
22.0 \\
22.0 \\
22.0 \\
21.0\end{array}$ & $\begin{array}{l}24.0 \\
24.0 \\
25.0 \\
23.0 \\
22.0\end{array}$ \\
\hline $\begin{array}{l}11 \\
12 \\
13 \\
14 \\
15\end{array}$ & $\begin{array}{l}12.0 \\
12.0 \\
12.0 \\
15.0 \\
16.0\end{array}$ & $\begin{array}{l}13.0 \\
14.0 \\
16.0 \\
17.0 \\
17.0\end{array}$ & $\begin{array}{l}17.0 \\
17.0 \\
17.0 \\
20.0 \\
19.0\end{array}$ & $\begin{array}{l}18.0 \\
19.0 \\
21.0 \\
22.0 \\
21.0\end{array}$ & $\begin{array}{l}21.0 \\
22.0 \\
23.0 \\
23.0 \\
23.0\end{array}$ & $\begin{array}{l}27.0 \\
27.0 \\
26.0 \\
26.0 \\
26.0\end{array}$ & $\begin{array}{l}26.0 \\
26.0 \\
26.0 \\
26.0 \\
25.0\end{array}$ & $\begin{array}{l}28.0 \\
29.0 \\
30.0 \\
28.0 \\
27.0\end{array}$ & $\begin{array}{l}26.0 \\
26.0 \\
26.0 \\
24.0 \\
24.0\end{array}$ & $\begin{array}{l}27.0 \\
27.0 \\
26.0 \\
26.0 \\
27.0\end{array}$ & $\begin{array}{l}20.0 \\
19.0 \\
20.0 \\
21.0 \\
20.0\end{array}$ & $\begin{array}{l}22.0 \\
22.0 \\
22.0 \\
22.0 \\
23.0\end{array}$ \\
\hline $\begin{array}{l}16 \\
17 \\
18 \\
19 \\
20\end{array}$ & $\begin{array}{l}15.0 \\
13.0 \\
14.0 \\
16.0 \\
15.0\end{array}$ & $\begin{array}{l}17.0 \\
16.0 \\
17.0 \\
17.0 \\
17.0\end{array}$ & $\begin{array}{l}1 \overline{18.0} \\
18.0 \\
17.0 \\
16.0\end{array}$ & $\begin{array}{l}21.0 \\
20.0 \\
20.0 \\
18.0 \\
18.0\end{array}$ & $\begin{array}{l}24.0 \\
23.0 \\
21.0 \\
23.0 \\
24.0\end{array}$ & $\begin{array}{l}26.0 \\
24.0 \\
26.0 \\
26.0 \\
26.0\end{array}$ & $\begin{array}{l}25.0 \\
24.0 \\
24.0 \\
26.0 \\
28.0\end{array}$ & $\begin{array}{l}27.0 \\
27.0 \\
28.0 \\
27.0 \\
28.0\end{array}$ & $\begin{array}{l}26.0 \\
26.0 \\
27.0 \\
26.0 \\
26.0\end{array}$ & $\begin{array}{l}28.0 \\
28.0 \\
28.0 \\
28.0 \\
31.0\end{array}$ & $\begin{array}{l}21.0 \\
21.0 \\
21.0 \\
20.0 \\
21.0\end{array}$ & $\begin{array}{l}22.0 \\
22.0 \\
22.0 \\
22.0 \\
23.0\end{array}$ \\
\hline $\begin{array}{l}21 \\
24 \\
23 \\
24 \\
25\end{array}$ & $\begin{array}{l}16.0 \\
16.0 \\
16.0 \\
17.0 \\
15.0\end{array}$ & $\begin{array}{l}18.0 \\
18.0 \\
17.0 \\
17.0 \\
17.0\end{array}$ & $\begin{array}{l}16.0 \\
16.0 \\
16.0 \\
17.0 \\
18.0\end{array}$ & $\begin{array}{l}18.0 \\
18.0 \\
18.0 \\
19.0 \\
22.0\end{array}$ & $\begin{array}{l}24.0 \\
24.0 \\
26.0 \\
26.0 \\
25.0\end{array}$ & $\begin{array}{l}29.0 \\
28.0 \\
28.0 \\
27.0 \\
27.0\end{array}$ & $\begin{array}{l}28.0 \\
26.0 \\
28.0 \\
27.0 \\
26.0\end{array}$ & $\begin{array}{l}29.0 \\
28.0 \\
29.0 \\
29.0 \\
27.0\end{array}$ & $\begin{array}{l}27.0 \\
28.0 \\
28.0 \\
28.0 \\
28.0\end{array}$ & $\begin{array}{l}30.0 \\
30.0 \\
30.0 \\
30.0 \\
29.0\end{array}$ & $\begin{array}{l}21.0 \\
22.0 \\
21.0 \\
22.0 \\
22.0\end{array}$ & $\begin{array}{l}23.0 \\
24.0 \\
23.0 \\
24.0 \\
23.0\end{array}$ \\
\hline $\begin{array}{l}26 \\
27 \\
28 \\
29 \\
30 \\
31\end{array}$ & $\begin{array}{l}16.0 \\
14.0 \\
16.0 \\
14.0 \\
13.0\end{array}$ & $\begin{array}{l}16.0 \\
16.0 \\
17.0 \\
14.0 \\
14.0\end{array}$ & $\begin{array}{l}=- \\
19.0 \\
18.0 \\
16.0 \\
16.0\end{array}$ & $\begin{array}{l}21.0 \\
21.0 \\
20.0 \\
18.0 \\
19.0\end{array}$ & $\begin{array}{l}24.0 \\
24.0 \\
22.0 \\
23.0 \\
27.0 \\
\end{array}$ & $\begin{array}{l}31.0 \\
24.0 \\
26.0 \\
28.0 \\
29.0\end{array}$ & $\begin{array}{l}25.0 \\
27.0 \\
27.0 \\
25.0 \\
24.0 \\
24.0\end{array}$ & $\begin{array}{l}27.0 \\
27.0 \\
27.0 \\
27.0 \\
25.0 \\
26.0\end{array}$ & $\begin{array}{l}24.0 \\
23.0 \\
21.0 \\
20.0 \\
21.0 \\
23.0\end{array}$ & $\begin{array}{l}27.0 \\
26.0 \\
24.0 \\
22.0 \\
24.0 \\
24.0\end{array}$ & $\begin{array}{l}21.0 \\
21.0 \\
22.0 \\
19.0 \\
18.0 \\
\end{array}$ & $\begin{array}{l}23.0 \\
23.0 \\
22.0 \\
21.0 \\
19.0 \\
\end{array}$ \\
\hline
\end{tabular}

6.0
AM

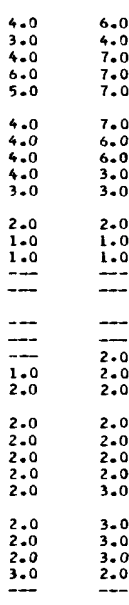


03414110 CUMBERLAND RIVER NEAR BURKESVILLE, KY,

to stream from Raft Creek, 3.2 miles south of Burkesville and about 37 miles downstream from gaging station near Rowena.

DRAINAGE AREA. $--6,050 \mathrm{sq} \mathrm{mt}$.

PERIOD OF RECORD. --Chemical analyses: January 1952 to September 1954 ,

Water

EXTREMES, --1967-68:

Water temperatures: Maximum, $23,0^{\circ} \mathrm{C}$ July $15-29$; minimum, $8,0^{\circ} \mathrm{C}$ on many days during February to May,

Period of record:

Waximum, $29.0^{\circ} \mathrm{C}$ July 30,1956 ; minimum, 1. $0^{\circ} \mathrm{C} \mathrm{Feb.} \mathrm{2-4,} \mathrm{1951,} \mathrm{Jan.} 22,1956$.

REMARKS. --Samples for tron filtered clear when collected. No discharge records available. Flow regulated by take Cumber land.

CHEMICAL ANALYSES IN MILLIGRAMS PER LITER, WATER YEAR OCTOBER 1967 TO SEPTEMBER 1968

\begin{tabular}{|c|c|c|c|c|c|c|c|c|c|c|}
\hline DATE & $\begin{array}{l}\text { SILICA } \\
\text { (SIOZ) }\end{array}$ & $\begin{array}{l}\text { IRON } \\
\text { (FE) }\end{array}$ & $\begin{array}{l}\text { MAN- } \\
\text { GANESE } \\
\text { (MN) }\end{array}$ & $\begin{array}{l}\text { CAL } \\
\text { CIUN } \\
\text { (CA) }\end{array}$ & $\begin{array}{l}\text { MAG- } \\
\text { NE- } \\
\text { SIUM } \\
\text { (MG) }\end{array}$ & $\begin{array}{l}\text { SOD I UM } \\
\text { (NA) }\end{array}$ & $\begin{array}{l}\text { PO- } \\
\text { TAS- } \\
\text { SIIJM } \\
(K)\end{array}$ & $\begin{array}{l}\text { BICAR- } \\
\text { BONATE } \\
\text { (HCO3) }\end{array}$ & $\begin{array}{l}\text { CAR- } \\
\text { BONATE } \\
\text { (CD3) }\end{array}$ & $\begin{array}{l}\text { SULFATE } \\
(504)\end{array}$ \\
\hline $\begin{array}{l}\text { רс } 1 . \\
02 \ldots\end{array}$ & $6 . t$ & .00 & .07 & 16 & 4.5 & 4.8 & 1.1 & 52 & 0 & 22 \\
\hline vuv... & .. & .06 & - & -- & -- & -- & -- & 46 & 0 & 22 \\
\hline MAR. & -- & .06 & .06 & -- & -- & -- & -- & 54 & 0 & 23 \\
\hline $\begin{array}{l}\text { JHLY } \\
01 \ldots . .\end{array}$ & -- & .04 & .01 & -- & -- & -- & -- & 50 & 0 & 21 \\
\hline & $\begin{array}{l}\text { CHLJU- } \\
\text { RIUE }\end{array}$ & $\begin{array}{l}\text { FLUO- } \\
\text { RIOE }\end{array}$ & NITRATE & $\begin{array}{l}\text { OIS- } \\
\text { SOLVEO } \\
\text { SOLIOS } \\
\text { IRESI- } \\
\text { BUE AT }\end{array}$ & $\begin{array}{l}\text { HARD- } \\
\text { NESS }\end{array}$ & $\begin{array}{l}\text { NON- } \\
\text { CAR - } \\
\text { BONATE } \\
\text { HARD- }\end{array}$ & $\begin{array}{l}\text { SPECI- } \\
\text { FIC } \\
\text { COND- } \\
\text { UCTANCE } \\
\text { I MICRO- }\end{array}$ & PH & COLOR & $\begin{array}{l}\text { TEMP- } \\
\text { ERATURE }\end{array}$ \\
\hline DATE & $(C L)$ & $(F)$ & $\left(\mathrm{NO}_{3}\right)$ & $180 \mathrm{Cl}$ & $(C A, 4 C)$ & NESS & MHOSI & & & (DEG C) \\
\hline
\end{tabular}

\begin{tabular}{|c|c|c|c|c|c|c|c|c|c|c|}
\hline $\begin{array}{c}0 \text { СТ. } \\
02 . . .\end{array}$ & $4 \cdot C$ & .1 & 1.9 & 91 & 58 & 15 & 143 & 7.1 & 5 & 17 \\
\hline $03 . .$. & 4.0 & -- & 1.4 & 87 & 58 & 20 & 136 & 7.1 & - & 13 \\
\hline $\begin{array}{l}\text { YAR. } \\
04 . . . \\
\text { JILY }\end{array}$ & 4.0 & -- & 1.0 & RS & 62 & If & 148 & 7.7 & $\cdots$ & 7 \\
\hline $01 \ldots$ & 4.0 & -- & 1.9 & B5 & 58 & 17 & 144 & 7.5 & -- & 26 \\
\hline
\end{tabular}

TEMPERATURE $1{ }^{\circ} \mathrm{Cl}$ OF WATER, WATER YEAR OCTOBER 1967 TO SEPTEMBER 1968 (TWICE-DAILY MEASUREMENTS AT APPROXIMATELY 0700 AND 1500 )
(TIMATER

\begin{tabular}{|c|c|c|c|c|c|c|c|c|c|c|c|c|}
\hline \multirow[b]{2}{*}{ DAY } & \multicolumn{2}{|c|}{ DCTDBER } & \multicolumn{2}{|c|}{ NOVEMBER } & \multicolumn{2}{|c|}{ DECEMBER } & \multicolumn{2}{|c|}{ JANUARY } & \multicolumn{2}{|c|}{ FEBRUARY } & \multicolumn{2}{|c|}{ MARCH } \\
\hline & $A M$ & $P M$ & $A M$ & PM & $A M$ & PM & $\Delta M$ & $P M$ & $A M$ & PM & $A M$ & $P M$ \\
\hline $\begin{array}{l}1 \\
2 \\
3 \\
4 \\
5\end{array}$ & $\begin{array}{l}16.0 \\
16.0 \\
16.0 \\
16.0 \\
16.0\end{array}$ & $\begin{array}{l}16.0 \\
16.0 \\
16.0 \\
16.0 \\
16.0\end{array}$ & $\begin{array}{l}14.0 \\
14.0 \\
14.0 \\
14.0 \\
14.0\end{array}$ & $\begin{array}{l}14.0 \\
14.0 \\
14.0 \\
14.0 \\
14.0\end{array}$ & $\begin{array}{l}14.0 \\
14.0 \\
14.0 \\
14.0 \\
14.0\end{array}$ & $\begin{array}{l}14.0 \\
14.0 \\
14.0 \\
14.0 \\
14.0\end{array}$ & $\begin{array}{l}12.0 \\
12.0 \\
12.0 \\
12.0 \\
11.0\end{array}$ & $\begin{array}{l}12.0 \\
12.0 \\
12.0 \\
12.0 \\
11.0\end{array}$ & $\begin{array}{r}9.0 \\
9.0 \\
9.0 \\
9.0 \\
9.0\end{array}$ & $\begin{array}{l}9.0 \\
9.0 \\
9.0 \\
9.0 \\
9.0\end{array}$ & $\begin{array}{l}\text { B.0 } \\
8.0 \\
8.0 \\
8.0 \\
8.0\end{array}$ & $\begin{array}{l}8.0 \\
8.0 \\
8.0 \\
8.0 \\
8.0\end{array}$ \\
\hline $\begin{array}{r}6 \\
7 \\
8 \\
9 \\
10\end{array}$ & $\begin{array}{l}16.0 \\
16.0 \\
16.0 \\
16.0 \\
16.0\end{array}$ & $\begin{array}{l}16.0 \\
16.0 \\
16.0 \\
16.0 \\
16.0\end{array}$ & $\begin{array}{l}14.0 \\
14.0 \\
14.0 \\
14.0 \\
14.0\end{array}$ & $\begin{array}{l}14.0 \\
14.0 \\
14.0 \\
14.0 \\
14.0\end{array}$ & $\begin{array}{l}13.0 \\
13.0 \\
13.0 \\
13.0 \\
13.0\end{array}$ & $\begin{array}{l}13.0 \\
13.0 \\
13.0 \\
13.0 \\
13.0\end{array}$ & $\begin{array}{l}11.0 \\
11.0 \\
11.0 \\
11.0 \\
10.0\end{array}$ & $\begin{array}{l}11.0 \\
11.0 \\
11.0 \\
11.0 \\
10.0\end{array}$ & $\begin{array}{l}9.0 \\
9.0 \\
8.0 \\
8.0 \\
8.0\end{array}$ & $\begin{array}{l}9.0 \\
9.0 \\
8.0 \\
8.0 \\
8.0\end{array}$ & $\begin{array}{l}8.0 \\
9.0 \\
9.0 \\
9.0 \\
9.0\end{array}$ & $\begin{array}{l}8.0 \\
9.0 \\
9.0 \\
9.0 \\
9.0\end{array}$ \\
\hline $\begin{array}{l}11 \\
12 \\
13 \\
14 \\
15\end{array}$ & $\begin{array}{l}16.0 \\
16.0 \\
16.0 \\
16.0 \\
16.0\end{array}$ & $\begin{array}{l}16.0 \\
16.0 \\
16.0 \\
16.0 \\
16.0\end{array}$ & $\begin{array}{l}14.0 \\
14.0 \\
14.0 \\
14.0 \\
14.0\end{array}$ & $\begin{array}{l}14.0 \\
14.0 \\
14.0 \\
14.0 \\
14.0\end{array}$ & $\begin{array}{l}13.0 \\
13.0 \\
12.0 \\
12.0 \\
12.0\end{array}$ & $\begin{array}{l}13.0 \\
13.0 \\
12.0 \\
12.0 \\
12.0\end{array}$ & $\begin{array}{l}10.0 \\
10.0 \\
10.0 \\
10.0 \\
10.0\end{array}$ & $\begin{array}{l}10.0 \\
10.0 \\
10.0 \\
10.0 \\
10.0\end{array}$ & $\begin{array}{l}8.0 \\
8.0 \\
8.0 \\
8.0 \\
8.0\end{array}$ & $\begin{array}{l}8.0 \\
8.0 \\
8.0 \\
8.0 \\
8.0\end{array}$ & $\begin{array}{l}9.0 \\
9.0 \\
8.0 \\
8.0 \\
8.0\end{array}$ & $\begin{array}{l}9.0 \\
9.0 \\
8.0 \\
8.0 \\
8.0\end{array}$ \\
\hline $\begin{array}{l}16 \\
17 \\
18 \\
19 \\
20\end{array}$ & $\begin{array}{l}16.0 \\
16.0 \\
16.0 \\
15.0 \\
15.0\end{array}$ & $\begin{array}{l}16.0 \\
16.0 \\
16.0 \\
15.0 \\
15.0\end{array}$ & $\begin{array}{l}14.0 \\
14.0 \\
14.0 \\
14.0 \\
14.0\end{array}$ & $\begin{array}{l}14.0 \\
14.0 \\
14.0 \\
14.0 \\
14.0\end{array}$ & $\begin{array}{l}12.0 \\
12.0 \\
12.0 \\
12.0 \\
12.0\end{array}$ & $\begin{array}{l}12.0 \\
12.0 \\
12.0 \\
12.0 \\
12.0\end{array}$ & $\begin{array}{l}9.0 \\
9.0 \\
9.0 \\
9.0 \\
9.0\end{array}$ & $\begin{array}{l}9.0 \\
9.0 \\
9.0 \\
9.0 \\
9.0\end{array}$ & $\begin{array}{l}8.0 \\
8.0 \\
8.0 \\
8.0 \\
8.0\end{array}$ & $\begin{array}{l}8.0 \\
8.0 \\
8.0 \\
8.0 \\
8.0\end{array}$ & $\begin{array}{l}8.0 \\
8.0 \\
8.0 \\
8.0 \\
8.0\end{array}$ & $\begin{array}{l}8.0 \\
8.0 \\
8.0 \\
8.0 \\
8.0\end{array}$ \\
\hline $\begin{array}{l}21 \\
22 \\
23 \\
24 \\
25\end{array}$ & $\begin{array}{l}15.0 \\
15.0 \\
15.0 \\
15.0 \\
15.0\end{array}$ & $\begin{array}{l}15.0 \\
15.0 \\
15.0 \\
15.0 \\
15.0\end{array}$ & $\begin{array}{l}14.0 \\
13.0 \\
13.0 \\
13.0 \\
13.0\end{array}$ & $\begin{array}{l}14.0 \\
13.0 \\
13.0 \\
13.0 \\
13.0\end{array}$ & $\begin{array}{l}12.0 \\
12.0 \\
12.0 \\
12.0 \\
12.0\end{array}$ & $\begin{array}{l}12.0 \\
12.0 \\
12.0 \\
12.0 \\
12.0\end{array}$ & $\begin{array}{l}9.0 \\
9.0 \\
9.0 \\
9.0 \\
9.0\end{array}$ & $\begin{array}{l}9.0 \\
9.0 \\
9.0 \\
9.0 \\
9.0\end{array}$ & $\begin{array}{l}8.0 \\
8.0 \\
8.0 \\
8.0 \\
8.0\end{array}$ & $\begin{array}{l}8.0 \\
8.0 \\
8.0 \\
8.0 \\
8.0\end{array}$ & $\begin{array}{l}8.0 \\
8.0 \\
8.0 \\
8.0 \\
8.0\end{array}$ & $\begin{array}{l}8.0 \\
8.0 \\
8.0 \\
8.0 \\
8.0\end{array}$ \\
\hline $\begin{array}{l}26 \\
27 \\
28 \\
29 \\
30 \\
31\end{array}$ & $\begin{array}{l}14.0 \\
14.0 \\
14.0 \\
14.0 \\
14.0 \\
14.0\end{array}$ & $\begin{array}{l}14.0 \\
14.0 \\
14.0 \\
14.0 \\
14.0 \\
14.0\end{array}$ & $\begin{array}{l}13.0 \\
13.0 \\
13.0 \\
14.0 \\
14.0\end{array}$ & $\begin{array}{r}13.0 \\
13.0 \\
14.0 \\
14.0 \\
14.0 \\
\end{array}$ & $\begin{array}{l}12.0 \\
12.0 \\
12.0 \\
12.0 \\
12.0 \\
12.0\end{array}$ & $\begin{array}{l}12.0 \\
12.0 \\
12.0 \\
12.0 \\
12.0 \\
12.0\end{array}$ & $\begin{array}{l}9.0 \\
9.0 \\
9.0 \\
9.0 \\
9.0 \\
9.0\end{array}$ & $\begin{array}{l}9.0 \\
9.0 \\
9.0 \\
9.0 \\
9.0 \\
9.0\end{array}$ & $\begin{array}{l}8.0 \\
8.0 \\
8.0 \\
8.0 \\
-- \\
--\end{array}$ & $\begin{array}{l}8.0 \\
8.0 \\
8.0 \\
8.0 \\
- \\
\end{array}$ & $\begin{array}{l}8.0 \\
9.0 \\
9.0 \\
9.0 \\
9.0 \\
9.0\end{array}$ & $\begin{array}{l}9.0 \\
9.0 \\
9.0 \\
9.0 \\
9.0 \\
9.0\end{array}$ \\
\hline
\end{tabular}


03414110 CUMBELAND RIVER NEAR BURKESVILLE, KY, --CONTInued

TEMPERATURE $\left({ }^{\circ} \mathrm{C}\right)$ DF WATER, WATER YEAR OCTOBER 1967 TO SEPTEMBER 1968 ITWICE-DAILY MEASUREMENTS AT APPROXIMATELY O700 AND 15001

\begin{tabular}{|c|c|c|c|c|c|c|c|c|c|c|c|c|}
\hline \multirow[b]{2}{*}{ DAY } & \multicolumn{2}{|c|}{ APRIL } & \multicolumn{2}{|c|}{ MAY } & \multicolumn{2}{|c|}{ JUNE } & \multicolumn{2}{|c|}{ JuLY } & \multicolumn{2}{|c|}{ AUGUST } & \multicolumn{2}{|c|}{ SEPTEMBER } \\
\hline & $A M$ & PM & $4 M$ & PM & $\Delta M$ & PM & AM & PM & $A M$ & $P M$ & AM & PM \\
\hline $\begin{array}{l}1 \\
2 \\
3 \\
4 \\
5\end{array}$ & $\begin{array}{l}9.0 \\
9.0 \\
9.0 \\
9.0 \\
9.0\end{array}$ & $\begin{array}{l}9.0 \\
9.0 \\
9.0 \\
9.0 \\
9.0\end{array}$ & $\begin{array}{l}8.0 \\
8.0 \\
8.0 \\
8.0 \\
8.0\end{array}$ & $\begin{array}{l}8.0 \\
8.0 \\
8.0 \\
8.0 \\
8.0\end{array}$ & $\begin{array}{l}10.0 \\
10.0 \\
10.0 \\
10.0 \\
10.0\end{array}$ & $\begin{array}{l}10.0 \\
10.0 \\
10.0 \\
10.0 \\
10.0\end{array}$ & $\begin{array}{l}15.0 \\
15.0 \\
15.0 \\
16.0\end{array}$ & $\begin{array}{l}15.0 \\
15.0 \\
15.0 \\
16.0 \\
16.0\end{array}$ & $\begin{array}{l}22.0 \\
22.0 \\
22.0 \\
22.0 \\
22.0\end{array}$ & $\begin{array}{l}22.0 \\
22.0 \\
22.0 \\
22.0 \\
22.0\end{array}$ & $\begin{array}{l}21.0 \\
21.0 \\
21.0 \\
21.0 \\
20.0\end{array}$ & $\begin{array}{l}21.0 \\
21.0 \\
21.0 \\
21.0 \\
20.0\end{array}$ \\
\hline $\begin{array}{r}6 \\
7 \\
8 \\
9 \\
10\end{array}$ & $\begin{array}{l}9.0 \\
9.0 \\
8.0 \\
8.0 \\
8.0\end{array}$ & $\begin{array}{l}9.0 \\
9.0 \\
8.0 \\
8.0 \\
8.0\end{array}$ & $\begin{array}{l}8.0 \\
8.0 \\
9.0 \\
9.0 \\
9.0\end{array}$ & $\begin{array}{l}8.0 \\
9.0 \\
9.0 \\
9.0 \\
9.0\end{array}$ & $\begin{array}{l}10.0 \\
10.0 \\
10.0 \\
10.0 \\
10.0\end{array}$ & $\begin{array}{l}10.0 \\
10.0 \\
10.0 \\
10.0 \\
12.0\end{array}$ & $\begin{array}{l}16.0 \\
16.0 \\
17.0 \\
17.0 \\
18.0\end{array}$ & $\begin{array}{l}16.0 \\
17.0 \\
17.0 \\
18.0 \\
18.0\end{array}$ & $\begin{array}{l}22.0 \\
22.0 \\
22.0 \\
22.0 \\
22.0\end{array}$ & $\begin{array}{l}22.0 \\
22.0 \\
22.0 \\
22.0 \\
22.0\end{array}$ & $\begin{array}{l}20.0 \\
20.0 \\
20.0 \\
20.0 \\
20.0\end{array}$ & $\begin{array}{l}20.0 \\
20.0 \\
20.0 \\
20.0 \\
20.0\end{array}$ \\
\hline $\begin{array}{l}11 \\
12 \\
12 \\
14 \\
15\end{array}$ & $\begin{array}{l}8.0 \\
8.0 \\
8.0 \\
8.0 \\
8.0\end{array}$ & $\begin{array}{l}8.0 \\
8.0 \\
8.0 \\
8.0 \\
8.0\end{array}$ & $\begin{array}{l}9.0 \\
9.0 \\
9.0 \\
9.0 \\
9.0\end{array}$ & $\begin{array}{r}9.0 \\
9.0 \\
9.0 \\
9.0 \\
10.0\end{array}$ & $\begin{array}{l}12.0 \\
12.0 \\
12.0 \\
12.0 \\
12.0\end{array}$ & $\begin{array}{l}12.0 \\
12.0 \\
12.0 \\
12.0 \\
12.0\end{array}$ & $\begin{array}{l}18.0 \\
20.0 \\
21.0 \\
21.0 \\
23.0\end{array}$ & $\begin{array}{l}20.0 \\
20.0 \\
21.0 \\
21.0 \\
23.0\end{array}$ & $\begin{array}{l}22.0 \\
22.0 \\
22.0 \\
22.0 \\
22.0\end{array}$ & $\begin{array}{l}22.0 \\
22.0 \\
22.0 \\
22.0 \\
22.0\end{array}$ & $\begin{array}{l}20.0 \\
20.0 \\
20.0 \\
21.0 \\
20.0\end{array}$ & $\begin{array}{l}20.0 \\
20.0 \\
20.0 \\
21.0 \\
20.0\end{array}$ \\
\hline $\begin{array}{l}16 \\
17 \\
18 \\
19 \\
20\end{array}$ & $\begin{array}{l}8.0 \\
8.0 \\
8.0 \\
8.0 \\
8.0\end{array}$ & $\begin{array}{l}8.0 \\
8.0 \\
8.0 \\
8.0 \\
9.0\end{array}$ & $\begin{array}{l}10.0 \\
10.0 \\
10.0 \\
10.0 \\
10.0\end{array}$ & $\begin{array}{l}10.0 \\
10.0 \\
10.0 \\
10.0 \\
10.0\end{array}$ & $\begin{array}{l}13.0 \\
14.0 \\
14.0 \\
14.0 \\
14.0\end{array}$ & $\begin{array}{l}14.0 \\
14.0 \\
14.0 \\
14.0 \\
14.0\end{array}$ & $\begin{array}{l}23.0 \\
23.0 \\
23.0 \\
23.0 \\
23.0\end{array}$ & $\begin{array}{l}23.0 \\
23.0 \\
23.0 \\
23.0 \\
23.0\end{array}$ & $\begin{array}{l}22.0 \\
22.0 \\
22.0 \\
22.0 \\
22.0\end{array}$ & $\begin{array}{l}22.0 \\
22.0 \\
22.0 \\
22.0 \\
22.0\end{array}$ & $\begin{array}{l}20.0 \\
20.0 \\
20.0 \\
20.0 \\
20.0\end{array}$ & $\begin{array}{l}20.0 \\
20.0 \\
20.0 \\
20.0 \\
20.0\end{array}$ \\
\hline $\begin{array}{l}21 \\
22 \\
23 \\
24 \\
25\end{array}$ & $\begin{array}{l}8.0 \\
8.0 \\
8.0 \\
8.0 \\
8.0\end{array}$ & $\begin{array}{l}8.0 \\
8.0 \\
8.0 \\
8.0 \\
8.0\end{array}$ & $\begin{array}{l}10.0 \\
10.0 \\
10.0 \\
10.0 \\
10.0\end{array}$ & $\begin{array}{l}10.0 \\
10.0 \\
10.0 \\
10.0 \\
10.0\end{array}$ & $\begin{array}{l}14.0 \\
14.0 \\
14.0 \\
14.0 \\
14.0\end{array}$ & $\begin{array}{l}14.0 \\
14.0 \\
14.0 \\
14.0 \\
15.0\end{array}$ & $\begin{array}{l}23.0 \\
23.0 \\
23.0 \\
23.0 \\
23.0\end{array}$ & $\begin{array}{l}23.0 \\
23.0 \\
23.0 \\
23.0 \\
23.0\end{array}$ & $\begin{array}{l}22.0 \\
21.0 \\
21.0 \\
21.0 \\
21.0\end{array}$ & $\begin{array}{l}22.0 \\
21.0 \\
21.0 \\
21.0 \\
21.0\end{array}$ & $\begin{array}{l}20.0 \\
20.0 \\
20.0 \\
20.0 \\
20.0\end{array}$ & $\begin{array}{l}20.0 \\
20.0 \\
20.0 \\
20.0 \\
20.0\end{array}$ \\
\hline $\begin{array}{l}26 \\
27 \\
28 \\
29 \\
30 \\
31\end{array}$ & $\begin{array}{l}8.0 \\
8.0 \\
8.0 \\
8.0 \\
8.0 \\
---\end{array}$ & $\begin{array}{l}8.0 \\
8.0 \\
8.0 \\
8.0 \\
9.0 \\
-\end{array}$ & $\begin{array}{l}10.0 \\
10.0 \\
10.0 \\
10.0 \\
10.0 \\
10.0\end{array}$ & $\begin{array}{l}10.0 \\
10.0 \\
10.0 \\
10.0 \\
10.0 \\
10.0\end{array}$ & $\begin{array}{r}15.0 \\
15.0 \\
15.0 \\
15.0 \\
- \\
-\end{array}$ & $\begin{array}{l}15.0 \\
15.0 \\
15.0 \\
15.0 \\
-0 \\
-0\end{array}$ & $\begin{array}{l}23.0 \\
23.0 \\
23.0 \\
23.0 \\
22.0 \\
22.0\end{array}$ & $\begin{array}{l}23.0 \\
23.0 \\
23.0 \\
23.0 \\
22.0 \\
22.0\end{array}$ & $\begin{array}{l}21.0 \\
21.0 \\
21.0 \\
21.0 \\
21.0 \\
21.0\end{array}$ & $\begin{array}{l}21.0 \\
21.0 \\
21.0 \\
21.0 \\
21.0 \\
21.0\end{array}$ & $\begin{array}{l}20.0 \\
20.0 \\
20.0 \\
20.0 \\
20.0 \\
\end{array}$ & $\begin{array}{l}20.0 \\
20.0 \\
20.0 \\
20.0 \\
20.0 \\
-\end{array}$ \\
\hline
\end{tabular}

03438500 CUMBERLAND RIVER AT SNITHLAND, KY.

LOCATION.--Lat $37^{\circ} 08^{\prime} 45^{\prime \prime}$, long $88^{\circ} 24^{\prime} 25^{\prime \prime}$, Livingston County, temperature recorder at stage station at bridge on U.S. Highway 60 at Sithland, 1 mile downstream from McCormick Creek, 2.8 m1les upstream from mouth and 27.7 miles downstream from gaging station near Grand Rivers.

DRA INAGE AREA, $--17,913 \mathrm{sq} \mathrm{mi}$.

PERIOD OF RECORD.--Chemical analyses: October 1949 to September 1950, October 1956 to December 1961.

Water temperatures: October 1949 to July 1966, July 1967 to September 1968.

EXTREYES, --1967-68:

Water temperatures: Maximum, $31.0^{\circ} \mathrm{C}$ Aug. $9-11,22-26 ;$ min1mum, $3.0^{\circ} \mathrm{C}$ on many days during January to karch.

Period of record: Water temperatures: Haximum, $32.0^{\circ} \mathrm{C}$ Aug. 3, 1955; minimum, freezing point Jan. 28, Feb. 3, 1963, Jan. 28,
Feb. 1-3, 1966.

REMARKS, --Recorder stopped during the following perlods: Nov, 4-13, range $12,0^{\circ} \mathrm{C}$ to $16,0^{\circ} \mathrm{C} ;$ Dec. 16 to Jan. 4 range $3.0^{\circ} \mathrm{C}$ to $11.0^{\circ} \mathrm{C}$. Records of discharge are given for gaging station near Grand Rivers. Flow almost Water temperatures ma be affected by backwater from the ohio River during periods of high flow.

TEMPERATURE ( $\left.{ }^{\circ} \mathrm{C}\right)$ OF WATER, WATER YEAR OCTOBER 1967 TO SEPTEMBER 1968 [CONTINUDUS ETHYL ALCOHOL-ACTUATED THERMOGRAPH]

DAY

MONTH

DCTOBER

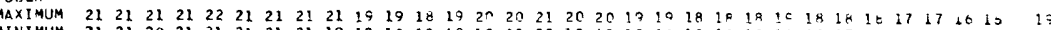

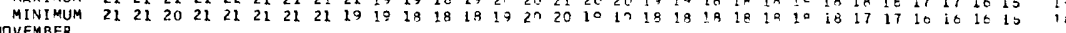

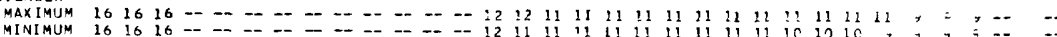

OECEMBER

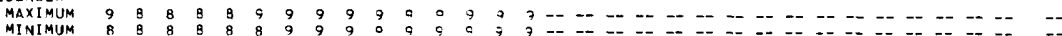

JANUARY

MAXIMUM --

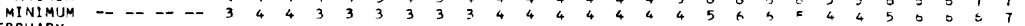
FEBRUARY

MAXIMUM

MARCH

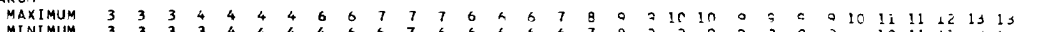

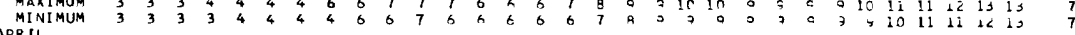

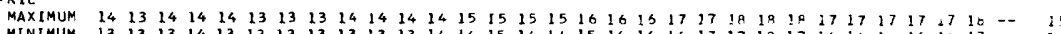

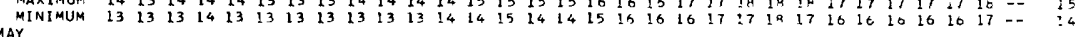

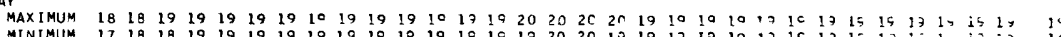

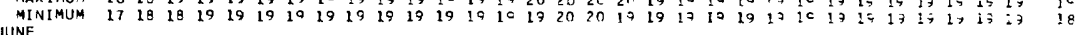

$\begin{array}{lllllllllllllllllllllllllllllllllllll}\text { MAXIMUM } & 19 & 20 & 20 & 20 & 21 & 21 & 21 & 22 & 23 & 23 & 24 & 24 & 24 & 24 & 25 & 25 & 25 & 25 & 24 & 25 & 27 & 27 & 27 & 27 & 27 & 27 & 27 & 20 & 47 & 27 & 0 & -2 & 2\end{array}$

$\begin{array}{llllllllllllllllllllllllllllllllll}\text { MINIMUM } & 19 & 19 & 19 & 19 & 20 & 20 & 20 & 21 & 22 & 23 & 23 & 24 & 24 & 24 & 24 & 24 & 25 & 25 & 25 & 26 & 26 & 27 & 27 & 27 & 27 & 27 & 20 & 20 & 20 & 47 & 0 . & 23\end{array}$

$\begin{array}{lllllllllllllllllllllllllllllllllllll}\text { MAXIMUM } & 27 & 27 & 27 & 26 & 27 & 27 & 27 & 27 & 27 & 27 & 27 & 29 & 28 & 28 & 28 & 28 & 28 & 27 & 29 & 29 & 20 & 30 & 30 & 30 & 30 & 25 & 30 & 3 j & <5 & 25 & 6 & 26\end{array}$

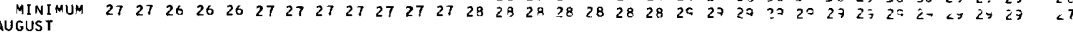

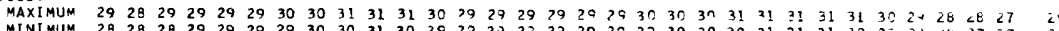

SEPTEMBEK $2828 \quad 2829292929$

MAXIMUM $\begin{array}{llllllllllllllllllllllllllllllllllll}27 & 27 & 26 & 26 & 26 & 26 & 25 & 26 & 26 & 25 & 25 & 24 & 24 & 24 & 24 & 24 & 24 & 24 & 23 & 23 & 23 & 23 & 24 & 24 & 24 & 24 & 23 & 29 & 4 & 23 & --\end{array}$ VEF-

$$
\begin{aligned}
& 8 \\
& - \\
& - \\
& 4 \\
& 4 \\
& 5 \\
& 4 \\
& 7 \\
& 7 \\
& 5 \\
& 4 \\
& 4 \\
& 8 \\
& 3 \\
& 28 \\
& 7 \\
& 9 \\
& 4
\end{aligned}
$$


LOCATION.--Lat $35^{\circ} 40^{\circ} 02^{\prime \prime}$, long $83^{\circ} 04^{\prime} 23^{\prime \prime}$, Haywood County, at gaging station on left bank $20 \mathrm{ft}$ downstream from bridge on State Highway 284, 500 ft upstream from Little Cataloochee Creek, and 2 miles north of Cataloochee.

DRAI NAGE AREA, --49.2 sq mi.

PERIOD OF RECORD. - - Chemical analyses: October 1962 to September 1968.

CHEMICAL ANALYSES IN MILLIGRAMS PER LITER, WATER YEAR OCTOBER 1967 TO SEPTEMBER 1968

\begin{tabular}{|c|c|c|c|c|c|c|c|c|c|c|c|c|}
\hline DATE & TIME & $\begin{array}{l}\text { DIS- } \\
\text { CHARGE } \\
\text { (CFS) }\end{array}$ & $\begin{array}{l}\text { SILICA } \\
\text { (SIO2) }\end{array}$ & $\begin{array}{l}\text { DIS- } \\
\text { SOLVED } \\
\text { IRON } \\
\text { (FE) }\end{array}$ & $\begin{array}{l}\text { CAL } \\
\text { CIUH } \\
\text { (CA) }\end{array}$ & $\begin{array}{l}\text { MAG- } \\
\text { NE- } \\
\text { SIUM } \\
(\text { MG })\end{array}$ & $\begin{array}{l}\text { SODIUM } \\
\text { (NA) }\end{array}$ & $\begin{array}{l}\text { PO- } \\
\text { TAS- } \\
\text { SIUM } \\
\text { (K) }\end{array}$ & $\begin{array}{l}\text { BICAR- } \\
\text { BONATE } \\
\text { (HCO3) }\end{array}$ & $\begin{array}{l}\text { CAR- } \\
\text { BONATE } \\
\text { (CO3) }\end{array}$ & $\begin{array}{l}\text { SULFATE } \\
(\mathrm{SO} 4)\end{array}$ & $\begin{array}{l}\text { CHLO- } \\
\text { RIDE } \\
(\mathrm{CL})\end{array}$ \\
\hline $\begin{array}{l}\text { OCT. } \\
\text { O3.... }\end{array}$ & 1100 & 53 & 8.5 & .01 & 1.3 & .4 & 1.3 & .3 & 7 & 0 & 1.0 & .1 \\
\hline $03 \ldots$ & 1100 & 53 & - & - & - & $\because$ & - & $-x$ & -- & - & - & 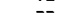 \\
\hline $\begin{array}{l}23 \ldots \\
23 \ldots\end{array}$ & $\begin{array}{l}1135 \\
1135\end{array}$ & $\begin{array}{l}46 \\
46\end{array}$ & 8.4 & .01 & 1.4 & .3 & 1.4 & .4 & $\begin{array}{r}7 \\
--\end{array}$ & $\begin{array}{r}0 \\
--\end{array}$ & 1.0 & 1.8 \\
\hline NOV. & & & & & & & & & & & & \\
\hline $\begin{array}{c}01 . . . \\
01 . . . \\
\text { DEC. }\end{array}$ & $\begin{array}{l}1100 \\
1100\end{array}$ & $\begin{array}{l}65 \\
65\end{array}$ & $\begin{array}{r}8.1 \\
--\end{array}$ & .01 & 1.0 & .4 & .9 & $\because 4$ & $\begin{array}{r}8 \\
--\end{array}$ & $\begin{array}{r}0 \\
--\end{array}$ & $\because 8$ & $\because 4$ \\
\hline $\begin{array}{l}06 . . . \\
06 \ldots \\
\text { JAN. }\end{array}$ & $\begin{array}{l}1030 \\
1030\end{array}$ & $\begin{array}{l}167 \\
167\end{array}$ & 6.6 & .00 & 1.1 & .2 & .8 & .5 & -- & $\begin{array}{r}0 \\
--\end{array}$ & .8 & .6 \\
\hline $\begin{array}{l}03 \ldots \\
03 \ldots \\
\text { FEB. }\end{array}$ & $\begin{array}{l}1130 \\
1130\end{array}$ & $\begin{array}{l}163 \\
163\end{array}$ & 7.3 & .00 & .8 & .4 & $\because 9$ & .6 & 6 & $\therefore$ & .6 & $\stackrel{.6}{-\infty}$ \\
\hline $01 \ldots$ & $\begin{array}{l}1030 \\
1030\end{array}$ & $\begin{array}{l}114 \\
114\end{array}$ & 7.1 & .00 & $\div 8$ & $\therefore 3$ & .9 & .5 & -2 & 0 & .8 & $\because 8$ \\
\hline $\begin{array}{l}\text { MAR. } \\
05 . . .\end{array}$ & 1125 & 64 & 8.0 & .01 & .7 & .3 & 1.0 & .4 & 6 & 0 & .8 & .6 \\
\hline $\begin{array}{l}05 \ldots . . \\
\text { APR. }\end{array}$ & 1125 & 64 & -- & -- & -- & -- & -- & -- & -- & -- & -- & -- \\
\hline $\begin{array}{l}03 \ldots \\
03 . . . \\
\text { MAY }\end{array}$ & $\begin{array}{l}1030 \\
1030\end{array}$ & $\begin{array}{l}174 \\
174\end{array}$ & $\begin{array}{r}6.7 \\
--\end{array}$ & .01 & .7 & .2 & .9 & .4 & $\begin{array}{r}5 \\
--\end{array}$ & -0 & 1.0 & $=9$ \\
\hline $\begin{array}{l}07 . . . \\
07 . . \\
\text { JUNE }\end{array}$ & $\begin{array}{l}1230 \\
1230\end{array}$ & $\begin{array}{l}81 \\
81\end{array}$ & $\begin{array}{r}7.9 \\
--\end{array}$ & .02 & -8 & $\therefore 2$ & 1.0 & .4 & -6 & - & -8 & $\therefore 9$ \\
\hline $\begin{array}{l}05 \ldots \\
05 \ldots\end{array}$ & $\begin{array}{l}1205 \\
1205\end{array}$ & $\begin{array}{l}72 \\
72\end{array}$ & 8.1 & .03 & .5 & $\therefore 2$ & 1.2 & .2 & - & - & .4 & $: 9$ \\
\hline $\begin{array}{l}13 \ldots \\
13 \ldots\end{array}$ & $\begin{array}{l}1035 \\
1035\end{array}$ & $\begin{array}{l}113 \\
113\end{array}$ & $\begin{array}{l}7.6 \\
--\end{array}$ & .02 & .4 & $\therefore 2$ & 1.1 & $\stackrel{-2}{--}$ & -6 & 0 & .4 & .6 \\
\hline $\begin{array}{l}\text { JULY } \\
05 \ldots . .\end{array}$ & 1000 & 53 & 8.6 & -- & .5 & .3 & 1.7 & .6 & 6 & 0 & .4 & .6 \\
\hline $\begin{array}{l}05 \ldots . . \\
\text { AUG. }\end{array}$ & 1000 & 53 & -- & -- & -- & $\sim$ & - & -- & -- & +- & -- & -- \\
\hline $\begin{array}{l}07 \ldots \\
07 \ldots\end{array}$ & $\begin{array}{l}0930 \\
0930\end{array}$ & $\begin{array}{l}49 \\
49\end{array}$ & 8.3 & $\overline{--}$ & .5 & .3 & 1.3 & .6 & $\begin{array}{r}8 \\
--\end{array}$ & -0 & $\because 4$ & $: 8$ \\
\hline $\begin{array}{l}\text { SEPT. } \\
05 . . .\end{array}$ & 1145 & 38 & 8.8 & - & 1.0 & .3 & 1.3 & .4 & 8 & 0 & .4 & 1.0 \\
\hline $05 \ldots$ & $\begin{array}{l}\text { FLUD- } \\
\text { RI DE } \\
\text { (F) }\end{array}$ & $\begin{array}{c}\text { NI TRATE } \\
\text { (NO3) }\end{array}$ & $\begin{array}{l}\text { ORTHO } \\
\text { PHOS- } \\
\text { PHATE } \\
\text { (PO4) }\end{array}$ & $\begin{array}{l}\text { DIS- } \\
\text { DOLVED } \\
\text { SOLIDS } \\
\text { SRESI- } \\
\text { DUE AT } \\
180^{\circ} \mathrm{C} \text { ) }\end{array}$ & $\begin{array}{l}-- \\
\text { DIS- } \\
\text { SOLVED } \\
\text { SOLIDS } \\
\text { (TONS } \\
\text { PER } \\
\text { AC-FT) }\end{array}$ & $\begin{array}{l}-- \\
\text { DIS- } \\
\text { SOLVED } \\
\text { SOLIDS } \\
\text { (TONS } \\
\text { PER } \\
\text { DAY) }\end{array}$ & $\begin{array}{l}\text { HARD- } \\
\text { NESS } \\
(C A, M G)\end{array}$ & $\begin{array}{c}\text { NON- } \\
\text { CAR- } \\
\text { BONATE } \\
\text { HARD- } \\
\text { NESS }\end{array}$ & $\begin{array}{l}-- \\
\text { SODIUM } \\
\text { AD- } \\
\text { SORP- } \\
\text { TION } \\
\text { RATIO }\end{array}$ & $\begin{array}{l}-- \\
\text { SPE- } \\
\text { CIFIC } \\
\text { CONDUCT- } \\
\text { ANCE } \\
\text { (MICRO- } \\
\text { MHOS) }\end{array}$ & $\mathrm{PH}$ & COLOR \\
\hline $\begin{array}{l}\text { OCT. } \\
03 . . .\end{array}$ & .1 & .4 & .00 & 15 & .02 & 2.17 & 5 & 0 & .3 & 15 & 6.0 & 10 \\
\hline $03 .$. & $=$ & - & - & $=$ & - & - & $=$ & $=$ & - & 15 & -- & -- \\
\hline $23 . \ldots$ & .0 & .2 & .00 & 17 & .02 & 2.11 & 4 & 0 & .3 & 15 & 6.8 & 10 \\
\hline $23 . .$. & -- & -- & -- & -- & -- & - & -- & -- & -- & 14 & 7.0 & -- \\
\hline $\begin{array}{l}01 \ldots \\
01 \ldots\end{array}$ & $\therefore$ & .1 & $=$ & 24 & .03 & $\begin{array}{r}4.27 \\
--\end{array}$ & $\begin{array}{r}4 \\
--\end{array}$ & - & $\therefore 2$ & $\begin{array}{l}15 \\
16\end{array}$ & $\begin{array}{l}6.4 \\
7.1\end{array}$ & -5 \\
\hline DEC. & & & & & & & & & & & & \\
\hline $06 \ldots$ & $\therefore 0$ & -2 & -- & -- & -- & -- & $\begin{array}{r}4 \\
--\end{array}$ & - & $\overline{--}$ & $\begin{array}{l}13 \\
12\end{array}$ & $\begin{array}{l}6.2 \\
7.4\end{array}$ & $\begin{array}{c}0 \\
--\end{array}$ \\
\hline $\begin{array}{l}\text { JAN. } \\
03 . . .\end{array}$ & $\therefore 0$ & $\therefore 2$ & -- & 15 & -- & -- & 4 & 0 & $=$ & 13 & 6.0 & 3 \\
\hline$\underset{F E B .}{03 . .}$ & -- & -- & -- & -- & -- & -- & -- & -- & -- & 14 & 7.4 & -- \\
\hline $01 . .$. & .0 & $\stackrel{-4}{-}$ & .01 & 15 & .02 & 4.62 & $-{ }^{3}$ & $\begin{array}{r}0 \\
--\end{array}$ & $\because 2$ & $\begin{array}{l}13 \\
14\end{array}$ & $\begin{array}{l}6.4 \\
7.2\end{array}$ & -3 \\
\hline $\begin{array}{l}\text { MAR. } \\
05 . \ldots \\
05 . \ldots\end{array}$ & -1 & $\therefore 0$ & $=-$ & 17 & $\stackrel{.02}{--}$ & $\begin{array}{r}2.95 \\
--\end{array}$ & $\begin{array}{r}2 \\
--\end{array}$ & $\begin{array}{r}0 \\
--\end{array}$ & .3 & $\begin{array}{l}14 \\
14\end{array}$ & $\begin{array}{l}5.7 \\
7.8\end{array}$ & $-{ }^{3}$ \\
\hline $\begin{array}{l}\text { APR. } \\
03 \ldots \\
03 . . . \\
\text { MAY }\end{array}$ & -2 & $\therefore$ & $=-$ & 15 & .02 & $\begin{array}{r}7.05 \\
--\end{array}$ & -2 & - & $\therefore 2$ & 13 & $\begin{array}{l}5.8 \\
7.4\end{array}$ & 5 \\
\hline $\begin{array}{l}07 \ldots \\
\text { O7.... } \\
\text { JUNE }\end{array}$ & $\therefore$ & .0 & $=$ & 15 & .02 & $\begin{array}{r}3.30 \\
-\end{array}$ & -2 & $\begin{array}{r}0 \\
--\end{array}$ & $\therefore 3$ & $\begin{array}{l}14 \\
16\end{array}$ & $\begin{array}{l}5.7 \\
7.4\end{array}$ & - \\
\hline $05 \ldots$ & .0 & .6 & - & 17 & .02 & 3.30 & 2 & 0 & .4 & 15 & 6.8 & 5 \\
\hline $\begin{array}{l}05 \ldots \\
13 \ldots\end{array}$ & .0 & .7 & -- & $\overline{15}$ &.$\overline{02}$ & $4 . \overline{58}$ & $-\overline{2}$ & $\overline{0}$ &.$\overline{4}$ & $\begin{array}{l}18 \\
15\end{array}$ & $\begin{array}{l}8.0 \\
6.0\end{array}$ & 4 \\
\hline $13 \ldots$ & - & - & -- & $=$ & - & - & -- & -- & - & 16 & - & -- \\
\hline $\begin{array}{l}\text { JULYY } \\
05 . \ldots \\
05 . . .\end{array}$ & .0 & .4 & $=$ & 19 & .03 & 2.72 & 2 & $\begin{array}{r}0 \\
-\end{array}$ & .5 & $\begin{array}{l}19 \\
17\end{array}$ & $\begin{array}{l}5.5 \\
6.8\end{array}$ & -5 \\
\hline AUG. & & & & & & & & & & & & \\
\hline $07 \ldots$ & .0 & $\therefore 2$ & - & 19 & .03 & 2.51 & -2 & -- & .4 & $\begin{array}{l}16 \\
18\end{array}$ & $\begin{array}{l}6.7 \\
7.1\end{array}$ & $\begin{array}{r}7 \\
--\end{array}$ \\
\hline $\begin{array}{l}\text { SEPT. } \\
05 \ldots . . \\
05 . .\end{array}$ & .1 & $\therefore 3$ & .01 & 20 & .03 & $\begin{array}{r}2.05 \\
-0\end{array}$ & -4 & $\begin{array}{r}0 \\
--\end{array}$ & -3 & $\begin{array}{l}15 \\
17\end{array}$ & $\begin{array}{l}5.9 \\
9.0\end{array}$ & -5 \\
\hline
\end{tabular}


03460000 CataloOche CREEk near CataloocheE, N.C.--Continued

CHEMICAL ANALYSES IN MILLIGRAMS PER LITER, WATER YEAR OCTOBER 1967 TO SEPTEMBER 1968

\begin{tabular}{|c|c|c|c|c|c|c|c|c|}
\hline DATE & $\begin{array}{l}\text { ALKA- } \\
\text { LINITY } \\
\text { AS } \\
\text { CACO3 }\end{array}$ & $\begin{array}{l}\text { DIS- } \\
\text { SOLVED } \\
\text { OXYGEN }\end{array}$ & $\begin{array}{l}\text { TEM- } \\
\text { PERA- } \\
\text { TURE } \\
\text { (DEG C) }\end{array}$ & $\begin{array}{l}\text { PHOS- } \\
\text { PHATE } \\
\text { (PO4) }\end{array}$ & $\begin{array}{l}\text { TOTAL } \\
\text { IRON } \\
\text { (FE) }\end{array}$ & $\begin{array}{l}\text { COLI- } \\
\text { FORM } \\
\text { (COL- } \\
\text { ONIES } \\
\text { PER } \\
\text { 100 ML) }\end{array}$ & $\begin{array}{l}\text { BIO- } \\
\text { CHEM- } \\
\text { ICAL } \\
\text { OXYGEN } \\
\text { DEMAND }\end{array}$ & $\begin{array}{l}\text { SUSPENDED } \\
\text { SEDIMENT }\end{array}$ \\
\hline \multicolumn{9}{|l|}{ OCT. } \\
\hline $03 \ldots$ & 6 & - & 9 & .00 & -- & - & -- & -- \\
\hline $03 \ldots$ & - & 11.0 & 9 & - & - & -- & -- & -- \\
\hline $23 \ldots$ & 6 & & 8 & .00 & -- & -- & .2 & - \\
\hline $23 \ldots$ & $=$ & 11.0 & 8 & - & -- & 12 & $=$ & -- \\
\hline \multicolumn{9}{|l|}{ NOV. } \\
\hline $01 \ldots$ & 6 & -- & 10 & .00 & -- & -- & .0 & -- \\
\hline \multirow{2}{*}{\multicolumn{6}{|c|}{$\begin{array}{l}\text { DEC. } \\
06 . . .\end{array}$}} & & & \\
\hline & 4 & -- & 5 & .03 & $\ldots$ & -- & .5 & - \\
\hline \multirow{2}{*}{\multicolumn{9}{|c|}{ JAN." }} \\
\hline & & & & & & & & \\
\hline $03 \ldots$ & 5 & -- & 6 & .01 & -- & -- & .9 & -- \\
\hline $\begin{array}{l}03 . . . \\
\text { FEB. }\end{array}$ & -- & 11.0 & 6 & - & - & 12 & $\because$ & - \\
\hline $01 .$. & 5 & -- & 5 & .01 & -- & -- & .5 & -- \\
\hline $01 \ldots$ & $-=$ & 11.0 & 5 & - & -- & 4 & - & - \\
\hline $05 . \ldots$ & 5 & -- & 0 & .00 & -- & -- & -- & 3 \\
\hline $05 \ldots$ & -- & 13.0 & 0 & - & - & 2 & -- & -2 \\
\hline \multicolumn{9}{|l|}{ APR. } \\
\hline $03 \ldots$ & 4 & $-\infty$ & 7 & .01 & -- & -- & .6 & B \\
\hline MAY & -- & 11.0 & 7 & - & $\ldots$ & 14 & - & - \\
\hline 07 & 5 & - & 7 & .00 & -- & -- & .4 & 5 \\
\hline $\begin{array}{l}07 \\
\text { JUNE }\end{array}$ & -- & 12.0 & 7 & - & -- & 22 & -- & -- \\
\hline $05 \ldots$ & 5 & -- & 12 & .00 & $\ldots$ & _- & .5 & -- \\
\hline $05 \ldots$ & -- & 10.0 & 12 & -- & -- & 30 & -- & -- \\
\hline $13 \ldots$ & 5 & - & 13 & .00 & -- & $=$ & -- & -- \\
\hline $13 \ldots$ & -- & 10.0 & 13 & - & -- & 38 & -- & -- \\
\hline \multicolumn{9}{|l|}{ JULY } \\
\hline $05 \ldots$ & 5 & -- & 14 & .00 & .08 & -- & 1.0 & -- \\
\hline $05 \ldots$ & $\therefore$ & 9.0 & 14 & - & - & 66 & -- & -- \\
\hline AUG.... & 7 & - & 17 & .00 & .08 & -- & .4 & -- \\
\hline \multirow{3}{*}{$\begin{array}{l}\text { SEPT. } \\
05 . . . \\
05 . .\end{array}$} & -- & 9.5 & 17 & - & - & 18 & - & -- \\
\hline & 7 & -- & 14 & .01 & .04 & -- & .6 & -- \\
\hline & -- & -- & 14 & - & -2 & -- & -- & $=$ \\
\hline
\end{tabular}

TRACE ELEMENTS, MILLIGRAMS PER LITER, WATER YEAR OCTOBER 1967 TO SEPTEMBER 1968

\begin{tabular}{|c|c|c|c|c|c|c|c|c|c|}
\hline DATE & $\begin{array}{l}\text { LI THIUM } \\
\text { (LI) }\end{array}$ & $\begin{array}{l}\text { TOTAL } \\
\text { CHRO- } \\
\text { MIUM } \\
\text { (CR) }\end{array}$ & $\begin{array}{l}\text { NICKEL } \\
\text { (NI) }\end{array}$ & $\begin{array}{l}\text { COPPER } \\
\text { (CU) }\end{array}$ & $\begin{array}{l}\text { LEAD } \\
\text { (PB) }\end{array}$ & $\begin{array}{l}21 N C \\
(2 N)\end{array}$ & $\begin{array}{l}\text { TOTAL } \\
\text { ALUM- } \\
\text { INUM } \\
\text { (AL) }\end{array}$ & $\begin{array}{l}\text { TOTAL } \\
\text { MAN- } \\
\text { GANESE } \\
\text { (MN) }\end{array}$ & $\begin{array}{l}\text { STRON- } \\
\text { TIUM } \\
\text { (SR) }\end{array}$ \\
\hline $\begin{array}{l}\text { NOV. } 1,1967 \\
\text { FEB. } 1,1968\end{array}$ & .00 & $\begin{array}{l}.00 \\
.00\end{array}$ & $\begin{array}{l}.00 \\
.00\end{array}$ & $\begin{array}{l}.00 \\
.00\end{array}$ & .00 & $\begin{array}{l}.00 \\
.00\end{array}$ & -- & .00 & .00 \\
\hline
\end{tabular}

DETERMINATIONS DF PESTICIDES IN MICROGRAMS PER LITER, WATER YEAR OCTOBER 1967 TO SEPTEMBER 1968

\begin{tabular}{|c|c|c|c|c|c|c|c|c|c|c|c|}
\hline DATE & ALDRIN & DDD & DDE & DDT & $\begin{array}{l}\text { DIEL- } \\
\text { DRIN }\end{array}$ & ENDR IN & $\begin{array}{l}\text { HEPTA- } \\
\text { CHLOR }\end{array}$ & $\begin{array}{l}\text { HEPTA- } \\
\text { CHLOR } \\
\text { EP- } \\
\text { OXIDE }\end{array}$ & $2,4-D$ & $2,4,5-T$ & SILVEX \\
\hline $\begin{array}{r}3,1967 \\
13,1968\end{array}$ & .00 & $\begin{array}{l}.00 \\
.00\end{array}$ & .00 & $\begin{array}{l}.00 \\
.00\end{array}$ & .00 & $\begin{array}{l}.00 \\
.00\end{array}$ & .00 & $\begin{array}{l}.00 \\
.00\end{array}$ & .00 & .00 & .00 \\
\hline
\end{tabular}

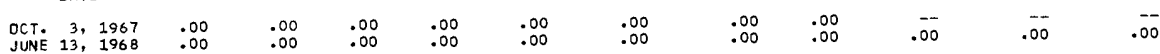

RADIOCHEMICAL ANALYSIS, WATER YEAR OCTOBER 1967 TO SEPTEMBER 1968

$\begin{array}{ccccc}\text { DATE } & \begin{array}{c}\text { URANIUM } \\ \text { (UG } / L \text { ) }\end{array} & \begin{array}{c}\text { RADIUM } \\ (P C / L)\end{array} & \begin{array}{c}\text { GROSS } \text { ALPHA } \\ \text { (UG ULL) }\end{array} & \begin{array}{c}\text { GROSS BETA } \\ \text { (PC/L) }\end{array} \\ \text { OCT. 3. } 1967 & <0.4 & <0.1 & <0.6 & <0.4\end{array}$


03473000 SOUTH FORK HOLSTON RIVER AT VESTAL, VA.

LOCATION, - $-36^{\circ} 39^{\prime} 06^{\prime \prime}$, long $81^{\circ} 50^{\prime} 39^{\prime \prime}$, Washington County, at gaging station on right bank 500 ft upstream from bridge , on U.S. H1 ghway 58 at Vestal, 0.7 mile downstream from Laurel
upstream from ulddle Fork Hoistion River, and at mile 77,2 .

DRAINAGE AREA. --301 sq $\mathrm{m} 1$.

PER IOD OF RECORD. --Chemical analyses: October 1949 to September 1950

Nater temperatures: October 1949 to September 1950, october 1967 to September 1968.

EXTRENES, --1967-68:

Water temperatures: Maximum, $27.0^{\circ} \mathrm{C}$ Aug. 22 ; minimum, freezing point on Jan, 8 and Feb. 13

Period of record:

Water temperatures: Maximum, 27.0 $0^{\circ}$ Aug. 22, 1968; minimum, freezing point on Jan. 8, Feb. 13, 1968.

REMARKS. --Records furnished by Tennessee Valley Authority.

TEMPERATURE $\left.1{ }^{\circ} \mathrm{C}\right)$ OF WATER, WATER YEAR OCTOBER 1967 TO SEPTEMBER 1968 (CONTINUOUS ETHYL AL COHOL-ACTUATED THERMOGRAPH]

DAY

MONTH

OC TOBER

$\begin{array}{lllllllllllllllllllllllllllllllllllllll}\text { MAXIMUM } & -- & -- & 17 & 17 & 16 & 17 & 17 & 16 & 16 & 15 & 14 & 14 & 15 & 15 & 17 & 16 & 15 & 11 & 11 & 12 & 11 & 12 & 13 & 12 & 11 & 9 & 9 & 9 & 10 & 11 & 13 \\ M I N I M U M & -- & -- & 13 & 13 & 14 & 13 & 14 & 15 & 14 & 13 & 12 & 11 & 11 & 13 & 13 & 14 & 11 & 9 & 7 & 8 & 9 & 9 & 10 & 11 & 9 & 9 & 8 & 12 & 7 & 9 & 11\end{array}$ NOVEMBER

$\begin{array}{lrrrrrrrrrrrrrrrrrrrrrrrrrrrrrrrrr}\text { MAXIMUM } & 12 & 12 & 11 & 11 & 8 & 9 & 6 & 6 & 6 & 8 & 10 & 12 & 11 & 9 & 8 & 6 & 6 & 8 & 7 & 6 & 8 & 10 & 9 & 9 & 9 & 9 & 9 & 7 & 4 & 7 & -- & 9 \\ \text { MINIMUM } & 11 & 10 & 8 & 8 & 6 & 4 & 3 & 3 & 3 & 6 & 7 & 9 & 0 & 9 & 6 & 3 & 4 & 6 & 6 & 4 & 6 & 7 & 7 & 6 & 8 & 6 & 7 & 4 & 10 & 4 & \cdots & 4\end{array}$

DECEMBER

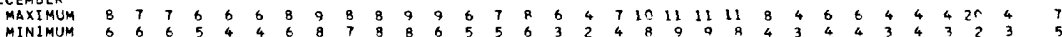

JANUARY

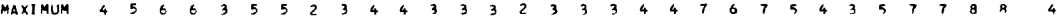

MINIMUM

FEBRUARY

MAXIMUM

ARCH

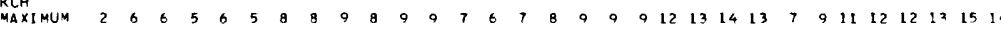

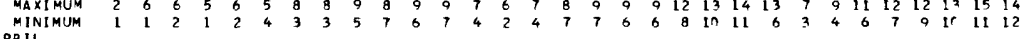

$\begin{array}{llllllllllllllllllllllllllllllllll}\text { MAXIMUM } & 13 & 8 & 9 & 12 & 12 & 12 & 13 & 12 & 11 & 11 & 13 & 13 & 15 & 14 & 15 & 14 & 13 & 15 & 16 & 18 & 19 & 18 & 17 & 16 & 13 & 13 & 13 & 14 & 12 & 14 & -\end{array}$ MINIMUM

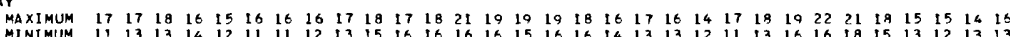
JNE

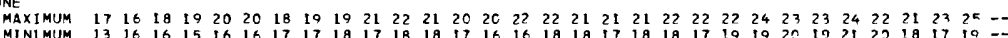
MINIMUM

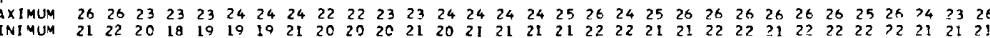
MUGUST

MAXIMUM

MINIMUM $\begin{array}{llllllllllllllllllllllllllllllllllll}23 & 24 & 23 & 23 & 25 & 26 & 26 & 26 & 26 & 24 & 22 & 23 & 23 & 22 & 23 & 23 & 24 & 26 & 26 & 26 & 26 & 27 & 26 & 25 & 25 & 24 & 24 & 21 & 21 & 21 & 21 \\ 21 & 21 & 21 & 21 & 21 & 22 & 22 & 22 & 22 & 21 & 21 & 19 & 19 & 20 & 21 & 21 & 21 & 21 & 22 & 22 & 22 & 22 & 27 & 23 & 22 & 21 & 10 & 17 & 17 & 17 & 17\end{array}$

MAXIMUM $20 \begin{array}{lllllllllllllllllllllllllllllllllll} & 20 & 21 & 21 & 19 & 20 & 20 & 20 & 20 & 19 & 19 & 18 & 18 & 18 & 19 & 18 & 19 & 19 & 18 & 20 & 20 & 20 & 19 & 19 & 18 & 18 & 18 & 17 & 17 & 17 & \ldots\end{array}$

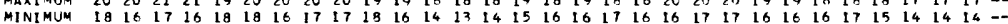
3 
LOCATION. --Lat $36^{\circ} 36^{\prime} 31^{\prime \prime}$, long $82^{\circ} 34^{\prime} 05^{\prime \prime}$, Scott County, at gaging station on left bank 75 ft upstream from bridge on U.S. Highway 23, 1.6 miles downstream from Big Maccasin Creek, 2.1 miles southeast of Gate City and at mile 8.8 . DRAI NAGE AREA, --672 sq mi.

PERIOD OF RECORD,.-.Chemical analyses: October 1949 to September 1951

Water temperatures: October 1949 to September 1951, October 1967 to september 1968.

EXTREMES. - - 1967-68:

Water temperature: Maximum, $31.0^{\circ} \mathrm{C}$ July 24 and on several days during August; minimum, $1.0^{\circ} \mathrm{C}$ on several days during January and February.

Period of record:

Water temperatures: Maximum, $31.0^{\circ} \mathrm{C}$ July 24 and on several days during August, 1968 ; mintmum, ereezing point on several days during November 1950.

REWARKS. --Records furnlshed by Tennessee valley Authority.

TEMPERATURE ( $\left.{ }^{\circ} \mathrm{C}\right)$ OF WATER, WATER YEAR OCTOBER 1967 TO SEPTEMBER 1968 (CONTINUOUS ETHYL ALCOHOL-ACTUATED THERMOGRAPH)

DAY

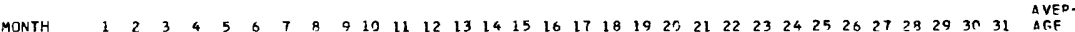

DCTMBER

MAXIMUM

MAXIMUM

NOVEMBER

$\begin{array}{llllllllllllllllllllllllllllllll}13 & 13 & 13 & 13 & 10 & 8 & 7 & 7 & 7 & 8 & 9 & 11 & 11 & 10 & 9 & 7 & 7 & 8 & 7 & 6 & 7 & 9 & 9 & 8 & 0 & 9 & 9 & 7 & 6 & 6 & -2 & 0\end{array}$

MINIMUMM

MAXIMUM

MINIMUM

JANUARY

MAXIMUM

MINI MUM

FEBRUARY

MAXI MUM

MINIMUM

MARCH

MAXIMUM

MINIMUM
APRIL

APRIL

MAXIMUM

MAY

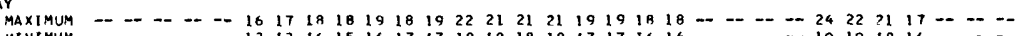
JUNF

MAXIMUM -JINY

MAXIMUM $29 \begin{array}{llllllllllllllllllllllllllllllllllllll}28 & 28 & 26 & 27 & 27 & 27 & 27 & 26 & 26 & 27 & 28 & 28 & 29 & 28 & 28 & 29 & 30 & 20 & 20 & 29 & 29 & 30 & 31 & 30 & 29 & 29 & 29 & 29 & 28 & 27\end{array}$

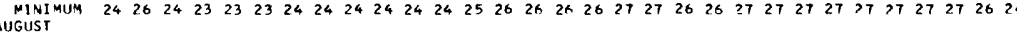
AUGUST

$\begin{array}{llllllllllllllllllllllllllllllllll}\text { MAXIMUM } & 26 & 27 & 28 & 27 & 29 & 29 & 29 & 29 & 29 & 27 & 27 & 27 & 27 & 27 & 28 & 29 & 29 & 30 & 31 & 31 & 31 & 31 & 29 & 20 & 29 & 29 & 26 & 23 & 23 & 23 & 24 \\ \text { MINIMUM } & 25 & 24 & 25 & 26 & 26 & 27 & 27 & 27 & 27 & 26 & 26 & 24 & 24 & 25 & 26 & 26 & 27 & 27 & 28 & 28 & 27 & 28 & 28 & 27 & 27 & 26 & 23 & 21 & 21 & 21 & 28\end{array}$ SEPTEMBER

MAXIMUM $\begin{array}{lllllllllllllllllllllllllllllllll}23 & 23 & 23 & 23 & 22 & 23 & 23 & 23 & 23 & 21 & 20 & 20 & 21 & 22 & 22 & 23 & 22 & 21 & 21 & 22 & 23 & 23 & 23 & 23 & 22 & 22 & 21 & 21 & 2 r & 2 r & \ldots\end{array}$

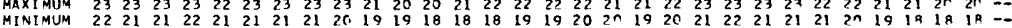


LOCATION.--lat $36^{\circ} 24^{\prime} 06^{\prime \prime}$, long $82^{\circ} 53^{\prime} 09^{\prime \prime}$, Hawkins County, at gaging station at Kepler, 150 ft off Burem Road, 5.9 miles east of intersection' of U.S. Highway $11 \%$ and Burem Road and 6.6 miles upstream from mouth.

DRA INAGE AREA. - -47.0 sq $\mathrm{mi}$.

PERIOD OF RECORD. --Water temperatures: October 1965 to September 1968.

EXTREMES. --1967-68:

Water temperatures: Maximum, $28.0^{\circ} \mathrm{C}$ Aug. 22,23 ; minimum, 1. $0^{\circ} \mathrm{C}$ Feb. 19-28, Mar. 1.

Period of record: Water temperatures: Maximum, $28.0^{\circ} \mathrm{C}$ July 27, 1966; Aug. 22, 23, 1968; minimum, freezing point Dec. 8, 27-30, 1965,
Jan, 26 to Feb. 6, 1966 .

REMARKS. --Missing record July 3 to Aug. 4.

TEMPERATURE $\left({ }^{\circ} \mathrm{C}\right)$ OF WATER, WATER YEAR OCTOBER 1967 TO SEPTEMBER 1968 (CONTINUOUS ETHTL ALCOHOL-ACTUATED THERMOGRAPH)

$$
\text { DAY }
$$

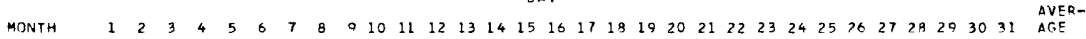

OC TOBER

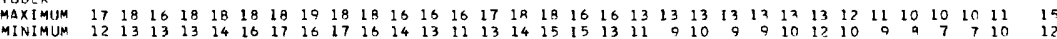
$\begin{array}{llllllllllllllllllllllllllllllllllll}\text { MINIMUM } & 12 & 13 & 13 & 13 & 14 & 16 & 17 & 16 & 17 & 26 & 14 & 13 & 11 & 13 & 14 & 15 & 15 & 13 & 11 & 9 & 10 & 9 & 9 & 10 & 12 & 10 & 9 & 9 & 7 & 10 & 12\end{array}$

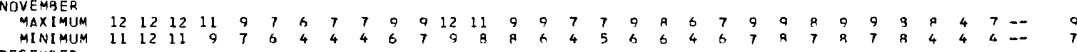

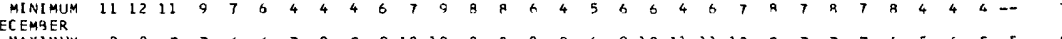

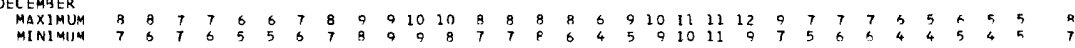
MINIFUHA
IANUARY

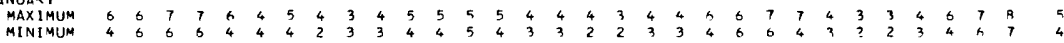
FEBRUARY $\begin{array}{llllllllllllllllllllllllllllllllll}\text { MAXIMUM } & 8 & 8 & 7 & 6 & 4 & 4 & 4 & 4 & 4 & 4 & 3 & 2 & 2 & 2 & 2 & 2 & 2 & 2 & 2 & 1 & 2 & 1 & 1 & 1 & 1 & 1 & 1 & 2 & 2 & -2 & -- & 2 & 1\end{array}$ MARCH

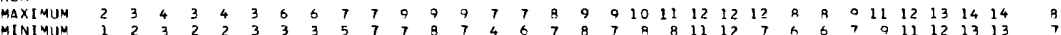
APRIL $\begin{array}{lllllllllllllllllllllllllllllllllllllllll}\text { MAXIMUM } & 14 & 13 & 12 & 13 & 14 & 12 & 13 & 14 & 13 & 13 & 13 & 13 & 13 & 14 & 16 & 16 & 16 & 14 & 13 & 16 & 17 & 19 & 18 & 19 & 17 & 17 & 15 & 14 & 14 & 16 & -- & 15 \\ \text { MINIMUM } & 13 & 11 & 11 & 12 & 13 & 11 & 11 & 11 & 13 & 13 & 12 & 11 & 11 & 17 & 14 & 14 & 12 & 13 & 13 & 13 & 15 & 17 & 17 & 14 & 17 & 14 & 12 & 17 & 12 & 12 & -2 & 13\end{array}$ MAY $\begin{array}{lllllllllllllllllllllllllllllllllllll}\text { MAXIMUM } & 17 & 18 & 18 & 18 & 17 & 16 & 15 & 16 & 17 & 17 & 17 & 18 & 18 & 20 & 20 & 20 & 20 & 19 & 18 & 18 & 17 & 17 & 18 & 20 & 21 & 20 & 20 & 19 & 18 & 10 & 18 & 18 \\ \text { MINIMUM } & 14 & 16 & 16 & 17 & 15 & 13 & 13 & 14 & 16 & 17 & 17 & 17 & 17 & 18 & 19 & 10 & 19 & 19 & 18 & 17 & 16 & 15 & 17 & 18 & 20 & 10 & 10 & 18 & 18 & 17 & 17 & 17\end{array}$ JUNE $\begin{array}{llllllllllllllllllllllllllllllllllll}\text { MAXIMUM } & 19 & 19 & 20 & 20 & 21 & 21 & 21 & 21 & 21 & 21 & 22 & 22 & 21 & 21 & 21 & 21 & 22 & 21 & 21 & 22 & 22 & 22 & 22 & 22 & 23 & 22 & 22 & 22 & 23 & 22 & -2 & 21 \\ \text { MINIMUM } & 17 & 19 & 18 & 19 & 19 & 19 & 20 & 20 & 21 & 21 & 21 & 21 & 20 & 20 & 19 & 19 & 20 & 20 & 20 & 20 & 21 & 19 & 19 & 21 & 21 & 22 & 27 & 22 & 22 & 20 & \ldots & 20\end{array}$

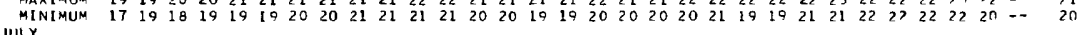
JULY

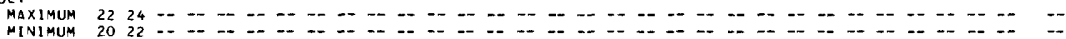

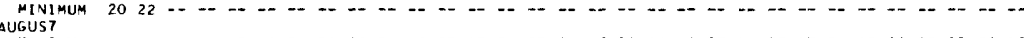

$\begin{array}{llllllllllllllllllllllllllllllllll}\text { MAXIMUM } & -- & -- & -- & -- & 23 & 24 & 24 & 26 & 24 & 24 & 24 & 23 & 23 & 24 & 23 & 24 & 25 & 26 & 26 & 26 & 27 & 28 & 29 & 27 & 25 & 25 & 22 & 22 & 32 & 22 & 22 & 24 \\ \text { MINIMUM } & -- & -- & -- & 22 & 23 & 23 & 23 & 23 & 24 & 23 & 22 & 22 & 22 & 22 & 23 & 23 & 23 & 23 & 24 & 24 & 24 & 24 & 24 & 22 & 21 & 19 & 17 & 17 & 17 & 19 & 72\end{array}$

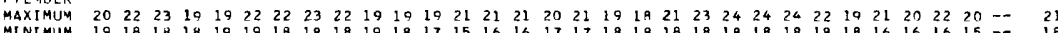


LOCATION, --Lat $36^{\circ} 22^{\prime} 17^{\prime \prime}$, long $83^{\circ} 00^{\prime} 12^{\prime \prime}$, Hawkins County, temperature recorder 0.2 mile downstream from former gaging station, 0.2 mile upstream from Southern Ra1lroad bridge, 0.5 mile upstream from new bridge on State Highways 66
and 70,3 miles south of Rogersville, and at mile 104.0.

DRAINAGE AREA.--3,035 sq $\mathrm{mi}$.

PERIOD OF RECORD. - - Water temperatures: October 1966 to September 1968.

EXTREYES. $--1967-68$ :

Water temperatures: Maximum, $29.0^{\circ} \mathrm{C}$ July 2,22 ; minimum, 4. $0^{\circ} \mathrm{C} \mathrm{Dec}, 16,17,24-27,31$, Feb. 21,22

period of record:

Water temperatures: Maximum, $29.0^{\circ} \mathrm{C}$ July $2,22,1968$; min1mum recorded, $3.0^{\circ} \mathrm{C} \mathrm{Feb.} 26,1967$.

REMARKS. --Records furnished by Tennessee Valley Authority.

TEMPERATURE $\left({ }^{\circ} \mathrm{C}\right)$ OF WATER, WATER YEAR OCTOBER 1967 TO SEPTEMBER 1968 (CONTINUOUS ETHYL ALCOHOL-ACTUATED THERMOGRAPH)

1234567 B $910111213141516171819202122 \quad 23242524 \quad 272 R \quad 2930 \quad 31$ AVER

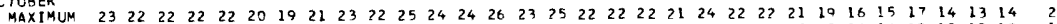

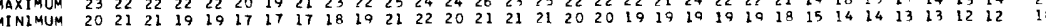

NOVEMAER

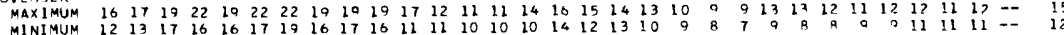
DECEMRER

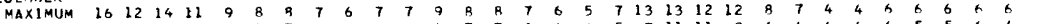

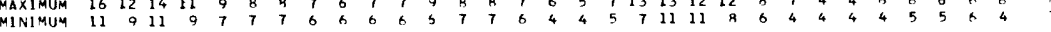
JANUARY

$\begin{array}{llllllllllllllllllllllllllllllllll}\text { MAXIMUM } & 7 & 7 & 7 & 7 & 7 & 7 & 7 & 6 & 6 & 6 & 6 & 6 & 6 & 5 & 6 & 6 & 6 & 6 & 5 & 6 & 7 & 9 & 8 & 9 & 7 & 6 & 5 & 6 & 7 & 9 & 0 & 7\end{array}$ $\begin{array}{llllllllllllllllllllllllllllllllll}\text { MINIMUM } & 7 & 7 & 7 & 7 & 7 & 7 & 6 & 5 & 6 & 6 & 6 & 5 & 5 & 5 & 5 & 6 & 4 & 5 & 5 & 5 & 6 & 7 & 8 & 7 & 6 & 5 & 6 & 6 & 6 & 7 & R\end{array}$

$\begin{array}{lllllllllllllllllllllllllllllllll}\text { MAXIMUM } & 9 & 9 & 9 & 8 & 8 & 8 & 9 & 8 & \text { A } & 7 & 7 & 6 & 6 & 7 & 6 & 6 & 6 & 6 & 4 & 6 & 6 & 5 & 7 & 7 & 7 & 9 & 9 & 9 & 9 & -- & --\end{array}$

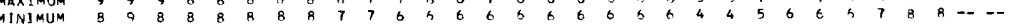

MARCH

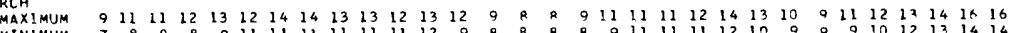
MINIMIJM

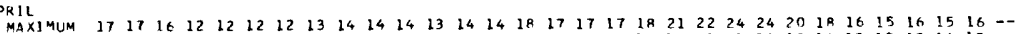

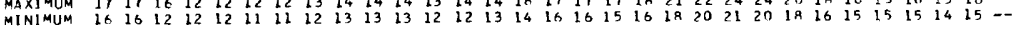

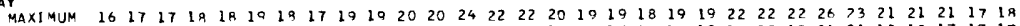

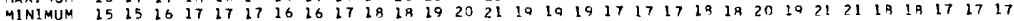
JUNE

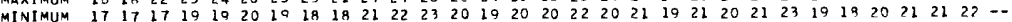

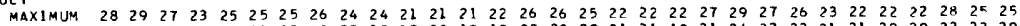

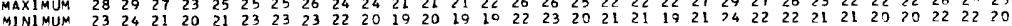
AUGUSI

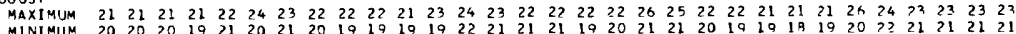
SEPTEMBER

MAXIMUM $2 \begin{array}{lllllllllllllllllllllllllllllll}23 & 25 & 28 & 27 & 24 & 23 & 21 & 23 & 26 & 24 & 23 & 23 & 24 & 26 & 24 & 27 & 2 B & 29 & 29 & 25 & 27 & 27 & 29 & 27 & 24 & 22 & 23 & 24 & 25 & 23 & --\end{array}$ $\begin{array}{lllllllllllllllllllllllllllllllll}\text { MAXIMUM } & 23 & 25 & 28 & 27 & 24 & 23 & 21 & 23 & 26 & 24 & 23 & 23 & 24 & 26 & 24 & 27 & 2 B & 27 & 27 & 25 & 27 & 27 & 29 & 27 & 24 & 22 & 23 & 24 & 25 & 23 & -- & 25 \\ \text { MINIMUM } & 22 & 22 & 22 & 22 & 22 & 21 & 20 & 19 & 22 & 20 & 22 & 21 & 20 & 22 & 22 & 22 & 24 & 24 & 23 & 21 & 24 & 24 & 24 & 23 & 21 & 20 & 19 & 19 & 72 & 21 & - & 22\end{array}$

\section{LITTLE RIVER ABOVE TOWNSEND, TENN.}

(Hydrologic bench-mark station)

LOCATION.--Lat $35^{\circ} 39^{\prime} 52^{\prime \prime}$, long $83^{\circ} 42^{\prime} 41^{\prime \prime}$, Blount County, hat gaging station on left bank along State H1ghway 73 in Great Smoky Mountains Nat1onal Park, 0.3 mile upstream from Rush Branch, 0.4 mile southest of Park entrance,
$2.2 \mathrm{miles}$ southeast of Townsend and at m1le 35.3 .

DRA INAGE AREA. --106 sq $\mathrm{m} 1$.

PERIOD OF RECORD.--Chemical analyses: October 1967 to September 1968.

Hater temperatures: October 1963 to September 1968 .

EXTREMES, $--1967-68$

Water temperatures: Maximum, $24.0^{\circ} \mathrm{C}$ Aug. 10, 23, 26; minimum, 1. $0^{\circ} \mathrm{C}$ Jan. 8, Feb, 18-20, 22-27.

Period of record:

Water temperatures: Maximum, $26.0^{\circ} \mathrm{C}$ June 23,1964 ; minimum, freezing point Feb. 3-6, 1965.

REMARKS. - Pest1c1de analyses: A sample taken on June 24, 1968, was analyzed for the following pesticides: Aldrin, DDD, DDE, DDT, Dieldrin, Endrin, Heptachlor, Heptachlor Epoxide Lindane, 2-4-D, following pesticides: Aldrin, case, concentration was determined to be 0.00 micrograms per liter. CHEMICAL AINALYSES IN MILLIGRAMS PER LITER, WATER YEAR OCTOBER 1967 TO SEPTEMBER 1968

\begin{tabular}{|c|c|c|c|c|c|c|c|c|c|c|c|c|}
\hline $\begin{array}{l}\text { DATE } \\
\text { OCT. }\end{array}$ & $\begin{array}{l}\text { O1S- } \\
\text { CHARGE } \\
\text { (CFS) }\end{array}$ & $\begin{array}{l}\text { SILICA } \\
\text { (5102) }\end{array}$ & $\begin{array}{l}\text { DIS- } \\
\text { SOLVED } \\
\text { IRON } \\
\text { (FE) }\end{array}$ & $\begin{array}{l}\text { MAN- } \\
\text { GANESE } \\
\text { (MN) }\end{array}$ & $\begin{array}{l}\text { CAL- } \\
\text { CIUM } \\
\text { (CA) }\end{array}$ & $\begin{array}{l}\text { MAG- } \\
\text { NE- } \\
\text { SIUM } \\
\text { (MG }\end{array}$ & $\begin{array}{l}\text { SODIUM } \\
\text { (NA) }\end{array}$ & $\begin{array}{l}\text { PO- } \\
\text { TAS- } \\
\text { SIUM } \\
(\mathrm{K})\end{array}$ & $\begin{array}{l}\text { B ICAR- } \\
\text { BONATE } \\
\text { (HCO3) }\end{array}$ & $\begin{array}{l}\text { CAR- } \\
\text { BOAATE } \\
\text { (COB) }\end{array}$ & $\begin{array}{l}\text { SULFATE } \\
\text { (504) }\end{array}$ & $\begin{array}{l}\text { CHLOO- } \\
\text { RIOE } \\
\text { (CL) }\end{array}$ \\
\hline $\begin{array}{l}\text { OCT. } \\
12 . . . \\
\text { NOV. }\end{array}$ & 96 & .0 & .05 & .02 & 1.7 & .5 & 1.0 & .7 & 9 & 0 & $1 . c$ & .6 \\
\hline $\begin{array}{l}20 \ldots . . \\
D E C .\end{array}$ & A119 & 5.6 & .01 & .03 & 1.8 & .1 & 1.2 & .5 & 10 & 0 & .8 & .5 \\
\hline $\begin{array}{l}12 \ldots \\
\text { JAN. }\end{array}$ & 523 & 4.6 & .10 & .03 & 1.4 & .0 & 1.0 & .5 & 4 & 0 & 1.2 & .6 \\
\hline $\begin{array}{l}17 \ldots \\
\text { FEB. }\end{array}$ & 350 & 5.3 & .02 & .00 & 1.2 & . $r$ & .9 & .4 & 8 & 0 & 1.2 & .7 \\
\hline $\begin{array}{l}05 . . . \\
\text { MAR. }\end{array}$ & 312 & 4.7 & .02 & .03 & 1.4 & .0 & .7 & .5 & 6 & 0 & 1.2 & .6 \\
\hline${ }_{\triangle P P}^{18} .$. & 496 & 5.3 & .02 & .00 & 1.2 & .4 & 1.4 & .5 & 10 & c & 2.1 & .4 \\
\hline $\begin{array}{c}16 \ldots . . \\
\operatorname{MAY} \\
{ }_{B} \\
B\end{array}$ & 325 & 5.2 & .00 & .03 & 2.0 & .4 & 1.1 & .5 & 3 & 0 & 1.8 & 2.1 \\
\hline JUNE & 138 & 4.4 & .02 & .00 & 1.0 & .3 & 1.0 & .5 & 6 & c & 2.3 & .3 \\
\hline $\begin{array}{c}24 \ldots . . \\
\text { JULY } \\
23 \ldots . . .\end{array}$ & 111 & 5.7 & .03 & .93 & 2.3 & .5 & 1.1 & .4 & 9 & 0 & 2.1 & .3 \\
\hline $\begin{array}{l}23 . . . \\
\text { AuG.... } \\
26 . .\end{array}$ & 49 & 3.8 & $\cdot 02$ & .00 & 2.1 & .6 & 1.0 & .6 & 12 & 0 & 2.1 & .7 \\
\hline $\begin{array}{c}26 \ldots . . \\
\text { SEPT. } \\
3 n . .\end{array}$ & 454 & 5.6 & .03 & .01 & 2.0 & .6 & 1.0 & .6 & 11 & 0 & 2.2 & .2 \\
\hline 3n... & 45 & $\begin{array}{l}5.5 \\
\end{array}$ & .06 & .01 & 2.2 & .6 & 1.1 & .6 & 22 & 0 & 2.2 & $\cdot 3$ \\
\hline
\end{tabular}


03497300 LITTLE RIVER ABOVE TOWSEND, TENN. --Continued CHEMICAL ANALYSES IN MILLIGRAMS PER LITER, WATER YEAR OCTOBER 1967 TO SEPTEMBER 1968

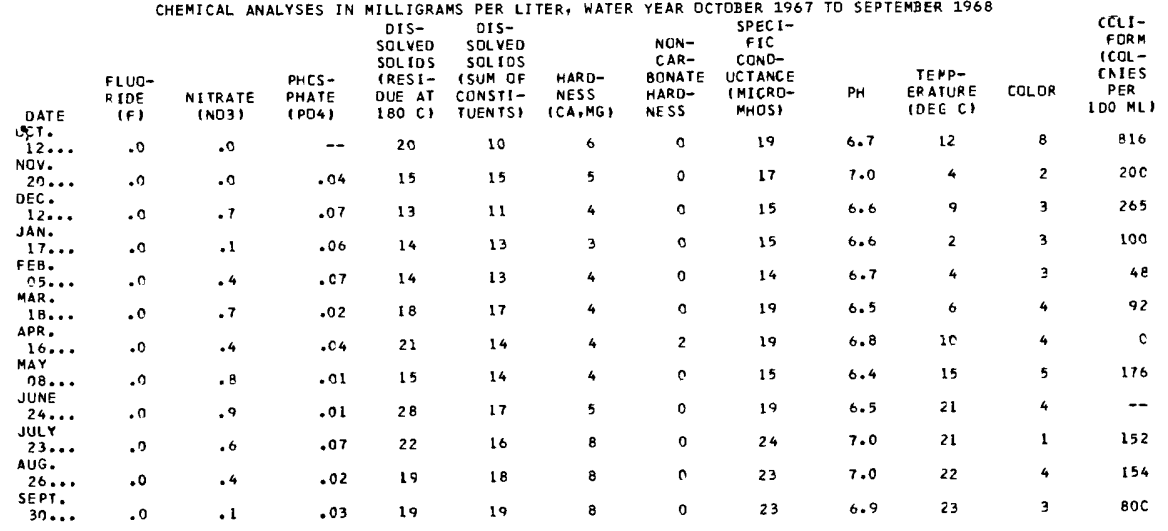

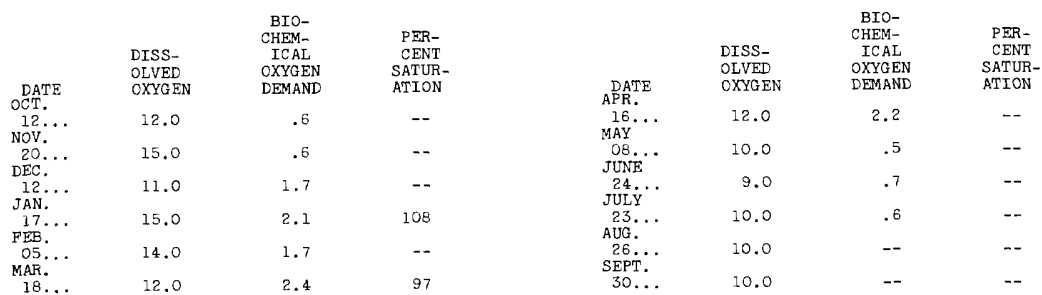

In addition, the sample taken on Sept. 30 was analyzed for heavy metals, with the following results (values expressed in milligrams per liter).

Lithium, .00; total chromium, .00; nickel, .00; copper, .00;

lead, ol; zinc, .00; cobalt, .00; strontium, .00; cadmium, .00;

RADIOI SOTOPES IN WATER

(Units of measurement: Uranium, micrograms per 11ter of water; radium, as radium-226, in picocuries per 1iter of water; gross beta radiation as strontium-90-yttrium-90, in picocuries per liter of water; gross alpha radiation, as micrograms of uranium equivalent per liter of water. A picocurie is one misented by one millionth of a gram of radium-226. A picocurie of radium results in 2.22 disintegrations per minute.)

\begin{tabular}{|c|c|c|c|c|c|c|c|c|}
\hline & \multicolumn{4}{|c|}{ DISSOLVED } & TOTAL & \multicolumn{2}{|c|}{ SUSPENDED } & \\
\hline 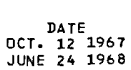 & $\begin{array}{l}\text { URANIUM } \\
\mu G / L \\
<.4 \\
<.4\end{array}$ & $\begin{array}{l}\text { RADIUM } \\
\text { PC/L } \\
<.1 \\
<.1\end{array}$ & $\begin{array}{c}\text { GROSS } \\
\text { PC/L } \\
1.1 \\
1.1\end{array}$ & $\begin{array}{l}\text { GROSS } \alpha \\
M G / L \\
<.4 \\
<.4\end{array}$ & $\begin{array}{l}\text { SOLIDS } \\
\text { MG/L } \\
15 \\
16\end{array}$ & $\begin{array}{c}\text { GROSS B } \\
P C / L \\
.6 \\
<.4\end{array}$ & $\begin{array}{c}\text { GROSS a } \\
\mu G / L \\
<.4 \\
<.4\end{array}$ & $\begin{array}{c}\text { SEDI MENTS } \\
\text { MG/L } \\
2 \\
3\end{array}$ \\
\hline
\end{tabular}
TEMPERATURE $\left({ }^{\circ} \mathrm{C}\right)$ OF WATER, WATER YEAR OCTOBER 1967 TO SEPTEMBER 1968 (CONTINUOUS ETHYL-ALCOHOL ACTUATED THERMOGRAPH)

$\begin{array}{lllllllllllllllllllllllllllllllllll}\text { MONTH } & 1 & 2 & 3 & 4 & 5 & 6 & 7 & 8 & 9 & 10 & 11 & 12 & 13 & 14 & 15 & 16 & 17 & 19 & 19 & 20 & 21 & 22 & 23 & 24 & 25 & 26 & 27 & 79 & 29 & 30 & 31 & \text { AVER }\end{array}$

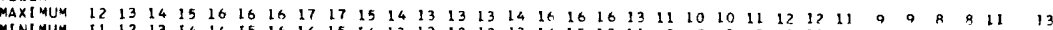

MINIMUMA
NOVEMEEA

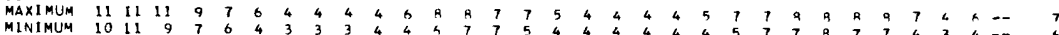

DECEMBER

$\begin{array}{llllllllllllllllllllllllllllllllllllll}\text { MAXIMUM } & 6 & 6 & 6 & 6 & 5 & 6 & 9 & 8 & 8 & 9 & 11 & 11 & 9 & 8 & 8 & 8 & 6 & 9 & 11 & 11 & 12 & 11 & 8 & 5 & 4 & 4 & 5 & 4 & 4 & 4 & 4 & 7\end{array}$

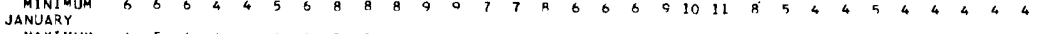

$\begin{array}{llllllllllllllllllllllllllllllllllll}\text { MAXIMUM } & 4 & 5 & 6 & 6 & 4 & 4 & 4 & 3 & 3 & 4 & 4 & 4 & 4 & 4 & 2 & 2 & 2 & 3 & 3 & 4 & 6 & 6 & 7 & 7 & 4 & 2 & 4 & 5 & 6 & 7 & A & 4\end{array}$

FERTURY

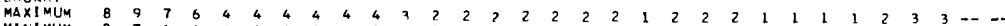

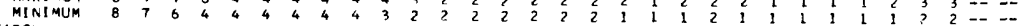

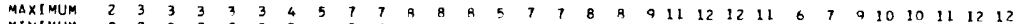

MINIMUM $\quad \begin{array}{llllllllllllllllllllllllllllllllll}2 & 2 & 3 & 2 & 2 & 3 & 3 & 4 & 5 & 7 & 7 & 9 & 5 & 3 & 4 & 7 & 7 & A & 7 & \text { A } & 11 & 11 & 4 & 4 & 5 & 7 & 9 & 9 & 10 & 11 & 12\end{array}$

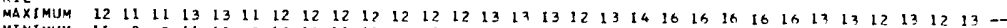

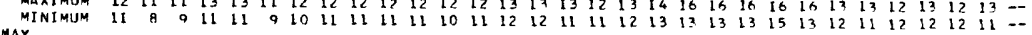

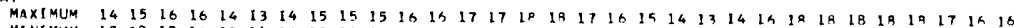

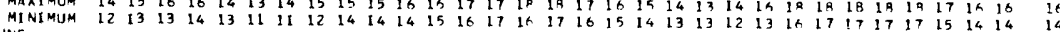

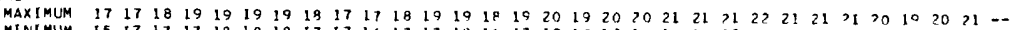

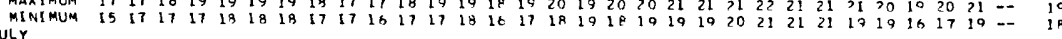
JULY

$\begin{array}{llllllllllllllllllllllllllllllllll}\text { MAXIMUM } & 22 & 22 & 21 & 21 & 21 & 23 & 21 & 22 & 21 & 21 & 22 & 22 & 22 & 23 & 23 & 23 & 23 & 23 & 23 & 22 & 23 & 22 & 22 & 22 & 22 & 23 & 22 & 22 & 22 & 22 & 22 \\ \text { MINIMUM } & 20 & 21 & 19 & 18 & 19 & 20 & 20 & 21 & 21 & 20 & 20 & 21 & 21 & 21 & 21 & 22 & 21 & 21 & 22 & 21 & 21 & 21 & 21 & 21 & 21 & 21 & 20 & 21 & 21 & 21 & 21\end{array}$

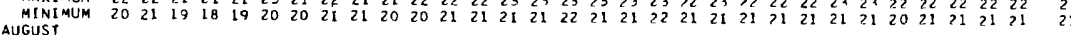

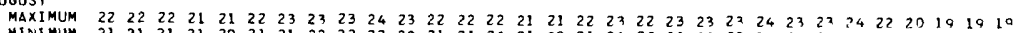

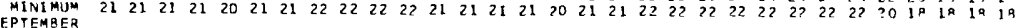


LOCATION. --Lat $35^{\circ} 32^{\prime} 48^{\prime \prime}$, long $84^{\circ} 03^{\prime} 50^{\prime \prime}$, Blount County, temperature recorder at gaging station on right bank on U.S. Highway 129 at Tallassee, $100 \mathrm{ft}$ upstream from Cochran Creek, 0.8 mile downstream from Chihowee Dam, 20 miles south of Maryville, and at mile 32.8 .

DRAINAGE AREA. --1,987 sq mi, including Cochran Creek.

PERIOD OF RECORD. --Fater temeratures: October 1963 to September 1968.

EXTREMES, - -1967-68:

Water temperatures: Haximum, $21.0^{\circ} \mathrm{C}$ Oct. 14,15 , Sept. 21, 22, 29, 30; minimum, 4.0 $0^{\circ} \mathrm{C}$ Feb. $12,22,24-26$.

Period of record:

Water temperatures: Maximum, $28.0^{\circ} \mathrm{C}$ Aug. 29,1964 ; minimum, $3.0^{\circ} \mathrm{C}$ Feb. 6, 1966.

REMARKS. --Recorder stopped Jan. 11 to Feb. 7 ( $r$ ange in temperature $10.0^{\circ} \mathrm{C}$ to $6.0^{\circ} \mathrm{C}$ ). Records furnished by Tennessee Valley Authortty.

TEMPERATURE $\left({ }^{\circ} \mathrm{C}\right)$ OF WATER, WATER YEAR OCTOBER 1967 TO SEPTEMBER 1968 (CONTINUOUS ETHYL ALCOHOL-ACTUATED THERMOGRAPH)

DAY

MONTH

OCTOUFR

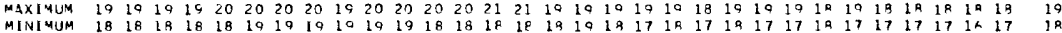
NOVEMAER

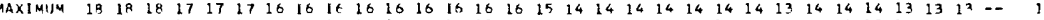

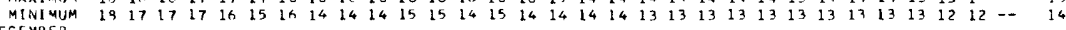

DECE MBER

$\begin{array}{llllllllllllllllllllllllllllllllllllllll}\text { MAXIMUM } & 13 & 13 & 13 & 13 & 13 & 12 & 13 & 13 & 13 & 13 & 13 & 13 & 13 & 13 & 12 & 12 & 12 & 12 & 12 & 12 & 12 & 12 & 12 & 12 & 11 & 11 & 11 & 11 & 11 & 11 & 11 & 12 \\ \text { MINIMUM } & 12 & 12 & 12 & 12 & 12 & 12 & 12 & 12 & 12 & 12 & 12 & 12 & 11 & 12 & 12 & 11 & 11 & 11 & 11 & 12 & 12 & 12 & 12 & 11 & 11 & 11 & 11 & 11 & 11 & 11 & 11 & 12\end{array}$

JANUARY

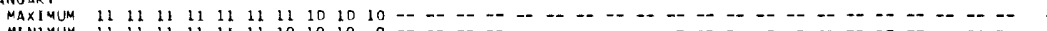

MINIMUM 11 il 11 li 11 ll 10 10 10 o

ERRUARY

MAXIYUM --

MINI

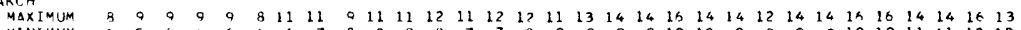

APRIL

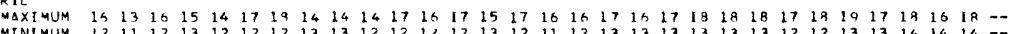

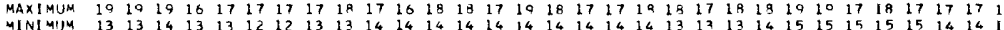

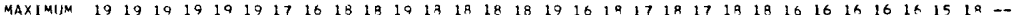
MINIYUM $14 \begin{array}{llllllllllllllllllllllllllllll} & 16 & 16 & 15 & 15 & 15 & 15 & 15 & 15 & 15 & 15 & 14 & 13 & 14 & 14 & 14 & 14 & 14 & 14 & 13 & 14 & 14 & 14 & 14 & 14 & 13 & 13 & 13 & 13 & --\end{array}$ JULY

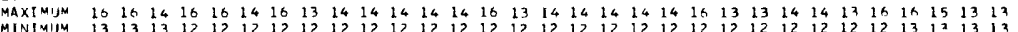
MUINIST

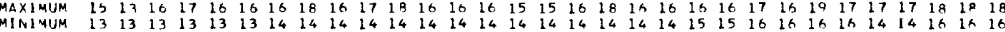

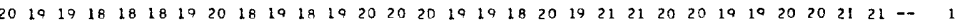


LOCATION, --Lat $35^{\circ} 21^{\prime} 42^{\prime \prime}$, long $84^{\circ} 16^{\prime} 44^{\prime \prime}$, Monroe County, temperature recorder at gaging station on right bank 200 ft upstream from bridge on Tellico plains-Rafter Hoad, 0.4 mile downstream from Laurel Creek, 0.8 mile east of Tellico Plains, and at mile 28.2

DRAINAGE AREA. - $118 \mathrm{sq} \mathrm{mi}$.

PERIOD OF RECORD.-.-Water temperatures: July 1964 to September 1968.

EXTREMES, - 1967-68:

Wa ter temperatures: Maximum, $29.0^{\circ} \mathrm{C}$ July 1, 2, Aug. 8, 9, 17, 18, 20-24; minimum, 1. $0^{\circ} \mathrm{C} \mathrm{Feb.11-16,} \mathrm{18-20,}$

Period of record: Water tempertures: Maximum, $31.0^{\circ} \mathrm{C}$ July 31, Aug. 2,1964 ; minimum, freezing point on many days during winter
periods.

REMARKS.--Recorder stopped July 15 to Aug. 7 (range in temperature $30.0^{\circ} \mathrm{C}$ to $21.0^{\circ} \mathrm{C}$ ). Records furinished by Tennessee valley Authority.

TEMPERATURE $\left({ }^{\circ} \mathrm{C}\right)$ OF WATER, WATER YEAR OCTOBER 1967 TO SEPTEMBER 1968 (CONTINUOUS ETHYL ALCOHOL-ACTUATED THERMOGRAPH)

DAY

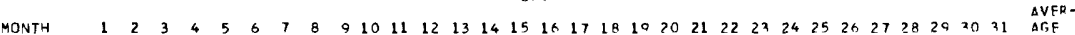

OCTOBER

$\begin{array}{llllllllllllllllllllllllllllllllllllllllll}\text { MAXIMUM } & 15 & 16 & 18 & 19 & 19 & 19 & 20 & 20 & 19 & 17 & 17 & 16 & 15 & 16 & 17 & 17 & 18 & 18 & 15 & 14 & 13 & 13 & 13 & 15 & 15 & 13 & 12 & 12 & 11 & 11 & 13 & 15 \\ \text { MINI } & 13 & 14 & 15 & 15 & 16 & 16 & 17 & 18 & 19 & 16 & 15 & 14 & 13 & 14 & 15 & 16 & 17 & 15 & 14 & 12 & 12 & 12 & 12 & 13 & 13 & 12 & 12 & 11 & 10 & 10 & 11 & 14\end{array}$

NOVEMBER

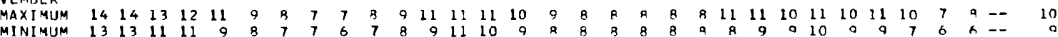

DECEMBER

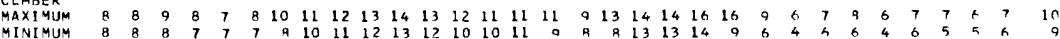

MINIMUM 8 B 8 - 8 -

$\begin{array}{llllllllllllllllllllllllllllllllllll}\text { MAXIMUM } & 7 & 8 & 9 & 9 & 7 & 8 & \text { A } & 4 & 6 & 8 & 8 & 9 & 7 & 6 & 3 & 4 & 4 & 4 & 5 & 6 & 9 & 8 & 9 & 9 & 4 & 4 & 5 & 6 & 8 & 9 & I 2 & 7 \\ \text { MINIMUM } & 6 & 6 & 8 & 5 & 4 & 4 & 4 & 2 & 3 & 6 & 8 & 7 & 4 & 3 & 3 & 3 & 3 & 3 & 3 & 4 & 6 & 8 & 9 & 4 & 3 & 2 & 3 & 4 & 4 & 7 & 9 & 5\end{array}$

FERTIAR

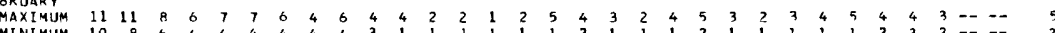

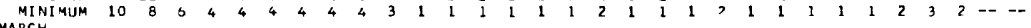

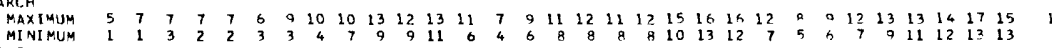

APR IL

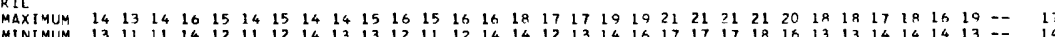
MAY

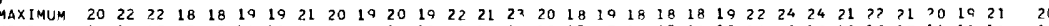

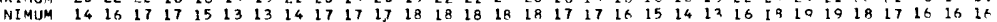

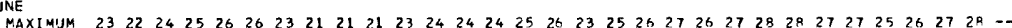

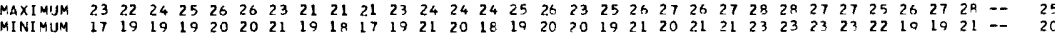

JULY

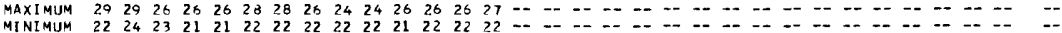
AUGUST

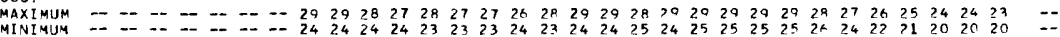
SEPTEMBER

$\begin{array}{lllllllllllllllllllllllllllllllllll}\text { MAXIMUM } & 24 & 24 & 25 & 24 & 23 & 24 & 24 & 23 & 23 & 24 & 22 & 22 & 22 & 22 & 22 & 22 & 22 & 22 & 22 & 23 & 24 & 24 & 24 & 23 & 23 & 20 & 22 & 22 & 22 & 21 & -- & 23 \\ \text { MINIMUM } & 21 & 20 & 20 & 22 & 22 & 21 & 10 & 19 & 21 & 21 & 19 & 18 & 17 & 18 & 19 & 19 & 20 & 20 & 19 & 20 & 20 & 21 & 21 & 21 & 21 & 21 & 19 & 19 & 19 & 19 & -- & 20\end{array}$ 

LOCATION.--Lat $36^{\circ} 06^{\prime} 52^{\prime \prime}$, long $63^{\circ} 59^{\prime} 16^{\prime \prime}$, Knox County, temperature recorder at gaging station on left bank on down stream side of br

DRA INAGE AREA, , 66.5 sq $\mathrm{ml}$.

PERIOD OF RECORD, --Water temperatures: October 1966 to September 1968.

EXTREMES. -1967-68:
Wa ter temperatures: Maximum, $27.0^{\circ} \mathrm{C}$ Aug. 7-10; minimum, 2. $0^{\circ} \mathrm{C} \mathrm{Jan.} \mathrm{8,} \mathrm{9,} \mathrm{Feb.} \mathrm{12-16,} \mathrm{19,} \mathrm{20,} 22-27$.

Water temperatures: Maximum, $27.0^{\circ} \mathrm{C}$ Aug. 7-10, $1968 ;$ min1mum, $1.0^{\circ} \mathrm{C} \mathrm{Dec} .26-28,1966$, Feb. $9,1967$. TEMPERATURE $11^{\circ} \mathrm{C} I$ OF WATER WATER YEAR OCTOBER 1967 TO SEPTEMBER 1968 (CONTINUOUS ETHYL ALCOHOL-ACTUATED THERMOGRAPH)

DAY

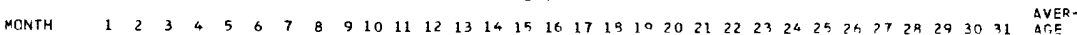

OCTOBER

MAXIMUM $14 \begin{array}{lllllllllllllllllllllllllllllllllllll} & 15 & 16 & 17 & 18 & 19 & 21 & 21 & 21 & 19 & 17 & 16 & 15 & 16 & 17 & 18 & 18 & 18 & 17 & 15 & 13 & 13 & 13 & 13 & 13 & 12 & 12 & 12 & 11 & 10 & 11 & 18\end{array}$ NOVEMBER

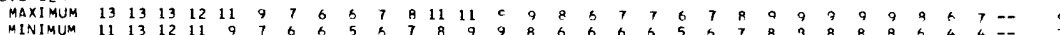

MINIMUM
DECEMAER

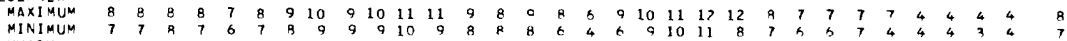

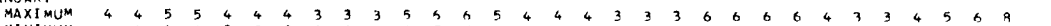

\begin{tabular}{lllllllllllllllllllllllllllllllllll} 
MINIMUM & 4 & 4 & 4 & 4 & 3 & 3 & 3 & 2 & 2 & 3 & 3 & 5 & 5 & 4 & 2 & 3 & 3 & 3 & 3 & 3 & 6 & 6 & 6 & 6 & 4 & 3 & 3 & 4 & 5 & 5 & 2 & 4 \\
\hline
\end{tabular}

$\begin{array}{llllllllllllllllllllllllllllllllllllllll}\text { MAXIMUM } & 8 & 8 & 8 & 6 & 4 & 4 & 5 & 4 & 5 & 5 & 4 & 3 & 2 & 2 & 2 & 3 & 3 & 3 & 3 & 3 & 3 & 3 & 2 & 2 & 3 & 3 & 3 & 3 & 2 & -- & -- & 4 \\ \text { MINIMUM } & 8 & 8 & 6 & 4 & 3 & 4 & 4 & 4 & 4 & 4 & 3 & 2 & 2 & 2 & 2 & 2 & 3 & 3 & 7 & 2 & 3 & 2 & 2 & 2 & 2 & 7 & 2 & 3 & 3 & -- & -- & 3\end{array}$

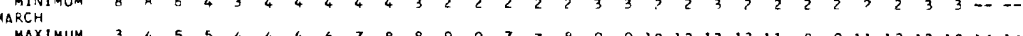

MAXIMUM

APKIL.

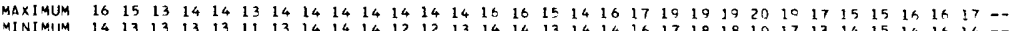

MAY

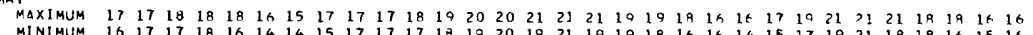
JUNE $\begin{array}{lllllllllllllllllllllllllllllllllllll}\text { MAXIMUM } & 17 & 17 & 18 & 16 & 19 & 19 & 19 & 19 & 20 & 20 & 22 & 22 & 22 & 21 & 20 & 20 & 20 & 20 & 21 & 21 & 21 & 22 & 23 & 23 & 23 & 23 & 23 & 21 & 21 & 22 & --\end{array}$ JULY

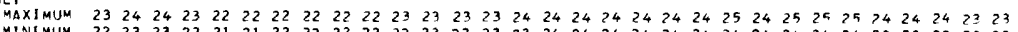

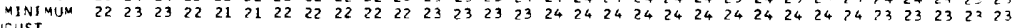
AUGIJST

MAXIMUM $\begin{array}{lllllllllllllllllllllllllllllllllllllllll}23 & 24 & 24 & 25 & 25 & 26 & 27 & 27 & 27 & 27 & 26 & 26 & 24 & 24 & 24 & 24 & 24 & 24 & 26 & 26 & 26 & 26 & 26 & 26 & 26 & 26 & 23 & ? 1 & 10 & 10 & 18\end{array}$

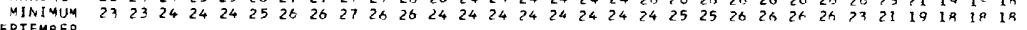
SEPTEMBER

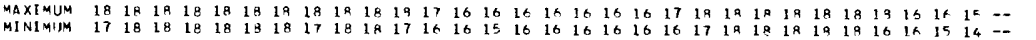
03538250 EAST FORK POPLAR CREEK NEAR OAK RIDGE, TENN.

LOCATION.--Lat $35^{\circ} 57^{\prime} 58^{\prime \prime}$, long $84^{\circ} 21^{\prime} 30^{\prime \prime}$, at gaging station near left bank on county road bridge 0.3 mile north of State Highway $95,1.7$ miles upstream from Bear Creek and 2.8 miles southwest of intersection of state Highway 95 and Anderson County line in Oak Ridge.

DRA INAGE AREA. $--19.5 \mathrm{sq} \mathrm{mi}$.

PERIOD OF RECORD.--Water temperatures: October 1961 to September 1968.

EXTREMES, $--1967-68$ :

water temperatures: Maximum, $27.0^{\circ} \mathrm{C}$ Aug. 24,$25 ; \operatorname{minimum}, 2.0^{\circ} \mathrm{C}$ Feb. 19

Period of record:

Water temperatures: Maximum, $27.0^{\circ} \mathrm{C}$ July 13-15, 1966, Aug. $24,25,1968$; minimum, 1. $0^{\circ} \mathrm{C}$ Feb. $3,4,1965$.

REMARKS. --Temperature recorder stopped Oct. 1-9, range in temperature $13.0^{\circ} \mathrm{C}$ to $20.0^{\circ} \mathrm{C} ; \mathrm{Jan}$. $24-29$, range in temperature $6.0^{\circ} \mathrm{C}$ to $9.0^{\circ} \mathrm{C}$; Apr. 1,2 , range in temperature $12.0^{\circ} \mathrm{C}$ to $14.0^{\circ} \mathrm{C}$; Apr. 20 to May 6 , range in temperperature $6.0^{\circ} \mathrm{C}$ to $9.0^{\circ} \mathrm{C}$; Apr. 1 2, range in temperature $12.0^{\circ} \mathrm{C}$ to $14.0^{\circ} \mathrm{C}$; Apr. 20 to May 6 , range
ature $13.0^{\circ} \mathrm{C}$ to $14.0^{\circ} \mathrm{C}$. Miscelianeous chemical analyses furnished by Tennessee Valley Authority.

CHEMICAL ANALYSES IN MIILIGRAMS PER LITER, WATER YeAR OCTOBER 1967 TO SEPTEMBER 1968

\begin{tabular}{|c|c|c|c|c|c|c|c|c|c|}
\hline DATE & $\begin{array}{l}\text { DIS- } \\
\text { CHARGE } \\
\text { (CFS) }\end{array}$ & $\begin{array}{l}\text { SILICA } \\
\text { (S102) }\end{array}$ & $\begin{array}{l}\text { DIS- } \\
\text { SOL VEO } \\
\text { IRCN } \\
\text { (FE) }\end{array}$ & $\begin{array}{l}\text { CAL- } \\
\text { CIUM } \\
\text { (CA) }\end{array}$ & $\begin{array}{l}\text { MAG- } \\
\text { NEE- } \\
\text { SIUM } \\
\text { (MG) }\end{array}$ & $\begin{array}{l}\text { SOO IUM } \\
\text { (NA) }\end{array}$ & $\begin{array}{l}\text { PO- } \\
\text { rAS- } \\
\text { SIUM } \\
\text { IK) }\end{array}$ & $\begin{array}{l}\text { BICAR- } \\
\text { SONATE } \\
\text { (HCD3) }\end{array}$ & $\begin{array}{l}\text { SULFATE } \\
\text { ISC4) }\end{array}$ \\
\hline JAN. & B3 & 5.2 & .05 & 42 & 9.5 & 6.8 & 1.5 & 121 & 27 \\
\hline $\begin{array}{l}\text { MAR. } \\
07 . . .\end{array}$ & A25 & 1.9 & .02 & 44 & 6.2 & 12 & 3.0 & 127 & 24 \\
\hline $\begin{array}{l}\text { MAY } \\
\text { O7... } \\
\text { SEPT. }\end{array}$ & 26 & 5.9 & .03 & 44 & 8.3 & 12 & 2.7 & 131 & 37 \\
\hline $17 \ldots$ & CHLO- & 7,7 & $\begin{array}{l}\text {.05 } \\
\text { DIS- } \\
\text { SOLVEO } \\
\text { SOLIDS } \\
\text { IRESI- }\end{array}$ & HARD- & $\begin{array}{l}7.7 \\
\text { SPECI- } \\
\text { FIC } \\
\text { COND- } \\
\text { UCTANCE }\end{array}$ & 17 & 3.7 & 132 & 35 \\
\hline ATE & $\begin{array}{l}\text { CHLO- } \\
\text { RIOE } \\
\text { (CL) }\end{array}$ & $\begin{array}{l}\text { NI TRATE } \\
\text { (NO3) }\end{array}$ & $\begin{array}{l}\text { IREST- } \\
\text { DUE AT } \\
\text { IBC CI }\end{array}$ & $\begin{array}{l}\text { HARD- } \\
\text { NESS } \\
\text { (CA,MG) }\end{array}$ & $\begin{array}{l}\text { (MICRO- } \\
\text { MHOS) }\end{array}$ & $\mathrm{PH}$ & $\begin{array}{l}\text { TEATURE } \\
\text { (OEA C) }\end{array}$ & COLOR & \\
\hline
\end{tabular}

\begin{tabular}{|c|c|c|c|c|c|c|c|}
\hline $\begin{array}{l}\text { JAA. } \\
\text { C3... }\end{array}$ & 5.0 & 8.0 & 160 & 128 & 272 & 7.2 & 9 \\
\hline $\operatorname{mar}=$ & 9.5 & 14 & 179 & 136 & 295 & 7.7 & 8 \\
\hline CP... & 9.5 & 15 & 191 & 145 & 335 & 7.2 & 14 \\
\hline $17 \ldots$ & 12 & 14 & 221 & 138 & 360 & 7.0 & 19 \\
\hline
\end{tabular}


03538250 EAST FORK POPLAR CREEK NEAR OAK RIDGE, TENN.--Continued

TEMPERATURE $\left({ }^{\circ} \mathrm{C}\right)$ OF WATER, WATER YEAR OCTOBER 1967 TO SEPTEMBER 1968 (CONTINUOUS ETHYL ALCOHOL-ACTUATED THERMOGRADH)

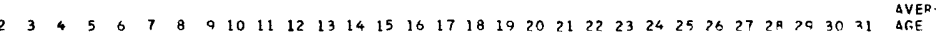

OCTOBE

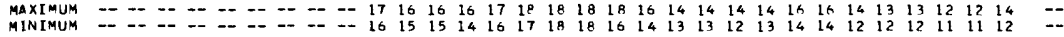

NOVEMBER

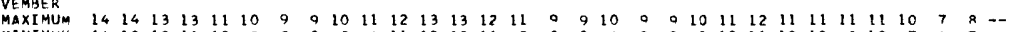

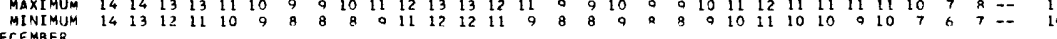

DECEMRER

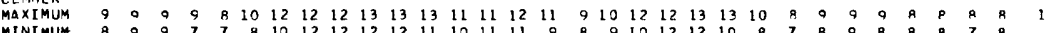

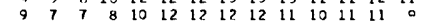

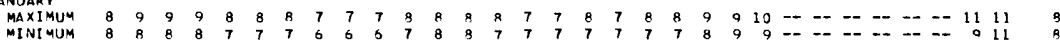

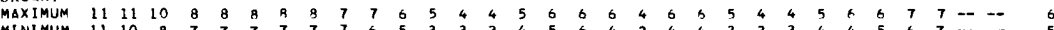

MINIMU

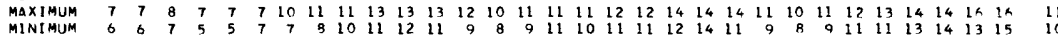

APRIL

MAXIMUM --

MAXIMUM -

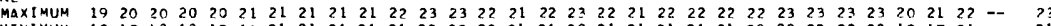

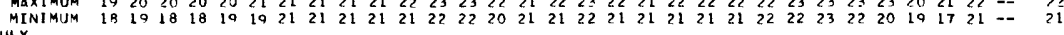

JULY

$\begin{array}{llllllllllllllllllllllllllllllllll}\text { MAXIMUM } & 23 & 23 & 23 & 22 & 21 & 22 & 22 & 22 & 22 & 22 & 22 & 22 & 22 & 22 & 22 & 23 & 23 & 23 & 23 & 23 & 23 & 23 & 23 & 23 & 23 & 23 & 23 & 23 & 23 & 22 & 23 & 23 \\ \text { MINIMUM } & 21 & 23 & 22 & 20 & 20 & 21 & 21 & 21 & 22 & 21 & 21 & 22 & 22 & 22 & 22 & 22 & 22 & 22 & 23 & 23 & 22 & 22 & 23 & 23 & 23 & 23 & 23 & 23 & 23 & 22 & 22 & 22\end{array}$

AUGUST

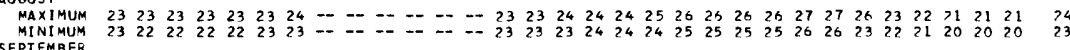

$\begin{array}{lllllllllllllllllllllllllllllllllllll}\text { MAXIMUM } & 21 & 22 & 21 & 22 & 22 & 22 & 22 & 21 & 22 & 22 & 21 & 20 & 19 & 20 & 21 & 21 & 21 & 21 & 21 & 21 & 22 & 22 & 22 & 21 & 22 & 21 & 21 & 10 & 10 & 20 & -- & 21 \\ \text { MINIMUM } & 20 & 21 & 20 & 21 & 22 & 22 & 21 & 20 & 21 & 21 & 20 & 19 & 18 & 10 & 19 & 21 & 20 & 21 & 20 & 20 & 21 & 21 & 21 & 21 & 21 & 21 & 17 & 18 & 10 & 10 & -- & 20\end{array}$

03540100 CRAB ORCHARD CREEK NEAR DEERMONT, TENN.

LOCATION.--Lat $36^{\circ} 00^{\prime} 40^{\prime \prime}$, long $84^{\circ} 36^{\prime} 44^{\prime \prime}$, Morgan County, at gaging station on county road bridge 0.15 mile above Smith Branch, 1.9 miles southest of Deermont and 2.9 miles upstream from mouth.

DRAINAGE AREA. $--33.7 \mathrm{sq} \mathrm{mt}$.

PERIOD OF RECORD.--Water temperatures: October 1966 to september 1968.

EXTREMES. - - 1967-68:

Water temperatures: Maximum, $28.0^{\circ} \mathrm{C}$ June 30 , July 1, 18, 19, 26, 27, Aug. 6, 8, 10, 24; minimum, $1.0^{\circ} \mathrm{C}$ Feb. $12-16,20,22-28$, Mar. 1,2 .

Period of record: Wa ter temperatures: Maximum, $28.0^{\circ} \mathrm{C}$ June 30, July $1,18,19,26,27$, Aug. $6,8,10,24,1968 ;$ minimum, $1.0^{\circ} \mathrm{C}$
Dec. $25-28,1966$, Feb. $26,27,1967$, Feb. 12-16, 19, 20, 22-28, Mar. 1, 2, 1968.

REMARKS.--Miscellaneous chemical analyses furnished by Tennessee Valley Authority.

CHEMICAL ANALYSES IN MILLIGRAMS PER LITER, WATER YEAR OCTOBER 1967 TO SEPTEMBER 1968

\begin{tabular}{|c|c|c|c|c|c|c|c|c|c|}
\hline DATE & $\begin{array}{l}\text { MEAN } \\
\text { DIS- } \\
\text { CHARGE } \\
\text { (CFS) }\end{array}$ & $\begin{array}{l}\text { SILICA } \\
\text { (S102) }\end{array}$ & $\begin{array}{l}\text { OIS- } \\
\text { SOLVED } \\
\text { IRCN } \\
\text { (FE) }\end{array}$ & $\begin{array}{l}\text { CAL- } \\
\text { CIUM } \\
\text { (CA) }\end{array}$ & $\begin{array}{l}\text { MAG- } \\
\text { NE- } \\
\text { SIUM } \\
(\text { MG })\end{array}$ & $\begin{array}{l}\text { SOO IUM } \\
\text { (NA) }\end{array}$ & $\begin{array}{l}\text { PO- } \\
\text { TAS- } \\
\text { SlUM } \\
(K)\end{array}$ & $\begin{array}{l}\text { 8ICAR- } \\
\text { BONATE } \\
\text { (HCO3) }\end{array}$ & $\begin{array}{l}\text { SULFA TE } \\
\text { (SC4) }\end{array}$ \\
\hline JAN. & $A 540$ & 3.1 & .08 & 2.5 & 1.0 & .5 & .6 & 2 & 8.4 \\
\hline $26 \ldots$ & 113 & 2.3 & .07 & 1.9 & 1.5 & .4 & .7 & 2 & e. 4 \\
\hline $24 \ldots$ & 12 & 4.8 & .00 & 4.3 & 2.4 &.$t$ & .8 & 1 & 20 \\
\hline
\end{tabular}

\begin{tabular}{|c|c|c|c|c|c|c|c|c|}
\hline DATE & $\begin{array}{l}\text { CHLC- } \\
\text { RIDE } \\
(\mathrm{CL})\end{array}$ & $\begin{array}{c}\text { NI TRATE } \\
\text { (NO3) }\end{array}$ & $\begin{array}{l}\text { DIS- } \\
\text { SDLVED } \\
\text { SOL IDS } \\
\text { (RESI- } \\
\text { DUE AT } \\
\text { IBO C) }\end{array}$ & $\begin{array}{l}\text { HARD- } \\
\text { NESS } \\
(C A, M G)\end{array}$ & $\begin{array}{l}\text { SPECI- } \\
\text { FIC } \\
\text { COND- } \\
\text { UCTANCE } \\
\text { (MICRO- } \\
\text { MHOS) }\end{array}$ & PH & $\begin{array}{l}\text { TEMP- } \\
\text { ERATURE } \\
\text { (OEG C) }\end{array}$ & COLCF \\
\hline JAN. & & & & & & & & \\
\hline $\begin{array}{l}11 \ldots \\
\text { MAR. }\end{array}$ & 1.5 & .1 & 21 & 10 & $3 t$ & 5.0 & 7 & 5 \\
\hline${ }_{\text {MYY }}^{26 . . .}$ & 1.5 & .2 & 21 & 10 & 36 & 4.7 & -- & 2 \\
\hline $24 \ldots$ & 1.5 & .0 & 30 & 20 & 62 & 4.8 & -- & \\
\hline
\end{tabular}

a discharge at time of sampling. 
03540100 CRAB ORCHARD CREEK NEAR DEERMONT, TENN. --Cont1InUEd

TEMPERATURE (OC) OF WATER, WATER YEAR OCTOBER 1967 TO SEPTEMBER 1968

(CONTINUDUS ETHYL ALCOHDL-ACTUATED THERMDGRAPH)

DAY

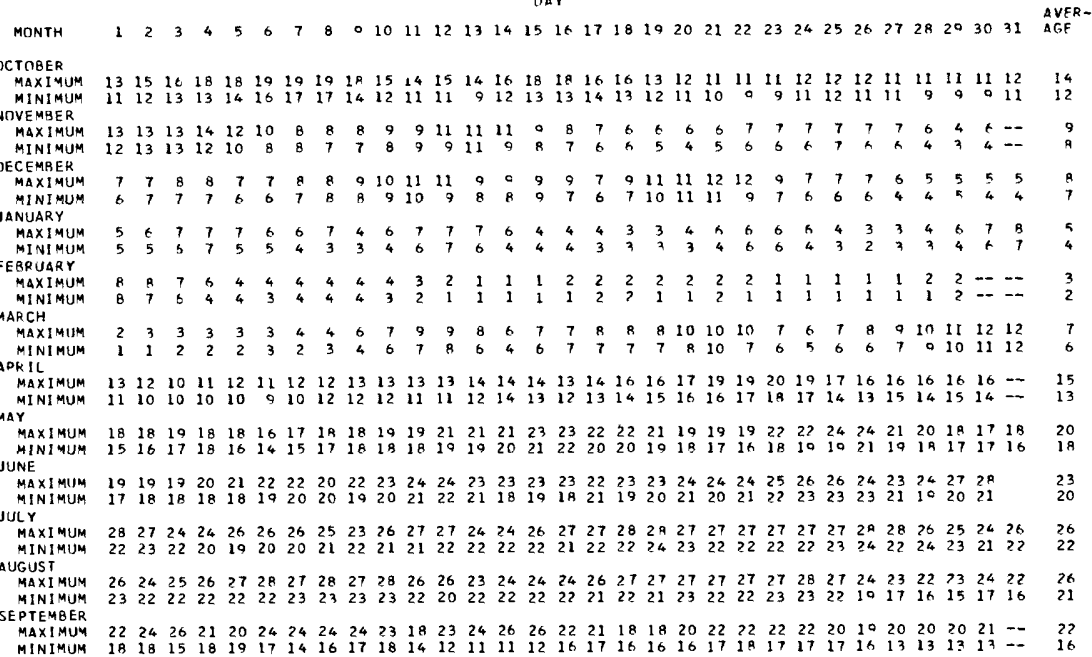

\section{SEQUATCHIE RIVER NEAR WHITWELL, TENN.}

LOCATION. --Lat $35^{\circ} 12 \cdot 22^{\prime \prime}$, long $85^{\circ} 29^{\prime} 48^{\prime \prime}$, Marion County, temperature recorder at gaging station on right bank $15 \mathrm{ft}$ downstream from highway bridge, 1.5 miles east of whitwel1, 3 miles upstream from bridge on state Highway 27 , 4.5 miles downstream from Griffith Creek and at mile 25.1.

DRAINAGE AREA,--402 sq mi (includes $17.8 \mathrm{sq} \mathrm{mi} \mathrm{in} \mathrm{Grassy,} \mathrm{Swaggerty,} \mathrm{and} \mathrm{Little} \mathrm{Coves).}$

PERIOD OF RECORD... Water temperatures: March 1962 to September 1968.

EXTREMES. - $1967-68$ :

Water temperatures: Maximum, 26. $0^{\circ} \mathrm{C}$ Aug. 19-26; minimum, $6.0^{\circ} \mathrm{C}$ Feb. $12-15,22-26$.

period of record:

Water temperatures: Maximum, $26,0^{\circ} \mathrm{C}$ on several days during July to september 1962, July 14-16, 29, 1966,

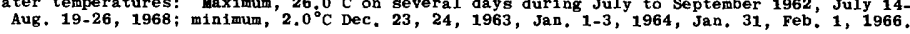

REMARKS.--Recorder pen failed to mark Aug. 1, 2, 8-12; thermograph out of water Sept. 12-15, 21-30.

TEMPERATURE $\left({ }^{\circ} \mathrm{C}\right)$ OF WATER, HATER YEAR OCTOBER 1967 TO SEPTEMBER 1968 (CONTINUDUS ETHYL ALCOHOL-ACTUATED THERMOGRAPH)

DAY

MONTH

OC TOSEP

$\begin{array}{lllllllllllllllllllllllllllllllllllll}\text { MAXIMUM } & 15 & 16 & 16 & 17 & 17 & 17 & 18 & 18 & 18 & 18 & 16 & 16 & 14 & 15 & 16 & 16 & 16 & 16 & 16 & 15 & 14 & 13 & 13 & 14 & 14 & 14 & 13 & 13 & 13 & 12 & 12 \\ \text { MINIMUM } & 15 & 15 & 16 & 16 & 17 & 17 & 17 & 18 & 18 & 16 & 16 & 14 & 14 & 14 & 15 & 16 & 16 & 16 & 15 & 14 & 13 & 13 & 13 & 13 & 14 & 13 & 13 & 13 & 12 & 12 & 12 \\ \text { NOEEMBER } & & & & & & & & & & & & & & & & & \end{array}$

NOVEMAER

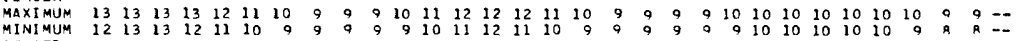

OECEMBER

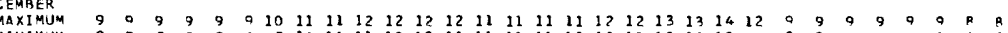

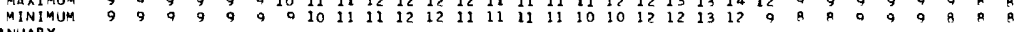

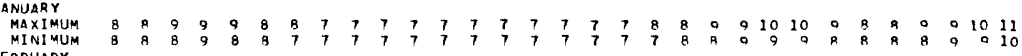

FERRUARY

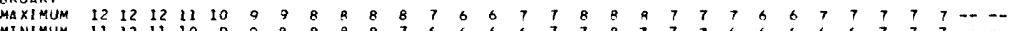

MINIMUM

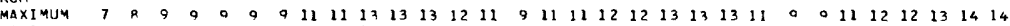

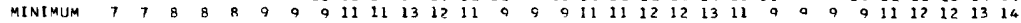

APRIL

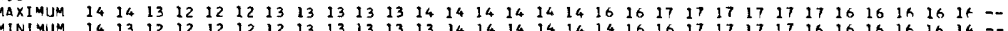

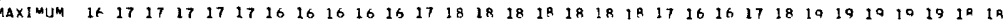

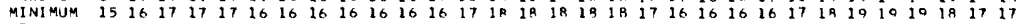
JINE

$\begin{array}{llllllllllllllllllllllllllllllllll}\text { MAXIMUM } & 18 & 19 & 19 & 20 & 21 & 21 & 21 & 21 & 21 & 21 & 21 & 22 & 22 & 22 & 21 & 21 & 21 & 22 & 22 & 22 & 22 & 22 & 23 & 29 & 23 & 23 & 23 & 22 & 22 & 22 & \cdots \\ \text { MINIMUM } & 18 & 18 & 19 & 18 & 20 & 20 & 21 & 20 & 20 & 21 & 21 & 21 & 21 & 21 & 21 & 21 & 21 & 21 & 22 & 22 & 22 & 22 & 22 & 22 & 23 & 23 & 22 & 22 & 22 & 22 & \cdots\end{array}$ JULY

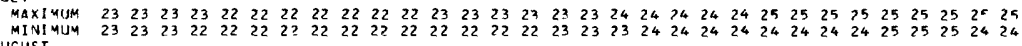
AUGUST

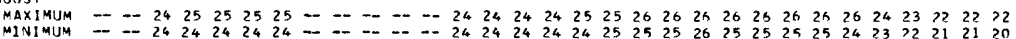
MINIMUM

SEPTEMBER

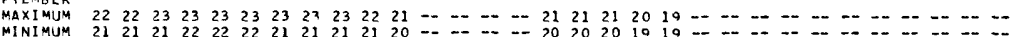


03572900 TOWN CREEK NEAR GERALDINE, ALA.

LOCATION, - - Lat $34^{\circ} 22^{\prime} 42^{\prime \prime}$, long $85^{\circ} 59^{\prime} 25^{\prime \prime}$, in SE

gaging station at bridge on State Hihgway $75,1,600 \mathrm{ft}$ downstream from Reedy Creek, 4,500 ft upstream from Tray.

lor Branch, 2 miles north northeast of Geraldine, and 15 miles northeast of Albertvilie.

DRAINAGE AREA, --141 sq mi.

PERIOD OF RECORD...Water temperatures: April to September 1968.

EXTREMES, $--1967-68$ :

Water temperatures: Maximum, $31.0^{\circ} \mathrm{C}$ Aug. 22-24.

CHEMICAL ANALYSES IN MILLIGRAMS PER LITER, WATER YEAR OCTOBER 1967 TD SEPTEMBER 1968

\begin{tabular}{|c|c|c|c|c|c|c|c|c|}
\hline DATE & $\begin{array}{l}\text { O1S- } \\
\text { CHARGE } \\
\text { (CFS) }\end{array}$ & $\begin{array}{l}\text { BICAR- } \\
\text { BONATE } \\
\text { (HCO3) }\end{array}$ & $\begin{array}{l}\text { CAR- } \\
\text { BONATE } \\
\text { (CO3) }\end{array}$ & $\begin{array}{l}\text { CHLO- } \\
\text { RIDE } \\
\text { ICLI }\end{array}$ & $\begin{array}{l}\text { HARD- } \\
\text { NESS } \\
\text { |CA, MG I }\end{array}$ & $\begin{array}{l}\text { NON- } \\
\text { CAR- } \\
\text { BONATE } \\
\text { HARD- } \\
\text { NESS }\end{array}$ & $\begin{array}{l}\text { SPECI- } \\
\text { FIC } \\
\text { COND- } \\
\text { UCIANCE } \\
\text { (MICRD- } \\
\text { MHOS I }\end{array}$ & PH \\
\hline $\begin{array}{l}\text { JAN. } \\
\text { O4... } \\
\text { FEB. }\end{array}$ & 1060 & 5 & 0 & 2.6 & 15 & 8 & 42 & $6 . t$ \\
\hline $\begin{array}{l}19 . . . \\
\text { JUNE }\end{array}$ & 95 & 28 & 0 & 3.2 & 15 & 0 & 45 & 6.9 \\
\hline $10 \ldots$ & 29 & 8 & 0 & 3.2 & 10 & 3 & 36 & 6.6 \\
\hline
\end{tabular}

TEMPERATURE $\left.1^{\circ} \mathrm{C}\right)$ DF WATER, APRIL TO SEPTEMBER 1968 (CONTINUOUS ETHYL ALCOHOL-ACTUATED THERMOGRAPH)

\begin{tabular}{|c|c|c|c|c|c|c|c|c|c|c|c|c|}
\hline \multirow[b]{2}{*}{ CAY } & \multicolumn{2}{|c|}{ APRIL } & \multicolumn{2}{|c|}{ yar } & \multicolumn{2}{|c|}{ JUNE } & \multicolumn{2}{|c|}{ JULY } & \multicolumn{2}{|c|}{ AUGUST } & \multicolumn{2}{|c|}{ SEPTEMEER } \\
\hline & $\operatorname{MAX}$ & MIN & $\operatorname{MAX}$ & MIN & $M \Delta x$ & MIA & $\operatorname{MAX}$ & MIA & $M \Delta x$ & MIN & $\max$ & MIN \\
\hline 1 & $\cdots$ & -- & 17.0 & 13.0 & 20.0 & $17 . c$ & $\cdots$ & -- & 28.0 & 24.0 & --- & -- \\
\hline 2 & -. & --- & 19.0 & 14.0 & 22.0 & $1 \% 0$ & -- & -- & 27.0 & 24.0 & -- & -- \\
\hline 3 & $=-$ & -- & 18.0 & 14.0 & 23.0 & 19.0 & $\cdots$ & -- & 27.0 & 23.0 & 27.0 & 18.0 \\
\hline 4 & -- & --- & $17 . ?$ & 15.0 & 23.0 & 19.0 & -- & $\cdots$ & 28.0 & 24.0 & 27.0 & 22.0 \\
\hline 5 & $\cdots$ & --- & 17.0 & 13.0 & 24.0 & 20.0 & $\cdots$ & $\cdots$ & 28.0 & 24.0 & 26.0 & 23.0 \\
\hline$\Rightarrow$ &.- & -- & 17.0 & 12.0 & 24.0 & 20.0 & 27.0 & 22.0 & 29.0 & 24.0 & 27.0 & 23.0 \\
\hline 7 & $=-$ & -- & 17.0 & 12.0 & 23.0 & $20 . c$ & 26.0 & 21.0 & 29.0 & 25.0 & 26.0 & 20.0 \\
\hline B & -. & $-\cdots$ & 17.0 & 15.0 & 24.0 & $20 . c$ & 24.0 & 22.0 & $3 n .0$ & $25 . n$ & 27.0 & 21.0 \\
\hline 9 & - & $\cdots$ & 19.0 & 16.0 & 26.0 & 21.0 & 23.0 & 22.0 & 29.0 & 26.0 & 27.0 & 21.0 \\
\hline 10 & $\cdots$ & $\cdots$ & 18.0 & $16 . \mathrm{C}$ & 27.0 & 23.0 & 23.0 & 21.0 & 29.0 & 25.0 & 26.0 & $\ldots$ \\
\hline 11 & -- & -- & 18.0 & 17.0 & 27.0 & 23.0 & 24.0 & 21.0 & 28.0 & 25.0 & --- & $16 . \mathrm{C}$ \\
\hline 12 & --- & $\cdots$ & 19.0 & $17 . \mathrm{C}$ & 28.0 & 23.0 & 24.0 & 22.0 & 28.0 & 24.0 & 22.0 & 14.0 \\
\hline 23 & -- & -- & 19.0 & 17.0 & 29.0 & 22.3 & 74.5 & $22 . c$ & 27.0 & 24.0 & $-\cdots$ & $\cdots$ \\
\hline 14 & $\cdots$ & --- & 18.0 & 17.0 & 27.0 & 21.0 & 26.0 & 22.0 & 28.0 & 24.0 & --- & $\cdots$ \\
\hline 15 & $\cdots$ & --- & 18.0 & 17.0 & 27.0 & 21.0 & 25.0 & 23.0 & $\cdots$ & 25.0 & $\cdots$ &.- \\
\hline 16 & -.. & --- & 18.0 & 17.0 & 28.0 & 23.0 & $24 * 0$ & 23.0 & $\ldots$ & $\ldots$ & -- & -- \\
\hline 17 & 16.0 & 13.0 & 17.0 & 16.0 & 27.0 & 24.0 & 24.0 & 22.0 & --- & --- & --- & $+\infty$ \\
\hline 18 & 17.0 & 15.0 & 17.0 & 16.0 & 28.0 & $2 \pi \cdot n$ & $26 . n$ & $22 . c$ & $\cdots$ & -- & -- & -- \\
\hline 19 & 17.2 & 10.0 & 17.0 & 16.0 & 27.0 & 24.0 & 27.0 & 24.0 & $\cdots$ & $\cdots$ & --- & $\cdots$ \\
\hline 20 & 17.0 & 26.0 & 17.0 & 14.0 & -- & 23.0 & 26.0 & 23.0 & -- & --- & -- & $\cdots$ \\
\hline 21 & 17.0 & 15.0 & 10.0 & $14 . c$ & --- & 23.0 & 26.0 & 23.0 & -- & --- & --- & $\cdots$ \\
\hline 22 & 17.0 & 16.0 & 16.0 & 13.0 & -- & 24.0 & 27.0 & 24.0 & 31.0 & 26.0 & --- & $\cdots$ \\
\hline 23 & 18.0 & 16.0 & 18.0 & $14 * 0$ & --- & 25.3 & 27.0 & 24.0 & 31.0 & 26.0 & -- & -- \\
\hline 24 & 13.0 & 15.0 & 19,0 & 16.0 & -- & 24.0 & 28.0 & 24.0 & 31.0 & 26.0 & -- & -- \\
\hline 25 & 17.0 & 13.0 & 21.0 & 18.0 & -- & $25 . \mathrm{C}$ & 27.0 & 24.0 & 30.0 & 26.0 & $\cdots$ & +- \\
\hline 26 & 17.0 & 13.0 & 20.0 & $18, \mathrm{C}$ & -- & 25.0 & 29.0 & 24.0 & -- & --- & -- & $\cdots$ \\
\hline 27 & 17.0 & 14.0 & 19.0 & 17.0 & -- & $\ldots$ & 29.0 & 26.0 & $\cdots$ & --- & $-\infty$ & -- \\
\hline 28 & 16.0 & 14.0 & 18.0 & 17.0 & - & $\cdots$ & 79.0 & 26.0 & $\cdots$ & $\cdots$ & $\cdots$ & $\cdots$ \\
\hline 29 & 15.0 & 14.0 & 19.0 & $16 . c$ & -- & -. & 23.0 & 23.0 &.- & -- & $\cdots$ & $-\infty$ \\
\hline 30 & 20.0 & 13.0 & 19.0 & 16.0 & -- & $\cdots$ & 26.0 & 23.0 & -- & -- & $\cdots$ & $\cdots$ \\
\hline 31 & - & -- & 10.0 & 16.0 & -- & $\cdots$ & 27.0 & 23.0 & $\cdots$ & -- & $\cdots$ & $\cdots$ \\
\hline $\mathrm{NTH}$ & $-\ldots$ & -- & 21.0 & 12.0 & -.. & 17.0 & 29.0 & 21.0 & -- & -- & --- & -- \\
\hline
\end{tabular}


LOCATION. - - Lat $35^{\circ} 12^{\prime} 51^{\prime \prime}$, long $87^{\circ} 06^{\prime} 05^{\prime \prime}$, Giles County, at gaging station on right bank 1,200 ft upstream from bridge on U.S. Highway 64, 1 mile downstream from Weakley Creek, 4 miles west of Pulaski and at mile 30.1 . DRAI NAGE AREA. $--366 \mathrm{sq} \mathrm{mi}$.

PERIOD OF RECORD.--Water temperatures: October 1964 to September 1967, March to September 1968.

EXTREMES. --1967-68:

Water temperatures: Maximum, $27,0^{\circ} \mathrm{C}$ Aug. 8,9 ; minimum, $4.0^{\circ} \mathrm{C}$ Mar, 23

period of record:

Wa ter temperatures: Maximum, $27.0^{\circ} \mathrm{C}$ July 14, 1966, Aug. 8, 9, 1968; minimum, 2.0 ${ }^{\circ} \mathrm{C}$ Jan. $29,1966$. REMARKS. --Records furnished by Tennessee Valley Authority.

TEMPERATURE $\left.1^{\circ} \mathrm{C}\right)$ OF WATER, MARCH TO SEPTEMBER 1968

(CONTINUOUS ETHYL ALCOHOL-ACTUATED THERMOGRAPHI

DAY

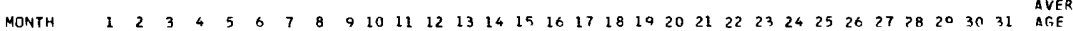
MARCH

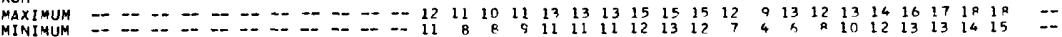

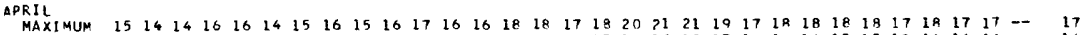

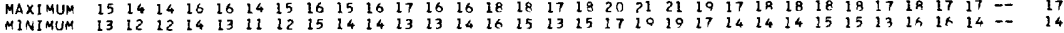

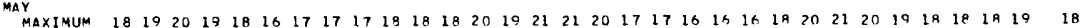

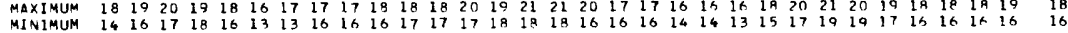
JUNE MAXIMUM $20 \begin{array}{llllllllllllllllllllllllllllllll} & 20 & 21 & 21 & 21 & 21 & 22 & 22 & 22 & 23 & 23 & 23 & 23 & 22 & 22 & 22 & 22 & 22 & 22 & 22 & 22 & 23 & 23 & 24 & 24 & 23 & 22 & 22 & 23 & 24 & -- & 22\end{array}$

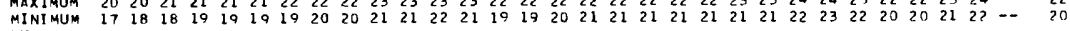
JULY

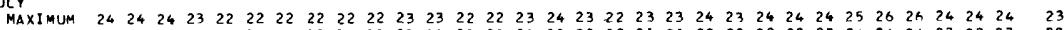

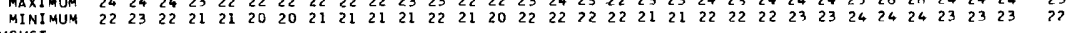
AUGUST

$\begin{array}{lllllllllllllllllllllllllllllllllll}\text { MAXIMUM } & 25 & 24 & 25 & 26 & 26 & 26 & 26 & 27 & 27 & 26 & 26 & 25 & 25 & 25 & 25 & 26 & 26 & 26 & 26 & 26 & 26 & 26 & 26 & 26 & 26 & 25 & 23 & 22 & 22 & 21 & 21 & 25 \\ \text { MINIMUM } & 24 & 23 & 23 & 24 & 24 & 24 & 24 & 24 & 24 & 24 & 24 & 23 & 23 & 23 & 23 & 24 & 24 & 24 & 24 & 24 & 24 & 24 & 24 & 24 & 24 & 22 & 21 & 19 & 19 & 10 & 19 & 23\end{array}$ SEPTEMBER

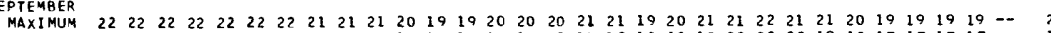

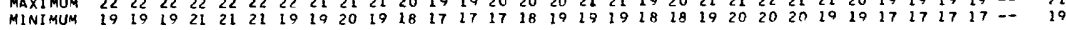
03591800 BEAR CREEK NEAR HACKLEBURG, ALA.

LOCATION.--Lat $34^{\circ} 17^{\circ} 01^{\prime \prime}$, long $87^{\circ} 46^{\prime} 26^{\prime \prime}$, in SWf sec. 11, T. 9 S., R. 12 W., Marion County, temperature recorder at gaging station on right bank downstream side of bridge on Alabama Highway 172,2 miles upstream from Bluff Creek
and 3,5 miles east of Hackleburg.

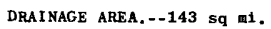

PERIOD OF RECORD,--Chemical analyses: December 1965 to September 1967.

Water temperatures: Harch 1965 to september 1968.

EXTREMES. - -1967-68:

Wa ter temperatures: Maximum, $29.0^{\circ} \mathrm{C}$ on several days during June, July and Aug.; minimum, $1.0^{\circ} \mathrm{C}$ Mar. 1 period of record:

water temperatures: Maximum, $31.0^{\circ} \mathrm{C}$ July 13-16, 1966; minimum, freezing point Jan. 29 to Feb. 1, 1966 . REMARKS. --Records furnished by Tennessee Valley Authority.

CHEMICAL ANALYSES IN MILLIGRAMS PER LITER, WATER YEAR OCTOBER 1967 TO SEPTEMBER 1968

\begin{tabular}{|c|c|c|c|c|c|c|c|c|}
\hline DATE & $\begin{array}{l}\text { OIS- } \\
\text { CHARGE } \\
\text { (CFS) }\end{array}$ & $\begin{array}{l}\text { BI CAR- } \\
\text { RONATE } \\
\text { (HCO3) }\end{array}$ & $\begin{array}{l}\text { CAR- } \\
\text { BONATE } \\
\text { (CO3) }\end{array}$ & $\begin{array}{l}\text { CHLO- } \\
\text { RIOE } \\
\text { (CL) }\end{array}$ & $\begin{array}{l}\text { HARO- } \\
\text { NESS } \\
\text { (CA, MG) }\end{array}$ & $\begin{array}{l}\text { NON- } \\
\text { CAR- } \\
\text { BONATE } \\
\text { HARD- } \\
\text { NESS }\end{array}$ & $\begin{array}{l}\text { SPECI- } \\
\text { FIC } \\
\text { CONO- } \\
\text { UCTANCE } \\
\text { (MICRO- } \\
\text { MHOS) }\end{array}$ & $P_{H}$ \\
\hline $\begin{array}{l}\text { NOV. } \\
\text { OB... } \\
\text { APR. }\end{array}$ & 78 & 12 & 0 & 2.4 & 14 & 4 & 36 & 7.1 \\
\hline $\begin{array}{l}\text { OS.... } \\
\text { JUNE }\end{array}$ & 553 & 6 & 0 & 1.8 & 10 & 5 & 25 & 6.8 \\
\hline $19 \ldots$ & 46 & 10 & 0 & 1.6 & 10 & 2 & 36 & 6.7 \\
\hline
\end{tabular}


TENNESSEE RIVER BASIN

03591800 BEAR CREEK NEAR HACKLEBURG, ALA.-- Continued

TEMPERATURE ( ${ }^{\circ} \mathrm{C}$ ) OF WATER, WATER YEAR OCTOBER 1967 TO SEPTEMBER 1968

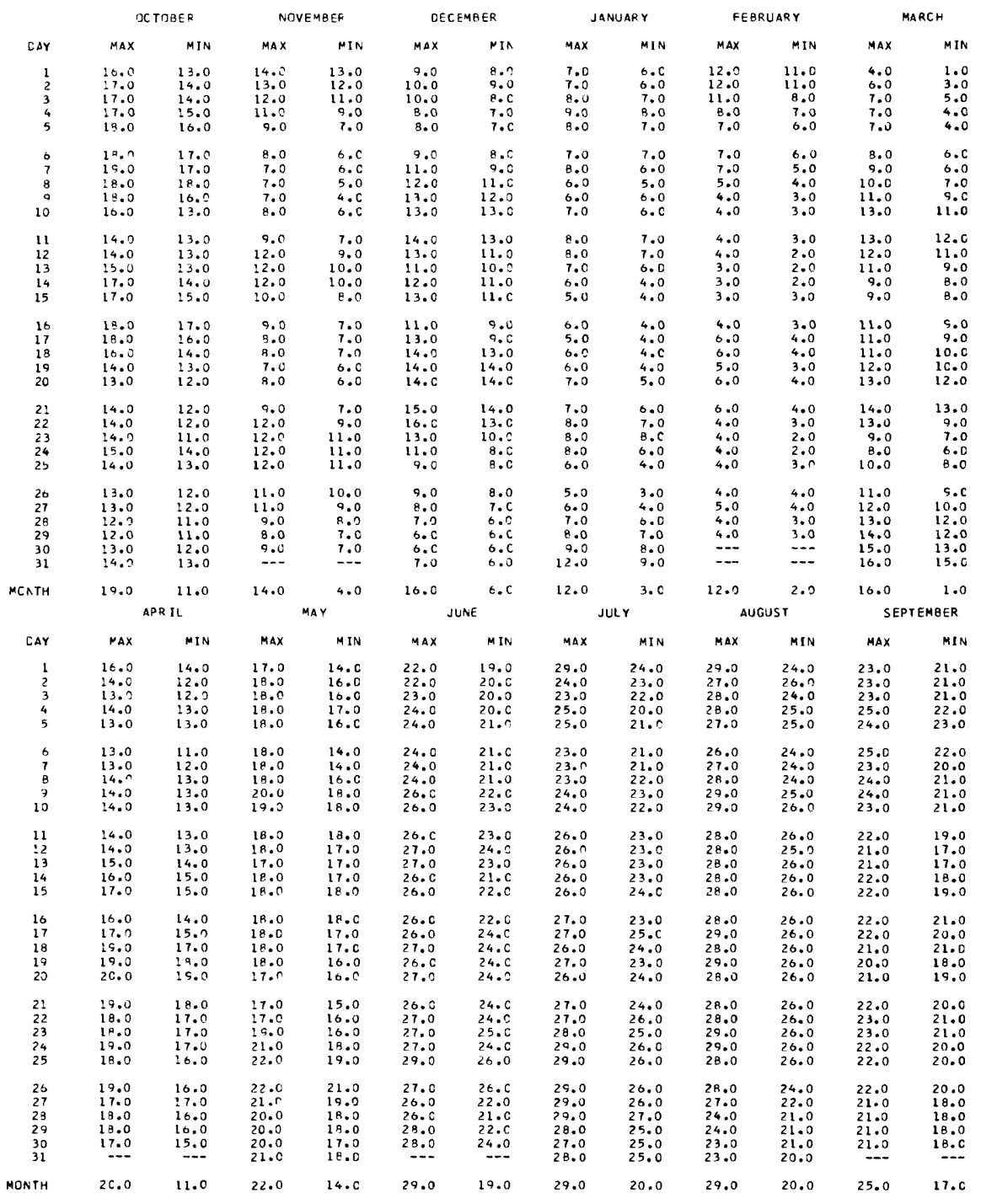


LOCATION.--Lat $34^{\circ} 32^{\prime} 56^{\prime \prime}$, Long $88^{\circ} 01^{\prime} 09^{\prime \prime}$, in SW $\frac{1}{4}$ sec. 9, T. 6 S., R. 14 W., Franklin County, temperature recorder at gaging station on left bank on downstream side of pier of highway bridge, 2.6 miles east of pleasant Site and 4.3 miles upstream from Little Bear Creek.

DRAINAGE AREA. --189 sq ml.

PERIOD OF RECORD. - - Mater temperatures: January 1963 to September 1968.

EXTREMES , $-1967-68$

Nater temperatures: Maximum, $29.0^{\circ} \mathrm{C}$ July 27, 28, Aug. 9, 10, 21, 23, 24; minimum, 2. $0^{\circ} \mathrm{C} \mathrm{Feb.12,} \mathrm{14,} \mathrm{23,} \mathrm{24,}$ Mar, 1 .

period of record: periods.

REMARKS, - Records furnished by Tennessee Valley Authority.

CHEMICAL ANALYSES IN MILLIGRAMS PER LITER, WATER YEAR OCTOBER 1967 TO SEPTEMBER 1968

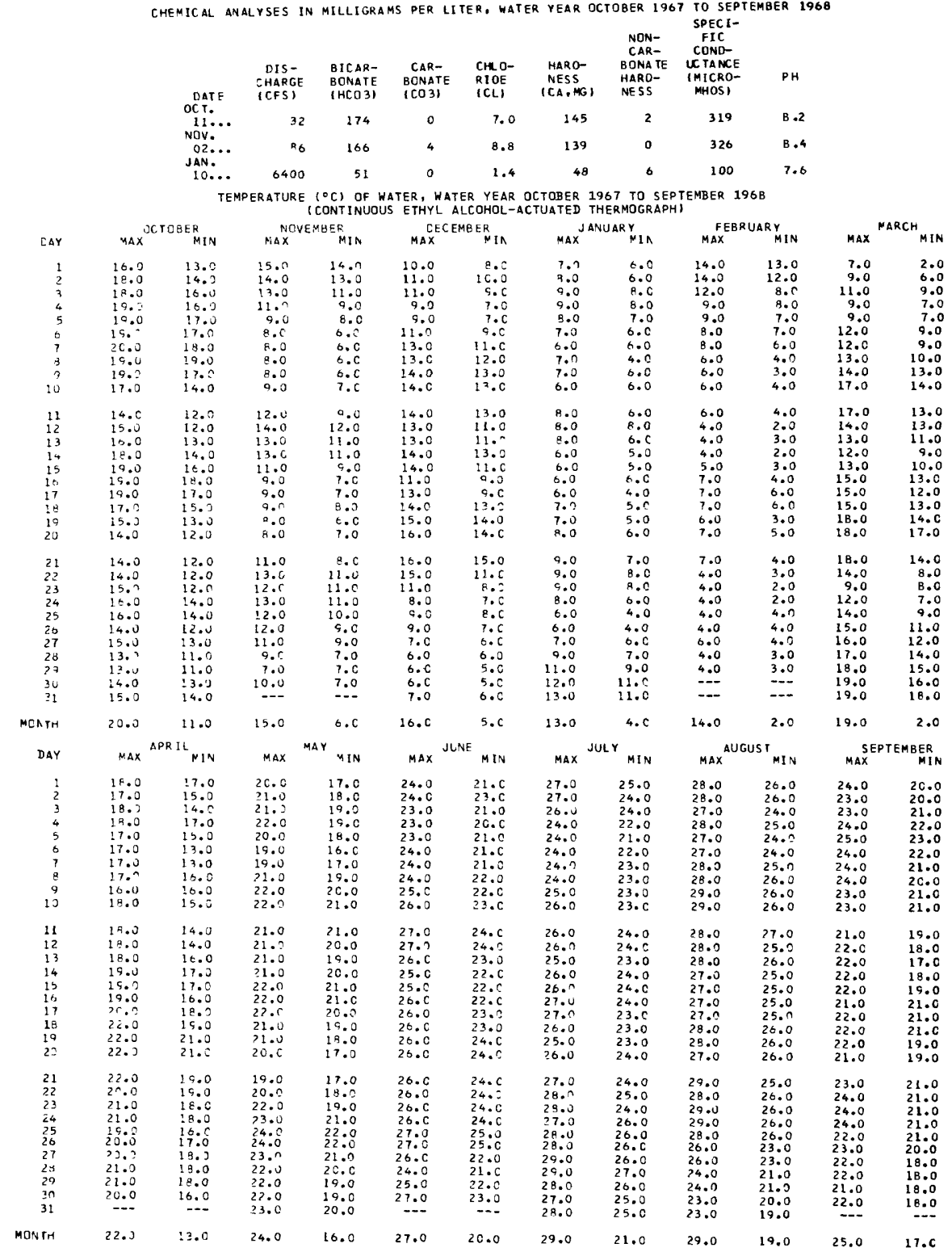


03592300 LITTLE BEAR CREEK NEAR HALLTOWN, ALA,

LOCATION. --Lat $34^{\circ} 29^{\prime} 19^{\prime \prime}$, long $88^{\circ} 02^{\prime} 07^{\prime \prime}$, in NW/ sec. 5, T. 7 S, , R, $14{ }^{\prime}$, , Franklin County, temperature recorder at gaging station near right bank on downstream side of pier of highway bridge, 2.7 miles northeast of Halltown, and 4.2 miles upstream from Cedar Creek.

DRAI NAGE AREA, $--78.2 \mathrm{sq} \mathrm{mi}$.

PERIOD OF RECORD. .. Tater temperatures: July 1962 to September 1968.

EXTREMES, - -1967-68:

Water temperatures: Maximum, $28.0^{\circ} \mathrm{C}$ July $25-28$; minimum, $1.0^{\circ} \mathrm{C} \mathrm{Feb} .14,24$.

period of record:

water temperatures: Maximum, $29.0^{\circ} \mathrm{C}$ July 29, 1966; minimum, freezing point on many days during winter periods. REMARKS.--Records furnished by Tennessee Valley Authority. CHEMICAL ANALYSES IN MILL IGRAMS PER LITER, WATER YEAR OC TOBER 1967 TO SEPTEMBER 1968

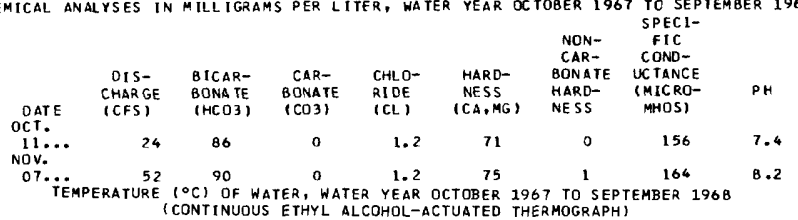

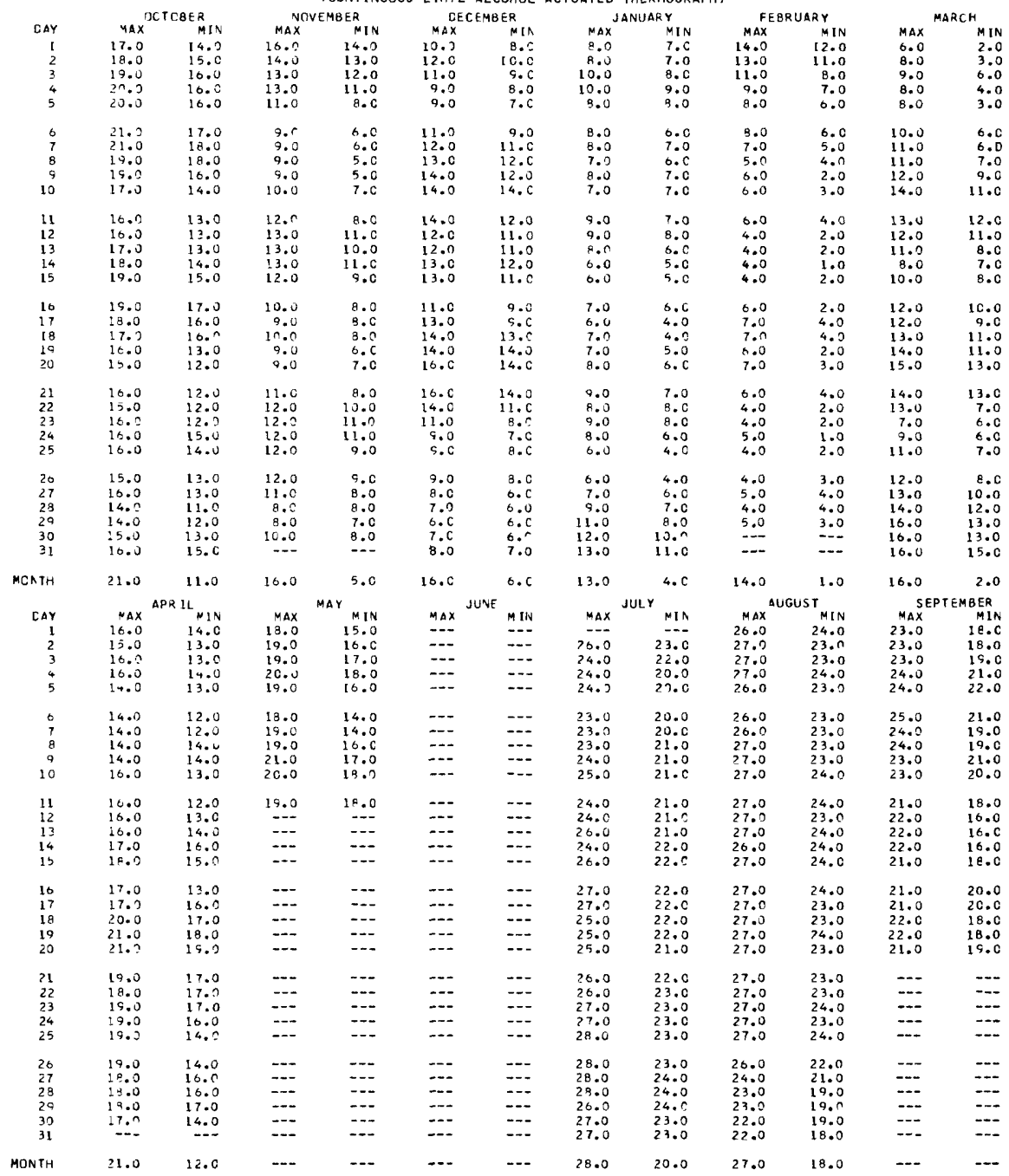


03592500 BEAR CREEK AT BISHOP, ALA.

LOCATION.--Lat $34^{\circ} 39^{\prime} 21^{\prime \prime}$, long $88^{\circ} 07^{\prime} 21^{\prime \prime}$, in SE sec. 5, T.5S., R. 15 W. , Colbert County, temperature recorder at gaging station on left bank $20 \mathrm{ft}$ upstream from higbway bridge, 0.5 mile downstream from Cedar Creek, $0.8 \mathrm{mile}$
southwest of Bishop and at mile 27.3 .

DRAINAGE ARBA. $--667 \mathrm{sq} \mathrm{mi}$.

PERIOD OF RECORD.--Water temperatures: February 1962 to September 1968.

EXTREMES, $-1967-68$ :

Water temperatures: Maxtmum, $30.0^{\circ} \mathrm{C}$ Aug, 24 ; minimum, $2.0^{\circ} \mathrm{C}$ Jan. 8,9

Period of record:

Water temperatures: Maximum, $31.0^{\circ} \mathrm{C}$ July 14-16, 1966; minimum, freezing point Dec. 26, 27, 1963, Jan. 1-3, 1964 .

REMARKS.--Records furnished by Tennessee Valley Authority.

CHEMICAL ANALYSES IN MILLIGRAMS PER LITER, hATER YEAR OCTOBER 1967 IO SEPTEMBER 1968

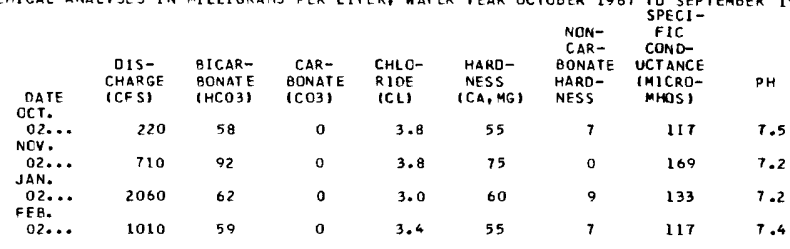

TEMPERATURE $\left({ }^{\circ} \mathrm{C}\right)$ OF WATER, WATER YEAR OCTDBER 1967 TD SEPTEMBER 1960

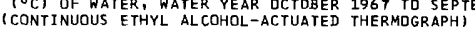

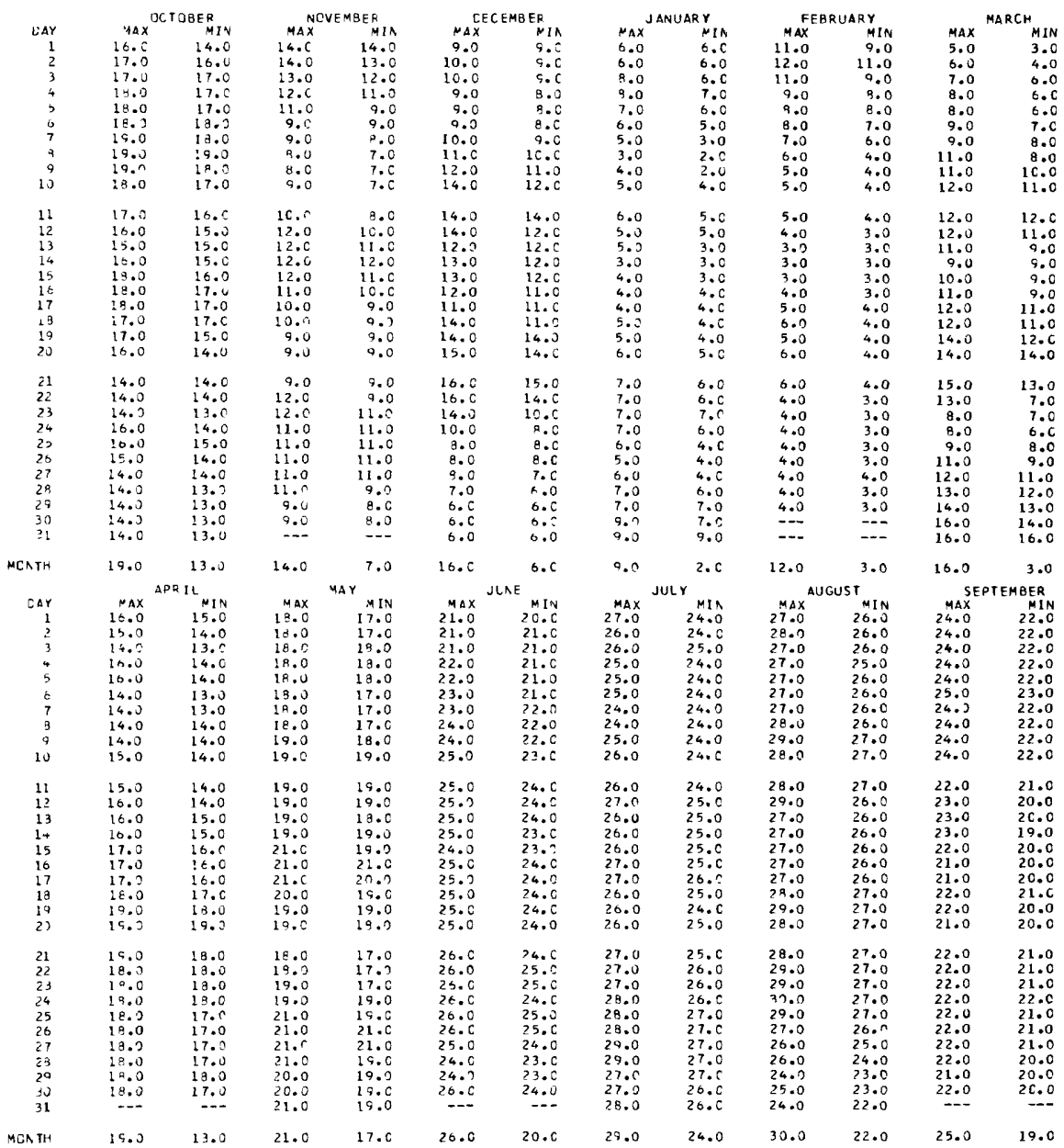


O3604000 BUFFALO RIVER NEAR FLAT WOODS, TENN. (Hydrologic bench-mark station)

LOCATION. --Lat $35^{\circ} 29^{\prime} 45^{\prime \prime}$, long $87^{\circ} 49^{\prime} 58^{\prime \prime}$, Perry County, temperature recorder at gaging station on right bank $0.5 \mathrm{mile}$ ditie opossum Creek' and bridge on State Higrway 13, 1.3 miles north of Flat Woods, 3.9 miles up. downstream from Little opossum Creek and br

DRAINAGE AREA, $-\mathbf{- 4 4 7} \mathrm{sq} \mathrm{mi}$.

PERIOD OF RECORD, --water temperatures: June 1964 to September 1968.

EXTREMES, - -1967-68:

Water temperatures: Maximum, $28.0^{\circ} \mathrm{C}$ July $1,27,28$, Aug. $9,10,18,19,22-24$; minimum, $3.0^{\circ} \mathrm{C} \mathrm{Feb.} 16,23,24$.

Period of record:

water temperatures: Haximum, $31.0^{\circ} \mathrm{C}$ July 13-15, 1966; mintmum, 1. $0^{\circ} \mathrm{C}$ Feb, 3, 1965, Jan. 31, Feb. $1,1966$.

REMARKS. --Pesticide analyses: A sample taken on $0 c t .23,1967$, was analyzed for the following pesticides: Aldrin, DDD, DDE, DDT, Dieldrin, Endrin, Heptachlor, Heptachlor Epoxide, and Lindane. In each case, concentration was determined to be 0.00 micrograms per liter. Temperature recorder stopped Oct. 1-9 (range in temperature $23.0^{\circ} \mathrm{C}$ to $14.0^{\circ} \mathrm{C}$ ). Thermograph record furnished by Tennessee Valley Authority.

CHEMICAL ANALYSES IN MILLIGRAMS PER LITER, WATER YEAR OCTOBER 1967 TO SEPTEMBER 1968

\begin{tabular}{|c|c|c|c|c|c|c|c|c|c|c|c|c|}
\hline DATE & $\begin{array}{l}\text { OIS- } \\
\text { CHARGE } \\
\text { ICFS I }\end{array}$ & $\begin{array}{l}\text { SILICA } \\
\text { (SIOZ) }\end{array}$ & $\begin{array}{l}\text { DIS- } \\
\text { SOLVED } \\
\text { IRON } \\
\text { (FE) }\end{array}$ & $\begin{array}{l}\text { MAN- } \\
\text { GANESE } \\
\text { (MN) }\end{array}$ & $\begin{array}{l}\text { CAL- } \\
\text { CIUM } \\
\text { (CA) }\end{array}$ & $\begin{array}{l}\text { MAG- } \\
\text { NE- } \\
\text { SIUM } \\
\text { (MG) }\end{array}$ & $\begin{array}{l}\text { SDOIUM } \\
\text { INA) }\end{array}$ & $\begin{array}{l}\text { PO- } \\
\text { TAS- } \\
\text { SIUM } \\
(K)\end{array}$ & $\begin{array}{l}\text { BICAR - } \\
\text { BONATE } \\
\text { (HCO3) }\end{array}$ & $\begin{array}{l}\text { CAR- } \\
\text { BOAATE } \\
\text { (CC3) }\end{array}$ & $\begin{array}{l}\text { SLLFATE } \\
\text { (SO4) }\end{array}$ & $\begin{array}{l}\text { CHLO- } \\
\text { PIDE } \\
\text { (CL) }\end{array}$ \\
\hline $\begin{array}{l}\text { ocr. } \\
23 \ldots \\
\text { NOV. }\end{array}$ & 217 & .2 & .93 & .24 & 18 & 2.5 & 1.3 & 1.3 & 60 & 0 & $4 \cdot t$ & 1.6 \\
\hline $\begin{array}{l}12 \ldots . \\
\text { DEC. }\end{array}$ & 234 & 4.1 & .46 & .08 & 21 & 2.2 & 1.4 & . 8 & 61 & 0 & 13 & 1.5 \\
\hline JAN. & 3720 & 5.7 & .24 & .08 & 10 & 1.2 & 2.7 & 1.3 & 32 & 0 & 5.4 & 1.5 \\
\hline $\begin{array}{l}31 . . \\
\text { FEB. }\end{array}$ & 560 & 4.3 & .07 & .03 & 12 & 1.5 & 1.4 & .6 & 41 & 0 & 3.8 & 1.4 \\
\hline $\begin{array}{l}16 . . . \\
\text { MAR. }\end{array}$ & 466 & 3.6 & .04 & .03 & 13 & 1.5 & 1.3 & .5 & 43 & 0 & 3.6 & 1.6 \\
\hline $\begin{array}{l}26 . \cdots \\
A P R .\end{array}$ & 2560 & 2,9 & .06 & .02 & 9.7 & 1.5 & 1.0 & .7 & 29 & 0 & 5.4 & 1.6 \\
\hline $\operatorname{MAY}_{\operatorname{maY}}^{19 \cdots}$ & 680 & 2.2 &. $\mathrm{Co}$ & .00 & 10 & 1.9 & 1.0 & .6 & 41 & $c$ & 2.5 & .7 \\
\hline $\begin{array}{l}\text { 31... } \\
\text { JUNE }\end{array}$ & 469 & 4.7 & 3.8 & .04 & 12 & 2.4 & 1.3 & .9 & 46 & $c$ & 3.1 & 1.8 \\
\hline $\begin{array}{l}\text { Do .... } \\
\text { Jut } r\end{array}$ & 375 & 4.1 & .03 & .01 & 13 & 2.6 & 1.2 & .7 & 50 & 0 & 2.7 & 1.4 \\
\hline $\begin{array}{l}31 . . . \\
\text { AUG. }\end{array}$ & 202 & 5.9 & -- & -- & 10 & 2.1 & 1.0 & .7 & 58 & 0 & 2.7 & 1.3 \\
\hline $\begin{array}{l}22 \ldots \\
\text { SEPT. }\end{array}$ & 218 & 5.6 & .18 & .04 & 16 & 2.2 & 1.1 & .7 & 59 & 0 & 2.5 & 1.3 \\
\hline $24 \ldots$ & A179 & 0.5 & .10 & .01 & 17 & 2.2 & 1.2 & .7 & 60 & 0 & 6.C & 1.0 \\
\hline
\end{tabular}

a DAILY MEAN DISCHARge.

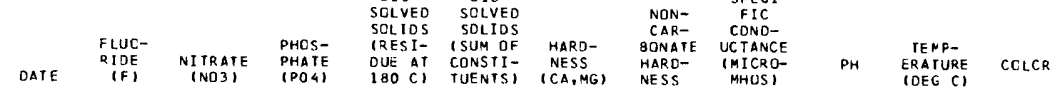

\begin{tabular}{|c|c|c|c|c|}
\hline $\begin{array}{l}\mathrm{OCt}, \\
23 . \ldots \\
\text { NOV: }\end{array}$ & .0 & .0 & -- & 66 \\
\hline $\begin{array}{l}\text { NOV. } \\
12 \ldots \\
\text { DEC. }\end{array}$ & .0 & .0 & - & 62 \\
\hline JAN. & .0 & .1 & - & 43 \\
\hline FEB. & .2 & .3 & - & 48 \\
\hline $\begin{array}{l}16 \ldots . . \\
\text { MAR. }\end{array}$ & .0 & .3 & -- & 50 \\
\hline $\begin{array}{l}26 \ldots \\
A P R\end{array}$ & . $n$ & .5 & .04 & 40 \\
\hline${ }_{\text {MAY }}^{19} \cdots$ & $\cdot n$ & .2 & .04 & 40 \\
\hline $\begin{array}{l}31 \ldots \\
\text { JUNE }\end{array}$ & .0 & .4 & - $n_{4}$ & 85 \\
\hline JULY... & .1 & .4 & .04 & 65 \\
\hline AUG... & .2 & .5 & .05 & 64 \\
\hline $\begin{array}{l}22 \ldots . \\
\text { SEPT. }\end{array}$ & .1 & .4 & .04 & 65 \\
\hline $24 \ldots$ & .1 & .1 & .03 & 66 \\
\hline
\end{tabular}

$\begin{array}{rrrrrrr}58 & 55 & 6 & 110 & 7.7 & 13 & 4 \\ 74 & 62 & 12 & 98 & 7.4 & -- & 2 \\ 43 & 30 & 4 & 66 & 6.8 & 12 & 3 \\ 46 & 36 & 2 & 79 & 7.2 & -- & 1 \\ 46 & 38 & 3 & 80 & 7.2 & 4 & 5 \\ 38 & 30 & 6 & 63 & 7.0 & -- & 3 \\ 40 & 33 & 0 & 77 & 7.1 & 18 & 4 \\ 53 & 40 & 2 & 138 & 7.4 & 18 & 1 \\ 51 & 43 & 2 & 92 & 7.5 & 22 & 1 \\ 59 & 48 & 1 & 107 & 7.6 & 24 & 1 \\ 59 & 48 & 0 & 102 & 7.7 & 28 & 1 \\ 64 & 51 & 2 & 102 & 7.7 & 22 & 8\end{array}$

\section{RADIOISOTOPES IN WATER}

(Units of measurement: Uranium, micrograms per liter of water; radium, as radium-226, in picocuries per 11ter of water; gross beta radiation as strontium-90-yttrium-90, in picocuries per liter of water; gross alpha radiation, as micrograms of uranium equivalent per liter of water. A picocurie is one millionth of the amount of radioactivity represented by a microcurie, which is the quantity of radiation represented by one millionth of a gram
of radium-226. A picocurie of radium results in 2.22 disintegrations per minute.)

\section{DISSOLVED}

DATE

OCT 231967

$\begin{array}{lll}\text { MAR } & 26 & 1968 \\ \text { SEPT } & 24 . \ldots .\end{array}$

$<1$
.1
.03

$\begin{array}{ccccc}\begin{array}{c}\text { URANIUM } \\ \text { UG/L }\end{array} & \begin{array}{c}\text { RADIUM } \\ \text { PC/L }\end{array} & \text { GROSS } B & \text { GROSS } & \text { TOTAL } \\ \text { PC/L } & \text { MG/L } & \text { DISSOLVED } \\ \text { SOLIDS } \\ M G / L\end{array}$

2.5
1.0
1.5

.6
1.4

15
41
60

SUSPENDED

$\begin{array}{lll}\text { GROSS } & \text { SUSPENDED } \\ \text { GROSS } \alpha & \text { SEDIMENTS }\end{array}$

$P C / L \quad U G / L \quad M G / L$

$\begin{array}{rrr}.7 & <.4 & 2 \\ 1.1 & .5 & 14 \\ .6 & .5 & 5\end{array}$


03604000 BUFFALO RIVER NEAR FLAT WOODS, TENN, --Continued

TEMPERATURE $\left({ }^{\circ} \mathrm{C}\right)$ OF WATER, WATER YEAR OCTOBER 1967 TO SEPTEMBER 1968 (CONTINUDUS ETHYL ALCOHOL-ACTUATED THERMOGRAPH)

DAY

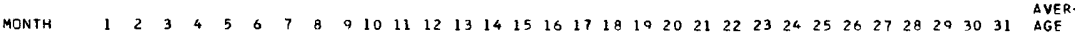

OCTOBER

MAXIMUM -

MINIMUM

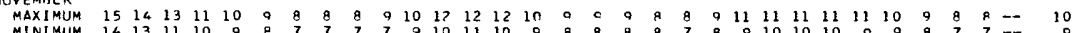

MINIMUM

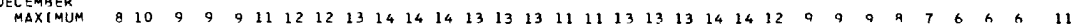

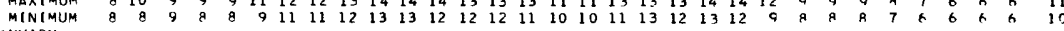

JANIIAR Y

MAXIMUM $6 \begin{array}{lllllllllllllllllllllllllllllllllll} & 6 & 6 & 7 & 8 & 7 & 7 & 7 & 6 & 6 & 7 & 7 & 7 & 7 & 6 & 5 & 6 & 6 & 6 & 6 & 7 & 9 & 9 & 9 & 8 & 7 & 6 & 7 & 9 & 11 & 11 & 12 & 7\end{array}$

MINIMUM $6 \begin{array}{lllllllllllllllllllllllllllllllll} & 6 & 6 & 6 & 7 & 6 & 7 & 6 & 4 & 5 & 6 & 5 & 6 & 6 & 5 & 4 & 5 & 4 & 4 & 5 & 6 & 7 & 8 & 8 & 7 & 6 & 5 & 6 & 7 & 9 & 10 & 11 & 6\end{array}$

FEBRUARY

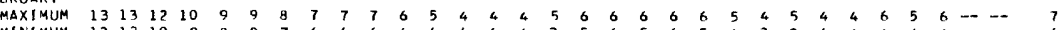

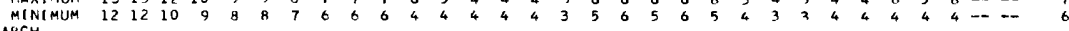

$\triangle A R C H$

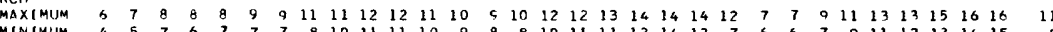

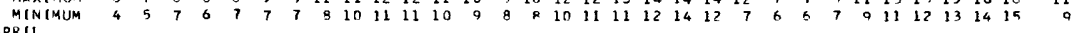

APRIL

$\begin{array}{llllllllllllllllllllllllllllllllll}\text { MAXIMUM } & 15 & 14 & 13 & 14 & 14 & 13 & 13 & 13 & 13 & 14 & 15 & 14 & 14 & 15 & 16 & 16 & 16 & 18 & 18 & 10 & 19 & 19 & 18 & 18 & 17 & 19 & 19 & 19 & 18 & 17 & -2 & 16 \\ \text { MINIMUM } & 14 & 12 & 12 & 13 & 12 & 11 & 12 & 13 & 13 & 13 & 13 & 13 & 13 & 14 & 14 & 14 & 16 & 16 & 17 & 19 & 17 & 17 & 17 & 17 & 16 & 16 & 17 & 17 & 17 & 16 & -2 & 15\end{array}$

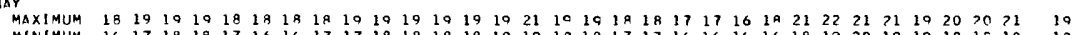

JUNF

$\begin{array}{lllllllllllllllllllllllllllllllllllllllll}\text { MAX1MUM } & 22 & 22 & 23 & 23 & 24 & 24 & 24 & 25 & 25 & 26 & 27 & 27 & 26 & 25 & 25 & 26 & 24 & 25 & 25 & 26 & 26 & 26 & 26 & 26 & 25 & 24 & 24 & 24 & 26 & 27 & -2 & 25\end{array}$

JULY

$\begin{array}{lllllllllllllllllllllllllllllllll}\text { MAXIMUM } & 28 & 27 & 26 & 23 & 25 & 24 & 24 & 24 & 23 & 25 & 26 & 26 & 26 & 26 & 26 & 26 & 27 & 26 & 27 & 27 & 26 & 27 & 25 & 26 & 27 & 27 & 28 & 28 & 27 & 25 & 26 & 26 \\ \text { MINIMUM } & 25 & 26 & 25 & 24 & 23 & 23 & 23 & 23 & 23 & 23 & 24 & 24 & 24 & 23 & 23 & 24 & 24 & 25 & 24 & 24 & 24 & 24 & 23 & 24 & 24 & 25 & 26 & 26 & 25 & 24 & 24 & 24\end{array}$ AUGUST

$\begin{array}{llllllllllllllllllllllllllllllllllllllllll}\text { MAXIMUM } 26 & 25 & 26 & 27 & 27 & 27 & 27 & 27 & 28 & 28 & 27 & 27 & 26 & 27 & 27 & 26 & 27 & 28 & 29 & 27 & 27 & 28 & 28 & 28 & 27 & 27 & 26 & 23 & 23 & 22 & 22 & 26\end{array}$

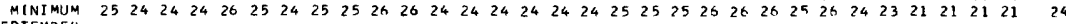
SEPTEMREK $\begin{array}{llllllllllllllllllllllllllllllllllll}\text { MAXIMUM } & 22 & 22 & 22 & 24 & 24 & 24 & 24 & 23 & 22 & 22 & 21 & 21 & 21 & 21 & 21 & 21 & 22 & 22 & 22 & 22 & 23 & 24 & 24 & 23 & 22 & 22 & 21 & 21 & 21 & 21 & -- & 22 \\ \text { MINIMUM } & 21 & 21 & 21 & 21 & 23 & 23 & 22 & 22 & 21 & 21 & 10 & 19 & 19 & 19 & 19 & 20 & 21 & 21 & 20 & 20 & 21 & 22 & 22 & 22 & 21 & 20 & 20 & 19 & 19 & 19 & - & 21\end{array}$

03609500 TENNESSEE RIVER AT KENTURKY DAM, NEAR PADUCAH, KY.

LOCATION,--Lat $37^{\circ} 00^{\prime} 54^{\prime \prime}$, long $88^{\circ} 16^{\prime} 12^{\prime \prime}$, Livingston County, at tallrace of powerplant at Kentucky Dam at Gilbertsville, 3,500 ft upstream from base gaging station, 3.0 miles upstream from Shadie Creek, and 16 miles east of Paducah.

DRAINAGE AREA. - 40,200 sq $\mathrm{mi}$, approximately (at Gilbertsville).

PERIOD OF RECORD.--Chemical analyses: October 1949 to August 1950, October 1951 to September 1954 , October 1956 to

September 1962 , October 1967 to September 1968.
nater temperatures: October 1949 to September 1968 , unpublished.

RENARKS.--Samples for iron and manganese filtered clear when collected, Flow almost completely regulated. BarkleyKentucky Canal diverts water from or to Lake Barkley in Cumberland River basin.

CHEMICAL ANALYSES IN MILLIGRAMS PER LITER, WATER YEAR OCTOBER 1967 TO SEPTEMBER 1968

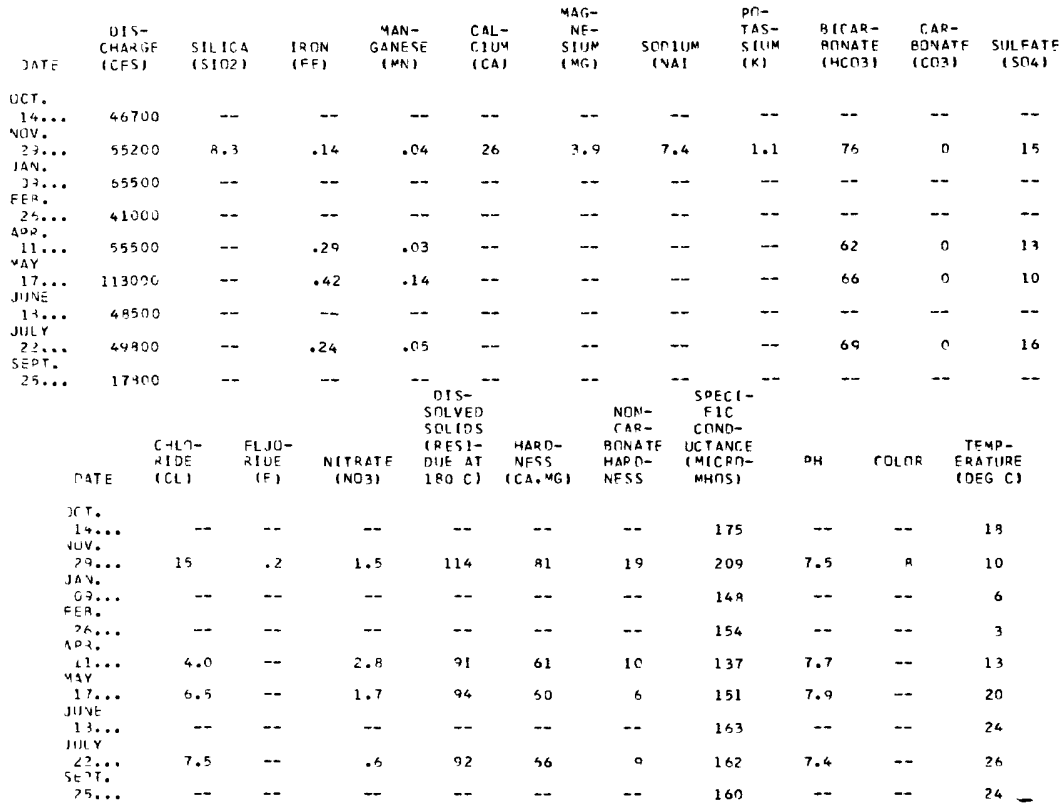


LOCATION. - Lat $37^{\circ} 08^{\prime} 51^{\prime \prime}$, long $88^{\circ} 44^{\prime} 27^{\prime \prime}$, Massac County, temperature recorder at gaging station at Paducah and Illinots Railroad_Bridge at Metropolis, 9.5 miles downstream from Tennessee River, and 37 miles upstrean fron mouth. DRA INAGE AREA. --203,000 sq mi (approximately).

PERIOD OF RECORD. - - Chemical analyses: October 1952 to September 1953.

Water temperatures: March 1954 to September 1968.

EXTREMES. $--1967-68$ :

Water temperatures: Maximum, $29.0^{\circ} \mathrm{C}$ on many days during July and August; minimum, 1. $0^{\circ} \mathrm{C} \mathrm{Feb.} 22,23$.

Period of record:

Water temperatures: Kaximum, $31.0^{\circ} \mathrm{C}$ Aug. 3-6, 1955; minimum, freezing point during February 1958, January and
February 1963.

REMARKS.--Recorder stopped Mar. 30-31; range $9.0^{\circ} \mathrm{C}$ to $11.0^{\circ} \mathrm{C}$. Flow partly regulated by many dams and reservoirs. TEMPERATURE $\left({ }^{\circ} \mathrm{C}\right)$ OF WATER, WATER YEAR OCTOBER 1967 TO SEPTEMBER 1968 (CONTINUOUS ETHYL ALCOHOL-ACTUATED THERMOGRAPH)

DAY

MONTH

$$
\begin{array}{llllllllllllllllll}
15 & 16 & 17 & 18 & 19 & 20 & 21 & 22 & 23 & 24 & 25 & 26 & 27 & 28 & 29 & 30 & 31 & \text { AGER- }
\end{array}
$$

OCTOBER

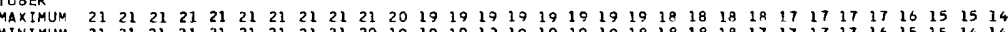
MINIMUM $\begin{array}{lllllllllllllllllllllllllllllllll}\text { MAXIMUMM } & 16 & 16 & 16 & 16 & 15 & 14 & 14 & 13 & 13 & 13 & 13 & 13 & 13 & 13 & 13 & 13 & 12 & 12 & 12 & 12 & 12 & 12 & 12 & 12 & 11 & 11 & 11 & 11 & 10 & 9 & -- \\ \text { MINIMUMM } & 14 & 16 & 16 & 15 & 14 & 14 & 13 & 13 & 13 & 13 & 13 & 13 & 13 & 13 & 13 & 12 & 12 & 12 & 12 & 12 & 12 & 12 & 12 & 11 & 11 & 11 & 11 & 10 & 9 & 9 & --\end{array}$ DECEMBER $\begin{array}{rlllllllllllllllllllllllllllllllll}\text { MAXIMUM } & 9 & 9 & 9 & 9 & 9 & 9 & 8 & 8 & 8 & 8 & 8 & 8 & 8 & 8 & 8 & 8 & 8 & 8 & 8 & 8 & 8 & 8 & 8 & 8 & 8 & 8 & 7 & 7 & 7 & 6 & 0 \\ \text { MINIMUM } & 8 & 9 & 9 & 9 & 9 & 8 & 8 & 8 & 8 & 8 & 8 & 8 & 8 & 8 & 8 & 8 & 8 & 8 & 8 & 8 & 8 & 8 & 8 & 8 & 8 & 7 & 7 & 7 & 6 & 6 & 6\end{array}$ JANUARY

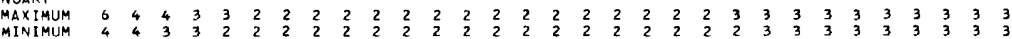
FEBRUARY

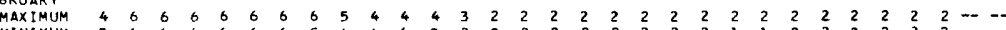

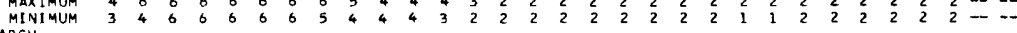
MARCH $\begin{array}{lllllllllllllllllllllllllllllllllllllll}\text { MAXIMUM } & 2 & 2 & 3 & 3 & 3 & 4 & 4 & 4 & 4 & 5 & 5 & 5 & 5 & 5 & 6 & 6 & 6 & 6 & 6 & 7 & 7 & 7 & 7 & 7 & 7 & 8 & 8 & 8 & 9 & -1 & -- \\ \text { MINIMUM } & 2 & 2 & 2 & 3 & 3 & 3 & 4 & 4 & 4 & 4 & 5 & 5 & 5 & 5 & 5 & 6 & 6 & 6 & 6 & 6 & 7 & 7 & 7 & 7 & 7 & 7 & 8 & 8 & 8 & -- & --\end{array}$ APRIL

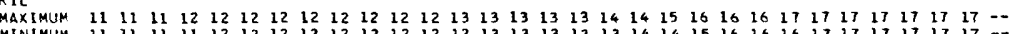

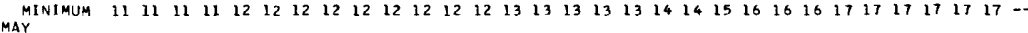

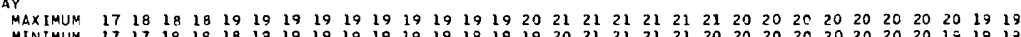
JUNE. $\begin{array}{llllllllllllllllllllllllllllllll}\text { MAXIMUM } & 10 & 19 & 19 & 20 & 20 & 21 & 21 & 22 & 22 & 23 & 23 & 23 & 23 & 23 & 23 & 23 & 24 & 24 & 24 & 25 & 26 & 26 & 26 & 26 & 26 & 26 & 26 & 26 & 26 & 26 & -- \\ \text { MINIMUM } & 19 & 19 & 19 & 19 & 20 & 20 & 21 & 21 & 22 & 22 & 23 & 23 & 23 & 23 & 23 & 23 & 23 & 23 & 24 & 24 & 25 & 26 & 26 & 26 & 26 & 26 & 26 & 26 & 26 & 26 & --\end{array}$ JULY

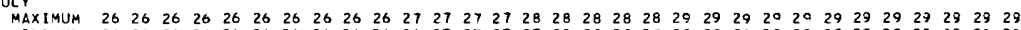

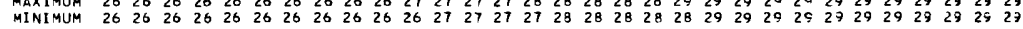
AUGUST

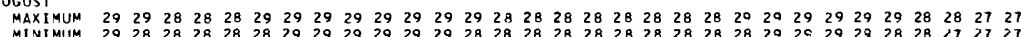

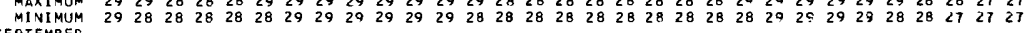
SEPTEMBER

$\begin{array}{llllllllllllllllllllllllllllllllllllll}\text { MAXIMUM } & 27 & 26 & 26 & 26 & 26 & 26 & 26 & 26 & 26 & 26 & 26 & 25 & 24 & 24 & 24 & 24 & 24 & 24 & 24 & 24 & 24 & 24 & 24 & 24 & 24 & 24 & 24 & 24 & 24 & 24 & -= \\ \text { MINIMUM } & 26 & 26 & 26 & 26 & 26 & 26 & 26 & 26 & 26 & 26 & 25 & 24 & 24 & 24 & 24 & 24 & 24 & 24 & 24 & 24 & 24 & 24 & 24 & 24 & 24 & 24 & 24 & 24 & 24 & 24 & --\end{array}$ 
03612500 OHIO RIVER AT LOCK AND DAM 53, NEAR GRAND CHAIN, ILL.

LOCATION.--Lat $37^{\circ} 12^{\prime} 11^{\prime \prime}$, long $89^{\circ} 02^{\prime} 30^{\prime \prime}$, pulaski County, about 1,500 ft upstream from dam, lock and dam 53 near Grand Chain, 1.4 milés downstream from Bledsoe Creek, 18,5 miles downstream from gaging station at Metropolis, Grand Chain, 1.4 miles downstream from Bledsoe

DRAINAGE AREA. ..203,100 sq $\mathrm{mi}$.

PERIOD OF RECORD.-.-Chemical analyses: October 1954 to September 1968.

Water temperatures: October 1954 to September 1968.

EXTREMES. -1967.68

Specific conductance: Maximum daily, 529 micromhos Nov, 5; minimum daily, 262 micromhos Mar. 22.

water temperatures: Maximum, $30.0^{\circ} \mathrm{C}$ Aug. $25,26,30,31$; minimum, $1.0^{\circ} \mathrm{C}$ Jan, $10,11$.

period of record:

Specific conductance: Maximum daily, 684 micromhos Nov, 16, 1962; minimum daily, 170 micromhos Feb, $9,1957$. water temperatures: Maximum, $31.0^{\circ} \mathrm{C}$ july 15,1964 ; minimum, freezing point on many days during winter periods.

REHARKS.--Daily samples were collected at this station and samples were selected for analysis on the following basis: (1) Maximum daily specific conductance for each month, (2) minimum daily specific conductance for each wonth, (3) median dally specific conductance for each month, and (4) a composite analysis each month for the determination of arsentc (As). Samples for 1ron and manganese were filtered clear when collected. Records of discharge are given for gaging station at Metropolis (drainage area 203,000 sq mi approximately). Flow partly regulated by many dams and reservoirs.

CHEMICAL ANALYSES IN MILLIGRAMS PER LITER, WATER YEAR OCTOBER 1967 TO SEPTEMBER 1968

\begin{tabular}{|c|c|c|c|c|c|c|c|c|}
\hline DATE & $\begin{array}{l}\text { DIS- } \\
\text { CHARGE } \\
\text { (CFS) }\end{array}$ & $\begin{array}{l}\text { IRON } \\
\text { (FE) }\end{array}$ & $\begin{array}{l}\text { MAN- } \\
\text { GANESE } \\
\text { (MN) }\end{array}$ & $\begin{array}{l}\text { BICAR- } \\
\text { BONATE } \\
\text { (HCO3) }\end{array}$ & $\begin{array}{c}\text { CAR- } \\
\text { BONATE } \\
\text { (CO3) }\end{array}$ & $\begin{array}{c}\text { SULFATE } \\
\text { (SO4) }\end{array}$ & $\begin{array}{l}\text { CHLO- } \\
\text { RIDE } \\
\text { (CL) }\end{array}$ & $\begin{array}{l}\text { FLUO- } \\
\text { RIDE } \\
\text { (F) }\end{array}$ \\
\hline \multicolumn{9}{|l|}{ OCT. } \\
\hline $01-31$ & -- & -- & -- & -- & -- & -- & -- & -- \\
\hline $09 .$. & 110000 & .12 & .05 & 82 & 0 & 107 & 41 & $\cdot 3$ \\
\hline $17 \ldots$ & 108000 & .40 & .11 & 80 & 0 & 50 & 19 & .3 \\
\hline $24 \ldots$ & 125000 & .13 & .03 & 85 & 0 & 78 & 30 & .3 \\
\hline \multicolumn{9}{|l|}{ NOV. } \\
\hline $\begin{array}{l}01-30 \\
05 . . .\end{array}$ & $1800 \overline{0}$ &.$\overline{16}$ & .09 & $\overline{72}$ & $\overline{0}$ & $\overline{116}$ & 48 & $-\overline{4}$ \\
\hline $12 \ldots$ & 155000 & .04 & .05 & 74 & 0 & 60 & 25 & .3 \\
\hline $30 .$. & 211000 & .21 & .02 & 78 & 0 & 84 & 29 & .4 \\
\hline \multicolumn{9}{|l|}{$\begin{array}{l}\text { DEC. } \\
\text { O1-31 }\end{array}$} \\
\hline $01-31$ & $2080-$ &.$\overline{51}$ & -- & $\overline{-z}$ & -- & - & -- & -- \\
\hline $01 \ldots$ & $\begin{array}{l}226000 \\
521000\end{array}$ & $\begin{array}{l}.51 \\
.64\end{array}$ & .12 & 76 & 0 & 77 & 26 & .3 \\
\hline $\begin{array}{l}20 \ldots \\
29 . .\end{array}$ & $\begin{array}{l}521000 \\
607000\end{array}$ & .26 & & 88 & 0 & 58 & 16 & -2 \\
\hline & 92 & 0 & 49 & 14 & .2 \\
\hline $01-31$ & -- & -- & -- & - & - & -- & -- & -- \\
\hline $01 .$. & 500000 & .40 & .06 & 100 & 0 & 62 & 12 & .0 \\
\hline $12 \ldots$ & 454000 & .20 & .05 & 108 & 0 & 61 & 20 & .2 \\
\hline $26 \cdots$ & 302000 & .18 & .12 & 108 & 0 & 75 & 24 & .4 \\
\hline \multicolumn{7}{|l|}{$\begin{array}{l}\text { FEB. } \\
01-29\end{array}$} & -- & - \\
\hline $03 . .$. & 427000 & .34 & .06 & 72 & 0 & 49 & 16 & 1 \\
\hline $09 .$. & 584000 & .22 & .07 & 76 & 0 & 55 & 21 & .2 \\
\hline $24 \ldots$ & 137000 & .11 & .12 & 133 & 0 & 63 & 24 & .2 \\
\hline \multicolumn{9}{|l|}{$\begin{array}{l}\text { MAR. } \\
01-31\end{array}$} \\
\hline $02 \ldots$ & 119000 & .30 & .20 & 121 & 0 & 56 & 24 & 1 \\
\hline $16 \ldots$ & 395000 & .69 & .10 & 117 & 0 & 79 & 32 & .2 \\
\hline $22 \ldots$ & 554000 & 1.4 & .09 & 54 & 0 & 55 & 18 & .2 \\
\hline \multicolumn{9}{|l|}{ APR. } \\
\hline $01-30$ & -- & -- & -- & - & -- & -- & -- & -- \\
\hline $06 \ldots$ & 670000 & 1.0 & .06 & 82 & 0 & 54 & 14 & .2 \\
\hline $13 \ldots$ & 626000 & 1.5 & .07 & 87 & 0 & 46 & 12 & .2 \\
\hline \multicolumn{9}{|l|}{ MAY } \\
\hline $01-31$ & -- & -- & -- & -- & -- & -- & -- & -- \\
\hline $02 \ldots$ & 184000 & .29 & .11 & 120 & 0 & 64 & 18 & .2 \\
\hline $13 \ldots$ & 218000 & .56 & .11 & 76 & 0 & 45 & 12 & .1 \\
\hline $25 \ldots$ & 337000 & .79 & .09 & 94 & 0 & 89 & 28 & .3 \\
\hline \multicolumn{9}{|l|}{ JUNE } \\
\hline $04 \ldots$ & 688000 & .27 & .06 & 84 & 0 & 39 & 10 & $\cdot 2$ \\
\hline $19 \ldots$ & 196000 & $\cdot 30$ & .19 & 136 & 4 & 63 & 14 & .3 \\
\hline $25 \ldots$ & 144000 & .22 & .12 & 114 & 0 & 52 & 14 & .4 \\
\hline \multicolumn{9}{|l|}{ JULY } \\
\hline $11 . .$. & 110000 & .14 & .01 & 112 & 0 & 47 & 16 & .2 \\
\hline $15 \ldots$ & 98300 & .13 & .02 & 128 & 0 & 57 & 16 & .4 \\
\hline $29 \ldots$ & 118000 & .29 & .04 & 130 & 0 & 77 & 24 & 3 \\
\hline \multicolumn{9}{|l|}{ AUG. } \\
\hline $01-31$ & -- & -- & -- & $-\infty$ & -- & -- & -- & -- \\
\hline $\begin{array}{l}14 \ldots \\
21 \ldots\end{array}$ & $\begin{array}{l}188000 \\
153000\end{array}$ & $\begin{array}{l}.25 \\
.18\end{array}$ & $\begin{array}{l}.05 \\
.02\end{array}$ & $\begin{array}{l}112 \\
124\end{array}$ & $\begin{array}{l}0 \\
0\end{array}$ & $\begin{array}{l}70 \\
85\end{array}$ & $\begin{array}{l}24 \\
32\end{array}$ & $: 3$ \\
\hline $30 \ldots$ & 58700 & .23 & .06 & 104 & 0 & 47 & 20 & .3 \\
\hline \multicolumn{9}{|l|}{ SEPT. } \\
\hline $01-30$ & - & -- & - & -- & -- & -- & -- & - \\
\hline $03 \ldots$ & 69200 & .12 & .12 & 100 & 0 & 41 & 18 & .3 \\
\hline $10 \ldots$ & 70300 & .14 & .08 & 124 & 0 & 60 & 28 & .3 \\
\hline $23 \ldots$ & 50800 & .10 & .06 & 102 & 0 & 53 & 26 & .3 \\
\hline
\end{tabular}


03612500 OHIO RIVER AT LOCK AND DAM 53, NEAR GRAND CHAIN, ILL.--Continued CHEMICAL ANALYSES IN MILLIGRAMS PER LITER, WATER YEAR OCTOBER 1967 TO SEPTEMBER 1968

\begin{tabular}{|c|c|c|c|c|c|c|c|c|}
\hline DATE & $\begin{array}{l}\text { NI TRATE } \\
\text { (N03) }\end{array}$ & $\begin{array}{l}\text { TOTAL } \\
\text { PHOS- } \\
\text { PHORUS } \\
\text { (PO4) }\end{array}$ & $\begin{array}{l}\text { DIS- } \\
\text { SOLVED } \\
\text { SOLIDS } \\
\text { (RESI- } \\
\text { DUE AT } \\
180^{\circ} \mathrm{C} \text { ) }\end{array}$ & $\begin{array}{l}\text { HARD- } \\
\text { NESS } \\
\text { (CA, MG) }\end{array}$ & $\begin{array}{l}\text { NON- } \\
\text { CAR- } \\
\text { BONATE } \\
\text { HARD- } \\
\text { NESS }\end{array}$ & $\begin{array}{l}\text { SPE- } \\
\text { CIFIC } \\
\text { CONDUCT- } \\
\text { ANCE } \\
\text { (MICRO- } \\
\text { MHOS) }\end{array}$ & $\mathrm{PH}$ & $\begin{array}{c}\text { ARSENIC } \\
\text { (AS) }\end{array}$ \\
\hline $\begin{array}{l}O \bar{C} T . \\
01-31\end{array}$ & - & -- & - & - & - & - & $\cdots$ & .00 \\
\hline $09 \ldots$ & 2.6 & .19 & 330 & 169 & 146 & 499 & 7.2 & - \\
\hline $17 \ldots$ & 2.7 & .30 & 214 & 110 & 86 & 296 & 7.2 & -- \\
\hline $\begin{array}{l}24 \ldots \\
\text { NOv. }\end{array}$ & 3.1 & .22 & 266 & 139 & 116 & 389 & 7.0 & + \\
\hline $\begin{array}{l}\text { NOV. } \\
01-30\end{array}$ & & & & & & & & \\
\hline $\begin{array}{l}01-30 \\
05 . . .\end{array}$ & - & -- & -- & $=$ & 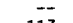 & $-\overline{0}$ & $=$ & .00 \\
\hline $\begin{array}{l}05 \ldots \\
12 . .\end{array}$ & 4.3 & .11 & 318 & 176 & 117 & 529 & 7.4 & - \\
\hline$\frac{12 \ldots}{30 . .}$ & 3.2 & .19 & 220 & 121 & 60 & 336 & 7.5 & -- \\
\hline $\begin{array}{l}30 . \cdots \\
\mathrm{DEC} .\end{array}$ & 4.5 & .33 & 256 & 146 & 82 & 400 & 7.5 & - \\
\hline $01-31$ & - & - & -- & - & - & -- & -- & .00 \\
\hline $01 . .$. & 6.2 & .42 & 214 & 140 & 78 & 388 & 7.2 & - \\
\hline $20 \ldots$ & 8.6 & .31 & 190 & 136 & 64 & 332 & 7.5 & - \\
\hline $\begin{array}{l}29 \ldots \\
\text { JAN. }\end{array}$ & 7.1 & .27 & 164 & 128 & 52 & 302 & 7.5 & - \\
\hline $\begin{array}{l}\text { JAN. } \\
01-31\end{array}$ & - & -- & -- & -- & -- & -- & $-\sim$ & .00 \\
\hline $01 . .$. & 5.2 & .38 & 210 & 133 & 51 & 325 & 7.4 & - \\
\hline $12 \ldots$ & 3.8 & .26 & 240 & 154 & 66 & 374 & 7.5 & - \\
\hline $26 \ldots$ & 4.4 & .28 & 288 & 165 & 76 & 434 & 7.6 & -- \\
\hline $\begin{array}{l}\text { FEB. } \\
01-29\end{array}$ & -- & - & -- & - & -- & -- & $\ldots$ & 00 \\
\hline $03 . .$. & 4.5 & .27 & 178 & 114 & 55 & 285 & 8.1 & .00 \\
\hline $09 . \ldots$ & 5.7 & .27 & 192 & 128 & 66 & 326 & 8.0 & $\ldots$ \\
\hline $24 \ldots$ & 5.7 & .24 & 264 & 184 & 75 & 427 & 8.1 & - \\
\hline $\begin{array}{l}\text { MAR. } \\
01-31\end{array}$ & -- & - & - & $=$ & -- & - & -- & 00 \\
\hline $02 .$. & 4.0 & .27 & 260 & 166 & 67 & 390 & 7.8 & .00 \\
\hline $16 \ldots$ & 5.4 & .49 & 312 & 168 & 72 & 462 & 8.1 & - \\
\hline $22 \ldots$ & 4.3 & .36 & 190 & 93 & 49 & 262 & 8.0 & 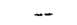 \\
\hline$A P R$. & & & & & & & & \\
\hline $\begin{array}{l}01-30 \\
06 . . .\end{array}$ & $-\overline{2}$ & $\overline{3}$ & -- & $=-$ & $=$ & $=$ & -- & .00 \\
\hline $\begin{array}{l}06 . . . \\
13 . .\end{array}$ & $\begin{array}{l}4.2 \\
4.5\end{array}$ & $\begin{array}{l}.26 \\
.25\end{array}$ & $\begin{array}{l}186 \\
162\end{array}$ & $\begin{array}{l}123 \\
119\end{array}$ & $\begin{array}{l}56 \\
48\end{array}$ & $\begin{array}{l}297 \\
274\end{array}$ & $\begin{array}{l}8.1 \\
8.2\end{array}$ & $=$ \\
\hline $28 \ldots$ & 3.8 & .18 & 222 & 157 & 65 & 365 & 7.8 & - \\
\hline MAY & & & & & & & & \\
\hline $\begin{array}{l}01-31 \\
02 \ldots\end{array}$ & $4 . \overline{4}$ & $\overline{.18}$ & $-\overline{248}$ & $=-$ & $\overline{5}$ & $\overline{387}$ & -3 & .01 \\
\hline $\begin{array}{l}02 \ldots \\
13 \ldots\end{array}$ & $\begin{array}{l}4.4 \\
4.4\end{array}$ & .19 & $\begin{array}{l}248 \\
173\end{array}$ & $\begin{array}{l}152 \\
110\end{array}$ & $\begin{array}{l}54 \\
48\end{array}$ & $\begin{array}{l}382 \\
274\end{array}$ & $\begin{array}{l}8.2 \\
8.0\end{array}$ & $=$ \\
\hline $25 \ldots$ & 8.8 & .14 & 279 & 174 & 97 & 445 & 7.4 & - \\
\hline JUNE & & & & & & & & \\
\hline $04 \ldots$ & 7.8 & .10 & 180 & 108 & 39 & 264 & 7.5 & - \\
\hline $\begin{array}{l}19 \ldots \\
25 . .\end{array}$ & 7.6 & .17 & 274 & 189 & 71 & 406 & 8.3 & -- \\
\hline${ }_{\text {JULY }}^{25}$ & 6.6 & .12 & 214 & 150 & 56 & 340 & 7.6 & .00 \\
\hline $01-31$ & -- & - & - & -- & -- & - & -- & .00 \\
\hline $11 \ldots$ & 4.4 & .23 & 218 & 142 & 50 & 325 & 7.5 & - \\
\hline $\begin{array}{l}15 \ldots \\
29 . .\end{array}$ & 2.9 & .19 & 240 & 166 & 61 & 376 & 7.3 & -- \\
\hline AUG. & 2.3 & .20 & 276 & 188 & 82 & 450 & 7.1 & - \\
\hline $01-31$ & - & -- & - & - & - & -- & - & .00 \\
\hline $14 \ldots$ & 5.8 & $\cdot 36$ & 244 & 166 & 74 & 409 & 7.2 & $=$ \\
\hline $21 \ldots$ & 7.0 & .34 & 302 & 192 & 90 & 485 & 7.2 & - \\
\hline SEPT. & 3.8 & .32 & 194 & 135 & 50 & 330 & 7.6 & -- \\
\hline $01-30$ & -- & - & -- & -. & -- & -- & -. & .01 \\
\hline $03 \ldots$ & 2.5 & .23 & 180 & 130 & 48 & 310 & 7.3 & - \\
\hline $10 \ldots$ & 4.0 & .23 & 226 & 166 & 64 & 413 & 7.7 & $=$ \\
\hline . & 2.5 & .23 & 204 & 142 & 58 & 369 & 7.6 & -- \\
\hline
\end{tabular}

SPECIFIC CONDUCTANCE (MICROMHOS AT $25^{\circ} \mathrm{C}$ ), WATER YEAR OCTOBER 1967 TO SEPTEMBER 1968 (ONCE-DAILY MEASUREMENT BETWEEN 0400 AND 0700)

\begin{tabular}{|c|c|c|c|c|c|c|c|c|c|c|c|c|}
\hline DAY & OCTOBER & NOVEMBER & DECE MBER & JANUARY & FEBRUARY & MARCH & APRIL & MAY & JUNE & JULY & AUGUST & SEPT EMBER \\
\hline $\begin{array}{c}6 \ldots \ldots \\
7 \ldots \ldots \\
8 \ldots \ldots \\
10 \ldots \ldots \\
10 \ldots \ldots\end{array}$ & $\begin{array}{l}452 \\
445 \\
492 \\
499 \\
460\end{array}$ & $\begin{array}{l}-5 \\
458 \\
431 \\
439 \\
424\end{array}$ & $\begin{array}{l}379 \\
373 \\
332 \\
332 \\
338\end{array}$ & $\begin{array}{l}355 \\
358 \\
376 \\
383 \\
379\end{array}$ & $\begin{array}{l}290 \\
307 \\
299 \\
326 \\
326\end{array}$ & $\begin{array}{l}369 \\
374 \\
382 \\
390 \\
400\end{array}$ & $\begin{array}{l}297 \\
302 \\
299 \\
299 \\
292\end{array}$ & $\begin{array}{l}408 \\
403 \\
398 \\
362 \\
381\end{array}$ & $\begin{array}{l}274 \\
272 \\
282 \\
295 \\
305\end{array}$ & $\begin{array}{l}391 \\
389 \\
383 \\
400 \\
376\end{array}$ & $\begin{array}{l}381 \\
370 \\
381 \\
401 \\
395\end{array}$ & $\begin{array}{l}372 \\
376 \\
392 \\
--1 \\
413\end{array}$ \\
\hline $\begin{array}{l}16 \ldots \ldots \\
17 \ldots \ldots \\
18 \ldots \ldots \\
19 \ldots \ldots \\
20 \ldots \ldots\end{array}$ & $\begin{array}{l}343 \\
296 \\
308 \\
360 \\
370\end{array}$ & $\begin{array}{l}374 \\
380 \\
373 \\
381 \\
374\end{array}$ & $\begin{array}{r}\overrightarrow{335} \\
302 \\
302 \\
332\end{array}$ & $\begin{array}{l}362 \\
366 \\
363 \\
388 \\
405\end{array}$ & $\begin{array}{l}332 \\
351 \\
368 \\
385 \\
403\end{array}$ & $\begin{array}{l}462 \\
464 \\
426 \\
423 \\
411\end{array}$ & $\begin{array}{l}292 \\
297 \\
285 \\
294 \\
309\end{array}$ & $\begin{array}{l}366 \\
385 \\
392 \\
379 \\
385\end{array}$ & $\begin{array}{l}369 \\
-2 \\
385 \\
406 \\
393\end{array}$ & $\begin{array}{l}343 \\
337 \\
364 \\
-- \\
375\end{array}$ & $\begin{array}{l}454 \\
455 \\
473 \\
460 \\
447\end{array}$ & $\begin{array}{l}408 \\
384 \\
384 \\
397 \\
374\end{array}$ \\
\hline $\begin{array}{l}26 \ldots \ldots \\
27 \ldots \ldots \\
28 \ldots \ldots \\
29 \ldots \ldots \\
30 \ldots \ldots \\
31 \ldots \ldots\end{array}$ & $\begin{array}{l}374 \\
385 \\
401 \\
440 \\
423 \\
462\end{array}$ & $\begin{array}{l}420 \\
422 \\
393 \\
422 \\
400 \\
---\end{array}$ & $\begin{array}{l}348 \\
315 \\
307 \\
302 \\
309 \\
312\end{array}$ & $\begin{array}{l}429 \\
426 \\
422 \\
395 \\
370 \\
345\end{array}$ & $\begin{array}{l}420 \\
393 \\
400 \\
409 \\
-- \\
--\end{array}$ & $\begin{array}{l}280 \\
280 \\
277 \\
313 \\
318 \\
305\end{array}$ & $\begin{array}{r}329 \\
326 \\
365 \\
358 \\
361 \\
--\end{array}$ & $\begin{array}{l}386 \\
409 \\
444 \\
428 \\
356 \\
311\end{array}$ & $\begin{array}{l}337 \\
360 \\
370 \\
371 \\
353 \\
-\end{array}$ & $\begin{array}{l}370 \\
377 \\
360 \\
450 \\
448 \\
404\end{array}$ & $\begin{array}{l}401 \\
410 \\
412 \\
346 \\
330 \\
349\end{array}$ & $\begin{array}{r}355 \\
369 \\
358 \\
342 \\
315 \\
--\end{array}$ \\
\hline AVER AGE & 392 & 407 & 335 & 373 & 348 & 370 & 304 & 376 & 336 & 379 & 411 & 365 \\
\hline
\end{tabular}


03612500 OHIO RIVER AT LOCK AND DAM 53, NEAR GRAND CHAIN, ILL, - COntinued TEMPERATURE $\left({ }^{\circ} \mathrm{C}\right)$ OF WATER, WATER YEAR OCTOBER 1967 TO SEPTEMBER 1968 (ONCE-DAILY MEASUREMENH BETWEEN O400 AND 0700 )

\begin{tabular}{|c|c|c|c|c|c|c|c|c|c|c|c|c|}
\hline DAY & UCT & dilv & $D E C$ & JAN & FEB & MAR & $\triangle P R$ & MAY & JUN & JUL & ANG & SEP \\
\hline $\begin{array}{l}1 \\
2 \\
3 \\
4 \\
5\end{array}$ & $\begin{array}{l}21.0 \\
21.0 \\
21.0 \\
21.0 \\
21.0\end{array}$ & $\begin{array}{l}14.0 \\
13.0 \\
14.0 \\
12.0 \\
12.0\end{array}$ & $\begin{array}{r}11.0 \\
10.0 \\
10.0 \\
9.0 \\
9.0\end{array}$ & $\begin{array}{l}4.0 \\
4.0 \\
4.0 \\
3.0 \\
3.0\end{array}$ & $\begin{array}{l}0.0 \\
9.0 \\
7.0 \\
7.0 \\
7.0\end{array}$ & $\begin{array}{l}3.0 \\
2.0 \\
3.0 \\
3.0 \\
3.0\end{array}$ & $\begin{array}{l}7.0 \\
7.0 \\
7.0 \\
7.0\end{array}$ & $\begin{array}{l}18.0 \\
18.0 \\
19.0 \\
20.0 \\
19.0\end{array}$ & $\begin{array}{l}19.0 \\
19.0 \\
19.0 \\
19.0 \\
21.0\end{array}$ & $\begin{array}{l}26.0 \\
26.0 \\
20.0 \\
26.0 \\
25.0\end{array}$ & $\begin{array}{l}27.0 \\
27.0 \\
27.0 \\
28.0 \\
27.0\end{array}$ & $\begin{array}{l}-\cdots \\
\cdots \\
\cdots \\
\cdots\end{array}$ \\
\hline $\begin{array}{r}6 \\
7 \\
9 \\
9 \\
10\end{array}$ & $\begin{array}{l}21.0 \\
21.0 \\
21.0 \\
21.0 \\
19.0\end{array}$ & $\begin{array}{l}--- \\
12.0 \\
12.0 \\
11.0 \\
12.0\end{array}$ & $\begin{array}{l}9.0 \\
7.0 \\
5.0 \\
4.0 \\
9.0\end{array}$ & $\begin{array}{l}3.0 \\
3.0 \\
2.0 \\
2.0 \\
1.0\end{array}$ & $\begin{array}{l}7.0 \\
7.0 \\
7.0 \\
5.0 \\
5.0\end{array}$ & $\begin{array}{l}3.0 \\
3.0 \\
6.0 \\
5.0 \\
0.0\end{array}$ & $\begin{array}{r}8.0 \\
8.0 \\
10.0 \\
12.0 \\
12.0\end{array}$ & $\begin{array}{l}17.0 \\
19.0 \\
19.0 \\
19.0 \\
17.0\end{array}$ & $\begin{array}{l}21.0 \\
20.0 \\
21.0 \\
20.0 \\
21.0\end{array}$ & $\begin{array}{l}24.0 \\
26.0 \\
26.0 \\
26.0 \\
27.0\end{array}$ & $\begin{array}{l}27.0 \\
27.0 \\
29.0 \\
29.0 \\
29.0\end{array}$ & $\begin{array}{l}-- \\
-- \\
-- \\
--\end{array}$ \\
\hline $\begin{array}{l}11 \\
12 \\
13 \\
14 \\
15\end{array}$ & $\begin{array}{l}13.0 \\
19.0 \\
18.0 \\
19.0 \\
19.0\end{array}$ & $\begin{array}{l}12.0 \\
12.0 \\
11.0 \\
12.0 \\
12.0\end{array}$ & $\begin{array}{l}9.0 \\
9.0 \\
8.0 \\
9.0 \\
8.0\end{array}$ & $\begin{array}{l}1.0 \\
2.0 \\
2.0 \\
2.0 \\
2.0\end{array}$ & $\begin{array}{r}4.0 \\
4.0 \\
4.0 \\
4.0\end{array}$ & $\begin{array}{l}7.0 \\
7.0 \\
7.0 \\
7.0 \\
6.0\end{array}$ & $\begin{array}{l}13.0 \\
13.0 \\
12.0 \\
14.0 \\
14.0\end{array}$ & $\begin{array}{l}19.0 \\
21.0 \\
19.0 \\
20.0 \\
19.0\end{array}$ & $\begin{array}{l}21.0 \\
20.0 \\
21.0 \\
21.0 \\
21.0\end{array}$ & $\begin{array}{l}27.0 \\
26.0 \\
27.0 \\
27.0 \\
27.0\end{array}$ & $\begin{array}{l}28.0 \\
27.0 \\
27.0 \\
27.0 \\
27.0\end{array}$ & $\ddot{-a}$ \\
\hline $\begin{array}{l}16 \\
17 \\
18 \\
16 \\
20\end{array}$ & $\begin{array}{r}19.0 \\
19.0 \\
17.0 \\
18.0\end{array}$ & $\begin{array}{l}11.0 \\
12.0 \\
11.0 \\
11.0 \\
11.0\end{array}$ & $\begin{array}{l}7.0 \\
7.0 \\
7.0 \\
7.0\end{array}$ & $\begin{array}{l}3.0 \\
3.0 \\
3.0 \\
3.0 \\
3.0\end{array}$ & $\begin{array}{l}3.0 \\
3.0 \\
3.0 \\
4.0 \\
3.0\end{array}$ & $\begin{array}{l}0.0 \\
7.0 \\
0.0 \\
7.0 \\
8.0\end{array}$ & $\begin{array}{l}14.0 \\
15.0 \\
16.0 \\
10.0 \\
16.0\end{array}$ & $\begin{array}{l}20.0 \\
21.0 \\
20.0 \\
19.0 \\
18.0\end{array}$ & $\begin{array}{r}20.0 \\
21.0 \\
21.0 \\
21.0\end{array}$ & $\begin{array}{r}27.0 \\
27.0 \\
27.0 \\
28.0\end{array}$ & $\begin{array}{r}27.0 \\
27.0 \\
27.0 \\
27.0 \\
-\end{array}$ & $\begin{array}{l}--- \\
-- \\
-\cdots \\
--\end{array}$ \\
\hline $\begin{array}{l}21 \\
22 \\
23 \\
24 \\
25\end{array}$ & $\begin{array}{l}18.0 \\
18.0 \\
19.0 \\
18.0 \\
13.0\end{array}$ & $\begin{array}{l}12.0 \\
12.0 \\
12.0 \\
11.0 \\
10.0\end{array}$ & $\begin{array}{r}10.0 \\
9.0 \\
9.0 \\
7.0 \\
7.0\end{array}$ & $\begin{array}{l}4.0 \\
4.0 \\
4.0 \\
4.0 \\
4.0\end{array}$ & $\begin{array}{l}3.0 \\
2.0 \\
2.0 \\
3.0\end{array}$ & $\begin{array}{l}8.0 \\
7.0 \\
7.0 \\
7.0 \\
7.0\end{array}$ & $\begin{array}{l}17.0 \\
17.0 \\
17.0 \\
16.0 \\
15.0\end{array}$ & $\begin{array}{l}20.0 \\
19.0 \\
19.0 \\
20.0 \\
20.0\end{array}$ & $\begin{array}{l}25.0 \\
20.0 \\
27.0 \\
21.0 \\
21.0\end{array}$ & $\begin{array}{l}28.0 \\
28.0 \\
28.0 \\
28.0 \\
20.0\end{array}$ & 30. & $\begin{array}{l}17.0 \\
18.0 \\
13.0 \\
13.0 \\
13.0\end{array}$ \\
\hline $\begin{array}{l}26 \\
27 \\
28 \\
29 \\
30 \\
31\end{array}$ & $\begin{array}{l}13.0 \\
13.0 \\
13.0 \\
12.0 \\
13.0 \\
13.0\end{array}$ & $\begin{array}{l}11.0 \\
11.0 \\
10.0 \\
10.0 \\
10.0 \\
\end{array}$ & $\begin{array}{l}6.0 \\
6.0 \\
7.0 \\
6.0 \\
6.0 \\
0.0\end{array}$ & $\begin{array}{l}4.0 \\
4.0 \\
4.0 \\
5.0 \\
6.0 \\
6.0\end{array}$ & $\begin{array}{l}3.0 \\
3.0 \\
4.0 \\
3.0 \\
-0 .\end{array}$ & $\begin{array}{l}6.0 \\
7.0 \\
7.0 \\
7.0 \\
7.0 \\
7.0\end{array}$ & $\begin{array}{l}17.0 \\
17.0 \\
16.0 \\
17.0 \\
17.0 \\
\end{array}$ & $\begin{array}{l}20.0 \\
20.0 \\
19.0 \\
19.0 \\
19.0 \\
18.0\end{array}$ & $\begin{array}{r}21.0 \\
21.0 \\
24.0 \\
24.0 \\
24.0 \\
-\end{array}$ & $\begin{array}{r}29.0 \\
29.0 \\
27.0 \\
27.0 \\
27.0\end{array}$ & $\begin{array}{l}30.0 \\
29.0 \\
29.0 \\
29.0 \\
30.0 \\
30.0\end{array}$ & $\begin{array}{r}13.0 \\
0-0 \\
14.0 \\
13.0 \\
-\end{array}$ \\
\hline ERAGE & 18.0 & 11.5 & $\dot{0} .0$ & 3.5 & 4.5 & 0.0 & 13.5 & 19.0 & 21.5 & 27.0 & 28.0 & $\cdots$ \\
\hline
\end{tabular}




\section{KANAWHA RIVER BASIN}

03161000 SOUTH FORK NEW RIVER NEAR JEFFERSON, N.C.

LOCATION.--Lat $36^{\circ} 23^{\prime} 40^{\prime \prime}$, long $81^{\circ} 24^{\prime} 27^{\prime \prime}$, Ashe County, at gaging station on right bank 600 ft upstream from bridge on State Highways 16 and $88,0.2$ mile downstream from Bear Creek, and 4 miles southwest of Jefferson.

DRAINAGE AREA. $--207 \mathrm{sq} \mathrm{mi}$.

PERIOD OF RECORD.--Chemical analyses: October 1949 to September 1950, October 1967 to September 1968.

Water temperatures: October 1949 to September 1950.

CHEMICAL ANALYSES IN MILLIGRAMS PER LITfR, hater yeAR OCtOBER 1967 TO SEPTEMBER 1968

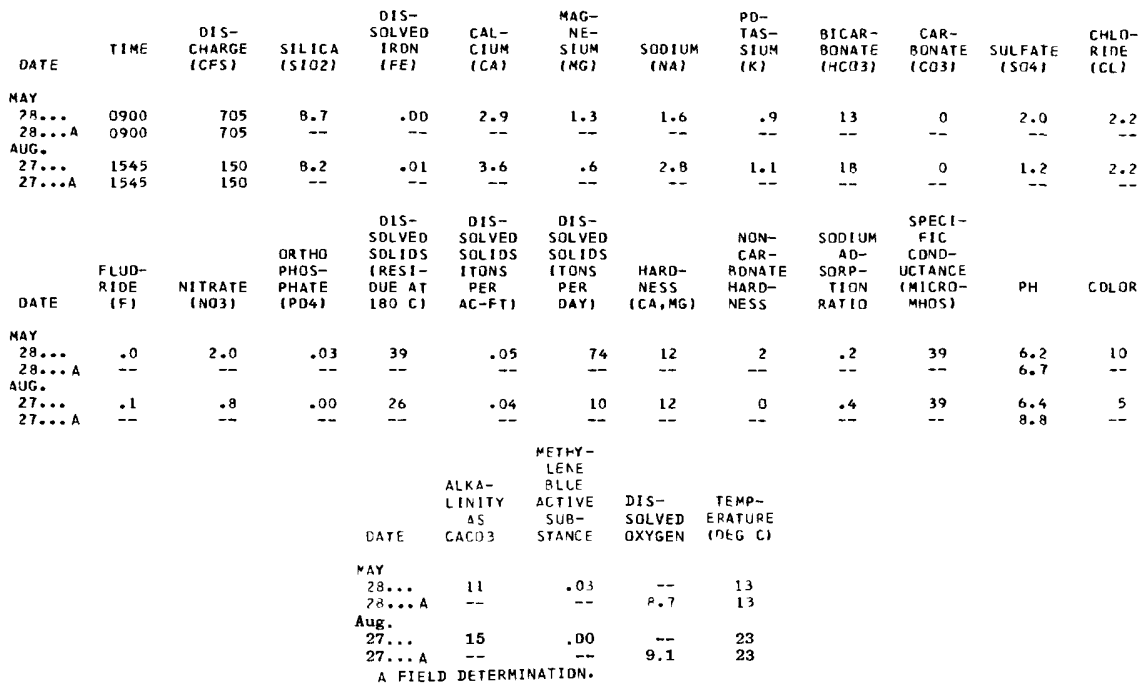

D3162500 NORTH FORK NEW RIVER AT CRUMPLER, N.C.

LOCATION.--Lat $36^{\circ} 31^{\circ} 04^{\prime \prime}$, long $81^{\circ} 23^{\prime} 18^{\prime \prime}$, Ashe County, at bridge on State Highway 16 at Crumpler, and 6 miles upstream from South Fork.

DRAINAGE AREA.--277 sq mi.

PERIOD OF RECORD.--Chemical analyses: October 1967 to September 1968.

CHEMICAL ANALYSES IN MILLIGRAMS PER LITER, hater YEAR OCTCBER 1967 TO SEPTEMBER 19Ee

\begin{tabular}{|c|c|c|c|c|c|c|c|c|c|c|c|c|}
\hline DATE & TIME & $\begin{array}{l}\text { CIS- } \\
\text { CHARGE } \\
\text { (CFS) }\end{array}$ & $\begin{array}{l}\text { SILICA } \\
\text { ISIO2I }\end{array}$ & $\begin{array}{l}\text { DIS- } \\
\text { SOLVED } \\
\text { IRCN } \\
\text { (FE) }\end{array}$ & $\begin{array}{l}\text { CAL- } \\
\text { CIUM } \\
\text { (CA) }\end{array}$ & $\begin{array}{l}\text { MAG- } \\
\text { NE- } \\
\text { SIUM } \\
\text { (MG) }\end{array}$ & $\begin{array}{c}\text { SOCIUM } \\
\text { (AA) }\end{array}$ & $\begin{array}{l}\text { PO- } \\
\text { IAS- } \\
\text { SIUM } \\
(\mathrm{K})\end{array}$ & $\begin{array}{l}\text { BICAR- } \\
\text { BONATE } \\
\text { (HCO3) }\end{array}$ & $\begin{array}{l}\text { CAR- } \\
\text { BOAATE } \\
\text { (CC } C 3)\end{array}$ & $\begin{array}{l}\text { SLLFATE } \\
\text { (SOA) }\end{array}$ & $\begin{array}{l}\text { CFLC- } \\
\text { FICE } \\
\text { (CL) }\end{array}$ \\
\hline $\begin{array}{l}\text { JUNE } \\
25 \ldots \\
\text { SEPT. }\end{array}$ & 1500 & 317 & 11 & .02 & 3.5 & 1.7 & 3.3 & .9 & 21 & D & $1 . \varepsilon$ & 3.0 \\
\hline $24 \ldots$. & $\begin{array}{l}1530 \\
1530\end{array}$ & $\begin{array}{l}89 \\
89\end{array}$ & 12 & .00 & 5.3 & 1.4 & 6.0 & 1.1 & 18 & $\begin{array}{r}c \\
--\end{array}$ & 4.0 & 7.6 \\
\hline DATE & $\begin{array}{l}\text { FIUC- } \\
\text { RIOE } \\
\text { (F) }\end{array}$ & $\begin{array}{l}\text { NI TRA A TE } \\
\text { (NO 3) }\end{array}$ & $\begin{array}{l}\text { OR THO } \\
\text { PHOS- } \\
\text { PHATE } \\
\text { (PD4) }\end{array}$ & $\begin{array}{l}\text { DLS- } \\
\text { SCLVED } \\
\text { SOLIDS } \\
\text { (RESI- } \\
\text { DUE AT } \\
\text { I8O C) }\end{array}$ & $\begin{array}{l}\text { DLS- } \\
\text { SCLVEC } \\
\text { SCLIOS } \\
\text { ITONS } \\
\text { PER } \\
\text { AC-FTI }\end{array}$ & $\begin{array}{l}\text { DIS- } \\
\text { SCLVEO } \\
\text { SCLIDS } \\
\text { (TONS } \\
\text { PER } \\
\text { DAY) }\end{array}$ & $\begin{array}{l}\text { HARD- } \\
\text { NESS } \\
\text { (CA,MGI }\end{array}$ & $\begin{array}{l}\text { NON- } \\
\text { CAR- } \\
\text { BONATE } \\
\text { HARO- } \\
\text { NESS }\end{array}$ & $\begin{array}{l}\text { SOOI UM } \\
\text { AD- } \\
\text { SORP- } \\
\text { TION } \\
\text { RAT IO }\end{array}$ & $\begin{array}{l}\text { SPECI- } \\
\text { FLC } \\
\text { COND- } \\
\text { UCTAACE } \\
\text { (MICRO- } \\
\text { MHCS) }\end{array}$ & PH & COLCR \\
\hline $\begin{array}{l}\text { JUNE } \\
25 \ldots . \\
\text { SEPT. }\end{array}$ & .2 & 2.8 &. $\mathrm{co}$ & 32 & .04 & 27 & 16 & D & .4 & 50 & 7.0 & 5 \\
\hline $24 \ldots$. & $\because 0$ & 0.0 & .00 & 56 & .08 & 13 & 19 & $\begin{array}{r}4 \\
--\end{array}$ & .6 & $\begin{array}{l}71 \\
75\end{array}$ & $\begin{array}{l}t .5 \\
t .5\end{array}$ & $\begin{array}{r}5 \\
--\end{array}$ \\
\hline & & & & DATE & $\begin{array}{l}\text { ALKA- } \\
\text { LINITY } \\
\text { AS } \\
C A C 03\end{array}$ & $\begin{array}{l}\text { MEIHY- } \\
\text { LENE } \\
\text { BLUE } \\
\text { ACTIVE } \\
\text { SUB- } \\
\text { STANCE }\end{array}$ & $\begin{array}{l}\text { D1S- } \\
\text { SOLVED } \\
\text { OXYGEN }\end{array}$ & $\begin{array}{l}\text { TEMP- } \\
\text { ERATURE } \\
\text { (DEG C) }\end{array}$ & & & & \\
\hline & & & & $\begin{array}{l}\text { JUNE } \\
25 \ldots . . \\
\text { SEPT. } \\
24 \ldots . \\
24 \ldots \text { A }\end{array}$ & 15 & $\begin{array}{l}.06 \\
.06 \\
.06\end{array}$ & 7.0 & $\begin{array}{l}23 \\
23 \\
23\end{array}$ & & & & \\
\hline
\end{tabular}


03162850 NEW RIVER AT AYELIA, N.C.

LOCATION.--Lat $36^{\circ} 33^{\prime} 08^{\prime \prime}$, long $81^{\circ} 11^{\circ} 00^{\prime \prime}$, Alleghany County, at bridge on Secondary Road $1345,0.8$ mile downstream from Rock Creek, and 1.3 miles northeast of Amelia.

DRAINAGE AREA. --820 sq $m 1$, approximately.

PERIOD OF RECORD. --Chemical analyses: October 1967 to September 1968.

CHEMICA' ANALYSES IN MILLIGRAMS PER LITER, WATER YEAR OCTOBER 1967 TO SEPTEMBER 1958

\begin{tabular}{|c|c|c|c|c|c|c|c|c|c|c|c|c|}
\hline DATE & TIME & $\begin{array}{l}\text { DIS- } \\
\text { CHARGE } \\
\text { (CFS) }\end{array}$ & $\begin{array}{l}\text { SILICA } \\
\text { (SIO2) }\end{array}$ & $\begin{array}{l}\text { DIS- } \\
\text { SOLVED } \\
\text { IRON } \\
\text { IFE I }\end{array}$ & $\begin{array}{l}\text { CAL- } \\
\text { CIUM } \\
(C A)\end{array}$ & $\begin{array}{l}\text { MAG- } \\
\text { NE- } \\
\text { SIUM } \\
(M G)\end{array}$ & $\begin{array}{l}\text { SODIUM } \\
\text { (NA) }\end{array}$ & $\begin{array}{l}\text { PO- } \\
\text { TAS- } \\
\text { SIUM } \\
\text { (K) }\end{array}$ & $\begin{array}{l}\text { BICAR- } \\
\text { BONATE } \\
\text { (HCO3) }\end{array}$ & $\begin{array}{l}\text { TAR- } \\
\text { BONATE } \\
\text { (CO3) }\end{array}$ & $\begin{array}{l}\text { SULFATE } \\
\text { (SO4) }\end{array}$ & $\begin{array}{l}\text { CHLD- } \\
\text { RIDE } \\
\text { (CL) }\end{array}$ \\
\hline $\begin{array}{l}\text { JUNE } \\
25 \ldots . . \\
\text { SEPT. }\end{array}$ & 1100 & 1023 & 10 & .01 & 3.4 & 1.3 & 2.5 & . 8 & 16 & 0 & 2.4 & 2.2 \\
\hline $\begin{array}{l}24 \ldots \ldots \\
24 \ldots A\end{array}$ & $\begin{array}{l}1200 \\
1200\end{array}$ & $\begin{array}{l}500 \\
500\end{array}$ & 9.6 & .00 & 3.4 & 1.6 & 3.7 & 1.3 & 18 & -- & $\begin{array}{r}2.4 \\
--\end{array}$ & 4.0 \\
\hline OATE & $\begin{array}{l}\text { FLUO- } \\
\text { RIOE } \\
\text { IF I }\end{array}$ & $\begin{array}{l}\text { NI TRATE } \\
\text { (NO3) }\end{array}$ & $\begin{array}{l}\text { JRTHO } \\
\text { PHOS- } \\
\text { PHATE } \\
\text { IPJ4) }\end{array}$ & $\begin{array}{l}\text { DIS- } \\
\text { SOLVEO } \\
\text { SOLIOS } \\
\text { (RESI- } \\
\text { DUE AI } \\
\text { I } 90 \mathrm{C} \text { ) }\end{array}$ & $\begin{array}{l}\text { DIS- } \\
\text { SOLVED } \\
\text { SOLIOS } \\
\text { I TONS } \\
\text { PER } \\
\text { AC-FII }\end{array}$ & $\begin{array}{l}\text { DIS- } \\
\text { SOLVED } \\
\text { SJLIDS } \\
\text { PTONS } \\
\text { PER } \\
\text { DAY) }\end{array}$ & $\begin{array}{l}\text { HARD- } \\
\text { NESS } \\
(C A, M G)\end{array}$ & $\begin{array}{l}\text { NON- } \\
\text { CAR- } \\
\text { BONATE } \\
\text { HARD- } \\
\text { NESS }\end{array}$ & $\begin{array}{l}\text { SODIUM } \\
\text { AD- } \\
\text { SORP- } \\
\text { TION } \\
\text { RATIO }\end{array}$ & $\begin{array}{l}\text { SPECI- } \\
\text { FIC } \\
\text { COND- } \\
\text { UCTANCE } \\
\text { (MICRO- } \\
\text { MHOSI }\end{array}$ & PH & COLOR \\
\hline $\begin{array}{l}\text { JUNE } \\
25 . . .\end{array}$ & .1 & .9 & .01 & 37 & .05 & 102 & 14 & 0 & $\cdot 3$ & 42 & 6.6 & 5 \\
\hline $\begin{array}{l}\text { SEPT. } \\
24 \ldots \text {. } \\
24 \ldots . . A\end{array}$ & -0 & -8 & .00 & 38 & $\stackrel{05}{--}$ & 51 & 15 & -0 & $\therefore 4$ & $\begin{array}{l}48 \\
50\end{array}$ & $\begin{array}{l}6.7 \\
7.0\end{array}$ & -5 \\
\hline
\end{tabular}

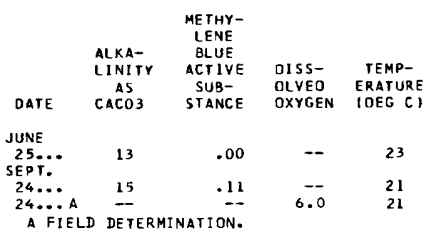

\section{TENNESSEF RIVER BASIN}

03439000 FRENCH BROAD RIVER AT ROSMAN, N.C.

LOCATION, - Lat $35^{\circ} 08^{\prime} 32^{\prime \prime}$, long $82^{\circ} 49^{\prime} 28^{\prime \prime}$, Transylvania County, at gaging station on left bank at upstream side of bridge on U.S. Highway 178 at Rosman, 1 mile upstream from East Fork, and at mile 216.4.

DRAI NAGE AREA. - $67.9 \mathrm{sq} \mathrm{ml}$.

PERIOD OF RECORD.--Chemical analyses: October 1957 to September 1968.

CHEMICAL ANALYSES IN MILLIGRAMS PER LITER, WATER YEAR OC TOBER 1967 TC SEPTEMBER 1SG8

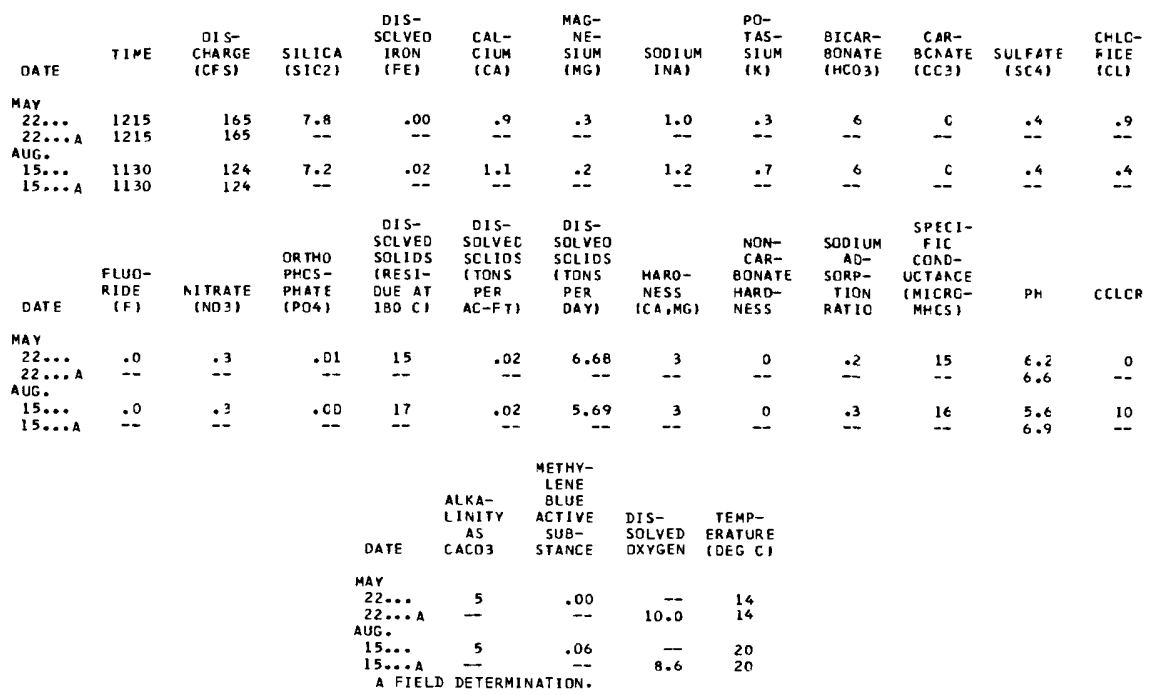


03443000 FRENCH BROAD RIVER AT BLANTYRE, N.C.

LOCATION.--Lat $35^{\circ} 17^{\prime} 56^{\prime \prime}$, long $82^{\circ} 37^{\prime} 27^{\prime \prime}$, Transylvania County, at gaging station on left bank $40 \mathrm{ft}$ upstream from bridge on secondary Road $1503,700 \mathrm{ft}$ east of railroad at Blantyre, 3.5 miles downstream from Little River, and at mile 183.7.

DRAINAGE AREA, - -296 sq mi.

PERIOD of RECORD.--Chemical analyses: October 1952 to September 1953, actober 1957 to September 1968. Water temperatures: October 1952 to September 1953.

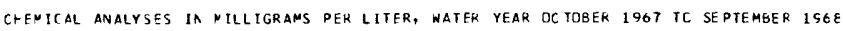

\begin{tabular}{|c|c|c|c|c|c|c|c|c|c|c|c|c|}
\hline DATE & TIME & $\begin{array}{l}\text { DIS- } \\
\text { CHARGE } \\
\text { (CFS) }\end{array}$ & $\begin{array}{l}\text { SILICA } \\
\text { (SIC2) }\end{array}$ & $\begin{array}{l}\text { DIS- } \\
\text { SCLVED } \\
\text { IRON } \\
\text { IFEI }\end{array}$ & $\begin{array}{l}\text { CAL- } \\
\text { CIUM } \\
\text { ICAI }\end{array}$ & $\begin{array}{l}\text { MAG- } \\
\text { NE- } \\
\text { SIUM } \\
\text { (MG) }\end{array}$ & $\begin{array}{l}\text { SODIUM } \\
\text { INAI }\end{array}$ & $\begin{array}{l}\text { PO- } \\
\text { TAS- } \\
\text { SIUM } \\
\text { (K) }\end{array}$ & $\begin{array}{l}\text { BICAR- } \\
\text { BONATE } \\
\text { (HCO3) }\end{array}$ & $\begin{array}{c}\text { CAR- } \\
\text { BCAATE } \\
\text { ICC } 1\end{array}$ & $\begin{array}{l}\text { SULFATE } \\
\text { (SC4) }\end{array}$ & $\begin{array}{l}\text { CHLC- } \\
\text { RICE } \\
\text { (CLI) }\end{array}$ \\
\hline \multicolumn{13}{|l|}{ MAY } \\
\hline $22 \ldots$ & 1405 & -- & 8.7 & .05 & 4.6 & .8 & 22 & 1.0 & 26 & c & 31 & 4.8 \\
\hline $22 \ldots A$ & 1405 & - & -- & -- & -- & -- & -- & -- & -- & -- & -- & - \\
\hline \multicolumn{13}{|l|}{ AUG. } \\
\hline $\begin{array}{l}19 . . . \\
19 . \ldots A\end{array}$ & $\begin{array}{l}1605 \\
1605\end{array}$ & $\begin{array}{l}501 \\
501\end{array}$ & 9.8 & .03 & 7.1 & $\therefore$ & 18 & .5 & 14 & -- & $\begin{array}{l}3 \varepsilon \\
--\end{array}$ & t. 8 \\
\hline & & & & $\begin{array}{c}\text { DIS- } \\
\text { SOLVED }\end{array}$ & $\begin{array}{l}\text { DIS- } \\
\text { SOLVEC }\end{array}$ & $\begin{array}{l}\text { DIS- } \\
\text { SOLVFO }\end{array}$ & & NON- & SOD I UM & $\begin{array}{l}\text { SPECI- } \\
\text { FIC }\end{array}$ & & \\
\hline & & & CR THO & SOLIDS & SCLIOS & SCLIOS & & CAR - & $A D=$ & COAC- & & \\
\hline & FLUC- & & PHCS- & IRESI- & ITONS & ITONS & HARD- & BONATE & SORP- & UCTAACE & & \\
\hline & RIDE & AITRATE & PHATE & CUE AT & PFR & PER & NESS & HAR D- & TION & IMICRC- & PH & CCLCR \\
\hline CATE & $(F)$ & (№2) & $(P 04)$ & $190 \mathrm{Cl}$ & $A C-F T I$ & DAYI & $(C A, M G)$ & NESS & RATIO & MHCSI & & \\
\hline
\end{tabular}

\begin{tabular}{|c|c|c|c|c|c|c|c|c|c|c|c|c|c|}
\hline $\begin{array}{r}\text { MAY } \\
22 \ldots .\end{array}$ & I & . & .04 & 94 & .13 & & - & 14 & 0 & 2.5 & 124 & $t .1$ & EC \\
\hline $22 \ldots A$ & $\because$ & $\ldots$ & - & - & - & & -- & $\because$ & - & - & $\ldots$ & 6.0 & -- \\
\hline AUG. & & & & & & & & & & & & & \\
\hline $19 \ldots$ & .1 & $\cdot t$ & $\cdot C \mathrm{C}$ & 86 & .12 & 116 & & 20 & 9 & 1.7 & 126 & $\epsilon .2$ & 10 \\
\hline $19 \ldots A$ & -- & -- & -- & -- & -- & & $\cdots$ & -- & -- & - & -- & 6.6 & - \\
\hline
\end{tabular}

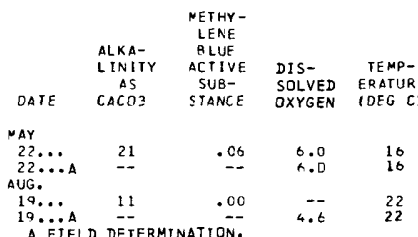

03448500 HOMINY CREEK AT CANDLER, N.C.

LOCATION, --Lat $35^{\circ} 32^{\prime} 28^{\prime \prime}$, long $82^{\circ} 40^{\prime} 35^{\prime \prime}$, Buncombe County, at gaging station 0.1 downstream from Pole Creek,

0.4 mile downstream from bridge on state Highway 112, and 1.0 mile east of Candier.

DRAINAGE AREA. $--79.8 \mathrm{sq} \mathrm{ml}$.

PERIOD OF RECORD.--Chetalcal analyses, October 1967 to September 1968.

REMRKs. - Records furnished by Tennessee Valley Authority.

CHemical analyses in MILLigrams Per liter, hater year oc tober 1967 to SePtember lste

\begin{tabular}{|c|c|c|c|c|c|c|c|c|c|c|c|}
\hline DATE & TIME & $\begin{array}{l}\text { DIS- } \\
\text { CHARGE } \\
\text { ICFSI }\end{array}$ & $\begin{array}{l}\text { SILICA } \\
\text { ISIC2) }\end{array}$ & $\begin{array}{l}\text { OIS- } \\
\text { SCLUED } \\
\text { IRON } \\
\text { IFEI }\end{array}$ & $\begin{array}{l}\text { CAL- } \\
\text { CIUMA } \\
\text { ( (A) }\end{array}$ & $\begin{array}{l}\text { MAG- } \\
\text { NE- } \\
\text { SIUM } \\
\text { (MG) }\end{array}$ & $\begin{array}{l}\text { SOD IUM } \\
\text { (NA) }\end{array}$ & $\begin{array}{l}\text { PO- } \\
\text { TAS- } \\
\text { SIUP } \\
\text { (K) }\end{array}$ & $\begin{array}{l}\text { B ICAR- } \\
\text { BONATE } \\
\text { (HCO3) }\end{array}$ & $\begin{array}{l}\text { CAR- } \\
\text { RCAATE } \\
\text { (CC3) }\end{array}$ & $\begin{array}{l}\text { SULFAIE } \\
\text { (SS(4) }\end{array}$ \\
\hline $\begin{array}{l}\text { APR. } \\
\text { OL.... } \\
\text { JUNE }\end{array}$ & 0950 & 151 & 7.5 & .56 & 4.7 & .0 & 2.8 & 2.0 & 16 & c & 4.4 \\
\hline $\begin{array}{c}03 . . . \\
\text { AUG. } \\
01 . . .\end{array}$ & $\begin{array}{l}0920 \\
0850\end{array}$ & 78 & 11 & $.7 t$ & 6.3 & .3 & 2.7 & 1.7 & 21 & 0 & $\begin{array}{l}3.8 \\
4.2\end{array}$ \\
\hline DATE & $\begin{array}{l}\text { CHLC- } \\
\text { RIDE } \\
\text { ICL) }\end{array}$ & $\begin{array}{l}\text { NI TRA TE } \\
\text { (NO3) }\end{array}$ & $\begin{array}{l}\text { DIS- } \\
\text { SCLVEC } \\
\text { SCLIOS } \\
\text { (RESI- } \\
\text { DUE AT } \\
\text { I80 C) }\end{array}$ & $\begin{array}{l}\text { DIS- } \\
\text { SDLVED } \\
\text { SOLIDS } \\
\text { (TONS } \\
\text { PER } \\
\text { AC-FT) }\end{array}$ & $\begin{array}{l}\text { DIS- } \\
\text { SOLVEC } \\
\text { SOLIDS } \\
\text { ITONS } \\
\text { PER } \\
\text { DAYI }\end{array}$ & $\begin{array}{l}\text { HARD- } \\
\text { NESS } \\
(C A, M G)\end{array}$ & $\begin{array}{l}\text { NON- } \\
\text { CAR- } \\
\text { BONATE } \\
\text { HARD- } \\
\text { NESS }\end{array}$ & $\begin{array}{l}\text { SOOIUM } \\
\text { AC- } \\
\text { SORP- } \\
\text { T ION } \\
\text { RATIO }\end{array}$ & $\begin{array}{l}\text { SPECI- } \\
\text { FIC } \\
\text { COND- } \\
\text { UCTANCE } \\
\text { (MICRO- } \\
\text { MHCS) }\end{array}$ & PH & CCLCR \\
\hline $\begin{array}{l}\text { APR. } \\
\text { OI... } \\
\text { JUNE }\end{array}$ & 2.5 & 1.3 & 32 & .04 & 13.0 & 14 & I & .4 & 47 & 6.7 & $=$ \\
\hline $\begin{array}{l}\text { 03... } \\
\text { AUG. }\end{array}$ & 2.5 & 1.0 & 41 & .06 & 8.63 & 16 & 0 & .3 & 48 & 6.7 & 5 \\
\hline $01 \ldots$ & 2.0 & .8 & 37 & .05 & 5.25 & 14 & c & .4 & 50 & 6.1 & 5 \\
\hline
\end{tabular}

$$
\begin{aligned}
& \begin{array}{ll}
\text { ALKA- } & \\
\text { LINITY } & \text { TEMP- } \\
\text { AS } & \text { ERATURE } \\
\text { DATE CACO3 } & \text { IDEG CI }
\end{array} \\
& \begin{array}{l}
\text { APR. } \\
\text { OL... } 13
\end{array}
\end{aligned}
$$

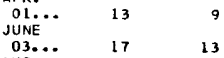

$$
\begin{aligned}
& \begin{array}{lll}
03 . . . & 17 & 13
\end{array}
\end{aligned}
$$


03451500 FRENCH BROAD RIVER AT ASHEVILLE, N.C.

LOCATION, -Lat $35^{\circ} 36^{\prime} 32^{\prime \prime}$, long $82^{\circ} 34^{\prime} 41^{\prime \prime}$, Buncombe County, at gaging station on right bank at downstream side of Pearson Bridge at Asheville, 2.3 miles downstream from Southern Railway station, 3.2 miles downstream from
Swannanoa River, and at mile 145.8 .

DRAINAGE AREA.,-.945 sq $\mathrm{ml}$.

PERIOD OF RECORD.--Chemical analyses: October 1950 to September 1951, October 1956 to September 1968. Water temperatures: October 1950 to September 1951. CHEMICAL ANALYSES IN MILL IGRAMS PER LITER, WATER YEAR DCTOBER 1967 TO SEPTEMBER 1968

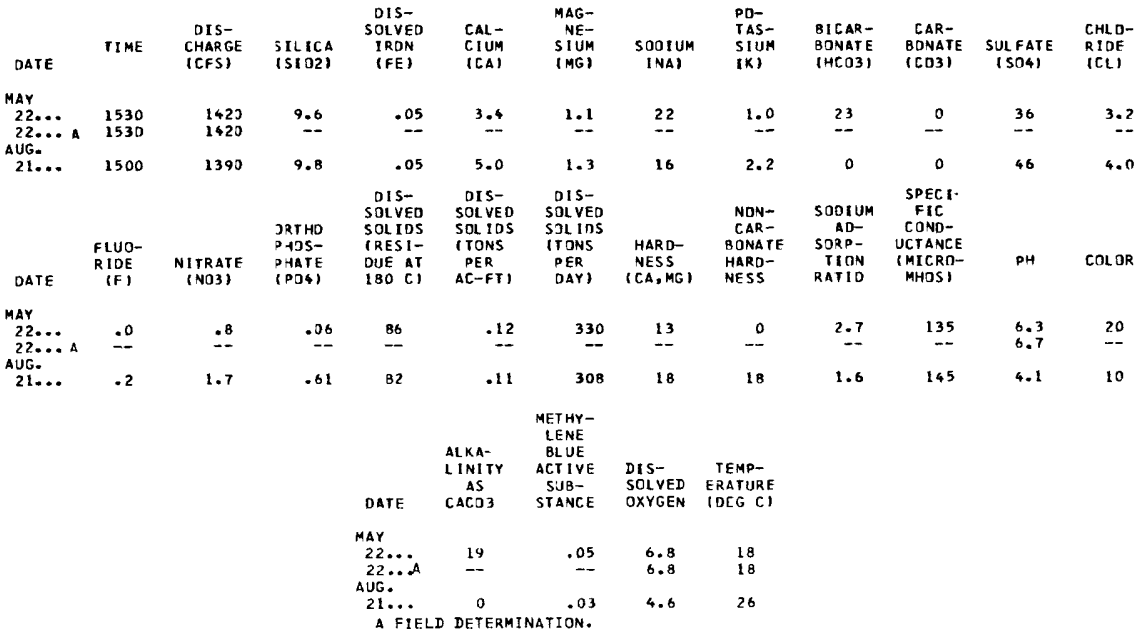

03454512 FRENCH BROAD RIVER AT U.S. HIGHWAY 25, AT HOT SPRINGS, N.C.

LOCATION,--Lat $35^{\circ} 53^{\circ} 41^{\prime \prime}$, long $82^{\circ} 49^{\prime} 23^{\prime \prime}$, Madison County at bridge on U.S. Highway 25 at Hot Springs and 0.2 mile upstream from Silver kine Creek.

DRAINAGE AREA, $--1,565 \mathrm{sq} \mathrm{mi}$.

PERIOD OF RECORD,--Chemical analyses: October 1967 to September 1968.

CHEMICAL ANALYSES IN MILLIGRAMS PER LITER, WATER YEAR OCTOBER 1967 TO SEPTEMBER ISGe

\begin{tabular}{|c|c|c|c|c|c|c|c|c|c|c|c|c|}
\hline CATE & TIME & $\begin{array}{l}\text { DIS- } \\
\text { CHARGE } \\
\text { (CFS) }\end{array}$ & $\begin{array}{l}\text { SIL1CA } \\
\text { (S102) }\end{array}$ & $\begin{array}{l}\text { OIS- } \\
\text { SOLVED } \\
\text { IRCN } \\
\text { IFE] }\end{array}$ & $\begin{array}{l}\text { CAL- } \\
\text { CIUA } \\
\text { (CA) }\end{array}$ & $\begin{array}{l}\text { NAG- } \\
N E- \\
\text { SIUA } \\
\text { (MG) }\end{array}$ & $\begin{array}{c}\text { SOCIUM } \\
\text { (NA) }\end{array}$ & $\begin{array}{l}\text { PO- } \\
\text { TAS- } \\
\text { SIUM } \\
\text { (K) }\end{array}$ & $\begin{array}{l}\text { BICAR- } \\
\text { BONATE } \\
\text { IHCO3) }\end{array}$ & $\begin{array}{l}\text { CAR- } \\
\text { BOAATE } \\
\text { (CC3) }\end{array}$ & $\begin{array}{c}\text { SLLFATE } \\
\text { (SO4) }\end{array}$ & $\begin{array}{l}\text { CrLC- } \\
\text { FICE } \\
\text { (CL) }\end{array}$ \\
\hline $\begin{array}{l}\text { JUNE } \\
27 \ldots . .\end{array}$ & 1030 & 2320 & 5.7 & .04 & 3.3 & .7 & 15 & 1.7 & 23 & 0 & 15 & 4.6 \\
\hline $27 \ldots A$ & 1030 & 2320 & - & -. & $\cdots$ & -- & -- & - & - & -- & $\cdots$ & 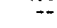 \\
\hline $\begin{array}{l}\text { AUG. } \\
09 \ldots . .\end{array}$ & 1200 & 1220 & $1 \mathrm{C}$ & .00 & 5.6 & 1.7 & 14 & 2.0 & 20 & 0 & 21 & E. \\
\hline $09 \ldots A$ & 1200 & 1220 & $10^{--}$ & $\overline{0}$ & $5 . \overline{1}$ & 5 & $\overline{17}$ & 1.0 & 19 & 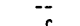 & $\overline{27}$ & $5 . t$ \\
\hline $22 \ldots A$ & 1545 & 1140 & - & $\cdots$ & - & - & - & - & - & - & -- & \\
\hline & $\begin{array}{l}\text { FLUC- } \\
\text { RIDE }\end{array}$ & NITRATE & $\begin{array}{l}\text { OR THO } \\
\text { PHCS- } \\
\text { PHATE }\end{array}$ & $\begin{array}{l}\text { OIS- } \\
\text { SCLVEC } \\
\text { SOLIDS } \\
\text { IRESI- } \\
\text { DUE AT }\end{array}$ & $\begin{array}{l}\text { OIS- } \\
\text { SCLVEC } \\
\text { SCLIDS } \\
\text { ITONS } \\
\text { PER }\end{array}$ & $\begin{array}{l}\text { OIS- } \\
\text { SCLYED } \\
\text { SCLIOS } \\
\text { I TONS } \\
\text { PER }\end{array}$ & $\begin{array}{l}\text { HARD- } \\
\text { NESS }\end{array}$ & $\begin{array}{l}\text { NDN- } \\
\text { CAR- } \\
\text { BONATE } \\
\text { HARD- }\end{array}$ & $\begin{array}{c}\text { SODIUM } \\
\text { AD- } \\
\text { SORP- } \\
\text { TION }\end{array}$ & $\begin{array}{l}\text { SPECI- } \\
\text { FIC } \\
\text { COAC- } \\
\text { UCTANCE } \\
\text { IMICRC- }\end{array}$ & PH & CCLOR \\
\hline DATE & $|F|$ & $\left(\mathrm{NO}_{3}\right)^{\prime}$ & $(P 04)$ & $180 \mathrm{Cl}$ & $A C-F T I$ & OAYI & $(C A, M G)$ & NESS & RATIO & $M+(S)$ & & \\
\hline JUNE & & & & & & & & & & & & \\
\hline $27 \ldots$ & .2 & 1.2 & .02 & 73 & .10 & 457 & 11 & 0 & 2.0 & 100 & $t .2$ & 15 \\
\hline $\begin{array}{r}27 \cdots A \\
A \cup G .\end{array}$ & -- & -- & -- & -- & -- & - & - & -- & - & 57 & 7.6 & -- \\
\hline $09 .$. & .1 & 1.2 & .16 & 81 & .11 & 267 & 21 & 4 & 1.3 & 118 & 7.0 & 5 \\
\hline $09 \ldots A$ & -- & -- & - & $=$ & -- & -- & - & $=$ & $\cdots$ & $14 \mathrm{C}$ & 7.5 & 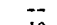 \\
\hline $22 \ldots$ & .1 & 1.7 & . It & 79 & .11 & 243 & 20 & 4 & 1.7 & I1E & 6.4 & 10 \\
\hline $22 \ldots A$ & -- & -- & -- & - & -- & -- & -- & - & - & - & 7.5 & \\
\hline
\end{tabular}

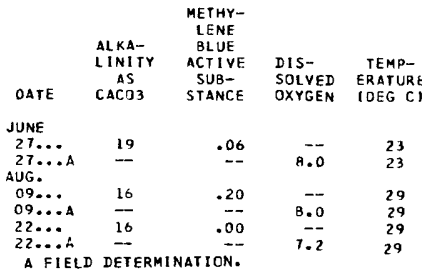


03457000 PIGEON RIVER AT CANTON, N.C.

LOCATION. - - Lat $35^{\circ} 31^{\prime} 30^{\prime \prime}$, long $82^{\circ} 50^{\prime} 28^{\prime \prime}$, Haywood County, at gaging station on left bank 100 ft upstream from small tributary, $200 \mathrm{ft}$ dowstream from P1geon Street bridge, 0.5 mile upstream from U.S. Highways 19 and 23 at Canton, and at mile 64.1.

DRAINAGE AREA.--133 sq mi, approximately.

PERIOD OF RECORD.--Chemical analyses: October 1957 to September 1968.

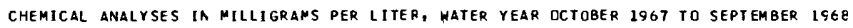

\begin{tabular}{|c|c|c|c|c|c|c|c|c|c|c|c|c|}
\hline OATE & TIME & $\begin{array}{l}\text { OIS- } \\
\text { CHARGE } \\
\text { (CFS) }\end{array}$ & $\begin{array}{l}\text { SILICA } \\
\text { (SIO2) }\end{array}$ & $\begin{array}{l}\text { DIS- } \\
\text { SOL VEO } \\
\text { IRCN } \\
\text { (FE) }\end{array}$ & $\begin{array}{l}\text { CAL- } \\
\text { CIUN } \\
\text { (CA) }\end{array}$ & $\begin{array}{l}\text { MAG- } \\
\text { NE- } \\
\text { SIUM } \\
\text { (MG) }\end{array}$ & $\begin{array}{l}\text { Soc IuM } \\
\text { (AA) }\end{array}$ & $\begin{array}{l}\text { PO- } \\
\text { YAS- } \\
\text { SIUM } \\
(K)\end{array}$ & $\begin{array}{l}\text { BICAR- } \\
\text { BONATE } \\
\text { (HCD } 3 \text { ) }\end{array}$ & $\begin{array}{l}\text { CAR- } \\
\text { BOAATE } \\
\text { (CC3) }\end{array}$ & $\begin{array}{l}\text { SLLFATE } \\
\text { (SCA) }\end{array}$ & $\begin{array}{l}\text { CHLC- } \\
\text { FICE } \\
\text { (CLI) }\end{array}$ \\
\hline $\begin{array}{l}\text { MAY } \\
16 \ldots . . . \\
16 . . .\end{array}$ & $\begin{array}{r}0940 \\
0940\end{array}$ & 297 & 6.3 & .04 & 1.9 & $\therefore 4$ & 1.1 & .6 & 9 & c & $\because 4$ & 8 \\
\hline $\begin{array}{l}A U G . \\
23 \ldots \\
23 \ldots A\end{array}$ & $\begin{array}{l}0930 \\
0930\end{array}$ & $\begin{array}{l}124 \\
124\end{array}$ & $\begin{array}{r}7.4 \\
-.\end{array}$ & .02 & 1.7 & $\therefore 5$ & $\begin{array}{r}1.5 \\
--\end{array}$ & 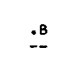 & 10 & $\begin{array}{l}0 \\
--\end{array}$ & $1 . t$ & 1.0 \\
\hline & FLUO- & & $\begin{array}{l}\text { CRTHO } \\
\text { FHCS- }\end{array}$ & $\begin{array}{l}\text { DIS- } \\
\text { SOL VED } \\
\text { SOL IDS } \\
\text { IRESI - }\end{array}$ & $\begin{array}{l}\text { CIS- } \\
\text { SDLVED } \\
\text { SOLIDS } \\
\text { IICAS }\end{array}$ & $\begin{array}{l}\text { CIS- } \\
\text { SCLVED } \\
\text { SOLIOS } \\
\text { TTONS } \\
\text { PER }\end{array}$ & $\begin{array}{l}\text { HARD- } \\
\text { NESS }\end{array}$ & $\begin{array}{l}\text { NON- } \\
\text { CAR- } \\
\text { BONATE }\end{array}$ & $\begin{array}{l}\text { SOOIUM } \\
\text { AD- } \\
\text { SORP- }\end{array}$ & $\begin{array}{l}\text { SPECI- } \\
\text { FIC } \\
\text { CCAC- } \\
\text { UCYANCE }\end{array}$ & & cn 08 \\
\hline DATE & $(F)$ & ( $\mathrm{NO}_{3}$ ) & (PO4) & $180(\mathrm{C})$ & $A C-F I I$ & OAY & $(C A, M G)$ & NESS & RATIO & MHCSI & $P H$ & COLOR \\
\hline
\end{tabular}

\begin{tabular}{|c|c|c|c|c|c|c|c|c|c|c|c|c|}
\hline MAY & & & & & & & & & & & & \\
\hline $16 \ldots A$ & $\because 2$ & $\therefore$ & 0 & 22 & 103 & 11.0 & - & $\begin{array}{r}0 \\
-\end{array}$ & $\because 2$ & 21 & 6.6 & 10 \\
\hline AUG. & & & & & & & & & & & & \\
\hline $\begin{array}{l}23 \ldots \\
23 \ldots\end{array}$ & $\because 1$ & $\therefore 4$ & .00 & 19 & .03 & 6.36 & 6 & 0 & .3 & 23 & 6.4 & 5 \\
\hline
\end{tabular}

$$
\begin{array}{cccc}
\text { METHY- } & & \\
\text { LENE } & & \\
\text { ALKA- } & \text { BLUE } & \\
\text { LINITY } & \text { ACIIVE } & \text { DIS- } & \text { TEMP- } \\
\text { AS } & \text { SUA- } & \text { SOLVED } & \text { ERATURE } \\
\text { DATE CACO3 } & \text { STANCE } & \text { OXYGEN IDFG C) }
\end{array}
$$

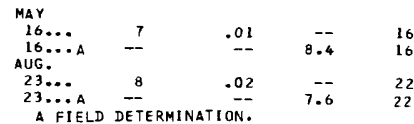

03459620 PIGEON RIVER AT HEPCO, N,C.

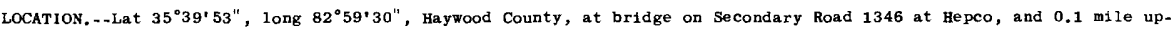
stream from Fines Creek.

DRAINAGE AREA. $--356 \mathrm{sq} \mathrm{mi}$.

PERIOD OF RECORD. -.-Chemical analyses: October 1967 to September 1968.

CHEMICAL aVALYSES IN MILLIGRAMS PER LITER, hateR YeAR OCTOBER 1967 TO SEPTEMBER 1968

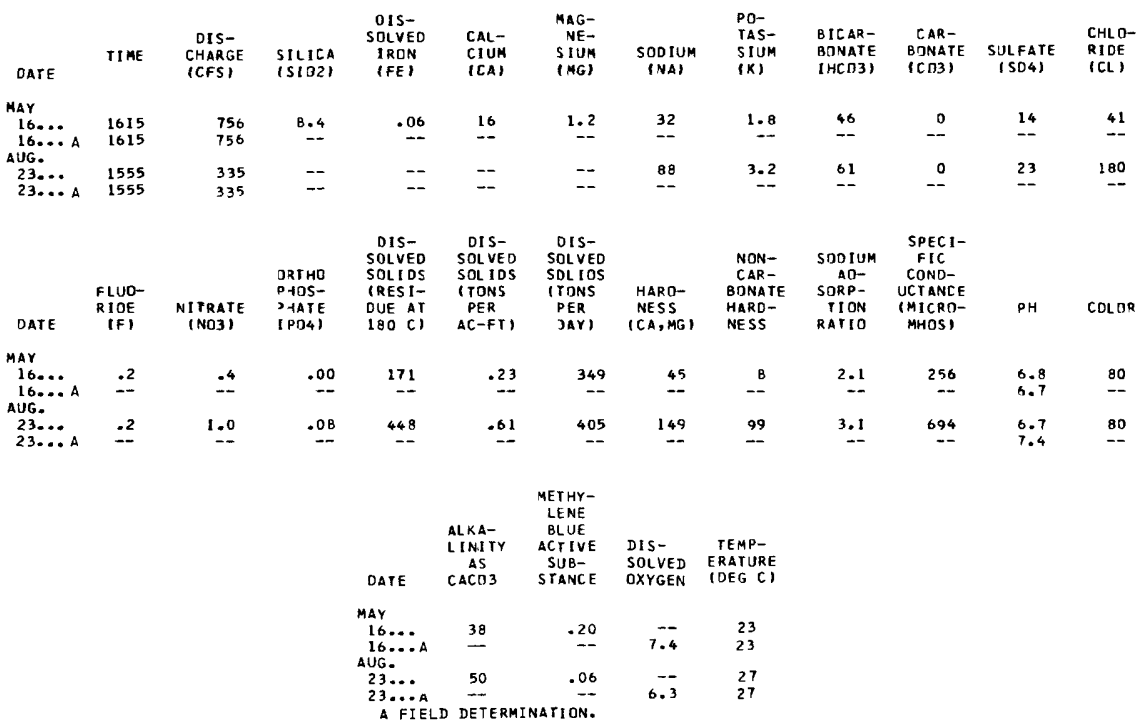


03460766 PIGEON RIVER AT WATERVILLE, N.C.

LOCATION.--Lat $35^{\circ} 46^{\prime} 32^{\prime \prime}$, long $83^{\circ} 06^{\circ} 01^{\prime \prime}$, Haywood County, at tailrace of Carolina Power and Light Co. powerplant, upstream from Big Creek, and at Waterville.

DRAINAGE AREA. $-536 \mathrm{sq} \mathrm{ml}$.

PERIOD OF RECORD.--Chemical analyses: October 1957 to September 1968.

CHEMICAL AYALYSES IN MILLIGRAMS PER LITER, hateR YEAR OCTOBER 1967 TU SEPTEMBER $196 \mathrm{~B}$

\begin{tabular}{|c|c|c|c|c|c|c|c|c|c|c|c|c|}
\hline DATE & TIME & $\begin{array}{l}\text { OIS- } \\
\text { CHARGE } \\
\text { (CFS) }\end{array}$ & $\begin{array}{l}\text { SILICA } \\
\text { ISIOZI }\end{array}$ & $\begin{array}{l}\text { DIS- } \\
\text { SDLVED } \\
\text { IRON } \\
\text { IFE }\end{array}$ & $\begin{array}{l}\text { CAL- } \\
\text { CIUM } \\
\text { (CA) }\end{array}$ & $\begin{array}{l}\text { MAG- } \\
\text { NE- } \\
\text { SIUMA } \\
\text { (MG) }\end{array}$ & $\begin{array}{l}\text { SOD IUM } \\
\text { (NA) }\end{array}$ & $\begin{array}{l}\text { PO- } \\
\text { TAS- } \\
\text { SIUM } \\
\text { [K] }\end{array}$ & $\begin{array}{l}\text { BICAR - } \\
\text { BDNATE } \\
\text { (HCD3) }\end{array}$ & $\begin{array}{l}\text { CAR- } \\
\text { BONATE } \\
\text { (CO3) }\end{array}$ & $\begin{array}{l}\text { SULFATE } \\
\text { I Sn } 41\end{array}$ & $\begin{array}{l}\text { CHLO- } \\
\text { RIOE } \\
\text { ICLI }\end{array}$ \\
\hline \\
\hline $27 \ldots A$ & $\begin{array}{l}1435 \\
1435\end{array}$ & $\begin{array}{l}1420 \\
1420\end{array}$ & 9.4 & $\begin{array}{l}.20 \\
.26\end{array}$ & 21 & 10 & 28 & 1.6 & 33 & - & 16 & $\begin{array}{l}56 \\
--\end{array}$ \\
\hline \multirow{2}{*}{$\begin{array}{l}\text { SEPT. } \\
11 \ldots \ldots \\
11 \ldots . . A\end{array}$} & & & & & & & & & & & & \\
\hline & $\begin{array}{l}1340 \\
1340\end{array}$ & 943 & 10 & .09 & 44 & 1.8 & 72 & 3.4 & 62 & 0 & 33 & 133 \\
\hline DATE & $\begin{array}{l}\text { RIDE } \\
\text { (F) }\end{array}$ & $\begin{array}{l}\text { NI TRATE } \\
\text { (N03) }\end{array}$ & $\begin{array}{l}\text { PHATE } \\
\text { (P) }\end{array}$ & $\begin{array}{l}\text { DUE AT } \\
180 \mathrm{CI}\end{array}$ & $\begin{array}{c}\text { PER } \\
\text { AC-FTI }\end{array}$ & $\begin{array}{l}\text { PER } \\
\text { DAYI }\end{array}$ & $\begin{array}{l}\text { NESS } \\
(C A, M G)\end{array}$ & $\begin{array}{l}\text { HARD- } \\
\text { NESS }\end{array}$ & $\begin{array}{l}\text { TION } \\
\text { RATIOO }\end{array}$ & $\begin{array}{l}\text { (MICRD- } \\
\text { MHOSS) }\end{array}$ & $\mathrm{PH}$ & COLOR \\
\hline \multirow{9}{*}{$\begin{array}{l}\text { JUNE } \\
27 \ldots . . \\
27 \ldots \ldots \\
\text { SEPT. } \\
11 \ldots \ldots \\
11 \ldots . . A\end{array}$} & & & & & & & & & & & & \\
\hline & .2 & .9 & - & 191 & .26 & 732 & 63 & 34 & 1.5 & 274 & 6.5 & 45 \\
\hline & -- & - & - & -- & -- & - & - & - & -- & 300 & 7.1 & -- \\
\hline & & & & JUNE & & & & & & & & \\
\hline & & & & $27 \ldots$ & 29 & $\cdots$ & 8.0 & -- & & & & \\
\hline & & & & SEPT. & - & $\cdots$ & 8.0 & -- & & & & \\
\hline & & & & $11 \ldots$ & 51 & .18 & 0 & 21 & & & & \\
\hline & & & & A FIELD & DETERI & TION. & & & & & & \\
\hline & & & & 46200 & TTH & VER & A & 8. & & & & \\
\hline
\end{tabular}

LOCATron.--Lat $35^{\circ} 53^{\prime} 59^{\prime \prime}$, long $82^{\circ} 01^{\prime} 50^{\prime \prime}$, Witchell County, 0.1 mile upstream from Rose Creek, and 1.0 mile norhtwest of Altapass.

DRAINAGE AREA. - $104 \mathrm{sq} \mathrm{mi}$.

PERIOD OF RECORD.--Chemical analyses: October 1948 to September 1949, October 1967 to September 1968. Water temperatures: October 1948 to September 1949.

CHEMICAL aVALYSES IN MILLIGRAMS PER LITER, MATER YEAR OCTOBER 1967 TO SEPTEMBER 1968

\begin{tabular}{|c|c|c|c|c|c|c|c|c|c|c|c|c|}
\hline DATE & TIME & $\begin{array}{l}\text { OIS- } \\
\text { CHARGE } \\
\text { (CFS) }\end{array}$ & $\begin{array}{l}\text { SILICA } \\
\text { ISIO2I }\end{array}$ & $\begin{array}{l}\text { DIS- } \\
\text { SOLVEO } \\
\text { IRON } \\
\text { IFEI }\end{array}$ & $\begin{array}{l}\text { CAL- } \\
\text { CIUM } \\
\text { ICAI }\end{array}$ & $\begin{array}{l}\text { MAG- } \\
\text { NE- } \\
\text { SIUM } \\
\text { (MG) }\end{array}$ & $\begin{array}{l}\text { SOD IUM } \\
\text { (NA) }\end{array}$ & $\begin{array}{l}\text { PO- } \\
\text { TAS- } \\
\text { SIUM } \\
\text { IKI }\end{array}$ & $\begin{array}{l}\text { BICAR- } \\
\text { BDNATE } \\
\text { (HCD3) }\end{array}$ & $\begin{array}{l}\text { CAR- } \\
\text { BDNATE } \\
\text { (CO3) }\end{array}$ & $\begin{array}{l}\text { SULFATE } \\
\text { (SO4) }\end{array}$ & $\begin{array}{l}\text { CHLO- } \\
\text { RIDE } \\
\text { (CL) }\end{array}$ \\
\hline $\begin{array}{l}\text { JUNE } \\
25 . . .\end{array}$ & 1545 & 143 & 9.9 & .04 & 1.9 & 1.2 & 2.0 & .7 & 13 & 0 & 1.8 & 1.0 \\
\hline JULY $25 \ldots A$ & 1545 & 143 & -- & - & -- & -- & - & -- & -- & -- & - & -- \\
\hline $30 \ldots$ & 1315 & 69 & 10 & .00 & 3.2 & .9 & 2.2 & .6 & 15 & 0 & 2.8 & 1.0 \\
\hline $\begin{array}{l}30 . \cdots A \\
\text { SEPY. A }\end{array}$ & 1315 & 69 & -- & -- & -- & -- & - & -- & -- & - & -- & \\
\hline $10 \ldots$ & $\begin{array}{l}1110 \\
1110\end{array}$ & $\begin{array}{l}144 \\
144\end{array}$ & 9.7 & .02 & 2.9 & 1.1 & 2.2 & $\because 7$ & 14 & 0 & 3.2 & 1.6 \\
\hline OATE & $\begin{array}{l}\text { FLUO- } \\
\text { RIDE } \\
\text { IF I }\end{array}$ & $\begin{array}{l}\text { NITRATE } \\
\text { (NO3) }\end{array}$ & $\begin{array}{l}\text { JPTHD } \\
\text { PHOS- } \\
\text { PHATE } \\
\text { (PJ4) }\end{array}$ & $\begin{array}{l}\text { DIS- } \\
\text { SDLVEO } \\
\text { SOLIDS } \\
\text { IRESI- } \\
\text { DUE AT } \\
\text { IBO CI }\end{array}$ & $\begin{array}{l}\text { DIS- } \\
\text { SOLVED } \\
\text { SOLIDS } \\
\text { ITDNS } \\
\text { PER } \\
\text { AC-FTI }\end{array}$ & $\begin{array}{l}\text { DIS- } \\
\text { SOLVED } \\
\text { SOLIDS } \\
\text { ITONS } \\
\text { PER } \\
\text { DAYI }\end{array}$ & $\begin{array}{l}\text { HARD- } \\
\text { NESS } \\
\text { (CA, MG })\end{array}$ & $\begin{array}{l}\text { NDN- } \\
\text { CAR- } \\
\text { BONATE } \\
\text { HARD- } \\
\text { NESS }\end{array}$ & $\begin{array}{l}\text { SOOIUM } \\
\text { AD- } \\
\text { SORP- } \\
\text { TIDN } \\
\text { RATIO }\end{array}$ & $\begin{array}{l}\text { SPECI- } \\
\text { FIC } \\
\text { COND- } \\
\text { UCTANCE } \\
\text { (MICRO- } \\
\text { MHOS I }\end{array}$ & PH & COLOR \\
\hline JUNE & & & & & & & & & & & & \\
\hline $25 \ldots$ & .2 & .2 & -- & 30 & .04 & 11.6 & 10 & 0 & $\cdot 3$ & 29 & 9.2 & 5 \\
\hline JULY & - & - & - & -- & - & & -- & - & -- & 34 & 8.4 & - \\
\hline $30 \ldots$ & -1 & .5 & .02 & 27 & .04 & 5.03 & 12 & 0 & .3 & 35 & 6.8 & 5 \\
\hline $\begin{array}{l}\text { 30...A } \\
\text { SEPT. }\end{array}$ & - & $\cdots$ & $\cdots$ & - & - & - & - & -- & - & -- & 7.8 & -- \\
\hline $10 \ldots$ & .0 & .6 & .00 & 29 & .04 & 11.3 & 12 & 0 & .3 & 35 & 6.2 & 5 \\
\hline $10 \ldots A$ & - & - & - & - & $=$ & $\cdots$ & -- & -- & + & 40 & 7.1 & \\
\hline & & & & & & METHY- & & & & & & \\
\hline & & & & & ALKA- & BLUE & & & & & & \\
\hline & & & & & LINITY & ACTIVE & DIS5- & TEMP- & & & & \\
\hline & & & & OATE & $\begin{array}{c}\mathrm{ASO}_{3} \\
\mathrm{ACO} 3\end{array}$ & STANCE & $\begin{array}{l}\text { OLVED } \\
\text { OXYGEN }\end{array}$ & $\begin{array}{l}\text { ERATURE } \\
\text { IOEG CI }\end{array}$ & & & & \\
\hline & & & & JUNE & & & & & & & & \\
\hline & & & & & 11 & .02 & -- & 22 & & & & \\
\hline & & & & $25 \ldots A$ & $-\infty$ & & 9.0 & 22 & & & & \\
\hline & & & & JuLr & 12 & .04 & -- & 21 & & & & \\
\hline & & & & $30 \ldots A$ & - & - & 3.0 & 21 & & & & \\
\hline & & & & SEPT. & & & & & & & & \\
\hline & & & & $10 \ldots$ & 11 & .06 & $\overrightarrow{0}$ & 17 & & & & \\
\hline & & & & A FIEL & & NATION. & & 21 & & & & \\
\hline
\end{tabular}


03463786 NORTH TOE RIVER AT HUNTDALE, N.C.

LOCATION.--Lat $36^{\circ} \mathrm{O} 1^{\prime} 35^{\prime \prime}$, long $82^{\circ} 19^{\prime} 16^{\prime \prime}$, Mitchell County, at bridge on State Highway 26 at Huntdale and $0.5 \mathrm{~m} 1 \mathrm{le}$ upstream from Cane River.

DRAINAGE AREA. $-\mathbf{- 4 4 2}$ sq $\mathrm{mi}$.

RECORDS AVAILABLE. -. Chemical analyses: October 1967 to September 1968.

Chemical analyses in MiLligrams per liter, hater year october ly67 to SEPTEMBer $15 E$

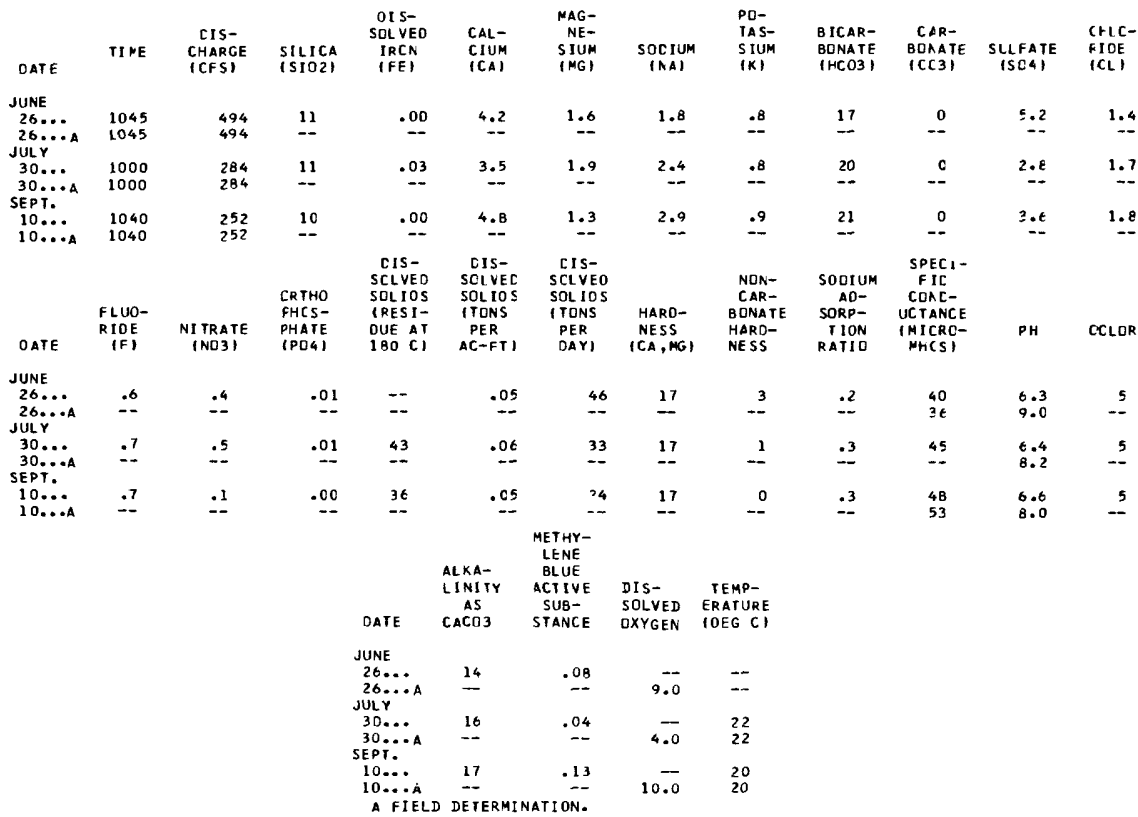

03464000 CANE RIVER NEAR SIOUX, N.C.

LOCATION.--Lat $36^{\circ} 00^{\prime} 52^{\prime \prime}$, long $82^{\circ} 19^{\prime} 40^{\prime \prime}$, Yancey County, at gaging station on right bank on Secondary Road 1417 ,

1.3 miles upstream from mouth, and 1.5 miles east of S1oux.

DRAINAGE AREA. $--157 \mathrm{sq} \mathrm{mt}$.

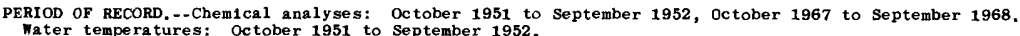

CHENICAL ANALYSES IN NILLIGRAMS PER LITER, WATER YEAK OC TOBER 1967 TC SEPTEMBER 1968

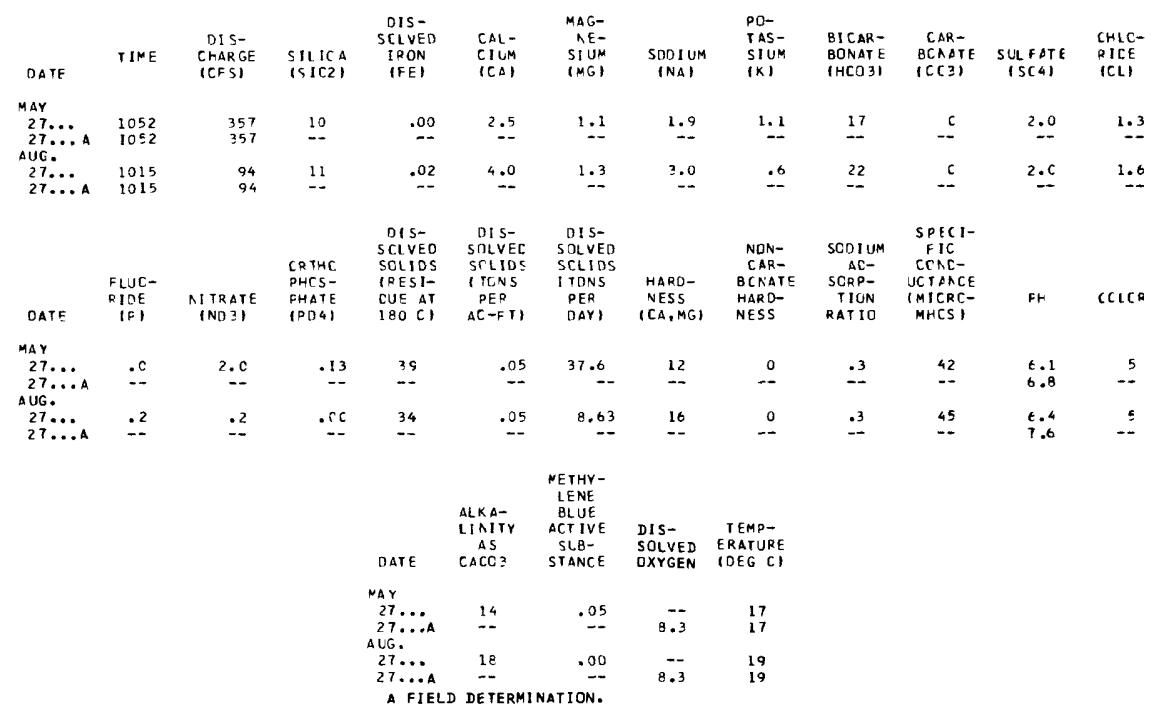


03464500 NOLICHUCKY RIVER AT POPLAR, N.C.

LOCATION.--Lat $36^{\circ} 04^{\prime} 29^{\prime \prime}$, long $82^{\circ} 20^{\circ} 41^{\prime \prime}$, Mitchel1 County, at Poplar, and 0.7 mile upstream from Hollow Poplar Creek. DRAINAGE AREA, $--608 \mathrm{sqq} \mathrm{mi}$.

PERIOD OF RECORD. -.-Chem1Cal ana1yses: October 1967 to September 1968.

CHEMICAL ANALYSES IN MILLIGRAMS PER LITER. HATER YEAR OCTOBER 1967 IC SEPTEMBER 1968

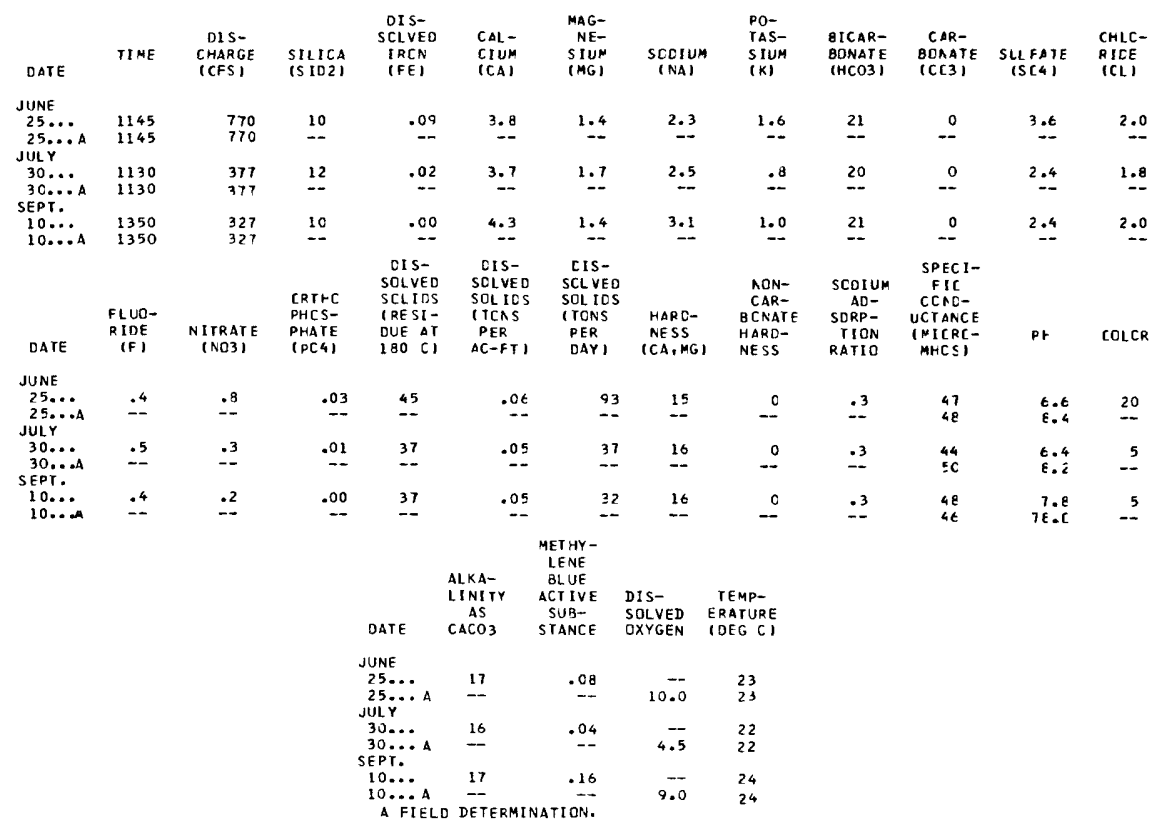

03479000 WATAUGa RIVER NEAR SUGAR Grove, N.C.

LOCATION. --Lat $36^{\circ} 14^{\prime} 18^{\prime \prime}$, long $81^{\circ} 49^{\prime} 22^{\prime \prime}$, Watauga County, at gaging station on right bank 250 ft upstream from bridge on Secondary Road 1121, $300 \mathrm{ft}$ downstream from Cove Creek, and $2.3 \mathrm{miles}$ southwest of Sugar Grove, and at mile 64.4.

DRAINAGE AREA, . - 90,8 sq m1.

PERIOD OF RECORD.--Chemical analyses: October 1952 to September 1953, October 1967 to September 1968. Water temperatures: October 1952 to September 1953.

CHEMICAL ANALYSES IN NILLIGRAMS PER LITER, WATER YEAR OC TOBER 1967 TO SEPTEMBER 1968

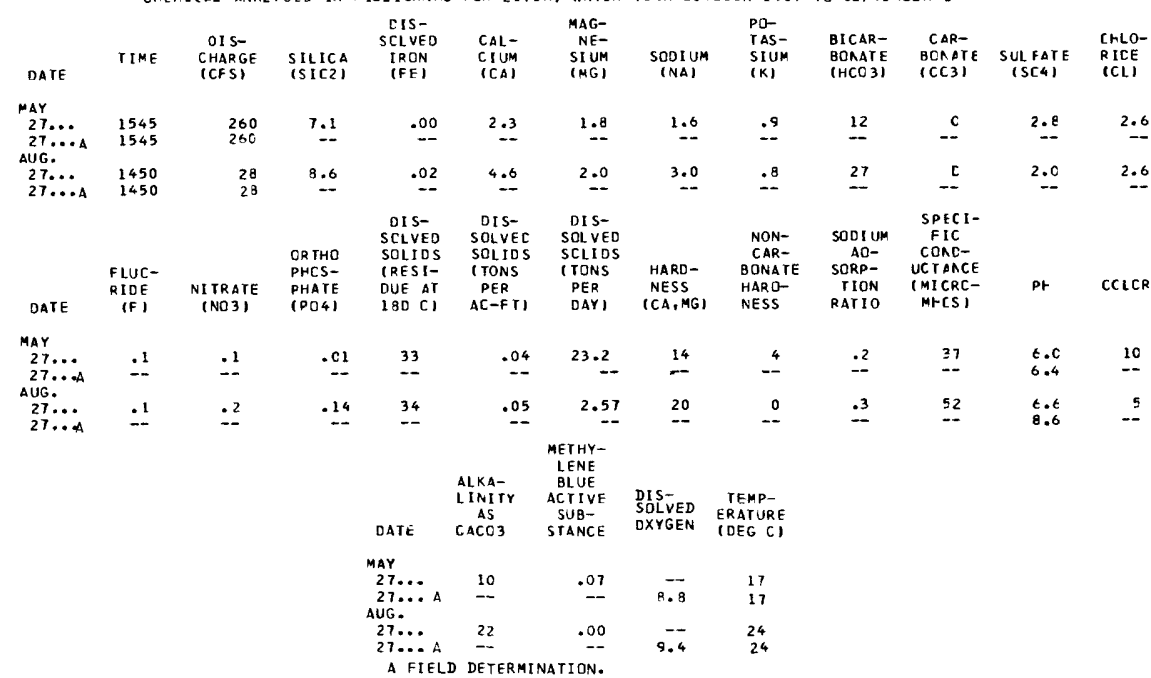


03481000 ELK RIVER NEAR ELK PARK, N.C.

LOCATION.--Lat $36^{\circ} 11^{\circ} 01^{\prime \prime}$, long $81^{\circ} 57^{\circ} 45^{\prime \prime}$, Avery County, 0.3 mile domstream from Skalley creek and 2.0 miles northeast of E1k Park.

DRA INAGE AREA, - -42.0 sq $\mathrm{mi}$.

PERIOD OF RECORD.--Chemical analyses: October 1967 to September 1968.

CHEMICAL ANALYSES IN MILLIGRAMS PER LITER, WATER YEAR CCTCBER 1967 TO SEPTEMBER 1968

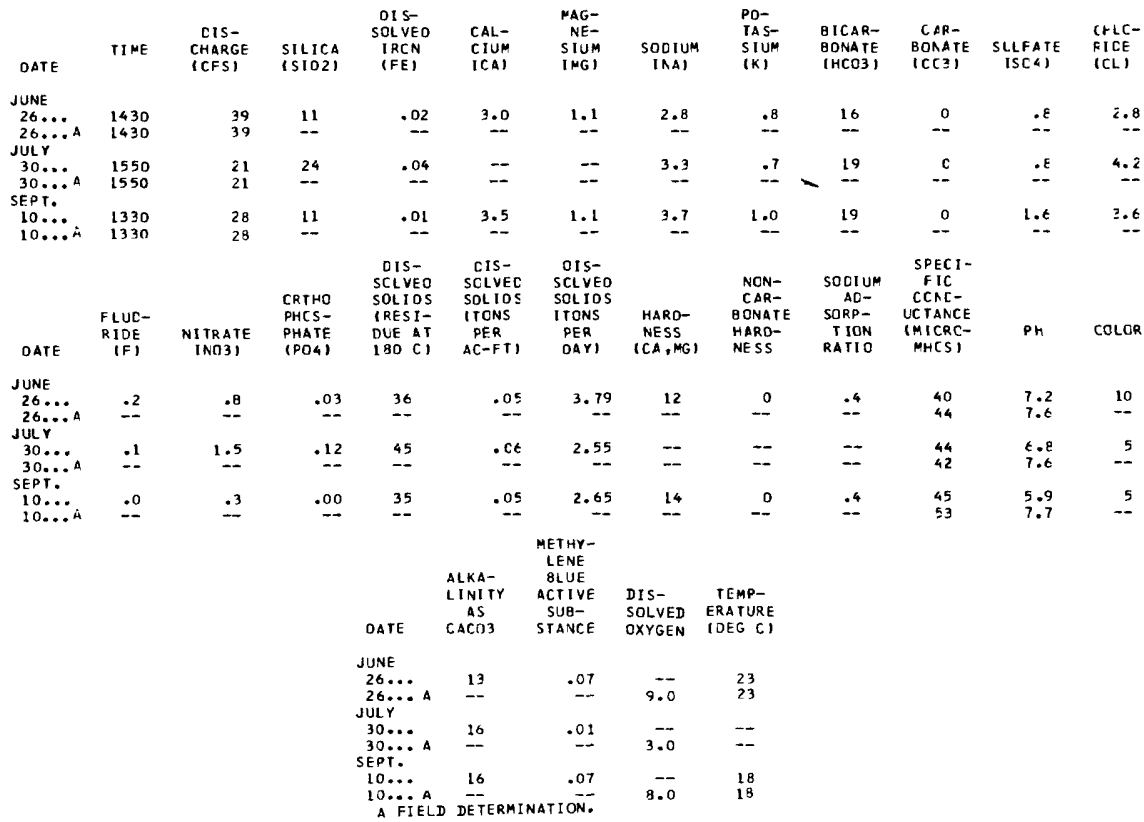

03500000 LITTLE TENNESSEE RIVER NEAR PRENTISS, N.C.

LOCATION.--Lat $35^{\circ} 08^{\prime} 57^{\prime \prime}$, long $83^{\circ} 22^{\prime} 46^{\prime \prime}$, Macon County, at gaging station on left bank 600 ft upstream from Owensby

Branch, 0.5 mile upstream from Cartoogechaye Creek, 2 miles north of Prentiss, and at mile 119.5 .

DRAINAGE AREA. --140 sq $\mathrm{mi}$,

PER IOD OF RECORD.--Chemical analyses: October 1952 to September 1953, October 1967 to September 1968.

Nater temperatures: October 1952 to September 1953.

CHEMICAL ANALYSES IN MILLIGRAMS PER LITER, HATER YEAR OC TOBER 1967 TC SEPTEMBER 1968

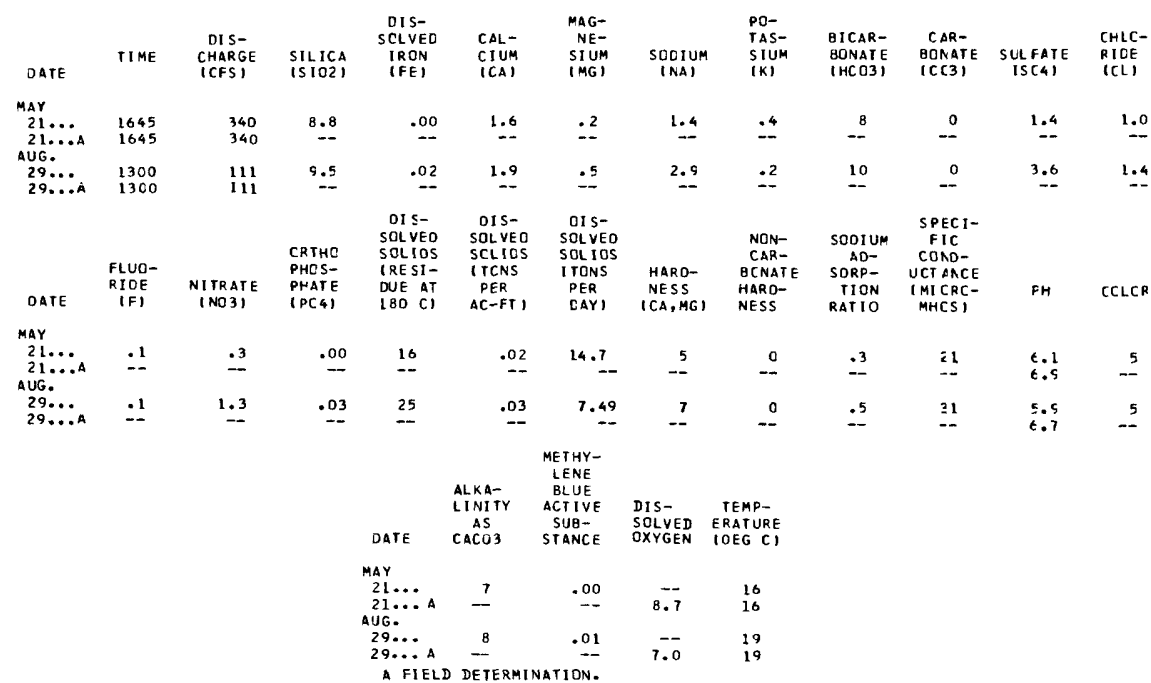


03500240 CARTOOGECHAYE CREEK NEAR FRANKLIN, N.C.

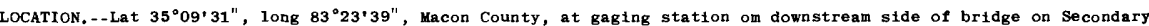
Road $1152,0.1$ mtle downstream from unnamed creek, 1.8 mtles south of Franklin, and 1.9 miles upstream from mouth. DRAINAGE AREA., $-57,1 \mathrm{sq} \mathrm{mi}$

PERIOD OF RECORD. -.-Chentcal ana1yses: October 1967 to September 1968.

REXARKs.--Records furnished by Tennessee Valley Authority.

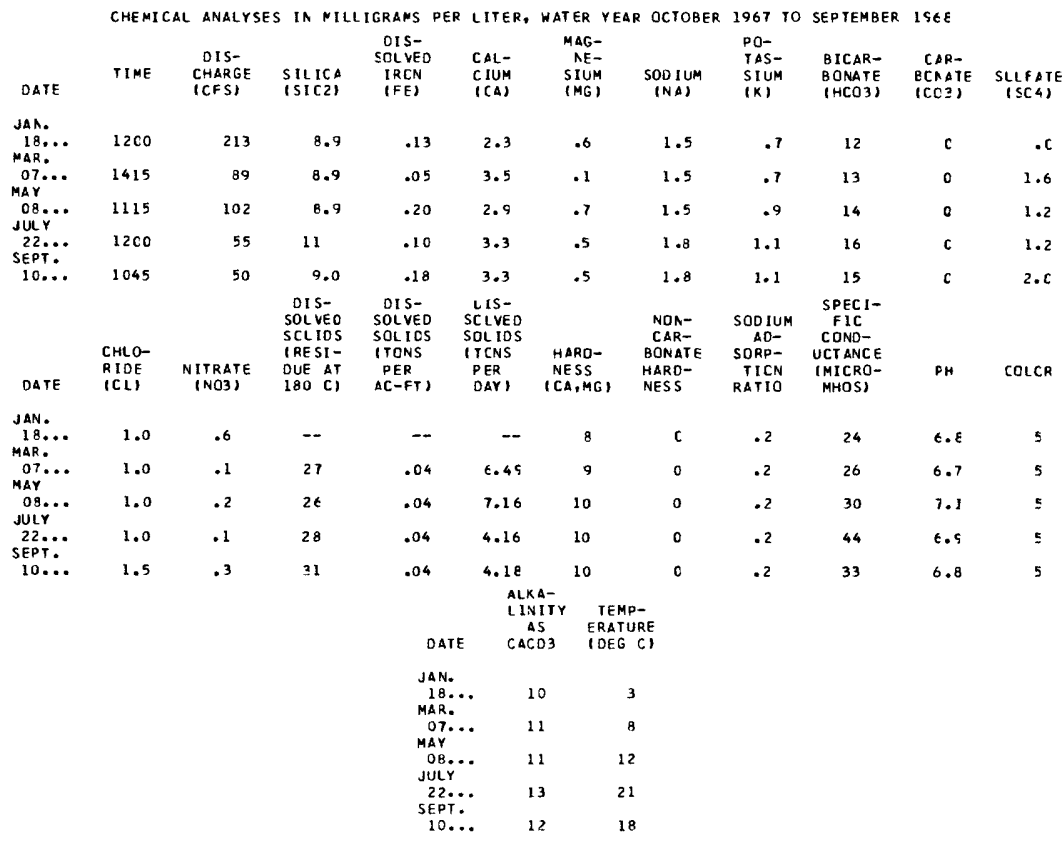

03501000 CULLASAJA RIVER AT CULLASAJA, N.C.

LOCATION, --Lat $35^{\circ} 09^{\prime} 59^{\prime \prime}$, long $83^{\circ} 19^{\prime} \mathbf{2 5}^{\prime \prime}$, Macon County, at gaging station on right bank at Cullasa ja, $150 \mathrm{ft}$ upstream from bridge on U.S. Highway 64, 1.4 miles downstream from Ellijay Creek, and 4.1 miles upstream from mouth.

DRAINAGE AREA.--86.5 sq $\mathrm{mt}$.

PERIOD OF RECORD, --Chemical analyses: October 1954 to September 1956, October 1967 to September 1968.

REMRKS.--Records furnished by Tennessee valley Authority.

\begin{tabular}{|c|c|c|c|c|c|c|c|c|c|c|c|}
\hline DATE & CHEMICAL & $\begin{array}{l}\text { ANALYSES } \\
\text { CIS- } \\
\text { CHARGE } \\
\text { (CFS) }\end{array}$ & $\begin{array}{l}\text { SILICA } \\
\text { (SIO2) }\end{array}$ & $\begin{array}{l}\text { IGRAMS PER } \\
\text { DIS- } \\
\text { SOL VED } \\
\text { IRCN } \\
\text { (FE) }\end{array}$ & $\begin{array}{l}\text { LITER, } \\
\text { CAL- } \\
\text { CIUM } \\
\text { (CA) }\end{array}$ & $\begin{array}{l}\text { WATER YEAR } \\
\text { MAG- } \\
\text { NE- } \\
\text { SIUMM } \\
\text { (MG) }\end{array}$ & $\begin{array}{l}\text { SOOLUM } \\
\text { INA) }\end{array}$ & $\begin{array}{l}1967 \text { 10 } \\
\text { PO- } \\
\text { IAS- } \\
\text { SIUM } \\
\text { (K) }\end{array}$ & $\begin{array}{l}\text { SEPTEMBER } \\
\text { BICAR- } \\
\text { BONATE } \\
\text { (HCO3) }\end{array}$ & $\begin{array}{l}1968 \\
\text { CAR- } \\
\text { BONATE } \\
\text { (CC3) }\end{array}$ & $\begin{array}{l}\text { SLLFATE } \\
\text { ISC 4) }\end{array}$ \\
\hline $\begin{array}{l}\text { NOV. } \\
\text { O6... } \\
\text { JAR. }\end{array}$ & 1430 & 238 & $6 . C$ & .06 & 1.9 & .1 & 1.2 & .6 & 8 & 0 & $1, \mathrm{c}$ \\
\hline MAR... & 1415 & 329 & 6.2 & .06 & 2.3 & .0 & 1.3 & .0 & 5 & c & $1 . \varepsilon$ \\
\hline$\underset{\operatorname{ma}}{07}$ & 1545 & 133 & 4.2 & .05 & 2.5 & .1 & 1.5 & .5 & 10 & 0 & 1.6 \\
\hline JULY... & 1245 & 173 & 6.7 & .04 & 1.9 & .3 & 1.2 & .7 & 8 & 0 & $2 \cdot c$ \\
\hline $\begin{array}{l}\text { D5... } \\
\text { SEPI. }\end{array}$ & 1040 & 104 & 7.4 & .12 & 2.5 & .0 & 1.4 & .7 & 10 & C & 1.2 \\
\hline $10 \ldots$ & 1200 & 75 & 4.7 & .11 & 1.9 & .6 & 1.6 & 1.1 & 12 & 0 & 1.6 \\
\hline DATE & $\begin{array}{l}\text { CHLO- } \\
\text { RIOE } \\
\text { (CL) }\end{array}$ & $\begin{array}{l}\text { NITRA TE } \\
\text { (NO3) }\end{array}$ & $\begin{array}{l}\text { OIS- } \\
\text { SCLVEO } \\
\text { SOLIOS } \\
\text { (RESI- } \\
\text { DUE AT } \\
\text { I8O C) }\end{array}$ & $\begin{array}{l}\text { DIS- } \\
\text { SOLVED } \\
\text { SOLIDS } \\
\text { (TOAS } \\
\text { PER } \\
\text { AC-FT) }\end{array}$ & $\begin{array}{l}\text { CIS- } \\
\text { SCLLED } \\
\text { SOLIDS } \\
\text { ITCNS } \\
\text { PER } \\
\text { DAYI }\end{array}$ & $\begin{array}{l}\text { HARD- } \\
\text { NESS } \\
(\mathrm{CA}, \mathrm{MG})\end{array}$ & $\begin{array}{l}\text { NON- } \\
\text { CAR- } \\
\text { BONATE } \\
\text { HARO- } \\
\text { NESS }\end{array}$ & $\begin{array}{l}\text { SOCIUM } \\
\text { AD- } \\
\text { SORP- } \\
\text { TION } \\
\text { RATIO }\end{array}$ & $\begin{array}{l}\text { SPECI- } \\
\text { FIC } \\
\text { COND- } \\
\text { UCTANCE } \\
\text { (MICRO- } \\
\text { MHOS) }\end{array}$ & PH & COLCR \\
\hline $\begin{array}{l}\text { NOV. } \\
\text { O6.... } \\
\text { JAN. }\end{array}$ & 1.0 & .0 & -- & - & -- & 5 & 0 & .2 & 17 & 6.6 & 5 \\
\hline $\begin{array}{l}18 . . . \\
\text { MAR. }\end{array}$ & 1.5 & .1 & 15 & .02 & 13.3 & 5 & 1 & .2 & 18 & $c .7$ & 5 \\
\hline$\underset{\text { MAY }}{07 \cdots}$ & 1.0 & $\cdot 1$ & 20 & .03 & 7.18 & 6 & 0 & .3 & 20 & 6.5 & 5 \\
\hline Juir... & 1.0 & .0 & 15 & .02 & 7.01 & 6 & C & .2 & 21 & 6.7 & 5 \\
\hline $\begin{array}{l}05 \ldots . \\
\text { SEPT. }\end{array}$ & 1.0 & .2 & 13 & .02 & 3.65 & 6 & 0 & .2 & 23 & 6.6 & 5 \\
\hline $10 \ldots$ & 1.0 & 1 & $2 c$ & .03 & 4.05 & 7 & 0 & .3 & 27 & 6.5 & 5 \\
\hline
\end{tabular}


03501000 CULLASAJA RIVER AT CULLASAJA, N.C.--Cont1nued

CHEMICAL ANALYSES IN MILLIGRAMS PER LITER, WATER YEAR OCTOBER 1967 TO SEPTEMBER 1968

\begin{tabular}{|c|c|c|}
\hline DATE & $\begin{array}{l}\text { ALKA- } \\
\text { LINITY } \\
\text { AS } \\
\text { CACO3 }\end{array}$ & $\begin{array}{l}\text { TEMP- } \\
\text { ERATURE } \\
\text { (DEG C) }\end{array}$ \\
\hline $\begin{array}{l}\text { Nov. } \\
\text { 06... }\end{array}$ & 7 & 6 \\
\hline JAN. & & \\
\hline $\begin{array}{l}18 \ldots . . \\
\text { MAR. }\end{array}$ & 4 & 4 \\
\hline $07 .$. & 8 & 7 \\
\hline MAY & & \\
\hline$\underset{\text { JULY... }}{08 . .}$ & 7 & 12 \\
\hline $\begin{array}{l}05 . . \\
\text { SEPT. }\end{array}$ & 8 & 17 \\
\hline $10 \ldots$ & 10 & 18 \\
\hline
\end{tabular}

03503000 LITTLE TENNESSEE RIVER AT NEEDMORE, N.C.

LOCATION,--Lat $35^{\circ} 20^{\prime} 11^{\prime \prime}$, long $83^{\circ} 31^{\prime} 39^{\prime \prime}$, Swain County, at gaging station on left bank 0.8 mile downstream from DeHart Creek, $0.8 \mathrm{mile}$ north of Needmore, $2.4 \mathrm{miles}$ domstream from Brush Creek, $6.3 \mathrm{miles}$ downstream from Tellico Creek, and at mile 92,9 .

DRAINAGE AREA. $--436 \mathrm{sq} \mathrm{mi}$.

PERIOD OF RECORD, --Chemical analyses: October 1967 to September 1968.

CHFMICAL ANALYSES IN MILLIGRAMS PER LITER, WATER YEAR OCTOBER 1967 TO SEPTEMBER 1968

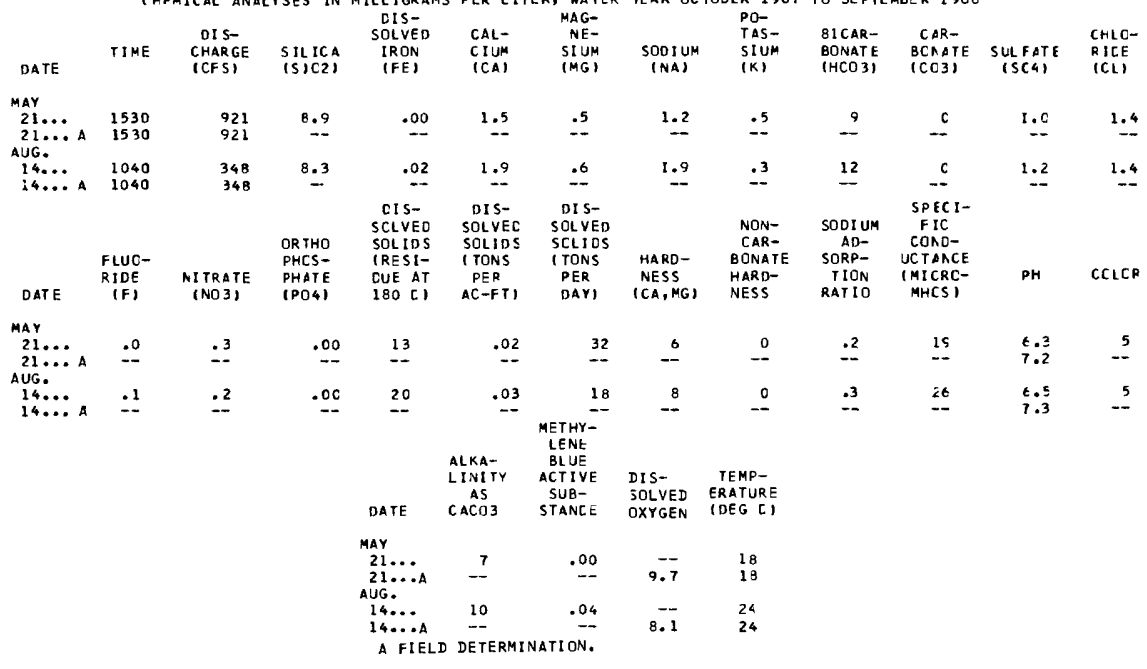

03504000 NANTAHALA RIVER NEAR RAINBOW SPRINGS, N.C.

LOCATION.--Lat $35^{\circ} 07^{\prime} 35^{\prime \prime}$, long $83^{\circ} 37^{\prime} 11^{\prime \prime}$, Macon County, at gaging station on right bank on Nantahala Forest Service Road, $300 \mathrm{ft}$ upstream from Roaring Fork, 0.2 mile downstream from Buck Creek, 5 miles downstream from town of Rainbow Springs, and at mile 34,3 .

DRAINAGE AREA. $--51.9 \mathrm{sq} \mathrm{mi}$.

PER IOD OF RECORD,--Chemical analyses: October 1967 to September 1968.

CHEMICAL ANALYSES IN MILLIGRAMS PER LITER, WATER YEAP CCTOBER 1967 TO SEPTEMBER $196 \mathrm{~B}$

\begin{tabular}{|c|c|c|c|c|c|c|c|c|c|c|c|}
\hline DATE & TINE & $\begin{array}{l}\text { CIS- } \\
\text { CHARGE } \\
\text { (CFS) }\end{array}$ & $\begin{array}{l}\text { SILICA } \\
\text { (SIOL2) }\end{array}$ & $\begin{array}{l}\text { DIS- } \\
\text { SOL VED } \\
\text { IRCN } \\
\text { (FE) }\end{array}$ & $\begin{array}{l}\text { CAL- } \\
\text { CIUM } \\
\text { (CA) }\end{array}$ & $\begin{array}{l}\text { MAG- } \\
\text { NE- } \\
\text { SIUM } \\
\text { (MG) }\end{array}$ & $\begin{array}{l}\text { SOD IUM } \\
\text { (NA) }\end{array}$ & $\begin{array}{l}\text { PO- } \\
\text { TAS- } \\
\text { SIUM } \\
\text { (K) }\end{array}$ & $\begin{array}{l}\text { B ICAR- } \\
\text { BONATE } \\
\text { (HCO3) }\end{array}$ & $\begin{array}{c}\text { CAR- } \\
\text { BONATE } \\
\text { (CC3) }\end{array}$ & $\begin{array}{l}\text { SLLFA IE } \\
\text { (SC4) }\end{array}$ \\
\hline $\begin{array}{l}\text { JAN. } \\
11 . . . \\
\text { MAR. }\end{array}$ & 1500 & 654 & 4.6 & .02 & 1.7 & .0 & .7 & .0 & 6 & 0 & 1.2 \\
\hline MAY 08 & 1100 & 104 & 5.5 & .00 & 2.1 & .5 & .9 & .5 & 9 & c & 1.8 \\
\hline JULY & 1500 & 309 & 4.8 & .07 & 2.1 & .3 & .9 & .7 & B & 0 & 1.2 \\
\hline SEPT. & 1200 & B5 & 6.5 & .04 & 2.1 & .0 & .8 & .7 & 8 & 0 &.$t$ \\
\hline $20 \ldots$ & 1410 & 115 & 5.7 & .07 & 1.7 & .1 & .8 & .6 & 5 & c & $2 . c$ \\
\hline
\end{tabular}


03504000 NANTAHALA RIVER NEAR RAINBOW SPRINGS, N.C.--Continued CHEMICAL ANALYSES IN MILLIGRAMS PER LITER, WATER YEAR OCTOBER 1967 TO SEPTEMBER 2968

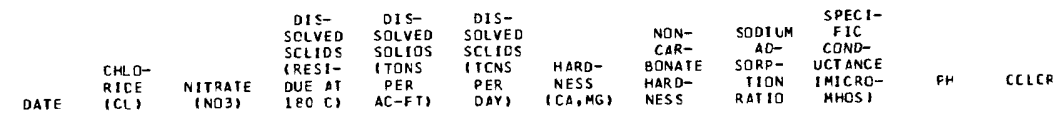

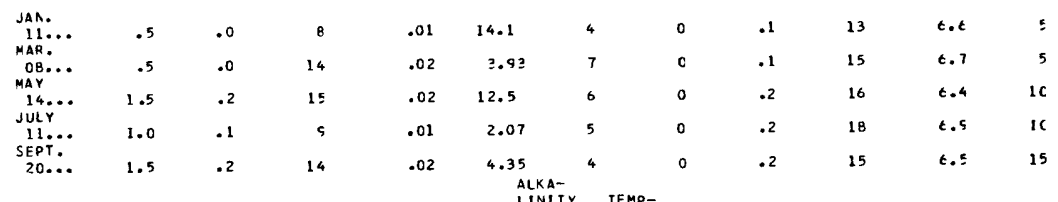

$$
\begin{aligned}
& \begin{array}{cc}
\text { ALKA- } & \\
\text { LINITY } & \text { TEMP- } \\
\text { AS } & \text { ERATURE } \\
\text { DATE CACO3 } & \text { IOEG CI }
\end{array}
\end{aligned}
$$

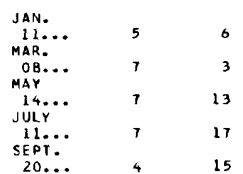

LOCATION,--Lat $35^{\circ} 17^{\prime} 55^{\prime \prime}$, long $83^{\circ} 39^{\prime} 22^{\prime \prime}$, Swain County, at gaging station on left bank on U.S. Highway 19, 1.0 mile northeast of Nantahala, 2.3 miles downstream from Rowlin Creek, 2.8 miles downstream from Nantahala Dam powernortheast of Nantahala,
house, and at mile 10.8 .

DRAINAGE AREA, --144 sq mt.

PERIOD OF RECORD.--Chemical analyses: October 2967 to September 1968.

ChEMICAL ANALYSES IN MILLIGRAMS PER LITER, MATER YEAR OC TOBER 196T TC SEPTEMBER 19EB

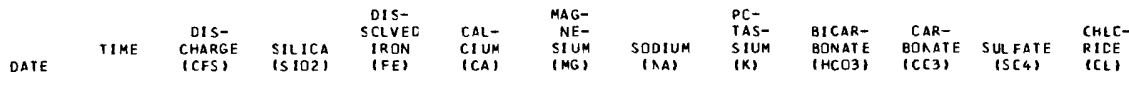

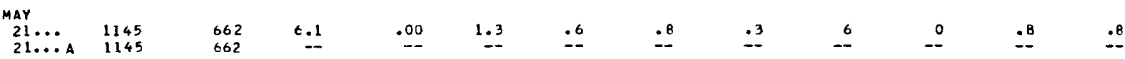

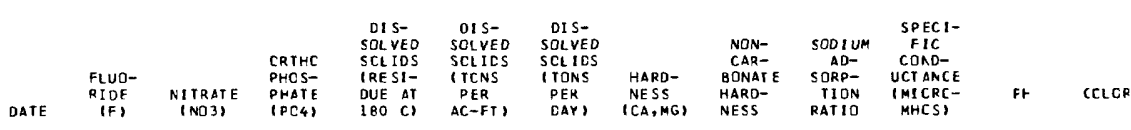

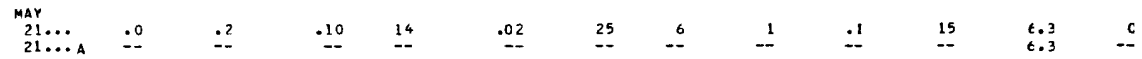

$$
\begin{aligned}
& \begin{array}{cccc}
\multicolumn{4}{c}{\text { METHY- }} \\
\text { LENE } \\
\text { ALKA- } & \text { BLUE } & \\
\text { LINITY } & \text { ACTIVE } & \text { DIS- } & \text { TEMP- } \\
\text { DAS } & \text { SUB- } & \text { SOLVED ERATURE } \\
\text { CACT3 } & \text { STANCE } & \text { OXYGEN TOEG CI }
\end{array}
\end{aligned}
$$

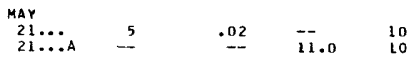

03517533 LITTLE TENNESSEE RIVER AT TAPOCO, N.C. LOCATION,--Lat $35^{\circ} 27^{\prime} 01^{\prime \prime}$, long $83^{\circ} 56^{\prime} 31^{\prime \prime}$, Graham County, at bridge on U.S. Kighway $129,0.2$ mile downstream from
Cheoph River, and 0.4 mile north of Tapoco.

DRAINAGE AREA. --1,823 sq m1.

\begin{tabular}{|c|c|c|c|c|c|c|c|c|c|c|c|c|}
\hline DATE & TI ME & $\begin{array}{l}\text { CIS- } \\
\text { CHARGE } \\
\text { (CFS) }\end{array}$ & $\begin{array}{l}\text { SILICA } \\
\text { ISIC2I }\end{array}$ & $\begin{array}{l}\text { DIS- } \\
\text { SOLVED } \\
\text { IRCN } \\
\text { (FE) }\end{array}$ & $\begin{array}{l}\text { CAL- } \\
\text { CIUM } \\
\text { (CA) }\end{array}$ & $\begin{array}{l}\text { MAG- } \\
\text { NE- } \\
\text { SIUM } \\
\text { IMG }\end{array}$ & $\begin{array}{l}\text { SODIUM } \\
\text { (NA) }\end{array}$ & $\begin{array}{l}\text { PO- } \\
\text { TAS- } \\
\text { SIUM } \\
\text { (K) }\end{array}$ & $\begin{array}{l}\text { BICAR- } \\
\text { BONATE } \\
\text { IHCO3) }\end{array}$ & $\begin{array}{l}\text { CARE } \\
\text { BOAAIE } \\
\text { (CCB) }\end{array}$ & $\begin{array}{l}\text { SLLFATE } \\
\text { (SO4) }\end{array}$ & $\begin{array}{l}\text { CrLO- } \\
\text { FICE } \\
\text { (CL) }\end{array}$ \\
\hline \multicolumn{13}{|l|}{ MAY } \\
\hline $\begin{array}{l}21 \ldots A \\
21 \ldots A\end{array}$ & $\begin{array}{l}1325 \\
1325\end{array}$ & $\begin{array}{r}2880 \\
2880\end{array}$ & 7.1 & .00 & 1.6 & .5 & 1.5 & .5 & 7 & c & 2.4 & 1.0 \\
\hline AUG. & & & & & & & & & 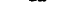 & - & 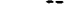 & \\
\hline $\begin{array}{l}14 \ldots \\
14 \ldots A\end{array}$ & $\begin{array}{l}1500 \\
1500\end{array}$ & $\begin{array}{l}7930 \\
7930\end{array}$ & $t .4$ & .02 & 1.6 & $: 3$ & 1.4 & .5 & $\begin{array}{r}5 \\
--\end{array}$ & $\therefore$ & 2.8 & 1.4 \\
\hline
\end{tabular}

PERIOD OF RECORD. -Chemical analyses: October 1967 to September 1968.

CHFMICAL ANALYSES IN MILLIGRANS PER LIIER, HATER YEAR OCTOBER 1967 TO SEPTEMBER 1 SER 
03517533 LITTLE TENNESSEE RIVER AT TAPOCO, N.C.--Continued

CHEMICAL ANALYSES IN MILLIGRAMS PER LITER, WATER YEAR OCTOBER 1967 TO SEPTEMBER 1968

\begin{tabular}{|c|c|c|c|c|c|c|c|c|c|c|c|c|}
\hline OATE & $\begin{array}{l}\text { FLUO- } \\
\text { RIDE } \\
\text { (F) }\end{array}$ & $\begin{array}{l}\text { N ITRATE } \\
\text { (NO3) }\end{array}$ & $\begin{array}{l}\text { CRTHO } \\
\text { PHCS } \\
\text { PHATE } \\
\text { (PO4) }\end{array}$ & $\begin{array}{l}\text { OIS- } \\
\text { SOL VED } \\
\text { SOL IDS } \\
\text { IRESI- } \\
\text { DUE AT } \\
\text { IBO CI }\end{array}$ & $\begin{array}{l}\text { OIS- } \\
\text { SOLVEO } \\
\text { SOLIOS } \\
\text { ITCNS } \\
\text { PER } \\
\text { AC-FT I }\end{array}$ & $\begin{array}{l}\text { DIS- } \\
\text { SCLVED } \\
\text { SOLIOS } \\
\text { (TONS } \\
\text { PER } \\
\text { DAY) }\end{array}$ & $\begin{array}{l}\text { HARD- } \\
\text { NESS } \\
\text { (CA,MG) }\end{array}$ & $\begin{array}{l}\text { NON- } \\
\text { CAR- } \\
\text { BONATE } \\
\text { HARD- } \\
\text { NESS }\end{array}$ & $\begin{array}{l}\text { SODIUM } \\
\text { AD- } \\
\text { SORP- } \\
\text { TIUN } \\
\text { RATIOO }\end{array}$ & $\begin{array}{l}\text { SPECI- } \\
\text { FIC } \\
\text { CCAC- } \\
\text { UCTANCE } \\
\text { IMICRC- } \\
\text { MHCSI }\end{array}$ & $\mathrm{Ph}$ & CGLOR \\
\hline \multirow{10}{*}{$\begin{array}{l}\text { MAY } \\
21 \ldots . \\
21 \ldots A \\
\text { AUG.. } \\
14 \ldots . . \\
14 \ldots \text { A }\end{array}$} & & & & & & & & & & & & \\
\hline & .0 & .5 & .00 & 18 & .02 & 140 & 6 & 1 & .3 & 23 & 6.2 & 5 \\
\hline & -- & $\cdots$ & + & - & -- & - & $\cdots$ & $\rightarrow$ & - & -- & 6.3 & -- \\
\hline & .0 & 1.1 & .00 & 18 & .02 & 385 & 6 & 0 & .3 & 23 & 5.7 & 5 \\
\hline & -- & $\cdots$ & -- & - & - & 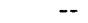 & $=$ & - & $=$ & -- & $t .1$ & -- \\
\hline & & & & DATE & $\begin{array}{l}\text { ALKA- } \\
\text { LINITY } \\
\text { AS } \\
\text { CACח3 }\end{array}$ & $\begin{array}{l}\text { METHY- } \\
\text { LENE } \\
\text { BLUE } \\
\text { ACTIVE } \\
\text { SUB- } \\
\text { STANCE }\end{array}$ & $\begin{array}{l}\text { DIS- } \\
\text { SOLVED } \\
\text { OXYGEN }\end{array}$ & $\begin{array}{l}\text { TEMP- } \\
\text { ERATURE } \\
\text { (DEG C) }\end{array}$ & & & & \\
\hline & & & & MAY & & & & & & & & \\
\hline & & & & $21 \ldots$ & 6 & .04 & - & 11 & & & & \\
\hline & & & & $\begin{array}{l}21 \ldots A \\
\text { AUG. }\end{array}$ & - & - & 10.0 & 11 & & & & \\
\hline & & & & $\begin{array}{l}14 \ldots \\
14 \ldots .\end{array}$ & - & .01 & 7.5 & $\begin{array}{l}14 \\
14\end{array}$ & & & & \\
\hline & & & & A FIEL & DETE & ION. & & & & & & \\
\hline
\end{tabular}

03547000 HIWASSEE RIVER BELOW CHATUGE DAM, NEAR HAYESVILLE, N.C.

LOCATION,--Lat $35^{\circ} 01^{\prime} 45^{\prime \prime}$, long $83^{\circ} 47^{\prime} 45^{\prime \prime}$, Clay County, at gaging station on left bank 0.3 mile downstream from bridge on Secondary Road $1146,0.4$ mile upstream from Hyatt Mill Creek, 1.6 miles southeast of Hayesville, 1.7 miles downstream from Chatuge Dam, and at mile 119,3 .

DRAINAGE AREA. $-\mathbf{- 1 9 0} \mathrm{sq} \mathrm{mi}$.

PERIOD OF RECORD.--Chemical analyses: October 1946 to September 1947, October 1967 to September 1968.

CHEMICAL ANAIYSES IA MILLIGRAMS PER LITER, WATER YEAR OC TOBER 1967 to SEPTEMBER 1 SEE

\begin{tabular}{|c|c|c|c|c|c|c|c|c|c|c|c|c|}
\hline DATE & TIME & $\begin{array}{l}\text { DIS- } \\
\text { CHARGE } \\
\text { (CFS) }\end{array}$ & $\begin{array}{l}\text { SILICA } \\
\text { (SIC2) }\end{array}$ & $\begin{array}{l}\text { OIS- } \\
\text { SCLVED } \\
\text { IRON } \\
\text { IFEI }\end{array}$ & $\begin{array}{l}\text { CAL- } \\
\text { CIUM } \\
\text { (CA) }\end{array}$ & $\begin{array}{l}\text { MAG- } \\
\text { NE- } \\
\text { SI UM } \\
\text { I MGI }\end{array}$ & $\begin{array}{l}\text { SOOI UM } \\
\text { (NA) }\end{array}$ & $\begin{array}{l}\text { PO- } \\
\text { TAS - } \\
\text { SIUM } \\
\text { (K) }\end{array}$ & $\begin{array}{l}\text { B ICAR- } \\
\text { BONATE } \\
\text { (HCO 3) }\end{array}$ & $\begin{array}{l}\text { CAR- } \\
\text { BCAATE } \\
\text { (CCB) }\end{array}$ & $\begin{array}{l}\text { SULFATE } \\
\text { (SC4) }\end{array}$ & $\begin{array}{l}\text { CHLO- } \\
\text { FICE } \\
\text { (CLI }\end{array}$ \\
\hline $\begin{array}{l}\text { JURE } \\
03 \ldots \ldots \text { A } \\
03 \ldots \ldots \text { A }\end{array}$ & $\begin{array}{l}0915 \\
0915\end{array}$ & $\begin{array}{l}1290 \\
1290\end{array}$ & 6.5 & .00 & 1.4 & $\therefore 2$ & 1.0 & .5 & $\begin{array}{r}7 \\
--\end{array}$ & $\begin{array}{c}c \\
--\end{array}$ & $\varepsilon$ & $\because 4$ \\
\hline $\begin{array}{l}\text { AUG. } \\
13 . . . \\
13 \ldots \text { A }\end{array}$ & $\begin{array}{l}1225 \\
1225\end{array}$ & $\begin{array}{l}1280 \\
1280\end{array}$ & 6.8 & .01 & 1.1 & .7 & 1.2 & .5 & -9 & -0 & 1.2 & 1.4 \\
\hline OATE & $\begin{array}{l}\text { FLUC- } \\
\text { RIDE } \\
\text { (F) }\end{array}$ & $\begin{array}{l}\text { NI IRATE } \\
\text { (NO3) }\end{array}$ & $\begin{array}{l}\text { OR THO } \\
\text { PHOS- } \\
\text { PHA IE } \\
\text { (PO4) }\end{array}$ & $\begin{array}{l}\text { DIS- } \\
\text { SCLVED } \\
\text { SOLIDS } \\
\text { IRES 1- } \\
\text { DUE AT } \\
\text { L80 CI }\end{array}$ & $\begin{array}{l}\text { DIS- } \\
\text { SOLVEC } \\
\text { SOLIOS } \\
\text { (IONS } \\
\text { PER } \\
\text { AC-FT) }\end{array}$ & $\begin{array}{l}\text { DIS- } \\
\text { SOLVEO } \\
\text { SCLIDS } \\
\text { I TONS } \\
\text { PER } \\
\text { DAY I }\end{array}$ & $\begin{array}{l}\text { HARD- } \\
\text { NESS } \\
(C A, M G)\end{array}$ & $\begin{array}{l}\text { NON- } \\
\text { CAR- } \\
\text { BDNA TE } \\
\text { HARD- } \\
\text { NESS }\end{array}$ & $\begin{array}{c}\text { SODIUM } \\
\text { AD- } \\
\text { SOKP- } \\
\text { TIDN } \\
\text { RATIO }\end{array}$ & $\begin{array}{l}\text { SPECI- } \\
\text { FIC } \\
\text { CCAD- } \\
\text { UCTAACE } \\
\text { (MICRD- } \\
\text { MHCS }\end{array}$ & PH & COLOR \\
\hline $\begin{array}{l}\text { JUNE } \\
03 \ldots . \\
03 \ldots \text { A }\end{array}$ & $\therefore$ & .7 & .00 & 11 & 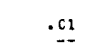 & 38 & -4 & $\begin{array}{r}0 \\
--\end{array}$ & .2 & 19 & $\begin{array}{l}6.1 \\
6.2\end{array}$ & -0 \\
\hline $\begin{array}{l}A \cup G \\
13 \ldots . \\
13 \ldots \text {. }\end{array}$ & $\therefore$ & $\therefore$ & .00 & 18 & $\begin{array}{l}\text { ALKA- } \\
\text { LINI TY } \\
\text { AS } \\
C A C{ }_{3}\end{array}$ & $\begin{array}{l}62 \\
\text { METHY- } \\
\text { LENE } \\
\text { BLUE } \\
\text { ACTIVE } \\
\text { SUB- } \\
\text { STANCE }\end{array}$ & $\begin{array}{l}\text { DIS- } \\
\text { SOLVED } \\
\text { OXYGEN }\end{array}$ & $\begin{array}{l}\text { TEMP- } \\
\text { ERATURE } \\
\text { IDEG CI }\end{array}$ & $\therefore 2$ & 19 & $\begin{array}{l}6.5 \\
6.1\end{array}$ & -5 \\
\hline
\end{tabular}

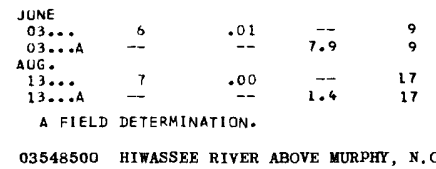

LOCATION,-Lat $35^{\circ} 04^{\prime} 50^{\prime \prime}$, long $84^{\circ} 00^{\prime} 10^{\prime \prime}$. Cherokee County, at gaging station on right bank on U.S, Highway 64 , $600 \mathrm{ft}$ upstream from Will Scott Creek, and 2 miles east of Murphy, and at mile 99.1 . DRAINAGE AREA. --406 sq $\mathrm{mi}$.

PERIOD OF RECORD. --Chemical analyses: October 1946 to September 1947, October 1967 to September 1968.

CHEMICAL analYSES IN MILLIGRAMS PER LITER, hater Year OC TOBER 1967 TC SEPTEMBER 1968

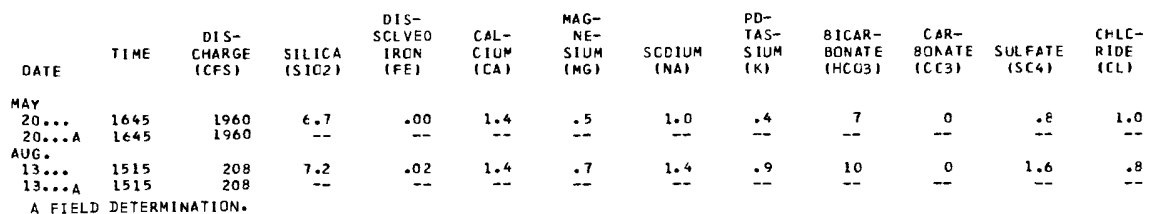


03548500 HIWASSEE RIVER ABOVE YURPHY, N.C.--Cont inued

CHEMICAL ANALYSES IN MILLIGRAMS PER LITER, WATER YEAR OCTOBER 1967 TO SEPTEMBER 1968

\begin{tabular}{|c|c|c|c|c|c|c|c|c|c|c|c|c|}
\hline DATE & $\begin{array}{l}\text { FLUD- } \\
\text { RICE } \\
\text { (F) }\end{array}$ & $\begin{array}{l}\text { NITRATE } \\
\text { (NO3) }\end{array}$ & $\begin{array}{l}\text { CRTHC } \\
\text { PHDS- } \\
\text { PHATE } \\
\text { IPC4) }\end{array}$ & $\begin{array}{l}\text { DI S- } \\
\text { SOLVED } \\
\text { SCLIDS } \\
\text { (RESI - } \\
\text { DUE AT } \\
180 \mathrm{CI}\end{array}$ & $\begin{array}{l}\text { DIS- } \\
\text { SOLVED } \\
\text { SCLIDS } \\
\text { I TCNS } \\
\text { PER } \\
\text { AC-FT I }\end{array}$ & $\begin{array}{l}\text { DI S- } \\
\text { SOL VED } \\
\text { SCL IOS } \\
\text { I TONS } \\
\text { PER } \\
\text { DAY) }\end{array}$ & $\begin{array}{l}\text { HARD- } \\
\text { NESS } \\
(C A, M G)\end{array}$ & $\begin{array}{l}\text { NON- } \\
\text { CAR- } \\
\text { BCNAIE } \\
\text { HARO- } \\
\text { NESS }\end{array}$ & $\begin{array}{l}\text { SODIUM } \\
\text { AD- } \\
\text { SORP- } \\
\text { TION } \\
\text { RATIO }\end{array}$ & $\begin{array}{l}\text { SPECI- } \\
\text { FIC } \\
\text { COAD- } \\
\text { UCTAACE } \\
\text { INICRC- } \\
\text { MHCSI }\end{array}$ & Fr & CCLCR \\
\hline $\begin{array}{l}\text { MAY } \\
20 . . . \\
20 . . \text { A } \\
\text { AUG. }\end{array}$ & $=0$ & -3 & .02 & 18 & .02 & 95 & -2 & 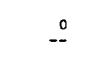 & $\therefore 2$ & Is & $\begin{array}{l}t=c \\
t \neq 1\end{array}$ & -- \\
\hline $\begin{array}{l}\text { AUG. } \\
13 \ldots \ldots \\
13 \ldots \text { A }\end{array}$ & $\therefore 0$ & .5 & .00 & 18 & .02 & 10 & $\begin{array}{l}7 \\
-\end{array}$ & 0 & $\therefore 2$ & 23 & $\begin{array}{l}t .2 \\
t .9\end{array}$ & -5 \\
\hline & & & & DATE & $\begin{array}{l}\text { ALKA- } \\
\text { LINITY } \\
\text { AS } \\
\text { CACO3 }\end{array}$ & $\begin{array}{l}\text { METHY- } \\
\text { LENE } \\
\text { BLUE } \\
\text { ACTIVE } \\
\text { SUB- } \\
\text { STANCE }\end{array}$ & $\begin{array}{l}\text { DIS- } \\
\text { SOLVED } \\
\text { OXYGEN }\end{array}$ & $\begin{array}{l}\text { TEMP- } \\
\text { ERATURE } \\
\text { IDEG CI }\end{array}$ & & & & \\
\hline & & & & $\begin{array}{l}\text { MAY } \\
20 \ldots . \\
20 \ldots \text { A } \\
\text { AUG.. } \\
13 \ldots \ldots \text { A } \\
13 \ldots \text { A } \\
\text { A FIEL }\end{array}$ & $\begin{array}{c}- \\
- \\
- \\
\text { DETERM }\end{array}$ & $\begin{array}{r}.00 \\
.- \\
.00 \\
-- \\
\text { NATION. }\end{array}$ & $\begin{array}{l}9.8 \\
-\overline{9.4}\end{array}$ & $\begin{array}{l}17 \\
17 \\
20 \\
20\end{array}$ & & & & \\
\hline
\end{tabular}

03550000 VALLEY RIVER AT TOMOTLA, N.C.

LOCATION.--Lat $35^{\circ} 08^{\prime} 20^{\prime \prime}$, long $8^{\circ} 58^{\prime} 50$, Cherokee County, at gaging station on right bank $15 \mathrm{ft}$ downstream from bridge on Secondary Road 1373 at Tomotla, 0.2 mile upstream from Rogers Creek, 4.7 m1les northeast of Murphy, and at mile 6,4 .

DRAINAGE AREA $=-104 \mathrm{sq} \mathrm{mt}$.

PERTOD OF RECORD.--Chemical analyses: October 1952 to September 1953, October 1967 to September 1968.

Viater temperatures: October 1952 to September 1953, October 1961 to September 1967.

CHENICAL ANALYSES IA NILLIGRAMS PER LITER, hater YeAR OCTOBER 1967 TO SEP TEmber ISEE

\begin{tabular}{|c|c|c|c|c|c|c|c|c|c|c|c|c|}
\hline DATE & TIME & $\begin{array}{l}\text { CIS- } \\
\text { CHARGE } \\
\text { ICFSI }\end{array}$ & $\begin{array}{l}\text { SItICA } \\
\text { ISIC2) }\end{array}$ & $\begin{array}{l}\text { OIS- } \\
\text { SDLVED } \\
\text { IRCN } \\
\text { (FE) }\end{array}$ & $\begin{array}{l}\text { CAL- } \\
\text { CIUMA } \\
\text { (CA) }\end{array}$ & $\begin{array}{l}\text { MAG- } \\
\text { NE- } \\
\text { SIUM } \\
\text { IMG }\end{array}$ & $\begin{array}{l}\text { SOOIUM } \\
\text { (AA) }\end{array}$ & $\begin{array}{l}\text { PO- } \\
\text { TAS- } \\
\text { SIUM } \\
\text { (K) }\end{array}$ & $\begin{array}{l}\text { EICAR- } \\
\text { BONATE } \\
\text { IHCO } 3 \text { I }\end{array}$ & $\begin{array}{l}\text { CAR- } \\
\text { BCAATE } \\
\text { ICCZI }\end{array}$ & $\begin{array}{c}\text { SLLFATE } \\
\text { (SOA) }\end{array}$ & $\begin{array}{l}\text { C+LO- } \\
\text { PICE } \\
\text { ICLI }\end{array}$ \\
\hline $\begin{array}{l}\text { Mar } \\
21 \ldots \ldots \\
21 \ldots \text { A }\end{array}$ & $\begin{array}{l}1025 \\
1025\end{array}$ & $\begin{array}{l}249 \\
249\end{array}$ & 7.0 & .00 & 3.5 & 1.2 & 1.1 & $\because 4$ & 14 & -. & 1.2 & 1.6 \\
\hline $\begin{array}{l}\text { AUG. } \\
13 \ldots . \\
13 \ldots \text { A }\end{array}$ & $\begin{array}{l}1625 \\
1625\end{array}$ & 94 & 6.7 & .02 & 5.9 & 1.0 & 1.5 & $\therefore 8$ & 24 & -- & $2 . c$ & .6 \\
\hline DATE & $\begin{array}{l}\text { FLUD- } \\
\text { RIOE } \\
\text { IF I }\end{array}$ & $\begin{array}{l}\text { NITRATE } \\
\text { (ND3) }\end{array}$ & $\begin{array}{l}\text { CRTHO } \\
\text { PHCS } \\
\text { PHATE } \\
\text { (PD4) }\end{array}$ & $\begin{array}{l}\text { OIS- } \\
\text { SOLVEO } \\
\text { SOLIDS } \\
\text { IRESI- } \\
\text { OUE AT } \\
180 \mathrm{CI}\end{array}$ & $\begin{array}{l}\text { CIS- } \\
\text { SOLVEC } \\
\text { SOLIDS } \\
\text { ITONS } \\
\text { PER } \\
\text { AC-FT) }\end{array}$ & $\begin{array}{l}\text { CIS- } \\
\text { SCLVED } \\
\text { SOLIDS } \\
\text { ITDNS } \\
\text { PER } \\
\text { DAYI }\end{array}$ & $\begin{array}{l}\text { HARD- } \\
\text { NESS } \\
\text { \{CA, MG }\end{array}$ & $\begin{array}{l}\text { NON- } \\
\text { CAR- } \\
\text { BONATE } \\
\text { HARD- } \\
\text { NESS }\end{array}$ & $\begin{array}{l}\text { SODIUM } \\
\text { AC- } \\
\text { SORP- } \\
\text { TION } \\
\text { RATIO }\end{array}$ & $\begin{array}{l}\text { SPECI- } \\
\text { FIC } \\
\text { CCAL- } \\
\text { UCTANCE } \\
\text { ( MICRE- } \\
\text { MHCS I }\end{array}$ & PH & COLOR \\
\hline Mar & & & & & & & & & & & & \\
\hline $\begin{array}{l}21 \ldots A \\
21 \ldots A\end{array}$ & $\therefore$ & $\therefore 6$ & .00 & 22 & .03 & 14.8 & 14 & -3 & 1 & 32 & 6.3 & 5 \\
\hline $\begin{array}{l}\text { AUG. } \\
13 \ldots \text {. } \\
13 \ldots \text { A }\end{array}$ & $\therefore$ & $\therefore 1$ & .00 & 27 & .04 & 6.85 & 19 & 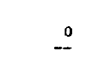 & .2 & 45 & $\begin{array}{l}0.5 \\
6.5 \\
7.1\end{array}$ & 5 \\
\hline & & & & DATE & $\begin{array}{l}\text { ALXA- } \\
\text { LINITY } \\
\text { AS } \\
\text { CACD3 }\end{array}$ & $\begin{array}{l}\text { METHY- } \\
\text { LENE } \\
\text { BLUE } \\
\text { ACTIVE } \\
\text { SUB- } \\
\text { STANCE }\end{array}$ & $\begin{array}{l}\text { DIS- } \\
\text { SOLVED } \\
\text { OXYGEN }\end{array}$ & $\begin{array}{l}\text { TEMP- } \\
\text { ERATURE } \\
\text { IDEG CI }\end{array}$ & & & & \\
\hline & & & & $\begin{array}{l}\text { MAY } \\
21 \ldots . \\
21 \ldots \text { A } \\
\text { AUG.. } \\
13 \ldots . . \\
13 \ldots \text { A }\end{array}$ & 20 & $\begin{array}{l}-- \\
.00 \\
.-\end{array}$ & $\begin{array}{r}9 . \overline{8} \\
\overline{8 . \overline{1}}\end{array}$ & $\begin{array}{l}13 \\
13 \\
23 \\
23\end{array}$ & & & & \\
\hline
\end{tabular}


03555500 HIWASSEE RIVER AT APALACHIA DAM, N.C.

LOCATION,--Lat $35^{\circ} 10^{\prime} 04^{\prime \prime}$, long $84^{\circ} 17^{\prime} 49^{\prime \prime}$, Cherokee County, at Apalachia Dam, and 0.1 mile upstream from North Carolina-Tennessee state Line, and at mile 66.0 .

DRA INAGE AREA. $--1,018 \mathrm{sq} \mathrm{mi}$.

PER IOD OF RECORD. .-Chemical analyses: October 1967 to September 1968.

CrEMICAL ANALYSES IN MILL IGRAMS PER LITER, WATER YEAR OCTCBER I967 TC SEPTEMBER 1968

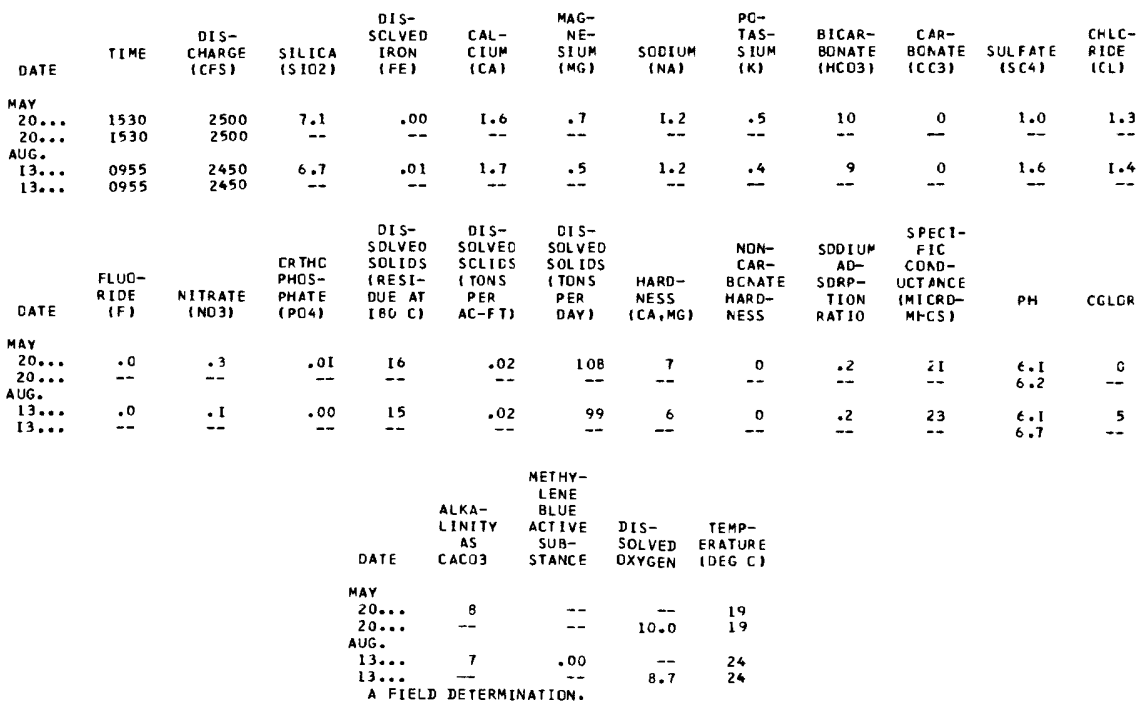




\begin{tabular}{|c|c|c|c|c|c|c|c|c|c|c|c|c|}
\hline & & & & & & & $\begin{array}{l}\text { DIS } \\
\text { SOLVED } \\
\text { SOLIDS }\end{array}$ & & $\begin{array}{l}\text { NON- } \\
\text { CAR- }\end{array}$ & $\begin{array}{l}\text { SPECI- } \\
\text { FIC } \\
\text { COND- }\end{array}$ & & \\
\hline DATE & TIME & $\begin{array}{l}\text { DIS- } \\
\text { CHARGE } \\
\text { (CFS) }\end{array}$ & $\begin{array}{l}\text { BICAR- } \\
\text { BONATE } \\
\text { (HCO3) }\end{array}$ & $\begin{array}{l}\text { CAR } \\
\text { BONATE } \\
\text { (CD3) }\end{array}$ & $\begin{array}{l}\text { SULFATE } \\
\text { (SO4) }\end{array}$ & $\begin{array}{l}\text { CHLO- } \\
\text { RIDE } \\
\text { (CL) }\end{array}$ & $\begin{array}{l}\text { (RESI - } \\
\text { DUE AT } \\
180 \mathrm{C} \text { ) }\end{array}$ & $\begin{array}{l}\text { HARD- } \\
\text { NESS } \\
(C A, M G)\end{array}$ & $\begin{array}{l}\text { BONATE } \\
\text { HARD- } \\
\text { NESS }\end{array}$ & $\begin{array}{l}\text { UCTANCE } \\
\text { (MICRD- } \\
\text { MHOS) }\end{array}$ & $\mathrm{PH}$ & $\begin{array}{l}\text { TEMP - } \\
\text { ERATURE } \\
\text { (DEG C) }\end{array}$ \\
\hline
\end{tabular}

MUSKINGUM RIVER BASIN

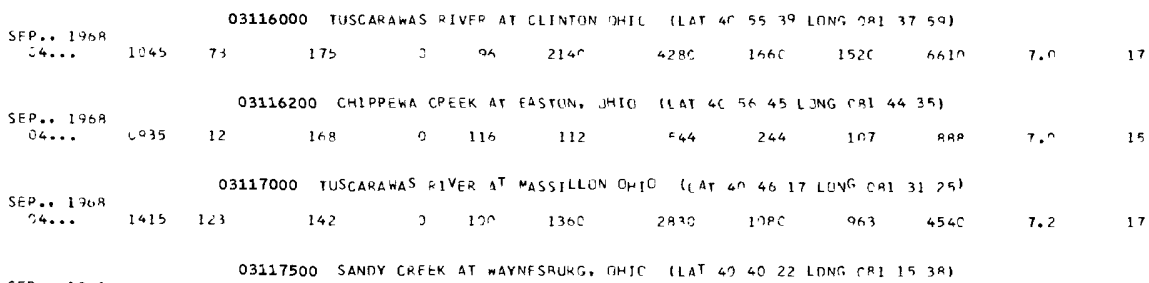


03228500 HIG WALNUT CREEK AT CENTRAL CILLEGE UHIO ILAT 40 O6 12 LONF NA2 53 C31

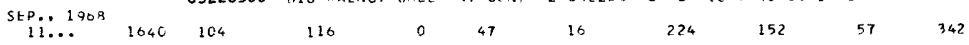
03230400 SIG DARBY CREFK AT DARAYDALE, DHIO (LAT 395055 LONG D83 1120 )

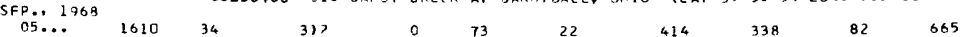




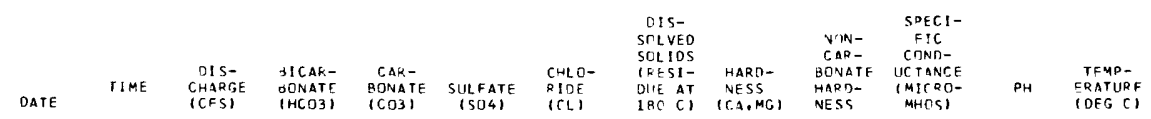

LITTLE MIAMI RIVER BASIN

SEP.. 1968 03240000 LITILE MIAMI RIVER. NR. DLOTGNN. OHIO ILAT 394455 LONG OR3 5550 I

$\begin{array}{ccccccccccccc}\text { SEP.. } 1968 \\ 1 . . . & 1210 & 27 & 368 & 6 & 13 & 22 & 386 & 35 C & 87 & 675 & 8.4\end{array}$

03240500 NURTH FORK MASSIES CREEK. AT CEQARVILLE, OHIO ILAT 394525 LONG O83 49251

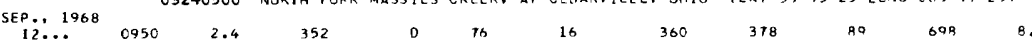

03241000 SOUIH FORK MASSIES CREEK, NR. CEOARVILLE, OHIO ILAT $33^{\circ} 4420$ LONG OR3 4550 )

$\begin{array}{lllllllllll}\text { SFP., } 1968 & 1115 & .44 & 328 & 0 & \text { OS } & 16 & 376 & 350 & \text { RC } & 651\end{array}$

03241500 MASSIES CREEK AT WILBERFORCE. OHIO ILAT 394320 LONG OB3 5255 I

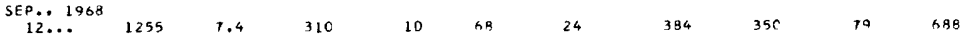

03242050 LITTLE MIAMI R(VER NR. SPFING VALLEY, CIHIO (LAT 3935 DO (ONG OB4 0149 )

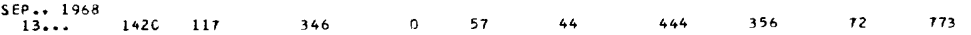

03242150 CAESAR CREEK NR. XENIA, OHIO (LAT 393735 LONG $023 \quad 54 \quad 29$ )

$\begin{array}{llllllllll}\text { SEP... } 1969 \\ 13 . . . & 13 C 5 & 1.5 & 202 & 0 & 42 & 18 & 256 & 264 & 49\end{array}$

03242200 ANDERSON FORK NR NORTH BURLINFITIN HHIO ILAT 393359 LNNG A93 54 INI

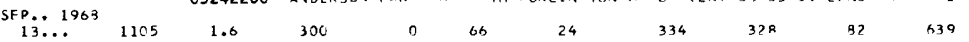

GREAT MIAMI RIVER BASIN

03264000 GREENVILLE CREEK NR. BRADFORD. CHIC ILAT 40 O6 OR LONG CB4 25 4RI

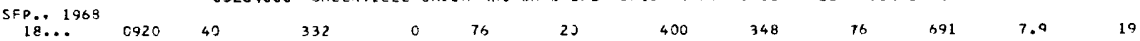

03265000 SIILlhater RIVER at PLeASANT HILl, OHIC (LAT 4? 03 28 LONG 084 21 2?)

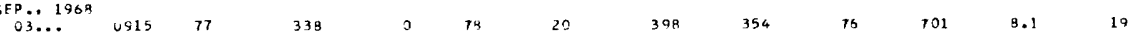

03267500 MAO RIVER AT TREMONT CITY OHIC ILAT 4C CN 25 LONG, OA3 4924 )

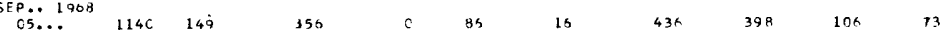

03267600 CHAPMAN CFEEK AT TREMENT CITY. OHIO (LAT 40 OC 38 LONG 283 5R C8)

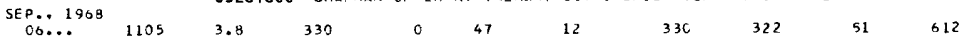

03267700 MOQRE RUN NR. EAGLE CITY, OHIO ILAT 395924 LONG O83 $49 \quad 031$

$\begin{array}{lllllllllll}\text { SEP.. 1968 } & 1950 & 13 & 36 C & O & R 9 & 19 & 488 & 396 & 94 & 155\end{array}$

03267800 MAD RIVER AT EAGLE CITY, OHIO ILAT 395836 LONG 28349211

SEP.. 1969

$\begin{array}{llllllllllllll}05 . . & 140 C & 150 & 356 & C & 86 & 16 & 430 & 396 & 104 & 730 & 8.2 & -2\end{array}$

03267900 MA.) KIVER (ST.PARIS PIKE) AT EAGLE CITY GHIT (LAT 395751 LONG CA3 4954 )

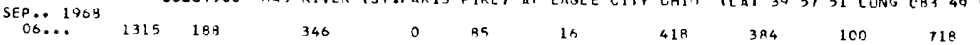

SHP.. 1968267950 BUCK CREEK. NR. NFW MODREFIELD. OHIO (LAT 40 OC 38 LONG OB3 4156 )

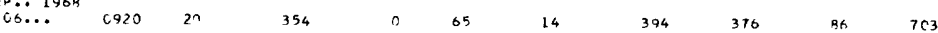

SEP.. 1968 03267960 E. FORK BUCK CREFK NR. NEW MONREFIELO. GHIO ILAT 40 OC 22 LONG OB3 4137 ,

$\begin{array}{lllllllllllll}06 . . . & C 905 & 22 & 354 & n & 94 & 12 & 462 & 404 & 114 & 730 & B .6\end{array}$

AIJG.. 196803271300 HOLES CREEK. NR. KETTERINF. OHIN (LAT 303915 LONG CB4 1145 )

$\begin{array}{llllllllllllll}30 . . & 1010 & 2.0 & 284 & 5 & 56 & 50 & 414 & 316 & 83 & 100 & 7.9 & 11\end{array}$

03271400 BEAR CREEK AT ELLERTON, OHIO ILAT 39 4325 LONG 0841 1R 351

$\begin{array}{llllllllllll}\text { AJG.. } 1969 \\ 26 . . . & 1525 & 3.3 & 352 & 0 & 14 & 29 & 436 & 366 & 77 & 732 & 8.2\end{array}$

AIHG.. 1968 03271700 CLEAR CREEK AT FRANKLIN, OHIO (LLAT 3933 O6 LONG 084 18 18)

$\begin{array}{llllllllllll}26 . . . & 1250 & 4.6 & 328 & 0 & 56 & 30 & 376 & 332 & 62 & 682 & 8.1\end{array}$

SEP., 196803272300 DICKS CREEK NR. EXCELLA, OHIO ILAT 39 2825 LONG OR4 23501

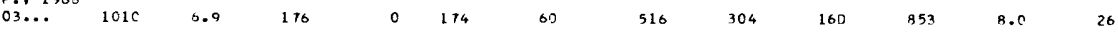




$$
\text { ALDRIN DDD DOE DOT ELTRIN ENDRIN CHLTR }
$$

03144600 MUSKINGUM RIVER AT ZANESVILLE, AT BOAT DOCK AT ZANESVILLe MUNICIPAL hateR PLANTILAT 395741 LONG O81 5939

\begin{tabular}{|c|c|c|c|c|c|c|c|}
\hline $\begin{array}{l}\text { AAY } \\
10-14\end{array}$ & .00 & .00 & .00 & .00 & .00 & .3n & .01 \\
\hline $\begin{array}{l}\text { JUNE } \\
26-3 \mathrm{C}\end{array}$ & .00 & .50 & .30 & . On & -nc & .30 & . 3n \\
\hline $\begin{array}{l}\text { JULY } \\
09-13\end{array}$ & .00 & $.0 c$ & .70 & .00 &. no & .00 & .79 \\
\hline $\begin{array}{l}\text { AUG. } \\
17-21 \\
\text { SEPT. }\end{array}$ & .00 &.$O C$ & . no & . nn & .00 &.$n 0$ & .11 \\
\hline $19-23$ & .00 & .00 & . & .03 & .00 & .00 & .03 \\
\hline
\end{tabular}

03149000 MUSKINGUM RIVER BELOW ZANESVILLE, AT BRIDGE ON STATE HIGHWAY 60 (LAT 395248 LONG O81 58 46)

\begin{tabular}{|c|c|c|c|c|c|c|c|}
\hline $\begin{array}{l}\text { OC } 7 . \\
24-28\end{array}$ & .00 & .00 & .00 & $.0 n$ & .00 & .00 & .02 \\
\hline NOV. & חת & .00 & .00 & . & . $0^{n}$ & $\cdot 3 r$ & .77 \\
\hline $\begin{array}{l}\text { APR } \\
25-30\end{array}$ & .00 & .00 & .00 & . & 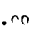 & - or & .nn \\
\hline $\begin{array}{l}\text { MAY } \\
10-14\end{array}$ & . C3 & .00 & . 06 & .00 & ron. & חת. & ?? \\
\hline $\begin{array}{l}\text { JUNE } \\
26-30\end{array}$ & .00 & .00 & $\cdot 3^{n}$ & .00 & .00 & .70 & $.7 n$ \\
\hline $\begin{array}{l}\text { JULY } \\
16-20\end{array}$ & .00 & .00 & . & n & - 30 & .00 & .17 \\
\hline $\begin{array}{l}\text { AUG. } \\
17-21 \\
\text { SEPT. }\end{array}$ & .00 & .00 & - n & n & - & - $0 n$ & .72 \\
\hline $19-2.4$ & .00 & .00 & .00 & $.7 n$ & - on & ח0 & .07 \\
\hline
\end{tabular}

03222010 SCIOTO RIVER AT COLUMBUS, AT RAH WATER INTAKE TO CITY OF COLUMBUS , DUBLIN ROAD HATER TREATMENT PLANT (LAT 3958 O5 LONG $08302 \quad 06$ )

\begin{tabular}{|c|c|c|c|c|c|c|c|}
\hline $\begin{array}{l}\text { OCT. } \\
17-21\end{array}$ & .00 & .00 & .00 & . Cl & .00 & . no & . on \\
\hline $\begin{array}{l}\text { NOV. } \\
111-15\end{array}$ & .00 & .00 & $.3 n$ & .00 & .00 & $\cdot 2^{n}$ & . \\
\hline $\begin{array}{l}\text { APR. } \\
26-30\end{array}$ & .00 & . on & . on & .20 & $=0$ & .00 & .71 \\
\hline $\begin{array}{l}\text { MAY } \\
14-18\end{array}$ & .00 & .00 & .00 & 99. &.$\cap n$ & .70 & . nn \\
\hline JUNE & (2) & 00 & on & on & 01 & .00 & 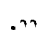 \\
\hline $\begin{array}{l}\text { JULY } \\
24-28\end{array}$ & .00 & .00 & .00 & .01 & on & .09 & .72 \\
\hline AUG. & .00 & . & . $\cap n$ & .10 & . nn & .3n & . $3 n$ \\
\hline $\begin{array}{l}\text { SEPT. } \\
20-24\end{array}$ & .00 & $.0 \mathrm{C}$ & .00 & .00 & .00 & .00 & .0 .0 \\
\hline
\end{tabular}

03270010 MAD RIVER AT DAYTON, AT MAN-MADE CHANNEL OF MAD RIVER, JUST EAST OF HARSHMAN ROAD ILAT 394722 LONG OB4 0642 )

\begin{tabular}{|c|c|c|c|c|c|c|c|}
\hline $\begin{array}{l}\text { APR. } \\
\text { P2-26 } \\
\text { MAY }\end{array}$ & $.0 \mathrm{C}$ & .00 & .02 & .07 & .00 &.$r 0$ & . 03 \\
\hline $\begin{array}{l}10-14 \\
\text { JUNF }\end{array}$ & .00 & . On & .01 & .04 & n &.$m$ & \\
\hline $\begin{array}{l}25-29 \\
\text { JuLY }\end{array}$ & .00 & .00 & . or & $.3 n$ & .02 & . & .2 \\
\hline $\begin{array}{l}24-28 \\
\text { AUG. }\end{array}$ & .00 & .00 & . on & .00 & .04 & . Dn & \\
\hline $\begin{array}{l}\text { n8-12 } \\
\text { SFPT. }\end{array}$ & .00 & . On & חמ. & . Co & .01 & .00 & \\
\hline $16-20$ & .00 & .00 & . & .00 & . nl & .00 & n \\
\hline
\end{tabular}

ANALYSES OF SAMPLES COLLECTED AT MISCELLANEOUS SITES IN NEW YORK

CHEMICAL, ANALYSES IN MILLIGRAMS PER LITER, WATER YEAR OCTOBER 1967 TO SEPTEMBER 1968

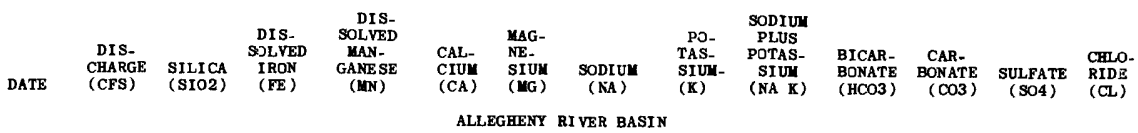

03011025 LITTLE VALLEY CREEK AT LITTLE VALLEY, N. Y. (LAT 421522 LONG 0784816 ).

AUG.

$\begin{array}{llllllllllllll}14 . . . A & 1.0 & 2.6 & .65 & .17 & 27 & 3.3 & 3.8 & .8 & \ldots & 78 & \ldots & 15 & 5.0\end{array}$

A TIUE OF COLLECTION 1430 
PESTICIDE ANALYSES OF STREAMS IN THE OHIO RIVER BASIN IN OHIO

PESTICIDE ANALYSES, IN MICROGRAMS PER LITER, WATER YEAR OCTUBER 1967 TO SEPTEMBER 1968

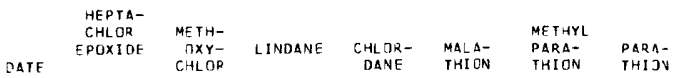

03144600 MUSKINGUM RIVER AT ZANESVILLE,AT BOAT DOCK AT ZANESVILLE MUNICIPAL WATER PLANT(LAT 395741 LONG D81 5939 )

\begin{tabular}{|c|c|c|c|c|c|c|c|}
\hline MAY & & & & & & & \\
\hline $10-14$ & .00 & .00 & .20 & .00 & . nn & .00 & .3 \\
\hline $\begin{array}{l}\text { JUNE } \\
26-30\end{array}$ & .00 & .00 & .30 & .00 &.$n \cap$ & . 00 & $.3^{n}$ \\
\hline JULY & & & & & & & \\
\hline $\begin{array}{l}09-13 \\
\text { AUG. }\end{array}$ & .00 & . or & .00 & .00 & .00 & $\cdot 7^{n}$ & .33 \\
\hline $\begin{array}{l}17-2 I \\
\text { SEPT. }\end{array}$ & .00 & .00 & .00 & .00 & $\cdot 3 n$ & .70 & .99 \\
\hline $19-23$ & .00 & .00 & 00 & .00 & .00 & .00 & r \\
\hline
\end{tabular}

03149000 MUSKINGUM RIVER BELOW ZANESVILLE, AT BRIDGE ON STATE HIGHWAY 60 (LAT 395248 LONG O81 5846 )

\begin{tabular}{|c|c|c|c|c|c|c|c|}
\hline $\begin{array}{l}\text { OCT. } \\
24-28 \\
\text { NOV. }\end{array}$ & . 0 ) & . 0 n & n & חמה & . n & $.2 n$ & $\cdot 3^{n}$ \\
\hline Q3-07. & .00 & . Dn & .00 & .00 & ח ח & $.2 n$ & 03 \\
\hline APR. & & & & & & & \\
\hline$\underset{\text { MAY }}{25-30}$ & .00 & .00 & .20 & .00 & . an & $.3^{n}$ & .37 \\
\hline $\begin{array}{l}10-14 \\
\text { JUNE }\end{array}$ & .00 & . On & $.0 n$ & .00 & . no & .37 & $\cdot n^{n n}$ \\
\hline $\begin{array}{l}26-30 \\
\text { JULY }\end{array}$ & ח &.$n 0$ & .00 & .30 & .00 & . no & ח \\
\hline $\begin{array}{l}16-20 \\
\text { AUG. }\end{array}$ & .00 & . nn & .26 & .00 & . no & .20 & .31 \\
\hline $\begin{array}{l}17-21 \\
\text { SEPT. }\end{array}$ & .00 & .00 & .00 & .00 & .00 & .20 & $\cdot n n$ \\
\hline $19-24$ & .00 & .00 & .00 & .00 & $\cdot \cap C$ & $.3 n$ & .33 \\
\hline
\end{tabular}

03222010 SCIOTO RIVER AT COLUMBUS, AT RAW WATER INTAKE TO CITY OF COLUMBUS, DUBLIN ROAD WATER TREATMENT PLANT (I AT 3958 O5 LONG 08302 O6)

\begin{tabular}{|c|c|c|c|c|c|c|c|}
\hline $\begin{array}{l}\text { OCT. } \\
17-21\end{array}$ & .00 & .00 & .00 & .00 & . nn & .30 & .37 \\
\hline $\begin{array}{l}\text { Nov. } \\
11-15\end{array}$ & .00 & .00 & .00 & . 0 n & . & . & .20 \\
\hline $\begin{array}{l}\triangle P R \text {. } \\
26-30\end{array}$ & 00 & ח0? & 00 & 000 & חת ח & 30 & ר? \\
\hline MAY & & & & & & & \\
\hline $\begin{array}{c}\text { 14-18 } \\
\text { JUNE }\end{array}$ & .00 & .on & . & .00 & . no & $.2 n$ & .77 \\
\hline $\begin{array}{l}17-21 \\
\text { JULY }\end{array}$ & .00 & .00 & . & .30 &.$n n$ & .70 & .07 \\
\hline $24-28$ & .00 & $.0 n$ & .00 & $.0 \mathrm{C}$ & n & $\cdot n n$ & .07 \\
\hline $\begin{array}{l}\text { AUG. } \\
04-08\end{array}$ & .00 & .00 & .70 & .00 & $.0 n$ & $.0 n$ & $\cdot n$ \\
\hline $20-24$ & .00 & .20 & ח. &.$\cap 0$ &. . & . & . \\
\hline
\end{tabular}

03270010 MAD RIVER AT DAYTON, AT MAD-MADE CHANNEL OF MAD RIVER, JUST EAST OF HARSHMAN ROAD (LAT 394722 LONG 084 O6 42 )

\begin{tabular}{|c|c|c|c|c|c|c|c|}
\hline $\begin{array}{l}A P R \text {. } \\
22-26\end{array}$ & .00 & - ne & . 00 & $.3 n$ &.$\cap c$ & $.7 n$ & .32 \\
\hline $\begin{array}{l}\text { YAY } \\
10-14\end{array}$ & & & & & & & \\
\hline $\begin{array}{l}10-14 \\
\text { JUNE }\end{array}$ & .00 & .00 & .30 & .00 & .00 &.$n a$ & .27 \\
\hline $\begin{array}{l}25-29 \\
\text { JULY }\end{array}$ & .00 & $.0 n$ & .30 & O0 & .00 & .00 & .32 \\
\hline $\begin{array}{l}24-28 \\
\text { AUG. }\end{array}$ & .00 & .00 & .00 & .00 & . no & $.7 n$ & .09 \\
\hline $\begin{array}{l}08-12 \\
\text { SEPT. }\end{array}$ & .00 & .00 & .30 & .00 & .00 & . nn & . on \\
\hline $16-20$ & .00 & . ne & .00 & .00 & .00 & .20 & 0 ? \\
\hline
\end{tabular}

ANALYSES OF SAMPLES COLLECTED AT MISCELLANEOUS SITES IN NEW YORK CHEMICAL ANALYSES IN MILLIGRAMS PER LITER. WATBR YEAR OCTOBER 1967 TO SEPTEMBER 1968

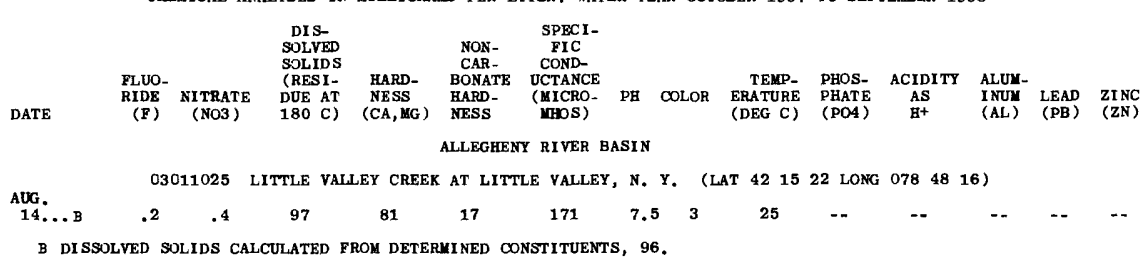




\begin{tabular}{|c|c|c|c|c|c|c|c|c|c|c|c|c|c|}
\hline DATE & $\begin{array}{l}\text { DIS- } \\
\text { CHARGE } \\
\text { (CFS) }\end{array}$ & $\begin{array}{l}\text { SILICA } \\
\text { (SIO2) }\end{array}$ & $\begin{array}{l}\text { DIS- } \\
\text { SOLVED } \\
\text { I RON } \\
\text { (FE) }\end{array}$ & $\begin{array}{c}\text { DIS- } \\
\text { SOLVED } \\
\text { YAN } \\
\text { GANESE } \\
\text { (MN) }\end{array}$ & $\begin{array}{l}\text { CAL- } \\
\text { CIUH } \\
\text { (CA) }\end{array}$ & $\begin{array}{l}\text { MAG- } \\
\text { NE } \\
\text { SIUM } \\
\text { (WG) }\end{array}$ & $\begin{array}{c}\text { SODI UN } \\
\text { (NA) }\end{array}$ & $\begin{array}{l}\text { PO- } \\
\text { TAS- } \\
\text { SIUM- } \\
\text { (X) }\end{array}$ & $\begin{array}{c}\text { SODIUY } \\
\text { PLUS } \\
\text { POTAS- } \\
\text { SIUY } \\
\text { (NA K) }\end{array}$ & $\begin{array}{l}\text { B ICAR- } \\
\text { BONATE } \\
\text { (HCO3) }\end{array}$ & $\begin{array}{c}\text { CAR- } \\
\text { BONATE } \\
(\infty 03)\end{array}$ & $\begin{array}{c}\text { SULFATE } \\
\text { (SO4) }\end{array}$ & $\begin{array}{l}\text { CHLO- } \\
\text { RIDZ } \\
\text { (CL) }\end{array}$ \\
\hline
\end{tabular}

POTATO CREEK BASIN

03009000 POTATO CREEK AT BETULA (LAT 414015 LONG 07823 11)

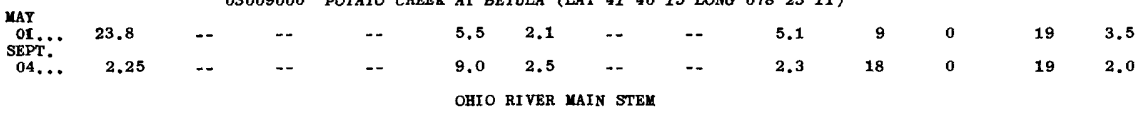

03010500 ALLEGHENY RIVER AT ELDRED (LAT 415750 LONG 07823 10)

$\begin{array}{rrrrrrrrrrrrrrrrr}\text { JUNE } & \text { A538 } & 3.1 & .00 & .00 & 11 & 2.2 & 8.0 & .9 & \ldots & 22 & 0 & 15 & 16\end{array}$

03010650 OSTAYO CREEK AT CONEVILLE (LAT 415429 LOHG 07803 26)

\begin{tabular}{|c|c|c|c|c|c|c|c|c|c|c|c|c|c|}
\hline 8 & & & & & & & & & & & & & \\
\hline $01 . .$. & 23.9 & -- & -- & -- & 8.2 & 2.3 & -. & -. & 3.9 & 27 & 0 & 12 & 3.0 \\
\hline $04 \ldots$ & 3.55 & -- & -- & -- & 10 & 2.8 & $=-$ & -- & 1.8 & 30 & 0 & 11 & 3.0 \\
\hline
\end{tabular}

KINZHA CREEK BASIN

03011800 KINZUA CREEK NEAR GUFFEY (LAT $4145 \quad 59$ LOFG 0784308 )

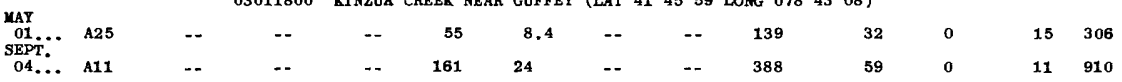

BROKENSTRAT CREEK BASIN

03015500 BROKGMETRAT CREET AT YOUNGSVILLE (LAT 415110 LONG 0791905 )

$\begin{array}{llllllllllllll}19 . . & 123 & 2.8 & C .29 & D .00 & 30 & 5.8 & 4.5 & 1.0 & \ldots & 102 & 0 & 16 & 7.5\end{array}$ EAST HICKORT CREEK BASIN

03015800 EAST HICKORY CREEK AT ENDEAVOR (LAT $41 \quad 3617$ LONG $07922 \quad 27$ )

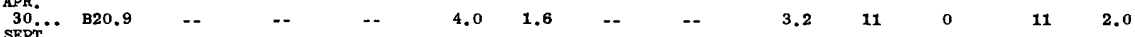

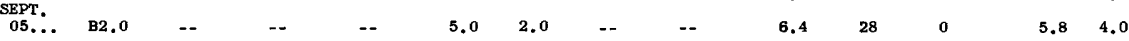

TIONESTA CREEK BASIN

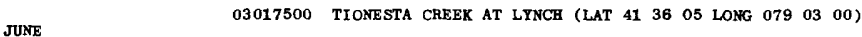

$\begin{array}{llllllllllllll}\text { JUNE } \\ 20 . . & 1.53 & 3.4 & \text { C. } 33 & \text { D. } 00 & 7.0 & 2.2 & 6.0 & 1.0 & -. & 22 & 0 & 11 & 9.0\end{array}$ OIL CREEK BASIN

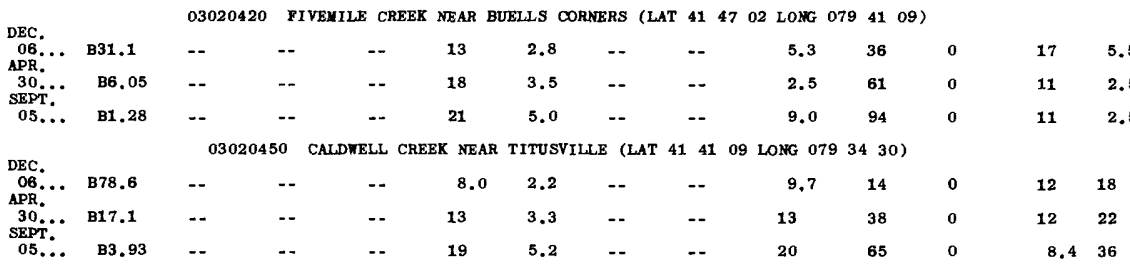

JUNE 03020500 OIL CREEK AT ROUSEVILLE (LAT 412855 LONG 0794140 )

$\begin{array}{lllllllllllllll}\text { JUNE } & 18 . . & 158 & 3.1 & \text { C.24 } & \text { D. } 00 & 23 & 5.6 & 10 & 1.3 & -. & 74 & 0 & 19 & 18\end{array}$

FRENCH CREEK BASIN

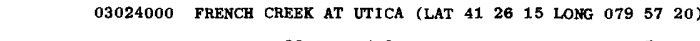

\begin{tabular}{|c|c|c|c|c|c|c|c|c|c|c|c|c|}
\hline $\begin{array}{r}\text { O7. } \\
07 . .\end{array}$ & 3540 & -- & -- & -- & 22 & 4.8 & -- & -- & 6.7 & 60 & 0 & 22 \\
\hline $24 .$. & 1350 & - & -- & - & 20 & 5.3 & -- & $=$ & 9.7 & 78 & o & 24 \\
\hline $\begin{array}{l}14 . . \\
A P R\end{array}$ & 2330 & - & -- & -- & 19 & 3.8 & -- & -- & 8.7 & 50 & 0 & 19 \\
\hline$\underset{\text { JUNE }}{24}$ & 745 & 2.9 & $=$ & -- & 32 & 5.8 & 7.5 & 1.3 & -- & 98 & 0 & 24 \\
\hline $\operatorname{s\Omega l}_{18}^{18}$ & 378 & 1.7 & C. 23 & D. 00 & 36 & 7.5 & 7.7 & 1.4 & -- & 118 & 0 & 24 \\
\hline $10 .$. & 262 & -- & - & -- & 35 & 7.0 & -- & -- & 13 & 120 & o & 24 \\
\hline $\begin{array}{l}15, \ldots \\
\text { SEPT. }\end{array}$ & 111 & -- & -- & -- & 48 & 8.4 & $\ldots$ & -- & 8.3 & 136 & 0 & 31 \\
\hline 12. & 322 & -- & -- & -- & 41 & 7.9 & -. & -- & 10 & 127 & 0 & 30 \\
\hline
\end{tabular}

$\begin{array}{ll}\text { A DAILT MEAN DI SCHARGE. } & \text { C TOTAL IRON. } \\ \text { B DI SCHARGE AT TIME OF SAMPLING. } & \text { D TOTAL YANGANESE. }\end{array}$ 


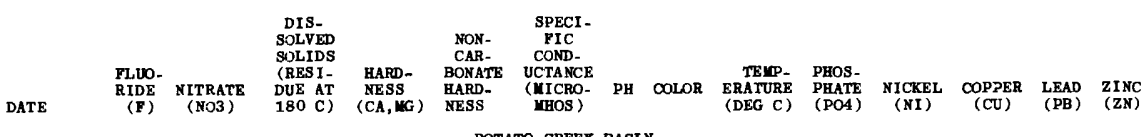

POTATO CREEK BASIN

03009000 POTATO CREEK AT BETULA (LAT 414015 LONG 07823 11)

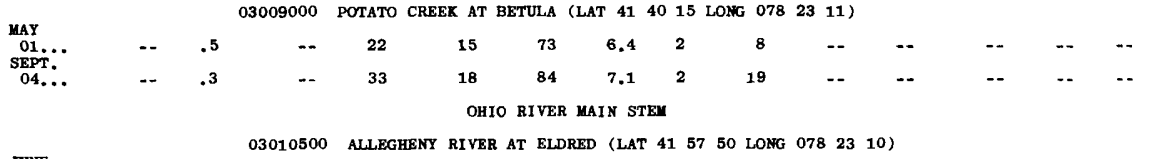

$$
\begin{aligned}
& \begin{array}{llllllll}
74 & 37 & 19 & 125 & 7.4 & 15 & 16
\end{array} \\
& \text { OSTAYO CREET BASIN }
\end{aligned}
$$

03010650 OSWAYO CREEK AT CONEVILLE (LAT 415429 LONG 07803 26)

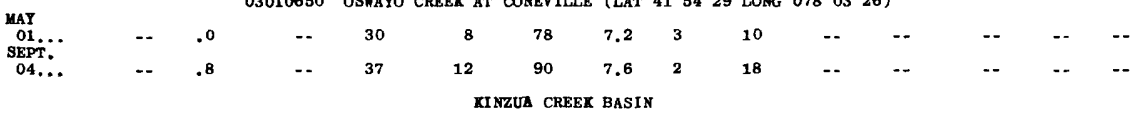

03011800 KINZUA CREEK NEAR GUFFEY (LAT 414559 LONG 0784308 )

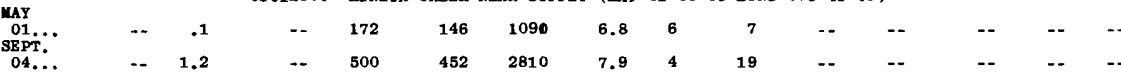

BROKENSTRAT CREET BASIN

03015500 BROKENSTRAT CREEK AT YOUNGSVILLLE (LAT 415110 LONG 07919 05)

$\begin{array}{lllllllllll}\text { JUNE } & .3 & 1.7 & 121 & 99 & 16 & 219 & 7.7 & 20 & 16 & \ldots\end{array}$

\section{EAST HICKORY CREEK BASIN}

03015800 EAST HICKORY CREEK AT ENDEAVOR (LAT 413617 LONG 07922 27)

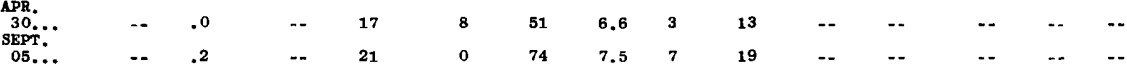

TIONESTA CRBEX BASIN

03017500 TIONESTA CREEX AT LYNCH (LAT 4136 O5 LONG 0790300 )

JUNE
20.

OIL CREEX BASIN

\begin{tabular}{|c|c|c|c|c|c|c|c|c|c|c|c|c|c|}
\hline $\begin{array}{c}\text { DEC. } \\
06 . . . \\
\text { APR. }\end{array}$ & -. & .6 & -- & 44 & 15 & 115 & 7.1 & 3 & 2 & -. & $=$ & -- & - \\
\hline 30... & -- & .1 & -- & 60 & 10 & 135 & 7.1 & 3 & 9 & $\cdots$ & -- & -- & $\cdots$ \\
\hline $05 \ldots$ & $=$ & .4 & $\ldots$ & 73 & 0 & 123 & 8.1 & 5 & 18 & -- & .. & -. & -- \\
\hline
\end{tabular}

03020420 FIVEMILE CREEK NEAR BURLLS CORNERS (LAT 414702 LONG 0794109 )

03020450 CALDWELL CREEK NEAR TITUSVILLE (LAT 4141 09 LONG 0793430 )

$\begin{array}{lllllllllll}\text { DEC. } & \ldots & 6 & \ldots & 29 & 18 & 120 & 6.6 & 3 & \ldots & \ldots\end{array}$

$\begin{array}{cccccccccc}\text { APR... } & -. & .6 & -- & 29 & 18 & 120 & 6.6 & 3 & \\ 30 . . . & -- & .2 & -. & 46 & 15 & 153 & 6.8 & 6 & 11\end{array}$

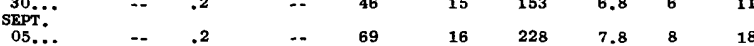

JUNE
18.

03020500 OIL CREEK AT ROUSEVILLE (LAT 412855 LONG 0794140 )

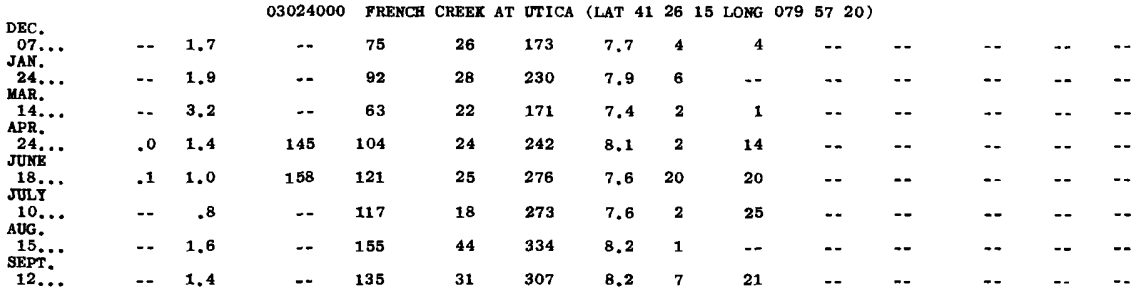




\begin{tabular}{|c|c|c|c|c|c|c|c|c|c|c|c|c|c|}
\hline TE & $\begin{array}{l}\text { DIS- } \\
\text { CHARGE } \\
\text { (CFS) }\end{array}$ & $\begin{array}{l}\text { SILICA } \\
\text { (SIO2) }\end{array}$ & $\begin{array}{l}\text { DIS- } \\
\text { SOLVED } \\
\text { IRON } \\
\text { (FE) }\end{array}$ & $\begin{array}{l}\text { DIS- } \\
\text { SOLVED } \\
\text { YAN- } \\
\text { GANE SE } \\
\text { ( } \text { MN ) }\end{array}$ & $\begin{array}{l}\text { CAL- } \\
\text { CIUN } \\
\text { (CA) }\end{array}$ & $\begin{array}{l}\text { MAG- } \\
\text { NE- } \\
\text { SIUN } \\
\text { (NG) }\end{array}$ & $\underset{\text { (NA) }}{\text { SODIUY }}$ & $\begin{array}{l}\text { PO- } \\
\text { TAS- } \\
\text { SIUU. } \\
\text { (K) }\end{array}$ & $\begin{array}{l}\text { SODIUI } \\
\text { PLUS } \\
\text { POTAS- } \\
\text { SIUI } \\
\text { (NA K) }\end{array}$ & $\begin{array}{l}\text { BICAR- } \\
\text { BONATE } \\
\text { (HCO3) }\end{array}$ & $\begin{array}{l}\text { CAR- } \\
\text { BONATE } \\
\text { (CO3) }\end{array}$ & $\begin{array}{c}\text { SULFATE } \\
\text { (SO4) }\end{array}$ & $\begin{array}{l}\text { CHLO- } \\
\text { RIDE } \\
\text { (CL) }\end{array}$ \\
\hline
\end{tabular}

FRENCH CREEK BASIN--CONTINUED

03024200 WEST BRANCH SUGAR CREEK NEAR BRADLEYTOWN (LAT 413431 LONG 07951 54)

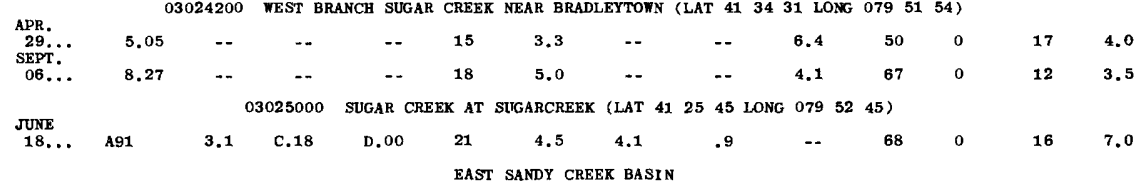

\section{EAST SANDY CREEK BASIN}

03025800 EAST SANDY CREEK AT VAN (LAT 41 19 03 LONG 0793922 )

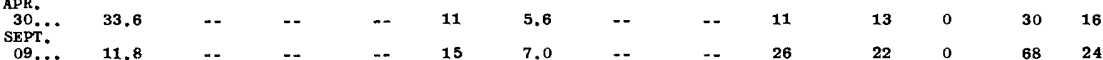

SANDY CREEK BASIN

03025900 SANDY CREEK NEAR SHEAKLEYVILLE (LAT 412551 LONG 0801002 )

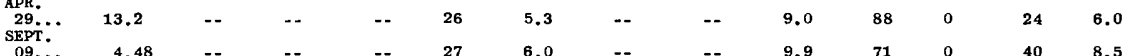

REDBANK CREEK BASI N

03031800 MILL CREEK AT ALLENS MILLS (LAT 4112 O1 LONG 07854 23)

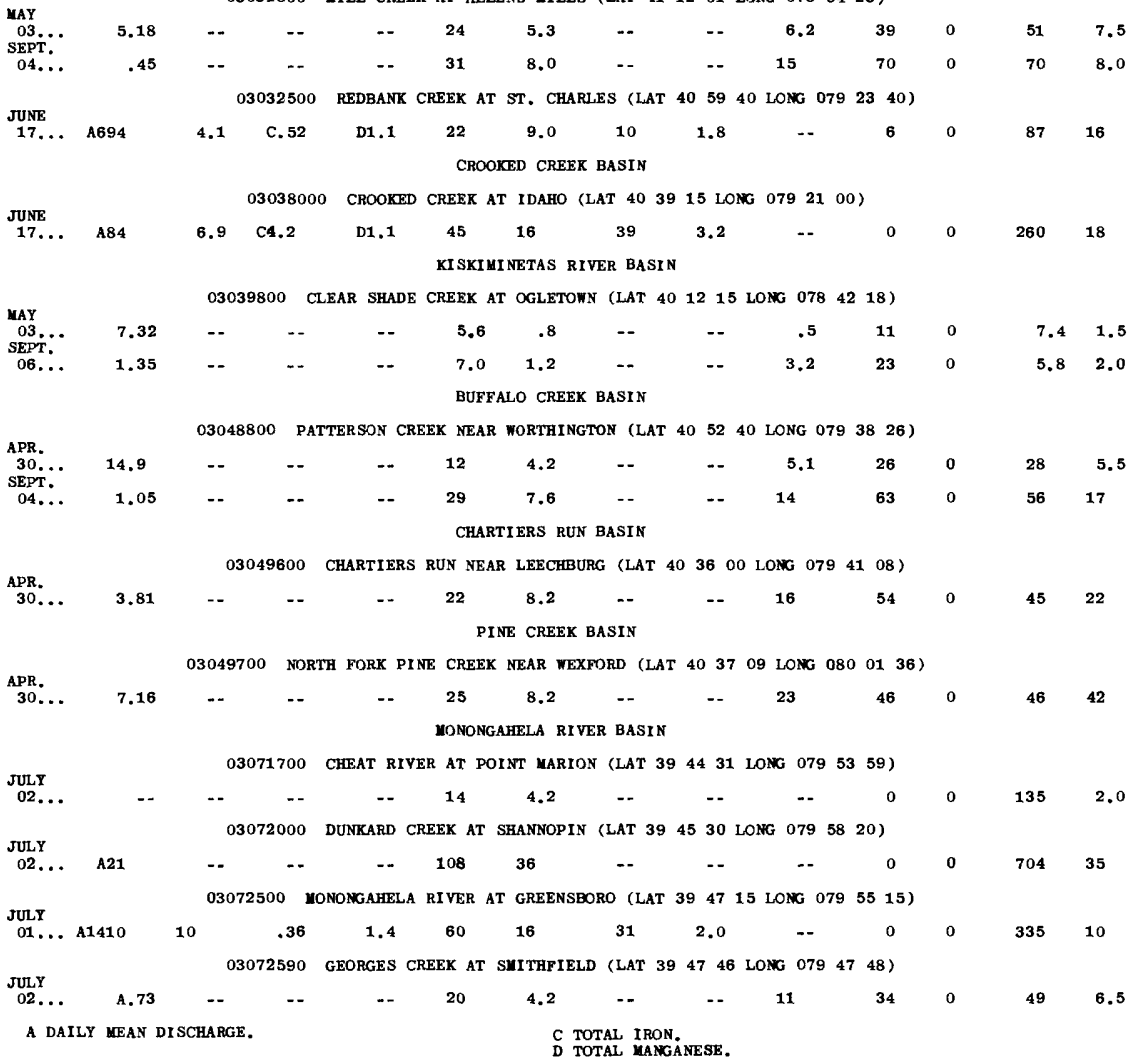




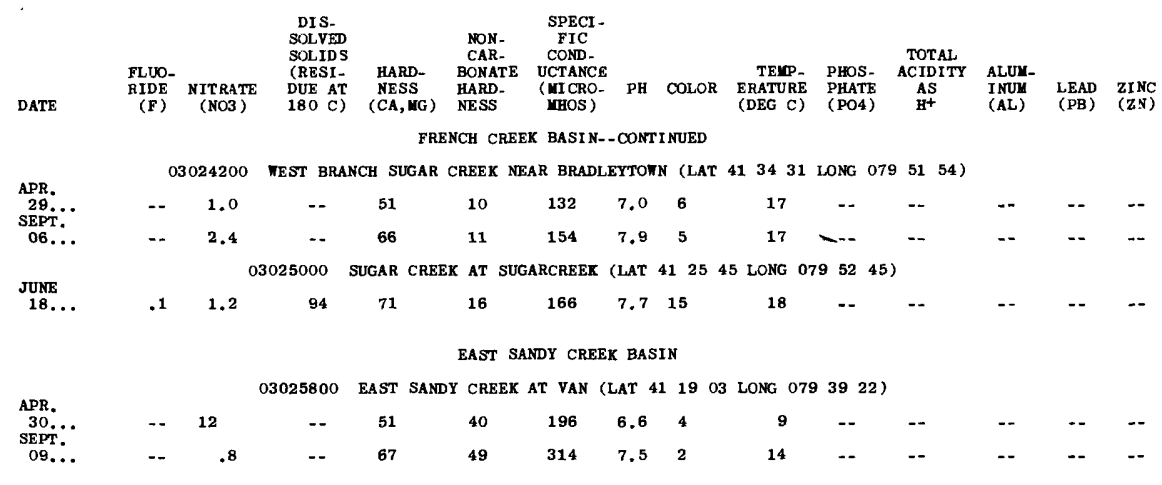

SANDY CREEK BASIN

O3025900 SANDY CREEK NEAR SHEAKLETVILLE (LAT 412551 LONG 0801002 )

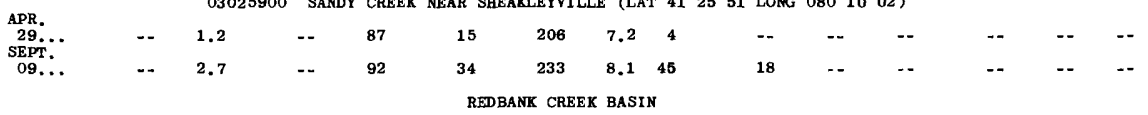

KAY 03031800 MTLL CREEK AT ALLENS MILLS (LAT 411201 LONG 0785423 )

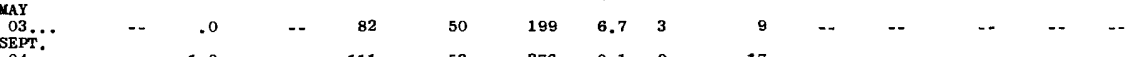

$\begin{array}{lllllllllllllllll}\text { SEPT. } & -. & 1.0 & \ldots & 111 & 53 & 276 & 8.1 & 9 & 17 & \ldots & \ldots & \ldots & \ldots\end{array}$

JUNE 03032500 REDBANK CREEK AT ST. CHARLES (LAT 405940 LONG 0792340 )

$\begin{array}{lllllllllll}\text { JUNE } & & & & & & & & & \\ 17 \ldots & .3 & 1.4 & 166 & 92 & 87 & 271 & 6.3 & 15 & 19 & \ldots\end{array}$

CROOKED CREEK BASIN

03038000 CROOKED CREEK AT IDAHO (LAT 403915 LONG 07921 OO)

$\begin{array}{lllllllll}\text { JUNE } & & . & & & & \\ 17 . . & 3 & .8 & 408 & 179 & 179 & 607 & 3.6 & 25\end{array}$

KISKIMINETAS RIVER BASIN

03039800 CLEAR SHADE CREEK AT OGLETOWN (LAT 401215 LONG $07842 \quad 18$ )

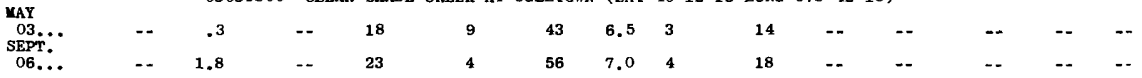

BUFFALO CREEK BASIN

03048800 PATTERSON CREEK NEAR TORTHINGTON (LAT $40 \quad 5240$ LONG 07938 26)

$\begin{array}{llllllllllll}\text { APR. } & & & & & & & & & & & \\ 30 . . . & -- & .3 & -. & 48 & 26 & 127 & 8.0 & 2 & 11 & \ldots & \ldots\end{array}$

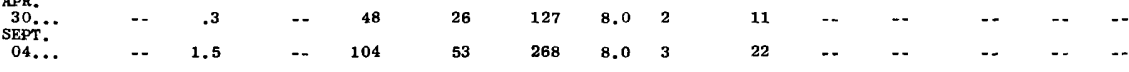

CHARTIERS RUN BASIN

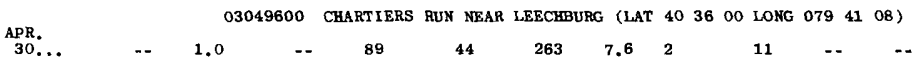

PINE CREEK BASIN

APR.

03049700 NORTH FORK PINE CREEK NEAR TEXFORD (LAT 4037 O9 LONG 0800136 )

MONONGAHELA RIVER BASIN

JULY 03071700 CHEAT RIVER AT POINT MARION (LAT 394431 LONG O79 53 59)

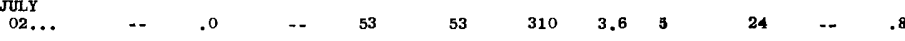

03072000 DUNKARD CREEK AT SHANNOPIN (LAT 394530 LONG 07958 20)

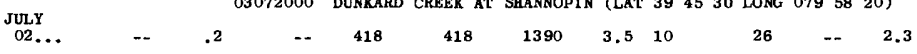

03072500 MONONGAHELA RIVER AT GREENSBORO (LAT $3947 \quad 15$ LONG 07955 15)

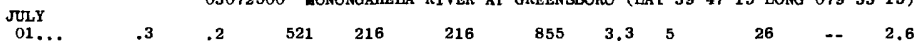

03072590 GEORGES CREEK AT SMITHFIELD (LAT 394746 LONG 0794748 )

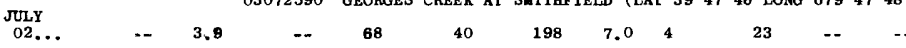


ANALYSES OF SAMPLES COLLECTED AT MISCELLANEOUS SITES IN PENNSYLVANIA

CHEMICAL ANALYSES IN MILLIGRAUS PER LITER, WATER YEAR OCTOBER 1967 TO SEPTBMBER 1968

\begin{tabular}{|c|c|c|c|c|c|c|c|c|c|c|c|c|c|}
\hline DATE & $\begin{array}{l}\text { DIS- } \\
\text { CHARGE } \\
\text { (CFS) }\end{array}$ & $\begin{array}{l}\text { SILICA } \\
\text { (SIO2) }\end{array}$ & $\begin{array}{l}\text { DIS- } \\
\text { SOLVED } \\
\text { IRON } \\
\text { (FE) }\end{array}$ & $\begin{array}{l}\text { DIS- } \\
\text { SOLVED } \\
\text { MAN- } \\
\text { GANESE } \\
\text { (MN) }\end{array}$ & $\begin{array}{l}\text { CAL- } \\
\text { CIUM } \\
\text { (CA) }\end{array}$ & $\begin{array}{l}\text { MAG- } \\
\text { NE- } \\
\text { SI UM } \\
(\text { MG ) }\end{array}$ & $\begin{array}{c}\text { SODIUM } \\
\text { (NA) }\end{array}$ & $\begin{array}{l}\text { PO- } \\
\text { TAS- } \\
\text { SIUK- } \\
\text { (K) }\end{array}$ & $\begin{array}{l}\text { SODIUM } \\
\text { PLUS } \\
\text { POTAS- } \\
\text { S IUM } \\
\text { (NA K) }\end{array}$ & $\begin{array}{l}\text { BYCAR- } \\
\text { BONATE } \\
\text { (HOO3) }\end{array}$ & $\begin{array}{c}\text { CAR- } \\
\text { BONATE } \\
(\mathrm{COB})\end{array}$ & $\begin{array}{c}\text { SULFATE } \\
\text { (SO4) }\end{array}$ & $\begin{array}{l}\text { CHLO- } \\
\text { RIDE } \\
\text { (CL) }\end{array}$ \\
\hline & & & & & & RI VER & ASIN- - C & INUE? & & & & & \\
\hline
\end{tabular}

03072850 SOUTH FORK TENILE CREEK NEAR ROGERSVILLE (LAT 3953 O0 LONG 08018 59)

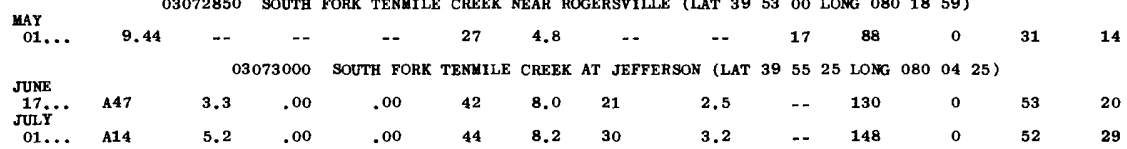

03074300 LICK RUN AT HOPWOOD (LAT $3952 \quad 04$ LONG 0794140 )

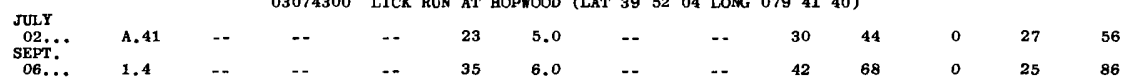

03074500 REDSTONE CREEK AT TALTERSBURG (LAT $3958 \quad 45$ LONG $07945 \quad 50$ )

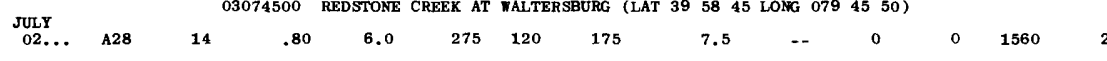

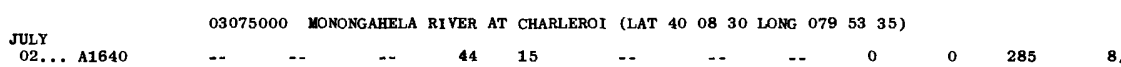

TUIY 03077500 YOUGHIOGHENY RIVER AT YOUGHIOGHENY RIVER DAM (LAT 394820 LONG 0792150 )

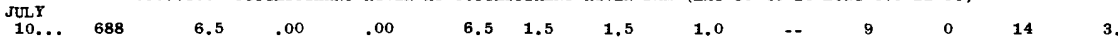

MAY 03078700 BLKLICK CREEK AT SUMAIT MILLS (LAT 394841 LONG 0790401 )

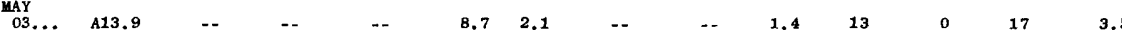

03078800 COXES CREEK NEAR ROCKMOOD (LAT 395726 LONG 07906 13)

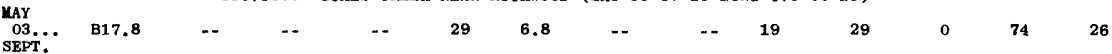

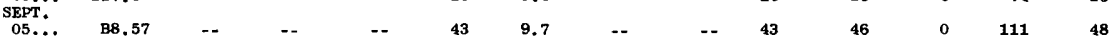

JULY 03079000 CASSELMAN RIVER AT MARKLETON (LAT 395135 LONG 07913 40)

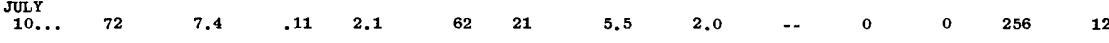

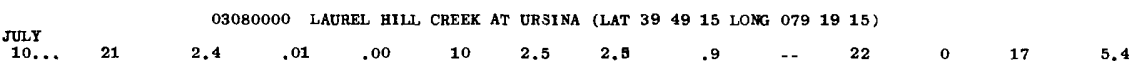

JULY 03081000 YOUGHIOGHENY RIVER BELOW CONFLUENCE (LAT 394940 LONG 07922 25)

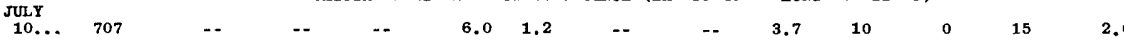

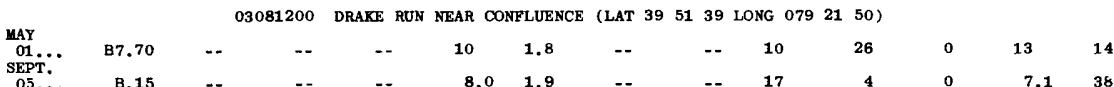

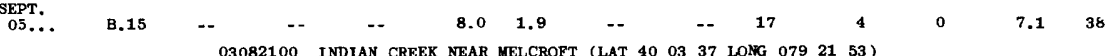

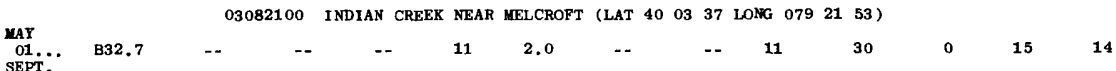

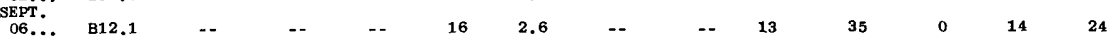

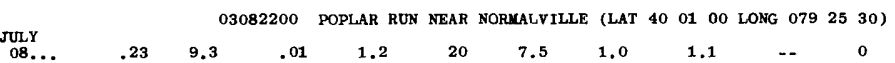

$\begin{array}{lllllllllllllllll}08 & . . & .23 & 9.3 & .01 & 1.2 & 20 & 7.5 & 1.0 & 1.1 & -- & 0 & 0 & 88 & 2.0\end{array}$

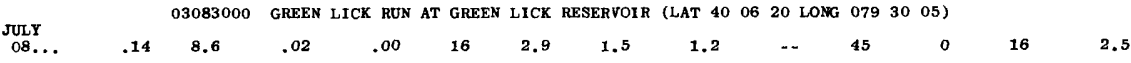

03083200 SEWICKLEY CREEK TRIBUTARY NEAR NEW STANTON (LAT 401242 LONG 07939 27)

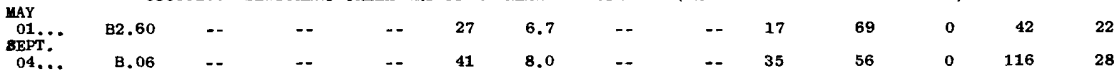

JULY 03083500 YOUGHIOGHENY RIVER AT SUTERVILLE (LAT 401425 LONG 07948 25)

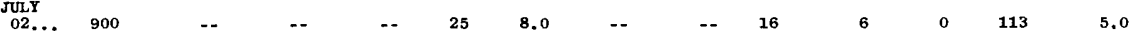

03084000 ABERS CREEK NEAR MURRYSVILLE (LAT $40 \quad 2701$ LONG 0794250 )

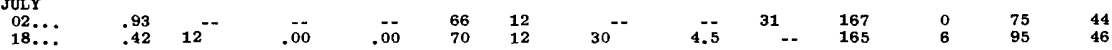

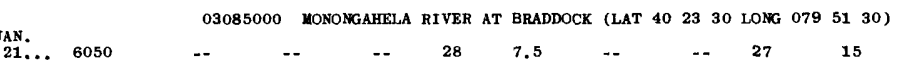

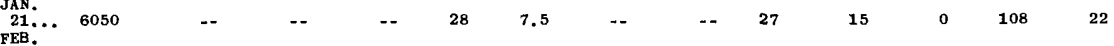

$\begin{array}{rllllllllllllll}15 . . . & 5600 & - & - & - & 22 & 7.2 & -- & -- & 18 & 4 & 0 & 103 & 9.5\end{array}$

A DAILY MEAN DISCHARGE.
B DISCHARGE AT TIME OF SAMPLING. 
CHEMICAL ANALYSES IN MLLIGRAMS PER LITER, TATER YEAR OCTOBER 1967 TO SEPTEMBER 1968

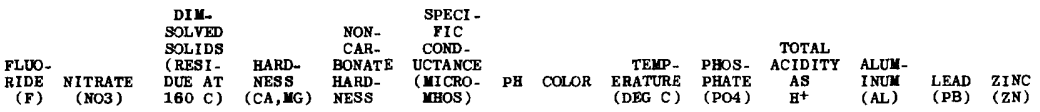

HONONGAHELA RIVER BASIN--CONTI NUED

03072850 SOUTH FORK TENMILE CREEK NEAR ROGERSVILLE (LAT $3953 \quad 00$ LONG 08018 59)

MAY

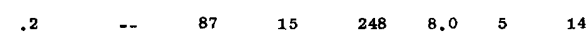

03073000 SOUTH FORK TENMILE AT JEFFERSON (LAT 395525 LONG 0800425 )

$\begin{array}{llllllllllll}\text { JUNE } & & 17 & 1.9 & 219 & 138 & 32 & 380 & 7.7 & 25 & 19 & \ldots\end{array}$

03074300 LICK RUN AT HOPWOOD (LAT 395204 LONG 0794140 )

JULY

JULY 03074500 REDSTONE CREEK AT NALTERSBURG (LAT 395845 LONG $07945 \quad 50$ )

$\begin{array}{lllllllllllll}\text { JULY } & & & & & & \end{array}$

JULY 03075000 KONONGAHELA RIVER AT CHARLEROI (LAT 400830 LONG 07953 35)

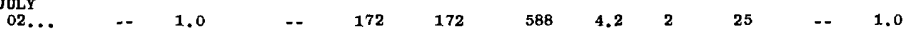

03077500 YOUGHIOGHENY RIVER AT YOUGHIOGHENY RIVER DAY (LAT 3948 20 LONG 079 21 50)

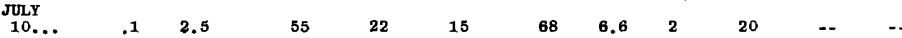

03078700 HLKLICK CREEK AT SUNIT MILLS (LAT $3948 \quad 41$ LONG 0790401 )

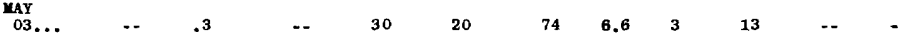

03078800 COXES CREEK NEAR ROCKTOOD (LAT 395726 LONG 07906 13)

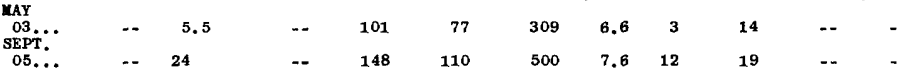

03079000 CASSELIAN RIVER AT MARKLETON (LAT 395135 LONG 079 13 40)

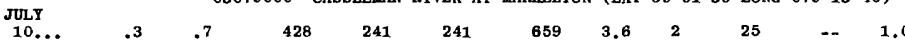

03080000 LAUREL HILL CREEK AT URSINA (LAT 394915 LONG 0791915 )

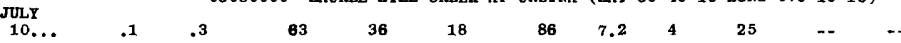

03081011 YOUGHIOGHENY RIVER BELOW CONFLUENCE (LAT 394940 LONG 07922 25)

$\begin{array}{lllllllllllll}\text { JULY } & & & & & & & & & & & & \end{array}$

03081200 DRAKE RUN NEAR CONFLUENCE (LAT 395139 LONG 0792150 )

MAY
SEPT.
SET.

MAY

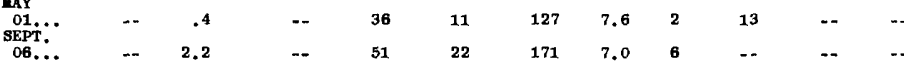

03082200 POPLAR RUN NEAR NORKALVILLE (LAT 40 01 O0 LONG 0792530 )

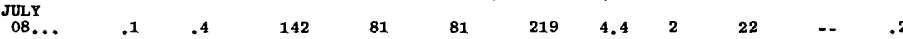

03083000 GREEN LICK RUN AT GREEN LICK RESERVOIR (LAT 40 O6 20 LONG 07930 05)

$\begin{array}{llllllllllll}\text { JULY } & .1 & 1.0 & 80 & 52 & 15 & 115 & 7.5 & 3 & 17 & \ldots & \ldots\end{array}$

03083200 SEWICKLEY CREEK TRIBUTARY NEAR NEW STANTON (LAT 401242 LONG 0793927 )

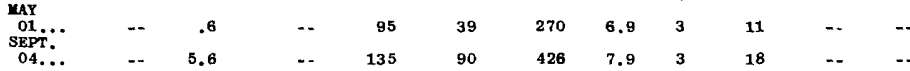

03083500 YOUGHIOGHENY RIVER AT SUTERVILLE (LAT $4014 \quad 25$ LONG 0794825 )

$\begin{array}{llllllllllll}\text { JULY } & & & & & & & \end{array}$

03084000 ABERS CREEK NEAR YURRYSVILLE (LAT 4027 01 LONG 0794250 )

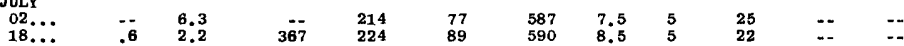

03085000 WONONGAHELA RIVER AT BRADDOCK (LAT 4023 30 LONG 0795130 )

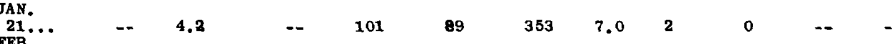

$\begin{array}{rrrrrrrrr}21 . . . & -- & 4.2 & -- & 101 & 89 & 353 & 7.0 & 2 \\ \text { FEB. } & -- & 4 & \ldots & 85 & 81 & 283 & 5.6 & 2\end{array}$ 


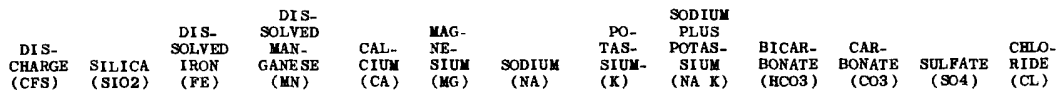

\section{MONONGABELA RIVER BASIN--CONTINUED}

03085000 MONONGAHELA RIVER AT BRADDOCK (LAT $40 \quad 23$ 30 LONG 07951 30)--Cont1nued

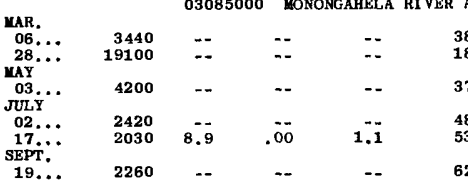

\section{OHIO RIVER MAIN STEY}

03086000 OHIO RIVER AT SEWICKGEY (LAT 403150 LONG 0801120 )

Nov.

$\begin{array}{llllll}- & 21 & 5.5 & - & & \end{array}$

DEC.

LEFT

22500

RAR.

O5..

APR.

11... 34800

MAY

JUL $\mathrm{Y}$

12... 8100 4.8

AUG.

23
21
30
22
22
32
64

$\begin{array}{lllll}6.9 & -- & -- & 15 & 21 \\ 6.4 & -- & -- & 19 & 24\end{array}$

$9.5 \quad--\quad--\quad 36 \quad 14$

6.111

1.7

- 15

5.16 .8

-- 12

$\begin{array}{lllll}9.5 & 27 & 3.4 & \ldots & 17\end{array}$

BEAVER RIVER BASIN

03102800 BIG RUN NEAR SHENANGO (LAT $4122 \quad 26$ LONG 0802553 )

APR. $\quad 56.55-0.03102800$ BIG RUN

29.

06..

B6.55 -

28

7.0

-. 1395

$35 \quad 11$

03106100 WOLF CREEK NEAR GROVE CITY (LAT 412450 LONG 08003 40)

APR.

SEPT. B2.88 -

$5.4 \quad--\quad n-11 \quad 84$

$\begin{array}{rrc}0 & 203 & 20 \\ 0 & 81 & 8.5 \\ 0 & 179 & 12 \\ 0 & 244 & 12 \\ 0 & 249 & 18 \\ 0 & 324 & 10\end{array}$

09 ..

$$
\begin{array}{rrrr}
B 2.88 & - & - & \\
B .47-- & -- & -- & 44
\end{array}
$$$$
8.2 \quad--
$$$$
-
$$

03106300 MUDDY CREEK NEAR PORTERSVILLE (LAT $4057 \quad 47$ LONG $080 \quad 0741$ )

AUG.
$15 .$.
SEPT.
10.

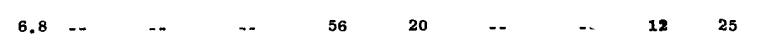

$\begin{array}{rrc}0 & 46 & 17 \\ 0 & 73 & 16 \\ 0 & 73 & 17 \\ 0 & 136 & 24 \\ 0 & 70 & 12 \\ 0 & 68 & 7.5 \\ 0 & 129 & 20 \\ 0 & 281 & 26\end{array}$

JUNE
$18 . .$.

0.- - -

26 --

-. 21

$\begin{array}{llll}440 & 5.8 & .03 & .00\end{array}$

MGURG (LAT 4053 OO LONG 0801355 )

RACCOON CREEX BASIN

03107800 SERVICE CREEK NEAR SHIPPINGPORT (LAT $40 \quad 3412$ LONG 0802407 )

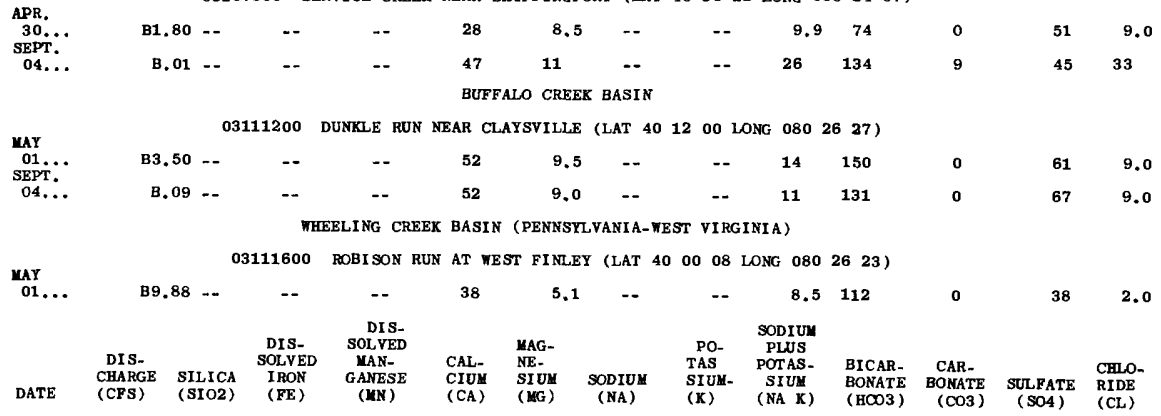

FISH CREEK BASIN

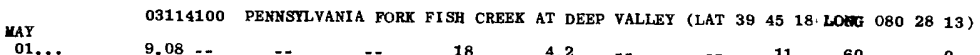

B DISCHARGE AT TIME OF SAMPLING. 
CHEMICAL ANALYSES IN MILLIGRAMS PER LITER, WATER YEAR OCTOBER 1967 TO SEPTEMBER 1968

\begin{tabular}{|c|c|c|c|c|c|c|c|c|c|c|c|c|c|c|}
\hline DATE & $\begin{array}{l}\text { FLUO- } \\
\text { RIDE } \\
\text { (F) }\end{array}$ & $\begin{array}{l}\text { NITRATE } \\
\text { (NO3) }\end{array}$ & $\begin{array}{l}\text { DIS- } \\
\text { SOLVED } \\
\text { SOLIDS } \\
\text { (RES I- } \\
\text { DUE AT } \\
180 \mathrm{C} \text { ) }\end{array}$ & $\begin{array}{l}\text { HARD- } \\
\text { NESS } \\
(\mathrm{CA}, \mathrm{MG})\end{array}$ & $\begin{array}{l}\text { NON- } \\
\text { CAR- } \\
\text { BONATE } \\
\text { HARD- } \\
\text { NESS }\end{array}$ & $\begin{array}{l}\text { SPECI - } \\
\text { FIC } \\
\text { COND- } \\
\text { UCTANCE } \\
\text { (MICBO- } \\
\text { MHOS) }\end{array}$ & PH & COLOR & $\begin{array}{l}\text { TEMP- } \\
\text { ERATURE } \\
\text { (DEG C ) }\end{array}$ & $\begin{array}{l}\text { PHOS- } \\
\text { PHATE } \\
\text { (PO4) }\end{array}$ & $\begin{array}{c}\text { TOTAL } \\
\text { ACIDITY } \\
\text { AS } \\
\text { H }^{+}\end{array}$ & $\begin{array}{l}\text { ALUH- } \\
\text { INUM } \\
\text { (AL) }\end{array}$ & $\begin{array}{l}\text { LEAD } \\
\text { (PB) }\end{array}$ & $\begin{array}{l}\operatorname{ZINC} \\
(\mathrm{ZN})\end{array}$ \\
\hline \multicolumn{15}{|c|}{ MONONGAHELA RIVER BASIN--CONTINUED } \\
\hline \multirow{3}{*}{$\begin{array}{r}06 . . . \\
28, . \\
\text { WAY }\end{array}$} & & 3085000 & MONONGAHELA & A RIVER & AT BRADD & OCK (LAT & 4023 & 330 LONC & NG $079 \quad 51$ & $30)--c$ & ontinued & & & \\
\hline & $\ddot{--}$ & $\begin{array}{l}7.2 \\
2.9\end{array}$ & $\because$ & $\begin{array}{r}140 \\
70\end{array}$ & $\begin{array}{r}139 \\
63\end{array}$ & $\begin{array}{l}488 \\
235\end{array}$ & $\begin{array}{l}4.7 \\
6.7\end{array}$ & $\begin{array}{l}1 \\
2\end{array}$ & $\begin{array}{r}7 \\
12\end{array}$ & $\because$ & $\because$ & $\because$ & $\overline{-}$ & -- \\
\hline & & & & & & & & & & & & & & \\
\hline JuL... & -- & 2.3 & -- & 138 & 132 & 438 & 6.4 & 15 & 20 & -- & -- & -- & -- & -- \\
\hline $02 \ldots$ & -- & 3.3 & - & 178 & 178 & 536 & 4.3 & 3 & 29 & -- & - & -- & -- & -- \\
\hline SEPT; & .4 & 6.2 & 444 & 194 & 193 & 624 & 4.8 & 5 & 32 & -- & .0 & .5 & -- & -- \\
\hline $19 \ldots$ & - & 5.6 & $\ldots$ & 221 & 221 & 733 & 4.5 & 3 & 19 & -- & -- & -- & -- & -- \\
\hline
\end{tabular}

OHIO RIVER MAIN STEM

03086000 OHIO RIVER AT SEW ICKLEY (LAT 403150 LONG OBO 11 20)

03102800 BIG RUN NEAR SHENANGO (LAT 412226 LONG O80 25 53)

$\begin{array}{rrrrrrrrrr}A P R . & & & & & & & & & \\ 29 . & -. & 1.0 & - & 90 & 25 & 234 & 7,1 & 6 & 15\end{array}$

$\begin{array}{llllllllll}06 . & - & 1.8 & \ldots & 99 & 21 & 248 & 8.1 & 15 & 21\end{array}$

03106100 WOLP CREEK NEAR GROVE CITY (LAT 411450 LONG O80 03 40)

$\begin{array}{llllllllll}\text { APR. } & & & & & & & & & \\ 29 . . . & \ldots & 1.0 & \ldots & 85 & 16 & 208 & 7.2 & 12 & 10\end{array}$

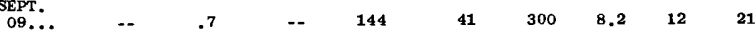

AUG.

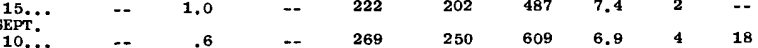

03106500 SLIPPERY ROCK CREEK AT WURTEMBURG (LAT 4053 OO LONG 0801355 )

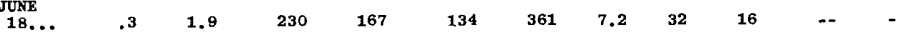

RACCOON CREEK BASIN

O3107800 SERVICE CREEX NEAR SHIPPINGPORT (LAT 403412 LONG 0802407 )

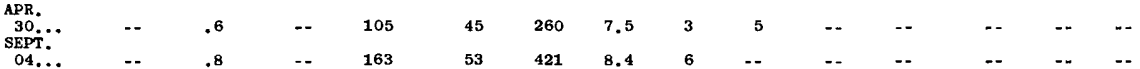

BUFPALO CREEK BASIN

O3111200 DUNRQE RUN NEAR CLAYSVILLE (LAT 4012 OO LONG 0802627 )

MAY
O1.
SEPT.

SEPT.

$2 \quad 2 \quad 169 \quad 46$

- 167

$\begin{array}{lllll}59 & 352 & 8.2 & 4 & 18\end{array}$

WHEELING CREEX BASIN (PENNSYLVANIA-NEST VIRGINIA)

$\underset{01 .}{\text { MaY }}$

03111600 ROBISON RUN AT WEST PINLEY (LAT 40 O0 08 LONG 08028 23)

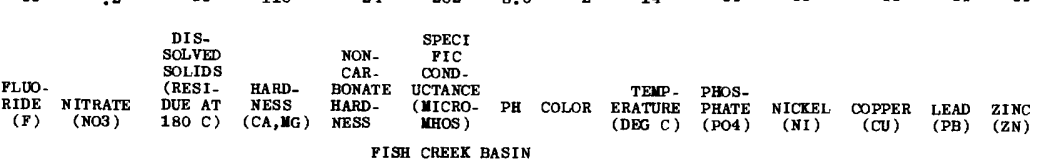

03114100 PENNSYLVANIA FORK PISH CREEK AT DEEP VALLEY (LAT 394518 LONG 08028 13)

MAY 


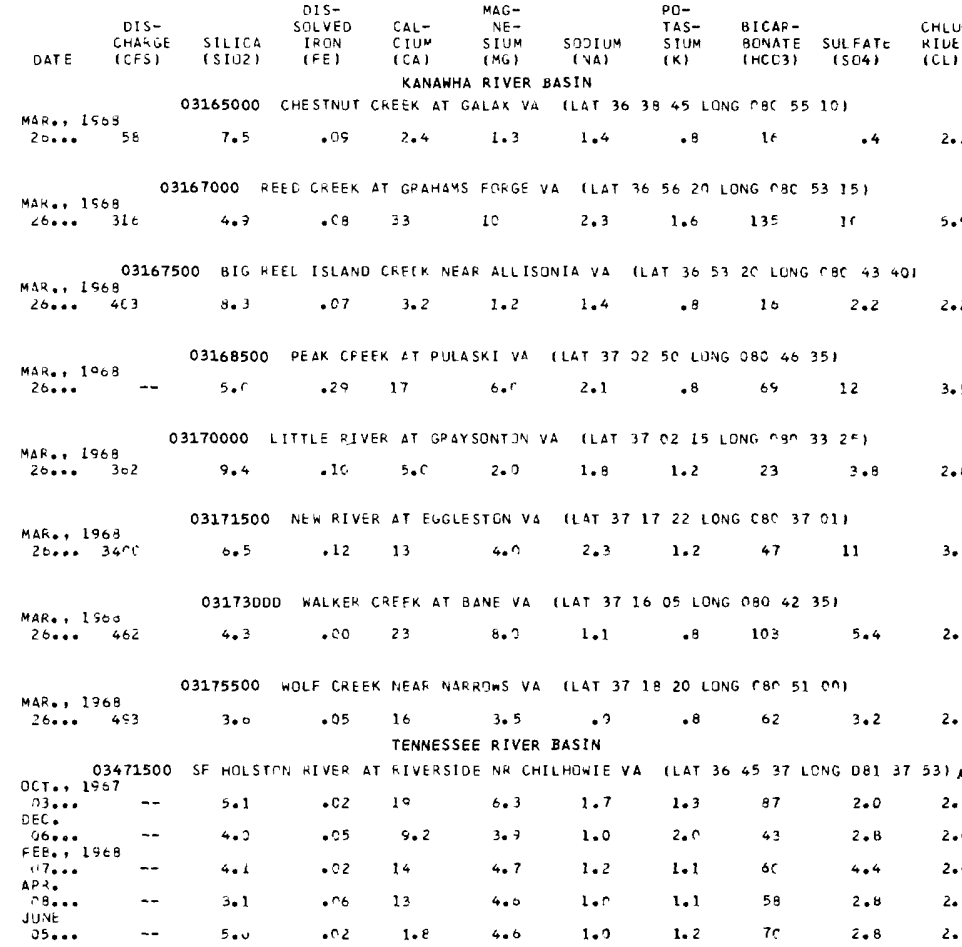

03474000 MIODLE FUHK HOLSTON RIVER AT SEVENMILE FORO VA ILAT 364826 LONG $08137201 \mathrm{~A}$

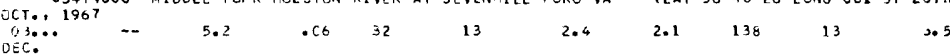
$\begin{array}{lllllllllll}05 . .0 & - & 4.3 & .10 & 20 & 5.9 & 2.0 & 2.7 & 76 & 13 & 4.0\end{array}$

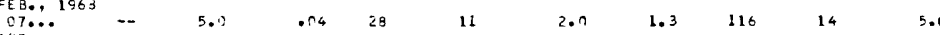
$\begin{array}{lllllllllll}\text { APR. } & \\ \text { OB... } & -- & 3.2 & .66 & 28 & 7.8 & 1.7 & 1.1 & 101 & 10 & 4.5\end{array}$

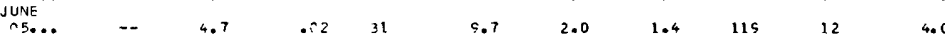

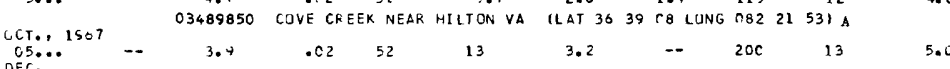

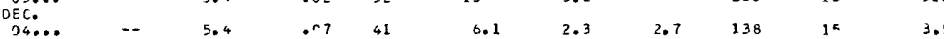
FEB., 1963

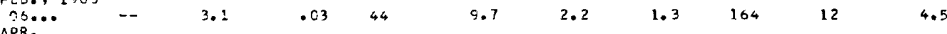

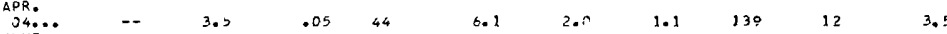

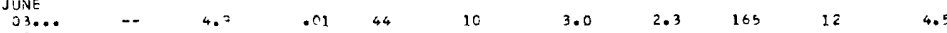
AUG.

MAY, 19E9 03527000 CLIICH RIVER AT SPEERS FERRY VA ILAT 363855 LONG J82 45 C21

$\begin{array}{llllllllll}30 . . .01726 & 4.3 & . r_{4} & 30 & 8.3 & 3.0 & .8 & 111 & 18 & 2.6\end{array}$

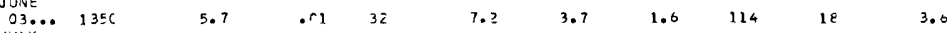

$\begin{array}{lllllllllll}\text { JULY } & 22 t & 2.1 & .04 & 36 & 12 & 6.7 & 2.3 & 152 & 22 & 5.4\end{array}$

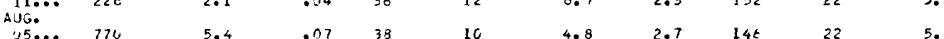

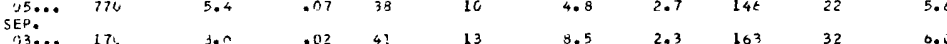

APR., 1568 03527500 NGRTH FOPK CLINCH PIVER $\triangle T$ UUFFIELD VA ILAT 364240 LCNG C82 $47451 \mathrm{~A}$

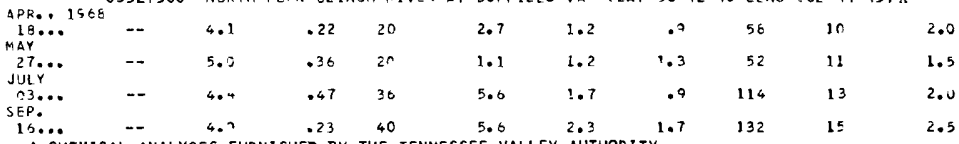

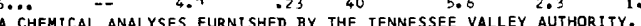


CHEMICAL ANALYSES IN MILLIGRAMS PER LITER, TATER YEAR OCTOBER 1967 TO SEPTEMBER 1968

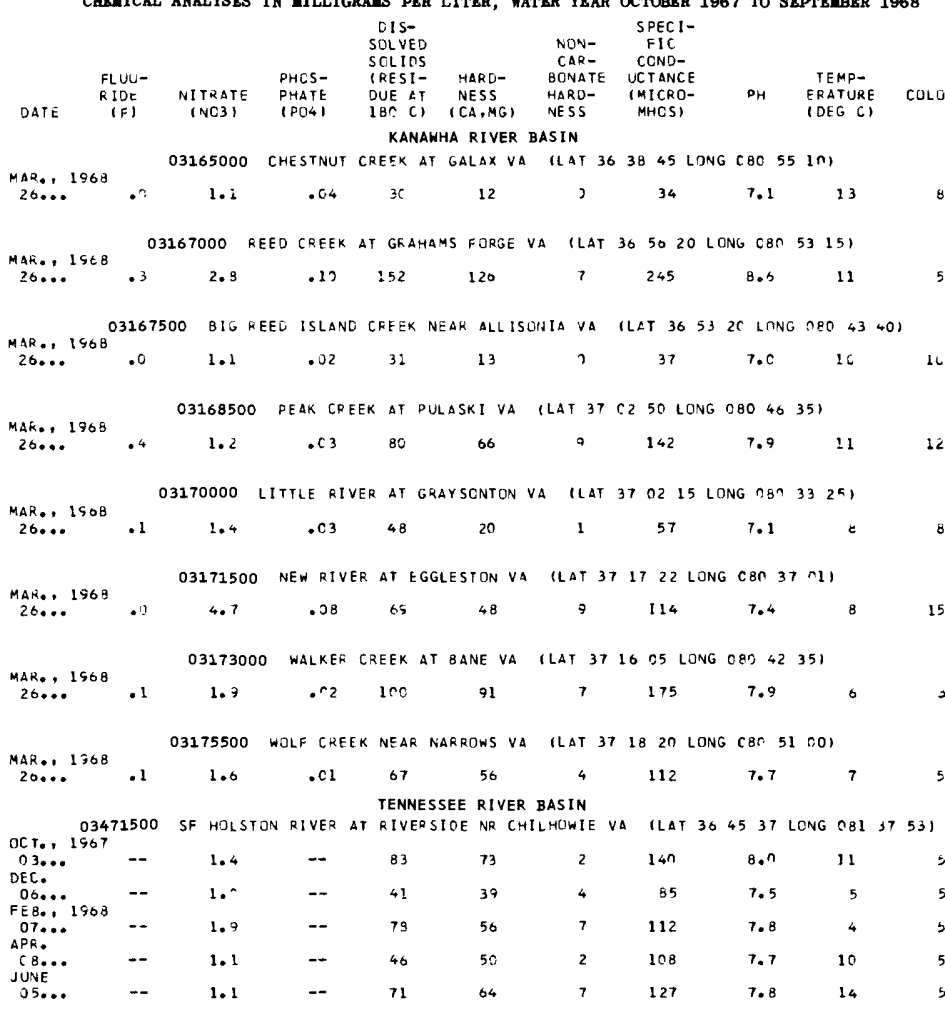

03474000 MIOQLE FOPK HCLSTON RIVER AT SEVENMILE FORD VA (LAT 364826 LONG 0813720 )

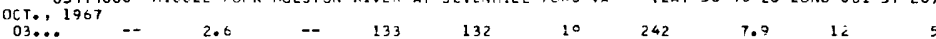

\begin{tabular}{|c|c|c|c|c|c|c|c|c|c|}
\hline $\begin{array}{l}03 \ldots \\
\text { OEC... }\end{array}$ & -- & 2.6 & -- & 133 & 132 & 10 & 242 & 7.9 & 12 \\
\hline $\begin{array}{l}\text { OEC. } \\
\text { O5... } \\
\text { FEB.. 1968 }\end{array}$ & - & 1.6 & -- & 103 & 79 & 16 & 168 & 7.3 & 6 \\
\hline APR... & -- & 4.2 & - & 119 & 116 & $2 !$ & 208 & 7.9 & 0 \\
\hline JUNE & -- & 2.1 & -- & 143 & 101 & 18 & 200 & 7.5 & 12 \\
\hline $35 \ldots$ & -- & 2.7 & -- & 126 & 118 & 22 & 223 & 7.5 & 19 \\
\hline $50 T_{0}, 1907$ & & 03489850 & COVE CKEEK & K NEAR & HILTON VA & ILAT 36 & $30 \cap 8$ LONG & C $82 \quad 21$ & 531 \\
\hline $\begin{array}{l}\text { CCF..1 } 1907 \\
05 . . \\
\text { DEC. }\end{array}$ & -- & .2 & -- & 192 & 183 & 17 & 330 & 7.7 & 19 \\
\hline 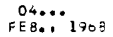 & -- & 3.5 & -- & 147 & 128 & 15 & 270 & 7.8 & 8 \\
\hline$\underset{\triangle{ }_{\triangle P K}}{36 . .}$ & - & 2.5 & - & 153 & 156 & 15 & 280 & 8.2 & 0 \\
\hline JUNE & -- & 1.3 & -- & 116 & 134 & $2^{n}$ & 241 & 7.7 & 14 \\
\hline $\begin{array}{l}03 . . . \\
\text { AUG. }\end{array}$ & -- & 1.4 & - & $16 \mathrm{C}$ & 152 & 17 & 290 & 9.3 & $2 \mathrm{c}$ \\
\hline $06 \ldots$ & - & 1.3 & - & 150 & 194 & 22 & 362 & 8.7 & 22 \\
\hline
\end{tabular}

\begin{tabular}{|c|c|c|c|c|c|c|c|c|c|c|c|}
\hline & & 000 & CLINCH & KIVER & $A T$ & SPEERS & $S$ FERRY VA & ILAT & 363855 & LONG 08245 & $(2)$ \\
\hline $\begin{array}{l}\text { MAY } \\
\text { OG.... } \\
\text { JUNE }\end{array}$ & $\cdot \cdot 3$ & 2.3 & & .13 & 122 & & 108 & 17 & 215 & 8.0 & $2 c$ \\
\hline $\begin{array}{l}\text { J3.... } \\
\text { JuLYy }\end{array}$ & $\bullet !$ & 3.2 & & .04 & 131 & & 108 & 14 & 220 & 7.9 & 18 \\
\hline $\begin{array}{l}11 \ldots \\
\text { AUG. }\end{array}$ & .1 & .8 & & .06 & 162 & & $14 \mathrm{C}$ & 15 & 305 & 8.9 & 25 \\
\hline $\begin{array}{l}\text { U5... } \\
\text { SEP. }\end{array}$ & .3 & 4.4 & & .04 & 167 & & 137 & 13 & 315 & 7.6 & $2 \hat{C}$ \\
\hline $03 \ldots$ & .1 & 1.0 & & .03 & 192 & & 155 & 22 & 330 & 8.2 & 21 \\
\hline
\end{tabular}

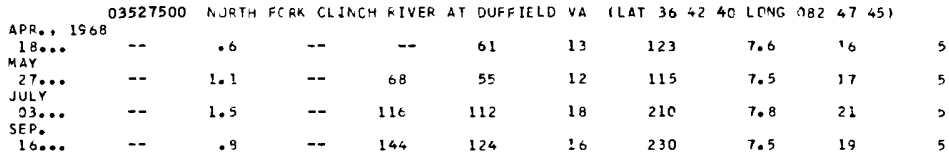




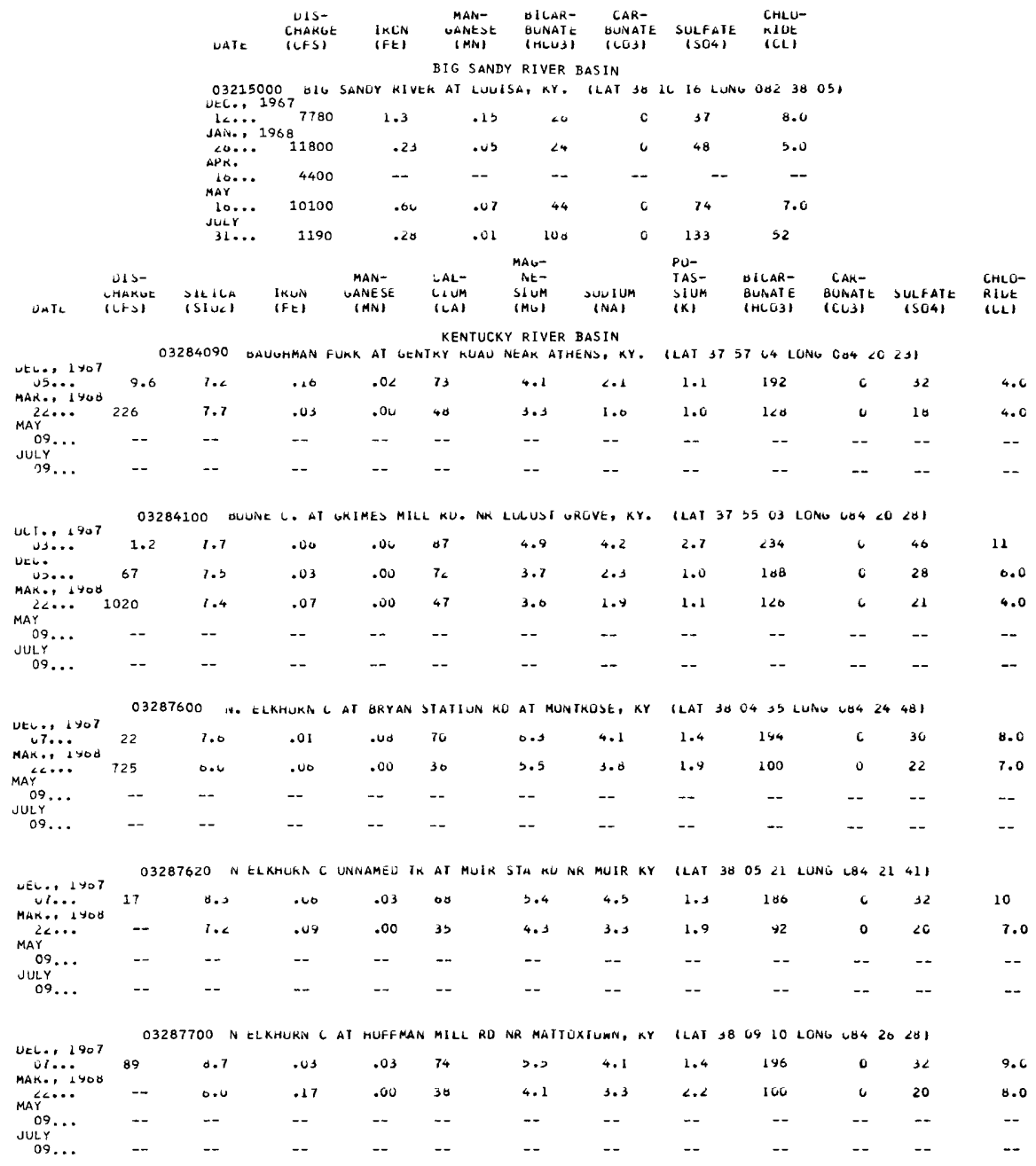


ANALYSES OF SAMPLES COLLECTED AT MISCELLANEOUS SITES IN KENTUCKY

CHEMICAL ANALYSES IN MILLIGRAMS PER LITER, WATER YEAR OCTOBER 1967 TO SEPTEMBER 1968

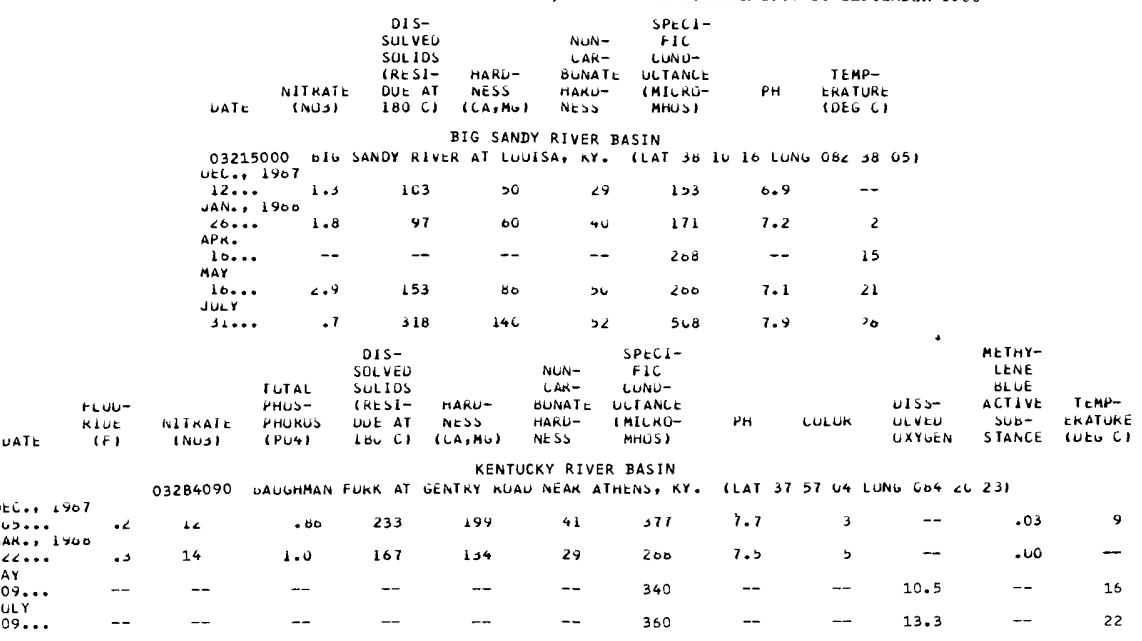

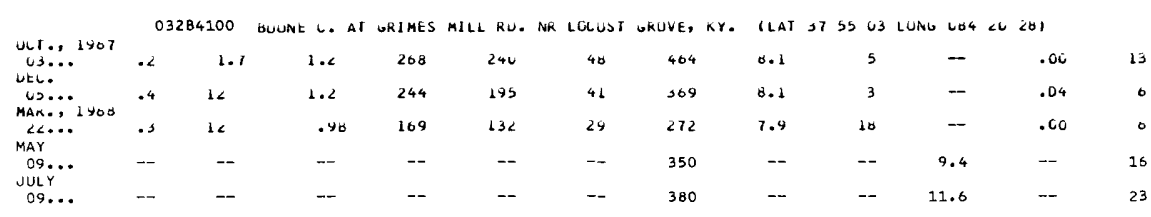

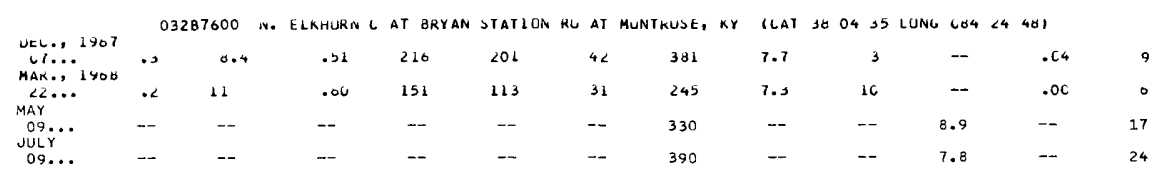

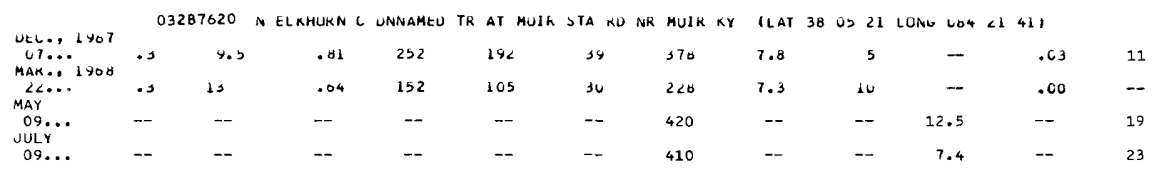

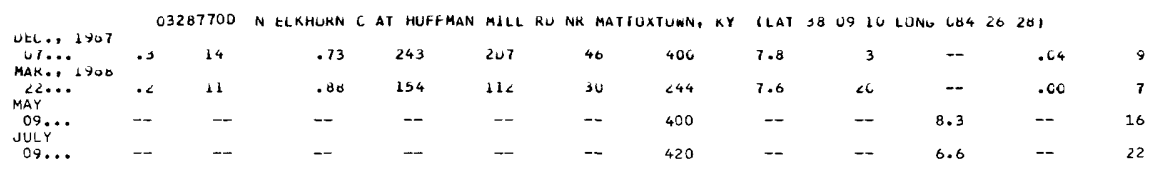




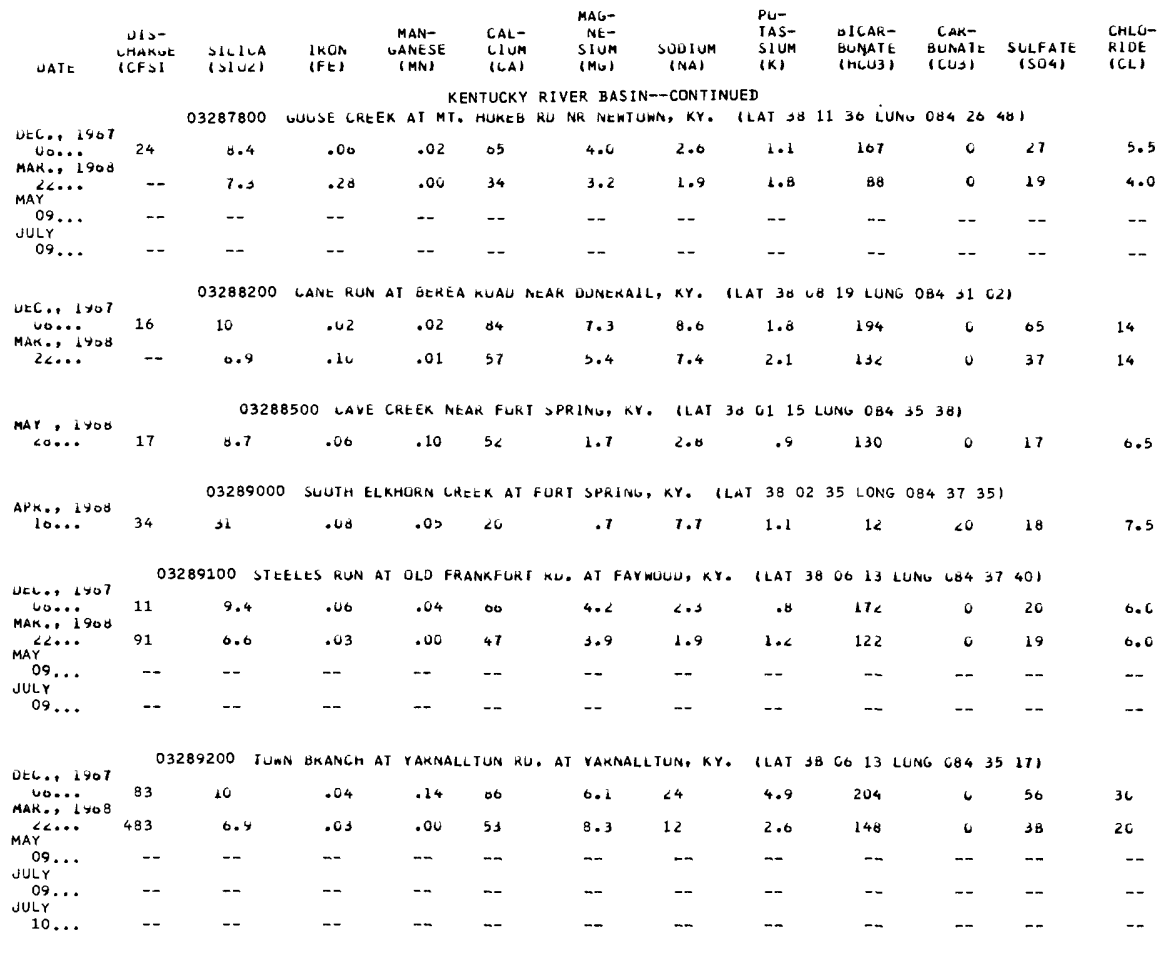


ANALYSES OF SAMPLES COLLECTED AT MISCELLANEOUS SITES IN KTNTUCKY

CHEMICAL ANALYSES IN MILLIGRAMS PER LITER, WATER YEAR OCTOBER 1967 TO SEPTEMBER 1968

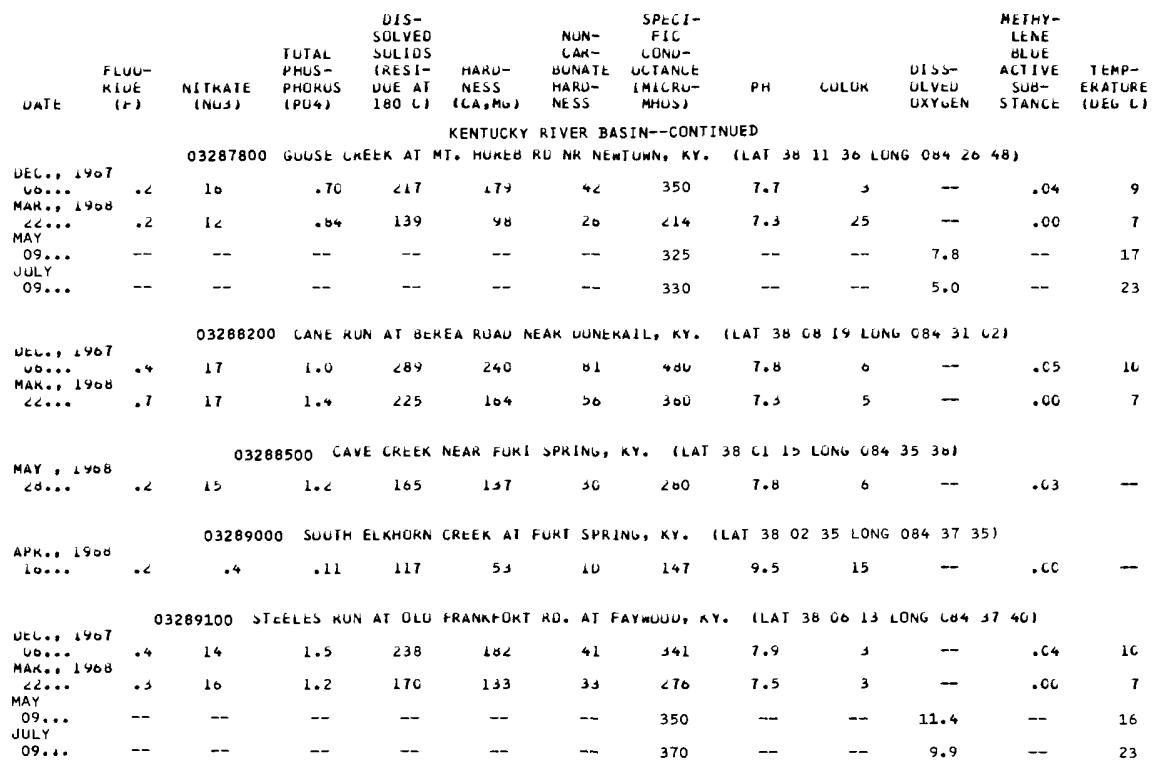

03289200 TÜNN GKANLH AT YARNALLTON KU. AT YARNALLIUN, KY. (LAT 380613 LUNG 6643517 )

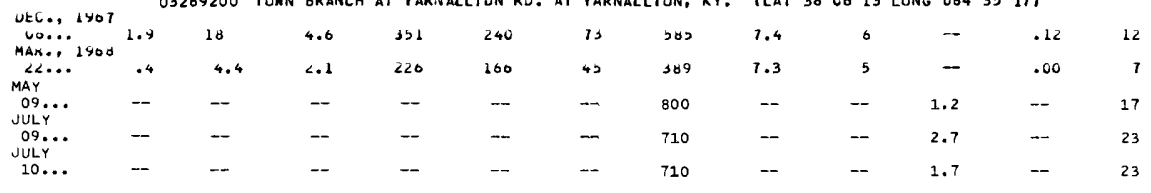


ANALYSES OF SAMPLES COLLECTED AT MISCELLANEOUS SITES IN KENTUCTY

CHEMICAL ANALYSES IN MILLIGRAMS PER LITER, WATER YEAR OCTOBER 1967 TO SEPTEMBER 1968

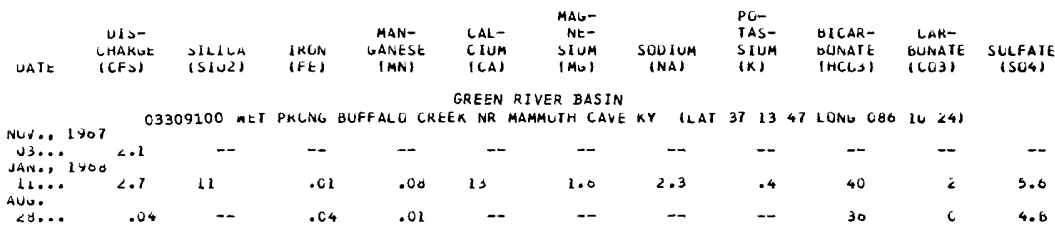

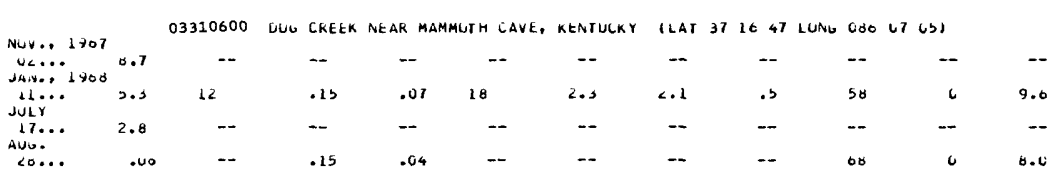

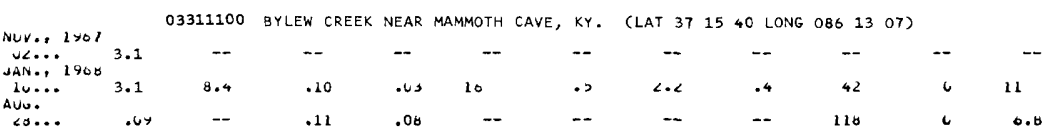

03311600 BEAVER DAM CREEK AT RHODA, KY. (LAT 370918 LONG 08613 35)

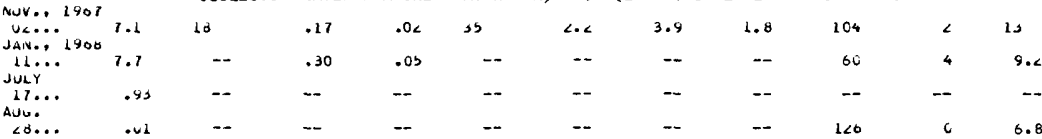

03313570 baYS FUKK AT LLAYPLLL KENTULKY ILAT 3024 25 LUNG CBO 14 Co

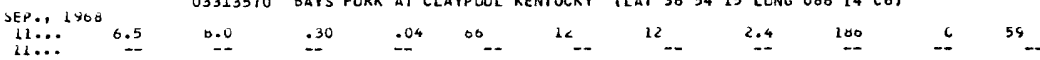

MAK., IYOS 03313590 JNNAMEU NUN-CONTKIB. STREAM AT GKEENHILL, KY. ILAT SO DS 47 LUNO 0 EO 60281

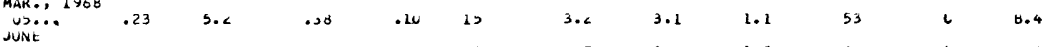

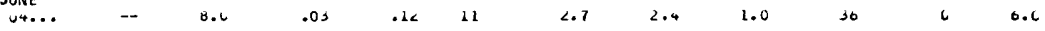

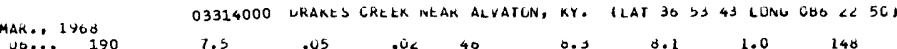

$\begin{array}{lllllllllll}190 & 7.5 & .05 & .0 & 40 & 0.3 & 0.1 & 1.0 & 148 & 0 & 24\end{array}$

03314595 UNNAMEN NLN-CUNTKIB STKEAM AT TAKEE DFKIMUS KY (LAI 30 bD UI LUNG LOO 20 15]

SEP... 1960
$11 .$.

03314610 JENNINGS CREEK NEAK LOST KIVEK, KY. NLAT 30 50 10 LUNL QBO 2416

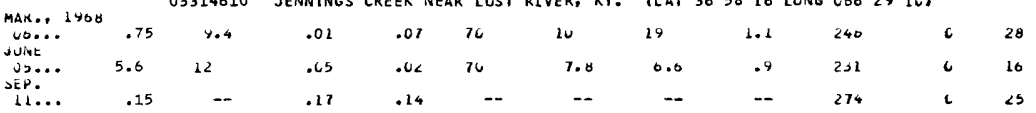

MAR.. IYOB 03314650 JENNINGS $C$ AT US 231 AT BOWLING GREEN, KY. (LAT 365922 LONG 0862933$)$

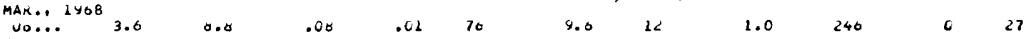

$\begin{array}{lllllllllll}\text { JuISt } & 10 & 9.1 & .01 & .02 & 90 & 0.3 & 4.3 & 4.6 & 190 & 0\end{array}$

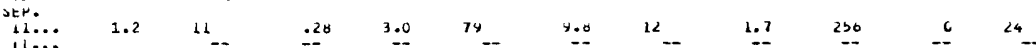




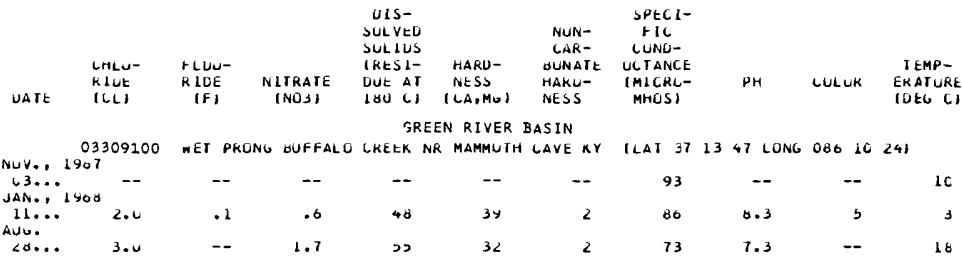

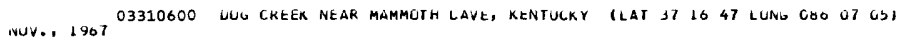

\begin{tabular}{|c|c|c|c|c|c|c|c|c|c|c|}
\hline $0<\ldots$ & -- & -- & -- & -- & -- & -. & 132 & -- & -- & 12 \\
\hline $\begin{array}{l}\text { JAN.., } 1 \text { yoo } \\
11 . . .\end{array}$ & 1.2 & .1 & .8 & 70 & 24 & 7 & 118 & 8.0 & 3 & 2 \\
\hline JuLY & - & - & 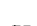 & 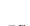 & 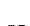 & 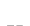 & $2+0$ & & 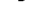 & 4 \\
\hline $\begin{array}{l}17 . . \\
\text { AUG. }\end{array}$ & -- & $\cdots$ & & -- & $\cdots$ & -- & $1<3$ & - & -- & 41 \\
\hline$\angle 8$. & 2.0 & $=$ & 1.0 & du & >4 & 4 & 125 & 7.9 & -- & 16 \\
\hline
\end{tabular}

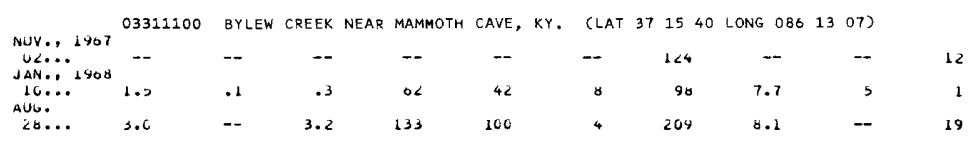

NuV., 1907 03311600 BEAVER DAM CREEK AT RHODA, KY. (LAT 37 O9 18 LONG OB6 13 35)

\begin{tabular}{|c|c|c|c|c|c|c|c|c|c|c|}
\hline $62 \ldots$ & 4.6 & .2 & 1.8 & 134 & 90 & 7 & $2 \mathrm{Cl}_{3}$ & 8.4 & 16 & 13 \\
\hline JuLY & 4.0 & -- & 3.6 & 104 & 38 & 0 & 142 & 8.7 & -- & 4 \\
\hline Aub... & -- & -- & -- & - & -- & + & $\angle 30$ & -- & - & 23 \\
\hline$<0 \ldots$ & 3.0 & $\cdots$ & 4.2 & 109 & 110 & 7 & $\angle 31$ & 7.7 & - & 19 \\
\hline
\end{tabular}

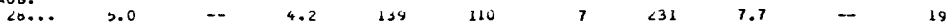

SEP., L YOO 03313570 BAYS FORK AT GLAYPOOL KENTULKY ILAT 365415 LUNG GOG 1406 I

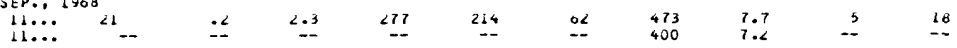

03313590 UHNAMEU NUN-CUNTRI8. JIREAM AT GKEENHILL, KY. ILAT 36 \$3 47 LUNG OEG 1828 J

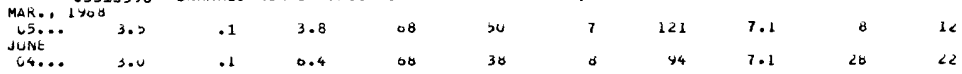

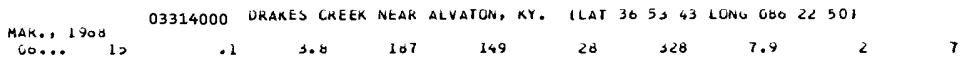

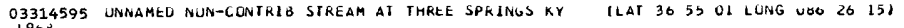

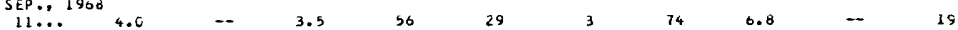
03314610 JENNINGS LKEEK NEAK LOST RIVEK, KY. ILAT 36 38 16 LUNG C86 29101 MAK., 1900

\begin{tabular}{|c|c|c|c|c|c|c|c|c|c|}
\hline JUNE & 15 & .2 & 8.5 & 280 & 210 & 14 & 482 & 8.0 & 2 \\
\hline GS... & 0.5 & .2 & 7.7 & 241 & 207 & 20 & 400 & 7.9 & , \\
\hline $11 \ldots$ & $\angle 2$ & -- & 2.7 & 314 & 244 & 20 & 550 & 7.7 & - \\
\hline
\end{tabular}

MAR., 1900314650 JENNINGS C AT US 231 AT BOWLING GREEN, KY. (LAT 365922 LONG 0862933 )

\begin{tabular}{|c|c|c|c|c|c|c|c|c|c|c|}
\hline Oo... & 10 & .1 & 7.1 & $\angle 70$ & 224 & $\angle 7$ & 472 & 8.2 & i & 12 \\
\hline $\begin{array}{l}\text { wh... } \\
\text { SEP. }\end{array}$ & 5.3 & .1 & B. 1 & 203 & 174 & 18 & 353 & 7.7 & 7 & 14 \\
\hline $11 \ldots$ & 18 & د. & 5.1 & $3 v 3$ & 238 & 28 & 499 & $7 . y$ & -5 & 17 \\
\hline
\end{tabular}




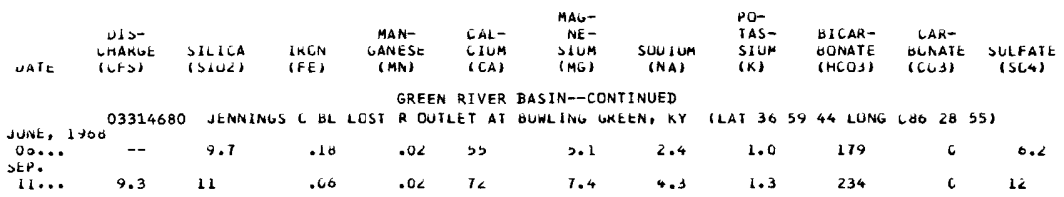

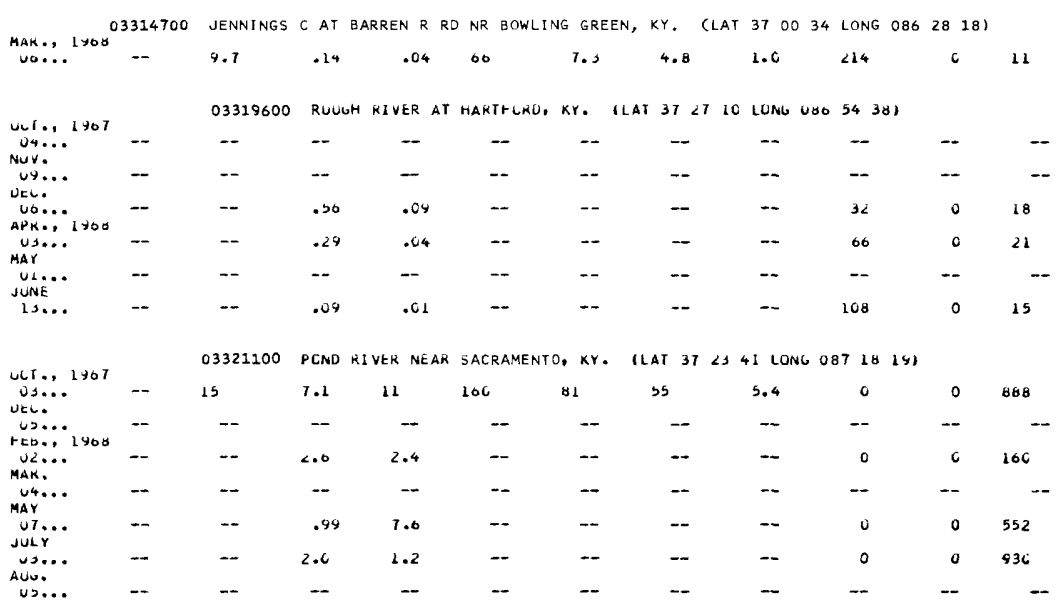

03321500 GREEN RIVER AT L AND D 1 AT SPOTTSVILLE, Kr. (LAT 375130 LONG 0872435 )

\begin{tabular}{|c|c|c|c|c|c|c|c|c|c|c|c|}
\hline $\begin{array}{l}\text { Nur... } 1907 \\
17 \ldots .\end{array}$ & - & -- & -- & -- & -- & -- & -- & -- & -- & - & - \\
\hline $\begin{array}{l}r C 0 . .11 \times 08 \\
\text { U7... } \\
\text { MAK. }\end{array}$ & - & - & .80 & .42 & -- & -- & -- & - & 76 & 4 & $4 d$ \\
\hline MAY & -- & -- & .12 & .24 & -- & -- & - & -- & 70 & G & 46 \\
\hline $27 \ldots$ & -- & -- & .07 & .39 & -- & -- & - & -- & 78 & 0 & 61 \\
\hline $\begin{array}{l}\text { AUG. } \\
12 . . .\end{array}$ & -- & -- & .03 & .55 & -- & -- & -- & -- & 86 & $v$ & 85 \\
\hline
\end{tabular}


CHEMiCAL ANalloes IN MILLIGRAMS PER LIIER, WATER YEAR OCTOBER 1967 TO SEPTEMBER 1968

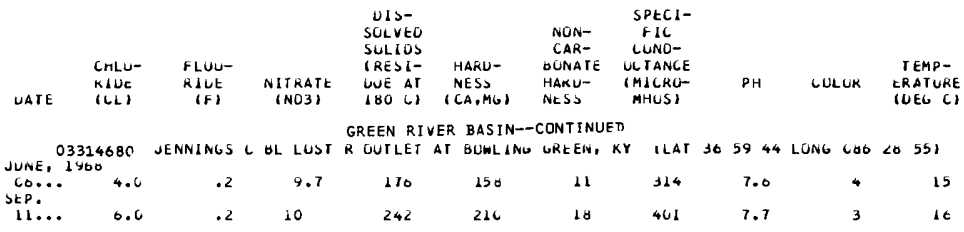

03314700 JENNINGS C AT BARREN R RD NR BOWLING GREEN, KY. ILAT 370034 LONG OB6 2818 I

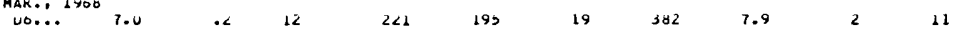

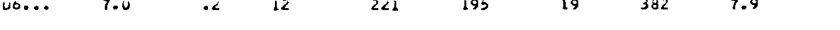

03319600 RUUGH RIVER AT HARIFUKO, KY, (LAT 3727 10 LONG COG 54381

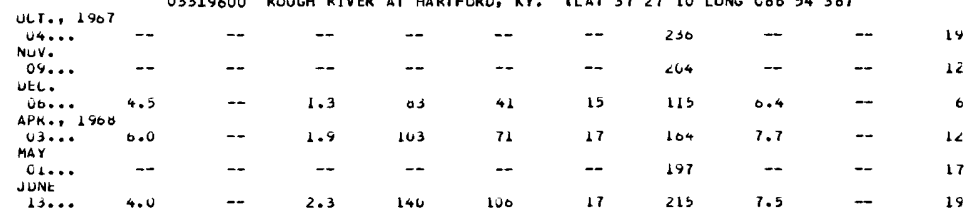

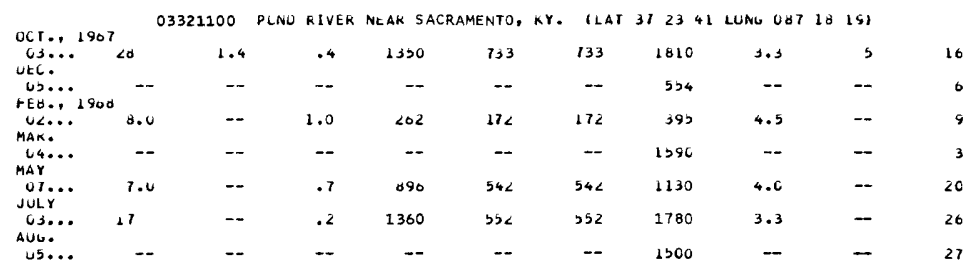

03321500 GREEN KIVER AT L AND D 1 AT SPOTTSVILLE, KY. (LAT 375130 LONG 08724 35) NuV.. 1967

\begin{tabular}{|c|c|c|c|c|c|c|c|c|c|c|}
\hline $11 \ldots$ & - & $=-$ & -- & -- & -- & $\rightarrow$ & 314 & -- & -- & 16 \\
\hline V7... & 9.0 & - & 2.0 & $1>3$ & 112 & 50 & 240 & 4.1 & - & 7 \\
\hline$\underset{M A Y}{\text { MAR. }}$ & 9.0 & $\cdots$ & 3.2 & 142 & 108 & 40 & 238 & 7.7 & -- & 9 \\
\hline $\begin{array}{l}21 \ldots \\
\text { AUs... }\end{array}$ & 9.0 & - & 3.1 & $\lfloor d t$ & 132 & 68 & $\angle 90$ & 7.6 & - & 19 \\
\hline 15. & 14 & - & 2.2 & $2<4$ & 124 & 84 & 372 & 7.2 & - & 8 \\
\hline
\end{tabular}


ANALYSES OF SAMPLES COLLECTED AT UISCELLANEOUS SITES IN KENTUCKY

CHEMICAL ANALYSES IN MILLIGRAMS PER LITER, WATER YEAR OCTOBER 1967 TO SEPTEMBER 1968

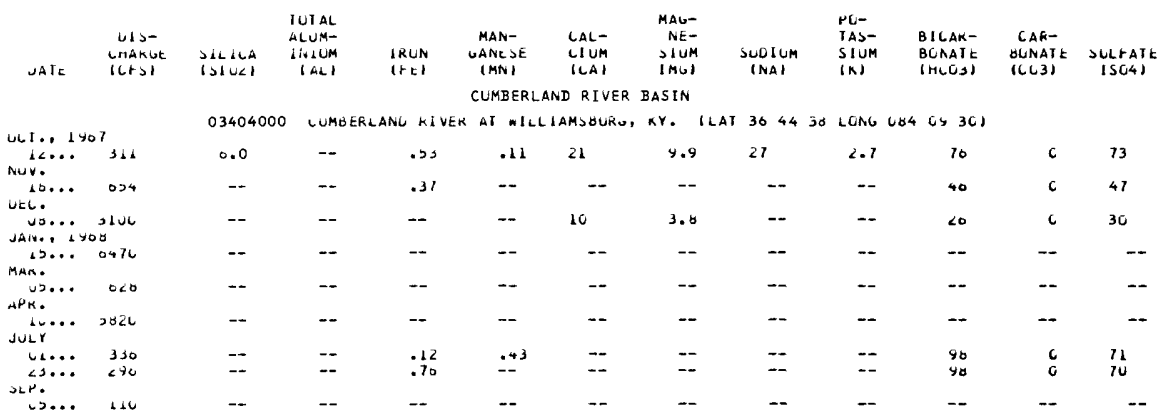

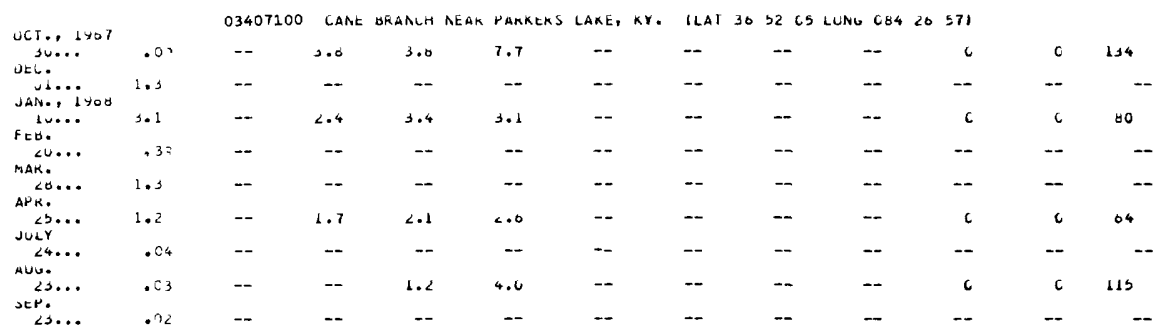

Nuv., 1 y०7

03438220 CUMEEKLANU KIVEK NEAK GKANU RIVERS, KY. ILAI 370115 LUNG OH8 LS Z3I

Ni... 43022

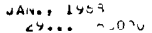

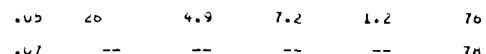

- - - . . .

$.61 \quad--$

Hy... 21303

MAY $\$ 7 . . .67030$

JuLY

Str.

$+\quad-.04$

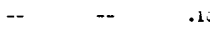

.02

13... ool 
CHEMICAL ANALYSES IN MILLIGRAMS PER LITER, WATER YEAR OCTOBER 1967 TO SEPTEMBER 1968

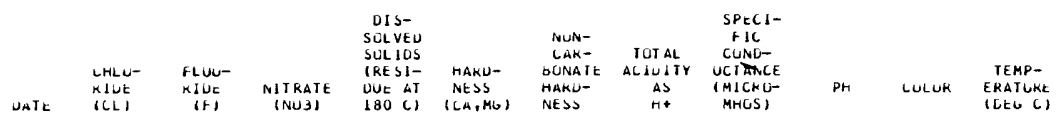

03404000 CUMBERLANU RIVEK AI MILLIAMSOUKG, KY. (LAI 304430 LUNG 084 Uy $3 U$

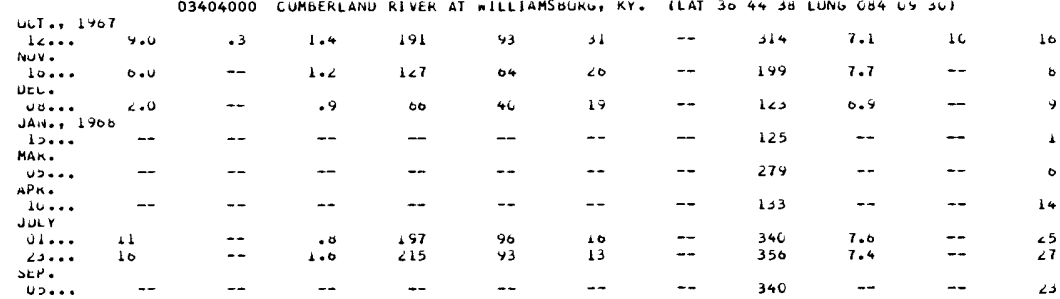

Uน1., 2907

03407100 CANE BKANLH NEAK PAKKERS LAKE, KY. (LAT SO DL OS LUNG $084 \angle 6$ DI)

\begin{tabular}{|c|c|c|c|c|c|c|c|c|c|c|c|}
\hline $\begin{array}{l}46 .+1967 \\
30 . . .\end{array}$ & 3.0 & $\cdots$ & . 1 & $<20$ & 100 & buo & 1.0 & $4 \angle 2$ & 3.5 & -- & B \\
\hline $\begin{array}{l}\text { UEL. } \\
\text { Ui... }\end{array}$ & $\ldots$ & $\ldots$ & -- & -- & -- & -- & -- & 162 & -- & -- & 0 \\
\hline $\begin{array}{l}\text { JA.r., } 1908 \\
\text { tu... }\end{array}$ & & & & 1 & & & 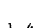 & & 14 & - & \\
\hline reo... & 400 & -- & .2 & 114 & 60 & oc & 1.4 & 238 & 3.9 & -- & 2 \\
\hline ¿ & -- & -- & - & -- & - & -- & -- & 550 & -- & - & 6 \\
\hline $\begin{array}{l}\text { MAK. } \\
\text { LO... } \\
\text { APK . }\end{array}$ & -- & - & $\cdots$ & -- & -- & -- & -- & 231 & - & -- & 11 \\
\hline SULY... & נ.u & - & .1 & 90 & 50 & 36 & .7 & 192 & 4.1 & - & $2<$ \\
\hline Lu... & -- & -- & $=$ & + & - & - & - & 380 & - & - & $<5$ \\
\hline$<3 \ldots$ & 2.6 & -- & .1 & 178 & $8<$ & 02 & .8 & 351 & 3.0 & -- & $<4$ \\
\hline $2, \ldots$ & -- & - & - & -- & -- & - & -- & $\mathrm{SCC}$ & - & - & 19 \\
\hline
\end{tabular}

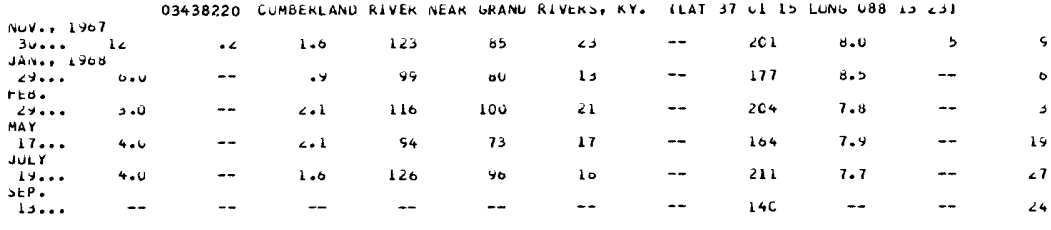




\begin{tabular}{|c|c|c|c|c|c|c|c|c|c|c|c|c|}
\hline DATE & $\begin{array}{l}\text { MEAN } \\
\text { DIS- } \\
\text { CHARGE } \\
\text { (CFS) }\end{array}$ & $\begin{array}{l}\text { SILICA } \\
\text { (SIO2) }\end{array}$ & $\begin{array}{l}\text { DI S- } \\
\text { SOLVED } \\
\text { I RON } \\
\text { (FE) }\end{array}$ & $\begin{array}{l}\text { YAN- } \\
\text { GANESE } \\
(\text { UN })\end{array}$ & $\begin{array}{l}\text { CAL- } \\
\text { CIUM } \\
\text { (CA) }\end{array}$ & $\begin{array}{l}\text { MAG- } \\
\text { NE- } \\
\text { SIUM } \\
\text { (MG) }\end{array}$ & $\begin{array}{l}\text { SODIUM } \\
\text { (NA) }\end{array}$ & $\begin{array}{l}\text { PO. } \\
\text { TAS- } \\
\text { SIUH } \\
(K)\end{array}$ & $\begin{array}{l}\text { BICAR- } \\
\text { BONATE } \\
\text { (HCO3) }\end{array}$ & $\begin{array}{l}\text { CAR- } \\
\text { BONATE } \\
\text { (CO3) }\end{array}$ & $\begin{array}{c}\text { SULFATE } \\
\text { (SO4) }\end{array}$ & $\begin{array}{l}\text { CHLO- } \\
\text { RIDE } \\
\text { (CL) }\end{array}$ \\
\hline
\end{tabular}

CUYRERLAND RIVER BASIN

JUNE 03420400 MUD CREEK NEAR SUMMITVILLE (LAT 353723 LONG $086 \quad 0000$ )

NOV. 03426800 EAST FORK STONES RIVER AT WOODBURY (LAT 354941 LONG 0860436 )

$\begin{array}{lllllllllllll}\text { 15... } & 12 & 4.8 & .04 & .04 & 50 & 7.4 & 1.5 & .9 & 176 & 0 & 14 & 2.1\end{array}$

03426850 CARSON FORK AT BURT (LAT $3546 \quad 29$ LONG $086 \quad 0756$ )

$\begin{array}{llllllllll}\text { NOV. } & & & & & & & & & \\ 15 & 4.3 & 4.3 & .02 & .02 & 51 & 6.0 & 1.3 & .9 & 172\end{array}$

03426880 BRAWLEYS FORK NEAR READYVILLE (LAT $3548 \quad 06$ LONG $086 \quad 0904$ )

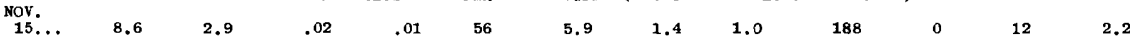

NOV. 03426900 EAST FORK STONES RIVER BELOW READYVILLE (LAT 355016 LONG 0861121 )

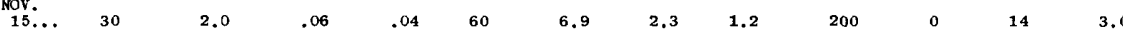

03426920 MCKNIGHT BRANCH NEAR HALLS HILL (LAT 3552 01 LONG 08611 57)

Nov.

NOV. $\quad .15$

$\begin{array}{llllllll}5.6 & .02 & .04 & 91 & 5.1 & 1.3 & .7 & 276\end{array}$

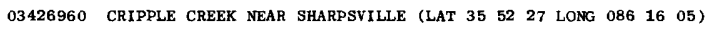

Nov.

$\begin{array}{llllllll}4.1 & .02 & .02 & 86 & 6.3 & 1.8 & 1.0 & 262\end{array}$

03427000 BRADLEY CREEK AT LASCASSAS (LAT 355539 LONG 0861725 )

OCT.

$\begin{array}{lllllllll}1.3 & .02 & .00 & 63 & 5.7 & 1.8 & 1.3 & 202 & 0\end{array}$

03427500 EAST FORK STONES RIVER NEAR LASCASSAS (LAT 355507 LONG 08620 01)

$\begin{array}{ll}\text { MAR. } & \\ \text { OS... } & 75\end{array}$

$\begin{array}{lllllllll}2.1 & .00 & .02 & 55 & 6.0 & 1.9 & .7 & 181 & 0\end{array}$

$\begin{array}{lllllllll}1.2 & .49 & .06 & 66 & 5.5 & 1.5 & .7 & 210 & 0\end{array}$

$\begin{array}{lllllllll}4.4 & .00 & .02 & 65 & 5.7 & 1.5 & .9 & 207 & 0\end{array}$

$\begin{array}{lllllllll}2.6 & .03 & .01 & 60 & 5.3 & 1.5 & .7 & 192 & 0\end{array}$

03427700 BUSHMAN CREEK NEAR MURFREESBORO (LAT $35 \quad 5344$ LONG $086 \quad 2053$ )

OCT.

$\begin{array}{lllllllll}6.8 & .05 & .02 & 77 & 6.1 & 2.7 & 1.7 & 245 & 0\end{array}$

03427800 WEST FORK STONES RIVER AT BARFIELD (LAT $3547 \quad 13$ LONG 0862520 )

ocT.
6.4
$\begin{array}{lll}5.3 & 1.8 & 1.5\end{array}$
240
0

$\begin{array}{ll}.05 & .03\end{array}$

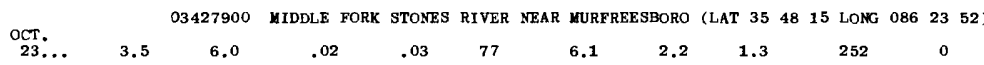

03428000 WEST FORK STONES RIVER NEAR MURFREESBORO (LAT 354920 LONG 0862503 )

$\begin{array}{lr}\text { FEB. } & \\ \text { O5... } & 167 \\ \text { MAR. } & \\ 04 . . & 31 \\ \text { APR. } & \\ 03 . . . & 520 \\ \text { MAY } & \\ 07 \ldots & 61 \\ \text { JUNE } & \\ 11 \ldots & 28\end{array}$

APR.

$\stackrel{\text { APR. }}{12 . .} \quad 11$

APR. $\quad 41$

Nov. $\quad 11$

$\quad \begin{array}{ll}\text { OCT. } \\ 23 . . . & 46\end{array}$

JUNE

$\begin{array}{llll}5.9 & .03 & .02 & 75 \\ 6.6 & .00 & .01 & 63 \\ 4.6 & .06 & .02 & 68 \\ 5.4 & .00 & .02 & 63 \\ 4.6 & .70 & .02 & 63\end{array}$

$\begin{array}{llll}4.6 & .70 & .02 & 63\end{array}$

03428300 SNAIL SHELL CAVE SPRING NEAR ROCKVALE (LAT 354657 LONG 0863211 )$$
4.5 \quad .00 \quad .00 \quad 84
$$

03428301 OVERALL SPRING NEAR ROCKVALE (LAT 3548 10 LONG 08681 20)

$$
\begin{array}{llllllllll}
3.7 & .00 & .00 & 59 & 4.8 & 1.0 & .6 & 182 \\
03428400 & \text { OVERALL } & \text { CREEK NEAR MURFREESBORO (LAT } & 35 & 54 & 22 & \text { LONG } & \text { O86 } & 27 & 41 \text { ) }
\end{array}
$$

$$
\begin{array}{llllllll}
6.4 & .02 & .02 & 91 & 5.3 & 1.6 & .9 & 284
\end{array}
$$

$$
\begin{aligned}
& 03428500 \text { TEST FORK STONES RIVER NEAR SMYRNA (LAT } 35 \quad 56 \quad 25 \text { LONG } 086 \quad 2754 \text { ) } \\
& \begin{array}{lllllllll}
5.4 & 01 & .00 & 77 & 6.1 & 14 & 2.9 & 229
\end{array}
\end{aligned}
$$

03435030 RED RIVER NEAR PORTLAND (LAT $36 \quad 3324$ LONG 08634 14)

\section{7}

1

.8

2


CHEMICAL ANALYSES IN HILLIGRAMS PER LITER, WATER YEAR OCTOBER 1967 TO SEPTEMBER 1968

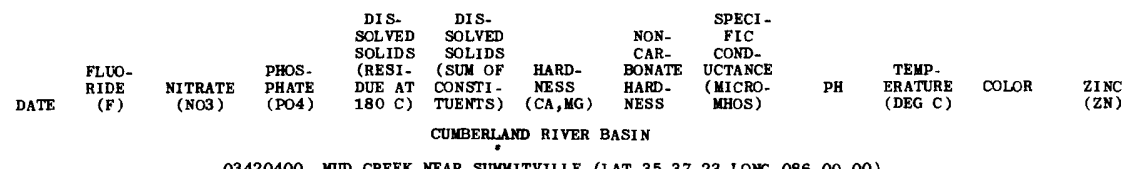
03420400 MUD CREEK NEAR SUMITVILLE (LAT 353723 LONG 086 OO 00 )

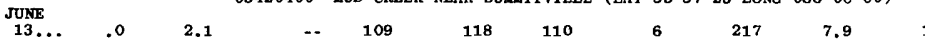

NOY. 03426800 EAST FORK STONES RIVER AT NOODBURY (LAT 354941 LONG O86 04 36)

$\begin{array}{ccccccccccccccc}15 & . . & .0 & .0 & .00 & 168 & 167 & 156 & 14 & 300 & 7.8 & 11 & 2 & .01\end{array}$

03426850 CARSON FORK AT BURT (LAT $3546 \quad 29$ LONG 086 O7 56)

$\begin{array}{llllllllll}\text { NoV. } & 0 & .0 & .05 & 163 & 161 & 152 & 10 & 295 & 7.7\end{array}$

NOY. 03426880 BRATLEYS FORK NEAR READYVILLE (LAT 3548 06 LONG 088 09 04)

$\begin{array}{lllllllllllllll}\text { N5... } & .0 & .0 & .08 & 174 & 174 & 164 & 10 & 315 & 8.2 & 11 & 3 & .01\end{array}$

NOV. 03426900 EAST FORK STONES RIVER BELON READYVILLE (LAT 355016 LONG 0861121 )

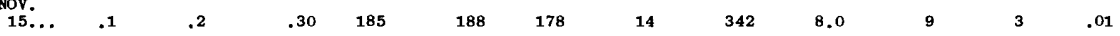

03426920 MCKNIGHT BRANCH NEAR HALLS HILL (LAT 3552 01 LONG O86 11 57)

$\begin{array}{lllllllllllllll}\text { 15... } & .0 & .9 & .01 & 253 & 256 & 248 & 22 & 440 & 8.0 & 13 & 3 & .01\end{array}$

03426960 CRIPPLE CREEK NEAR SHARPSVILLE (LAT $3552 \quad 27$ LONG $086 \quad 1605$ )

Nov.

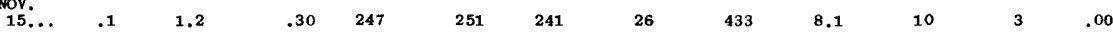

03427000 BRADLEY CREEK AT LASCASSAS (LAT 355539 LONG 0861725 )

$\begin{array}{ccccccccccccc}\text { OCT. } & .1 & .0 & .00 & 196 & 193 & 181 & 15 & 342 & 8.0 & 19 & 11 & .01\end{array}$

MAR. 03427500 EAST FORK STONES RIVER NEAR LASCASSAS (LAT 3555 O7 LONG O86 20 01)

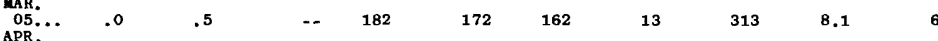

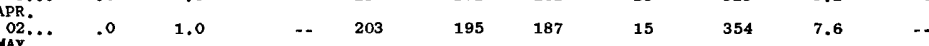

$\begin{array}{lllllllllll}\text { CAY } & & & & & & & & & \\ 06 & .0 & .6 & -. & 187 & 194 & 184 & 14 & 341 & 7.6 & -\end{array}$

$\begin{array}{llllllllllll}\text { JUNE } & 11 \ldots & .1 & .7 & -- & 182 & 179 & 172 & 14 & 321 & 8.0 & --\end{array}$

OCT. 03427700 BUSHMAN CREEK NEAR MURFREESBORO (LAT 355344 LONG OB6 20 53)

$\begin{array}{llllllllllllllll}\text { OCT. } & .0 & .0 & .00 & 238 & 231 & 217 & 16 & 409 & 8.0 & 18 & 4 & .01\end{array}$

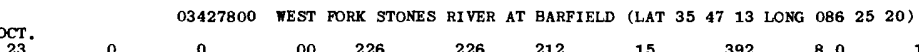

03427900 MIDDLE FORK STONES RIVER NEAR MURFREESBORO (I.AT $3548 \quad 15$ LONG 0862352 )

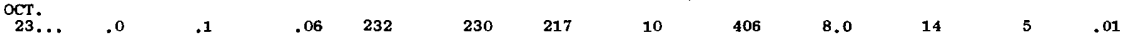

TEB. 03428000 TEST FORK STONES RI VER NEAR MURFREESBORO (LAT 354920 LONG 0862503 )

$\begin{array}{cccccccccccc}\text { FEB. } & . . & .0 & .4 & -- & 231 & 220 & 207 & 13 & 390 & 7.9 & 10\end{array}$

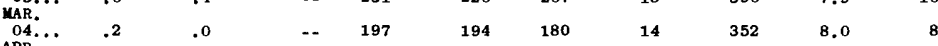

$\begin{array}{ccccccccccc}\text { APR. } & 1 & 1.0 & \ldots & 208 & 204 & 191 & 11 & 366 & 7.8 & \ldots\end{array}$

$\begin{array}{rllllllllll}\text { MAY } \\ 07 \ldots & .0 & .2 & \ldots & 191 & 189 & 178 & 11 & 343 & 7.8 & -.\end{array}$

$\begin{array}{llllllllllll}11 \ldots & .1 & 1.7 & \ldots & 186 & 186 & 174 & 12 & 336 & 7.9 & \ldots\end{array}$

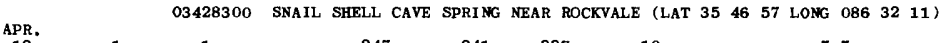

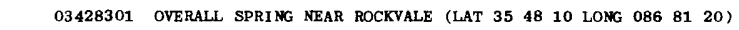

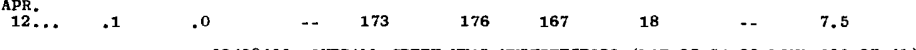
03428400 OVERALL CREEK NEAR MURFREESBORO (LAT $35 \quad 5422$ LONG $086 \quad 2741$ )

$\begin{array}{llllllllll}\text { NOV. } & 0 & 1.4 & .00 & 261 & 260 & 249 & 16 & 453 & 8.1\end{array}$

OCT. 03428500 NEST FORK STONES RIVER NEAR SMYRNA (LAT 355625 LONG OB6 27 54)

$\begin{array}{cccccccccccccc}\text { OCT. } & 2 & . . & .2 & 3.8 & 4.9 & 272 & 263 & 217 & 30 & 462 & 7.4 & 14 & 5\end{array}$ 03435030 RED RIVER NEAR PORTLAND (LAT $36 \quad 3324$ LONG 08634 14) 
ANALYSES OF SAMPLES COLLECTED AT MISCELLANEOUS SITES IN TENNESSEE

CHEMICAL ANALYSES IN MILLIGRAMS PER LITER, WATER YEAR OCTOBER 1967 TO SEPTEMBER 1968

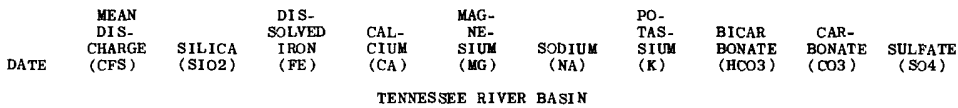

03461180 COSBY CREEK NEAR BLUFFTON (LAT $3545 \quad 47$ LONG $083 \quad 1238$ )

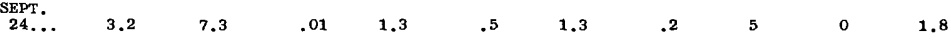

03469100 LITTLE PIGEON RIVER NEAR PITTMAN CENTER (LAT 354420 LONG OB3 24 59)

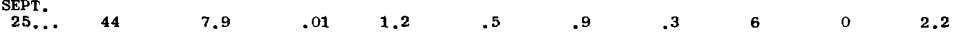

03469225 WEST PRONG LITTLE PIGEON RIVER NEAR MOUNT LE CONTE (LAT 353814 LONG 0832934 )

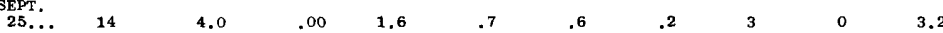

03469290 DUDLEY CREEK NEAR GATLINBURG (LAT 354348 LONG 0832702 )

$\begin{array}{ccccccccccc}\text { SEPT. } & .74 & 13 & .02 & 2.0 & .6 & 2.2 & .4 & 15 & 0 & .2\end{array}$

03469400 WEST PRONG LITTLE PIGEON RIVER AT GATLINBURG (LAT 3544 O1 LONG 08331 13)A

\begin{tabular}{|c|c|c|c|c|c|c|c|c|c|c|}
\hline $\begin{array}{l}06, . . \\
\text { FEB. }\end{array}$ & 74 & 6.9 & -- & 4.9 & .3 & 2.0 & .7 & 15 & -- & 3,0 \\
\hline$\underset{\text { MAY }}{01} \cdots$ & 146 & 4.9 & .02 & 3.7 & .0 & 1.5 & .7 & 10 & -- & 2.0 \\
\hline $\begin{array}{l}\text { O6.... } \\
\text { AUG. }\end{array}$ & 75 & 6.5 & .04 & 5.1 & .3 & 1.7 & .7 & 15 & -- & .0 \\
\hline 0 & 71 & 4.8 & .05 & 5.1 & .5 & 2.0 & 1.0 & 15 & -- & 4.0 \\
\hline
\end{tabular}

03469500 WEST PRONG LITTLE PIGEON RIVER NEAR PIGEON FORGE (LAT $\begin{array}{llllllll}35 & 48 & 21 & \text { LONG } & 083 & 34 & 28\end{array}$

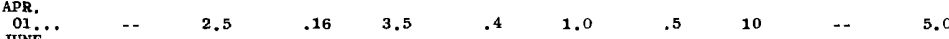

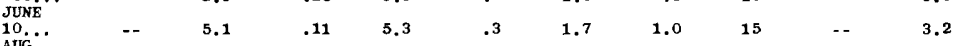

$\begin{array}{lllllllllll}26 . . . & \ldots & 5.2 & .07 & 9.9 & .6 & 3.5 & 1.5 & 30 & -- & 5.2\end{array}$

03470000 LITTLE PIGEON RIVER AT SEVIERVILLE (LAT 355352 LONG 08334 52)A

$\begin{array}{rrrrrrrrrrr}\text { FEB. } \\ \text { 01... } & 604 & 6.3 & .04 & 10 & 1.2 & 2.0 & .7 & 33 & -. & 5.0 \\ \begin{array}{r}\text { APR. } \\ \text { O2... }\end{array} & 1440 & 3.9 & .09 & 9.3 & .3 & 1.4 & .7 & 25 & -. & 5.8 \\ \begin{array}{r}\text { JUNE } \\ \text { O3... }\end{array} & 1560 & 4.1 & 1.7 & 21 & 1.2 & 1.4 & 2.0 & 61 & .- & 6.8 \\ \begin{array}{l}\text { AUG. } \\ \text { 20... }\end{array} & 307 & 5.2 & .15 & 13 & 1.7 & 2.5 & 1.2 & 47 & -. & 5.0\end{array}$

$20 . .307$

03485500 DOE RIVER AT ELIZABETHTON (LAT $36 \quad 2040$ LONG $082 \quad 1237$ ) A

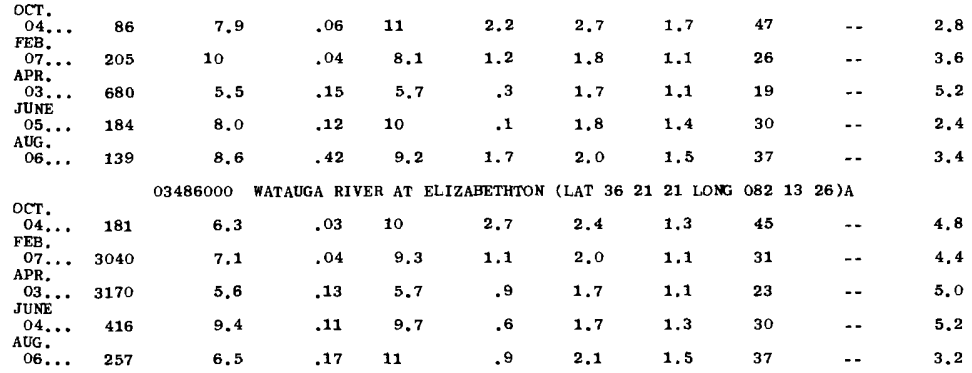

03486500 BRUSH CREEK AT JOHNSON CITY (LAT 361922 LONG O82 20 59)A

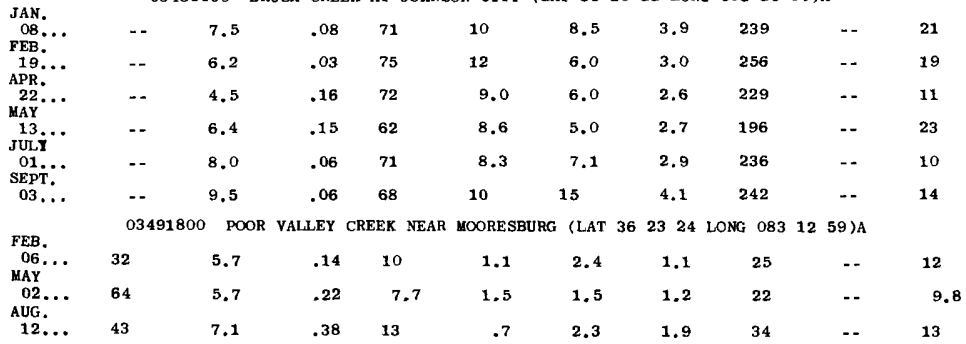

A ANALYSES FURNISHED BY TENNESSEE VALLEY AUTHORITY. 
CHEMICAL ANALYSES IN MILLIGRAMS PER LITER, WATER YEAR OCTOBER 1967 TO SEPTEMBER 1968

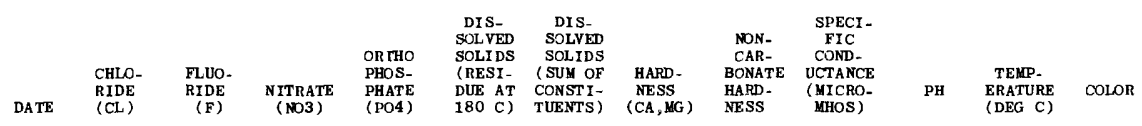

TENNESSEE RIVER BASIN

03461180 COSBY CREEK NEAR BLUFFTON (LAT 354547 LONG $083 \quad 1238$ )

03469100 LITTLE PIGEON RIVER NEAR PITTMAN CENTER (LAT 354420 LONG 0832459 )

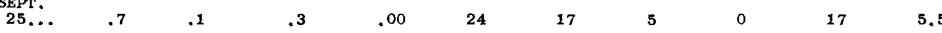

03469225 WEST PRONG LITTLE PIGEON RIVER NEAR MOUNT LE CONTE (LAT 3538 14 LONG 083 29 34)

SEPT.

$\begin{array}{rlllllllllllll}\text { SEPT. } & .7 & .2 & .3 & - & 27 & 27 & 8 & 0 & -. & 6.1 & -. & 10\end{array}$

03469400 TEST PRONG LITTLE PIGEON RIVER AT GATLINBURG (LAT 354401 LONG 08331 13)A

SEPT.

$\begin{array}{rrrrrrrrrrrrr}06 . . & 1.5 & - & 2.1 & - & 22 & - & 13 & - & 38 & 6.8 & 16 & 5\end{array}$

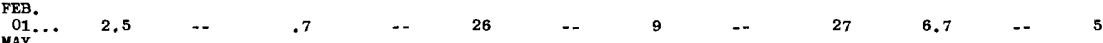

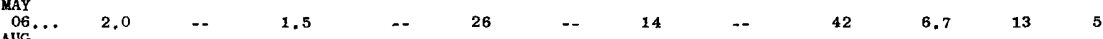

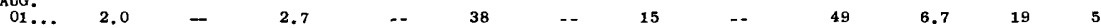

03469500 NEST PRONG LITTLE PIGEON RIVER NEAR PIGEON FORGE (LAT 354821 LONG 0833428 ) A

\begin{tabular}{|c|c|c|c|c|c|c|c|c|c|c|c|}
\hline JUNE & 1.0 & -- & 1.8 & - & 22 & -- & 12 & -. & 35 & 6.4 & 11 \\
\hline $\begin{array}{l}10 . . \\
\text { AUG. }\end{array}$ & 1.0 & -- & 1.5 & -- & 39 & - & 14 & -- & 41 & 6.8 & 21 \\
\hline $26 .$. & 4.0 & -- & 1.9 & -. & 54 & -- & 27 & -. & 80 & 6.7 & -. \\
\hline
\end{tabular}

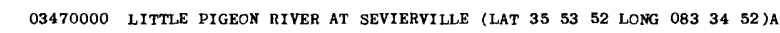

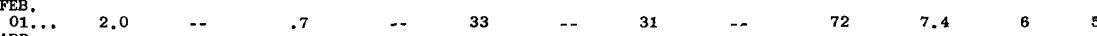

$\begin{array}{rrrrrrrrrrrrr}\text { APR. } & 1.0 & -- & .8 & -- & 39 & -- & 24 & \ldots & 57 & 7.3 & 11 & 5\end{array}$

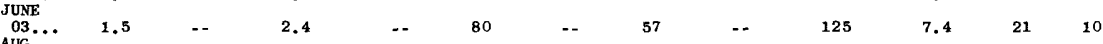

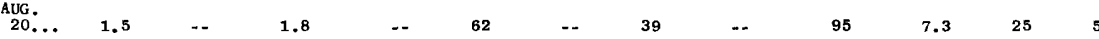

03485500 DOE RIVER AT ELIZABETHTON (LAT 362040 LONG 082 12 37)A

$\begin{array}{ccccccccccccccc}04 . . . & 1.0 & -- & .7 & -- & 45 & -- & 36 & -- & 82 & 7.3 & 13 & 5\end{array}$

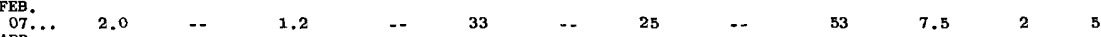

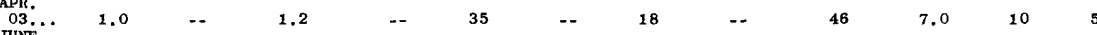

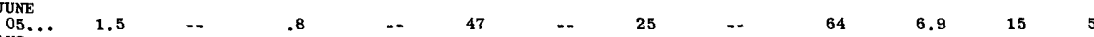

$\begin{array}{lllllllllllll}\text { AUG. } & 1.0 & - & & 1.2 & - & 51 & - & 30 & - & 73 & 7.6 & 22\end{array}$

\begin{tabular}{|c|c|c|c|c|c|c|c|c|c|c|c|}
\hline $04 .$. & 1.0 & -- & .6 & $=-$ & 52 & -- & 36 & $\ldots$ & 82 & 7.1 & 13 \\
\hline $\begin{array}{l}07 . . \\
A P R\end{array}$ & 1.5 & -- & 1.1 & -. & 25 & -- & 28 & -. & 63 & 7.4 & 3 \\
\hline JUNE & 1.0 & -- & 1.3 & -. & 37 & -- & 20 & - & 51 & 6.9 & 11 \\
\hline $\begin{array}{l}04 . . . \\
\text { AUG. }\end{array}$ & 1.0 & -- & .8 & -- & 46 & -- & 26 & - & 62 & 6.9 & 17 \\
\hline $06 . .$. & 2.0 & -- & 1.0 & -- & 55 & -- & 30 & - & 78 & 7.0 & 15 \\
\hline
\end{tabular}

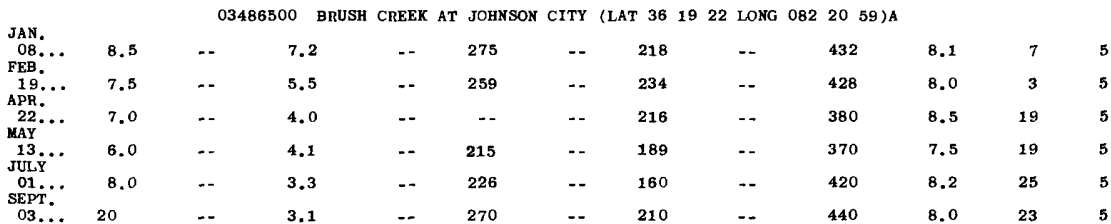

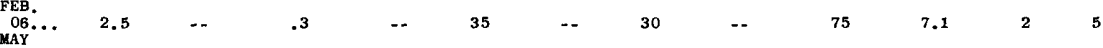

$\begin{array}{rrrrrrrrrrrrrrr}02 . . . & 2.0 & - & .0 & .0 & \ldots & 38 & - & 25 & \ldots & 66 & 6.8 & 19 & 5\end{array}$

$\begin{array}{cccccccccccccc}\text { AUG. } & 12 . . & 1.5 & \ldots & .1 & \ldots & 69 & \ldots & 35 & -. & 92 & 6.8 & 20 & 5\end{array}$

A ANALYSES FURNISHED BY TENNESSEE VALLEY AUTHORITY. 
ANALYSES OF SAMPLES COLLECTED AT MISCELlLANEOUS SITES IN TENNESSEE CHEMICAL ANALYSES IN MILLIGRAMS PER LITER, WATER YEAR OCTOBER 1967 TO SEPTEMBER 1968

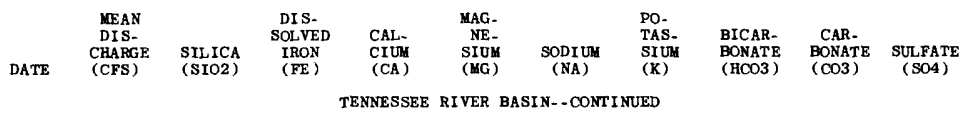

03594180 HARDIN CREEK AT CLIFTON JUNCTION (LAT 351826 LONG 08757 14)A

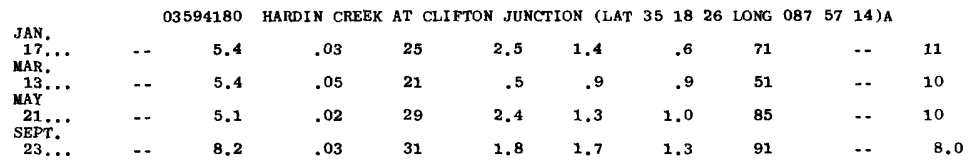

\begin{tabular}{|c|c|c|c|c|c|c|c|c|c|c|}
\hline & & 03596000 & DUCK RIVER & BELOW & MANCHESTER & (LAT 35 & 2815 LONG & 086 & $07 \quad 18) \mathrm{A}$ & \\
\hline $\begin{array}{l}\text { DEC. } \\
12 . \ldots \\
\text { JAN }\end{array}$ & 330 & 4.6 & .12 & 11 & 1.5 & 1.0 & .9 & 35 & -- & 3.2 \\
\hline $\begin{array}{l}18, \ldots \\
\text { MAR, }\end{array}$ & 256 & 4.5 & .02 & 13 & 1.1 & 2.4 & .6 & 37 &.- & 2.0 \\
\hline$\underset{\text { AUG. }}{21 . .}$ & 174 & 3.9 & .02 & 15 & .1 & 2.2 & 1.0 & 39 & -. & 3.8 \\
\hline $\begin{array}{l}13 \ldots \\
\text { SEPT. }\end{array}$ & 29 & 2.8 & .21 & 23 & 2.9 & 2.5 & 1.5 & 77 & $\cdots$ & 4.6 \\
\hline $09 \ldots$ & 23 & 5.1 & .14 & 25 & 2.8 & 3.0 & 1.1 & 84 & $\cdots$ & 4.2 \\
\hline
\end{tabular}

03604100 COON CREEK NEAR FOHENWALD (LAT $35 \quad 36 \quad 23$ LONG $08742 \quad 43$ )A

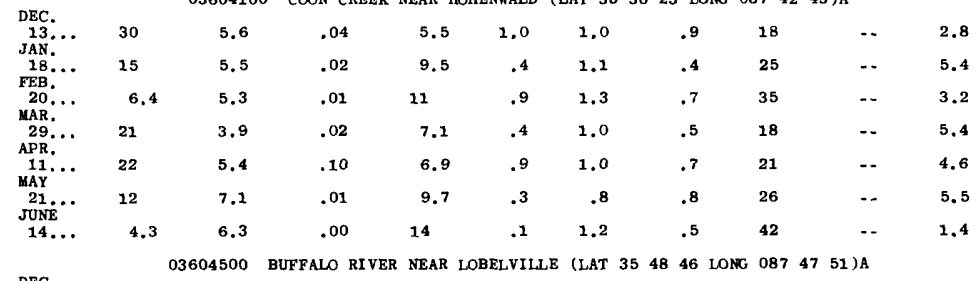

\begin{tabular}{|c|c|c|c|c|c|c|c|c|c|c|c|}
\hline $\begin{array}{l}\text { DEC, } \\
12, .\end{array}$ & 4620 & & 5.7 & .13 & 12 & 1.7 & 1.2 & 2,0 & 38 & -- & 8.4 \\
\hline & 994 & & 4.0 & .03 & 16 & 1.6 & 1.5 & .7 & 46 & - & 4.8 \\
\hline MAR. & 1140 & & 4.4 & .12 & 16 & 1.5 & .9 & .7 & 47 & -- & 4.8 \\
\hline $\begin{array}{l}\text { AUG. } \\
26 . .\end{array}$ & 315 & & 6.5 & .06 & 22 & .6 & 1.5 & 1.1 & 67 & - & 2.4 \\
\hline & & & $\begin{array}{l}\text { DIS. } \\
\text { SOLVED }\end{array}$ & MAN & & NAG- & & po. & & & \\
\hline & $\begin{array}{l}\text { RGE } \\
\text { S) }\end{array}$ & $\begin{array}{l}\text { SILICA } \\
\text { (SIO2) }\end{array}$ & $\begin{array}{l}\text { I RON } \\
\text { (FE) }\end{array}$ & $\begin{array}{c}\text { GANESE } \\
(\text { UN })\end{array}$ & $\begin{array}{l}\text { CIUK } \\
\text { (CA) }\end{array}$ & $\begin{array}{l}\text { SIUM } \\
\text { ( UG ) }\end{array}$ & $\underset{\text { (NA) }}{\text { SOD IUM }}$ & $\begin{array}{l}\text { SIUU } \\
\text { (K) }\end{array}$ & $\begin{array}{l}\text { BONATE } \\
\text { (HCO3) }\end{array}$ & $\begin{array}{l}\text { BONATE } \\
\text { (C03) }\end{array}$ & $\underset{\text { (SOLFATE }}{\text { SULAT }}$ \\
\hline
\end{tabular}

03606500 BIG SANDY RIVER AT BRUCETON (LAT 36 O2 19 LONG 088 13 42 ) A

\begin{tabular}{|c|c|c|c|c|c|c|c|c|c|c|}
\hline $\begin{array}{l}\text { FEB, } \\
09 . . \\
\text { MAR. }\end{array}$ & 135 & 7.8 & .30 & -- & 2.5 & 1.0 & 2.5 & 1,1 & 13 & - \\
\hline$\underset{\text { MAY }}{08 .}$ & 88 & 7.6 & .46 & $\ldots$ & 2.3 & 1.0 & 2.4 & 1.0 & 12 & $\cdots$ \\
\hline JUNE & 94 & 8.5 & .20 & $\cdots$ & 3.7 & 1.0 & 2.3 & .8 & 17 & - \\
\hline תLY... & 90 & 12 & .35 & $\cdots$ & 4.3 & .4 & 2.0 & 1.1 & 16 & -- \\
\hline DU... & $4 B$ & 9.9 & .49 & $\cdots$ & 3.3 & .9 & 2.0 & .8 & 16 & $\cdots$ \\
\hline 06. & 51 & 1.0 & .19 & -- & 2.9 & .2 & 2.0 & 1.6 & 14 & $\cdots$ \\
\hline
\end{tabular}

A ANALYSES FURNISHED BY TENNESSEE VALLEY AUTHORITY. 


\begin{tabular}{|c|c|c|c|c|c|c|c|c|c|c|c|c|}
\hline DATE & $\begin{array}{l}\text { CHLO- } \\
\text { RIDE } \\
\text { (CL) }\end{array}$ & $\begin{array}{l}\text { FLWW- } \\
\text { RIDE } \\
\text { (F) }\end{array}$ & $\begin{array}{c}\text { NITRATE } \\
\text { (NO3) }\end{array}$ & $\begin{array}{l}\text { ORTHO } \\
\text { PHOS- } \\
\text { PHATE } \\
\text { (PO4) }\end{array}$ & $\begin{array}{l}\text { DIS- } \\
\text { SOLVED } \\
\text { SOLIDS } \\
\text { (RESI } \\
\text { DUE AT } \\
180\end{array}$ & $\begin{array}{l}\text { DIS- } \\
\text { SOLVED } \\
\text { SOLIDS } \\
\text { (SUM OF } \\
\text { CONSTI } \\
\text { TUENTS) }\end{array}$ & $\begin{array}{l}\text { HARD. } \\
\text { NESS } \\
(\mathrm{CA}, \mathrm{MG})\end{array}$ & $\begin{array}{l}\text { NON- } \\
\text { CAR- } \\
\text { BONATE } \\
\text { HARD- } \\
\text { NESS }\end{array}$ & $\begin{array}{l}\text { SPECI - } \\
\text { FIC } \\
\text { COND- } \\
\text { UCTANCE } \\
\text { (MICRO } \\
\text { MHOS) }\end{array}$ & PH & $\begin{array}{l}\text { TELP- } \\
\text { ERATURE } \\
\text { (DEG C) }\end{array}$ & COLOR \\
\hline & & & & & & & CONTI NUED & & & & & \\
\hline
\end{tabular}

03594180 HARDIN CREEK AT CLIFTON JUNCTION (LAT $3518 \quad 26$ LONG 08757 14)A

\begin{tabular}{|c|c|c|c|c|c|c|c|c|c|c|c|c|}
\hline $\begin{array}{l}\text { JAN. } \\
17 . \ldots\end{array}$ & 2.5 & -- & .8 & . & 85 & - & 69 & - & 140 & 7.2 & 2 & 5 \\
\hline $\begin{array}{l}\text { MAR, } \\
13 . .\end{array}$ & 2.0 & -- & .4 & -- & - & -- & 55 & $\cdots$ & 114 & 7.5 & - & 5 \\
\hline $21 \ldots$ & 1.5 & -. & .8 & -- & 100 & -. & 84 & .. & 168 & 7.3 & 18 & 5 \\
\hline $\begin{array}{r}\text { SEPT. } \\
23 . .\end{array}$ & 3.5 & -- & .4 & - & 109 & -- & 84 & -- & 178 & 7.5 & 22 & 5 \\
\hline
\end{tabular}

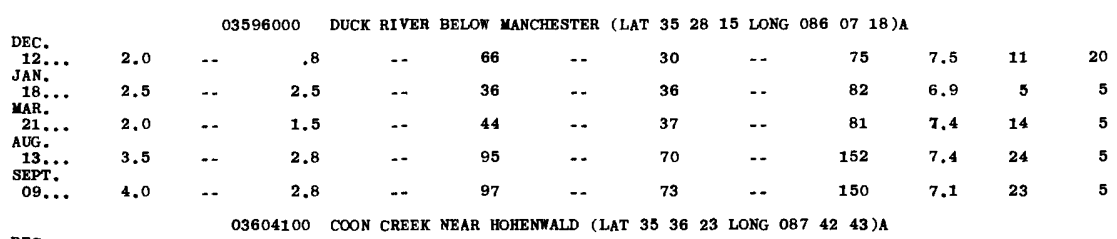

\begin{tabular}{|c|c|c|c|c|c|c|c|c|c|c|c|c|}
\hline $\begin{array}{l}\text { DEC. } \\
13 . . .\end{array}$ & 1.0 & -- & .0 & -. & 42 & $\ldots$ & 17 & -. & 44 & 7.2 & 13 & 10 \\
\hline $\begin{array}{l}\text { JAN. } \\
18 . . .\end{array}$ & 1.5 & -- & .0 & -- & 22 & -. & 25 & -. & 57 & 7.5 & -- & 5 \\
\hline $\begin{array}{l}\text { FEB. } \\
20 . . .\end{array}$ & 1.0 & -- & .0 & $\ldots$ & 50 & $\cdots$ & 31 & -- & 67 & 7.5 & 6 & 5 \\
\hline $\begin{array}{l}\text { MAR. } \\
29 . . . \\
\text { APR. }\end{array}$ & 1.5 & -- & .0 & $\cdots$ & 25 & $\ldots$ & 19 & -- & 42 & 6.8 & 16 & 5 \\
\hline & 1.5 & -- & .0 & .. & 36 & -. & 20 & - - & 51 & 6.9 & -. & 5 \\
\hline JUNE & 1.5 & -. & .0 & - & 31 & -. & 25 & - & 52 & 7.0 & 18 & 5 \\
\hline $14 .$. & 1.5 & $\ldots$ & .0 & - & 48 & $\cdots$ & 36 & -. & 80 & 7.2 & 21 & 5 \\
\hline
\end{tabular}

$\begin{array}{llllllllll}03604500 & \text { BUFFALO RIVER NEAR LOBELVILLE (LAT } 3548 & 46 & \text { LONG } & 087 & 47 & 51 \text { ) A }\end{array}$

\begin{tabular}{|c|c|c|c|c|c|c|c|c|c|c|c|}
\hline $12 .$. & 1.5 & -- & .7 & -. & 41 & -. & 38 & .. & 82 & 7.5 & 10 \\
\hline $\begin{array}{l}\text { JAN. } \\
31 . . .\end{array}$ & 2.0 & -. & .9 & $\cdots$ & 46 & $=$ & 47 & -- & 96 & 7.3 & 11 \\
\hline $20 .$. & 2.0 & . & .2 & .. & 61 & .. & 45 & . & 92 & 7.6 & 13 \\
\hline $26 \ldots$ & 2.5 & -. & .7 & .. & 74 & $\ldots$ & 56 & . & 117 & 7.0 & 21 \\
\hline
\end{tabular}

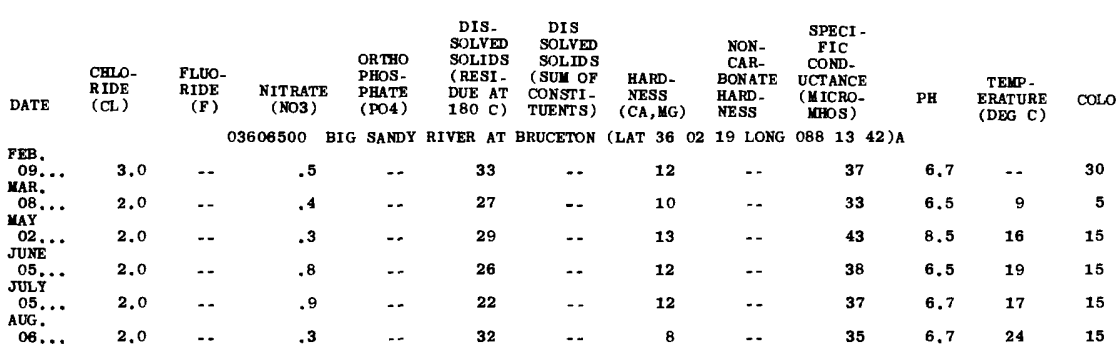

A ANALYSES FURNI SHED BY TENNESSEE VALLEY AUTHORITY, 
CHEMICAL ANALYSES IN MILLIGRAMS PER LITER, WATER YEAR OCTOBER 1967 TO SEPTEMBER 1968

\begin{tabular}{|c|c|c|c|c|c|c|c|c|c|c|}
\hline ATE & $\begin{array}{l}\text { MEAN } \\
\text { DIS- } \\
\text { CHARGE } \\
\text { (CFS) }\end{array}$ & $\begin{array}{l}\text { S1L1CA } \\
\text { (\$102) }\end{array}$ & $\begin{array}{l}\text { DIS- } \\
\text { SOLVED } \\
1 \text { RON } \\
\text { (FE) }\end{array}$ & $\begin{array}{l}\text { CAL- } \\
\text { CIUM } \\
\text { (CA) }\end{array}$ & $\begin{array}{l}\text { MAG- } \\
\text { NE- } \\
\text { SIUM } \\
\text { (MG) }\end{array}$ & $\begin{array}{l}\text { SODIUM } \\
\text { (NA) }\end{array}$ & $\begin{array}{l}\text { PO- } \\
\text { TAS. } \\
\text { SI UM } \\
(\mathrm{K})\end{array}$ & $\begin{array}{l}\text { BICAR- } \\
\text { BONATE } \\
\text { (HCO3) }\end{array}$ & $\begin{array}{l}\text { CAR- } \\
\text { BONATE } \\
(\infty 03)\end{array}$ & $\begin{array}{l}\text { SULFATE } \\
\text { (SO4) }\end{array}$ \\
\hline
\end{tabular}

TENNESSEE RIVER BASIN- - CONTI NUED

03496200 FIRST CREEK ABOVE POWERS AVENUE AT KNOXVILLE (LAT 360035 LONG 08355 17)A

\begin{tabular}{|c|c|c|c|c|c|c|c|c|c|c|c|}
\hline MAR. & 42 & 5.8 & .13 & 50 & 20 & 3.9 & 1.5 & 172 & & $\cdots$ & 12 \\
\hline${ }_{\text {MAY }}^{05}$ & 17 & 3.2 & .06 & 58 & 13 & 4.5 & 1.3 & 217 & & - & \\
\hline $08 \ldots$ & 14 & 5.6 & .24 & 59 & 13 & 4.0 & 1.5 & 219 & & -- & 9 \\
\hline & & 000 & TENNESSEE & RI VER AT & KNOXV1LLE & (LAT 35 & 5717 LONG & 08351 & 42) A & & \\
\hline DEC... & 16500 & 1.3 & .05 & 41 & 5,8 & 21 & 1.9 & 91 & & -- & 19 \\
\hline $\begin{array}{l}13, . . \\
\text { FEB. }\end{array}$ & 11000 & 6.2 & .28 & 27 & 4,3 & 13 & 3.0 & 74 & & -. & 24 \\
\hline $\begin{array}{l}06 . . \\
\text { APR. }\end{array}$ & 22000 & 4.5 & .10 & 30 & 5.4 & 10 & 1.6 & 88 & & - & 17 \\
\hline $18,$. & 500 & 6.2 & .15 & 29 & 4.4 & 9.3 & 1.7 & 84 & & -- & 18 \\
\hline
\end{tabular}

03497180 LITTLE RIVER AT ELKMONT (LAT 353917 LONG 0833450 )

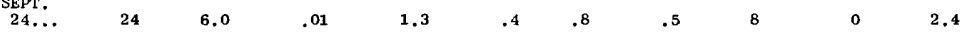

03497240 LYNN CAMP PRONG NEAR BLANKET MOUNTA1N (LAT 3537 O0 LONG 08340 07)

SEPT.

$$
\begin{array}{llllllllll}
4.6 & 6.9 & .03 & 1.0 & .3 & 1.0 & .4 & 6 & 0 & 2.2
\end{array}
$$

03497270 MIDDLE PRONG LITTLE RIVER AT WALKER F1ELDS NEAR TOWNSEND (LAT 353829 LONG 0834124 )

AUG.

$\begin{array}{cllllllllll}\text { SEPT. } & 7.0 & 6.6 & .00 & 1.6 & .6 & 1.0 & .4 & 8 & 0 & .8\end{array}$

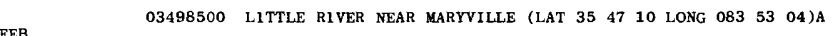

$\begin{array}{lllllllllll}\text { FEB. } & & & & & \\ \text { O1... } & 555 & 5.0 & .00 & 14 & 1.8 & 1.5 & .7 & 49 & -. & 3.2\end{array}$

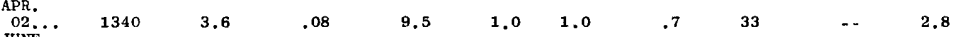

$\begin{array}{llllllllllll}04 \ldots & 307 & 6.9 & .10 & 18 & 1.8 & 1.2 & .8 & 58 & \ldots & 6.0\end{array}$

03517800 PARSON BRANCH NEAR CALDERWOOD (LAT 352928 LONG 08356 03)

$\begin{array}{clllllllllll}\text { SEPT. } & .70 & 10 & .03 & 4.0 & .8 & 1.6 & .7 & 21 & 0 & .8\end{array}$

03518100 ABRAMS CREEK BELOW CADES COVE (LAT 353535 LONG 0835042 )

AUG.

O5...A total coliform count of 148 colonies per $100 \mathrm{ml}$ was determined from a sample taken Aug. 5,1968

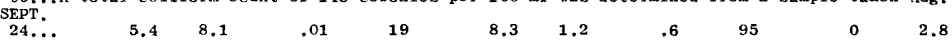

03518110 FORGE CREEK NEAR CADES COVE (LAT $3533 \quad 47$ LONG $08350 \quad 50$ )

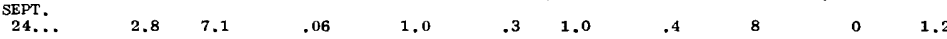

03527600 NORTH FORK CL1NCH RIVER NEAR KYLES FORD (LAT 363525 LONG 0825950 )A

$\begin{array}{ccccccccccc}\text { FEB. } \\ \text { O6... } & 104 & 4.4 & .07 & 30 & 6.6 & 1.7 & 1.1 & 109 & -- & 5.8\end{array}$

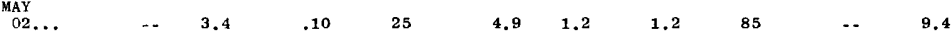

$\begin{array}{cllllllllllll}\text { FEB. } & 03528200 & \text { BlG } & \text { SYCAMORE } & \text { CREEK NEAR } & \text { SPRINGDALE (LAT } & 36 & 27 & 00 & \text { LONG } & 083 & 26 & 21 \text { )A } \\ 05 . . . & 32 & 3.4 & .04 & 19 & 1.6 & 1.7 & 1.1 & 54 & \ldots & 10\end{array}$

$\begin{array}{rllllllllll}05 \ldots & 32 & 3.4 & .04 & 19 & 1.6 & 1.7 & 1.1 & 54 & \ldots & 10 \\ \text { MAY } & & 40 & 4.8 & .09 & 17 & 2.6 & 1.2 & 1.2 & 51 & \end{array}$

$\begin{array}{rllllllllll}02 \ldots & 40 & 4.8 & .09 & 17 & 2.6 & 1.2 & 1.2 & 51 & .- & 16 \\ \text { AUG. } & 18 & 5.9 & .16 & 24 & 4.9 & 2.5 & 1.8 & 83 & \ldots & 14\end{array}$

03534200 HINDS CREEK NEAR CLINTON (LAT 36 O8 45 LONG 0840434 )A

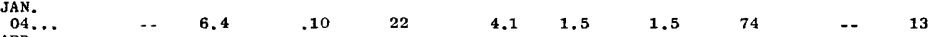

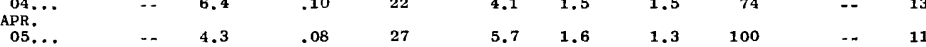

03535200 BEAVER CREEK NEAR POWELL (LAT 36 O1 O6 LONG 08403 06)A

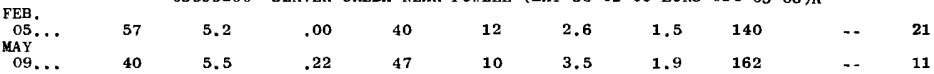

03539800 OBED RIVER NEAR LANCING (LAT 36 04 53 LONG 0844015 ) A

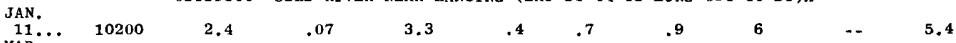

$\begin{array}{lllllllllll}\text { MAR. } & 26 . . . & 2110 & 2.8 & .01 & 2.9 & .5 & .9 & 1.0 & 6 & \ldots .4\end{array}$

$\begin{array}{rrrrrrrrrrr}\text { MAY } \ldots & 474 & 2.9 & .00 & 3.5 & .1 & 1.0 & 1.3 & 8 & \ldots & 3.6\end{array}$

A ANALYSES FURNI SHED BY TENNESSEE VALLEY AUTHORITY. 


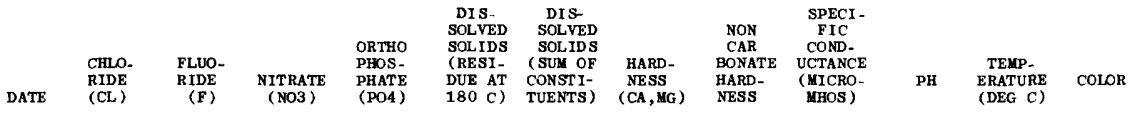

TENNESSEE RIVER BASIN--CONTINUED

03496200 FIRST CREEK ABOVE POWERS AVENUE AT KNOXVILLE (LAT 36 OO 35 LONG 08355 17) A

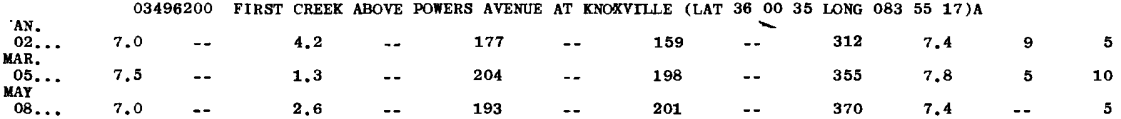

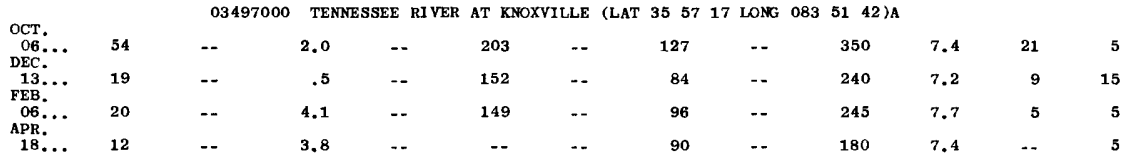

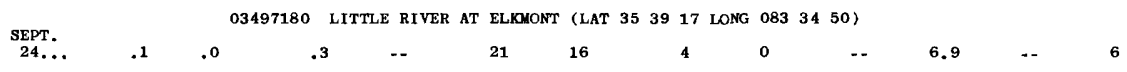

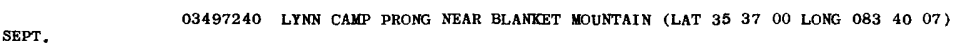

$\begin{array}{rllllllllllll}\text { SEPT. } & .7 & .0 & .4 & .00 & 18 & 16 & 4 & 0 & 15 & 5.5 & -- & 5\end{array}$

03497270 MIDDLE PRONG LITTLE RIVER AT WALKER FIELDS NEAR TOWNSEND (LAT $3538 \quad 29$ LONG 0834124 )

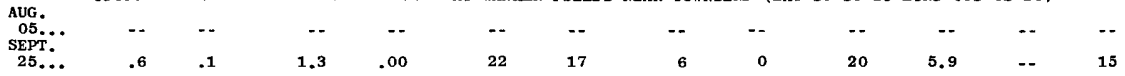

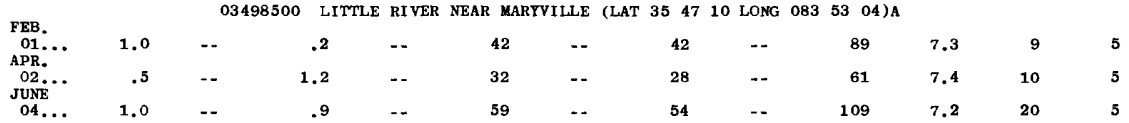

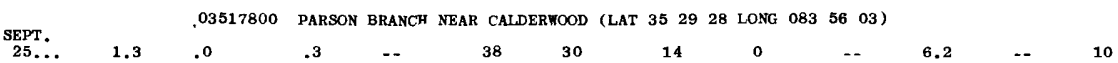

AUG. 03518100 ABRAMS CREEK BELOW CADES COVE (LAT 353535 LONG 08350 42)

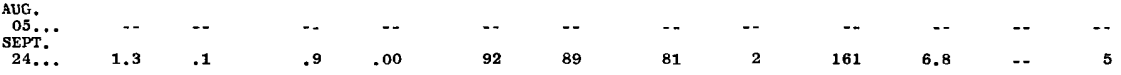

SEPT. 03518110 FORGE CREEK NEAR CADES COVE (LAT 353347 LONG O83 50 50)

$\begin{array}{ccccccccccccc}\text { SEPT. } & 1.1 & .1 & .3 & - & 28 & 17 & 4 & 0 & -- & 5.6 & -- & 15\end{array}$

03527600 NORTH FORK CLINCH RIVER NEAR KYLES FORD (LAT 363525 LONG 0825950 ) A

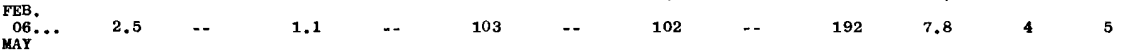

$\begin{array}{rrrrrrrrrrrrrr}\text { MAY } \\ 02 . . . & 1.0 & -- & 1.2 & -- & 88 & -- & 82 & -. & 160 & 7.6 & 14 & 5\end{array}$

03528200 BIG SYCAMORE CREEK NEAR SPRI NGDALE (LAT $36 \quad 27$ OO LONG $083 \quad 2621$ ) A

\begin{tabular}{|c|c|c|c|c|c|c|c|c|c|c|c|}
\hline YAY... & 1.5 & $\cdots$ & .3 & -. & 75 & -- & 54 & $=$ & 115 & 7.5 & 4 \\
\hline O2... & 1.0 & -- & .0 & -- & - & -- & 54 & - & 110 & 7.3 & 13 \\
\hline $12, \ldots$ & 2.0 & -. & .7 & -- & 103 & -- & 79 & -- & 175 & 7.9 & $=$ \\
\hline
\end{tabular}

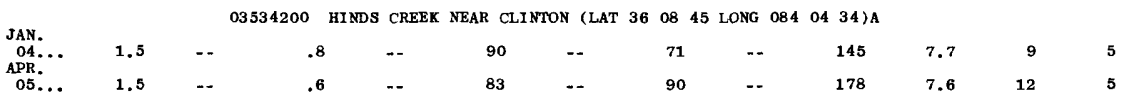

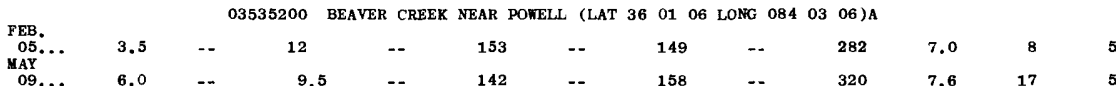

JAN. 03539800 OBED RIVER NEAR LANCING (LAT 36 O4 53 LONG 0844015 )A

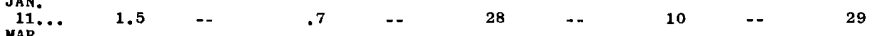

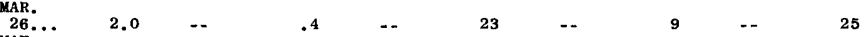

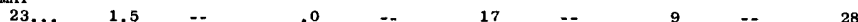

$6.8 \quad 4 \quad 10$

A ANALYSES FURNISHED BY TENNESSEE VALLEY AUTHORITY. 
ANALYSES OF SAMPLES COLLECTED AT MISCELLANEOUS SITES IN TENNESSEE

CHEMICAL ANALYSES IN MILLIGRAMS PER LITER, MATER YEAR OCTOBER 1967 TO SEPTEMBER 1968

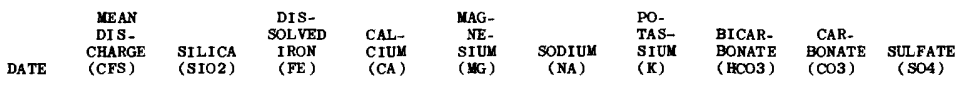
TENNESSEE RIVER BASIN_-CONTINUED

03539860 CROOKED FORK NEAR MARTBURG (LAT 36 O5 O5 LONG 08433 18) A

\begin{tabular}{|c|c|c|c|c|c|c|c|c|c|}
\hline $\begin{array}{l}\text { JAN. } \\
09 . . .\end{array}$ & 195 & 5.0 & .54 & 9.3 & 3.2 & 3.0 & .6 & 6 & -- \\
\hline$\underset{M A Y}{26} .$. & 132 & 4.9 & .44 & 9.0 & 4.4 & 3.5 & .9 & 4 & - \\
\hline$\underset{\operatorname{JUL}}{22} \ddot{Y}$ & 34 & 7.1 & .31 & 19 & 7.3 & 6.3 & 1.7 & 26 & $\therefore$ \\
\hline $29 .$. & 3.1 & 7.0 & .09 & 45 & 26 & 19 & 3.7 & 2 & -. \\
\hline
\end{tabular}

03566050 SOUTH MOUSE CREEK AT CLEVELAND (LAT 351203 LONG '084 51 10)A

\begin{tabular}{|c|c|c|c|c|c|c|c|c|c|}
\hline \multirow{3}{*}{$\begin{array}{r}11 . . . \\
\text { JAN, } \\
30 . . . \\
\text { APR. } \\
25 . .\end{array}$} & 9.1 & 6.9 & .14 & 52 & 10 & 20 & 2.7 & 180 & . \\
\hline & 24 & 5.8 & .04 & 40 & 10 & 8.8 & 2.1 & 157 & - \\
\hline & 16 & 6.4 & .06 & 50 & 8.1 & 20 & 1.9 & 162 & i \\
\hline
\end{tabular}

03566150 ROGERS CREEK NEAR LAMONTVILLE (LAT 3523 O4 LONG 0844737 )A

\begin{tabular}{|c|c|c|c|c|c|c|c|c|c|c|}
\hline $11 .$. & 19 & 4.7 & .09 & 30 & 8.1 & 2.7 & 3.3 & 125 & -- & 9.8 \\
\hline $\begin{array}{l}\text { JAN. } \\
25, \ldots\end{array}$ & 59 & 5.8 & .06 & 22 & 6.3 & 1.8 & 1.3 & 90 & -- & 6.6 \\
\hline $\begin{array}{l}\text { APR. } \\
25 . . .\end{array}$ & 35 & 5.2 & .12 & 31 & 6.1 & 1.4 & 1.4 & 118 & -. & 4.2 \\
\hline $26 \ldots$ & 15 & 7.7 & .09 & 36 & 9.0 & 1.7 & 2.0 & 150 & -- & 6.0 \\
\hline & & 66290 & SALE CREEK & AT GRAYSVII & LLE （LAT & 3526 & 30 LONG & $08504 \quad 46) A$ & & \\
\hline $\begin{array}{l}\text { JAN. } \\
\text { O3... } \\
\text { MAR. }\end{array}$ & 35 & 4.4 & .02 & 17 & 1.0 & 1.3 & 6 & 49 & -. & 5.6 \\
\hline${ }_{\text {JUL }}^{08} \times$ & 3.5 & 3.7 & .06 & 31 & 1.3 & 1.5 & 1.0 & 91 & -. & 8.4 \\
\hline $02 \ldots$ & .86 & 5.4 & .06 & 46 & 4.1 & 1.8 & 1.6 & 145 & -- & 4.4 \\
\hline JAN, & & 566400 & SODDY CREEK & K AT SODDY & (LAT 35 & 1805 & LONG 085 & $50956) A$ & & \\
\hline $\begin{array}{l}\text { O3... } \\
\text { APR. }\end{array}$ & 147 & 3.2 & .00 & 2.1 & .6 & .7 & .0 & 2 & $\cdots$ & 5.6 \\
\hline $\operatorname{JUL}_{\mathrm{Y}}^{25}$ & 40 & 3.2 & .15 & 2.9 & 1.0 & . 6 & .7 & 4 & - & 9.0 \\
\hline $02 \ldots$ & 1.0 & 4.1 & .06 & 10 & 1.7 & 1.8 & 1.1 & 9 & $\cdots$ & 28 \\
\hline
\end{tabular}

03568000 TENNESSEE RIVER AT CHATTANOOGA (LAT 35 O5 12 LONG 0851643 ) A

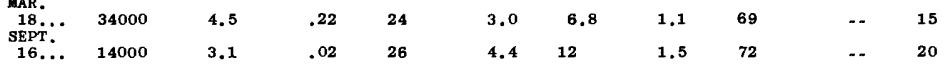

03571850 TENKESSEE RIVER AT SOUTH PITTSBURG (LAT 35 00 41 LONG 0854151 )A

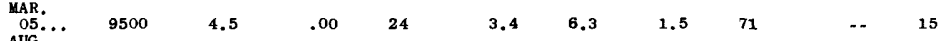

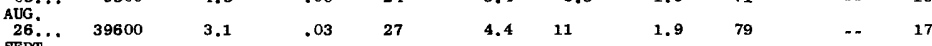

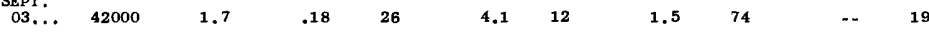

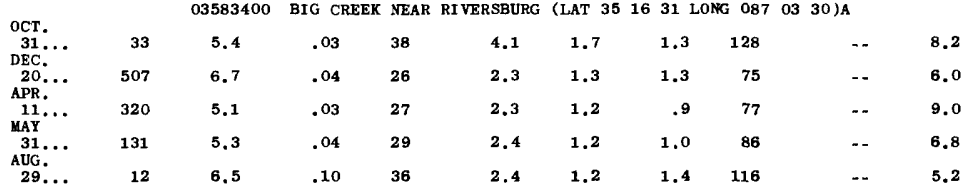

03588000 SHOAL CREEK AT LAWRENCEBURG (LAT 351431 LONG $08721 \quad 14$ ) A

\begin{tabular}{|c|c|c|c|c|c|c|c|c|c|c|}
\hline $\begin{array}{l}\text { DEC. } \\
21 . \ldots\end{array}$ & 136 & 5.0 & .04 & 17 & .7 & 1.7 & 1.3 & 46 & - & 4.6 \\
\hline $\begin{array}{l}\text { FEB. } \\
27 . . \\
\text { APR. }\end{array}$ & 56 & 2.9 & .02 & 21 & 2.4 & 1.6 & 1.0 & 66 & -- & 2.8 \\
\hline JUNE & 106 & 4.2 & .05 & 19 & 1.0 & 1.3 & .9 & 52 & -- & 3.8 \\
\hline $\begin{array}{l}17 . . . \\
\text { AUG. }\end{array}$ & 56 & 6.5 & .03 & 23 & .7 & 1.4 & 1.3 & 64 & -. & 3,4 \\
\hline 19. & 34 & 5.8 & .02 & 23 & 1.8 & 3.4 & 1.0 & 78 & -. & 2,4 \\
\hline
\end{tabular}

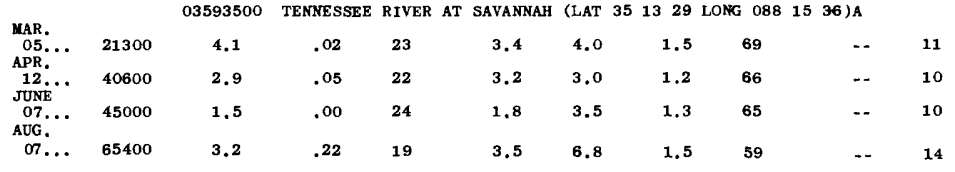

A ANALYSES FURNISHED BY TENNESSEE VALLEY AUTHORITY. 


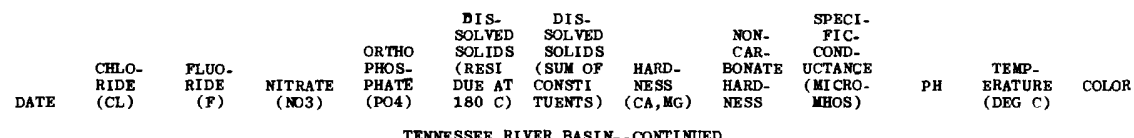

TENNESSEE RIVER BASIN--CONTINUED

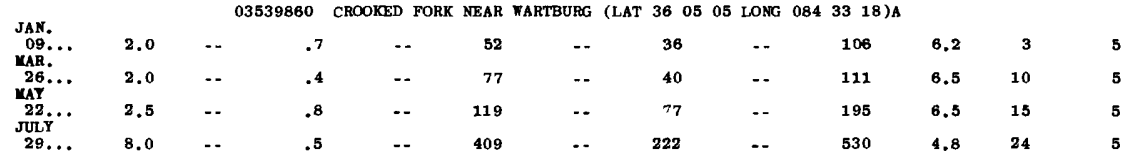

03586050 SOUTH MOUSE CREEK AT CLEVELAND (LAT 351203 LONG 08451 10)A

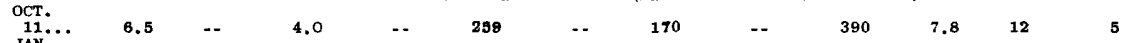

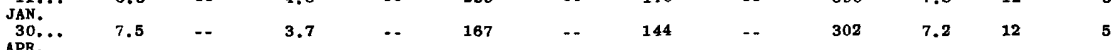

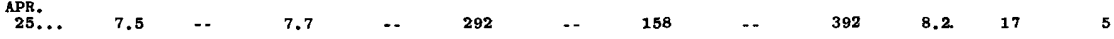

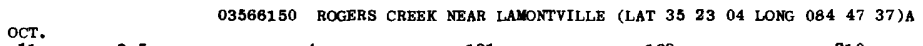

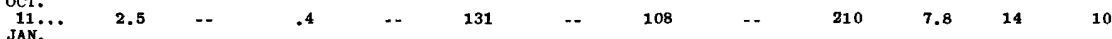

$\begin{array}{rrrrrrrrrrrrr}\text { JAN. } & 2.0 & \ldots & .4 & \ldots & 95 & -. & 82 & \ldots & 159 & 7.7 & 6 & 5\end{array}$

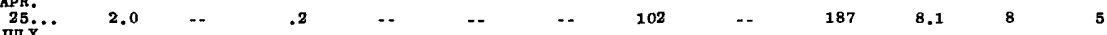

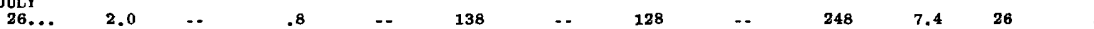

03566290 SALE CREEK AT GRAYSVILLE (LAT 3526 30 LONG 08504 46)A

JAN.

MAR.

$\begin{array}{ccc}08 & 2.5 \\ 02 \ldots & 3.0\end{array}$

$$
\begin{array}{lllllll}
1.2 & - & 47 & \ldots & 47 & \ldots & 109
\end{array}
$$

$7.2 \quad B \quad 5$

JAN.

JAN. $03 . . \quad 1.5 \quad--$

$\begin{array}{rrr}03 . . . & 1.5 & -- \\ 25, \ldots & .5 & --\end{array}$

JULY... 1.0

MAR.

18.

SEPT.

MAR:
O5.
AUG:
26.

AUG.

SEPT.

oc.

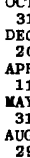

03568000 TENNESSEE RIVER AT CHATTANOOGA (LAT 350512 LONG $085 \quad 1643$ )A

03566400 SODDY CREEK AT SODDY (LAT 3518 O5 LONG 085 09 56)A

$\begin{array}{rrrrrrrrrr}.2 & -- & 13 & -- & 8 & -- & 26 & 6.2 & 7 & 5 \\ .0 & -. & -- & -- & 11 & -. & 32 & 6.3 & 11 & 5 \\ .0 & -. & 44 & \ldots & 32 & \ldots & 94 & 6.3 & 23 & 5\end{array}$

$\begin{array}{rrrrrrrrrr}2.4 & -- & 109 & \ldots & 74 & -- & 173 & 7.8 & 11 & 5\end{array}$

$\begin{array}{lllllllll}-- & 1.2 & - & 144 & - & 82 & \ldots & 220 & 7 . \\ 03571850 & & & & & & & & \end{array}$

03571850 TENNESSEE RIVER AT SOUTH PITTSBURG (LAT 35 O0 41 LONG 0854151 ) A

$\begin{array}{rrrrrrrrrrr}-. & 2.1 & -- & 99 & -- & 75 & -- & 160 & 7.2 & 6 & 5 \\ -- & 2.0 & -- & 140 & -- & 85 & -- & 225 & 7.2 & 26 & 5 \\ -- & 1.4 & -- & 139 & -- & 83 & -. & 220 & 7.1 & 26 & 5\end{array}$

03583400 BIG CREEK NEAR RIVERSBURG (LAT 35 16 31 LONG 087 03 30 ) A

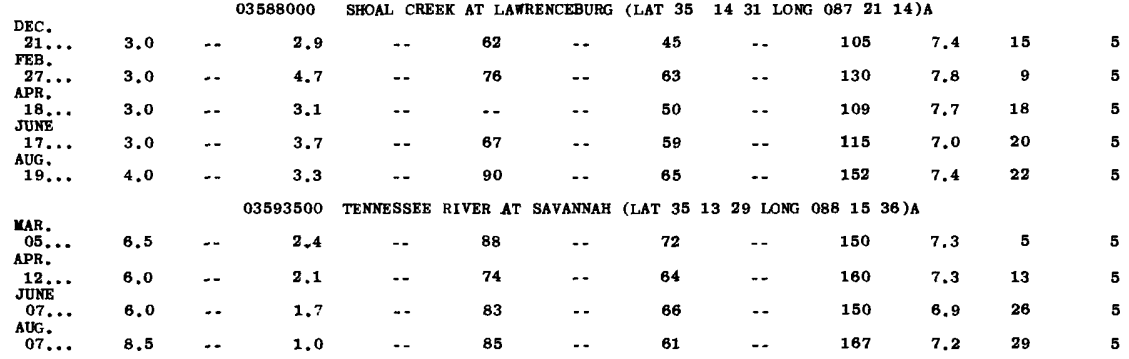

A ANALYSES FURNISHED BY TENNESSEE VALLEY AUTHORITY. 


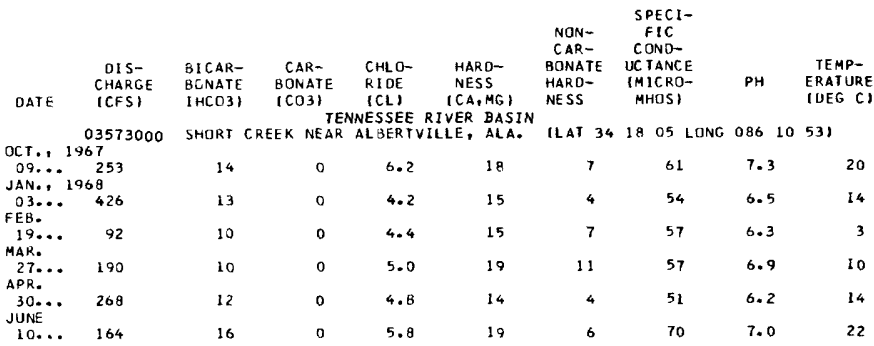

03573430 BIG SPRING CREEK NEAR BROOKSVILLE, ALA. ILAT 3413 OQ LANG 08624301

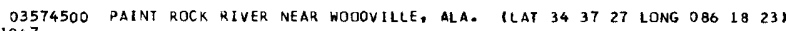
NOV., 1967

\begin{tabular}{|c|c|c|c|c|c|c|c|c|c|}
\hline $\begin{array}{l}02 \ldots \\
\text { OEC... }\end{array}$ & 3160 & 148 & 0 & -2 & $11 \mathrm{~B}$ & 0 & 270 & 7.5 & 13 \\
\hline $\begin{array}{l}\text { O1... } \\
\text { JAN.. }\end{array}$ & $\begin{array}{c}1830 \\
1968\end{array}$ & 154 & 0 & .4 & 122 & 0 & 279 & 7.7 & 11 \\
\hline $\begin{array}{l}02 \ldots . . \\
\text { MAR. }\end{array}$ & 1180 & 147 & 0 & .4 & 125 & 0 & 250 & 7.9 & 6 \\
\hline $\begin{array}{l}\text { MAR. } \\
\text { OPR... } \\
\text { APR. }\end{array}$ & 151 & 144 & 0 & .8 & 130 & 12 & 255 & 7.8 & 5 \\
\hline $\begin{array}{l}02 . . \\
\text { JULY }\end{array}$ & 1190 & 154 & 0 & .6 & 115 & 0 & 249 & 7.9 & 13 \\
\hline $\begin{array}{l}0<. \cdots \\
\text { AUG. }\end{array}$ & 37 & 158 & 0 & .8 & 142 & 12 & 271 & 7.5 & 26 \\
\hline O1... & 44 & 150 & 0 & 2.4 & 126 & 3 & 252 & 7.3 & 27 \\
\hline $03 . \ldots$ & 14 & 164 & 0 & 1.2 & 121 & 0 & 275 & 8.1 & 23 \\
\hline
\end{tabular}

03575000 FLINT RIVFr NEAR CHASE, ALA. (LAT 344908 LONG 08628 52)

or $\mathrm{T}$.

\begin{tabular}{|c|c|c|c|c|c|c|c|c|}
\hline $\begin{array}{l}12 . . \\
\text { NCV. }\end{array}$ & 156 & 70 & 0 & 2.0 & 69 & 12 & 130 & 7.6 \\
\hline CB... & 334 & 26 & 19 & 2.4 & 58 & 5 & 123 & 8.8 \\
\hline $\begin{array}{l}24 . . \\
\text { MAR." }\end{array}$ & 663 & 55 & 0 & .8 & 52 & 7 & 104 & 7.1 \\
\hline $\begin{array}{l}\text { Q4.... } \\
\text { APR. }\end{array}$ & 278 & 60 & D & .6 & 59 & 20 & 122 & 7.3 \\
\hline$\underset{\text { MAY }}{12 \ldots}$ & 716 & 60 & 0 & .8 & 56 & 12 & 116 & 7.7 \\
\hline$\underset{\text { JUNF }}{17 \ldots}$ & 460 & 48 & 0 & 1.0 & 46 & 7 & 97 & $7 . c$ \\
\hline $24 \ldots$ & $16 \%$ & 58 & 0 & 1.4 & 62 & 6 & 126 & 7.2 \\
\hline
\end{tabular}

03575500 TENNESSEE RIVER AT WHITESBURG, ALA. (LAT 343427 LONG 08632 42)

\begin{tabular}{|c|c|c|c|c|c|c|c|c|c|c|c|}
\hline DATE & $\begin{array}{l}\text { DIS- } \\
\text { CHARGE } \\
\text { (CFS) }\end{array}$ & $\begin{array}{l}\text { SILICA } \\
\text { (SID2) }\end{array}$ & $\begin{array}{l}\text { TחIAL } \\
\text { IRON } \\
\text { |FEI }\end{array}$ & $\begin{array}{l}\text { CAL- } \\
\text { C I UM } \\
\text { (CA) }\end{array}$ & $\begin{array}{l}\text { MAG- } \\
\text { NE- } \\
\text { SEUM } \\
(M G)\end{array}$ & $\begin{array}{c}\text { SODIUM } \\
\text { (NA) }\end{array}$ & $\begin{array}{l}\text { PO- } \\
\text { IAS- } \\
\text { SIUM } \\
\text { IKI }\end{array}$ & $\begin{array}{l}\text { BICAR- } \\
\text { BONATE } \\
\text { (HCO3) }\end{array}$ & $\begin{array}{l}\text { CAR- } \\
\text { RONATE } \\
\text { ICD3I }\end{array}$ & $\begin{array}{l}\text { SULFATE } \\
\text { (SO4) }\end{array}$ & $\begin{array}{l}\text { CHLO- } \\
\text { RIDE } \\
\text { ICLI }\end{array}$ \\
\hline $\begin{array}{l}\text { DEE. } \\
\text { O1... } \\
\text { JAN. }\end{array}$ & 54500 & 3.3 & .09 & 26 & 3.6 & 3.5 & 1.5 & 78 & 0 & 13 & 12 \\
\hline FEB. & 114000 & - & -- & $\cdots$ & - & -- & -- & 62 & 0 & -- & 13 \\
\hline MAY & $\cdots$ & 4.9 & .06 & 19 & 5.7 & $4 . ?$ & 1.1 & 70 & - & 11 & 6.0 \\
\hline JULY... & $\cdots$ & .9 & .16 & 24 & 2.8 & 4.7 & 1.2 & 68 & - & 9.4 & 6.5 \\
\hline $01 \ldots$ & - & 2.5 & .03 & 22 & 2.4 & 5.9 & 1.4 & 63 & -- & 13 & 8.0 \\
\hline DATE & $\begin{array}{l}\text { NI TRATE } \\
\text { (NO3) }\end{array}$ & $\begin{array}{l}\text { JIS- } \\
\text { SOLVEO } \\
\text { SDLIOS } \\
\text { (RFS)- } \\
\text { DUE AI } \\
\text { I30 C) }\end{array}$ & $\begin{array}{l}\text { OIS- } \\
\text { SOLVED } \\
\text { SOLIDS } \\
\text { (TONS } \\
\text { PER } \\
\text { OAY) }\end{array}$ & $\begin{array}{l}\text { DIS- } \\
\text { SOLVEO } \\
\text { SOLIOS } \\
\text { I IONS } \\
\text { PFR } \\
\text { AC-FTS }\end{array}$ & $\begin{array}{l}\text { HARO- } \\
\text { NESS } \\
(E A, M G)\end{array}$ & $\begin{array}{l}\text { NON- } \\
\text { CAR- } \\
\text { BONATE } \\
\text { HARD- } \\
\text { NESS }\end{array}$ & $\begin{array}{c}\text { SOOIUM } \\
\text { AO- } \\
\text { SORP- } \\
\text { TION } \\
\text { RATID }\end{array}$ & $\begin{array}{l}\text { SPECI- } \\
\text { FIC } \\
\text { COND- } \\
\text { UCTANCE } \\
\text { (MICRD- } \\
\text { MHOS) }\end{array}$ & $\mathrm{DH}_{\mathrm{H}}$ & COLOR & $\begin{array}{l}\text { TEMP- } \\
\text { ERATURE } \\
\text { (DEG C) }\end{array}$ \\
\hline
\end{tabular}

\begin{tabular}{|c|c|c|c|c|c|c|c|c|c|c|c|}
\hline DEC. & 1.9 & 111 & 16300 & .15 & 80 & 16 & .3 & 190 & 7.4 & 10 & 10 \\
\hline $\begin{array}{l}02 . . . \\
\text { FEA. }\end{array}$ & - & - & -- & -- & 75 & 24 & - & 173 & 7.3 & -- & 8 \\
\hline MAY & 2.1 & 91 & -- & .12 & 71 & 14 & .2 & 155 & 7.5 & 5 & 3 \\
\hline JULY & 1.2 & 86 & -- & .12 & 70 & 14 & .2 & 158 & 7.1 & 5 & 21 \\
\hline $01 . .$. &.$B$ & 100 & -- & .14 & 65 & 13 & .3 & $16 \pi$ & 7.1 & 5 & 26 \\
\hline
\end{tabular}


ANALYSES OF SAMPLES COLLECTED AT MISCELLANEOUS SITES IN ALABALA

CHEMICAL ANALYSES IN MILLIGRAMS PER LITER, WATER YEAR OCTOBER 1967 TO SEPTEMBER 1968

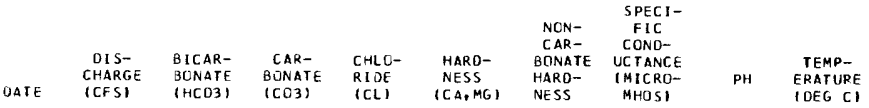

TENNESSEE RIVER BASIN--CONTINUED

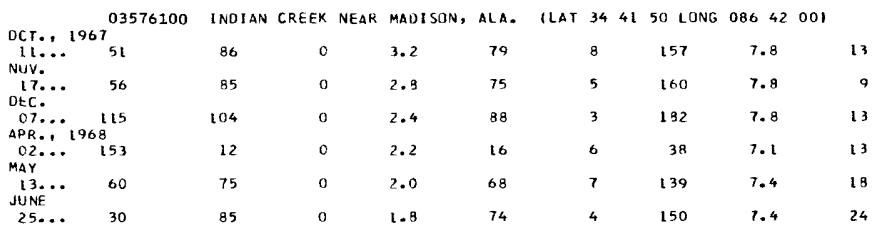

03576105 HUNTSVILLE SPRING AT HUNTSVILLE, ALA. (LAT 344346 LONG 0863512 ) OC T., 1967

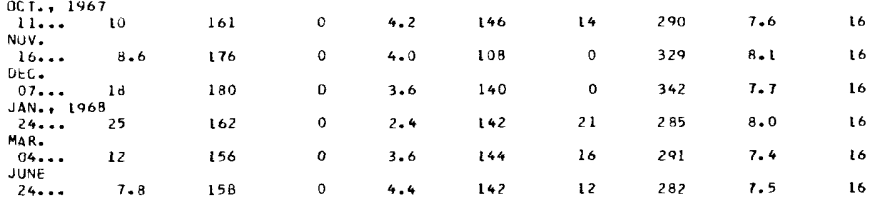

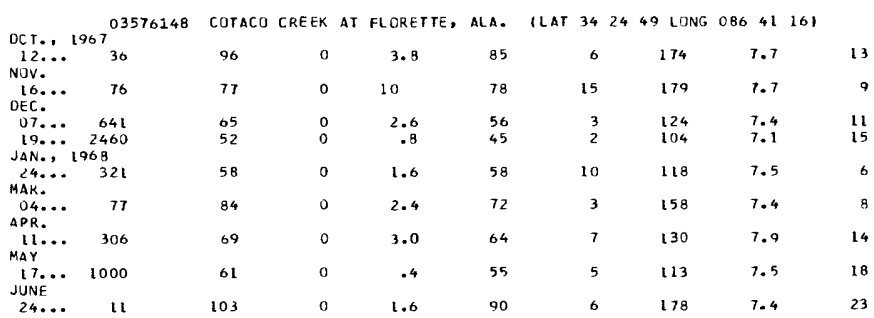

03576250 Limfstone cRefK nEAR ATHENS, ALA. (LAT 344506 LONG O86 49 24)

\begin{tabular}{|c|c|c|c|c|c|c|c|c|c|c|c|}
\hline DATE & $\begin{array}{l}\text { DIS- } \\
\text { CHARGE } \\
\text { ICFSI }\end{array}$ & $\begin{array}{l}\text { SILICA } \\
\text { (SI02) }\end{array}$ & $\begin{array}{l}\text { TOTAL } \\
\text { IRON } \\
\text { (FE) }\end{array}$ & $\begin{array}{l}\text { CAL- } \\
\text { CIUM } \\
\text { (CA) }\end{array}$ & $\begin{array}{l}\text { MAG- } \\
\text { NE- } \\
\text { SIUM } \\
\text { IMGI }\end{array}$ & $\begin{array}{l}\text { SOD IUM } \\
\text { (NA) }\end{array}$ & $\begin{array}{l}\text { PO- } \\
\text { TAS- } \\
\text { SIUM } \\
(\mathrm{K})\end{array}$ & $\begin{array}{l}\text { E ICAR- } \\
\text { RDNATE } \\
\text { (HCOB) }\end{array}$ & $\begin{array}{l}\text { CAR- } \\
\text { BONATE } \\
\text { (COZ) }\end{array}$ & $\begin{array}{l}\text { SULFATE } \\
\text { (S774) }\end{array}$ & $\begin{array}{l}\text { CHLO- } \\
\text { RIOE } \\
\text { (CL) }\end{array}$ \\
\hline $\begin{array}{c}\text { OCT. } \\
\text { O6.... }\end{array}$ & 39 & - & -- & - & -- & -- & -- & 40 & 0 & -- & 2.6 \\
\hline $\begin{array}{l}\text { NOV. } \\
17 . . .\end{array}$ & 65 & 4.6 & .08 & 12 & 1.1 & 1.3 & .6 & 37 & 0 & 1.6 & 3.5 \\
\hline $\begin{array}{l}\text { DEC. } \\
18 . . .\end{array}$ & 9540 & - & - & - & $\cdots$ & -- & - & 16 & 0 & -- & .0 \\
\hline $\begin{array}{l}19 . . \\
\text { JAN. }\end{array}$ & 1800 & - & -- & - & -- & -- & -- & 18 & 0 & -- & 1.0 \\
\hline $\begin{array}{l}24 \ldots . . \\
\text { MAR. }\end{array}$ & $\cdots$ & 3.8 & .07 & 8.5 & .6 & 1.5 & 1.1 & 22 & - & 3.2 & 3.5 \\
\hline $\begin{array}{l}05 \ldots . \\
\text { APR. }\end{array}$ & 72 & 3.8 & .06 & 11 & .3 & 1.3 & 1.0 & 26 & $n$ & 4.8 & 3.0 \\
\hline${ }_{\text {MAY }}^{12} \cdots$ & - & 3.4 & .10 & 7.5 & 1.0 & 1.2 & .7 & 23 & $\cdots$ & 3.6 & 3.0 \\
\hline JUNE & 539 & 4.1 & .32 & 8.3 & .6 & 1.2 & 1.2 & 21 & -- & 4.0 & 2.5 \\
\hline $25 \ldots$ & 34 & 5.7 & .06 & 14 & .3 & 1.0 & .8 & 36 & 0 & 2.9 & 3.0 \\
\hline $01 \ldots$ & -- & 4.8 & .06 & 14 &.$t$ & 1.4 & 1.0 & 39 & -- & 3.2 & 2.0 \\
\hline $\begin{array}{l}\text { AUG. } \\
\text { OG.... }\end{array}$ & -- & 4.4 & .12 & 10 & 1.2 & 1.0 & 1.7 & 33 & - & 3.2 & 2.0 \\
\hline
\end{tabular}


ANALYSES OF SAMPLES COLLECTED AT MISCERLANBOUS SITES IN ALABAMA

CEEMICAL ANALYSES IN MILLIGRAMS PER LITER, WATER YEAR OCTOBER 1967 TO SEPTEMBER 1968

DATE

$\begin{array}{ccccc} & \text { JIS- } & \text { OIS- } & \text { DIS- } \\ & \text { SDLVED } & \text { SOLVED } & \text { SDLVED } & \\ & \text { SOLIDS } & \text { SOLIDS } & \text { SOLIDS } & \\ & \text { (RESI- } & \text { ITONS } & \text { ITONS } & \text { HARO- } \\ \text { NITRATE } & \text { DJE AT } & \text { PER } & \text { PER } & \text { NESS } \\ \text { (NO3) } & \text { IBOC) } & \text { DAY) } & \text { AC-FI) } & \text { (CA,MG) }\end{array}$

$\begin{array}{lcc}\text { SPECI- } & \text { SONIUM } & \text { FIC } \\ \text { NON- } & \text { SONUM } & \text { COND- } \\ \text { CAR- } & \text { AD- } & \text { UCTANCE } \\ \text { RONATE } & \text { SORP- } & \text { UCIANCE } \\ \text { HARD- } & \text { IIDN } & \text { IMICRO- }\end{array}$

TENNESSEE RIVER BASIN--CONTINUED
03576250 LIMESTONE CREEK NEAR ATHENS, ALA.--CONTINUED

\begin{tabular}{|c|c|c|c|c|c|c|c|c|c|c|c|}
\hline $06 \ldots$ & - & -- & -- & -- & 38 & 5 & -- & 83 & 7.5 & - & 17 \\
\hline $\begin{array}{l}\text { NOV. } \\
1 \% . . . \\
\text { DEC. }\end{array}$ & 1.2 & 53 & 9.30 & .07 & 32 & 2 & .1 & 74 & 7.2 & 5 & 9 \\
\hline $18 \ldots$ & - & -- & -- & -- & 12 & 0 & -- & 29 & h. 9 & -- & 13 \\
\hline $19 \ldots$ & - & -- & -- & -- & 18 & 3 & -- & 51 & 6.8 & - & 14 \\
\hline $\begin{array}{l}24 \ldots . . \\
M A R .\end{array}$ & 2.8 & 32 & -- & .04 & 24 & 6 & .1 & 57 & 7.4 & 5 & 7 \\
\hline $\begin{array}{l}05 . . . \\
\text { APR. }\end{array}$ & 1.9 & 40 & 7.79 & .05 & 28 & 7 & .1 & 63 & 7.4 & 5 & 8 \\
\hline MAY $12 \ldots$ & 1.8 & 37 & -- & .05 & 25 & 6 & .1 & 61 & 6.9 & 5 & 16 \\
\hline JUNE & 1.4 & 33 & -- & .05 & 23 & 6 & .1 & 57 & 6.7 & 20 & 19 \\
\hline $\operatorname{JuLY}_{\text {JuY }} 25$ & 2.8 & 39 & 3.61 & .05 & 36 & 6 & .1 & 79 & 7.3 & 5 & 24 \\
\hline $\begin{array}{l}01 . . . \\
\text { AUG. }\end{array}$ & 2.8 & 63 & -- & .09 & 36 & 4 & .1 & 84 & 7.1 & 5 & 24 \\
\hline $06 \ldots$ & 2.1 & 53 & -- & .07 & 30 & 3 & .1 & 78 & 6.7 & 5 & 24 \\
\hline DATE & $\begin{array}{l}\text { DIS- } \\
\text { CHARGE } \\
\text { (CFS) }\end{array}$ & $\begin{array}{l}\text { BICAR- } \\
\text { BUNATE } \\
\text { (HCO3) }\end{array}$ & $\begin{array}{l}\text { CAR- } \\
\text { BDNATE } \\
\text { (CO3) }\end{array}$ & $\begin{array}{l}\text { CHLO- } \\
\text { RIOE } \\
\text { (CL) }\end{array}$ & $\begin{array}{l}\text { HARD- } \\
\text { NESS } \\
\text { (CA,MG) }\end{array}$ & $\begin{array}{l}\text { NON- } \\
\text { CAR- } \\
\text { BGNATE } \\
\text { HARD- } \\
\text { NESS }\end{array}$ & $\begin{array}{l}\text { SPECI- } \\
\text { FIC } \\
\text { COND- } \\
\text { UCTANCE } \\
\text { IMICRO- } \\
\text { MHOSI }\end{array}$ & PH & $\begin{array}{l}\text { TEMP- } \\
\text { ERATURE } \\
\text { (DEG C) }\end{array}$ & & \\
\hline
\end{tabular}

OCT., 1967 D3576350 PINEY CREEK NEAR REUNION, ALA. (LAT 345323 LONG OB6 5230 )

$\begin{array}{cccccccccc}\text { OCT., } 1967 & 1967.8 & 32 & 0 & 2.6 & 36 & 10 & 68 & 7.1 & 15\end{array}$

OCT., 1967 03576390 PINEY CREEK AT ATHENS, ALA. ILAT 344943 LONG OB6 53411

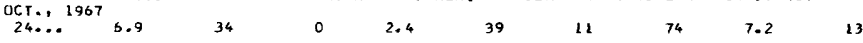

OCT., 196703576400 PINEY CREek near atHens, ala. ILAT 344810 LONG 086 5300 )

\begin{tabular}{|c|c|c|c|c|c|c|c|c|}
\hline $\begin{array}{l}06 \ldots \\
23 \ldots\end{array}$ & ${ }_{15}^{9.2}$ & $\begin{array}{l}34 \\
32\end{array}$ & $\begin{array}{l}0 \\
0\end{array}$ & $\begin{array}{l}2.8 \\
2.0\end{array}$ & $\begin{array}{l}31 \\
36\end{array}$ & $\begin{array}{r}3 \\
10^{2}\end{array}$ & $\begin{array}{l}66 \\
70\end{array}$ & $\begin{array}{l}7.3 \\
7.2\end{array}$ \\
\hline NOV. & & & & & & & & \\
\hline $\begin{array}{l}17 \ldots \\
\text { DEC. }\end{array}$ & 24 & 32 & 0 & 3.2 & 28 & 2 & 66 & 7.2 \\
\hline $05 \ldots$ & 154 & 18 & 0 & 2.4 & 18 & 3 & 51 & 6.9 \\
\hline $18 \ldots$ & 4060 & 14 & 0 & .4 & 12 & i & 28 & 7.0 \\
\hline MAR... & 833 & 24 & 0 & .8 & 28 & 8 & 45 & 6.5 \\
\hline $\begin{array}{l}05 \ldots . . \\
A P R .\end{array}$ & 25 & 24 & 0 & 3.0 & 24 & 4 & 62 & 6.9 \\
\hline MAY & 156 & 18 & 0 & 2.4 & 21 & 6 & 50 & 7.2 \\
\hline $\begin{array}{l}17 \ldots \\
\text { JUNE }\end{array}$ & 319 & 28 & 0 & 1.6 & 20 & 5 & 49 & 6.7 \\
\hline $25 \ldots$ & 12 & 30 & 0 & 2.2 & 28 & 3 & 65 & 7.0 \\
\hline
\end{tabular}

D3576500 FLINT CREEK NEAR falkVILLE, ALA. (LAT 342223 LONG 0365601 )

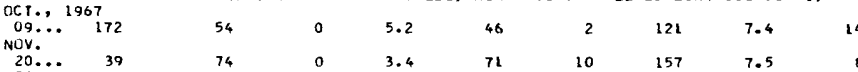
$\begin{array}{llllllllll}20 . . . & 39 & 74 & 0 & 3.4 & 71 & 10 & 157 & 7.5 & 8 \\ \text { OEC. } & & & 52 & & & & & & \end{array}$

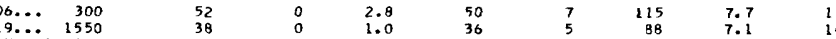

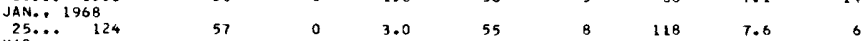

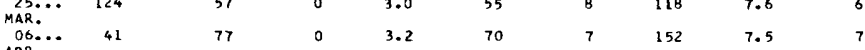

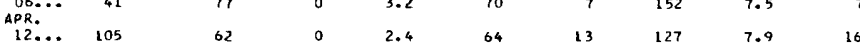

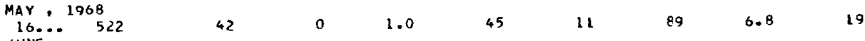

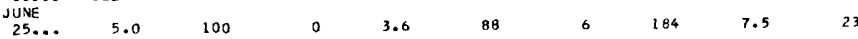

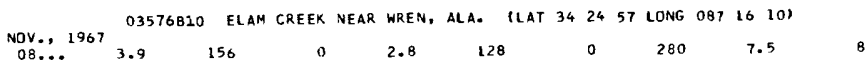


CHEMICAL ANALYSES IN MILLIGRAMS PER LITER, NATBR YEAR OCTOBER 1967 TO SEPTMUER 1968

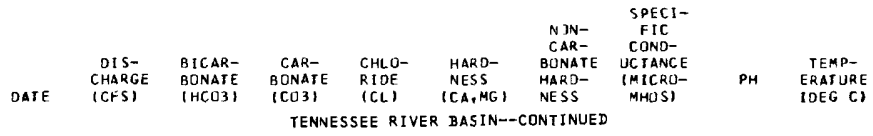

$$
03577000 \text { WEST FLINT CREEK NEAR OAKVILLE, ALA. (LAT } 342835 \text { LONG OB7 O8 } 30 \text { ) }
$$

\begin{tabular}{|c|c|c|c|c|c|c|c|c|c|}
\hline $\begin{array}{l}06 \ldots \\
22 \ldots\end{array}$ & $\begin{array}{r}193 \\
1330\end{array}$ & $\begin{array}{r}132 \\
80\end{array}$ & $\begin{array}{l}0 \\
0\end{array}$ & $\begin{array}{l}3.4 \\
1.8\end{array}$ & $\begin{array}{r}122 \\
72\end{array}$ & $\begin{array}{r}14 \\
6\end{array}$ & $\begin{array}{l}253 \\
160\end{array}$ & 7.7 & 12 \\
\hline MAR... & $\begin{array}{l}1330 \\
868\end{array}$ & & 0 & & & & & & \\
\hline $\begin{array}{c}06 . \cdots \\
A P R .\end{array}$ & 50 & 164 & 0 & 3.4 & 130 & 0 & 289 & 8.0 & 10 \\
\hline MAY & 160 & 132 & 0 & 3.4 & 111 & 3 & 229 & 8. 2 & 15 \\
\hline 16. & 920 & 84 & 0 & 1.8 & 76 & 7 & 152 & 7.4 & 19 \\
\hline
\end{tabular}

03577194 SWAN CREEK NEAR PINEY CHAPEL, Ala. (LAT 344955 LONG 0865705 I

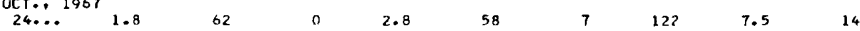

03577202 SHAN CR.(NR. ATHENSI AT US. HWY. 72 CROSSING,ALA. (LAT 3447 OS LONG 08656531

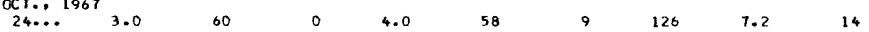

OCT., 1967 03577220 TOWN CREEK NEAR ATHENS, ALA. (LAT 344658 LONG 0865723 )

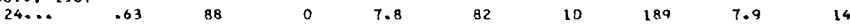

03584545 RAGSUALE CR (NR PETTUSVILLE) AT CD. RD. CROSSING, ALA. (LAT 345833 LONG 08655 I6)

OCT., 1967

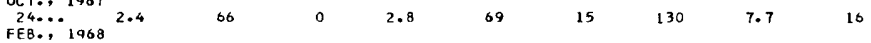

$\begin{array}{llllllllll}27 . . & 4.5 & 70 & 0 & 1.6 & 69 & 12 & 140 & 8.2 & 7\end{array}$

03585225 SULPHUR CREEK NEAR ELKMONT, ALA. (LAT 345436 LDNG O86 5918 )

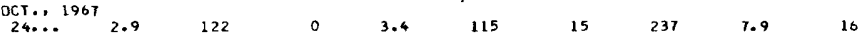

03585300 SUGAR CREEK NEAR GOODSPRINGS, ALA. (LAT 345640 LONG 0870920 )

\begin{tabular}{|c|c|c|c|c|c|c|c|c|c|}
\hline $\begin{array}{l}06 . . \\
\text { NDV. }\end{array}$ & 64 & 70 & 0 & .8 & 61 & 4 & 124 & 7.6 & 18 \\
\hline $\begin{array}{l}\text { Ol... } \\
\text { DEC. }\end{array}$ & 127 & 70 & 0 & 1.8 & 62 & 5 & 134 & 7.7 & 13 \\
\hline $\begin{array}{r}05 \ldots . . \\
\text { JAN., }\end{array}$ & $\begin{array}{l}40 B \\
68\end{array}$ & 50 & 0 & 1.4 & 50 & 9 & 108 & 7.1 & 8 \\
\hline $\begin{array}{l}04 . . \\
\text { MAR. }\end{array}$ & 857 & 40 & 0 & 1.2 & 39 & 0 & 88 & 7.1 & 1 \\
\hline $\begin{array}{l}\text { O5... } \\
\text { APR. }\end{array}$ & 107 & 56 & 0 & 1.0 & 52 & 6 & 108 & 8.2 & 8 \\
\hline $\operatorname{MAY}_{\text {MAY }}^{11 \ldots}$ & 644 & 40 & 0 & 1.2 & 41 & 8 & 82 & 7.5 & 14 \\
\hline $\begin{array}{l}13 \ldots . . \\
\text { JUNE }\end{array}$ & 354 & 50 & 0 & 1.4 & 46 & 5 & 96 & 7.0 & 17 \\
\hline $\begin{array}{l}07 . . . \\
\text { JuLY }\end{array}$ & 138 & 56 & 0 & .6 & 50 & 4 & 103 & 7.3 & 21 \\
\hline $\operatorname{SEP}_{\text {SEP }} 1 \ldots$ & 63 & 60 & 0 & .2 & 54 & 5 & 110 & $7 \cdot 2$ & 24 \\
\hline $20 \ldots$ & 81 & 52 & 0 & .4 & 48 & 5 & 93 & 6.9 & 18 \\
\hline
\end{tabular}

03586500 BIG NANCE CREEK AT CDURILAND, ALA. ILA7 344012 LONG 08719021

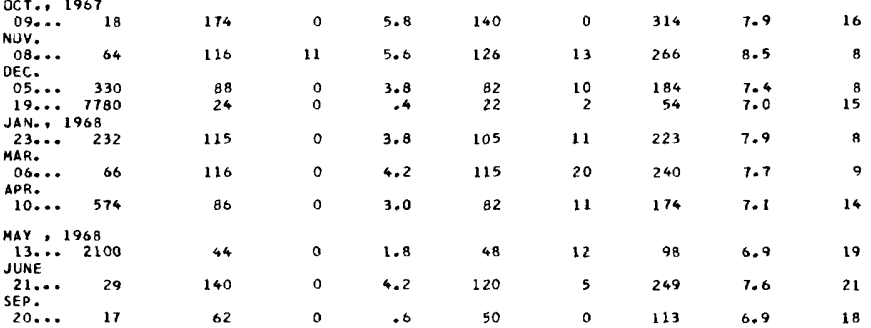


CHEMICAL ANALYSES IN YILLIGRAMS PER LITER, FATER YEAR OCTOBER 1967 TO SEPTEMBER 1968

\begin{tabular}{|c|c|c|c|c|c|c|c|c|c|c|}
\hline DATF & $\begin{array}{l}\text { SILIrA } \\
\text { (sIก2) }\end{array}$ & $\begin{array}{l}\text { TחTAL } \\
\text { IRCN } \\
\text { (FF) }\end{array}$ & $\begin{array}{l}\text { CAL } \\
\text { CIUM } \\
\text { IfAI }\end{array}$ & $\begin{array}{l}\text { NAF- } \\
\text { AF- } \\
\text { SIUM } \\
(M G)\end{array}$ & $\begin{array}{l}\text { 500IUM } \\
\text { (NA) }\end{array}$ & $\begin{array}{l}\text { PO- } \\
\text { TAS- } \\
\text { SI UM } \\
\text { (K) }\end{array}$ & $\begin{array}{l}\text { BICAR- } \\
\text { BONATE } \\
\text { (HCO 3) }\end{array}$ & $\begin{array}{l}\text { SULFATE } \\
(504)\end{array}$ & $\begin{array}{l}\text { CHLC- } \\
\text { RIDE } \\
\text { ICLI }\end{array}$ & \\
\hline & 03589500 & TENNESSEE & $\begin{array}{l}\text { IENNESSE } \\
\text { RIVER AT }\end{array}$ & $\begin{array}{l}\text { E RIVER B } \\
\text { FLORENCE, }\end{array}$ & $\begin{array}{l}\text { BASIN-CONT } \\
\text { ALA. ILAT }\end{array}$ & $\begin{array}{l}\text { INUED } \\
T 3447\end{array}$ & 13 LONG & $08740 \quad 12)$ & & \\
\hline $\begin{array}{l}\text { FFC. } \\
09 . . \\
\text { FEB. }\end{array}$ & 3.9 & .07 & 22 & 3.9 & 6.7 & 2.5 & 66 & 1.5 & 13 & \\
\hline Y?... & $h . n$ & .05 & 34 & 3.2 & 43 & 1.6 & 65 & 11 & 8.0 & \\
\hline JuL $^{29} \cdots$ & 3.0 & .07 & 29 & 2.6 & 0.2 & 1.3 & QI & 12 & 8.0 & \\
\hline $01 \ldots$ & 3.1 & .07 & 24 & 3.4 & 5.2 & 1.7 & 67 & 15 & 8.0 & \\
\hline & & $\begin{array}{l}\text { U1S- } \\
\text { SULVEO } \\
\text { SOLIOS } \\
\text { IRESI- }\end{array}$ & $\begin{array}{l}\text { OIS- } \\
\text { SOLVEO } \\
\text { SDLIOS } \\
\text { ITONS }\end{array}$ & HARD- & $\begin{array}{l}\text { NON- } \\
\text { CAR- } \\
\text { BONATE }\end{array}$ & $\begin{array}{c}\text { SODI UM } \\
\text { AO- } \\
\text { SORP- }\end{array}$ & $\begin{array}{l}\text { SPFCI- } \\
\text { FIC } \\
\text { CIND- } \\
\text { UCTANCF }\end{array}$ & & & TEMP- \\
\hline OATE & $\begin{array}{l}\text { NITRATE } \\
\text { (NO3) }\end{array}$ & $\begin{array}{l}\text { DUE AI } \\
180 \text { CI }\end{array}$ & $\begin{array}{c}P E R \\
A C-F T,\end{array}$ & $\begin{array}{c}N E S S \\
(C A, M G)\end{array}$ & $\begin{array}{l}\text { HARD- } \\
\text { NESS }\end{array}$ & $\begin{array}{l}\text { TION } \\
\text { RAIIE }\end{array}$ & $\begin{array}{l}\text { (M[CRO- } \\
\text { MHOS) }\end{array}$ & $\mathrm{PH}$ & C $\cap 10 R$ & $\begin{array}{l}\text { ERATURE } \\
\text { (DEG C) }\end{array}$ \\
\hline
\end{tabular}

\begin{tabular}{|c|c|c|c|c|c|c|c|c|c|}
\hline $\begin{array}{l}\text { DEC. } \\
09 . . .\end{array}$ & .9 & 91 & .12 & 71 & 17 & .3 & 180 & 7.5 & 5 \\
\hline FEB. & 5.1 & 109 & .15 & 73 & $>0$ & 2.2 & 165 & 7.1 & 5 \\
\hline $\begin{array}{l}\text { MAR. } \\
28 . . .\end{array}$ & 5.9 & 114 & .16 & 94 & 19 & .3 & 192 & 7.2 & 5 \\
\hline $01 \ldots$ & .4 & 88 & .12 & 73 & 19 & .3 & 180 & 7.0 & 5 \\
\hline 0 & $\begin{array}{l}\text { DIS- } \\
\text { CHARGE }\end{array}$ & BICAR- & $\begin{array}{l}\text { CAR- } \\
\text { 8ONATE } \\
\text { (CO3) }\end{array}$ & $\begin{array}{l}\text { CHLO- } \\
\text { RIOE }\end{array}$ & $\begin{array}{l}\text { HARD- } \\
\text { NFSS }\end{array}$ & $\begin{array}{l}\text { NON- } \\
\text { CAR- } \\
\text { BONATE } \\
\text { HARD- }\end{array}$ & $\begin{array}{l}\text { SPECI- } \\
\text { FIC } \\
\text { COND- } \\
\text { UCIANCE } \\
\text { (AICRU- } \\
\text { MHDS) }\end{array}$ & $P H$ & $\begin{array}{l}\text { TEMP- } \\
\text { ERATURE }\end{array}$ \\
\hline
\end{tabular}

03590500 IUSCUMBIA SPRING AT TUSCUMBIA, ALA. ILAT 344345 LONG 08742151

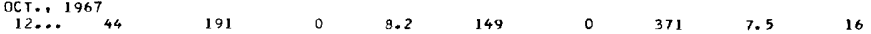

03592000 BEAR CREEK NEAR REO baY. ALA. ILAT 342639 LONG 0880655 ,

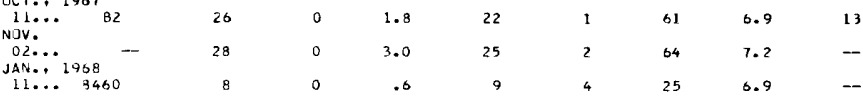


PERIODIC DETERUINATIONS OF SUSPENDED-SEDI MENT DISCHARGE, NATER YEAR OCTOBER 1967 TO SEPTEMBER 1968

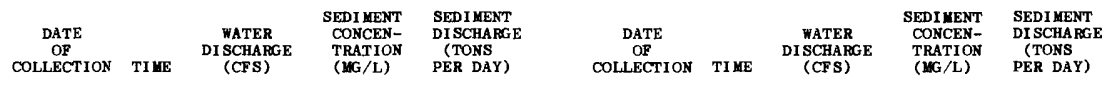

GREAT MIAMI RIVER BASIN

03275000 WHITEWATER RIVER NEAR ALPINE, IND. (LAT 393423 LONG 08509 27)

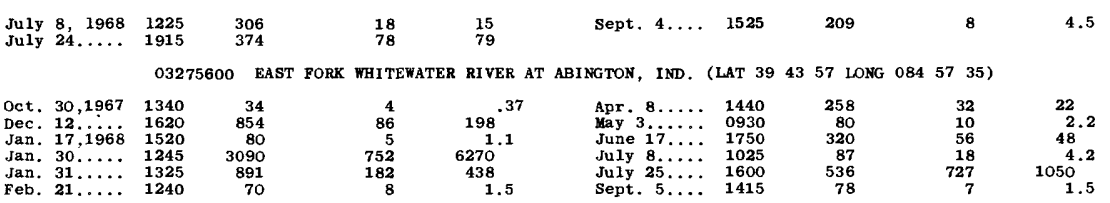

03276000 EAST FORK WHITEWATER RIVER AT BROOKVILLE, IND. (LAT 3926 O2 LONG 085 00 12)

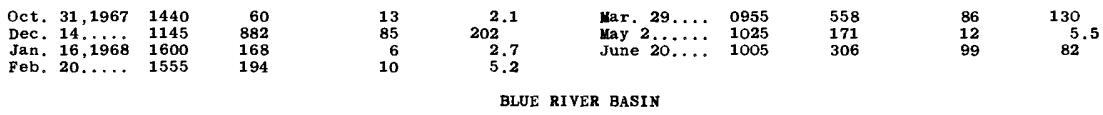

03303000 BLUE RIVER NEAR WHITE CLOUD, IND. (LAT 381404 LONG $086 \quad 1338$ )

$$
\begin{array}{lllll}
\text { July } 9,1968 & 0848 & 73 & 12 & 2.5 \\
& & &
\end{array}
$$

03303300 MIDDLE FORK ANDERSON RIVER AT BRISTOW, IND. (LAT 38 O8 19 LONG O86 43 16)

$\begin{array}{ll}\text { Nov. } 13,1967 & 1045 \\ \text { Dec. } 13, \ldots \ldots & 0920 \\ \text { Jan. } 22,1968 & 1050 \\ \text { Feb. } 19, \ldots \ldots & 1200\end{array}$

$\begin{array}{rr}20 & 21 \\ 69 & 29 \\ 81 & 24 \\ 102 & 3\end{array}$

$\begin{array}{ll}21 & 1.1 \\ 29 & 5 \\ 27 & 6 . \\ 24 & 2.7 \\ 30 & 8 .\end{array}$

$\begin{array}{lll}1.1 & \text { Apr. } 18 \ldots \ldots & 0930 \\ 5.4 & \text { May } 14 \ldots \ldots & 1205 \\ 6.1 & \text { July } 1 \ldots \ldots & 0915 \\ 2.7 & \text { July } 31 \ldots \ldots & 0930 \\ 8.3 & \text { Sept. } 11 \ldots & 1050\end{array}$

$\begin{array}{rr}96 & 26 \\ 46 & 18 \\ .45 & 3 \\ .19 & 8 \\ .80 & 5\end{array}$

MABASH RIVER BASIN

03323000 WABASH RIVER AT BLUFFTON, IND. (LAT 404430 LONG 085 10 19)

July $11,1968 \quad 1610$

$\begin{array}{rrr}43 & 54 & 6.2\end{array}$

03324300 SALAMONIE RIVER NEAR WARREN, IND. (LAT 404245 LONG 08527 13)

$\begin{array}{lll}\text { Oct. } 2,1967 & 1005 \\ \text { Oct. } 7 \ldots \ldots & 1645 \\ \text { Oct. } 30 \ldots \ldots & 0955 \\ \text { Nov. } 10 \ldots \ldots & 1610 \\ \text { Nov. } 27 \ldots \ldots & 1040 \\ \text { Dec. } 9 \ldots \ldots & 1415 \\ \text { Feb. } 8,1968 & 0700\end{array}$

July $10,1968 \quad 1725$

10
15
20
20
32
405
396

$\begin{array}{rl}28 & .76 \\ 36 & 1.5 \\ 88 & 4.8 \\ 8 & .43 \\ 42 & 3.6 \\ 10 & 11 \\ 50 & 53\end{array}$

$\begin{array}{lrr}\text { Mar. } 18 \ldots & 0945 & 1330 \\ \text { May } 13 \ldots \ldots & 0915 & 98 \\ \text { June } 10 \ldots & 0925 & 78 \\ \text { Ju1y } 8 \ldots \ldots & 1000 & 48 \\ \text { July } 15 \ldots & 1000 & 175 \\ \text { Aug. } 19 \ldots \ldots & 0920 & 311\end{array}$

03328500 EEL RIVER NEAR LOGANSPORT, IND. (LAT 404655 LONG 08615 50)

10,1968 1725

03331500 TIPPECANOE RIVER NEAR ORA, IND. (LAT 410926 LONG O86 33 49)

$\begin{array}{lll}\text { July } 10,1968 & 1520 \\ \text { July } & 11 \ldots \ldots & 1500\end{array}$

$\begin{array}{lll}1190 & 42 & 135 \\ 1130 & 58 & 177\end{array}$

03335000 WILDCAT CREEK NEAR LAFAYETTE, IND. (LAT $4026 \quad 26$ LONG 0864946 )

July $10,1968 \quad 0745$

$\begin{array}{lll}178 & 29 & 14 \\ 200 & 66 & 36\end{array}$

O3335500 WABASH RIVER AT LAFAYETTE, IND. (LAT 402519 LONG 08653 49)

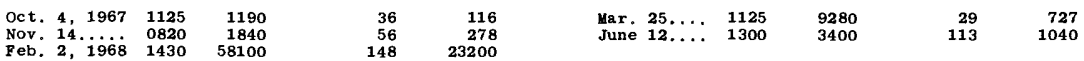

03340000 SUGAR CREEK NEAR BYRON, IND. (LAT $3955 \quad 52$ LONG 087 07 33)

July $9,1968 \quad 1755$

148

$38 \quad 15$

03347000 WHITE RIVER AT MUNCIE, IND, (LAT 401215 LONG $08523 \quad 14$ )

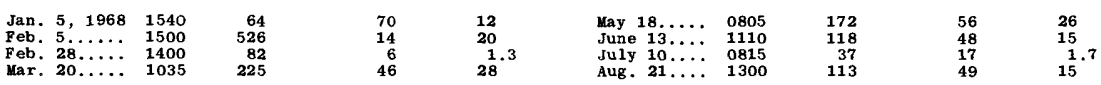

03348500 WHITE RIVER NEAR NOBLESVILLE, IND. (LAT 400746 LONG 0855746 )

July $11,1968 \quad 1005$

256

$36 \quad 25$ 


\begin{tabular}{|c|c|c|c|c|c|c|c|c|c|}
\hline $\begin{array}{c}\text { DATE } \\
\text { OF } \\
\text { COLLETION }\end{array}$ & I I IFT & $\begin{array}{l}\text { WATER } \\
\text { DISCHARBG } \\
\text { (CFS) }\end{array}$ & $\begin{array}{l}\text { SED I LENT } \\
\text { CONCEN- } \\
\text { TRATION } \\
(\text { MG } / L)\end{array}$ & $\begin{array}{l}\text { SED I URENT } \\
\text { DI SCHARGE } \\
\text { (TONS } \\
\text { PER DAY) }\end{array}$ & $\begin{array}{c}\text { DATE } \\
\text { OF } \\
\text { COLLECTION }\end{array}$ & I $\mathbf{~ M E}$ & $\begin{array}{l}\text { TATER } \\
\text { DI SCHARGE } \\
\text { (CF S) }\end{array}$ & $\begin{array}{l}\text { SEDI IERT } \\
\text { CONCEN- } \\
\text { TRATION } \\
(\text { MG } / L)\end{array}$ & $\begin{array}{l}\text { SEDI MENT } \\
\text { DI SCHARGE } \\
\text { (TONS } \\
\text { PER DAY) }\end{array}$ \\
\hline
\end{tabular}

03351500 FALL CREEK NEAR FORTVILLE, IND. (LAT $3957 \quad 15$ LONG $08552 \quad 05$ )

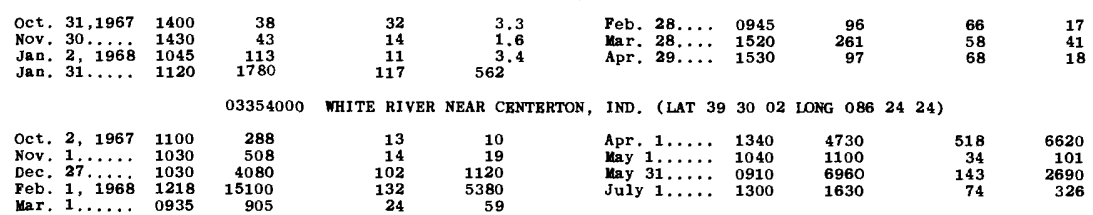

03361500 BIg BLUE RIVER AT SHELBYVILLE, IND. (LAT 393145 LONG 0854655 )

\begin{tabular}{|c|c|c|c|}
\hline $\begin{array}{l}\text { July } 8,1968 \\
\text { Aug. } 22 . \ldots \ldots\end{array}$ & $\begin{array}{l}1530 \\
1022\end{array}$ & $\begin{array}{l}156 \\
216\end{array}$ & $\begin{array}{l}14 \\
76\end{array}$ \\
\hline
\end{tabular}

03362500 SUGAR CREEK NEAR EDINBURG, IND. (LAT 392139 LONG 0855951 )

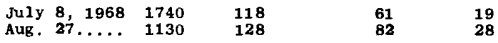

03366500 MUSCATATUCK RIVER NEAR DEPUTY, IND. (LAT $3848 \quad 15$ LONG O85 40 26)

$\begin{array}{rrrrrrrrr}\text { July } 8,1968 & 2030 & 5.8 & 14 & 29.22 & \text { Sept. } 4 \ldots . & 1050 & 7.8 & 20 \\ \text { July } 29 . \ldots . & 1205 & 115 & 94 & 29 & \end{array}$

03368000 BRUSH CREEK NEAR NEBRASKA, IND. (LAT $3904 \quad 13$ LONG 08529 10)

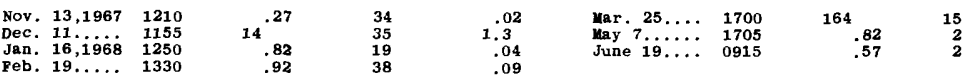

03376500 PATOKA RIVER NEAR PRINCETON, IND. (LAT 382330 LONG 0873255 )

Oct. $12,1967 \quad 1350$

Dec. $14 \ldots \ldots$... 1015

Jan. 29,19681100

23
450
2280
1410

$\begin{array}{rr}5 & 140^{-31} \\ 115 & 529 \\ 86 & 187 \\ 49 & 1120\end{array}$

$\begin{array}{lll}\text { Mar. } 25 \ldots \ldots & 1345 \\ \text { Apr. } 16 \ldots & 1345 \\ \text { May } 20 \ldots \ldots & 1230\end{array}$

2480

May $20, \ldots .1230 \quad 493$

493
158

RECORDS AVAILABLE FOR WATER TEMPERATURES

Unpublished records of water temperature have been collected for several years on 14 streans in the Ohto River basin in Kentucky. Water temperatures were measured one day each week, once or twice a day. These records are avatlable in fit
Water Resources Division, Loutsville, Ky.

Stations in the Ohto River basin for which water-temperature records are avallable

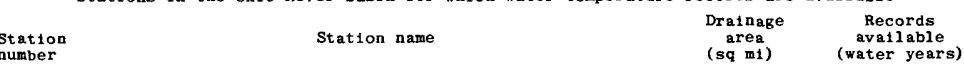

LITTLE SANDY RIVER BASIN

03216500 Little Sandy River at Grayson,

$400 \quad 1950-68$

KENTUCKY RIVER BASIN

03280000 North Fork Kentucky River at Jackson, Ky

03281000 Middle Fork Kentucky Rtver at Tallega, Ky

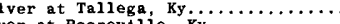

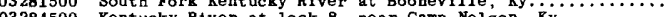

03284500 Kentucky River at lock 8, near Camp Nelson, Ky $\ldots \ldots \ldots \ldots$

SALT RIVER BASIN

03298500 Salt River at Shepherdsville, Ky.................. 1197

CUMBERLAND RIVER BASIN

03401000 Cumberland River near Harlan, Ky.

Yellow Creek near Yiddlest

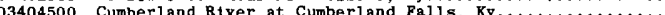

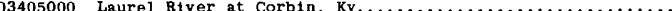

03406500 Rockcastle River at Billows, Ky.

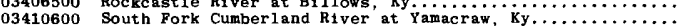
03438000

TENNESSEE RIVER BASIN

$\begin{array}{rc}1101 & 1949-68 \\ 537 & 1949-68 \\ 722 & 1949-68 \\ 4528 & 1949-62 ; 1965-68 \\ 318 & 1949-68\end{array}$

$1197 \quad 1949-52 ; 1963-68$

03609500 Tennessee R1ver at Kentucky Dam, near Paducah, Ky.

$\begin{array}{rr}374 & 1950-68 \\ 58.2 & 1949-68 \\ 1977 & 1949-68 \\ 201 & 1950-68 \\ 604 & 1949-68 \\ 1083 & 1949-68 \\ 244 & 1959-68\end{array}$

\footnotetext{
A Approximately (at Gilbertsville).
} 


\section{INDEX}

A

Acidity

Adamsviiie, Ohio, Raccoon Creek at

Africa, ohio, Alum Creek at

Kittanning ............. 103-105

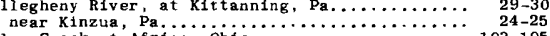

Alum Creek at Africa, Ohio................ 103-105

Analyses of sampies coilected at partial-record Analyses of samples collected at partial-record
stations in the Ohio River basin........... 249-263
Analyses of samples collected at low-fiow on

streams in the Ohio River basin in Ohio... 264-267

Anderson River basin.................. 305

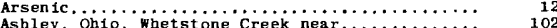

Ashley, Ohio, whetst one Creek near............

Barbourville, Ky., Cumberland River at.........

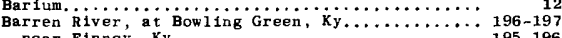

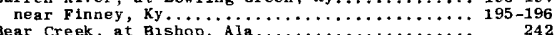

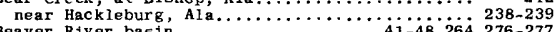

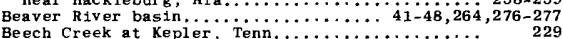

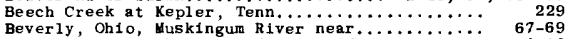
Bicarbonate, carbonate and hydroxide.......... 9-10 Big Raccoon Creek near Fincastie, Ind.......... 203-20 Big Sandy River basin............... $93-98,280-28$ Biochemical oxygen demand................... ${ }^{17}$

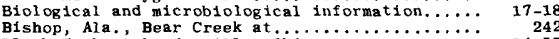
Bishop, Ala , Bear Creek at Black Fork at Loudonville, ohio..............

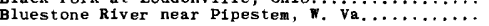

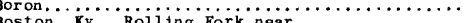

Boston, Ky., Rolling Fork near.....

Bowling Green, Ky, Barren River at.......... 114-116

Bow1ng Green, Ky. Barren River at.......... 196-197

Buffalo creek at state Highway 1338 , near Dawson Springs, Ky...................... 215

Buffalo Creek basin,............... 272-273,276-277 Buffalo River near Flat woods, Tenn........... 243-244 Bullrun Creek near Halls Crossroads, Tenn........ 178-179 Burkesville; Ky., Cumberland River near..........223-224

$$
\text { c }
$$

Cabin Creek, w. Va., Kanawha River at.......... Cadmium.

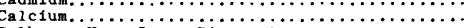

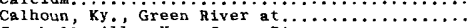

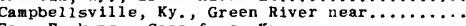

Carr Fork near' Sassafras, Ky.

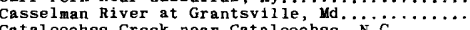

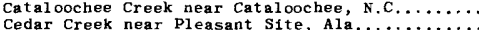

Cedar Creek near pleasant Site, Ala..

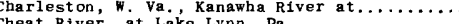

Cheat River, at Lake Lynn, Pa.

Che kowlesburg, w. Va...

Chemical quality

Chilhowee Dam, Tenn, , Littie Tennessee River

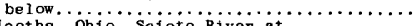

Chloride.

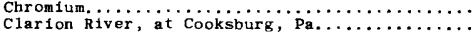

near P1ney, Pa.

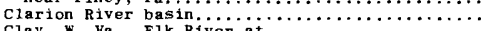

Clay, W. Va., Elk River at

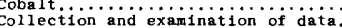

Color

Composition of surface waters

Conemaugh River at Seward, Pa...

Conewango Creek t waterboro $\ldots \ldots \ldots \ldots \ldots \ldots$

Connellsville, Pa. Waterboro, N. . . . . . . . . . .

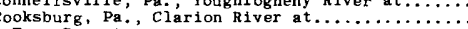

Toms Run at.

Cooperation

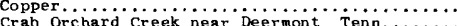

Crabsvile,

Craigsville, w. Va., Gauley River near.

at Smithland, Ky, Barbourville, Ky............

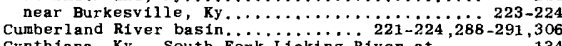

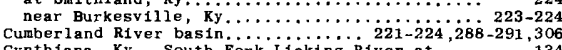

Cynthiana, Ky., South Fork Licking River at .....

Dawson Springs, Ky., Buffa1o Creek near........
Page

150-152

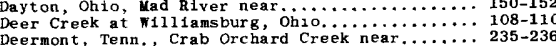
Deermont, Tenn, , Crab Orchard Creek near....... $235-236$

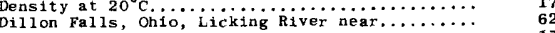

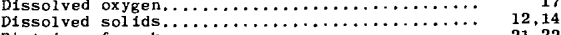

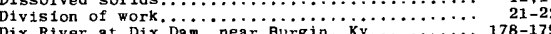
Dix River at Dix Dam, near Burgin, Ky....... 178-179

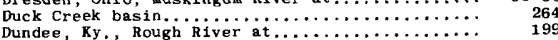

Eagle City, Ohro, Mad River at........... 147-150 Eagle Creek at Giencoe, Ky.............. 183-186 East Fork Little Miami River at Perintown, Ohio. 127-129 East Fork Poplar Creek near Oak Ridge, Tenn.... 234-235 East Fork white River at Seymour, Ind......... 211-214 Eizabetht own, Ohio, Great Milam at Queen Shoals, w. va $\ldots \ldots \ldots \ldots \ldots \ldots \ldots \ldots \ldots \ldots \ldots \ldots \ldots$ below Webster Springs, w. Va.................. Elkhorn City, Ky., Russell Fork at............. Elkins, w. Va., Tygart Valley River at ........ 146.147 Englewood, Ohio, stillwater River at $\ldots \ldots \ldots \ldots \ldots$ 146-147 Enterprise, W. Va., West Fork River at $\ldots \ldots \ldots \ldots \ldots \ldots \ldots \ldots \ldots \ldots \ldots \ldots$
Expression of results......

Falls of Rough, Ky., Rough River near....... 197-198 Farmers, Ky . Licking River at .............. Fincastie, Ind., Big Raccoon Creek near........ 203-205 F1at Woods, Tenn, , Buffalo River near......... $243-244$

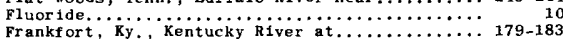
Frankf ort, Ky, Kentucky River at............ 179-183 Friendsvil le, Md., Youghiogheny River at........

Galax, Va., New River near.............. 75-77 Gate Caty, Va., North Fork Holston River near... 228 Gauley River near Craigsville, W. Va............
Geraldine, Ala., Town Creek near.............

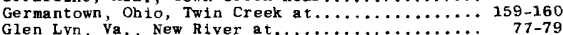
Glen Lyn, Va ., New River at $\ldots \ldots \ldots \ldots \ldots \ldots \ldots \ldots, \begin{array}{r}77-79 \\ \mathbf{1 8 3 - 1 8 6}\end{array}$

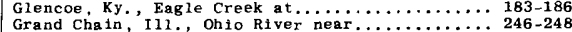
Grand Chatn, Il1., Ohio River near $\ldots \ldots \ldots \ldots \ldots \ldots . .246-248$ Grantsville, w. Va., Little Kanawha River at....
Great Miami River, at Elizabethtown, Ohio...... $170-172$

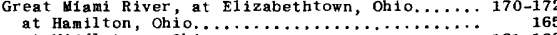

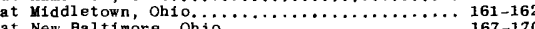

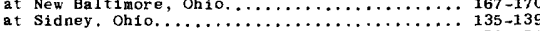
at West Carroliton, ohio...................... 153-154

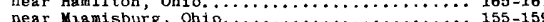

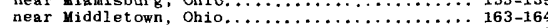
near Taylorsvil le Dam, at Taylorsvilie, Ohio.. 142-143 Great Miami River basin..............135-172, 267,305

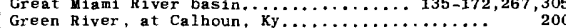

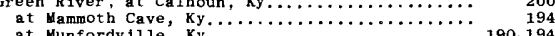

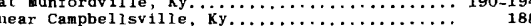

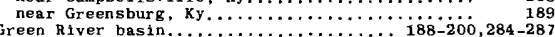
Green River basin ....................... 188-200, 284-28

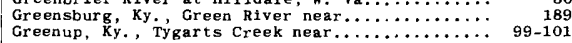

Hackleburg, Ala., Bear Creek near......... 238-239 Halls Crossroads, Tenn. Bul lrun Creek near......
Halltown, Ala., Little Bear Creek near.......... Hamilton, Ohio, Great Mami River at............

Great Hiami River near................... 165-167

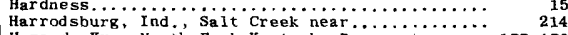
Hazrodsburg, Ind, Ky, North Fork Kentucky River a t........ $177-178$ Higby, Ohio, Sc1oto Raver at................ 117-123 Hilidale, Va., Greenbrier River at.......... Hock1ng River below Athens, Ohio.............

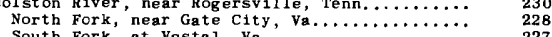
South Fork, at Vestal, Va $\ldots \ldots \ldots \ldots \ldots \ldots \ldots \ldots \ldots$
Huntingt on, Ind., Wabash River at $\ldots \ldots \ldots \ldots \ldots \ldots$ Hutsonvilie, Ili., wabash River at............ 206-208 Hydrogen-1on concentration.................. 
I

Introduction $\ldots \ldots \ldots \ldots \ldots \ldots \ldots \ldots \ldots \ldots, \ldots$,

Iodide.

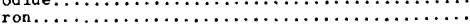

Johns Creek near Van Lear, $\mathrm{Ky}, \ldots$

Kanawha River, at Cabin Creek, w. Va

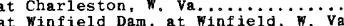

at Winfield Dan, at Winfleld, Va........ $^{86-88}$

Kantucky piver at lock 4, at Frankfort, Ky $250,278-279$

North Fork, at Hazard, Ky ............... 177-178 Kentucky River basin............. 176-186, 280-283,306 Kepler, Tenn., Beech Creek at.............. 229 Kermit, . Va., Tug Fork at ............... 98 Killbuck Creek at Xillbuck, Ohio........... $55-57$ Kinzua, Pa., A11 egheny River near............ 24-2 Kiskiminet as River at Leechburg (Vandergrift),

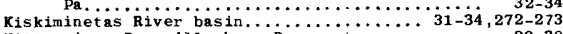
Kittanning, Pa., Allegheny River at.......... 29-3

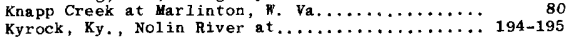

Lafayette, Ind., Wabash River at...........

Lake Lynn, Pa, Cheat River at.

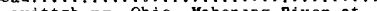
Leechburg (Vandergrift), Pa., Kiskiminetas

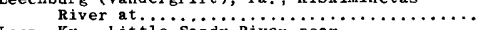

Leon, Ky, , Little Sandy River near

Licking Piver Paintsville, Ky.

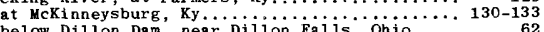

near Newark, Ohio.....

South Fork, at Cynthiana, ky..................

Licking River bastn...............

Literature cited.

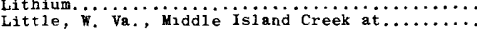

Litle Barren River near Monroe, Ky.

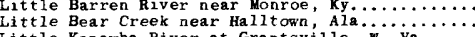

Little Kanawha River at Grantsville, w. Va.

Lit tle Miami River, East Fork, at Perintown,

Little Miami River basin...................

Little River above Townsend, Tenn........... 127-129,267

Little Sandy River below Grayson Dam, near

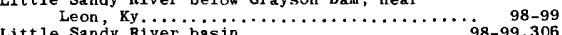

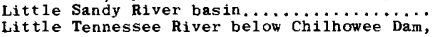
Teun

51

$89-190$

241
69

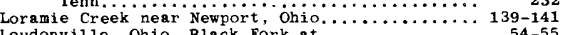

Loudonville, Ohio, Black Fork at............ $54-55$

Lowellville, Ohio, Mahoning River below.......
Lucasville, Ohio, Scioto River at $\ldots \ldots \ldots \ldots \ldots, 123-125$

cGaw, Ohio, Upper Creek at.

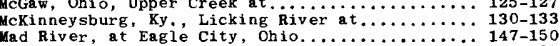

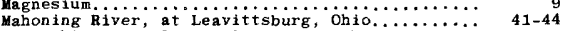

at Ohio-Pennsylvania State line, beiow

West Branch, near Ravenna, ohio................

Mammoth Cave, Ky... Green River at.

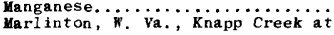

Mercury.

Metropolis, iii., ohio River at

Mamisburg, Ohio, Great Miami River nea...

Hiddle

middlesboro, Ky.

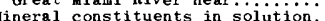

Hiscellaneo's analyses of streams in the ohio River basin in:

Al abama.

Indiana.

Kent ucky

Pennsylvania.

Tennessee.

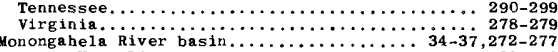

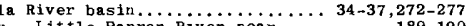
Munfordvilie, Ky. Garren River near......... 189-190 Muskingum River, at Dresden, Ohio............. 58.60

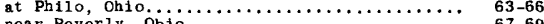

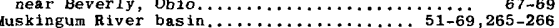

Navarre, Ohio, Tuscarawas River at .........

$51-53$

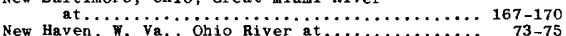

New River, at Glen Lyn, Va............ $77-79$

$77-79$
$75-77$

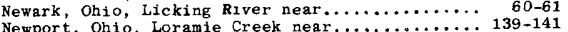

Newport, Ohio, Loramie Creek near............... 13

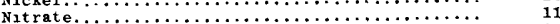

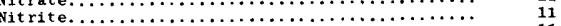

Nitrogen, ammonia....................... 11

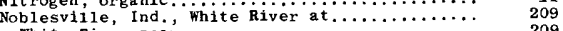

White River near. $\ldots \ldots \ldots \ldots \ldots \ldots \ldots \ldots \ldots \ldots \ldots \ldots \ldots \ldots \ldots \ldots \ldots \ldots \ldots$
$194-195$

Nora, Ind white River near........ 210

North Fork Holston hiver near Gate City, Va..... 228

North Fork Kentucky River at Hazard, Ky......... 177-178

$$
\text { o }
$$

Oak Ridge, Tenn., East Fork Poplar Creek

ohio niver, at iock and dam 53 , near Grand

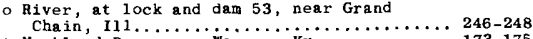

at Markland Dam, near Warsaw, Ky................. 173-175

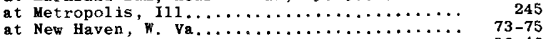

at South Heights, Pa............... $38-40$

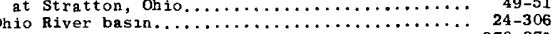

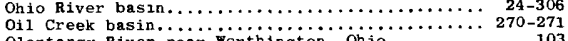

Olentangy River near Worthington, Ohio......... 103

Olney, Ky., Tradewater River at............ 216-220

Paducah, Ky., Tennessee River near........... 244

Paint Creek near Bourneville, Ohio.

Paintsville, Ky., Levisa Fork a t...............

Pesticide anai yses of streams in the ohio $\ldots \ldots \ldots{ }^{127-129}$

River basin in ohio $\ldots \ldots \ldots \ldots \ldots \ldots \ldots \ldots \ldots, 268-269$
Petersburg, Ind., White River at $\ldots \ldots \ldots \ldots \ldots \ldots$

Philippi, $w$. Va., Tygart Valley River at.......

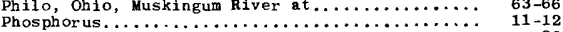

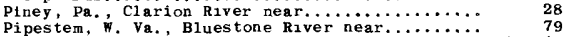

Pleasant Hill, Ohio, Stillwater River at........ 144-146

Pleasant Site, Ala., Cedar Creek near..........
Poplar Creek, East Fork, near Oak Ridge, Tenn... 234-235

Poplar Creek, East Fork, near Oak Ridge, Tenn... 234-235

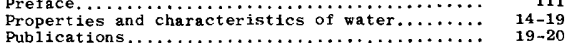

Publications...
Pulaski, Tenn., Richiand Creek near...............

$Q$

Queen Shoals, w. Va., E1k River at...........

84

Raccoon Creek at Adansville, Ohio.......... 88-93 Raccoon Creek basin.................. $88.93,276-277$ Ravenna, Ohio, Nest Branch Mahoning kiver $40-4$

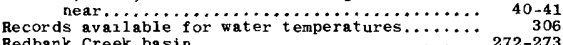
Redbank Creek basin..................... 272-273 Richland Creek near Puiaski, Tenn............... 272 Riverton, Ind, Wabash River at.............. 208 Rogersville, Tenn., Holston River near......... 230 Rolling Fork near Boston, Ky $\ldots \ldots \ldots \ldots \ldots \ldots \ldots \ldots \ldots \ldots \ldots \ldots \ldots$
Rough River, at Dundee, Ky 187 at Rough River Dam, near Fai is of Rough, Ky... 197-198
Rowlesburg, w. Va Cheat River at Rowlesburg, w. Va., Cheat River at $\ldots \ldots \ldots \ldots \ldots \ldots \ldots \ldots \ldots$
Russell Fork at Elkhorn City, Ky.........

Salt Creek near Harrodsburg, Ind $\ldots \ldots \ldots \ldots \ldots \ldots .214$

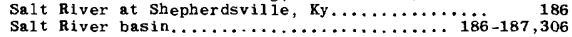

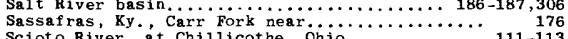
Scioto River, at Chillicothe, Ohio............ 111-113

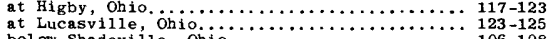

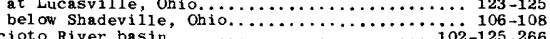
Scioto River basin..................... 102-125,266

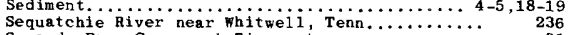

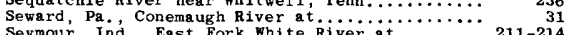
Seymour, Ind, East Fork White River at . . . . . Shadeville, ohio, Scioto River below........... 106-108 Shepherdsville, Ky., Salt River at............ 186 Sidney, Ohio, Great Miami River at ............. 135-139

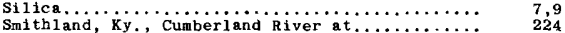
Sodium adsorption ratio.............................

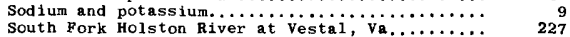
South Fork Holston River at Vestal, Va........ South Fork Licking River at Cynthiana, Ky......
South Feights, 134

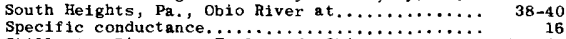
Stillwater Biver, at Engl ewood, ohio............ 146-147 at Pleasant Hili, Ohio................... 144-146

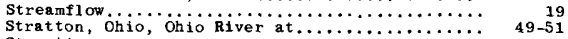

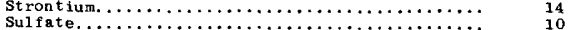


INDEX

309

Sulfide.

Sutton, va., Elk River

Taylorsville, Ohio, Great Miami River at...... 142-143

Telic plains, Tenn., Telic River at.

Temperature.

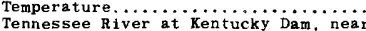

Paducah, Ky
Tennessee River

basin.

$250-263,278-279,292-304,2$

Townsend, Tenn., Little River above............ 230-23

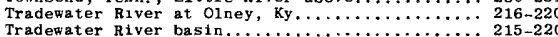

Tug Fork at Kermit, $F$. Va.

Turbidity.

Tuscarawas River at Navarre, Ohio

Twin Creek at Germantown, Ohio.

Tygart Valley River, at

Tygarts Creek near Greenup, Ky.

U

Upper Twin Creek at McGaw, Ohio.

V

Van Lear, Ky, Johns Creek near.

Vestal, Va., South Fork Holston River
Page

Wabash River, at Huntington, Ind. at Hutsonvilie, Ill.

at Lafayette, Ind

Wabash River , Ind.

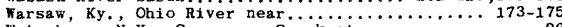

Wat erboro, N.Y., Conewango Creek at ..........

West Branch Mahoning River near Ravenna,

West Carroliton, ohio, Great Miami River

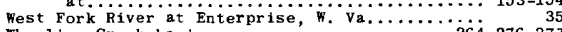

Wheeling Creek basin.

Whets tone Creek near Ashley, ohio.

at Petersburg, Ind

East Fork, at Seymour, Ind. near Noblesville, Ind.

near Nora, Ind.

Til ia, Tenn, Sequatchie River near.

Winfield, . Ohio, Deer Creek at.

Worthington, Ohio, olentangy River near.

$\mathbf{Y}$

Yellow Creek near Middlesboro, Ky

Yellow Creek basin.

Youghiogheny River, at Conneisisviije, ${ }_{\mathrm{Pa}}$

at Friendsville, Md...

Z

94

Zinc.

14

HUS. GOVERNMENT PRINTING OFFICE: $1973-515-659 / 84$ 